
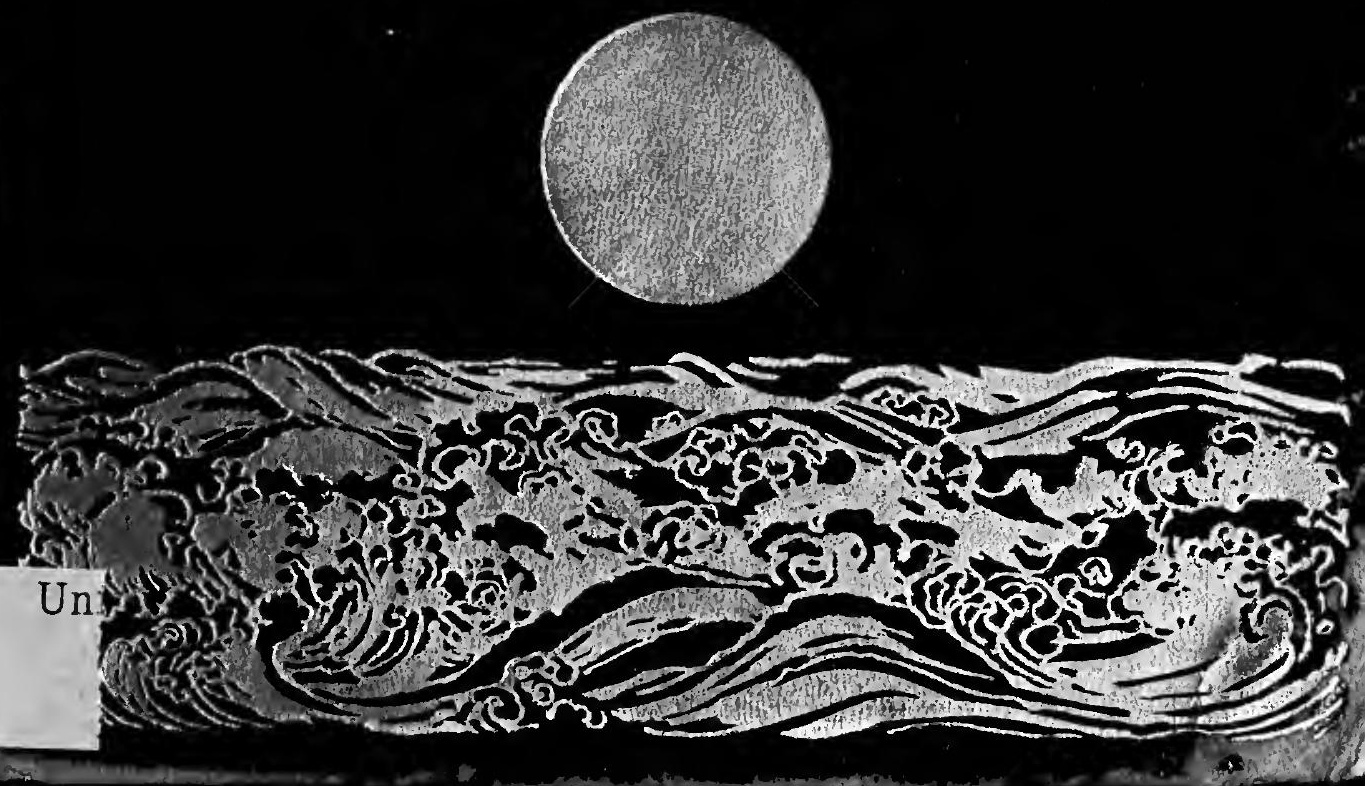


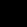


LIBRARY
UNIIERSITY OF
CALLFORNA

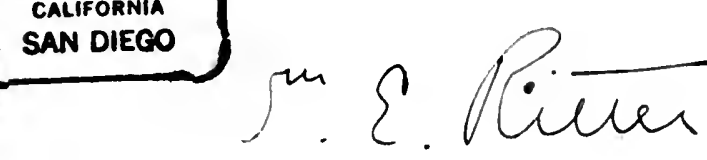


\lrcorner UNIVERSITY OF CALIFORNIA SAN DIEGO L.

31822026702738

Social Sciences \& Humanities Library

University of California, San Diego

Please Note: This item is subject to recall.

\section{Date Due}

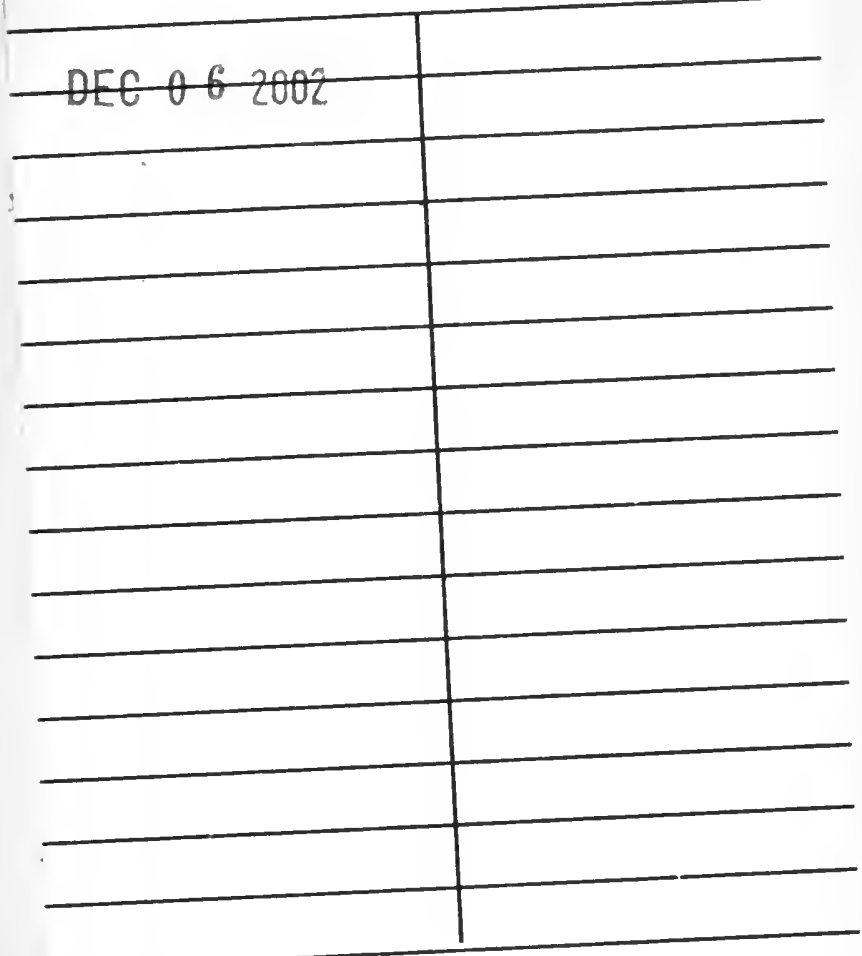

Cl $39(5 / 97)$

UCSD Lib. 


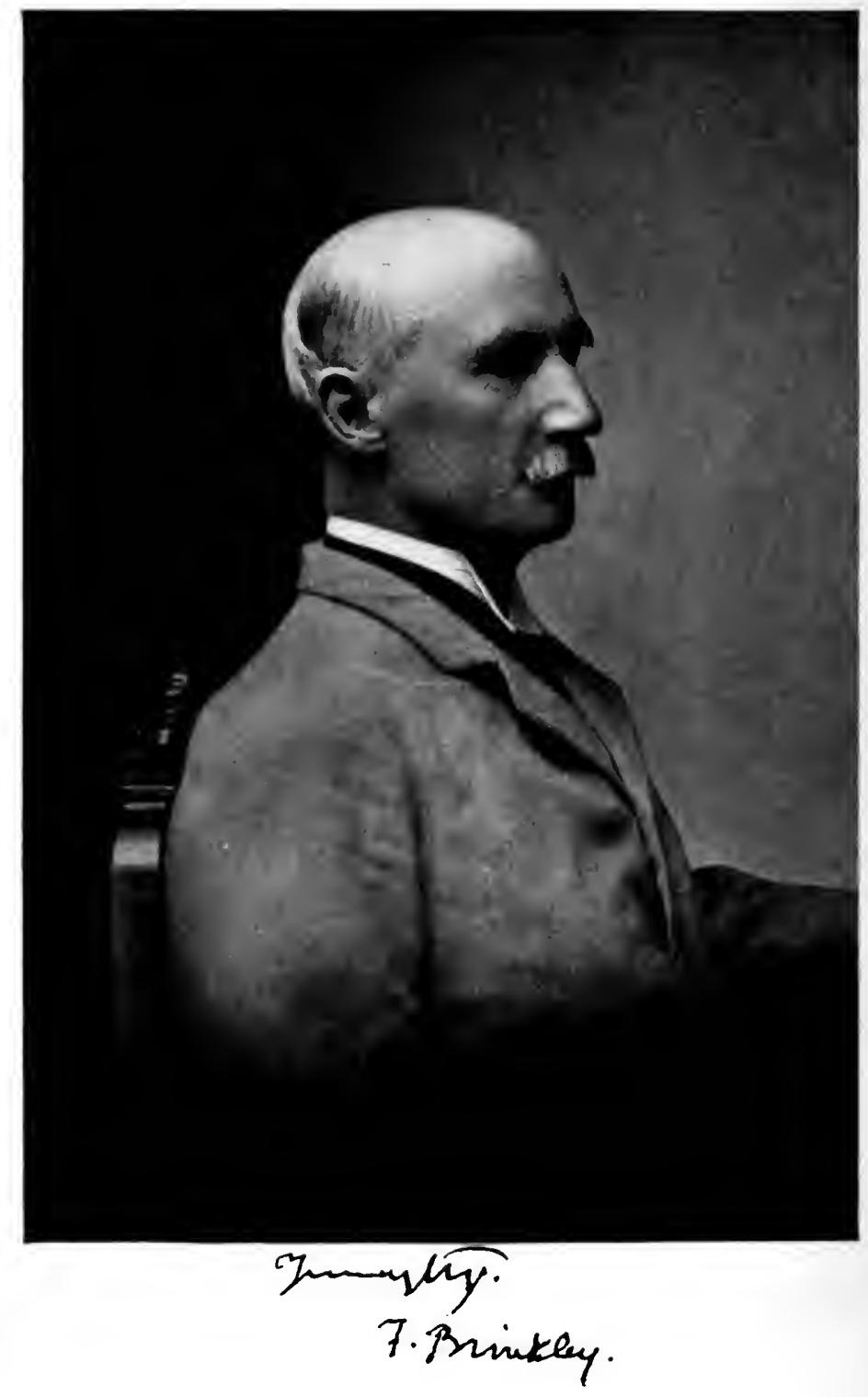




\title{
A HISTORY OF
}

\section{THE JAPANESE PEOPLE}

\author{
FROM THE EARLIEST TIMES TO THE \\ END OF THE MEIJI ERA
}

BY

CAPT. F. BRINKLEY, R. A.

Editor of the "JAPAN MAIL"

WITH THE COLLABORATION OF

BARON KIKUCHI

Former President of the Imperial University at Kyoto

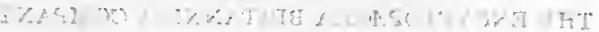

WITH 150 ILLUSTRATIONS ENGRAVED ON WOOD BY JAPANESE

ARTISTS; HALF-TONE PLATES, AND MAPS

The Encyclop edia Britannica Co.,

NEW YORK

The Encyclopadia Britannica Co., Limited, LoNDON 
Copyright, in the United States of America, 1915

BY

THE ENCYCLOPADIA BRITANNICA COMPANY 
-

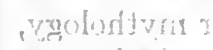

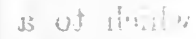

9 gantst.

rists

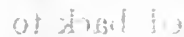

Jistilingis

Wirnot thit Dith DEDICATED

GY BY GRACIOUS PERMISSION

twathif from

Groprfegrat HIS MAJESTY MEIJI TENNŌ,

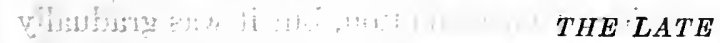

EXog

- teombtri

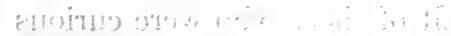

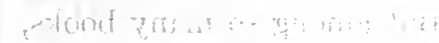

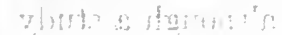

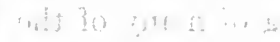

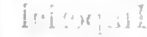

bomilnsit

$9 !$

\section{nitis}

+1] in of of

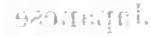

intilition

ris :mit

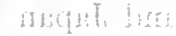

par? yes" 


\section{FOREWORD}

It is trite to remark that if you wish to know really any people, it is necessary to have a thorough knowledge of their history, including their mythology, legends and folk-lore: customs, habits and traits of character, which to a superficial observer of a different nationality or race may seem odd and strange, sometimes even utterly subversive of ordinary ideas of morality, but which can be explained and will appear quite reasonable when they are traced back to their origin. The sudden rise of the Japanese nation from an insignificant position to a foremost rank in the comity of nations has startled the world. Exeept in the case of very few who had studied us intimately, we were a people but little raised above barbarism trying to imitate Western civilisation without any capacity for really assimilating or adapting it. At first, it was supposed that we had somehow undergone a sudden transformation, but it was gradually pereeived that such could not be and was not the case; and a crop of books on Japan and the Japanese, deep and superficial, serious and fantastic, interesting and otherwise, has been put forth for the benefit of those who were curious to know the reason of this strange phenomenon. But among so many books, there has not yet been, so far as I know, a history of Japan, although a study of its history was most essential for the proper understanding of many of the problems relating to the Japanese people, such as the relation of the Imperial dynasty to the people, the family system, the position of Buddhism, the influence of the Chinese philosophy, etc. A history of Japan of moderate size has indeed long been a desideratum; that it was not forthcoming was no doubt due to the want of a proper person to undertake such a work. Now just the right man has been found in the author of the present work, who, an Englishman by birth, is almost Japanese in his understanding of, and sympathy with, the Japanese people. It would indeed be difficult to find any one better fitted for the task - by no means an easy one - of presenting the general features of Japanese history to Western readers, in a compact and intelligible form, and at the same time in general harmony with the Japanese feeling. The Western public and Japan are alike to be congratulated on the production of the present work. I may say this without any fear of reproach for self-praise, for although my name is mentioned in the title-page, my share is very slight, consisting merely in general advice and in a few suggestions on some special points.

Кчо̄то, 1912.

DaIRoKu KIKUChi. 


\section{AUTHOR'S PREFACE}

During the past three decades Japanese students have devoted much intelligent labour to collecting and collating the somewhat disjointed fragments of their country's history. The task would have been practically impossible for foreign historiographers alone, but now that the materials have been brought to light there is no insuperable difficulty in making them available for purposes of joint interpretation. That is all I have attempted to do in these pages, and I ibeg to solicit pardon for any defect they may be found to contain.

Тōкxō, 1912.

F. BRINKLEy. 


\section{CONTENTS}

CHAPTER
PAGE

I. The Historiographer's Art in Old Japan . . . . . . 1

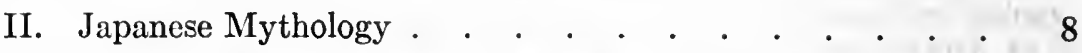

III. Japanese Mythology (Continued)

IV. Rationalization . . . . . . . • . . . . . 28

V. Origin of the Japanese Nation: Historical Evidences . . 34

VI. Origin of the Nation: Geographical and Archaological

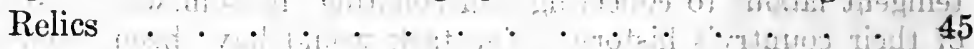

VII. Language and Physical Characteristics

VIII. Manners and Customs in Remote Antiquity 61

IX. The Prehistoric Sovereigns .

X. The Prehistoric Sovereigns (Continued) • . •

XI. The Prehistoric Sovereigns (Continued) $\quad$ • $\quad$ • $\quad$ • $\quad$ • $\quad 99$

XII. The Protohistoric Sovereigns . • • • . • . . . 108

XIII. The Protohistoric Sovereigns (Continued) • • • • • 117

XIV. From the 29 th to the 35 th Sovereign . . . . . . . 131

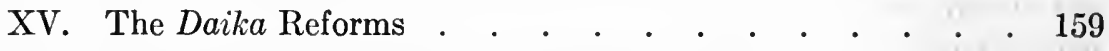

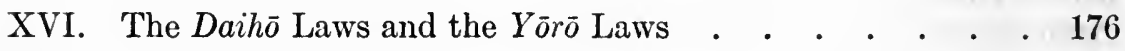

XVII. The Nara Epoch . • • . • • • . . . • . . 185

XVIII. The Heian Epoch . • • • • • • • • • • . 224

XIX. The Heian Epoch (Continued) . • • • • • • • 235

XX. The Heian Epoch (Continued) . • • • • • • • 245

XXI. The Capital and the Provinces . • • • • • • • 257

XXII. Recovery of Administrative Authority by the Throne . $\quad 269$

XXIII. Manners and Customs of the Heian Epoch . • . . • 275

XXIV. The Epoch of the Gen (Minamoto) and the Hei (Taira) . 284

XXV. The Epoch of the Gen and the Hei (Continued) . . . 302

XXVI. The Kamakura Bakufu • • • • • • • • • • • 335

XXVII. The Hōjōo • • • • • • • • • • • • • • • • • 347 
XXVIII. Art, Religion, Literature, Customs, and Commerce in the Kamakura Period . . . . . . . . . . . 365

XXIX. Fall of the Hōjō and Rise of the Ashikaga . . . . . 376

XXX. The War of the Dynasties . . . . . . . . . . 396

XXXI. The Fall of the Ashikaga . . . . . . 413

XXXII. Foreign Intercourse, Literature, Art, Religion, Manners, and Customs in the Muromachi Epoch . . . . . . 442

XXXIII. The Epoch of Wars (Sengoku Jidai)

XXXIV. Nobunaga, Hịdeyoshi, and Ieyasur. . . . . . . . . 473

oXXXV. The Invasion of Korea . . . . . • 509

XXXVI. The Momo-Yama Epoch 5 .

XXXVII. Christianity in Japan . . . . . . . . . . 530

XXXVIII. The Tokugawa Shōgunate _... . . . . . . . 556

XXXIX. First Period of the Tokugawa Bakufu; from the First Tokugawa Shogun, Ieyasu; to the Fourth, Ietsuna (1603-1680)

XL. Middle Period of the Tokugawa Bakufu; from the Fifth Shōgun, Tsunayoshi, to the Tenth Shōgun, Ieharu (16801786)

XLI. The Late Period of the Tokugawa Bakufu. The Eleventh Shōgun, Ienari (1786-1838)

XLII. Organization, Central and Local; Currency and the Laws of the Tokugawa Bakufu

XLIII. Revival of the Shintō Cult

XLIV. Foreign Relations and the Decline of the Tokugawa

644

$1 Q 1$ XLV. Foreign Relations and the Decline of the Tokugawa (Continued)

XLVI. The Meiji Government. .

XLVII. Wars with China and Russia

\section{APPENDIX}

1. Constitution of Japan, 1889

2. Anglo-Japanese Agreement, 1905

3. Treaty of Portsmouth, 1905 


\section{HISTORICAL MAPS}

Japan about 1337: Northern and Southern Courts.

Japan in Era of Wars, 1577: Distribution of Fiefs

466

Japan in 1615: Feudatories

570

Japan, Korea and the Mainland of Asia

706

\section{FULL PAGE HALF-TONES}

Capt. F. Brinkley, R. A.

Frontispiece

The Emperor Jimmu

34

The Shrine of Ise

Prehistoric Remains: Plate A

Prehistoric Remains: Plate B

Prince Shōtoku

Kaigen Ceremony of the Nara Daibutsu . . . . . . . . . 194

Thirty-six Versifiers (Painting by Kōrin) . . . . . ' . . . . 210

Cherry-Viewing Festival at Mukōjima

274

Kamakura Daibutsu

Kinkaku-ji (Golden Pavilion)

326

Court Costumes

Tokugawa Shrine at Nikko .

The Emperor Meiji (Mutsuhito)

578

Sinking of the Russian Battleship Osliabya 586

Admiral Togo 


\section{WORKS CONSULTED}

N. B. - When reference is made to books in languages other than Japanese the fact is noted in the text.

Kojiki. - . 古 事記. Koshi Kō ・. 古史考

Kojiki Den. ・古事 記 傅 Oyashima Ki. . 大八洲記

Nihon Shoki 日 本書 紀 Konjaku Monogatari A 昔物浯

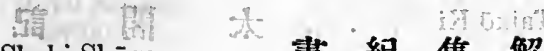

Shoki Shūge ・ ・書 紀 集 解

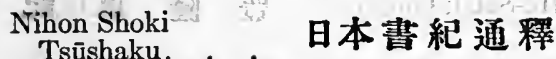

Shoku Nihongi. ・ 續 日 本 紀

Nihon Kōki 。. 日 本 後 紀

Shoku Nihon Kōki. 續 日 本後紀

Montoku Jitsuroku 文 德 實 錄

Sandai Jitsuroku 三代 貝 録

Mizu-Kagami . $\cdot$ 水

Ô-Kagami ·. · 大 鏡

Masu-Kagami . • 增 鏡

Azuma-Kagami • 吾 妻 鏡

Koshi Tsū. . 古史通

Kodai no Kenkyū. 古代, 研 究

Kokugaku Bengi . 國 學 㖖 疑

Jōzanrō Hitsuyo ・ 常山樓䈉 餘

Shinto Dokugo. - 神道獨 略

Shokka Shiryaku ·食貨志略

Rekichō Seiji

Yenkaku Shi.

Jinnō Shōtō Ki.
厢朝政事沿革史

神皇 正 統 記
Konjaku Monogatari

Reii $\mathrm{Ki}$.

Jōsei Kinen Kō

Teikoku Kinen Shian

Nichi-Kan Koshi Dan

So no Kuni Sengi Kõ

Shizoku Kō

Shin-sen Shōji Roku

Jindai Maki no Shō

दि

Kakai Shō

Kogo Shūi

Kana Hommatsu .

Nihongi Genkō.

Fusō Ryakki

Teiō Hennen Ki

Tōgoku Tsugan

Shōtoku Taishi Den

Taishi Den Hochū .

Shi-Tennō-ji Yengi. Wh -1

Shokugen Shō.
霝 異 記

上世紀年考

帝國紀年私案

日韓古史铉

毁國僣俑考

E 族

荨

新撰姓岻 錄

神代㐘抄

河海 抄

古語 拾 遺

假名本末

日本紀原考

扶桑 略 記

帝王縓年記

東國通鑑

鼠德太子傳

太子傅補註

四天王寺緣起

獞 原 
Ry̛ō no Gige

Konshoku Scido

Yenkaku Shi.

Hennen Shũsei

Gempei Seisui Ki

Taibei Ki

Honchō Kiseki Dan 本朝奇䟢談

Ruijū Kokushi . 類 聚 國史

Kokushi Okugi. ・國史 愿 議

Töko Kawa.

Taketori Monogatari 竹 取 物, 㝻

Eigwa Monogatari. 榮花物、語

Shōen Kō

Masakado Ki

Tokushi Yoron.

Tsurezure Gusa

Gukwan Shō

Hachiman Gudō Ki

Hōjō Kudai Ki.

Kemmu Ki .

Ashikaga Kefu .

Ashikaga Chiranki.

Zenrin Kokuhō Ki

Zoku Zenrin

Kokushō Ki .

Teijō Zakki.

Chirizuka

Monogatari .

Onin $\mathrm{Ki}$.

Yōshu Fu'Shi.
官娥制度沿革史

編年监成

源平盛镜記

太本記

東 湖 歌 話

莊 園“考

將 阴 記

蒷史 馀 論

徒 然草

感管抄

分幖感童記

北條九代記

建武記

定利家婹

定利治熖記

蒌筷國锤記

縝善隣國毁記

直丈䧴記

磨塚物語

照仁記

䔨州府志
Nihon Sozei Shi

日本租税志

Nōsei Homron

Myōkōji Monjo

妙興寺交書

Shū Kai Shō

拾 像

抄

Shinsho Shō

紳 漛

抄

Go-Nara-in Shinki：後奈良院宸記

Nobunaga Ki 。 信 長 記

Taikō Ki

太閣 記

Hō-Satsu Gunki

豊薩軍記

Chosen Seibatsu Ki

朝鮮征伐記

Buke Kandan .

武家 䦥 談

Butoku Ammin Ki

武德安民記

Hideyoshi Jiki .

秀吉事記

Toyotomi Hatto Kō.

Tenshō Ki .

豊臣法度考

天 正 記

Tokugawa Jikki

德 川 䨘即

Honehō Tsugan

本 朝 通 鑑

Irō Monogatari.

遗 老 物 語

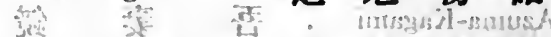

Rojin Zatsuwa .

老人 碓 話

Shiojiri

監

尼

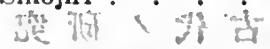

Nihon Jukyō Shi

日本儒数史

Kenbyō Jitsuroku .

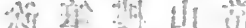

Tempō Nenki.

Jôken-inden

Go-jikki.

Hankampu .

I] .

Oritaku Shiba no Ki

I.

Kōto Bunken Roku
害廟 暂 錄

天 䆩 年 記 . ogusull os stirle

常憲院殿御顀記

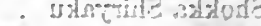

潘翰的諳

折てく柴の記

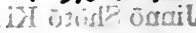

江都聞見錄 
Nochimi-Gusa. . 後見草

Zoku Saimu Kiji 。續 再夢記 事

Kaikoku Kigen. . 開 國 起 原

Bushidō. . . 武士 道

Dai Nihon Shi . 大日本史

Ōdai Ichiran . . 王代一覽

Kokushi-ryaku. 、國史略

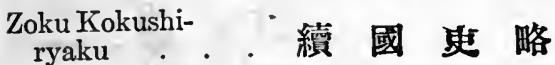

Isshi

逸

史

Kōchō Shiryaku 。皇朝 更 略

Nihon Seiki. ・ 日 本 政 記

Nihon Gwaishi. - 日 本 外史

Yashi . • . 野

史

Dai Nihon Teikoku Shi

Dai Nihon Rekishi.

Kokushi Gan . 國 串

Nihon Rekishi 。百本歴史

Nihon Kodai-hō Shakugi .

Nihon Bummei Shi.

Nihon Shiseki .

Dai Nihon Tsūshi 。 大日本通史

Rekichō Seitoku Roku .

Meishō Genkō Roku
日本古代法釋義

大日本帝國史

大日本歷史

日本交明史

日本史蹟

糜朝聖德錄

名將言行錄
Ryōshō Tattoku Shō

良將達德抄

Kokushi no Kenkyū 國史の研究

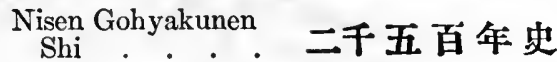

Nihon Kodai Shi . 日本古代史

Nara-chōShi . 奈良朝史

Heian-chō Shi . . 平安朝史

Kamakura Jidaishi 鐮倉時代史

Namboku Chō Jidai Shi

南北朝時代史

Muromachi Jidai Shi

Azuchi Momoyama Jidai Shi . . .

Tokugawa Jidai Shi

Baku-matsu Shi . 幕末 末

Ishin Shi • • 維新史

Kokushi Ronsan . 國史 論纂

Nihon Rekishi Hyōrin

日本䵇史評林

Nihon FūzokuShi 。 日本風俗史

Shigaku Sōsetsu • 史 學 菆 詮

KōchōHennen Shi. 皇朝編年史

Kabu Ongaku Ryaku Shi 。 . 歌舞音樂略史

Nihon Kyōiku Shi 。 日本教育史

Kōgei Shiryō . . I 藝 志 料

Shigaku Zasshi. . 史 學 雜 誌 


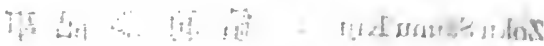

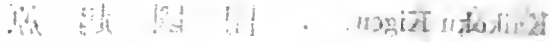

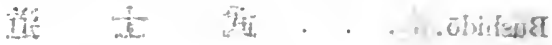

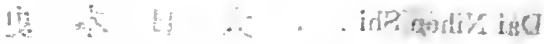

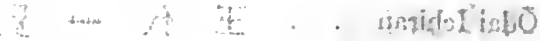

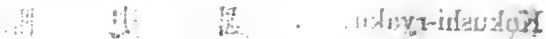

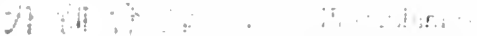

i. : ?

! i

If

-iftastort witunt

\& . . . inea]

th

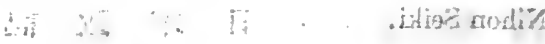

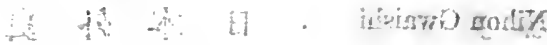

:

- inient $T$

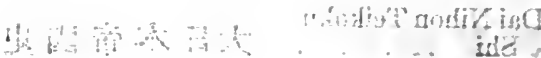

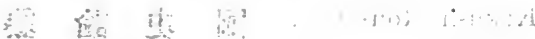

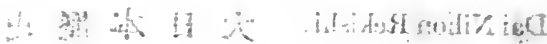

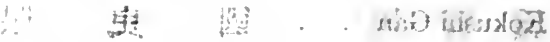

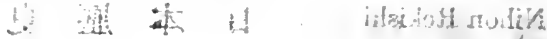

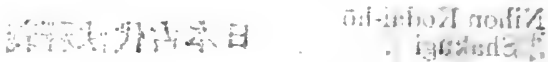

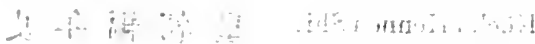

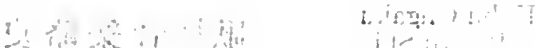

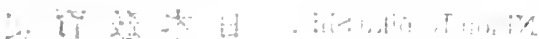

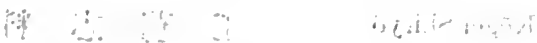

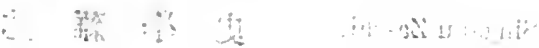

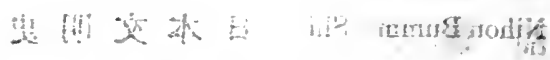

Hit

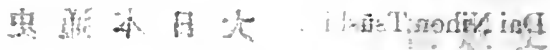

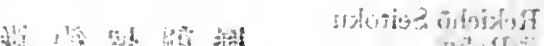

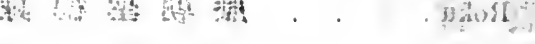

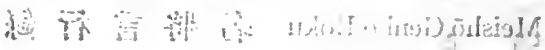



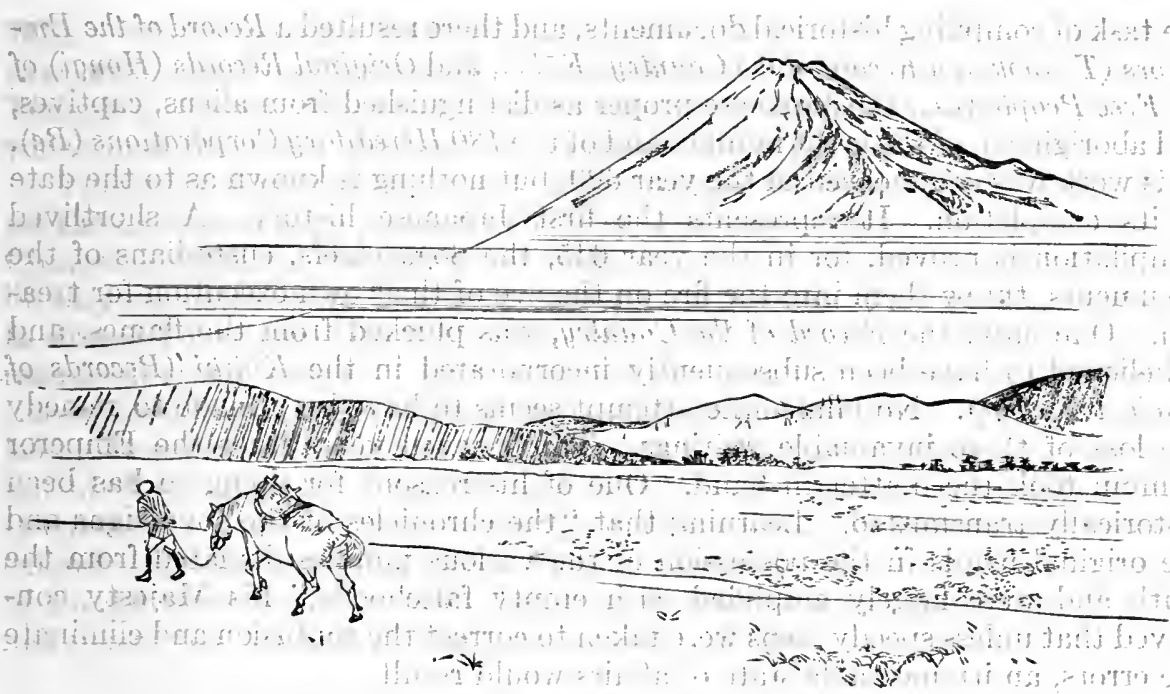

Mt. Fuji, seen from the FuJt-Gawa

\section{CHAPTER I}

\section{THE HISTORIOGRAPHER'S ART IN OLD JAPAN}

\section{MATERIALS FOR HISTORY}

IN the earliest eras of historic Japan there existed a hereditary corporation of raconteurs (Katari-be) who, from generation to generation, performed the function of reciting the exploits of the sovereigns and the deeds of heroes: They accompanied themselves on musical instruments, and naturally; as time went by, each set of raconteurs embellished the language of their predecessors, adding supernatural elements, and introducing details which belonged to the realm of romance rather than to that of ordinary history. These Katari-be would seem to have been the sole repository of their country's annals until the sixth century of the Christian era. Their repertories of recitation included records of the great families as well as of the sovereigns, and it is easy to conceive that the favour and patronage of these high personages were earned by ornamenting the traditions of their households and exalting their pedigrees. But when the art of writing was introduced towards the close of the fourth century, or at the beginning of the fifth, and it was seen that in China, then the centre of learning and civilization, the art had been applied to the compilation of a national history as well as of other volumes possessing great ethical value, the Japanese conceived the ambition of similarly utilizing their new attainment. For reasons which will be understood by and by, the application of the ideographic script to the language of Japan was a task of immense difficulty, and long years must have passed before the attainment of any degree of proficiency.

Thus it was not until the time of the Empress Suiko (593-628) that the historical project took practical shape. Her Majesty, at the instance, doubtless, of Prince Shōtoku, one of the greatest names in all Japan's annals, instructed the prince himself and her chief minister, Soga no Umako, to undertake 
the task of compiling historical documents, and there resulted a Record of the Emperors (Tennōki), a Record of the Country (Köki), and Original Records (Hongi) of the Free People (i.c., the Japanese proper as distinguished from aliens, captives, and aborigines), of the great families and of the 180 Hereditary Corporations $(\mathrm{Be})$. 'This work was commeneed in the year 620 , but nothing is known as to the date of its completion. It represents the first Japanese history. A shortlived compilation it proved, for in the year 645, the Soga chiefs, custodians of the doeuments, threw them into the fire on the eve of their own exeeution for treason. One only, the Record of the Country, was plucked from the flames, and is believed to have been subsequently incorporated in the Kojiki 'Records of Ancient Things). No immediate attempt seems to have been made to remedy the loss of these invaluable writings. Thirty-seven years later the Emperor Temmu took the matter in hand. One of his reasons for doing so has been historically transmitted. Learning that "the ehronicles of the sovereigns-and the original words in the possession of the various families deviated from the truth and were largely amplified with empty falsehoods," his Majesty conceived that unless speedy steps were taken to correct the confusion and eliminate the errors, an irremediable state of affairs would result.

Such a preface prepares us to learn that a body of experts was appointed to distinguish the true and the false, and to set down the former alone. The Emperor did, in fact, commission a number of prinees and officials to compile an authentic history, and we shall presently see how their labours resulted. But in the first place a special feature of the situation has to be noted. The Japanese language was then undergoing a transition. In order to fit it to the Chinese ideographs for literary purposes, it was being deprived of its mellifluous polysyllabic eharacter and reduced to monosyllabic terseness. The older words were disappearing, and with them many of the old traditions. Temmu saw that if the work of compilation was abandoned solely to prineely and official litterateurs, they would probably sacrifice on the altar of the ideograph much that was venerable and worthy to be preserved. He therefore himself undertook the collateral task of having the antique traditions colleeted and expurgated, and causing them to be memorized by a chamberlain, Hiyeda no Are, a man then in his twenty-eighth year, who was gifted with ability to repeat aceurately. everything heard once by him. Are's mind was soon stored with a mass of ancient facts and obsolescent phraseology, but before either the task of official compilation or that of private restoration had been carried to completion the Emperor died (686), and an interval of twenty-five years elapsed before the Empress Gemmyo, on the 18th of September, 711, ordered a seholar, Ono Yasumaro, to transcribe the records stored in Are's memory. Four months sufficed for the work, and on the 28th of January, 712, Yasumaro submitted to. the Throne the Kojiki (Records of Ancient Things) which ranked as the first history of Japan, and which will be here referred to as the Records.

THE NIHONGI AND THE NIHON SHOKI

It is necessary to revert now to the unfinished work of the classical compilers, as they may be called, whom the Emperor Temmu nominated in 682 , but whose labours had not been concluded when his Majesty died in 686. There is no evidence that their task was immediately continued in an organized form, but it is related that during the reign of Empress Jito $(690-696)$ further steps were taken to collect historical materials, and that the Empress Gemmyō (708- 
715) whom we have seen carrying out, in 712, her predecessor Temmu's plan with regard to Hiyeda no Are - added, in 714, two skilled littérateurs to Temmu's classical compilers; and thus enabled them to complete their task, which took the shape of a book called the Nihongi (Chronicle of Japan).

This work, however, did not prove altogether satisfactory. It was written, for the most part, with a script called the Manyō syllabary; that is to say, with Chinese ideographs employed phonetically, and it did not at all attain the literary standard of its Chinese prototype. Therefore, the Empress entrusted to Prince Toneri and Ōno Yasumaro the task of revising it, and their amended manuscript; concluded in 720, received the name of Nihon Shoki (Written Chronicles of Japan), the original being distinguished as Kana Nihongi, or Syllabic Chronicles. The Nihon Shoki consisted originally of thirty-one volumes, but of these one, containing the genealogies of the sovereigns, has been lost. It covers the whole of the prehistoric period and that part of the historic which extends from the accession of the Emperor Jimmu (660 B.c.) to the abdication of the Empress Jito (A.D. 697). The Kojiki extends back equally far, but terminates at the death of the Empress Suiko (A.D. 628).

\section{THE FÜDOKI}

In the year 713, when the Empress Gemmyo was on the throne, all the provinces of the empire received orders to submit to the Court statements setting forth the natural features of the various localities, together with traditions and remarkable occurrences.: These documents were called Findoki (Records of Natural Features). Many of them have-been lost, but a few survive, as those of Izumo, Harima, and Hitachi.

\section{CHARACTER OF THE RECORDS AND THE CHRONICLES}

The task of applying ideographic seript to phonetic purposes is exceedingly difficult. In the ideographic script each character has a distinct sound and a complete meaning. Thus, in China shan signifies "mountain," and ming "light." But in Japanese "mountain" becomes yama and "light" akari. It is evident; then, that one of two things has to be done. Either the sounds of the Japanese words must be changed to those of the.Chinese ideographs; or the sounds of the Chinese ideographs must alone be taken (irrespective of their meaning), and with them a phonetic syllabary must be formed. Both of these devices were employed by a Japanese scholar of early times. Sometimes disregarding the significance of the ideographs altogether, he used them simply as representing sounds, and with them built up pure Japanese words; at other times, he altered the sounds of Japanese words to those of their Chinese equivalents and then wrote them frankly with their ideographic symbols.

In this way each Japanese word came to have two pronunciations: first, its own original sound for colloquial purposes; and second; its borrowed sound for purposes of writing. At the outset the spoken and the, written languages were doubtless kept tolerably distinct. But by degrees, as respect for Chinese literature developed, it became a learned accomplishment to pronounce Japanese words after the Chinese manner, and the habit ultimately acquired such a vogue that the language of -men - who wrote and spoke ideographically - grew to be different from the language of women - who wrote and spoke phonetically. When Hiyeda no Are was required to memorize the annals and traditions collect- 
ed and revised at the Imperial Court, the language in which he committed them to heart was pure Japanese, and in that language he dictated them; twentynine years later, to the scribe Yasumaro. The latter, in setting down the products of Are's memory, wrote for the most part phonetically; but sometimes, finding that method too cumbersome, he had recourse to the ideographic language, with which he was familiar. At all events, adding nothing nor taking away anything, he produced a truthful record of the myths, traditions, and salient historical incidents credited by the Japanese of the seventh century:

It may well be supposed, nevertheless, that Are's memory, however tenacious, failed in many respects, and that his historical details were comparatively. meagre. An altogether different spirit presided at the work subsequently undertaken by this same Yasumaro, when, in conjunetion with other scholars, he was required to collate the historical materials obtained abundantly from various sourees since the vandalism of the Soga nobles. The prime object of these eollaborators was to produce a Japanese history worthy to stand side by side with the elassic models of China. Therefore, they used the Chinese language almost entirely, the chief exception being in the case of the old poems; a great number of which appear in the Records and the Chronicles alike. The actual words of these poems had to be preserved as well as the metre, and therefore it was necessary to indite them phonetically. For the rest, the Nihon Shoki, which resulted from the labours of these annalists and literati, was so Chinese that its authors did not hesitate to draw largely upon the cosmogonic myths of the Middle Kingdom, and to put into the mouths of Japanese monarchs, or into their decrees, quotations from Chinese literature. "As a repertory of ancient Japanese myth and legend there is little to choose between the Records and the Chronicles. The former is, on the whole, the fuller of the two, and eontains legends which the latter passes over in silence; but the Chronicles, as we now have them, are enriehed by variants of the early myths, the value of which, for purposes of comparison, is recognized by scientifie inquirers. But there can be no comparison between the two works when viewed as history. Hiyeda no Are's memory cannot be expected to compete in fullness and accuracy with the abundant documentary literature accessible to the writers of the Chronicles, and an examination of the two works shows that, in respect to the record of actual events, the Chronicles are far the more useful authority".."

It will readily be supposed, too, that the authors of both works confused the present with the past, and, in describing the manners and eustoms of by-gone eras, uneonsciously limned their pictures with eolours taken from the palette of their own times, "when the national thought and institutions had become deeply modified by Chinese influenees." Valuable as the two books are, therefore, they cannot be accepted without large limitations. The Nihon Shoki occupied a high place in national esteem from the outset. In the year following its eompilation, the Empress Genshō summoned eminent scholars to the Court and eaused them to deliver lectures on the contents of the book, a custom which was followed regularly by subsequent sovereigns and still finds a place among the New Year ceremonials. This book proved to be the precursor of five others with which it is commonly associated by Japanese scholars. They are the Zoku Nihongi (Supplementary Chronicles of Japan), in forty volumes, which covers the period from 697 to 791 and was finished in 798; the Nihon Köki' (Later Chronicles of Japan), in forty volumes - ten only survive which covers the period from 792 to 833; the Zoku Nihon Kōki (Supplementary 
Later Chronicles), in twenty volumes, which covers the single reign of the Emperor Nimmyo (834-850), and was compiled in 869; the Montoku Jitsu-roku (True Annals of Montoku), in ten volumes, covering the reign of Montoku (851-858), and compiled in 879, and the Sandai Jitsu-roku (True Annals of Three Reigns) in fifty volumes, covering the period from 859 to $887_{\text {ind }}$ and compiled in 901 . The five compilations 'together with the Nihon Shoki are honoured as the Six National Histories. It is noticeable that the writers were men of the highest rank; from prime ministers downwards: In such honour was the historiographer's art held in Japan in the eighth and ninth centuries:

\section{CHRONOLOGY}

Tio Before beginning to read Japanese history it is necessary to know something of the chronology followed in its pages. There have been in Japan four systems for counting the passage of time. The first is by the reigns of the Emperors. That is to say, the first year of a sovereign's reign - reckoning from the New Year's day following his accession - became the 1 of the series, and the years were thenceforth numbered consecutively until his death or abdication. This method might be sufficiently accurate if the exact duration of each reign were known as well as the exact sequence of the reigns. But no such precision could be expected in the case of unwritten history, transmitted orally from generation to generation: (c) Thus, while Japanese annalists, by accepting the aggregate duration of all the reigns known to them, arrive at the conclusion that the first Emperor, Jimmu, ascended the throne in the year 660 B.C., it is found on analysis that their figures assign to the first seventeen sovereigns an average age of 109 years. 9. The second system was by means of periods deriving their name (nengō) from some remarkable incident. Thus; the discovery of eopper in Japan was commemorated by calling the year $W a d \bar{o}$ (Japanese copper), and the era so called lasted seven years Such a plan was even more liable to error than the device of reckoning by reigns, and a specially confusing feature was that the first year of the period dated retrospectively from the previous, New Year's day; so that events were often recorded as having occurred in the final year of one period and in the opening year of another. This system was originally imported from China in the year A.D. 645, and is at present in use; the year 1910 being the forty-third of the $M e i j i$ (Enlightenment and Peace) period.

go The third system was that of the sexagenary cycle. This was operated after the manner of a clock having two concentric dials, the circumference of the larger dial being divided into ten equal parts; each marked with one of the ten "celestial signs," and the circumference of the smaller dial being divided into twelve equal parts each marked with one of the twelve signs of the zodiac. The long hand of the clock, pointing to the larger dial, was supposed to make one revolution in ten years, and the shorter hand, pointing to the small dial, revolved once in twelve years!s. Thus, starting from the point where the marks on the two dials coincide; the long hand gained upon the short hand by onesixtieth each year, and once in every sixty years the two hands were found at the point of conjunction. Years were indicated by naming the "celestial stem" and the zodiacal sign to which the imaginary hands happen to be pointing, just as clock-time is indicated by the minutes read from the long hand and the hours from the short. The sexagenary cycle came into use in China in $623 \mathrm{B.C}$ The exact date of its importation into Japan is unknown, but it was probably about the end of the fourth century A.D. It is a sufficiently aqcu- 
rate manner of counting so long as the tale of cycles is carefully kept, but any neglect in that respect exposes the calculator to an error of sixty years or some multiple of sixty. Keen scrutiny and collation of the histories of China, Korea, and Japan have exposed a mistake of at least 120 years connected with the earliest employment of the sexagenary cycle in Japan:

'The fourth method correspon's to that adopted in Europe where the number' of a year is referred to the birth 'of Christ. In Japan, the accession of the Emperor Jinmu - 660 B.c. - is taken for a basis; and thus the Occidental year 1910 becomes the 2570th year of the Japanese dynasty: With such methods of reckoning some collateral evidence is needed before accepting any of the dates given in Japanese annals. Kaempfer and even Rein were content to endorse the chronology of the Chronicles - the Records avoid dates altogether - but other Occidental scholars ${ }^{1}$ have with justice been more'sceptical; and their doubts' have been confirmed by several eminent Japanese historians in recent) times. Where, then, is collateral evidence to be found?

In the pages of Chinese and Korean history. There is, of course, no inherent reason for attributing to Korean history accuracy superior to that of Japanese' history. But in China the habit of continuously compiling written annals had been practised for many centuries before Japanese events began even to fur-i nish materials for romantic reeitations, and no serious errors have been proved against Chinese historiographers during the periods when comparison with Japanese annals is feasible. In Korea's case, too, verification is partially possible. Thus, during the first five centuries of the Christian era, Chinese annals contain sixteen notices of events in Korea. If Korean history be examined as to these events, it is found to agree in ten instances, to disagree in: two, and tó be silent in four. ${ }^{2}$ This record tends strongly to confirm the accuracy of the Korean annals, and it is further to be remembered that the Korean peninsula? was divided during many centuries into three principalities whose records serve, as mutual checks. Finally, Korean historians do not make-any such demand upon our credulity as the Japanese do in the matter of length of sovereigns? reigns. For example, while the number of successions to the throne of Japan during the first four centuries of the Christian era is set down as seven only, making fifty-six years the average duration of a reign, the corresponding num-? bers for the three Korean principalities are sixteen, seventeen, and sixteen, respectively, making the average length of a reign from twenty-four to twentyfive years. It is, indeed, a very remarkable fact that whereas theiverage age of the first seventeen Emperors of Japan, who are supposed to have reigned from 660 B.C. down to A.D. 399 , was 109 years, this incredible habit of longevity ceased abruptly from the beginning of the fifth century, the average age of the next seventeen having been only sixty-one and a half years; and lit is a most suggestive coincidence that the year A.D. 461 is the first date of the accepted Japanese chronology which is confirmed by Korean authorities.

srulisulavet

In fact, the conclusion is almost compulsory that Japanese authentic history, so far as dates are concerned; begins from the fifth century. Chinese annals, it is true, furnish one noteworthy and much earlier confirmation of Japanese records. They show that Japan was ruled by a very renowned queen during the first half of the third century of the Christian era; and it was precisely at: that epoch that the Empress Jingo is related by Japanese history to have made herself celebrated at home and abroad. Chinese historiographers, however,

[' Notably Bramsen, Aston, Satow, and Chamberlain.]

[2 Aston's essay on Early Japanese History.] 
put Jingō's death in the year A.D. 247, whereas Japanese annalists give the date as 269. Indeed there is reason to think that just at this time - second half of the third century - some special causes operated to disturb historical coherence in Japan, for not only does Chinese history refer to several signal events in Japan which find no place in the latter's records, but also Korean history indicates that the Japanese dates of certain cardinal incidents err by exactly 120 years. Two cycles in the sexagenary system of reckoning constitute 120 years, and the explanation already given makes it easy to conceive the dropping of that length of time by recorders having only tradition to guide them.

On the whole, whatever may be said as to the events of early Japanese history, its dates can not be considered trustworthy before the beginning of the fifth century. There is evidently one other point to be considered in this context; namely, the introduction of writing. Should it appear that the time when the Japanese first began to possess written records coincides with the time when, according to independent research, the dates given in their annals begin to synchronize with those of Chinese and Korean history, another very important landmark will be furnished. There is such sychronism, but it is obtained at the cost of considerations which cannot be lightly dismissed. For, although it is pretty clearly established that an event which occured at the beginning of the fifth century preluded the general study of the Chinese language in Japan and may not unreasonably be supposed to have led to the use of the Chinese script in compiling historical records, still it is even more clearly established that from a much remoter era Japan had been on terms of some intimacy with hèr neighbours, China and Korea, and had exchanged written communications with them, so that the art of 'writing was assuredly known to her long before' the fifth century of the Christian era, to whatever services she applied it. This subject will present itself again for examination in more convenient circumstances.

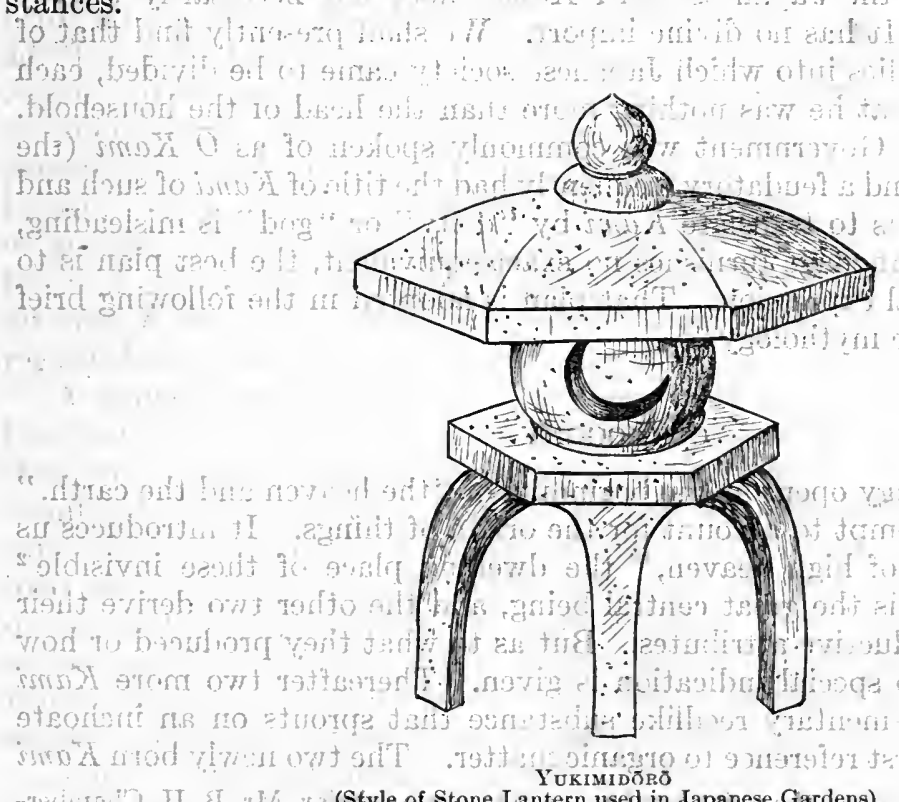




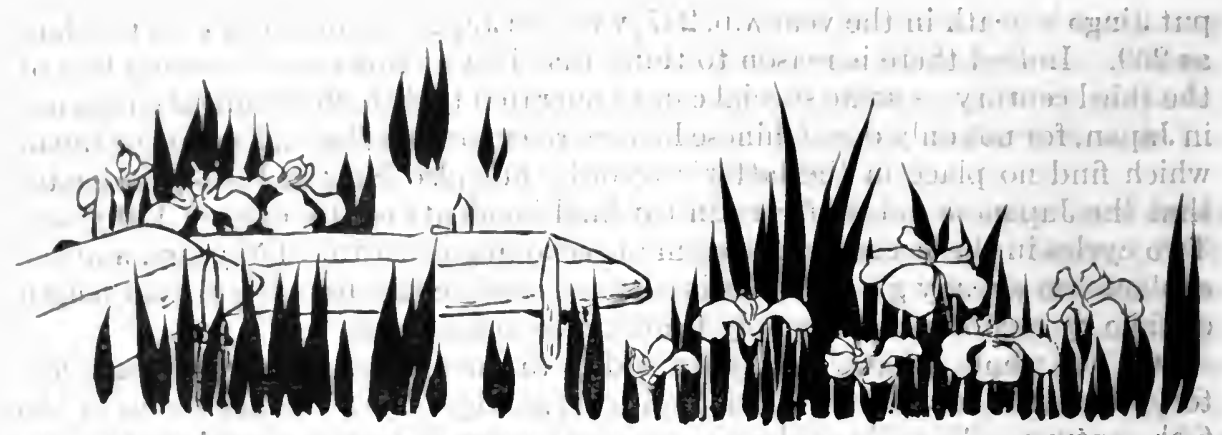

"Yatsuhashi" Style ó Garden Bridge

CHAPTER II

\section{JAPANESE MYTHOLOGY}

\section{$K A M I$}

THE mythological page of a country's history has an interest of its own apart from legendary, relations; it affords indications of the people's creeds and furnishes traces of the nation's genesis. In Japan's mythology there is a special diffeulty: for the interpreter - a difficulty of nomenclature. It has been the constant habit of foreign writers of Japan's story to speak of an "Age of Gods" (Kami no yo). But the Japanese word Kami ${ }^{1}$ docs not necessarily convey any such meaning. It has no divine import. We shall presently find that of the hundreds of families into which Japanese society came to be divided, each had its Kami, and that he was nothing more than the head of the household. Fifty years ago, the Government was commonly spoken of as $\bar{O}$ Kami (the Honourable Head), and a feudatory frequently had the title of Kami of such and such a locality. Thus to translate Kami by "deity" or "god" is misleading, and as the English language furnishes no exact equivalent, the best plan is to adhere to the original expression. That plan is adopted in the following brief summary of Japanese mythology.

\section{COSMOGONY}

Japanese mythology opens at the beginning of "the heaven and the earth." But it makes no attempt to account for the origin of things. It introduces us at once to a "plain of high heaven," the dwelling place of these invisible 2 Kami, one of whom is the great central being, and the other two derive their titles from their productive attributes. But as to what they produced or how they produced it, no special indication is given. Thereafter two more Kami are born from an elementary reedlike substance that sprouts on an inchoate earth. This is the first reference to organic matter. The two newly born Kami lain.]

[ ${ }^{2}$ Much stress is laid unon the point by that most accurate scholar, Mr. B. H. Chamber-

${ }^{2}$ The expression here translated "invisible" has been interpreted in the sense that the Kami "hid their persons," i.e., died, but the true meaning seems to be that they were invisible.] 
are invisible like their predecessors, and like them are not represented as taking any part in the creation. They are solitary, unseeable, and functionless, but the evident idea is that they have a more intimate connexion with cosmos than the Kami who came previously into existence, for one of them is named after the reed-shoot from which he emanated, and to the other is attributed the property of standing eternally in the heavens.

Up to this point there has not been any suggestion of measuring time. But now the record begins to speak of "generations!" Two more solitary and invisible beings are born, one called the Kami who stands eternally on earth, the other the "abundant integrator." Each of these represents a generation, and it will be observed that up to this time no direct mention whatever is made of sex. Now, however, five generations ensue, each consisting of two Kami, a male and a female, and thus the epithet "solitary" as applied to the first seven Kami becomes intelligible. All these generations are represented as gradually approximating to the exercise of creative functions, for the names ${ }^{1}$ become more and more suggestive of earthly relations. The last couple, forming the fifth generation, are Izanagi and Izanami, appellations signifying the male Kami of desire and the female Kami of desire. By all the other Kami these two are commissioned to "make, consolidate, and give birth to the drifting land," a jewelled spear being given to them as a token of authority, and a floating bridge being provided to carry them to earth. Izanagi and Izanami thrust the spear downwards and stir the "brine" beneath, with the result that it coagulates, and, dropping from the spear's point, forms the first of the Japanese islands, Onogoro. This island they take as the basis of their future operations, and here they beget, by ordinary human processes - which are described without any reservations - first," "a great number of islands, and next," a great number of Kami." It is related that the first effort of procreation was not successful, the outcome being a leechlike abortion and an island of foam, the former of which was sent adrift in a boat of reeds. The islands afterwards created form a large part of Japan, but between these islands and the Kami, begotten in succession to them, no connexion is traceable. In several cases the names of the Kami seem to be personifications of natural objects. Thus we have the Kami of the "wind's breath," of the sea, of the rivers, of the "water-gates" (estuaries and ports), of autumn, of "foam-calm," of "bubbling waves," of "water-divisions," of trees, of mountains, of moors, of valleys, etc. But with very rare exceptions, all these Kami have no subsequent share in the scheme of things and cannot be regarded as evidence that the Japanese were nature worshippers.

A change of method is now noticeable. Hitherto the process of production has been creative; henceforth the method is transformation preceded by destruction. Izanami dies in giving birth to the Kami of fire, and her body is disintegrated into several beings, as the male and female Kami of metal mountains, the male and female Kami of viscid clay; the female Kami of abundant food, and the Kami of youth; while from the tears of Izanagi as he laments her decease is born the female Kami of lamentation. Izanagi then turn's upon the child, the Kami of fire, which has cost Izanami her life, and cuts off its head; whereupon are born from the blood that stains his sword and spatters the rocks eight Kami, whose names are all suggestive of the violence that-called them into existence. An equal number of Kami, all having sway over mountains, are born from the head and body of the slaughtered child.

$\left[{ }^{1}\right.$ The Kami of mud-earth; the Kami of germ-integration; the Kami of the great place; the Kami of the perfect exterior, etc.] 
At this point an interesting episode is recorded. Izanagi visits the "land of night," with the hope of recovering his spouse. ${ }^{1}$ He urges her to return, as the work in which they were engaged is not yet completed. She replies that, unhappily having already eaten within the portals of the land of night, she may: not emerge without the permission of the $\mathrm{Kami}^{2}$ of the underworld, and she conjures him, while she is seeking that permission, not to attempt to look on her face. He, however, weary of waiting, breaks off one of the large teeth of the comb that holds his hair ${ }^{3}$ and, lighting it, uses it as a torch. He finds Izanami's body in astate of putrefaction, and amid the decaying remains eight Kami of thunder have been born and are dwelling. Izanagi, horrified, turns and flees, but Izanami, enraged that she has been "put to shame," sends the "hideous hag of hades" to pursue him.1. He obtains respite twice; first by throwing down his head-dress, which is converted into grapes, and then casting away his comb, which is transformed into bamboo sprouts, and while the hag stops to eat these delieacies, he flees. Then Izanami sends in his pursuit the eight Kami of thunder with fifteen hundred warriors of the underworld ${ }^{4} \mathrm{He}$ holds them off for a time by brandishing his sword behind him, and finally, on reaching the pass from the nether to the upper world, he finds three peaches growing there with which he pelts his pursuers and drives them back. The peaches are rewarded with the title of "divine fruit,", and entrusted with the duty of thereafter helping all living people ${ }^{5}$ in the central land of "reed plains" 6 as they have helped Izanagi.

This curious legend does not end here. Finding that the hag of hades, the eight Kami of thunder, and the fifteen hundred warriors have all been repulsed, Izanami herself goes in pursuit. But her way is blocked by a huge rock which Izanagi places in the "even pass of hades," and from the confines of the two worlds the angry pair exchange messages of final separation, she threatening to kill a thousand folk daily in his land if he repeats his acts of violence; and he declaring that, in such event, he will retaliate by causing fifteen hundred to be born.

In all this, no mention whatever is found of the manner in which human beings come into existence: they make their appearance upon the scene as though they were a primeval part of it. Izanagi, whose return to the upper world takes place in southwestern Japan, ${ }^{7}$ now cleanses himself from the pollution he has incurred by contaet with the dead, and thus inaugurates the rite of purification practised to this day in Japan. The Records describe minutely the process of his unrobing before entering a river, and we learn incidentally that he wore a girdle, a skirt, an upper garment, trousers, a hat, bracelets on each arm, and a necklace, but no mention is made of footgear. Twelve Kami are born from these various articles as he diseards them, but without exception these additions to Japanese mythology seem to have nothing to do with the scheme of the universe: their titles appear to be wholly capricious, and apart from figuring

${ }^{1}$ It is unnecessary to comment upon the identity of this incident with the legend of Orpheus and Eurydice.]

[2 It will be obseryed that we hear of these Kami now for the first time.]

[3 This is an obvious example of a charge of ten preferred against the compilers of the Records - that they inferred the manners and customs of remote antiquity from those of their own time.]

[ Again we have here evidence that the story of creation, as told in the Records, is not supposed to be complete. It says nothing as to how the denizens of the underworld came into existence.\}

[s The first mention of human beings.]

[6 This epithet is given to Japan.]

[7 At Himuka in Kyūshū, then called Tsukushi.] 
once upon the pages of the Records they have no claim to notice. The same may be said of eleven among fourteen Kami thereafter born from the pollution which Izanagi washes off in a river.

But the last three of these newly created beings act a prominent part in the sequel of the story. "They are the "heaven-shining Kami". (Amaterasu-ō-miKami), commonly spoken of as the "goddess of the Sun;" the Kami of the Moon, and the Kami of force. ${ }^{1}$ Izanagi expresses much satisfaction at the begetting of these three. He hands his necklace to the Kami of the Sun and commissions her to rule the "plain of heaven;" he confers upon the Kami of the Moon the dominion of night; and he appoints the Kami of force (Susanoo) to rule the sea-plain. The Kami of the Sun and the Kami of the Moon proceed at once to their appointed task, but the Kami of force, though of mature age and wearing a long beard, neglects his duty and falls to weeping, wailing, and fuming. Izanagi inquires the cause of his discontent, and the disobedient Kami replies that he prefers death to the office assigned him; whereupon he is forbidden to dwell in the same land with Izanagi and has to make his abode in Ömi province "Then he forms the idea of visiting the "plain of high heaven" to' bid farewell to his sister, the goddess of the Sun.

dit But his journey is attended with such a shaking of mountains and seething of rivers that the goddess, informed of his recalcitrancy and distrusting his purpose, makes preparations to receive him in warlike guise, by dressing her hair in male fashion (i.e. binding it into knots), by tying up her skirt into the shape of trousers, by winding a string of five hundred curved jewels round her head and wrists, by slinging on her back two quivers containing a thousand arrows and five hundred arrows respectively, by drawing a guard on her left forearm, and by providing herself with a bow and a sword:

97s The Records and the Chronicles agree in ascribing to her such an exercise of resolute force that she stamps her feet into the ground as though it had been soft snow and scatters the earth about. Susanoo, however, disavows all evil intentions, and agrees to prove his sincerity by taking an oath and engaging in a Kami-producing competition, the condition being that if his offspring be female, the fact' shall bear condemnatory import; but if male, the verdict shall be in his favour. For the purpose of this trial, they stand on opposite sides of a river (the Milky Way). Susanoo hands his sword to Amaterasu-o-mi-Kami; who breaks it into three pieces, chews the fragments, and blowing them from her mouth, produces three female Kami. She then lends her string of five hundred jewels to Susanoo and, he, in turn, crunches them in his mouth and blows out the fragments which are transformed into five male Kami. The beings thus strangely produced have comparatively close connexions with the mundane scheme, for the three female Kami- euphoniously designated Kami of the torrent mist, Kami of the beautiful island; and Kami of the cascadebecome tutelary goddesses of the shrines in Chikuzen province (or the sacred island Itsuku-shima), and two of the male Kami become ancestors of seven and twelve families, respectively, of hereditary nobles.

On the "high plain of heaven," however, trouble is not allayed. The Sun goddess judges that since female Kami were produced from the fragments of Susanoo's sword and male Kami from her own string of jewels, the test which he himself proposed has resulted in his conviction; but he, repudiating that verdict, proceeds to break down the divisions of the rice-fields laid out by the

[1,Mr. Chamberlain translates the title of this Kami "brave, swift, impetuous, male, augustness."] 
goddess, to fill up the ditches, and to defile the palace-details which suggest either that, according to Japanese tradition, heaven has its agriculture and architecture just as earth has, or that the "plain of high heaven" was really the name of a place in the Far East. The Sun goddess makes various excuses for her brother's lawless conduct, but he is not to be placated. His next exploit is to flay a piebald horse and throw it through a hole which he breaks in the roof of the hall where the goddess is weaving garments for the Kami. In the alarm thus created, the goddess ${ }^{1}$ is wounded by her shuttle, whereupon she retires into a cave and places a rock at the entrance, so that darkness falls upon the "plain of high heaven". and upon the islands of Japan, ${ }^{2}$ to the consternation of the Kami of evil, whose voices are heard like the buzzing of swarms of flies.

Then follows a scene perhaps the most celebrated in all the mythological legends; a scene which was the origin of the sacred dance in Japan and which furnished to artists in later ages a frequent motive. The "eight hundred myriads" of Kami - so numerous have the denizens of the "plain of high heaven" unaccountably become - assemble in the bed of the "tranquil river", to confer about a means of enticing the goddess from her retirement. They entrust the duty of forming a plan to the Kami of "thought combination," now heard of for the first time as a son of one of the two producing Kami, who, with the "great central" Kami, constituted the original trinity of heavenly denizens. This deity gathers together a number of barn-yard fowl to signal sunrise, places the Kami of the "strong arm" at the entrance of the cave into which the goddess has retired, obtains iron from the "mines of heaven" and causes it to be forged into an "eight-foot". mirror, appoints two Kami to procure from Mount Kagu a "five-hundred branched" sakaki tree (cleyera Japonica), from whose branches the mirror together with a "five-hundred beaded" string of curved jewels and blue and white streamers of hempen cloth and paper-mulberry cloth are suspended, and causes divination to be performed with the shoulder blade of a stag.

Then, while a grand liturgy is recited, the "heaven-startling" Kami, having girdled herself with moss, crowned her head with a wreath of spindle-tree leaves and gathered a bouquet of bamboo grass, mounts upon a hollow wooden vessel and dances, stamping so that the wood resounds and reciting the ten numerals repeatedly. Then the "eight-hundred myriad" Kami laugh in unison, so that the "plain of high heaven": shakes with the sound, and the Sun goddess, surprised that such gaiety should prevail in her absence, looks out from the cave to ascertain the cause. She is taunted by the dancer, who tells her that a greater than she is present, and the mirror being thrust before her, she gradually comes forward, gazing into it with astonishment; whereupon the Kami of the "strong arm" grasps her hand and drags her out; while two other Kami ${ }^{4}$ stretch behind her a rope made of straw, pulled up by the roots, ${ }^{5}$ to prevent her return, and sunshine once more floods the "plain of high heaven."

[1 According to the Records, it is the attendants of the goddess that suffer injury.]

[2 Referring to this episode, Aston writes in his Nihongi: "Amaterasu-ō-mi-Kami is throughout the greater part of this narrative an anthropomorphic deity, with little that is speeially characteristic of her solar functions. Here, however, it is plainly the sun itself which witholds its light and leaves the world to darkness. This inconsistency, which has greatly exercised the native theologians, is not peculiar to Japanese inyth."]

[3 The Milky Way.]

[ These two are the ancestors of the Kami of the Nakatomi and the Imibe hereditary corporations, who may be described as the high priests of the indigenous cult of Japan.]

[ ${ }^{5}$ This kind of rope - called shime-nawa, an abbreviation of shiri-kume-nawa - may be seen festooning the portals of any Shintō shrine.] 
The details of this curious legend deserve attention for the sake of their close relation to the observances of the Shinto cult. Moreover, the mythology now täkes a new departure. At the time of Iżanagi's return from hades; vague reference is made to human beings, but after Susanoo's departure from the "plain of high heaven," he is represented as holding direct converse with them. There is an interlude which deals with the foodstuffs of mortals. Punished with a fine of a great number of tables ${ }^{1}$ of votive offerings, his beard cut off, and the nails of his fingers and toes pulled out; Susanoo is sentenced to expulsion from heaven. He seeks sustenance from the Kami of food, and she responds by taking from the orifices of her body various kinds of viands which she offers to him. But he, deeming himself insulted, kills her, whereupon from her corpse are born rice, millet,' small and large beans, and barley. "These are taken by one of the two Kami of production, and by him they are caused to be used as seeds.

Thereafter Susanoo descends to a place at the headwaters of the river Hi (Izumo province). Seeing a chop-stick float down the stream, he infers the existence of people higher up the river, and going in search of them; finds an old man and an old woman lamenting over and caressing a girl. The old man says that he is an earthly Kami, son of the Kami of mountains, who was one of the thirty-five Kami borne by Izanami before her departure for hades. : He explains that he had originally eight daughters, but that every year an eightforked serpent has come from the country of Koshi and devoured one of the maidens, so that there remain's only Lady Wonderful, whose time to share her sisters ' fate is now at hand. It is a huge monster, extending over eight valleys and eight hills, its eyes red like winter cherries, its belly bloody and inflamed, and its back overgrown with moss and conifers. Susanoo, having announced himself as the brother of the Sun goddess, receives Lady Wonderful and at once transforms her into a comb which he places in his hair. He then instructs the old man and his wife to build a fence with eight gates, placing in every gate a vat of rice wine.

Presently the serpent arrives, drinks the wine, and laying down its heads to sleep, is cut to pieces by Susanoo with his ten-span sabre. In the body of the serpent the hero finds a sword, "great and sharp,". which he sends to the Sun goddess, at whose shrine in Ise it is subsequently found and given to the famous warrior, Yamato-dake, when he is setting out on his expedition against the Kumaso of the north. The sword is known as the "Herb-queller." Susanoo then builds for himself and Lady Wonderful a palace at Suga in Izumo, and composes a celebrated verse of Japanese poetry. ${ }^{2}$ Sixth in descent from the offspring of this union is the "Kami of the great land," called also the "GreatName Possessor," or the "Kami of the reed plains," or the "Kami of the eight thousand spears, " or the "Kami of the great land of the living," the last name being antithetical to Susanoo's title of "Ruler of Hades."

Several legends are attached to the name of this multinominal being legends in part romantic, in part supernatural, and in part fabulous. His eighty brethren compel him to act as their servant when they go to seek the hand of Princess Yakami of Inaba. But on the way he succours a hare which

[ ${ }^{1}$ The offerings of food in religious services were always placed upon small, low tables.]

[2" Many clouds arise,

"On all sides a manifold fence,

"To receive within it the spouse,

"They form a manifold fence -

"Ah! that manifold fence."] 
they have treated brutally, and the little animal promises that he, not they, shall win the princess, though he is only their baggage-bearer., Enraged at the favour she shows him, they seek in various ways to destroy him: first by rolling down on him from a mountain a heated rock; then by wedging him into the cleft of a tree, and finally by shooting him... But he is saved by his mother, and takes refuge in the province of Kii (the Land of Trees) at the palace of the "Kami of the great house." Acting on the latter's advice, he visits his ancestor, Susanoo, who is now in hades, and seeks eounsel as to some méans of overcoming his eighty enemies. But instead of helping him, that unruly Kami endeavours to compass his death by thrusting him into a snake-house; by putting him into a nest of centipedes and wasps, and finally by shooting an arrow into a moor, sending him to seek it and then setting fire to the grass. $\mathrm{He}_{\mathrm{l}}$ is saved from the first two perils through the agency of miraculous searves given to him by Princess Forward, Susanoo's daughter, who has fallen in love with him; and from the last dilemma a mouse instructs him how to emerge.

A curious episode concludes this recital: Susanoo requires that the parasites shall be removed from his head by his visitor. These parasites are centipedes, but the Great-Name Possessor, again acting under the instruction of Princess Forward, pretends to be removing the centipedes, whereas he is in reality spitting out a mixture of berries and red earth. Susanoo falls asleep during the process, and the Great-Name.Possessor binds the sleeping Kami's hair to the rafters of the house, places a huge rock at the entrance, seizes Susanoo's life-preserving sword and life-preserving bow and arrows as also his saered lute, and taking Princess Forward on his back, flees. The lute brushes against a tree, and its sound rouses Susanoo. But before he can disentangle his hair from the rafters, the fugitives reach the confines of the underworld, and the enraged Kami, while execrating this visitor who has outwitted him, is constrained to direct him how to overcome his brethren and to establish his rule firmly. In all this he succeeds, and having married Princess Yakami, to whom he was previously engaged, ${ }^{3}$ he resumes the work left unfinished by Izanagi and Izanami, the work of " making the land."

The exact import of this process, "making the land," is not discernible. In the hands of Izanagi and Izanami it resolves itself into begetting, first, a number of islands and, then, a number of Kami. At the outset it seems to have no more profound significance for the Great-Name Possessor. Several generations of Kami are begotten by him, but their names give no indication of the parts they are supposed to have taken in the "making of the land." They are all born in Japan, however, and it is perhaps significant that among them the one child - the Kami of wells - brought forth by Princess, Yakami, is not included. Princess Forward has no children, a fact which doubtless augments her jealousy of her husband's amours; jealousy expressed in verses that show no mean poetic skill. Thus, the Great-Name Possessor on the eve of a journey from Izumo to Yamato, sings as he stands, with one hand on his saddle and one foot in the stirrup:-

Though thou sayest thou willst not weep

If like the flocking birds, I flock and depart,

[' ${ }^{1}$ A son of Susanoo. Under the name of Iso-Takeru he is recorded to have brought with him a quantity of seeds of trees and shrubs, which he planted, not in Korea, but in Tsukushi (Kyưshū) and the eight islands of Japan. These words "not in Korea" are worthy of note, as will presently be appreciated.]

[" "Sacred" because divine revelations were supposed to be made through a lute-player.]

$\left[{ }^{3}\right.$ In the story of this Kami, we find the first record of conjugal jealousy in Japan. Princess Forward strongly objects to her husband's excursions into novel fields.] 
If like the led birds, I am led away and

Depart; thou wilt hang down thine head like

A single Eulalia upon the mountain and

Thy weeping shall indeed rise as the mist of

The morning shower.

Then the Empress, taking a wine-cup, approaches and offers it to him, saying :-

Oh! Thine Augustness, the Deity-of-Eight-Thousand-Spears! Thou, my dear Master-of-the-Great-Land indeed,

Being a man, probably hast on the various island headlands thou seest,

And on every beach-headland that thou lookest on,

A wife like the young herbs. But as for me, alas!

Being a woman, I have no man except thee; I have no spouse except thee.

Beneath the fluttering of the ornamented fence,

Beneath the softness of the warm coverlet,

Beneath the rustling of the cloth coverlet,

Thine arms, white as rope of paper-mulberry bark softly patting my breast soft as the melting snow,

And patting each other interlaced, stretching out and pillowing ourselves on each other's arms,

True jewel arms, and with outstretched legs, will we sleep. ${ }^{1}$

"Having thus sung, they at once pledged each other by the cup with their hands on each other's necks." It is, nevertheless, from among the children born on the occasion of the contest between the Sun goddess and Susanoo that the Great-Name Possessor first seeks a spouse - the Princess of the Torrent Mist - to lay the foundation of fifteen generations of Kami, whose birth seems to have been essential to the "making of the land," though their names afford no clue to the functions discharged by them. From over sea, seated in a gourd and wearing a robe of wren's feathers, there comes a pigmy, Sukuna Hikona, who proves to be one of fifteen hundred children begotten by the Kami of the original trinity. Skilled in the arts of healing sickness and averting calamities from men or animals, this pigmy renders invaluable aid to the Great-Name Possessor. But the useful little Kami does not wait to witness the conclusion of the work of "making and consolidating the country." Before its completion he takes his departure from Cape Kumano in Izumo to the "everlasting land" I- a region commonly spoken of in ancient Japanese annals but not yet definitely located. He is replaced by a spirit whose coming is thus described by the Chronicles:-

After this (i.e. the departure of Sukuna), wherever there was in the land a part which was imperfect, the Great-Name Possessor visited it by himself and succeeded in repairing it. Coming at last to the province of Izumo, he spake and said: "This central land of reed plains had always been waste and wild. The very rocks, trees, and hutswere all given to violence. But I have now reduced it to submission, and there is none that is not compliant." Therefore he said finally: "It is I; and I alone; who now govern this land. Is there, perchance, anyone who could join with me in governing the world?" Upon this a divine radiance illuminated the sea, and of a sudden there was something which floated towards him and said: "Were I not here, how couldst thou subdue this land? It is because I am here that thou hast been enabled to accomplish this mighty undertaking.", Then the Great-Name Possessor inquired, saying, "Then who art thou?" It replied and said: "I am thy guardian spirit, the wonderous spirit." Then' said the Great-Name Possessor: "True, I know therefore that thou art my guardian spirit, the wonderous spirit. Where dost thou now wish to dwell?" The spirit answered and said, "I wish to dwell on Mount Mimoro in the province of Yamato." Accordingly he built a shrine in that place and made the spirit go and dwell there. This is the Kami of Ōmiwa. ${ }^{2}$

After the above incident, another begetting of Kami takes place on a large scale, but only a very few of them - such as the guardian of the kitchen, the protector of house-entrances, the Kami of agriculture, and so forth-have any intelligible place in the scheme of things.

${ }^{1}$ B. H. Chamberlain.l 


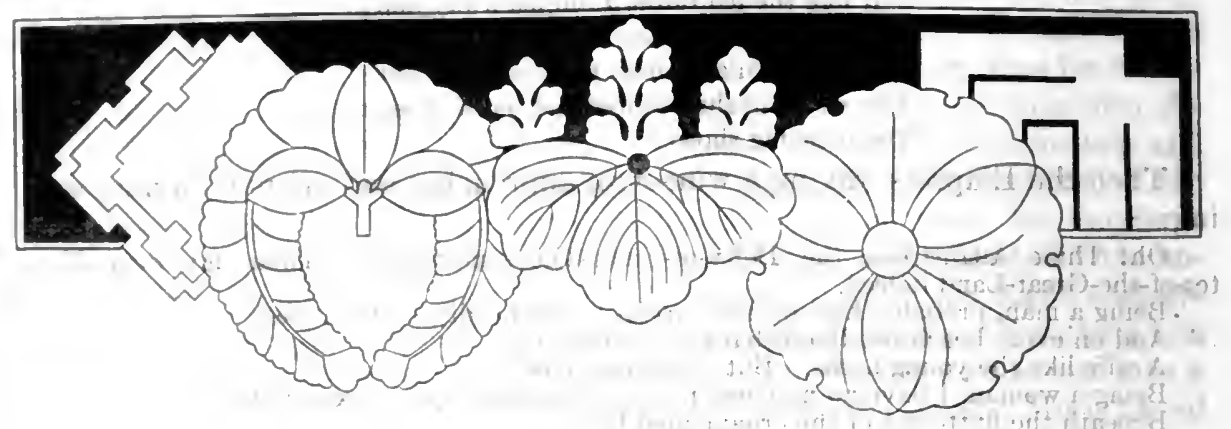

Cresta

\section{CHAPTER III}

\section{JAPANESE MYTHOLOGY (Continued)}

\section{THE SUBJUGATION OF JAPAN}

THE dividing line between mythological tradition and historical legend is now reached. It will have been observed that, after the descent of Susanoo, the Kami on the "plain of high heaven" took no further part in "making" or "ruling" the "ever fruitful land of reed-covered moors, and luxuriant ricefields," as Japan was called. Everything was left in the hands of Susanoo, the insubordinate Kami, who had been expelled from heaven for his destructive violence. His descendant in the sixth generation, the Great-Name Possessor, now held supreme sway over the islands, in conjunction with a number of his own relations, his seat of power being in the province of Izumo. At this juncture the goddess of the Sun decided that a sovereign should be sent down to govern the land of many islands, and she chose for this purpose the son of the eldest ${ }^{1}$ of the five Kami born from her necklace during the procreation competition with Susanoo.

In the first place, however, it was considered necessary to reduce the country, to order, observation having shown it to be in a state of tumult. For that purpose the second of the five necklace Kami - considered "the most heroic"? of all the beings on the "plain of high heaven" - was despatched. But he "curried favour" with the Great-Name Possessor and took up his abode in Japan. At the end of three years, ${ }^{2}$ seeing that he had not returned, it was decided by the Kami in council to send another envoy, the Heavenly Young Prince. But he proved even more disloyal, for he married the daughter of the Great-Name Possessor, famous for her beauty, ${ }^{3}$ and planning to succeed his father-in-law as sovereign of the land, remained in Izumo for eight years. A third conclave of the Kami was now convened by the Sun goddess and her coadjutor, the Great-Producing Kami, ${ }^{1}$ and they decided to despatch a pheasant to make observations.

[1 This Kami married a daughter of one of the two Great-Producing Kami who belonged to the original trinity, and who eo-operates with the Sun goddess throughout.]

[? This is the first mention of a measure of time in the Records.]

[ ${ }^{3}$ She was ealled Princess Undershining, because her beauty shone through her raiment.] 
The bird flew down and lit on a cassia tree at the gate of the Heavenly Young Prince's dwelling, whereupon the prince, at the instigation of a female spy, taking a bow given to him originally by the Great-Producing Kami, shot a shaft which pierced the bird's bosom; and, reaching the Milky Way where sat the Sun goddess and the Great-Producing Kami, was recognized by the latter, who threw it back to earth, decreeing that it should strike the prince were he guilty of treason, and leave him unharmed if the blood on the arrow was that of the earthly Kami whom he had been sent to quell. The shaft struck the prince and killed him.

At this point the course of the history is interrupted by an unintelligible description of the resulting obsequies - held in heaven according to the Chronicles, on earth according to the Records. Wild geese, herons, kingfishers, sparrows, and pheasants were the principal officiators; the mourning rites, which included singing, and dancing, ${ }^{1}$ continued for eight days and eight nights, and the proceedings were rudely interrupted by the prince's brother-in-law, who, coming to condole and being mistaken for the deceased; is so enraged by the error that he draws his sword, cuts down the mortuary house, and kicks away the pieces.

These two failures did not deter the Great-Producing Kami and the Sun goddess. They again took counsel with the other beings on the "plain of high heaven," and it was decided to have recourse to the Kami born from the blood that dropped from Izanagi's sword when he slew the Kami of fire. To one of these - the Kami of courage - the mission of subduing the land of many islands was entrusted, and associated with him in the work was the Kami of boats; a son of Izanagi and Izanami. The two descended to Izumo. They carried swords ten hand-breadths long, and having planted these upside down, they seated themselves on the points and delivered their message to the GreatName Possessor, requiring him to declare whether or not he would abdicate in favour of the newly named sovereign.

The Great-Name Possessor replied that he must consult his son, who was absent on a hunting expedition. Accordingly, the Kami of boats went to seek him, and, on being conducted into his father's presence, the latter declared his willingness to surrender, sealing the declaration by suicide. ${ }^{2}$ There remained, then, only the second son of the Great-Name Possessor to be consulted. He did not submit so easily. Relying on his great strength, he challenged the Kami of courage to a trial of hand grasping. 'But when he touched the Kami's hand it turned first into an icicle and then into a sword-blade, whereas his own hand, when seized by the Kami, was crushed and thrown aside like a young reed $\mathrm{He}$ fled away in terror, and was pursued by the Kami as far as the distant province of Shinano, when he saved his life by making formal submission and promising not to contravene the decision of his father and elder brother.

Then the Great-Name Possessor; having "lost his sons, on whom he relied,". agreed to abdicate provided that a shrine were built in memory of him," having its pillars made stout on the nethermost rock-bottom; and its cross-beams raised to the "plain of high heaven." " 3 :He handed over the broad-bladed

[ ${ }^{1}$ It has been conjectured, with much probability, that this singing and dancing was a ceremony in imitation of the rites performed to entice the Sun goddess from her cave. The motive was to resuscitate the dead.]

[ ${ }^{2} \mathrm{He}$ stepped on the side of his boat so as to upset it, and with hands crossed behind his back sank into the sea.]

[ ${ }^{3}$ This hyperbolical language illustrates the tone of the Records and the Chronicles. Applied to the comparatively humble buildings that served for residences in ancient Japan, the 
spear which had assisted him to pacify the land, and declaring that if he offered resistance, all the earthly $K a m i$, too, would certainly resist, he "hid in the eighty road-windings."

Thus, already in the eighth century when the Records and the Chronicles were compiled, suicide after defeat in battle had become a recognized practice. The submission and self-inflicted death of the Great-Name Possessor did not, however, save his followers. All the rebellious $K a m i$ were put to the sword by the envoys from the "plain of high heaven." This chapter of the annals ends with an account of the shrine erected in memory of the Great-Name Possessor. It was placed under the care of a grandson of the Kami born to Izanagi and Izanami, who is represented as declaring that he "would continue drilling fire for the Kami's kitehen until the soot hung down eight hand-breadths from the roof of the shrine of the Great-Producing Kami and until the earth below was baked to its nethermost rocks; and that with the fire thus drilled he would cook for him the fish brought in by the fishermen, and present them to him in baskets woven of split bamboos which would bend beneath their weight.":

\section{THE DESCENT UPON TSUKUSHI}

It had been originally intended that the dominion of Japan should be given to the senior of the five Kami born of the five-hundred-jewel string of the Sun goddess. But during the interval devoted to bringing the land to a state of submission, this Kami's spouse, the Princess of the Myriad Looms of the Luxuriant Dragon-fly Island, ${ }^{1}$ had borne a son, Hikoho no Ninigi, (Rice-Ears of Ruddy Plenty), and this boy having now grown to man's estate, it was decid? ed to send him as ruler of Japan. A number of Kami were attached to him as guards and assistants, among them being the Kami of "thought combination," who conceived the plan for enticing the Sun goddess from her cave and who occupied the position of chief councillor in the eonclave of high heaven the female $K a m i$ who danced before the cave; the female $K a m i$, who forged the mirror, and, in short, all the Kami who assisted in restoring light to the world. There were also entrusted to the new sovereign the curved-jewel chaplet of the Sun goddess, the mirror that had helped to entice her, and the sword (herbqueller) which Susanoo had taken from the body of the eight-headed serpent

These three objects thenceforth became the three sacred things of Japan. Strict injunetion was given that the mirror was to be regarded and revereneed exactly as though it was the spirit of the Sun goddess, and it was ordered that the Kami of "thought combination" should administer the affairs of the new kingdom. The fact is also to be noted that among the Kami attached to Hikoho no Ninigi's person, five - three male and two female - are designated by the Records as ancestors and ancestresses of as many hereditary corporations; a distinctive feature of the early Japan's polity. As to the manner of Hikoho no Ninigi's journey to Japan, the Chronicles say that the Great-Produeing Kami threw the coverlet of his couch over him and eaused him to cleave his way downwards through the clouds; but the Records allege that he deseended "shut up in the floating bridge of heaven."

The point has some interest as furnishing a traditional trace of the nature of this so-ealled invasion of Japan, and as helping to confirm the theory that description in the text is curiously exaggerated. The phrase here quoted finds frequent reproduction in the Shintō rituals.] shape.]

[ "Dragon-fly Island" was a name anciently given to Japan on account of the country's 
the "floating bridge of heaven," from which Izanagi thrust his spear downiwards into the brine of chaos, was nothing more than a boat. It will naturally be supposed that as Hikoho no Ninigi's migration to Japan was in the sequel of a long campaign having its main field in the province of Izumo, his immediate destination would have been that province, where a throne was waiting to be occupied by him, and where he knew that a rich region existed. But the Records and the Chronicles agree in stating that he descended on Kirishimayama ${ }^{1}$ in Tsukushi, which is the ancient name of the island of Kyūshü. This is one of the first eight islands begotten by Izanagi and Izanami. Hence the alternative name for Japan, "Land of the Eight Great Islands."

It was, moreover, to a river of Tsukushi that Izanagi repaired to cleanse himself from the pollution of hades. But between Kyūshū (Tsukushi) and Izumo the interval, is immense, and it is accentuated by observing that the mountain Kirishima, specially mentioned in the story, raises its twin peaks at the head of the Bay of Kagoshima in the extreme south of Kyūshü.. There is -very great diffieulty: in conceiving that an army whose ultimate destination was Izumo should have deliberately embarked on the shore of Kagoshima. The landing of Ninigi - his full name need not be repeated - was made with all precautions, the van of his army (kume) being commanded by the ancestor of the men who thenceforth held the highest military rank (otomo) through many centuries, and the arms carried being bows, arrows, and swords. ${ }^{2}$

bofl All the annals agree in suggesting that the newcomers had no knowledge of the locality, but whereas one account makes Ninigi consult and obtain permission from an inhabitant of the place, another represents him as expressing satisfaction that the region lay opposite to Kara (Korea) and received the beams of the rising and the setting sun, qualifications which it is not easy to associate with any part of southern Kyūshū.

At all events he built for himself a palace in accordance with the orthodox formula - its pillars made stout on the nethermost rock-bottom and its crossbeams made high to the plain of heaven - and apparently abandoned all idea of proceeding to Izumo. Presently he encountered a beautiful girl. She gave her name as Brilliant Blossom, and described herself as the daughter of the Kami of mountains - one of the thirty-five beings begotten by Izanagi and Izanami who would seem to have been then living in Tsukushi, and who gladly consented to give Brilliant Blossom. He sent with her a plentiful dower - many "tables" ${ }^{3}$ of merchandise - but he sent also her elder sister, Enduring-as-Rock, a maiden so ill favoured that Ninigi dismissed her with disgust, thus provoking the curse of the Kami of mountains, who declared that had his elder daughter been welcomed, the lives of the heavenly sovereigns ${ }^{4}$ would have been as long as her name suggested, but that since she had been treated with contumely, their span of existence would be comparatively short. Presently Brilliant Blossom became enceinte! Her lord, however, thinking that sufficient time had not elapsed for such a result, suspected her of infidelity with one of the earthly Kami,${ }^{5}$ whereupon she challenged the ordeal of fire, and building a parturition

[i Takachiho-dake is often spoken of as the mountain thus celebrated, but Takachiho is only the eastern, and lower, of the two peaks of Kirishima-yama.]:

[2 The swords are said to have been "mallet-headed," but the term still awaits explanation.]

[ This expression has reference to the fact that offerings at religious ceremonials were always heaped on low tables for laying before the shrine:]

[ The expression "heavenly sovereign" is here applied for the first time to the Emperors of Japan:]

[ The term "earthly" was applied to Kami born on earth, "heavenly" Kami being those born in heaven.] 
hut, passed in, plastered up the entrance, and set fire to the building. She was delivered of three children without mishap, and their names were Hosuseri (Fire-climax), Hohodemi (Fire-shine), and Hoori (Fire-subside).

\section{THE CASTLE OF THE SEA DRAGON}

At this stage the annals digress to relate an episode which has only collateral interest. Hosuseri and Hohodemi made fishing and hunting, respectively, their avocations. But.Hohodemi conceived a fancy to exchange pursuits; and importunel Hosuseri to agree. When, however, the former tried his luck at angling, he not only failed to catch anything but also lost the hook which his brother had lent him. This became the cause of a quarrel. Hosuseri taunted Hohodemi on the foolishness of the original exchange and demanded the restoration of his hook, nor would he be placated though Hohodemi forged his sabre into five hundred hooks and then into a thousand. "Wandering disconsolate, by the seashore, Hohodemi met the Kami of salt, who, advising him to consult the daughter of the ocean $K a m i,{ }^{2}$ sent him to sea in a "stout little boat."

After drifting for a time, he found himself at a palace beside which grew a many-branched cassia tree overhanging a well. He climbed into the tree and waited. Presently the handmaidens of Princess Rich Gem; daughter of the ocean Kami, came to draw water, and seeing a shadow in the well, they detected Hohodemi in the cassia tree. At his request they gave him water in a jewelled vessel, but instead of drinking, he dropped into the vessel a gem from his own neeklace, and the handmaidens, unable to detach the gem, carried the vessel to their mistress. Then the prineess went to look and, seeing a beautiful youth in the cassia tree, "exchanged glances". with him: The ocean Kami quickly recognized Hohodemi; led him in; seated him on a pile of many layers of sealskins ${ }^{3}$ overlaid by many layers of silk rugs; made a banquet for him, and gave him for wife Princess Rich Gem.

Three years passed tranquilly without the bridegroom offering any explanation of his presence. At the end of that time, thoughts of the past visited him and he "sighed." Princess Rich Gem took note of this despondency and reported it to her father, who now, for the first time, inquired the cause of Hohodemi's coming. Thereafter all the fishes of the sea, great and small, were summoned; and being questioned about the lost hook, declared that the $t_{a} i^{4}$ had recently complained of something sticking in its throat and preventing it from eating. "So the lost hook was recovered, and the ocean Kami instructed Hohodemi, when returning it to his brother, to warn the latter that it was a useless hook which would not serve its purpose, but would rather lead its possessor to ruin. He further instructed him to follow a method of rice culture the converse of that adopted by his brother, since he, the ocean Kami, would rule the waters. so as to favour Hohodemi's labours, and he gave him two jewels' having the property of making the ticle ebb and flow, respectively. 'These jewels were to be used against Hosuseri, if necessary:

Finally the Kami of the ocean instructed a crocodile to carry Hohodemi to his home. This was accomplished, and in token of his safe arrival, Hohodemi placed his stiletto on the crocodile's neck for conveyance to the ocean Kami.

[" "Weeping and lamenting" are the words in the Records.]

[2. One of the Kami begotten by Izanagi and Izanami.]

["Chamberlain translates this "sea-asses' skins," and conjectures that sea-lions or seals may be meant.]

[' Pagrus major.] 
The programme prescribed by the latter was now faithfully pursued, so that Hosuseri grew constantly poorer; and finally organized a fierce attack upon his younger brother, who, using the tide-flowing jewel, overwhelmed his assailants until they begged for mercy, whereupon the power of the tide-ebbing jewel was invoked to save them. The result was that Hosuseri, on behalf of himself and nis descendants for all time, promised to guard and respectfully serve his brother by day and by night. In this episode the hayabito had their origin. They were palace guards, who to their military functions added the duty of occasionally performing a dance which represented the struggles of their ancestor, Hosuseri, when he was in danger of drowning.

\section{BIRTH OF THE EMPEROR JIMMU}

After the composition of the quarrel described above, Princess Rich Gem arrived from the castle of the ocean Kami, and built a parturition hut on the seashore, she being about to bring forth a child. 'Before the thatch of cormorants' feathers could be completed, the pains of labour overtook her, and she entered the hut conjuring her husband not to spy upon her privacy, since, in order to be safely delivered, she must assume a shape appropriate to her native land. He, however, suffered his curiosity to overcome him, and peeping in, saw her in the form of an eight-fathom crocodile. It resulted that having been thus put to shame, she left her child and returned to the ocean Kami's palace, declaring that there should be no longer any free passage between the dominions of the ocean Kami and the world of men. "Nevertheless afterwards, although angry at her husband's having wished to peep, she could not restrain her loving heart," "and she sent her younger sister, Good Jewel, to nurse the baby and to be the bearer of a farewell song to Hohodemi.

ynir The Records state that the latter lived to the age of 580 years and that his mausoleum was built to the west of Mount Takachiho, on which his palace -stood. Thus for the first time the duration of a life is stated in the antique annals of Japan: His son, called Fuki-ayezu (Unfinished Thatch), in memory of the strange incident attending his birth, married Princess Good Jewel, his lown aunt; and by her had four sons... The first was named Itsuse (Five Reaches) and the youngest, Iware (a village in Yamato province). "This latter ultimately: became Emperor of Japan, and is known in history as Jimmu (Divine Valour), a posthumous name given to him many centuries after his death. ${ }^{1}$ From the time of this sovereign dates and events are recorded with full semblance of (accuracy in the Chronicles, but the compilers of the Records do not attempt to give more than a bald statement of the number of years each sovereign lived or reigned.

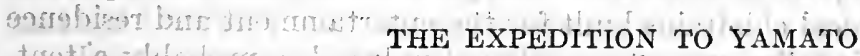

According to the Chronicles, the four sons of Fuki-ayezu engaged in a celebrated expedition from Tsukushi (Kyushu) to Yamato, but one alone, the youngest, survived. According to the Records, two only took part in the expedition, the other two having died before it set out. The former version seems more consistent with the facts, and with the manner of the two princes' deaths, as described in the Records. Looking from the east coast of the island of Kyūshū,

[ ${ }^{1}$ Posthumous names for the earthly Mikados were invented in the reign of Kwammu (A.D: 782-805), i.e., after the date of the compilation of the Records and the Chronicles. " But they are in universal use' by the Japanese, though to speak of a living sovereign by his posthumous name is a manifest anomaly.]

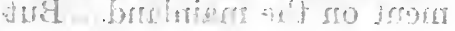


the province of Yamato lies to the northeast, at a distance of about 350 miles, and forms the centre of the Kii promontory.' From what has preceded, a reader of Japanese history is prepared to find that the objective of the expedition was Izumo, not Yamato, since it was to prepare for the occupation of the former province that the Sun goddess and her coadjutors expended so much energy. No explanation whatever of this discrepancy is offered, but it cannot be supposed that Yamato was regarded as a halfway house to Izumo, seeing that they lie on opposite coasts of $J$ apan and are two hundred miles distant.

The Chronicles assign the genesis of the enterprise to Prince Iware, whom they throughout call Hohodemi, and into whose mouth they put an exhortation - obviously based on a Chinese model - speaking of a land in the east encircled by blue mountains and well situated, as the centre of administrative authority. To reach Yamato by sea from Kyūshü two routes offer; one, the more direet, is by the Pacific Ocean straight to the south coast of the Kii promontory; the other is by the Inland Sea to the northwestern coast of the same promontory. The latter was chosen, doubtless because nautical knowledge and seagoing vessels were alike wanting.

It is not possible, however, to speak with confidence as to the nature of the ships possessed by the Japanese in early times. The first mention of : ships occurs in the story of Susanoo's arrival in Japan. He is said to have carried with him quantities of tree seeds which he planted in the Eight Island Country, the cryptomeria and the camphor being intended to serve as "floating riches," namely ships. This would suggest, as is indeed commonly believed, that the boats of that era were simply hollow trunks of trees.

Five centuries later, however, without any intervening reference, we find the Emperor Sujin urging the construction of ships as of cardinal importance for purposes of coastwise transport - advice which is hardly consistent with the idea of $\log$ boats. Again, in A.D. 274, the people of Izu are recorded as having built and sent to the Court a vessel one hundred feet long; and, twenty-six years later, this ship having become old and unserviceable, was used as fuel for manufacturing salt, five hundred bags of which were distributed among the provinces with directions to construct as many ships.

There is no mention in either the Chronicles or the Records of any marked change in the matter of marine architecture during all these years. The nature of the Kyūshū expeditionary ships must therefore remain a matter of conjecture, but that they were propelled by oars, not sails, seems pretty certain. Setting out from some point in Kyūshu - probably the present Kagoshima Bay - the expedition made its way up the east coast of the island, and reaching the Bungo Channel, where the tide is very rapid, obtained the services of a fisherman as pilot. Thence the fleet pushed on to Usa in the province of Buzen, at the north of Kyūshū, when two local chieftains built for the entertainment and residence of the princes and their followers a "one pillared palace" - probably a tent. The next place of call was Oka (or Okada) in Chikuzen, where they passed a year before turning eastward into the Inland Sea, and pushing on to one of the many islands off the coast of Aki, they spent seven years before proceeding to another island (Takashima) in Kibi, as the present three provinces of Bingo, Bitchū, and Bizen were then called. There they delayed for eight years - the Chronicles say three - in order to repair the oars of their vessels and to procure provisions.

Up to this time there had been no fighting or any attempt to effect a lodgment on the mainland. But the expedition was now approaching the narrow 
westerly entrance to the present Ōsaka Bay, where an army might be encountered at any moment The boats therefore sailed in line ahead, "the prow of each ship touching the stern of the other." Off the: mouth of the river, now known as the Yodo, they encountered such a high sea that they called the place Nami-hana (Wave Flowers), a name I subsequently abbreviated to Naniwa. Pushing on; the expeditionary force finally landed at a place - not now identifiable - in the province of Kawachi, which bounds Yamato on the west.

The whole voyage had occupied four years according to the Chronicles, sixteen according to the Records. At Kusaka they fought their first battle against the army of Prince Nagasune and were repulsed, Prince Itsuse being wounded by an arrow which struck his elbow. It was therefore decided to change the direction of advance, so that instead of moving eastward in the face of the sun, a procedure unpleasing to the goddess of that orb, they should move westward with the sun behind them. This involved re-embarking and sailing southward round the Kii promontory so as to land on its eastern coast, but the dangerous operation of putting an army on board ship in the presence of a victorious enemy was successfully achieved by the aid of skilfully used shields.

On the voyage round Kii, where stormy seas are frequent, the fleet encountered a heavy gale and the boats containing two of the princes were lost.1. Prince Itsuse had already died of his wound, so of the four brothers there now remained only the youngest, Prince Iware. It is recorded that, at the age of fifteen, he had been made heir to the throne, the principle of primogeniture not being then recognized, and thus the deaths of his brothers did not affect that question. Landing ultimately at Kumano on the southeast of Kii, the expeditionary force was stricken by! a pestilence, the prince himself not escaping. But at the behest of the Sun goddess, the Kami of thunder caused a sword of special virtue to come miraculously into the possession of an inhabitant of Kii, who carried it to the prince, and at once the sickness was stayed. When, however, the army attempted to advance into the interior, no roads were found and precipitous mountains barred the progress. In this dilemma the Sun goddess sent down the three-legged crow of the Sun ${ }^{2}$ to act as guide.

4\%. Thus indiscriminately are the miraculous and the commonplace intermixed. Following this bird, the invading force pushed on into Yamato, receiving the allegiance of a body of men who fished with cormorants in the Yoshino River and who doubtless supplied the army with food, and the allegiance of fabulous beings with tails; who came out of wells or through cliffs. It is related that the invaders forced the elder of two brothers into a gyn which he had prepared for their destruction; and that on ascending a hill to reconnoitre, Prince Iware observed an army of women and a force of eighty "earth-hiders (Tsuchi-gumo) with tails," by which latter epithet is to be understood bandits or raiders who inhabited caves.

How it fared with the amazons the annals do not say, but the eighty bandits were invited to a banquet and slaughtered in their cups... Still the expeditionary force encountered great opposition, the roads and passes being occupied by numerous hostile bands. An appeal was accordingly made for divine assistance by organizing a public festival of worship, the vessels employed - eighty platters and as many jars - being made by the hands of the prince himself with clay.

${ }^{1}$ In the Chronicles the two princes are represented as having deliberately entered the stormy sea, angered that such hardships should overtake the descendants of the ocean Kami.]

[2 The Yang-wu, or Sun-erow (Japanese Yata-garasu), is a creature of purely Chinese myth. It is supposed to be red in colour, to have three legs, and to inhabit the sun.] 
outained from Mount.Kagu in Yamato. ${ }^{1}$, Several minor arrangements followed, and finally swords were crossed with the army of Nagasune, who had inflicted a defeat on the invaders on the occasion of their first landing at Kusaka, when Prince Itsuse received a mortal wound: A fierce battle ensued.1 Prince Iwaré burned to avenge his brother's death, , but repeated attacks upon Nagásune's troops proved abortive until sucldenly a golden-plumaged kite perched on the end of Prince Iware's bow, and its effulgence dazzled the enemy'so that they could not fight stoutly.?

From this incident the place: where the battle occurred was called Tabi-nomura, a name now corrupted into Tomi-no-mura. It does not appear, however; that anything like a decisive victory was gained by the aid of this miraculous intervention. Nagasune sought a conference with Prince Iware, and declared that the ruler of Yamato, whom he served, was a Kami who had formerly descended from heaven. He offered in 'proof of this statement an arrow and a quiver belonging to the Kami: But. Prince Iware demonstrated their correspondence with those he himself carried. Nagasune, however, declining to abstain from resistance, was put to death by the Kami he served, who then made act of submission to Prince Iware.

The interest of this last incident lies in the indication it seems to afford that a race identical with the invaders had already settled in Yamato Prince Iware now caused a palace to be built on the plain of Kashiwa-bara (called Kashihara by some historians), to the southwest of Mount Unebi, and in it assumed the imperial dignity, on the first day of the first month of the year 660 B.c. It is scarcely necessary to say that this date must be received with all reserve, and that the epithet "palace" is not to be interpreted in the European . sense of the term. "The Chronicles, which alone attempt to fix the early dates with accuracy, indicate 667 B.c. as the year of the expedition's departure from Kyūshū, and assign to Prince Iware an age of forty-five at the time. He was therefore fifty-two when crowned at Kashiwa-bara, and as the same authority makes him live to an age of 127 , it might be supposed that much would be told of the last seventy-five years of his life.

But whereas many pages are devoted to the story of his adventures before ascending the throne, a few paragraphs suffice for all that is subsequently related of him. While residing in Kyūshū he married and had two sons, the elder of whom, Tagishi-mimi, accompanied him on his eastward expedition. In Yamato he married again and had three sons, the youngest of whom succeeded to the throne. The bestowing of titles and rewards naturally occupied much attention, and to religious observances scarcely less importance seems to have been attached. All references to these latter show that the offices of priest and king were united in the sovereign of these days. Thus it was by the Emperor that formulae of incantation to dissipate evil influences were dictated; that sacrifices were performed to the heavenly Kami so as to develop filial piety; and that shrines were consecrated for worshiping the Imperial ancestors. Jimmu was buried in a tumulus (misasagi) on the northeast of Mount Unebi. The site is officially recognized to this day, and on the $3 \mathrm{rd}$ of April every year it is visited by an Imperial envoy; who offers products of mountain, river, and sea.

[ 1 The Chronicles state that the prince made ame on the platters. Ame is confectioned from malted millet and is virtually the same as the malt extract of the Occident.1.

[2 This tradition of the golden kite is cherished in Japan.: The "Order of the Golden Kite" is the most coveted military distinction.] 


\section{TRACES OF FOREIGN INFLUENCE}

What traces of Chinese or foreign influence are to be found in the legends. and myths set down above? It is tolerably certain that communication existed between China and Japan from a date shortly prior to the Christian era, and we naturally expect to find that since China was at that time the author of Asiatic civilization, she contributed materially to the intellectual development: of her island neighbour. Examining the cosmogonies of the two countries, we find at the? outset a striking difference. The Chinese did not conceive any? creator, ineffable, formless, living in space, whereas the Japanese imagined a greät central Kami and two producing powers, invisible and working by occult prócesses.

On the other hand, there is a marked similarity of thought. For, as on the death of Panku, the giant toiler of Chinese myth on whom devolved the task of chiselling out the universe, his left eye was transmuted into the orb of day and his right into the $\overline{m o o n}$, so when the Japanese $K a \dot{a} i$ returned from his visit to the underworld; the sun emerged from the washing of his.left eye and the moon from the washing of his right. Japanese writers have sought to differentiate the two myths by pointing out that the sûn is masculine in China and feminine in Japan; ibut such an objection is inadequate to impair the close resemblance. $f_{n}$ In truth "creation from fragments of a fabulous anthropomorphic being is common to Chaldeans, Iroquois, Egyptians, Greeks, Tinnehs; Mangaianns, and Aryan Indians, "' and from that fact a eonnexion between ancient Japan and West Asia might be deduced by reference to the beings formed out of the parts of Ithe fire Kami's body when Izanagi put him to the sword: On the other hand, the tale of which the birth of the sun and the moon forms a part, namely; the visit of Izanagi to hades in search of Izanami; is an obvious reproduction of the Babylonian myth of Ishtar's journey to the underworld in search of Du'uzu, which formed the basis of the Grecian legend of Orpheus and Eurydice. , Moreover,Izanami's objection to return, on the ground of having already eaten of the food of the underworld, is a feature of many ancient myths; among which may, be mentioned the Indian story of Nachikétas, where the name Yama; the Indian god of the lower world, bears an obvious resemblance to the Japanese yomi (hades), as does, indeed, the whole Indian myth of Yami and Yama to that of Izanagi and Izanami.

is Is it not also more than a mere coincidence that as all the Semitic tribes worshipped the goddess Isis; so the Japanese worshipped, for supreme being, the goddess of the Sun? Thus, here again there would seem to have been some path of communication other than that via China between Japan and the west of Asia. Further, the "river of heaven" - the Milky Way - which so often figures in Japanese mythology, is prominent in Chinese also, and is there associated with theispinning Damsel; just as in the Japanese legend it serves the Kami for council-place after the injury done by Susanoo's violence to the Sun goddess and her spinning maidens. It has been remarked [Chamberlain] that the chop-stick which Susanoo found floating down a river in Izumo, and the sake (rice-wine) which he caused to be made for the purpose of intoxicating the eight-headed serpent, are obviously products of Chinese civilization; but as for the rescue of the maiden from the serpent, it is a plain replica of the legend of Perseus and Andromeda, which, if it came through China, left no mark in transit: $\therefore$ Liess palpable, but istill sufficiently striking, is the resemblance between the story of Atalanta's golden apples and the casting down of Izanagi?'s head-dresis) 
and comb as grapes and bamboo. sprouts to arrest the pursuit of the "hag of hades." But indeed this throwing of his comb behind him by Izanagi and its conversion into a thicket are common incidents of ancient folk-lore; while in the context of this Kami's ablutions on his return from hades', it may be noted that Ovid makes Juno undergo lustration after a visit to the lower regions and that Dante is washed in Lethe when he passes out of purgatory. Nor is there any great stretch of imagination needed to detect a likeness between the feathered messenger sent from the Ark and the three envoys - the last a bird-despatched from the "plain of high heaven" to report upon the condition of disturbed Japan. This comparison is partially vitiated, however, by the fact that there is no tradition of a deluge in Japanese annals, though such phenomena are likely to occur occasionally in all lands and to produce a great impression on the national imagination.. "Moreover, what is specially known to us as the deluge has been claimed as an ancient Altaic myth. Yet here we have the oldest of the undoubtedly Altaic nations without any legend of the kind." [Chamberlain.]

It appears, further, from the account of the Great-Name Possessor's visit to' the underworld; that one Japanese conception of hades corresponded exactly with that of the Chinese, namely; a place where people live and act just as they: do on earth. But the religion out of which this belief grew in China had its origin at a date long subsequent to the supposed age of the Gods in Japan. The peaches with which Izanagi pelted and drove back the thunder Kami sent by Izanami to pursue him on his return from the underworld were evidently: suggested by the fabulous female, Si Wang-mu, of Chinese legend, who possessed a peach tree, the fruit of which conferred immortality and repelled the demons of disease. So, too, the tale of the palace of the ocean Kami at the bottom of the sea, with its castle gate and eassia tree overhanging a well which serves as a mirror, forms a page of Chinese legendary lore, and, in a slightly altered form, is found in many ancient annals.

The sea monster mentioned in this myth is written with a Chinese ideograph signifying "crocodile," but since the Japanese cannot have had any knowledge of crocodiles, and since the monster is usually represented pictorially as a dragon, there can be little doubt that we are here confronted by the Dragon King of Chinese and Korean folk-lore which had its palace in the depths of the ocean. In fact, the Japanese, in all ages, have spoken of this legendary edifice as $R y \bar{u} n \bar{o} j \bar{o}$ (the Dragon's castle).

The eminent sinologue, Aston, has shrewdly pointed out that the term wani (crocodile) may be a corruption of the Korean word, wang-in (king), which the Japanese pronounced "wani." As for the "curved jewels," which appear on so many occasions, the mineral jade, or jadelike stone, of which many of them were made, has never been met with in Japan and must therefore have come from the continent of Asia. The reed boat in which the leech, first offspring of Izanagi and Izanami, was sent adrift, "recalls the Accadian legend of Sargon, and his ark of rushes, the biblical story of Moses as an infant and many more,", though it has no known counterpart in Chinese mythology.

It is noticeable that in spite of the honour paid to the stars in the Chinese cosmogony, the only star specially alluded to in Japanese myth is Kagase, who: is represented as the last of the rebellious Kami on the oceasion of the subjuga-1 tion of Izumo by order of the Sun goddess and the Great-Producing Kami. S So far as the Records and the Chronicles are concerned, "the only stars mentioned are: Venus, the Pleiades, and the Weaver," the last being connected with a Chinese legend; as shown above. 
Two other points remain to be noticed. One is that divination by cracks in a deer's roasted shoulder blade, a process referred to more than once in the Records and the Chronicles, was a practice of the Chinese, who seem to have borrowed it from the Mongolians; the other, that the sounding arrow (narikabura) was an invention of the Huns, and came to Japan through China. It had holes in the head, and the air passing through these produced a humming sound. As for the Chronicles, they are permeated by Chinese influence throughout. The adoption of the Chinese sexagenary cycle is not unnatural, but again and again speeches made by Chinese sovereigns and sages are put into the mouths of Japanese monarchs as original utterances, so that without the Records for purposes of reference and comparison, even the small measure of solid ground that can be constructed would be eut from under the student's feet.
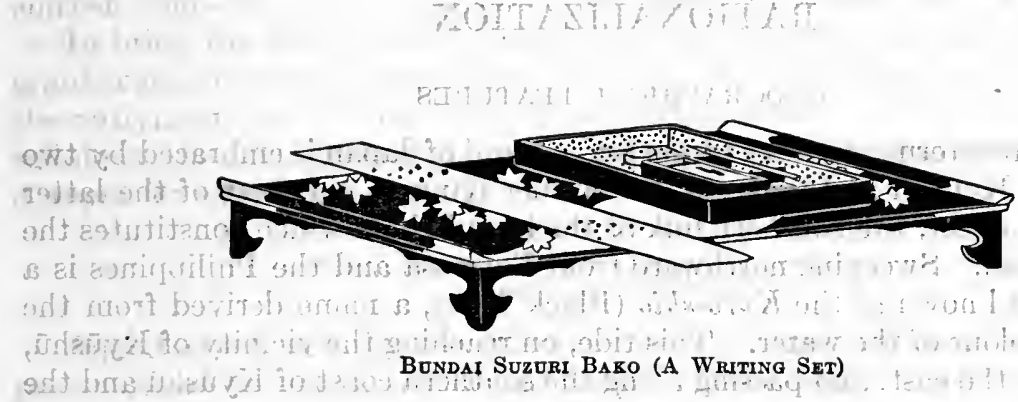

(I0) Lowirelsis 


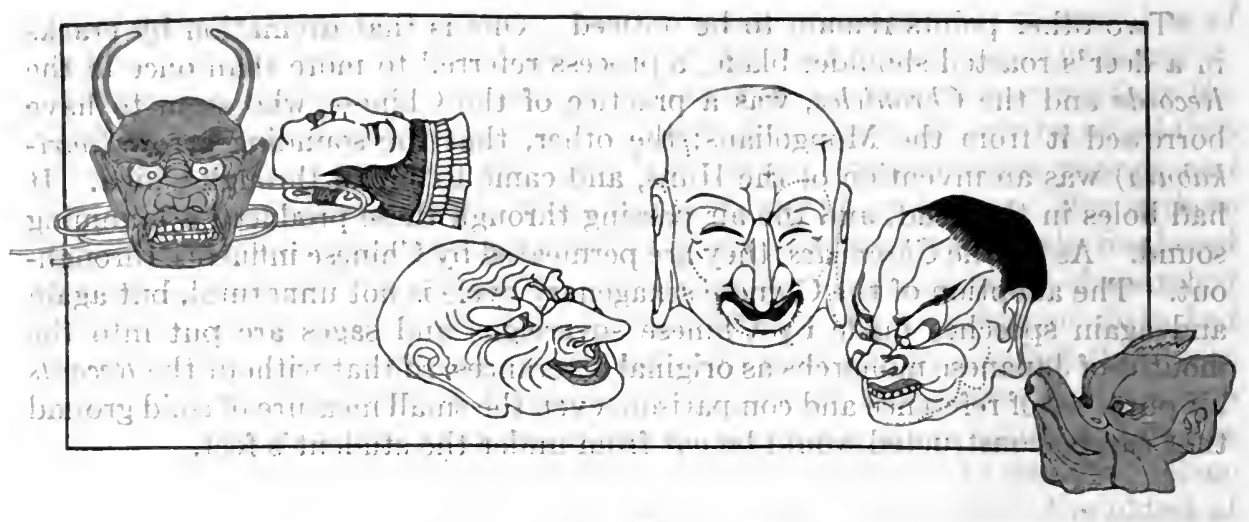

"Nó" MAsks

\section{CHAPTER IV}

\section{RATIONALIZATION}

\section{GEOGRAPHICAL FEATURES}

THE southwestern extremity of the main island of Japan is embraced by two large islands, Kyushū and Shikoku, the former lying on the west of the latter and being, in effect, the southern link of the island chain which constitutes the empire of Japan. Sweeping northward from Formosa and the Philippines is a strong current known as the Kuro-shio (Black Tide), a name derived from the deep indigo colour of the water. This tide, on reaching the vicinity of Kiyūshū, is deflected to the east, and passing along the southern coast of Kyūshū and the Kii promontory, takes its way into the Pacific. Evidently boats carried on the bosom of the Kuro-shio would be likely to make the shore of Japan at one of three points, namely, the south, or southeast, of Kyūshū, the south of Shikoku or the Kii promontory.

Now, according to the Records, the first place "begotten" by Izanagi and Izanami was an island called Awa, supposed to be in the vicinity of Awaji. The latter is a long, narrow island stretehing from the northeast of Shikoku towards the shore of the main island - which it approaches very closely at the Strait of Yura - and forming what may be called a gate, closing the eastern entrance to the Inland Sea. After the island of Awa, the producing couple gave birth to Awaji and subsequently to Shikoku, which is deseribed as an island having four faces, namely, the provinces of Awa, Iyo, Tosa, and Sanuki.

Rejecting the obviously allegorical phantasy of "procreation," we may reasonably suppose ourselves to be here in the presence of an emigration from the South Seas or from southern China, which debarks on the coast of Awaji and thence erosses to Shikoku. Thereafter, the immigrants touch at a triplet of small islands, deseribed as "in the offing," and thence cross to Kyūshū, known at the time as Tsukushi. This large island is described in the Records as having, like Shikoku, one body and four faces, and part of it was inhabited by Kumaso, of whom much is heard in Japanese history. From Kyūshū the invaders pass to the islands of Iki and Tsushima, which lie between Kyūshū and Korea, and 
thereafter they sail northward along the coast of the main island of Japan until they reach the island of Sado.

sis All this - and the order of advance follows exactly the procreation sequence given in the Records - - lends itself /easily to the supposition of a party of immigrants coming originally from the south, voyaging in a tentative manner round the country described by them, and establishing themselves primarily on its outlying islands.

ns.sThenext step, according to the Records, was to Yamato About this name; Yamáto, there has been some dispute. Alike in ancient and in modern times the term has been applied, on the one hand, to the whole of the main island, and; on the other, to the single province of Yamato. The best authorities, however, interpret it in the latter sense for the purposes of the Izanagi-and-Izanami legend, and that interpretation is plainly consistent with the probabilities, for the immigrants would naturally have proceeded from Awaji to the Kii promontory, where the province of Yamato lies: Thereafter - on their "return," say the Records, and the expression is apposite - they explored several small islands' not identifiable by their names but said to have been in Kibi, which was the term then applied to the provinces of Bingo, Bitchū, and Bizen, lying along the south coast of the Inland Sea and thus facing the sun, so that the descriptive epithet "sun-direction" applied to the region was manifestly appropriate.

IIoi In brief, the whole narrative concerts well with the idea of a band of emigrants carried on the breast of the "Black Tide," who first make the circuit of the outlying fringe of islands, then enter the mainland at Yamato, and finally sail down the Inland Sea, using the small islands off its northern shore as points d'appui for expeditions inland.

rxeismones ginil?

\section{JAPANESE OPINION}

Japanese euhemerists, several of whom, in former times as well as in the present; have devoted much learned research to the elucidation of their country's mythology, insist that tradition never intended to make such a demand upon human credulity as to ask it to believe in the begetting of islands by normal process of procreation. They maintain that such descriptions must be read as allegories. It then becomes easy to interpret the doings of Izanagi and Izanami as simple acts of warlike aggression, and to suppose that they each commanded forces which were to have co-operated, but which; by failing at the outset to synchronize their movements, were temporarily unsuccessful. It will seem; as we follow the course of later history, that the leading of armies by females was common enough to be called a feature of early Japan; and thus the rôle assigned to Izanami need not cause any astonishment. At their first miscarriage the two Kami, by better organization, overran the island of Awaji and then pushed on to Shikoku, which they brought completely under their sway.

mo But what meaning is to be assigned to the "plain of high heaven" (Takama: ga-hara)?- Where was the place thus designated? By a majority of Japanese interpreters Takama-ga-hara is identified as the region of.Taka-ichi in Yamato province. The word/did not refer to anything supernatural but was used simply in an honorific sense. In later agès Court officials were called "lords of the moon" (gekkei) or "cloud-guests" (unkaku), while officials not permitted to attend the Court I were known as "groundlings" (jige); the residence of the Emperor was designated "purple-clouds hall" (shishin-den); to go from the Imperial capital to any other part of the country was to "descend," the converse 
proceeding being called to "ascend,". and the palace received the names of "blue sky" and "above the elouds."

"To-day in Yamato provinee there is a hill ealled Takama-yama and a plain named :Takama-no. The Records say that when the Sun goddess retired to a rock cave, a multitude of Kami met at Taka-ichi to concert measures for enticing her out; and this Taka-ichi is considered to be undoubtedly the place of the same name in Yamato. But some learned men hold that Takama-ga-hara was in a foreign eountry, and that the men who emigrated thence to Japan belonged to a race very superior to that then inhabiting the islands. When; however, the leader of the invaders had established his Court in Yamato the designation Takama-ga-hara came to be applied to the latter place.

Whichever theory be correct - and the latter certainly commends itself as the more probable - it will be observed that both agree in assigning to Takama-ga-hara a terrestrial location; both agree in assigning the sense of "unsettled and turbulent", to the "floating; drifting" condition predicated of the country when the Kami first interested themselves in it, and both agree in interpreting as an insignium of military authority the "jewelled spear" "given to Izanagi and Izanami - an interpretation borne out by the fact that, in subsequent eras of Japanese history, it was customary for a ruler to delegate authority in this manner. Applying the same process of reasoning to the soealled "birth" of Kami, that process resolves itself very simply into the creation of chieftains and administrators.

\section{RATIONALIZATION OF THE LEGEND OF THE VISIT TO HADES.}

It would seem that from Yamato the invaders prosecuted their campaign into the interior, reaching Izumo on the west coast. The Records say that after Izanami's death in giving birth to the Kami of fire, she was buried at Mount Kagu on the confines of Izumo and Hōki. "Now the land of Yomi-generally interpreted "underworld" - - which Izanagi visited in search of Izanami, was really identical with Yomi-shima, located between the provinces of Hōki and Izumo, and Ne-no-Kuni ${ }^{1}-$ eommonly taken to mean the "netherland" subsequently the place of Susanoo's banishment, was in fact a designation of Izumo, or had the more extensive application of the modern Sanin-do and Sanyō-dō (districts in the shadow of the hill and districts on the sunny side of the hill), that is to say, the western provinces and the south coast of the Inland Sea.

What the allegory of the visit to hades would seem to signify, therefore, was that Izanami was defeated in a struggle with the local chieftains of Izumo or with a rebellious faction in that province; was compelled to make act of submission before Izanagi arrived to assist her - allegorically speaking she had eaten of the food of hades - and therefore the conference between her and Izanagi proved abortive. The hag who pursued Izanagi on his retreat from Yomi represents a band of amazons - a common feature in old Japan - and his assailant, the Kami of thunder, was a rebel leader.

As for the idea of blocking the "'even pass of hades" with rocks, it appears to mean nothing more than that a military foree was posted at Hirasaka - now called Ifuyo-saka in Izumo - to hold the defile against the insurgent troops under Izanami, who finally took the field against Izanagi. It may be inferred

[ ${ }^{1}$ In the language of ancient Japan ne meant "mountain," and Ne-no-Kun $i$ signified simply "Land of Mountains."] 
that the struggle ended indecisively, although Izanagi killed the chieftain who had instigated the rebellion (the so-called "Kami of fire"), and that Izanami remained in Izumo, becoming ruler of that province, while Izanagi withdrew to the eastern part of Tsukushi (Kyūshū), where he performed the ceremony of grand lustration.

\section{THE STORY OF SUSANOO}

The story of Susanoo lends itself with equal facility to rationalization. His desire to go to his "mother's land" instead of obeying his father and ruling the "sea-plain" (unabara) - an appellation believed by some learned commentators to apply to Korea - may easily be interpreted to mean that he threw in his lot with the rebellious chiefs in Izumo. Leading a force into Yamato, he laid waste the land so that the "green mountains" were changed into withered mountains,". and the commotion throughout the country was like the noise of "flies swarming in the fifth month:" Finally he was driven out of Yamato, and retiring to Izumo, found that the local prefect was unable to resist the raids of a tribe from the north under the command of a chief whose name Yachimatá no Örochi - signified "eight-headed serpent."

This tribe had invaded the province and taken possession of the hills and valleys in the upper reaches of the river $\mathrm{Hi}$, whence tradition came to speak of the tribe as a monster spreading over hills and dales and having pine forests growing on its back. The tribute of females, demanded yearly by the tribe, indicates an exaction not uncommon in those days, and the sword said to have been found by Susanoo in the serpent's tail was the weapon worn by the last and the stoutest of Orochi's followers:

There is another theory equally accordant with the annals and in some respects more satisfying. It is that Susanoo and his son, Iso-takeru, when they were expelled from Yamato, dwelt in the land of Shiragi - the eastern of the three kingdoms into which Korea was formerly divided - and that they subsequently built boats and rowed over to Izumo. This is distinctly stated in one version of the Chronicles, and another variant says that when Iso-takeru descended from Takama-ga-hara, he carried with him the seeds of trees in great quantities but did not plant them in "the land of Han" (Korea). Further, it is elsewhere stated that the sword found by Susanoo in the serpent's tail was called by him Orochi no Kara-suki (Orochi's Korean blade), an allusion which goes to strengthen the reading of the legend.

\section{THE DESCENT OF NINIGI}

Omitting other comparatively trivial legends connected with the age of Susanoo and his descendants, we come to what may be called the second great event in the early annals of Japan, namely, the descent of Ninigi on the southern coas̀t of Tsukushi (Kyūshü). The Records and the Chronicles explicitly state that this expedition was planned in the court at Takama-ga-hara (the "plain of high heaven"), and that, after sending forces to subdue the disturbed country and to obtain the submission of its ruler, the grandson (Ninigi) of the Sun goddess was commissioned to take possession of the land. "It is also clearly shown that Izumo was the centre of disturbance and that virtually all the preliminary fighting took place there. Yet when Ninigi descends from Takama-ga-haraa descent which is described in one account as having taken place in a closed boat, and in another, as having been effected by means of the coverlet of a 
couch - he is said to have landed, not in Izumo or in Yamato, but at a place in the far south, where he makes no recorded attempt to fulfil the purposse of his mission, nor does that purpose receive any practical recognition until the time of his grandson Iware. The latter pushes northward, encountering the greatest resistance in the very provinee (Yamato) where his grandfather's expedition was planned and where the Imperial Court was held.

It is plain that these conditions cannot be reconeiled exeept on one of two suppositions: either that the Takama-ga-hara of this section of the annals was in a foreign country, or that the descent of Ninigi in the south of Japan was in the sequel of a complete defeat involving the Court's flight from Yamato as well as from Izumo.

Let us first consider the theory of a foreign country. Was it Korea or was it China? In favour of Korea there are only two arguments, one vague and the other improbable. The former is that one of Ninigi's alleged reisons for choosing Tsukushi as a landing-place was that it faced Korea The latter, that Tsukushi was selected beeause it offered a convenient base for defending Japan against Korea. It will be observed that the two hypotheses are mutually conflicting, and that neither accounts for debarkation at a part of Tsukushi conspicuously remote from Korea. It is not wholly impossible, however, that Ninigi came from China, and that the Court which is said to have commissioned him was a Chinese Court.

In the history of China a belief is recorded that the Japanese sovereigns are descended from a Chinese prince, Tai Peh, whose father wished to disinherit him in favour of a younger son. Tai Peh fled to $\mathrm{Wu}$ in the present Chekiang, and thence passed to Japan about 800 B.c. Another record alleges that the first sovereign of Japan was a son of Shao-kang of the Hsia dynasty (about 850 B.c.), who tattooed his body and eut off his hair for purposes of disguise and lived on the bank of the Yangtsze, occupying himself with fishing until at length he fled to Japan.

That Ninigi may have been identical with one of these persons is not inconceivable, but such a hypothesis refuses to be reconciled with the story of the fighting in Izumo which preceded the descent to Tsukushi, The much more credible supposition is that the Yamato Court, confronted by al formidable rebellion having its centre in Izumo, retired to Tsukushi; and there, in the course of years, mustered all its followers for an expedition ultimately led by the grandson of the fugitive monarch to restore the sway of his house. This interpretation of the legend consists with the fact that when Jimmu reached Yamato, the original identity of his own race with that of the then ruler of the province was proved by a comparison of weapons.

\section{THE CASTLE OF THE OCEAN KAMI}

With regard to the legend of the ocean Kami, the rationalists conceive that

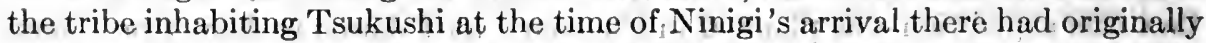
immigrated from the south and had gradually spread inland. Those:inhabiting the littoral districts were ultimately placed by Ninigi under the rule of Prince Hohodemi, and those inhabiting the mountain regions under the sway of Prince Hosuseri. The boats and hooks of the legend are symbolical of military and naval power respectively. The brothers having quarrelled about the limits of their jurisdictions, Hohodemi was worsted, and by the advice of a local elder he went to Korea to seek assistance. There he married the daughter of the 
Ocean King - so called because Korea lay beyond the sea from Japan - and, after some years' residence, was given a force of war-vessels (described in the legend as "crocodiles") together with minute instructions (the tide-ebbing and the tide-flowing jewels) as to their skilful management. These ships ultimately enabled him to gain a complete victory over his elder brother.

\section{WHAT THE JAPANESE BELIEVE}

These rationalizing processes will commend themselves in different degrees to different minds." One learned author has compared such analyses to estimating the historical residuum of the Cinderella legend by subtracting the pumpkin coach and the godmother-But we are constrained to acknowledge some background of truth in the annals of old Japan, and anything that tends to disclose that background is welcome. It has to be noted, however, that though many learned Japanese commentators have sought to rationalize the events described in the Records and the Chronicles, the great bulk of the nation believes in the literal accuracy of these works as profoundly as the great bulk of Anglo-Saxon people believes in the Bible, its cosmogony, and its miracles.

The gist of the Japanese creed, as based on their ancient annals, may be briefly summarized. They hold that when the Sun goddess handed the three sacred objects to Ninigi - generally called Tenson, or "heavenly grandchild" - she ordained that the Imperial Throne should be coeval with heaven and earth. They hold that the instructions given with regard to these sacred objects comprised the whole code of administrative ethics. The mirror neither hides nor perverts; it reflects evil qualities as faithfully as good; it is the emblem of honesty and purity. The jewel illustrates the graces of gentleness, softness, amiability, and obedience, and is therefore emblematic of benevolence and virtue. ${ }^{1}$ The sword indicates the virtues of strength; sharpness, and practical decision, and is thus associated with intelligence and knowledge. So long as all these qualities are exercised in the discharge of administrative functions, there can be no misrule.

They further hold that when the Sun goddess detailed five Kami to form the suite of Ninigi, these Kami were entrusted with the ministerial duties originally discharged by them, and becoming the heads of five administrative departments, transmitted their offices to generation after generation of their descendants. Thus Koyane was the ancestor of the Nakatomi family who discharged the priestly duties of worship at the Court and recited the Purification Rituals; Futodama became the ancestor of the Imibe (or Imbe), a hereditary corporation whose members performed all offices connected with mourning and funerals; Usume became ancestress of the Sarume, whose duties were to perform dances in honour of the deities and to act as mediums of divine inspiration; Oshihi was the ancestor of the $\bar{O}$ tomo chief who led the Imperial troops, and Kume became the ancestor of the Kumebe; a hereditary corporation of palace guards. Further, they hold that whereas Ninigi and his five adjunct Kami all traced their lineage to the two producing $K a m i$ of the primal trinity, the special title of sovereignty conferred originally on the Sun goddess was transmitted by her to the Tenson (heavenly grandchild), Ninigi, the distinction of ruler and ruled being thus clearly defined. Finally they hold that Ninigi and these five adjunct Kami; though occupying different places in the national polity, had ia common ancestor whom they jointly worshipped; thus forming an eternal union.

[1. It must be remembered that the jewel referred to was a piece of green or white jade.] 


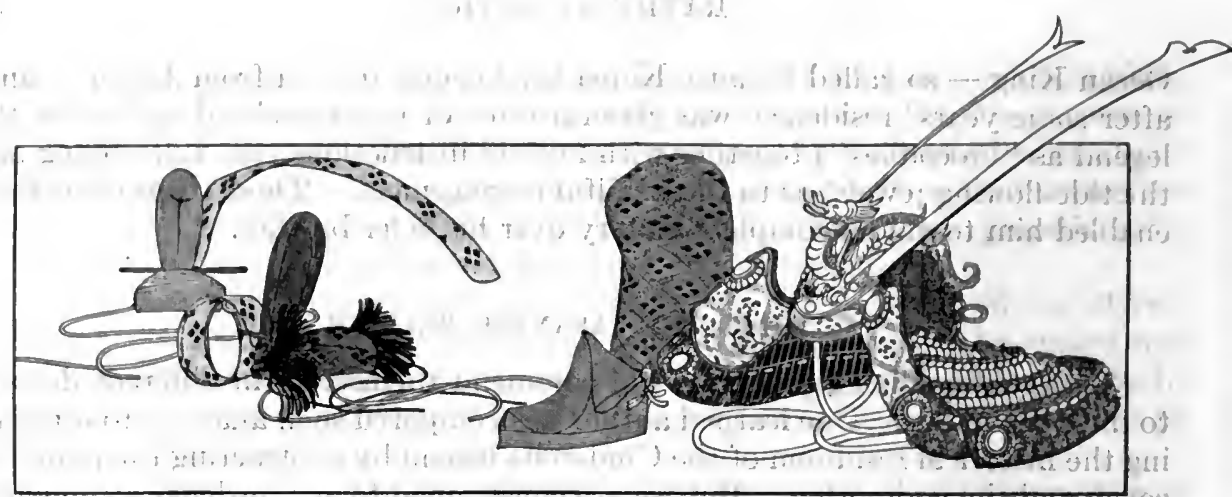

Ancient Givil and Military Head-gear

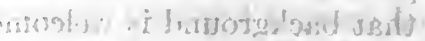

CHAPTER V

\section{ORIGIN OF THE JAPANESE NATION: HISTORICAL EVIDENCES}

IN considering the question of the origin of the Japanese nation four guides are available; namely, written annals, archaeological relics, physical features, and linguistic affinities.

\section{WRITTEN ANNALS}

The annals, that is to say, the Records and the Chronicles, speak of six peoples; namely, first, Izanagi and his fellow Kami, who, as shown above, may reasonably be identified, with the original immigrants represented in the story of the so-called "birth" of the islands; secondly, Jimmu and his followers, who re-conquered the islands; thirdly, the Yemishi, who are identical with the modern Ainu; fourthly, the Kumaso; fifthly, the Sushen; and sixthly the Tsuchigumo (earth-spiders). By naming these six separately it is not intended to imply that they are necessarily different races: that remains to be decided. It will be convenient to begin with the Sushen.

\section{THE SUSHEN}

The Sushen were Tungusic ancestors of the Manchu. They are first mentioned in Japanese annals in A.D. 549, when a number of them arrived by boat on the north of Sado Island and settled there, living on fish eaught during spring and summer and salted or dried for winter use. The people of Sado regarded them as demons and carefully avoided them, a reception which implies total absence of previous intercourse. Finally they withdrew, and nothing more is heard of their race for over a hundred years, when, in A.D. 658, Hirafu, omi of Abe and warden of Koshi (the northwestern provinces, Etchū, Echizen, and Echigo), went on an expedition against them.

Nothing is recorded as to the origin or incidents of this campaign. One account says that Hirafu, on his return; presented two white bears to the Empress; that he fought with the Sushen and carried back forty-nine captives. It may be assumed, however, that the enterprise proved abortive, for, two 


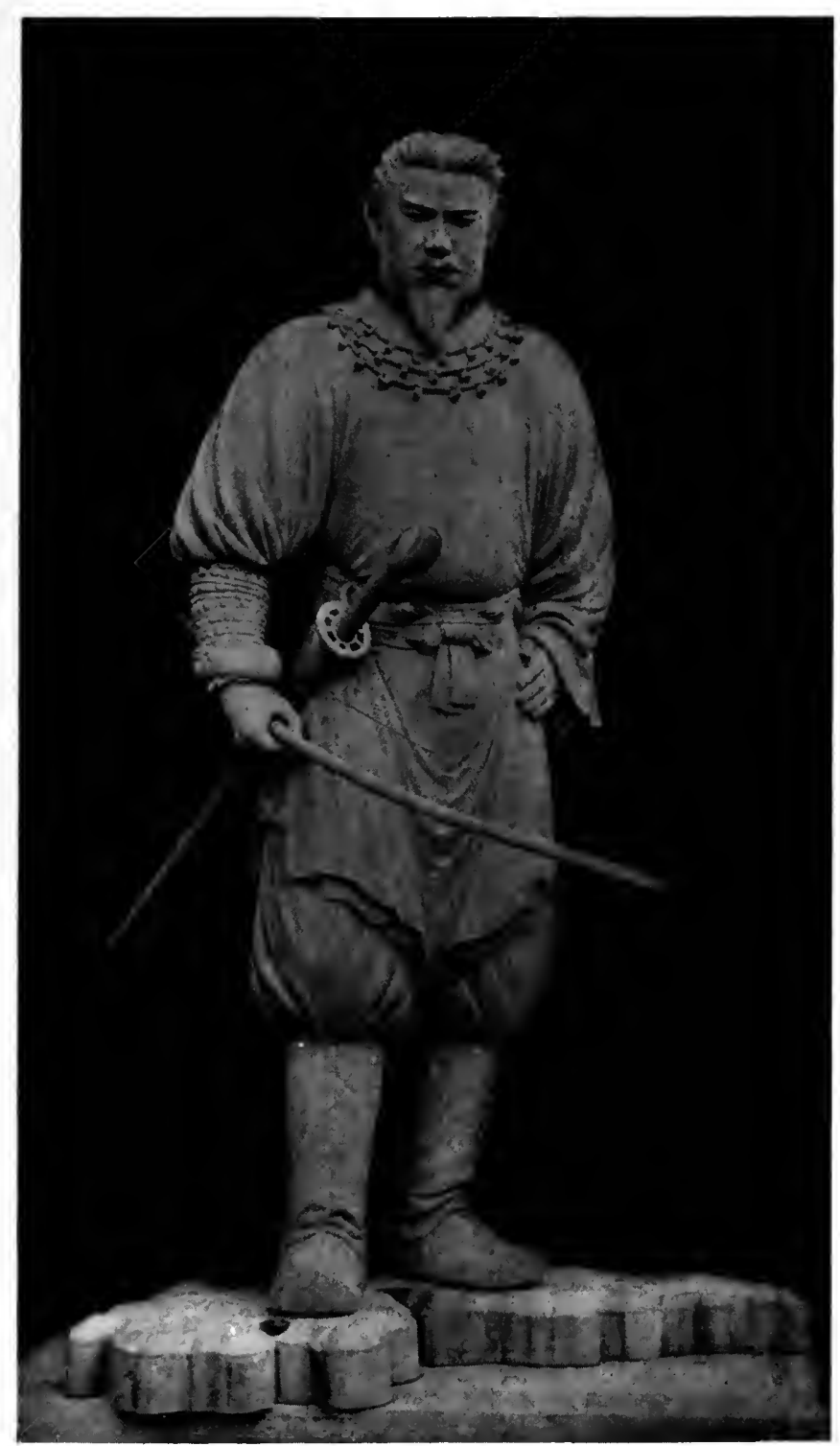
WOODEN STATUE OF THE EMPEROR JIMMU 

years later (660), he was again sent against the Sushen with two hundred ships. En routa for his destination he took on board his own vessel some of the inhabitants of Yezo (Yemishi) to act as guides, and the flotilla arrived presently in the vicinity of a long river; unnamed in the annals but supposed to have been the Ishikari, which debouches on the west coast of Yezo. ' There a body of over a thousand Yemishi in a camp facing the river sent messengers to report that the Sushen fleet had arrived in great force and that they were in imminent danger. The Sushen had over twenty vessels and were lying in a concealed port whence Hirafu in vain sent messengers to summon them.

What ensued in thus told in the Chronicles: "Hirafu heaped up on the beach coloured silk stuffs, weapons, iron, etc.," to excite the cupidity of the Sushen, who thereupon drew up their fleet in order, approached "with equal oars, flying flags made of feathers tied to poles, and halted in a shallow place. Then from one of their ships they sent forth two old men who went round the coloured silk.stuffs and other articles which had been piled up, examined them closely, whereafter they changed the single garments they had on, and each taking up a piece of cloth went on board their ship and departed." Meanwhile the Japanese had not made any attempt to molest them. Presently the two old men returned, took off the exchanged garments and, laying them down together with the cloth they had taken away, re-embarked and departed.

$-s_{s}$ ? Up to this Hirafu seems to have aimed at commercial intercourse.' But his overtures having been rejected, he sent to summon the Sushen. They refused to come, and their prayer for peace having been unsuccessful, they retired to "their own palisades.". There the Japanese attacked them, and the Sushen, seeing that defeat was inevitable, put to death their own wives and children. How they themselves fared is not recorded, nor do the Chronicles indicate where "their own palisades" were situated, but in Japan it has always been believed that the desperate engagement was fought in the Amur River, and its issue may: be inferred from the fact that although the Japanese lost one general officer, Hirafu was able on his return to present to the Empress more than fifty "barbarians," presumably Sushen. Nevertheless; it is recorded that in the same year (A.D. 660), forty-seven men of Sushen were entertained at Court, and the inference is either that these were among the above "savages" - in which case Japan's treatment of her captured foes in ancient times would merit applause or that the Sushen had previously established relations with Japan, and that Hirafu's campaign was merely to repel trepass.

During the next sixteen years nothing more is heard of the Sushen, but, in A.D. 676, seven of them arrived in the train of an envoy from Sinra, the eastern of the three kingdoms into which Korea was then divided. This incident evokes no remark whatever from the compilers of the Chronicles, and they treat with equal indifference the statement that during the reign of the Empress Jitō, in the year A.D. 696, presents of coats and trousers made of brocade, together with dark-red and deep-purple coarse silks, oxen, and other things were given to two men of Sushen. Nothing in this brief record suggests that any considerable intercourse existed in ancient times between the Japanese and the Tungusic Manchu, or that the latter settled in Japan in any appreciable numbers:

THE YEMISHI

The Yemishi are identified with the modern Ainu. It appears that the continental immigrants into Japan applied to the semi-savage races encount- 
ered by them the epithet "Yebisu" or "Yemishi,", terms which may have been interchangeable onomatopes for "barbarian." The Yemishi are a moribund race. Only a remnant, numbering a few thousands; survives, now in the northern island of Y Yezo. Nevertheless it has been proved by Chamberlain's investigations into the origin of place-names, that in early times the Yemishi extended from the north down the eastern section of Japan as far as the region where the present capital (Tōkyō) stands, and on the west to the provinee now called Echizen; and that, when the Nihongi was written, they still occupied a large part of the main island.

We find the first mention of them in a poem attributed to the Emperor Jimmu. Conducting his campaign for the re-conquest of Japan, Jimmu, uncertain of the disposition of a band of inhabitants, ordered his general, Michi, to construct a spacious hut (muro) and invite the eighty doubtful characters to a banquet. An equal number of Jimmu's soldiers acted as hosts, and, at a given signal, when the guests were all drunk, they were slaughtered. Jimmu composed a couplet expressing his troops' delight at having disposed of a formidable foe so easily, and in this verselet he spoke of one Yemishi being reputed to be a mateh for a hundred men.

Whether this couplet really belongs to its context, however, is questionable; the eighty warriors killed in the muro may not have been Yemishi at all. But the verse does certainly tend to show that the Yemishi had a high fighting reputation in ancient times, though it will presently be seen that such fame scarcely consists with the facts revealed by history. It is true that when next. we hear of the Yemishi more than seven and a half centuries have passed, and during that long interval they may have been engaged in a fierce struggle for the right of existence. There is no evidence, however, that such was the case.

On the contrary; it would seem that the Japanese invaders encountered no great resistance from the Yemishi in the south, and were for a long time content to leave them unmolested in the northern and eastern regions. In A.D. 95, however, Takenouchi-no-Sukune was commissioned by the Emperor Keiko to explore those regions. He devoted two years to the task, and, on his return in 97 , he submitted to his sovereign this request: "In the eastern wilds there is a country called Hi-taka-mi (Sun-height). The people of this country, both men and women, tie up their hair in the form of a mallet and tattoo their bodies. They are of fierce temper and their general name is Yemishi-Moreover, the land is wide and fertile. We should attack it and take it." [Aston's translation.] It is observable that the principal motive of this advice is aggressive. The-Yemishi had not molested the Japanese or shown any turbulence. They ought to be attacked because their conquest would be profitable: that was suffieient:

Takenouchi's counsels could not be immediately followed. Other business of a cognate nature in the south occupied the Court's attention, and thirteen years elapsed before (A.D. 110) the celebrated hero, Prince Yamato-dake, led an expedition against the Yemishi of the east. In commanding him to undertake this task, the Emperor, according to the Chronicles, made a speech which, owing to its Chinese, tone, has been ealled apocryphal, though some, at any rate, of the statements it embodies are attested by modern observation of Ainu manners and customs. He spoke of the Yemishi as being the most powerful among the "eastern savages," said that their "men and women lived together promiscuously;" that there was "no distinction of father and child;" that in winter "they dwelt in holes and in summer they lived in huts;" that their elothing consisted 
of furs and that they drank blood; that when they received a favour they forgot it, but if an injury was done them they never failed to avenge it, and that they kept arrows in their top-knots and carried swords within their clothing. How correct these attributes may have been at the time they were uttered, there are no means of judging, but the customs of the modern Ainu go far to attest the accuracy of the Emperor Keikō's remarks about their ancestors.

Yamato-dake prefaced his campaign by worshipping at the shrine of Ise, where he received the sword "Herb-queller," which Susanoo had taken from the last chieftain of the Izumo tribesmen. Thence he sailed along the coast to Suruga, where he landed, and was nearly destroyed by the burning of a moor into which he had been persuaded to penetrate in search of game. Escaping with difficulty, and having taken a terrible vengeance upon the "brigands" who had sought to compass his destruction, he pushed on into Sagami, crossed the bay to Kazusa and, sailing north, reached the southern shore of Shimōsa, which was the frontier of the Yemishi. The vessels of the latter assembled with the intention of offering resistance, but at the aspect of the Japanese fleet and the incomparably superior arms and arrows of the men it carried, they submitted unconditionally and became personal attendants on Yamato-dake.

Three things are noticeable in this narrative. The first is that the "brigands of Suruga" were not Yemishi; the second, that the Yemishi offered no resistance, and the third, that the Yemishi chiefs are called in the Chronicles "Kami of the islands" and "Kami of the country" - titles which indicate that they were held in some respect by the Japanese. It is not explicitly recorded that Yamatodake had any further encounter with the Yemishi, but figurative references show that he had much fighting. The Chronicles quote him as saying, after his return to Kii from an extended march through the northeastern provinces and after penetrating as far as Hi-taka-mi (modern Hitachi), the headquarters of the Yemishi, that the only Yemishi who remained unsubmissive were those of Shinano and Koshi (Eehigo, Etchū, and Echizen). But although Yamato-dake subsequently entered Shinano, where he suffered much from the arduous nature of the ground, and though he sent a general to explore Koshi, he ultimately retired to Owari, where he died from the effects of fatigue and exposure according to some authorities, of a wound from a poisoned arrow according to others. His last act was to present as slaves to the shrine of Ise the Yemishi who had originally surrendered and who had subsequently attached themselves to his person. They proved so noisy, however, that the priestess of the shrine sent them to the Yamato Court, which assigned for them a settlement on Mount Mimoro. Here, too, their conduct was so turbulent that they received orders to divide and take up their abode at any place throughout the five provinces of Harima, Sanuki, Iyo, Aki, and Awa, where, in after ages, they constituted a hereditary corporation of Saeki (Saekibe).

These details deserve to be recorded, for their sequel shows historically that there is an Yemishi element in the Japanese race. Thus, in later times we find the high rank of muraji borne by a member of the Saekibe. Fifteen years (A.D. 125) after the death of Yamato-dake, Prince Sajima was appointed governorgeneral of the fifteen provinces of Tōsan-dō (the Eastern Mountain circuit); that is to say, the provinces along the east coast. He died en route and his son, Prince Mimoro, succeeded to the office. During his tenure of power the Yemishi raised a disturbance, but no sooner was force employed against them than they made obeisance and threw themselves on the mercy of the Japanese, who pardoned all that submitted. 
This orderly condition remained uninterrupted until A.D. 367, when the Yemishi in Kazusa made one of the very few successful revolts on record. They killed Tamichi, a Japanese general sent against them, and they drove back his forces, who do not appear to have taken very effective measures of retaliation. In 482 we find the Yeinishi rendering homage to the Emperor Kensō, a ceremony, which was repeated on the accession of the Emperor Kimmei (540).

But, though meek in the presence of peril, the Yemishi appear to have been of a brawling temperament. Thus, in 561, several thousands of them showed hostility on the frontier, yet no sooner were their ehiefs threatened with death than they submitted. At that time all the provinces in the northeast and northwest - then included in Mutsu and Dewa - were in Yemishi possession. They rebelled again in 637 , and at first gained a signal success, driving the Japanese general, Katana, into a fortress where he was deserted by his troops. His wife saved the situation. She upbraided her husband as he was scaling the palisades to escape by night, fortified him with wine, girded his sword on herself, and caused her female attendants - of whom there were "several tens" to twang bowstrings. Katana, taking heart of grace, advanced single handed; the Yemishi, thinking that his troops had rallied, gave way, and the Japanese soldiers, returning to their duty, killed or captured all the insurgents.

No other instance of equally determined resistance is recorded on the part of the Yemishi. In 642, several thousands made submission in Koshi. Four years later (646), we find Yemishi doing homage to the Emperor Kōtoku. Yet in 645 it was deemed necessary to establish a barrier settlement against them in Echigo; and whereas, in 655, when the Empress Saimei ascended the throne, her Court at Naniwa entertained ninety-nine of the northern Yemishi and fortyfive of the eastern, conferring cups of honour on fifteen, while at the same time another numerous body came to render homage and offer gifts, barely three years had elapsed when, in 655, a Japanese squadron of 180 vessels, under the command of Hirafu, omi of Abe, was engaged attacking the Yemishi at Akita on the northwest coast of the main island.

All this shows plainly that many districts were still peopled by Yemishi and that their docility varied in different localities. In the Akita campaign the usual surrender was rehearsed. The Yemishi declared that their bows and arrows were for hunting, not for fighting, and the affair ended in a great feast given by Hirafu, the sequel being that two hundred Yemishi proceeded to Court, carrying presents, and were appointed to various offices in the localities represented, receiving also gifts of arms, armour, drums, and flags. ${ }^{1}$

An interesting episode is recorded of this visit. One of the Yemishi, having been appointed to a high post, was instructed to investigate the Yemishi population and the captive population. Who were these captives? They seem to have been Sushen, for at the feast given by Hirafu his Yemishi guests came aecompanied by thirty-five captives, and it is incredible that Japanese prisoners would have been thus humiliated in the sight of their armed countrymen. There will be occasion to reeur to this point presently. Here we have to note that in spite of frequent contact, friendly or hostile, and in spite of so many years of intercourse, the Yemishi seem to have been still regarded by the Japanese as objects of euriosity. For, in the year 654, envoys from Yamato to the Tang Emperor of China took with them a Yemishi man and woman to show to his Majesty.

The Chinese sovereign was much struck by the unwonted appearance of these

[ ${ }^{1} \mathrm{It}$ is related that these flags had tops shaped like cuttlefish.] 
people. He asked several questions; which are recorded verbatim in the Chronicles; and the envoys informed him that there were three tribes of Yemishi; namely, the Tsugaru ${ }^{1}$ Yemishi, who were the most distant; next, the Ara Yemishi (rough or only partially subdued); and lastly, the Nigi Yemishi (quiet or docile); that they sustained life by eating, not cereals, but flesh, and that they dispensed with houses, preferring to live under trees and in the recesses of mountains: The Chinese Emperor finally remarked; "When we look at the unusual bodily appearance of these Yemishi, it is strange in the extreme.".

Evidently whatever the original provenance of the Yemishi, they had never been among the numerous peoples who observed the custom of paying visits of ceremony to the Chinese capital. They were apparently not included in the family of Far Eastern nations. From the second half of the seventh century they are constantly found carrying tribute to the Japanese Court and receiving presents or being entertained in return. But these evidences of docility and friendship were not: indicative of the universal mood. The Yemishi located in the northeastern section of the main island continued to give trouble up to the beginning of the ninth century, and throughout this region as well as along the west coast from the thirty-eighth parallel of latitude northward the Japanese were obliged to build six castles and ten barrier posts between A.D. 647 and 800 .

These facts, however, have no concern with the immediate purpose of this historical reference further than to show that from the earliest times the Yamato immigrants found no opponents in the northern half of the island except the Yemishi and the Sushen.: One more episode; however, is germane. In the time (682) of the Emperor Temmu, the Yemishi of Koshi, who had by that time become quite docile, asked for and received seven thousand families of captives to found a district. A Japanese writing alleges that these captives were subjects of the Crown who had been seized and enslaved by the savages. But that is inconsistent with all probabilities. The Yamato might sentence these people to serfdom among men of their own race, but they never would have condemned Japanese to such a position among the Yemishi. Evidently these "captives". were prisoners taken by the Yamato from the Koreans; the Sushen, or some other hostile nation.

\section{THE KUMASO}

There has been some dispute about the appellation "Kumaso." One high authority thinks that Kuma and So were the names of two tribes inhabiting the extreme south of Japan; that is to say; the provinces now called Hyüga, Ōsumi, and Satsuma. Others regard the term as denoting one tribe only: The question is not very material. Among all the theories formed about the Kumaso; the most plausible is that they belonged to the Sow race of Borneo and that they found their way to Japan on the breast of the "Black Tide."! Many similarities of custom have been traced between the two peoples. Both resorted freely to ornamental tattooing; both used shields decorated with hair; both were skilled in making articles of bamboo, especially hats; both were fond of dancing with accompaniment of singing and hand-clapping; and both dressed their hair alike. Japanese annals use the word "Kumaso" for the first time in connexion with the annexation of Tsukushi (Kyüshū) by the Izanagi expedition, when one of the four faces of the island is called the "land of Kumaso.". "Plainly if this nomenclature may be taken as evidence, the Kumaso must have arrived in Japan at a date prior to the advent of the immigrants represented by Izanagi and Izanami; and 
it would further follow that they did not penetrate far into the interior, butremained in the vicinity of the place of landing, which may be supposed to have been some point on the southern coast of Kyūshū. Nor does there appear to have been any collision between the two tides of immigrants, for the first appearance of the Kumaso in a trueulent rôle was in A.D. 81 when they are said to have rebelled.

The incident, though remote from the capital, was sufficiently formidable to induce the Emperor Keiko to lead a force against them in person from Yamato. En route he had to deal with " "brigands." infesting Suwō and Buzen; provinces separated by the Inland Sea and situated respectively on the south of the main island and the north of Kyüshu. These provinces were ruled by chieftainesses, who declared themselves loyal to the Imperial cause; and gave informa: tion about the haunts and habits of the "brigands," who in Suwō had no special appellation but in Buzen were known as Tsuchi-gumo, a name to be spoken of presently. They were disposed of partly by stratagem and partly by open warfare. But when the Yamato troops arrived in Hyuga within striking distance of the Kumaso, the Emperor hesitated. . He deemed it wise not to touch the spear-points of these puissant foes. Ultimately he overcame them by enticing the two daughters of the principal leaders and making a show of affection for one of them. She conducted Japanese soldiers to her father's residence, and having plied him with strong drink, cut his bow-string while he slept so that the soldiers could kill him with impunity. It is recorded that Keikō put the girl to death for her unfilial conduct, but the assassination of her father helped the Japanese materially in theircampaign against the Kumaso, whom they:succeeded in subduing and in whose land the Emperor remained six years.

The Kumaso were not quelled, however. Scarcely, eight years had elapsed from the time of Keikō's return to Yamato when they rebelled again, "making ceaseless raids upon the frontier districts;" and he sent against them his son; Yamato-dake; with a band of skilled archers. This youth, one of the most heroic figures in ancient Japanese history, was only sixteen. He disguised himself as a girl and thus gained access to a banquet given by the principal Kumaso leader to celebrate the opening of a new residence. Attracted by the beauty of the supposed girl, the Kumaso chieftain placed her beside him, and when he had drunk heavily, Yamato-dake stabbed him to the heart, ${ }^{1}$ subsequently serving all his band in the same way. After this, the Kumaso remained quiet for nearly a century, but in the year $193,{ }^{2}$ during the reign of the Emperor Chuai, they once more rebelled, and the Emperor organized an expedition against them. He failed in the struggle and was killed by the Kumaso's arrows. Thenceforth history is silent about them.

Who, then, were they? It is related in the Chronicles that, after breaking the power of the Kumaso, the Emperor Keiko made a tour of inspection in Tsukushi (Kyūshū), and arriving at the distriet of Kuma, summoned two brothers, princes of Kuma, to pay homage. One obeyed, but the other refused, and soldiers were therefore sent to put him to death. Now Kuma was the name of the three kingdoms into which the Korean peninsula was divided in ancient

[ The Chronicles relate that when the Kumaso was struck down he asked for a moment's respite to learn the name of his slayer, whose prowess astounded him. On receiving an answer, he sought the prince's permission to give him' a title, and deelared that instead of being called Yamato Oguna, the name hitherto borne by him, he should be termed, Yamato-dake (Champion of Japan) because he had conquered the hitherto unconquerable. The prince accepted the name, and then gave the Kumaso his coup de grace.]

[2 It should be understood that these dates, being prenistoric, are not wholly reliable.] 
times; and it has been suggested [Aston] that the land of Kuma in Korea was the parent country of Kuma in Japan, Kom in the Korean language having the sane meaning (bear) as Kuma in the Japanese. This, of course, involves the conclusion that the Kumaso were originally Korean emigrants; a theory somewhat difficult to reconcile with their location in the extreme south of Kyūshū. (1) The apparent silence of the annals about the subsequent career of the tribe is accounted for by supposing that the Kumaso were identical with the Hayato (falcon men); who make their first appearance upon the scene in prehistoric days as followers of Hosuseri in his contest with his younger brother, Hohodemi, the hero of the legend about the palace of the sea god. Hohodemi - according to the rationalized version of the legend - having obtained assistance in the shape of ships and mariners from an oversea monarch (supposed to have reigned in Korea), returned to Tsukushi to fight his brother, and being victorious, spared Hosuseri's life on condition that the descendants of the vanquished through eighty generations should serve the victor's desceridants as mimes.

"On that account," says the Chronicles, "the various Hayato, descended from Hosuseri to the present time, do not leave the vicinity of the Imperial palace enclosure and render service instead of watch-dogs." The first mention of the name Hayato after the prehistoric battle in Kyūshū, occurs in the year 399, when Sashihire, one of the tribe, was induced to assassinate his master, an Imperial prince. This incident goes to show that individual members of the tribe were then employed at Court; an inference confirmed fifty-one years later, when, on the death of Emperor Yüryaku, "the Hayato lamented night and day beside the misasagi (tomb) and refused the food offered to them, until at the end of seven days they died."

It'can scarcely be doubted that we have here a reversion to the old custorn which compelled slaves to follow their lords to the grave. The Hayato serving in the Court at that epoch held the status generally assigned in ancient days to vanquished people, the status of serfs or slaves. Six times during the next 214 years we find the Hayato repairing to the Court to pay homage, in the performance of which function they are usually bracketted with the Yemishi. Once (682) a wrestling match took place in the Imperial presence between the Hayato of Ôsumi and those of Satsuma, and once (694) the viceroy of Tsukushi (Kyūshü) presented 174 Hayato to the Court.

\section{THE TSUCHI-GUMO}

In ancient Japan there was a class of men to whom the epithet "Tsuchi-gumo" (earth-spiders) was applied. Their identity has been a subject of much controversy. The first mention made of them in Japanese annals occurs in connexion with the slaughter of eighty braves invited to a banquet by the Emperor Jimmu's general in a pit-dwelling at Ōsaka.' The Records apply to these men the epithet, "Tsuchi-gumo," whereas the Chronicles represent the Emperor as celebrating the incident in a couplet which speaks of them as Yemishi. It will be seen presently that the apparent confusion of epithet probably conveys a truth.

The next allusion to Tsuchi-gumo occurs in the annals of the year (662 B.c.) following the above event, according to the chronology of the Chronicles. The Emperor, having commanded his generals to exercise tlie troops, Tsuchi-gumo were found in three places, and as they declined to submit, a detachment was

[" This incident has been already referred to under the heading "Yemishi." It is to be observed that the "Osaka" here mentioned is not the modern city of Osaka.] 
sent against them. Concerning a fourth band of these defiant folk, the Chronicles say: "They had short bodies and long legs and arms. They were of the same class as the pigmies. The Imperial troops wove nets of dolichos, which they flung over them and then slew them."

There are four comments to be made on this. The first is that the scene of the fighting was in Yamato. The second, that the chiefs of the Tsuchi-gumo had Japanese names - names identical, in two cases, with those of a kind of Shinto priest (hafuri), and therefore most unlikely to have been borne by men not of Japanese origin. The third, that the presence of Tsuchi-gumo in Yamato preceded the arrival of Jimmu's expedition. And the fourth, that the Records are silent about the whole episode. As for the things told in the Chronicles about short bodies, long limbs, pigmies, and nets of dolichos, they may be dismissed as mere fancies suggested by the name Tsuchi-gumo, which was commonly supposed to mean "earth-spiders." If any inference may be drawn from the Chronicles' story, it is that there were Japanese in Yamato before Jimmu's time, and that Tsuchi-gumo were simply bands of Japanese raiders.

They are heard of next in the province of Bungo (on the northeast of Kyūshū) where (A.D. 82) the Emperor Keiko led an army to attack the Kumaso. on Two bands of :Tsuchi-gumo are mentioned as living there, and the Imperial forces had no little difficulty in subduing them. Their chiefs are described as "mighty

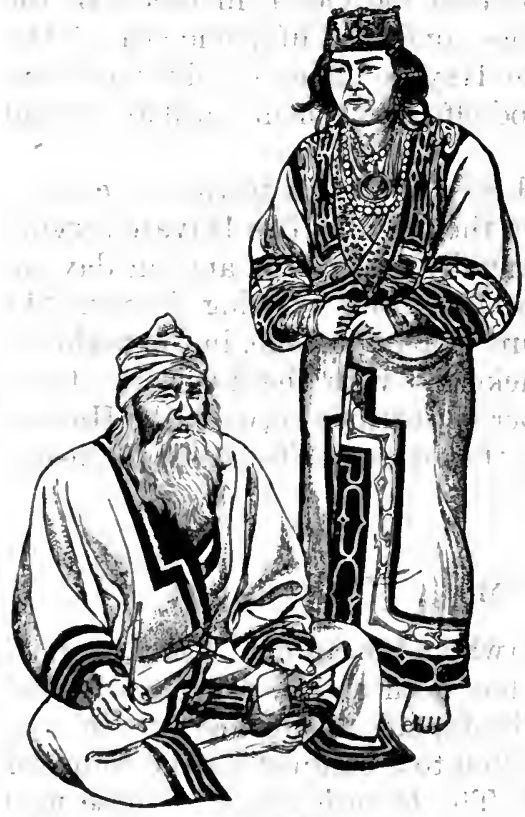

Arvus

(INHabitants of Hokkaido, the Northers IsLAND) of frame and having numerous followers." In dealing with the first band, Keiko caused his bravest soldiers to carry mallets made from camellia trees, though why such weapons should have been preferred to the trenchant swords used by the Japanese there is nothing to show. (Another account says "mallet-headed swords," , which is much more credible). In dealing with the second, he was, driven back once by their rain of arrows, and when he attacked from another quarter, the Tsuchi-gumo, their submission having been refused, flung themselves into a ravine and perished.

Here again certain points have to be noticed: that there were Tsuchi-gumo in Kyūshū as well as in Yamato; that if one account describes them as pigmies, another depicts them as "mighty of frame," and that in Kyüshü, as in Yamato, the Tsuchigumo had Japanese names Only once again do the annals refer to Tsuchi-gumo. They relate curtly that on his return from quelling the Kumaso the Emperor Keikō killed a Tsuchi-gumo in the province of

Hizen. The truth seems to be that factitious import has been attached to the Tsuchi-gumo. Mainly because they were pit-dwellers, it was assumed for a time that they represented a race which had immigrated to Japan at some date prior to the arrival of the Yemishi (modern Ainu). This theory was founded on the supposed discovery of relics of pit-dwellers in the islands of Yezo and Itorop, and their hasty identification as Kuro-pok-guru - the Ainu term for 


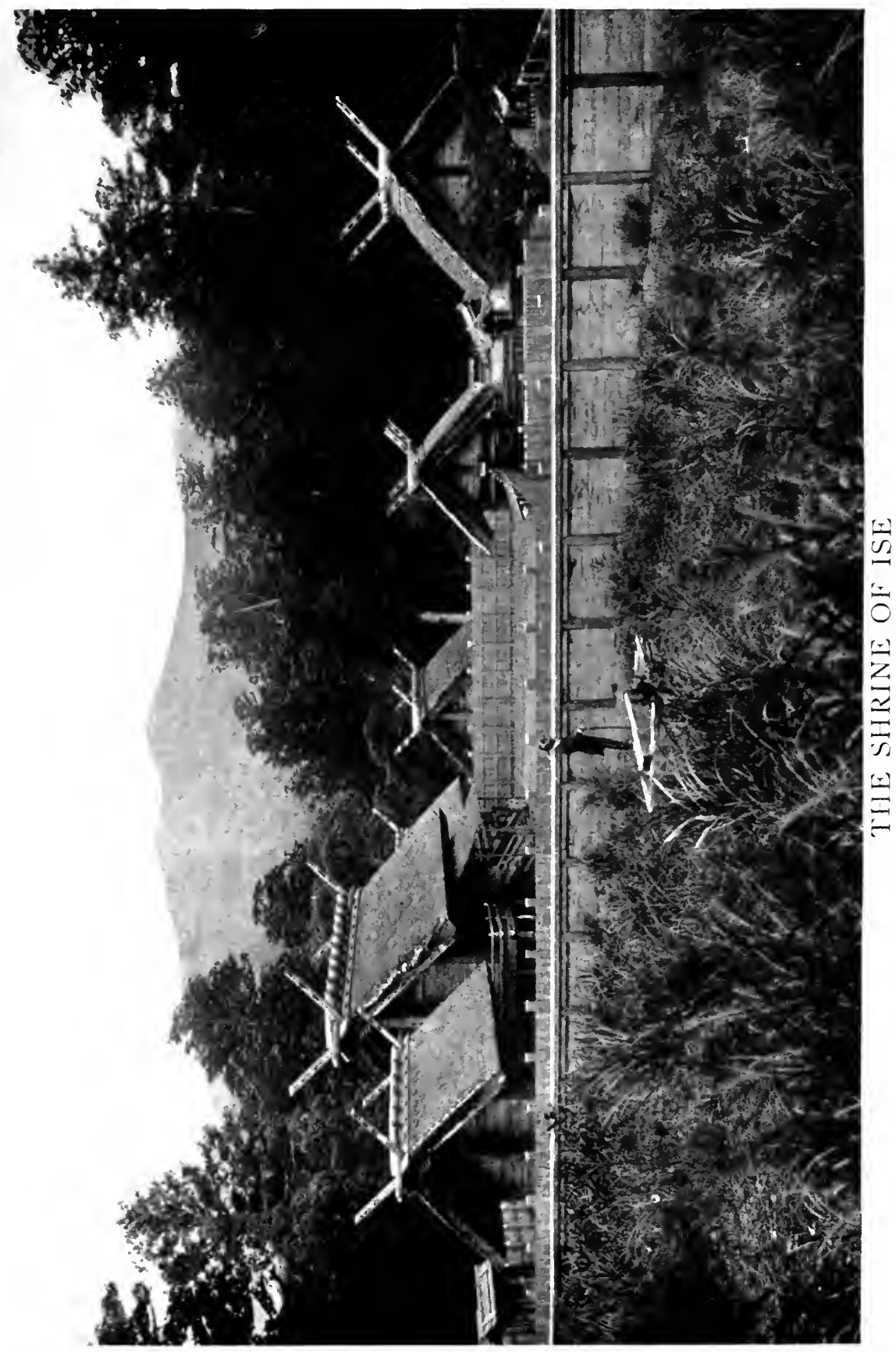



cunderground dwellers - whose modern representatives are seen among the Kurilsky or their neighbours in Kamchatka and Saghalien. But closer examination of the Yezo and Itorop pits showed that there was complete absence of any mark of antiquity - such as the presence of large trees or even deep-rooted brushwood;-that they were arranged in regular order, suggesting a military encampment rather than the abode of savages; that they were of uniform size, with few exceptions; that on excavation they yielded fragments of hard wood, unglazed pottery, and a Japanese dirk, and, finally, that their site corresponded with that of military encampments established in Yezo and the Kuriles by the Japanese Government in the early part of the nineteenth century as a defence against Russian aggression.

Evidently the men who constructed and used these pit-dwellings were not prehistoric savages but modern Japanese soldiers. Further very conclusive testimony has been collected by the Rev. John Batchelor, who has devoted profound study to the Ainu. He found that the inhabitants of Shikotan, who had long been supposed to be a remnant of pre-Ainu immigrants, were brought thither from an island called Shimushir in the Kurile group in 1885 by order of the Japanese Government; that they declared themselves to be descended from men of Saghalien; that they spoke nothing but the Ainu language, and that they inhabited pits in winter, as do also the Ainu now living in Saghalien. If any further proof were needed, it might be drawn from the fact that no excavation has brought to light any relics whatever of a race preceding and distinct from the Yemishi (Ainu), all the pits and graves hitherto searched having yielded Yamato or Yemishi skulls. Neither has there been found any trace of pigmies.

An Ainu myth is responsible for the belief in the existence of such beings: "In very ancient times, a race of people who dwelt in pits lived among us. They were so very tiny that ten of them could easily take shelter beneath one burdock leaf. When they went to catch herrings they used to make boats by sewing the leaves together, and always fished with a hook. If a single herring was caught, it took all the strength of the men of five boats, or ten sometimes, to hold it and drag it ashore, while whole crowds were required to kill it with their clubs and spears. Yet, strange to say, these divine little men used even to kill great whales. Surely these pit-dwellers were gods." 1

Evidently if such legends are to be credited, the existence of fairies must no longer be denied in Europe. Side by side with the total absence of all tangible relics may be set the fact that, whereas numerous place-names in the main island of Japan have been identified as Ainu words, none has been traced to any alien tongue such as might be associated with earlier inhabitants. Thus, the theory of a special race of immigrants anterior to the Yemishi has to be abandoned so far as the evidence of pit-dwelling is concerned. The fact is that the use of partially underground residences cannot be regarded as specially characteristic of any race or as differentiating one section of the people of Japan from another. To this day the poorer classes in Korea depend for shelter upon pits covered with thatch or strong oil-paper. They call these dwellings um or um-mak, a term corresponding to the Japanese muro. "Pit-dwellers are mentioned in old Chinese literature, and the references to the muro in the Records and Chronicles show that the muro of those days had a character similar to that of the modern Korean um-mak" [Aston]. We read of a muro being dug; of steps down to it; and we read of a muro big enough to hold 160 persons at one time. The muro was not always simply a hole roofed over; it sometimes contained a house having a wood- 
en frame lashed together with vine-tendrils; the walls lined with sedges and reeds and plastered with a mixture of grass and clay. The roof was thatched with reeds; there was a door opening inwards, and a raised platform served for sleeping purposes. A dwelling closely resembling this description was actually unearthed near Akita in $\bar{O}-\mathrm{U}$, in 1807. Muro were used in ancient times by the highest as well as the poorest classes. "Susanoo is said by the IzumorF.üdoki to have made for himself a muro; Jimmu's son is represented as sleeping in a great muro, and the Emperor Keikō, when (A.D. 82) prosecuting his campaign in Kyūshū, is said to have constructed a muro for a temporary palace." "In fact, pit-dwelling in northern climates affords no indication of race.".

\section{CONCLUSION FROM HISTORICAL EVIDENCE}

Thus the conclusion suggested by historical evidence is that the Japanese nation is composed of four elements: the Yamato; the Yemishi (modern Ainu); the Kumaso (or Hayato), and the:Sushen. "As to the last of these, there is no conclusive indication that they ever immigrated in appreciable numbers. It does not follow, of course, that the historical evidence is exhaustive, especially Japanese historical evidence; for the annalists of Japan do not appear to have paid any special attention to racial questions.

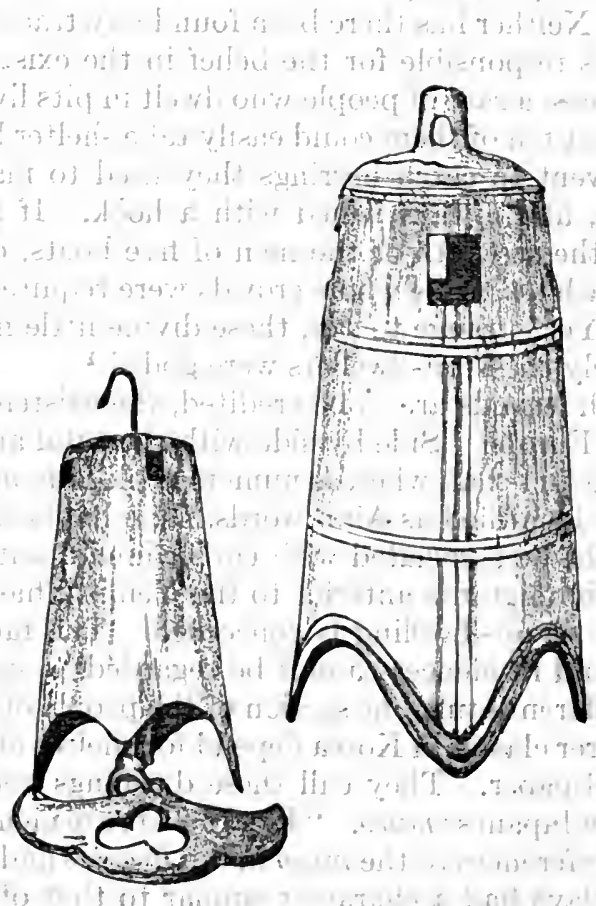

ri Issits $n k$

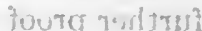

fysuat! =-3il

isn $f$ int-inn'y

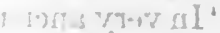

Ancient Hanglno Bells 


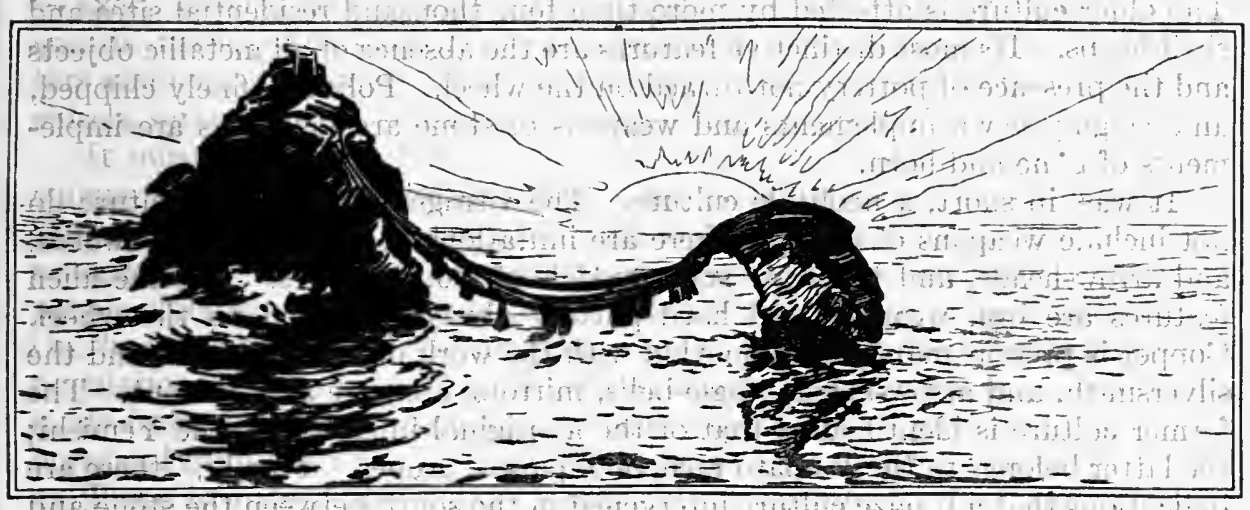

Futami-Ga-Ura

(The Husband and Wife Rocks)

\section{CHAPTER VI}

\section{ORIGIN OF THE NATION: GEOGRAPHICAL AND ARCHAE- OLOGICAL RELICS}

\section{JAPAN'S CONNEXION WITH THE ASIATIC CONTINENT}

4t THE group of islands forming Japan may be said to have routes of communication with the continent of Asia at six places: two in the north; two in the southwest, and two in the south. The principal connexion in the north is across the narrow strait of Soya from the northwest point of Yezo to Saghalien and thence to the Amur region of Manchuria. The secondary connexion is from the northeast point of Yezo via the long chain of the Kuriles to Kamchatka. The first of the southwestern routes is from the northwest of Kyūshu via the islands of Iki and Tsushima to the southeast of Korea; and the second is from the south of the Izumo promontory in Japan, by the aid of the current which sets up the two southern routes. One of these is from the southwest of Kyūshü viâ the Gotō Islands to southeastern China; the other is from the south of Kyūshū viâ the Ryūky $\bar{u}:$ Islands, Formosa, and the Philippines to Malaysia and Polynesia. It has also been proved geologically 1 that the islands now forming Japan must at one time have been a part of the Asiatic continent. Evidently these various avenues may have given access to immigrants from Siberia, from China, from Malaysia, and from Polynèsia.

\section{CULTURE}

Archaeological research indicates the existence of two distinct cultures in Japan together with traces of a third. One of these cultures has left its relics chiefly in shell-heaps or embedded in the soil, while the remains of another are found mainly in sepulchral chambers or in caves. The relics themselves are palpably distinct except when they show transitional approach to each other.

[ ${ }^{1}$ There have been found in the gravel Tertiary mammals including elephas primigenius, elephas Namadicus, stegodon Clifti, and unnamed varieties of bear, deer, bison, ox; horse, rhinoceros, and whale. (Outlines of the Geology of Japan; Imperial Geological Survey).] 
The older culture is attested.by more than four thousand residential sites and shell-heaps. Its most distinctive features are the absence of all metallic objects and the presence of pottery not turned on the wheel. Polished, finely chipped, and roughly hewn implements and weapons of stone are found, as are implements of bone and horn.

It was, in short, a neolithic culture. The vestiges of the other culture do not include weapons of stone. There are imitations of sheath-knives, swords, and arrow-hearls, and there are some models of stone articles. But the alien features are iron weapons and hard pottery always moulded on the wheel. Copper is present mainly in connexion with the work of the goldsmith and the silversmith, and arrow-heads, jingle-bells, mirrors, etc., are also present. The former culture is identified as that of the aboriginal inhabitants, the Yemishi; the latter belongs to the Yamato race, or Japanese proper. Finally, "there are indications that a bronze culture intervened in the south between the stone and the iron phases." 1

\section{PRIMITIVE CULTURE}

The neolithic sites occur much more frequently in the northern than in the southern half of Japan. They are, indeed, six times as numerous on the north as on the south of a line drawn across the main island from the coast of Ise through Ōmi. The neighbourhood of the sea, at heights of from thirty to three hundred feet, and the alluvial plains are their favourite positions. ${ }^{2}$ So far as the technical skill shown by the relics - especially the pottery - is concerned, it grows higher with the latitude. The inference is that the settlements of the aborigines in the south were made at an earlier period than those in the north; which may be interpreted to mean that whereas the stone-using inhabitants were driven back in the south at an early date, they held their ground in the north to a comparatively modern era.

That is precisely what Japanese history indieates. Jimmu's conquests, which took place several centuries before the Christian era, earried him as far as the Ise-Ömi line, but Yamato-dake's expedition against the Yemishi north of that line was not planned until the second century after Christ. Apart from the rough evidence furnished by the quality of the relies, calculations have been made of the age of an important shell-heap by: assuming that it originally stood at the seaside, and by estimating the number of years required to separate it by the present interval from the coast at a fixed annual rate of silting. The result is from five thousand to ten thousand years. A book (the Hitachi Fi údoki), published in A.D. 715, speaks of these kaizuka (shell-heaps) as existing already at that remote period, and attributes their formation to a giant living on a hill who stretched out his hand to pick up shell-fish. This myth remained current until the eighteenth century, and stone axes exhumed from the heaps were called thunder-axes (rai-fu) just as similar relies in Europe were called elf-bolts or thunder-stones.

There is great diversity of size among the shell-heaps, some being of insignificant dimensions and others extending to five hundred square yards. They, are most numerous in the eight provinces forming the Kwantō. In fact, in these ancient times, the Yamato race and the aborigines had their headquarters in the same localities, respectively, as the Imperial and Feudal governments had in mediaeval and modern times. But there are no distinct traces of palaeolithic culture; the neolithic alone can be said to be represented. Its relics are numerous 
4. axes, knives, arrow-heads, arrow-necks, bow-tips, spear-heads, batons, swords, maces, sling-stones, needles, drill-bows, drill and spindle weights, mortars and pestles, paddles, boats, sinkers, fishing-hooks, gaffs, harpoons, mallets, chisels, scrapers, hoes, sickles, whetstones, hammers, and drills.

It must be premised that though so many kinds of implements are here enumerated, the nomenclature cannot be accepted as universally accuratc. The so-called "hoe," for example, is an object of disputed identity, especially as agriculture has not been proved to have been practised among the primitive people of Japan, nor have any traces of grain been found in the neolithic sites. On the other hand, the modern Ainu, who are believed to represent the ancient population, include in their religious observances the worship of the first cakes made from the season's millet, and unless that rite be supposed to have been borrowed from the Yamato, it goes to indicate agricultural pursuits.

There is, indeed, one great obstacle to any confident differentiation of the customs and creeds prevalent in Japan. That obstacle consists in the great length of the period covered by the annals. It may reasonably be assumed that the neolithic aborigines were in more or less intimate contact with the invading Yamato for something like twenty-five centuries, an interval quite sufficient to have produced many interactions and to have given birth to many new traditions. An illustration is furnished by the mental attitude of the uneducated classes in Japan towards the neolithic implements. So completely has all memory of the human uses of these implements faded, that they are regarded as relics of supernatural beings and called by such names as raifu (thunder-axe), raitsui (thunder-club), kitsune no kuwa (fox-hoe), raiko (thunder-pestle), and tengu no, meshigai (rice-spoon of the goblins). Many of the neolithic relics show that the people who used them had reached a tolerably high level of civilization.

This is specially seen in the matter of ceramics: It is true that the whecl was not employed and that the firing was imperfect, but the variety of vessels was considerable, ${ }^{1}$ and the shapes and decorations. were often very praiseworthy. Thus, among the braziers are found shapes obviously the originals of the Japanese choji-buro (clove-censer) and the graceful rice-bowl, while community of conception with Chinese potters would seem to be suggested by some of the forms of these ancient vases. Particularly interesting are earthenware images obtained from these neolithic sites. Many of them have been conventionalized into mere anthropomorphs and are rudely moulded. But they afford valuable indications of the clothing and personal adornments of the aborigines.

What end these effigies were intended to serve remains an unsettled question. Some suggest that they were used as substitutes for human sacrifices, and that they point to a time when wives and slaves were required to follow their husbands and masters to the grave. They may also have been suggested by the example of the Yamato, who, at a very remote time, began to substitute clay images for human followers of the dead; or they may have been designed to serve as mere mementoes. This last theory derives some force from the fact that the images are found, not in graves or tombs, but at residential sites. No data have been obtained, however, for identifying burying-places: sepulture may have been carried out in the house of the deceased. Whichever explanation be correct, the fact confronts us that these clay effigies have no place in the cult of the modern Ainu. History teaches, however, that degeneration may become so

[' Cooking-pots and pans, jars and vases, bowls and dishes, cups, bottles, nipple pots, lamps," braziers, ewers, strainers, spindles or 'drill weights, stamps, ornaments, images, and plaques (Munro's Prehistoric Japan).] 
complete as to deprive a nation of all traces of its original civilization. Such seems to have been the case with the Ainu.

\section{INTERMEDIATE CULTURE}

Traces of a culture occupying a place intermediate between the primitive culture and that of the Yamato are not conclusive. They are seen in pottery which, like the ware of the neolithic sites, is not turned on the wheel, and, like the Yamato ware, is decorated in a very subdued and sober fashion: It is found from end to end of the main island and even in Yezo, and in pits, shell-heaps, and independent sites as well as in tombs, burial caves, and cairns of the Yamato. Thus, there does not seem to be sufficient warrant for associating it with a special race. It was possibly supplied to order of the Yamato by the aboriginal craftsmen, who naturally sought to copy the salient features of the conquering immigrants' ware.

\section{BRONZE VESTIGES}

There are also some bronze vestiges to which considerable interest attaches, for evidently people using bronze weapons could not have stood against men carrying iron arms, and therefore the people to whom the bronze implements belonged must have obtained a footing in Japan prior to the Yamato, unless they came at the latter's invitation or as their allies. Moreover, these bronze relics - with the exception of arrow-heads - though found in the soil of western and southern Japan, do not occur in the Yamato sepulchres, which feature constitutes another means of differentiation. Daggers, swords, halberds, and possibly spear-heads constitute the hand-weapons. The daggers have a certain resemblance to the Malay kris, and the swords and halberds are generally leaf-shaped. But some features, as overshort tangs and unpierced loops, suggest that they were manufactured, not for service in battle but for ceremonial purposes, being thus mere survivals from an era when their originals were in actual use, and possibly those originals may have been of iron. Some straight-edged specimens have been classed as spear-heads, but they closely resemble certain ancient bronze swords of China. As for bronze arrow-heads, they occur alike in Yamato sepulchres and in the soil, so that no special inference is warranted in their case. The bronze hand-weapons have been found in twelve provinces of southern and western Japan: namely, five provinces of northwest Kyūshū; three on the Inland Sea; one facing Korea and China, and the rest on the islands of Iki and Tsushima.

These localities and the fact that similar swords have been met with in Shantung, suggest that the bronze culture came from central and eastern Asia, which hypothesis receives confirmation from the complete absence of bronze vestiges in the southern provinces of Kyūshū, namely, Ōsumi and Satsuma. Bronze bells, of which there are many, belong to a separate page of archacology. Though they have been found in no less than twenty-four provinces, there is no instance of their presence in the same sites with hand-weapons of bronze. In' Kyūsh $\bar{u}$, Higo is the only province where they have been seen, whereas in the main island they extend as far east às Tōtomi, and are conspicuously numerous in that province and its neighbour, Mikawa, while in Ōmi they are most abundant of all. They vary in height from about one foot four inches to four and a half feet, and are of highly specialized shape, the only cognate type being bells used in China cluring the Chou dynasty (1122-225 B.c.) for the purpose of giv- 
ing military signals. A Chinese origin is still more clearly indicated by the decorative designs, which show a combination of the circle, the triangle, and the spiral, obviously identical with the decorative motive ${ }^{1}$ on Chinese drums of the Han dynasty (202 B.C.-A.D. 220). The circle and the triangle occur also in the sepulchral pottery of the Yamato sites, and considering the fact together with the abundance of the bells in districts where the Yamato were most strongly established, there seems to be warrant for attributing these curious relies to the Yamato eulture.

Earo this inference it has been objected that no bells have been found in the tombs of the Yamato. The same is true, however, of several other objects known to have belonged to that people. If, then, the bells be classed as adjuncts of the Yamato culture, shall we be justified in assigning the bronze weapon to a different race? On the whole, the most reasonable conclusion seems to be that all the bronze relics, weapons, and bells alike, are "vestiges of the Yamato procession at a time anterior to the formation of the great dolmens and other tombs" [Munro]: A corollary would be that the Yamato migrated from China in the days of the Chou dynasty $(1122-225$ в.C.), and that; having landed in the province of Higo, they conquered the greater part of Tsukushi (Kyūshū), and subsequently passed up the Inland Sea to Yamato; which hypothesis would invest with some accuracy the date assigned by the Chronicles to Jimmu's expedition and would constitute a general confirmation of the Japanese account of his line of advance.

\section{YAMATO CULTURE}

The ancient Yamato are known chiefly through the medium of relics found in their sepulchres. Residential sites exist in comparatively small numbers, so far as research has hitherto shown, and such sites yield nothing except more or less scattered potsherds and low walls enclosing spaces of considerable area. Oceasionally. Yamato pottery and other relies are discovered in pits; and these evidences, combined with historical references, go to show that the Yamato themselves sometimes used pit-dwellings.

The tombs yield much more suggestive relics of metal; stone, and pottery. Some four thousand of such sepulchres have been officially catalogued, but it is believed that fully ten times that number exist. The most characteristic is a tomb of larger dimensions enclosing a dolmen which contains a coffin hollowed out from the trunk of a tree, or a sarcophagus of stone, ${ }^{2}$ the latter being much more commonly found, as might be expected from its greater durability. Burialjars were occasionally used, as were also sarcophagi of clay or terracotta, ${ }^{3}$ the latter chiefly in the provinces of Bizen and Mimasaka; probably because suitable. materials existed there in special abundance. Moreover, not: a few tombs belonged to the category of cists; that is to say, excavations in rock, with $a$ single-slabbed or many-slabbed cover; or receptacles formed with stone elubs, cobbles, or boulders.

There is great difficulty in arriving at any confident estimate of age amid such varity. "Dolmens of a most primitive kind "exist side by side with stone

[ ${ }^{1}$ This resemblance has been pointed out by a Japanese archaeologist, Mr. Teraishi. Dr. Munro states that the same elements are combined in an Egyptian decorative design.]

[2 The stone sarcophagus was of considerable size and various shapes; forming an oblong box with a lid of a boatlike form.]

$\left[{ }^{3}\right.$ The terracotta sarcophagi were generally parallel, oblong or elongated oval in shape, with an arched or angular covering and several feet. One has been found with doors moving on hinges.] 
chambers of highly finished masonry in circumstances which suggest contemporaneous construction" so that "the type evidently furnishes little or no criterion of age," and, moreover, local facilities must have largely influenced the method of building. The dolmen is regarded by archaeologists as the most characteristic feature of the Yamato tombs. It was a chamber formed by setting up large slabs of stone, inelined slightly towards each other, which served as supports for another slab forming the roof. Seen in plan, the dolmens presented many shapes: a simple chamber or gallery; a chamber with a gallery, or a series of chambers with a gallery. Above the dolmen a mound was built, sometimes of huge dimensions (as, for example, the misasagi ${ }^{1}$ of the Emperor Tenchi-d. A.D. 671 - which with its embankments, measured 5040 feet square), and within the dolmen were deposited many articles dedicated to the service of the deceased. Further, around the covering-mound there are generally found, embedded in the earth, terracotta cylinders (haniwa), sometimes surmounted with figures or heads of persons or animals.

According to the Chronicles, incidents so shocking occurred in connexion with the sacrifice of the personal attendants ${ }^{2}$ of Prince Yamato at his burial (A.D. 2) that the custom of making such sacrifices was thenceforth abandoned, clay images being substituted for human beings. The Records speak of a "hedge of men set up round a tumulus," and it would therefore seem that these terracotta figures usually found encircling the principal misasagi, represented that hedge and served originally as pedestals for images. Within the dolmen, also, clay. effigies are often found, which appear to have been substitutes for retainers of high rank. Had the ancient custom been effectually abolished in the year A.D. 3, when the Emperor Suinin is recorded to have issued orders in that sense, a simple and conclusive means would be at hand for fixing the approximate date of a dolmen, since all tombs containing clay effigies or encireled by terracotta haniwa would necessarily be subsequent to that date, and all tombs containing skeletons. other than the occupants of the sarcophagi would be referable to an earlier era.) But although compulsory sacrifices appear to have ceased from about the first century of the Christian era, it is certain that voluntary sacrifices continued. through many subsequent ages. This clue is therefore illusory. Neither does the custom itself serve to connect the Yamato with any special race, for it is a wide-spread rite of animistic religion, and it was practised from time immemorial by the Chinese, the Manchu Tatars, and many other nations of northeastern Asia.

The substitution of images for living beings, however, appears to have been a direct outcome of contact with China, for the device was known there as early as the seventh century before Christ. It would seem, too, from the researches of a learned Japanese archaeologist (Professor Miyake), that the resemblance between Japanese and Chinese burial eustoms was not limited to this substitution. The dolmen also existed in China in very early times, but had been replaced by a chamber of finished masonry not later than the ninth century B.c. In the Korean peninsula the dolmen with a megalithic roof is not uncommon, and the sepulchral pottery bears a elose resemblance to that of the Yamato tombs. It was at one time supposed that the highly specialized form of dolmen found in Japan had no counterpart anywhere on the continent of Asia, but that supposition has proved erroneous.

[ ${ }^{1}$ By this name all the Imperial tombs were called.]

[2 They are said to have been buried upright in the precinets of the misasagi. "For several days they died not, but.wept and wailed day and night. At last they died and rotted. 
The contents of the sepulchres, however, are more distinctive.: They consist of "noble weapons and armour, splendid horse-trappings, vessels for food and drink, and various objects de luxe," though articles of wood and textile fabrics have naturally perished. Iron swords are the commonest relics. They are found in all tombs of all ages, and they bear emphatic testimony to the warlike habits of the Yamato, as well as to their belief that in the existence beyond the grave weapons were not less essential than in life. Arrow-heads are also frequently found and spear-heads sometimes. ${ }^{1}$ The swords are all of iron. There is no positive evidence showing that bronze swords were in use, though grounds exist for supposing, as has been already noted, that they were employed at a period not much anterior to the commencement of dolmen building, which secms to have been about the sixth or seventh century before Christ. The iron swords themselves appear to attest this; for although the great majority are singleedged and of a shape essentially suited to iron, about ten per cent. are doubleedged with a central ridge distinctly reminiscent of casting - in fact, a hammerediron survival of a bronze leaf-shaped weapon. ${ }^{2}$ Occasionally these swords have, at the end of the tang, a disc with a perforated design of two dragons holding a ball, a decorative motive which already betrays Chinese origin. Other swords have pommels surmounted by a bulb set at an angle to the tang, ${ }^{3}$ and have been suspected to be. Turanian origin.

Yet another form - found mostly in the Kwantō provinces and to the north of them, from which fact its comparatively recent use may be inferred - was known in western Asia and especially in Persia, whence it is: supposed to have been exported to the Orient in connexion with the flourishing trade carried on between China and Persia from the seventh to the tenth century. That a similar type is not known to exist in China proves nothing conclusive, for China's attitude towards foreign innovations was always more conservative than Japan's. Scabbards, having been mostly of wood, have not survived, but occasionally one is found having a sheeting of copper thickly plated with gold, Arrow-heads are very numerous. Those of bronze have, for the most part, the

[1 The most comprehensive list of these objects is that given in Munro's Prehistoric Japan: "Objects of iron - (1), Swords and daggers; (2), Hilt-guards and pommels; (3), Arrow-heads; (4), Spear-heads and halberd-heads; (5) Armour and helmets; (6), Stirrups and bridle-bits; (7), Ornamental trappings for horses; (8), Axes, hoes, or chisels; (9), Hoes or spades; (10), Chains; (11), Rings; (12), Buckles; (13), Smith's tongs or pincers; (14), Nails; (15), Caskets; handles, hinges, and other fittings. Objects of copper and bronze - (1), Arrow-heads; (2); Spear-heads; (3), Hilt-guards and pommels; (4), Scabbard-covers and pieces of sheet-copper for ornamental uses; (5), Helmets; (6), Arm-and-leg guards; (7), Shoes; (8), Horse-trappings; (9), Belts; (10), Mirrors; (11), Bracelets and rings; (12), Various fittings. Silver and gold were employed chiefly in plating, but fine chains and pendants as well as rings of pure gold and silver have been met with.

"The stone objects may be divided into two classes, viz:-

A. Articles of use or ornaments - (1), Head-rest; (2), Mortar and pestle; (3), Caskets and vessels; (4), Cups and other vessels; (5), Bracelets; (6), Magatama; (7), Other-ornaments; (8), Plumb-line pendant; (9), Spindle-weight; (10), Objects of unascertained function.

B. Sepulchral substitutes - (1), Swords and daggers; (2); Sheath-knife; (3), Arrow-head; (4), Spear-head; (5); Shield; (6); Armour; (7), Wooden dogs; (8), Mirror; (9), Comb; (10), Magatama; (11), Cooking-knife; (12), Sickle or scythe-blade; (13), Hoe or chisel; (14), Head of chisel or spear; (15), Bowl; (16), Table; (17), Sword-pommel; (18), : Nondescript objects." The above list does not include pottery.]

[2 The leaf-shaped bronze sword is found over all Europe from the Mediterranean to Lapland, but generally without a central ridge.]

${ }^{3} \mathrm{Mr}$. Takahashi, a Japanese archaeologist, suggests that these weapons were the so called "mallet-headed swords"'said to have been used by Keikō's soldiers (A.D. 82) against the Tsuchigumo. The name, kabutsuchi, supports this theory, kabu being the term for "turnip," which is also found in kabuya, a humming arrow having a turnip-shaped head perforated with holes:] 
leaf shape of the bronze sword, but those' of iron show many forms, the most remarkable being the chisel-headed, a type used in Persia.

Spear-heads are not specially suggestive as to provenance, with the exception of a kind having a cross-arm like the halberd commonly used in China from the seventh century before Christ. Yamato armour affords little assistance to the archacologist: it bears no particularly elose resemblance to any type familiar elsewhere. There was a corset made of sheet iron, well rivetted. It fastened in front and was much higher behind than before, additioned protection for the back being provided by a lattice-guard which depended from the helmet and was made by fastening strips of sheet iron to leather or cloth. The helmet was usually of rivetted iron, but occasionally of bronze, with or without a peak in front. There were also guards of copper or iron for the legs, and there were shoulder-curtains constructed in the same manner as the back-curtain pendan't from the helmet. Shoes of eopper complete the panoply.

The workmanship of these weapons and armour is excellent: it shows an advanced stage of manufacturing skill. This characteristic is even more remarkable in the case of horse-trappings. The saddle and stirrups, the bridle and bit, are practically the same as those that were used in modern times, even a protective toe-piece for the stirrup being present. A close resemblance is obscrvable between the ring stirrups of old Japan and those of mediaeval Europe, and a much closer affinity is shown by the bits, which had cheek-pieces and were usually jointed in the centre precisely like a variety common in Europe; metal pendants, garnished with silver and gold and carrying globular jinglebells in their embossed edges, served for horse decoration. These facts are learned, not from independent relics alone, but also from terracotta steeds found in the tumuli and moulded so as to show all their trappings.

Other kinds of expert iron-work have also survived; as chains, rings and, buckles, which differ little from corresponding objects in Europe at the present day; and the same is true of nails, handles, hinges, and other fittings. Tools used in working metal are rarely found, a fact easily accounted for when we remember that such objects would naturally be excluded from sepulchres.

There is another important relie which shows that the Yamato were "indebted to China for the best specimens of their decorative art." This is a round bronze mirror, of which much is heard in early Japanese annals from the time of Izanagi downwards. In China the art of working in bronze was known and practised during twenty centuries prior to the Christian era; but although Japan seems to have possessed the knowledge at the outset of the dolmen epoch, (circ. 600 B.c.), she had no copper mine of her own until thirteen centuries later, and was obliged to rely on Korea for occasional supplies. This must have injuriously affected her progress in the art of bronze casting.

Nevertheless, in almost all the dolmens and later tombs mirrors of bronze were placed. This custom came into vogue in China at an early date, the mirror being regarded as an amulet against decay or a symbol of virtue. That Japan borrowed the idea from her neighbour ean scarcely be doubted. She certainly procured many Chinese mirrors, which are easily distinguished by finely executed and beautiful decorative designs in low relief on their backs; whereas her own mirrors - occasionally of iron - did not show equal skill of technique or ornamentation. Comparative roughness distinguished them, and they had often a garniture of jingle-bells (suzu) cast around the rim, a feature not found in Chinese mirrors. They were, in fact, an inferior copy of a Chinese prototype, the kinship of the two being further attested by the common use of the dragon as a 
decorative motive. Bronze vases and bowls, simple or covered, are occasionally found in the Yamato sepulchres. Sometimes they are gilt, and in no case do their shapes differentiate them from Chinese or modern Japanese models.

It might be supposed that in the field of personal ornament some special features peculiar to the Yamato civilization should present themselves. There is none. Bronze or copper bracelets, ${ }^{1}$ closed or open and generally gilt, recall the Chinese bangle precisely, except when they are cast with a garniture of suzu. In fact, the suzu (jingle-bell) seems to be one of the few objects purely of Yamato origin. It was usually globular, having its surface divided into eight parts, and it served not only as part of a bangle and as a pendant for horse-trappings but also as a post-bell (ekirei), which, when carried by nobles and officials, indicated their right to requisition horses for travelling purposes.

-rito another object:interest attaches because of its wide use in western Asia and among the Celtic peoples of Europe. This is the penannular (or open) ring. In Europe, it was usually of solid gold or silver, but in Japan, where these metals were very scarce in early days, copper, plated.with beaten gold or silver, was the material generally employed. Sometimes these rings were hollow and sometimes; but very rarely, flattened. The smaller ones seem to have served as earrings, worn either plain or with pendants.

ous Prominent among personal ornaments were magatama (curved jewels) and kudatama (cylindrical jewels). It is generally supposed that the magatama represented a tiger's claw; which is known to have been regarded by the Koreans as an amulet. But the ornament may also have taken its comma-like shape from the $Y \bar{Q}$ and the $Y \ddot{i n}$; the positive and the negative principles which by Chinese cosmographists were accounted the great primordial factors, and which occupy a prominent place in Japanese decorative art as the tomoye. ${ }^{2}$; The cylindrical jewels evidently owed their shape to facility for stringing into necklaces or chaplets. The Chronicles and the Records alike show that these jewels, especially the magatama, acted an important part in some remarkable scenes in the mythological age. ${ }^{3}$ Moreover, a sword, a mirror, and a magatama, may be called the regalia of Japan. But these jewels afford little aid in identifying the Yamato. Some of them - those of jade, chrysoprase, and nephrite -4 must have been imported, these minerals never having been found in Japan. But the latter fact, though it may be held to confirm the continental origin of the Yamato, gives no indication as to the part of Asia whence they emigrated.

\section{YAMATO POTTERY}

The pottery found in the Yamato tombs is somewhat more instructive than the personal ornaments. It seems to have been specially manufactured, or at any rate selected, for purposes of sepulture, and it evidently retained its shape and character from very remote if not from prehistoric times. Known in

LS ' $\left[{ }^{1}\right.$ Jásper also was employed for making bracelets', and there is some evidence that shells were similarly used.]

[2 Professor Takashima has found magatama among the relics of the primitive culture, but that is probably the result of imitation.]

1 The goddess of the Sun; when awaiting the encounter with Susanoo, twisted a complete string, eight feet long, with five hundred magatama. Lesser Kami were created by manipulating the jewels. 17 When Amaterasu retired into a cave, magatama were hung from the branches of a sakaki tree to assist in enticing her out. Several other reverential allusions are made to the jewels in later times:]

[ 4 The jewels lwere of jasper, agate, chalcedony, serpentine, nephrite, steatite, quartz, crystal, glass, jade (white and green); and chrysoprase. Mention is also made of rakan, but the meaning of the term is obscure. Probably it was a variety of jade.] 
Japan as iwaibe (sacred utensils), it resembles the pottery of Korea so closely that identity has been affirmed by some archaeologists and imitation by others. It has comparatively fine paste - taking the primitive pottery as standard is hard, uniformly baked, has a metallic ring, varies in colour from dark brown to light gray, is always turned on the wheel, has only accidental glaze, and is decorated in a simple, restrained manner with conventionalized designs. The shapes of the various vessels present no marked deviation from Chinese or Korean models, except that the tazzas and occasionally other utensils are sometimes pierced in triangular, quadrilateral, and circular patterns, to which various meanings more or less fanciful have been assigned.

There is, however, one curious form of iwaibe which does not appear to have any counterpart in China or Korea. It is a large jar, or tazza, having several small jars moulded around its shoulder, these small jars being sometimes interspersed with, and sometimes wholly replaced by, figures of animals. 2 It is necessary to go to the Etruscan "black ware" to find a parallel to this most inartistic kind of ornamentation.

With regard to the general decorative methods of the iwaibe potters, it is noticeable, first, that apparent impressions of textiles are found (they are seldom actual imprints, being usually imitations of such), and, secondly, that simple line decoration replaces the rude pictorial representations of a primitive culture and suggests propagation from a centre of more ancient and stable civilization than that of the Yamato hordes: from China, perhaps from Korea - who knows? As for the terracotta figures of human beings and sometimes of animals found in connexion with Y amato sepulchres, they convey little information about the racial problem. ${ }^{3}$ The idea of substituting such figures for the human beings originally obliged to follow the dead to the grave seems to have come from China, and thus constitutes another evidence of intercourse, at least, between the two countries from very ancient times.

It has been remarked that "the faces seen on these images by no means present a typical Mongolian type; on the contrary, they might easily pass! for European faces, and they prompt the query whether the Yamato were not allied to the Caucasian race." Further, "the national vestiges of the Yamato convey an impression of kinship to the civilization which we are accustomed to regard as our own, for their intimate familiarity with the uses of swords, armour, horsegear, and so forth brings us into sympathetic relation to their civilization:" [Munro.]

\section{SUMMARY}

It will be seen from the above that archaeology, while it discloses to us the manners and customs of the ancient inhabitants of Japan, does not afford material for clearly differcntiating more than three cultures: namely, the neolithic culture of the Yemishi; the iron culture of the Yamato, and the intermediate bronze culture of a race not yet identified. There are no archaeological traces of the existence of the Kumaso or the Tsuchi-gumo, and however probable it may seem, in view of the accessibility of Japan from the mainland, not only while she formed part of the latter but even after the two had become separate,

[1 This style of ornamentation was called komochi (child-bearing), the small jars being regarded as children of the large.]

$\left[^{2} \mathrm{Mr}\right.$. Wakabayashi, a Japanese archaeologist, has enumerated seven varieties of figures thus formed on vases: horses, deer, wild boars, dogs, birds, tortoises; and human beings.]

$\left[{ }^{3}\right.$ Chinese archaie wine-pots of bronze sometimes have on the lid figures of human beings and animals, but these served a useful purpose.] 
that several races co-existed with the Yemishi and that a very mixed population carried on the neolithic culture, there is no tangible evidence that such was the case. Further, the indications furnished by mythology that the Yamato were intellectually in touch with central, if not with western Asia, are re-enforced by archaeological suggestions of a civilization and even of physical traits cognate with the Caucasian.
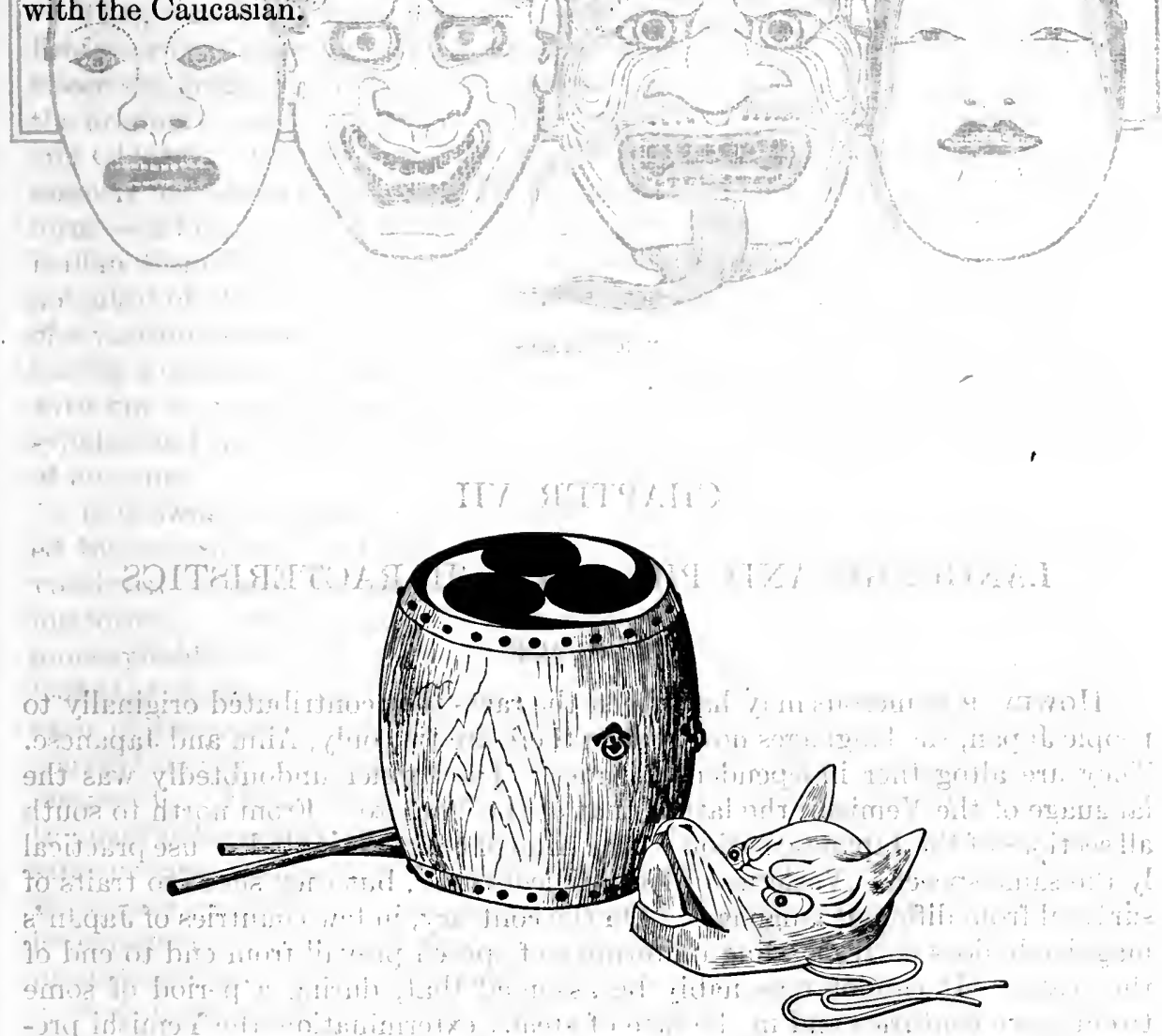

DrUM AND : Magk 


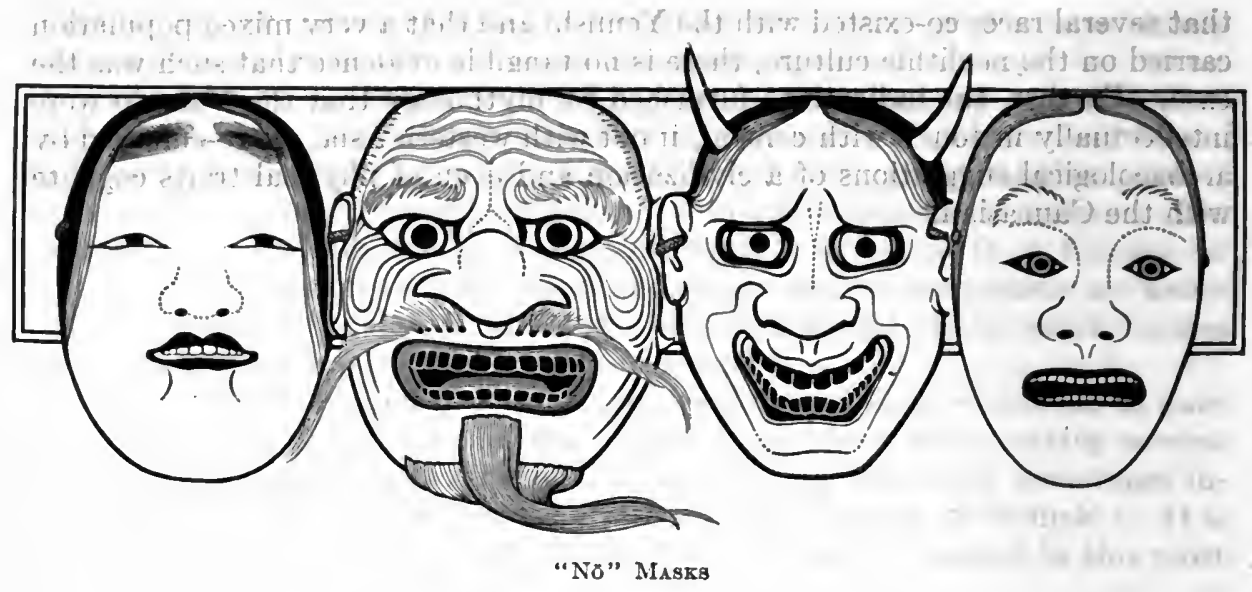

CHAPTER VII

\section{LANGUAGE AND PHYSICAL CHARACTERISTICS}

\section{LANGUAGE}

However numerous may have been the races that eontributed originally to people Japan, the languages now spoken there are two only, Ainu and Japanese. 'They are altogether independent tongues. The former undoubtedly was the language of the Yemishi; the latter, that of the Yamato. From north to south all sections of the Japanese nation - the Ainu of course excepted - use practical ly the same speech. Varieties of local dialects exist, but they show no traits of survival from different languages. On the contrary, in few countries of Japan's magnitude does corresponding uniformity of speech prevail from end to end of the realm. - It cannot reasonably be assumed that, during a period of some twenty-five centuries and in the face of steady extermination, the Yemishi preserved their language quite distinet from that of their conquerors, whereas the various languages spoken by the other races peopling the island were fused into a whole so homogeneous as to defy all attempts at differentiation. The more credible alternative is that from time immemorial the main elements of the Japanese nation belonged to the same race, and whatever they received from abroad by way of immigration became completely absorbed and assimilated in the course of centuries.

No diligent attempt has yet been made to trace the connexion - if any exist - between the Ainu tongue and the languages of northeastern Asia, but geology, history, and archaeology suffice to indicate that the Yemishi reached Japan at the outset from Siberia. The testimony of these three sources is by no means so explicit in the case of the Yamato, and we have to consider whether the language itself does not furnish some better guide. "Excepting the twin sister tongue spoken in the Ryūkyū Islands," writes Professor Chamberlain," the Japanese language has no kindred, and its classification under any of the recognized linguistic families remains doubtful. In structure, though not to any appreciable extent in vocabulary, it elosely resembles Korean, and both it and 
Korean may possibly be related to Mongol and to Manchu; and might therefore lay claim to be included in the so-called 'Altaic group.' In any case, Japanese is what philologists call an agglutinative tongue; that is to say, it builds up its words and grammatical forms by means of suffixes loosely soldered to the root or stem, which is invariable."

This, written in 1905, has been supplemented by the ampler researches of Professor S. Kanazawa, who adduces such striking evidences of similarity between the languages of Japan and Korea that one is almost compelled to admit the original identity of the two. There are no such affinities between Japaneso and Chinese. Japan has borrowed largely, very largely, from China. It could searcely have been otherwise. For whereas the Japanese language in its original form - a form which differs almost as much from its modern offispring as does Italian from Latin - has little capacity for expansion, Chinese is the most potential of all known tongues in that respect. Chinese may be said to consist of a vast number of monosyllables, each expressed by a different ideograph, each having a distinct significance, and each capable of combination and permutation with one or more of the others, by which combinations and permutations disyllabic and trisyllabic words are obtained representing every conceivable shade of meaning.

It is owing to this wonderful elasticity that Japan, when suddenly confronted by foreign arts and sciences, soon succeeded in building up for herself a vocabulary containing all the new terms, and containing them in self-explaining forms. Thus "railway" is expressed by tetsu-d $\overline{0}$; which consists of the two monosyllables tetsu (iron) and $d \bar{o}$ (way); "chemistry" by kagaku, or the learning (galku) of changes ( $k a)$; "torpedo" by suirai, or water (sui) thunder (rai); and each of the component monosylables being written with an ideograph which conveys its own meaning; the student has a term not only appropriate but also instructive. Hundreds of such words have been manufactured in Japan during the past half-century to equip men' for the study of .Western learning; and the same process, though on a very much smaller scale, had been going on continuously for many centuries, so that the Japanese language has come to embody a very large number of Chinese words, though they are not pronounced as the Chinese pronounce the corresponding ideographs:

Yet in spite of this intimate relation, re-enforced as it is by a common script, the two languages remain radically distinct; whereas between Japanese and Korean the resemblance of structure and accidence amounts almost to identity. Japanese philologists allege that no affinity can be traced between their language and the tongues of the Malay, the South Sea islanders, the natives of America and Africa, or the Eskimo, whereas they do find that their language bears a distinct resemblance to Manchu, Persian, and Turkish. Some go so far as to assert that Latin, Greek, and Sanskrit are nearer to Japanese than they are to any European language. These questions await fuller investigation.

\section{PHYSICAL CHARACTERISTICS OF RACES}

The Japanese are of distinctly small stature. The average height of the man is 160 centimetres ( 5 feet $31 / 2$ inches) and that of the woman 147 centimetres (4 feet 10 inches)." They are thus smaller than any European race, the only Occidentals over whom they possess an advantage in this respect being-the inhabitants of two Italian provinces. [Baelz.] Their neighbours, the Chinese and the Koreans, are taller, the average height of the northern Chinese being 
168 centimetres ( 5 feet 7 inches), and that of the Koreans 164 centimetres ( 5 feet $51 / 2$ inches). Nevertheless, Professor Dr. Baelz, the most eminent authority. on this subject, avers that "the three great nations of eastern Asia are essentially of the same race," and that observers who consider them to be distinet "have been misled by external appearances." He adds: "Having made a special study of the race question in eastern Asia, I can assert that comity of race in general is elearly proved by the anatomical qualities of the body. In any case the difference between them is much smaller than that between the inhabitants of northern and southern Europe."

The marked differences in height, noted above, do not invalidate this dictum: they show merely that the Asiatic yellow race has several subdivisions. Among these subdivisions the more important are the Manchu-Korean type, the Mongol proper, the Malay, and the Ainu. To the first, namely the Manchu-Korean, which predominates in north China and in Korea, Baelz assigns the higher classes in Japan; that is to say, the men regarded as descendants of the Yamato. They have "slender, elegant, and often tall figures, elongated faces with not very. prominent cheek-bones, more or less slanting eyes; aquiline noses, large upper teeth, receding ehins, long slender neeks, narrow chésts, long trunks, thin limbs, and often long fingers, while the hair on the face and body is scarce."ßsis Dr. Munro, however, another eminent authority, holds that, "judging from the Caucasian and often Semitic physiognomy seen in the aristocratic type of Japanese, the Yamato were mainly of Caucasic, perhaps Iranian, origin. These were the warriors, the conquerors of Japan, and afterwards the aristocracy; modified to some extent by mingling with a Mongoloid rank and file, and by a considerable addition of Ainu." He remarks' that a white skin was the ideal of the Yamato, as is proved by their ancient poetry.

As for the Mongol-proper type, which is seen in the lower classes and even then not:very frequently, its representative is squarely built, and has prominent cheek-bones, oblique eyes, a more or less flat nose with a large mouth. The Malay type is much commoner. Its characteristics are small stature, good and sometimes square build, a face round or angular, prominent cheek-bones, large horizontal eyes, a weak chin, a short neek, broad well-developed chest, short legs, and small delicate hands. As for the Ainu type, Dr. Baelz finds;it astonishing that they have left so little trace in the Japanese nation. "Yet those who have studied the pure Ainu closely will observe, particularly in the northern provinces, a not insignificant number of individuals bearing the marks of Ainu blood. The most important marks are: a short, thickly set body; prominent bones with bushy hair, round deep-set eyes with long divergent lashes, a straight nose, and a large quantity of hair on the face and body - all qualities which bring the Ainu much nearer to the European than to the Japanese proper."

\section{GENERAL PHYSICAL CHARACTERISTICS}

In addition to physical characteristics which indicate distinctions of race among the inhabitants of Japan, thcre are peculiarities common to a majority of the nation at large. One of these is an abnormally large head. In the typical European the height of the head is less than one-seventh of the stature and in Englishmen it is often one-eighth. In the Japanese is it appreciably more than one-seventh. : Something of this may be attributed to smallness of stature, but such an explanation is only partial.

Shortness of legs in relation to the trunk is another marked feature. 


\section{Prehistoric Remains Plate A.}

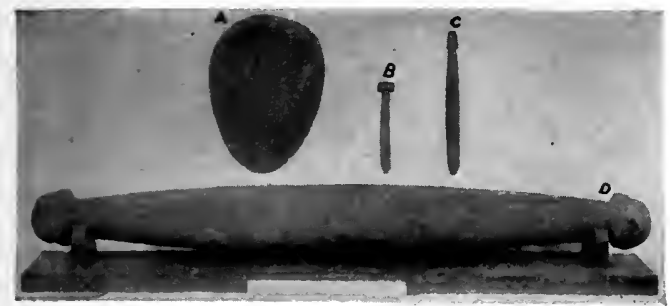

I
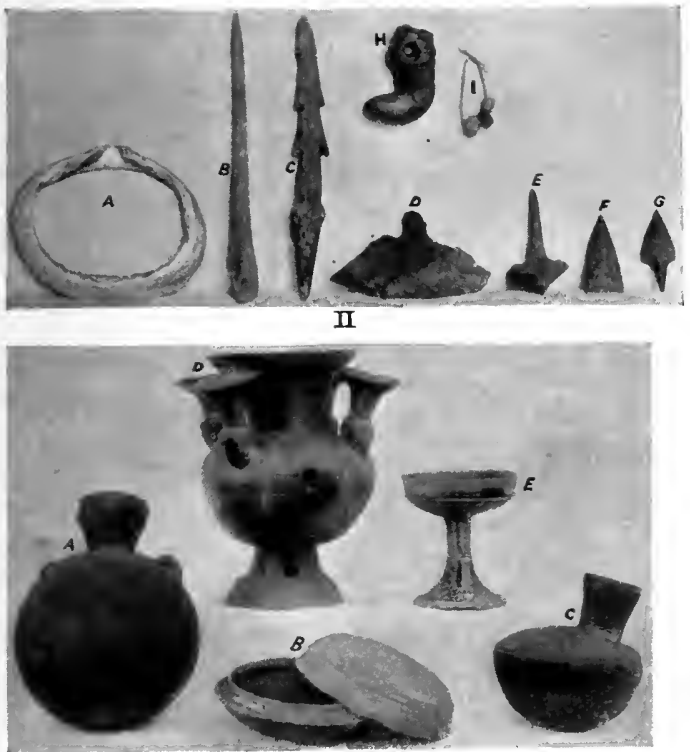

III

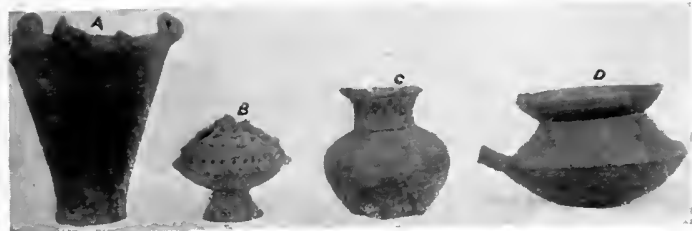

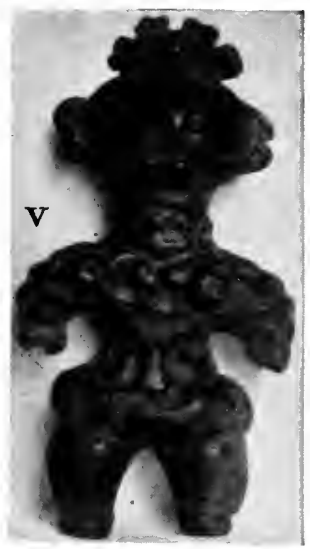
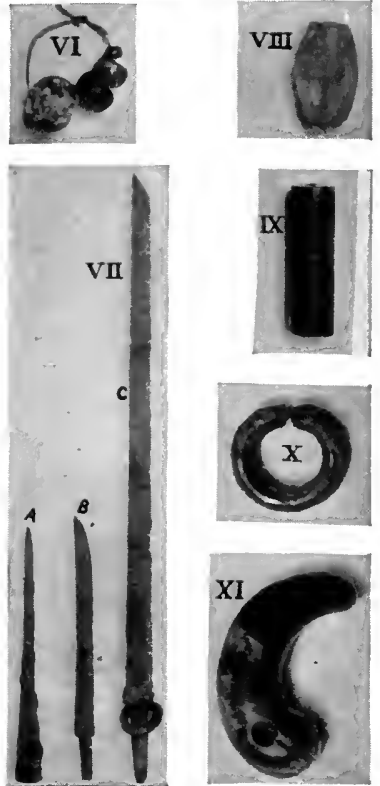

IV

1.-A-"Stone plate" or mortar for nut flour (suburb of Tōkyō); $B$ and $C$-Stone sticks or batons, marks of rank (Rikuchū and Hitachi); $D$-Stone club, probably religious (suburb of Tōkyō). II.-A-Shell ring (Shimōsa); $B$-Bone nail (Rikuzen); $C$-Bone spear-head (Rikuzen) ; $D$-Stone spoon (Mutsu) ; $E$-Stone chisel (Iwashiro) ; $F$ and $G$-Arrow heads (Uzen) ; H-Magatama (Izumo) ; I-Kazaridama, beads for ornament (Mutsu). III. $-A$ Vessel with handles, front rounded, back flat (Tötōmi) ; $B$-Grayish earthenware dish, possibly for rice, with lathe marks (Mino); $C$-Jar with spout on sides (Tōtōmi); $D$-Wine jar with hole in center to draw off sake with bamboo (Bizen); E-Cup (Mino). IV.-Brownish earthenware decorated by spatula and by fabric pressed on the moist clay. $A-$ From Hitachi; $B$-Incense-burner shaped vessel (Ugo) ; $C$-From Rikuzen; $D$-Probably a drinking vessel (Mutsu). V.-Wooden doll (Mutsu); probably a charm. VI.-Beads or gems (Rikuchū); the largest at the left, a marutama of plaster; next, a kodama of a substance like glass. VII. - $A$-Spear-head with socket: $B$-Sword; $C$-Sword with ring. VIII.-Cut gem of rock crystal (Bitchū). IX.-Kudatama, jasper ornament (Bizen). X.-Gold ring, copper core, ear decoration (Musashi). XI.-Magatama, probably strung on necklace (Yamashiro). 

or short legs are mainly racial in origin. Thus, in Europe, tne northern, or Teutonic race - namely Anglo-Saxons, North Germans, Swedes, and Danes are tall, long-legged, and small-headed, while the Alpine, or central European race are short of stature, have short legs and large heads with short necks, thus resembling the Mongolian race in general, with which it was probably originally connected."'

In the Japanese face, too, there are some striking points. The first is in the osseous cavity of the eyeball and in the skin round the eye. "The socket of the Japanese eye is comparatively small and shallow, and the osseous ridges at the brows being little marked, the eye is less deeply set than in the European. . Seen in profile, forehead and upper lid often form one unbroken line.". Then "the shape of the eye proper, as modelled by the lids, shows a most striking difference between the European and the Mongolian races; the open eye being almost invariably horizontal in the former but very often oblique in the latter on account of the higher level of the outer corner. But even apart from obliqueness the shape of the corner is peculiar in the Mongolian eye. : The inner corner is partly or entirely covered by a fold of the upper lid continuing more or less into the lower lid. This fold, which has been called the Mongolian fold, often also covers the whole free rim of the upper lid, so that the insertion of the eyelashes is hidden. When the fold takes an upward direction towards the outer corner, the latter is a good deal higher than the inner corner, and the result is the obliqueness mentioned above. The eyelashes are shorter and sparser than in the European, and whereas in the European the lashes of the upper and the lower -lid diverge,'so that their free ends are farther distant than their roots, in the Japanese eye they converge, the free ends being nearer together than the insertions. Then again in the lower class the cheek-bones are large and prominent, making the face look flat and broad, while in the higher classes narrow and elongated faces are quite common. Finally, the Japanese is less hairy than the European, and the hair of the beard is usually straight."'

\section{VIEWS OF JAPANESE ETHNOLOGISTS}

It may well be supposed that the problem of their nation's origin has occupied much attention among the Japanese, and that their ethnologists have arrived at more or less definite conclusions. The outlines of their ideas are that one of the great waves of emigration which, in a remote age, emerged from the cradle of the human race in central Asia, made its way eastward with a constantly expanding front, and, sweeping up the Tarim basin, emerged in the region of the Yellow River and in Manchuria. Thëse wanderers, being an agricultural, not a maritime, race, did not contribute much to the peopling of the oversea islands of Japan. But in a later - or an earlier - era, another exodus took place from the interior of Asia. It turned in a southerly direction through India, and coasting along the southern seaboard, reached the southeastern region of China; whence, using as stepping-stones the chain of islands that festoon eastern Asia, it made its way ultimately to Korea and Japan.

if Anterior to both of these movements another race, the neolithic Yemishi of the shell-heaps, had pushed down from the northeastern regions of Korea or from the Amur valley, and peopled the northern half of Japan. The Korean peninsula, known in Chinese records as Han, appears in the form of three kingdoms at the earliest date of its historical mention: they were Sin-Han and 
Pyon-Han on the east and Ma-Han on the West: The northeastern portion, from the present Won-san to Vladivostok, bore the name of Yoso, which is supposed to liave been the original of Yezo, the Yoso region thus constituting the eradle of the Yemishi race.

Japanese ethnólogists interpret the aneient annals as pointing to very close intereourse between Japan and Korea in early days, ${ }^{1}$ and regard this as confirming the theory stated above as to the provenance of the Yamato race. Connexion with the colonists of northern China was soon established via Manehuria, and this fact may aecount for some of the similarities between the civilization as well as the legends of the Yamato and those of Europe, since there is evidence that the Greeks and Romans had'some hazy knowledge of China; and that the Chinese had a similarly vague knowledge of the Roman Empire, ${ }^{2}$ possibly through commereial relations in the second century B.c.

The first mention of Japan in Chinese records is contained in a book called Shan-hai-ching, which states that "the northern and southern Wo ${ }^{3}$ were subject to the kingdom 'of Yen." Yen was in the modern province of Pechili. It existed as an independent kingdom from 1122 to 265 B.c. That the inhabitants of Japan were at any time subject to Yen is highly improbable, but that they were tributaries is not unlikely. In other words; intercourse between Japan and northern China was established in remote times via the Korean peninisula, and people from Japan, travelling by this route, earried presents to the Court of Yen, a procedure which, in Chinese eyes eonstitnted an acknowledgement of suzerainty. The "northern and southern Wo" were probably the kingdom of Yamato and that set up in Kyūshū by Ninigi, a supposition which lends approximate confirmation to the date assigned by Japanese historians for the expedition of Jimmu Tennō. It is also recorded in the Chronicles of the Eastern Barbarians, a work of the Han dynasty.(A.D. 25-221), that Sin-Han;one of the three Korean kingdoms, produeed iron, and that Wo and Ma-Han, the western of these Korean kingdoms, traded in it and used it as currency. It is very possible that this was the iron used for manufacturing the ancient double-edged swords (tsurugi) and halberds of the Yamato, a hypothesis strengthened by the fact that the sword of Susanoo was ealled Orochi no Kara-suki, Kara being a Japanese name for Korea.

[1 The annals state of Princes Mikeno and Inahi, elder brothers of Prince Iware (afterwards Jimmu Tennō), that the former "crossed over to the Eternal Land" (Tokoyo-no-kuni) and the latter went down to the sea plain, it being his deceased mother's land.' Japanesc arehaeologists identify "mother's land" as Shiragi in Korea, and Tokoyo-no-kuni as the western country where the sun sets, namely China. They further point out that 'Susanoo with his son, Itakeru, went to Shiragi and lived at Soshi-mori, for which reason Susanog's posthumous title was Gozu Tennō, gozu being the Japanese equivalent for the Korean soshi-mori (ox head). Susanoo is also quoted as saying," there are gold and silver in Koma and it were well that there should be a floating treasury;"' so he built a vessel of pine and camphor-wood to export these treasures to Japan. The "Korea" here spoken of is the present Kimhai in Kyongsan-dō. It is further recorded that Susanoo lived for a time at Kumanari-mine, which is the present Kongju. Aga:n, a Japanese book, compiled in the tenth century A.D., enumerates six shrines in the provinee of 'Izumo which were ealled Kara-kuni Itate Jinja, or "shrine of Itakeru of Korea." A much abler work, Izuma F üdoki, speaks of Cape Kitsuki in Izumo as a place where cotton-stuffs were imported from Shiragi by Omitsu, son of Susanoo.' There are other evidences to the same effect, and taken in conjunction with the remarkable similarity of the Korean and Japanese'lauguages, these facts are held to warrant the conclusion that the most important element of the Japanese nation came via Korea, its Far Eastern colony being the ultima thule of its long wanderings from central Asia.]

[2 See Encyclopaedia Britannica', 11th' Edition, Vol. 6, p. 189 b.]

${ }^{3}$ This word was originally pronounced $W a$, and is written with the ideograph signifying "dwarf." It was applied to the Japanese by Chinese writers in earliest times, but on what ground such an epithet was chosen there is no evidence.] 


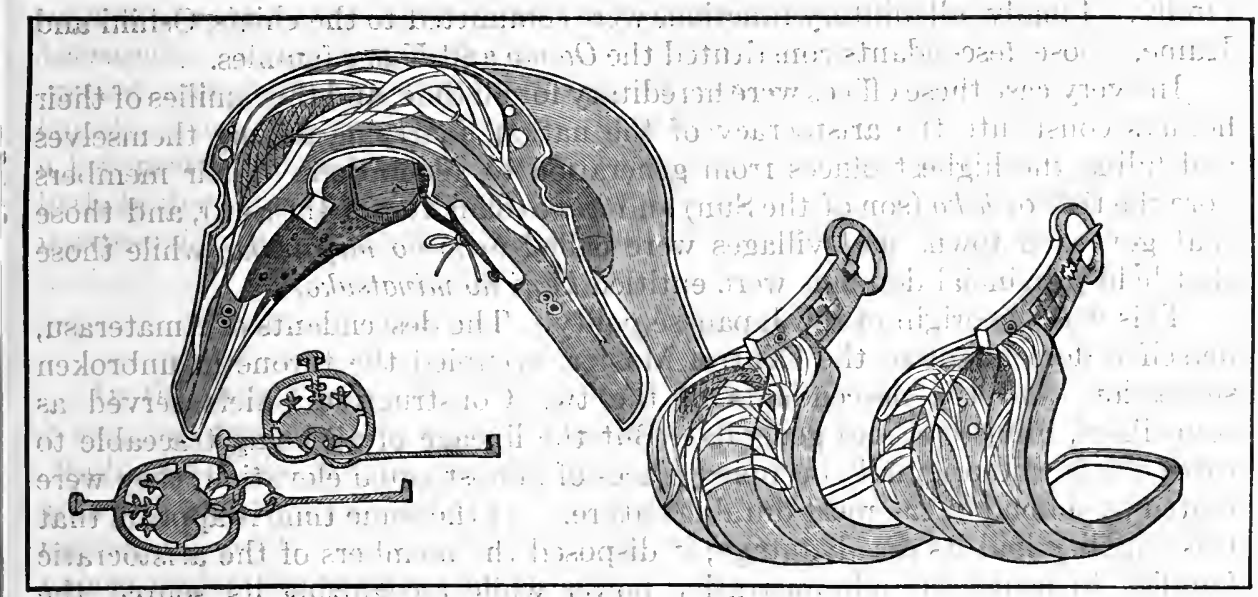

Japánese SadDLe, BRIDLe, and StrRrups

1

\section{CHAPTER VIII}

\section{MANNERS AND CUSTOMS IN REMOTE ANTIQUITY}

IF it be insisted that no credence attaches to traditions unsupported by written annals, then what the Records and the Chronicles, compiled in the eighth century, tell of the manners and customs of Japan twelve or thirteen hundred years previously, must be dismissed as romance. A view so extreme is scarcely justified, 1 There must be a foundation of truth in works which, for the most part, have received the imprimatur of all subsequent generations of Japanese. Especially does that hold as to indications of manners, customs, and institutions. These, at least, are, likely to be mirrored with a certain measure of accuracy, though they may often reflect an age later than that to which they are referred, and may even have been partially moulded to suit the ideas of their narrators. In briefly epitomizing this page of history, the plan here pursued is to adhere as far as possible to Japanese interpretations, since these must of necessity be most intelligent:

\section{THE SOCIAL STRUCTURE}

At the basis of the social structure stand the trinity of Kami, my thologically called the Central Master (Naka-Nushi) and the two Constructive Chiefs (Musubi no Kami). The Central Master was the progenitor of the Imperial family; the Constructive Chiefs were the nobility, the official class. What was originally involved in the conception of official-functions, we learn from incidents prefatory to the expedition conducted by Ninigi for the subjugation of Japan. Amaterasu (the Sun goddess) attached to the person of her grandson four chiefs and one chieftainess. To two of the former (Koyane and Futodama) she entrusted all matters relating to religious rites, and they became respectively the ancestors of the Nakatomi and the Imibe families. To the female Kami (Usume) was entrusted the making of sacred music and she founded the Sarume 
family. Finally, all military funetions were eommitted to the chiefs, Oshihi and Kume, whose descendants constituted the Ōtomo and Kume families.

In every case these offices were hereditary for all time, and the families of their holders constitute the aristocracy of the nation, marrying among themselves and filling the highest offices from generation to generation. Their members bore the title of hiko (son of the Sun) and hime (daughter of the Sun), and those that governed towns and villages were called tomo no miyatsuko, while those that held provincial domains were entitled kuni no miyatsuko.

This was the origin of the Japanese polity. The descendants of Amaterasu, herself a descendant of the Central Master, occupied the throne in unbroken succession, and the descendants of the two Constructive Chiefs served as councillors, ministers, and generals. But the lineage of all being traceable to three ehiefs who originally occupied places of almost equal elevation, they were united by a bond of the most durable nature. At the same time it appears that this equality had its disadvantage; it disposed the members of the aristocratic families to usurp the administrative power while recognizing its - source, the Throne, and it encouraged factional dissensions, which sometimes resulted disastrously. As to the middle and lower classes, no evidence bearing on their exact composition is forthcoming. It is plain, however, that they accepted a subordinate position without active protest, for nothing like a revolt on their part is alluded to, directly or indirectly, in the Records or the Chronicles. The term for all subjects was tomobe.

\section{DWELLING-HOUSES}

The palace of the sovereign - called miya or odono - corresponded in appearance and construction with the shrines of the deities. It was built by erecting central pillars - originally merely sunk in the ground but in later times having a stone foundation - from which rafters sloped to corner posts, similarly. erected, the sides being clapboarded. Nails were used, but the heavy timbers were tied together with ropes made by twisting the fibrous stems of climbing plants. A conspicuous feature was that the upper ends of the rafters projected across each other, and in the $\mathrm{V}$-shaped receptacle thus formed, a ridge-pole was laid with a number of short logs crossing it at right angles. This disposition of timbers was evidently devised to facilitate tying and to impart stability to the thatch, which was laid to a considerable thickness:

It is not eertain whether in the earliest times floors were fully boarded, or whether boarding was confined to a dais running round the sides, the rest of the interior being of beaten mud. Subsequently, however, the whole floor was boarded. Chimneys were not provided; charcoal being the principal fuel, its smoke did not incommode, and when firewood was employed, the fumes escaped through openings in the gable. For windows there were holes closed by shutters which, like the doors, swung upon hooks and staples. Rugs of skin or of rush matting served to spread on the boarded floor, and in rare cases silk cushions were employed.

The areas on which buildings stood were generally surrounded by palisades, and for a long time no other kind of defence save these palings seems to have been devised. Indeed, no mention of eastles occurs until the first century B.c., when the strange term "rice-castle" (ina-ki) is found; the reference being apparently to a palisade fortified with rice-bags, or to a rice-granary used as a fortress. The palace of the sovereign towered so high by comparison that it was termed Asahi- 
no-tada-sasu-miya (miya on which the morning sun shines direct), or Yühi-nohiteru-miya (miya illumined by the evening sun), or some other figurative epithet, and to the Emperor himself was applied the title $\bar{O}$-mikado (great august Gate). The dwellings occupied by the nobility were similarly built, though on a less pretentious scale, and those of the inferior classes appear to have been little better than huts, not a few of them being partially sunk in the ground, as is attested by the fact that the term "enter" took the form of "creep in" (hairu).

\section{ADMINISTRATION AND WORSHIP}

In the instruction said to have been given by Amaterasu to her grandson Ninigi, on the eve of his expedition to Japan, the words are recorded: "My child, regard this mirror as you regard me. Keep it in the same house with yourself, and make it the mirror of purity." Accordingly the insignia - the mirror, the jewel, and the sword - were always kept in the main hall of the palace under the care of the Nakatomi and the Imibe families. An ancient volume (Kogo-shui $)$ records that when the palace of Kashihara was reached by Jimmu's army, the grandson of the founder of the Imibe family - cutting timber with a consecrated axe (imi-ono) and digging foundations with a consecrated spade (imi-suki)-constructed a palace in which he placed the mirror, the jewel, and the sword, setting out offerings and reciting prayers to celebrate the completion of the building and the installation of the insignia.

"At that time the sovereign was still very close to the Kami, and the articles and utensils for the latter were little distinguished from those for the former. Within the palace there stood a store house (imi-kura), the Imibe family discharging daily and nightly the duties relating to it." Thus it is seen that in remoteantiquity religious rites and administrative functions were not distinguished. The sovereign's residence was the shrine of the Kami, and the term for "worship" (matsuri) was synonymous with that for "government."

\section{RELIGIOUS RITES}

The ceremony spoken of above - the Ōdono matsuri, or consecration of the palace - is the earliest religious rite mentioned. Next in importance was the "harvest festival." In the records of the mythological age it is related that Amaterasu obtained seeds of the "five cereals," and, recognizing their value as food, caused them to be cultivated, offering a part to the Kami when they were ripe and eating some herself. This became a yearly custom, and when Ninigi set out to conquer Japan, his grandmother gave rice seed to the ancestors of the Nakatomi and the Imibe families, who thenceforth conducted the harvest festival (nii-name, literally "tasting the new rice") every autumn, the sovereign himself taking part, and the head of the Nakatomi reciting a prayer for the eternity of the Imperial line and the longevity of the Emperor. Other important rites were the "great purification" (Ōharai) performed twice a year, on the last day of the sixth month and the last day of the twelfth month; the "fire-subduing fête,". the "spirit-tranquillizing fête,". etc.

Of all these rites the principal features were the recitation of rituals and the offering of various objects, edible or otherwise useful. The rituals (norito) being, in several cases, set formulas, lent themselves with special facility to oral transmission from generation to generation. It is certain that they were familiar to the compilers of the Records and the Chronicles, and they contain 
expressions dating from such a remote era as to have become incomprehensible before history began to be written in Japan. In the year A:D. 927, seventy-five of the norito were transeribed into a book (Yengi-shiki, or Ceremonial Law) which contains, in addition to these rituals, particulars as to the practice of the Shinto religion; as to the organization of the priesthood - which included two virgin princesses of the Imperial family, one each for the two great temples of Watarai in Ise and Kamo in Yamashiro - and as to the Shinto shrines qualified to receive State support. These shrines totalled 3132, among which number 737 were maintained at the Emperor's charges. Considering that the nation at that time (tenth century) did not comprise more than a very few millions, the familiar criticism that the Japanese are indifferent to religion is certainly not proved by any lack of places of worship. The language of the rituals is occasionally poetic, of ten figurative and generally solemn, ${ }^{1}$ but they are largely devoted to enumeration of $\mathrm{Kami}$, to formulae of praise for past favours, to petitions for renewed assistance, and to recapitulations of the offerings made in support of these requests. As for the offerings, they comprise woven stuffs, and their raw materials, models of swords, arrows, shields, stags' antlers, hoes, fish (dried and fresh), salt, saké, and, in some cases, a horse, a cock, and a pig. In short, the things offered were essentially objects serviceable to living beings:

\section{THE KAMI}

The Kami may be broadly divided into two groups, namely, those originally regarded as superior beings and those elevated to that rank in consideration of illustrious deeds performed during life. Of the former group the multitudinous and somewhat heterogenous components have been supposed to suggest the amalgamation of two or more religious systems in consequence of a blending of races alien to one another. But such features may be due to survivals incidental to the highest form of nature religion, namely, anthropomorphic poly theism.

There were the numerous Kami, more or less abstract beings without any distinguishing functions, who preceded the progenitors of the Yamato race, and there was the goddess of the Sun, pre-eminent and supreme, together with deities of the Moon, of the stars, of the winds, of the rain, of fire, of water, of mountains, of mines, of fields, of the sea, of the trees, and of the grass - the last a female divinity (Kaya-no-hime). The second group - those deified for illustrious services during life - furnished the tutelary divinities (uji-gami or ubusuna-Kami) of the localities where their families lived and where their labours had been performed. Their protection was specially solicited by the inhabitants of the regions where their shrines stood, while the nation at large worshipped the Kami of the first group. Out of this apotheosis of distinguished mortals there grew, in logical sequence, the practice of ancestor worship. It was merely a question of degrees of tutelary power. If the blessings of prosperity and deliverance could be bestowed on the denizens of a region by the deity enshrined there, the same benefits in a smaller and more circumseribed measure might be conferred by the deceased head of a family. As for the sovereign, standing to the whole nation in the relation of priest and intercessor with the deities, he was himself regarded as a sacred being, the direct descendant of the heavenly ancestor (Tenson).

[1 The Norito of the Great Purification Service has been translated by Mr. W. G. Aston in his Japanese Literature.] 


\section{THERIANTHROPIC ELEMENTS}

That the religion of ancient Japan - known as Shinto, or "the way of the gods" - had not fully emerged from therianthropic polytheism is proved by the fact that, though the deities were generally represented in human shape, they were frequently conceived as spiritual beings, embodying themselves in all kinds of things, especially in animals, reptiles, or insects. Thus, tradition relates that the Kami of Mimoro Mountain appeared to the Emperor Yūryaku (A.D. 457-459) in the form of a snake; that during the reign of the Emperor Keitai (A.D. 507-531), a local deity in the guise of a serpent interfered with agricultural operations and could not be placated until a shrine was built in its honour; that in the time of the Emperor Kōgyoku, the people of the eastern provinces devoted themselves to the worship of an insect resembling a silkworm, which they regarded as a manifestation of the Kami of the Moon; that the Emperor Keiko (A.D. 71-130) declared a huge tree to be sacred; that in the days of the Empress Suiko (A.D. 593628 ), religious rites were performed before cutting down a tree supposed to be an incarnation of the thunder Kami; that on the mountain Kannabi, in Izumo, there stood a rock embodying the spirit of the Kami whose expulsion from Yamato constituted the objective of Ninigi's expedition, and that prayer to it was efficacious in terminating drought, that the deity Koto-shiro-nushi became transformed into a.crocodile, and that the hero Yamato-dake emerged from his tomb in the shape of a white swan.

Many other cognate instances might be quoted. A belief in amulets and charms, in revelations by dreams and in the efficacy of ordeal, belongs to this category of superstitions. The usual form of ordeal was by thrusting the hand into boiling water. It has been alleged that the Shinto religion took no account of a soul or made any scrutiny into a life beyond the grave. Certainly no ideas as to places of future reward or punishment seem to have engrossed attention, but there is evidence that not only was the spirit (tama) recognized as surviving the body, but also that the spirit itself was believed to consist of a rough element (ara) and a gentle element (nigi), either of which predominated according to the nature of the functions to be performed; as when a nigi-tama was believed to have attached itself to the person of the Empress Jingo at the time of her expedition to Korea, while an ara-tama formed the vanguard of her forces.

Some Japanese philosophers, however - notably the renowned Motoori have maintained that this alleged duality had reference solely to the nature of the influence exercised by a spirit on particular occasions. Shintō has no sacred canon like the Bible, the Koran, or the Sutras. Neither has it any code of morals or body of dogma. Cleanliness may be called its most prominent feature. Izanagi's lustrations to remove the pollution contracted during his visit to the nether world became the prototype of a rite of purification (misogi) which always prefaced acts of worship. A cognate ceremony was the harai (atonement). By the misogi the body was cleansed; by the harai all offences were expiated; the origin of the latter rite having been the exaction of certain penalties from Susanoo for his violent conduct towards the Sun goddess. ${ }^{1}$ "The two ceremonies, physical cleansing and moral cleansing, prepared a worshipper to approach the shrine of the Kami. In later times both rites were compounded into one, the misogi-harai, or simply the harai. When a calamity threatened the country or befel it, a grand harai ( $\bar{o}$-harai) was performed in atonement for the sins supposed to have invited the catastrophe. This principle of cleanliness found expression 
in the architecture of Shintō shrines; plain white wood was everywhere employed and ornamentation of every kind eschewed. In view of the paramount importance thus attached to purity, a celebrated couplet of ancient times is of ten quoted as the unique and complete canon of Shinto morality,

\footnotetext{
"Unsought in prayer,

"The gods will guard

"The pure of heart.",
}

It is plain, however, that Shintō cannot be included in the category of ethical religions; it belongs essentially to the family of nature religions.

\section{CRIMES}

The acts which constituted crimes in ancient Japan were divided into two classes: namely, sins against heaven and sins against the State. At the head of the former list stood injuries to agricultural pursuits, as breaking down the ridges of rice-fields, filling up drains, destroying aqueducts, sowing seeds twice in the same place, putting spits in rice-fields, flaying an animal alive or against the grain, etc. The crimes against the State were cutting and wounding (whether the living or the dead), defilement on account of leprosy or cognate diseases, unnatural off ences, evil acts on the part of children towards parents or of parents towards chililren, etc. Methods of expiating crime were recognized, but; ; as was the universal custom in remote times, very cruel punishments were employed against evil-doers and enemies. Death was inflicted for comparatively trivial offences, and such tortures were resorted to as cutting the sinews, extracting the nails and the hair, burying alive, roasting, ete. Branding or tattooing seems to have been oceasionally practised; but essentially as a penalty or a mark of ignominy.

\section{DIVINATION}

As is usually the case in a nation where a nature religion is followed, divination and augury were practised largely in ancient Japan. The earliest method of divination was by roasting the shoulder-blade of a stag and comparing the cracks with a set of diagrams. The Records and the Chronicles alike represent Izanagi and Izanami as resorting to this method of presaging the future, and the practice derives interest from the fact that a precisely similar custom has prevailed in Mongolia from time immemorial. Subsequently this device was abandoned in favour of the Chinese method, heating a tortoise-shell; and ultimately the latter, in turn, gave way to the Eight Trigrams of Fuhi. The use of auguries seems to have eome at a later date. They were obtained by playing a stringed instrument called koto, by standing at a cross-street and watching the passers, by manipulating stones, and by counting footsteps.

\section{MILITARY FORCES}

It has been related that when the "heavenly grandson" undertook his expedi. tion to Japan, the military duties were entrusted to two mikoto ${ }^{2}$ who became

[ ${ }^{1}$ Kokoro dani

Makoto no michi ni

Kanai naba

Inorazu tote mo

Kami ya mamoran.]

[2 "August being," a term of respect applied to the descendants of the Kami.] 


\section{Prehistoric Remains Plate B.}

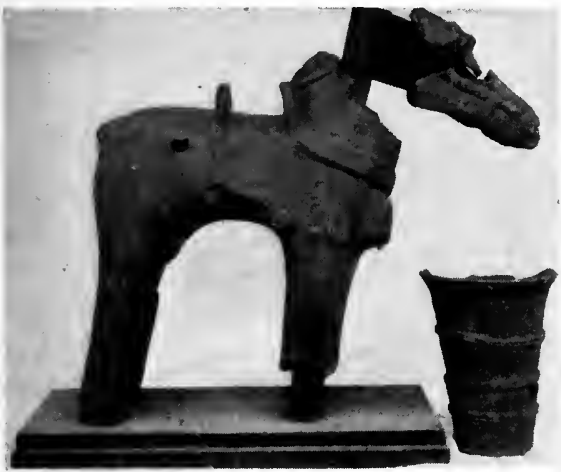

Earthenware horse (MUSASHI); Haniwa or offering at the tomb

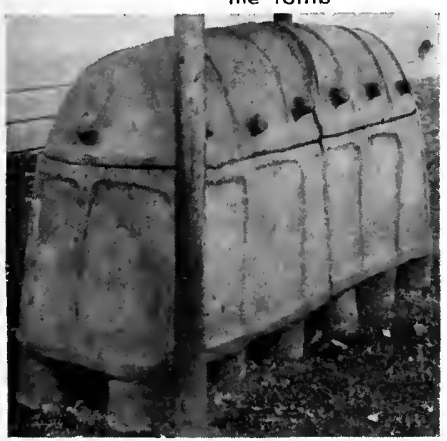

Porcelain cottin (MIMASAKA) rarer than

the stone cotfins usually found in early mounds.

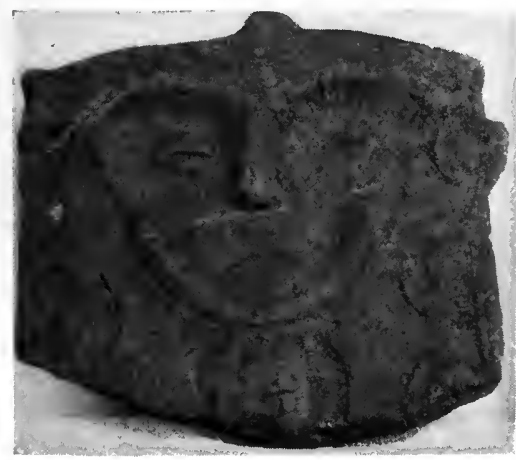

Broken piece of earthenware showing a human

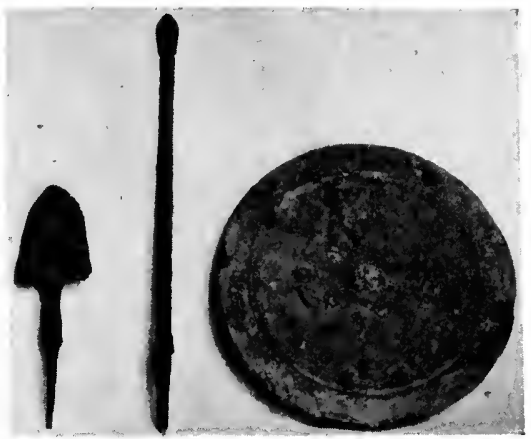

Arrowhead and lance head (SHINANO); and bronze mirror (TAMBA).

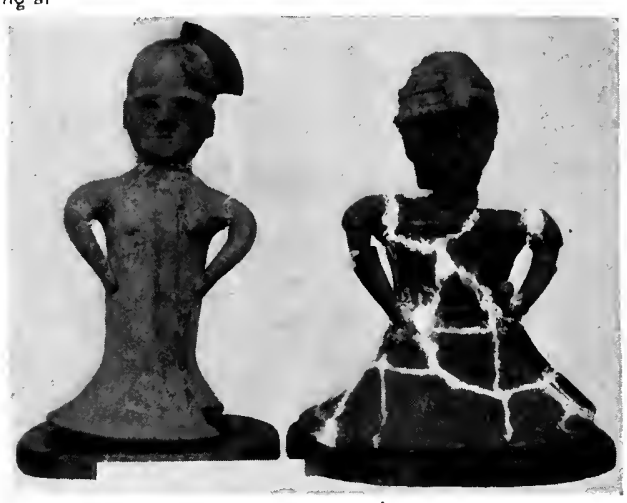

Haniwa, earthenware images offered at the tomb. Female figure with elaborate coiffure and dress lapping left over right. Man with steel helmet and coat of mail.

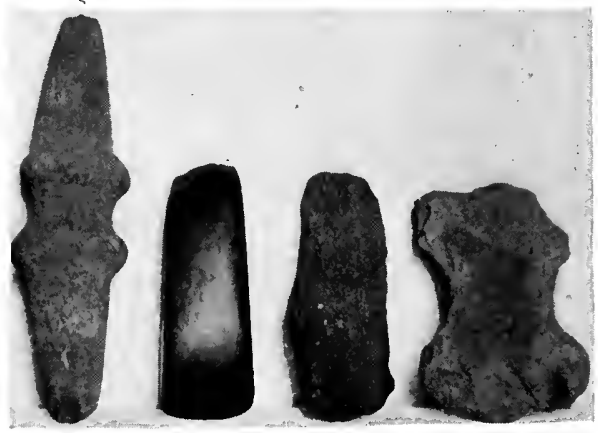

Stone axes and hatchets (MUTSU, OTARU, a polished stone; Meguro, near TOKYO; and SHIMOSA). 

the ancestors of the Ōtomo and the Kume families. There is some confusion about the subsequent differentiation of these families, but it is sufficient to know that, together with the Mononobe family, they were the hereditary repositories of military authority. They wore armour, carried swords, spears and bows, and not only mounted guard at the palace but also asserted the Imperial authority throughout the provinces. No exact particulars of the organization of these forces are on record, but it would seem that the unit was a battalion divided into twenty-five companies, each company consisting of five sections of five men per section, a company being under the command of an officer whose rank was miyatsuko.

\section{FINANCE AND ADMINISTRATION}

No mention is made of such a thing as currency in prehistoric Japan. Commerce appears to have been conducted by barter only. In order to procure funds for administrative and religious purposes, officers in command of forces were despatched to various regions, and the inhabitants were required to contribute certain quantities of local produce. Steps were also taken to cultivate useful plants and cereals and to promote manufactures. The Kogo-shu $i$ states that a certain mikoto inaugurated the fashioning of gems in Izumo, and that his descendants continued the work from generation to generation, sending annual tribute of articles to the Court every year. Another mikoto was sent to plant papermulberry and hemp in the province of Awa (awa signifies "hemp"), and a similar record is found in the same book with regard to the provinces of Kazusa and Shimōsa, which were then comprised in a region named Fusa-kuni. Other places owed their names to similar causes.

It is plain that, whatever may have been the case at the outset, this assignment of whole regions to the control of officials whose responsibility was limited to the collection of taxes for the uses of the Court, could not but tend to create a provincial nobility and thus lay the foundations of a feudal system. The mythological accounts of meetings of the Kami. for purposes of consultation suggest a kind of commonwealth, and recall "the village assemblies of primitive times in many parts of the world, where the cleverness of one and the general willingness to follow his suggestions fill the place of the more definite organization of later times." " But though that may be true of the Yamato race in the region of its origin, the conditions found by it in Japan were not consistent with such a system, for Chinese history shows that at about the beginning of the Christian era the Island Empire was in a very uncentralized state and that the sway of the Yamato was still far from receiving general recognition. A great Japanese scholar ${ }^{2}$ has contended that the centralization which prevailed in later ages was wholly an imitation of Chinese bureaucracy, and that organized feudalism was the original form of government in Japan. The annals appear to support that view to a limited extent, but the subject will presently be discussed at greater length.

\section{RAIMENT}

"In the use of clothing and the specialization of garments the early Japanese had reached a high level: We read in the ancient legends of upper garments, skirts, trousers, anklets, and head-ornaments of stones considered precious.". The principal material of wearing apparel was cloth woven from threads of hemp and mulberry bark. According - to the annals, the arts of spinning, weaving,

[' B. H. Chamberlain.]

[2 Hirata Atsutane.] 
and dyeing were known and practised from the earliest age. The Sun goddess herself is depicted as seated in the hall of the sacred loom, reeling silk from cocoons held in her mouth, and at the ceremony of enticing her from her retirement, the weaving of blue-and-white stuffs constituted an important adjunct. "Terms are used (akaru-tae and teru-tae) which show that colour and lustre were esteemed as much as quality. Ara-tae and nigi-tae were the names used to designate coarse and fine cloth respectively; striped stuff was called shidori, and the name of a princess, Taku-hata-chiji, goes to show that corrugated cloth was woven from the bark of the taku. Silken fabries were manufactured, but the device of boiling the cocoons had not yet been invented. They were held in the mouth for spinning purposes, and the threads thus obtained being coarse and uneven, the loom could not produce good results. "Silk stuffs therefore did not find much favour: they were employed chiefly for making cushions, cloth woven from cotton, hemp, or mulberry bark being preferred for raiment. Pure white was the favourite colour; red, blue, and black being placed in a lower rank in that order. It has been conjectured that furs and skins were worn, but there is no explicit mention of anything of the kind. It would seem that their use was limited to making rugs and covering utensils. ${ }^{1}$ Sewing is not explicitly referred to, but the needle is; and in spite of an assertion to the contrary made by the Chinese author of the Shan-hai-ching (written in the fourth century A.D.) there is no valid reason to doubt that the process of sewing was familiar:

As to the form of the garments worn, the principal were the hakama and the koromo. The hakama was a species of divided skirt, used by men and women alike. It has preserved its shape from age to age, and is to-day worn by schoolgirls throughout Japan. The koromo was a tunic having tight sleeves reaching nearly to the knees. It was folded across the breast from right to left and secured by a belt of cloth or silk tied round the loins." Veils also were used by both sexes, one kind (the katsugi) having been voluminous enough to cover the whole body. "Combs are mentioned, and it is evident that much attention was devoted to the dressing of the hair." 2 Men divided theirs in " the middle and bound it up in two bunches, one over each ear. Youths tied theirs into a topknot; girls wore their locks hanging down the back but bound together at the neck, and married ladies "dressed' theirs after a fashion which apparently combined the last two methods." Decoration of the head was carried far on ceremonial occasions, gems, veils, and even coronets being used for the purpose. "There is no mention in any of the old books of cutting the hair or beard except in token of disgrace; neither do we gather that the sexes, but for this inatter of head-dress, were distinguished by a diversity of apparel 'or ornamentation."

\section{FOOD AND DRINK}

Rice was the great staple of diet in ancient, as it is in modern, times. The importance attaching to it is shown by the fact that the Sun goddess herself is represented as engaging in its cultivation and that injuring a rice-field was among

${ }^{1}$ In China the case was different. There, garments made of skins or covered with feathers were worn in remote antiquity before the art of weaving had become known. The Records recount that in the age of the Kami."there came": (to Japan) "riding on tha crest of the waves, a Kami dressed in skins of geese," and this passage has been quoted as showing that skins were used for garments in Japan. But it is pointed out by Japanese commentators that this Kami - Sukuna-bikona - is explicitly stated to have come from a foreign country, and that if the passage warrants any inference, it is that the visitor's place of departure had been China.]

$\left[{ }^{2}\right.$ B. H. Chamberlain.]

$\left[{ }^{3}\right.$ B. H. Chamberlain.] 
the greatest offences. Barley, millet, wheat; and beans are mentioned, but the evidence that they were grown largely in remote antiquity is not conclusive. The flesh of animals and birds was eaten, venison and wild boar being particularly esteemed. Indeed, so extensively was the hunting of deer practised that bows and arrows were often called kago-yumi and kago-ya (kago signifies "deer"). Fish, however, constituted a much more important staple of diet than flesh, and fishing in the abundantly stocked seas that surround the Japanese islands was largely engaged in. Horses and cattle were not killed for food. It is recorded in the Kogo-shui that the butchering of oxen to furnish meat for workers in a rice-field roused the resentment of a Kami called Mitoshi. There does not appear to have been any religious or superstitious scruple connected with this abstention: the animals were spared simply because of their usefulness. Girs Vegetables occupied a large space in the list of articles of food. There were the radish, the cabbage, the lotus, the melon, and the wild garlic, as well as as several kinds of seaweed. Salt was used for seasoning, the process of its manufacture having been familiar from the earliest times. Only: one kind of intoxicating liquor was, ever known in Japan until the opening of intercourse with the Occident. It was a kind of beer brewed 1 from rice and called saké. The proeess is said to have been taught by Sukuna, who, as shown above, came to Japan from a foreign country - probably China - when the Kami, Ōkuni-nushi, was establishing order in the Japanese islands.

\section{COOKING AND TABLE EQUIPAGE}

From time immemorial there were among the officials at the Imperial Court men called kashiwa-de, or oak-leaf hands. They had charge of the food and drink, and their appellation was derived from the fact that rice and other edibles were usually served on oak leaves. . Earthenware utensils were used; but their surface, not being glazed, was not allowed to come into direct contact with the viands placed on them. In this practice another example is seen of the love of cleanliness that has always characterized and distinguished the Japanese nation. Edibles having been thus served, the vessels containing them were ranged on a table, one for each person, and chop-sticks were used. Everything was cooked, with the exception of certain vegetables and a few varieties of fish. Friction of wood upon wood provided fire, a fact attested by the name of the tree chiefly used for the purpose, $h i-n o-k i$, or fire-tree. To this day the same method of obtaining la spark is practised at the principal religious ceremonials. Striking metal upon stone was another device for the same purpose, and there is no record in Japan, as there is in Ghina, of any age when food was not cooked. Various vessels of unglazed pottery are mentioned in the Records, as bowls, plates, jars, and wine-holders, the last being often made of metal. These were all included in the term suemono, which may be translated "table-utensils."

\section{ARMS, ARMOUR, AND GEMS}

It has already been stated that archaeological research shows the Yamato race to have been in possession of iron swords and spears, as well as metal armour

[ 1 The term for "brew" being kamu or kamosu, the former of which is homonymous with the equivalent for "to chew," some commentators have supposed that saké was manufactured in early times by grinding rice with the teeth. This is at once disproved by the term for "yeast," namely, kabi-tachi (fermenting).] 
and shields, from a very early period, probably the date of these colonists' first coming to Japan. They also used saddles, stirrups, bridles, and bits for horses, so that a Yamato warrior in full mail and with complete equipment was perhaps as formidable a fighting man as any contemporary nation could produce. Bows and arrows were also in use. The latter, tipped with iron or stone and feathered, were carried in a quiver. The swords employed by men were originally doubleerlged. Their names ${ }^{1}$ show that they were used alike for cutting and thrusting, and that they varied in length from ten "hands" to five. There was also a small single-edged sword ${ }^{2}$ carried by women and fastened inside the robe." The value attached to the sword is attested by numerous appellations given to blades of special quality. In later times the two-edged sword virtually fell out of use, being replaced by the single-edged.

Sometimes a spear was decorated with gems. It is curious that gems should have been profusely used for personal adornment in ancient times by people who subsequently eschewed the custom well-nigh altogether; as the Japanese did. The subject has already been referred to in the archaeological section, but it may be added here that there were guilds of gem-makers (Tama-tsukuri-be) in several provinces, and that, apart from imported minerals; the materials with which they worked were coral, quartz, amber, gold, silver, and certain pebbles found in Izumo.

\section{AGRICULTURE AND INDUSTRY}

It appears that when the Yamato immigrants reached Japan, the coast lands were overgrown with reeds and the greater part of the island was covered with primeval forests. Fabulous accounts are given of monster trees. Thus, in the Tsukushi Füdoki we read of an oak in Chikugo which towered to a height of 9700 feet, its branches shading the peaks of Hizen in the morning and the mountains of Higo in the evening. The Konjaku Monogatari tells of another oak with a stem measuring 3000 feet in circumference and easting its shadow over Tamba at dawn and on Ise at sunset. In the $F u d o k i$ of other provinces reference is made to forest giants in Harima, Bungo, Hitachi, etc., and when full allowance has been made for the exaggerations of tradition, there remains enough to indicate that the aboriginal inhabitants did not attempt any work of reclamation.

Over regions measuring scores of miles perpetual darkness reigned, and large districts were often submerged by the overflow of rivers. There is no mention, however, of a deluge, and Professor Chamberlain has called attention to the remarkable fact that a so-called "Altaic myth" finds no place in the traditions of "the oldest of the undoubtedly Altaie nations.".

The annals are eloquent in their aecounts of the peopling of the forests by wild and fierce animals and the infesting of the vallies by noxious reptiles. The Nihongi, several of the Fudoki, the Konjaku Monogatari, etc., speak of an eightheaded snake in Izumo, of 'a horned serpent in Hitachi, and of big snakes in Yamato, Mimasaka, Bungo, and other provinces; while the Nihon Bummei Shiryaku tells of wolves, bears, monkeys, monster centipedes, whales, etc., in Harima, Hida, Izumo, Oki, Tajima, and Kaga. In some eases these gigantic serpents were probably bandit chiefs transfigured into reptiles by tradition, but of the broad fact that the country was, for the most part, in a state of natural wilderness there can be little doubt. 
(2) Under the sway of the Yamato, however, a great change was gradually effected. Frequent allusions are made to the encouragement of agriculture and even its direct pursuit by the Kami. The Sun goddess is represented as having obtained seeds of the five cereals from the female Kami, Ukemochi, ${ }^{1}$ and as having appointed a village chief to superintend their culture. She had three regions of her own specially devoted to rice growing; and her unruly; brother, Susanoo, had a similar number, but the latter proved barren. The same goddess inaugurated sericulture, and entrusted the care of it to a princess, who caused mulberry trees to be planted and was able to present silk fabrics to Amaterasu. In the reign of Jimmu, hemp is said to have been cultivated, and Susanoo, after his reformation, became the guardian of forests; one of his functions being to fix the uses of the various trees, as pine and hinoki (ground-cypress) for house building, maki (podocarpus Chinensis) for coffin making, and camphor-wood for constructing boats: He also planted various kinds of fruit-trees. Thenceforth successive sovereigns encouraged agriculture; so that the face of the country was materially changed.

In the matter of farming implements, however, neither archaeology nor history indicates anything more than iron spades, wooden hoes shod with bronze or iron, hand-ploughs, and axes. As to manufacturing industries; there were spinners and weavers of cotton and silk, makers of kitchen utensils; polishers of gems, workers in gold, silver, copper, and iron, forgers of arms and armour, potters of ornamental vessels, and dressers of leather. In later eras the persons skilled in these various enterprises formed themselves into guilds (be), each of which carried on its own industry from generation to generation.

The fact that there must have been an exchange of goods between these various groups is almost the only indication furnished by the annals as to trade or commerce. In the name of a daughter of Susa (Princess Kamu-ō-ichi) we find a suggestion that markets ( $i c h i)$ existed, and according to the Wei Records (A.D. 211-265) there were, at that time, "in each province of Japan markets where the people exchanged their superfluous produce for articles of which they were in need." But Japanese history is silent on this subject.

About the $b e$, however, a great deal is heard. It may be described as a "corporated association having for purpose the securing of efficiency by specialization: Its members seem to have been at the outset men who independently pursued some branch of industry. These being ultimately formed into a guild, carried on the same pursuit from generation to generation under a chief officially appointed. "Potters, makers of stone coffins, of shields, of arrows, of swords, of mirrors, saddlers, painters, weavers, seamstresses, local recorders, scribes, farmers, fleshers, horse-keepers, bird-feeders, the mibu who provided wet-nurses for Imperial princes, palace attendants, and reciters (katari) were organized into be under special chiefs who were probably responsible for their efficient services. It , would appear, however, that "chief of $b e$ ' was sometimes a title bestowed for exceptional service and that it was occasionally posthumous."?

$B e$ were also organized for the purpose of commemorating a name quite irrespective of industrial pursuits. "The religious be were for general or special purposes. For instance, there was a be of sun-worshippers, while the Imibe, a body of abstainers, were obliged to avoid ritual contamination or impurity. They carried out a technique of spiritual aseptics, both in their persons and

[1 The Sun goddess, Amaterasu, and the goddess of Food (Ukemochi no Kami) are the two deities now worshipped at the great shrine of Ise.]

[2 Munro.] 
through the utensils which they employed, much as a modern surgeon guards against infection of his patient. Thus they were prepared to perform sacred functions." 1

\section{NAVIGATION AND FISHING}

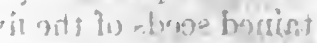

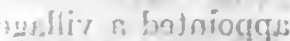

No information is obtainable as to the nature of the boats used in very early times, but it may reasonably be inferred that the Yamato and other immigrant races possessed craft of some capacity. Several names of boats are incidently mentioned. They evidently refer to the speed of the craft-as bird-boat (tori-fune), pigeon-boat (hato-fune) - or to the material employed, as "rockeainphor boat" (iwa-kusu-bune). "The presence of neolithic remains on the islands around Japan proves that the boats of the primitive people were large enough to traverse fifty miles, or more, of open sea." 2 Only one distinct reference to sailing occurs, however, in the ancient annals. On the occasion of the alleged expedition to Korea (A.D. 200) under the Empress Jingo, the Chronicles say, "Sail was set from the harbour of Wani." At a date nearly three centuries earlier, there appears to have been a marked deficiency of coasting vessels, for the Chronicles quote an Imperial deeree issued B.c. 81 , which says:" "Ships are of cardinal importance to the Empire. At present the people of the coast, not having ships, suffer grievously by land transport. Therefore let every province be eaused to have ships built;" ${ }^{3}$ and it is related that, a few months later; the building of ships was begun. Again, in A.D. 274, a vessel (the Karano) one hundred feet'in length, was constructed in the province of Izu, and twenty-six years later, according to the Chronicles, the Emperor issued this order: "The Government ship named Karano was sent as tribute by the Lord of Izu. It is rotten and unfit for use. It has, however, been in the Government use for a long time, and its services should not be forgotten. Shall we not keep the name of that ship from being lost and hand it down to after ages?" The Karano was then broken and her timbers being employed as firewood for roasting salt, the latter was given to the various provinces, which, in return, were caused to build ships for the State, the result being a fleet of five hundred vessels.

It would seem that there was always an abundance of fishing-boats, for fishing by traps, hooks, and nets was industriously carried on. A passage in the Records speaks of a thousand-fathom rope of paper-mulberry which was used to draw the net in perch fishing. Spearing was also practised by fishermen, and in the rivers cormorants were used just as they are to-day.

\section{MARRIAGE}

It does not appear that the marriage tie possessed any grave significance in ancient Japan, or that any wedding ceremony was performed; unless, indeed, the three circuits made by Izanagi and Izanami prior to cohabitation round a "heavenly august pillar" be interpreted as the circumambulatory rite observed in eertain prinitive societies. Pouring water over a bride seems, however, to have been practised and is still customary in some provinees, though as to its antiquity nothing can be said. An exchange of presents is the only fact made clear by the annals. There did not exist in Japan, as in China, a veto on marriages between people of the same tribe, but this difference does not signify any reproach to Japan: the interclict was purely political in China's case, and corresponding conditions did not exist in Japan.

['Munro.]

[2 Aston's Nihongi.]

[ ${ }^{3}$ Aston's Nihongi.] 
On the other hand, the Japanese system permitted a degree of licence which in the Occident is called incest: brothers and sisters might intermarry provided that they had not been brought up together. To understand this condition it is necessary to observe that a bride generally continued to live in her family dyelling where she received her husband's yisits, and since there was nothing to prevent a husband from contracting many such alliances, it was possible for him to have several groups of children, the members of each group being altogether unknown to the members of all the rest. In a later, but not definitely ascertained era, it became customary for a husband to take his wife to his own home, and thereafter the veto upon such unions soon became imperative, so that a Prince Imperial in the fifth century who cohabited with his sister forfeited the succession and had to commit suicide, his conduct being described in the Chronicles as " a barbarous outrage."

In all eras sisters might marry the same man, and polygamy was common. A Chinese book, compiled in the early years of the Christian epoch, speaks of women being so numerous in Japan that nobles had four or five wives and commoners two or three. Of course; the reason assigned for this custom is incorrect: not plenitude of females but desire of abundant progeny was primarily the cause. It is notable that although the line between nobles and commoners was strictly drawn and rigidly observed, it did not extend to marriage in one sense: a nobleman could always take a wife or a concubine from the family of an inferior. In fact, orders were commonly issued to this or that province to furnish so many ladies-in-waiting (uneme) - a term having deeper significance than it suggests and several instances are recorded of sovereigns summoning to court girls famed for beauty. That no distinction was made between wives and concubines has been alleged, but is not confirmed by the annals. Differentiation by rank appears to have been always practised, and the offspring was certainly, thus distinguished.

\section{BIRTH AND EDUCATION}

A child in ancient Japan was born under considerable difficulties: its mother had to segregate herself in a parturition hut (ubuya), whence even light was excluded and where she was cut off from all attendance. This strange custom was an outcome of the Shinto canon of purity. Soon after birth, a child received from its mother a name "generally containing some appropriate personal reference. In the most ancient times each person (so far as we can judge) bore one name, or rather one string of words compounded together into a sort of personal designation. But already at the dawn of the historical epoch we are met by the mention of surnames and of 'gentile names,' bestowed by the sovereign as a recompense for some noteworthy deed."1 These names constantly occur. The principal of them áre suzerain (atae), departmental suzerain (agata-no-atae), departmental lord (agata-no-nushi), Court noble (ason), territorial lord (inaki), lord (iratsuko), lady (iratsume), duke (kimi), ruler (miyatsuko), chief (muraji), grandee (ómi), noble (sukune), and lord (wake). In the case of the Emperors, there are also canonical names, which were applied at a comparatively late date in imitation of Chinese usages, and which may be said to have completely replaced the names borne during life. Thus, the Emperor known to posterity as Jimmu was called Iware in life; the Emperor named Homuda while he sat on the throne is now designated Ojin, and the Emperor who ruled as $\bar{O}$ sazaki is remembered as Nintoku. In the Imperial family, and 
doubtless in the houscholds of the nobility; wet-nurses were employed, if necessary, as also were bathing-women, washing-women, and rice-chewers. ${ }^{i}$

"To what we should eall education, whether mental or physical,' there is absolutely no reference made in the histories. All that can be inferred is that; when old enough to do so, the boys began to follow one of the callings of hunter or fisherman, while the girls stayed at home weaving the garments of the family. There was a great deal of fighting, generally of a treacherous kind, in the intervals of which the warriors occupied themselves in cultivating patches of ground:" 2 ?

\section{BURIAL OF THE DEAD}

Burial rites were important ceremonials. The house hitherto tenanted by the deceased was abandoned - a custom exemplified in the removal of the capital to a new site at the commencement of each reign - and the body was transferred to a specially erected mourning-hut draped inside with fine, white cloth? The relatives and friends then assembled, and for several days performed a ceremony which resembled an Irish wake, food and sake being offered to the spirit of the dead, prayers put up, and the intervals devoted to weird singing and solemn dancing. Wooden coffins appear to have been used until the beginning of the Christian era, when stone is said to have come into vogue.

At the obsequies of nobles there was considerable organization. Men (mike-hito) were duly told off to take charge of the offerings of food and liquor; others (kisari-mochi) were appointed to carry the viands; others (hahaki-mochi) carried brooms to sweep the cemetery; there were females (usu-me) who pounded rice, and females (naki-me) who sung dirges interspersed with eulogies of the deceased. The Records mention that at the burial of Prince Waka a number of birds were used instead of these female threnodists. It appears, further, that those following a funeral walked round the coffin waving blue-and-red banners; carrying lighted torches, and playing music.

In the sepulchres the arms, utensils, and ornaments used daily by the deceased were interred, and it was customary to bury alive around the tombs of Imperial personages and great nobles a number of the deceased 's principal retainers: The latter inhuman habit was nominally abandoned at the close of the last century before Christ, images of baked clay being substituted for human sacrifices, but the spirit which informed the habit survived, and even down to modern times there were instances of men and women committing suicide for the purpose of rejoining the deceased beyond the grave. 'As to the nature of the tombs raised over the dead, the main facts have been stated in Chapter VI.

\section{TEETH BLACKENING AND FACE PAINTING}

The habit of blackening the teeth has long prevailed among married women in Japan, but the Yamato tombs have thus far furnished only one example of the practice, and no mention occurs in the ancient annals. Face painting, however, would seem to have been indulged in by both sexes. Several of the pottery images (haniwa) taken from the tombs indicate that red pigment was freely and invariably used for that purpose. It was applied in broad streaks or large

[1 "Rice, which is mainly carbohydrate, is transformed into grape-sugar by the aetion of the saliva. This practice is still common in China and used to be so in Japan where it is now rarely miet with. It was employed only until dentition was complete." (Munro.)]

[2 B. H. Chamberlain.] 
patches, the former encircling the face or forming bands across it; the latter, covering the eyes or triangulating the cheeks. It is probable that this bizarre decoration was used only on ceremonial occasions and that it appears in a greatly accentuated form on the haniwa.

\section{AMUSEMENTS}

As to amusements in prehistoric times little information is furnished. Hunting the boar and the stag was the principal pastime, and hawking is described as having been practised in the fourth century of the Christian era. Music and dancing seem to have been in vogue from time immemorial, but there is nothing to tell what kind of musical instruments were in the hands of the early Yamato. The koto, a kind of horizontal lute, and the flute are spoken of in the Chronicles, but the date of their introduction is not indicated. Wrestling, cockfighting (with metal spurs), picnics, a kind of drafts, gambling with dice, and football are all referred to, and were probably indulged in from a very early date.

\section{SLAVERY}

The institution of slavery existed among the Yamato. It will be presently spoken of.

\section{POSITION OF WOMEN}

There is evidence to show that in the prehistoric age a high position was accorded to women and that their rights received large recognition. The facts that the first place in the Japanese pantheon was assigned to a goddess; that the throne was frequently occupied by Empresses; that females were chiefs of tribes and led armies on campaign; that jealous wives turned their backs upon faithless husbands; that mothers chose names for their children and often had complete charge of their upbringing - all these things go to show that the selfeffacing rank taken by Japanese women in later ages was a radical departure from the original canon of society. It is not to be inferred, however, that fidelity to the nuptial tie imposed any check on extra-marital relations in the case of men: it had no such effect.

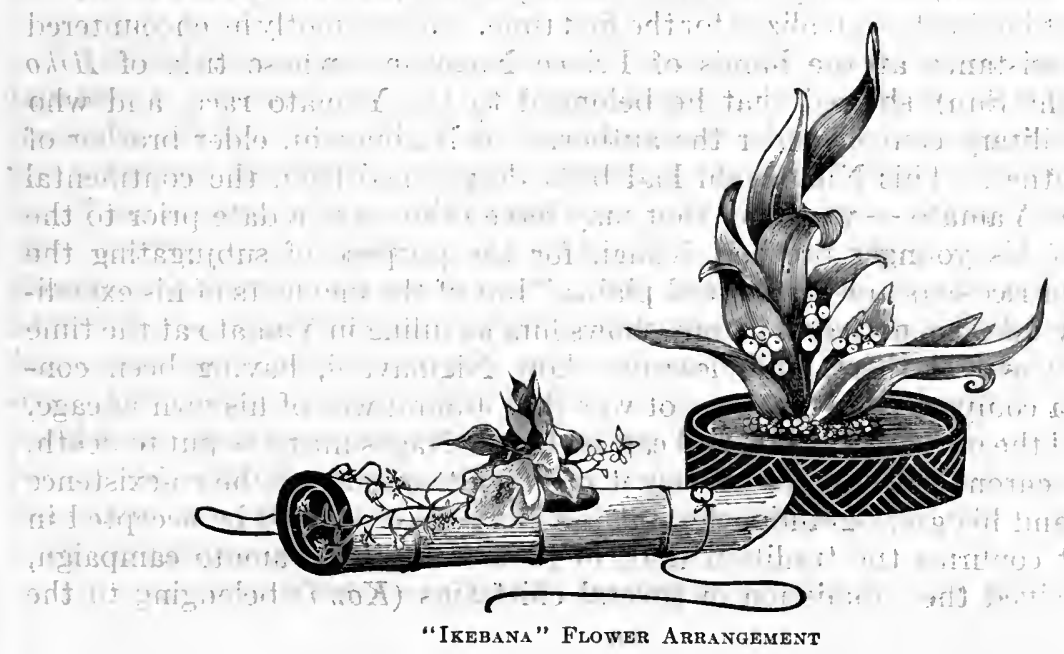




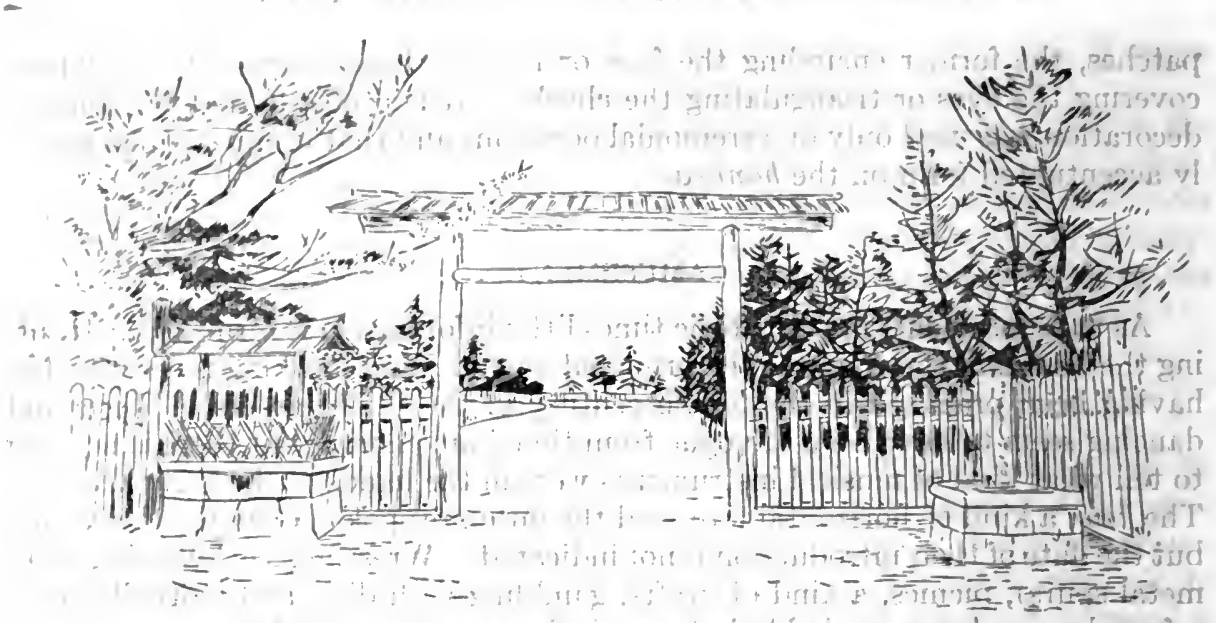

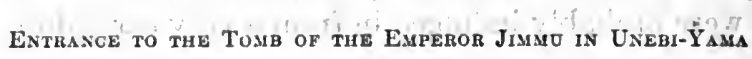

CHAPTER IX

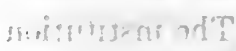

in ringinge

\section{THE PREHISTORIC SOVEREIGNS}

\section{JIMMU}

IT is held by eminent Japanese historians that the Emperor Jimmu, when he set out for Yamato, did not contemplate an armed campaign but merely intended to change his capital from the extreme south to the centre of the country. This theory is based on the words of the address he made to his elder brothers and his sons when inviting them to accompany him on the expedition- "Why should we not proceed to Yainato and make it the capital?" - and on the fact that, on arriving in the Kibi district, namely, the region now divided into the three provinces of Bizen, Bitchū, and Bingo, he made a stay of three years for the purpose of amassing an army and provisioning it, the perception that he would have to fight having been realized for the first time. Subsequently he encountered strongest resistance at the hands of Prince Nagasune, whose title of Hiko (Child of the Sun) showed that he belonged to the Yamato race, and who exercised military control under the authority of Nigihayahi, elder brother of Jimmu's father. 'This Nigihayahi had been despatehed from the continental realm of the Yamato - wherever that may have been - at a date prior to the despatch of his younger brother, Ninigi, for the purpose of subjugating the "land of fair rice-ears and fertile reed plains," but of the incidents of his expedition history takes no notice: it merely shows him as ruling in Yamato at the time of Jimmu's arrival there, and describes how Nigihayahi, having been convinced by a comparison of weapons of war that Jimmu was of his own lineage, surrendered the authority to him and caused Prince Nagasune to be put to death.

From a chronological point of view it is difficult to inagine the co-existence of Jimmu and his great-granduncle, but the story may perhaps be accepted in so far as it confirms the tradition that, in prosecuting his Yamato campaign, Jimmu received the submission of -several chieftains (Kami) belonging to the 
same race as himself, Reference to these facts is essential to an understanding of the class distinetions found in the Japanese social system. All the chieftains who led the expedition from Kyushu were, subsequently designated Tenshin a term which may be conveniently rendered "Kami of the descent" - and all those who, like Nigihayahi, had previously been in occupation of the country, were styled kumi-tsu-Kami, or "territorial Kami." Another method of distinguishing was to include the former in the $K w \overline{o b e t s u}$ and the latter in the Shimbetsu distinctions which will be more fully explained hereafter - and after apotheosis the members of these two classes became respectively deities of heaven"1 and "deities of earth," a distinction possessing historical rather than qualificatory force.

As for subdivisions, the head of a Kwōbetsu family had the title of omi (grandee) and the head of a Shimbetsu family that of muraji.(chief). Thus, the organization of the State depended primarily on the principle of ancestor worship. The sceptre descended by divine right without any regard to its holder's competence, while the administrative posts were filled by men of the same race with a similar hereditary title. Aliens like the Yezo, the Tsuchi-gumo, and the Kumaso were either exterminated or made slaves. (nuhi).

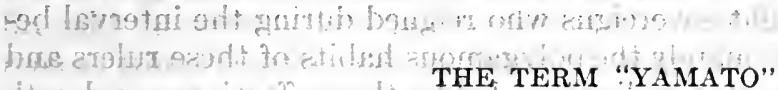

As to the term "Yamato," it appears that, in the earliest times, the whole country now called Japan was known as Yamato, and that subsequently the designation became restricted to the province which became the seat of government. The Chinese, when they first took cognizance of the islands lying on their east, seem to have applied the name Wado - pronounced "Yamato" by the Japanese - to the tribes inhabiting the western shores of Japan, namely, the Kumaso or the Tsuchi-gumo, and in writing the word they used ideographs conveying a sense of contempt. The Japanese, not unnaturally, changed these ideographs to others having the same sounds but signifying "great peace." At a later time the Chinese cr the Koreans began to designate these eastern islands, Jih-pen, or "Sunrise Island," a term which, in the fifteenth century, was perverted by the Dutch into Japan.

\section{THE FIRST NINE EMPERORS}

In attempting to construct coherent annals out of the somewhat fragmentary Japarese histories of remote ages, the student is immediately confronted by chronological difficulties. Apart from the broad fact that the average age of the first seventeen Emperors from Jimmu downwards is 109 years, while the average age of the next seventeen is only sixty-one and a half years, there are irreconcilable discrepancies in some of the dates themselves. Thus, according to the Records, the eighth Emperor, Koggen; died at iffty-seven, but according to the Chronicles he ascended the throne at fifty-ninel and reigned fifty-six -years. Again, whereas the ninth sovereign, Kaikwa, is by the Records given a life of only sixty-three years; the Chronicles make him assume the sceptre at fifty-one and wield it for fifty-nine years. Such conflicts of evidence are fatal to confidence. Nor do they disappear wholly until the beginning of the fifth century, at which time, moreover, the incidents of Japanese history receive their first confirmation from the history of China and Korea.

It is therefore not extravagant to conclude that the first ten and a half cen- 
turies covered by Japanese annals must be regarded as prehistoric. On the other hand, the incidents attributed to this long interval are not by any means of such a nature as to suggest deliberate fabrication. An annalist who was also a courtier, applying himself to construct the story: of his sovereign's ancestors, would naturally be disposed to embellish his pages with narratives of great exploits and brilliant achievements. Neither the Records nor the Chronicles can be said to display such a propensity in any marked degree. The Chronicles do; indeed, draw upon the resources of Chinese history to construct ethical codes and scholarly diction for their Imperial figures, but the Records show no traces of adventitious colour nor make an attempt to minimize the evil and magnify the good.

Thus, while it is evident that to consolidate Jimmu's conquest and to establish order among the heterogeneous elements of his empire he must have been followed by rulers of character and prowess, the annals show nothing of the kind. On the contrary, the reigns of his eight immediate successors are barren of all striking incident. "The closing chapter of Jimmu himself is devoted chiefly to his amours, and the opening page in the life of his immediate successor, Suisei, shows that the latter reached the throne by assassinating his elder brother: For the rest, the annals of the eight sovereigns who reigned during the interval between 561 and 98 в.c. recount mainly the polygamous habits of these rulers and give long genealogies of the noble families founded by their offspring - a dearth of romance which bears strong witness to the self-restraint of the compilers. We learn incidentally that on his accession each sovereign changed the site of his palace, seldom passing, however, beyond the limits of the province of Yamato, and we learn, also, that the principle of primogeniture, though generally observed; was often violated.

\section{HSU FUH}

A Japanese tradition assigns to the seventy-second year of the reign of Kōrei the advent of a Chinese Taoist, by name Hsu Fuh. Körei, seventh in descent from Jimmu, held the sceptre from 290 to 215 B.C., and the seventy-second year. of his reign fell, therefore, in 219 B.c. Now; to the east of the town of Shingu in Kii province, at a place on the seashore in the vicinity of the site of an ancient castle, there stands a tomb bearing the inseription "Grave of Hsu Fuh from China," and near it are seven tumuli said to be the burial-places of Hsu's companions. Chinese history states that Hsu Fuh was a learned man who served the first Emperor of the Chin dynasty (255-206 B.c.), and that he obtained his sovereign's permission to sail to the islands of the east in search of -the elixir of life. Setting out from Yentai (the present Chefoo) in his native province: of Shantung, Hsu landed at Kumano in the Kii promontory, and failing to find the elixir, preferred to pass his life in Japan rather than to return unsuccessful to the Court of the tyranical Chin sovereign, burner of the books and builder of the Great Wall. A poem composed in the Sung dynasty (A.D. 960-1280) says that when Hsu Fuh set out, the books had not been burned, and that a hundred volumes thus survived in his keeping. Of course, the date assigned by Japanese tradition to the coming of Hsu may have been adapted to Chinese history, and it therefore furnishes no evidence as to the accuracy of the Chronicles'chronology. But the existence of the tomb may be regarded as proving that some communication took place between China and Japan at that remote epoch. ${ }^{1}$

$\{1$ The route taken by $\mathrm{Hsu}$ Fuh - namely, from Chefoo down the China Sea and round the south of Japan - is difficult to understand.] 


\section{THE TENTH EMPEROR, SUUJIN}

The reign of this sovereign (97-30 в.c.) is the first eventful period since the death of Jimmu. It is memorable for the reorganization of religious rites; for the extension of the effective sway of the Throne, and for the encouragement of agriculture. When the first Emperor installed the sacred insignia in the palace where he himself dwelt; the instinct of filial piety and the principle of ancestor worship were scarcely distinguishable." But as time passed and as the age of the Kami became more remote, a feeling of awe began to pervade the rites more strongly than a sense of family affection, and the idea of residing and worshipping in the same place assumed a character of sacrilege. This may have been directly suggested by a pestilence which, decimating the nation, was interpreted as implying the need of greater purity. A replica of the sacred mirror was manufactured, and the grandson of the great worker in metal - Mahitotsu; the "One-eyed" - was ordered to forge an imitation of the sacred sword. These imitations, together with the sacred jewel, were kept in the palace, but the originals were transferred to Kasanui in Yamato, where a shrine for the worship of the Sun goddess had been built. But though the pestilence was stayed, it brought an aftermath of lawlessness and produced much unrest in the regions remote from Yamato. Sujin therefore organized a great military movement, the campaign of the Shidō shögun, or "Generalissimo of the four Circuits." 1

The leaders chosen for this task were all members of the Imperial family a great-uncle, an uncle, a younger brother, and a first cousin of the Emperor and the fields of operation assigned to them were: first, to the west along the northern shore of the Inland Sea; secondly; to the northwest into Tamba, Tango, and Tajima; thirdly, to the north along the sea of Japan, and finally to the east along the route now known as the Tokaido. No attempt is made by the writers of either the Records or the Chronicles to describe the preparations for this extensive campaign. Tradition seems to have preserved the bare fact only.

One interesting interlude is described, however. Before the first body of troops had passed beyond range of easy communication with.Mizugaki in Yamato, where the Court resided, the prince in command heard a girl singing by the wayside, and the burden of her song seemed to imply that, while foes at home menaced the capital, foes abroad should not be attacked. The prince, halting his forces, returned to Mizugaki to take counsel, and the Emperor's aunt interpreted the song to signify that his Majesty's half-brother, Haniyasu, who governed the adjacent province of Yamato, was plotting treason. Then all the troops having been recalled, preparations to guard the capital were made, and soon afterwards, news came that Haniyasu, at the head of an army; was advancing from the direction of Yamashiro, while his wife, Ata, was leading another force from $\bar{O}$ saka, the plan being to unite the two armies for the attack on Yamato. The Emperor's generals at once assumed the offensive. They moved first against Princess Ata, killed her and exterminated her forces; after which they dealt similarly with Haniyasu. This chapter of history illustrates the important part taken by women in affairs of State at that epoch, and incidentally confirms the fact that armour was worn by men in battle.

The four Imperial generals were now able to resume their temporarily interrupted campaigns: According to the Chronicles they completed the tasks assigned to them and retirned to the capital within six months. But such chronology cannot be reconciled with facts. For it is related that the generals sent

"[ 1 The term " $d \vec{o}$." indicates a group of provinces.] 
northward by the western seaboard and the eastern seaboard, respectively, came together at $A i z u,{ }^{1}$ one reaching that place via Hitachi, the other via Echigo. 'Thus, it would result that $Y$ amato armies at that remote epoch marehed hundreds of iniles through country in the face of an enemy within a few months. Further, to bring the aboriginal tribes into subjugation, an isolated campaign would have been quite inadequate. Some kind of permanent control was essential, and there is collateral evidence that the descendants of the four princely generals, during many generations, occupied the position of provincial magnates and exercised virtually despotic.sway within the localities under their jurisdiction. 'Thus in the provinces of $\bar{O} \mathrm{mi}$, of Suruga, of Mutsu, of Iwashiro, of Iwaki, of Echigo, of Etchū, of Echizen, of Bizen, of Bitchū, of Bingo, of Harima, of Tamba, and elsewhere, there are found in later ages noble families all traeing their descent to one or another of the Shido shōguns despatched on the task of pacifying the country in the days of the Emperor Sujin. The genealogies which fill pages of the Records from the days of Jimmu downwards point clearly to the growth of a powerful feudal aristocracy, for the younger sons born to successive sovereigns bear, for the most part, names indicative of territorial lordship; but it seems justifiable to conclude that the first great impetus to that kind of decentralization was given by Sujin's despatch of the Shidō shöguns.

\section{AGRICULTURE AND TAXATION}

The digging of reservoirs and tunnels for irrigating rice-fields received unprecedented attention in the reign of this Emperor, and mention is for the first time made of taxes - tributes of "bow-notches and of finger-tips," "in other words, the produce of the chase and the products of the loom. A census was taken for taxation purposes, but unhappily the results are nowhero recorded. The Court gave itself some eoncern about maritime transport also.s A rescript ordered that ships should be built by every province, but nothing is stated as to their dimensions or nature. In this reseript it is mentioned that "the people of the coast, not having ships, suffer grievously by land transport.". suffered may be inferred from a description in the Chronicles where we read that at the building of the tomb of a princess, "the people, standing close to each other, passed the stones from hand to hand, and thus transported them from Ōsaka to Yamato."

\section{FOREIGN INTERCOURSE}

Korea, when Japanese history is first explicitly concerned with it, was peopled by a number of semi-independent tribes, and the part of the peninsula lying southward of the Han River - that is to say, southward of the present Seoul-eomprised three kingdoms. Of these Ma-Han oecupied the whole of the western half of the peninsula along the eoast of the Yellow Sea; while Sin-Han and Pyong-Han formed the eastern half, lying along the shore of the Sea of Japan. The three were collectively spoken of as Sam-Han (the three Han). But Japan's relations with the peninsula did not always involve these inajor divisions. Her annals speak of Shiragi (or Sinra), Kara, Kudara, and Koma. Shiragi and Kara were principalities carved respectively out of the southeast and south of Pyong-Han. Thus, they lay nearest to Japan, the Korea Strait alone intervening, and the Korea Strait was almost bridged by islands. Kudara constituted the modern Seoul and its vicinity; Koma; (called also Kōrai and in ['Hence the term "Aizu," for $a i$, signifies :" to meet."'] 
Korea, Kokuli), the modern Pyong-yang and its distriet. These two places were rendered specially accessible by the rivers. Han and Tadong which flowed through them to the Yellow Sea; but of course in this respect they could not compare with Shiragi (Sinra) and Kara, of which latter place the Japanese usually spoke as Mimana:

There can scarcely: be any doubt that the Korean peninsula was largely permeated with Chinese influences from a very early date, but the processes which produced that result need not be detailed here. It has been also shown above that in the era prior to Jimmu, indications are found of intercourse between Japan and Korea, and even that Susanoo and his son held sway in Shiragi. But the first direct reference made by Japanese annals to Korea occurs in the reign of Sujin; 33 B.c. when an envoy from Kara arrived at the Mizugaki Court, praying that a Japanese general might be sent to compose a quarrel which had long raged between Kara and Shiragi, and to take the former under Japan's protection. It appears that this envoy had travelled by a very circuitous route. He originally made the port of Anato (modern Nagato), but Prince Itsutsu, who ruled there, claimed to be the sole monarch of Japan and refused to allow the envoy to proceed, so that the latter had to travel north and enter Japan viâ Kehi-no-ura (now Tsuruga).

Incidentally this narrative corroborates a statement made in Chinese history (compiled in the Later Han era, A.D. 25-220) to the effect that many Japanese provinces claimed to be under hereditary rulers who exercised sovereign rights. Such, doubtless, was the attitude assumed by several of the Imperial descendants who had obtained provincial estates. The Emperor Sujin received the envoy courteousiy and seemed disposed to grant his request, but his Majesty's death (30 B.c.) intervened, and not until two years, later was the envoy able to return. His mission had proved abortive, but the Emperor Suinin, Sujin's successor, gave him some red-silk fabrics to carry home and conferred on his country the name Mimana, in memory of Sujin, whose appellation during life had been Mimaki.

These details furnish an index to the relations that existed in that era between the neighbouring states of the Far East. The special interest of the incident lies, however, in the fact that it furnishes the first opportunity of comparing Japanese history with Korean. The latter has two claims to credence. The first is that it assigns no incredible ages to the sovereigns whose reigns it records. According to Japanese annals there were only seven accessions to the throne of Yamato during the first four centuries of the Christian era: According to Korean annals, the three peninsular principalities had sixteen, seventeen, and sixteen accessions, respectively, in the same interval. "The second claim is that, during the same four centuries, the-histories of China and Korea agree in ten dates and differ in two only. ${ }^{1}$ On the whole, therefore, Korean annals deserve to be credited. But whereas Japanese history represents warfare as existing between Kara and Shiragi in 33 B.c., Korean history represents the conflict as having broken out in A.D. 77. There is a difference of just 110 years, and the strong probability of accuracy is on the Korean side.

\section{THE ELEVENTH SOVEREIGN, SUININ (29 B.C.-A.D. 70)}

Suinin, second son of his predecessor, obtained the throne by a process which frankly ignored the principles of primogeniture. For Sujin, having an equal

[1 For a masterly analysis of this subject see a paper on Early. Japanese History by Mr. W. G. Aston in Vol. XVI of the "Translations of the Asiatic Society of Japan."] 
affection for his two sons, confessed himself unable to choose which of them should he his successor and was therefore guided by a comparison of their dreams, the result being that the younger was declared Prince Imperial, and the elder became duke of the provinces of Kamitsuke (now Kōtsuke) and Shimotsuke. Suinin, like all the monarchs of that age, had many consorts: nine are catalogued in the Records and their offspring numbered sixteen, many of whom received local titles and had estates conferred in the provinces. In fact, this process of ramifying the Imperial family went on continuously from reign to reign.

There are in the story of this sovereign some very pathetic elements. Prince Saho, elder brother of the Empress, plotted to usurp the throne. Having cajoled his sister into an admission that her brother was dearer than her husband, he bade her prove it by killing the Emperor in his sleep. But when an opportunity offered to perpetrate the deed as the sovereign lay sleeping with her knees as pillow, her heart melted, and her tears, falling on the Emperor's face, disturbed his slumber. He sought the cause of her distress, and learning it, sent a force to seize the rebel. Remorse drove the Empress to die with Prince Saho. Carrying her little son, she entered the fort where her brother with his followers had taken refuge. The Imperial troops set fire to the fort - which is described as having been built with rice-bags piled up - and the Empress emerged with the child in her arms; but having thus provided for its safety, she fled again to the fort and perished with her brother. This terrible scene appears to have given the child such a shock that he lost the use of speech, and the Records devote large space to describing the means employed for the amusement of the child, the long chase and final capture of a swan whose cry, as it flew overhead, had first moved the youth to speech, and the eure ultimately effected by building a shrine for the worship of the deity of Izumo, who, in a previous age, had been compelled to abdicate the sovereignty of the country in favour of a later descendant of the Sun goddess, and whose resentment was thereafter of ten responsible for calamities overtaking the Court or the people of Japan.

\section{THE ISE SHRINE AND THE PRACTICE OF JUNSHI}

Two events specially memorable in this reign were the transfer of the shrine of the Sun goddess to Ise, where it has remained ever since, and the abolition of the custom of junshi, or following in death." The latter shocking usage; a common rite of animistic religion, was in part voluntary, in part compulsory. In its latter aspect it came vividly under the notice of the Emperor Suinin when the tomb of his younger brother, Yamato, having been built within earshot of the palace, the cries of his personal attendants, buried alive around his grave, were heard, day and night, until death brought silence. In the following year (A.D. 3), the Empress having died, a courtier, Nomi-no-Sukune, advised the substitution of 'clay figures for the victims hitherto' sacrificed. Nominally, the practice of compulsory junshi ceased from that date, ${ }^{1}$ but voluntary junshi continued to find occasional observance until modern times.

\section{WRESTLING}

The name of Nomi-no-Sukune is associated with the first mention of wrestling in Japanese history. By the Chronicles a brief account is given of a match be-

I' Of course it is to be remembered that the dates given by Japanese historians prior to the fifth century A.D. are very apocryphal.] 
tween Nomi and Taema-no-Kuehaya. The latter was represented to be so strong that he could break horns and straighten hooks. His frequently expressed desire was to find a worthy competitor. Nomi-no-Sukune, summoned from Izumo by the Emperor, met Kuehaya in the lists of the palace of Tamaki and kicked him to death. Wrestling thereafter became a national pastime, but its methods underwent radical change, kicking being abolished altogether.

\section{FOREIGN INTERCOURSE}

It is believed by Japanese historians that during the reign of Suinin a local government station (chinju-fu) was established in Anra province of Mimana, and that this station, subsequently known as Nippon-fu, was transferred to Tsukushi (Kyüshü) and named Dazaï-fu when Japan's influence in Mimana waned. The first general (shogun) of the chinju-fu was Prince Shihotari, and the term kishi - which in Korea signified headman - was thenceforth incorporated into his family name. To the members of that family in later generations was entrusted the conduct of the Empire's foreign affairs. But it does not appear that the Imperial Court in Yamato paid much attention to oversea countries in early eras. Intercourse with these was conducted, for the most part, by the local magnates who held sway in the western regions of Japan.

It was during the reign of Suinin, if Japanese chronology be accepted, that notices of Japan began to appear in Chinese history - a history which justly claims to be reliable from 145 B.c. Under the Later Han dynasty (A.D. 25-220), great progress was made in literature and art by the people of the Middle Kingdom, and this progress naturally extended, not only to Korea, which had been conquered by the Chinese sovereign, $\mathrm{Wu}-\mathrm{Ti}$, in the second century before Christ and was still partly under the rule of Chinese governors, but also to the maritime regions of Japan, whence the shores of Korea were almost within sight. China in those ages was incomparably the greatest and most enlightened country in the Orient, and it had become the custom with adjacent States to send emissaries to her Court, bearing gifts which she handsomely requited; so that while, from one point of view, the envoys might be regarded as tribute-carriers, from another, the ceremony presented the character of a mere interchange of neighbourly civilities. In Japan, again, administrative centralization was still imperfect. Some of the local magnates had not yet been brought fully under the sway of the Yamato invaders, and some, as scions of the Imperial family, arrogated a considerable measure of independence. Thus it resulted that several of these provincial dukes - or "kings," as not a few of them were called - maintained relations with Korea, and through her despatched tribute missions to the Chinese Court from time to time.

In these circumstances it is not surprising to find the Chinese historians of the first century A.D. writing: "The $W a$ (Japanese) dwell southeast of Han ${ }^{1}$ (Korea) on a mountainous island in midocean. Their country is divided into more than one hundred provinces. Since the time when Wu-Ti (140-86 в.c.) overthrew Korea, they (the Japanese) have communicated with the Han (Korean) authorities by means of a postal service. There are thirty-two provinces which do so, all of which style their rulers 'kings,' who are hereditary. 'The sovereign of Great Wa resides in Yamato, distant 12,000 li (4000 miles) from the frontier of the province of Yolang (the modern Pyong-yang in Korea). In the second year of

[ 1 It is necessary to distinguish carefully between the Han dynasty of China and the term "Han" as a designation of Korea.] 
Chung-yuan (A.D. 57), in the reign of Kwang-wu, the Ito ${ }^{1}$ country sent an envoy with tribute, who styled himself $\mathrm{Ta}-\mathrm{fu}$. He came from the most western part of the Wa country. Kwang-wu presented him with a seal and ribbon." [Aston's translation.]

These passages have provoked much discussion, but Japanese annalists are for the most part agreed that "I to" should be read "I-no-na," which corresponds with the ancient $\mathrm{Na}$-no-Agata, the present Naka-göri in Chikuzen, an identification consistent with etymology and supported by the fact that, in 1764, a gold seal supposed to be the original of the one mentioned above, was dug out of the ground in that region. In short, Na-no-Agata is identical with the ancient Watazumi-no-Kuni, which was one of the countries of Japan's intercourse. Further, the Yamato of the Hou-Han historians is not to be regarded as the province of that name in central Japan, but as one of the western districts, whether Yamato in Higo, or Yamato in Chikugo. It has been shrewdly suggested ${ }^{2}$ that the example of Korea had much influence in inducing the local rulers in the western and southern provinces to obtain the Chinese Court's recognition of their administrative status, but, whatever may have been the dominant motive, it seems certain that frequent intercourse took place between Japan and China via Korea immediately before and after the beginning of the Christian era. Again, that Koreans came freely to Japan and settled there is attested by the case of a son of the King of Shiragi who, coming to the Tajima region, took a Japanese wife and established himself there, founding a distinguished family. The closing episode of the Emperor Suinin's life was the despatch of Tajima Mori, this immigrant's descendant, to the country of Tokoyo, nominally for the purpose of obtaining orange-sceds, but probably with the ulterior motive of exploration.

The reader is already familiar with this Tokoyo-no-Kuni (Eternal Land). We hear of it first as the home of "long-singing birds" summoned to take part in enticing the Sun goddess from her cave. Then it figures as the final retreat of Sukuna-hikona, the Escalapius of the mythological age. Then we find one of Jimmu's elder brothers treading on the waves to reach it. Then we hear of it as the birthplace of the billows that make Ise their bourne, and now it is described by Tajima Mori in his death-song as the "mysterious realm of gods and genii," so distant that ten years were needed to reach it and return. It appears in fact to have been an epithet for China in general, and the destination of Tajima Mori is believed to have been Shantung, to reach which place by sea from Japan was a great feat of navigation in those primitive days. Tajima Mori returned to find the Emperor dead, and in despair he committed suicide.

\section{AGRICULTURE AND ADMINISTRATION}

The reclamation of land for purposes of rice cultivation went on vigorously during Suinin's reign. More than eight hundred ponds and aqueducts are said to have been constructed by order of the sovereign for irrigation uses throughout the provinces. It would seem, too, that the practice of formally consulting Court officials about administrative problems had its origin at this time. No definite organization for the purpose was yet created, but it became customary

[ 1 The ideographs composing this word were pronouneed "I-to" at the time when they were "Written by the Hou-Han historians, but they subsequently received the sound of "Wo-nu" or

[² By Dr. Ariga, an eminent Japanese authority.] 
to convene distinguished scions of the Imperial line and heads of great subjectfamilies to discuss and report upon affairs of State. Another innovation referred to in this era was the offering of weapons of war at the shrines. We read of as many as a thousand swords being forged to form part of the sacred treasures at the shrine of Ise-no-Kami, and the occasion was seized to organize a number of hereditary corporations (be) of arm-makers and armourers. These were placed under the control of Prince Inishiki, another of the captains of the Imperial life-guards (mononobe no Obito). It is thus evident that something more than a religious rite was involved in these measures.

\section{THE TWELFTH EMPEROR, KEIKŌ (A.D. 71-130)}

According to the Records, Keikō was ten feet two inches high, and his shank measured four feet one inch. His nomination as Prince Imperial was an even more arbitrary violation of the right of primogeniture than the case of his predecessor had been, for he was chosen in preference to his elder brother merely because, when the two youths were casually questioned as to what they wished for, the elder said, "a bow and arrows," and the younger, "the empire." The delusive nature of the Nihongi's chronology in these prehistoric epochs is exemplified in the annals of this sovereign, for he is represented as having been in his eightythird year when he ascended the throne, yet, in the third year of his reign, he took a consort who bore him thirteen children, and altogether his progeny numbered eighty sons and daughters by seven wives. His plan of providing for these numerous scions constituted the first systematization of a custom which had been observed in a fitful manner by several of his predecessors. They had given to their sons local titles and estates but had not required them to leave the capital. Keikō, however, appointed his sons, with three exceptions, to the position of provincial or district viceroy, preserving their Imperial connexion by calling them wake, or branch families. This subject will present itself for further notice during the reign of Keikō's successor.

One of the most memorable events in this epoch was the Emperor's military expedition in person to quell the rebellious Kumaso (q.v.) in Kyūshū. There had not been any instance of the sovereign taking the field in person since Jimmu's time, and the importance attaching to the insurrection is thus shown. Allowance has to be made, however, for the fact that the territory held by these Kumaso in the south of Kyūshū was protected by a natural rampart of stupendous mountain ranges which rendered military access arduous, and which, in after ages, enabled a great feudatory to defy the Central Government for centuries. In connexion with this expedition a noteworthy fact is that female chieftains were found ruling in the provinces of Suwō and Bingo. They were not aliens, but belonged to the Yamato race, and their existence goes far to account for the appellation, "Queens' Country," applied by Chinese historians to the only part of Japan with which the people of the Middle Kingdom were familiar, namely, Kyūshū-and the west-coast provinces. Keikō's reign is remarkable chiefly for this expedition to the south, which involved a residence of six years in Hyūga, and for the campaigns of one of the greatest of Japan's heroes, Prince Yamato-dake. The military prowess of the sovereign, the fighting genius of Yamato-dake, and the administrative ability of Takenouchi-noSukune, the first "prime minister" mentioned in Japanese history, combined to give signal éclat to the reign of Keikō.

Arriving at this stage of the annals, we are able to perceive what an influence 
was exercised on the fortunes of the country by its topographical features. The southwestern sections of the islands are comparatively accessible from the centre (Chügoku or Ininai), whether by sea or by land, but the northeastern are guardcll by mountain chains which can be crossed only by arduous and easily defended passes. It was, therefore, in these northeastern provinces that the Yemishi maintained their independence until their strength was broken by the splendid campaign of Yamato-dlake; it was in these northeastern provinces that the bushi, noblest product of Japanese civilization, was nurtured; it was in the same provinces that the Taira family made its brilliant début, and it was by abandoning these provinces for the sweets of Kyōto that the Taira fell; it was in the northeastern provinces that Minamoto Yoritomo, the father of military feudalism, established himself, to be followed in succession by the Hōjō, the Ashikaga, and the Toliugawa, and it is in the northeastern provinces that the Meiji Government has its seat of power.

We can not wonder, therefore, that modern historiographers have devoted much labour to tracing the route followed by Yamato-dake's troops and rationalizing the figurative or miraculous features of the narratives told in the Kojiki and the Nihongi. It is enough to know, however, that he overran the whole region stretching from the provinces along the Eastern Sea as far as Iwaki; crossed westward through Iwashiro to Echigo on the west coast, and turning southward, made his way through Shinano and Mino to Owari, whence, suffering from a wound caused by a poisoned arrow, he struggled on to Ise and died there. This campaign seems to have occupied ten years, and Yamato-dake was only thirty at the time of his death. He had marched against the Kumaso in the south at the age of sixteen. The Chronicles relate that when erossing the Usui Pass and looking down on the sea where his loved consort had cast herself in to the waves to quell their fury, the great warrior sighed thrice and exclaimed, "My wife, my wife, my wife!" (Aga tsuma haya), whereafter the/provinces east of the mountain were designated Azuma.

It was imagined until quite recent times that the pass referred to was the well-known Usui Tōge on the Nakasendō road; but Dr. Kume has shown that such a supposition is inconsistent with any rational itinerary of Yamato-dake's march, and that the sea in question cannot be seen from that defile. The pass mentioned in the Chronicles is another of the same name not far from the Hakone region, and the term "Azuma" "had always been used to designate the Eastern Provinces." Throughout the Records and the Chronicles frequent instances occur of attempts to derive place-names from appropriate legends, but probably in many cases the legend was suggested by the name. In connexion with Yamato-dake's carcer, a circumstance is recorded which indirectly points to the absence of history at that period. In order to immortalize the memory of the hero, hereditary corporations (be) called after him were created. These Take-be gave their names to the distriets where they lived, in Ise, Izumo, Mimasaka, and Bizen.

\section{FEMALE HOSTAGES}

Another custom inaugurated by this sovereign was to require that the rulers of provinces should send to the Yamato Court female hostages. The first example of this practice took place on the occasion of an Imperial visit to the regions overrun by Yamato-dake's forces. Each of twelve kuni-yatsukio (provincial rulers) was required to send one damsel for the purpose of serving in the culinary department of the palace. They were called makura-ko (pillow-child) and they 
seem to have been ultimately drafted into the ranks of the uneme (ladies-inwaiting). Japanese historians hold that the makura-ko were daughters of the local magnates by whom they were sent, though the fact of that relationship is not clearly stated in either the Records or the Chronicles.

\section{TABE AND $M I Y A K E$}

In the annals of Suinin's reign brief reference is made to granaries (miyake) erected by order of the Court. The number of these was increased in Keikō's time, and it is further mentioned that a hereditary corporation of rice-field cultivators (tabe) were organized for service on the Imperial estates. The miyake were at once storehouse and offices for administering agricultural affairs.

\section{THE THIRTEENTH EMPEROR, SEIMU (A.D. 131-190)}

The thirteenth Emperor, Seimu, occupied the throne for fifty-nine years, according to the Chronicles, but the only noteworthy feature of his reign was the organization of local government, and the details of his system are so vaguely stated as to be incomprehensible without much reference and some hypotheses. Speaking broadly, the facts are these: Imperial princes who had distinguished themselves by evidences of ability or courage were despatched to places of special importance in the provinces, under the name of wake, a term conveying the signification of "branch of the Imperial family." There is reason to think that these appointments were designed to extend the prestige of the Court rather than to facilitate the administration of provincial affairs. The latter duty was entrusted to officials called kuni-no-miyatsuko and agata-nushi, which may be translated "provincial governor" and "district headman." The word miyatsuko literally signifies "honourable ( $m i$ ) servant (yatsuko or yakko)."

In the most ancient times all subjects were yakko, but subsequently those holding office at Court were distinguished as omi (grandee). Persons eligible for the post of provincial governor seem to have been chosen from among men of merit, or Imperial princes, or chiefs of aboriginal tribes. There was little exclusiveness in this respect. The rate of expansion of the area under Imperial sway may be inferred from the fact that whereas there were nine provinces (kuni) in Jimmu's time, one was added by Kaikwa, eleven by Sujin, seven by Keiko, and sixty-three by Seimu, making a total of ninety-one. Yet, though by the time of the last named sovereign almost the whole of the southern and central regions were included in the administrative circle, the northern provinces, some of the western, and certain regions in the south (Kyūshū) were not yet fully wrested from the Yemishi and the Kumaso. In subsequent reigns the rate of growth was as follows: Chūai (A.D. 192-200), two provinces; Ōjin (270310), twenty-one; Nintoku (313-399), seven; Hanshō (406-411) and Inkyō (412453), one each; Yūryaku (457-459), three; Keitai (507-531), one; and eight others at untraceable periods, the total being one hundred thirty-five.

The agata was a division smaller than a province (kuni). It corresponded to the modern köri or gun, and its nearest English equivalent is "district." A distinction must be made, however, between agata and mi-agata. The latter were Imperial domains whence the Court derived its resources, and their dimensions varied greatly. A smaller administrative district than the agata was the inagi. ${ }^{1}$ This we learn from a Chinese book - the Japanese annals being silent

[ ${ }^{1}$ Supposed to be derived from ine (rice) and oki (store).] 
on the subject - consisted of eighty houses, and ten inagi constituted a kuni. The term inagi was also applied to the chief local official of the region, who may be designated "Mayor."

THF FOURTEENTII EMPEROR, CHŪAI (A.D. 192-200) AND THE EMPRESS JINGÖ (A.D. 201-269)

Were the Records our sole guide, the early incidents of Chūai's reign would be wrapped in obscurity. For when we first meet him in the pages of the Kojiki, he is in a palace on the northern shores of the Shimonoseki Strait, whence he soon crosses to the Kashii palace in Kyūshū. His predecessors, while invariably changing their residences on mounting the throne, had always chosen a site for the new palace in Yamato or a neighbouring province, but the Records, without any explanation, carry Chūai to the far south after his accession. The Chronicles are more explicit. From them we gather that Chūai - who was the second son of Yamato-dake and is described as having been ten feet high with "a countenance of perfect beauty" — was a remarkably active sovereign. He commenced his reign by a progress to Tsuruga (then called Tsunuga) on the west coast of the mainland, and, a month later, he made an expedition to Kii on the opposite shore. While in the latter province he received news of a revolt of the Kumaso, and at once taking ship, he went by sea to Shimonoseki, whither he summoned the Empress from Tsuruga. An expedition against the Kumaso was then organized and partially carried out, but the Emperor's force was beaten and he himself received a fatal arrow-wound. Both the Records and the Chronicles relate that, on the eve of this disastrous move against the Kumaso, the Empress had a revelation urging the Emperor to turn his arms against Korea as the Kumaso were not worthy of his steel. But Chūai rejected the advice with scorn, and the Kojiki alleges that the outraged deities punished him with death, though doubtless a Kumaso arrow was the instrument. His demise was carefully coneealed, and the Empress, mustering the troops, took vengeance upon the Kumaso.

Thereafter her Majesty became the central figure in a page of history $\div$ or. romance - which has provoked more controversy than any incident in Japanese annals. A descendant of the Korean prince, Ama-no-Hihoko, who settled in the province of Tajina during the reign of the Emperor Suinin, she must have possessed traditional knowledge of Shiragi, whence her ancestor had emigrated. She was the third consort of Chüai. His first had borne him two sons who were of adult age when, in the second year of his reign, he married Jingō, ${ }^{1}$ a lady "intelligent, shrewd, and with a countenance of such blooming loveliness that her father wondered at it." To this appreciation of her character must be added the attributes of boundless ambition and brave resourcefulness. The annals represent her as bent from the outset on the conquest of Korea and as receiving the support and encouragement of 'Takenonchi-no-Sukune, who had served her husband and his predecessor as prime minister. A military expedition oversea led by a sovereign in person had not been heard of since the days of Jimmu,

${ }^{1}$ It should be clearly understood that the names by which the sovereigns are called in these jages, are the posthumous appellations given to them in later times when Chinese ideographs eame into use and Chinese customs began to be followed in such matters. The postlumous name was compiled with reference to the character or achievements of the sovereign. "Thus "Jingō" signifies "divine merit," on account of her conquests; "Chūai" means "lamentable second son," with reference to his evil fate, and "Keikō" implies "great deeds." These three sovereigns were called during life, Okinaga-Tarashi, Tarashi-Nakatsu, and $\bar{O}-$ Tarashi,
respectively.] 
and to reconcile officials and troops to such an undertaking the element of divine revelation had to be introduced. At every stage signs and portents were'vouchsafed by the guardian deities. By their intervention the Empress was shown to be possessed of miraculous prowess, and at their instance troops and ships assembled spontaneously. The armada sailed under divine guidance, a gentle spirit protecting the Empress, and a warlike spirit leading the van of her forces. The god of the wind sent a strong breeze; the god of the sea ruled the waves favourably; all the great fishes accompanied the squadron, and an unprecendented tide bore the ships far inland. Fighting became unnecessary. The King of Shiragi did homage at once and promised tribute and allegiance forever, and the other monarchs of the peninsula followed his example. In short, Korea was conquered and incorporated with the dominions of Japan.

\section{CRITICISM OF THE ALLEGED CONQUEST OF KOREA}

By some learned historiographers the whole of the above account is pronounced a fiction. There was no such invasion of Korea, they say, nor does the narrative deserve more credit than the legend of the Argonauts or the tale of Troy. But that is probably too drastic a view. There can indeed be little doubt that the compilers of the Nihongi embellished the bald tradition with imaginary details; used names which did not exist until centuries after the epoch referred to; drew upon the resources of Chinese history for the utterances they ascribe to the Empress and for the weapons they assign to her soldiers, and were guilty of at least two serious anachronisms.

But none of these faults disfigures the story as told in the pages of the Kojiki, which was written before the Nihongi. It has always to be remembered that the compilers of the latter essayed the impossible task of adjusting a new chronology to events extending over many centuries, and that the resulting discrepancies of dates does not necessarily discredit the events themselves. It has also to be remembered that the same compilers were required to robe their facts in Chinese costume and that the consequent ill-fits and artificialities do not of necessity vitiate the facts. In the particular case under consideration did the Kojiki stand alone, little doubt would ever have been entertained about the reality of an armed expedition to Korea, under the Empress Jingō. The sober and unexaggerated narrative of that history would have been accepted, less only the miraculous portents which accompany it.

As to the date of the invasion, however; it must have remained obscure: the Kojiki's narrative furnishes one clue. According to Korean history, an apparently unimportant descent upon Sinra (Shiragi) took place in A.D. 219; a more serious one in 233 , when the Japanese ships were burned and their crews massacred, and a still more formidable one in 249 , when a Sinra statesman who had brought on the invasion by using insulting language towards the sovereign of Japan in presence of a Japanese ambassador, gave himself up to the Japanese in the hope of appeasing their anger. They burnt him, and proceeded to beseige Keumsyong, the Sinra capital, but were ultimately beaten off. "No less than twenty-five descents by Japanese on the Sinra coast are mentioned in Korean history in the first five centuries of the Christian era, but it is impossible to identify any one of them with Jingō's expedition." [Aston.] Nevertheless, modern Japanese historians are disposed to assign the Jingō invasion to the year 364, when Nai-mul ruled Shiragi, from which monarch's era tribute seems to have been regularly sent to Yamato. Indeed the pages of the Nihongi which 
deal with the last sixty years of Jingo's reign are devoted almost entirely to descriptions of incidents connected with the receipt of tribute and the advent or despateh of envoys. The chronology is certainly erroneous. In no less than four several cases events obviously the same are attributed by the Korean annals to dates differing from those of the Nihongi by exactly two cycles; and in one important instance the Japanese work assigns to A.D. 205 an occurrence which the Tongkan ${ }^{1}$ puts in the year 418.

Whichever annals be correct - and the balance sways in favour of the Korean so far as those protohistoric eras are coneerned - "there can be no doubt that Japan, at an early period, formed an alliance with Paikehe" (spoken of in Japan as "Kudlara," namely, the regions surrounding the modern Seoul), "and laid the foundation of a controlling power over the territory known as Imna (or Mimana), which lasted for several centuries." [Aston.] One evidence of this control is furnished in the establishment of an office called uchi-tsu-miyake in addition to the chinju-fu already spoken of. From early times it had been customary in Japan that whenever any lands were acquired, a portion of them was included in the Imperial domain, the produce being thenceforth stored and the affairs of the estate managed at a miyake presided over by a mikoto-mochi. Thus, on the inclusion of certain Korean districts in Japan's dominions, this usage was observed, and the new miyake had the syllables uchi-tsu ("of the interior"), prefixed to distinguish it as a part of Japan. It is on record that a mikoto-mochi was stationed in Shiragi, and in the days of Jingō's son. (Ōjin) the great statesman, Takenouchi-no-Sukune, took up his residence for a time in Tsukushi to assist this mikoto-mochi and the chinju-fu, should occasion arise. Modern Japanese historians describe this era as the first period of Japanese national development, for an almost immediate result of the oversea relations thus established was that silk and cotton fabries of greatly improved quality, gold, silver, iron, implements, arts, and literature were imported in increasing quantities to the great benefit of civilization.

\section{SHIFTING OF POLITICAL INFLUENCE}

An important change dates from the reign of Jingō. It has been shown above that, from a period prior to the death of Suinin, the power and influence of the Imperial princes and nobles was a constantly growing quantity. But the political situation developed a new phase when the Sukune family appeared upon the scene. The first evidence of this was manifested in a striking incident. When the Emperor Chūai died, his consort, Jingō, was enceinte. ${ }^{2}$. But the Emperor left two sons by a previous marriage, and clearly one of them should have succeeded to the throne. Nevertheless, the prime minister, Takenouchi-no-Sukune, contrived to have the unborn child recognized as Prince Imperial. ${ }^{3}$.Naturally the deceased Emperor's two elder sons refused to be arbitrarily set aside in favour of a baby step-brother. - The principle of primogeniture did not possess binding force in those days, but it had never previously been violated except by

[' Korean history. Its full title is Tong-kuk-lhong-kan.]

[2 As illustrating the confused chronology of the Nihongi, it may be noted that, calculated by the incident of Chüai's career, he must have been fully one hundred years old when he begot this child. That is marvellous enough, but to add to the perplexity the Nihongi says that Chūai died at fifty-two.]

$\left[{ }^{3}\right.$ The legend snys of this child that its birth was artificially delayed until the return of the Empress from the Korean expedition, but the fact scems to be that the Emperor died at the end of June and the Empress' accouchement took place in the following April.] 
the deliberate and ostensibly reasonable choice of an Emperor. The two princes, therefore, called their partisans to arms and prepared to resist the return of Jingō to Yamato. Here again Takenouchi-no-Sukune acted a great part. He carried the child by the outer sea to a place of safety in Kii, while the forces of the Empress sailed up the Inland Sea to meet the brothers at Naniwa (modern Osaka). Moreover, when the final combat took place, this same Takenouchi devised a strategy which won the day, and in every great event during the reign of the Empress his figure stands prominent. Finally, his granddaughter became the consort of the Emperor Nintoku (313-399), an alliance which opened a channel for exercising direct influence upon the Throne and also furnished a precedent adopted freely in subsequent tinies by other noble families harbouring similarly ambitious aims. In short, from the accession of the Empress Jingo a large part of the sovereign power began to pass into the hands of the prime minister.

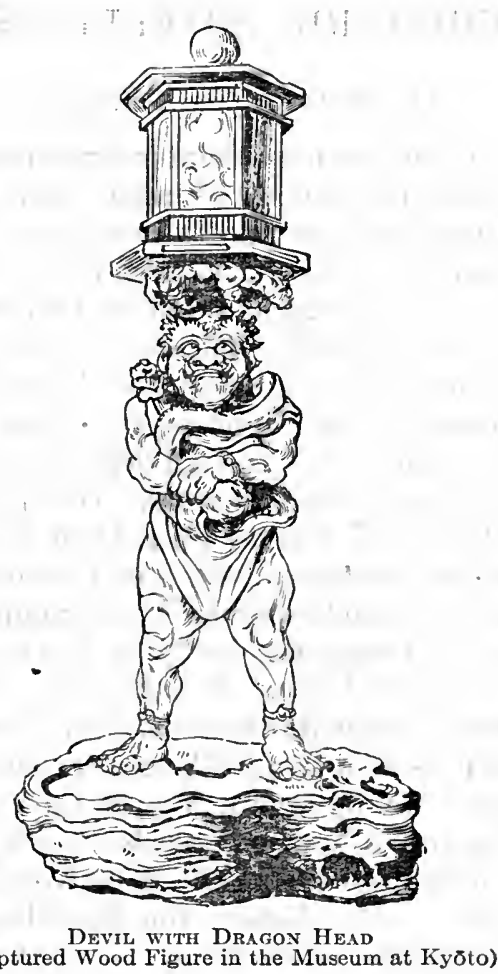




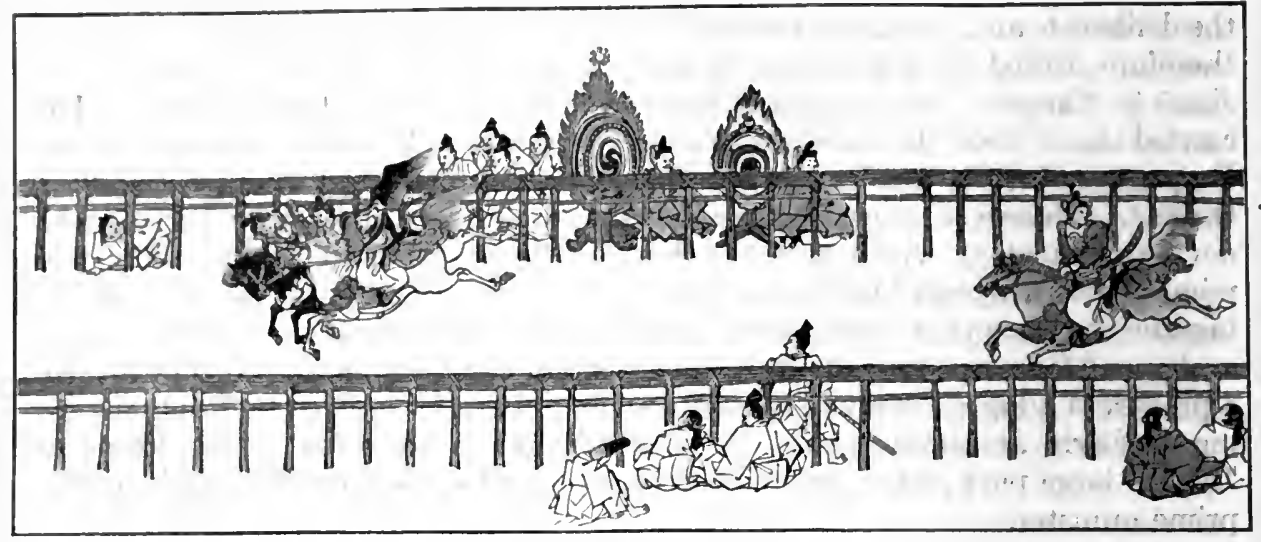

HORSE IRACE IN OLD JAPAN

\section{CHAPTER X}

\section{THE PREHISTORIC SOVEREIGNS (Continued)}

\section{THE SOCIAL ORGANIZATION}

AT the beginning of the previous chapter brief reference was made to the three great divisions of the inhabitants of Japan; namely, the Shimbetsu (Kami class) the Kwöbetsu (Imperial class) and the Bambetsu (aboriginal class). The Shimbetsu comprised three sub-classes; namely, first, the Tenjin, a term used to designate the descendants of the great primeval trinity and of the other Kami prior to the Sun goddess; secondly, the Tenson, or descendants of the Sun goddess to Jimmu's father (Ugaya-fukiaezu), and thirdly, the Chigi, an appellation applied to the chiefs found in Izumo by the envoys of the Sun goddess and in Yamato by Jimmu - chiefs who, though deprived of power, were recognized to be of the same lineage as their conquerors. It is plain that few genealogical trees could be actually traced further back than the Chigi. Hence, for all practical purposes, the Shimbetsu consisted of the descendants of vanquished chiefs, and the fact was tacitly acknowledged by assigning to this class the second place in the social seale, though the inclusion of the Tenjin and the Tenson should have assured its precedence. The Kwōbetsu comprised all Emperors and Imperial prinees from Jimmu downwards. This was the premier elass. The heads of all its families possessed as a birthright the title of omi (grandee), while the head of a Shimbetsu family was a muraji (group-chief). The Bambetsu ranked incomparably below either the $K$ wöbetsu or the Shimbetsu. It consisted of foreigners who had immigrated from China or Korea and of aboriginal tribes alien to the Yamato race. Members of the Ban elass were designated yakko (or yatsuko), a term signifying "subject" or "servant."

\section{THE UJI}

In adldition to the above three-elass distribution, the whole Yamato nation was divided into $u j i$, or families. An $u j i$ founded by one of the Tenson took precedence of all others, the next in rank being one with an Imperial prince for 
ancestor, and after the latter came the families of the Tenjin and Chigi. All that could not thus trace their genealogy were attached to the various $u j i$ in a subordinate capacity. It is not to be supposed that one of these families consisted simply of a husband and wife, children, and servants. There were great $u j i$ and small $u j i$, the former comprising many of the latter, and the small $u j i$ including several households. In fact, the small uji (ko-uji) may be described as a congeries of from fifty to ninety blood relations.

In the $u j i$ the principle of primogeniture was paramount. A successor to the headship of an $u j i$ must be the eldest son of an eldest son. Thus qualified, he became the master of the household, ruled the whole family, and controlled its entire property. The chief of an ordinary uji (uji no Kami) governed all the households constituting it, and the chief of a great uji ( $\bar{o}$-uji no Kami) controlled all the small $u j i$ of which it was composed. In addition to the members of a family, each uji, small and great alike, had a number of dependants (kakibe or tomobe). In colloquial language, an $\bar{o}-u \ddot{i} i$ was the original family; a $k o-u j i$, a branch family. For example, if the Abe family be considered, Abe-uji is a great $u j i(\bar{o}-u j i)$, while such names as Abe no Shii, Abe no Osada, Abe no Mutsu, etc. designate small $u j i(k o-u j i)$. If a great $u j i$ was threatened with extinction through lack of heir, the proper Kami of a small uji succeeded to the vacant place. As for the kakibe or tomobe, they were spoken of as "so and so of such and such an uji:" they had no uji of their own.

All complications of minor importance were dealt with by the Kami ${ }^{1}$ of the uji in which they occurred, consultation being held with the Kami of the appropriate $\tilde{o}-u j i$ in great cases. Reference was not made to the Imperial Court except in serious matters. On the other hand, commands from the sovereign were conveyed through the head of an $\bar{o}-u j i$, so that the chain of responsibility was well defined. An interesting feature of this ancient organization was that nearly every uji had a fixed occupation which was hereditary, the name of the occupation being prefixed to that of the $u j i$. Thus, the $u j i$ of gem-polishers was designated Tamatsukuri-uji, and that of boat builders, Fune-uji.

There were also $u j i$ whose members, from generation to generation, acted as governors of provinces (kuni no miyatsuko) or headmen of districts (agata-nushi). In these cases the name of the region was prefixed to the uji; as Munakata-uji, Izumo-uji, etc. Finally, there were uji that carried designations given by the sovereign in recognition of meritorious deeds.": These designations took the form of titles. Thus the captor of a crane, at sight of which a dumb prince recovered his speech, was called Totori no Miyatsuko (the bird-catching governor), and Nomi-no-Sukune, who devised the substitution of clay figures (haniwa) for human sacrifices at Imperial obsequies, was designated as Hashi no Omi (the Pottery Grandee).

\section{THE TOMOBE}

The tomobe (attendants) - called also mure (the herd) or kakibe (domestics) - constituted an important element of the people. They were, in fact, serfs. We find them first spoken of in an active rôle as being sent to the provinces to provide foodstuffs for the Imperial household, and in that capacity they went by the name of provincial Imibe. Perhaps the most intelligible description of them is that they constituted the peasant and artisan class, and that they were attached to the $u j i$ in subordinate positions for purposes of manual labour. By degrees, when various kinds of productive operations came to be engaged in as 
hereditary pursuits, the tomobe were grouped according to the specialty of the uji to which they were attached, and we hear of Kanuchibe, or the corporation of blacksmiths; Y umibe, or the eorporation of bow-makers; Oribe, or the corporation of wearers, and so on.

It is not to be supposed, however, that all the tomobe were thus organized as special classes. Such was the case only when the $u j i$ to which they belonged pursued some definite branch of productive work. Moreover, there were corporations instituted for purposes quite independent of industry; namely, to perpetuate the memory of an Imperial or princely personage who had died without issue or without attaining ancestral rank. Such tomobe were collectively known as nashiro (namesakes) or koshiro (child substitutes). For example, when Prince Itoshi, son of the Emperor Suinin, died without leaving a son to perpetuate his name, the Itoshibe was established for that purpose; and when Prince Yamato-dake perished without ascending the throne, the Takebe was formed to preserve the memory of his achievements. A be thus organized in behalf of an Emperor had the title of toneri (chamberlain) suffixed. Thus, for the Emperor Öhatsuse (known in history as Yūryaku) the Hatsuse-be-no-toneri was formed; and for the Emperor Shiraga (Seinei), the Shiraga-be-no-toneri. There can be little doubt that underlying the creation of these nashiro was the aim of extending the Imperial estates, as well as the number of subjects over whom the control of the Throne could be exercised without the intervention of an uji no Kami. For it is to be observed that the sovereign himself was an $\bar{o}$-uji no Kami, and all tomobe created for nashiro purposes or to discharge some other functions in comnexion with the Court were attached to the Imperial $u j i$.

\section{$T A M I B E$}

Another kind of be consisted of aliens who had been naturalized in Japan or presented to the Japanese Throne by foreign potentates. These were formed into tamibe (corporations of people). They became directly dependent upon the Court, and they devoted themselves to manufacturing articles for the use of the Imperial household. These naturalized persons were distinguished, in many eases, by technical skill or literary attainments. Hence they received treatment different from that given to ordinary tomobe, some of them being allowed to assume the title and enjoy the privilege of $u j i$, distinguished, however, as uji of the Bambetsu. Thus, the descendants of the seamstresses, E-hime and Oto-hime, and of the weavers, Kure-hatori and Ana-hatori, who were presented to the Yamato Court by an Emperor of the Wu dynasty in China, were allowed to organize themselves into Kinu-nui-uji (uji of Silk-robe makers); and that a Hata-uji (Weavers' $u j i$ ) was similarly organized is proved by a passage in the records of the Emperor Ojin (A.D. 284) which relates that the members of the Hata-uji had become scattered about the country and were carrying on their manufacturing work in various jurisdictions. This fact having been related to the Throne, steps were taken to bring together all these weavers into the Hata-uji, and to make them settle at villages to which the name of Kachibe was given in commemoration of the weavers' ancestor, Kachi. The records show that during the first four centuries of the Christian era the people presented to the Yamato Court by the sovereigns of the Wu dynasty and of Korea must have been very numerous, for no less than $710 u j i$ were formed by them in consideration of their skill in the arts and crafts. 


\section{SLAVES}

The institution of slavery (nuhi) existed in ancient Japan as in so many other countries. The slaves consisted of prisoners taken in war and of persons who, having committed some serious offence, were handed over to be the property of those that they had injured. The first recorded instance of the former practice was when Yamato-dake presented to the Ise shrine the Yemishi chiefs who had surrendered to him in the sequel of his invasion of the eastern provinces. The same fate seems to have befallen numerous captives made in the campaign against the Kumaso, and doubtless wholesale acts of self-destruction committed by Tsuchi-gumo and Kumaso when overtaken by defeat were prompted by preference of death to slavery. The story of Japan's relations with Korea includes many references to Korean prisoners who became the property of their captors, and that a victorious general's spoils should comprise some slaves may be described as a recognized custom. Of slavery as a consequence of crime there is also frequent mention, and it would appear that even men of rank might be overtaken by that fate, for when (A.D. 278) Takenouchi-no-Sukune's younger brother was convicted of slandering him, the culprit's punishment took the form of degradation and assignment to a life of slavery. The whole family of such an offender shared his fate. There is no evidence, however, that the treatment of the nuhi was inhuman or even harsh: they appear to have fared much as did the tomobe in general.

\section{THE LAND}

There are two kinds of territorial rights, and these, though now clearly differentiated, were more or less confounded in ancient Japan. One is the ruler's right - that is to say, competence to impose taxes; to enact rules governing possession; to appropriate private lands for public purposes, and to treat as crown estates land not privately owned. The second is the right of possession; namely, the right to occupy definite areas of land and to apply them to one's own ends. At present those two rights are distinct. A landowner has no competence to issue public orders with regard to it, and a lessee of land has to discharge certain responsibilities towards the lessor. It was not so in old Japan. As the Emperor's right to rule the people was not exercised over an individual direct but through the uji no Kami who controlled that individual, so the sovereign's right over the land was exercised through the territorial owner, who was usually the uji no Kami. The latter, being the owner of the land, leased a part of it to the members of the $u ̈ i$, collected a percentage of the produce, and presented a portion to the Court when occasion demanded. Hence, so long as the sovereign's influence was powerful, the $u j i$ no Kami and other territorial magnates, respecting his orders, refrained from levying taxes and duly paid their appointed contributions to the Court.

But in later times, when the Throne's means of enforcing its orders ceased to bear any sensible ratio to the puissance of the uji no Kami and other local lords, the Imperial authority received scanty recognition, and the tillers of the soil were required to pay heavy taxes to their landlords. It is a fallacy to suppose that the Emperor in ancient times not only ruled the land but also owned it. The only land held in direct possession by the Throne was that constituting the Imperial household's estates and that belonging to members of the Imperial family. The private lands of the Imperial family were called mi-agata. ${ }^{1}$. The 
province of Yamato contained six of these estates, and their produce was wholly devoted to the support of the Court. Lands cultivated for purposes of State revenue were called miyake. ${ }^{1}$ They existed in several provinees, the custom being that when land was newly acquired, a miyake was at once established and the remainder was assigned to princes or Court nobles (asomi or ason). The cultivators of miyake were designated ta-be (rustic corporation); the overseers were termed ta-zukasa (or mi-ta no tsukasa), and the officials in charge of the stores were mi-agata no obito.

As far back as 3 B.c., aecording to Japanese chronology, we read of the establishment of a miyake, and doubtless that was not the first. Thenceforth there are numerous examples of a similar measure. Confiseated lands also formed a not unimportant part of the Court's estates. Comparatively trifling offences were sometimes thus expiated. Thus, in A.D. 350, Aganoko, suzerain of the Sacgi, being convicted of purloining jewels from the person of a princess whom he had bcen ordered to execute, escaped capital punishment only by surrendering all his lands; and, in A.D. 534, a provincial ruler who, being in mortal terror, had intruded into the ladies' apartments in the palace, had to present his landed property for the use of the Empress. These facts show incidentally that the land of the country, though governed by the sovereign, was not owned by him. Lands in a conquered country were naturally regarded as State property, but sufficient allusion has already been made to that custom.

\section{THE SPHERE OF THE SOVEREIGN'S RULE}

It is related in the Records that, in prehistoric days, the last of the chieftains sent by Amaterasu to wrest Japan from its then holders addressed the leaders of the latter in these terms, "The central land of reed plains owned (ushi-haku) by you is the country to be governed (shirasu) by my son." Japanese historiographers attach importanee to the different words here used. Ushi-haku signifies "to hold in intimate lordship" - as one wears a garment - whereas shirasu means "to exercise public rights as head of a State." A Japanese Emperor occupied both positions towards mi-nashiro (q.v.), toward naturalized or conquered folks, towards mi-agata, miyake, and confiscated estates, but his functions with regard to the people and the land in general were limited to governing (shirasu).

If the ancient prerogatives of the sovereign be tabulated, they stand thus: (1) to conduct the worship of the national deities as general head of all the uji; (2) to declare war against forcign countries and to make peace with them, as representative of the $u j i$, and (3) to establish or abolish $u j i$, to nominate $u j i$ no Kami, and to adjudicate disputes between them. The first of these prerogatives remains unaltered to the present day. The second was partly delegated in medieval times to the military class, but has now been restored to the Throne. As for the third, its exercise is to-day limited to the office of the hereditary nobility, the Constitution having replaced the Crown in other respects.

Two thousand years have seen no change in the Emperor's function of officiating as the high priest of the nation. It was the sovereign who made offerings to the deities of heaven and earth at the great religious festivals. It was the sovereign who prayed for the aid of the gods when the country was

[' In ancient Japan, officials and their offices were often designated alike. Thus, miyake signified a public estate or the store for keeping the produce, just as tsukasa was applied alike to an overseer and to his place of transacting business.] 
confronted by any emergency or when the people suffered from pestilence. In short; though the powers of the Emperor over the land and the people were limited by the intervention of the uji, the whole nation was directly subservient to the Throne in matters relating to religion. From the earliest eras, too, war might not be declared without an Imperial rescript, and to the Emperor was reserved the duty of giving audience to foreign envoys and receiving tribute. By foreign countries, China and Korea were generally understood, but the Kumaso, the Yemishi, and the Sushen were also included in the category of aliens. It would seem that the obligation of serving the country in arms was universal, for in the reign of Sujin, when an oversea expedition was contemplated, the people were numbered according to their ages, and the routine of service was laid down. Contributions, too, had to be made, as is proved by the fact that a command of the same sovereign required the various districts to manufacture arms and store them in the shrines.

\section{THE THRONE AND THE $U J I$}

The sovereign's competence to adjudicate questions relating to the $u j i$ is illustrated by a notable incident referred to the year A.D. 415 , during the reign of Inkyō. Centuries had then passed since the inauguration of the $u j i$, and families originally small with clearly defined genealogies had multiplied to the dimensions of large clans, so that much confusion of lineage existed, and there was a wide-spread disposition to assert claims to spurious rank. It was therefore commanded by the Emperor that, on a fixed day, all the uji no Kami should assemble, and having performed the rite of purification, should submit to the ordeal of boiling water (kuga-dachi). Numerous cauldrons were erected for the purpose, and it was solemnly proclaimed that only the guilty would be scalded by the test. At the last moment, those whose claims were willingly false absconded, and the genealogics were finally rectified.

Instances of $u j i$ created by the sovereign to reward merit, or abolished to punish offences, are numerously recorded. Thus, when (A.D. 413) the future consort of the Emperor Inkyo was walking in the garden with her mother, a provincial ruler (miyatsuko), riding by, peremptorily called to her for a branch of orchid. She asked what he needed the orchid for and he answered, "To beat away mosquitoes when I travel mountain roads." "Oh, honourable sir, I shall not forget," said the lady. When she became Empress, she caused the nobleman to be sought for, and had him deprived of his rank in lieu of execution. There is also an instance of the killing of all the members of an $u j i$ to expiate the offence of the uji no Kami. This happened in A.D. 463, when Yūryaku sat on the throne. It was reported to the Court that Sakitsuya, Kami of the Shimotsumichi-uji, indulged in pastimes deliberately contrived to insult the occupant of the throne. Thus he would match a little girl to combat against a grown woman, calling the girl the Emperor and killing her if she won; or would set a little cock with clipped wings and plucked feathers to represent the sovereign in a fight with "a big, lusty cock, which he likened to himself, and if the small bird won, he would slaughter it with his own sword. The Emperor sent a company of soldiers, and Sakitsuya with all the seventy members of his $u j i$ were put to death.

The administrative organization in ancient Japan was simply a combination of the uji. It was purely Japanese. Not until the seventh century of the 
Christian era were any forcign elements introduced. From ministers and generals of the highest elass down to petty functionaries, all offices were discharged by uji no Kami, and as the latter had the general name of kabane- root of the uji-the system was similarly termed. In effect, the kabane was an order of nobility. Offices were hereditary and equal. The first distribution of posts took place when five chiefs, attached to the person of the Tenson at the time of his descent upon Japan, were ordered to discharge at his Court the same duties as those which had devolved on them in the country of their origin. The uji they formed were those of the Shimbetsu, ${ }^{1}$ the official title of the Kami being muraji (group chicf) in the case of an ordinary $u j i$, and $\bar{o}$-muraji (great muraji) in the case of an $\bar{o}-u j i$, as already stated. These were the men who rendered most assistance originally in the organization of the State, but as they were merely allherents of the Tenson, the latter's direct descendants counted themselves superior and sought always to assert that superiority.

Thus, the title omi (grandee) held by the Kami of a Kwōbetsu-uji was deemed higher than that of muraji (chief) held by the Kami of a Shimbetsu-uji. The blood relations of sovereigns either assisted at Court in the administration of State affairs or went to the provinces in the capacity of governors. They received various titles in addition to that of omi, for example sukune (noble), ason or asomi (Court noble), kimi (duke), wake (lord), etc.

History gives no evidence of a fixed official organization in ancient times. The method pursued by the sovereign was to summon such omi and muraji as were notably influential or competent, and to entrust to them the duty of discharging functions or dealing with a special situation. Those so summoned were termed mae-tsu-gimi (dukes of the Presence). The highest honour bestowed on a subject in those days fell to the noble, Takenouchi, who, in consideration of his services, was named $\bar{O}$-mae-tsu-gimi (great duke of the Presence) by the Emperor Seimu (A.D. 133). Among the omi and muraji, those conspicuously powerful were charged with the superintendence of several $u j i$, and were distinguished as $\bar{o}$-omi and $\bar{o}$-muraji. It became customary to appoint an $\bar{o}$-om $i$ and an $\bar{o}$-muraji at the Court, just as in later days there was a sa-daijin (minister of the Left) and an $u$-daijin (minister of the Right). The $\bar{o}$-omi supervised all members of the $K w \bar{o} b e t s u-u j i$ occupying administrative posts at Court, and the $\bar{o}$-muraji discharged a similar function in the case of members of Shimbetsu-uji. Outside the capital local affairs were administered by kuni-no-miyatsuko or tomo-no-miyatsuko. ${ }^{2}$ Among the former, the heads of $K w \bar{o} b e t s u$-uji predominated: among the latter, those of Shimbetsu-uji.

\section{VALUE OF LINEAGE}

It will be seen from the above that in old Japan lineage counted above everything, alike officially and socially. 'The offices, the honours and the lands were all in the hands of the lineal descendants of the original Yamato chiefs. : Nevertheless the omi and the muraji stood higher in national esteem than the kuni-nomiyatsuko or the tomo-no-miyatsuko; the $\bar{o}$-omi and the $\bar{o}$-muraji, still higher; and the sovereign, at the apex of all. That much deference was paid to functions, Things remained unaltered in this respect until the sixth century when the force of foreign example began to make itself felt.

['The distinction of Shimbetsu and Kwöbetsu was not nominally recognized until the fourth century, but it undoubtedly existed in practice at an early date.]

[2 Tomo is an abbreviation of tomo-be.] 


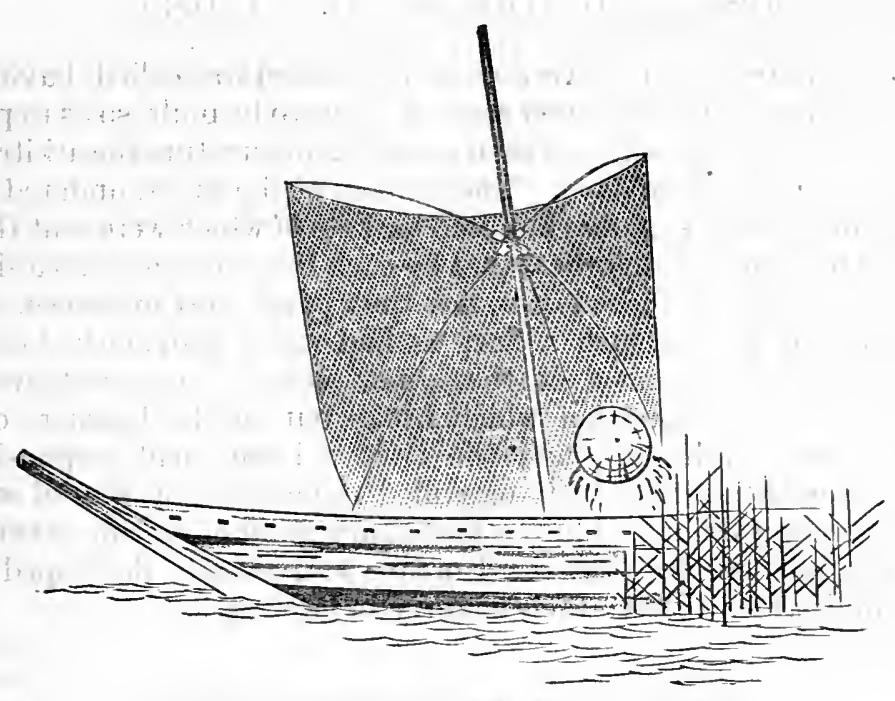

Fisherman's Boat and Net

\section{CHAPTER XI}

\section{THE PREHISTORIC SOVEREIGNS (Continued)}

\section{THE FIFTEENTH SOVEREIGN, ŌJIN (A. D. 270-310)}

The fifteenth Sovereign, Ojin, came to the throne at the age of seventy, according to the Chronicles, and occupied it for forty years. Like a majority of the sovereigns in that epoch he had many consorts and many children three of the former (including two younger sisters of the Emperor) and twenty of the latter. Comparison with Korean history goes to indicate that the reign is antedated by just 120 years, or two of the sexagenary cycles, but of course such a correction cannot be applied to every incident of the era.

\section{MARITIME AFFAIRS}

One of the interesting features of Ōjin's reign is that maritime affairs receive notice for the first time. It is stated that the fishermen of various places raised a commotion, refused to obey the Imperial. commands, and were not quieted until a noble, Ohama; was sent to deal with them. Nothing is stated as to the cause of this complication, but it is doubtless connected with requisitions of fish for the Court, and probably the fishing folk of Japan had already developed the fine physique and stalwart disposition that distinguish their modern representatives. Two years later, instructions were issued that hereditary corporations (be) of fishermen should be established in the provinces, and, shortly afterwards, the duty of constructing a boat one hundred feet in length was imposed upon the people of Izu, a peninsular province so remote from Yamato that its choice for such a purpose is difficult to explain. There was no question of recompensing the builders of this boat: the product of their labour was regarded as "tribute." 
Twenty-six years later the Karano, as this vessel was called, having become unserviceable, the Emperor ordered a new Karano to be built, so as to perpetuate her name. A curious procedure is then recorded, illustrating the arbitrary methods of government in those days. The timbers of the superannuated ship were used as fuel for roasting salt, five hundred baskets of which were sent throughout the maritime provinces, with orders that by each body of recipients a ship should be constructed. Five hundred Karanos thus came into existence, and there was assembled at Hyōgo such a fleet as had never previously been seen in Japanese waters. A number of these new vessels were destroyed almost immediately by a conflagration which broke out in the lodgings of Korean envoys from Sinra (Shiragi), and the envoys being held responsible, their sovereign hastened to send a body of skilled shipmakers by way of atonement, who were thereafter organized into a hereditary guild of marine architects, and we thus learn incidentally that the Koreans had already developed the shipbuilding skill destined to save their country in later ages.

\section{IDEALISM OF THE THIRD CENTURY}

In connexion with the Karano incident, Japanese historians record a tale which materially helps our appreciation of the men of that remote age. A portion of the Karano's timber having emerged unscathed from the salt-pans, its indestructibility seemed curious enough to warrant special treatment. It was accordingly made into a lute (koto), ${ }^{1}$ and it justified that use by developing "a ringing note that could be heard from afar off." The Emperor eomposed a song on the subject: -

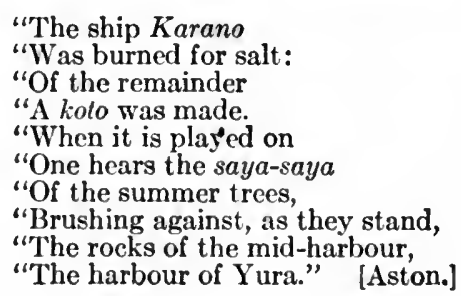

\section{LAW, INDUSTRY, LOYALTY}

Five facts are alrcady deducible from the annals of this epoch: the first, that there was no written law, unless the prohibitions in the Rituals may be so regarded; the second, that there was no form of judicial trial, unless ordeal or torture may be so regarded; the third, that the death penalty might be inflicted on purely ex-parte evidence; the fourth, that a man's whole family had to suffer the penalty of his crimes, and the fifth, that already in those remote times the code of splendid loyalty which has distinguished the Japanese race through all ages had begun to find disciples.

An incident of Ōjin's reign illustrates all these things. Takenouchi, the sukune (noble) who had served Ōjin's mother so ably, and who had saved Ōjin's life in the latter's childhood, was despatched to Tsukushi (Kyūshū) on State business. During his absence his younger brother accused him of designs upon the Emperor. At once, without further inquiry, Ōjin sent men to kill the illustri-

['The Japanese lute, otherwise called the Azuma koto, was an instrument five or six feet long and having six strings. History first alludes to it in the reign of Jingō, and such as it was then, such it has remained until to-day.] 
ous minister. But Maneko, suzerain (atae) of Iki, who bore a strong resemblance to Takenouchi, personified him, and committing suicide, deceived the soldiers who would have taken the sukune's life, so that the latter was enabled to return to Yamato. Arriving at Court, he protested his innocence and the ordeal of boiling water was employed. It took place on the bank of the Shiki River. Takenouchi proving victorious; his brother with all his family were condemned to become tomo-be of the suzerain of Kii.

\section{THE GRACE OF LIFE}

Side by side with these primitive conditions stands a romantic story of Ōjin's self-denial in ceding to his son, Ōsazaki, a beautiful girl whom the sovereign has destined to be his own consort. Discovering that the prince loved her, Öjin invited him to a banquet in the palace, and, summoning the girl, made known by the aid of poetry his intention of surrendering her to his son, who, in turn, expressed his gratitude in verse. It is true that the character of this act of renunciation is marred when we observe that Ojjin was eighty years old at the time; nevertheless the graces of life were evidently not wanting in old-time Japan, nor did her historians deem them unworthy of prominent place in their pages. If at one moment they tell us of slanders and cruelty, at another they describe how a favourite consort of Ōjin, gazing with him at a fair landscape from a high tower, was moved to tears by the memory of her parents whom she had not seen for years, and how the Emperor, sympathizing with her filial affection, made provision for her return home and took leave of her in verse:-

\footnotetext{
"Thou Island of Awaji

"With thy double ranges;

"Thou Island of Azuki

"With thy double ranges-

"Ye good islands,

"Ye have seen face to face

"My spouse of Kibi."
}

\section{FOREIGN INTERCOURSE}

The most important feature of the Ōjin era was the intercourse then inaugurated with China. It may be that after the establishment of the Yamato race in Japan, emigrants from the neighbouring continent settled, from early times, in islands so favoured by nature. If so, they probably belonged to the lowest orders, for it was not until the third and fourth centuries that men of erudition and skilled artisans began to arrive. Modern Japanese historians seem disposed to attribute this movement to the benign administration of the Emperor Ōjin and to the repute thus earned by Japan abroad. Without altogether questioning that theory, it may be pointed out that much probably depended on the conditions existing in China herself. Liu Fang, founder of the Han dynasty (202 B.c.), inaugurated the system of competitive examinations for civil appointments, and his successors, Wen-Ti, Wu-Ti, and Kwang-wu, "developed literature, commerce, arts, and good government to a degree unknown before anywhere in Asia." It was Wu-Ti (140-86 в.c.) who conquered Korea, and unquestionably the Koreans then received many object lessons in civilization. The Han dynasty fell in A.D. 190, and there ensued one of the most troubled periods of Chinese history. Many fugitives from the evils of that epoch probably made their way to Korea and even to Japan. Then followed 
the after-Han dynasty (A.D. 211-265) when China was divided into three principalities; one of which, since it ruled the littoral regions directly opposite to Japan, represented China in Japanese eyes, and its name, Wu, came to be synonymous with China in Japanese years.

It was, however, in the days of the T'sin dynasty (A.D. 265-317) and in those of the Eastern T'sin (A.D. 317-420) that under the pressure of the Hur inroads and of domestic commotions, numbers of emigrants found their way from China to Korea and thence to Japan. The Eastern Tsin occupied virtually the same regions as those held by the $W u$ dynasty: they, too, had their capital at Nanking, having moved thither from Loh-yang, and thus the name Wu was perpetuated for the Japanese. In the year A.D. 283, according to Japanese chronology, Koreans and Chinese skilled in useful arts began to immigrate to Japan. The first to come was a girl called Maketsu. She is said to have been sent by the monarch of Kudara, the region corresponding to the metropolitan province of modern Korea. It may be inferred that she was Chinese, but as to her nationality history is silent. She settled permanently in Japan, and her descendants were known as the kinu-nui (silk-clothiers) of Kume in Yamato. In the same year (A.D. 283), Yūzu (called Yutsuki by some authorities), a Chinese Imperial prince, came from Korea and memorialized the Yamato Throne in the sense that he was a descendant of the first Tsin sovereign and that, having migrated to Korea at the head of the inhabitants of 120 districts, he had desired to conduct them to Japan, but was unable to accomplish his purpose owing to obstruction offered by the people of Sinra (Shiragi). Ojjin sent two embassies - the second accompanied by troops - to procure the release of these people, and in A.D. 285 they reached Japan, where they received a hearty welcome, and for the sake of their skill in sericulture and silk weaving, they were honoured by organization into an $u j i$ - Hata-uji (hata in modern Japanese signifies "loom," but in ancient days it designated silk fabries of all kinds).

An idca of the dimensions of this Chinese addition to the population of Japan is furnished by the fact that, 175 years later, the Hata-uji having been dispersed and reduced to ninety-two groups, steps were taken to reassemble and reorganize them, with the result that 18,670 persons were brought together. Again, in A.D. 289, a sometime subjeet of the after-Han dynasty, accompanied by his son, emigrated to Japan. The names of these Chinese are given as Achi anr T'suka, and the former is described as a great-grandson of the Emperor ling of the aftor-Han dynasty, who reigned from A.D. 168 to 190. Like Yüu he had escaped to Korea during the troublous time at the close of the Han sway, and, like Y uzu, he had been followed to the peninsula by a large body of Chinese; who, at his request, were subsequently escorted by Japanese envoys to Japan. These inmigrants also were allowed to assume the status of an $u j i$, and in the fifth century the title of $A$ ya no atae (suzerain of Aya) was given to Achi's descendants in consideration of the skill of their followers in designing and manufacturing figured fabrics (for which the general term was aya).

When Achi had resided seventeen years in Japan, he and his son were sent to $\mathrm{Wu}$ (China) for the purpose of engaging women versed in making dress materials. The title of omi (chief ambassador) seems to have been then conferred on the two men, as envoys sent abroad were habitually so designated. They did not attempt to go by sea. The state of navigation was still such that ocean-going voyages were not seriously thought of. Achi and his son proceeded in the first instance to Koma (the modern Pyong-yang) and there obtained guides for the overland journey round the shore of the Gulf of Pechili. They 
are said to have made their way to Loh-yang where the Tsin sovereigns then had their capital (A.D. 306). Four women were given to them, whom they carried back to Japan, there to become the ancestresses of an uji known as Kure no kinu-nui and Kaya no kinu-nui. (clothiers of Kure and of Kaya), appellations which imply Korean origin, but were probably suggested by the fact that Korea had been the last continental station on their route. The journey to and from Loh-yang occupied four years. This page of history shows not only the beginning of Japan's useful intercourse with foreign countries, but also her readiness to learn what they had to teach and her liberal treatment of alien settlers.

\section{THE ART OF WRITING}

It is not infrequently stated that a knowledge of Chinese ideographs was acquired by the Japanese for the first time during the reign of Ōjin. The bases of this belief are that, in A.D. 284, according to the Japanese chronology - a date to which must be added two sexagenary cycles, bringing it to A.D. $404-$ the King of Kudara sent two fine horses to the Yamato sovereign, and the man who accompanied them, Atogi by name, showed himself a competent reader of the Chinese classics and was appointed tutor to the Prince Imperial. By Atogi's advice a still abler scholar, Wani (Wang-in), was subsequently invited from Kudara to take Atogi's place, and it is added that the latter received the title of fumi-bito (scribe), which he transmitted to his descendants in Japan. But close scrutiny does not support the inference that Chinese script had remained unknown to Japan until the above incidents. What is proved is merely that the Chinese classics then for the first time became an open book in Japan.

As for the ideographs themselves, they must have been long familiar, though doubtless to a very limited circle. Chinese history affords conclusive evidence. Thus, in the records of the later Han (A.D. 25-220) we read that from the time when Wu-Ti (140-86 в.c.) overthrew Korea, the Japanese of thirty-two provinces communicated with the Chinese authorities in the peninsula by means of a postal service. The Wei annals (A.D. 220-265) state that in A.D. 238, the Chincse sovereign sent a written reply to a communication from the "Queen of Japan" - Jingō was then on the throne. In the same year, the Japanese Court addressed a written answer to a Chinese rescript forwarded to Yamato by the governor of Thepang - the modern Namwön in Chöllado - and in A.D. 247, a despatch was sent by the Chinese authorities admonishing the Japanese to desist from internecine quarrels. These references indicate that the use of the ideographs was known in Japan long before the reign of Ojjin, whether we take the Japanese or the corrected date for the latter. It will probably be just to assume, however, that the study of the ideographs had scarcely any vogue in Japan until the coming of Atogi and Wani, nor does it appear to have attracted much attention outside Court circles even subsequently to that date, for the records show that, in the reign of the Emperor Bidatsu (A.D. 572-585), a memorial sent by Korea to the Yamato Court was illegible to all the officials except one man, by name Wang-sin- $i$; who seems to have been a descendant of the Paikche emigrant, Wan-i.

Buddhism, introduced into Japan in A.D. 552, doubtless supplied the chief incentive to the acquisition of knowledge. But had the Japanese a script of their own at any period of their history? The two oldest manuscripts which contain a reference to this subject are the Kogo-shüi, compiled by Hironari in A.D. 808, and a memorial (kammon) presented to the Throne in A.D. 801 by 
Miyoshi Kiyotsura. Both explicitly state that in remote antiquity there were no letters, and that all events or discourses had to be transmitted orally. Not until the thirteenth century does the theory of a purely Japanese script seem to have been conceived, and its author ${ }^{1}$ had no basis for the hypothesis other than the idea that, as divination was practised in the age of the Kami, letters of some kind must have been in use. Since then the matter has been much discussed. Caves used in ancient times as habitations or sepulchres and old shrines occasionally offer evidence in the form of symbols which, since they bear some resemblance to the letters of the Korean alphabet (onmun), have been imagined to be at once the origin of the latter and the script of the Kami-no-yo (Age of the Kami). But such fancies are no longer seriously entertained. It is agreed that the socalled "letters" are nothing more than copies of marks produced by the action of fire upon bones used in divination. The Japanese cleverly adapted the Chinese ideographs to syllabic purposes, but they never devised a script of their own.

\section{ETHICAL EFFECTS OF THE INTRODUCTION OF CHINESE LITERATURE}

A generally accepted belief is that the study of the Chinese classics exercised a marked ethical influence upon the Japanese nation. That is a conclusion which may be profitably contrasted with the views of Japan's most distinguished histcrians. Mr. Abe Kōzō says: "Acquaintance with the Chinese classics may be supposed to have produced a considerable moral effect on the people of Japan. Nothing of the kind seems to have been the case. The practical civilization of China was accepted, but not her ethical code. For any, palpable moral influence the arrival of Buddhism had to be awaited. Already the principles of loyalty and obedience, propriety, and righteousness were recognized in Japan though not embodied in any written code." Dr. Ariga writes: "Our countrymen did not acquire anything specially new in the way of moral tenets. They must have been surprised to find that in China men did not respect the occupants of the throne. A subject might murder his sovereign and succeed him without incurring the odium of the people." Rai Sanyō says: "Moral principles are like the sun and the moon; they cannot be monopolized by any one country. In every land there are parents and children, rulers and ruled, husbands and wives. Where these relations exist, there also filial piety and affection, loyalty and righteousness may naturally be found. In our country we lack the precise terminology of the classics, but it does not follow that we lack the principles expressed. What the Japanese acquired from the classics was the method of formulating the thought, not the thought itself."

\section{THE SIXTEENTH SOVEREIGN, NINTOKU (A.D. 313-399)}

This sovereign is represented by the Chronicles as having reigned eighty-six years, and by the Records as having died at the age of eighty-three. The, same Chronicles make him the lover of a girl whom his father, also her lover, generously ceded to him. This event happened in A.D. 282. Assuming that Nintoku was then sixteen, he eannot have been less than 133 at the time of his death. It is thus scen that the chronology of this period, also, is untrustworthy. Nintoku's reign is remembered chiefly on account of the strange circumstances in which be came to the throne, his benevolent charity, and the slights he suffered at the 
hands of a jealous consort. His father, Ōjin, by an exercise of caprice not uncommon on the part of Japan's ancient sovereigns, had nominated a younger son, Waka-iratsuko, to be his heir. But this prince showed invincible reluctance to assume the sceptre after Ōjin's death. He asserted himself stoutly by killing one of his elder brothers who conspired against him, though he resolutely declined to take precedence of the other brother, and the latter, proving equally diffident, the throne remained unoccupied for three years when Waka-iratsuko solved the problem by committing suicide.

Such are the simplest outlines of the story. But its details, when filled in by critical Japanese historians of later ages, suggest a different impression. When Ōjin died his eldest two sons were living respectively in Naniwa (Ōsaka) and Yamato, and the Crown Prince, Waka-iratsuko, was at Uji. They were thus excellently situated for setting up independent claims. From the time of Nintoku's birth, the prime minister, head of the great Takenouchi family, had taken a special interest in the child, and when the lad grew up he married this Takenouchi's granddaughter, who became the mother of three Emperors. Presently the representatives of all branches of the Takenouchi family came into possession of influential positions at Court, among others that of $\bar{o}$-omi, so that in this reign were laid the foundations of the controlling power subsequently vested in the hands of the Heguri, Katsuragi, and Soga houses. In short, this epoch saw the beginning of a state of affairs destined to leave its mark permanently' on Japanese history, the relegation of the sovereign to the place of a fainéant and the usurpation of the administrative authority by a group of great nobles.

Nintoku had the active support of the Takenouchi magnates, and although the Crown Prince may have desired to assert the title conferred on him by his father, he found himself helpless in the face of obstructions offered by the prime minister and his numerous partisans. These suffered him to deal effectively with that one of his elder brothers who did not find a place in their ambitious designs, but they created for Waka-iratsuko a situation so intolerable that suicide became his only resource. Nintoku's first act on ascending the throne explains the ideographs chosen for his posthumous name by the authors of the Chronicles, since nin signifies "benevolence" and toku, "virtue." He made Naniwa (Ōsaka) his capital, but instead of levying taxes and requisitioning forced labour to build his palace of Takatsu, he remitted all such burdens for three years on observing from a tower that no smoke ascended from the roofs of the houses and construing this to indicate a state of poverty. During those three years the palace fell into a condition of practical ruin, and tradition describes its inmates as being compelled to move from room to room to avoid the leaking rain. ${ }^{1}$

Under Nintoku's sway riparian works and irrigation improvements took place on a large scale, and thus the eminent historian, Rai Sanyō, may not be without warrant for attributing to this ruler the sentiment quoted in the Chronicles: "A sovereign lives for his people. Their prosperity is his enrichment; their poverty, his loss." Yet it is in connexion with Nintoku's repairs of the Manda river-bank that we find the first mention of a heinous custom occasionally practised in subsequent ages - the custom of sacrificing human life to expedite the progress or secure the success of some public work.

At the same time, that habits indicating a higher civilization had already

${ }^{1}$ Doubts have been thrown on the reality of this incident because a poem, attributed to Nintoku on the occasion, is couched in obviously anachronistic language. But the poem does not appear in either the Records or the Chronicles: it was evidently an invention of later ages.] 
begun to gain ground is proved by an incident which oceurred to one of the Imperial princes during a hunting expedition. Looking down over a moor from a mountain, he observed a pit, and, on inquiry, was informed by the local headman that it was an "ice-pit." The prince, asking how the ice was stored and for what it was used, received this answer: "The ground is exeavated to a depth of over ten feet. 'The top is then covered with a roof of thatch. A thick layer of reed-grass is then spread, upon which the ice is laid. The months of summer have passed and yet it is not melted. As to its use - when the hot months come it is placed in water or sake and thus used." [Aston's Nihongi.] Thenceforth the eustom of storing ice was adopted at the Court. It was in Nintoku's era that the pastime of hawking, afterward widely practised, became known for the first time in Japan. Korea was the place of origin, and it is recorded that the falcon had a soft leather strap fastened to one leg and a small bell to the tail. Pheasants were the quarry of the first hawk flown on the moor of Mozu.

Light is also thrown in Nintoku's annals on the method of boatbuilding practised by the Japanese in the fourth century. They used dug-outs. The provincial governor ${ }^{2}$ of Tōtomi is represented as reporting that a huge tree had floated down the river $\vec{O} \mathrm{i}$ and had stopped at a bend. ' It was a single stem forked at one end, and the suzerain of Yamato was ordered to make a boat of it. The craft was then brought round by sea to -Naniwa, "where it was enrolled among the Imperial vessels." Evidently from the days of Ojjin and the Karano a fleet formed part of the Imperial possessions. This two-forked boat figures in the reign of Nintoku's successor, Richū, when the latter and his concubine went on board and feasted separately, each in one fork.

\section{THE FAMILY OF TAKENOUCHI-NO-SUKUNE}

For the better understanding of Japanese history at this stage, a word must be said about a family of nobles (sukune) who, from the days of Nintoku, exereised potent sway in the councils of State. It will have been observed that, in the annals of the Emperor Keikō's reign, prominenee is given to an official designated Takenouchi-no-Sukune, who thereafter seems to have served sovereign after sovereign until his death in the year 368 , when he must have been from two hundred to three hundred years old. This chronological diffieulty has provoked much scepticism. Dr. Kume, an eminent Japanese historian, explains, however, that Takenouehi was the name not of a person but of a family, and that it was borne by different scions in suceeeding reigns. The first was a grandson of the Emperor Kogen (в.c. 214-158), and the representatives of the family in Nintoku's era had seven sons, all possessing the title sukune. They were Hata no Yashiro, Koze no Ogara, Soga no Ishikawa, Heguri no Tsuku, Ki no' Tsunu, Katsuragi no Sotsu, and Wakugo.

From these were deseended the five $u \dddot{i} i$ of Koze, Soga, Heguri, Ki, and Katsuragi. Although its founder was an Emperor's grandson and therefore entitled to be called "Imperial Prince" $(\bar{O})$, the family connexion" with the Throne naturally beeame more remote as time passed, and from the reign of Ojin we find its members classed among subjects. Nevertheless, the Empress

[" This term, "provincial governor," appears now for the first time written with the ideographs "kokushi." Hitherto it has been written "kuni-no-miyatsuko." Mueh is heard of the kokushi in later times. They are the embryo of the daimyō, the central figures of military feudal-
ism.] 
Iwa, whose jealousy harrassed Nintoku so greatly, was a daughter of Katsuragi no Sotsu, and, as with the sole exception of the Emperor Shōmu, every occupant of the throne had taken for his Empress a lady of Imperial blood, it may be assumed that the relationship between the Imperial and the Takenouchi families was recognized at that time. The rôles which the five uji mentioned above acted in subsequent history deserve to be studied, and will therefore be briefly set down here.

\section{THE KOZE-UJI}

This $u j i$ had for founder Koze no Ogara. The representative of the fourth generation, Koze no Ohito, held the post of $\bar{o}$-omi during the reign of the Emperor Keitai (A.D. 507-531), and his great-grandson was minister of the Left under Kotoku (A.D. 545-654). Thereafter, the heads of the uji occupied prominent positions under successive sovereigns.

\section{THE SOGA-UJI}

Soga no Ishikawa founded this $u j i$. His son, Machi, shared the administrative power with Heguri no Tsuku in the reign of Richū (A.D. 400-405), and Machi's great-grandson, -Iname, immortalized himself by promoting the introduction of Buddhism in the reign of Kimmei (A.D. 540-571). Iname's son, Umako, and the latter's son, Yemishi, will be much heard of hereafter. No family, indeed, affected the course of Japanese history in early days more than did the Soga-uji.

\section{THE HEGURI-UJI}

During the reign of the Emperor Richū (A.D. 400-405), Hegúri no Tsuku, founder of this uji, shared in the administration with Soga no Machi. His son, Heguri no Matori, was minister under Yūryaku (A.D. 457-459), and the fate which he and his son, Shibi, brought upon their family is one of the salient incidents of Japanese history.

\section{THE KI-UJI}

The representatives of this $u j i$, from the days of its founder, Ki no Tsunu, took a prominent share in the empire's foreign affairs, but served also in the capacity of provincial governor and commander-in-chief.

\section{THE KATSURAGI-UJI}

Nintoku's Empress, Iwa, was a daughter of the ancestor of this uji, Katsuragi no Sotsu, and the latter's great-granddaughter, Hae, was the mother of two sovereigns, Kensō (A.D. 485-487) and Ninken (A.D. 488-498).

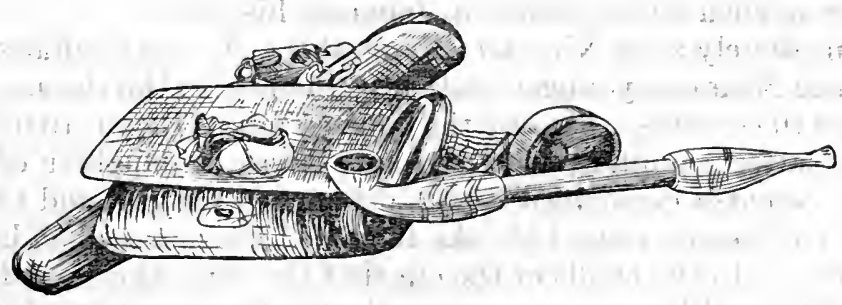




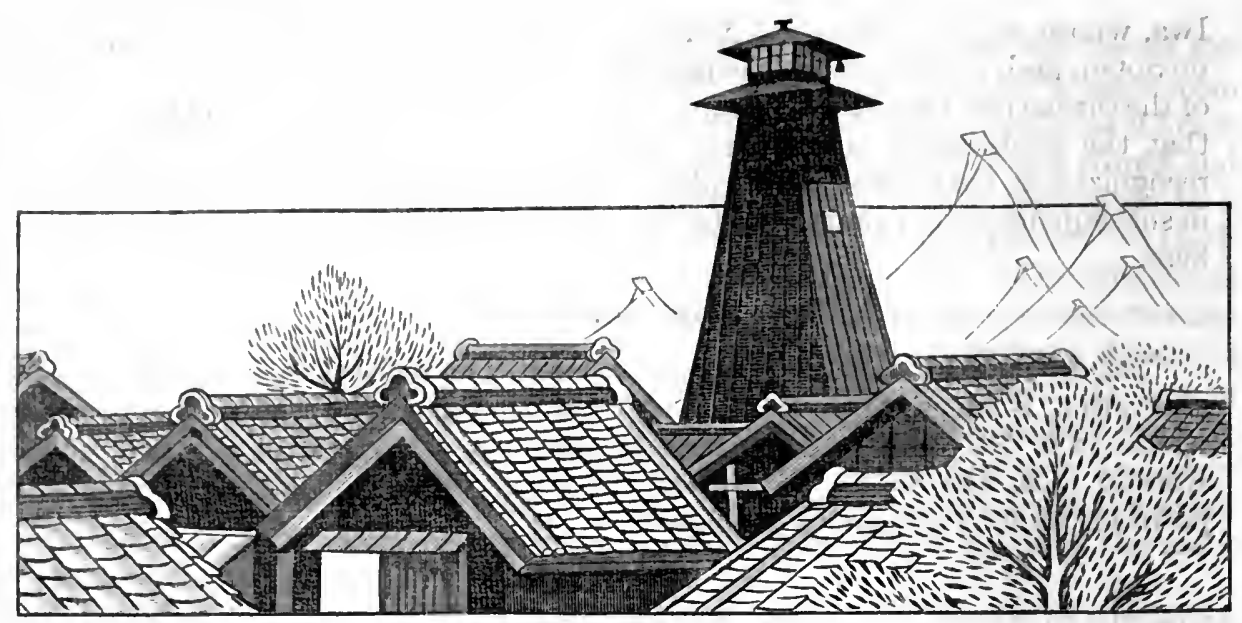

Hinomi Yagura (Fire Watch Tower)

\section{CHAPTER XII}

\section{THE PROTOHISTORIC SOVEREIGNS}

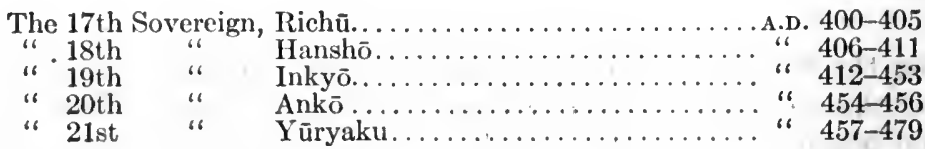

\section{RICHŪ'S REIGN}

THE prehistoric era may be said to terminate with the accession of Richū. Theneeforth the lives and reigns of successive sovereigns cease to extend to incredible lengths, and though the chronology adopted by the writers of the Nihongi may not yet be implicitly accepted, its general accuracy is not open to dispute. The era of the five sovereigns standing at the head of this ehapteran era of fifty-nine years - inherited as legacies from the immediate past a wellfurnished treasury, a nation in the enjoyment of peace, a firmly established throne, and a satisfactory state of foreign relations. These comfortable conditions seem to have exereised demoralizing influenee. The bonds of discipline grew slack; fieree quarrels on account of women involved fratricide among the princes of the blood, and finally the life of an Emperor was sacrificed - the only instance of such a catastrophe in Japanese history.

Immediately after Nintoku's death this evil state of affairs was inaugurated by Prince Nakatsu, younger brother of the heir to the throne, who had not yet assumed the sceptre. Sent by the Crown Prince (Richū) to make arrangements for the latter's nuptials with the lady Kuro, a daughter of the Takenouchi family, Nakatsu personified Richũ, debauched the girl, and to avoid the consequenees of the act, sought to take the life of the man he had betrayed. It does not reclound to the eredit of the era that the debaucher found support and was enabled to hold his own for a time, though his treachery ultimately met with 
its merited fate. At this crisis of his life, Richū received loyal assistance from a younger brother, and his gratitude induced him to confer on the latter the title of Crown Prince. In thus acting, Richū may have been influenced by the fact that the alternative was to bequeath the throne to a baby, but none the less he stands responsible for an innovation which greatly impaired the stability of the succession. It should be noted, as illustrating the influence of the Takenouchi family that, in spite of the shame she had suffered, the lady Kuro became the Emperor's concubine. In fact, among the four nobles who administered the affairs of the empire during Richū's-reign, not the least powerful were Heguri no Tsuku and Soga no Machi. Moreover, Richū, as has been stated already, was a son of Iwa, a lady of the same great family, and his two successors, Hanshō and Inkyō, were his brothers by the same mother.

\section{MANNERS AND CUSTOMS}

The annals of Richū's reign confirm a principle which received its first illustration when the Emperor Keikō put to death for parricide the daughter of a Kumaso chief, though she had betrayed her father in the interest of Keiko himself. Similar deference to the spirit of loyalty led to the execution of Sashihire in the time of Richū. A retainer of the rebellious Prince Nakatsu, Sashihire, assassinated that prince at the instance of Prince Mizuha, who promised large reward. But after the deed had been accomplished, Heguri no Tsuku advised his nephew, Mizuha, saying, "Sashihire has killed his own lord for the sake of another, and although for us he has done a great service, yet towards his own lord his conduct has been heartless in the extreme." Sashihire was therefore put to death. That this principle was always observed in Japan cannot be asserted, but that it was always respected is certain.

In Richū's reign there is found the first clear proof that tattooing was not practised in Japan for ornamental purposes. . Tattooing is first mentioned as a custom of the Yemishi when their country was inspected by. Takenouchi at Keikō's orders. But in Richū's time it was employed to punish the muraji of Atsumi, who had joined the rebellion of Prince Nakatsu. He was "inked" on the face. It appears also that the same practice had hitherto been employed to distinguish horse-keepers, but the custom was finally abandoned in deference to an alleged revelation from Izanagi, the deity of Awaji, on the occasion of a visit by Richū to that island. In the context of this revelation it is noticeable that belief in the malign influence of offended deities was gaining ground. Thus, on the occasion of the sudden death of Princess Kuro, the voice of the wind was heard to utter mysterious words in the "great void" immediately before the coming of a messenger to announce the event, and the Emperor attributed the calamity to the misconduct of an official who had removed certain persons from serving at a shrine.

The annals of this reign are noteworthy as containing the earliest reference to the compilation of books. It is stated that in the year A.D. 403 "local recorders were appointed for the first time in the various provinces, who noted down statements and communicated the writings of the four quarters." An eminent critic - Mr. W. G. Aston - regards this as an anachronism, since the coming of the Korean scholar, Wani (vide sup.), did not take place until the year 405 , which date probably preceded by many years the appointment of recorders. But it has been shown above that the innovation due to Wani was, not the art of writing, but, in all probability, a knowledge of the Chinese classics. 
Another institution established during this tra was a treasury (A.D. 405), and the two learned Koreans who had come from Paikche (Kudara) were appointed to keep the accounts. A work of later date than the Chronicles or Records - the Shokuin-rei - says that in this treasury were stored "gold and silver, jewels, precious utensils, brocade and satin, sar cenet, rugs and mattresses, and the rare objects sent as tribute by the various barbarians."

\section{HANSHŌ}

The Emperor Hanshō's short reign of five years is not remarkable for anything except an indirect evidence that Chinese customs were beginning to be adopted at the Japanese Court. In the earliest eras, the ladies who enjoyed the sovereign's favour were classed simply as "Empress" or "consort." But from the days of Hanshō we find three ranks of concubines.

\section{INKYŌ}

Inkyō was a younger brother of his predecessor, Hanshō, as the latter had been of Richū. No formal nomination of Inkyō as Prince Imperial had taken place, and thus for the first time the sceptre was found without any legalized heir or any son of the deceased sovereign to take it. In these circumstances, the ministers held a council and agreed to offer the throne to Inkyō, the elder of two surviving sons of Nintoku. Inkyō was suffering from a disease supposed to be incurable, and, distrusting his own competence, he persistently refused to accept the responsibility. The incident responsible for his ultimate consent was the intervention of a concubine, Ōnakatsu, afterwards Empress. Under pretext of carrying water for the prince she entered his chamber, and when he turned his back on her entreaty that he would comply with the ministers' desire, she remained standing in the bitter cold of a stormy day of January, until the water, which she had spilled over her arm, became frozen and she fell in a faint. Then the prince yielded. A year later envoys were sent to seek medical assistance in Korea, which was evidently regarded as the home of the healing science as well as of many other arts borrowed from China. A physician arrived from Sinra, and Inkyō's malady was cured.

In this reign took place a celebrated incident, already referred to, when the lineage of the nobles was corrected by recourse to the ordeal of boiling water. But a much larger space in the annals is occupied with the story of an affair, important only as illustrating the manners and customs of the time. From an early period it had been usual that Japanese ladies on festive occasions should go through the graceful performance of "woven paces and waving hands," which constituted dancing, and, in the era now occupying our attention, there prevailed in the highest circles a custom that the danscuse should offer a maiden to the most honoured among the guests. One winter's day, at the opening of a new palace, the Empress Onakatsu danced to the music of the Emperor's lute. Onakatsu had a younger sister, Oto, of extraordinary beauty, and the Emperor, fain to possess the girl but fearful of offending the Empress, had planned this dance so that Ōnakatsu, in compliance with the recognized usage, might be constrained to place her sister at his disposal. It fell out as Inkyō wished, but there then ensued a chapter of incidents in which the dignity of the Crown fared ill. Again and again the beautiful Oto refused to obey her sovereign's summons, and when at length, by an unworthy ruse, she was induced to repair 
to the palace, it was found impossible to make her an inmate of it in defiance of the Empress' jealousy. She had to be housed elsewhere, and still the Imperial lover was baffled, for he dared not brave the elder sister's resentment by visiting the younger. Finally he took advantage of the Empress' confinement to pay the long-deferred visit, but, on learning of the event, the outraged wife set fire to the parturition house and attempted to commit suicide. "Many years have passed," she is recorded to have said to the Emperor, "since I first bound up my hair and became thy companion in the inner palace. It is too cruel of thee, $\mathrm{O}$ Emperor! Wherefore just on this night when I am in childbirth and hanging between life and death, must thou go to Fujiwara?" Inkyō had the grace to be "greatly shocked" and to "soothe the mind of the Empress with explanations," but he did not mend his infidelity. At Oto's request he built a residence for her at Chinu in the neighbouring province of Kawachi, and thereafter the compilers of the Chronicles, with fine irony, confine their record of three consecutive years': events to a repetition of the single phrase, "the Emperor made a progress to Chinu."

It is not, perhaps, extravagant to surmise that the publicity attending this sovereign's amours and the atmosphere of loose morality thus created were in part responsible for a crime committed by his elder son, the Crown Prince Karu. Marriage-between children of the same father had always been permitted in Japan provided the mother was different, but marriage between children of the same mother was incest. Prince Karu was guilty of this offence with his sister, Oiratsume, and so severely did the nation judge him that he was driven into exile and finally obliged to commit suicide. With such records is the reign of Inkyō associated. It is perplexing that the posthumous name chosen for him by historians should signify "sincerely courteous." Incidentally, four facts present themselves - that men wore wristbands and garters to which grelots were attached; that a high value was set on pearls; that metal was used for the construction of great men's gates, and that the first earthquake is said to have been experienced in A.D. 416.

\section{ANKŌ}

The records of this sovereign's reign make a discreditable page of Japanese history. Ankō, having ascended the throne after an armed contest with his elder brother, which ended in the latter's suicide, desired to arrange a marriage between his younger brother, Ōhatsuse, and a sister of his uncle, Ōkusaka. He despatched Ne no Omi, a trusted envoy, to confer with the latter, who gladly consented, and, in token of approval, handed to Ne no Omi a richly jewelled coronet for conveyance to the Emperor. But Ne no Omi, covetous of the gems, secreted the coronet, and told the Emperor that Ōkusaka had rejected the proposal with scorn. Ankō took no steps to investigate the truth of this statement. It has been already seen that such investigations were not customary. in those days. Soldiers were at once sent to slaughter Ōkusaka; his wife, Nakashi, was taken to be the Emperor's consort, and his sister, Hatahi, was married to Prince Ōhatsuse.

Now, at the time of his death, Ōkusaka had a son, Mayuwa, seven years old. One day, the Emperor, having drunk heavily, confessed to the Empress, Nakashi, that he entertained some apprehension lest this boy might one day seek to avenge his father's execution. The child overheard this remark, and creeping to the side of his step-father, who lay asleep with his head in Nakashi's lap, killed him with his own sword. Such is the tale narrated in the Chronicles and the Records. 
But its incredible features are salient. A deed of the kind would never have been conceived or committed by a child, and the Empress must have been a conniving party.

To what quarter, then, is the instigation to be traced? An answer seems to be furnished by the conduct of Prince Ōhatsuse. Between this prince and the throne five lives intervened; those of the Emperor Ankō, of the latter's two brothers, Yatsuri no Shiro and Sakai no Kuro, both older than Ōhatsuse, and of two sons of the late Emperor Richū, Ichinobe no Oshiwa and Mima. Every one of these was removed from the scene in the space of a few days. Immediately after Ankō's assassination, Ōhatsuse, simulating suspicion of his two elder brothers, killed the $\bar{o}$-omi, who refused to give them up. Ōhatsuse then turned his attention to his grand-uncles, the two sons of Richū. He sent a military force to destroy one of them without any pretence of cause; the other he invited to a hunting expedition and treacherously shot. If Ōhatsuse did not contrive the murder of Ankō, as he contrived the deaths of all others standing between himself and the throne, a great injustice has been done to his memory.

\section{LOYALTY}

These shocking incidents are not without a relieving feature. They furnished opportunities for the display of fine devotion. When Prince Ōkusaka died for a crime of which he was wholly innocent, two of his retainers, Naniwa no Hikaga, father and son, committed suicide in vindication of his memory. When Prince Sakai no Kuro and Mayuwa took refuge in the house of the $\bar{o}$-omi Tsubura, the latter deliberately chose death rather than surrender the fugitives. When Prince Kuro perished, Nie-no-Sukune took the corpse in his arms and was burned with it. When Prince Ichinobe no Oshiwa fell under the treacherous arrow of Prince Ōhatsuse, one of the former's servants embraced the dead body and fell into such a paroxysm of grief that Ōhatsuse ordered him to be despatched. And during this reign of Yūryaku, when Lord Ōtomo was killed in a fatal engagment with the Sinra troops, his henchman, Tsumaro, crying, "My master has fallen; what avails that I alone should remain unhurt?" threw himself into the ranks of the enemy and perished. Loyalty to the death characterized the Japanese in every age.

\section{YŨRYAKU}

This sovereign was the Ōhatsuse of whose unscrupulous ambition so much has just been heard. Some historians have described him as an austere man, but few readers of his annals will be disposed to endorse such a lenient verdict. He ordered that a girl, whose only fault was misplaced affection, should have her four limbs stretched on a tree and be roasted to death; he slew one of his stewards at a hunt, because the man did not understand how to cut up the meat of an animal; he removed a high official - Tasa, omi of Kibi - to a distant post in order to possess himself of the man's wife (Waka), and he arbitrarily and capriciously killed so many men and women that the people called him the "Emperor of great wickedness." One act of justice stands to his credit. The slanderer, Ne no Omi, who for the sake of a jewelled coronet had caused the death of Prince Okusaka, as related above, had the temerity to wear the coronet, sixteen years subsequently, when he presided at a banquet given in honour of envoys from China; and the beauty of the bauble having thus been noised abroad, $\mathrm{Ne}$ no Omi was required to show it at the palace. It was immediately recognized 
by the Empress, sister of the ill-starred prince, and Ne no Omi, having confessed his crime, was put to death, all the members of his $u j i$ being reduced to the rank of serfs. One moiety of them was formed into a hereditary corporation which was organized under the name of Ōkusakabe, in memory of Prince Ōkusaka.

\section{ARTS AND CRAFTS}

The reign of Yüryaku is partially saved from the reproach of selfish despotism by the encouragement given to the arts and crafts. It has already been related that the members of the Hata-uji, which had been constituted originally with artisans from China, gradually became dispersed throughout the provinces and were suffering some hardships when Yūryaku issued orders for their reassembly and reorganization. Subsequently the sovereign gave much encouragement to sericulture, and, inspired doubtless by the legend of the Sun goddess, inaugurated a custom which thereafter prevailed in Japan through all ages, the cultivation. of silkworms by the Empress herself. At a later date, learning from a Korean handicraftsman (tebito) - whose name has been handed down as Kwan-in Chiri - that Korea abounded in experts of superior skill, Yūryaku commissioned this man to carry to the King of Kudara (Paikche) an autograph letter asking for the services of several of these experts. This request was complied with, and the newcomers were assigned dwellings at the village of Tsuno in Yamato; ${ }^{1}$ but as the place proved unhealthy, they were afterwards distributed among several localities.

It is also recorded that, about this time, there came from China a man called An Kikō, a descendant of one of the Wu sovereigns. He settled in Japan, and his son, $\mathbf{R y} \bar{u}$ - afterwards named Shinki - is reputed to have been the first exponent of Chinese pictorial art in Japan. In the year A.D. 470, there was another arrival of artisans, this time from Wu (China), including weavers and clothiers. They landed in the province of Settsu, and to commemorate their coming a road called the "Kure-saka" (Wu acclivity) was constructed from that port to the Shihatsu highway. The descendants of these immigrants were organized into two hereditary corporations (be) of silk-clothiers, the Asuka no Kinu-nui-be and the Ise no Kinu-nui-be. Two years later (472), orders were issued for the cultivation of mulberry trees in all suitable provinces, and at the same time the previously reassembled members of the Hata-uji were once more distributed to various localities with the object of widening their sphere of instruction.

In the year 473 a very interesting event is recorded. The muraji of the Hanishi was ordered to furnish craftsmen to manufacture "pure utensils" for serving viands daily in the palace. These Hanishi are first spoken of as having been employed at the suggestion of Nomi-no-Sukune, in the days of the Emperor Suinin (A.D. 3), to make clay substitutes for the human beings thitherto inhumed at the sepulchres of notables. In response to this order the muraji summoned his own tami-be (private hereditary corporation) then located at seven villages in the provinces of Settsu, Yamashiro, Ise, Tamba, Tajima, and Inaba. They were organized into the Nie no Hanishibe, or hereditary corporation of potters of table-utensils. Ceramists had previously come from Kudara (Paikche), and there can be no doubt that some progress was made in the art from the fifth century onwards. But there does not appear to be sufficient ground for a conclusion formed by some historians that the "pure utensils" mentioned above

[ ${ }^{1}$ There were potters, saddlers, brocade-weavers, and interpreters.] 
were of glazed pottery. The art of applying glaze to ceramic manufactures was not discovered until a much later period.

\section{RELATIONS WITH KOREA}

When Yüryaku ascended the throne, Japan still enjoyed her original friendship with Paikche (Kudara), whence ladies-in-waiting were sent periodically to the Yamato Court. She also retained her military post at Mimana (Imna) and kept a governor there, but her relations with Shiragi (Sinra) were somewhat strained, owing to harsh treatment of the latter's special envoys who had come to convey their sovercign's condolences on the death of the Emperor Inkyo (453). From the time of Yurryaku's aceession, Shiragi eeased altogether to send the usual gifts to the Emperor of Japan. In the year 463, Y ūryaku, desiring to possess himself of the wife of a high official, Tasa, sent him to be governor of Mimana, and in his absence debauched the lady. Tasa, learning how he had been dishonoured, raised the standard of revolt and sought aid of the Shiragi people. Then Yüryaku, with characteristic refinement of cruelty, ordered Tasa's son, Oto, to lead a force against his father. Oto seemingly complied, but, on reaching the peninsula, opened communication with his father, and it was agreed that while Tasa should hold Imna, breaking off all relations with Japan, Oto should adopt a similar course with regard to Paikche. This plot was frustrated by Oto's wife, Kusu, a woman too patriotic to connive at treason in any cireumstances. She killed her husband, and the Court of Yamato was informed of these events.

From that time, however, Japan's hold upon the peninsula was shaken. Yūryaku sent four expeditions thither, but they accomplished nothing permanent. The power of Koma in the north inereased steadily, and it had the support of China. Yūryaku's attempts to establish close relations with the latter - the Sung were then on the throne - seem to have been inspired by a desire to isolate Korea. He failed, and ultimately Kudara was overrun by Koma, as will be seen by and by. It is searcely too much to say that Japan lost her paramount status in Korea because of Y ūryaku's illicit passion for the wife of one of his subjects.

\section{CHRONOLOGY}

The first absolute agreement between the dates given in Japanese history and those given in Korean oceurs in this reign, namely, the year A.D. 475. The severest erities therefore consent to admit the trustworthiness of the Japanese annals from the third quarter of the fifth century.

\section{TREASURIES}

In the record of Richū's reign, brief mention has been made of the establishment of a Government treasury. In early days, when religious rites and administrative functions were not differentiated, articles needed for both purposes were kept in the same store, under the charge of the Imibe-uji. But as the Court grew richer, owing to receipt of domestie taxes and foreign "tribute," the necessity of establishing separate treasuries, was felt and a "domestic store" (Uchi-kura) was formed during Richū's reign, the Koreans, Achi and Wani, being appointed to keep the aceounts. In Yurryaku's time a third treasury had to be added, owing to greatly increased production of textile fabries and other 
manufactures. This was called the Ökura, a term still applied to the Imperial treasury, and there were thus three stores, Ōkura, Uchi-kura, and Imi-kura. Soga no Machi was placed in supreme charge of all three, and the power of the Soga family grew proportionately.

\section{MANNERS AND CUSTOMS}

It is observable that at this epoch the sovereigns of Japan had not yet begun to affect the sacred seclusion which, in later ages, became characteristic of them. It is true that, after ascending the throne, they no longer led their troops in war, though they did so as Imperial princes. But in other respects they lived the lives of ordinary men - joining in the chase, taking part in banquets, and mixing freely with the people. As illustrating this last fact a strange incident may be cited. One day the Emperor Yüryaku visited the place where some carpenters were at work and observed that one of them, Mane, in shaping timber with an axe, used a stone for ruler but never touched it with the axe. "Dost thou never make a mistake and strike the stone?" asked the monarch. "I never make a mistake," replied the carpenter. Then, to disturb the man's sang-froid, Yūryaku caused the ladies-in-waiting (uneme) to dance, wearing only waistcloths. Mane watched the spectacle for a while, and on resuming his work, his accuracy of aim was momentarily at fault. The Emperor rebuked him for having made an unwarranted boast and handed him over to the monono-be for execution. After the unfortunate man had been led away, one of his comrades chanted an impromptu couplet lamenting his fate, whereat the Emperor, relenting, bade a messenger gallop off on "a black horse of Kai" to stay the execution. The mandate of mercy arrived just in time, and when Mane's bonds were loosed, he, too, improvised a verse:-

\footnotetext{
"Black as the night

"Was the horse of Kai.

"Had they waited to

"Saddle him, my life were lost

"O, horse of Kai!"
}

The whole incident is full of instruction. A sovereign concerning himself about trivialities as petty as this pretext on which he sends a man to death; the shameful indignity put upon the ladies-in-waiting to minister to a momentary whim; the composition of poetry by common carpenters, and the ride for life on a horse which there is not time to saddle. It is an instructive picture of the ways of Yūryaku's Court.

In truth, this couplet-composing proclivity is one of the strangest features of the Yamato race as portrayed in the pages of the Records and the Chronicles. From the time when the fierce Kami, Susanoo, put his thoughts into verse as he sought for a place to celebrate his marriage, great crises and little crises in the careers of men and women respectively inspire couplets. We find an Emperor addressing an ode to a dragon-fly which avenges him on a gad-fly; we find a prince reciting impromptu stanzas while he lays siege to the place whither his brother has fled for refuge; we find a heartbroken lady singing a verselet as for the last time she ties the garters of her lord going to his death, and we find a sovereign corresponding in verse with his consort whose consent to his own dishonour he seeks to win.

Yet in the lives of all these men and women of old, there are not many other traces of corresponding refinement or romance. We are constrained to con- 
jecture that many of the verses quoted in the Records and the Chronicles were fitted in after ages to the events they commemorate. Another striking feature in the lives of these early sovereigns is that while on the one hand their residences are spoken of as muro, a term generally applied to dwellings partially underground, on the other, we find more than one reference to high towers. Thus Y üryaku is shown as "ordering commissioners to erect a lofty pavilion in which he assumes the Imperial dignity," and the Emperor Nintoku is represented as "ascending a lofty tower and looking far and wide" on the occasion of his celebrated sympathy with the people's poverty.

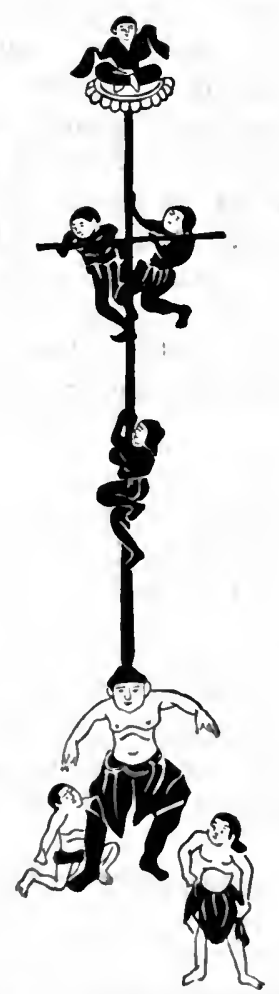

Asciest Acrobatic Permormance 


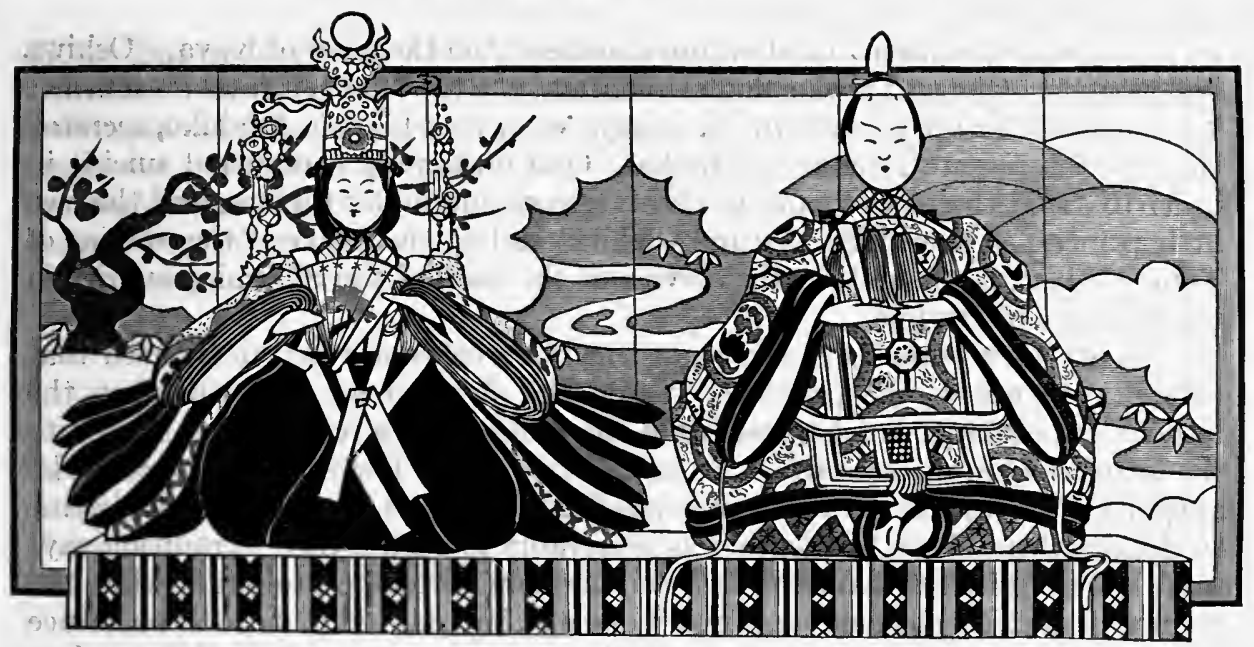

Dairigama (King) and Orusamä (Queen) of the Feast of the Dolls

\section{CHAPTER XIII}

\section{THE PROTOHISTORIC SOVEREIGNS (Continued)}

\begin{tabular}{|c|c|c|}
\hline $23 \mathrm{rd}$ & & $\ldots “ 485-487$ \\
\hline 24th & “ & “ $488-498$ \\
\hline 25 th & “" & $\ldots \ldots \ldots$ “ $499-506$ \\
\hline 26 th & “ & .... “ 507-531 \\
\hline 27 th & $"$ & " $534-535$ \\
\hline 3 th & “ & . " $536-53$ \\
\hline
\end{tabular}

\section{DISPUTE ABOUT THE SUCCESSION}

The Emperor Yüryaku's evil act in robbing Tasa of his wife, Waka, entailed serious consequences. He selected to succeed to the throne his son Seinei, by Princess Kara, who belonged to the Katsuragi branch of the great Takenouchi family. But Princess Waka conspired to secure the dignity for the younger of her own two sons, Iwaki and Hoshikawa, who were both older than Seinei. She urged Hoshikawa to assert his claim by seizing the Imperial treasury, and she herself with Prince Iwaki and others accompanied him thither. They underestimated the power of the Katsuragi family. Siege was laid to the treasury and all its inmates were burned, with the exception of one minor official to whom mercy was extended and who, in token of gratitude, presented twentyfive acres of rice-land to the $\bar{o}$-muraji, Lord Ōtomo, commander of the investing force.

\section{THE FUGITIVE PRINCES}

The Emperor Seinei had no offspring, and for a time it seemed that the succession in the direct line would be interrupted. For this lack of heirs the responsibility ultimately rested with Yūryaku. In his fierce ambition to sweep away every obstacle, actual or potential, that barred his ascent to the throne, he inveigled Prince Oshiwa, eldest son of the Emperor Richū, to accompany him 
on a lunting expedition, and slew him mercilessly on the moor of Kaya. Oshiwa had two sons, Oke and Woke, mere children at the time of their father's murder. They fled, under the care of Omi, a muraji, who, with his son, Adahiko, secreted them in the remote province of Inaba. Omi ultimately committed suicide in order to avoid the risk of capture and interrogation under torture, and the two little prinees, still accompanied by Adahiko, calling themselves "the urchins of Tamba," became menials in the service of the obito of the Shijimi granaries in the province of Harima.

Twenty-four years had been passed in that seclusion when it chanced that Odate, governor of the provinee, visited the obito on an occasion when the latter was holding a revel to celebrate the building of a new, house. It fell to the lot of the two princes to act as torch-bearers, the lowest rôle that could be assigned to them, and the younger counselled his brother that the time had come to declare themselves, for death was preferable to such a life. Tradition says that, being invited to dance "when the night had become profound, when the revel was at its height and when every one else had danced in turn," the Prince Woke, accompanying his movements with verses extemporized for the occasion, dancel so gracefully that the governor twice asked him to continue, and at length he announced the rank and lineage of his brother and himself. The governor, astonished, "made repeated obeisance to the youths, built a palace for their temporary accommodation, and going up to the capital, disclosed the whole affair to the Emperor, who expressed profound satisfaction."

Öke, the elcler of the two, was made Prince Imperial, and should have ascended the throne on the death of Seinei, a few months later. Arguing, however, that to his younger brother, Woke, it was entirely due that they had emerged from a state of abject misery, Öke announced his determination to cerle the honour to Woke, who, in turn, declined to take precedence of his elder brother. This dispute of mutual deference continued for a whole year, during a part of which time the administration was carried on by Princess Awo, elder sister of Woke. At length the latter yielded and assumed the sceptre. His first care was to collect the bones of his father, Prince Oshiwa, who had been murdered and buried uneeremoniously on the moor of Kaya in Ōmi province. It was long before the place of interment could be discovered, but at length an old woman served as guide, and the bones of the prince were found mingled in inextricable confusion with those of his loyal vassal, Nakachiko, who had shared his fate.

'The ethies of that remote age are illustrated vividly in this page of the record. A double sepulchre was erected in memory of the murdered prince and his faithful follower and the old woman who had pointed out the place of their unhonoured grave was given a house in the vicinity of the palace, a rope with a bell attached being stretched between the two residences to serve as a support for her infirm feet and as a means of announcing her coming when she visited the palace. But the same benevolent sovereign who directed these gracious doings was with difficulty dissuaded from demolishing the tomb and scattering to the winds of heaven the bones of the Emperor Yüryaku, under whose hand Prince Oshiwa had fallen.

\section{TIL VENDETTA}

In connexion with this, the introduction of the principle of the vendetta has to be noted. Its first practical application is generally referred to the act of the boy-prince, Mayuwa, who stabbed his father's slayer, the Emperor Ankō (A.D. 
456). But the details of Ankō's fate are involved in some mystery, and it is not until the time (A.D. 486) of Kenso that we find a definite enunciation of the Confucian doctrine, afterwards rigidly obeyed in Japan, "A man should not live under the same heaven with his father's enemy:" History alleges that, by his brother's counsels, the Emperor Kenso was induced to abandon his intention of desecrating Yurryaku's tomb, but the condition of the tomb to-day suggests that these counsels were not entirely effective.

\section{BANQUETS}

The annals of this epoch refer more than once to banquets at the palace. Towards the close of Seinei's reign we read of " a national drinking-festival which lasted five days," and when Kenso ascended the throne he "went to the park, where he held revel by the winding streams," the high officials in great numbers being his guests. "On this latter occasion the ministers are said to have "uttered reiterated cries of "banzai" ", which has come into vogue once more in modern times as the equivalent of "hurrah."

\section{THE EMPEROR NINKEN}

The twenty-fourth sovereign, Ninken, was the elder of the two brothers, Ōke and Woke, whose escape from the murderous ambition of the Emperor Yüryaku and their ultimate restoration to princely rank have been already described. He succeeded to the throne after the death of his younger brother, and occupied it for ten years of a most uneventful reign. Apart from the fact that tanners were invited from Korea to improve the process followed in Japan, the records contain nothing worthy of attention. One incident, however, deserves to be noted as showing the paramount importance attached in those early days to all the formalities of etiquette. The Empress dowager committed suicide, dreading lest she should be put to death for a breach of politeness committed towards Ninken during the life of his predecessor, Kensō. "At a banquet in the palace she had twice neglected to kneel when presenting, first, a knife and, secondly, a cup of wine to Ninken, then Prince Imperial. It has already been related that the Empress Ōnakatsu, consort of Inkyō, was disposed to inflict the death penalty on a high official who had slighted her unwittingly prior to her husband's accession. There can be no doubt that differences of rank received most rigid recognition in early Japan.

\section{THE EMPEROR MURETSU}

This sovereign was the eldest son of his predecessor, Ninken. According to the Chronicles, his reign opened with a rebellion by the great Heguri family; whose representative, Matori, attempted to usurp the Imperial dignity while his son, Shibi, defiantly wooed and won for himself the object of the Emperor's affections. Matori had been Yūryaku's minister, and his power as well as his family influence were very great, but the military nobles adhered to the sovereign's cause and the Heguri were annihilated. In the Records this event is attributed to the reign of Seinei in a much abbreviated form, but the account given in the Chronicles commands the greater credence. The Chronicles, however, represent Muretsu as a monster of cruelty, the Nero of Japanese

['Banzai means literally "ten thousand years," and thus corresponds to viva.] 
history, who plucked out men's nails and made them dig up yams with their inutilated fingers; who pulled out people's hair; who made them ascend trees which were then cut down, and who perpetrated other hideous excesses. Here again the Records, as well as other ancient authorities are absolutely silent, and the story in the Chronicles has attracted keen analyses by modern historiographers. Their almost unanimous conclusion is that the annals of King Multa of Kudara have been eonfused with those of the Emperor Muretsu. This Korean sovereign, contemporary with Muretsu, committed all kinds of atrocities and was finally deposed by his people. There are evidences that the compilers of the Chronicles drew largely on the pages of Korean writers, and it is not difficult to imagine aceidental intermixing such as that suggested by the crities in this ease.

\section{KEITAI}

The death of the Emperor Muretsu left the throne without any successor in the direct line of descent, and for the first time since the foundation of the Empire, it became necessary for the great officials to make a selection among the seions of the remote Imperial families. Their choice fell primarily on the representative of the fifth generation of the Emperor Chūai's descendants. But as their method of announcing their decision was to despatch a strong foree of armed troops to the provineial residence of the ehosen man, he naturally misinterpreted the demonstration and sought safety in flight. Then the $\bar{o}$-omi and the $\bar{o}$-muraji turned to Prince Ōdo, fifth in descent from the Emperor Ōjin on his father's side and eighth in descent from the Emperor Suinin on his mother's. Arako, head of the horse-keepers, had secretly informed the prinee of the ministers' intentions, and thus the sudden apparition of a military foree inspired no alarm in Ōdo's bosom. He did, indeed, show seemly hesitation, but finally he accepted the insignia and ascended the throne, confirming all the high dignitaries of State in their previous offices. From the point of view of domestic affairs his reign was uneventful, but the empire's relations with Korea continued to be much disturbed, as will be presently explained.

\section{ANKAN}

The Emperor Keitai had a large family, but only one son was by the Empress; and as he was too young to ascend the throne immediately after his father's death, he was preceded by his two brothers, Ankan and Senkwa, sons of the senior concubine. This complication seems to have caused some difficulty, for whereas Keitai died in 531, Ankan's reign did not commence until 534. The most noteworthy feature of his era was the establishment of State granaries in great numbers, a proof that the Imperial power found large extension throughout the provinees. In connexion with this, the o-muraji, Kanamura, is quoted as having laid down, by command of the Emperor, the following important doetrine, "Of the entire surface of the soil, there is no part which is not a royal grant in fee; under the wide heavens there is no place which is not royal territory." The annals show, also, that the eustom of accepting tracts of land or other property in expiation of offences was obtaining increased vogue.

Senkwa was the younger brother of Ankan. He reigned only three years and the period of his sway was uneventful, if we except the growth of eomplica- 
tions with Korea, and the storing of large quantities of grain in Tsukushi, as a "provision against extraordinary occasions," and "for the cordial entertainment of our good guests" from "the countries beyond the sea."

\section{RELATIONS WITH KOREA}

With whatever scepticism the details of the Empress Jingō's expedition be regarded, it appears to be certain that at a very early date, Japan effected lodgement on the south coast of Korea at Mimana, and established there a permanent station (chinju-fu) which was governed by one of her own officials. It is also apparent that, during several centuries, the eminent military strength of Yamato received practical recognition from the principalities into which the peninsula was divided; that they sent to the Court of Japan annual presents which partook of the nature of tribute, and that they treated her suggestions, for the most part, with deferential attention. This state of affairs received a rude shock in the days of Yüryaku, when that sovereign, in order to possess himself of the wife of a high official named Tasa, sent the latter to distant Mimana as governor, and seized the lady in his absence. Tasa revolted, and from that time Japan's position in the peninsula was compromised. The Koreans perceived that her strength might be paralyzed by the sins of her sovereigns and the disaffection of her soldiers. Shiragi (Sinra), whose frontier was conterminous with that of the Japanese settlement on the north, had always been restive in the proximity of a foreign aggressor. From the time of Yurryaku's accession she ceased to convey the usual tokens of respect to the Yamato Court, and, on the other hand, she cultivated the friendship of Koma as an ally in the day of retribution.

It may be broadly stated that Korea was then divided into three principalities: Shiragi in the south and east; Kudara in the centre and west, with its capital at the modern Seoul, and Koma in the north, having Pyong-yang for chief city. This last had recently pushed its frontier into Manchuria as far as the Liao River, and was already beginning to project its shadow over the southern regions of the peninsula, destined ultimately to fall altogether under its sway. In response to Shiragi's overtures, the King of Koma sent a body of troops to assist in protecting that principality against any retaliatory essay on the part of the Japanese in Mimana. But the men of Shiragi, betrayed into imagining that these soldiers were destined to be the van of an invading army, massacred them, and besought Japanese succour against Koma's vengeance. The Japanese acceded, and Shiragi was saved for a time; but at the cost of incurring, for herself and for Japan alike, the lasting enmity of Koma. Shiragi appears to have concluded, however, that she had more to fear from Koma than from Japar, for she still withheld her tribute to the latter, and invaded the territory of Kudara, which had always maintained most friendly relations with Yamato. The Emperor Yurryaku sent two expeditions to punish this contumacy, but the result being inconclusive, he resolved to take the exceptional step of personally leading an army to the peninsula.

This design, which, had it matured, might have radically changed the history of the Far East, was checked by an oracle, and Yūryaku appointed three of his powerful nobles to go in his stead. The Shiragi men fought with desperate tenacity. One wing of their army was broken, but the other held its ground, and two of the Japanese generals fell in essaying to dislodge it. Neither side could claim a decisive victory, but both were too much exhausted to renew the 
combat. 'This was not the limit of Japan's misfortunes. A feud broke out among the leaders of the expedition, and one of them, Oiwa, shot his comrade as they were en route for the Court of the Kudara monareh, who had invited them in the hope of composing their dissensions, since the existence of his own kingelom depended on Japan's intervention between Koma and Shiragi.

Uwing to this feud among her generals, Japan's hold on Mimana became more precarious than ever while her prestige in the peninsula declined perceptibly. Nevertheless her great military name still retained much of its poteney. 'Tlus, ten years later (A.D. 477), when the IKing of Koma invaded Kudara and held the land at his mercy, he declined to follow his generals' counsels of extermination in deference to Kudara's long friendship with Yamato. It is related that, after this disaster, the Japanese Empcror gave the town of Ung-chhon (Japanese, Kumanari) to the remnant of the Kudara people, and the latter's capital was then transferred from its old site in the centre of the peninsula - a place no longer tenable - to the neighbourhood of Mimana. Thenceforth Y'üryaku aided Kudara zealously. He not only despatched a force of five hundred men to guard the palace of the King, but also sent (480) a flotilla of war-vessels to attack Koma from the west coast. The issue of this attempt is not recorcled, and the silence of the annals may be construed as indieating failure. Koma maintained at that epoch relations of intimate friendship with the powerful Chinese dynasty of the Eastern Wei, and Yüryaku's essays against such a combination were futile, though he prosecuted them with considerable vigour.

After his death the efficiency of Japan's operations in Korea was greatly impaired by factors hitherto happily unknown in her foreign affairs-treason and corruption. Lord Oiwa, whose shooting of his fellow general, Karako, has already been noted, retained his post as governor of Mimana for twenty-one years, and then (487), ambitious of wider sway, opened relations with Koma for the joint invasion of Kudara, in order that he himself might ascend the throne of the latter. A desperate struggle ensued. Several battles were fought, in all of which the victory is historically assigned to Oiwa, but if he really did achive any success, it was purely ephemeral, for he ultimately abandoned the campaign and returned to Japan, giving another shock to his country's waning reputation in the peninsula. If the Yamato Court took any steps to punish this act of lawless ambition, there is no record in that sense. The event occurred in the last year of Kensō's reign, and neither that monareh nor his suecessor, Ninken, seems to have devoted any special attention to Korean affairs.

Nothing notable took place until 509, when Keitai was on the throne. In that year, a section of the Kudara people, who, in 477 , had been driven from their country by the Koma invalers and had taken refuge within the Japanese dominion of Minuana, were restored to their homes with Japanese co-operation and with renewal of the friendly relations which had long existed between the Courts of Yamato and Kudara. 'Three years later (512), Kudara preferred a singulár request. She asked that four regions, forming an integral part of the Yamato domain of Mimana, should be handed over to her, apparently as an act of pure benevolence. Japan consented. There is no explanation of her complaisance exeept that she deemed it wise policy to strengthen Kudara against the growing might of Shiragi, I amato's perennial foe. The two officials by whose advice the throne made this sacrifice were the $\bar{o}$-muraji, Kanamura, and the governor of Mimana, an omi called Oshiyama. They went down in the pages of history as corrupt statesmen who, in consicleration of bribes from the Kudara Court, 
surrendered territory which Japan had won by force of arms and held for five centuries.

In the following year (513) the Kudara Court again utilized the services of Oshiyama to procure possession of another district, Imun (Japanese, Komom), which lay on the northeast frontier of Mimana. Kudara falsely represented that this region had been wrested from her by Habe, one of the petty principalities in the peninsula, and the Yamato Court, acting at the counsels of the same ó-muraji (Kanamura) who had previously espoused Kudara's cause, credited Kudara's story. This proved an ill-judged policy. It is true that Japan's prestige in the peninsula received signal recognition on the occasion of promulgating the-Imperial decree which sanctioned the transfer of the disputed territory. All the parties to the dispute, Kudara, Shiragi, and Habe, were required to send envoys to the Yamato Court for the purpose of hearing the rescript read, and thus Japan's pre-eminence was constructively acknowledged. But her order provoked keen resentment in Shiragi and Habe. The general whom she sent with five hundred warships to escort the Kudara envoys was ignominiously defeated by the men of Habe, while Shiragi seized the opportunity to invade Mimana and to occupy a large area of its territory.

For several years the Yamato Court made no attempt to re-assert itself, but in 527 an expedition of unprecedented magnitude was organized. It consisted of sixty thousand soldiers under the command of Keno no Omi, and its object was to chastise Shiragi and to re-establish Mimana in its original integrity. But here an unforeseeable obstacle presented itself. For all communication with the Korean peninsula, Tsukushi (Kyūshū) was an indispensable basis, and it happened that, just at this time, Kyūshū had for ruler (miyatsuko) a nobleman called Iwai, who is said to have long entertained treasonable designs. A knowledge of his mood was conveyed to Shiragi, and tempting proposals were made to him from that place conditionally on his frustrating the expedition under Keno no Omi." Iwai thereupon occupied the four provinces of Higo, Hizen, Bungo, and Buzen, thus effectually placing his hand on the neck of the communications with Korea and preventing the embarkation of Keno no Omi's army. He established a pseudo-Court in Tsukushi and there gave audience to tributebearing envoys from Koma, Kudara and Shiragi.

ins For the space of a twelvemonth this rebel remained master of the situation, but, in A.D. 528, the $\bar{o}-m u r a j i$, Arakahi, crushed him after a desperate conflict in the province of Chikugo. ${ }^{1}$ Iwai effected his escape to Buzen and died by his own hand in a secluded valley. Although, however, this formidable rebellion was thus successfully quelled, the great expedition did not mature.: Keno, its intended leader, did indeed proceed to Mimana and assume there the duties of governor, but he proved at once arrogant and incompetent, employing to an extravagant degree the ordeal of boiling water, so that many innocent people suffered fatally, and putting to death children of mixed Korean and Japanese parentage instead of encouraging unions which would have tended to bring the two countries closer together.

In all her relations with Korea at this epoch, Japan showed more loyalty than sagacity. She was invariably ready to accede to proposals from her old friend, Kudara, and the latter, taking astute advantage of this mood, secured

$\left[{ }^{1}\right.$ In the Chikugo Fu $\bar{u}$ doki a minute description is given of Iwai's sepulchre, built during his lifetime but presumably never occupied by his body. The remarkable feature of the tomb was a number of stone images, several representing grave-guards, and one group being apparently designed to represent the judicial trial of a poacher.] 
her endorsement of territorial transfers which brought to the Yamato Court nothing but the enmity of Kudara's rivals. By these errors of statesmanship and by the misgovernment of officials like Keno, conditions were ereated which, as will be seen hereafter, proved ultimately fatal to Japan's sway in the peninsula. Meanwhile, every student of Japanese ancient annals cannot but be struek by the large space devoted to recording her relations with Korea. As the eminent historian, Rai Sanyō, said in later times, her soldiers were wearied by constant eampaigns oversea, and her agriculturists were exhausted by frequent requisitions for supplies. During the epoch of Jingō and Ōjin, Japan was palpably inferior to her peninsular neighbour in civilization, in wealth, and in population. But in one respect the superiority was largely on her side; namely, in the quality of her soldiers. Therefore, she utilized her military strength for campaigns which cost comparatively little and produced much. The peninsula, at that time, verified the term commonly applied to it, Uchi-tsu-miyake, or the "Granary of the Home-land." But as the material development of Japan and her civilization progressed, she stood constantly to lose more and gain less by despatehing expeditions to a land which squandered much of its resourses on interneeine quarrels and was deteriorating by comparison. The task of maintaining Mimana and suceouring Kudara then became an obligation of prestige which gradually ceased to interest the nation.

\section{FINANCE}

In the period now under consideration no system of land taxation had yet come into existence. The requirements of the Court were met by the produce of the mi-agata (Imperial domains), and rice for public use was grown in the miyake districts, being there stored and devoted to the administrative needs of the region. Oecasionally the contents of several miyake were collected into one distriet, as, for example, when (A.D. 536) the Emperor Senkwa ordered a concentration of foodstuffs in Tsukushi. The miyake were the property of the Crown, as were also a number of hereditary corporations (be), whose members discharged duties, from building and repairing palaces - no light task, seeing that the site of the palace was ehanged with each change of oceupant - to serieulture, weaving, tailoring, cooking, and arts and handierafts of all deseriptions, each be exercising its own function from generation to generation, and being superintended by its own head-man (obito or atae).

Any insuffieiency in the supplies furnished by the sovereign's own people was made good by levying on the tomo-no-miyatsuko. It will be seen that there was no annual tax regularly imposed on the people in general, though universal requisitions were occasionally made to meet the requirements of publie. works, festivals or military operations. Hence when it is said that the Emperor Nintoku remitted all taxes for the space of three years until the people's burdens were lightened, reference is made only to the be and tomobe belonging to the Throne itself. Doubtless this special feature of Yamato finance was due in part to the fact that all the land and all the people, except those appertaining to the Crown, were in the possession of the $u j i$, without whose co-operation no general fiscal measure could be adopted. When recourse to the nation at large was necessitated to meet some exeeptional purpose, orders had to be given, first, to the $\bar{o}-o m i$ and $\bar{o}$-maraji; next, by these to the Kami of the several $\bar{o}-u j i$; then, by the latter to the Kami of the various ko-uji, and, finally, by these last to every houschold.

The machinery was thorough, but to set it in motion required an effort which 
constituted an automatic obstacle to extortion. The lands and people of the uji were governed by the Emperor but were not directly controlled by him. On the other hand, to refuse a requisition made by the Throne was counted contumelious and liable to punishment. Thus when (A.D. 534) the Emperor Ankan desired to include a certain area of arable land in a miyake established for the purpose of commemorating the name of the Empress, and when Ajihari, suzerain (atae) of the region, sought to evade the requisition by misrepresenting the quality of the land, he was reprimanded and had to make atonement by surrendering a portion of his private property. There can be no doubt, however, that as the population increased and as uncultivated areas grew less frequent, the arbitrary establishment of koshiro or of nashiro became more and more irksome, and the pages of history indicate that from the time of Keitai (A.D. 507-531) this practice was gradually abandoned.

\section{CRIMINAL LAW}

Although the use of the ideographic script became well known from the fifth century, everything goes to show that no written law existed at that time, or, indeed, for many years afterwards. Neither are there any traces of Korean or Chinese influence in this realm. Custom prescribed punishments; and the solemnity of a judicial trial found no better representative than the boiling-water ordeal. If a man took oath to the deities of his innocence and was prepared to thrust his arm into boiling mud or water, or to lay a red-hot axe on the palm of his hand, he was held to have complied with all the requirements. The familiar Occidental doctrine, "the King can do no wrong," received imperative recognition in Japan, and seems to have been extended to the Crown Prince also. There were no other exemptions. If a man committed a crime, punishment extended to every member of his family. On the other hand, offences might generally be expiated by presenting lands or other valuables to the Throne. As for the duty of executing sentences, it devolved on the mononobe, who may be described as the military corporation. Death or exile were common forms of punishment, but degradation was still more frequent. It often meant that a family, noble and opulent to-day, saw all its members handed over to-morrow to be the serfs or slaves of some $u j i$ in whose be they were enrolled to serve thenceforth, themselves and their children, through all generations in some menial position, - it might be as sepulchre-guards, it might be as scullions.

Tattooing on the face was another form of penalty. The first mention of it occurs in A.D. 400 when Richū condemned the muraji, Hamako, to be thus branded, but whether the practice originated then or dated from an earlier period, the annals do not show. It was variously called hitae-kizamu (slicing the brow), me-saku (splitting the eyes), and so on, but these terms signified nothing worse than tattooing on the forehead or round the eyes. The Emperor Richū deemed that such notoriety was sufficient penalty for high treason, but Yūryaku inflicted tattooing on a man whose dog had killed one of his Majesty's fowls.

Death at the stake appears to have been very uncommon. This terrible form of punishment seems to have been revived by Yūryaku. - He caused it to be inflicted on one of the ladies-in-waiting and her paramour, who had forestalled him in the girl's affections. The first instance is mentioned in the annals of the Empress Jingō, but the victim was a Korean and the incident happened in war. To Yüryaku was reserved the infamy of employing such a penalty in the case 
of a woman. Highly placed personages were often allowed to expiate an offence by performing the religious rite of harai (purification), the offender defraying all expenses.

\section{ARCHITECTURE}

As Chinese literature became familiar and as the arts of the Middle Kingdom and Korea were imported into Japan, the latter's customs naturally underwent some changes. This was noticeable in the case of architecture. Lofty buildings, as has been already stated, began to take the place of the partially subterranean muro. The annals make no special reference to the authors of this innovation, but it is mentioned that among the descendants of the Chinese, Achi, and the Korean, Tsuka, there were men who practised carpentry. Apparently the fashion of high buildings was established in the reign of Ankō when (A.D. 456) the term ro or takadono (lofty edifice) is, for the first time, applied to the palace of Ankō in Yamato. A few years later (468), we find mention of two carpenters, ${ }^{1}$ Tsuguno and Mita, who, especially the latter, were famous experts in Korean arehitecture, and who received orders from Yüryaku to erect high buildings. It appears further that silk curtains (tsumugi-kaki) came into use in this age for partitioning rooms, and that a species of straw mat (tatsu-gomo) served for carpet when people were hunting, travelling, or campaigning.

\section{SHIPS}

Occasional references have been made already to the art of shipbuilding in Japan, and the facts elicited may be summed up very briefly. They are that the first instance of naming a ship is recorded in the year A.D. 274, when the Karano (one hundred feet long) was built to order of the Emperor Ōjin by the carpenters of Izu promontory,- which place was famed for skill in this respect; that the general method of building was to hollow out tree-trunks, ${ }^{2}$ and that the arrival of naval architeets from Shiragi (A.D. 300) inaugurated a superior method of construction, differing little from that employed in later ages.

\section{VEHICLES}

A palanquin (koshi) used by the Emperor Ōjin (A.D. 270-310) was preserved in the Kyōto palace until the year 1219, when a conflagration consumed it. The records give no description of it, but they say that Yüryaku and his Empress returned from a hunting expedition on a cart (kuruma), and tradition relates that a man named Isa, a descendant in the eighth generation of the Emperor Sujin, built a covered eart which was the very one used by Yurryaku. It is, indeed, more than probable that a vehicle which had been in use in China for a long time must have become familiar to the Japanese at an early epoch.

\section{MEDICAL AR'T}

For relief in sickness supplication to the gods and the performance of religious rites were chiefly relied on. But it is alleged ${ }^{3}$ that medicines for internal and

${ }^{1}$ It should be remembered that as all Japanese edifices were made of timber, the carpenter and the architect were one and the same.]

['Such dug-outs were named maruki-bune, a distinguishing term which proves that some other method of building was also employed.]

[ ${ }^{3}$ By the Nihon Bummei Shiryaku.] 
external use were in existence and that recourse to thermal springs was commonly practised from remote times.

\section{PICTORIAL ART}

While Yūryaku was on the throne, Korea and China sent pictorial experts to Japan. The Korean was named Isuraka, and the Chinese, Shinki. The latter is said to have been a descendant of the Emperor Wen of the Wei dynasty. His work attracted much attention in the reign of Muretsu, who bestowed on him the $u j i$ title of Óoka no Obito. His descendants practised their art with success in Japan, and from the time of the Emperor Tenchi (668-671) they were distinguished as Yamato no eshi (painters of Yamato).

\section{POETRY}

If we credit the annals, the composition of poetry commenced in the earliest ages and was developed independently of foreign influences. From the sovereign down to the lowest subject, everyone composed verses. These were not rhymed; the structure of the Japanese language does not lend itself to rhyme. Their differentiation from prose consisted solely in the numerical regularity of the syllables in consecutive lines; the alternation of phrases of five and seven syllables each. A tanka (short song) consisted of thirty-one syllables arranged thus, $5,7,5,7$, and 7 ; and a naga-uta (long song) consisted of an unlimited number of lines, all fulfilling the same conditions as to number of syllables and alternation of phrases. No parallel to this kind of versification has been found yet in the literature of any other nation. The Chronicles and the Records abound with tanka and naga-uta, many of which have been ascribed by skeptics to an age not very remote from the time when those books were compiled. But the Japanese themselves think differently. They connect the poems direcily with the events that inspired them. Further reference to the subject will be made hereafter. Here it will suffice to note that the composing of such verselets was a feature of every age in Japan.

\section{$U T A-G A K I$}

A favourite pastime during the early historic period was known as uta-gaki or uta-kai. In cities, in the country, in fields, and on hills, youths and maidens assembled in springtime or in autumn and enjoyed themselves by singing and dancing. Promises of marriage were exchanged, the man sending some gifts as a token, and the woman, if her father or elder brother approved, despatching her head-ornament (oshiki no tamakatsura) to her lover. On the wedding day it was customary for the bride to present "table-articles" (tsukue-shiro) to the bridegroom in the form of food and drink. There were places specially associated in the public mind with uta-gaki - Tsukuba Mountain in Hitachi, Kijima-yama in Hizen, and Utagaki-yama in Settsu. Sometimes men of noble birth took part in this pastime, but it was usually confined to the lower middle classes. The great festival of bon-odori, which will be spoken of by.and by, is said to be an outgrowth of the uta-gaki.

\section{SUPERSTITIONS}

No influences of alien character affected the religious beliefs of the Japanese during the period we are now considering (fourth, fifth, and sixth centuries). 
The most characteristic feature of the time was a belief in the supernatural power of reptiles and animals. This credulity was not limited to the uneducated masses. The Throne itself shared it. Yūryaku, having expressed a desire to see the incarnated form of the Kami of Mimoro Mountain, was shown a serpent seventy feet long. In the same year a group of snakes harrassed a man who, was reclaiming a marsh, so that he had to take arms against them and enter into a compact of limitations and of shrine building. Other records of maleficent deities in serpent shape were current, and monkeys and dragons inspired similar terror. Of this superstition there was born an evil custom, the sacrifice of human beings to appease the hostile spirits. The Kami of Chūsan in Mimasaka province was believed to be a giant ape, and the Kami of Kōya, a big reptile. 'The people of these two districts took it in turn to offer a girl at the shrines of those Kami, and in the province of Hida another eolossal monkey was similarly appeased. There were further cases of extravagant superstition.

\section{ARTS AND CRAFTS}

Of the development of sericulture and of the arts of weaving and ceramics in this era enough has already been written; but, as showing the growth of refinement, it may be noted that among the articles ordered by the Emperor Yüryaku were a silk hat and a sashiha, or round fan with a long handle. The colour of the fan was purple, and it is said to have been hung up as an ornament in the palace.

\section{FORM OF GOVERNMENT}

The original form of government under the Yamato seems to have been feudal. The heads of $u j i$ were practically feudal ehiefs. Even orders from the Throne had to pass through the uji no Kami in order to reach the people. But from the time of Nintoku (313-349) to that of Yurryaku (457-479), the Court wielded much power, and the greatest among the uji chiefs found no opportunity to interfere with the exercise of the sovereign's rights. Gradually, however, and mainly owing to the intrusion of love affairs or of lust, the Imperial household fell into disorder, which prompted the revolt of Heguri, the $\bar{o}$-omi of the $K w \bar{b}$ etsu (Imperial families); a revolt subdued by the loyalty of the $\bar{o}$-muraji of the Shimbetsu (Kami families).

From the days of the Emperor Muretsu (499-506), direct heirs to succeed to the sceptre were wanting in more than one instance, and a unique opportunity thus offered for traitrous essays. There was none. Men's minds were still deeply imbued with the conviction that by the Tenjin alone might the Throne be occupied. But with the introduction of Buddhism (A.D. 552), that convietion received a shock. That the Buddha directed and controlled man's destiny was a doctrine inconsistent with the traditional faith in the divine authority of the "son of heaven." Hence from the sixth century the prestige of the Crown began to decline, and the puissance of the great uji grew to exceed that of the sovereign. During a short period $(645-670)$ the authority of the Throne was reasserted, owing to the adoption of the Tang systems of China; but thereafter the great Fujiwara-uji became paramount and practically administered the empire.

For the sake, therefore, of an intelligent sequence of conception, there is evidently much importance in determining whether, in remote antiquity, the prevailing system was feudal, or prefectural, or a mixture of both. Unfortunate- 
ly the materials for accurate differentiation are wanting. Much depends on a knowledge of the functions discharged by the kuni-no-miyatsuko, who were hereditary officials, and the kuni-no-tsukasa (or kokushi) who were appointed by the Throne. The closest researeh fails to elucidate these things with absolute clearness. It is not known even at what date the office of kokushi was established. The first mention of these officials is made in the year A.D. 374, during the reign of Nintoku, but there can be little doubt that they had existed from an earlier date. They were, however, few in number, whereas the miyatsuko were numerous, and this comparison probably furnishes a tolerably just basis for estimating the respective prevalence of the prefectural and the feudal systems.

In short, the method of government inaugurated at the foundation of the empire appears to have been essentially feudal in practice, though theoretically no such term was recognized; and at a later period - apparently about the time of Nintoku - when the power of the hereditary miyatsuko threatened to grow inconveniently formidable, the device of reasserting the Throne's authority by appointing temporary provincial governors was resorted to, so that the prefectural organization came into existence side by side with the feudal, and the administration preserved this dual form until the middle of the seventh century. There will be occasion to refer to the matter again at a later date.

\section{ANNALS OF THE UJI}

It is essential to an intelligent appreciation of Japanese history that some knowledge should be acquired of the annals of the great $u j i$.

From the time of Nintoku (A.D. 313-399) until the introduction of Buddhism (A.D. 552), there were four uji whose chiefs participated conspicuously in the government of the country. The first was that of Heguri. It belonged to the Imperial class (Kwöbetsu) and was descended from the celebrated Takenouchino-Sukune. In the days of the Emperor Muretsu (499-506), the chief of this uji attempted to usurp the throne and was crushed. The second was the Ötomo. This uji belonged to the Kami class (Shimbetsu) and had for ancestor Michi no Omi, the most distinguished general in the service of the first Emperor Jimmu. The chiefs of the Ötomo-uji filled the post of general from age to age, and its members guarded the palace gates. During the reign of Yüryaku the office of $\bar{o}$-muraji was bestowed upon Moroya, then chief of this uji, and the influence he wielded may be inferred from the language of an Imperial rescript where it is said that "the tami-be of the $\bar{o}$-muraji fill the country." His son, Kanamura, succeeded him. By his sword the rebellion of Heguri no Matori was quelled, and by his advice Keitai was called to the Throne. He served also under Ankan, Senkwa, and Kimmei, but the miscarriage of Japan's relations with Korea was attributed to him, and the title of $\bar{o}$-muraji was not conferred on any of his descendants.

The uji of Mononobe next calls for notice. "Monono-be" literally signifies, when expanded, a group (be) of soldiers (tsuwamono). In later times a warrior in Japan was called mono-no-fu (or bushi), which is written with the ideographs mono-be. This $u i j$ also belonged to the Kami class, and its progenitor was Umashimade, who surrendered Yamato to Jimmu on the ground of consanguinity. Thenceforth the members of the $u j i$ formed the Imperial guards (uchi-tsu-mononobe) and its chiefs commanded them. Among all the uji of the Kami class the Mononobe and the Ötomo ranked first, and after the latter's failure in connexion with Korea, the Mononobe stood alone. During the reign 
of Y'üryaku, the uji's chief became $\bar{o}$-muraji, as did his grandson, Okoshi, and the latter's son, Moriya, was destroyed by the ō-omi, Soga no Umako, in the tumult on the accession of Sushun (A.D. 588).

The fourth of the great $u j i$ was the Soga, descended from Takenouchi-noSukune. After the ruin of the Heguri, this uji stood at the head of all the Imperial class. In the reign of Senkwa (536-539), Iname, chief of the Soga; was appointed $\bar{o}$-omi, and his son, Umako, who held the same rank, occupies an important place in connexion with the introduction of Buddhism. It will be observed that among these four uji, Heguri and Soga served as eivil officials and Ōtomo and Mononobe as military.

There are also three other uji which figure prominently on the stage of Japanese history. They are the Nakotomi, the Imibe, and the Kume. The Nakatomi discharged the functions of religious supplication and divination, standing, for those purposes, between ( $N a k a)$ the Throne and the deities. The Imibe had charge of everything relating to religious festivals; an office, which required that they should abstain ( $\mathrm{imi}$ suru) from all things unclean. The Kume were descended from Amatsu Kume no Mikoto, and their duties were to act as chamberlains and as guards of the Court.

Finally, there was the $\bar{O} g a-u j i$, descended from Ōkuninushi, which makes the eighth of the great uji. From the time of the Emperor Jimmu to that of the Empress Suiko (A.D. 593-628), the nobles who served in ministerial capacities numbered forty and of that total the Mononobe furnished sixteen; the Ōtomo, six; the $\bar{o}$-omi houses (i.e. the Kwöbetsu), nine; the Imibe, one; the Nakatomi, six; and the $\bar{O} g a$, two. Thus, the military uji of Mononobe and $\bar{O} t o m o$ gave to the State twenty-two ministers out of forty during a space of some twelve centuries.

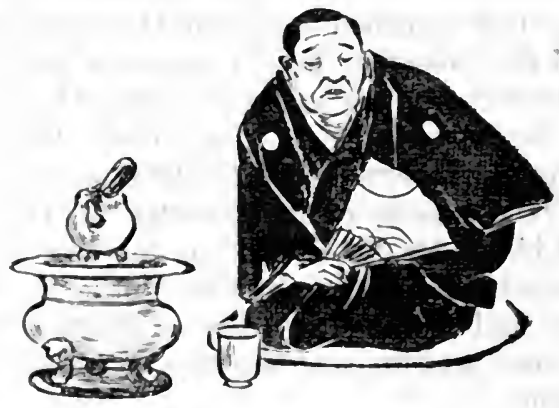

Prozessional Stort-tellek 


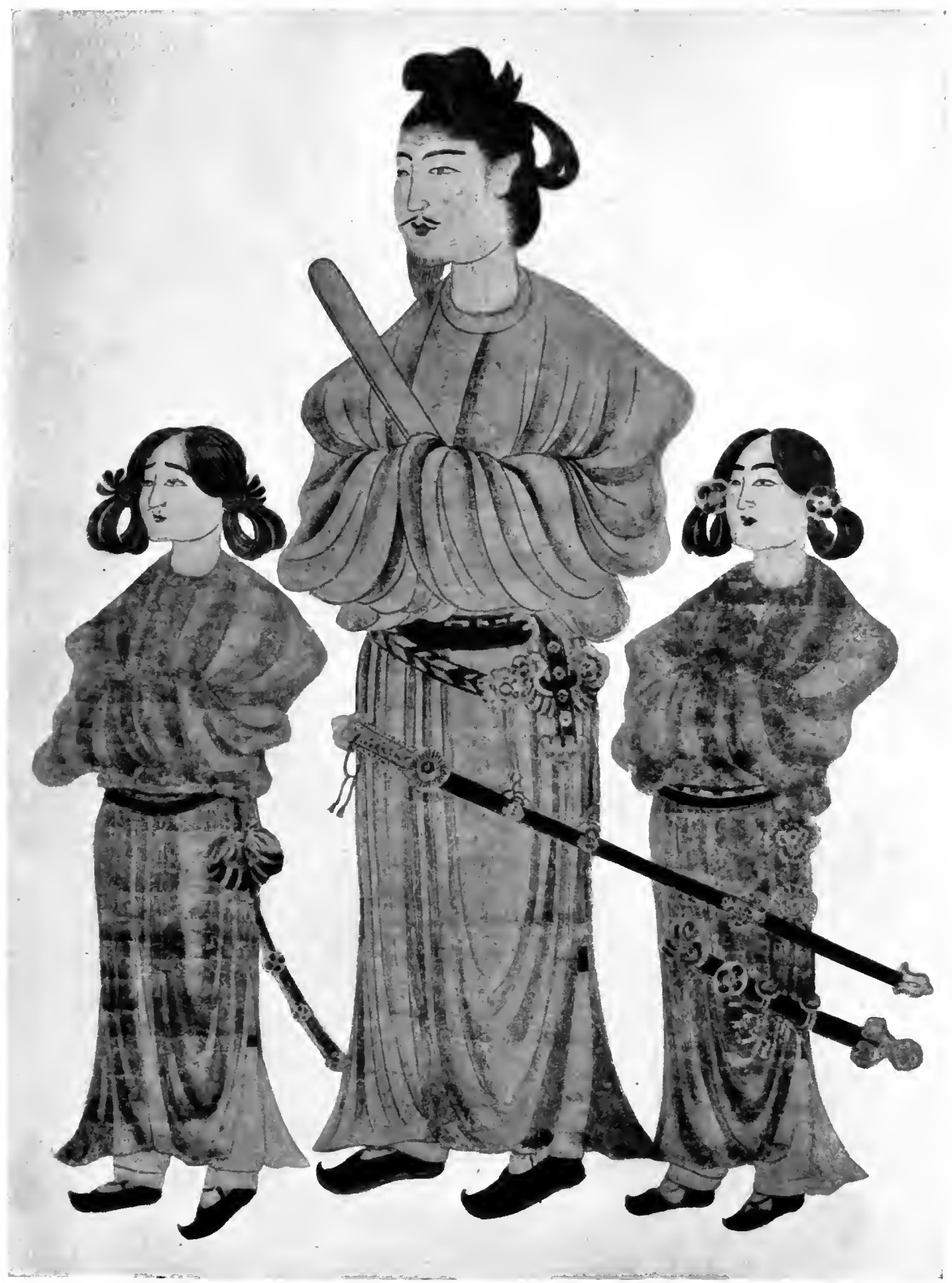

PRINCE SHŌTOKU (572-621 A. D.) (From a painting in the collection of The Imperial Household) 



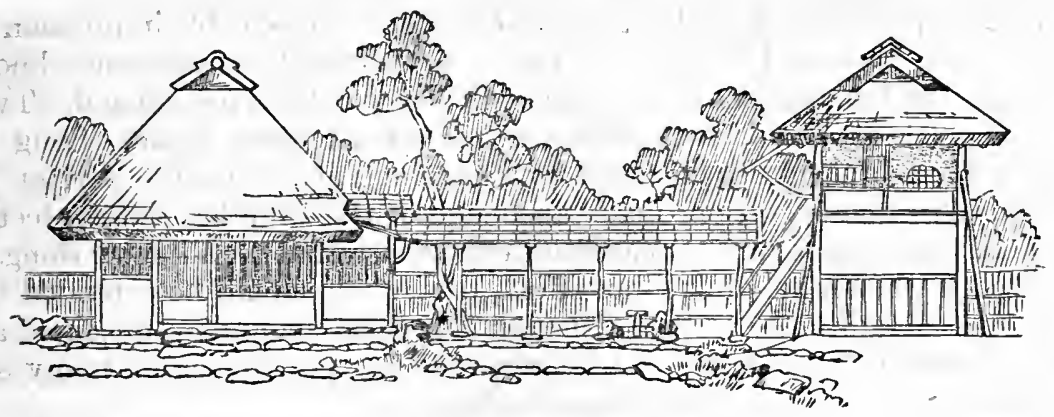

Shiguretei aNd Kisa-no-chaya in the KōdaijI

(Examples of Ancient Tea Houses)

\section{CHAPTER XIV}

\section{FROM THE 29TH TO THE 35TH SOVEREIGN}

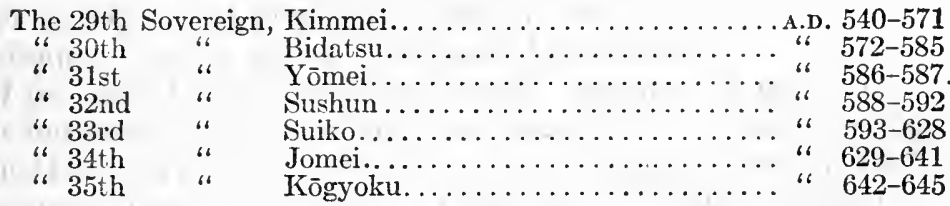

The seven reigns - five Emperors and two Empresses - commencing with the Emperor Kimmei and ending with the Empress Koggyoku, covered a period of. 105 years, from 540 to 645 , and are memorable on three accounts: the introduction of Buddhism; the usurpation of the great uji, and the loss of Japan's possessions in Korea.

\section{THE INTRODUCTION OF BUDDHISM}

During the reign of the Emperor Ming of the Hou-Han dynasty, in the year A.D. 65 , a mission was sent from China to procure the Buddhist Sutras as well as some teachers of the Indian faith. More than three centuries elapsed before, in the year 372, the creed obtained a footing in Korea; and not for another century and a half did it find its way (522) to Japan. It encountered no obstacles in Korea. The animistic belief of the early Koreans has never been clearly studied, but whatever its exact nature may have been, it certainly evinced no bigotry in the presence of the foreign faith, for within three years of the arrival of the first image of Sakiya Muni in Koma, two large monasteries had been built, and the King and his Court were all converts.

No such reception awaited Buddhism in Japan when, in 522, a Chinese bonze, Shiba Tachito, arrived, erected a temple on the Sakata plain in Yamato, enshrined an image of Buddha there, and endeavoured to propagate the faith. At that time, Wu, the first Emperor of the Liang dynasty in China, was employing all his influence to popularize the Indian creed. Tradition says that Shiba Tachito came from Liang, and in all probability he took the overland route vi $\hat{a}$ 
the Korean peninsula, but the facts are obseure. No sensible impression seems to have been produced in Japan by this essay. Buddhism was made known to a few, but the Japanese showed no disposition to worship a foreign god. Twentythree years later (545), the subject attracted attention again. Song Wang Myong, King of Kudara, menaced by a crushing attack on the part of Koma and Shiragi in co-operation, made an image of the Buddha, sixteen feet high, and petitioned the Court of Yamato in the sense that as all good things were promised in the sequel of such an effort, protection should be extended to him by Japan. Tradition says that although Biddhism had not yet secured a footing in Yamato, this image must be regarded as the pioneer of many similar objects subsequently set up in Japanese temples.

Nevertheless, A.D. 552 is usually spoken of as the date of Buddhism's introduction into Japan. In that year the same King of Kudara presented direct to the Yamato Court a copper image of Buddha plated with gold; several canopies (tengai), and some volumes of the sacred books, by the hands of Tori Shichi (Korean pronunciation, Nori Sachhi) and others. The envoys carried also a memorial which said: "This doctrine is, among all, most excellent. But it is difficult to explain and difficult to understand. Even the Duke Chou and Confucius did not attain to comprehension. It can produce fortune and retribution, immeasurable, illimitable. It can transform a man into a Bôdhi. Imagine a treasure capable of satisfying all desires in proportion as it is used. Such a treasure is this wonderful doctrine. Every earnest supplication is fulfilled and nothing is wanting. Moreover, from farthest India to the three Han, all have embraced the doctrine, and there is none that does not receive it with reverence wherever it is preached. Therefore thy servant, Myong, in all sincerity, sends his retainer, Nori Sachhi, to transmit it to the Imperial country, that it may be diffused abroad throughout the home provinces, ${ }^{1}$ so as to fulfil the recorded saying of the Buddha, 'My law shall spread to the East." " 2 It is highly probable that in the effort to win the Yamato Court to Buddhism, King Myong was influenced as much by political as by moral motives. He sought to use the foreign faith as a link to bind Japan to his country, so that he might count on his oversea neighbour's powerful aid against the attacks of Koma and Shiragi.

A more interesting question, however, is the aspect under which the new faith presented itself to the Japanese when it first arrived among them as a rival of Shinto and Confucianism. There can be no doubt that the form in which it became known at the outset was the Hinayana, or Exoteric, as distinguished from the Mahayana, or Esoteric. But how did the Japanese converts reconcile its acceptance with their allegiance to the traditional faith, Shintō? The clearest available answer to this question is contained in a book called Taishiden Hochu, where, in reply to a query from his father, Yōmei, who professed inability to believe foreign doctrines at variance with those handed down from the age of the Kami, Prince Shōtoku is recorded to have replied:-

Your Majesty has considered only one aspect of the matter. I am young and ignorant, but I have carefully studied the teachings of Confucius and the doctrine of the Kami. I find that there is a plain distinction. Shintô, since its roots spring from the Kami, came into existence simultaneously with the heaven and the earth, and thus expounds the origin of human beings. Confucianism, being a system of moral principles, is coeval with the people and deals with the middle stage of humanity. Buddhism, the fruit of prineiples, arose when the human

[1 That is to say, the Kinai, or five provinees, of which Yamato is the centre.]

['The memorial is held by some crities to be of doubtful authenticity, though the compilers of the Chronicles may have inserted it in good faith.] 
intellect matured. It explains the last stage of man. To like or dislike Buddhism without any reason is simply an individual prejudice. Heaven commands us to obey reason. 'The individual cannot contend against heaven. Recognizing that impossibility, nevertheless to rely on the individual is not the act of a wise man or an intelligent. Whether the Emperor desire to encourage this creed is a matter within his own will. Should he desire to reject it, let him do so; it will arise one generation later. Should he desire to adopt it, let him do so; it will arise one generation earlier. A generation is as one moment in heaven's eyes. Heaven is eternal. The Emperor's reign is limited to a generation; heaven is boundless and illimitable. How can the Emperor struggle against heaven? How can heaven be concerned about a loss of time?

The eminent modern Japanese historiographer, Dr. Ariga, is disposed to regard the above as the composition of some one of later date than the illustrious Shōtoku, but he considers that it rightly represents the relation assigned to the three doctrines by the Japanese of the sixth and seventh centuries. "Shintō teaches about the origin of the country but does not deal with the present or the future. Confucianism discusses the present and has no concern with the past or the future. Buddhism, alone, preaches about the future. That life ends with the present cannot be believed by all. Many men think of the future, and it was therefore inevitable that many should embrace Buddhism."

But at the moment when the memorial of King Myong was presented to the Emperor Kimmei, the latter was unprepared to make a definite reply. The image, indeed, he found to be full of dignity, but he left his ministers to decide whether it should be worshipped or not. A division of opinion resulted. The $\bar{o}$-omi, Iname, of the Soga family, advised that, as Buddhism had won worship from all the nations on the West, Japan should not be singular. But the $\bar{o}-$ muraji; Okoshi, of the Mononobe-uji, and Kamako, muraji of the Nakatomi-uji, counselled that to bow down to foreign deities would be to incur the anger of the national gods. In a word, the civil officials advocated the adoption of the Indian creed; the military and ecclesiastical officials opposed it. That the head of the Mononobe-uji should have adopted this attitude was natural: it is always the disposition of soldiers to be conservative, and that is notably true of the Japanese soldier (bushi). In the case of the Nakatomi, also, we have to remember that they were, in a sense, the guardians of the Shinto ceremonials: thus, their aversion to the acceptance of a strange faith is explained.

What is to be said, however, of the apparently radical policy of the Soga chief? Why should he have advocated so readily the introduction of a foreign creed? There are two apparent reasons. One is that the Hata and Aya groups of Korean and Chinese artisans were under the control of the Soga-uji, and that the latter were therefore disposed to welcome all innovations coming from the Asiatic continent. The other is that between the $\bar{o}$-muraji of the Kami class (Shimbetsu) and the $\bar{o}$-omi of the Imperial class (Kwōbetsu) there had existed for some time a political rivalry which began to be acute at about the period of the coming of Buddhism, and which was destined to culminate, forty years later, in a great catastrophe. The Emperor himself steered a middle course. He neither opposed nor approved but entrusted the image to the keeping of the Soga noble. Probably his Majesty was not unwilling to submit the experiment to a practical test vicariously, for it is to be noted that, in those days, the influence of the Kami for good or for evil was believed to be freely exercised in human affairs.

This last consideration does not seem to have influenced Soga no Iname at all. He must have been singularly free from the superstitions of his age, for he not only received the image with pleasure but also enshrined it with all solemnity in his Mukuhara residence, which he converted wholly into a temple. 
Very shortly afterwards, however, the country was visited by a pestilence, and the calamity being regarded as an expression of the Kami's resentment, the $\bar{o}$-muraji of the Mononobe and the muraji of the Nakatomi urged the Emperor to cast out the emblems of a foreign faith. Accordingly, the statue of the Buddha was thrown into the Naniwa eanal and the temple was burned to the ground. Necessarily these events sharply accentuated the emnity between the Soga and the Mononobe. Twenty-five years passed, however, without any attempt to restore the worship of the Buddha. Iname, the $\bar{o}$-omi of the Soga, died; Okoshi, the o-muraji of the Mononobe, died, and they were succeeded in these high offices by their sons, Umako and Moriya, respectively.

When the Emperor Bidatsu ascended the throne in A.D. 572, the political stage was practically occupied by these two ministers only; they had no competitors of equal rank. In 577, the King of Kudara made a second attempt to introduce Buddhism into Japan. He sent to the Yamato Court two hundred volumes of sacred books; an ascetic; a yogi (meditative monk); a nun; a reciter of mantras (magic spells); a maker of images, and a temple architect. If any excitement was caused by this event, the annals say nothing of the fact. It is briefly related that ultimately a temple was built for the new-comers in Naniwa (modern Osaka). Two years later, Shiragi also sent a Buddhist eidolon, and in 584 - just sixty-two years after the coming of Shiba Tachito from Liang and thirty-two years after Soga no Iname's attempt to popularize the Indian faith - two Japanese high officials returned from Korea, carrying with them a bronze image of Buddha and a stone image of Miroku. ${ }^{1}$ These two images were handed over, at his request, to the $\bar{o}$-omi, Umako, who had inherited his father's ideas about Buddhism. He invited Shiba Tachito, then a village mayor, to accompany one Hida on a search throughout the provinces for Buddhist devotees. They found a man called Eben, a Korean who had originally been a priest, and he, having resumed the stole, consecrated the twelve-year-old daughter of Shiba Tachito, together with two other girls, as nuns. The $\bar{o}$-omi now built a temple, where the image of Miroku was enshrined, and a pagoda on the top of whose central pillar was deposited a Buddhist relic which had shown miraculous powers.

Thus, once more the creed of Sakiya Muni seemed to have found a footing in Japan. But again the old superstitions prevailed. The plague of small-pox broke out once more. This fell disease had been carried from Cochin China by the troops of General Ma Yuan during the Han dynasty, and it reached Japan almost simultaneously with the importation of Buddhism. The physicians of the East had no skill in treating it, and its ravages were terrible, those that eseaped with their lives having generally to lament the loss of their eyes. So soon as the malady made its second appearance in the immediate sequel of the new honours paid to Buddhism, men began to cry out that the Kami were punishing the nation's apostacy, and the ó-muraji, Moriya, urged the Emperor (Bidatsu) to authorize the suppression of the alien religion. Bidatsu, who at heart had always been hostile to the innovation, consented readily, and tha $\bar{o}-m u r a j i$, taking upon himself the duty of directing the work of iconoclasm, caused the pagoda and the temple to be razed and burned, threw the image into the canal, and flogged the nuns. But the pestilence was not stayed. Its ravages grew more unsparing. The Emperor himself, as well as the $\overline{0}$-omi, Umako, were attacked, and now the popular outery took another tone: men ascribed the plague to the wrath of Buddha. Umako, in turn, pleaded with the Emperor, and was per- 
mitted to rebuild the temple and reinstate the nuns, on condition that no efforts were made to proselytize.

Thus Buddhism recovered its footing, but the enmity between the $\bar{o}-m u r a j i$ and the $\bar{o}$-omi grew more implacable than ever. They insulted each other, even at the obsequies of the sovereign, and an occasion alone was needed to convert their anger into an appeal to arms.

\section{DISPUTES ABOUT THE ACCESSION}

When the Emperor Bidatsu died (A.D. 585) no nomination of a Prince Imperial had taken place, and the feud known to exist between the $\overline{0}$-omi and the $\bar{o}$-muraji increased the danger of the situation. The following genealogical table will serve to elucidate the relation in which the Soga-uji stood to the Imperial Family, as well as the relation between the members of the latter:

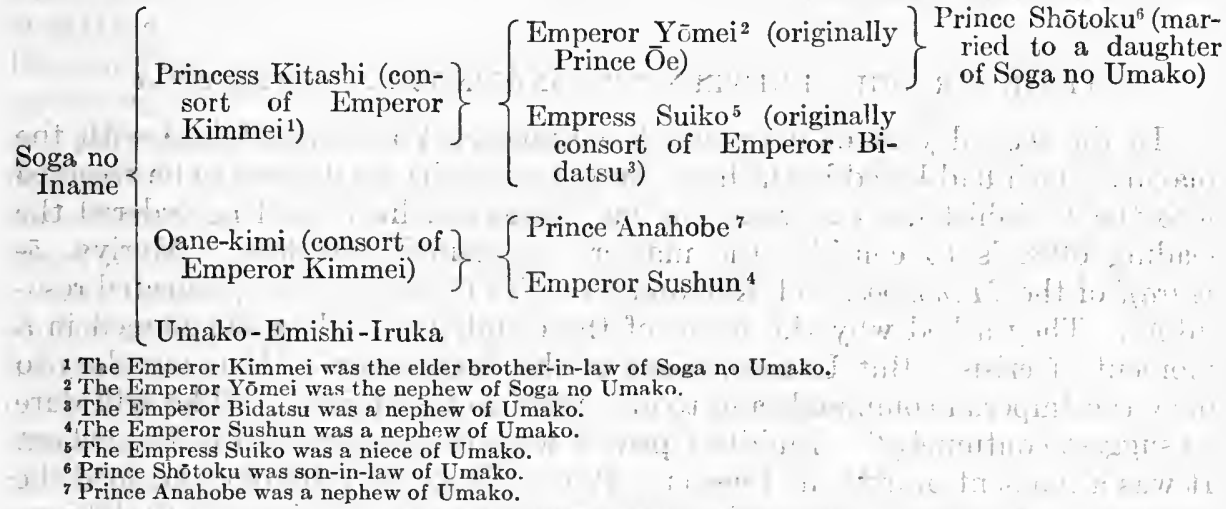

It is thus seen that the great $u j i$ of Soga was closely related to all the Imperial personages who figured prominently on the stage at this period of Japanese history.

\section{THE EMPEROR YŌMEI}

The Emperor. Yōmei was the fourth son of the Emperor Kimmei and a nephew of the $\bar{o}$-omi, Umako. The Chronicles say that he "believed in the law of Buddha and reverenced Shintō," which term now makes its first appearance on the page of Japanese history, the Kami alone having been spoken of hitherto. Yōmei's accession was opposed by his younger brother, Prince Anahobe (vide above genealogical table), who had the support of the $\bar{o}$-muraji, Moriya; but the Soga influence was exerted in Yōmei's behalf. Anahobe did not suffer his discomfiture patiently. He attempted to procure admission to the mourning chamber of the deceased Emperor for some unexplained purpose, and being resisted by Miwa Sakō, who commanded the palace guards, he laid a formal complaint before the $\bar{o}$-omi and the $\bar{o}$-muraji. In the sequel Sakō was killed by the troops of the $\bar{o}$-muraji, though he merited rather the latter's protection as a brave soldier who had merely done his duty, who opposed Buddhism, and who enjoyed the confidence of the Empress Dowager. To Umako, predicting that this deed of undeserved violence would prove the beginning of serious trouble, Moriya insultingly retorted that small-minded men did not understand such matters. Moriya's mind was of the rough military type. He did not fathom the subtle unscrupulous intellect of an adversary like Umako, and was destined to learn the truth by a bitter process. 


\section{SHŌTOKU TAISHI}

Umayado, eldest son of the Emperor Yōmei, is one of the most distinguished figures in the annals of Japan. He has been well called "the Constantine of Buddhism." In proof of his extraordinary sagacity, the Chronicles relate that in a lawsuit he could hear the evidence of ten men without confusing them. From his earliest youth he evinced a remarkable disposition for study. A learned man was invited from China to teach him the classics, and priests were brought from Koma to expound the doctrine of Buddhism, in which faith he ultimately became a profound believer. In fact, to his influence, more than to any other single factor, may be ascribed the final adoption of the Indian creed by Japan. He never actually ascended the throne, but as regent under the Empress Suiko he wiclded Imperial authority. In history he is known as Shotoku'Taishi (Prince Shōtoku).

\section{FINAL STRUGGLE BETWEEN THE MONONOBE AND THE SOGA}

In the sccond year of his reign, the Emperor Yomei was seized with the malady which had killed his father. In his extremity he desired to be received into the Buddhist faith to which he had always inclined, and he ordered the leading officials to consider the matter. A council was held. Moriya, $\bar{o}-$ muraji of the Mononobe, and Katsumi, muraji of the Nakatomi, objected resolutely. They asked why the Kami of the country should be abandoned in a moment of erisis. But Umako, o-omi of the Soga, said: "It is our duty to obey the Imperial commands and to give relief to his Majesty. Who will dare to suggest contumely?" Buddhist priests were then summoned to the palace. It was a moment of extreme tension. Prince Umayado (Shōtoku) grasped the hands of the $\bar{o}$-omi and exclaimed, "If the minister had not believed in Buddhism, who would have ventured to give such counsel?" Umako's answer is said to have been: "Your Imperial Highness will work for the propagation of the faith. I, a humble subject, will maintain it to the death." Moriya, the $\bar{o}$-muraji, made no attempt to hide his resentment, but recognizing that his adherents in the palace were comparatively few, he withdrew to a safe place and there concentrated his forces, endeavouring, at the same time, to enlist by magic rites the assistance of the Kami against the disciples of the foreign faith. Meanwhile the Emperor's malady ended fatally. His reign had lasted only one year. At the point of death he was comforted by an assurance that the son of Shiba Tachito would renounce the world to revere his Majesty's memory and would make an image of the Buddha sixteen feet high.

Buddhism had now gained a firm footing at the Yamato Court, but its opponents were still active. Their leader, the $\overline{\boldsymbol{o}}$-muraji, thought that his best chance of success was to contrive the accession of Prince Anahobe, whose attempt to take precedence of his elder brother, the Emperor Yomei, has becn already noted. The conspiracy was discovered, and the Soga forces, acting under the nominal authority of the deceased Emperor's consort, Umako's niece, moved against Anahobe and Moriya, who had not been able to combine their strength: The destruction of Prince Anahobe was easily effected, but the work of dealing with the $\overline{0}$-muraji taxed the resourees of the Soga to the utmost. Moriya himself ascended a tree and by skill of archery held his assailants long at bay. Archery had been practised assiduously by the Yamato warrior from time immemorial, and arrows possessing remarkable power of penetration had been 
devised. During the reign of Nintoku, when envoys from Koma presented to the Court iron shields and iron targets, a Japanese archer, Tatebito, was able to pierce them; and in the time of Yüryaku, a rebel named Iratsuko shot a shaft which, passing through his adversary's shield and twofold armour, entered the flesh of his body to the depth of an inch. There was an archery hall within the enclosure of the palace; whenever envoys or functionaries from foreign countries visited Yamato they were invited to shoot there; frequent trials of skill took place, and when oversea sovereigns applied for military aid, it was not unusual to send some bundles of arrows in lieu of soldiers.

Thus, the general of the Mononobe, perched among the branches of a tree, with an unlimited supply of shafts and with highly trained skill as a bowman, was a formidable adversary. Moriya and his large following of born soldiers drove back the Soga forces three times. Success seemed to be in sight for the champion of the Kami. At this desperate stage Prince Shōtoku - then a lad of sixteen - fastened to his helmet images of the "Four Guardian Kings of Heaven" and vowed to build a temple in their honour if victory was vouchsafed to his arms. At the same time, the $\bar{o}$-omi, Umako, took oath to dedicate temples and propagate Buddhism. The combat had now assumed a distinctly religious character. Shōtoku and Umako advanced again to the attack; Moriya was shot down; his family and followers fled, were put to the sword or sent into slavery, and all his property was confiscated.

An incident of this campaign illustrates the character of the Japanese soldier as revealed in the pages of subsequent history: a character whose prominent traits were dauntless courage and romantic sympathy. Yorozu, a dependent of the $\bar{o}$-muraji, was reduced to the last straits after a desperate fight. The Chronicles say: "Then he took the sword which he wore, cut his bow into three pieces, and bending his sword, flung it into the river. With a dagger which he had besides, he stabbed himself in the throat and died. The governor of Kawachi having reported the circumstances of Yorozu's death to the Court, the latter gave an order by a stamp ${ }^{2}$ that his body should be cut into eight pieces and distributed among the eight provinces." 3 In accordance with this order the governor was about to dismember the corpse when thunder pealed and a great rain fell. "Now there was a white dog which had been kept by Yorozu. Looking up and looking down, it went round, howling beside the body, and at last, taking up the head in its mouth, it placed it on an ancient mound; lay down close by, and starved to death. When this was reported to the Court, the latter, moved by profound pity, issued an order that the dog's conduct should be handed down to after ages, and that the kindred of Yorozu should be allowed to construct a tomb and bury his remains."

\section{BUILDING OF TEMPLES}

After order had been restored, Prince Shōtoku fulfilled his vow by building in the province of Settsu a temple dedicated to the Four Guardian Kings of Heaven (Shitennō-ji), and by way of endowment there were handed over to it one-half of the servants of the $\bar{o}$-muraji, together with his house and a quantity of

[ 1 The "Four Guardian Kings" (Shi-Tennō) are the warriors who guard the world against the attacks of demons.]

[ ${ }^{2}$ A stamp in red or black on the palm of the hand:]

[ 3 This custom of dismembering and distributing the remains was practised in Korea until the time, at the close of the nineteenth century, when the peninsula came under Japanese protection. It was never customary in Japan.] 
other property. The ō-omi, Umako, also erected a temple ealled Hōkō-ji in Asuka near Nara. It has been shown above that Soga no. Iname converted one of his houses into a temple to receive the Buddhist image sent by Myong in 552 , and that his son, Umako, erected a temple on the east of his residenee to enshrine a stone image of Miroku, in 584. But these two edifices partook largely of the nature of private worship. The first publie temples for the service of Buddhism were Shōtoku's Shitennō-ji and Umako's Hōkō-ji erected in 587.

\section{AMOUNT OF THE $\bar{O}-M U R A J I ' S$ PROPERTY}

In the Annals of Prince Shotoku (Taishi-den) it is recorded that the parts of the $\bar{o}$-muraji's estate with which the temple of the Four Kings was endowed were 273 members of his family and household; his three houses and movable property, together with his domain measuring 186,890 shiro, and consisting of two areas of 128,640 shiro and 58,250 shiro in Kawachi and Settsu, respectively. The shiro is variously reckoned at from $51 / 2$ to 7.12 tsubo ( 1 tsubo $=36$ square feet). Taking the shiro as 6 tsubo, the above three areas total 1000 acres approximately. That this represented a part only of the $\bar{o}$-muraji's property is held by historians, who point to the fact that the $\bar{o}$-om $i$ 's wife, a younger sister of the $\bar{o}$-muraji, incited her husband to destroy Moriya for the sake of getting possession of his wealth.

\section{THE EMPEROR SUSHUN}

The deaths of Prince Anahobe and Moriya left the Government completely in the hands of Soga no Umako. There was no ō-muraji; the $\bar{o}$-omi was supreme. At his instance the crown was placed upon the head of his youngest nephew, Sushun. But Sushun entertained no friendship for Umako nor any feeling of gratitude for the latter's aetion in contriving his suecession to the throne. Aetive, daring, and astute, he judged the $\bar{o}$-omi to be swayed solely by personal ambition, and he placed no faith in the sincerity of the great official's Buddhist propaganda. Meanwhile, the fortunes of the new faith prospered. When the dying Emperor, Yōmei, asked to be qualified for Nirvana, priests were summoned from Kudara. They came in 588, the first year of Sushun's reign, earrying relies (sarira), and they were accompanied by ascetics, temple-architects, metalfounders, potters, and a pietorial artist.

The Indian creed now began to present itself to the Japanese people, not merely as a vehicle for securing insensibility to suffering in this life and happiness in the next, but also as a great protagonist of refined progress, gorgeous in paraphernalia, impressive in rites, eminently practical in teachings, and substituting a vivid rainbow of positive hope for the negative pallor of Shintō. Men began to adopt the stole; women to take the veil, and people to visit the hills in search of timbers suited for the frames of massive temples. Soga no Umako, the ostensible leader of this great movement, grew more and more arrogant and arbitrary. The youthful Emperor umbosomed himself to Prince Shötoku, avowing his aversion to the $\bar{o}$-omi and his uncontrollable desire to be freed from the incubus of such a minister. Shōtoku counselled patience, but Sushun's impetuosity could not brook delay, nor did he reflect that he was surrounded by partisans of the Soga.

A Court lady betrayed his designs to the $\bar{o}$-omi, and the latter decided that the Emperor must be destroyed. An assassin was found in the person of Koma, a naturalized Chinese, suzerain of the $A y a-u j i$, and, being introduced into the 
palace by the $\bar{o}$-omi under pretence of offering textile fabrics from the eastern provinces, he killed the Emperor. So omnipotent was the Soga chief that his murderous envoy was not even questioned. He received open thanks from his employer and might have risen to high office had he not debauched a daughter of the $\bar{o}$-omi. Then Umako caused him to be hung from a tree and made a target of his body, charging him with having taken the Emperor's life. "I knew only that there was an $\bar{o}-o m i$," retorted the man. "I did not know there was an Emperor." Many others shared Koma's comparative ignorance when the Soga were in power. At the Emperor Yōmei's death, only one person honoured his memory by entering the Buddhist priesthood. When Soga no Umako died, a thousand men received the tonsure. The unfortunate Sushun was interred on the day of his murder, an extreme indignity, yet no one ventured to protest; and even Prince Shōtoku, while predicting that the assassin would ultimately suffer retribution, justified the assassination on the ground that previous misdeeds had deserved it.

Shōtoku's conduct on this occasion has inspired much censure and surprise when contrasted with his conspicuous respect for virtue in all other cases. But the history of the time requires intelligent expansion. Cursory reading suggests that Umako's resolve to kill Sushun was taken suddenly in consequence of discovering the latter's angry mood. The truth seems to be that Sushun was doomed from the moment of his accession. His elder brother had perished at the hands of Umako's troops, and if he himself did not meet the same fate, absence of plausible pretext alone saved him. To suffer him to reign, harbouring, as he must have harboured, bitter resentment against his brother's slayer, would have been a weakness inconsistent with Umako's character. Sushun was placed on the throne as a concession to appearance, but, at the same time, he was surrounded with creatures of the $\bar{o}$-omi, so that the latter had constant cognizance of the sovereign's every word and act.

When the $\bar{o}$-omi judged the time fitting, he proposed to the Emperor that an expedition should be despatched to recover Mimana, which had been lost to Japan some time previously: An army of twenty thousand men, commanded by a majority of the omi and muraji, was sent to Tsukushi, and all potential opponents of the Soga chief having been thus removed, he proceeded to carry out his design against the Emperor's life. The very indignity done to Sushun's remains testifies the thoroughness of the Soga plot. It has been shown that in early days the erection of a tomb for an Imperial personage was a heavy task, involving much time and labour. Pending the completion of the work, the corpse was put into a coffin and guarded day and night, for which purpose a separate palace was ${ }^{1}$ erected. When the sepulchre had been fully prepared, the remains were transferred thither with elaborate ceremonials, ${ }^{2}$ and the tomb was thenceforth under the care of guardians (rioko).

All these observances were dispensed with in the case of the Emperor Sushun. His remains did not receive even the measure of respect that would have been paid to the corpse of the commonest among his subjects. Nothing could indicate more vividly the omnipotence of the $\bar{o}$-omi; everything had been prepared so that his partisans could bury the body almost before it was cold. Had Prince Shōtoku protested, he would have been guilty of the futility described

["Called Araki-no-miya, or the "rough palace." The interval during which time the coffin remained there was termed kari-mo-gari, or "temporary mourning."]

[" Known as kakushi-matsuri, or the "rite of hiding." It would seem that the term of one year's mourning prescribed in the case of a parent had its origin in the above arrangement.] 
by a Chinese proverb as "spitting at the sky." "Besides, Shōtoku and Umako were allies otherwise. The Soga minister, in his struggle with the military. party, had needed the assistance of Shōtoku, and had secured it by community of allegiance to Buddhism. The prince, in his projected struggle against the $u j i$ system, needed the assistance of Buddhist disciples in general, and in his effort to reach the throne, needed the assistance of Umako in particular. In short, he was building the edifice of a great reform, and to have pitted himself, at the age of nineteen, against the mature strength of the $\bar{o}$-om $i$ would have been to perish on the threshold of his purpose.

THE EMPRESS SUIKO

By the contrivance of Umako, the consort of the Emperor Bidatsu was now placed on the throne, Prince Shōtoku being nominated Prince Imperial and regent. The Soga-uji held absolute power in every department of State affairs.

\section{THE CONSTITUTION OF SHŌTOKU}

One of the most remarkable documents in Japanese annals is the Jushichi Kempō, or Seventeen-Article Constitution, compiled by Shōtoku Taishi in A.D. 604. It is commonly spoken of as the first written law of Japan. But it is not a body of laws in the proper sense of the term. There are no penal provisions, nor is there any evidence of promulgation with Imperial sanction. The seventeen articles are simply moral maxims, based on the teachings of Buddhism and Confucianism, and appealing to the sanctions of conscience. Prince Shōtoku, in his capacity of regent, compiled them and issued them to officials in the guise of "instructions."

I. Harmony is to be valued, and the avoidance of wanton opposition honoured. All men are swayed by class feeling and few are intelligent. Hence some disobey their lords and fathers or maintain feuds with neighbouring villages. But when the high are harmonious and the low friendly, and when there is concord in the discussion of affairs, right views spontaneously find acceptance. What is there that cannot be then accomplished?

II. Reverence sineerely the Three Treasures - Buddha, the Law, and the Priesthood for these are the final refuge of the Four Generated Beings ${ }^{1}$ and the supreme objects of faith in all countries. What man in what age can fail to revere this law? Few are utterly bad: they may be taught to follow it. But if they turn not to the Three Treasures, wherewithal shall their crookedness be made straight?

III. When you receive the Imperial Commands fail not to obey serupulously. The lord is Heaven; the vassal, Earth. Heaven overspreads; Earth upbears. When this is so, the four seasons follow their due course, and the powers of Nature develop their efficiency. If the Earth attempt to overspread, Heaven falls in ruin. Hence when the lord speaks, the vassal hearkens; when the superior acts, the inferior yields compliance. When, therefore, you receive an Imperial Command, fail not to carry it out serupulously. If there be want of care in this respect, a catastrophe naturally ensues.

IV. Ministers and funetionaries should make decorous behavior their guiding principle, for decorons bchavior is the main factor in governing the people. If superiors do not behave with decorum, inferiors are disorderly; if inferiors are wanting in proper behaviour, offences are inevit able. Thus it is that when lord and vassal behave with propriety, the distinetions of rank are not confused; and when the people behave with propriety, the government of the State proceeds of itself.

V. Refraining from gluttony and abandoning covetous desires, deal impartially with the suits brought before you. Of complaints preferred by the people there are a thousand in one day: how many, then, will there be in a series of years? Should he that decides suits at law make gain his ordinary motive and hear eauses with a view to receiving bribes, then will the suits of the rich man be like a stone flung into water, ${ }^{2}$ while the plaints of the poor will resemble

[1 Beings produced in transmigration by the four processes of being born from eggs, from a womb, from fermentation, or from metamorphosis.]

[' That is to say, they will encounter no opposition.] 
water cast on a stone. In such circumstances, the poor man will not know whither to betake himself, and the duty of a minister will not be discharged.

VI. Chastise that which is evil and encourage that-which is good. This was the excellent rule of antiquity. Conceal not, therefore, the good qualities of others, and fail not to correct that which is wrong when you see it. Flatterers and deceivers are a sharp weapon for the overthrow of the State, and a pointed sword for the destruction of the people. Sycophants are also fond, when they meet, of dilating to their superiors on the errors of their inferiors; to their inferiors, they censure the faults of their superiors. Men of this kind are all wanting in fidelity to their lord, and in benevolence towards the people. From such an origin great civil disturbances arise.

VII. Let every man have his own charge, and let not the spheres of duty be confused. When wise men are entrusted with office, the sound of praise arises. If unprincipled men hold office, disasters and tumults are multiplied. In this world, few are born with knowledge: wisdom is the product of earnest meditation. In all things, whether great or small, find the right man, and they will surely be well managed: on all occasions, be they urgent or the reverse, meet with but a wise man and they will of themselves be amenable. In this way will the State. be eternal and the Temples of the Earth and of Grain ${ }^{1}$ will be free from danger. Therefore did the wise sovereigns of antiquity seek the man to fill the office, and not the office for the sake of the man.

VIII. Let the ministers and functionaries attend the Court early in the morning, and retire late. The business of the State does not admit of remissness, and the whole day is hardly enough for its accomplishment. If, therefore, the attendance at Court is late, emergencies cannot be met: if officials retire soon, the work cannot be completed.

IX. Good faith is the foundation of right. In everything let there be good faith, for in it there surely consists the good and the bad, success and failure. If the lord and the vassal observe good faith one with another, what is there which cannot be accomplished? If the lord and the vassal do not observe good faith towards one another, everything without exception ends in failure.

X. Let us cease from wrath, and refrain from angry looks. Nor let us be resentful when others differ from us. For all men have hearts, and each heart has its own leanings. Their right is our wrong, and our right is their wrong. We are not unquestionably sages nor are they unquestionably fools. Both of us are simply ordinary men. How can anyone lay down a rule by which to distinguish right from wrong? For we are all, one with another, wise and foolish like a ring which has no end. Therefore, although others give way to anger, let us, on the contrary, dread our own faults, and though we alone may be in the right, let us follow the multitude and act like them.

XI. Give clear appreciation to merit and demerit, and deal out to each its sure reward or punishment. In these days, reward does not attend upon merit, nor punishment upon crime. Ye high functionaries who have charge of public affairs, let it be your task to make clear rewards and punishments.

XII. Let not the provincial authorities or the kuni no miyatsuko levy exactions on the people. In a country there are not two lords; the people have not two masters. The sovereign is the master of the people of the whole country. The officials to whom he gives charge are all his vassals. How can they, as well as the Government, presume to levy taxes on the people?

XIII. Let all persons entrusted with office attend equally to their functions. Owing to illness or despatch on missions their work may sometimes be neglected. But whenever they are able to attend to business, let them be as accommodating as though they had cognizance of it from before, and let them not hinder public affairs on the score of not having had to do with them.

XIV. Ministers and functionaries, be not envious. If we envy others, they, in turn, will envy us. The evils of envy know no limit. If others excel us in intelligence, it gives us no pleasure; if they surpass us in ability, we are envious. Therefore it is not until after the lapse of-five hundred years that we at last meet with a wise man, and even in a thousand years we hardly obtain one sage. But if wise men and sages be not found, how shall the country be governed?

XV. To turn away from that which is private and to set one's face towards that which is public - this is the path of a minister. If a man is influenced by private motives, he will assuredly feel resentment; if he is influenced by resentment, he will assuredly fail to act harmoniously with others; if he fails to act harmoniously with others, he will assuredly sacrifice the public interest to his private feelings. When resentment arises, it interferes with order and is subversive of law. Therefore, in the first clause it was said that superiors and inferiors should agree together. The purport is the same as this.

XVI. Let the employment of the people in forced labour be at seasonable times. This is an ancient and excellent rule. Let them be employed, therefore, in the winter months when they have leisure. But from spring to autumn, when they are engaged in agriculture or with the mulberry trees, the people should not be employed. For if they do not attend to agriculture, what will they have to eat? If they do not attend to the mulberry trees, what will they do for clothing? 
XVII. Decisions on import ant matters should not be rendered by one person alone: they should be diseussed by many. But small mat ters being of less consequenee, need not be consulted about by a numiber of people. It is only in the discussion of weighty affairs, when there is an apprehension of miscarritge, that matters should be arranged in concert with others so as to arrive at the right conclusion.'

For a document compiled at the beginning of the seventh century these seventeen ethical precepts merit much approbation. With the exception of the doctrine of expediency, enunciated at the close of the tenth article, the code of Shōtoku might be taken for guide by any community in any age. But the prince as a moral reformer ${ }^{2}$ cannot be eredited with originality; his merit consists in having studied Confucianism and Buddhism intelligently. The political purport of his code is more remarkable. In the whole seventeen articles there is nothing to inculcate worship of the Kami or observance of Shinto rites: Again, whereas, according to the Japanese creed, the sovereign power is derived from the Imperial ancestor, the latter is nowhere alluded to. The seventh article makes the eternity of the State and the security of the Imperial house depend upon wise administration by well-selected officials, but says nothing of hereditary rights. How is such a vital omission to be interpreted, except on the supposition that Shottoku, who had witnessed the worst abuses incidental to the hereditary system of the $u j i$, intended by this code to enter a solemn protest against that system?

Further, the importance attached to the people ${ }^{3}$ is a very prominent feature of the code. Thus, in Article IV, it is stated that "when the people behave with propriety the government of the State proceeds of itself;" Article V speaks of "complaints preferred by the people;" Artiele VI refers to "the overthrow of the State" and "the destruction of the people;" Article VII emphasises "the eternity of the State;" that "the sovereign is the master of the people of "the whole country;" that "the officials to whom he gives charge are all his vassals," and that these officials, whether miyatsuko or provincial authorities, must not "presume, as well as the Government, to levy taxes on the people." All these expressions amount to a distinct condemnation of the $u j i$ system, under which the only pcople directly subject to the sovereign were those of the minashiro, and those who had been naturalized or otherwise specially assigned, all the rest being practically the property of the $u j i$, and the only lands paying direct taxes to the Throne were the domains of the miyake.

Forty-two years later (A.D. 646), the abolition of private property in persons and lands was destined to become the policy of the State, but its foundations seem to have been laid in Shōtoku's time. It would be an error to suppose that the neglect of Shintō suggested by the above code was by any means a distinct feature of the era, or even a praetice of the prince himself. Thus, an Imperial edict, published in the year 607 , enjoined that there must be no remissness in the worslip of the Kami, and that they should be sincerely reverenced by all officials, In the sequel of this ediet Prince Shotoku himself, the $\bar{o}$-omi, and a number of functionaries worshipped the Kami of heaven and of earth. In fact, Shōtoku, for all his enthusiasm in the cause of Buddhism, seems to have shrunk from anything like bigoterl exclusiveness. He is quoted ${ }^{4}$ as saying: "The management of State affairs cannot be achieved unless it is based on knowledge, and the sources of knowledge are Confucianism, Buddhism, and Shintō."

[' The above is taken almost verbatim from Aston's translation of the Nihongi.]

$\left[{ }^{2}\right.$ It is a curious fact that tradition represents this prince as having been born at the door of a stable. Honce his original name, Umayado (Stable-door).]

[3 The word used is hyakusho, which ultimately eame to be applied to farmers only.]

['In the Sankyō-ron.]

[ ${ }^{5}$ The order of this enumeration is significant.] 
one of these three, must study the other two also; for what one knows seems reasonable, but that of which one is ignorant appears unreasonable. Therefore an administrator of public affairs should make himself acquainted with all three and should not affect one only, for such partiality signifies maladministration.

\section{DEATH OF SHŌTOKU TAISHI}

Prince Shōtoku died in the year 621. The Records' do not relate anything of his illness: they say merely that he foresaw the day and hour of his own death, and they' say also that when the Buddhist priest, Hyecha of Koma, who had instructed the prince in the "inner doctrine," learned of his decease, he also announced his determination to die on the same day of the same month in the following year so as "to meet the prince in the Pure Land and, together with him, pass through the metempsychosis of all living creatures."

The last months of Shōtoku's life were devoted to compiling, in concert with the $\bar{o}$-omi Umako, "a history of the Emperors; a history of the country, and the original record of the omi, the muraji, the tomo no miyatsuko, the kuni no miyatsuko, the 180 be, and the free subjects." This, the first Japanese historical work, was completed in the year 620 . It was known afterwards as the Kujihongi, and twenty-five years later (645) when - as will presently be seen - the execution of the Soga chief took place, the book was partially consumed by fire. Yet that it had not suffered beyond the possibility of reconstruction, and that it survived in the $\mathrm{Ko}-j i k i$ was never doubted until the days (1730-1801) of "the prince of Japanese literati," Motoori Norinaga. The question of authenticity is still unsettled.

Shōtoku's name is further connected with calendar making, though no particulars of his work in that line are on record. Japanese historians speak of him as the father of his country's civilization. They say that he breathed life into the nation; that he raised the status of the Empire; that he laid the foundations of Japanese learning; that he fixed the laws of decorum; that he imparted a new character to foreign relations, and that he was an incarnation of the Buddha, specially sent to convert Japan. The Chronicles say that at his death nobles and commoners alike, "the old, as if they had lost a dear child, the young, as if they had lost a beloved parent, filled the ways with the sound of their lamenting."

\section{THE SPREAD OF BUDDHISM AND THE CONTROL OF ITS PRIESTS}

The roots of Japanese Buddhism were watered with blood, as have been the roots of so many religions in so many countries. From the day of the destruction of the military party under the $\bar{o}$-muraji Moriya, the foreign faith flourished. Then - as has been shown - were built the first two great temples, and then, for the first time, a Buddhist place of worship was endowed ${ }^{1}$ with rich estates and an ample number of serfs to till them. Thenceforth the annals abound with references to the advent of Buddhist priests from Korea, bearing relics, or images. The omi and the muraji vied with each other in erecting shrines, and in 605, we find the Empresss Suiko commanding all high dignitaries of State to make 16-foot images of copper ${ }^{2}$ and of embroidery.

[ ${ }^{1}$ The endowment of religious edifices was not new in Japan. " A conspicuous instance was in A.D. 487, when rice-fields were dedicated to the Moon god and to the ancestor of the Sun goddess.]

$\left[{ }^{2}\right.$ The metal employed was of gold and copper; in the proportion of one part of the former 
Buddhist festivals were instituted in 606, and their magnificence, as compared with the extreme simplicity of the Shinto rites, must have deeply impressed the pcople. In a few decades Buddhism became a great social power, and since its priests and nuns were outside the sphere of ordinary administration, the question of their control soon presented itself. It became pressing in 623 when a priest killed his grandfather with an axe. The Empress Suiko, who was then on the throne, would have subjected the whole body of priests and nuns to judicial examination, a terrible ordeal in those days of torture; but at the instance of a Korean priest, officials corresponding to bishops $(s \bar{j} j \bar{o})$, high priests $(s \bar{z} z u)$ and abbots (hotto) were appointed from the ranks of Buddhism, and the duty of prescribing law and order was entrusted to them. This involved registration of all the priesthood, and it was thus found (623) that the temples numbered 46; the priests 816 , and the nuns 569 .

\section{INTERCOURSE WITH CHINA}

That not a few Chinese migrated to Japan in remote times is clear. The Records show that in the year A.D. 540, during the reign of Kimmei, immigrants from Tsin and Han were assembled and registered, when their number was found to be 7053 households. The terms "Tsin" and "Han" refer to Chinese dynasties of those names, whose sway covered the period between 255 B.c. and A.D. 419. Hence the expression is too vague to suggest any definite idea of the advent of those settlers; but the story of some, who came through Korea; has already been traced. It was in A.D. 552, during the reign of this same Kimmei, that Buddhism may be said to have found a home in Japan. China was then under the sceptre of the Liang dynasty, whose first sovereign, $\mathrm{Wu}$, had been such an enthusiastic Buddhist that he abandoned the throne for a monastery.. Yet China took no direct part in introducing the Indian faith to Japan, nor does it appear that from the fourth century A.D. down to the days of Shötoku Taishi, Japan thought seriously of having recourse to China as the fountain-head of the arts, the crafts, the literature, and the moral codes which she borrowed during the period from Korea.

Something of this want of enterprise may have been attributable to the unsettled state of China's domestic polities; something to the well-nigh perpetual troubles between Japan and Korea - troubles which not only taxed Japan's resources but also blocked the sole route by which China was then accessible, namely, the route through Korea. But when the Sui dynasty (A.D. 589-619) came to the Chinese throne, its founder, the Emperor Wen, on the one hand, devoted himself to encouraging literature and commerce; and on the other, threw Korea and Japan into a ferment by invading the former country at the head of a huge army. ${ }^{1}$ This happened when Shōtoku Taishi was in his sixteenth year, and though the great expedition proved abortive for aggressive purposes, it brought China into vivid prominenee, and when news reached Japan of extensions of the Middle Kingdom's territories under Wen's successor, the Japanese Crown Prinee determined to open direct intercourse with the Sui Court; not only for literary and religious purposes, but also to study the form of civilization which the whole Orient then revered. This resolve found practical expres-

to 430 of the latter. It is related that when these images were completed, the temple door proved too low to admit them, and the artisan - Tori the Saddle-maker - whose ingenuity overcame the diffieulty without pulling down the door, received large honour and reward.]

[' Reputed to have mustered 300,000 strong.] 
sion in the year 607, when the omi Imoko was sent as envoy to the Sui Court, a Chinese of the Saddlers' Corporation, by name Fukuri, being attached to him in the capacity of interpreter. China received these men hospitably and sent an envoy of her own, with a suite of twelve persons, to the Yamato sovereign in the following year.

The annals contain an instructive description of the ceremony connected with the reception of this envoy in Japan. He was met in Tsukushi (Kyūshū) by commissioners of welcome, and was conducted thence by sea to Naniwa (now Ōsaka), where, at the mouth of the river, thirty "gaily-decked" boats awaited him, and he and his suite were conducted to a residence newly built for the occasion. Six weeks later they entered the capital, after a message of welcome had been delivered to them by a muraji. Seventy-five fully caparisoned horses were placed at their disposal, and after a further rest of nine days, the envoy's official audience took place. He did not see the Empress' face. Her Majesty was secluded in the hall of audience to which only the principal ministers were admitted. Hence the ceremony may be said to have taken place in the court-yard. There the gifts brought by the envoy were ranged, and the envoy himself, introduced by two high officials, advanced to the front of the court, made obeisance twice, and, kneeling, declared the purport of his mission. The despatch carried by him ran as follows:-

The Emperor greets the sovereign of Wa. ${ }^{1} \quad$ Your envoy and his suite have arrived and have given us full information. We, by the grace of heaven, rule over the universe. It is Our desire to diffuse abroad our civilizing influence so as to cover all living things, and Our sentiment of loving nurture knows no distinction of distance. Now We learn that Your Majesty, dwelling separately beyond the sea, bestows the blessings of peace on Your subjects; that there is tranquillity within Your borders, and that the customs and manners are mild. With the most profound loyalty You have sent Us tribute from afar, and We are delighted at this admirable token of Your sincerity. Our health is as usual, notwithstanding the increasing heat of the weather. Therefore We have sent Pei Shieh-ching, Official Entertainer of the Department charged with the Ceremonial for the Reception of Foreign Ambassadors, and his suite, to notify to you the preceding. We also transmit to you the products of which a list is given separately. ${ }^{2}$

When the reading of the document was concluded, a high noble stepped forward, took it from the envoy's hands and advanced with it towards the audience-hall, from which another noble came out to meet him, received the letter, deposited it on a table before the chief entrance, and then reported the facts to the Empress. This ended the ceremony. The haughty condescension of the Chinese despatch does not appear to have offended the Japanese, nor did they cavil at the omission of one important ideograph from the title applied to their Empress. China's greatness seems to have been fully recognized. When, a month later, the envoy took his departure, the same Imoko was deputed to accompany him, bearing a despatch ${ }^{3}$ in which, to China's simple "greeting," Japan returned a "respectful address;" to China's expression of ineffable superiority Japan replied that the coming of the embassy had "dissolved her long-harboured cares;" and to China's grandiloquent prolixity Japan made

[ ${ }^{1}$ It has already been stated that Japan was generally known in China and Korea by the term "Wa," which, being written with an ideograph signifying "dwarf" or "subservient," was disliked by the Japanese. The envoy sent from Yamato in 607 was instructed to ask for the substitution of Nippon (Place of Sunrise), but the Sui sovereign declined to make the change and Japan did not receive the designation "Nippon" in China until the period Wu Teh (A.D. 618-626) of the Tang dynasty. It is not certain at what time exactly the Japanese themselves adopted this nomenclature, but it certainly was before the seventh century.]

[ ${ }^{2}$ Translated by Aston in the Nihongi.]

[ In this despatch Japan called herself "the place where the sun comes forth," and designated China as "the place where the sun sets." The idea, doubtless, was merely to distinguish between east and west, but the Sui sovereign resented the diction of this "barbarian letter."] 
answer with half a dozen brief lines. Imoko was now accompanied by eight students - four of literature and four of religion. Thus was established, and for long afterwards maintained, a bridge over which the literature, arts, ethics, and philosophies of China were copiously imported into Japan.

\section{RANKS}

It will be recognized by considering the $u j i$ system that while many titles existed in Japan, there was practically no promotion. A man might be raised to $u j i$ rank. Several instances of that kind have been noted, especially in the case of foreign artists or artisans migrating to the island from Korea or China. But nothing higher was within reach, and for the hereditary Kami of an uji no reward offered except a gift of land, whatever services he might render to the State. Such a system could not but tend to perfunctoriness in the discharge of duty. Perception of this defect induced the regent, Shōtoku, to import from China (A.D. 603) the method of official promotion in vogue under the Sui dynasty and to employ caps as insignia of rank. 1 Twelve of such grades were instituted; and the terminology applied to them was based on the names of six moral qualities - virtue, benevolence, propriety, faith, justice, and knowledge - each comprising two degrees, "greater" and "lesser." The caps were made of sarcenet, a distinctive colour for each grade, the cap being gathered upon the crown in the shape of a bag with a border attached. The three highest ranks of all were not included in this category.

\section{THE EMPEROR JOMEI AND THE EMPRESS KŌGYOKU}

In the year 626 , the omnipotent Soga chief, the $\bar{o}$-omi Umako, died. His brief eulogy in the Chronicles is that he had "a talent for military tactics". Was "gifted with eloquenee," and deeply reverenced "the Three Precious Things"! (Buddha, Dharma, and Sangha). In the court-yard of his residence a pond was dug with a miniature island in the centre, and so much attention did this innovation attract that the great minister was popularly called Shima (island) no $\bar{o}$-omi. His office of $\bar{o}$-omi was conferred on his son, Emishi, who behaved with even greater arrogance and arbitrariness than his father had shown. The Empress Suiko died in 628, and the question of the aecession at once became acute. Two prinees were eligible; Tamura, grandson of the Emperor Bidatsu, and Yamashiro, son of Shōtoku Taishi. Prince Yamashiro was a calm, virtuous, and faithful man. He stated explicitly that the Empress, on the eve of her demise, had nominated him to be her successor. But Prince Tamura had the support of the $\bar{o}$-omi, Emishi, whose daughter he admired. No one ventured to oppose the will of the Soga chieftain except Sakaibe no Marise, and he with his son were ruthlessly slain by the orders of the $\bar{o}-o m i$.

Prince Tamura then (629) ascended the throne - he is known in history as Jomei - but Soga no Emishi virtually ruled the empire. Jomei died in 641, after a reign of twelve years, and by the contrivance of Emishi the sceptre was placed in the hands of an Empress, Kōgyoku, a great-granddaughter of the Emperor Bidatsu, the claims of the son of Shōtoku Taishi being again ignored. One of the first aets of the new sovereign was to raise Emishi to the rank held by his father, the rank of $\bar{o}$-omi, and there then eame into prominence Emishi's son,

['In China to-day the distinguishing mark is a button of varying material fastened on the top of the cap.] 
Iruka, who soon wielded power greater than even that possessed by his father. Iruka's administration, however, does not appear to have been altogether unwholesome. The Chronicles say that "thieves and robbers were in dread of him; and that things dropped on the highway were not picked up." But Emishi rendered himself conspicuous chiefly by aping Imperial state. He erected an ancestral temple; organized performances of a Chinese dance (yatsura) which was essentially an Imperial pageant; levied imposts on the people at large for the construction of tombs - one for himself, another for his son, Iruka which were openly designated misasagi (Imperial sepulchres); called his private residence mikado (sacred gate); conferred on his children the title of miko (august child), and exacted forced labour from all the people of the Kamutsumiya estate, which belonged to the Shōtoku family.

This last outrage provoked a remonstrance from Shōtoku Taishi's daughter, and she was thenceforth reckoned among the enemies of the Soga. One year later (643); this feud ended in bloodshed. Emishi's usurpation of Imperial authority was carried so far that he did not hesitate to confer the rank. of $\bar{o}$-omi on his son, Iruka, and upon the latter's younger brother also. Iruka: now. conceived the design of placing upon the throne: Prince Furubito, a son of the Emperor Jomei It will be remembered that the Soga chief, Emishi, had lent his omnipotent influence to secure the sceptre for Jomei, because of the latter's affection for Emishi's daughter. "This lady, having become one of Jomei's consorts, had borne to him Prince Furubito, who was consequently Iruka's uncle. Iruka determined that the prince should succeed the Empress Kōgyoku. To that end it was necessary to remove the Shotoku family, against which; as shown above, the Soga had also a special grudge. Not even the form of devising a protest was observed. Orders were simply

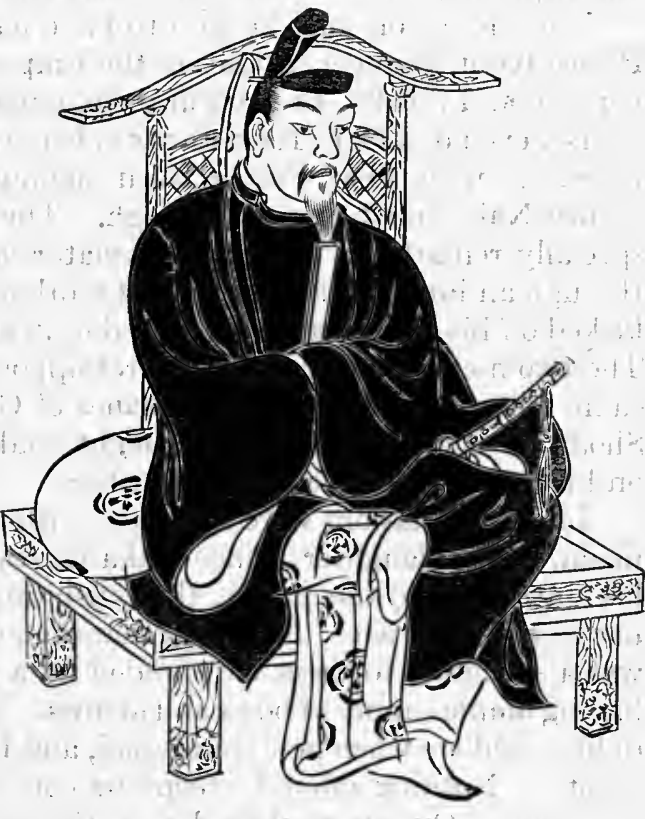

Fujtwara Kamatari issued to a military force that the Shōtoku house should be extirpated. Its representative was Prince Yamashiro, the same who had effaced himself so magnanimously at the time of Jomei's accession. He behaved with ever greater nobility on this occasion. Having by a ruse escaped from the Soga troops, he was urged by his followers to flee to the eastern provinces, and there raising anlarmy, to march back to the attack of the Soga.

There is reason to think that this policy would have succeeded. But the prince replied: "I do not wish it to be said by after generations that, for my sake, anyone has mourned the loss of a father or a mother. Is it only when one has conquered in battle that one is to be called a hero? Is he not also a hero who has made firm his country at the expense of his own life?" He then returned to the temple at Ikaruga, which his father had built, and being presently besieged 
there by the Soga forces, he and the members of his family, twenty-three.in all, committed suicide. This tragedy shocked even Emishi. He warned Iruka against the peril of such extreme measures.

There now appears a statesman destined to leave his name indelibly written on the pages of Japanese history, Kamatari, muraji of the Nakatomi-uji. The Nakatomi's functions were specially connected with Shintō rites, and Kamatári must be supposed to have entertained little good-will towards the Soga, who were the leaders of the Buddhist faction, and whose feud with the military party sixty-seven years previously had involved the violent death of Katsumi, then (587) muraji of the Nakatomi. Moreover, Kamatari makes his first appearance in the annals as chief Shintō official. Nevertheless, it is not apparent that religious zeal or personal resentment was primarily responsible for Kamatari's determination to compass the ruin of the Soga. Essentially an upright man and a loyal subject, he seems to have been inspired by a frank resolve to proteet the Throne against schemes of lawless ambitions, unconscious that his own family, the Fujiwara, were destined to repeat on a still larger scale the same abuses.

The succession may be said to have had three aspirants at that time: first, Prince Karu, younger brother of the Empress Kōgyoku; secondly, Prince Naka, her son, and thirdly, Prince Furubito, uncle of Soga no Iruka. The last was, of course, excluded from Kamatari's calculations, and as between the first two he judged it wiser that Prince Karu should have precedence in the succession, Prince Naka not being old enough. The conspiracy that ensued presents no specially remarkable feature. Kamatari and Prince Naka beeame acquainted through an incident at the game of football, when the prince, having accidently kicked off his shoe, Kamatari picked it up and restored it to him on bended knee. The two men, in order to find seeret opportunities for maturing their plans, became fellow students of the doctrines of Chow and Confucius under the priest Shōan, who had been among the eight students that accompanied the Sui envoy on his return to China in the year 608 .

Intimate relations were cemented with a section of the Soga through Kurayamada, whose daughter Prince Naka married, and trustworthy followers having been attached to the prince, the conspirators watched for an oceasion. It was not easy to find one. The Soga mansion, on the eastern slope of Mount Unebi, was a species of fortress, surrounded by a moat and provided with an armoury having ample supply of bows and arrows. Emishi, the $\bar{o}$-omi, always had a guard of fifty soldiers when he went abroad, and Iruka, his son, wore a sword "day and night." Nothing offered except to convert the palace itself into a place of execution. On the twelfth day of the sixth month, 645, the Empress held a Court in the great hall of audience to receive memorials and tribute from the three kingdoms of Korea. All present, except her Majesty and Iruka, were privy to the plot. Iruka having been beguiled into laying aside his sword, the reading of the memorials was commeneed by Kurayamada, and Prince. Naka ordered the twelve gates to be closed simultaneously. At that signal, two swordsmen should have advanced and fallen upon Iruka; but they showed themselves so timorous that Prince Naka himself had to lead them to the attack. Iruka, severely wounded, struggled to the throne and implored for succour and justice; but when her Majesty in terror asked what was meant, Prinee Naka charged Iruka with attempting to usurp the sovereignty. The Empress, seeing that her own son led the assassins, withdrew at once, and the work of slaughtering Iruka was completed, his corpse being thrown into the court-yard, where it lay covered with straw matting. 
EST Prince Naka and Kamatari had not been so incautious as to take a wide circle of persons into their confidence. But they were immediately joined by practically all the nobility and high officials, and the $\bar{o}$-omi's troops having dispersed without striking a blow, Emishi and his people were all executed. The Empress Kögyoku at once abdicated in favour of her brother, Prince Karu, her son, Prince Naka, being nominated Prince Imperial. Her Majesty had worn the purple for only three years. All this was in accord with Kamatari's carefully devised plans. : They were epoch making.

\section{RELATIONS WITH KOREA DURING THE SEVEN REIGNS FROM KIMMEI TO} KŌGYOKU (A.D. $540-645)$

The story of Japan's relations with Korea throughout the period of over a century, from the accession of Kimmei (540) to the abdication of Kōgyoku (645), is a series of monotonously similar chapters, the result for Japan being that she finally lost her position at Mimana. There was almost perpetual fighting between the petty kingdoms which struggled for mastery in the peninsula, and Kudara, always nominally friendly to Japan, never hesitated to seek the latter's assistance against Shiragi and Koma. To these appeals the Yamato Court lent a not-unready ear, partly because they pleased the nation's vanity, but mainly because Kudara craftily suggested danger to Mimana unless Japan asserted herself with arms. But when it came to actually rendering material aid, Japan did nothing commensurate with her gracious demeanour. She seems to have been getting weary of expensive interference, and possibly it may also have occurred to her that no very profound sympathy was: merited by a sovereign who, like the King of Kudara, preferred to rely on armed aid from abroad rather than risk the loss of his principality to his own countrymen.

cirl At all events, in answer to often iterated entreaties from Kudara, the Yamato Court did not make any practical response until the year 551, when it sent five thousand koku of barley-seed (?), followed, two years later, by two horses, two ships, fifty bows with arrows, and - a promise. Kudara was then ruled by a very enterprising prince (Yo-chang). Resolving to strike separately at his enemies, Koma and Shiragi, he threw himself with all his forces against Koma and gained a signal victory (553). Then, at length, Japan was induced to assist. An omi was despatched (554) to the peninsula with a thousand soldiers, as many horses and forty ships. Shiragi became, at once the objective of the united forces of Kudara and Japan. A disastrous defeat resulted for the assailants. The Kudara army suffered almost complete extermination, losing nearly thirty thousand men, and history is silent as to the fate of the omi's contingent. Nevertheless the fear of Japanese vengeance induced Shiragi to hold its hand, and, in the year 561, an attempt was made twice to renew friendly. relations with the Yamato Court by means of tribute-bearing envoys. Japan did not repel these overtures, but she treated the envoy of the victorious Shiragi with less respect than that extended to the envoy of the vanquished Kudara.

In the spring of the following year (562), Shiragi invaded Mimana, destroyed the Japanese station there and overran the whole region (ten provinces). No warning had reached Japan. She was taken entirely unawares, and she regarded it as an act of treachery on Shiragi's part to have transformed itself suddenly from a tribute-bearing friend into an active enemy. Strangely enough, the King of Shiragi does not appear to have considered that his act precluded a continuance of friendly relations with the Yamato Court. Six months after 
his invasion of Mimana he renewed the despatch of envoys to Japan, and it was not until their arrival in Yamato that they learned Japan's mood. : Much to the credit of the Yamato Court, it did not wreak vengeance on these untimely envoys, but immediately afterwards an armed expedition was despatched to call Shiragi to account. The forces were divided into two corps, one being ordered to march under Ki no Omaro northwest from Mimana and effect a junction with Kudara; the other, under Kawabe no Nie, was to move eastward against Shiragi. This scheme became known to the Shiragi generals owing to the seizure of a despatch intended for Kudara. They attempted to intercept Omaro's corps, but were signally defeated.

The movement under Kawabe no Nie fared differently. Japanese annals attempt to palliate his discomfiture by a story about the abuse of a flag of truce, but the fact seems to have been that Kawabe no Nie was an incompetent and pusillanimous captain. He and his men were all killed or taken prisoners, the only redeeming feature being the intrepidity of a Japanese officer, Tsugi no Ikina, who, with his wife and son, endured to be tortured and killed rather than utter an insult against their country.

It is difficult to interpret the sequence of events after this catastrophe. Japan immediately despatched a strong army - from thirty to forty thousand men - but instead of directing it against Shiragi, sent it to the attack of Koma, under advice of the King of Kudara. Possibly the idea may have been to crush Koma, and having thus isolated Shiragi, to deal with the latter subsequently. If so, the plan never matured. Koma, indeed, suffered a signal defeat at the hands of the Japanese, Satehiko, muraji of the Ōtomo, but Shiragi remained unmolested, and nothing accrued to Japan except some attractive spoils curtains of seven-fold woof, an iron house, two suits of armour, two gold-mounted swords, three copper belts with chasings, two variously coloured flags, and two beautiful women. Even as to the ultimate movements of Satehiko and his army the annals are silent.

Things remained thus for nine years. Tribute-bearing envoys arrived at intervals from Koma, but with Shiragi there was no communication: At last; in 571, an official was sent to demand from Shiragi an explanation of the reasons for the destruction of Mimana. The intention may have been to follow up this formality with the despatch of an effective force, but within a month the Emperor Kimmei died. On his death-bed he is said to have taken the Prince Imperial - Bidatsu - by the hand and said: "That which comes after devolves on thee. 'Thou must make war on Shiragi and establish Mimana as a feudal dependeney, renewing a relationship like that of husband and wife, just as it was in former days. If this be done, in my grave I shall rest content."

Twelve years passed before Bidatsu took any step to eomply with this dying injunction. During that long interval there were repeated envoys from Koma, now a comparatively feeble principality, and Shiragi made three unsuccessful overtures to renew amicable relations. At length, in 583, the Emperor announced his intention of carrying out the last testament of his predecessor: To that end his Majesty desired to consult with a Japanese, Nichira, who had served for many years at the Kudara Court and was thoroughly familiar with the conditions existing in Korea. Nichira came to Japan, but the annals indicate that his counsels were directed wholly against Kudara, which was ostensibly on the friendliest terms with Japan, and not at all against Shiragi, whose punishment was alone in question. Besides, instead of advising an appeal to arms, he urged the necessity of developing Japan's material resources, so that 
her neighbours might learn to count her formidable and her people might acquire ardour in her cause. Whether the wisdom of this advice appealed to Bidatsu, or whether the disputes consequent upon the introduction of Buddhism paralyzed his capacity for oversea enterprise, he made no further attempt to resolve the Korean problem.

In the year 591, the ill-fated Emperor Sushun conceived the idea of sending a large army to re-establish his country's prestige in the peninsula, but his own assassination intervened, and for the space of nine years the subject was not publicly revived. Then, in 600, the Empress Suiko being on the throne, a unique opportunity presented itself. War broke out between Shiragi and Mimana. The Yamato Court at once despatched a force of ten thousand men to Mimana's aid, and Shiragi, having suffered a signal defeat, made act of abject submission, restoring to Mimana six of its original provinces and promising solemnly to abstain from future hostilities. The Japanese committed the error of crediting Shiragi's sincerity. They withdrew their forces, but no sooner had their ships passed below the horizon than Shiragi once more invaded Mimana. It seemed at this juncture as though the stars in their courses fought against Japan. Something, indeed, must be ascribed to her own methods of warfare which appear to have been overmerciful for the age. Thus, with the bitter experience of Shiragi's treachery fresh in her recollection, she did not execute a Shiragi spy siezed in Tsushima, but merely banished him to the province of Kōzuke. Still, she must be said to have been the victim of special ill-fortune when an army of twenty-five thousand men, assembled in Tsukushi for the invasion of Shiragi, was twice prevented from sailing by unforseeable causes, one being the death of Prince Kume, its commander-in-chief; the other, the death of the consort of his successor, Prince Taema. ${ }^{1}$

These things happened in the year 603, and for the next five years all relations with Korea seem to have been severed. Then (608) a brief paragraph in the Chronicles records that "many persons from Shiragi came to settle in Japan." It is certainly eloquent of the Yamato Court's magnanimity that it should have welcomed immigrants from a country with which it was virtually at war. Two years later (610), Shiragi and Mimana, acting in concert, sent envoys who were received with all the pomp and ceremony prescribed by Shōtoku Taishi's code of decorum. Apparently this embassy was allowed to serve as a renewal of friendly relations, but it is not on record that the subject of former dispute was alluded to in any way, Inor was the old-time habit of annual tribute-bearing envoys revived. Visitors from Korea were, indeed, few and far-between, as when, in 616, Shiragi sent a golden image of Buddha, two feet high, whose effulgence worked wonders; or in 618, when an envoy from Korea conveyed the important tidings that the invasion of the peninsula by the Sui sovereign, Yang, at the head of three hundred thousand men, had been beaten back. This envoy carried to Yamato presents in the form of two captive Chinese, a camel, and a number of flutes, cross-bows, and catapults (of which instruments of war mention is thus made for the first time in Japanese history).

The Yamato Court had evidently now abandoned all idea of punishing Shiragi or restoring the station at Mimana; while Shiragi, on her side, was inclined to maintain friendly relations though she did not seek frequent intercourse. After an interval of five years' aloofness, she presented (621) a memorial on an unrecorded subject, and in the following year, she presented, once more, a

$\left[{ }^{1}\right.$ Early Japanese history furnishes several examples showing that wives often accompanied their husbands on campaigns.] 
gold image of Buddha, a gold pagoda, and a number of baptismal flags. ${ }^{1}$. But Shiragi was nothing if not treacherous, and, even while making these valuable presents to the Yamato Court, and while despatehing envoys in company with those from Mimana, she was planning another invasion of the latter. It took place that very year (622). When the news reached Japan, the Empress Suiko would have sent an envoy against Shiragi, but it was deemed wiser to employ diplomacy in the first place, for the principalities of Korea were now in close relations with the great Tang dynasty of China and might even count on the latter's protection in case of emergeney.

Two plenipotentiaries were therefore sent from Japan. Their mission proved very simple. Shiragi acquiesced in all their proposals and pledged herself once for all to recognize Mimana as a dependency of Japan. But after the despateh of these plenipotentiaries, the war-party in Japan had gained the ascendancy, and just as the plenipotentiaries; accompanied by tribute-bearing envoys from Shiragi and Mimana, were about to embark for Japan, they were astounded by the apparition of a great flotilla carrying thousands of armed men. The exact dimensions of this foree are not on record: it is merely described as having consisted of "several tens of thousands of men," but as it was commanded by two generals of the first rank and seven of the second, it must have been a very formidable army, and nothing is more remarkable about it than that it was assembled and embarked in the space of a few weeks. Shiragi did not attempt to resist. The King tendered his submission and it was accepted without a blow having been struck. But there were no tangible results. Japan did not attempt to re-establish her miyake in Mimana, and Shiragi refrained from sending envoys to Yamato except on special occasions. Friendly, though not intimate, relations were still maintained with the three kingdoms of Korea, mainly because the peninsula long continued to be the avenue by which the literature, arts, and crafts of China under.the Tang dynasty found their way to Japan. Since, however, the office in Mimana no longer existed to transact business connected with this intercourse, and since Yamato was too distant from the port of departure and arrival - Anato, now Nagato - a new office was established in Tsukushi (Kyūshū) under the name of the Dazai-fiu.

\section{LESSONS TAUGHT BY THE INTERCOURSE BETWEEN JAPAN AND KOREA}

The record of Japan's relations with Korea, so far as it has been carried above - namely, to the elose of the Empress Kogyoku's reign (A.D. 645) diseloses in the Korean people a race prone to self-seeking feuds, never reluctant to import foreign aid into domestic quarrels, and careless of the obligations of good faith. In the Japanese we see a nation magnanimous and trustful but of aggressive tendencies.

\section{IMPORTATION OF CHINESE CIVILIZATION}

Although Japan's military influence on the neighbouring continent waned perceptibly from the reign of Kimmei (540-571) onwards, a stream of Chinese civilization flowed steadily into the Island Empire from the west, partly coming

[1 "The Buddhist baptism consists in washing the top of the head with perfumed water. The baptismal flags were so called because they had the same efficiency, raising those who passed under them, first, to the rank of Tchakra Radja, and, ultimately, to that of a Buddha."
(Aston.)] 
direct from the fountain head; partly filtering, in a more or less impure form, through Korean channels. Many of the propagandists of this civilization remained permanently in Japan, where they received a courteous welcome, being promoted to positions of trust and admitted to the ranks of the nobility. Thus a book (the Seishi-roku), published in 814, which has been aptly termed the "peerage of Japan," shows that, at that time; nearly one-third of the Japanese nobility traced their descent to Chinese or Korean ancestors in something like equal proportions. The numbers are, China, 162 families; Kudara, 104; Koma, 50; Mimana, 9; Shiragi, 9; doubtful, 47. Total, 381 Chinese and Korean families out of a grand aggregate of 1177 . But many of the visitors returned home after having sojourned for a time as teachers of literature, art, or industrial science.

This system of brief residence for purposes of instruction seems to have been inaugurated during the reign of Keitai, in the year 513, when Tan Yang-i, a Chinese expounder of the five classies, was brought to Yamato by envoys from Kudara as a gift valued enough to purchase political intervention for the restoration of lost territory; and when, three years later, a second embassy from the same place, coming to render thanks for effective assistance in the matter of the territory, asked that Tan might be allowed to return in exchange for another Chinese pundit, Ko An-mu. The incident suggests how great was the value attached to erudition even in those remote days. Yet this promising precedent was not followed for nearly forty years, partly owing to the unsettled nature of Japan's relations.with Korea.

After the advent of Buddhism (552), however, Chinese culture found new expansion eastward. In 554, there arrived from Kudara another Chinese literatus, and, by desire of the Emperor, Kimmei, a party of experts followed shortly afterwards, including a man learned in the calendar, a professor of divination, a physician, two herbalists, and four musicians. The record says that these men, who, with the exception of the Chinese doctor of literature, were all Koreans, took the place of an equal number of their countrymen who had resided in Japan for some years. Thenceforth such incidents were frequent. Yet, at first, a thorough knowledge of the ideographic script seems to have spread very slowly in Japan, for in 572, when the Emperor Bidatsu sought an interpretation of a memorial presented by the Koma sovereign, only one man among all the scribes (fumi-bito), and he (Wang Sin-i) of Chinese origin, was found capable of reading the document.

But from the accession of the Empress Suiko (593), the influence of Shōtoku Taishi made itself felt in every branch of learning, and thenceforth China and Japan may be said to have stood towards each other in the relation of teacher and pupil. Literature, the ideographic script, ${ }^{1}$ calendar compiling, astronomy, geography, divination, magic, painting, sculpture, architecture, tile-making, ceramics, the casting of metal, and other crafts were all cultivated assiduously under Chinese and Korean instruction. In architecture, all substantial progress must be attributed to Buddhism, for it was by building temples and pagodas that Japanese ideas of dwelling-houses were finally raised above the semisubterranean type, and to the same influence must be attributed signal and rapid progress in the art of interior decoration. The style of architecture adopted in temples was a mixture of the Chinese and the Indian. Indeed, it is

[ ${ }^{1}$ The oldest ideographic inscription extant in Japan is carved on a stone in Iyo province dating from A.D. 596. Next in point of antiquity is an inscription on the back of an image of Yakushi which stands in the temple Horyū-ji. It is ascribed to the year A.D. 607.] 
characteristic of this early epoch that traces of the architectural and glyptic fashions of the land where Buddhism was born showed themselves much more conspicuously than they did in later eras; a fact which illustrates Japan's constant tendency to break away from originals by modifying them in accordance with her own ideals.

None of the religious edifices then constructed has survived in its integrity to the present day. One, however, - the Hōryū-ji, at Nara - since all its restorations have been in strict accord with their originals, is believed to be a true representative of the most ancient type. It was founded by Shotoku Taishi and completed in 607 . At the time of its construction, this Hōryū-ji was the chief academy of Buddhist teaching, and it therefore received the name of Gakumon$\mathrm{ji}$ (Temple of Learning). Among its treasures is an image of copper and gold which was cast by the Korean artist, Tori - commonly called Tori Busshi, or Tori the image-maker - to order of Shōtoku; and there is mural decoration from the brush of a Korean priest, Donchō. This building shows that already.

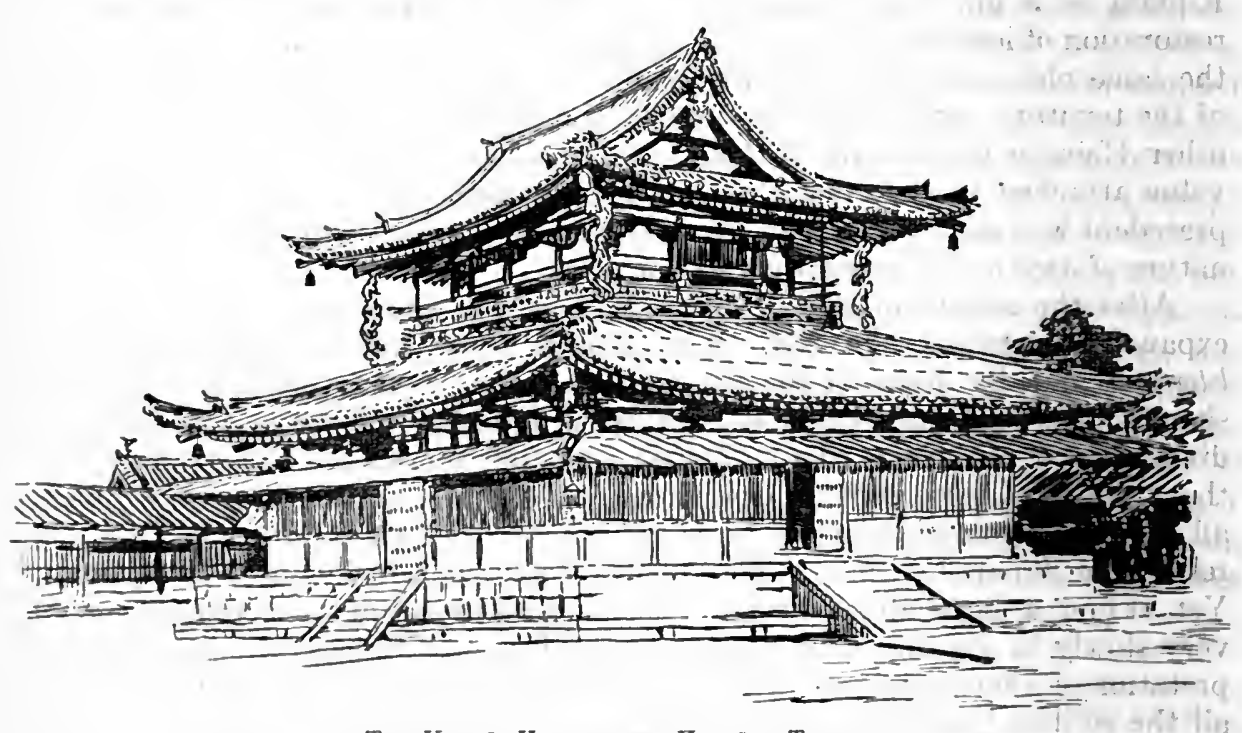

Tur londe, Ilate of the IIoRye-Ji Temple

(Ji means temple)

in the seventh century an imposing type of wooden edifice had been elaborated - an edifice differing from those of later epochs in only a few features; as, slight inequality in the scantling of its massive pillars; comparatively gentle pitch of roof; abnormally overhanging eaves, and shortness of distance between each storey of the pagoda. These sacred buildings were roofed with tiles, and were therefore called kawara-ya (tiled house) by way of distinction, for all private dwellings, the Imperial palace not excepted, continued to have thatched roofs in the period now under consideration, ${ }^{1}$ or at best roofs covered with boards. The annals show that when the Empress Kōgyoku built the Asuka palace, timber was obtained from several provinces; labour was requisitioned throughout a district extending from Ömi in the east to Aki in the west; the floor of the "great hall"2 was paved with tiles; there were twelve gates, three on each of the four

[1 Down to A.D. 645.]

[2 It was here that the assassination of Sōga no Iruka took place.] 
sides, and the whole was in the architectural style of the Tang dynasty. Yet for the roofs, boards alone were used.

\section{PAINTING}

Little is recorded about the progress of painting in this epoch. It has been shown above that during Yüryaku's reign pictorial experts crossed to Japan from Korea and from China. The Chronicles add that, in A.D. 604, when the Empress Suiko occupied the throne, two schools of painters were established, namely, the Kibumi and the Yamashiro. It is elsewhere explained that the business of those artists was to paint Buddhist pictures, the special task of the Kibumi men being to illuminate scrolls of the Sutras. We read also that, in 603 , on the occasion of the dedication of the temple of Hachioka, Prince Shōtoku painted banners as offerings. These had probably the same designs as those spoken of a century later (710) when, at a ceremony in the great hall of the palace, there were set up flags emblazoned with a crow, ${ }^{1}$ the sun, an azure dragon, a red bird, and the moon, all which designs were of Chinese origin. Shōtoku Taishi himself is traditionally reported to have been a skilled painter and sculptor, and several of his alleged masterpieces are preserved to this day, but their authenticity is disputed.

\section{AGRICULTURE}

In the field of agriculture this epoch offers nothing more remarkable than the construction of nine reservoirs for irrigation purposes and the digging of a large canal in Yamashiro province. It is also thought worthy of historical notice that a Korean prince unsuccessfully attempted to domesticate bees on a Japanese mountain.

\section{COMMERCE}

Considerable progress seems to have been made in tradal matters. Markets were opened at several places in the interior, and coastwise commerce developed so much that, in A.D. 553, it was found expedient to appoint an official for the purpose of numbering and registering the vessels thus employed. The Chinese settler, Wang Sin-i, who has already been spoken of as the only person able to decipher a Korean memorial, was given the office of fune no osa (chief of the shipping bureau) and granted the title of fune no fubito (registrar of vessels). Subsequently, during the reign of Jomei (629-641), an akinai-osa (chief of irade) was appointed in the person of Munemaro, whose father, Kuhi, had brought scales and weights from China during the reign of Sushun (558-592), and this system was formally adopted in the days of Jomei (629-641). There had not apparently been any officially recognized weights and measures in remote antiquity. The width of the hand (ta or tsuka) and the spread of the arms (hiro) were the only dimensions employed. By and by the Korean shaku (foot), which corresponds to 1.17 shaku of the present day, came into use. In Kensō's time (485-487) there is mention of a measure of rice being sold for a piece of silver, and the Emperor Kimmei (540-571) is recorded to have given 1000 koku of seed-barley to the King of Kudara. But it is supposed that the writer of the Chronicles, in making these entries, projected the terminology of his own time into the previous centuries. There were neither coins nor koku in those eras. 


\section{COSTUME AND COIFFURE}

Up to the time (A.D. 603) of the institution of caps as marks of rank, men were in the habit of dividing their hair in the centre and tying it above the ears in a style called mizura. But such a fashion did not accord with the wearing of caps which were gathered up on the crown in the shape of a bag. Hence men of rank took to binding the hair in a queue on the top of the head. The old style was continued, however, by men having no rank and by youths. A child's hair was looped on the temples in imitation of the flower of a gourd - hence called hisago-bana - and women wore their tresses hanging free. The institution of caps interfered also with the use of hairpins, which were often made of gold and very elaborate. These now came to be thrust, not directly into the hair, but through the cord employed to tie the cap above. It is recorded that, in the year 611 , when the Empress Suiko and her Court went on a pienic, the colour of the ministers' garments agreed with that of their official caps, and that each wore hair-ornaments which, in the case of the two highest functionaries, were made of gold; in the case of the next two, of leopard's tails; and in the case of. lower ranks, of birds' tails.

On a more ceremonious occasion, namely, the reception of the Chinese envoys from the Sui Court, the Chronicles state that Japanese princes and ministers "all wore gold hair-ornaments," and their garments were of brocade, purple, and embroidery, with thin silk stuffs of various colours and patterns." Costume had become thus gorgeous after the institution of Buddhism and the establishment of intercourse direct with the Sui, and, subsequently, the Tang dynasty. Even in the manner of folding the garments over the breast - not from right to left but from left to right - the imported fashion was followed. Wadded garments are incidently mentioned in the year A.D. 643.

\section{MUSIC AND AMUSEMENTS}

It has already been recorded that, in the middle of the sixth century, musicians were sent from the Kudara Court to the Yamato, and since these are said to have taken the place of others then sojourning in Japan, the fact is established that such a visit was not then without precedent. Music, indeed, may be said to have benefitted largely by the advent of Buddhism, for the services of the latter required a special kind of music. The first foreign teacher of the art was a Korean, Mimashi, who went to Japan in A.D. 612, after having studied both music and dancing for some years in China. A dwelling was assigned to him at Sakurai (in Yamato) and he trained pupils. At the instance of Prince Shōtoku and for the better performance of Buddhist services, various privileges were granted to the professors of the art. They were exempted from the discharge of official duties and their occupation became hereditary. Several ancient Japanese books contain reference to music and dancing, and in one, work ${ }^{2}$ illustrations are given of the wooden masks worm by dancers and the instruments used by musicians of the Wu (Chinese) school. These masks were introduced by Mimashi and are still preserved in the temple Hōryū-ji.

In the matter of pastimes, a favourite practice, first mentioned in the reign of the Empress Suiko, was a species of pienic called "medicine hunting" (kusurikari). It took place on the fifth day of the fifth month. The Empress; her

[1 These were called usu. They were, in fact, hairpins, generally shaped like a flower.]

[2 The Höryü-ji Shizai-chō, composed in A.D. 747.] 
ladies, and the high functionaries, all donned gala costumes and went to hunt stags, for the purpose of procuring the young antlers, and to search for "deerfungus" (shika-take), the horns and the vegetables being supposed to have medical properties. All the amusements mentioned in previous sections continued to be followed in this era, and football is spoken of as having inaugurated the afterwards epoch-making friendship between Prince Naka and Kamatari. It was not played in the Occidental manner, however. The game consisted in kicking a ball from player to player without letting it fall. This was apparently a Chinese innovation. Here, also, mention may be made of thermal springs. Their sanitary properties were recognized, and visits were paid to them by invalids. The most noted were those of Dōgo, in Iyo, and Arima, in Settsu. The Emperor Jomei spent several months at each of these, and Prince Shōtoku caused to be erected at Dōgo a stone monument bearing an inscription to attest the curative virtues of the water.

\section{CONDITION OF THE PEOPLE}

That Buddhism obtained a firm footing among the upper classes during the first century after its introduction must be attributed in no small measure to the fact that the throne was twice occupied by Empresses in that interval. The highly decorative aspects of the creed appealing to the emotional side of woman's nature, these Imperial ladies encouraged Buddhist propagandism with earnest munificence. But the mass of the people remained, for the most part, outside the pale. They continued to believe in the Kami and to worship them. Thus, when a terribly destructive earthquake ${ }^{1}$ occured in 599 , it was to the Kami of earthquakes that prayers were offered at his seven shrines in the seven home provinces (Kinai), and not to the Merciful Buddha, though the saving grace of the latter had then been preached for nearly a eycle. The first appeal to the foreign deity in connexion with natural calamity was in the opening year (642) of the Empress Kōgyoku's reign when, in the presence of a devastating drought, sacrifices of horses and cattle to the Shintō Kami, changes of the market-places, ${ }^{2}$ and prayers to the river gods having all failed to bring relief, an imposing Buddhist service was held in the south court of the Great Temple. "The images of Buddha, of the bosatsu, and of the Four Heavenly Kings were magnificently adorned; a multitude of priests read the Mahayana Sutra, and the $\bar{o}$-omi, Soga no Emishi, held a censer, burned incense, and prayed." But there was no success; and not until the Empress herself had made a progress to the source of a river and worshipped towards the four quarters, did abundant rain fall.

Such an incident cannot have contributed to popularize the Indian ereed. The people at large adhered to their traditional cult and were easily swayed by superstitions. The first half of the seventh century was marked by abnormal occurrences well calculated to disturb men's minds. There were comets (twice); there was a meteor of large dimensions; there were eclipses of the sun and moon; there were occultations of Venus; there was snow in July and hail "as large as peaches" in May, and there was a famine (621) when old people ate roots of herbs and died by the wayside, when infants at the breast perished with their mothers, and when thieves and robbers defied authority. It is not, perhaps, surprising in such circumstances, and when witches and wizards abounded, that

[1 Only three earthquakes are recorded up to the year A.D. 645, and the second alone (A.D. 599) is described as destructive.]

[2 This was a Chinese custom, as was also the sacrificial rite mentioned in the same context.] 
people fell into strange moods, and were persuaded to regard a caterpillar as the "insect of the everlasting world," to worship it, and to throw away their valuables in the belief that riches and perpetual youth would be thus won. A miyatsuko, by name Kawakatsu, had the courage to kill the designing preacher of this extravagance, and the moral epidemic was thus stayed.

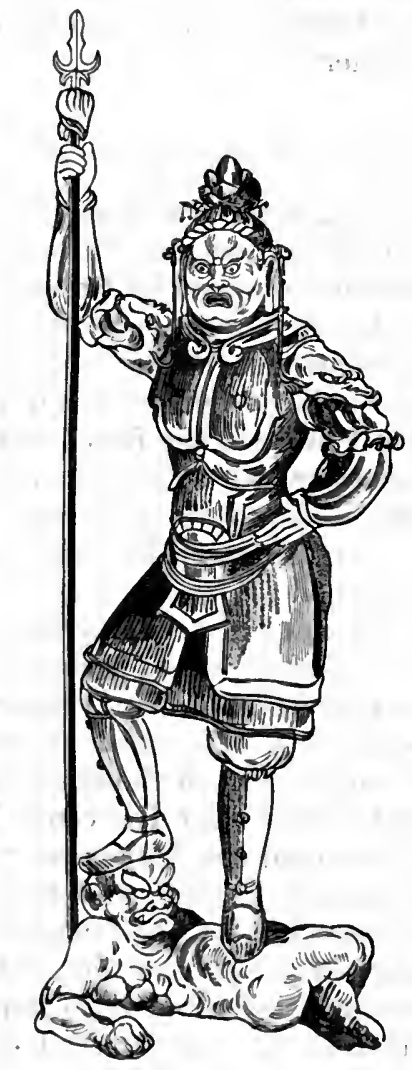

ONe of the Statueg of "Shrtenso" in the Kaidan-in, Tôdaist

(Tembyō Sculpture, Eighth Century) 


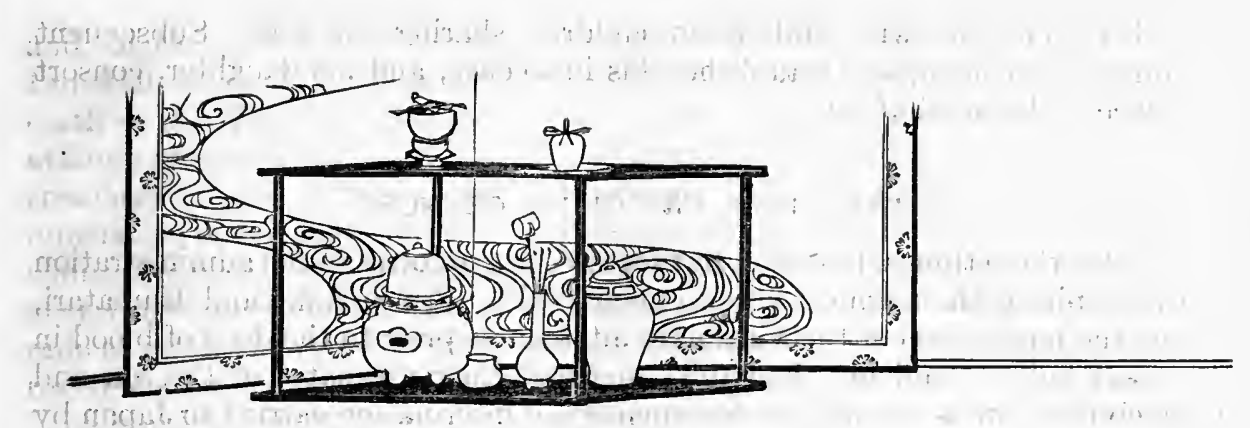

Utensils Used in the Tea Ceremony (Cha-no-yo)

\section{CHAPTER XV}

\section{THE DAIKA REFORMS}

\section{THE THIRTY-SIXTH SOVEREIGN, THE EMPEROR KŌTOKU (A.D. 645-654)}

After the fall of the Soga and the abdication of the Empress Koggyoku, her son, Prince Naka, would have been the natural successor, and such was her own expressed wish. But the prince's procedure was largely regulated by Kamatari, who, alike in the prelude and in the sequel of this crisis, proved himself one of the greatest statesmen Japan ever produced. He saw that the Soga influence, though broken, was not wholly shattered, and he understood that the great administrative reform which he contemplated might be imperilled were the throne immediately occupied by a prince on whose hands the blood of the Soga chief was still warm. Therefore he advised Prince Naka to stand aside in favour of his maternal uncle, Prince Karu, who could be trusted to co-operate loyally in the work of reform and whose connexion with the Soga overthrow had been less conspicuous. But to reach Prince Karu it was necessary to pass over the head of another prince, Furubito, Naka's half-brother, who had the full sympathy of the remnant of the Soga clan, his mother having been a daughter of the great Umako. The throne was therefore offered to him. But since the offer followed, instead of preceding the Empress' approval of Prince Karu, Furubito recognized the farce, and knowing that, though he might rule in defiance of the Kamatari faction, he could not hope to rule with its consent, he threw away his sword and declared his intention of entering religion.

Very soon the Buddhist monastery at Yoshino, where he received the tonsure, became a rallying point for the Soga partisans, and a war for the succession seemed imminent. Naka, however, now Prince Imperial, was not a man to dally with such obstacles. He promptly sent to Yoshino a force of soldiers who killed Furubito with his children and permitted his consorts to strangle themselves. Prince Naka's name must go down to all generations as that of a great reformer, but it is also associated with a terrible injustice. Too readily crediting a slanderous charge brought against his father-in-law, Kurayamada, who; had stood at his right hand in the great coup d'etat of 645 , he despatched a force to seize the alleged traitor. Kurayamada fled to a temple, and there, declaring that he would "leave the world, still cherishing fidelity in his bosom," he com- 
mitted suicide, his wife and seven children sharing his fate. Șubsequent examination of his effects established his innocence, and his daughter, consort of Prince Naka, died of grief.

\section{THE DAIKA, OR "GREAT CHANGE"}

Not for these things, however, but for sweeping reforms in the administration of the empire is the reign of Kōtoku memorable. Prinee Naka and Kamatari, during the long period of their intimate intercourse prior to the deed of blood in the great hall of audience, had fully matured their estimates of the Sui and Tang civilization as revealed in clocuments and information carried to Japan by priests, literati. and students, who, since the establishment of Buddhism, had paid many visits to China. They appreciated that the system prevailing in their own country from time immemorial had developed abuses which were sapping the strength of the nation, and in sweeping the Soga from the path to the throne, their ambition had been to gain an eminence from which the new civilization might be authoritatively proclaimed.

Speaking broadly, their main objects were to abolish the system of hereditary office-holders; to differentiate aristocratic titles from official ranks; to bring the whole mass of the people into direct subjection to the Throne, and to establish the Imperial right of ownership in all the land throughout the empire. What these changes signified and with what tact and wisdom the reformers proceeded, will be clearly understood as the story unfolds itself. Spectacular effect was enlisted as the first ally. A coronation ceremony of unprecedented magnificence took place. High officials, girt with golden quivers, stood on either side of the dais forming the throne, and all the great functionaries - omi, muraji, and miyatsuko - together with representatives of the 180 hereditary corporations (be) filed past, making obeisance. The title of "Empress Dowager" was conferred for the first time on Kōgyoku, who had abdicated; Prince Naka was made Prince Imperial; the head of the great uji of Abe was nominated minister of the Left (sa-daijin); Kurayamada, of the Soga-uji, who had shared the dangers of the conspiracy against Emishi and Iruka, became minister of the Right $(u$-daijin), and Kamatari himself received the post of minister of the Interior (nai-daijin), being invested with the right to be consulted on all matters whether of statecraft or of official personnel.

These designations, "minister of the Left", "minister of the Right," and "minister of the Interior," were new in Japan. ${ }^{2}$ Hitherto, there had been $\bar{o}$-om and $\bar{\delta}$-muraji, who stood between the Throne and the two great classes of $u j i$, the $\bar{o}$-omi and the $\bar{o}$-muraji receiving instructions direct from the sovereign, and the two classes of $u j i$ acknowledging no control except that of the $\bar{o}-o m i$ and the $\bar{o}$-inuraji. But whereas the personal status of Kurayamada was only om $i$ (not $\bar{o}-o m i$ ), and the personal status of Kamatari, only muraji (not $\bar{o}$-muraji), neither was required, in his new eapacity, to take instructions from any save the Emperor, nor clid any one of the three high dignitaries nominally represent this or that congeries of $u j i$. A simultaneous innovation was the appointment of a Buddhist priest, Bin, and a literatus, Kuromaro, to be "national doctors." These men had spent some years at the Tang Court and were well versed in Chinese systems.

The next step taken was to assemble the ministers under a patriarchal tree;

[ ${ }^{1}$ The left takes precedence of the right in Japan.]

[2 The offices were borrowed from the Tang system of China - a remark which applies to nearly'all the innovations of the epoch.] 
and, in the presenee of the Emperor, the Empress Dowager, and the Prince Imperial, to pronounce,' in the names of the Kami of heaven and the Kami of earth - the Tenshin and the Chigi - a solemn imprecation on rulers who attempted double-hearted methods of government, and on vassals guilty of treachery in the service of their sovereign. This amounted to a formal denunciation of the Soga as well as a pledge on the part of the new Emperor. The Chinese method of reckoning time by year-periods was then adopted, and the year A.D: 645 became the first of the Daika era. But before proceeding to really radical innovations, two further precautions were taken. In order to display reverence for the foundations of the State, the sovereign publicly declared that "the empire should be ruled by following the footsteps of the Emperors of antiquity," and in order to win the sympathy of the lower orders, his Majesty directed that inquiry should be made as to the best method of alleviating the hardships of foreed labour. Further, a solemn ceremony of Shinto worship was held by way of preface.

tru Then the reformers commenced their work in earnest. Governors (kokushi) were appointed to all the eastern provinees. These offieials were not a wholly novel institution. It has been shown that they existed previously to the Daika era; but in a fitful and uncertain way, whereas, under the system now adopted, they beeame an integral part of the administrative machinery. That meant that the government of the provinces, instead of being administered by hereditary officials; altogether irrespective of their competence, was entrusted for a fixed term to men chosen on account of special aptitude. The eastern provinces were selected for inaugurating this experiment, because their distance from the capital rendered the change less conspicuous. Moreover, the appointments were given, as far as possible, to the former miyatsuko or mikotomochi. An ordinance was now issued for placing a petition-box in the Court and hanging a bell near it. The box was intended to serve as a receptacle for complaints and representations. : Anyone had a right to present such documents. They were to be collected and conveyed to the Emperor every morning, and if a reply was tardy, the bell was to be struck.

uf Side by side with these measures for bettering the people's lot, precautions against any danger of disturbance were adopted by taking all weapons of war out of the hands of private individuals and storing them in arsenals specially constructed on waste lands. Then followed a measure which seems to have been greatly needed. It has been already explained that a not ineonsiderable element of the population was composed of slaves, and that these consisted of two main classes, namely, aborigines or Koreans taken prisoners in war, and members of an $u j i$ whose Kami had been implicated in crime. As time passed, there resulted from intercourse between these slaves and their owners a number of persons whose status was confused, parents asserting the manumission of their children and masters insisting on the permanence of the bond. To correct these complieations the whole nation was now divided into freemen (ryömin) and bondmen (senmin), and a law was enacted that, since among slaves no marriage tie was officially recognized, a child of mixed parentage must always be regarded as a bondman. On that basis a census was ordered to be taken, and in it were included not only the people of all classes, but also the area of cultivated and throughout the empire.

At the same time stringent regulations were enacted for the control and guidance of the provincial governors. They were to take counsel with the people in dividing the profits of agrieulture. They were not to act as judges in 
criminal eases or to accept bribes from suitors in civil ones; their staff, when visiting the capital, was strictly limited, and the use of public-service horses ${ }^{1}$ as well as the eonsumption of State provisions was vetoed unless they were travelling on public business. Finally, they were enjoined to investigate carefully all claims to titles and all alleged rights of land tenure. The next step was the most drastic and far-reaching of all. Hereditary eorporations ivere entirely abolished, alike those established to commemorate the name of a sovereign or a prince and those employed by the nobles to cultivate their estates. The estates themselves were escheated. Thus, at one stroke, the lands and titles of the hereditary aristocracy were annulled, just as was destined to be the case in the Meiji era, twelve centuries later.

This reform involved a radical change in the system and method of taxation; but the consideration of that phase of the question is deferred for a moment in order to explain the nature and the amount of the new fiscal burdens. Two kinds of taxes were thenceforth imposed, namely, ordinary taxes and commuted taxes. The ordinary consisted of twenty sheaves of rice per cho ${ }^{2}$ (equivalent to about eight sheaves per acre), and the commuted tax - in lieu of forced labour - was fixed at a piece of silk fabric forty feet in length by two and a half feet in breadth per $c h \bar{o}$, being approximately a length of sixteen feet per acre: The dimensions of the fabric were doubled in the case of coarse silk, and quadrupled in the case of eloth woven from hemp or from the fibre of the inner bark of the paper-mulberry. A commuted tax was levied on houses also; namely, a twelve-foot length of the above cloth per house. No currency existed in that age. All payments were made in kind. There is, therefore, no method of calculating accurately the monetary equivalent of a sheaf of rice. But in the case of fabrics we have some guide. Thus, in addition to the above imposts; every two townships - a township was a group of fifty houses - had to contribute one horse of medium quality (or one of superior quality per two hundred houses) for public service; and since a horse was regarded as the equivalent of a total of twelve feet of cloth per house, it would follow, estimating a horse of medium quality at $£ 5,(\$ 25$.$) , that the commuted tax in the case of land was$ above 5 s., 4 d., (\$1.30) per acre. Finally, each homestead was required to provide one labourer as well as rations for his support; and every two homesteads had to furnish one palace waiting-woman (uneme), who must be goodlooking, the daughter or sister of a district official of high rank, and must have one male and two female servants to attend on her - these also being supported by the two homesteads. In every homestead there was an alderman who kept the register, directed agricultural operations, enforced taxes, and took measures to prevent crime as well as to judge it.

Thus it is seen that a regular system of national taxation was introduced and that the land throughout the whole empire was considered to be the property of the Crown. As for the nobles who were deprived of their estates, sustenance gifts were given to them, but there is no record of the bases upon which these gifts were assessed. With regard to the people's share in the land, the plan pursued was that for every male or female over five years of age two tan (about half an acre) should be given to the former and one-third less to the latter, these grants being made for a period of six years, at the end of which time a general

[ ${ }^{1}$ Everyone having a right to use public-service horses was required to carry a token of his right in the shape of a small bronze bell, or group of bells, indicating by their shape and number how many horses the bearer was entitled to.]

[ ${ }^{2}$ The cho was two and a half acres approximately.] 
restoration was to be effected. A very striking evidence of the people's condition is that every adult male had to contribute a sword, armour, a bow and arrows, and a drum. This impost may well have outweighed all the others.

\section{SEPULCHRES}

Another important reform regulated the dimensions of burial mounds. The construction of these on the grand scale adopted for many sovereigns, princes, and nobles had long harrassed the people, who were compelled to give their toil gratis for such a purpose. What such exactions had entailed may be gathered from Kōtoku's edict, which said, "Of late the poverty of our people is absolutely due to the construction of tombs." Nevertheless, he did not undertake to limit the size of Imperial tombs. The rescript dealt only with those from princes downwards. Of these, the greatest tumulus permitted was a square mound with a side of forty-five feet at the base and a height of twenty-five feet, measured along the slope, a further restriction being that the work must not occupy more than one thousand men for seven days. The maximum dimensions were similarly prescribed in every case, down to a minor official, whose grave must not give employment to more than fifty men for one day. When ordinary people died, it was directed that they should be buried in the ground without a day's delay, and, except in the case of an Emperor or an Empress, the custom of temporary interment was strictly vetoed. Cemeteries were ordered to be constructer for the first time, and peremptory injunctions were issued against self-destruction to accompany the dead; against strangling men or women by way of sacrifice; against killing the deceased 's horse, and against cutting the hair or stabbing the thighs by way of showing grief. It must be assumed that all these customs existed.

\section{ABUSES}

Other evil practices are incidentally referred to in the context of the Daika reforms. Thus it appears that slaves occasionally left their lawful owners owing to the latter's poverty and entered the service of rich men, who thereafter refused to give them up; that when a divorced wife or concubine married into another family, her former husband, after the lapse of years, often preferred claims against her new husband's property ; that men, relying on their power, demanded people's daughters in marriage, and in the event of the girl entering another house, levied heavy toll on both families; that when a widow, of ten or twenty years' standing, married again, or when a girl entered into wedlock, the people of the vicinity insisted on the newly wedded couple performing the Shinto rite of harai (purgation), which was perverted into a device for compelling offerings of goods and wine; that the compulsory performance of this ceremony had become so onerous as to make poor men shrink from giving burial to even their own brothers who had died at a distance from home, or hesitate to extend aid to them in mortal peril, and that when a forced labourer cooked his food by the roadside or borrowed a pot to boil his rice, he was often obliged to perform expensive purgation.

\section{OFFICIAL ORGANIZATION}

At the head of all officials were the sa-daijin (minister of the Left), the $u$ daijin (minister of the Right) and the nai-daijin (minister of the Interior), and after them came the heads of departments, of which eight were established, after 
the model of the Tang Court in China. They were the Central Department (Nakatsukasa-shō); the Department of Ceremonies (Shikibu-shō); the Department of Civil Government (Jibu-shō); the Department of Civil Affairs (Mimbushō); the Department of War (Hyōbu-shō); the Department of Justice (Gyōbu$s h \bar{o})$; the Treasury (Ōkura-shō), and the Household Department (Kunai-shō). These departments comprised a number of bureaux. All officials of high rank had to assemble at the south gate of the palace in time to enter at sunrise, and they remained there until some time between $11 \mathrm{~A}$. M. and 1 P. M.

In a province the senior official was the governor, and under him were heads of districts, aldermen of homesteads (fifty houses), elders of five householdsall the houses being divided into groups of five for purposes of protection - and market commissioners who superintended the currency (in kind), commerce, the genuineness of wares, the justness of weights and measures, the prices of commodities, and the observance of prohibitions. Since to all official posts men of merit were appointed without regard to lineage, the cap-ranks inaugurated by Prince Shötoku were abolished, inasmuch as they designated personal statis by inherited right only, and they were replaced by new cap-grades, nineteen in all, which were distinguished partly by their borders, partly by their colours, and partly by their materials and embroidery. Hair-ornaments were also a mark of rank. They were cicada-shaped, of gold and silver for the highest grades, of silver for the medium grades, and of copper for the low grades: 'The caps indicated official status without any reference to hereditary titles.

\section{RATIONALE OF THE NEW SYSTEM}

The radical changes outlined above were all effected in the short space of eight years. If it be asked what motive inspired the reformers, the obvious answer is that experience, culminating in the usurpations of the Soga, had fully displayed the abuses incidental to the old system. Nothing more memorable than this flood of reforms has left its mark upon Japan's ancient history.' During the first thirteen centuries of the empire's existence - if we accept the traditional chronology - the family was the basis of the State's organization. Each unit of the population either was a member of an $u j i$ or belonged to the tomobe of an $u j i$, and each $u j i$ was governed by its own omi or muraji, while all the $u j i$ of the Kwōbetsu class were under the $\bar{o}$-omi and all those of the Shimbetsu class, under the $\bar{o}$-muraji. Finally, it was through the $\bar{o}$-omi and the $\bar{o}$-muraji alone that the Emperor communicated his will. In other words, the Japanese at large were not recognized as public people, the only section that bore that character being the units of the hereditary corporations instituted in memory of some Imperial personage and the folk that cultivated the miyake (State domains):

All these facts, though already familiar to the reader, find a fitting place in the context of the great political development of the Daika era. For the main features of that development were that the entire nation became the public people of the realm and the whole of the land became the property of the Crown, the hereditary nobles being relegated to the rank of State pensioners. This metamorphosis entailed taking an accurate census of the population; making a survey of the land; fixing the boundaries of provinces, districts, and villages; appointing officials to administer the affairs of these local clivisions, and organizing the central government with boards and bureaux. The system of taxation also had to be changed, and the land had to be apportioned to the people. In former days, the only charges levied by the State on the produce of the land were 
those connected with religious observances and military operations, and even in imposing these the intervention of the heads of $u j i$ had to be employed. But by the Daika reforms the interest of the hereditary nobility in the taxes was limited to realizing their sustenance allowances; while as for the land, it was removed entirely beyond their control and partitioned among the people, in the proportion already noted, on leases terminable at the end of six years.

Of course, whatever political exigency may have dictated this short-tenure system, it was economically unsound and could not remain long in practice. The measures adopted to soften the aspect of these wholesale changes in the eyes of the hereditary nobility whom they so greatly affected, have been partly noted above. It may here be added, however, that not only was the office of district governor - who ranked next to the provineial governor (kokushi) - filled as far as possible by former kuni no miyatsuko, but also these latter were entrusted with the duty of observing and reporting upon the conduct of the new officials as to assiduity and integrity, to which duty there were also nominated special officials called choshu-shi. By the aid of these and other tactful devices, the operation of the new system was guaranteed against disturbance. 'Nothing was deemed too trivial to assist in promoting that end. Even such a petty incident as the appearance of a white pheasant was magnified into a special indication of heaven's approval, and a grand Court ceremony having been held in honour of the bird, the Emperor proclaimed a general amnesty and ordered that the name of the period should be changed to Haku-chi (White Pheasant). Something of this may be set down frankly to the superstitious spirit of the time. But much is evidently attributable to the statecraft of the Emperor's advisers, who sought to persuade the nation that this breaking away from all its venerable old traditions had supernatural approval.

There was, indeed, one defect in the theory of the new system. From time immemorial the polity of the empire had been based on the family relation. The sovereign reigned in virtue of his lineage, and the hereditary nobles owed their high positions and administrative competence equally to descent. To discredit the title of the nobles was to disturb the foundation of the Throne itself, and to affirm that want of virtue constituted a valid reason for depriving the scions of the gods of their inherited functions, was to declare constructively that the descendant of Amaterasu also held his title by right of personal worthiness. That was the Chinese theory. Their history shows plainly that they recognized the right of men like Tang or Wu to overturn tyrants like Chieh of the Hsia dynasty, and Chou of the Yen dynasty. The two Japanese Emperors, Kōtoku and Tenchi (668-671), secm to have partially endorsed a cognate prineiple. But nothing could be at greater variance with the cardinal tenet of the Japanese polity, which holds that "the King can do no wrong" and that the Imperial line must remain unbroken to all eternity.

\section{ENVOYS TO CHINA}

The importance attached to intercourse with China during the reign of Kötoku was illustrated by the dimensions of the embassies sent to the Tang Court and by the quality of the envoys. Two embassies were sent in 653 , one consisting of 121 persons and the other of 120.1 The former included seventeen student-priests, and among them was the eldest son of Kamatari himself. An-

[ ${ }^{1}$. The ship carrying the embassy was wrecked off the south coast of Japan, and out of 120 persons only five escaped.] 
other embassy was despatched in 654 , and the records show incidently that the sea route was taken, for after a voyage lasting some months and therefore presumably of a coasting character, the envoys landed at Laichou in Shantung. They finally reached Changan, the Tang capital, and were most hospitably received by the Emperor Kao-sung. The hardships of the journey are attested by the fact that three of the student-priests died at sea. One remained in China for thirty-six years, and Joye, Kamatari's son, did not return to Japan for twelve years.

In short, when these students left their country in search of literary, religious, and politieal lore, they had no assurance of ever thereafter finding an opportunity to see their homes again. The overland journey was almost impossible without guides and guards, and communication by sea seems to have been fitful and uneertain. The last of the above three embassies was led by no less a person than the renowned scholar, Kuromaro, who had been associated with the priest; Bin, in modelling the new administrative system of Japan. Kuromaro never returned from China; he died there. A few months before the despatch of Kuromaro as envoy, his illustrious coadjutor, Bin, expired in the temple of Azumi. The Emperor repaired in person to the sick priest's chamber, and said, "If you die to-day, I will follow you to-morrow." So great was the reverence showed towards learning and piety in that era. Thus, hazardous and wearisome as was the voyage to China over stormy waters in a rude sailing boat, its successful accomplishment established a title to official preferment and high honour. It will be seen by and by that similar treatment was extended in the nineteenth century to men who visited Europe and America in the pursuit of knowledge.

\section{THE THIRTY-SEVENTH SOVEREIGN, THE EMPRESS SAIMEI (A.D. 655-661)}

On the demise of Kōtoku, in 654, his natural successor would have been Prince Naka, who, ten years previously, had chosen to reform the empire rather than to rule it. But the prince deemed that the course of progress still claimed his undivided attention, and therefore the Empress Kogyoku was again raised to the throne under the name of ${ }^{1}$ Saimei - the first instance of a second accession in Japanese history. She reigned nearly seven years, and the era is remarkable chiefly for expeditions against the Yemishi and for complications with Korea. To the former chapter of history sufficient reference had already been made, but the latter claims a moment's attention.

\section{RELATIONS WITH KOREA}

It has been shown how, in A.D. 562, the Japanese settlement in Mimana was exterminated; how the Emperor Kimmei's dying behest to his successor was that this disgrace must be removed; how subsequent attempts to carry out his testament ended in failure, owing largely to Japan's weak habit of trusting the promises of Shiragi, and how, in 618, the Sui Emperor, Yang, at the head of a great army, failed to make any impression on Korea.

Thereafter, intercourse between Japan and the peninsula was of a fitful character unmarked by any noteworthy event until, in the second year (651) of the "White Pheasant" era, the Yamato Court essayed to assert itself in a futile

[ ${ }^{1}$ It is scarcely necessary to remind the reader that all the names given in these pages to Japanese sovereigns are posthumous. Thus Saimei, during her lifetime, was called Ame-toyotakara-ikashi-hi-tarashi-hime.] 
fashion by refusing to give audience to Shiragi envoys because they wore costumes after the Tang fashion without offering any excuse for such a caprice. Kōtoku was then upon the Japanese throne, and Japan herself was busily occupied importing and assimilating Tang institutions. That she should have taken umbrage at similar.imitation on Shiragi's part seems capricious. Shiragi sent no more envoys, and presently (655), finding herself seriously menaced by a coalition between Koma and Kudara, she applied to the Tang Court for assistance. The application produced no practical response, but Shiragi, who for some time had been able to defy the other two principalities, now saw and seized an opportunity offered by the debauchery and misrule of the King of Kudara. She collected an army to attack her neighbour and once more supplicated Tang's aid. This was in the year 660. The second appeal produced a powerful response. Kao-sung, then the Tang Emperor, despatched a general, Su Ting-fang, at the head of an army of two hundred thousand men. There was now no long and tedious overland march round the littoral of the Gulf of Pechili and across Liaotung. Su embarked his forces at Chengshan, on the east of the Shantung promontory, and crossed direct to Mishi-no-tsu - the modern Chemulpo - thus attacking Kudara from the west while Shiragi moved against it from the east. Kudara was crushed. It lost ten thousand men, and all its prominent personages, from the debauched King downwards, were sent as prisoners to Tang. But one great captain, Pok-sin, saved the situation. Collecting the fugitive troops of Kudara he fell suddenly on Shiragi and drove her back, thereafter appealing for Japanese aid.

At the Yamato Court Shiragi was now regarded as a traditional enemy. It had played fast and loose again and again about Mimana, and in the year 657 it had refused safe conduct for a Japanese embassy to the Tang Court. The Empress Saimei decided that Kudara must be succoured. Living in Japan at that time was Phung-chang, ${ }^{1}$ a younger brother of the deposed King of Kudara. It was resolved that he should be sent to the peninsula accompanied by a sufficient force to place him on the throne. But Saimei died before the necessary preparations were completed, and the task of carrying out a design which had already received his endorsement devolved upon Prince Naka, the great reformer. : A fleet of 170 ships carrying an army of thirty-seven thousand men escorted Phung-chang from Tsukushi, and the kingdom of Kudara was restored. But the conclusive battle had still to be fought. It took place in September, 662, at Paik-chhon-ku (Ung-jin), between the Chinese under Liu Jen-kuei, a Tang general, and the Japanese under Atsumi no Hirafu. The forces were about equal on each side, and it was the first signal trial of strength between Chinese and Japanese. No particulars have been handed down by history. Nothing is known except that the Japanese squadron drove straight ahead, and that the Chinese attacked from both flanks. The result was a crushing defeat for the Japanese. They were shattered beyond the power of rallying, and only a remnant found its way back to Tsukushi. Kudara and Koma fell, and Japan lost her last footing in a region where her prestige had stood so high for centuries.

Shiragi continued during more than a hundred years to maintain a semblance of deferential intercourse, but her conduct became ultimately so unruly that, in the reign of Nimmyō (834-850), her people were prohibited from visiting Japan.

$\left[{ }^{1} \mathrm{He}\right.$ was a hostage. The constant residence of Korean hostages in Japan speaks eloquently of the relations existing between the two countries. There were no Japanese hostages in Korea.] 
From Kudara, however, after its overthrow by China, there migrated almost continuously for some time a number of inhabitants who became naturalized in Japan. They were distributed ehiefly in the provinces of Ōmi and Musashi, Son-Kiwang, a brother of the former King of Kudara, being required to live in Naniwa (Ōsaka) for the purpose of controlling them. Koma, also, when it fell into Chinese hands, sent many settlers to Japan, and during the reign of the Empress Gemmyo (708-715), they were transferred from the six provinces of Suruga, Kai, Sagami, Kazusa, Shimōsa, and Hitachi to Musashi, where the district inhabited by them was theneeforth called Koma-gōi. Thus, Japan extended her hospitality to the men whose independence she had not been able to assert. Her relations with her peninsular neighbour ended humanely though not gloriously. They had cost her heavily in life and treasure, but she had been repaid fully with the eivilization which Korea helped her to import.

\section{THE THIRTY-EIGHTH SOVEREIGN, THE EMPEROR TENCHI (A.D. 668-671)}

It will be observed that although the thirty-seventh sovereign, the Empress Saimei, died in the year 661, the reign of her suceessor, Tenchi, did not commence historically until 668. There thus appears to have been an interregnum of seven years. The explanation is that the Crown Prince, Naka, while taking the sceptre, did not actually wield it. He entrusted the administrative functions to his younger brother, Ōama, and continued to devote himself to the great work of reform. He had stood aside in favour of Kōtoku sixteen years previously and in favour of the Empress Saimei six years previously, and now, for seven years longer, he refrained from identifying himself with the Throne until the fate of his innovations was known. Having assumed the task of eradicating abuses which, for a thousand years, had been growing unchecked, he shrank from assoeiating the Crown directly with risks of failure. But in the year 668; judging that his reforms had been sufficiently assimilated to warrant confidence, he formally ascended the throne and is known in history as Tenchi (Heavenly Intelligenee).

Only four years of life remained to him, and almost immediately after his accession he lost his great coadjutor, Kamatari. Of the four men who had worked out the "Daika restoration," Kuromaro, the student, died in China a year (654) after the demise of the illustrious priest, Bin; Kamatari barely survived until success eame in sight, and Prinee Naka (Tenchi) was taken two years later (671). It is related that in the days when the prince and Kamatari planned the outlines of their great scheme, they were accustomed to meet for purposes of conference in a remote valley on the east of the capital, where an aged wistaria happened to be in bloom at the most critical of their consultations. Kamatari therefore desired to ehange his uji name from Nakatomi to Fujiwara (wistaria), and the prince, on ascending the throne, gave effect to this request. There thus came into existence a family, the most famous in Japanese history. The secluded valley where the momentous meetings took place received the name of Tamu ${ }^{2}$ no Mine, and a shrine stands there now in memory of Kamatari. The Emperor would fain have attended Kamatari's obsequies in person, but his ministers dissuaded him on the ground that such a course would be unprecedented. His Majesty confined himself therefore to conferring on the deceased statesman posthumous official rank, the first instance of a practice destined to became habitual in Japan.

$$
\text { [1 "Tamu" signifies to eonverse about military affairs.] }
$$




\section{THE ŌMI STATUES AND THE CENSUS REGISTER}

During the reign of Tenchi no rescript embodying signal administrative changes was issued, though the reforms previously inaugurated seem to have made steady progress. But by a legislative office specially organized for the purpose there was enacted a body of twenty-two laws called the $\bar{O}$ mi Ritsu-ry' (the Ōmi Statutes), $\bar{O} \mathrm{mi}$, on the shore of Lake Biwa, being then the seat of the Imperial Court. Shōtoku Taishi's Jüshichi Kempō, though often spoken of as a legislative ordinance, was really an ethical code, but the $\bar{O} m i$ Ritsu-ryō had the character of genuine laws, the first of their kind in Japan. Unfortunately this valuable document did not survive. Our knowledge of it is confined to a statement in the Memoirs of Kamatari that it was compiled in the year 667. Two years later-that is to say, in the year after Tenchi's actual accession-the census register, which had formed an important feature of the Daika reforms, became an accomplished fact. Thenceforth there was no further occasion to appeal to the barbarous ordeal of boiling water (kuga-dachi) when questions of lineage had to be determined.

\section{THE THIRTY-NINTH SOVEREIGN, THE EMPEROR KŌBUN (A.D 672-672)}

Among four "palace ladies" (uneme) upon whom the Emperor Tenchi looked with favour, one, Yaka of Iga province, bore him a son known in his boyhood days as Prince Iga but afterwards called Prince Ōtomo. For this lad his father conceived a strong affection, and would doubtless have named him heir apparent had he not been deterred by the consideration that during his own abstention from actually occupying the throne, administrative duties would have to be entrusted mainly to the hands of a Prince Imperial, and Ōtomo, being only thirteen years of age, could not undertake such a task. Thus, on Tenchi's younger brother, Ōama, the dignity of Crown Prince was conferred, and he became the Emperor's locum tenens, in which position he won universal applause by $y_{i}$ sagacity and energy. But during these seven years of nominal interregnum, the fame of Prince Ōtomo also grew upon men's lips. An ancient book speaks of him as "wise and intelligent; an able administrator alike of civil and of military affairs; commanding respect and esteem; sage of speech, and rich in learning." When the Emperor actually ascended the throne, Ōtomo had reached his twentieth year, and four years later (671) the sovereign appointed him prime minister (dajō daijin), an office then created for the first time:

Thenceforth the question of Tenchi's successor began to be disquieting. The technical right was on Ōama's side, but the paternal sympathy was with Ōtomo. Tradition has handed down a tale about a certain Princess Nukata, who, having bestowed her affections originally on Prince Öama, was afterwards constrained to yield to the addresses of the Emperor Tenchi, and thus the two brothers became enemies. But that story does not accord with facts. It is also related that during a banquet at the palace on the occasion of Tenchi's accession, Prince Ōama thrust a spear through the floor from below, and the Emperor would have punished the outrage with, death had not Kamatari interceded for the prince. . These narratives are eited to prove that the Emperor Tenchi's purpose was to leave the throne to Ōtomo, not Ōama. There is, however, no valid reason to infer any such intention. What actually occurred was that when, within a few months of Ōtomo's appointment as dajo daijin, the sovereign found himself mortally sick, he summoned Ōama and named him to succeed 
But Ōama, having been warned of a powerful conspiracy to place Ōtomo on the throne, and not unsuspicious that it had the Emperor's sympathy, declined the honour and announced his intention of entering religion, which he did by retiring to the monastery at Yoshino. The conspirators, at whose head were the minister of the Left, Soga no Akae, and the minister of the Right, Nakatomi no Kane, aimed at reverting to the times when, by placing on the throne a prince of their own choice, one or two great $u j i$ had grasped the whole political power. The prime mover was Kane, muraji of the Nakatomi.

Immediately after Tenchi's death, which took place at the close of 671 ; and after the accession of Prince Ōtomo - known in history as the Emperor Kōbun - the conspirators began to concert measures for the destruction of Prince Ōama, whom they regarded as a fatal obstacle to the achievement of their purpose. But the Emperor Köbun's consort, Toichi, was a daughter of Prince Ōama, and two sons of the latter, Takaichi and Ötsu, were also in the Court at Ōmi. By these three persons Yoshino was kept fully informed of everything happening at Ōmi. Ōama fled precipitately. He did not even wait for a palanquin or a horse. His course was shaped eastward, for two reasons: the first, that his domains as Prince Imperial had been in Ise and Mino; the second, that since in the eastern provinees the Daika reforms had been first put into operation, in the eastern provinces, also, conservatism might be expected to rebel with least reluctance.

The struggle that ensued was the fiercest Japan had witnessed since the foundation of the empire. For twenty days there was almost continuous fighting. The prince's first measure was to block the passes on the eastward highroads, so that the Ōmi forces could not reach him till he was fully ready to receive them. Thousands flocked to his standard, and he was soon able to assume the offensive. On the other hand, those whom the Ōmi Court summoned to arms declined for the most part to respond. The nation evidently regarded Prince Ōama as the champion of the old against the new. The erowning contest took place at the Long Bridge of Seta, which spans the waters of Lake Biwa at the place where they narrow to form the Seta River. Deserted by men who had sworn to support him, his army shattered, and he himself a fugitive, the Emperor fled to Yamazaki and there committed suicide. His principal instigator, muraji of the Nakatomi and minister of the Right, with eight other high officials; suffered the extreme penalty; Akae, omi of the Soga and minister of the Left, had to go into exile, but the rest of Köbun's followers were pardoned. Not because of its magnitude alone but because its sequel was the dethronement and suicide of a legitimate Emperor, this struggle presents a shocking aspect to Japanese eyes. It is known in history as the "Jinshin disturbance," so called after the cyclical designation of the year (672) when it occurred

THE FORTIETH SOVEREIGN, THE EMPEROR TEMMU (A.D. 673-686)

Prince $\bar{O}$ ama succeeded to the throne and is known in history as the fortieth Sovereign, Temmu. During the fourteen years of his reign he completed the administrative systems of the Daika era, and asserted the dignity and authority of the Court to an unprecedented degree. Among the men who espoused his cause in the Jinshin struggle there are found many names of aristocrats who boasted high titles and owned hereditary estates. Whatever hopes these conservatives entertained of a reversion to the old-time.order of things, they were signally disappointed. The Daika reformers had invariably contrived that 
conciliation should march hand in hand with innovation. Temmu relied on coercion. He himself administered State affairs with little recourse to ministerial aid but always with military assistance in the background. He was especially careful not to sow the seeds of the abuses which his immediate predecessors had worked to eradicate. Thus, while he did not fail to recognize the services of those that had stood by him in the Jinshin tumult, he studiously refrained from rewarding them with official posts, and confined himself to bestowing titles of a purely personal character together with posthumous rank in special cases.

It has been shown that in the so-called "code" of Shötoku Taishi prominent attention was directed to the obligations of decorum. This principle received much elaboration in Temmu's reign. A law, comprising no less than ninety-two articles, was enacted for guidance in Court ceremonials, the demeanour and salutation of each grade of officials being explicitly set forth. It is worthy of note that a veto was imposed on the former custom of kneeling to make obeisance and advancing or retreating in the presence of a superior on the knees and hands; all salutations were ordered to be made standing. Further, the clear differentiation of official functions, which had been commenced under the sway of Tenchi, was completed in this reign.

But, though relying on military force in the last resort, Temmu did not neglect appeals to religion and devices to win popularity. On the one hand, we find him establishing a War-Office (Heisei-kan) and making it second in grade and importance to the Privy Council (Dajo-kwan) alone; on the other, he is seen endowing shrines, erecting temples, and organizing religious fêtes on a sumptuous scale. If, again, all persons in official position were required to support armed men; if the provincials were ordered to practise military exercises, and if arms were distributed to the people in the home provinces (Kinai), at the same time taxes were freely remitted, and amnesties were readily granted. Further, if much attention was paid to archery, and if drastic measures were adopted to crush the partisans of the Ōmi Court who still occasionally raised the standard of revolt, the sovereign devoted not less care to the discharge of the administrative functions, and his legislation extended even to the realm of fishery, where stakenets and other methods of an injurious nature were strictly interdicted. The eating of flesh was prohibited, but whether this veto was issued in deference to Buddhism or from motives of economy, there is no evidence to show.

One very noteworthy feature of Temmu's administration was that he never appointed to posts in the Government men who did not give promise of competence. All those who possessed a claim on his gratitude were nominated chamberlains (toneri), and having been thus brought under observation, were subsequently entrusted with official functions commensurate with their proved ability. The same plan was pursued in the case of females. With regard to the titles conferred by this sovereign in recognition of meritorious services, they were designed to replace the old-time kabane (or sei), in that whereas the kabane had always been hereditary, and was generally associated with an office, the new sei was obtained by special grant, and, though it thereafter became hereditary, it was never an indication of office bearing. Eight of these new titles were instituted by Temmu, namely, mahito, asomi, sukune, imiki, michi-no-shi, omi, muraji, and inagi, and their nearest English equivalents are, perhaps, duke, marquis, count, lord, viscount, baron, and baronet. It is unnecessary to give any etymological analysis of these terms; their order alone is important. But two points have to be noted. The first is that the title $i m i k i$ was generally that 
chosen for bestowal on naturalized foreigners; the second, that a conspicuously low place in the list is given to the revered old titles, omi and muraji. This latter feature is signifieant. The new peerage was, in fact, designed not only to supplant, but also to discredit, the old.

'Thus, in the first place, the system was abolished under which all $u j i$ having the title of omi were controlled by the $\bar{o}$-omi, and all having the title of muraji by the $\bar{o}$-muraji; and in the second, though the above eight sei were established, not every $u j i$ was necessarily granted a title. Only the most important received that distinction, and even these found themselves relegated to a comparatively low place on the list. All the rest, however, were permitted to use their old, but now depreciated kabane, and no change was made in the traditional custom of entrusting the management of each uji's affairs to its own Kami. But, in order to guard against the abuses of the hereditary right, an uji no Kami ceased in certain cases to succeed by birthright and became elective, the election requiring Imperial endorsement.

The effect of these measures was almost revolutionary. They changed the whole fabric of the Japanese polity. But in spite of all Temmu's precautions to accomplish the centralization of power, success was menaced by a factor which could scarcely have been controlled. The arable lands in the home provinees at that time probably did not exceed 130,000 acres, and the food stuffs produced cannot have sufficed for more than a million persons. As for the forests, their capacities were ill developed, and thus it fell out that the sustenance fiefs granted to omi and muraji of the lower grades did not exceed a few acres. Gradually, as families multiplied, the conditions of life became too straightened in such circumstances, and relief began to be sought in provincial appointments, which furnished opportunities for getting possession of land. It was in this way that local magnates had their origin and the seeds of genuine feudalism were sown. Another direction in which success fell short of purpose was in the matter of the hereditary guilds (be). The Daika reforms had aimed at converting everyone in the empire into a veritable unit of the nation, not a mere member of an uji or a tomobe. But it proved impossible to carry out this system in the case of the tomobe (called also kakibe), or labouring element of the uji, and the yakabe, or domestic servants of a family. To these their old status had to be left.

THE FORTY-FIIST SOVEREIGN, THE EMPRESS JITŌ (A.D. 690-697)

The Emperor Temmu died in 686 , and the throne remained nominally unoccupied until 690. A similar interregnum had separated the accession of Tenchi from the death of his predecessor, the Empress Saimei, and both events were due to a cognate cause. Tenchi did not wish that his reforms should be direetly associated with the Throne until their success was assured; Temmu desired that the additions made by him to the Daika system should be consolidated by the genius of his wife before the sceptre passed finally into the hands of his son. Jitō had stood by her husband's side when, as Prince Ōama; he had barely escaped the menaces of the Ömi Court, and there is reason to think that she had subsequently shared his administrative confidence as she had assisted at his military councils. The heir to the throne, Prince Kusakabe, was then in his twenty-fifth year, but he quietly endorsed the paternal behest that his mother should direct State affairs. The arrangement was doubtless intended to be temporary, but Kusakabe died three years later, and yielding to the solicitations of her ministers, Jito then (690) finally ascended the throne. 
Her reign, however, was not entirely free from the family strife which too often accompanied a change of sovereigns in Japan's early days. In addition to his legitimate offspring, Kusakabe, the Emperor Temmu left several sons by secondary consorts, and the eldest survivor of these, Prince Ōtsu, listening to the counsels of the $\bar{O}$ mi Court's partisans and prompted by his own well-deserved popularity and military prowess, intrigued to seize the throne. He was executed in his house, and his fate is memorable for two reasons: the first, that his young wife, Princess Yamanobe, "hastened thither with her hair dishevelled and her feet bare and joined him in death;" the second, that all his followers, over thirty in number, were pardoned - rare clemency in those days. Prince Ōtsu is said to have inaugurated a pastime which afterwards became very popular - the composition of Chinese verses.

\section{SLAVES}

The most important legislation of the Empress Jitō's reign related to slares. ${ }^{1}$ In the year of her accession (690), she issued an edict ordering that interest on all debts contracted prior to, or during the year (685) prior to Temmu's death should be cancelled. Temmu himself had created the precedent for this. When stricken by mortal illness, he had proclaimed remission of all obligations, "whether in rice or in valuables," incurred on or before the last day of the preceding year. But Jitō's edict had a special feature. It provided that anyone already in servitude on account of a debt should be relieved from serving any longer on account of the interest. Thus it is seen that the practice of pledging the service of one's body in discharge of debt was in vogue at that epoch, and that it received official recognition with the proviso that the obligation must not extend to interest. Debts, therefore, had become instruments for swelling the ranks of the slave class.

But while sanctioning this evil custom; the tendency of the law was to minimize its results. In another edict of the same reign it was laid down that, when a younger brother of the common people (hyakusei) was sold by his elder brother, the former should still be classed as a freeman (ryōmin), but a child sold by its father became a serf (senmin); that service rendered to one of the senmin class by a freeman in payment of a debt must not affect the status of the freeman, and that the children of freemen so serving, even though born of a union with a slave, should be reckoned as freemen. 'It has been shown already that degradation to slavery, was a common punishment or expiation of a crime; and the annals of the period under consideration indicate that men and women of the slave class were bought and sold like any other chattels. Documents certainly not of more recent date than the ninth century, show particulars of some of these transactions. One runs as follows:-

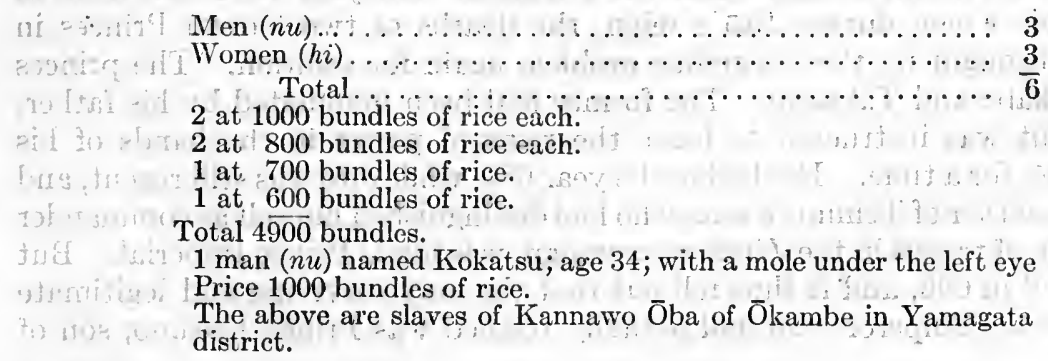

$\left[{ }^{1}\right.$ The senmin, or slave class, was divided into two groups, namely, public slaves (kwankō ryōko, and $k \bar{o}-n u h i)$, and private slaves (kenin and shi-nuhi).] 
Comparison of several similar vouchers indicates that the usual price of an able-bodied slave was one thousand bundles of rice, and as one bundle gave five sho of unhulled rice, one thousand bundles represented fifty koku, which, in the modern market, would sell for about six hundred yen. It is not to be inferred, however, that the sale of freemen into slavery was sanctioned by law. During the reign of the Emperor Temmu, a farmer of Shimotsuke province wished to sell his child on account of a bad harvest, but his application for permission was refused, though forwarded by the provincial governor. In fact, sales or purchases of the junior members of a family by the seniors were not publicly permitted, although such transactions evidently took place. Even the manumission of a slave required official sanction. Thus it is recorded that, in the reign of the Empress Jitō, Komaro, an asomi, asked and obtained the Court's permission to grant their freedom to six hundred slaves in his possession. Another rule enacted in Jito's time was that the slaves of an $u j i$, when once manumitted, could not be again placed on the slaves' register at the request of a subsequent uji no Kami. Finally this same sovereign enacted that yellow-coloured garments should be worn by freemen and black by slaves. History shows that the sale and purchase of human beings in Japan, subject to the above limitations, was not finally forbidden until the year 1699 .

\section{THE MILITARY SYSTEM}

It has been seen that the Emperors Kōtoku and Temmu attached much importance to the development of military efficiency and that they issued orders with reference to the training of provincials, the armed equipment of the people, the storage of weapons of war, and the maintenance of men-at-arms by officials. Compulsory service, however, does not appear to have been inaugurated until the reign of the Empress Jito, when (689) her Majesty instructed the local governors that one-fourth of the able-bodied men in each province should be trained every year in warlike exercises. This was the beginning of the conscription system in Japan.

\section{THE ORDER OF SUCCESSION OF THE THRONE}

That the throne should be occupied by members of the Imperial family only had been a recognized principle of the Japanese polity from remotest epochs. But there had been an early departure from the rule of primogeniture, and since the time of Nintoku the eligibility of brothers also had been acknowledged in practice. To this latitude of ehoice many disturbances were attributable, notably the fell Jinshin struggle, and the terrors of that year were still fresh in men's minds when, during Jitō's reign, the deaths of two Crown Princes in succession brought up the dangerous problem again for solution. The princes were Kusakabe and Takaichi. The former had been nominated by his father, Temmu, but was instructed to leave the reins of power in the hands of his mother, Jitō, for a time. He died in the year 689 , while Jitō was still regent, and Takaichi, another of 'Temmu's sons, who had distinguished himself as commander of a division of troops in the Jinshin campaign, was made Prince Imperial. But he, too, died in 696 , and it thus fell out that the only surviving and legitimate offspring of an Emperor who had actually reigned was Prince Kuzuno, son of Kōbun.

To his accession, however, there was this great objection that his father, 
though wielding the sceptre for a few months, had borne arms in the Jinshin disturbance against Temmu and Jito, and was held to have forfeited his title by defeat and suicide. His assumption of the sceptre would have created a most embarrassing situation, and his enforced disqualification might have led to trouble. In this dilemma, the Empress convened a State council, Prince Kuzuno also being present, and submitted the question for their decision. But none replied until Kuzuno himself, coming forward, declared that unless the principle of primogeniture were strictly followed, endless complications would be inevitable. This involved the sacrifice of his own claim and the recognition of Karu, eldest son of the late Kusakabe. The 14th of March, 696, when this patriotic declaration was made, is memorable in Japanese history as the date when the principle of primogeniture first received official approval. Six months afterwards, the Empress abdicated in favour of Prince Karu, known in history as forty-second sovereign, Mommu. She herself was honoured by her successor with the title of Dajo-Tennō (Great Superior).

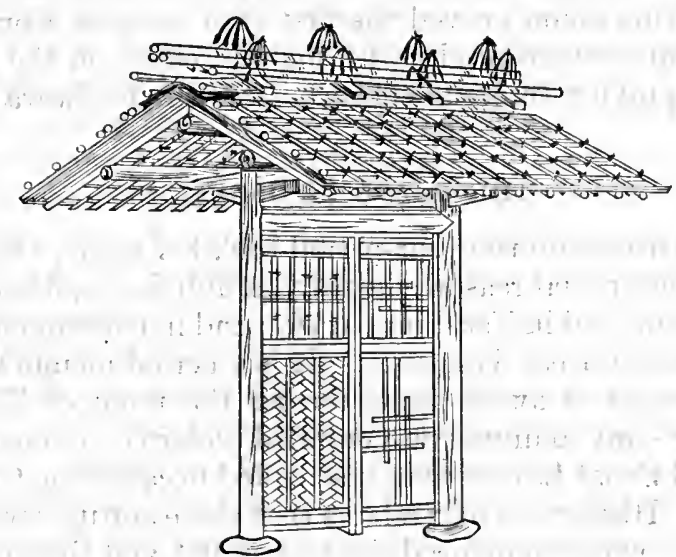

One of the Ornamental Gates Used in Japanese Gardens 


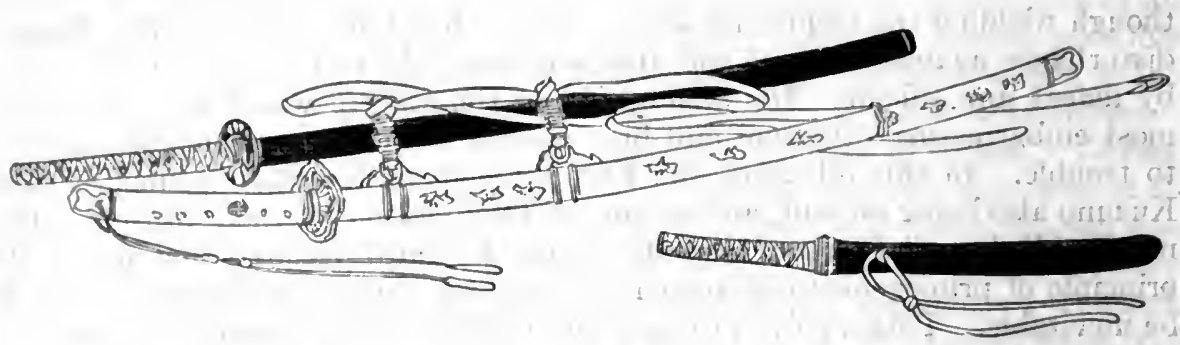

Swonds

\section{CHAPTER XVI}

\section{THE DAIHŌ LAWS AND THE YŌRŌ LAWS}

\section{THE FORTY-SECOND SOVEREIGN, THE EMPEROR MOMMU (A.D. 697-707)}

The Emperor Mommu took for consort a daughter of Fuhito, representative of the Fujiwara family and son of the great Kamatari. She did not reeeive the title of Empress, that distinetion having been hitherto strictly confined to spouses ehosen from a $K w \bar{o} b e t s u$ family, whereas the Fujiwara belonged to the Shimbetsu. But this union proved the first step towards a practice which soon became habitual and which produced a marked effeet on the history of Japan, the practice of supplying Imperial consorts from the Fujiwara family.

\section{THE DAIHŌ LEGISLATION}

On Mommu's accession the year-period took his name, that being then the custom unless some special reason suggested a different epithet. Such a reason was the discovery of gold in Tsushima in 701, and in consequence the year-name was altered to Daiho (Great Treasure). It is a period memorable for legislative activity. The reader is aware that, during the reign of Tenchi, a body of statutes in twenty-two volumes was compiled under the name of $\bar{O}$ mi Ritsu-ryo, or the "Code and Penal Law of Ömi," so ealled because the Court then resided at Shiga in Ōmi. History further relates that these statutes were revised by the Emperor Mommu, who commenced the task in 681 and that, eleven years later, when the Empress Jito occupied the throne, this revised code was promulgated.

But neither in its original nor in its revised form has it survived, and the inference is that in practice it was found in need of a second revision, which took place in the years 700 and 701 under instruetions from the Emperor Mommu, the revisers being a committee of ten, headed by Fuhito of the Fujiwara family, and by Mahito (Duke) Awada. There resulted eleven volumes of the Code (ryō) and six of the Penal Law (ritsu), and these were at onee promulgated, expert jurists being despatehed, at the same time, to various quarters to expound the new legislation. Yet again, seventeen years later (718), by order of the Empress Genshō, revision was carried out by another committee headed by the same Fujiwara Fuhito, now prime minister, and the amended volumes, ten of the Code and ten of the Law, were known thenceforth as the "New Statutes," or the "Code and Law of the Yōro Period." They were supplemented by a body of 
official rules (kyaku) and operative regulations (shiki), the whole forming a very elaborate assemblage of laws.

The nature and scope of the code will be sufficiently understood from the titles of its various sections: (1) Official Titles; (2) Duties of Officials; (3) Duties of Officials of the Empress' Household; (4) Duties of Officials in the Household of the Heir Apparent; (5) Duties of Officials in the Households of Officers of High Rank; (6) Services to the Gods; (7) Buddhist Priests; (8) the Family; (9) the Land; (10) Taxation; (11) Learning; (12) Official Ranks and Titles; (13) The Descent of the Crown and Dignities of Imperial Persons; (14) Meritorious Discharge of Official Duties; (15) Salaries; (16) Court Guards; (17) Army and Frontier Defences; (18) Ceremonies; (19) Official Costumes; (20) Public Works; (21) Mode of addressing Persons of Rank; (22) Stores of Rice and other Grain; (23) Stables and Fodder; (24) Duties of Medical Officers attached to the Court; (25) Official Vacations; (26) Funerals and Mourning; (27) Watch and Ward and Markets; (28) Arrest of Criminals; (29) Jails, and (30) Miscellaneous, including Bailment, Finding of Lost Goods, etc. ${ }^{1}$

This "Code and the Penal Law" accompanying it went into full operation from the Daiho era and remained in force thereafter, subject to the revisions above.indicated. There is no reason to doubt that the highly artificial organization of society which such statutes indicate, existed, in outline at all events, from the reign of Kōtoku, but its plainly legalized reality dates, so far as history is concerned, from the Daiho era. Ass for the rules (kyaku) and regulations (shiki), they were re-drafted: first, in the Konnin era (810-824) by a commission under the direction of the grand councillor, ${ }^{1}$ Fujiwara Fuyutsugu; next, in the Jokkwan era (859-877) by Fujiwara Ujimune and others, and finally in the Engi era (901923) by a committee with Fujiwara Tadahira for president. These three sets of provisions were spoken of in subsequent ages as the "Rules and Regulations of the Three Generations" (Sandai-kyaku-shiki). It will be observed that just as this remarkable body of enactments owed its inception in Japan to Kamatari, the great founder of the Fujiwara family, so every subsequent revision was presided over by one of his descendants. The thirty scctions of the code comprise 949 articles, which are all extant, but of the penal laws in twelve sections there remain only 322 articles.

It may be broadly stated that the Daika reformation, which formed the basis of this legislation, was a transition from the Japanese system of heredity to the Chinese system of morality. The penal law (ritsu), although its Chinese original has not survived for purposes of comparison, was undoubtedly copied from the work of the Tang legislators, the only modification being in degrees of punishment; but the code, though it, too, was partially exotic in character, evidently underwent sweeping alterations so as to bring it into conformity with Japanese customs and traditions. Each of the revisions recorded above must be assumed to have extended this adaptation.

The basic principle of the Daiho code was that the people at large, without regard to rank or pedigree, owed equal duty to the State; that only those having special claims on public benevolence were entitled to fixed exemptions, and that not noble birth but intellectual capacity and attainments constituted a qualification for office. Nevertheless Japanese legislators did not find it possible to apply fully these excellent principles. Habits of a millennium's growth could not be so lightly eradicated. Traces of the old obtrude themselves plainly from between the lines of the new. Thus the "Law of Descent" (Keishi-ryō), which 
formed the thirteenth section of the code, was a special embodiment of Japanese social institutions, having no parallel in the Tang statutes, and further, while declaring erudition and intelligence to be the unique qualifications for office, no adequate steps were taken to establish schools for imparting the former or developing the latter. In short, the nobles still retained a large part of their old power, and the senmin (slave) class still continued to labour under various disabilities.

That several important provisions of the Land Code (Den-ryō) should have fallen quickly into disuse will be easily comprehended when we come presently to examine that system in detail, but for the neglect of portions of the Military. Code $(G u m b \bar{o}-r y \bar{o})$, of the Code of Offieial Ranks and Titles, and of the Code relating to the Meritorious Discharge of Official Duties, it is necessary to lay the responsibility on the shoulders of the hereditary nobles, whose influence outweighed the force of laws. It may indeed be broadly stated that the potency of the Daiho code varied in the direct ratio of the centralization of administrative authority. Whenever feudalism prevailed, the code lost its binding force. In the realm of criminal law it is only consistent with the teaching of all experience to find that mitigation of penalties was provided according to the rank of the culprit. There were eight major crimes (hachi-gyaku), all in the nature of offences against the State, the Court, and the family, and the order of their gravity was: (1) high treason (against the State); (2) high treason (against the Crown); (3) treason; (4) parricide, fratricide, etc.; (5) offences against humanity; (6) lèse majesté; (7) unfilial conduct, and (8) crimes against society. But there were also six mitigations (roku-gi), all enacted with the object of lightening punishments according to the rank, official position, or public services of an offender. As for slaves, being merely a part of their proprietor's property like any other goods and chattels, the law took no cognizance of them.

OFFICIAL ORGANIZATION

Under the Daiho eode a more elaborate system of administrative organization was effected than that conceived by the Daika reformers. In the Central Government there were two boards, eight departments, and one office, namely:

(1). The Jingi-kwan, or Board of Religion (Shintō). This stood at the head of all, in recognition of the divine origin of the Imperial family. A Japanese work (Nihon Kodaiho Shakugi) explains the fundamental tenet of the nation's creed thus: "If a State has its origin in military prowess, which is essentially human, then by human ageneies also a State may be overthrown. To be secure against such vieissitudes a throne must be based upon something superior to man's potentialities. Divine authority alone fulfils that definition, and it is because the throne of Japan had a superhuman foundation that its existence is perennial. Therefore the Jingi-kwan stands above all others in the State." In another. book (Jingi-ryō) we find it stated: "All the deities ${ }^{1}$ of heaven and earth are worshipped in the Jingi-kwan. On the day of the coronation the Nakatomi performs service to the deities of heaven and the Imibe makes offerings of three kinds of sacred articles."

Thus, though the models for the Daihō system were taken from China, they were adapted to Japanese customs and traditions, as is proved by the premier

[ ${ }^{1}$ The eight Kami specially worshipped in the Jingi-kwan were Taka-mi-musubi, Kammimusubi, Tamatsume-musubi, Iku-musubi, 'Taru-musubi, Omiya no me, Miketsu, and Kotoshiro-nushi.] 
place given to the Jingi-kwan. Worship and religious ceremonial have always taken precedence of secular business in the Court of Japan. Not only at the central seat of government did the year commence with worship, but in the provinces, also, the first thing recorded by a newly appointed governor was his visit to the Shinto shrines, and on the opening day of each month he repaired thither to offer the gohei. ${ }^{1}$ Religious rites, in short, were the prime function of government, and therefore, whereas the office charged with these duties ranked low: in the Tang system, it was placed at the head of all in Japan.

(2). The Daijo-kwan (called also Dajō-kwan), or Board of Privy Council. This office ranked next to the Board of Religion and had the duty of superintending the eight State departments. Its personnel consisted of the prime minister (daijo-daijin or dajo-daijin), the minister of the Left (sa-daijin), and the minister of the Right (u-daijin).

(3), The Nakatsukasa-shō, or Central Department of State (literally, "Intermediate Transacting Department"), which was not an executive office, its chief duties being to transmit the sovereign's decrees to the authorities concerned and the memorials of the latter to the former, as well as to discharge consultative functions.

(4). The Shikibu-shō, or Department of Ceremonies. This office had to consider and determine the promotion and degradation of officials according to their competence and character.

(5). The Jibu-shō, or Department of Civil Government, which examined and determined everything concerning the position of noblemen, and administered affairs relating to priests, nuns, and members of the Bambetsu, ${ }^{2}$ that is to say; men of foreign nationality residing in Japan.

(6). The Mimbu-shō, or Department of Civil Affairs. An office which managed affairs relating to the land and the people, to taxes and to forced services.

(7). The Gyōbu-shō, or Department of Justice.

(8). The Ōkura-shō, or Department of Finance.

(9). The Kunai-shō, or Imperial Household Department.

(10). The Hyōbu-shō, or Department of War.

(11). The Danjo-dai, or Office of Censorship. This office had the duty of correcting civil customs and punishing and conduct on the part of officials. In the year 799, Kwammu being then on the throne, a law was enacted for the Danjo-dai. It consisted of eighty-three articles, and it had the effect of greatly augmenting the powers of the office. But in the period 810-829, it was found necessary to organize a special bureau of kebiishi, or executive police, to which the functions of the Danjo-dai subsequently passed, as did also those of the Gyōbu-shō in great part. These two boards, eight departments, and one office all had their locations within the palace enclosure, so that the Imperial Court and the Administration were not differentiated.

\section{LOCAL ADMINISTRATIVE MACHINERY}

For administrative purposes the capital was divided into two sections, the Eastern and the Western, which were controlled by a Left Metropolitan Office

1 Angular bunches of white paper stripes, representing the cloth offerings originally tied to branches of the sacred cleyera tree at festival time.].

[2 The reader is already familiar with the terms "Kwöbetsu" and "Shimbetsu." All aliens were classed as Bambetsu.] 
and a Right Metropolitan Office, respectively. In Naniwa (Ōsaka) also, which ranked as a city of special importance, there was an executive office called the Setisu-shoku - Settsu being the name of the pr svince in which the town stood and in Chikuzen provinee there was the Dazai-fu (Great Administrative Office), which had charge of foreign relations in addition to being the seat of the governor-generalship of the whole island of Kyūshū. In spite of its importance as an administrative post, the Dazai-fu, owing to its distance from the capital, came to be regarded as a place of exile for high officials who had fallen out of Impcrial favour.

The empire was divided into provinces (kuni) of four classes - great, superior, medium, and inferior, - and each province was subdivided into distriets (kōri) of five classes - great, superior, medium, inferior, and small. The term "province" had existed from remote antiquity, but it represented at the outset a comparatively small area, for in the time of the Emperor Keitai (A.D. 507-531), there were $144 \mathrm{kuni}$. This number was largely reduced in the sequel of surveys and re-adjustments of boundaries during the Daika era (645-650), and after the Daiho reforms (701-704) it stood at fifty-cight, but subsequently, at an uncertain date, it grew to sixty-six and remained permanently thus. The kōri (district) of the Daika and Daiho reforms had originally been called agata (literally "arable land"), and had been subdivided into inaki (granary) and mura (village). A miyatsuko had administered the affairs of the kuni, holding the office by hereditary right, and the agata - of which there were about 590 , a frequently changing total - as well as the inaki and the mura had been under officials called nushi. But according to the Daika and Daiho systems, each kuni was placed under a governor (kokushi), chosen on account of eompetence and appointed for a term of four years; each district (kōri) was administered by a chō (chief).

\section{MILITARY INSTITUTIONS}

In the capital there were three bodies of guards; namely, the emon-fu (gate guards); the $s a-e j i-f u$ and the $u$-eji-fu (Left and Right watehes). There was also the sa-ma-ryō and the $u-m a-r y \bar{o}$ (cavalry of the Left and of the Right), and the sa-hyōgo-ryō and the $u$-hyōgo-ryō (Left and Right Departments of Supply). These divisions into "left" and "right," and the precedence given to the left; were derived from China, but it has to be observed in Japan's case that the metropolis itself was similarly divided into left and right quarters. Outside the eapital each province had an army corps (gundan), and one-third of all the able-bodied men (seitei), from the age of twenty to that of sixty, were required to serve with the colours of an army corps for a fixed period each year. From these provincial troops drafts were taken every year for a twelve-month's duty as palace guards (eji) in the metropolis, and others were detached for three-years' service as frontier guards (saki-mori) in the provinces lying along the western sea board.

The army corps differed numerically according to the extent of the province where they had their headquarters, but for each thousand men there were one colonel (taiki) and two lieutenant-colonels (shoki); for every five hundred men, one major (gunki); for every two hundred, one captain (kōi); for every one hundred, a lieutenant (ryosui), and for every fifty, a sergeant-major (taisei). As for the privates, they were organized in groups of five (go); ten (kwa), and fifty (tai). Those who could draw a bow and manage a horse were enrolled in the cavalry, the rest being infantry. From each tai two specially robust men were 
selected as archers, and for each $k w a$ there were six pack-horses. The equipment of a soldier on campaign included a large sword (tachi) and a small sword (katana or sashi-zoe) together with a quiver (yanagui or ebira); but in time of peace these were kept in store, the daily exercises being confined to the use of the spear, the catapult (ishi-yumi) and the bow, and to the practice of horsemanship. When several army corps were massed to the number of ten thousand or more, their staff consisted of a general (shōgun), two lieutenant-generals (fuku-shōgun), two army-inspectors (gunkan), four secretaries (rokuji), and four sergeants (gun$s \bar{o})$. If more than one such force took the field, the whole was commanded by a general-in-chief.

\section{APPOINTMENT AND PROMOTION}

The law provided that appointment to office and promotion should depend, not upon rank, but upon knowledge and capacity. Youths who had graduated at the university were divided into three categories: namely, those of eminent talent (shusai); those having extensive knowledge of the Chinese classics (meikei), and those advanced in knowledge (shinshi). Official vacancies were filled from these three classes in the order here set down, and promotion subsequently depended on proficiency. But though thus apparently independent of inherited rank, the law was not so liberal in reality." For admission to the portals of the university was barred to all except nobles or the sons and grandsons of literati. Scions of noble families down to the fifth rank had the right of entry, and scions of nobles of the sixth, seventh, and eighth ranks were admitted by nomination.

\section{OFFICIAL EMOLUMENT}

Remuneration to officials took the form of revenue derived from lands and houses, but this subject can be treated more intelligently when we come to speak of the land.

\section{THE PEOPLE}

According to the Daiho laws one family constituted a household. But the number of a family was not limited: it included brothers and their wives and children, as well as male and female servants, so that it might comprise as many as one hundred persons. The eldest legitimate son was the head of the household, and its representative in the eyes of the law. A very minute census was kept. Children up to three years of age were classed as "yellow" (kwō); those between three and sixteen, as "little" (shō); those members of the household between sixteen and twenty, as "middling" (chü); those between twenty and sixty, as "able-bodied" (tei), and those above sixty as "old" or "invalids," so as to secure their exemption from forced labour (kayaku or buyaku). The census was revised every six years, two copies of the revised document being sent to the privy council (Daijo-kwan) and one kept in the district concerned. It was customary, however, to preserve permanently the census of every thirtieth year ${ }^{1}$ for purposes of record, and moreover the census taken in the ninth year of Tenchi's reign (670) ${ }^{2}$ was also kept as a reference for personal names. To facilitate the preservation of good order and morality, each group of five households was formed into an "association of five" (goho or gonin-gumi) with a recognized head (hōcho) ; and fifty households constituted a village (sato or mura),

[ ${ }^{1}$ This was called gohi-seki; i.e., comparative record for a period of five times six years.]

[2 It was designated the Kögoanen-seki, from the cyclical name of the year.] 
which was the smallest administrative unit. The village had a mayor (richō), whose functions were to keep a record of the number of persons in each household; to encourage diligence in agriculture and sericulture; to reprove, and, if necessary, to report all evil conduct, and to stimulate the discharge of public service. Thus the distriet chief (guncho or gunryō) had practically little to do beyond superintending the richō.

\section{THE LAND}

The land laws of the Daiho era, like those of the Daika, were based on the liypothesis that all land throughout the country was the property of the Crown, and that upon the latter devolved the responsibility of equitable distribution among the people. Rice being the chief staple of diet and also the standard of exchange, rice-lands - that is to say, irrigated fields - were regarded as most important. The law - already referred to in connexion with the Daika era but here eited again for the sake of clearness - enacted that all persons, on attaining the age of five, became entitled to two tan of such land, females receiving two-thirds of that amount. Land thus allotted was called kubun-den, or "sustenance land" (literally, "mouth-share land"). The tan was taken for unit, because it represented $360 b u$ (or $h o$ ), and as the rice produced on one $b u$ constituted one day's ration for an adult male, a tan yielded enough for one year (the year being 360 days). ${ }^{1}$

The theory of distribution was that the produce of one tan served for food, while with the produce of the second tan the cost of clothes and so forth was defrayed. The Daika and Daiho legislators alike laid down the principle that rice-fields thus allotted should be held for a period of six years only, after which they were to revert to the Crown for redistribution, and various detailed regulations, were compiled to meet contingeneies that might arise in carrying out the system. But, of course, it proved quite unpracticable, and though that lesson obviously remained unlearned during the cycle that separated the Daika and the Daiho periods, there is good reason to think that these particular provisions of the land law $($ Den-ryō) soon became a dead letter.

A different method was pursued, however, in the case of uplands (as distinguished from wet fields). These - called onch $i^{2}$ - were parcelled out among the families residing in a distriet, without distinetion of age or sex, and were held in perpetuity, never reverting to the Crown unless a family beeame extinct: Such land might be bought or sold - except to a Buddhist temple - but its tenure was conditional upon planting from one hundred to three hundred mulberry trees (for purposes of sericulture) and from forty to one hundred lacquer trees, according to the grade of the tenant family. Ownership of building-land (takuchi) was equally in perpetuity, though its transfer required official approval, but dwellings or warehouses - which in Japan have always been regarded as distinet from the land on which they stand - might be disposed of at pleasure. It is not to be inferred from the above that all the land throughout the Empire was divided among the people. Considerable : tracts were reserved for special purposes. Thus, in five home provinces (Go-Kinai) two

[' The In in early times represented 5 shaku square, or 25 square shaku $(1$ sek $i=1$ foot very nearly); but as the shaku (10 sun) then measured 2 sun $(1$ sun $=11 / 5$ inch) more than the shaku of later ages, the modern bu (or tsubo) is a square of 6 shaku side, or 36 square shaku, though in actual dimensions the ancient and the modern are equal.] fields.]

$\left[{ }^{2}\right.$ Called also yenchi. These uplands were regarded as of little value compared with rice-
ds. $]$ 
tracts of seventy-five acres each were kept for the Court in Yamato and Settsu, and two tracts of thirty acres each in Kawachi and Yamashiro, such land being known as kwanden (official fields), and being under the direct control of the Imperial.Houschold Department.

There were also three other kinds of special estates, namely, iden, or lands granted to mark official ranks; shokubunden, or lands given as salary to officeholders; and $k \bar{o} d e n$, or lands bestowed in recognition of merit. As to the iden, persons of the four Imperial ranks received from one hundred to two hundred acres, and persons belonging to any of the five official grades - in each of which there were two classes - were given from twenty to two hundred, females receiving two-thirds of a male's allotment. Coming to salary lands, we find a distinction between officials serving in the capital (zaikyō) and those serving in the provinces (zaige). Among the former, the principal were the prime minister (one hundred acres), the ministers of the Left and Right (seventy-five acres each) and the great councillor (fifty acres). As for provincial officials, the highest, namely, the governor of Kyüshū (who had his seat at the Dazai-fu), received twenty-five acres, and the lowest, one and a half acres. Governors of provinces - which were divided into four classes (great, superior, medium, and inferior) received from four acres to six and a half acres; an official (dai-hanji), corresponding to a chief-justice, had five acres; a puisne justice (sho-hanji), four acres; an officer in command of an army corps, four acres, and a literary professor (hakushi), four acres. Grants of land as salaries for official duties were made even to posttowns for the purpose of defraying the expense of coolies and horses for official use. Finally, there were $k \bar{o} d e n$, or lands bestowed in recognition of distinguished public services. Of such services four grades were differentiated: namely, "great merit" (taikō), for which the grant was made in perpetuity; "superior merit" $(j \bar{o} k \bar{o})$, which was rewarded with land held for three generations; "medium merit" (chukō), in which case the land-title had validity to the second generation only, and "inferior merit" (gekō), where the land did not descend beyond a son or a daughter. It is worthy of note that in determining the order of eligibility for grants of sustenance land (kubunden), preference was given to the poor above the rich, and that the officials in a province were allowed to cultivate unoccupied land for their own profit.

\section{TAXATION}

There were three kinds of imposts; namely, $\operatorname{tax}(s o)$, forced service (yō or kayaku) and tribute $(c h \bar{o})$. The tax was three per cent. of the gross produce of the land - namely, three sheaves of rice out of every hundred in the case of a male, and two out of sixty-six in the case of a female. The tribute was much more important, for it meant that every able-bodied male had to pay a fixed quantity of silk-fabric, pongee, raw-silk, raw-cotton, indigo (675 grains troy), rouge (the same quantity), copper (two and a quarter lbs.), and, if in an Imperial domain, an additional piece of cotton cloth, thirteen feet long. Finally, the forced service meant thirty days' labour annually for each able-bodied male and fifteen days for a minor. Sometimes this compulsory service might be commuted at the rate of two and a half feet of cotton cloth for each day's work. Exemption from forced labour was granted to persons of and above the grade of official rank and to their families through three generations; to persons of and above the fifth grade and to their families for two generations; to men of the Imperial blood; to the sick, the infirm, the deformed, females, and slaves. Forced labour. 
ers were allowed to rest from noon to 4 P.M. in July and August. They were not required to work at night. If they fell sick so as to be unable to labour out of doors, they were allowed only half rations. If they were taken ill on their way to their place of work, they were left to the care of the local authorities and fed at public charge. If they died, a coffin was furnished out of the public funds, and the corpse, unless claimed, was cremated, the ashes being buried by the wayside and a mark set up. Precise rules as to inheritance were laid down. A mother and a step-mother ranked equally with the eldest son for that purpose, each receiving two parts; younger sons received one part, and concubines and female children received one-half of a part. There were also strict rules as to the measure of relief from taxation granted in the event of crop-failure.

\section{IMPORTANCE OF DAIHŌ LAWS}

What has been set down above constitutes only a petty fraction of the Daiho legislation, but it will suffice to furnish an idea of Japanese civilization in the eighth century of the Christian era - a civilization which shared with that of China the credit of being the most advanced in the world at that time.

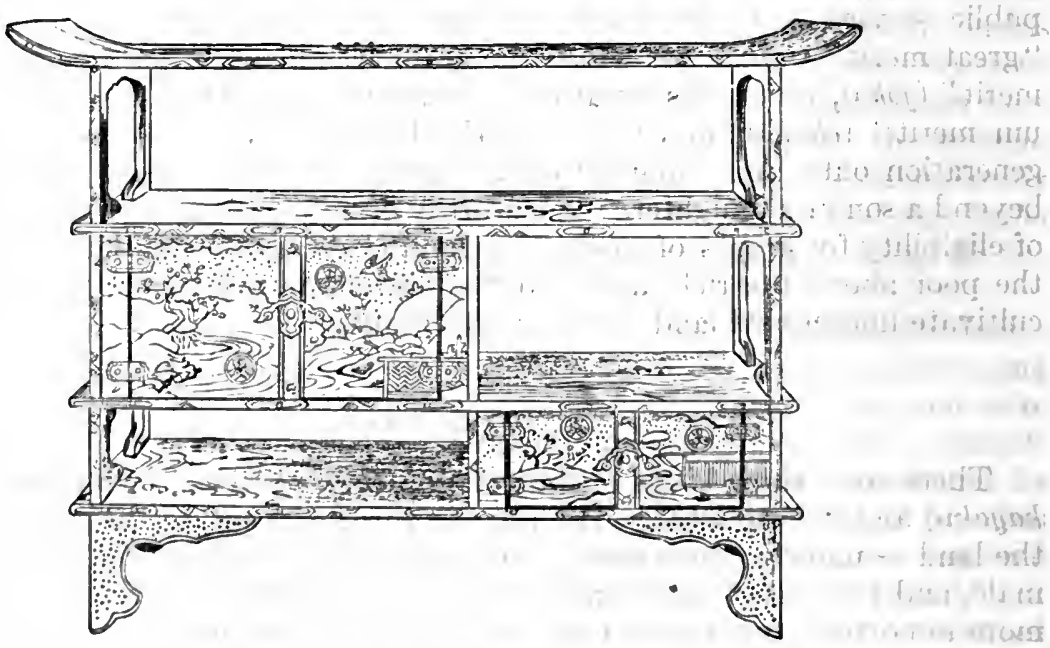

Hatgune-No-TANa

(A Gold-lacquered Stand or Cabinet) 


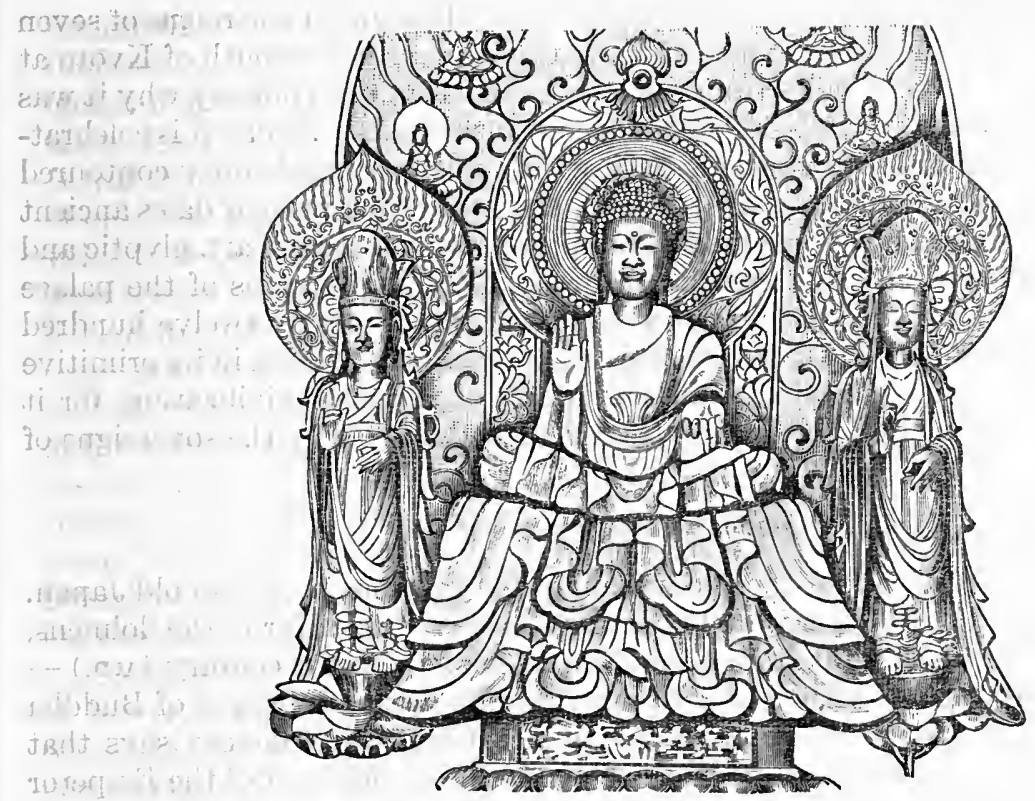

Sratueg of Siaka and two Bosatsus in the Kondō of the IIoryē-ji

\section{CHAPTER XVII}

\section{THE NARA EPOCH}

THE FORTY-THIRD SOVEREIGN, THE EMPRESS GEMMYŌ (A.D. 708-715)

The Empress Gemmyō, fourth daughter of the Emperor Tenchi and consort of Prince Kusakabe, was the mother of the Emperor Mommu, whose accession had been the occasion of the first formal declaration of the right of primogeniture (vide Chapter XV). Mommu, dying, willed that the throne should be occupied by his mother in trust for his infant son - afterwards Emperor Shōmu.

\section{REMOVAL OF THE CAPITAL TO NARA}

In ancient times it was customary to change the locality of the Imperial capital with each change of sovereign. This custom, dictated by the Shinto conception of impurity attaching to sickness and death, exercised a baleful influence on architectural development, and constituted a heavy burden upon the people, whose forced labour was largely requisitioned for the building of the new palace. Kōtoku, when he promulgated his system of centralized administration, conceived the idea of a fixed capital and selected Naniwa. But the Emperor Tenchi moved to Ōmi, Temmu to Asuka (in Yamato) and the Empress Jitō to Fujiwara (in Yamato). Mommu remained at the latter place until the closing year (707) of his reign, when, finding the site inconvenient, he gave orders for the selection of another. But his death interrupted the project, and it was not until the second year of the Empress Gemmyō's reign that the Court finally removed 
to Nara, where it remained for seventy-five years, throughout the reigns of seven sovereigns. Nara, in the province of Yamato, lies nearly due south of Kyoto at a distance of twenty-six miles from the latter. History does not say why it was selected, nor have any details of its plan been transmitted. To-day it is celebrated for scenic beauties - a spacious park with noble trees and softly contoured hills, sloping down to a fair expanse of lake, and enshrining in their dales ancient temples, wherein are preserved many fine specimens of Japanese art, glyptic and pictorial, of the seventh and eighth centuries. Nothing remains of the palace where the Court resided throughout a cycle and a half, nearly twelve hundred years ago, but one building, a storehouse called Shōsō-in, survives in its primitive form and constitutes a landmark in the annals of Japanese civilization, for it contains specimens of all the articles that were in daily use by the sovereigns of the Nara epoch.

\section{JAPANESE COINS}

There is obscurity about the production of the precious metals in old Japan. That gold, silver, and copper were known and used is certain, for in the dolmens, - which ceased to be built from about the close of the sixth century (A.D.) copper ear-rings plated with gold are found, and gold-copper images of Buddha were made in the reign of the Empress Suiko (605), while history says that silver was discovered in the island of Tsushima in the second year of the Emperor Temmu's reign (674). From the same island, gold also is recorded to have come in 701 , but in the case of the yellow and the white metal alike, the supply obtained was insignificant, and indeed modern historians are disposed to doubt whether the alleged Tsushima gold was not in reality brought from Korea via that island. On the whole, the evidence tends to show that, during the first seven centuries of the Christian era, Japan relied on Korea mainly, and on China partially, for her supply of the precious metals. Yet neither gold, silver, nor copper coins seem to have been in anything like general use until the Wado era (708-715).

Coined money had already been a feature of Chinese civilization since the fourth century before Christ, and when Japan began to take models from her great neighbour during the Sui and Tang dynasties, she cannot have failed to appreciate the advantages of artificial media of exchange. The annals allege that in A.D. 677 the first mint was established, and that in 683 an ordinance prescribed that the silver coins struck there should be superseded by copper. But this rule did not remain long in force, nor have there survived any coins, whether of silver or of copper, certainly-identifiable as antecedent to the Wado era. It was in the year of the Empress Gemmyo's accession (708) that deposits of copper were found in the Chichibu district of Musashi province, and the event seemed sufficiently important to call for a change of year-name to Wadō (refined copper). Thenceforth, coins of copper-or more correctly, bronze - were regularly minted and gradually took the place of rice or cotton cloth as units of value.

It would seem that, from the close of the seventh century, a wave of mining industry swept over Japan. Silver was procured from the provinces of Iyo and Kii; copper from Inaha and Suō, and tin from Ise, Tamba, and Iyo. All this happened between the years 690 and 708 , but the discovery of copper in the latter year in Chichibu was on comparatively the largest scale, and may be said to have given the first really substantial impetus to coining. For some unrecorded reason silver pieces were struck first and were followed by copper a few months later. Both were of precisely the same form - round with a square hole in the 
middle to facilitate threading on a string - both were of the same denomination (one mon), and both bore the same superscription (Wadō Kaiho, or "opening treasure of refined copper"), the shape, the denomination, and the legend being taken from a coin of the Tang dynasty struck eighty-eight years previously. It.was ordered that in using these pieces silver should be paid in the case of sums of or above four mon, and copper in the case of sums of or below three mon, the value of the silver coin being four times that of the copper. But the silver tokens soon ceased to be current and copper mainly occupied the field, a position which it held for 250 years, from 708 to 958 . During that interval, twelve forms of sen $^{1}$ were struck. They deteriorated steadily in quality, owing to growing scarcity of the supply of copper; and, partly to compensate for the increased cost of the metal, partly to minister to official greed, the new issues were declared, on several occasions, to have a value ten times as great as their immediate predecessors. Concerning that value, the annals state that in 711 the purchasing power of the mon (i.e., of the one-sen token) was sixty $g \bar{o}$ of rice, and as the daily ration for a full-grown man is five $g \overline{0}$, it follows that one sen originally sufficed for twelve days' sustenance. ${ }^{2}$

Much difficulty was experienced in weaning the people from their old custom of barter and inducing them to use coins. The Government seems to have recognized that there could not be any effective spirit of economy so long as perishable goods represented the standard of value, and in order to popularize the use of the new tokens as well as to encourage thrift, it was decreed that grades of rank would be bestowed upon men who had saved certain sums in coin. At that time (711), official salaries had already been fixed in terms of the Wado sen. The highest received thirty pieces of cloth, one hundred hanks of silk and two thousand mon, while in the case of an eighth-class official the corresponding figures were one piece of cloth and twenty mon. ${ }^{3}$ The edict for promoting economy embodied a schedule according to which, broadly speaking, two steps of executive rank could be gained by amassing twenty thousand mon and one step by saving five theusand.

Observing that the fundamental principle of a sound token of exchange was wholly disregarded in these $W a d \bar{o}$ sen, since their intrinsic value bore no appreciable ratio to their purchasing power, and considering also the crudeness of their manufacture, it is not surprising to find that within a few months of their appearance they were extensively forged. What is much more notable is that the $W a d \bar{o}$ sen remained in circulation for fifty years. The extraordinary ratio, however, by which copper and silver were linked together originally, namely, 4 to 1 , did not survive; in 721 it was changed to 25 to 10 , and in the following year to 50 to 10 . Altogether, as was not unnatural, the early treatment of this coinage question by Japanese statesmen showed no trace of scientific perception. The practice, pursued almost invariably, of multiplying by ten the purchasing power of each new issue of sen, proved, of course, enormously profitable to the

[ ${ }^{1}$ The ideograph sen signified originally a "fountain," and its employment to designate a coin seems to have been suggested by an idea analogous to that underlying the English word "currency."]

[ "At the present time the wages of a carpenter are almost a yen a day. Now the yen is equal to 1000 mon of the smaller sen and to 500 mon of the larger ones, so that he could have provided himself with rice, if we count only 500 mon to the yen, for sixteen years on the wages which he receives for one day's labour in 1900." (Munro's Coins of Japan.)]

[ ${ }^{3}$ These figures sound ludicrously small if translated into present-day money, for 1000 mon go to the yen, and the latter being the equivalent of two shillings, 20 mon represents less then a half-penny. But of course the true calculation is that 20 mon represented 240 days' rations of rice in the $W$ ado schedule of values.] 
issuers, but could not fail to distress the people and to render unpopular such arbitrarily varying tokens.

The Government spared no effort to correct the latter result, and some of the devices employed were genuinely progressive. In that epoch travellers had to carry their own provisions, and not uncommonly the supply ran short before they reached their destination, the result sometimes being death from starvation on the roadside. It was therefore ordered that in every district (kōri) a certain portion of rice should be stored at a convenient place for sale to wayfarers, and these were advised to provide themselves with a few sen before setting out. It is evident that, since one of the Wado coins sufficed to buy rice for twelve days' rations, a traveller was not obliged to burden himself with many of these tokens. Wealthy persons in the provinces were also admonished to set up roadside shops for the sale of rice, and anyone who thus disposed of one hundred koku in a year was to be reported to the Court for special reward. Moreover, no district governor (gunryō), however competent, was counted eligible for promotion unless he had saved six thousand sen, and it was enacted that all taxes might be paid in copper coin. In spite of all this, however, the use of metallic media was limited for a long time to the upper classes and to the inhabitants of the five home provinces. Elsewhere the old habit of barter continued.

\section{THE FORTY-FOURTH SOVEREIGN, THE EMPRESS GENSHŌ (A.D. 715-723)}

In the year 715 , the Empress Gemmyō, after a reign of seven years, abdicated in favour of her daughter, Genshō. This is the only instance in Japanese history of an Empress succeeding an Empress.

\section{HISTORICAL COMPILATION}

The reigns of these two Empresses are memorable for the compilation of the two oldest Japanese histories which have been handed down to the present epoch, the Kojiki and the Nihongi; but as the circumstances in which these works, as well as the Füdoki (Records of Natural Features), were written have been sufficiently described already (vide Chapter I), it remains only to refer to a custom inaugurated by Gemmyō in the year (721) after the compilation of the $N$ ihongi, the custom of summoning to Court learned men (hakase) and requiring them to deliver lectures on that work. Subsequent generations of sovereigns followed this example, and to this day one of the features of the New Year's observances is a historical discourse in the palace. The writing of history became theneeforth an imperially patronized occupation. Six works, covering the period from 697 to 887 , appeared in succession and were known through all ages as the Six National Histories. It is noticeable that in the compilation of all these a leading part was taken by one or another of the great Fujiwara ministers, and that the fifth numbered among its authors the illustrious Sugawara Michizane.

THE FORTY-FIFTH SOVEREIGN, THE EMPEROR SHŌMU (A.D. 724-748)

When the Emperor Mommu died (707), his son, the Prince Imperial, was too young to succeed. Therefore the sceptre came into the hands of Mommu's mother, who, after a reign of seven years, abdicated in favour of her daughter, the Empress Genshō, and, eight years later, the latter in turn abdicated in favour of her nephew, Shōmu, who had now reached man's estate. Shōmu's 
mother, Higami, was a daughter of Fujiwara Fuhito, and as the Fujiwara family did not belong to the Kwöbetsu class, she had not attained the rank of Empress, but had remained simply Mommu's consort (fujin). Her son, the Emperor Shōmu, married another daughter of the same Fujiwara Fuhito by a different mother; that is to say, he took for consort his own mother's half-sister, Asuka. This lady, Asuka, laboured under the same disadvantage of lineage and could not properly be recognized as Empress. It is necessary to note these details for they constitute the preface to a remarkable page of Japanese history. Of Fujiwara Fuhito's two daughters, one, Higami, was the mother of the reigning Emperor, Shōmu, and the other, Asuka, was his consort. The blood relationship of the Fujiwara family to the Court could scarcely have been more marked, but its public recognition was impeded by the defect in the family's lineage.

\section{THE FUJIWARA CONSPIRACY}

Immediately after Shōmu's accession, his mother, Higami, received the title of $K w \bar{o}$-taifujin (Imperial Great Lady). But the ambition of her family was to have her named $K w \bar{o}$-taiko (Empress Dowager). The Emperor also desired to raise his consort, Asuka, to the position of Empress. Consulting his ministers on the subject, he encountered opposition from Prince Nagaya, minister of the Left. This prince, a great-grandson of the Emperor Temmu, enjoyed high reputation as a scholar, was looked up to as a statesman of great wisdom, and possessed much influence owing to his exalted official position. He urged that neither precedent nor law sanctioned nomination of a lady of the Shimbetsu class to the rank of Empress. The Daiho code was indeed very explicit on the subject. In China, whither the drafters of the code went for models, no restrictions were imposed on a sovereign's choice of wife. But the Japanese legislators clearly enacted that an Empress must be taken from among Imperial princesses. Prince Nagaya, in his position as minister of the Left, opposed any departure from that law and thus thwarted the designs of the Fujiwara.

Bs The lady Asuka bore a son to the Emperor three years after his accession. His Majesty was profoundly pleased. He caused a general amnesty to be proclaimed, presented gratuities to officials, and granted gifts to all children born on the same day. When only two months old, the child was created Prince Imperial, but in his eleventh month he fell ill. Buddhist images were cast; Buddhist Sutras were copied; offerings were made to the Kami, and an amnesty was proclaimed. Nothing availed. The child died, and the Emperor was distraught with grief. In this incident the partisans of the Fujiwara saw their opportunity. They caused it to be laid to Prince Nagaya's charge that he had compassed the death of the infant prince by charms and incantations. Two of the Fujiwara nobles were appointed to investigate the accusation, and they condemned the prince to die by his own hand. He committed suicide, and his wife and children died with him. The travesty of justice was carefully acted throughout. A proclamation was issued promising capital punishment to any one, of whatever rank or position, who compassed the death or injury of another by spells or incantations, and, six months later, the lady Asuka was formally proclaimed Empress.

In one respect the Fujiwara conspirators showed themselves clumsy. The rescript justified Asuka's elevation by reference to the case of Iwa, a daughter of the Takenouchi, whom the Emperor Nintoku had made his Empress. But the Takenouchi family belonged to the Kwöbetsu class, and the publication of a 
special edict in justification could be read as self-condemnation only. Nevertheless, the Fujiwara had compassed their purpose. Thenceforth they wielded the power of the State through the agency of their daughters. They furnished Empresses and consorts to the reigning sovereigns, and took their own wives from the Minamoto family, itself of Imperial lineage. To such an extent was the former practice followed that on two occasions three Fujiwara ladies served simultaneously in the palace. This happened when Go-Reizei (1222-1232) had a Fujiwara Empress, Kwanko, and two Fujiwara consorts, Fumi and Hiro. At one moment it had seemed as though fate would interfere to thwart these astute plans. An epidemic of small-pox, originating (735) in Kyūshū, spread over the whole country, and carried off the four sons of Fuhito - Muchimaro; Fusazaki, Umakai, and Maro-leaving the family's fortunes in the hands of juniors, who oecupied only minor official positions. But the Fujiwara genius rose superior to all vieissitudes. The elevation of the lady Asuka to be Empress Kōmyō marks an epoch in Japanese history.

\section{COMMUNICATIONS WITH CHINA}

In spite of the length and perils of a voyage from Japan to China in the seventh and eighth centuries - one embassy which sailed from Naniwa in the late summer of 659 did not reach China for 107 days - the journey was frequently made by Japanese students of religion and literature, just as the Chinese, on their side, travelled often to India in search of Buddhist enlightenment. This access to the refinement and civilization of the Tang Court contributed largely to Japan's progress, both material and moral, and is frankly acknowledged by her historians as a main factor in her advance. When Shōmu reigned at Nara, the Court in Changan had entered the phase of luxury and epicurism which usually preludes the ruin of a State. Famous literati thronged its portals; great poets and painters enjoyed its patronage, and annalists descanted on its magnificence. Some of the works of these famous men were carried to Japan and remained with her as models and treasures. She herself showed that she had competence to win some laurels even amid such a galaxy. In the year 716, Nakamaro, a member of the great Abe family, accompanied the Japanese ambassador to Tang and remained in China until his death in 770. He was known in China as Chao Heng, and the great poet, Li Pai, composed a poem in his memory, while the Tang sovereign conferred on him the posthumous title of "viceroy of Luchou." Not less celebrated was Makibi, ${ }^{1}$ who went to China at the same time as Nakamaro, and after twenty years' close study of Confucius; returned in 735, having earned such a reputation for profound knowledge of history, the five classies, jurisprudence, mathematics, philosophy, calendar making, and other seiences that the Chinese parted with him reluctantly. In Japan he was raised to the high rank of asomi, and ultimately became minister of the Right during the reign of Shōtoku.

Such incidents speak eloquently of the respect paid in Japan to mental attainments and of the enlightened hospitality of China. In the realm of Buddhism perhaps even more than in that of secular science, this close.intercourse made its influence felt. Priests went from Japan to study in China, and priests came from China to preach in Japan. During the Nara era, three of these men attained to special eminence. They were Dōji, Gembō, and Kanshin.

['Generally spoken of as "Kibi no Mabi," and credited by tradition with the invention of the katakana syllabary.] 
Dōji was the great propagandist of the Sanron sect, whose tenets he had studied in China for sixteen years (701-717). From plans prepared by him and taken from the monastery of Hsi-ming in China, the temple Daian-ji was built under the auspices of the Emperor Shōmu, and having been richly endowed; was placed in Dōji's charge as'lord-abbot. Gembō, during a sojourn of two years at the Tang Court, studied the tenets of the Hossō sect, which, like the Sanron, constituted one of the five sects originally introduced into Japan. Returning in 736, he presented to the Emperor Shömu five thousand volumes of the Sutras, together with a number of Buddhist images, and he was appointed abbot of the celebrated temple, Kōfuku-ji. The third of the above three religious celebrities was a Chinese missionary named Kanshin. He went to Japan accompanied by fourteen priests, three nuns, and twenty-four laymen, and the mission carried with it many Buddhist relies, images, and Sutras. Summoned to Nara in 754 , he was treated with profound reverence, and on a platform specially erected before the temple Todai-ji, where stood the colossal image of Buddha - to be presently spoken of - the sovereign and many illustrious personages performed the most solemn rite of Buddhism under the ministration of Kanshin. He established a further claim on the gratitude of the Empress by curing her of an obstinate malady, and her Majesty would fain have raised him to the highest rank $(d a i-s \bar{j} j \bar{o})$ of the Buddhist priesthood. But he declined the honour. Subsequently, the former palace of Prince Nittabe was given to him as a residence and he built there the temple of Shödai-ji, which still exists.

\section{RELIGION AND POLITICS}

The great Confucianist, Makibi, and the Buddhist prelate, Gembō, met with misfortune and became the victims of an unjust accusation because they attempted to assert the Imperial authority as superior to the growing influence of the Fujiwara. Makibi held the post of chamberlain of the Empress' household, and Gembō officiated at the "Interior monastery" (Nai-dōjo $)$ where the members of the Imperial family worshipped Buddha. The Emperor's mother, Higami, who on her son's accession had received the title of "Imperial Great Lady." (vide sup.), fell into a state of melancholia and invited Gembō to prescribe for her, which he did successfully. . Thus, his influence in the palace became very great, and was augmented by the piety of the Empress, who frequently listened to discourses by-the learned prelate. Makibi naturally worked in union with Gembō in consideration of their similar antecedents. Fujiwara Hirotsugu was then governor of Yamato. Witnessing this state of affairs with uneasiness, he impeached Gembō. But the Emperor credited the priest's assertions, and removed Hirotsugu to the remote post of Dazai-fu in Chikuzen. There he raised the standard of revolt and was with some difficulty captured and executed: The Fujiwara did not tamely endure this check. They exerted their influence to procure the removal of Makibi and Gembo from the capital, both being sent to Tsukushi (Kyūshū), Makibi in the capacity of governor, and Gembō to build the temple Kwannon-ji. Gembō died a year later, and it was commonly reported that the spirit of Hirotsugu had compassed his destruction, while more than one book, professing to be historical, alleged that his prime offence was immoral relations with the "Imperial Great Lady," who was then some sixty years of age! There can be little doubt that the two illustrious scholars suffered for their fame rather than for their faults, and that their chief offences were overshadowing renown and independence of Fujiwara patronage. 


\section{BUDDHISM IN THE NARA EPOCH}

From what has been related above of the priests Kanshin and Gembō, it will have been observed that the Emperor Shomu was an earnest disciple of Buddhism. The heritage of administrative reforms bequeathed to him by Tenchi and Temmu should have engrossed his attention, but he subserved everything to religion, and thus the great national work, begun in the Daika era and carried nearly to completion in the Daiho, suffered its first check. Some annalists have pleaded in Shōmu's behalf that he trusted religious influence to consolidate the system introduced by his predecessors. However that may be, history records as the most memorable event of his reign his abdication of the throne in order to enter religion, thus inaugurating a practice which was followed by several subsequent sovereigns and which materially helped the Fujiwara family to usurp the reality of administrative power. Shômu, on receiving the tonsure, changed his name to Shoman, and thenceforth took no part in secular affairs.

In all this, however, his procedure marked a climax rather than a departure. In fact, never did any foreign creed receive a warmer welcome than that accorded to Buddhism by the Japanese after its first struggle for tolerance. Emperor after Emperor worshipped the Buddha. Even Tenchi, who profoundly admired the Confucian philosophy and whose experience of the Soga nobles' treason might well have prejudiced him against the faith they championed; and even Temmu;, whose ideals took the forms of frugality and militarism, were lavish in their offerings at Buddhist ceremonials. The Empcror Mommu enacted a law for the better control of priests and nuns, yet he erected the temple Kwannon-ji. The great Fujiwara statesmen, as Kamatari, Fuhito, and the rest, though they belonged to a family (the Nakatomi) closely associated with Shinto worship, were reverent followers of the Indian faith. Kamatari approved of his eldest son, Joye, entering the priesthood, and sent him to China to study the Sutras. He also gave up his residence at Yamashina for conversion into'a monastery. Fujiwara Fuhito built the Kofuku-ji, and his son, Muchimaro; when governor of Ömi, repaired temples in the provinces, protected their domains, and ereeted the Jingū-ji.

That among the occupants of the throne during 165 years, from 593 to 758 , no less than seven were females could not but contribute to the spread of a religion which owed so much to spectacular effect. Every one of these sovereigns lent carnest aid to the propagation of Buddhism, and the tendency of the age culminated in the fanaticism of Shomu, re-enforced as it was by the devotion of his consort, Kōmyō. Tradition has woven into a beautiful legend the nation's impression of this lady's piety. In an access of humility she vowed to wash the bodies of a thousand beggars. Nine hundred and ninety-nine had been completed when the last presented himself in the form of a loathsome leper. Without a sign of repugnance the Empress continued her task, and no sooner was the ablution concluded than the mendicant ascended heavenwards, a glory of light radiating from his body. It is also told of her that, having received in a dream a miniature golden image of the goddess of Mercy (Kwannon) holding a baby in her arms, she conceived a daughter who ultimately reigned as the Empress Kōken. ${ }^{1}$

In spite, however, of all this zeal for Buddhism, the nation did not entirely

[1 The resemblance between the legend and the Buddhist account of the Incarnation is plain. It has to be remembered that Nestorians had carried Christianity to the Tang Court long before the days of Kōmyō.] 
abandon its traditional faith. The original cult had been ancestor worship. Each great family had its uji no Kami, to whom it made offerings and presented supplications. These deities were now supplemented, not supplanted. They were grafted upon a Buddhist stem, and shrines of the uji no Kami became uji-tera, or "uji temples." of the shrine (yashiro). When spoken of together they became $j i$-sha. This was the beginning of Ryōbu Shintō, or mixed Shintō, which found full expression when Buddhist teachers, obedient to a spirit of toleration born of their belief in the doctrines of metempsychosis and universal perfectibility, asserted the creed that the Shinto Kami were avatars (incarnations) of the numerous Buddhas.

The Nara epoch has not bequeathed to posterity many relies of the great religious edifices that came into existence under Imperial patronage during its seventy-five years. Built almost wholly of wood, these temples were gradually destroyed by firc. One object, however, defied the agent of destruction. It is a bronze Buddha of huge proportions, known now to all the world as the "Nara Daibutsu." On the fifteenth day of the tenth month of the fiftecnth year of Temby 0 - 7th of November, 743 - the Emperor Shōmu proclaimed his intention of undertaking this work. The rescript making the announcement is extant. It sets out by declaring that "through the influence and authority of Buddha the country enjoys tranquillity," and while warning the provincial and district governors against in any way constraining the people to take part in the project, it promises that every contributor shall be welcome, even though he bring no more than a twig to feed the furnace or a handful of clay for the mould. The actual work of casting began in 747 and was completed in three years, after seven failures. The image was not cast in its entirety; it was built up with bronze plates soldered together. A sitting presentment of the Buddha, it had a height of fifty-three and a half feet and the face was sixteen feet long, while on either side was an attendant bosatsu standing thirty feet high. For the image, 986,030,$000 \mathrm{lbs}$. of copper were needed, and on the gilding of its surface $870 \mathrm{lbs}$. of refined gold were used.

These figures represented a vast fortune in the eighth century. Indecd it seemed likely that a sufficiency of gold would not be procurable, but fortunately in the year 749 the yellow metal was found in the province of Mutsu, and people regarded the timely discovery as a special dispensation of Buddha. The great hall in which the image stood had a height of 120 feet and a width of 290 feet from east to west, and beside it two pagodas rose to a height of 230 fect each. Throughout the ten years occupied in the task of collecting materials and casting this Daibutsu, the Emperor solemnly worshipped Rushana Buddha three times daily, and on its completion he took the tonsure. It was not until the year 752, however, that the final ceremony of unveiling took place - technically called "opening the eyes" (kaigan). On that occasion the Empress Kōken, attended by all the great civil and military dignitaries, held a magnificent fête, and in the following year the temple - Tódai-ji - was endowed with the taxes of five thousand households and the revenue from twenty-five thousand acres of rice-fields.

PROVINCIAL TEMPLES

While all this religious fervour was finding costly expression among the aristocrats in Nara, the propagandists and patrons of Buddhism did not neglect

$\left[{ }^{1}\right.$ Thus, Kōfuku-ji, built by Kamatari and Fuhito was called $\bar{O}_{-N a k a t o m i}$ no uji-tera; $\bar{O}$ njō-ji, erected by Ōtomo Suguri, was known as Ōtomo no uji-tera, and so forth.] 
the masses. In the year 741 , provincial temples were officially declared essential to the State's well-being. These edifices had their origin at an earlier date. During the reign of 'Temmu (673-686) an Imperial rescript ordered that throughout the whole country every household should provide itself with a Buddhist shrine and place therein a sacred image. When the pious Empress Jitō occupied the throne (690-696), the first proselytizing mission was despatched to the Ezo, among whom many converts were won; and, later in the same reign, another

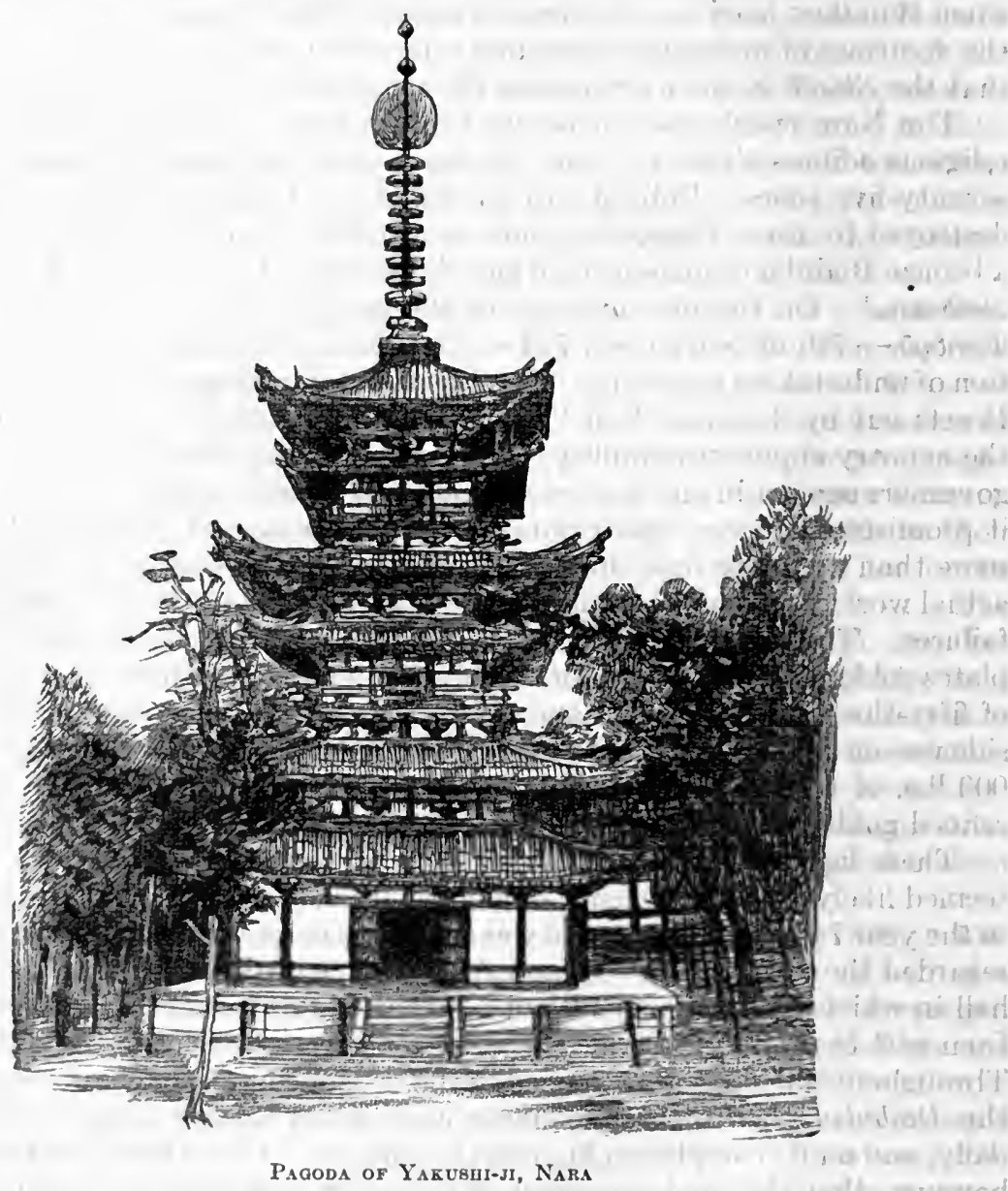

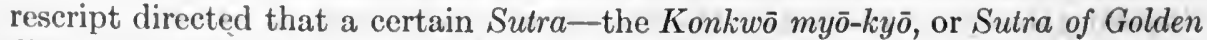
Effulgence-should be read during the first month of every year in each province, the fees of the officiating priests and other expenses being defrayed out of the local official exchequers.

During Mommu's time (697-707), Buddhist hierarchs (kokushi) .were appointed to the provinees. Their chief functions were to expound the Sutra and to offer prayers. The devout Shōmu not only distributed numerous eopies of the Sutras, but also carried his zeal to the length of commanding that every province should erect a sixteen-foot image of Shaka with attendant bosatsu (Bödhisattva), and, a few years later, he issued another command that each province must provide itself with a pagoda seven storeys high. By this 


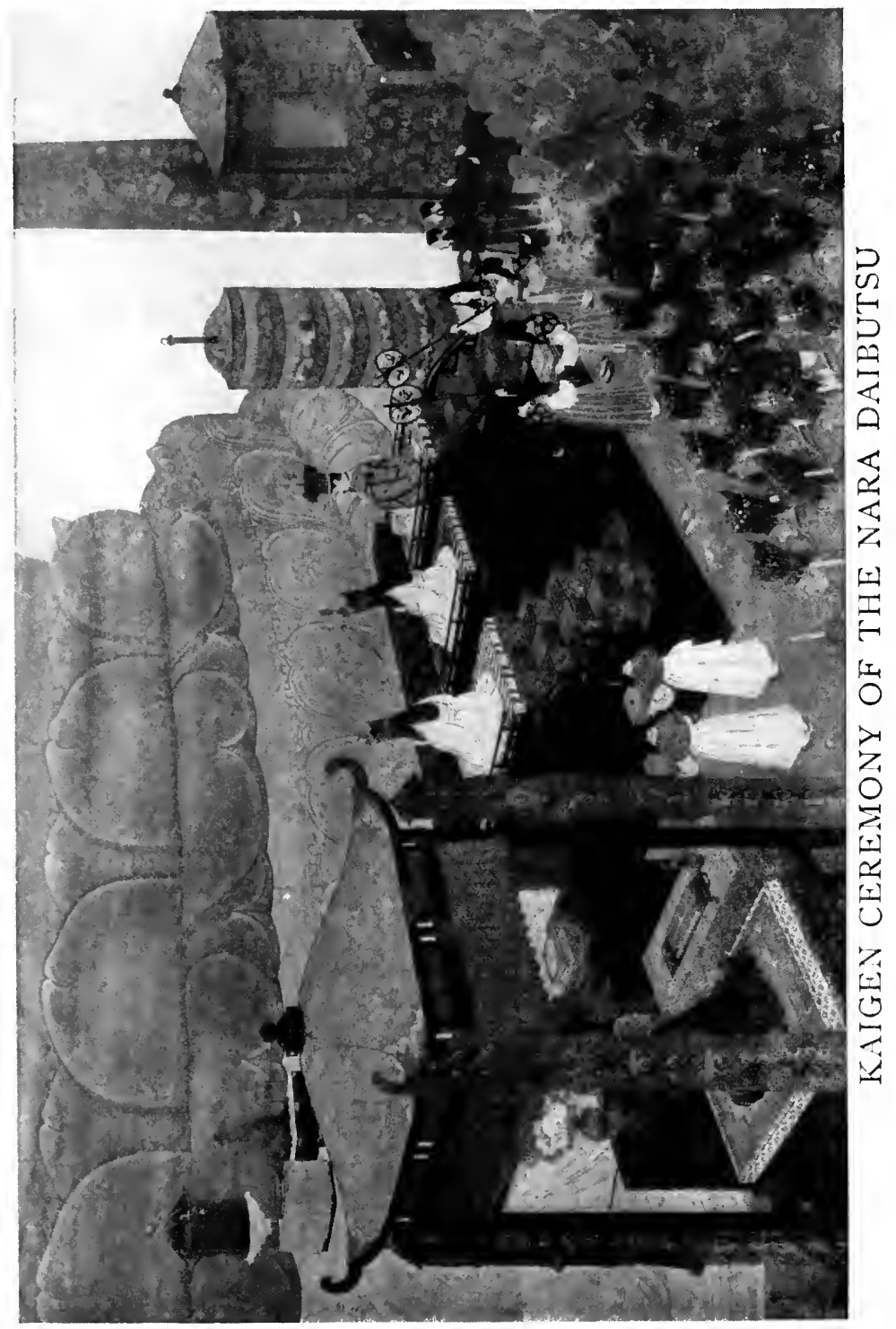



last rescript the provincial temples (kokubun-ji) were called into official existence, and presently their number was increased to two in each province, one for priests and one for nuns. The kokushi attached to these temples laboured in the cause of propagandism and religious education side by side with the provincial pundits (kunihakase), whose duty was to instruct the people in law and literature; but it is on record that the results of the former's labours were much more conspicuous than those of the latter.

\section{GYōGI}

It is said to have been mainly at the instance of the Empress Kōmyō that the great image of Tōdai-ji was constructed and the provincial temples were established. But undoubtedly the original impulse came from a priest, Gyogi. He was one of those men who seem to have been specially designed by fate for the work they undertake. Gyogi, said to have been of Korean extraction, had no learning like that which won respect for Kanshin and Gembō. But he was amply gifted with the personal magnetism which has always distinguished notably: successful propagandists of religion. Wherever he preached and prayed, thousands of priests and laymen flocked to hear him, and so supreme was his influence that under his direction the people gladly undertook extensive works of bridge building and road making. Like Shōtoku Taishi, his name is associated by tradition with achievements not properly assignable to him, as the invention of the potter's wheel - though it had been in use for centuries before his time - and the production of various works of art which can scarcely have occupied the attention of a religious zealot. By order of the Empress Genshō, Gyōgi was thrown into prison for a time, such a disturbing effect did his propagandism produce on men's pursuit of ordinary bread winning; but he soon emerged from durance and was taken into reverent favour by the Emperor Shōmu, who attached four hundred priests as his disciples and conferred on him the titles of $D a i-S \bar{o} j \bar{o}$ (Great Hierarch) and Dai-Bosatsu (Great Bodhisattva).

The enigma of the people's patience under the stupendous burdens imposed on them by the fanatic piety of Shōmu and his consort, Kōmyō, finds a solution in the co-operation of Gyoggi, whose speech and presence exercised more influence than a hundred Imperial edicts. It is recorded that, by way of corollary to the task of reconciling the nation to the Nara Court's pious extravagance, Gyōgi compassed the erection of no less than forty-nine temples. But perhaps the most memorable event in his career was the part he took in reconciling the indigenous faith and the imported. However fervent Shōmu's belief in Buddhism, the country he ruled was the country of the Kami, and on descent from the Kami his own title to the throne rested. Thus, qualms of conscience may well have visited him when he remembered the comparatively neglected shrine of the Sun goddess at Ise. Gyōgi undertook to consult the will of the goddess, and carried back a revelation which he interpreted in the sense that Amaterasu should be regarded as an incarnation of the Buddha. The Emperor then despatched to Ise a minister of State who obtained an oracle capable of similar interpretation, and, on the night after receipt of this utterance, the goddess, appearing to his Majesty in a vision, told him that the sun was Birushana (Vairotchana Tathagata); or Dainishi (Great Sun) Nyorai.

Thus was originated a theory which enabled Buddhism and Shintō to walk' hand in hand for a thousand years, the theory that the Shinto Kami are avatars of the Buddha. Some historians contend that this idea must have been evolved 
and aecepted before the maturity of the project for casting the colossal image at Nara, and that the credit probably belongs to Gembö; others attribute it to the immortal priest Kūkai (Kōbō Daishi), who is said to have elaborated the doctrine in the early years of the ninth century. Both seem wrong.

\section{SUPERSTITIONS}

Side by side with the vigorous Buddhism of the Nara epoch, strange superstitions obtained eurrency and eredenee. Two may be mentioned as illustrating the mood of the age. One related to an ascetic, En no Ubasoku, who was worshipped by the people of Kinai under the name of En no Gyoja (En the anchorite). He lived in a cave on Katsuragi Mount for forty years, wore garments made of wistaria bark, and ateonly pine leaves steeped in spring water. During the night he compelled demons to draw water and gather firewood, and during the day he rode upon clouds of five colours. The Kami Hitokotonushi, having been threatened by him for neglecting his orders, inspired a man to accuse him of treasonable designs, and the Emperor Mommu sent soldiers to arrest him. But as he was able to evade them by recourse to his art of flying, they apprehended his mother in his stead, whereupon he at once gave himself.up? In consideration of his filial piety his punishment was commuted to exile on an island off the Izu coast, and in deference to the Imperial orders he remained there quietly throughout the day, but devoted the night to flying to the summit of Mount Fuji or gliding over the sea. This En no Gyōja was the founder of a sect of priests calling themselves Yamabushi.

The second superstition relates to one of the genii named Kume." By the practice of aseetieism he obtained supernatural power, and while riding one day upon a cloud, he passed above a beautiful girl washing clothes in a river, and became so enamoured of her that he lost his superhuman capacities and fell at her feet. She beeame his wife. Years afterwards it chanced that he was called out for forced labour, and, being taunted by the officials as a pseudo-genius, he fasted and prayed for seven days and seven nights. On the eighth morning a thunder-storm visited the seene, and after it, a quantity of heavy timber was found to have been moved, without any human effort, from the forest to the site of the projected building. The Emperor, hearing of this, granted him forty-five acres, on which he built the temple of Kume-dera.

Such tales found credence in the Nara epoch, and indeed all through the annals of early Japan there runs a well-marked thread of superstition which owed something of its obtrusiveness to intercourse with Korea and China, whence came professors of the arts of invisibility and magic. A thunder deity making his occasional abode in lofty trees is gravely spoken of in the context of a campaign, and if at one moment a river is inhabited by a semi-human monster, at another a fish formed like a child is caught in the sea. There is, of course, an herb of longevity - "a plant resembling coral in shape, with clustering leaves and branches; some red, others purple, others black; others golden coloured, and some changing their colours in the four seasons." In the reign of the Empress Kōgyoku, witches and wizards betray the people into all sorts of extravagancés;

- and a Korean acolyte has for friend a tiger which teaches him all manner of wonderful arts, anong others that of healing any disease with a magic needle. Later on, these and cognate creations of credulity take their appropriate places in the realm of folk-lore, but they rank with sober history in the ancient annals. In this respect Japan did not differ from other early peoples. 


\section{THE FORTY-SIXTH SOVEREIGN, THE EMPRESS KŌKEN (A.D. 749-758)}

In July, 749 , the Emperor Shōmu abdicated in favour of his daughter, Princess Abe, known in history as Kōken. Her mother was the celebrated Princess Asuka; who, in spite of the Shimbetsu lineage of her Fujiwara family, had been made Shōmu's Empress, and whose name had been changed to Kōmyō (Refulgence) in token of her illustrious piety. The daughter inherited all the mother's romance, but in her case it often degenerated into a passion more elementary than religious ecstasy. Shōmu, having no son, made his daughter heir to the throne. Japancse history furnished no precedent for such a step. The custom had always been that a reign ceased on the death of a sovereign unless the Crown Prince had not yet reached maturity, in which event his mother, or some other nearly related princess, occupied the throne until he came of age and then surrendered the reigns of government to his hands. Such had been the practice in the case of the Empresses Jitō, Gemmyō, and Genshō. Shömu, however, not only bequeathed the throne to a princess, but while himself still in the prime of life, abdicated in her favour.

Thereafter, at the recognized instance of the all-powerful Fujiwara family, Emperors often surrendered the sceptre to their heirs, themselves retiring into religious life with the secular title of $D a-j \bar{o} k \bar{o}$. (Great ex-Emperor) and the ecclesiastical designation of $H \bar{o}-\bar{o}$ (pontiff). Shōmu was the originator of this practice, but the annals are silent as to the motive that inspired him. It will be presently seen that under the skilful manipulation of the Fujiwara nobles, this device of abdication became a potent aid to their usurpation of administrative power, and from that point of view the obvious inference is that Shomu's unprecedented step was taken at their suggestion. But the Buddhist propagandists, also, were profoundly interested. That the sovereign himself should take the tonsure could not fail to confer marked prestige on the Church. It is probable, therefore, that Shōmu was swayed by both influences - that of the Buddhists, who worked frankly in the cause of their ereed, and that of the Fujiwara, who desired to see a lady of their own lineage upon the throne.

\section{KŌKEN AND NAKAMARO}

The fanaticism of the Emperor Shōmu and his consort, Kōmyō, bore fruit during the reign of Kōken. In the third year after Shōmu's abdication, a decree was issued prohibiting the taking of life in any form. This imposed upon the State the responsibility of making donations of rice to support the fishermen, whose source of livelihood was cut off by the decree. Further, at the ceremony of opening the public worship of the great image of Buddha, the Empress in person led the vast procession of military, civil, and religious dignitaries to the temple Tódai-ji. It was a fête of unparalleled dimensions. All officials of the fifth grade and upwards wore full uniform, and all of lesser grades wore robes of the colour appropriate to their rank. Ten thousand Buddhist priests officiated, and the Imperial musicians were re-enforced by those from all the temples throughout the home provinces. Búddhism in Japan had never previously received such splendid homage.

In the evening, the Empress visited the residence of the grand councillor, Fujiwara no Nakamaro. Fourteen hundred years had elapsed, according to Japanese history, since the first of the Yamato sovereigns set up his Court, and never had the Imperial house.incurred such disgrace as now befell it. Fujiwara 
no Nakamaro was a grandson of the great Kamatari. He held the rank of dainagon and was at once a learned man and an able administrator. From the time of that visit to the Tamura-no-tei (Tamura mansion), as his residence was called, the Empress repaired thither frequently, and finally made it a detached palace under the name of Tamura-no-miya. Those that tried to put an end to the liaison were themselves driven from office, and Nakamaro's influence became daily stronger.

THE FORTY-SEVENTI SOVEREIGN, THE EMPEROR JUNNIN (758-764 A.D.)

In August, 758, the Empress, after a reign of four years, nominally abdicated in favour of the Crown Prince, Junnin, but continued to discharge all the funetions of government herself. Her infatuation for Nakamaro seemed to increase daily. She bestowed on him titles of admiration and endearment under the guise of homonymous ideographs, and she also bestowed on him in perpetuity: the revenue from 3000 households and 250 acres of land. But Kōken's caprice

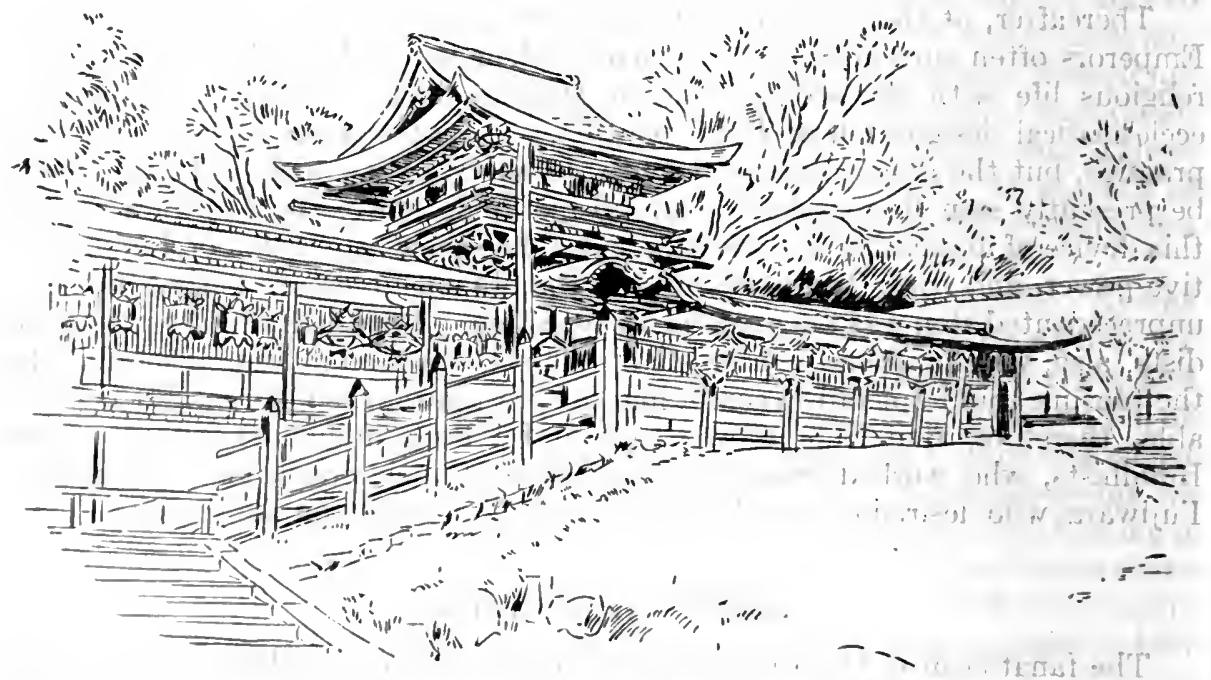

The Kaguga Jinja Shrine at Nara

took a new turn. She became a nun and transferred her affection to a priest, Yuge no Dōkyō. Nakamaro did not tamely endure to be thus disearded. He raised the standard of revolt and found that the nun could be as relentless as the Empress had been graeious. The rebellion - known by irony of fate as that of Oshikatsu (the Conqueror), which was one of the names bestowed on him by: Kōken in the season of her favour - proved a brief struggle. Nakamaro fell in battle and his head, together with those of his wife, his children, and his devoted followers to the number of thirty-four, was despatched to Nara. The tumult had a more serious sequel. It was mainly through Nakamaro's influence that Junnin had been crowned six years previously, and his Majesty naturally made no seeret of his aversion for the new favourite. The Dowager Empress - so Kōken had called herself - did not hesitate a moment. In the very month following Nakamaro's destruetion, she eharged that the Emperor was in collusion with the rebel; despatched a force of troops to surround the palace; dethroned 
Junnin; degraded him to the rank of a prince, and sent him and his mother into exile; where the conditions of confinement were made so intolerable that the exEmperor attempted to escape, was captured and killed.

\section{THE FORTY-EIGHTH SOVEREIGN, THE EMPRESS SHŌTOKU (765-770 A.D.)}

The nun Koken now abandoned the veil and re-ascended the throne under the name of Shōtoku. Her affection for Dōkyō had been augmented by his constant ministrations during her illness while on a visit to the "detatched palace " at Ōmi, and she conferred on him a priestly title which made him rank equally with the prime minister. All the civil and military magnates had to pay homage to him at the festival of the New Year in his exalted capacity. Yet her Majesty was not satisfied. Another step of promotion was possible. In the year after her second ascent of the throne she named him $H \bar{o}-\bar{o}$ (pontiff), a title never previously borne by any save her father, the ex-Emperor Shōmu. Dōkyō rose fully to the level of the occasion. He modelled his life in every respect on that of a sovereign and assumed complete control of the administration of the empire. He not only fared sumptuously but also built many temples, and as the Empress was not less extravagant, the burden of taxation became painfully heavy. But the priestly favourite, who seems to have now conceived the ambition of ascending the throne, abated nothing of his pomp. Whether at his instigation or because his favour had become of paramount importance to all men of ambition, Asomaro, governor of the Dazai-fu, informed the Empress that, according to an oracle delivered by the god of War (Hachiman) at Usa, the nation would enjoy tranquillity and prosperity if Dōkyō were its ruler.

The Empress had profound reverence for Hachiman, as, indeed, was well known to Asomaro and to Dōkyō. Yet she hesitated to take this extreme step without fuller assurance. She ordered Wake no Kiyomaro to proceed to Usa and consult the deity once more. Kiyomaro was a fearless patriot. That Shōtoku's choice fell on him at this juncture might well have been regarded by his countrymen as an intervention of heaven. Before setting out he had unequivocal evidence of what was to be expected at Dōkyō's hands by the bearer of a favourable revelation from Hachiman. Yet the answer carried back by him from the Usa shrine was explicitly fatal to Dōkyō's hope. "Since the establishment of the State the distinction of sovereign and subject has been observed. . There is no instance of a subject becoming sovereign. The successor of the throne must be of the Imperial family and a usurper is to be rejected." Dōkyō's wrath was extreme. He ordered that Kiyomaro's name should be changed to Kegaremaro, which was equivalent to substituting "foul" for "fair;" he banished him to Ōsumi in the extreme south of Kyūshū, and he sent emissaries whose attempt to assassinate him was balked by a thunder-storm. But before he could bring any fresh design to maturity, the Empress died. Dōkyō and Asomaro were banished, and Kiyomaro was recalled from exile.

Historians have been much perplexed to account for the strangely apathetic demeanour of the high dignitaries of State in the presence of such disgraceful doings as those of the Empress and her favourite. They specially blame Kibi no Makibi, the great scholar. He had recovered from his temporary eclipse in connexion with the revolt of Fujiwara Hirotsugu, and he held the office of minister of the Right during a great part of Kōken's reign. Yet it is not on record that he offered any remonstrance. The same criticism, however, seems to apply with not less justice to his immediate predecessors in the post of 
munisters of the Right, Tachibana no Moroe and Fujiwara no Toyonari; to the minister of the Left, Fujiwara no Nagate; to the second councillor, Fujiwara no Matate, and to the privy councillors, Fujiwara no Yoshitsugu, Fujiwara no Momokawa, and Fujiwara no Uwona. It was with the Fujiwara families that the responsibility rested chiefly, and the general conduct of the Fujiwara at that period of history forbids us to construe their apparent indifference in a wholly bad sense. Probably the simplest explanation is the true one: Kōken herself was a Fujiwara.

\section{STATE OF THE PROVINCES}

In the days of Shōmu and Kōken administrative abuses were not limited to the capital, they extended to the provinces also. Among the Daika and Daiho laws, the first that proved to be a failure was that relating to provincial governors. At the outset men of ability were chosen for these important posts, and their tcrm of service was limited to four years. Soon, however, they began to petition for reappointment, and under the sway of the Empress Kōken a via media was found by extending the period of office to six years. Moreover, whereas at first a newly appointed governor was supposed to live: in the official residence of his predecessor, it quickly became the custom to build a new mansion for the incoming dignitary and leave the outgoing undisturbed.

What that involved is plain when we observe that such edifices were all construeted by forced labour. These governors usually possessed large domains, acquired during their period of office. The Court endeavoured to check them by despatching inspectors (ansatsu-shi) to examine and report on current conditions; but that device availed little. Moreover, the provincial governors exercised the power of appointing and dismissing the district governors (gunshi) in their provinces, although this evil system had been prohibited in the time of Gemmyō. In connexion, too, with the rice collected for public purposes, there were abuses. This rice, so long as it lay in the official storehouses, represented so much idle capital. The provincial governors utilized it by lending the grain to the farmers in the spring, partly for seed purposes and partly for food, on condition that it should be paid back in the autumn with fifty per cent.inerement. Subsequently this exorbitant figure was reduced to thirty per cent. But the result was ruin for many farmers. They had to hand over their ficlds and houses or sell themselves into bondage.

Thus, outlaws, living by plunder, became a common feature of the time, and there arose a need for guards more capable than those supplied by the system of partial conscription. Hence, in the reign of Shōmu, the sons and brothers of district governors (gunshi) proficient in archery and equestrianism were summoned from Ōmi, Ise, Mino, and Echizen, and to them was assigned the duty of guarding the public storehouses in the provinces. At the same time many men of prominence and influence began to organize guards for their private protection. This was contrary to law, but the condition of the time seemed to warrant it, and the authorities were powerless to prevent it. 'The ultimate supremacy of the military class had its origin in these circumstances. The Government, itself was constrained to organize special corps for dealing with the brigands and pirates who infested the country and the coasts.

It has been well said by a Japanese historian that the fortunes of the Yamato were at their zenith during the reigns of the three Emperors Jimmu, Temmu, and Mommu. From the beginning of the eighth century they began to decline. For that decline, Buddhism was largely responsible. Buddhism gave to Japan 
a noble creed in the place of a colourless cult; gave to her art and refinement, but gave to her also something like financial ruin. The Indian faith spread with wonderful rapidity among all classes and betrayed them into fanatical extravagance. Anyone who did not erect or contribute largely to the erection of a temple or a pagoda was not admitted to the ranks of humanity. Men readily sacrificed their estates to form temple domains or to purchase serfs (tera-yakko) to till them. The sublimity of these edifices; the solemn grandeur of the images enshrined there; the dazzling and exquisite art lavished on their decoration; the strange splendour of the whole display might well suggest to the Japanese the work of some supernatural agencies.

In the Nara epoch, the Government spent fully one-half of its total income on works of piety. No country except in time of war ever devoted so much to unproductive expenditures. The enormous quantities of copper used for casting images not only exhausted the produce of the mines but also made large inroads upon the currency, hundreds of thousands of cash being thrown into the meltingpot. In 760 it was found that the volume of privately coined cash exceeded onehalf of the State income, and under pretext that to suspend the circulation of such a quantity would embarrass the people, the Government struck a new coin - the mannen tsūho - which, while not differing appreciably from the old cash in intrinsic value, was arbitrarily invested with ten times the latter's purchasing power. The profit to the treasury was enormous; the disturbance of values and the dislocation of trade were proportionately great. Twelve years later (772), another rescript ordered that the new coin should circulate at par with the old. Such unstable legislation implies a very crude conception of financial requirements.

\section{RECLAIMED UPLANDS}

It has been shown that the Daika reforms regarded all "wet fields" as the property of the Crown, while imposing no restriction on the ownership of uplands, these being counted as belonging to their reclaimers. Thus, large estates began to fall into private possession; conspicuously in the case of provincial and district governors, who were in a position to employ forced labour, and who frequently abused their powers in defiance of the Daika code and decrees, where it was enacted that all profits from reclaimed lands must be shared with the farmers. ${ }^{1}$ So flagrant did these practices become that, in 767, reclamation was declared to constitute thereafter no title of ownership. Apparently, however, this veto proved unpractical, for five years later (772), it was rescinded, the only condition now attached being that the farmers must not be distressed. Yet again, in 784, another change of policy has to be recorded. A decree declared that governors must confine their agricultural enterprise to public lands, on penalty of being punished criminally. If the language of this decree be read literally, a very evil state of affairs would seem to have existed, for the governors are denounced as wholly indifferent to public rights or interests, and as neglecting no means of exploiting the farmers. Finally, in 806, the pursuit of productive enterprise by governors in the provinces was once more sanctioned.

Thus, between 650 and 806 , no less than five radical changes of policy are recorded. It - resulted that this vascillating legislation received very little practical attention. Great landed estates (shōen) accumulated in private hands

[ ${ }^{1}$ The term "farmers," as used in the times now under consideration, must not be interpreted strictly in the modern sense of the word. It meant, rather, the untitled and the unofficial classes in the provinces.] 
throughout the empire, some owned by nobles, some by temples; and in order to protect their titles against the interference of the Central Government, the holders of these estates formed alliances with the great Court nobles in the capital, so that, in the course of time, a large part of the land throughout the provinces fell under the control of a few dominant families.

In the capital (Nara), on the other hand, the enormous sums squandered upon the building of temples, the casting or carving of images, and the performance of costly religious ceremonials gradually produced such a state of impecuniosity that, in 775 , a decree was issued ordering that twenty-five per cent. of the revenues of the public lands (kugaiden) should be appropriated to increase the emoluments of the metropolitan officials. This decree spoke of the latter officials as not having sufficient to stave off cold or hunger, whereas their provincial confrères were living in opulence, and added that even men of high rank were not ashamed to apply for removal to provincial posts. As illustrating the straits to which the metropolitans were reduced and the price they had to pay for relief, it is instructive to examine a note found among the contents of the Shōsō-in at Nara.

\section{STATEMENT OF MON (COPPER CASH) LENT}

$\begin{array}{cc} & \text { Total, } 1700 \mathrm{Mon} . \\ \text { Debtors } & \text { Sums lent } \\ \text { Tata no Mushimaro } & 500 \text { mon. }\end{array}$

Ayabe no Samimaro 700 mon.

Kiyono no Hitotari 500 mon.
Monthly interest, 15 per hundred.

\section{A mounts to be returned}

605 mon, on the 6 th of the 11th month; namely, original debt, 500 mon, and interest for 1 month and 12 days, 105 mon.

840 mon, on the 6 th of the 11th month; namely, original debt, 700 mon, and interest for 1 month and 10 days, 140 mon.

605 mon, on the 6 th of the 11th month; namely, original debt, 500 mon, and interest for 1 month and 12 days, 105 mon.

The above to be paid back when the debtors receive their salaries. Dated the 22nd of the 9 th month of the 4 th year of the Höki era. (October 13, 773.)

Another note shows a loan of 1000 mon carrying interest at the rate of 130 mon monthly. The price of accomodation being so onerous, it is not difficult to infer the costliness of the necessaries of life. When the Daika reforms were undertaken, the metropolitan magnates looked down upon their provincial brethren as an inferior order of beings, but in the elosing days of the Nara epoch the situations were reversed, and the ultimate transfer of administrative power from the Court to the provincials began to be foreshadowed.

\section{THE FUJIWARA FAMILY}

The religious fanaticism of the Emperor Shōmu and his consort, Kōmyō, brought disorder into the affairs of the Imperial Court, and gave rise to an abuse not previously recorded, namely, favouritism with its natural outcome, treasonable ambition. It began to be doubtful whether the personal administration of the sovereign might not be productive of danger to the State. Thus, patriotic politicians conceived a desire not to transfer the sceptre to outside hands but to find among the scions of the Imperial family some one competent to save the situation, even though the selection involved violation of the principle of primogeniture. The death of the Empress Shōtoku without issue and the consequent extinction of the Emperor Temmu's line furnished an opportunity to these loyal 
statesmen, and they availed themselves of it to set Kōnin upon the throne, as will be presently described.

In this crisis of the empire's fortunes the Fujiwara family acted a leading part. Fuhito, son of the illustrious Kamatari, having assisted in the compilation of the Daika code and laws, and having served throughout four reigns - Jitō, Mommu, Gemmyō, and Genshō-died at sixty-two in the post of minister of the Right, and left four sons, Muchimaro, Fusazaki, Umakai, and Maro. These, establishing themselves independently, founded the "four houses" of the Fujiwara. 'Muchimaro's home, being in the south (nan) of the capital, was called Nan-ke; Fusazaki's, being in the north (hoku), was termed Hoku-ke; Umakai's was spoken of as Shiki-ke, since he presided over the Department of Ceremonies (Shiki), and Maro's went by the name of Kyō-ke, this term also having reference to his office. The descendants of the four houses are shown in the following table:-

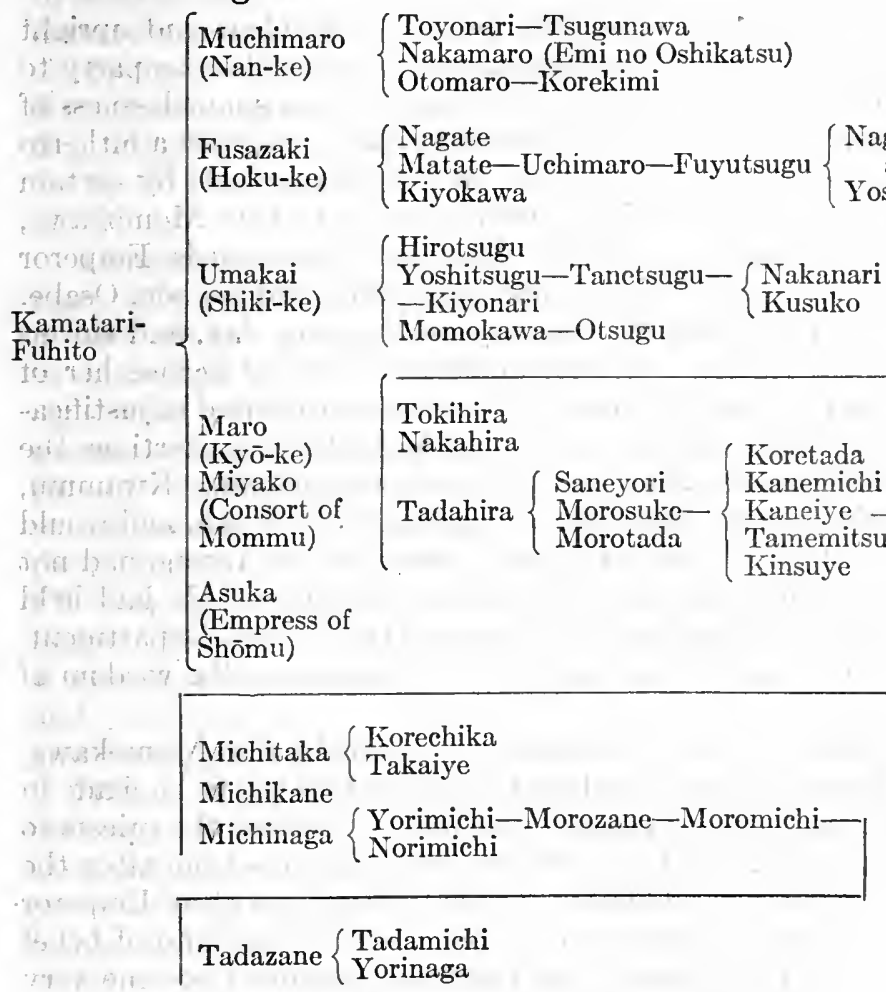

It has already been related how the four heads of these families all died in one year (736) during an epidemic of small-pox, but it may be doubted whether this apparent calamity did not ultimately prove fortunate, for had these men lived, they would have occupied commanding positions during the scandalous reign of the Empress Kōken (afterwards Shōtoku), and might have supported the ruinous disloyalty of Nakamaro or the impetuous patriotism of Hirotsugu. However that may be, the Fujiwara subsequently took the lead in contriving the selection and enthronement of a monarch competent to stem the evil tendency of the time, and when the story of the Fujiwara usurpations comes to be written, we should always remember that it had a long preface of loyal service, a preface extending to four generations. 
THE FORTY-NINTI SOVEREIGN, THE EMPEROR KŌNIN (A.D. 770-781)

When the Empress Shōtoku died, no successor had been designated, and it seemed not unlikely that the country would be thrown into a state of civil war. The ablest among the princes of the blood was Shirakabe, grandson of the Emperor Tenchi. He was in his sixty-second year, had held the post of nagon, and unquestionably possessed erudition and administrative competence. Fujiwara Momokawa warmly espoused his cause, but for unrecorded reason Kibi no Makibi offered opposition. Makibi being then minister of the Right and Momokawa only a councillor, the former's views must have prevailed had not Momokawa enlisted the aid of his brother, Yoshitsugu, and of his cousin, Fujiwara Nagate, minister of the Left. By their united efforts Prince Shirakabe was proclaimed and became the Emperor Kōnin, his youngest son, Osabe, being appointed Prince Imperial.

Kōnin justified the zeal of his supporters, but his benevolent and upright reign has been sullied by historical romanticists, who represent him as party to an unnatural intrigue based on the alleged licentiousness and shamelessness of his consort, Princess Inokami, a lady then in her fifty-sixth year with a hitherto blameless record. Much space has been given to this strange tale by eertain annalists, but its only apparent basis of fact would seem to be that Momokawa, wishing to secure the succession to Prince Yamabe - afterwards Emperor Kwammu - compassed the deaths of the Empress Inokami and her son, Osabe, the heir apparent. They were probably poisoned on the same day, and stories injurious to the lady's reputation - stories going so far as to accuse her of attempting the life of the Emperor by incantation - were circulated in justification of the murder. Certain it is, however, that to Momokawa's exertions the Emperor Kwammu owed his accession, as had his father, Konin. Kwammu, known in his days of priesthood as Yamabe, was Könin's eldest son, and would have been named Prince Imperial on his father's ascent of the throne had not his mother, Takano, been deficient in qualifications of lineage. He had held the posts of president of the University and minister of the Central Department, and his career, alike in office and on the throne, bore witness to the wisdom of his supporters.

As illustrating the religious faith of the age, it is noteworthy that Momokawa, by way of promoting Prince Yamabe's interests, eaused a statue to be made in his likeness, and, enshrining it in the temple Bonshaku-ji, ordered the priests to offer supplications in its behalf. The chronicle further relates that after the cleaths of the Empress (Inokami) and her son (Osabe), Momokawa and Emperor Konnin were much troubled by the spirits of the deceased. That kind of belief in the maleficent as well as in the beneficent powers of the dead beeame very prevalent in later times. Momokawa died before the accession of Kwammu, but to him was largely due the great influence subsequently wielded by the Fujiwara at Court. It is on record that Kwammu, speaking in after years to Momokawa's son, Otsugu, recalled his father's memory with tears, and said that but for Momokawa he would never have reigned over the empire.

The fact is that the Fujiwara were a natural outcome of the situation. The Tang systems, which Kamatari, the great founder of the family, had been chiefly instrumental in introducing, placed in the hands of the sovereign powers much too extensive to be safely entrusted to a monareh qualified only by heredity. Comprehending the logic of their organization, the Chinese made their monarehs' tenure of authority depend upon the verdict of the nation. But in Japan the 
title to the crown being divinely bequeathed, there could be no question of appeal to a popular tribunal. So long as men like Kōtoku, Tenchi, and Temmu occupied the throne, the Tang polity showed no flagrant defects. But when the exercise of almost unlimited authority fell into the hands of a religious fanatic like Shōmu, or a licentious lady like Kōken, it became necessary either that the principle of heredity should be set aside altogether, or that some method of limited selection should be employed.

It was then that the Fujiwara became a species of electoral college, not possessing, indeed, any recognized mandate from the nation, yet acting in the nation's behalf to secure worthy occupants for the throne. For a time this system worked satisfactorily, but ultimately it inosculated itself with the views it was designed to nullify, and the Fujiwara became flagrant abusers of the power handed down to them. Momokawa's immediate followers were worthy to wear his mantle. Tanetsugu, Korekimi, Tsugunawa - these are names that deserve to be printed in letters of gold on the pages of Japan's annals. They either prompted or presided over the reforms and retrenchments that marked Kwammu's reign, and personal ambition was never allowed to interfere with their duty to the State.

\section{IMPERIAL PRINCES}

Contemporaneously with the rise of the Fujiwara to the highest places within reach of a subject, an important alteration took place in the status of Imperial princes. There was no relation of cause and effect between the two things, but in subsequent times events connected them intimately. According to the Daika legislation, not only sons of sovereigns but also their descendants to the fifth generation were classed as members of the Imperial family and inherited the title of "Prince" $(\bar{O})$. Ranks (hon-i) were granted to them and they often participated in the management of State affairs. But no salaries were given to them; they had to support themselves with the proceeds of sustenance fiefs. The Emperor Kwammu was the first to break away from this time-honoured usage. : He reduced two of his own sons, born of a non-Imperial lady, from the $K w \bar{o} b e t s u$ class to the Shimbetsu, conferring on them the uji names of Nagaoka and Yoshimine, and he followed the same course with several of the Imperial grandsons, giving them the name of Taira.

Thenceforth, whenever a sovereign's offspring was numerous, it became customary to group them with the subject class under a family name. A prince thus reduced received the sixth official rank (roku-i). and was appointed to a corresponding office in the capital or a province, promotion following according to his ability and on successfully passing the examination prescribed for Court officials. Nevertheless, to be divested of the title of "Prince" did not mean less of princely prestige. Such nobles were always primi inter pares. The principal uji thus created were Nagaoka, Yoshimine, Ariwara, Taira, and Minamoto.

\section{THE TAIRA FAMILY}

Prince Katsurabara was the fifth son of the Emperor Kwammu. Intelligent, reserved, and a keen student, he is said to have understood the warnings of history as clearly as its incentives. He petitioned the Throne that the title of $\bar{O}$ should be exchanged in his children's case for that of Taira no Asomi (Marquis of Taira). This request, though several times repeated, was not granted until the time (889) of his grandson, Takamochi, who became the first Taira no 
Asomi and governor of Kiazusa provinee. He was the grandfather of Masakado and great-grandfather of Tadamori, names celebrated in Japanese history. For generations the Taira asomi were appointed generals of the Imperial guards conjointly with the Minamoto, to be presently spoken of. The name of Taira was conferred also on three other sons of Kwammu, the Princes Mamta, Kaya, and Nakano, so that there were four Taira houses just as there were four Fujiwara.

\section{THE MINAMOTO FAMILY}

The Emperor Saga (810) had fifty children. From the sixth son downwards they were grouped under the uji of Minamoto. All received appointments to important offices. This precedent was even more drastically followed in the days of the Emperor Seiwa (859-876). To all his Majesty's sons, exeept the Crown Prince, the uji of Minamoto was given. The best known among these early Minamoto was Tsunemoto, commonly called Prince Rokuson. He was a grandson of the Emperor Seiwa, celebrated for two very dissimilar attainments, which, nevertheless, were often combined in Japan - the art of composing couplets and the science of commanding troops. Appointed in the Shōhyo era (931-937) to be governor of Musashi, the metropolitan province of modern Japan, his descendants eonstituted the prineipal among fourteen Minamoto houses. They were called the Seiwa Genji, and next in importance came the Saga Genji and the Murakami Genji. ${ }^{1}$

\section{UJI NO CHŌJA AND GAKU-IN NO BETTO}

The imperially desecnded $u j i$ spoken of above, each consisting of several houses, were grouped according to their names, and each group was under the supervision of a chief, called uji no chōja or uji no chō. Usually, as has been already stated, the corresponding position in an ordinary uji was called uji no Kami and belonged to the first-born of the principal house, irrespective of his official rank. But in the ease of the imperially descended $u j i$, the chief / was seleeted and nominated by the sovereign with regard to his administrative post. With the appointment was generally combined that of Gaku-in no bettō, or commissioner of the academies established for the youths of the $u j i$. The principal of these academies was the Kwangaku-in of the Fujiwara. Founded by Fujiwara Fuyutsugu, minister of the Left, in the year 821 , and endowed with a substantial part of his estate in order to afford educational advantages for the poorer members of the great family, this institution rivalled even the Imperial University, to be presently spoken of. It was under the superintendence of a special commissioner (benkwan).

Next in importance was the Shōgaku-in of the Minamoto, established by Ariwara Yukihira in the year 881. Ariwara being a grandson of the Emperor Saga, a member of the Saga Genji received the nomination of chief commissioner; but in the year 1140, the minister of the Right, Masasada, a member of the Murakami Genji, was appointed to the office, and thenceforth it remained in the hands of that house. Two other educational institutions were the Junna-in of the $\bar{O}-u j i$ and the Gakukwan-in of the Tachibana-uji, the former dating from

[1 That is to say, descended from the Emperor Murakami (947-967). Gen is the Chinese sound of Minamoto and $j i(s h i)$ represents uji. The Minamoto are alluded to in history as either the Genji or the Minamoto. Similarly, hei being the Chinese pronunciation of Taira, the latter are indiscriminately spoken of Taira or Heike (ke=house). Both names are often combined into Gen-pei.] 
the year 834 and the latter from 820. It is not on record that there existed any special school under Taira auspices.

\section{AGRICULTURE}

One of the principal duties of local governors from the time of the Daika reforms was to encourage agriculture. A rescript issued by the Empress Genshō in the year 715 declared that to enrich the people was to make the country prosperous, and went on to condemn the practice of devoting attention to rice culture only and neglecting upland crops, so that, in the event of a failure of the former, the latter did not constitute a substitute. It was therefore ordered that barley and millet should be assiduously grown, and each farmer was required to lay down two $\tan (\% / 3$ acre) annually of these upland cereals. Repeated proclamations during the eighth century bear witness to official solicitude in this matter, and in 723 there is recorded a distribution of two koku (nearly ten bushels) of seeds, ten feet of cotton cloth, and a hoe (kuwa) to each agriculturist throughout the empire. Such largesse suggests a colossal operation, but, in fact, it meant little more than the remission of about a year's taxes. Necessarily, as the population increased, corresponding extension of the cultivated area became desirable, and already, in the year 722, a work of reclamation on a grand scale was officially undertaken by organizing a body of peasants and sending them to bring under culture a million cho (two and a half million acres) of new land. This interesting measure is recorded without any details whatever.

Private initiative was also liberally encouraged. An Imperial rescript promised that any farmer harvesting three thousand koku (fifteen thousand bushels) of cereals from land reclaimed by himself should receive the sixth class order of merit (kun roku-tō), while a crop of over a thousand koku and less than three thousand would carry lifelong exemption from forced labour. The Daika principle that the land was wholly the property of the Crown had thus to yield partially to the urgency of the situation, and during the third decade of the eighth century it was enacted that, if a man reclaimed land by utilizing aqueducts and reservoirs already in existence, the land should belong to him for his lifetime, while if the reservoirs and aqueducts were of his own construction, the right of property should be valid for three generations. ${ }^{1}$ From the operation of this law the provincial governors were excepted; the usufruct of lands reclaimed by them was limited to the term of their tenure of office, though, as related already, legislation in their case varied greatly from time to time.

1: For a certain period the system of "three generations, or one life" worked smoothly enough; but subsequently it was found that as the limit of time approached, farmers neglected to till the land and suffered it to lie waste. Therefore, in the year 743, the Government enacted that all reclaimed land should be counted the perpetual property of the reclaimer, with one proviso, namely, that three years of néglect to cultivate should involve confiscation. The recognition of private ownership was not unlimited. An area of five hundred chō (1250 acres) was fixed as the superior limit, applicable only to the case of a "First Class" prince, the quantities being thereafter on a sliding scale down to ten cho (twentyfive acres). Any excess resulting from previous accretions was to revert to the State. Evidently the effective operation of such a system predicated accurate

$\left[{ }^{1}\right.$ This system was called Sansei-isshin no hö. It is, perhaps, advisable to note that the Daika system of dividing the land for sustenance purposes applied only to land already under cultivation.] 
surveys and strict supervision. Neither of these conditions existed in Japan at that remote period. The prime purpose of the legislators was achieved, since the people devoted themselves assiduously to land reclamation; but by free recourse to their power of commanding labour, the great families acquired estates largely in excess of the legal limit. A feature of the Nara epoch was the endowment of the Buddhist temples with land by men of all classes, and the.shō-en, or temple domain, thus came into existence.

\section{STOCK FARMING}

Information on the subject of stock farming is scanty and indirect, but in the year 713 we find a reseript ordering the provincials of Yamashiro to provide and maintain fifty milch-cows, and in 734, permission was given that all the districts in the Tōkai-dō, the Tōsan-dō, and the Sanin-dō might trade freely in cattle and horses. Seven years later (741), when Shomu occupied the throne, and when Buddhism spread its protecting mantle over all forms of life, an edict appeared condemning anyone who killed a horse or an ox to be flogged with a hundred strokes and to be fined heavily. Only one other reference to stock farming appears in the annals of the Nara epoch: the abolition of the two pastures at Osumi and Himeshima in the province of Settsu was decreed in 771, but no reason is recorded.

\section{SERICULTURE}

From the remotest times sericulture was assiduously practised in Japan, the ladies of the Imperial Court, from the Empress downwards, taking an active part in the pursuit. The wave of Buddhist zeal which swept over Japan in the eighth century gave a marked impulse to this branch of industry, for the rich robes of the priests constituted a special market.

\section{ORANGES}

It is recorded in the Chronicles that Tajimamori, a Korean emigrant of royal descent, was sent to the "Eternal Land" by the Emperor Suinin, in the year A.D. 61, to obtain "the fragrant fruit that grows out of season;" that, after a year's absence, he returned, and finding the Emperor dead, committed suicide at his tomb. The "fragrant fruit" is understood to have been the orange, then called tachibana (Citrus nobilis). If the orange really reached Japan at that remote date, it does not appear to have been cultivated there, for the importation of orange trees from China is specially mentioned as an incident of the early Nara epoch.

\section{INDUSTRIES}

One of the unequivocal benefits bestowed on Japan by Buddhism was a strong inclustrial and artistic impulse. Architecture made notable progress owing to the construction of numerous massive and magnificent temples and pagodas. One of the latter, erected during the reign of Temmu, had a height of thirteen storeys. The arts of easting and of sculpture, both in metal and in wood, received great development, as did also the lacquer industry. 'Vermilion lacquer was invented in the time of Temmu, and soon five different colours could be produced, while to the Nara artisans belongs the inception of lacquer strewn with makie. Lacquer inlaid with mother-of-pearl was another beautiful 
concept of the Nara epoch. A special tint of red was obtained with powdered coral, and gold and silver were freely used in leaf or in plates. As yet, history does not find any Japanese painter worthy of record. Chinese and Korean masters remained supreme in that branch of art.

\section{TRADE}

Commerce with China and Korea was specially active throughout the eighth century, and domestic trade also flourished. In the capital there were two markets where people assembled at noon and dispersed at sunset. Men and women occupied different sections, and it would seem that transactions were subject to strict surveillance. Thus, if any articles of defective quality or adulterated were offered for sale, they were liable to be confiscated officially, and if a buyer found that short measure had been given, he was entitled to return his purchase. Market-rates had to be conformed with, and purchasers were required to pay promptly. It appears that trees were planted to serve as shelter or ornament, for we read of "trees in the Market of the East" and "orange trees in the market of Kaika."

\section{HABITATIONS}

The Buddhist temple, lofty, spacious, with towering tiled roof, massive pillars and rich decoration of sculpture and painting, could not fail to impart an impetus to Japanese domestic architecture, especially as this impressive apparition was not evolved gradually under the eyes of the nation but was presented to them suddenly in its complete magnificence. Thus it is recorded that towards the close of the seventh century, tiled roofs and greater solidity of structure began to distinguish official buildings, as has been already noted. But habitations in general remained insignificant and simple. A poem composed by the Dowager Empress Genshō (724) with reference to the dwelling of Prince Nagaya is instructive:-

"Hata susuki
"Obana sakafuki
"Kuro-ki mochi
"Tsukureru yado wa
"Yorozu yo made ni."
"Thatched with miscanthus

"And eularia

"Of ebon timbers built, a house

"Will live a myriad years."

This picture of a nobleman's dwelling in the eighth century is not imposing. In the very same year the Emperor Shōmu, responding to an appeal from the council of State, issued an edict that officials of the fifth rank and upwards and wealthy commoners should build residences with tiled roofs and walls plastered in red. This injunction was only partly obeyed: tiles came into more general use, but red walls offended the artistic instinct of the Japanese. Nearly fifty years later, when (767-769) the shrine of Kasuga was erected at Nara in memory of Kamatari, founder of the Fujiwara family, its pillars were painted in vermilion, and the fashion inaugurated found frequent imitation in later years.

Of furniture the houses had very little as compared with Western customs. Neither chairs nor bedsteads existed; people sat and slept on the floor, separated from it only by mats made of rice-straw, by cushions or by woollen carpets, and in aristocratic houses there was a kind of stool to support the arm of the sitter, a lectern, and a dais for sitting on. Viands were served on tables a few inches high, and people sat while eating. From the middle of the seventh century a clepsydra of Chinese origin was used to mark the hours.

The first of thëse instruments is recorded to have been made in A.D. 660, and 
tradition does not tell what deviee had previously served the purpose. When temple bells came into existence, the hours were struck on them for public information, and there is collateral evidenee that some similar system of marking time had been resorted to from early eras. But the whole story is vague. It seems, however, that the method of counting the hours was influenced by the manner of striking them. Whether bronze bell or wooden clapper was used, three preliminary strokes were given by way of warning, and it therefore became inexpedient to designate any of the hours "one," "two," or "three." Accordingly the initial number was four, and the day being divided into six hours, instead of twelve, the highest number beeame nine, which corresponded to the Occidental twelve. ${ }^{1}$

\section{BELLS}

Concerning the bells here mentioned, they are one of the unexplained achicvements of Japanese casters. In Europe the method of producing a really fine-toned bell was evolved by "ages of empirical trials," but in Japan bells of huge size and exquisite note were cast in apparent defiance of all the rules elaborated with so much difficulty in the West. One of the most remarkable hangs in the belfry of Tōdai-ji at Nara. It was cast in the year 732 when Shömu occupied the throne; it is 12 feet 9 inches high; 8 feet 10 inches in diameter; 10 inches thick, and weighs 49 tons. There are great bells also in the temples at Ōsaka and Kyōto, and it is to be noted that early Japanese bronze work was largely tributary and subsidiary to temple worship. Temple bells, vases, gongs, mirrors and lanterns are the principal items in this class of metalworking, until a much later period with its smaller ornaments.

\section{ROADS AND MEANS OF COMMUNICATION}

Very few references to road making are found in the ancient annals, but the reign of the Empress Genshō (715-723) is distinguished as the time when the Nakasen-dō, or Central Mountain road, was constructed. It runs from Nara to Kyōto and thence to the modern Tōkyō, traversing six provinces en route. Neither history nor tradition tells whether it was wholly made in the days of Genshō or whether, as seems more probable, it was only commenced then and earried to completion in the reign of Shōmu (724-748), when a large force of troops had to be sent northward against the rebellious Yemishi. Doubtless the eustom of changing the capital on the accession of each sovereign had the effect of calling many roads into existence, but these were of insignificant length compared with a great trunk highway like the Nakasen-dō.

Along these roads the lower elasses travelled on foot; the higher on horseback, and the highest in carts drawn by bullocks. For equestrians who carried official permits, relays of horses eould always be obtained at posting stations: Among the ox-carts whieh served for carriages, there was a curious type, distinguished by the fact that between the shafts immediately in front of the dashboard stood a figure whose outstretched arm perpetually pointed south: This compass-cart, known as the "south-pointing chariot," was introduced from China in the year 658. There was also a "cloud-chariot," but this served for war purposes only, being a movable erection for overlooking an enemy's defensive work, corresponding to the turris of Roman warfare. Borrowed also from

['There were no subdivisions into minutes and seconds in old Japan. The only fraction of an hour was one-half.l 


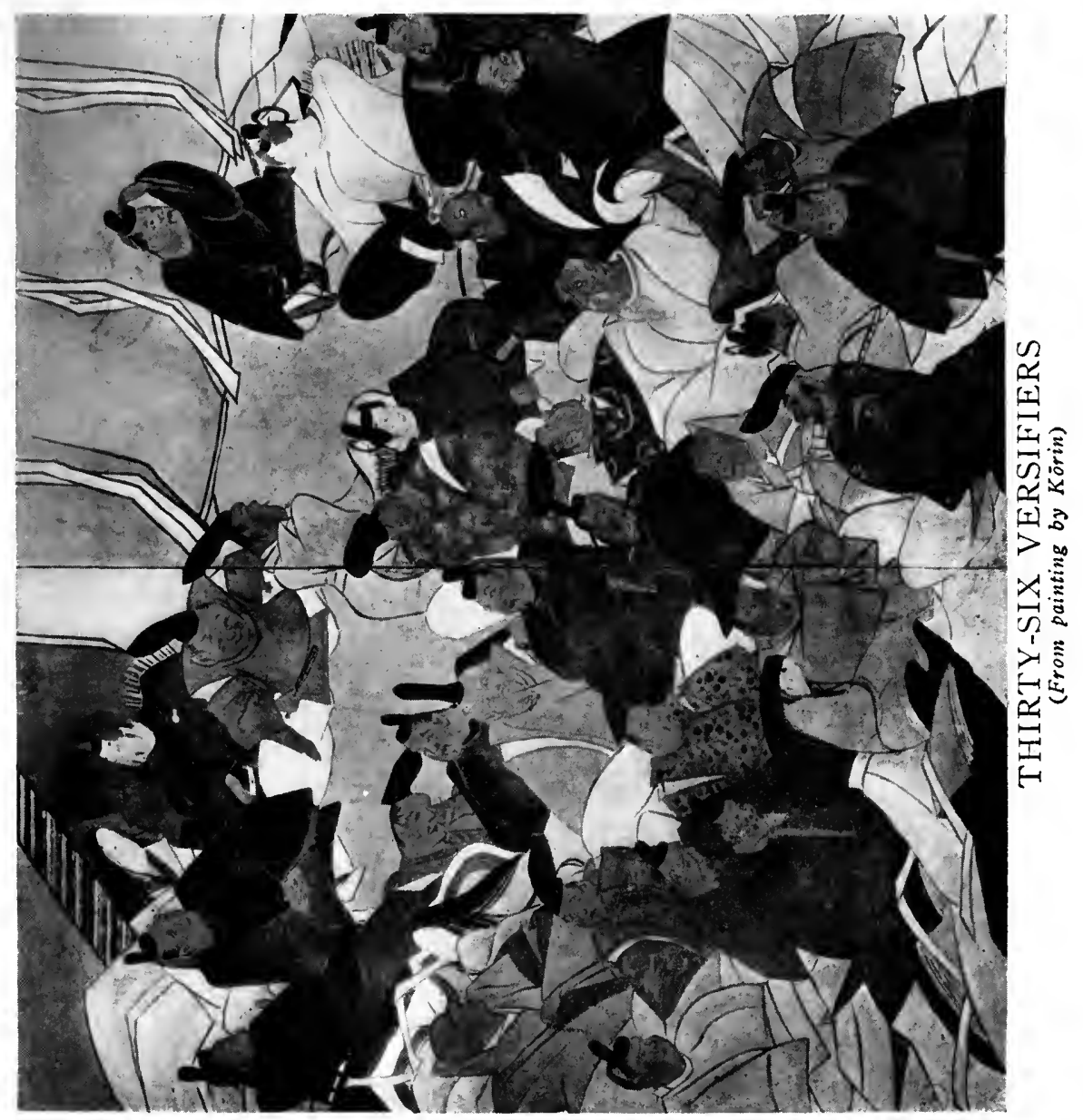



China was a battering engine which moved on four wheels, and, like the cloudchariot, dated from 661, when a Tang army invaded Korea.

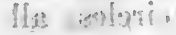

\section{HABILIMENTS}

A reader of the Chronicles is struck by the fact that from the close of the seventh century much official attention seems to have been bestowed on the subject of costume. Thus, during the last five years of the Emperor Temmu's reign - namely, from 681 - we find no less than nine sumptuary regulations issued. The first was an edict, containing ninety-two articles, of which the prologue alone survives, "The costumes of all, from the princes of the Blood down to the common people, and the wearing of gold and silver, pearls and jewels, purple, brocade, embroidery, fine silks, together with woollen carpets, head-dresses, and girdles, as well as all kinds of coloured stuffs, are regulated according to a scale, the details of which are given in the written edict." In the next year (682), another edict forbids the wearing of caps of rank, aprons, broad girdles, and leggings by princes or public functionaries, as well as the use of shoulder-straps or mantillas by palace stewards or ladies-in-waiting. The shoulder-strap was a mark of manual labour, and its use in the presence of a superior has always been counted as rude in Japan.

A few days later, this meticulous monarch is found commanding men and women to tic up their hair, eight months being granted to make the change, and, at the same time, the practice of women riding astride on horseback came into vogue, showing that female costume had much in common with male. Caps of varnished gauze, after the Chinese type, began to be worn by both sexes simultaneously with the tying-up of the hair. Two years later, women of forty years or upwards were given the option of tying up their hair or letting it hang loose, and of riding astride or side-saddle as they pleased. At the same time, to both sexes, except on State occasions, liberty of choice was accorded in the matter of wearing sleeveless jackets fastened in front with silk cords and tassels, though in the matter of trousers, men had to gather theirs in at the bottom with a lace. By and by, the tying up of the hair by women was forbidden in its turn; the wearing of leggings was sanctioned, and the colours of Court costumes were strictly determined according to the rank of the wearer - red, deep purple, light purple, dark green, light green, deep grape-colour and light grapecolour being the order from above downwards.

All this attention to costume is suggestive of much refinement. From the eighth century even greater care was devoted to the subject. We find three kinds of habiliments prescribed - full dress (reifuku), Court dress (chöfuku) and uniform (seifuku) - with many minor distinctions according to the rank of the wearer. Broadly speaking, the principal garments were a paletot, trousers, and a narrow girdle tied in front. The sleeves of the paletot were studiously regulated. A nobleman wore them long enough to cover his hands, and their width - which in after ages became remarkable - was limited in the Nara epoch to one foot. The manner of folding the paletot over the breast seems to have perplexed the legislators for a time. At first they prescribed that the right should be folded over the left (hidarimae), but subsequently (719) an Imperial decree ordered that the left should be laid across the right (migimae), and since that day, nearly twelve hundred years ago, there has not been any departure from the latter rule. Court officials carried a baton (shaku), that, too, being a habit borrowed from China. 
When the influence of Buddhism became supreme in Court circles, all taking of life for purposes of food was interdicted. 'The first prohibitory decree in that sense was issued by Temmu (673-686), and the veto was renewed in more peremptory terms by Shōmu (724-748), while the Empress Shōtoku (765-770) went so far as to forbid the keeping of dogs, falcons, or cormorants for hunting or fishing at Shintō ceremonials. But such vetoes were never effectually enforced. The great staple of diet was rice, steamed or boiled, and next in importance came millet, barley, fish of various kinds (fresh or salted), seaweed, vegetables, fruit (pears, chestnuts, etc.), and the flesh of fowl, deer, and wild boar. Salt, bean-sauce, and vinegar were used for seasoning. There were many kinds of dishes; among the commonest being soup (atsumono) and a preparation of raw fish in vinegar (namasu). In the reign of Kotoku (645-654), a Korean named Zena presented a mileh cow to the Court, and from that time milk was recognized as specially hygienic diet. Thus, when the Daiho laws were published at the beginning of the eighth century, dairies were attached to the medical department, and certain provinces received orders to present butter (gyüraku), for the Court's use.

\section{MARRIAGES AND FUNERALS}

Very little is known of the marriage ceremony in old Japan. That there was a nuptial hut is attested by very early annals, and from the time of the Emperor Richū (400-405) wedding presents are recorded. But for the rest, history is silent, and it is impossible to fix the epoch when a set ceremonial began to be observed.

As to funerals, there is fuller but not complete information. That a mortuary chamber was provided for the corpse pending the preparation of the tomb is shown by the earliest annals, and from an account, partly allegorical, contained in the records of the prehistoric age, we learn that dirges were sung for eight days and eight nights, and that in the burial procession were marshalled bearers of viands to be offered at the grave, bearers of brooms to sweep the path, women who prepared the viands, and a body of hired mourners. But the Kojiki, describing the same ceremony, speaks of "making merry" with the object of recalling the dead to life, as the Sun goddess had been enticed from her cave. From the days of the Emperor Bidatsu (572-585), we find the first mention of funeral orations, and although the contents of tombs bear witness to the fact that articles other than food were offered to the deceased, it is not until the burial, of the Emperor's consort, Katachi, (612) that explicit mention is made of such a custom. On that occasion Tori, omi of the Abe-uji, offered to the spirit of the dead "sacred utensils and sacred garments, fifteen thousand kinds in all." Fifty years later, white is mentioned as the mourning colour, but when next (683) we hear of funerals, it is evident that their realm had been invaded by Chinese customs, for it is recorded that "officials of the third rank were allowed at their funerals one hearse, forty drums, twenty great horns, forty little horns, two hundred flags, one metal gong, and one hand-bell, with lamentation for one day." At Temmu's obsequies (687) mention is made of an "ornamented chaplet," the first reference to the use of flowers, which constitute such a prominent, feature of Buddhist obsequies.

But there is no evidence that Buddhist rites were employed at funerals until the death of the retired Emperor Shomu (756). Thereafter, the practice became 
common. It was also to a Büddhist priest, Dōshō, that Japan owed the inception of cremation. Dying in the year 700, Dōshồ ordered his disciples to cremate his body at Kurihara, and, two years later, the Dowager Empress Jito willed that her corpse should be similarly disposed of. From the megalithic tombs of old Japan to the little urn that holds the handful of ashes representing a cremated body, the transition is immense. It has been shown that one of the signal reforms of the Daika era was the setting of limits to the size of sepulchres, a measure which afforded to the lower classes much relief from forced labour. But an edict issued in 706 shows that the tendance of the resting place of the dead was still regarded as a sacred duty, for the edict ordered that, alike at the ancestral tombs of the $u j i$ and in the residential quarter of the common people, trees should be planted.

Not yet, however, does the custom of erecting monuments with inscriptions seem to have come into vogue. The Empress Gemmyō (d. 721) appears to have inaugurated that feature, for she willed not only that evergreens should be planted at her grave but also that a tablet should be set up there. Some historians hold that the donning of special garments by way of mourning had its origin at that time, and that it was borrowed from the Tang code of etiquette. But the Chronicles state that in the year A.D. 312, when the Prince Imperial committed suicide rather than occupy the throne; his brother, Ōsasagi, "put on plain unbleached garments and began mourning for him." White ultimately became the mourning colour, but in the eighth century it was dark, ${ }^{1}$ and mourning habiliments were called fuji-koromo, because they were made from the bark of the wisteria ( $f u j i)$. Among the Daiho statutes was one providing that periods of mourning should be of five grades, the longest being one year and the shortest seven days.

\section{PASTIMES}

Foremost among the pastimes of the Japanese people in all epochs was dancing. We hear of it in the prehistoric age when the "monkey female" (Sarume) performed a pantominic dance before the rock cave of the Sun goddess; we hear of it in protohistoric times when Inkyō's consort was betrayed into an offer that wrecked her happiness, and we hear of it in the historic epoch when the future Emperor Kensō danced in the disguise of a horse-boy. But as the discussion of this subject belongs more intelligently to the era following the Nara, we confine ourselves here to noting that even the religious fanatic Shōmu is recorded as having repaired to the Shujaku gate of the palace to witness a performance of song and dance (utagaki) in which 240 persons, men and women, took part; and that, in the same year (734), 230 members of six great uji performed similarly, all robed in blue garments fastened in front with long red cords and tassels:

The tendency of the Japanese has always been to accompany their feasting and merry-making with music, versifying, and dancing. At the time now under consideration there was the "winding-water fête" (kyoku-sui no en), when princes, high officials, courtiers, and noble ladies seated themselves by the banks of a rivulet meandering gently through some fair park, and launched tiny cups of mulled wine upon the current, each composing a stanza as the little messenger reached him, or drinking its contents by way of penalty for lack of

[ "On the death of the Emperor Inkyō (A.D. 453), the Korean Court sent eighty musicians robed in black, who marched in procession to the Yamato palace, playing and singing a dirge as they went?!'] 
poetic inspiration. There were also the flower festivals - that for the plum blossoms, that for the iris, and that for the lotus, all of which were instituted in this same Nara epoch - when the composition of couplets was quite as important as the viewing of the flowers. There was, further, the grand New Year's banquet in the Hall of Tranquillity at the Court, when all officials from the sixth grade downwards sang a stanza of loyal gratitude, accompanying themselves on the lute $(k o t o)$. It was an era of refined effeminate amusements. Wrestling had now become the pursuit of professionals. Aristocrats engaged in no rougher. pastime than equestrian arehery, a species of football, hawking, and hunting. Everybody gambled. It was in vain that ediets were issued against dicing (chobo and sugoroku). The vice defied official restraint.

\section{LITERATURE AND POETRY}

Having no books of her own, Japan naturally borrowed freely from the rich mine of Chinese literature. By the tutors of the Imperial family, at the colleges: of the eapital, and in the provincial schools the classies constituted virtually the whole eurriculum. The advantages of education were, however, enjoyed by: a comparatively small element of the population. During the Nara epoch, it does not appear that there were more than five thousand students attending the sehools and colleges at one time. The aim of instruction was to prepare men: for official posts rather than to impart general culture or to encourage seientific research. Students were therefore selected from the aristocrats or the official elasses only. There were no printed books; everything had to be laboriously: copied by hand, and thus the difficulties of learning were much enhanced. To be able to adapt the Chinese ideographs skilfully to the purposes of written Japanese was a feat achieved by comparatively few. What the task involved has been roughly described in the opening ehapter of this volume, and with what measure of success it was achieved may be estimated from the preface to the Records (Kojiki), written by Ōno Yasumaro, from the Chronicles (Nihon Shoki), and from the Daiho Ritsu-ryō, which three works may be called the sole surviving prase essays of the epoch.

Much richer, however, is the realm of poetry. It was during the Nara epoch that the first Japanese anthology, the Manyō-shu (Collection of a Myriad Leaves), was compiled. It remains to this day a revered classic and "a whole mountain of commentary has been devoted to the elucidation of its obscurities.". [Chamberlain.] In the Myriad Leaves are to be found poems dating nominally. from the reigns of Yūryaku and Nintoku, as well as from the days of Shōtoku. Taishi, but much more numerous are those of Jomei's era (629-641) and especially those of the Nara epoch. The compilor's name is not known certainly; he is believed to have been either Tachibana no Moroe or Ōtomo no Yakamochi. Old manuseripts and popular memory were the sources, and the verselets total 4496 , in twenty volumes. Some make love their theme; some deal with sorrow; some are allegorical; some draw their inspiration from nature's beauties, and some have miscellaneous motives. Hitomaru, who flourished during the reign of the Empress Jito (690-697), and several of whose verses are to be found in the Myriad Leaves, has been counted by all generations the greatest of Japanese poets. Not far below him in fame is Akahito, who wrote in the days of Shomu (724-749). To the same century - the eighth - as the Manyō-sh $\bar{u}$, belongs the Kwaifü-sō, a volume containing 120 poems in Chinese style, composed by sixty-four poets during the reigns of Temmu, Jito, and Mommu, that is to say, 
between 673 and 707. Here again the compiler's name is unknown, but the date of compilation is clear, November, 751.

From the fact that, while bequeathing to posterity only two national histories and a few provincial records (the $F \bar{u} d o-k i$ ), the Nara epoch has left two anthologies, it will be inferred readily that the writing of poetry was a favourite pursuit in that age. Such, indeed, was the case. The taste developed almost into a mania. Guests bidden to a banquet were furnished with writing materials and invited to spend hours composing versicles on themes set by their hosts. But skill in writing verse was not merely a social gift; it came near to being a test of fitness for office.

"0) "In their poetry above everything the Japanese have remained impervious to alien influences. It owes this conservation to its prosody. Without rhyme, without variety of metre, without elasticity of dimensions, it is also without known counterpart. To alter it in any way would be to deprive it of all distinguishing characteristics. At some remote date a Japanese maker of songs seems to have discovered that a peculiar and very fascinating rhythm is produced by lines containing 5 syllables and 7 syllables alternately. That is Japanese poetry (uta or tanka). There are generally five lines: the first and third consisting of 5 syllables, the second, fourth and fifth of 7, making a total of 31 in all. The number of lines is not compulsory: sometimes they may reach to thirty, forty or even more, but the alternation of 5 and 7 syllables is compulsory. The most attenuated form of all is the hokku (or haikai) which consists of only three lines, namely, 17 syllables. Necessarily the ideas embodied in such a narrow vehicle must be fragmentary. Thus it results that Japanese poems are, for the most part, impressionist; they suggest a great deal more than they actually express: Here is an example:-

\title{
Momiji-ha wo \\ Kaze ni makasete \\ Miru yori mo \\ Hakanaki mono wa \\ Inochi nari keri
}

This may be translated:-

More fleeting than the glint of withered leaf wind-blown, the thing called life." ?

The sketchy nature of Japanese poetry, especially in this five-line stanza, may be illustrated further by two poems quoted by Prof. B. H. Chamberlain in his Things Japanese (pp. 375-376),

The first:

\author{
Hototogisu \\ Nakitsuru kata wo \\ Nagamureba- \\ Tada ari-ake no \\ Tsuki zo nokoreru
}

is literally translated by Professor Chamberlain as follows:

"When I gaze towards the place where the cuckoo has been singing, nought remains but the moon in the early dawn."

And the conventional and pictorial character of the literary form is illustrated again in the lines:

[ ${ }^{1}$ See Encyclopaèdia Britannica, 11th Edition, article "Japan."] 


\section{Shira-kumo ni \\ Hane uchi-kawashi \\ Tobu kari no- \\ Kazu sae miyuru \\ Aki no yo no tsuki!}

which the same eminent scholar translates: "The moon on an autumn night making visible the very number of the wild-geese that fly past with wings intercrossed in the white clouds." It is to be noted that this last is; to Occidental notions, a mere poetic phrase and not a unit.

Of course, the very exigencies of the case make the three-line stanza (or hokku), containing only 17 syllables, even more sketchy - hardly: more indeed than a tour de force composed of a limited number of brush strokes! The Western critic, with his totally different literary conventions, has difficulty in bringing himself to regard Japanese verse as a literary form or in thinking of it otherwise than as an exercise in ingenuity, an Oriental puzzle; and this notion is heightened by the prevalence of the couplet-composing contests, which did much to heighten the artificiality of the genre.

\section{RELATIONS BETWEEN THE SEXES}

There was probably no more shocking sexual vice or irregularity in the Nara epoch than there had been before nor than there was afterwards. The only evidence adduced to prove that there was anything of the sort is the fact that laws were promulgated looking to the restraint of illicit intercourse: These laws seem to have accomplished little or nothing and the existence of the laws argues rather a growing sense of the seriousness of the evil than any sudden increase in the prevalence of the evil itself. There can be no question, however, of the wide diffusion of concubinage in this period. Not morals nor repute nor public opinion, but the wealth and wishes of each man limited him in his amours of this sort. The essential of a virtuous woman was that she be faithful to her husband or lover; no such faithfulness was expected of him. And neither in the case of man nor woman did the conventions of the period depend at all on the nature of the relationship between the two. Wives no longer lived in their fathers' homes after marriage, but the newly-wedded husband built new rooms for his wife's especial use, so that, by a fiction such as the Oriental delights in and Occillental law is not entirely ignorant of, her home was still not his. Before betrothal, girls were not allowed to call themselves by a family name. At the betrothal her affianeed first bound up in a fillet the hair that she had formerly worn loose around her face. Even more symbolical was the custom upon lovers' parting of tying to the woman's undergarment a string from the man's; this knot was to be unloosed only when they met again.

\section{THE SHŌSŌ-IN}

At Nara, in Yamato province, near the temple of Tōdai-ji, a store house built of wood and called the Shōsō-in was constructed in the Nara epoch $/$ and it still stands housing a remarkable collection of furniture and ornaments from the Imperial palace. There is some question whether this collection is truly typical of the period, or even of the palace of the period; but the presence of many utensils from China, some from India (often with traces of Greek influence), 
and a few from Persia certainly shows the degree of cosmopolitan culture and elegance there was in the palace at Nara. At the present day, strangers may visit the collection only by special permission and only on two days each year; and the museum has always had a mingled imperial and sacred character. When the power of the shogunate was at its height, the Shöso-in was never opened except by orders of the Emperor. Among the contents of this museum are: polished mirrors with repoussé backs, kept in cases lined with brocaded silk;

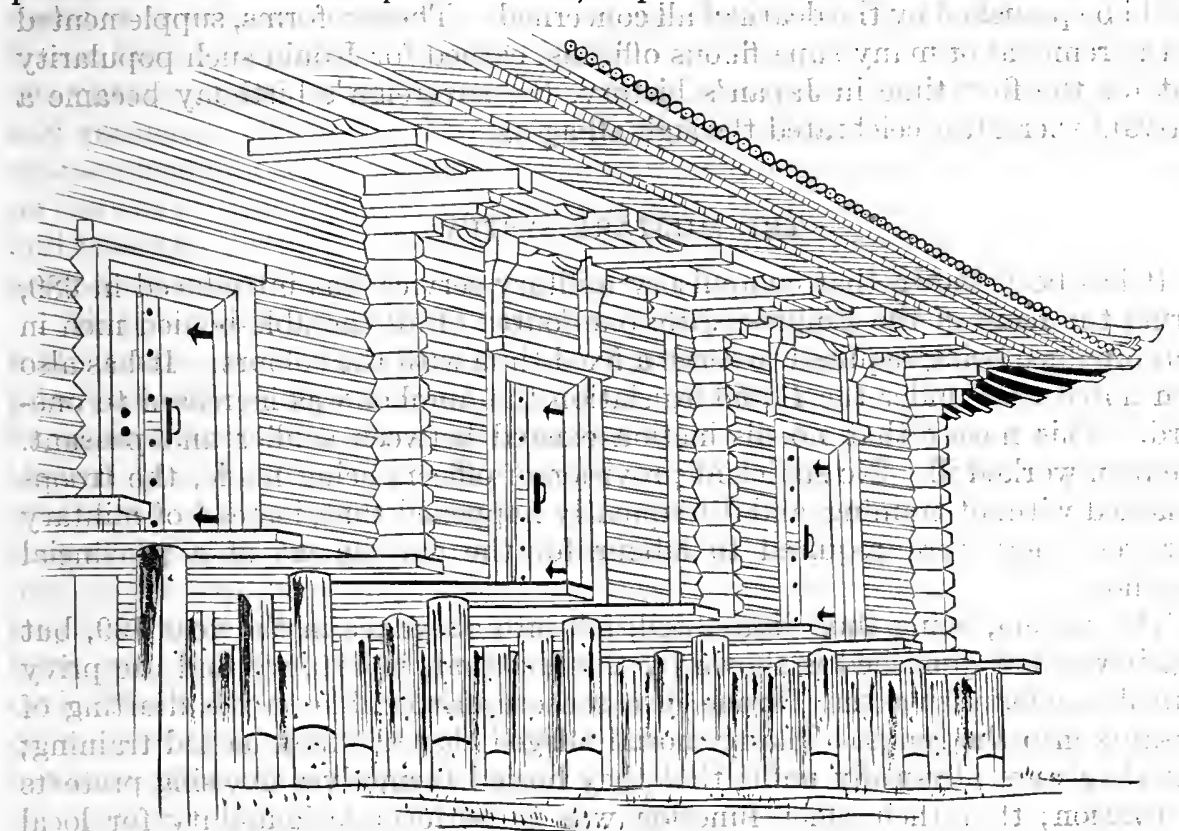

OUtuine Sketch of THe Shōsō-in at Nara

bronze vases; bronze censers; incense-boxes made of Paulownia wood or of Chinese ware; two-edged swords, which were tied to the girdle, instead of being thrust through it; narrow leather belts with silver or jade decoration; bamboo flutes; lacquer writing-cases, etc.

\section{REFORM OF LOCAL ADMINISTRATIONS}

To the Emperor Kōnin belongs the credit of correcting some flagrant abuses in provincial administration. There was an inconvenient outcome of the religious mania which pervaded the upper classes during the reigns of Shōmu and Kōken. To meet the expense of building temples and casting images, men of substance in the provinces were urged to make contributions of money, cereals, or land, and in return for this liberality they were granted official posts. It resulted that no less than thirty-one supernumerary provincial governors were borne on the roll at one time, and since all these regarded office as a means of recouping the cost of nomination, taxpayers and persons liable to the corvée fared ill. In 774, Kōken issued an edict that provincial governors who had held office for five years or upwards should be dismissed at once, those of shorter terms being allowed to complete five years and then removed.

Another evil, inaugurated during the reign of Shōmu, when faith in the potency 
of supernatural influences obsessed men's minds, was severely dealt with by Kōnin. Office-seckers resorted to the device of contriving conflagrations of official property, rewarding the incendiaries with the plunder, and circulating rumours that these calamities were visitations of heaven to punish the malpractices of the provincial governors in whose jurisdictions they occurred. It is on record that, in several cases, these stories, led to the dismissal of governors and their replacement by their traducers. Konin decreed that such crimes should be punished by the death of all concerned. These reforms, supplemented by the removal of many superfluous officials, earned for Kōnin such popularity that for the first time in Japan's history, the sovereign's birthday became a festival, ${ }^{1}$ thereafter celebrated through all ages.

\section{THE MILITARY SYSTEM}

It has been shown that compulsory military service was introduced in 689 , during the reign of the Empress Jitō, one-fourth of all the able-bodied men in each province being required to serve a fixed time with the colours. It has also been noted that under the Daiho legislation the number was increased to onethird. This meant that no distinction existed between soldier and peasant. The plan worked ill. No sufficient provision of officers being made, the troops remained without training, and it frequently happened that, instead of military exercises, they were required to labour for the enrichment of a provincial governor.

The system, being thus discredited, fell into abeyance in the year 739, but that it was not abolished is shown by the fact that, in 780 , we find the privy council memorializing the Throne in a sense unfavourable to the drafting of peasants into the ranks. The memorial alleged that the men lacked training; that they were physically unfit; that they busied themselves devising pretexts for evasion; that their chief function was to perform fatigue-duty for local governors, and that to send such men into the field of battle would be to throw away their lives fruitlessly. The council recommended that indiscriminate conscription of peasants should be replaced by a system of selection, the choice being limited to men with some previous training; that the number taken should' be in proportion to the size of the province, and that those not physically robust should be left to till the land. These recommendations were approved: They constituted the first step towards complete abolishment of compulsory service and towards the glorifying of the profession of arms above that of agriculture. Experience quickly proved, however, that some more efficient management was necessary in the maritime provinces, and in 792, Kwammu being then on the throne, an edict abolished the provincial troops in all regions except those which, by their proximity to the continent of Asia, were exposed to danger, namely, Dazai-fu in Kyūshū, and in Mutsu, Dewa, and Sado in the north. Some specially organized force was needed also for extraordinary service and for guarding official storehouses, offices, and places where post-bells (suzu) were kept. To that end the system previously practised during the reign of Shomu (724-749) was reverted to; that is to say, the most robust among the sons and younger brothers of provincial governors and local officials were enrolled in corps of strength varying with the duties to be performed. These were called kondei or kenji. We learn from the edict that the abuse of employing soldiers' as labourers was still practised, but of course this did not apply to the kondei. 
The tendency of the time was against imposing military service on the lower classes. During the period $810-820$, the forces under the Dazai-fu jurisdiction, that is to say, in the six provinces of Chikuzen, Chikugo, Hizen, Higo, Buzen, and Bungo,, were reduced from 17,100 to 9000. Dazai-fu and Mutsu being littoral regions, the conscription system still existed there, but in Mutsu there were not only, heishi, that is to say, local militiamen of the ordinary type and kenji or kondei, but also chimpei, or guards who were required to serve at a distance from home. Small farmers, upon whom this duty devolved, had no choice but to take their wives and children with them, the family subsisting on the pittance given as rations eked out by money realized from sales of chattels and garments. Thus, on the expiration of their service they returned to their native place in a wholly destitute condition, and sometimes perished of hunger on the way. In consideration of the hardships of such a system, it was abolished, and thus the distinction between the soldier and the peasant received further accentuation.

There is no record as to the exact dimensions of Japan's standing army in the ninth century, but if we observe that troops were raised in the eight littoral provinces only - six in the south and two in the north - and in the island of Sado, and that the total number in the six southern provinces was only nine thousand, it would seem reasonable to conclude that the aggregate did not exceed thirty thousand. There were also the kondei (or kenji), but these, since they served solely as guards or for special purposes, can scarcely be counted a part of the standing army. The inference is that whatever the Yamato race may have been when it set out upon its original career of conquest, or when, in later eras, it sent great armies to the Asiatic continent, the close of the fifth cycle after the coming of Buddhism found the country reduced to a condition of comparative military weakness. As to that, however, clearer judgment may be formed in the context of the campaign - to be now spoken of - conducted by the Yamato against the Yemishi tribes throughout a great part of the eighth century and the early years of the ninth.

\section{REVOLT OF THE YEMISHI}

It has been shown that the close of the third decade of the eighth century saw the capital established at Nara amid conditions of great refinement, and saw the Court and the aristocracy absorbed in religious observances, while the provinicial governments were, in many cases, corrupt and inefficient. In the year 724, Nara received news of an event which illustrated the danger of such a state of affairs. The Yemishi of the east had risen in arms and killed Koyamaro, warden of Mutsu. At that time the term "Mutsu" represented a much wider area than the modern region of the same name: it comprised the five provinces now distinguished as Iwaki, Iwashiro, Rikuzen, Rikuchū, and Mutsu - in other words, the whole of the northeastern and northern littoral of the main island. Similarly, the provinces now called Ugo and Uzen, which form the northwestern littoral, were comprised in the single term "Dewa." Nature has separated these two regions, Mutsu and Dewa, by a formidable chain of mountains, constituting the backbone of northern Japan. Within Dewa, Mutsu, and the island of Yezo, the aboriginal Yemishi had been held since Yyamato-dake's signal campaign in the second century A.D., and though not so effectually quelled as to preclude all danger of insurrection, their potentialities caused little uneasiness to the Central Government. 
But there was no paltering with the situation which arose in 724 . Recourse was immediately had to the Fujiwara, whose position at the Imperial Court was paramount, and Umakai, grandson of the renowned Kamatari, set out at the head of thirty thousand men, lcvied from the eight Bando provinces; -by which term Sagami, Musashi, Awa, Kazusa, Shimōsa, Hitachi, Kōtsuke, and Shimotsuke were designated. The expanded system of conscription established under the Daiho code was then in force, and thus a large body of troops could easily be assembled. Umakai's army did not experience any serious resistance: But neither did it achieve anything signal. Marching by two routes, it converged on the castle of Taga, a fortress just constructed by Ōno Azumahito, the lord warden of the Eastern Marches. The plan pursued by the Yamato commanders was to build castles and barriers along the course of rivers giving access to the interior, as well as along the coast line. Taga Castle was the first of such works; and, by the year 767, the programme had been carried in Mutsu as far a's the upper reaches of the Kitakami River, ${ }^{1}$ and in Dewa as far as Akita:

History has nothing further to tell about the Yemishi until the year 774, when they again took up arms, captured one (Monō) of the Japanese forts and drove out its garrison. Again the eight Bandō provinces were ordered to send levies, and at the head of the army thus raised a Japanese general penetrated far into Mutsu and destroyed the Yemishi's chief stronghold. This success was followed by an aggressive policy on the part of the lord-warden, Ki no Hirozumi. He extended the chain of forts to Kabe in Dewa, and to Isawa in Mutsu. This was in 780. But there ensued a strong movement of reprisal on the part of the Yemishi. Led by Iharu no Atamaro, they overwhelmed Hirozumi's army, killed the lord-warden himself, and pushed on to Taga Castle, which they burned; destroying vast stores of arms and provisions. It was precisely at this time that the State council, as related above, memorialized the Throne, denouncing the incompetency of the provincial conseripts and complaining that the provincial authorities, instead of training the soldiers, used them for forced labour.: $\mathrm{T}$ The overthrow of the army in Mutsu and the destruction of Taga Castle justified this memorial.

The Court appointed Fujiwara Tsugunawa to take command of a punitive expedition, and once again Bando levies converged on the site of the dismantled castle of Taga. But beyond that point no advance was essayed, in spite of bitter reproaches from Nara.. " In summer," wrote the Emperor (Konnin), "you plead that the grass is too dry; in winter you allege that bran is too scant. You discourse adroitly but you get no nearer to the foe:" Kōnin's death followed shortly afterwards, but his successor, Kwammu, zealously undertook the pursuit of the campaign. Notice was sent (783) to the provincial authorities directing them to make preparations and to instruct the people that an armed expedition was inevitable. News had just been received of fresh outrages in Dewa. The Yemishi had completely dispersed and despoiled the inhabitants of two districts, so that it was found necessary to allot lands to them elsewhere and to erect houses for their shelter.

The Emperor said in his decree that the barbarian tribes, when pursued; fled like birds; when unmolested, gathered like ants; that the conscripts from the Bandō provinces were reported to be weak and unfit for campaigning, and that those skilled in archery and physically robust stood aloof from military service, forgetting that they all owed a common duty to their country and their sovereign.

[ ${ }^{1}$ A monument still stands on the site of the old Taga Castle. It was put up in A.D.762, and it records that the castle stood fifty miles from the island of Yezo.] 
Therefore, his Majesty directed that the sons and younger brothers of all local officials or provincial magnates should be examined with a view to the selection of those suited for military service, who should be enrolled and drilled, to the number of not less than five hundred and not more than two thousand per province according to its size. Thus, the eight Bando provinces must have furnished a force of from four to sixteen thousand men, all belonging to the aristocratic class. These formed the nucleus of the army. They were supplemented by 52,800 men, infantry and cavalry; collected from the provinces along the Eastern Sea (Tōkai) and the Eastern Mountains (Tōsan), so that the total force must have aggregated sixty thousand. The command in chief was conferred on Ki no Kosami, thirteenth in descent from the renowned Takenouchino-Sukune, who had been second in command of the Fujiwara Tsugunawa expedition nine years previously. A sword was conferred on him by the Emperor, and he received authority to act on his own discretion without seeking instructions from the Throne.

Meanwhile, the province of Mutsu had been ordered to send 35,000 koku $(175,000$ bushels) of hulled rice to Taga Castle, and the other provinces adjacent were required to store $23,000 \mathrm{koku}(115,000$ bushels) of hoshi-i (rice boiled and dried) and salt at the same place. The troops were to be massed at Taga, and all the provisions and munitions were: collected there by April, 789. These figures are suggestive of the light in which the Government regarded the affair. Kosami moved out of Taga at the appointed time and pushed northward. But with every forward movement the difficulties multiplied. Snow in those regions lies many feet deep until the end of May, and the thaw ensuing brings down from the mountains heavy floods which convert the rivers into raging torrents and the roads into quagmires. On reaching the bank of the Koromo River, forty-five miles north of Taga, the troops halted. Their delay provoked much censure in the capital where the climatic conditions do not appear to have been fully understood or the transport difficulties appreciated. Urged by the Court to push on rapidly, Kosami resumed his march in June; failed to preserve. efficient connexion between the parts of his army; had his van ambushed; fled precipitately himself, and suffered a heavy defeat, though only 2500 of his big army had come into action. His casualties were 25 killed, 245 wounded, and 1036 drowned. A truce was effected and the forces withdrew to Taga, while, as for Kosami, though he attempted to deceive the Court by a bombastic despatch, he was recalled and degraded together with all the senior officers of his army.

It would seem as though this disaster to one comparatively small section of a force aggregating from fifty to sixty thousand men need not have finally interrupted the campaign, especially when the enemy consisted of semi-civilized aborigines. The Government thought differently, however. There was no idea of abandoning the struggle, but the programme for its renewal assumed large dimensions, and events in the capital were not propitious for immediate action: The training of picked soldiers commenced at once, and the provision of arms and horses. Kosami's discomfiture took place in 789, and during the next two: years orders were issued for the manufacture of 2000 suits of leather armour and 3000 of iron armour; the making of $34,500 \mathrm{arms}$, and the preparation of 110,000 bushels of hoshi-i. To the command-in-chief the Emperor (Kwammu) appointed Saka-no-ye no Tamuramaro.

This selection illustrates a conclusion already proved by the annals, namely, that racial prejudice had no weight in ancient Japan. For Tamuramaro was a direct descendant of that Achi no Omi who, as already related, crossed from 
China during the Han dynasty and became naturalized in Japan. His father, Karitamaro, distinguished himself by reporting the Dōkyō intrigue, in the year 770 , and received the post of chief of the palace guards, in which corps his son; Tamuramaro, thereafter served. Tradition has assigned supernatural capacities to Tamuramaro, and certainly in respect of personal prowess no less than strategical talent he was highly gifted. In June, 794, he invaded Mutsu at the head of a great army and, by a series of rapidly delivered blows, effectually crushed the aborigines, taking 457 heads, 100 prisoners, and 85 horses, and destroying the strongholds of 75 tribes. Thereafter, until the year of his death (811), he effectually held in check the spirit of revolt, crushing two other insurrections - in 801 and 804 - and virtually annihilating the insurgents. He transferred the garrison headquarters from Taga to Isawa, where he erected a castle, organizing a body of four thousand militia (tonden-hei) to guard it; and in the following year (803), he built the castle of Shiba at a point still further north.

\section{NATIONALITY OF THE INSURGENTS}

Annals of historieal repute are confined to the above aceount. There is, however, one unexplained feature, which reveals itself to even a casual reader. In their early opposition to Yamato aggression, the Yemishi - or Ainu, or Yezo, by whatever name they be called - displayed no fighting qualities that could be called formidable. Yet now, in the eighth century, they suddenly show themselves men of such prowess that the task of subduing them taxes the resources of the Yamato to the fullest. Some annalists are disposed to seek an explanation of this diserepaney in climatic and topographical difficulties. Kosami, in his despatch referring to the Koromo-gawa campaign, explains that 12,440 men had to be constantly employed in transporting provisions and that the quantity carried by them in twenty-four days did not exceed eleven days' rations for the troops. The hardship of campaigning in a country where means of communication were so defective is easily conjectured, and it has also to be noted that during only a brief period in summer did the climate of Mutsu permit taking the field. But these conditions existed equally in the eras of Yamatodake and Hirafu. Whatever obstacles they presented in the eighth century must have been equally potent in the second and in the seventh.

Two explanations are offered. They are more or less conjectural. One is that the Yemishi of Mutsu were led by chieftains of Yamato origin, men who had migrated to the northeast in search of fortune or impelled by disaffection. It seems scarcely credible, however, that a fact so special would have eluded historical reference, whereas only one passing allusion is made to it and that, too, in a book not fully credible. The other explanation is that the Yemishi were in league with hordes of Tatars who had crossed from the mainland of Asia, or travelled south by the islands of Saghalien and Yezo. The main evidence in support of this theory is furnished by the names of the insurgent leaders Akuro-o, Akagashira, and Akahige. Ideographists point out that the character $a k u$ is frequently pronounced $\bar{o}$, and with that reading the name "Akuro-ō" becomes " Oro--̄," which was the term used for "Russian." As for "Akagashira", and "Akahige," they frankly signify "red head" and "red beard," common Japanese names for foreigners. In a shrine at Suzuka-yama in Ise, to which point the insurgents pushed southward before Tamuramaro took the field, there used to be preserved a box, obviously of foreign construction, said to have been left there by the "Eastern Barbarians;" and in the Tsugaru district of the modern 
Mutsu province, relics exist of an extensive fortress presenting features not Japanese, which is conjectured to have been the basis of the Tatar invaders. But all these inferences rest on little more than hypothesis.

\section{RISE OF MILITARY HOUSES}

What is certain, however, is that a collateral result of these disturbances was to discredit the great Court nobles - the Ōtomo, the Tachibana, the Ki, and the Fujiwara - as leaders of armies, and to lay the foundation of the military houses (buke) which were destined to become feudal rulers of Japan in after ages. Ki no Hirozumi, Ki no Kosami, Ōtomo Yakamochi, Fujiwara Umakai, and Fujiwara Tsugunawa having all failed, the Court was compelled to have recourse to the representatives of a Chinese immigrant family, the Saka-no-ye. By those who trace the finger of fate in earthly happenings, it has been called a dispensation that, at this particular juncture, a descendant of Achi no Omi should have been a warrior with a height of six feet nine inches, ${ }^{1}$ eyes of a falcon, a beard like plaited gold-wire, a frown that terrified wild animals, and a smile that attracted children. For such is the traditional description of Tamuramaro. Another incidental issue of the situation was that conspicuous credit for fighting qualities attached to the troops specially organized in the Bando (Kwantō) provinces with the sons and younger brothers of local officials. These became the nucleus of a military class which ultimately monopolized the profession of arms.

\section{RELATIONS WITH KOREA}

During the eighth century relations of friendship were once more established with Koma. A Manchurian tribe, migrating from the valley of the Sungali River (then called the Sumo), settled on the east of the modern province of Shengking, and was there joined by a remnant of the Koma subjects after the fall of the latter kingdom. Ultimately receiving investiture at the hands of the Tang Court, the sovereign of the colony took the name of Tsuying, King of Pohai, and his son, Wu-i, sent an envoy to Japan in 727, when Shomu was on the throne. Where the embassy embarked there is no record, but, being blown out of their course, the boats finally made the coast of Dewa, where several of the envoy's suite were killed by the Yemishi. The envoy himself reached Nara safely, and, representing his sovereign as the successor of the Koma dynasty, was hospitably received, the usual interchange of gifts taking place.

Twenty-five years later (752), another envoy arrived. The Empress Kōken then reigned at Nara, and her ministers insisted that, in the document presented by the ambassador, Pohai must distinctly occupy towards Japan the relation of vassal to suzerain, such having been the invariable custom observed by Koma in former times. The difficulty seems to have been met by substituting the name "Koma" for "Pohai," thus, by implication, admitting that the new kingdom held towards Japan the same status as that formerly held by Koma. Throughout the whole of her subsequent intercourse with the Pohai kıngdom, intercourse which, though exceedingly fitful, lasted for nearly a century and a half, Japan uniformly insisted upon the maintenance of that attitude.

$[1$ The height recorded is five feet eight inches, but as that would be a normal stature, there can be little doubt that "great" (dai) measure is referred to and that the figures indicate six feet nine inches.] 


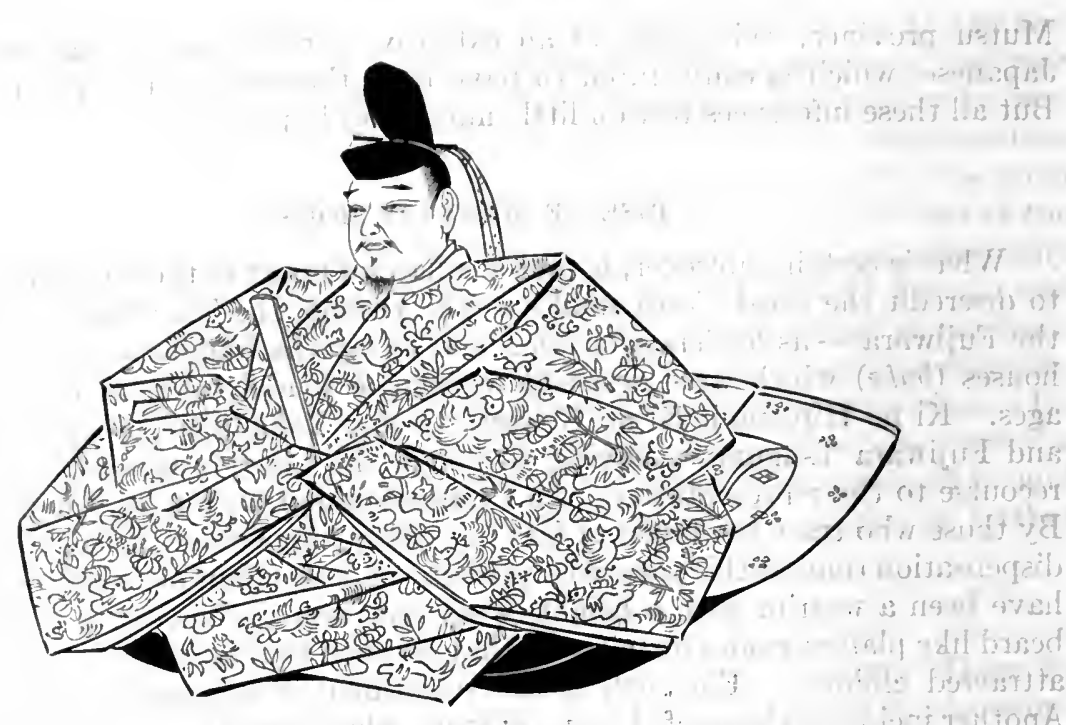

EMPEROR KWAMMO

\section{CHAPTER XVIII}

\section{THE HEIAN EPOCH}

THE FIFTIETH SOVEREIGN, THE EMPEROR KWAMMU (A.D. 782-805)

JAPANESE history divides itself readily into epochs, and among them not the least sharply defined is the period of 398 years separating the transfer of the Imperial palace from Nara to Kyōto (794) and the establishment of an administrative capital at Kamakura (1192). It is called the Heian epoch, the term "Heian-jo" (Castle of Peace) having been given to Kyōto soon after that eity became the residence of the Mikado. The first ruler in the epoch was Kwammu. This monarch, as already shown, was specially seleeted by his father, Kōnin, at the instance of Fujiwara Momokawa, who observed in the young prince qualities essential to a ruler of men. Whether Kwammu's career as Emperor reached the full standard of his promise as prinee, historians are not agreed.

Kōnm receives a larger meed of praise. His reforms of local abuses showed at once courage and zeal But he did not reach the root of the evil, nor did his son Kwammu, though in the matter of intention and ardour there was nothing to choose between the two The basic trouble was arbitrary and unjust oppression of the lower classes by the upper. These latter, probably educated in part by the be system, which tended to reduce the worker with his hands to a position of marked subservience, had learned to regard their own hereditary privileges as practically unlimited, and to conclude that well nigh any measure of forced labour was due to them from their inferiors. Kōnin could not correct this conception, and neither could Kwammu. Indeed, in the latter's case, the Throne was specially disqualified as a source of remonstrance, for the sovereign himself had to make extravagant demands upon the working classes on account of the transfer of the capital from Nara to Kyōto. Thus, although Kwammu's 
warnings and exhortations were earnest, and his dismissals and degradations of provincial officials frequent, he failed to achieve anything radical.

\section{TRANSFER OF THE CAPITAL TO KYŌTO}

The reign of Kwammu is remarkable for two things: the conquest of the eastern Yemishi-by. Tamuramaro and the transfer of the capital from Nara to Kyōto. Nara is in the province of Yamato; Kyōto, in the neighbouring province of Yamashiro, ${ }^{1}$ and the two places, lie twenty miles apart as the crow flies. It has been stated that to change the site of the capital on the accession of a sovereign was a common custom in Japan prior to the eighth century. In those early days the term "miyako," though used in the sense of "metropolis,", bore chiefly the meaning "Imperial residence," and to alter its locality did not originally suggest a national effort. But when Kwammu ascended the throne, Nara had been the capital during eight reigns, covering a period of seventy-five years, and had grown into a great city, a centre alike of religion and of trade. To transfer it involved a correspondingly signal sacrifice. What was Kwammu's motive? Some have conjectured a desire to shake off the priestly influences which permeated the atmosphere of Nara; others; that he found the Yamato eity too small to satisfy his ambitious views or to suit the quickly developing dimensions and prosperity of the nation. Probably both explanations are correct. Looking back only a few years, a ruler of Kwammu's sagacity must have appreciated that religious fanaticism, as practised at Nara, threatened to overshadow even the Imperial Court, and that the influence of the foreign creed tended to undermine the Shinto cult, which constituted the main bulwark of the Throne.

We shall presently see how this latter danger was averted at.Kyōto, and it certainly does not appear extravagant to credit Kwammu with having promoted that result. At all events, he was not tempted by the superior advantages of any other site in particular. In 784, when he adopted the resolve to found a new capital, it was necessary to determine the place by sending out a search party under his most trusted minister, Fujiwara Tanetsugu. The choice of Tanetsugu fell, not upon Kyōto, but upon Nagaoka in the same province. There was no hesitation. The Emperor trusted Tanetsugu implicitly and appointed him chief eommissioner of the building, which was commenced at once, a decree being issued that all taxes for the year should be paid at Nagaoka where also forced labourers were required to assemble and materials were collected. The Records state that the area of the site for the new palace measured 152 acres, for which the owners received compensation amounting to the equivalent of $£ 2580(\$ 12,550)$; or an average of $£ 17(\$ 82)$; per acre. The number of people employed is put at $314,000,{ }^{2}$ and the fund appropriated, at 680,000 sheaves of rice, having a value of about $£ 40,800$ ( $\$ 200,000)$ accortling to modern prices.

The palace was never finished. While it was still uncompleted, the Emperor took up his abode there, in the fall of 784, and efforts to hasten the work were redoubled. But a shocking incident occurred. The Crown Prince, Sagara, procured the elevation of a member of the Saeki family to the high post of State councillor (sangi), and having been impeached for this unprecedented act by

[ 1 Previously to becoming the metropolitan province, Yamashiro was written with ideographs signifying "behind the mountain" (yama no ushiro), but these were af terwards changed to "mountain castle" (yamashiro).]

$\left[{ }^{2}\right.$ This does not mean that 314,000 persons were employed simultaneously, but only that the number of workmen multiplied by the number of days of work equalled 314,000 .] 
Fujiwara Tanetsugu, was deprived of his title to the throne. Shortly afterwards, the Emperor repaired to Nara, and during the absence of the Court from Nagaoka, Prince Sagara compassed the assassination of Tanetsugu. Kwammu exacted stern vengeance for his favourite minister. He disgraced the prince and sent him into exile in the island of Awaji, which place he did not reach alive, as was perhaps designed.

These oceurrences moved the Emperor so profoundly that Nagaoka became intolerable to him. Gradually the work of building was abandoned; and, in 792, a new site was selected by Wake no Kiyomaro at Uda in the same province.' So many attractions were claimed for this village that failure to choose it originally becomes difficult to understand. Imperial decrees eulogized its mountains and rivers, and people recalled a prediction uttered 170 years previously

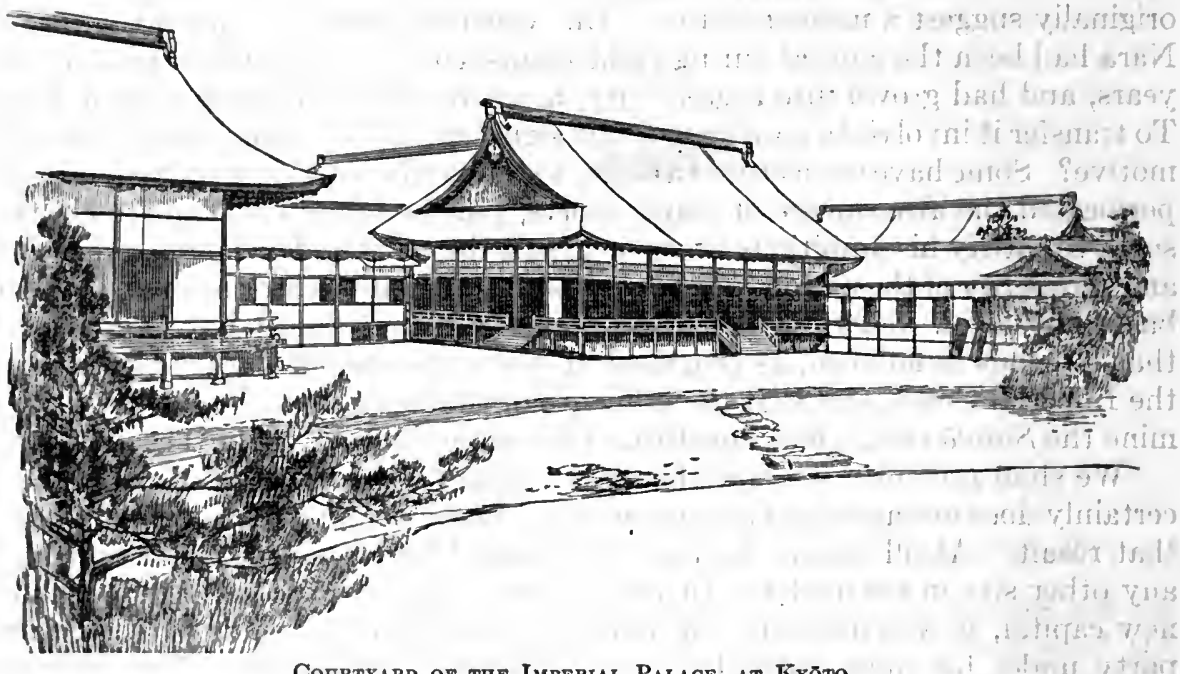

Codrtyand of the Imperial Palace; at Krōto

by Prince Shotoku that the place would ultimately be selected for the perpetual capital of the empire. The Tang metropolis, Changan, was taken for model. Commenced in April, 794, the new metropolis was finished in December, 805.

The city was laid out with mathematical exactness in the form of a rectangle, nearly three and one-half miles long, from north to south, and about three miles wide, from east to west. In each direction were nine principal thoroughfares, those running east and west crossing the north and south streets at right angles. The east and west streets were numbered from 1 to 9 , and, although the regularity of structure and plan of the city has been altered by fire and other causes. in eleven hundred years, traces of this early system of nomenelature are still found in the streets of Kyoto. ${ }^{1}$ Running north from the centre of the south side was a great avenue, two hundred and eighty feet wide, which divided the city into two parts, the castern, called "the left metropolis" (later Tōkyō, "eastern capital"), and "the right metropolis" (or Saikyo, "western capital"), - the left, as always in Japan, having precedence over the right, and the direction being taken not from the southern entrance gate but from the Imperial palace, to which this great avenue led and which was on the northern limits of the city and,

[ 1 The Kyōto of to-day is only a remnant of the ancient city; it was almost wholly destroyed by fire in the Onin war of 1467.] 
as the reader will see, at the very centre of the north wall. Grouped around the palace were government buildings of the different administrative departments and assembly and audience halls.

The main streets, which have already been mentioned as connecting the gates in opposite walls, varied in width from 80 feet to 170 feet. They divided the city into nine districts, all of the same area except the ones immediately east of the palace. The subdivisions were as formal and precise. Each of the nine districts contained four divisions. Each division was made up of four streets. A street was made up of four rows, each row containing eight "house-units." The house-unit was 50 by 100 feet. The main streets in either direction were crossed at regular intervals by lanes or minor streets, all meeting at right angles.

The Imperial citadel in the north central part of the city was 4600 feet long (from north to south) and 3840 feet wide, and was surrounded by a fence roofed with tiles and pierced with three gates on either side. The palace was roofed with green tiles of Chinese manufacture and a few private dwellings had roofs made of slate-coloured tiles, but most of them were shingled. In the earlier period, it is to be remembered, tiles were used almost exclusively for temple roofs. The architecture of the new city was in general very simple and unpretentious. The old canons of Shinto temple architecture had some influence even in this city built on a Chinese model. Whatever display or ornament there was, appeared not on the exterior but in inner rooms, especially those giving on inner court yards. That these resources were severely taxed, however, cannot be doubted, especially when we remember that the campaign against the Yemishi was simultaneously conducted. History relates that three-fifths of the national revenues were appropriated for the building.

\section{INTERCOURSE WITH CHINA AND BUDDHIST PROPAGANDISM}

The fact that the metropolis at Changan was taken for model in building Kyôto prepares us to find that intercourse with the Middle Kingdom was frequent and intimate. But although China under the Tang dynasty in the ninth century presented many industrial, artistic, and social features of an inspiring and attractive nature, her administrative methods had begun to fall into disorder, which discredited them in Japanese eyes. "We find, therefore, that although renowned religionists went from Japan during the reign of $\mathrm{K}$ wammu and familiarized themselves thoroughly with the Tang civilization, they did not, on their return, attempt to popularize the political system of China, but praised only her art, her literature,

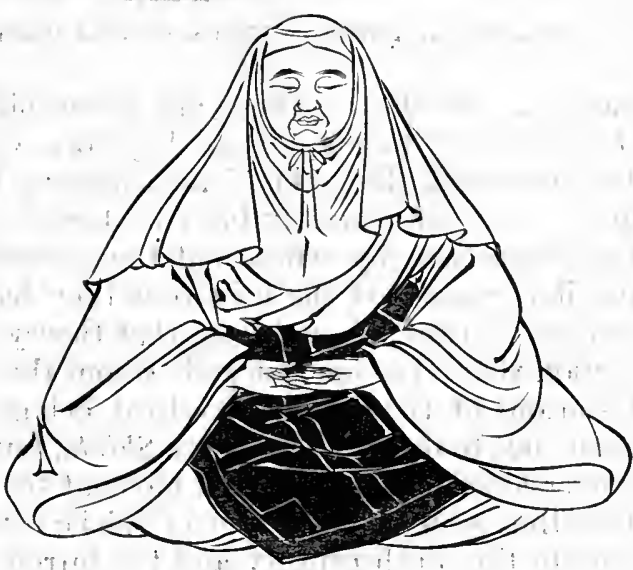

Priegt Saichō, Afterward Known as Dengyō Daishi. and certain forms and conceptions of Buddhism which they found at Changan.

The most celebrated of these religionists were Saichō and Kūkai - immortalized under their posthumous names of Dengyō Daishi and Kōbō Daishi, respect- 
ively. The former went to Changan in the train of the ambassador, Sugawara Kiyokimi, in 802, and the latter accompanied Fujiwara Kuzunomaro, two years later. Saichō was specially sent to China by his sovereign to study Buddhism, in order that, on his return, he might become lord-abbot of a monastery which his Majesty had caused to be built on Hie-no-yama - subsequently known as Hiei-zan - a hill on the northeast of the new palace in Kyōto. A Japanese superstition regarded the northeast as the "Demon's Gate," where a barrier must be erected against the ingress of evil influences. Saichō also brought from China many religious books.

Down to that time the Buddhist doctrine preached in Japan had been of a very dispiriting nature. It taught that salvation could not be reached except by efforts continued through three immeasurable periods of time. But Saichō acquired a new doctrine in China. From the monastery of Tientai (Japanese, Tendai) he carried back to Hiei-zan a creed founded on the "Lotus of the Good Law" - a creed that salvation is at once attainable by a knowledge of the

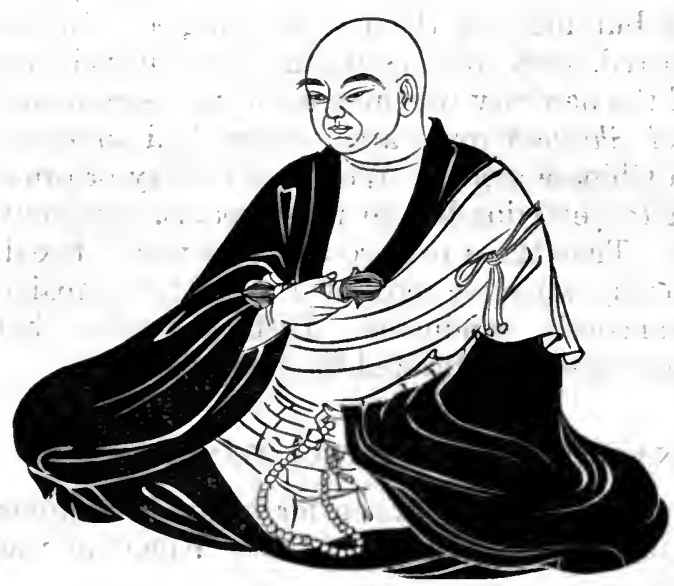

Priegt Kókai, Afterward Known as Köbō Daishi

Buddha nature, and that such knowledge may be acquired by meditation and "wisdom. That was the basic conception, but it underwent some modification at Japanese hands. "It became" a system of Japanese eclecticism, fitting the disciplinary and meditative methods of the Chinese sage to the pre-existing foundations of earlier sects." This is not the place to discuss details of religious doctrine, but the introduction of the Tendai belief has historical importance. In the first place, it illustrates a fact which may be read between the lines of all Japanese annals, namely, that the Japanese are never blind borrowers from foreign systems: their habit is "to adapt what they borrow so as to fit it to what they possess." In the second place, the Tendai system became the parent of nearly all the great seets subsequently born in Japan. In the third place, the Buddhas of Contemplation, by whose aid the meditation of absolute truth is rendered possible, suggested the idea that they had frequently been incarnated for the welfare of mankind, and from that theory it was but a short step to the conviction that "the ancient gods whom the Japanese worshipped are but manifestations of these same mystical beings, and that the Buddhist faith had come, not to destroy the native Shintō, but to embody it into a higher and more universal system. From that moment the triumph of Buddhism was secured.." It is thus seen that the visit of Saicho (Dengyo Daishi) to China at the beginning of the ninth century and the introduction of the Tendai creed into Japan constitute landmarks in Japanese history. ${ }^{2}$

[' Developments of Japanese Buddhism, by the Rev. A. Lloyd. M. A.]

['The doetrines that the Shintō deities were incarnations of the Buddhas of Contemplation (Dhyani) had already becn enunciated by Gyōgi but its general acceptance dates from the days of Dengyō Daishi. The doctrinc was called honchi-suishaku.] 


\section{KŌBŌ DAISHI}

Contemporary with and even greater in the eyes of his countrymen than Dengyō Daishi, was Kōbō Daishi (known as Kükkai during his lifetime). He, too, -visited China as a student of Buddhism; especially to learn the interpretation of a Sutra which had fallen into his hands in Japan, and on his return he founded the system of the True Word (Shingon), which has been practically identified with the Gnosticism of early Christian days. Kōbō:Daishi is the most famous of all Japanese Buddhist teachers; famous alike as a saint, as an artist, and as a calligraphist. His influence on the intellectual history of his country was marked, for he not only founded a religious system which to this day has a multitude of disciples, but he is also said to have invented, or at any rate to have materially improved, the Japanese syllabary (hira-gana).

\section{THE SUBSERVIENCE OF SHINTŌ}

That the disciples of the Shinto cult so readily endorsed a do doctrine which relegated their creed to a subordinate place has suggested various explanations, but the simplest is the most convincing, namely, that Shinto possessed no intrinsic power to assert itself in the presence of a religion like Buddhism. At no period has Shintō produced a great propagandist: No Japanese sovereign ever thought of exchanging the tumultuous life of the Throne for the quiet of

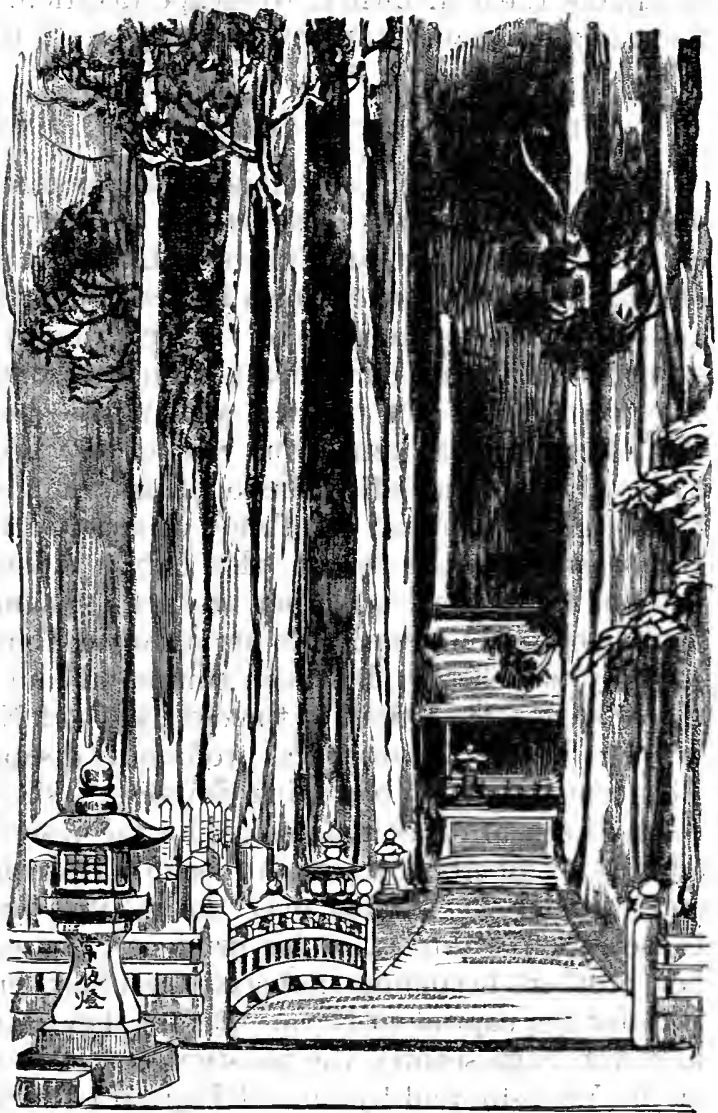

OKuno-IN (Kōbō Daishi's ShriNe) at MT. Kōyasan

a Shintō shrine, nor did Shintō ever become a vehicle for the transmission of useful knowledge.

With Buddhism, the record is very different. Many of its followers were inspired by the prospect of using it as a stepping-stone to preferment rather than as a route to Nirvana. Official posts being practically monopolized by the aristocratic classes, those born in lowlier families found little opportunity to win honour and emoluments. But by embracing a religious career, a man might aspire to become an abbot or even a tutor to a prince or sovereign. Thus, learned and clever youths flocked to the portals of the priesthood, and the Emperor Saga is said to have lamented that the Court nobility possessed few great and able men, whereas the cloisters abounded in them. On the other 
hand, it has been observed with mueh reason that as troublers of the people the Buddhist priests were not far behind the provineial governors. In faet, it fared with Buddhism as it commonly fares with all human institutions - success begot abuses. The example of Dōkyō exereised a demoralizing influence. tonsure became a means of escaping official exactions in the shape of taxes or forced labour, and the building of temples a device to acquire property and wealth as well as to evade fiseal burdens. Sometimes the Buddhist priests lent themselves to the deception of becoming nominal owners of large estates in order to enable the real owners to eseape taxation. Buddhism in Japan ultimately became a great militant power, ready at all times to appeal to force.

\section{THE FIFTY-FIRST SOVEREIGN, THE EMPEROR HEIJŌ (A.D. 806-809)}

Heijō, the fifty-first sovereign; was the eldest son of Kwammu. The latter, warned by the distress that his own great expenditures on aecount of the new capital had produced, and fully sensible of the abuses practised by the provineial officials, urged upon the Crown Prince the imperative necessity of retrenchment, and Heijo, on ascending the throne, showed much resolution in discharging superfluous officials, curtailing all unneeded outlays, and simplifying administrative procedure. But physical weakness - he was a confirmed invalid - and the influence of an ambitious woman wreeked his career. While still Crown Prince, he fixed his affections on Kusu, daughter of Fujiwara Tanetsugu, who had been assassinated by Prince Sagara during Kwammu's reign, and when Heijo ascended the throne, this lady's influence made itself felt within and without the palace, while her brother, Nakanari, a haughty, headstrong man, trading on his relationship to her, usurped almost Imperial authority.

Heijo's ill-health, however, compelled him to abdicate after a reign of only three years. He retired to the old palace at Nara, entrusting the sceptre to his brother, Saga. This step was profoundly disappointing to Kusu and her brother. The former aimed at becoming Empress - she possessed only the title of consort - and Fujiwara Nakanari looked for the post of prime minister. They persuaded the ex-Emperor tointimate a desire of reascending the throne. Saga acquiesced and would have handed over the sceptre, but at the eleventh hour, Heijō's eonscientious scruples, or his prudence, caused a delay, whereupon Kusu and her brother, becoming desperate, publicly proclaimed that Heijo wished to transfer the capital to Nara. Before they could consummate this programme, however, Saga seeured the assistance of Tamuramaro, famous as the conqueror of the Yemishi, and by his aid Fujiwara Nakanari was seized and thrown into prison, the lady Kusu being deprived of her rank as consort and condemned to be banished from Court. Heijo might have bowed to Nakanari's fate; but Kusu's sentence of degradation and exile overtaxed his patience. He raised an army and attempted to move to the eastern provinees. In Mino, his route was intercepted by a force under Tamuramaro, and the ex-Emperor's troops being shattered, no recourse offered exeept to retreat to Nara. Then the $J \bar{o}-\overline{0}$ (Heijō) took the tonsure, and his consort Kusu committed suicide. Those who had rallied to the ex-Emperor's standard were banished.

THE FIRST JAPANESE THAT ENTERED INDIA

When Heijō ceded the throne to Saga, the former's son, Takaoka, was nominated Crown Prince, though Saga had sons of his own. Evidently that step 
was taken for the purpose of averting precisely such incidents as those subsequently precipitated by the conspiracy to restore Heijo. Therefore on the day following Heijō's adoption of the tonsure, Takaoka was deprived of his rank. ${ }^{1}$ Entering the priesthood, he called himself Shinnyo, retired to Higashi-dera and studied the doctrine of the True Word (Shingon). In 836, he proceeded to. China to prosecute his religious researches, and ultimately made his way to India (in his eighty-first year), where he was killed by a tiger in the district now known as the Laos States of Siam. This prince is believed to have been the first Japanese that travelled to India. His father, the ex-Emperor Heijo, was a student of the same Buddhist doctrine (Shingon) and received instruction in it from Kūkai. Heijō died in 824, at the age of fifty-one.

\section{THE FIFTY-SECOND SOVEREIGN, THE EMPEROR SAGA (A.D. 810-823)}

It is memorable in the history of the ninth century that three brothers occupied the throne in succession, Heijō, Saga, and Junna. Heijō's abdication was certainly due in part to weak health, but his subsequent career proves that this reason was not imperative. Saga, after a most useful reign of thirteen years, stepped down frankly in favour of his younger brother. There is no valid reason to endorse the view of some historians that these acts of self-effacement were inspired by an indolent distaste for the cares of kingship. Neither Heijō nor Saga shrank from duty in any form. During his brief tenure of power the former unflinchingly effected reforms of the most distasteful kind, as the dismissal of superfluous officials and the curtailing of expenses; and the latter's reign was distinguished by much useful legislation and organization. Heijō's abdication seems to have been due to genuine solicitude for the good of the State, and Saga's to a sense of reluctance to be outdone in magnanimity. Reciprocity of moral obligation (giri) has been a canon of Japanese conduct in all ages.

\section{SANGI AND KURANDO}

One of the earliest acts of Saga's reign was to establish the office of Court councillor (sangi) definitely and to determine the number of these officials at eight. The post of sangi had been instituted more than a century previously, but its occupants had neither fixed function, rank, nor number: they merely gave fortuitous advice about political affairs. Another office, dating from the same time (810), was that of kurando (called also kurōo). This seems to have been mainly a product of the political situation. At the palace of the retired Emperor in Nara - the Inch $\bar{u}$, as it was called - the ambitious Fujiwara Nakanari and the Imperial consort, Kusu, were arrogating a large share of administrative and judicial business, and were flagrantly abusing their usurped authority. Saga did not know whom to trust. He feared that the council of State (Dajo-kwan) might include some traitors to his cause, and he therefore instituted a special office to be the depository of all secret documents, to adjudicate suits at law, to promulgate Imperial rescripts and decrees, to act as a kind of palace cabinet, and to have charge of all supplies for the Court. Ultimately this last function became the most important of the kurando's duties.

\section{KEBIISHI AND TSUIHOSHI}

It has already been explained that the Daiho legislators, at the beginning of the eighth century, having enacted a code (ryō) and a penal law (ritsu), supple- 
mented these with a body of official rules (kyaku) and operative regulations (shiki). The necessity of revising these rules and regulations was appreciated by the Emperor Kwammu, but he did not live to witness the completion of the work, which he had entrusted to the sa-daijin, Fujiwara Uchimaro, and others! The task was therefore re-approached by a committee of which the dainagon, Fujiwara Fuyutsugu, was president, under orders from the Emperor Saga. Ten volumes of the rules and forty of the regulations were issued in 819 , the former being a collection of all rescripts and decrees issued since the first year of Daiho (701), and the latter a synopsis of instruetions given by various high officials and proved by practice since the same date. Here, then, was a sufficiently precise and comprehensive body of administrative guides. But men competent to utilize them were not readily forthcoming. The provincial governors and even the metropolitan officials, chosen from among men whose qualifications were generally limited to literary ability or aristocratic influence, showed themselves incapable of dealing with the lawless conditions existing in their districts.

This state of affairs had been noticeable ever since the reign of Shomu (724749), but not until the time of Saga was a remedy devised. It took the form of organizing a body of men called kebiishi, upon whom devolved the duty of pursuing and arresting lawbreakers. At first this measure was on a small scale and of a tentative character. But its results proved so satisfactory that the system was extended from the capital to the provinces, and, in 830, a Kebiishi$c h \bar{o}$ (Board of Kebiishi) was duly formed, the number and duties of its staff being definitely fixed four years later. The importance attaching to the post of chief of this board is attested by the fact that only the emon no Kami or the hyoye no $K a i^{1}$ was eligible originally, the bushi (military men) in the hereditary service of these high dignitaries being entrusted - under the name of tsuihosh $i$ - with the duty of enforcing the law against all violators. Ultimately the judicial functions hitherto discharged by the $E f u$ (Guard Office), the Danjo-dai (Police Board) and the Gyōbu-shō (Department of Justice) were all transferred to the Kebiishi-cho, and the latter's orders ranked next to Imperial decrees.

These kebiishi and tsuiho-shi have historical importance. They represent the unequivocal beginning of the military class which was destined ultimately to impose its sway over the whole of Japan. Their institution was also a distinct step towards transferring the conduct of affairs, both military and civil, from the direct control of the sovereign to the hands of officialdom. The Emperor's power now began to cease to be initiative and to be limited to sanction or veto. The Kurando-dokoro was the precursor of the kwampaku; the Kebiishi-cho, of the sō-tsuihoshi.

\section{FUJIWARA FUYUTSUGU}

Fujiwara Fuyutsugu, who, as mentioned above, took such an important part in the legislation of his era, may be adduced as illustrating the error of the too common assertion that because the Fujiwara nobles abused their opportunities in the later centuries of the Heian epoch, the great family's services to its country were small. Fujiwara Fuyutsugu was at once a statesman, a legislator, an historian, and a soldier. Serving the State loyally and assiduously, he

$\left[{ }^{1}\right.$ Three corps of military guards formed part of the organization. The senior corps were the Imperial guards (konoe): then came the military guards (hyoye) and then the gate-guards (yemon). Each was divided into two battalions; a battalion of the Left and a battalion of the Right. Then there were the sa-konye and the $u$-konye, the sa-hyōye and the $u$-hyōye, the sa-yemon and the $u$-yemon. These six offices were known as roku-yefu, and the officer in chief command of each corps was a kami.] 
reached the rank of first minister (sa-daijin) though he died at the early age of fifty-two, and it is beyond question that to his ability must be attributed a large measure of the success achieved by his Imperial master, Saga. The story of his private life may be gathered from the fact that he established and richly endowed an asylum for the relief of his indigent relatives; a college (the Kwangaku-in) for the education of Fujiwara youths, and an uji-tera (Nanyen-dō) at Nara for soliciting heaven's blessing on all that bore his name.

\section{THE JAPANESE PEERAGE}

An interesting episode of Saga's reign was the compilation of a record of all the uji (family names). Originally the right to use a family name bad been guarded as carefully as is a title of nobility in Europe. The $u j i$ was, in truth, a hereditary title. But, as has been occasionally noted in these pages, an $u j i$ was from time to time bestowed on families of aliens, and thus, in the course of ages, confusion gradually arose. From the middle of the eighth century, efforts to compile a trustworthy record were made, and in:Kwammu's reign a genealogical bureau (kankei-jo) was actually organized, its labours resulting in a catalogue of

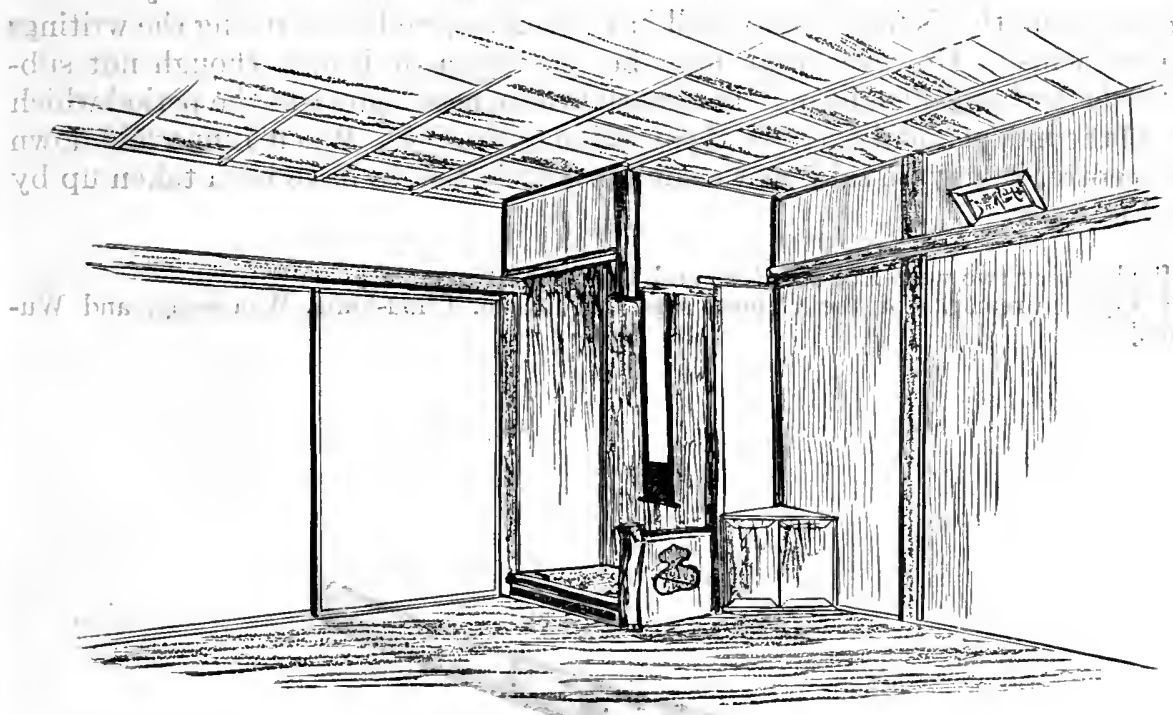

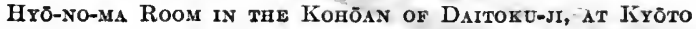

titles (seishi mokuroku). This proved defective, however, as did a subsequent effort in Heijo's time. Finally, the-Emperor Saga entrusted the task to Prince Mamta, who, with a large staff of assistants, laboured for ten years, and, in 814, produced the Seishi-roku (Record of $U j i$ ) in thirty volumes. Though not absolutely exhaustive, this great work remained a classic down to modern times. It divided into three classes the whole body of $u j i-1182$ - enrolled in its pages: namely, Kwōbetsu, or those of Imperial lineage; Shimbetsu, or those descended from the Kami, and Bambetsu, or those of alien origin (Chinese or Korean). A few who could not be clearly traced were placed in a "miscellaneous list." This paragraph of history suggests the quality of Japanese civilization in the ninth century. 
THE FIFTY-THIRD SOVEREIGN, THE EMPEROR JUNNA (A.D. 824-833)

Junna was Kwammu's third son. He ascended the throne on the abdication of his elder brother, Saga, and he himself abdicated in favour of the latter's son, Nimnyō, nine years later. Junna's reign is not remarkable for any achievemeut. No special legislation was inaugurated nor any campaign against abuses undertaken. The three brothers, Heijō, Saga, and Junna, may be said to häve devoted paramount attention to the study of Chinese literature. History refuses, however, to connect this industry with a desire for ethical instruction. Their efforts are said to have been limited to the tracing of ideographs and the composition of verselets. A perfectly formed ideograph possesses in Japanese eyes many of the qualities that commend a pictorial masterpiece to Western appreciation. Saga achieved the distinction of being reckoned among the "Three Penmen" of his era, ${ }^{1}$ and he carried his enthusiasm so far as to require that all the scions of the aristocracy should be instructed in the Chinese classies. Junna had less ability, but his admiration was not less profound for a fine specimen of script or a deftly turned couplet. It is, nevertheless, difficult to believe that these enthusiasts confined themselves to the superficialities of Chinese learning. The illustrations of altruism which they furnished by abdicating in one another's favour may well have been inspired by perusing the writings of Confucius. ${ }^{2}$ However that may be, the reign of Junna, though not subjectively distinguished, forms a landmark in Japanese history as the period which closed the independent exercise of sovereign authority. When Junna laid down the sceptre, it may be said, as we shall presently see, to have been taken up by the Fujiwara.

$[1$ The other two were Kōbō Daishi, and Tachibana Hayanari.] wang.]

[ ${ }^{2}$ Vide the remarks of the Chinese sage on Tai-pei, Chou-kung, Wen-wang, and Wu-
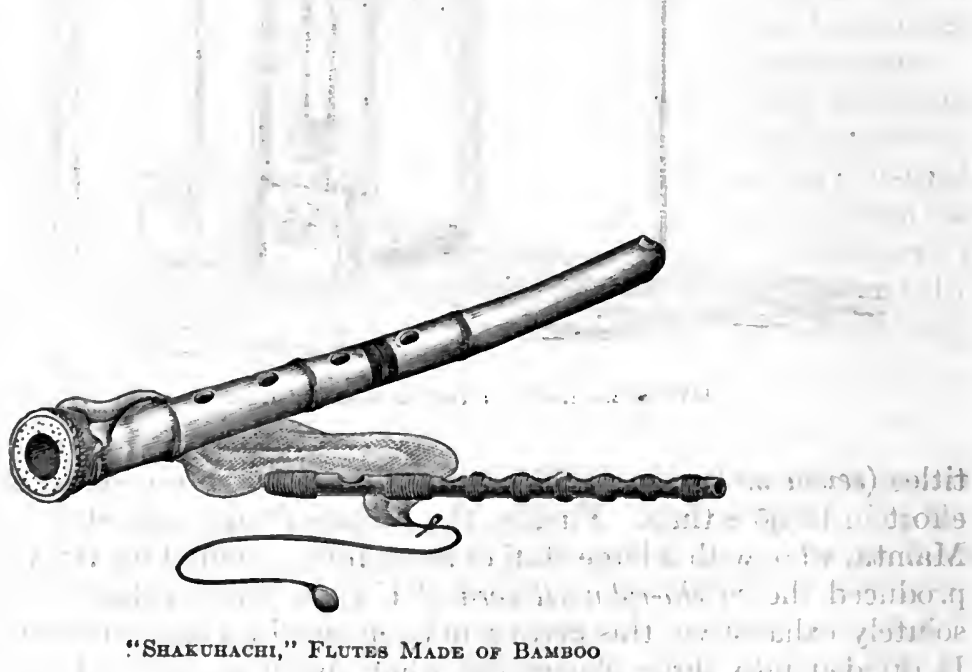

"Shaxugachi," Flutes Made of Bamboo 


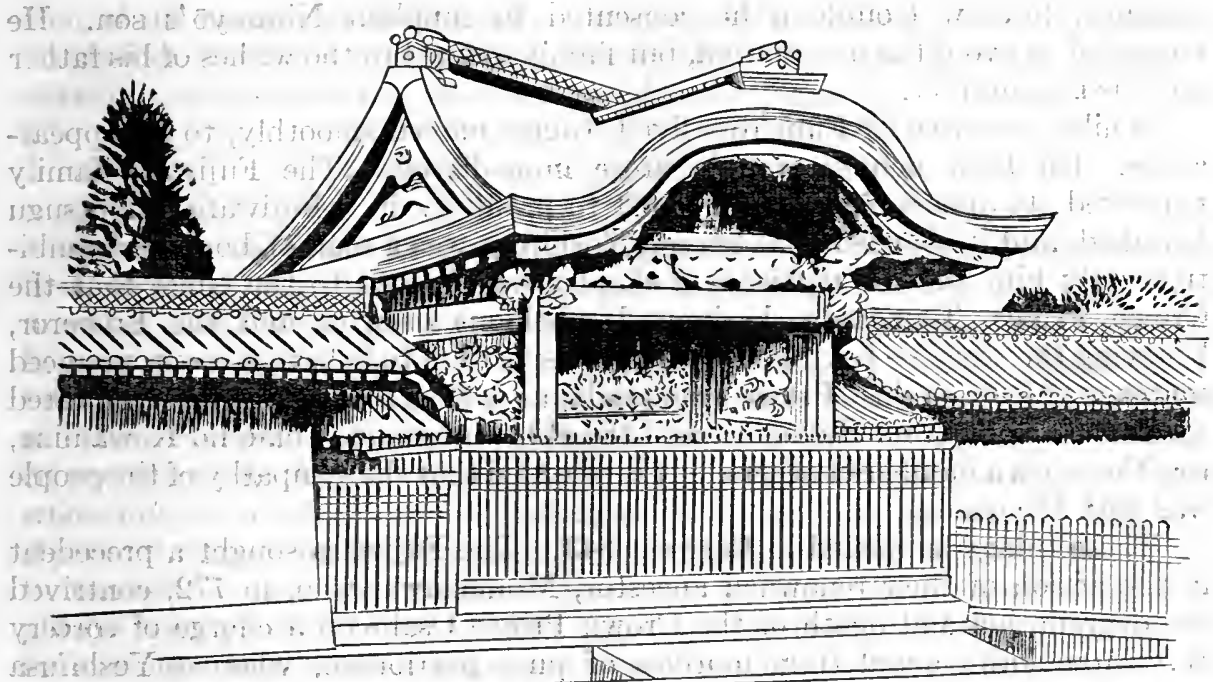

"Karamon" Gate of Nishi Hongwan-Ji Temple, at Kyōto

\section{CHAPTER XIX}

\section{THE HEIAN EPOCH (Continued)}

The 54th Sovereign, Nimmyō. ....................... $834-850$

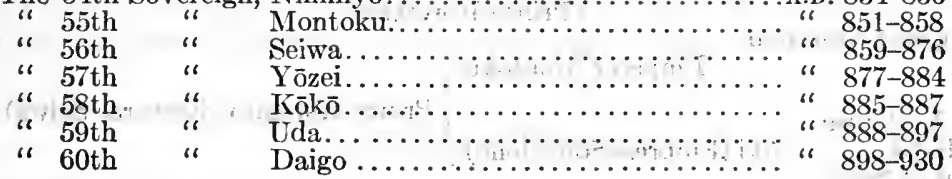

\section{BEGINNING OF FUJIWARA SUPREMACY}

THE events that now occurred require to be prefaced by a table:

$$
\text { Kwammu }\left\{\begin{array}{c}
\text { Heijō } \\
\text { Saga-Nimmyo (m. Jun, } \\
\text { daughter of Fujiwara } \\
\text { Fuyutsugu) } \\
\left.\begin{array}{c}
\text { Junna (m. Masa, } \\
\text { daughter of Saga }
\end{array}\right\} \text { Prince Tsunesada }
\end{array}\right.
$$

In the year 834, Junna abdicated in favour of his elder brother Saga's second son, who is known in history as Emperor Nimmyo. The latter was married to Jun, daughter of Fujiwara Fuyutsugu, and had a son, Prince Michiyasu. But, in consideration of the fact that Junna had handed over the sceptre to Nimmyō, Nimmyō, in turn, set aside the claim of his own son, Michiyasu, and conferred the dignity of Prince Imperial on Prince Tsunesada; 'Junna's son. A double debt of gratitude was thus paid, for Tsunesada was not only Junna's son but also Saga's grandson, and thus the abdications of Saga and Junna were both compensated. The new Prince Imperial, however, being a man of much 
sagacity, foresaw trouble if he consented to supplant Nimmyō's son. He struggled to avoid the nomination, but finally yielded to the wishes of his father and his grandfather.

While these two ex-Emperors lived, things moved smoothly, to all appearances. On their demise trouble arose immediately. The Fujiwara family perecived its opportunity and decided to profit by it. Fujiwara Fuyutsugu had died, and it chanced that his son Yoshifusa was a man of boundless ambition. By him and his partisans a slander was framed to the effect that the Crown Prince, Tsunesada, harboured rebellious designs, and the Emperor, believing the story - having, it is said, a disposition to believe it - pronounced sentence of exile against Prince Tsunesada, as well as his friends, the celebrated seholar, Tachibana no Hayanari, and the able statesman, Tomo no Kowamine, together with a number of others. It is recorded that the sympathy of the people was with the exiles.

These things happened in the year 843. The Fujiwara sought a precedent in the action of their renowned ancestor, Momokawa, who, in 772, contrived the degradation and death of the Crown Prince Osabe on a charge of sorcery But Momokawa acted from motives of pure patriotism, whereas Yoshifusa worked in the Fujiwara interests only. This, in fact, was the first step towards the transfer of administrative power from the Throne to the Fujiwara.

\section{FRESH COMPLICATIONS ABOUT THE SUCCESSION}

Another table may be consulted with advantage:-

Emperor Heijō - Prince Aho - Ariwara no Narihira )

Ki no Natora

$$
\text { Aritsune-a daughter }
$$

Emperor Montoku $\}$ Prince Koretaka

Emperor Montoku

Fujiwara Yoshifusa

$\left.\begin{array}{c}\text { Princess Kiyo } \\ \text { (daughter of Saga) }\end{array}\right\}$ Aki (Empress Somedono)

Prince Korehito (Emperor Seiwa)

In the year 851, the Emperor Montoku ascended the throne, and Fujiwara Yoshifusa was appointed minister of the Right. Yoshifusa married Prineess Kiyo, daughter of the Emperor Saga. She had been given the uji of Minamoto in order to legalize this union, and she bore to Yoshifusa a daughter who became Montoku's Empress under the name of Somedono. By her, Montoku had a son, Prince Korehito, whose chance of succeeding to the crown should have been very slender since he had three half-brothers, the oldest of whom, Prince Koretaka, had already attained his fourth year at the time of Korehito's birth, and was his father's favourite. In fact, Montoku would certainly have nominated Koretaka to be Prince Imperial had he not feared to offend the Fujiwara. These let it be seen very plainly what they designed: The baby, Korehito, was taken from the palace into Yoshifusa's mansion, and when only nine months old was nominated Crown Prince. The event enriched Japanese literature For Montoku's first born, Prince Koretaka, seeing himself deprived of his birthright, went into seclusion in Ono at the foot of Mount Hiei, and there, in the shadow of the great Tendai monastery, devoted his days to composing verselets. In that pastime he was frequently joined by Ariwara no Narihira, who, as a grandson of the Emperor Heijo, possessed a title to the succession more valid than even 
that of the disappointed Koretaka. In the celebrated Japanese anthology, the Kokin-shiu, compiled at the beginning of the tenth century, there are found several couplets from the pens of Koretaka and Narihira.

\section{THE FUJIWARA REGENCY}

It was in the days of Fujiwara Yoshifusa that the descendants of Kamatari first assumed the role of kingmakers. Yoshifusa obtained the position of minister of the Right on the accession of Montoku (851), and, six years later, he was appointed chancellor of the empire (dajo daijin) in the sequel of the intrigues which had procured for his own grandson (Korehito) the nomination of Prince Imperial. The latter, known in history as the Emperor Seiwa, ascended the throne in the year 859. He was then a child of nine, and naturally the whole duty of administration devolved upon the chancellor: This situation fell short of the Fujiwara leader's ideal in nomenclature only. There had been many "chancellors" but few "regents" (sesshō). In fact, the office of regent had always been practically confined to princes of the Blood, and the qualifications for holding it were prescribed in very high terms by the Daihō statutes. Yoshifusa did not possess any of the qualifications, but he wielded power sufficient to dispense with them, and, in the year 866, he celebrated the Emperor's attainment of his majority by having himself named sessho. The appointment carried with it a sustenance fief of three thousand houses; the privilege of being constantly attended by squadrons of the Right and Left Imperial guards, and the honour of receiving the allowances and the treatment of the Sangu, that is to say, of an Empress, a Dowager Empress, or a Grand Dowager Empress. Husband of an Empress, father of an Empress Dowager, grandfather of a reigning Emperor, chancellor of the empire, and a regent - a subject could climb no higher. Yoshifusa died in 872 at the age of sixty-eight. Having no son of his own, he adopted his nephew, Mototsune, son of Fujiwara Nagara.

\section{SEIWA'S EMPRESS}

Seiwa abdicated in 876 , at the age of twenty-seven. Some historians ascribe his abdication to a sentiment of remorse. He had aiscended the throne in despite of the superior claims of his elder brother, Koretaka, and the usurpation weighed heavily on his conscience. - It is at least credible that since, in taking the sceptre he obeyed the dictates of the Fujiwara, so in laying it down he followed the same guidance. We cannot be sure as to the exact date when the great family's policy of boy-sovereigns first took definite shape, but the annals seem to show that Yoshifusa conceived the programme and that his adopted son, Mototsune, carried it out. A halo rests on Seiwa's head for the sake of his memorable descendants', the Minamoto chiefs, Yoritomo, Takauji, and Ieyasu. Heaven is supposed to have compensated the brevity of his own tenure of power by the overwhelming share that his posterity enjoyed in the administration of the empire.

But Seiwa was undoubtedly a good man as well as a zealous sovereign. ' One episode in his career deserves attention as illustrating the customs of the era. Mention has already been made of Ariwara no Narihira, a grandson of the Emperor Heijō and one of the most renowned among Japanese poets. He was a man of singular beauty, and his literary attainments, combined with the melancholy that marked his life of ignored rights; made him a specially interest- 
ing figure. He won the love of Taka, younger sister of Fujiwara Mototsune and niece of Yoshifusa. Their liaison was not hidden. But Yoshifusa, in default of a child of his own, was just then seeking some Fujiwara maiden suitable to be the consort of the young Emperor, Seiwa, in pursuance of the newly coneeived poliey of building the Fujiwara power on the influence of the ladies'

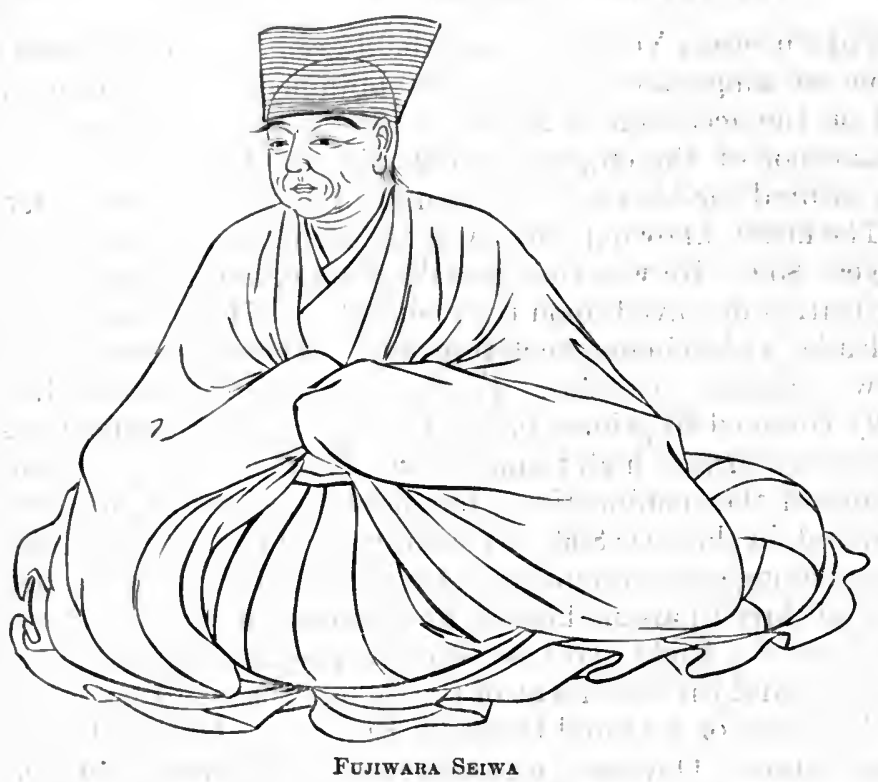

apartments in the palace. Taka possessed all the necessary qualifications. In another age the obstacle of her blemished purity must have proved fatal. Yoshifusa's audacity, however, was as limitless as his authority. $\mathrm{He}$ ordered the poet prince to cut his hair and go eastward in expiation of the crime of seeking to win Taka's affections; and having thus officially? reh a bilitated her reputation, he introduced her into the household of the Empress Dowager, his own daughter, through whose connivance the lady soon found her way to the young Emperor's chamber and became the mother of his successor, Yozzei.

Nor was this all. Though only a Fujiwara, and a soiled Fujiwara at that, Taka was subsequently raised to the rank of Empress. Ultimately, when Empress Dowager, her name was coupled with that of the priest Zenyū of Tōkō-ji, as the Empress Kōken's had been with that of Dōkyō, a hundred years previously, and she suffered deprivation of Imperial rank. As for Narihira, after a few years he was allowed to return from exile, but finding that all his hopes of preferment were vain, he abandoned himself to a life of indolence and debauchery. His name, however, will always stand next to those of Hitomaro and Akahito on the roll of Japanese poets.

\section{YŌZEI, UDA, AND THE KWAMPAKU}

The fifty-seventh sovereign was Yōzei, offspring of the Emperor Seiwa's union with the lady Taka. He ascended the throne in the year 877 , at the age of ten, and Fujiwara Mototsune - Yoshifusa had died five years previously became regent (sesshō), holding also the post of ehancellor (dajo-daijin): When Yozzei was approaching his seventeenth year he was overtaken by an illness which left him a lunatic. It is related that he behaved in an extraordinary manner. He set dogs and monkeys to fight and then slaughtered them; he fed toads to snakes, and finally compelling a man to aseend a tree, he stabbed him among the branches. The regent decided that he must be dethroned, and a couneil of 
State was convened to consider the matter. There had never been an example of an act so sacrilegious as the deposition of an Emperor at the dictate of his subjects. The ministers hesitated. Then one of the Fujiwara magnates (Morokuzu) loudly proclaimed that anyone dissenting from the chancellor's proposal would have to answer for his contumacy. Thereafter, no one hesitated - so overshadowing was the power of the Fujiwara. When carried to a special palace-thenceforth called $Y \bar{o} z e i$-in - and informed that he had been dethroned for killing a man, the young Emperor burst into a flood of tears.

- tut Nó hesitation was shown in appointing Yōzei's successor. Prince Tokiyasu, son of the Emperor Nimmyō, satisfied all the requirements. His mother, a daughter of Fujiwara Tsugunawa, was Mototsune's maternal aunt, and the Prince himself, already in his fifty-fifth year, had a son, Sadami, who was married to the daughter of Fujiwara Takafuji, a close relation to Mototsune. There can be no doubt that the latter had the whole programme in view when he proposed the dethronement of Yōzei. Shortly after his accession, Prince Tokiyasu - known in history as the Emperor Kōkō-fell ill, and at Mototsune's instance the sovereign's third son (Sadami) was nominated Prince Imperial. He succeeded to the throne as Emperor Uda on the death of his father, which occurred (887) after a reign of two years.

arrich This event saw fresh extension of the Fujiwara's power. Uda was twentytwo years of age when he received the sceptre, but recognizing that he owed his elevation to Mototsune's influence and that his prospects of a peaceful reign depended upon retaining the Fujiwara's favour, his first act was to decree that the administration should be carried on wholly by the chancellor, the latter merely reporting to the Throne. This involved the exercise of power hitherto unprecedented. To meet the situation a new office had to be created, namely, that of kwampaku. The actual duties of this post were those of regent to a sovereign who had attained his majority; whereas sessh $\bar{o}$ signified regent to a minor. Hence the kwampaku was obviously the more honourable office, since its incumbent officiated in lieu of an Emperor of mature years. Accordingly, the kwampaku - or mayor of the palace, as the term is usually translated took precedence of all other officials. A subject could rise no higher without ceasing to yield allegiance. As Mototsune was the first kwampaku, he has been called the most ambitious and the least scrupulous of the Fujiwara. But Mototsune merely stood at the pinnacle of an edifice, to the building of which many had contributed, and among those builders not a few fully deserved all they achieved. The names of such members of the Fujiwara family as Mimori, Otsugu, Yoshino, Sadanushi, Nagara, Yoshisuke, and Yasunori, who wrought and ruled in the period from Heijo and Saga to Montoku and Seiwa, might justly stand high in any record. ${ }^{1}$

\section{THE AKŌ INCIDENT}

The Emperor Uda, as already stated, owed everything to the Fujiwara. ' $\mathrm{He}$ himself did not possess even the elaim of primogeniture, since he was the third among several sons, and he had stepped out of the ranks of the Imperial princes by accepting a family name. His decree conferring administrative autocracy on Mototsune was thus a natural expression of gratitude.

Yet this very document proved a source of serious trouble. It was drafted 1868.]

['The office of Kwampaku was continued from the time of its creation, 882, to 
by Tachibana Hiromi, a ripe scholar, whose family stood as high on the aristoeratic roll as did that of the Fujiwara themselves. At that time literary attainments conferred immense prestige in Kyōto. To be skilled in calligraphy; to be well versed in the classics; to be capable of composing a sonorous decree or devising a graceful couplet - such accomplishments constituted a passport not only to high office but even to the love of women. Tachibana Hiromi was one of the leading literati of his era.; He rendered into most academieal terms the Emperor's intentions towards Mototsune. From time immemorial it has alway's been a canon of Japanese etiquette not to receive anything with avidity. Mototsune declined the rescript; the Emperor directed Hiromi to re-write it. 1u Thus far the procedure, had been normal. But Hiromi's second draft ran thus: "You have toiled for the welfare of the country. You have aided me in accordance with the late sovereign's will. You are the chief servant of the empire, not my vassal. You will henceforth discharge the duties of $a k \bar{o} . "$, This term "akō" occurs in Chinese history. It signifies "reliance on equity,"] a name given by an early Emperor to the administration of the sage, I Yin. Hiromi inserted it solely to impart a classical flavour to the decree and in all good faith.

But Fujiwara Sukeyo, a rival literatus who possessed the confidence of Mototsune, persuaded the latter that the epithet "ako" could not apply to the discharge of active duties. What followed was characteristic. : Mototsune caused a number of horses to be let loose in the city, his explanation being that, as he had no official functions to discharge, neither had he any need of horses. Naturally a number of horses running wild in the streets of the capital caused confusion which soon eame to the notice of the palace. The Emperor at once convoked a meeting of literati to discuss the matter, but these hesitated so long between their scholarly convietions and their political apprehensions that, for several months, a state of administrative anarchy prevailed, and the Emperor recorded in his diary a lament over the corruption of the age. At last, by the advice of the minister of the Left, Minamoto Tōru, his Majestylsacrificed Hiromi. A third decree: was drafted, laying the blame on Hiromi's shoulders, and Mototsune graciously consented to resume the duties of the first subject in the empire. Just forty-five years previously; Hayanari, another illustrious scholar of the Tachibana family, had been among the victims of the false charge preferred against the Crown Prinee, Tsunesada, by the Fujiwara partisans. Mototsune may well have been desirous of removing from the immediate neighbourhood of the throne the representative of a family having such a cause of umbrage against the Fujiwara.

At the same time, it is only just to note that he found ready coadjutors among the jealous schoolmen of the time. Rival colleges, rival academies, and rival literati quarrelled with all the rancour of medieval Europe. The great: luminaries of the era were Sugawara Michizane, Ki no Haseo, Koze no Fumio, Miyoshi Kiyotsura, and Tachibana Hiromi. There was little mutual recognition of talent. Kiyotsura abused Haseo as a pundit inferior to any of his predecessors. Michizane ridiculed Fumio's panegyric of Kiyotsura. The pupils of these men endorsed their teachers' verdicts. Among them all, Tachibana Hiromi oceupied the most important position until the day of his downfall. He practically managed the affairs of the Court under Yōzei, Kōkō, and Uda. Fujiwara Sukeyo, a greatly inferior scholar, served as his subordinate, and was the willing tool in contriving his degradation. It did not cause the Fujiwara any serious concern that in compassing the ruin of Hiromi, they effectually alienated the sympathies of the sovereign. 


\section{CESSATION OF EMBASSIES TO CHINA}

It may be supposed that in an era when Chinese literati attracted so much attention, visits' to the Middle Kingdom were frequent." But from the closing years of the eighth century, the great Tang dynasty began to fall into disorder, and the embassies sent from Japan reported a discouraging state of affairs. The last of these embassies (kentō-shi) was in the year 838. II It häd long'ceased to take the overland route via Liaoyang; the envoys' vessels were obliged to go by long sea, and the dangers were so great that to be named for this duty was regarded with consternation. In Uda's reign a project wàs formed to appoint Sugawara Michizane as kentō-shi, and Ki no Haseo as his lieutenant. There is reason to think that this suggestion came from Michizane's enemies who wished to remove him from a scene where his presence threatened to become embarrassing. The course Michizane adopted at this crisis showed moral courage, whatever may be thought of its expediency. He memorialized the Throne in the sense that the dangers of the journey were not compensated by its results. The memorial was approved. Since the days of the Empress Suiko, when the first kentō-shi was despatched by Prince Shōtoku, 294 years had elapsed, and by some critics the abandonment of the custom has been condemned. But it is certain that China in the ninth century had little to teach Japan in the matter of either material or moral civilization.

\section{THE AFFAIR OF THE ENGI ERA}

The Emperor Uda not only possessed great literary knowledge but.was also deeply sensible of the abuse that had grown out of the virtual usurpation of administrative authority by one family. As illustrating his desire to extend the circle of the Throne's servants and to enlist erudite men into the service of the State, it is recorded that he caused the interior of the palace to be decorated ${ }^{1}$ with portraits of renowned statesmen and literati from the annals of China. Fate seemed disposed to assist his design, for, in the year 891, the all-powerful Fujiwara Mototsune died, leaving three sons, Tokihira, Nakahira, and Tadahira; the eldest of whom was only twenty-one. During the life of Mototsune, to whom the Emperor owed everything, it would not have been politically or morally possible to contrive any radical change of system, and even after his death, the Fujiwara family's claim to the Throne's gratitude precluded any direct attempt on Uda's part to supplant them. Therefore, he formed the plan of abdicating in favour of his son, as soon as the latter should attain a suitable age - a plan inspired in some degree by his own feeble health and by a keen desire to pass the closing years of his life in comparative retirement. He carried out this design in the year 897, and was thenceforth known as Uda-in. ${ }^{2}$

His son, Daigo, who now ascended the throne, was thirteen years old; but no Fujiwara regent was appointed, Tokihira, the one person eligible in respect of lineage, being precluded by youth. Therefore the office of minister of the Left was conferred on Tokihira, and Sugawara Michizane (called also Kwankō) became minister of the Right.

It was to this Michizane that the ex-Emperor looked for material assistance in the prosecution of his design. The Sugawara family traced its descent to

[ ${ }^{1}$ It is on this occasion that we hear of Koze no Kanaoka, the first Japanese artist of great repute.]

[ ${ }^{2}$ The suffix in was now first used for the names of retired Emperors.] 
Nomi no Sukune, the champion wrestler of the last century before Christ and the originator of clay substitutes for human sacrifices at burials, though the name "Sugawara" did not belong to the family until eight hundred years later, when the Emperor Konnin bestowed it on the then representative in recognition of his great scholarship. Thenceforth, the name was borne by a suceession of renowned literati, the most erudite and the most famous of all being Michizane.

The ex-Emperor, on the accession of his thirtecn-year-old son, Daigo, handed to the latter an autograph document known in history as the Counsels of the Kuampei Era. Its gist was:. "Be just. Do not be swayed by love or hate. Study to think impartially. Control your emotion and never let it be externally

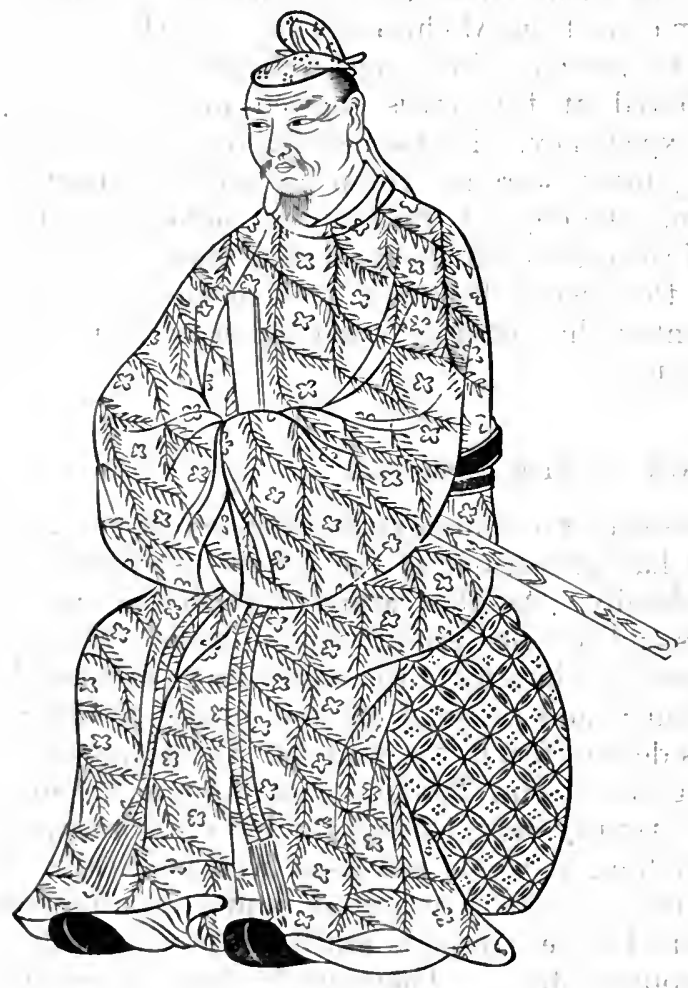

Sugawara Michrzane visible. The sa-daijin, Fujiwara Tokihira, is the descendant of meritorious servants of the Crown. Though still young, he is already well versed, in the administration of State affairs. Some years ago, he sinned with a woman, ${ }^{1}$ but I have no. longer any memory of the event. You will consult him and be guided by his counsels. The u-daijin, Sugawara Michizane, is a man of profound literary knowledge. He is also acquainted with politics. Frequently I have profited by his admonitions. When $I$ was elected Crown Prince I had but Michizane to advise me Not only has he been a loyal servant to me, but he will be a loyal servant to my successor also."

Plainly the intention of the document was to place Michizane on a footing at least equal to that of Tokihira. Michizane understood the perils of such preferment. He knew that the scion of a comparatively obscure family would not be tolerated as a rival by the Fujiwara. Three times he declined the high post offered to him. In his second refusal he compared himself to a man walking on thin ice, and in the third he said: "If I myself am astounded at my promotion, how must others regard it? The end will come like a flash of lightning." But the Emperor and the ex-Emperor had laid their plans, and Michizane was an indispensable factor.

Events moved rapidly. Two years later (900), the Emperor, in concert with the cloistered sovereign, proposed to raise Michizane to the post of chancellor and to entrust the whole administration to him. This' was the signal for the Fujiwara to take action. One opportunity for slandering Michizane offered; his daughter had been married to Prince Tokiyo, the Emperor's younger 
brother A rumour was busily circulated that this meant a plot for the dethronement of Daigo in favour of Tokiyo. Miyoshi Kiyotsura, an eminent scholar, acting subtly at the instance of the Fujiwara, addressed a seemingly friendly letter to Michizane, warning him that his career had become dangerously rapid and explaining that the stars presaged a revolution in the following year. At the same time, Minamoto Hikaru, son of the Emperor Nimmyō; Fujiwara Sadakuni, father-in-law of Dáigo, and several others who were jealous of Michizane's preferment or of his scholarship, separately or jointly memorialized the Throne, impeaching Michizane as a traitor who plotted against his sovereign.

-irf Supplemented by:Miyoshi's "friendly" notice of a star-predicated cataclysm, this cumulative evidence convinced, and doubtless the number and rank of the accusers alarmed, the Emperor, then only in his seventeenth year. : Michizane was not invited to defend himself. In the first year (901) of the Engi era, a decree went out stripping him of all his high offices, and banishing him to Daza $i f f u$ in Kyūshu as vice-governor. Many other officials were degraded as his partisans. The ex-Emperor, to whose pity he pleaded in a plaintive couplet, made a resolute attempt to aid him. His Majesty repaired to the palace for the

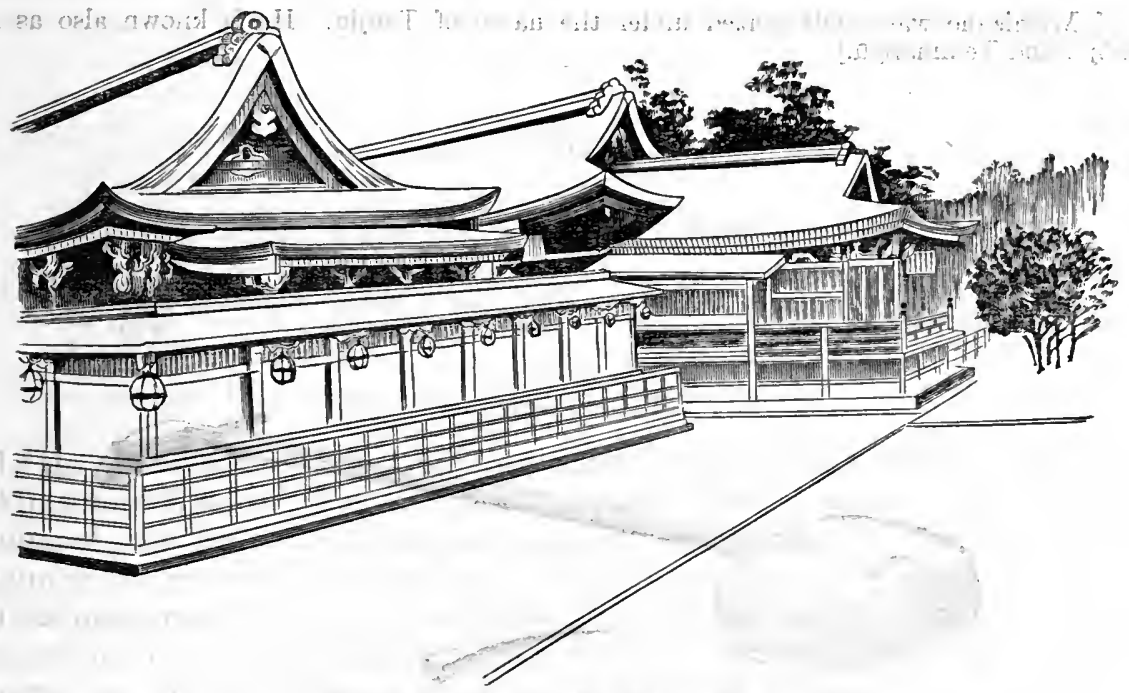

Shrine of Sugawara Mrchizane at Kitano, Kyōto

purpose of remonstrating with his son, Daigo. Had a meeting taken place, Michizane's innocence would doubtless have been established. But the Fujiwara had provided against such an obvious miscarriage of their design. The palace guards refused to admit the ex-Emperor, and, after waiting throughout a winter's day seated on a straw mat before the gate, Uda went away in the evening, sorehearted and profoundly humiliated. Michizane's twenty-three children were banished to five places, and he himself, having only a nominal post, did not receive emoluments sufficient to support him in comfort. Even oil for a night-lamp was often unprocurable, and after spending twenty-five months in voluntary confinement with only the society of his sorrows, he expired (903) at the age of fifty-eight, and was buried in the temple Anraku-ji in Chikuzen.

No figure in Japanese history has received such an abundant share of national sympathy. His unjust fate and the idea that he suffered for his sovereign appealed 
powerfully to popular imagination. Moreover; lightning struek the palace in Kyōto, and the three principal contrivers of Michizane's disgrace, Fujiwara Tokihira, Fujiwara Sugane, and Minamoto Hikaru, all expired within a few years' interval. At that epoch a wide-spread belief existed in the powers of disembodied spirits for evil or for good. Such a ereed grew logically out of the cult of ancestor worship. It began to be whispered abroad that Michizane's spirit was taking vengeance upon his enemies. The Emperor was the first to act upon this superstition. He restored Michizane's titles, raised him to the first grade of the second rank, and caused all the documents relating to his exile to be burned. . Retribution did not stop there.' Forty-fivo years after Michizane's'death, the people of Kyoto erected to his memory the shrine of Temman Tenjin, ${ }^{1}$ and in the year 1004 , the Emperor Ichijo not only conferred on him the posthumous office of chancellor with the unprecedented honour of first grade of the first rank, but also repaired in person to worship at the shrine. In later times, memorial shrines were built in various places, and to this day he is fervently worshipped as the deity of calligraphy, so high was he elevated by the Fujiwara's attempt to drag him down.

$\left[{ }^{1}\right.$ Michizane was apotheosized under the name of Tenjin. He is known also as Kan Shöjō, and Temmanga.]

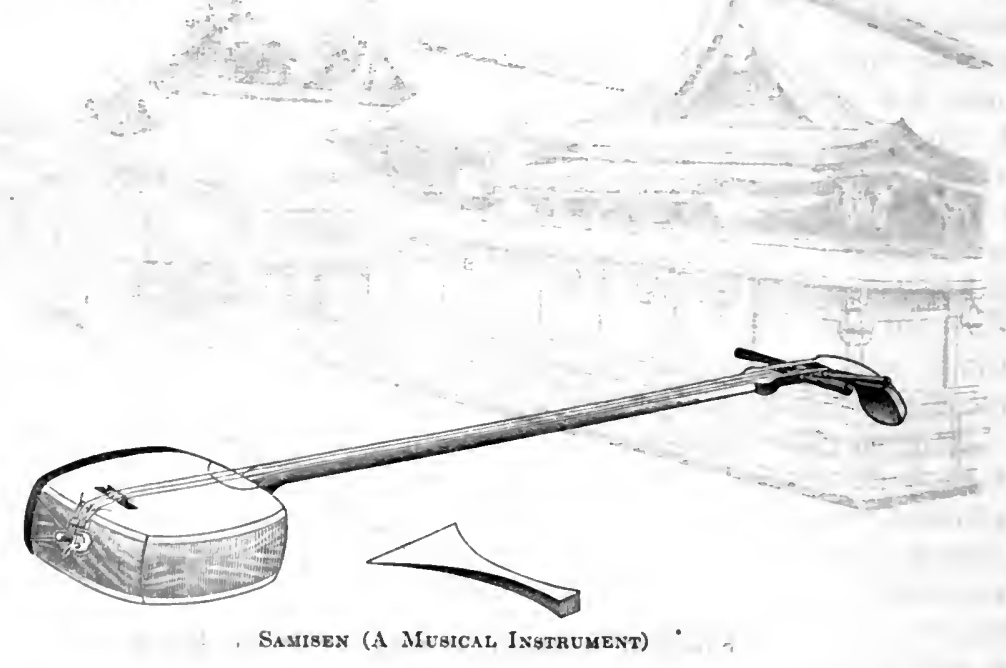




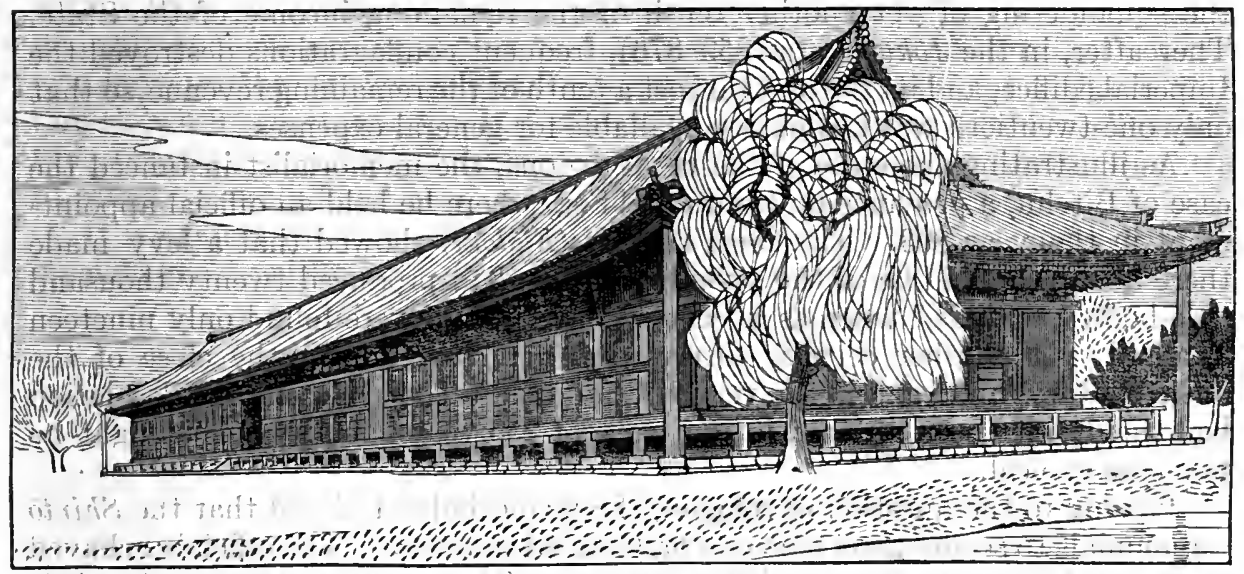

SANJÜ-SANGEN-DŌ TEMPLE AT KYŌTO

\section{CHAPTER XX}

\section{THE HEIAN EPOCH (Continued)}

The 60th Sovereign, Daigo (Continued)

" 61st “ "Emperor Shujaku.................... 931-946

THE ENGI ERA (A.D. 901-923)

In the year 909, Fujiwara Tokihira died and was followed to the grave, in 913, by Minamoto Hikaru. For an interval of some years no minister of State was nominated; the Emperor Daigo himself administered affairs. For this interregnum in the sway of the Fujiwara, the Engi era is memorable,

It is memorable for other things also; notably for the compilation of documents which throw much light on the conditions then existing in Japan. The Emperor, in 914, called upon the Court officials to submit memorials which should supply materials for administrative reforms. The great scholar, Miyoshi Kiyotsura, responded with ability so conspicuous that posterity has been disposed to question the justice of the charges against him in connexion with Michizane's fate. He set out by stating that, in the early times, the national sentiment had been kind and simple; the people loyal to the Throne and obedient to parents; the taxes moderate. But, thereafter, customs had gradually deteriorated. Laws and regulations were promulgated with bewildering rapidity. Taxes and forced labour grew heavier day by day. Cultivated lands were suffered to lie fallow. Buddhism established such a hold upon men's minds that people of all classes impoverished themselves to build places of worship and to cast images. Upon the erection of the provincial temples (Kokubun-ji) five-tenths of the national taxes were expended; and in connexion with the removal of the capital to Kyōto and the building of new palaces, a further sum of three-tenths was paid out. Again, the Emperor Nimmyō's (834-850) love of luxury and display led to architectural extravagance entirely unprecedented, and involved 
the squandering of yet another tenth of the remaining income of the State. Thereafter, in the $J \bar{o} k w a n$ era (859-876), frequent conflagrations destroyed the Imperial edifice, and its restoration cost a tenth of the remaining revenue, so that only one-twentieth was ultimately available for general expenses.

As illustrating the state of the rural regions, the memorialist instanced the case of Bitehū, a province on the Inland Sea, where he held an official appointment in the year 893 . The local records ( $F \bar{u}$ doki) showed that a levy made there about the middle of the seventh century had produced twenty thousand able-bodied soldiers, ${ }^{1}$ whereas a century later, there were found only nineteen hundred; yet another century afterwards, only seventy; at the close of the ninth century, nine, and in the year 911 , not one. To such a state of desolation had the district been reduced in the space of 250 years, and its story might be taken as typical.

Passing to the question of religion, the memorialist declared that the Shintō ceremonials to secure good harvests had lost all sincerity. The officials behaved as though there were no such thing as deities. They used the offerings for their own private purposes, sold the sacred horses, and recited the rituals without the least show of reverence. As for Buddhist priests, before asking them to pray for the welfare of their parishioners, they must be asked to purge themselves of their own sins. The priests who ministered at the provincial temples had lost all sense of shame. They had wives, built houses, cultivated lands, and engaged in trade. Was it to be supposed that heaven would hearken to the intervention of such sinners?

Meanwhile, luxury and extravagance had reached an extreme degree. On one suit of elothes a patrimony was expended, and sometimes a year's income barely sufficed for a single banquet. At funeral services all classes launched into flagrant excesses. Feasts were prepared on such a scale that the trays of viands covered the entire floor of a temple. Thousands of picces of gold were paid to the officiating priests, and a ceremony, begun in mourning, ended in revelry. Corresponding disorder existed with regard to the land. The original distribution into kubuinden, as we saw, had been partly for purposes of taxation. But now these allotments were illegally appropriated, so that they neither paid imposts nor furnished labourers; and while governors held worthless regions, wealthy magnates annexed great tracts of fertile land. Another abuse, prevalent according to Miyoshi Kiyotsura's testimony, was that accusations were falsely' preferred by officials against their seniors. Provincial governors were said to have frequently indulged in this treacherous practice and to have been themselves at times the victims of similar attacks. The Court, on receipt of such charges, seldom scrutinized them closely, but at once despatched offieers to deal with the ineriminated persons, and in the sequel, men occupying exalted positions were obliged to plead on an equal footing with officials of low grade or even common people. Self-respecting persons chose to stand aside altogether from official life rather than to encounter such risks.

This was an almost inevitable result of the exceptional facilities given to petitioners under the Daika and Daihō systems. Miyoshi Kiyotsura urged that all petitioning and all resulting inquiries by specially appointed officials should be interdicted, exeept in matters relating to political crime, and that all offenders should be handed over to the duly constituted administrators of justice. As to these latter, he spoke very plainly. The kebiishi, he wrote, who, being appointed to the various provinees, have to preserve law and order

[ ${ }^{1}$ The district was consequently named Nima, an abbreviation of ni (two) man (ten thousand).] 
within their jurisdictions, should be men specially versed in law, whereas a majority of those serving in that capacity are ignorant and incompetent persons who have purchased their offices. To illustrate further the want of discrimination shown in selecting officials, he refers to the experts appointed in the maritime provinces for manufacturing catapults, and declares that many of these so-called "experts" had never seen a catapult.

It is against the Buddhist priests and the soldiers of the six guards that he inveighs most vehemently, however. He calls them "vicious and ferocious."

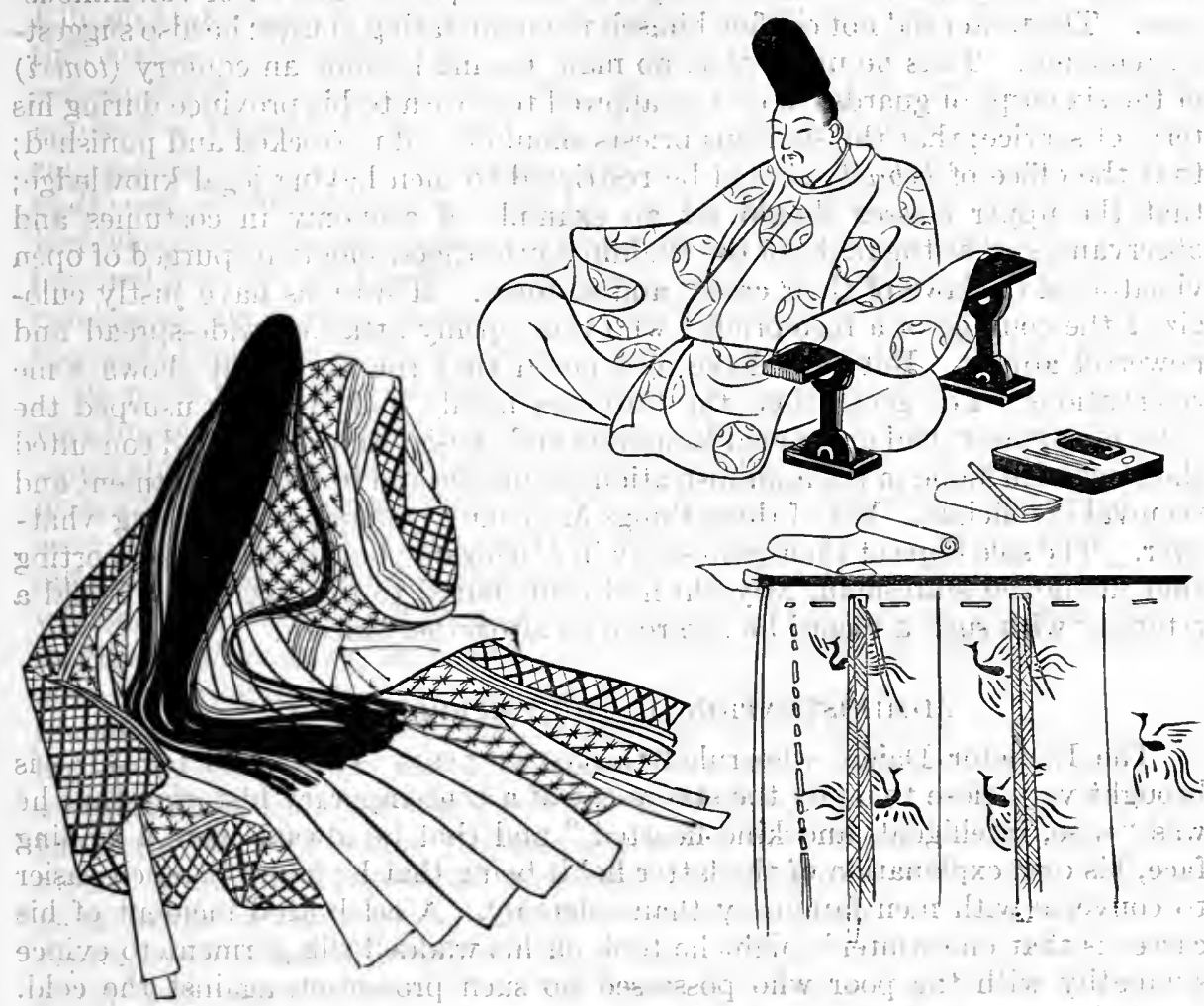

Family life of Nobles, Heian Epoch, A.D. 782-1192

Those who take the tonsure, he says, number from two to three thousand yearly; and about one-half of that total are wicked men - low fellows who, desiring to evade taxation and forced labour, have shaved their heads and donned priests vestments, aggregate two-thirds of the population. They marry, eat animal food, practise robbery, and carry on coining operations without any fear of punishment. If a provincial governor attempts to restrain them, they flock together and have recourse to violence. It was by bandits under the command of wicked priests that Fujiwara Tokiyoshi, governor of Aki, and Tachibana Kinkado, governor of Kii, were waylaid and plundered.

As for the soldiers of the guards, instead of taking their monthly term of duty at the palace, they are scattered over the country, and being strong and audacious, they treat the people violently and the provincial governors with contumacy, sometimes even forming leagues to rob the latter and escaping to the capital when they are hard pressed. (These guardsmen had arms and horses of their 
own and called themselves bushi, a term destined to have wide vogue in Japan.) It is interesting to note that they make tneir historical début thus unfavourably introduced. Miyoshi Kiyotsura says that instead! of being "metropolitan tigers" to guard the palace, they were "rural wolves" to despoil the provinces.

\section{APPRECIATIONS OF THE MIYOSHI MEMORIAL}

This celebrated document consisted of twelve articles and contained five thousand ideographs, so that nothing was wanting in the matter of voluminousness. The writer did not confine himself to enumerating abuses: he also suggested remedies. Thus he urged that no man, having become an equerry (toneri) of the six corps of guards, should be allowed to return to his province during his term of service; that the spurious priests should be all unfrocked and punished; that the office of kebiishi should be restricted to men having legal knowledge; that the upper classes should set an example of economy in costumes and observances; that the ranks of the Buddhist priesthood should be purged of open violators of the laws of their creed, and so forth. Historians have justly eulogized the courage of a memorialist who thus openly attacked wide-spread and powerful abuses. But they have also noted that the document shows some reservations. For generations the Fujiwara family had virtually usurped the governing power; had dethroned Emperors and chosen Empresses; had consulted their own will alone in the administrations of justice and in the appointment and removal of officials. Yet of these things Miyoshi Kiyotsura says nothing whatever. The sole hope of their redress lay in Michizane; but instead of supporting that ill-starred statesman, Miyoshi had contributed to his downfall. Could a reformer with such a record be regarded as altogether sincere?

\section{ADMINISTRATION OF THE EMPEROR DAIGO}

The Emperor Daigo, who ruled thirty-two years - from 898 to 930 - is brought very close to us by the statement of a contemporary historian that he was "wise, intelligent, and kind-hearted," and that he always wore a smiling face, his own explanation of the latter habit being that he found it much easier to converse with men familiarly than solemnly. A celebrated incident of his career is that one winter's night he took off his wadded silk garment to evince sympathy with the poor who possessed no such protection against the cold. Partly because of his debonair manner and charitable impulses he is popularly remembered as "the wise Emperor of the Engi era." But close readers of the annals do not fully endorse that tribute. They note that Daigo's treatment of his father, Uda, on the celebrated occasion of the latter's visit to the palace to intercede for Michizane, was markedly unfilial; that his Majesty believed and acted upon slanders which touched the honour of his father no less than that of his well-proved servant, and that he made no resolute effort to correct the abuses of his time, even when they had been clearly pointed out by Miyoshi Kiyotsura: The usurpations of the Fujiwara; the prostitution of Buddhism to evil ends; the growth of luxurious and dissipated habits, and the subordination of practical ability to pedantic scholarship - these four malignant growths upon the national life found no healing treatment at Daigo's hands.

\section{THE ClASSICAL AGE OF LITERATURE}

The Engi.era and the intervals of three or four decades before and after it may be regarded as the classical age of literature in Japan. Prose composition 
of a certain class was wholly in Chinese. All works of a historical, scientific, legal, or theological nature were in that language, and it cannot be said that they reached a very high level. Yet their authors had much honour. During the reigns of Uda and Daigo (888-930), Sugawara Michizane, Miyoshi Kiyotsura, Ki no Haseo, and Koze no Fumio, formed a quartet of famous masters of Chinese literature. From one point of view, Michizane's overthrow by Fujiwara Tokihira may be regarded as a collision between the Confucian doctrines which informed the polity of the Daika epoch and the power of aristocratic heredity. Kibi no Makibi and Sugawara no Michizane were the only two Japanese subjects that attained to be ministers of State solely in recognition of their learning, but several littérateurs reached high office, as chief chamberlain, councillor of State, minister of Education, and so forth. Miyoshi Kiyotsura ranks next to Michizane among the scholars of that age. He was profoundly versed in jurisprudence, mathematics (such as they were at the time), the Chinese classies, and history. But whereas Michizane bequeathed to posterity ten volumes of poems and two hundred volumes of a valuable historical work, no production of Kiyotsura's pen has survived except his celebrated memorial referred to above. He received the post of minister of the Household in 917 and died in the following year.

sil It must be understood that the work of these scholars appealed to only a very limited number of their countrymen. The $a k \bar{o}$ incident (pp. 239-240) illustrates this; the rescript penned by Tachibana no Hiromi was not clearly comprehended outside a narrow circle of scholars. Official notices and enactments were intelligible by few men of the trading classes and by no women. But a different record is found in the realm of high literature. Here there is much wealth: The Nara epoch gave to Japan the famous Manyō-sh $\bar{u}$ (Myriad Leaves), and the Engi era gave her the scarcely less celebrated Kokin-sh $\bar{u}$, an anthology of over eleven hundred poems, ancient and modern. As between the two books, the advantage is with the former, though not by any means in a marked degree, but in the abundance and excellence of its prose writings - pure Japanese writings apart from the Chinese works referred to above - "the Heian epoch leaves the Nara far behind. The language had now attained to its full development. With its rich system of terminations and particles it was a pliant instrument in the writer's hands, and the vocabulary was varied and copious to a degree which is astonishing when we remember that it was drawn almost exclusively from native sources. The few words of Chinese origin which it contains seem to have found their way in through the spoken language and are not taken straight from Chinese books, as at a later stage when Japanese authors loaded their periods with alien vocables."

This Heian literature "reflects the pleasure-loving and effeminate, but cultured and refined, character of the class of Japanese who produced it. It has no serious masculine qualities and may be deseribed in one word as belles-lettres poetry, fiction, diaries, and essays of a desultory kind. The lower classes of the people had no share in the literary activity of the time. Culture had not as yet penetrated beyond a very narrow circle. Both writers and readers belonged exclusively to the official caste. It is remarkable that a very large and important part of the best literature which Japan has produced was written by women. A good share of the Nara poetry is of feminine authorship, and, in the Heian period, women took a still more conspicuous part in maintaining the honour of the native literature. The two greatest works which have come down from Heian time are both by women. ${ }^{1}$ This was no doubt partly due to the absorp-

[' The Genji Monogatari by Murasaki Shikibu, and the Makura Sōshi by Sei Shōnagon:] 
tion of the masculine intellect in Chinese studies. But there was a still more effective cause. The position of women in ancient Japan was very different from what it afterwards became when Chinese ideals were in the ascendant. The Japanese of this early period did not share the feeling common to most Eastern countries that women should be kept in subjection and as far as possible
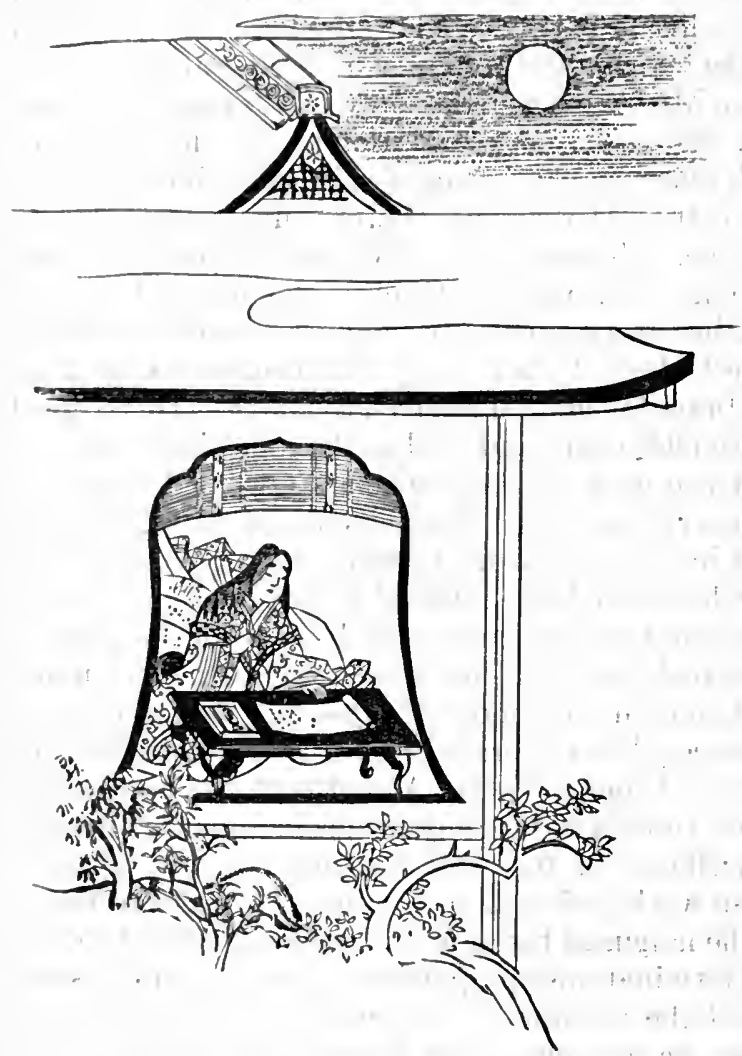

Murasaki Shikibu (Court lady and Poetegs) in seclusion. Though the morality which the Heian literature reveals is anything but strait-laced, the language is uniformly refined and decent; in this respect resembling the best literature of China:" $\mu$

With the Heian epoch is connected the wide use of the phonetic script known as kana, which may be described as a syllabary of forty-seven symbols formed from abbreviated Chinese ideographs. There are two varieties of the kana-the kata-kana and the hiragana. ${ }^{2}$ The former is said to have been devised by Makibi, the lattèr by.Kōbō Daishi (Kūkai), but doubts have been cast on the accuracy of that record; and nothing can be certainly affirmed except that both were known before the close of the ninth century, though they do not.seem to have been largely used until the Heian epoch; and even then almost entirely by women.

"Much of the poetry of this time was the outcome of poetical tournaments at which themes were proposed to the competitors by judges who examined each phrase and word with the minutest critical care before pronouncing their verdiet. As might be expected, the poetry produced in those circumstances is of a more or less artificial type, and is wanting in the spontaneous vigour of the earlier essays of the Japanese muse. Conceits, acrostics, and untranslatable word-plays hold much too prominent a place, but for perfection of form the poems of this time are unrivalled. It is no doubt to this quality that the great popularity of the Kokin-shü is due. Sei Shōnagon, writing in the carly years of the eleventh century, sums up a young lady's education as consisting of writing, music, and the twenty volumes of the Kokin-shū."'1

The first notable specimen of prose in Japanese style (wabun) was the preface

[1'Japanese Literature, by W. G. Aston.] $\left[{ }^{2}\right.$ Katakana means "side kana" because its symbols are fragments (sides) of Chinese forms
of whole ideographs.] 
to the Kokin-shu, written by $\mathrm{Ki}$ no Tsurayuki, who contended, and his own composition proved, that the introduction of Chinese words might well be dispensed with in writing Japanese. But what may be called the classical form of Japanese prose was fixed by the Taketori Monogatari, ${ }^{1}$ an anonymous work which appeared at the beginning of the Engi era (901), ${ }^{2}$ and was quickly followed by others. Still, the honour in which the ideograph was held never diminished. When Tsurayuki composed the Tosa Nikki (Tosa Diary), he gave it out as the work of a woman, so reluctant was he to identify himself with a book written in the kana syllabary; and the Emperor Saga, Kōbō Daishi, and Tachibana Hayanari will be remembered forever in Japan as the "Three Calligraphists" (Sämitsu).

1. In short, an extraordinary love of literature and of all that pertained to it swayed the minds of Japan throughout the Nara and the Heian epochs. The ninth and tenth centuries produced such poets as Ariwara no Yukihira and his younger brother, Narihira; Ōtomo no Kuronushi, Ōchikōchi no Mitsune, Sōjō Henjō, and the poetess Ono no Komachi; gave us three anthologies (Sandai-sh $\bar{u}$ ), the Kokin-shu, the Gosen-shu, and the Shüi-shu, as well as five of the Six National Histories (Roku Kokushi), the Zoku Nihonki, the Nihon Kōki, the Zoku Nihon Kōki, the Montoku Jitsuroku, and the Sandai Jitsuroku; and saw a bureau of poetry ( $W a k a-d o k o r o$ ) established in Kyōto. Fine art also was cultivated, and it is significant that calligraphy and painting were coupled together in the current expression (shogwa) for products of pictorial art. Kudara no Kawanari and Koze no Kanaoka, the first Japanese painters to achieve great renown, flourished in the ninth and tenth centuries, as did also a famous architect; Hida no Takumi.

Ifr. Al:

\section{INTERVAL BETWEEN THE CAPITAL AND THE PROVINCES}

Thus, in the capital, Kyōto, where the Fujiwara family constituted the power behind the Throne, refinements and luxury were constantly developed, and men as well as women amused themselves composing Chinese and Japanese poems, playing on musical instruments, dancing, and making picnics to view the blossoms of the four seasons. But in the provincial districts very different conditions existed. There, men, being virtually without any knowledge of the ideographic script, found the literature and the laws of the capital a sealed book to them, and as for paying periodical visits to Kyoto, what that involved may be gathered from the fact that the poet Tsurayuki's return to the capital from the province of Tosa, where he had served as acting governor, occupied one hundred days, as shown in his Tosa Nikki (Diary of a Journey from Tosa), and that thirteen days were needed to get from the mouth of the Yodo to the city. The pageant of metropolitan civilization and magnificence never presented itself to provincial eyes.

\section{ORIGIN OF THE SHŌEN}

Much has already been said on the subject of land tenure; but as this problem is responsible for some cardinal phases of Japanese history, a brief résumé will be useful here. There were four chief causes for the existence of shoen, or manors. The first was reclamation. In the year 723, it was decreed that persons

[1 The expression "monogatari" finds its nearest English equivalent in "narrative."]

$\left[^{2}\right.$ An excellent translation of this has been made by Mr. F. V. Dickins in the "Journal of the Royal Asiatic Society," Jan., 1887.] 
who reelaimed land should aequire a de facto title of tenure for three generations, and, twenty years later, the tenure of title was made perpetual, limits of area being fixed, however - 1250 acres for princes and nobles of the first rank, and thereafter by various gradations, to twenty-five acres for a commoner. But these limits were not enforced, and in the year 767 it became necessary to issue a decree prohibiting further reclamation, which was followed, seventeen years later, by a rescript forbidding provincial governors to exact forced labour for tilling their manors.

That this did not check the evil is proved by an official record, compiled in 797, from which it appears that prinees and influential nobles possessed manors of great extent; that they appointed intendants to manage them; that these intendants themselves engaged in operations of reclamation; that they abused their power by despoiling the peasants, and that dishonest farmers made a practice of evading taxes and tribute by settling within the bounds of a manor. These abuses reached their acme during the reigns of Uda and Daigo (888-930), when people living in the vicinity of a manor were ruthlessly robbed and plundered by the intendant and his servants, and when it became habitual to elude the payment of taxes by making spurious assignments of lands to influential officials in the capital. In vain was the ownership of lands by powerful nobles interdicted, and in vain its purchase by provincial governors: the metropolis had no power to enforee its vetoes in the provinces, and the provincials ignored them. Thus the shoen grew in number and extent.

The second factor which contributed to the extension of manors was the bestowal of estates in perpetuity on persons of conspicuous ability, and afterwards on men who enjoyed Imperial favour. Land thus granted was called shiden and enjoyed immunity from taxation. Then there were tracts given in recognition of publie merit. These kōden were originally of limited tenure, but that condition soon ceased to be observed, and the koden fell into the same category with manors (shöen).

Finally we have the jiden, or temple lands. These, too, were at the outset granted for fixed terms, but when Buddhism became powerful the limitation ccased to be operative, and moreover, in defiance of the law, private persons presented tracts, large or small, to the temples where the mortuary tablets of their families were preserved, and the temples, on their own account, acquired estates by purchase or by reclamation. The jiden, like the other three kinds of land enumerated above, were exempt from taxation. Owned by powerful nobles or influential families, the shōen were largely cultivated by forced labour, and as in many cases it paid the farmers better to rent such land; and thus escape all fiscal obligations, than to till their own ficlds; the latter were deserted pari passu with the development of the manor system, and thus the State revenues suffered dual reduetion.

During the last quarter of the tenth century peremptory edicts were issued to check this state of affairs, but the power of the Court to exact obedience had then dwindled almost to cipher. History records that during the $H \bar{o}$-en era (1135-1140), the regent Fujiwara 'Tadamichi's manor of Shimazu comprised one-fourth of the province of Ōsumi. On these great manors, alike of nobles and of temples, armed forces soon began to be maintained for purposes nominally of police protection but ultimately of military aggression. This was especially the case on the shoen of the puissant families of Taira and Minamoto. Thus, Minamoto Yoshitomo came to own fifteen of the eastern provinces, and in the tumult of the Heiji era (1159-1160), he lost all these to Taira no Kiyomori, who, 
supplementing them with his own already large manors and with the shoen of many other nobles and temples, became owner of five hundred districts comprising about one-half of the empire. Subsequently, when the Minamoto crushed the Taira (1185), the whole of the latter's estates were distributed by the former among the nobles who had fought under the Minamoto standard.

In that age the holders of manors were variously called ryōshu, ryōke, shôya; or honjo, and the intendants were termed shōcho, shōji, kengyō, betto, or yoryudo, a diversity of nomenclature that is often very perplexing. In many cases reclaimed lands went by the name of the person who had reclaimed them. Such manors were spoken of as myoden (name-land), and those owning large tracts were designated daimyō (great name), while smaller holders were termed shömyo. Yet another term for the intendants of these lands was nanushi-shoku.

It will be readily seen that in the presence of such a system the lands paying taxes to the Central Government became steadily less and less. Thus, in the reign of the Emperor Toba (1108-1123), the State domains administered by the provincial governors are recorded to have been only one per cent. of the area of the provinces: In these circumstances, the governors deemed it unnecessary to proceed themselves to their posts; they remained in Kyoto and despatched deputies to the provinces, a course which conspired to reduce the authority of the Crown.

For the sake of intelligent sequence of ideas, the above synopsis makes some departure from the chronological order of these pages. Returning to the early part of the tenth century, the histcrian may affirm that the salient features of the era were virtual abrogation of the Daiho laws imposing restrictions upon the area and period of land-ownership; rapid growth of tax-free manors and consequent impoverishment of the Court in Kyoto; the appearance of provincial magnates who yielded scant obedience to the Crown, and the organization of military classes which acknowledged the authority of their own leaders only.

\section{REVOLT OF TAIRA NO MASAKADO}

The above state of affairs soon bore practical fruit. In the year 930, the Emperor Daigo died and was succeeded by his son Shujaku, a child of eight, whose mother was a daughter of Fujiwara Mototsune. In accordance with the system now fully established, Fujiwara Tadahira became regent. History depicts this Tadahira as an effeminate dilettante, one of whose foibles was to have a cuckoo painted on his fan and to imitate the cry of the bird whenever he opened it. But as representative of the chief aristocratic family in an age when to be a Fujiwara was to possess a title superior to that conferred by ability in any form and however conspicuous, his right to administer the government in the capacity of regent obtained universal recognition.

It had become the custom at that time for the provincial magnates to send their sons to Kyōto, where they served in the corps of guards, became acquainted with refined life, and established relations of friendship with the Taira and the Minamoto, the former descended from the Emperor Kwammu, the latter from the Emperor Seiwa. Thus, at the time of Daigo's death, a scion of the Taira, by name Masakado, was serving under Tadahira in the capital. Believing himself endowed with high militäry eapacity, Masakado aspired to be appointed kebiishi of his native province, Shimossa But his archery, his horsemanship, and his fencing elicited no applause in Kyōto, whereas a relative, Sadabumi, attracted admiration by a licentious life. 
Masakado finally retired to Shimōsa in an angry mood. At first, however, the idea of revolt does not seem to have occurred to him. On the contrary, the evidence is against such a hypothesis. For his military career began with family feuds, and after he had killed one of his uncles on account of a dispute about the boundaries of a manor, and sacked the residence of another in consequence of a trouble about a woman, he did not hesitate to obey a summons to Kyōto to answer for his acts of violence. Such quarrels were indeed of not uncommon occurrence in the provinces, as is shown by the memorial of Miyoshi Kiyotsura, and the capital appears to have left them severely alone; so far as practical interference was concerned, though the pretence of jurisdiction might be preserved. Thus, Masakado was acquitted after the formality of investigation had been satisfied. Naturally this judgment did not prove a deterrent; on the contrary, it ammounted to a mandate.

On his return to Kwantō, Masakado was soon found once more in the arena. The details of his campaign have little interest except as indicating that the provincial officials followed the example of Kyoto in suffering local disturbances to settle themselves, and that the abuses catalogued in the Miyoshi memorial were true to fact. A raid that Masakado made into Musashi province is memorable as the occasion of the first collision betwc in the Taira and the Minamoto, which great families were destined ultimately to convert all Japan into a battlefield. Finally, Masakado carried his raids so far that he allowed himself to be persuaded of the hopelessness of pardon. It was then that he resolved to revolt. Overrunning the whole eight provinces of the Kwanto, he appointed his own partisans to all posts of importance and set up a court after the Kyōto model. A letter written by him at this time to the regent Tadahira affords an interesting guide to the ethics of the era:-

The genealogy of my house shows that I am the fifth in descent from the Emperor Kwammu. Therefore, though I hold one-half of a province, that cannot be attributed to mere good fortune. In the history of ancient times there are oecasions where a whole country was appropriated by foree of arms. Nature has endowed me with military talent. None, I presume, excels me in that respect. You, however, had no praise to bestow on me. Rather was I frequently reprimanded when. I served in the capital, so that my shame was unendurable, whereas your sympathy would have delighted me. While Masakado was still a youth he served Tadahira, the prime minister, for tens of years, and when Tadahira became regent, Masakado never entertained his present project. I have. no words to express my regret? Though I have conspired to revolt, I will not forget my old master, and I hope that he will make allowances for the cireumstanees in which I am placed.

Had it rested with Kyōto to subdue this revolt, Masakado might have attained his goal. But chance and the curious spirit of the time fought for the Court. A trifling breach of etiquette on the part of Masakado $\rightarrow$ not pausing to bind up his hair before receiving a visitor - forfeited the co-operation of a great soldier, Fujiwara Hidesato, (afterwards known as Tawara Tōda), and the latter, joining forces with Taira Sadamori, whose father Masakado had killed, attacked the rebels in a moment of elated carelessness, shattered them completely, and sent Masakado's head to the capital. The whole affair teaches that the Fujiwara aristocrats, ruling in Kyōto, had neither power nor inclination to meddle with provineial administration, and that the districts distant from the metropolis were practically under the sway of military magnates in whose eyes might constituted right. This was especially notable in the case of the Kwantō, that is to say the eight provinces surrounding the present Tōkyō Bay, extending north to the Nikko Mountains. Musashi, indeed, was so infested with law-

[ ${ }^{1}$ The vice-governor of Musashi, Minamoto Tsunemoto, was at feud with the governor, Prince Okiyo, and Masakado espoused the latter's cause.] 
breakers that, from the days of the Emperor Seiwa (859-876), it became customary to appoint one kebiishi in each of its districts; whereas elsewhere the establishment was one to each province. The kebiishi represented the really puissant arm of the law, the provincial governors, originally so powerful, having now degenerated into weaklings.

\section{THE REVOLT OF FUJIWARA SUMITOMO}

Another event, characteristic of the time, occurred in Nankai-dō (the four provinces of the island of Shikoku) contemporaneously with the revolt of Masakado. During the Shōhei era (931-937) the ravages of pirates became so frequent in those waters that Fujiwara no Sumitomo was specially despatched from Kyōto to restrain them. This he effected without difficulty. But instead of returning to the capital, he collected a number of armed men together with a squadron of vessels, and conducted a campaign of spoliation and outrage in the waters of the Inland Sea as well as the channels of Kii and Bungo. Masakado's death, in 939, relieved the Court from the pressure in the east, and an expedition was despatched against Sumitomo under the command of Ono no Yoshifuru, general of the guards.

Yoshifuru mustered only two hundred ships whereas Sumitomo had fifteen hundred. The issue might have been foretold had not the pirate chief 's lieutenant gone over to the Imperial forces. ' Sumitomo, after an obstinate resistance and after one signal success, was finally routed and killed. Some historians ${ }^{1}$ have contended that Masakado and Sumitomo, when they were together in Kyōto, conspired a simultaneous revolt in the east and the south; but such a conclusion is inconsistent with the established fact that Masakado's treason was not premeditated.

That the two events synchronized is attributable wholly to the conditions of the time. We have seen what was the state of affairs in Kwantō, and that of Kyūshū and Shikoku is clearly set forth in a memorial presented (946) by Ono Yoshifuru on his return from the Sumitomo campaign. In that document he says: "My information is that those who pursue irregular courses are not necessarily sons of provincial governors alone. Many others make lawless use of power and authority; form confederacies; engage daily in military exercises; collect and maintain men and horses under pretext of hunting game; menace the district governors; plunder the common people; violate their wives and daughters, and steal their beasts of burden and employ them for their own purposes, thus interrupting agricultural operations. Yesterday, they were outcasts, with barely sufficient clothes to cover their nakedness; to-day, they ride on horseback and don rich raiment. Meanwhile the country falls into a state of decay, and the homesteads are desolate. My appeal is that, with the exception of provincial governors' envoys, any who enter a province at the head of parties earrying bows and arrows, intimidate the inhabitants, and rob them of their property, shall be recognized as common bandits and thrown into prison on apprehension."

In a word, the aristocratic officialdom in Kyōto, headed by the Fujiwara, though holding all the high administrative posts, wielded no real power outside the capital, nor were they competent to preserve order even within its precincts, for the palace itself was not secure against incendiarism and depredation. When the heads of the Minamoto and the Taira families were appointed provincial governors in the Kwantō, they trained their servants in the use of arms, calling 
them iye-no-ko (house-boys) or rōdo (retainers), and other local magnates purchased freedom from molestation by doing homage and obeying their behests. Taira Masakado, Minamoto Tsunemoto, Fujiwara Hidesato, and Taira Sadamori, who figure in the above narrative, were all alike provincial chiefs, possessing private estates and keeping armed retinues which they used for protection or for plunder. The Imperial Court, when confronted with any crisis, was constrained to borrow the aid of these magnates, and thus there came into existence the buke, or military houses, as distinguished from the kuge, or Court houses.

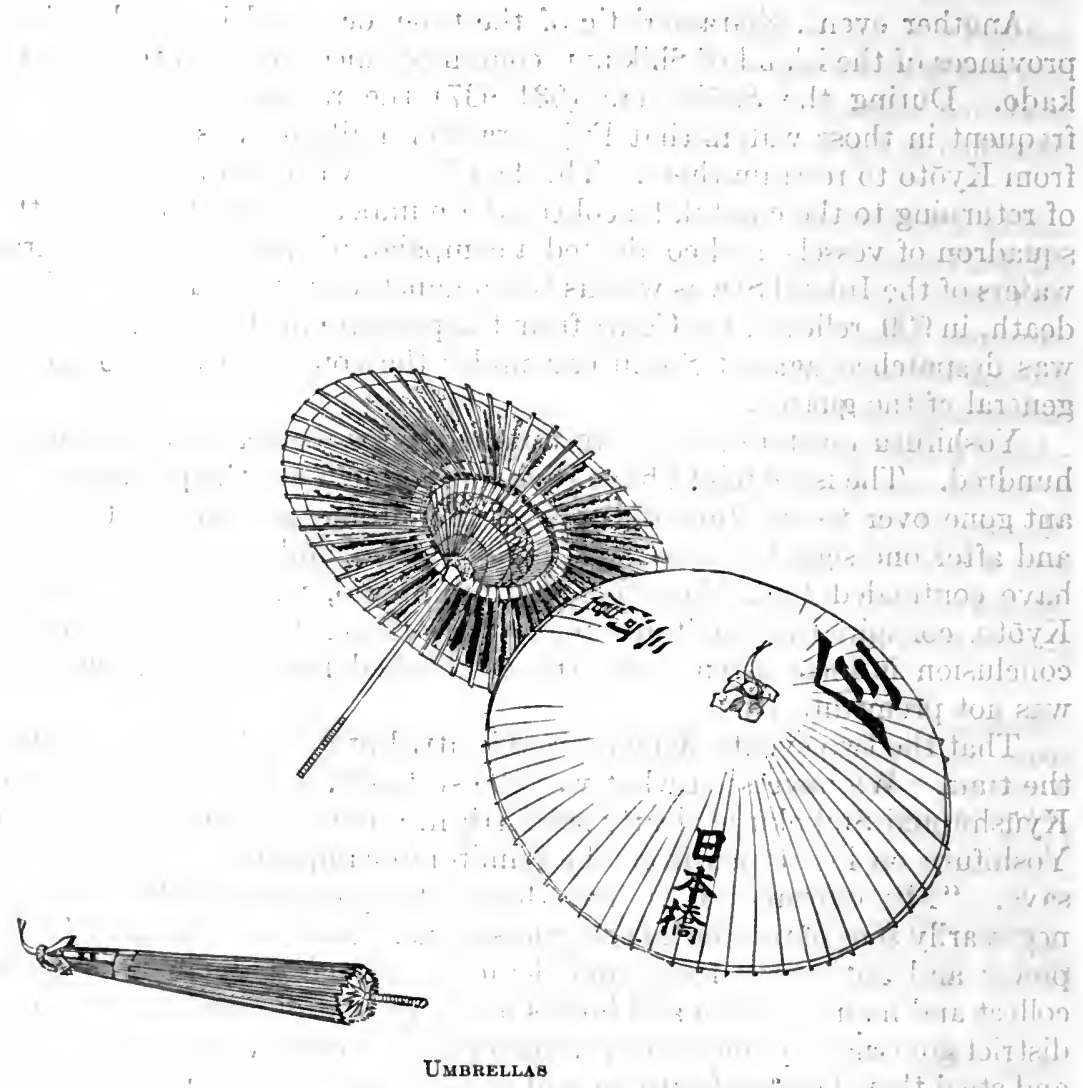




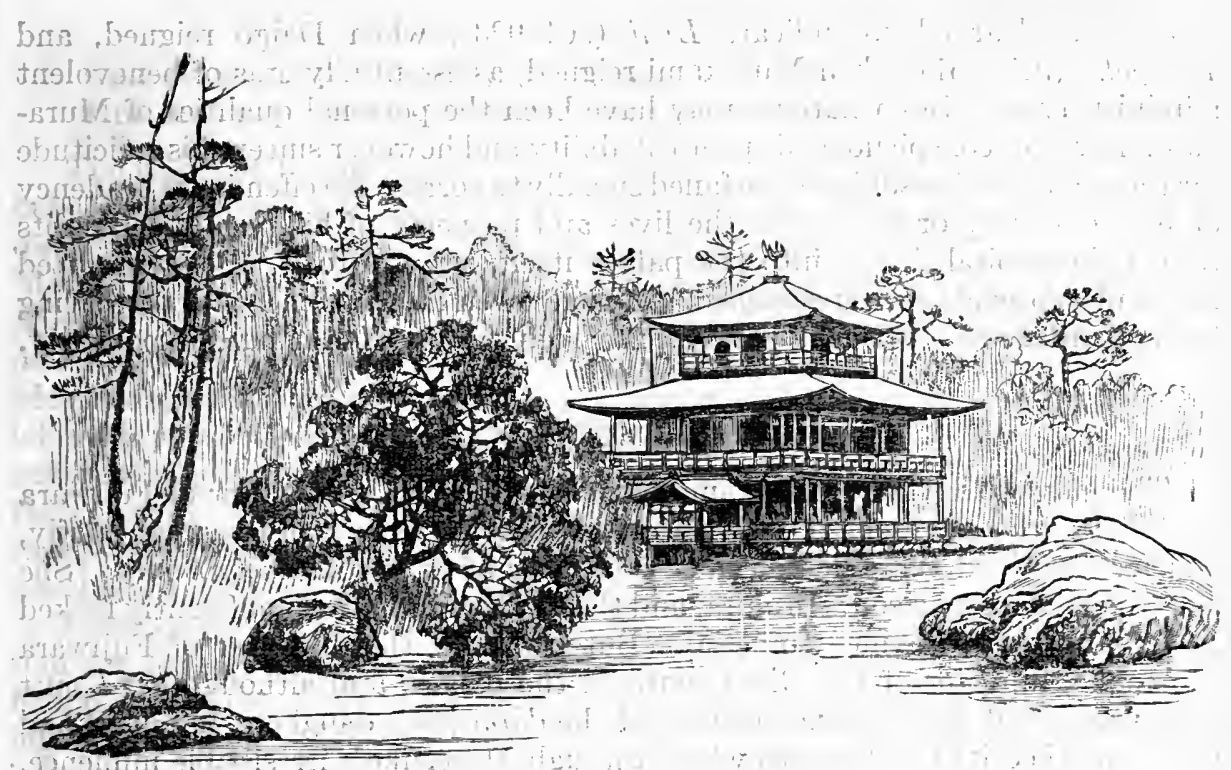

KINKAKU-J̃, AT KYÕTó

\section{CHAPTER XXI}

\section{THE CAPITAL AND THE : PROVINCES}

\section{RELATIONS BETWEEN THE COURT AND THE FUJIWARA}

WE now arrive at a period of Japanese history in which the relations of the Fujiwara family to the Throne are so complicated as greatly to perplex even the most careful reader. But as it is not possible to construct a genealogical table of a really helpful character, the facts will be set down here in their simplest form:

THE SIXTY-SECOND SOVEREIGN, THE EMPEROR MURAKAMI (A.D. 947-967)

Murakami, son of Daigo by the daughter of the regent, Fujiwara Mototsune, ascended the throne in succession to Shujaku, and Fujiwara Tadahira held the post of regent, as he had done in Shujaku's time, his three sons, Saneyori, Morosuke, and Morotada, giving their daughters; one, Morosuke's offspring, to be Empress, the other two to be consorts of the sovereign. Moreover, Morosuke's second daughter was married to the Emperor's younger brother, Prince Takaaki, who afterwards descended from princely rank to take the family name of Minamoto. Saneyori, Morosuke, and Takaaki took a prominent part in the administration of State affairs, and thus indirectly by female influence at Court, or by their own direct activity, the Fujiwara held a supreme place. Murakami has a high position among Japan's model sovereigns. He showed keen and intelligent interest in "polities; he sought to employ able officials; he endeavoured to check luxury, and he solicited frank guidance from his elders. Thus later 
generations learned to indieate Engi (901-923), when Daigo reigned, and Tenryaku (947-957), when Murakami reigned, as essentially eras of benevolent administration. But whatever may have been the personal qualities of Murakami, however conspicuous his poetical ability and however sincere his solicitude for the welfare of his subjects, he failed signally to correct the effeminate tendency of Kyoto society or to protect the lives and property of his people. Bandits raicled the capital, broke into the palace itself, set fire to it, and committed frequent depredations unrestrained. An age when the machinery for preserving law and order was practically paralyzed scarcely deserves the eulogies of posterity.

\section{THE SUCCESSION}

The lady with whom Murakami first consorted was a daughter of Fujiwara Motokata, who represented a comparatively obscure branch of the great family, and had attained the office of chief councillor of State (dainagon) only. She bore to his Majesty a son, Hirohira, and the boy's grandfather confidently looked to see him named Prince Imperial. But presently the daughter of Fujiwara Morosuke, minister of the Right, entered the palace, and although her Court rank was not at first superior to that of the dainagon's daughter, her child had barely reached its third month when, through Morosuke's irresistible influence, it was nominated heir to the throne. Motokata's disappointment proved so keen that his health became impaired and he finally died - of chagrin, the people said. In those days men believed in the power of disembodied spirits for evil or for good. The spirit of the ill-fated Sugawara Michizane was appeased by building shrines to his memory, and a similar resource exorcised the angry ghost of the rebel, Masakado; but no such prevention having been adopted in the ease of Motokata, his spirit was supposed to have compassed the early deaths of his grandson's supplanter, Reizei, and of the latter's successors, Kwazan and Sanjo, whose three united reigns totalled only five years.

A more substantial calamity resulted, however, from the habit of ignoring the right of primogeniture in favour of arbitrary selection. Murakami, seeing that the Crown Prince (Reizei) had an exeeedingly feeble physique, deemed it expedient to transfer the succession to his younger brother, Tamehira. But the latter, having married into the Minamoto family, had thus become ineligible for the throne in Fujiwara eyes. The Emperor hesitated, therefore, to give open expression to his views, and while he waited, he himself fell mortally ill. On his death-bed he issued the necessary instruction, but the Fujiwara deliberately ignored it, being determined that a consort of their own blood must be the leading lady in every Imperial household. Then the indignation of the other great families, the Minamoto and the Taira, blazed out." Mitsunaka, representing the former, and Shigenobu the latter, entered into a conspiracy to collect an army in the Kwantō and march against Kyōto with the sole object of compelling obedience to Murakami's dying behest. The plot was divulged by Minamoto Mitsunaka in the sequel of a quarrel with Taira no Shigenobu; the plotters were all exiled, and Takaaki, youngest son of the Emperor Daigo, though wholly ignorant of the conspiracy, was falsely accused to the Throne by Fujiwara Morotada, deprived of his post of minister of the Left, to which his accuser was nominated, and sent to that retreat for disgraced officials, the Dazai-fu. Another instance is here furnished of the readiness with which political rivals slandered one another in old Japan, and another instance, also, of the sway exercised over the sovereign by his Fujiwara ministers. 
THE SIXTY-THIRD SOVEREIGN, THE EMPEROR REIZEI (A.D. 968-969) THE SIXTY-FOURTH SOVEREIGN, THE EMPEROR ENYŨ (A.D. 970-984)

The reigns of Reizei and Enyū are remarkable for quarrels among the members of the Fujiwara family - quarrels which, to be followed intelligently, require frequent reference to the genealogical table (page 203). Fujiwara Morosuke had five sons, Koretada, Kanemichi, Kaneiye, Tamemitsu, and Kinsuye. Two of these, Koretada and Kaneiye, presented one each of their daughters to the Emperor Reizei, and Koretada's daughter gave birth to Prince Morosada, who afterwards reigned as Kwazan, while Kaneiye's daughter bore Okisada, subsequently the Emperor Sanjō. After one year's reign, Reizei, who suffered from brain disease, abdicated in favour of his younger brother, Enyū, then only in his eleventh year. Fujiwara Saneyori acted as regent, but, dying shortly afterwards, was succeeded in that office by his nephew, Koretada, who also had to resign on account of illness.

Between this latter's two brothers, Kanemichi and Kaneiye, keen competition for the regency now sprang up. Kanemichi's eldest daughter was the Empress of Enyū, but his Majesty favoured Kaneiye, who thus attained much higher rank than his elder brother. Kanemichi, however, had another source of influence. 'His sister was Murakami's Empress and mother of the reigning sovereign, Enyū. This Imperial lady, writing to his Majesty Enyū at Kanemichi's dictation, conjured the Emperor to be guided by primogeniture in appointing a regent, and Eny $\bar{u}$, though he bitterly disliked Kanemichi, could not gainsay his mother. Thus Kanemichi became chancellor and acting regent. The struggle was not concluded, however. It ended in the palace itself, whither the two brothers repaired almost simultaneously, Kanemichi rising from his sick-bed for the purpose. In the presence of the boy Emperor, Kanemichi arbitrarily transferred his own office of kwampaku to Fujiwara Yoritada and degraded his brother, Kaneiye, to a comparatively insignificant post. The sovereign acquiesced; he had no choice. A few months later, this dictator died. It is related of him that his residence was more gorgeous than the palace and his manner of life more sumptuous than the sovereign's. The men of his time were wont to say, "A tiger's mouth is less fatal than the frown of the regent, Kanemichi."

\section{THE SIXTY-FIFTH SOVEREIGN, THE EMPEROR KWAZAN (A.D. 985-986) THE SIXTY-SIXTH SOVEREIGN, THE EMPEROR ICHIJŌ (A.D. 987-1011)}

Eldest son of the Emperor Reizei, Kwazan ascended the throne in 985. His mother was a daughter of Fujiwara Koretada, and Yoritada, whose appointment as regent has just been described, continued to act in that capacity. Kaneiye's opportunity had now come. Kwazan having succeeded Enyū, nominated the latter's son to be Crown Prince, instead of conferring the position on his own brother, Prince Okisada (afterwards Sanjō). Now the Crown Prince was the son of Kaneiye's daughter, and that ambitious noble determined to compass the sovereign's abdication without delay. Kwazan, originally a fickle lover, had ultimately conceived an absorbing passion for the lady Tsuneko. He could not be induced to part with her even at the time of her pregnancy, and as there was no proper provision in the palace for such an event, Tsuneko died in labour. Kwazan, distraught with grief, was approached by Kaneiye's son, Michikane, who urged him to retire from the world and seek in Buddhism the perfect peace thus alone attainable. Michikane declared his own intention of 
entering the "path," and on a moonlight night the two men, leaving the palace, repaired to the temple Gwangyō-ji to take the tonsure." There, Michikane, pretending he wished to bid final farewell to his family, departed to return no more, and the Emperor understood that he had been deceived.

Retreat was now impossible, however." He abdicated in favour of Ichijo, a child of seven, and Kaneiye became regent and chancellor. He emulated the magnificence of his deceased brother and rival, Kanemichi, and his residence at Higashi-Sanjo in Kyōto was built after the model of the "hall of freshness" in the palace. He had five sons, the most remarkable of whom were Michitaka, Michikane, and Michinaga. It will be presently seen that in the hands of the last the power of the Fujiwara reached its zenith. On the death of Kaneiye the office of kwampaku fell to his eldest son, Michitaka, and, in 993, the latter being seriously ill, his son, Korechika, looked to be his successor. But the honour fell to Michitaka's brother, Michikane. Seven days after his nomination, Michikane died, and, as a matter of course, men said that he had been done to death by. the incantations of his ambitious nephew. Again, however, the latter was disappointed. Kaneiye's third son, Michinaga, succeeded to the regency.

Almost immediately, the new regent seems to have determined that his daughter should be Empress. But the daughter of his elder brother, the late Michitaka, already held that position. This, however, constituted no sort of obstacle in the eyes of the omnipotent Michinaga. He induced - "required". would probably be a more accurate expression - the Empress to abandon the world, shave her head, and remove to a secluded palace, (the Kókiden); whereafter he caused his own daughter to become the Imperial consort under the title of $\operatorname{ch} \bar{u} g \bar{u},{ }^{1}$ her residence being fixed in the Fujitsubo, which was the recognized. palace of the Empress.

It is not to be imagined that with such a despotic regent, the Emperor himself exereised any real authority. The annals show that Ichijo was of benevolent disposition; that he sympathized with his people; that he excelled in prose composition and possessed much skill in music. . Further, during his reign of twenty-four years many able men graced the era. But neither their capacity, nor his own found opportunity for exercise in the.presence of Michinaga's protégés, and, while profoundly disliking the Fujiwara autocrat, Ichijo was constrained to suffer him.

THE SIXTY-SEVENTH SOVEREIGN, THE EMPEROR SANJŌ (A.D. 1012-1017) THE SIXTY-EIGHTH SOVEREIGN, THE EMPEROR GO-ICHIJŌ (A.D. 1017-1036)

Prince Okisada, younger brother of the Emperor Kwazan, ascended the throne at the age of thirty-six, on the abdication of Ichijo, and is known in history as Sanjō. Before his accession he had married the daughter of Fujiwara Narito$\mathrm{ki}$, to whom he was much attached, but with the crown he had to accept the second daughter of Michinaga as chügü, his former consort becoming Empress. His Majesty had to acquiesce in another arbitrary arrangement also. It has been shown above that Michinaga's eldest daughter had been given the title of chügū in the palace of Ichijō, to. whom she bore two sons, Atsunari and Atsunaga. Neither of these had any right to be nominated Crown Prince in preference to Sanjō's offspring. Michinaga, however, caused Atsunari to be

[1 A lady on introduction to the palace received the title of jokwan. If the daughter of a minister of State, she was called nyogo: Chügu was a still higher title devised specially for Michinaga's purpose, and naturally it became a precedent.] 
appointed Prince Imperial; ignoring Sanjo's son, since his mother belonged to an inferior branch of the Fujiwara." Further, it did not suit the regent's convenience that a ruler of mature age should occupy the throne. An eye disease from which Sanjo suffered became the pretext for pressing him to abdicate, and, in 1017, Atsunari, then in his ninth year, took the sceptre as Emperor Go-Ichijo, or IchijōII. Michinaga continued to act as regent; holding, at the same time, the office of minister of the-Left, but he subsequently handed over the regency to his son, Yorimichi, becoming himself chancellor.

Go-Ichijō was constrained to endure at Michinaga's hands the same despotic treatment as that previously meted out to Sanjō. The legitimate claim of his offspring to the throne was ignored in favour of his brother, Atsunaga, who received for consort the fourth daughter of Michinaga. Thus, this imperious noble had controlled the administration for thirty years; had given his daughters to three Emperors; had appointed his son to be regent in his place, and had the Crown Prince for grandson. Truly, as his historians say, he held the empire in the hollow of his hand. His estates far exceeded those of the Crown; the presents offered to him by all ranks reached an enormous total; he built for himself a splendid mansion (Jōtōmon) with forced labour requisitioned from the provinces, and for his wife a scarcely less magnificent residence (Kyōgoku) was erected at the charges of the Emperor Go-Ichijo. . At the approach of illness he took refuge in Buddhism, but even here the gorgeous ostentation of his life was not abated. He planned the building of a monastery which should prove a worthy retreat for his declining years, and it is on record that his order to the provincial governor was, "though you neglect your official duties, do not neglect to furnish materials and labour for the building of Hōjō-ji." Even from the palace itself stones were taken for this monastery, and the sums lavished upon it were so enormous that they dwarfed Michinaga's previous extravagances. Michinaga retired there to die; and on his death-bed he received a visit from the Emperor, who ordered three months' Court mourning on his decease. There is a celebrated work entitled Eigwa Monogatari (Tales of Splendour), wherein is depicted the fortunes and the foibles of the Fujiwara family from the days (889) of the Emperor Uda to those (1092) of the Emperor Horikawa. Specially minute is the chronicle'when it treats of the Mido kwampaku, as Michinaga was called after he set himself to build the monastery Hōjō-ji.

Loyal Japanese historians shrink from describing this era, when the occupants of the throne were virtually puppets in the hands of the Fujiwara. There was, however, one redeeming feature: amid this luxury and refinement literature flourished vigorously, so that the era of Tenryaku (947-957) lives in the memory of the nation as vividly as that of Engi (901-923)." O'ye Tomotsuna, Sugawara Fumitoki, Minamoto Shitagō - these were famous littérateurs, and Minamoto Hiromasa, grandson of the Emperor Uda, attained celebrity as a musical genius. Coming to the reigns of Kwazan, Enyū, and Ichijo (985-1011), we find the immortal group of female writers, Murasaki Shikibu, Izumi Shikibu, Sei Shōnagon, and Akazome Emon; we find also in the Imperial family, Princes Kaneakira and Tomohira; we find three famous scribes, Fujiwara Yukinari, Fujiwara Sari, and Ono no Tōfū, and, finally the "Four Nagon" (Shi-nagon), Fujiwara Yukinari, Fujiwara Kintō. Minamoto Narinobu, and Minamoto Toshikata.

It is observable that in this necessarily brief summary the name "Minamoto" occurs several times, as does that of "Fujiwara" also. But that the scions' of either family confined themselves to the arts of peace; is not to be inferred. There were Fujiwara among the military magnates in the provinces, and we 
shall presently see the Minamoto taking the lead in the science of war. Already, indeed, the Fujiwara in the eapital were beginning to recognize the power of the Minamoto. It has been related above that one of the rebel Masákado's earliest opponents was a Minamoto, vice-governor of Musashi. His son, Mitsunaka, a redoubtable warrior, assisted the Fujiwara in Kyōto, and Mitsunaka's /sons; Yorimitsu and Yorinobu, contributed materially to the autocracy of the regent Michinaga. Yorimitsu was appointed by the regent to command the cavalry of the guard, and he is said to have brought that corps to a state of great efficiency.

There was, indeed, much need of a strong hand. One had onlyi to emerge from the palace gates to find oneself among the haunts of bandits. The names of such robber chiefs as Hakamadare no. Yasusuke, Kidōmaru, Ōeyama Shutendōji, and Ibaraki-dōji have been handed down as the heroes in many a strange adventure and the perpetrators of many heinous crimes. Even the Fujiwara residences were not secure against the torches of these plunderers; and during the reign of Ichijo the palace itself was frequently fired by them... In Go-Ichijō's time, an edict was issued forbidding men to carry bows and arrows in the streets; but had there been power to enforce such a veto, its enactment would not have been necessary. Its immediate sequel was that the bandits broke into Government offices and murdered officials there.

\section{THE INVASION OF JAPAN BY THE TÖI}

In the spring of 1019, when Go-Ichijo occupied the throne, a large host of invaders suddenly poured into the island of Tsushima. There had not been any warning. Tsushima lies half-way between the south of Korea and the northeast of Kyūshū, distant about sixty miles from either coast. Since the earliest times, its fine harbours had served as a military station for ships plying between Japan and Korea, but such intercourse had long been interrupted when this invasion took place.

The invaders were the Toi, originally called Sushen or Moho, under the former of which names they make their appearance in Japanese history in the middle of the sixth century. They inhabited that part of the Asiatic continent which lies opposite to the island of Ezo, but there is nothing to show what impulse they obeyed in making this sudden descent upon Japan. Their fleet comprised some fifty vessels only, each from forty to sixty feet long and propelled by, thirty or forty oars, but of how many fighting men the whole force consisted, no record has been preserved. As to arms, they carried swords, bows, spears, and shields, and in their tactical formation spearmen occupied the front rank, then eame swordsmen, and finally bowmen. Every man had a shield. Their arrows were short, measuring little over a foot, but their bows were powerful, and they seem to have fought with fierce courage.

At first they carried everything before them. The governor of Tsushima, being without any means of defence, fled to the Dazai-fu in Kyūshū, and the inhabitants were left to the mercy of the invaders, who then pushed on to the island of Iki. There the governor, Fujiwara Masatada, made a desperate resistance, losing his own life in the battle. It is said that of all the inhabitants, one only, a Buddhist priest, escaped to tell the.story.

Ten days after their first appearance off 'Tsushima, the Toi effected a landing in Chikuzen and marched towards Hakata, plundering, burning, massacring old folks and children, making prisoners of adults, and slaughtering cattle and horses for food. It happened, fortunately, that Takaiye, younger brother of 
Fujiwara Korechika, was in command at the Dazai-fu, whither he had repaired partly out of pique, partly to undergo treatment for eye disease at the hands of a Chinese doctor. He met the crisis with the utmost coolness, and made such skilful dispositions for defence that, after three days' fighting, in which the Japanese lost heavily; Hakata remained uncaptured.

High winds and rough seas now held the invaders at bay, and in that interval the coast defences were repaired and garrisoned, and a fleet of thirty-eight boats having been assembled, the Japanese assumed the offensive, ultimately driving the Toi to put to sea. A final attempt was made to effect a landing at Matsuura in the neighbouring province of Hizen, but, after fierce fighting, the invaders had to withdraw altogether:- The whole affair had lasted sixteen days, and the Japanese losses were 382 killed and 1280 taken prisoners. Two hundred and eighty of the latter - 60 men and 220 women - were subsequently returned. They were brought over from Koma six months later by a Koma envoy, Chong Cha-ryang, to whom the Court presented three hundred pieces of gold.

Kyōto's attitude towards this incident was most instructive." When the first tidings of the invasion reached the capital, the protection of heaven was at once invoked by services at Ise and ten other shrines. But when, on receipt of news that the danger had been averted, the question of rewarding the victors came up for discussion, a majority of the leading statesmen contended that, as the affair had been settled before the arrival of an Imperial mandate at the Dazai-fu, no official cognizance could be taken of it. This view was ultimately overruled since the peril had been national, but the rewards subsequently given were insignificant, and the event clearly illustrates the policy of the Central Government - a policy already noted in connexion with the revolt of Masakado namely, that any emergency dealt with prior to the receipt of an Imperial rescript must be regarded as private, whatever its nature, and therefore beyond the purview of the law.

A more effective method of decentralization could not have been devised. It was inevitable that, under such a system, the provincial magnates should settle matters to their own liking without reference to Kyōto, and that, the better to enforce their will, they should equip themselves with armed retinues. In truth, it is not too much to say that, from the tenth century, Japan outside the capital became an arena of excursions and alarms, the preservation of peace being wholly dependent on the ambitions of local magnates.

A history of all these happenings would be intolerably long and tedious. Therefore only those that have a national bearing will be here set down. Prominent among such is the struggle between the Taira and the Minamoto in the Kwantō. The origin of these two families has already been recounted. Some historians have sought to differentiate the metropolitan section of the Minamoto from the provincial section - that is to say, the men of luxury and literature who frequented the capital, from the men of sword and bow who ruled in the provinces. Such differentiation is of little practical value. Similar lines of demarcation might be drawn in the case of the Taira and Fujiwara themselves. If there were great captains in each of these famous families, there were also great courtiers. To the former category belonged Taira Tadatsune. For generations his family had ruled in the province of Shimōsa and had commanded the allegiance of all the bushi of the region. Tadatsune held at one time the post of vice-governor of the neighbouring province of Kazusa, where he acquired large manors (shōen). In the year 1028, he seized the chief town of the latter province, and pushing on into Awa, killed the governor and obtained complete 
control of the province. ${ }^{1}$ The Court, on receiving news of these events, ordered Minamoto Yorinobu, governor of Kai, and several other provincial governors to attack the Taira chief.

Yorinobu did not wait for his associates. Setting out with his son, Yoriyoshi, in 1031, he moved at once against Tadatsune's castle, which stood on the seashore of Shimōsa, protected by moats and palisades, and supposed to be unapproachable from the sea except by boats, of which Tadatsune had taken care that there should not be any supply available. But the Minamoto general learned that the shore sloped very slowly on the eastle front, and marching his men boldly through the water, he delivered a erushing attack.

For this exploit, which won loud plaudits, he was appointed commandant of the local government office, a post held by his grandfather, Tsunemoto, whom we have seen as vice-governor of Musashi in the days of Masakado; by his father, Mitsunaka, one of the pillars of the Minamoto family, and by his elder brother, Yorimitsu, who commanded the cavalry of the guards in Kyōto. The same post was subsequently bestowed on Yorinobu's son, Yoriyoshi, and on the latter's son, Yoshiiye, known by posterity as "Hachiman Tarō," Japan's most renowned archer, to whom the pre-eminence of the Minamoto family was mainly due. Tadatsune had another son, Tsunemasa, who was appointed vice-governor of Shimōsa and who is generally spoken of as Chiba-no-suke. The chief importance of these events is that they laid the foundation of the Minamoto family's supremacy in the Kwantō, and thus permanently influenced the course of Japanese history.

ingur ortj goria

\section{THE CAMPAIGN OF $Z E N-K U N E N$}

It is advisable at this stage to make closer acquaintance with the Japanese bushi (soldier), who has been eursorily alluded to more than once in these pages, and who, from the tenth century, acts a prominent rôle on the Japanese stage. History is silent as to the exact date when the term "bushi", came into use, but from a very early era its Japanese equivalent, "monono-fu," was applied to the guards of the sovereign's palace, and when great provincial magnates began; about the tenth century, to support a number of armed retainers, these gradually camc to be distinguished as bushi. In modern times the ethics of the bushi have been analysed under the name "bushido" (the way of the warrior), but of course no such term or any such complete code existed in ancient days. The conduct most appropriate to a bushi was never embodied in a written code. It derived its sanctions from the practice of recognized models, and only by observing those models can we reach a clear conception of the thing itself.

To that end, brief study may be given to the principal campaigns of the eleventh century, namely, the century immediately preceding the establishment of military feudalism. It must be premised, however, that although the bushi figured mainly on the provincial stage, he acted an important part in the capital also. There, the Throne and its Fujiwara entourage were constrained to enlist the co-operation of the military nobles for the purpose of controlling the lawless elements of the population. The Minamoto family were conspieuous in that respect. Minamoto Mitsunaka - called also Manchū - served at the Court

[1 Murdoch, in his Hislory of Japan, says that in three years Tadatsune's aggressions "reduced the $K$ wanto to a tangled wilderness. Thus, in the province of Shimósa, in 1027 , there had been as much as 58,000 acres under cultivation; but in 1031 this had shrunk to forty-five acres."] 
of four consecutive sovereigns from Murakami downwards, was appointed governor of several provinces, and finally became commandant of the local Government office. Yorimitsu, his son, a still greater strategist, was a prominent figure at five Courts, from the days of Enyū, and his brothers, Yorichika and Yorinobu, rendered material assistance in securing the supremacy of the great

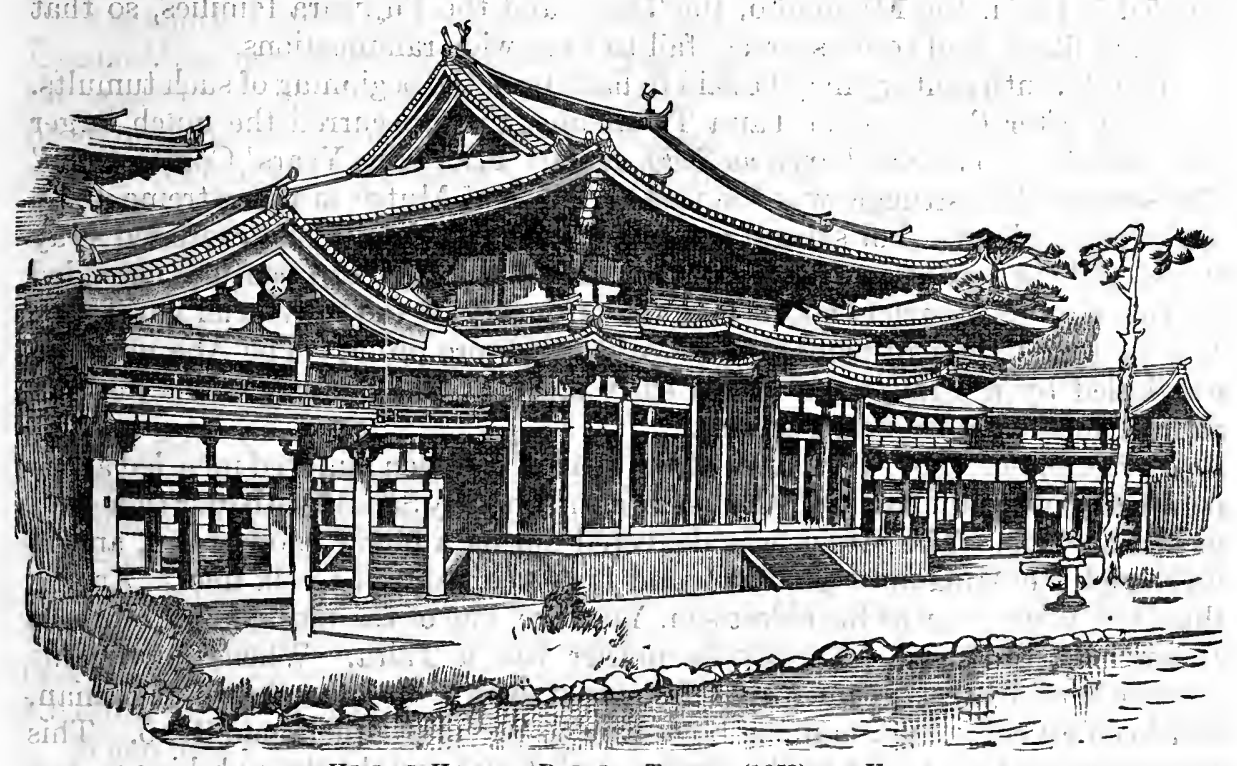

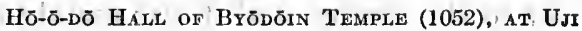

Fujiwara chief, Michinaga. Indeed, the Minamoto were commonly spoken of as the "claws" of the Fujiwara. It was this Yorinobu who won such fame by escalading the castle of Taira Tadatsune and who established his family's footing in the Kwantō. His uncle, Yoshimitsu, had a large estate at Tada in Settsu, and this branch of the family was known as Tada Genji. ${ }^{1}$

Then there were:-

The Yamato Genji descended from Yorichika."

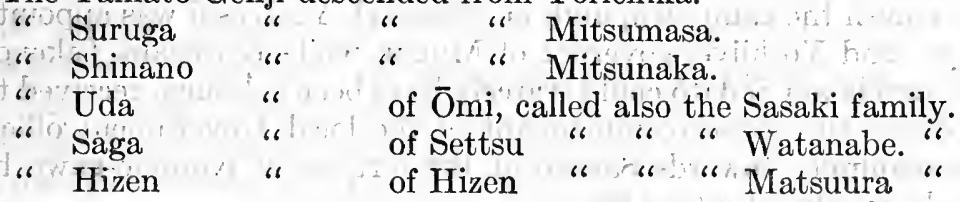

The Taira family became famous from the time of Sadamori, who quelled the insurrection of Masakado. Of this clan, there were these branches:-

The Daijo-uji of Hitachi, so called because for generations they held the office of daijo in Hitachi.

The Ise-Heishi of Ise, descended from Korehira, son of Sadamori.

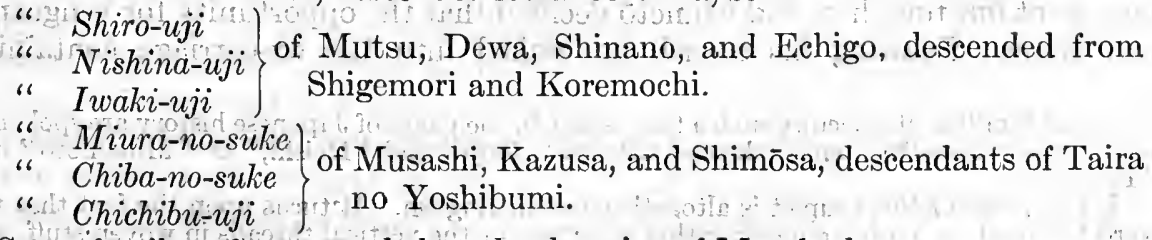

Sôma family, who succeeded to the domains of Masakado.

[1 "Gen" is the alternative pronunciation of "Minamoto" as "Hei" is of "Taira." The 
The Fujiwara also had many provincial representatives, descended mainly from Hidesato, (called also Tawara Tôda), who distinguished himself in the Masakado crisis. There were the Sano-uji of Shimotsuke, Mutsu, and Dewa; and there were the Kondō, the Mutō, the Koyama, and the Yūki, all in different parts of the Kwantō. In fact, the empire outside the capital was practically divided between the Minamoto, the Taira, and the Fujiwara families, so that anything like a feud could searcely fail to have wide ramifications.

The eleventh century may be said to have been the beginning of such tumults. Not long after the affair of Taira Tadatsune, there occurred the much larger campaign known as Zen-kunen no Sōdo, or the "Prior Nine Years' Commotion." The scene of this struggle was the vast province of Mutsu in the extreme north of the main island. For several generations the Abe family had exercised sway there, and its representative in the middle of the eleventh century extended his rule over six districts and defied the authority of the provincial governors. The Court deputed Minamoto Yoriyoshi to restore order. The Abe magnate was killed by a stray arrow at an early stage of the campaign, but his son, Sadatō, made a splendid resistance.

In December, 1057, Yoriyoshi, at the head of eighteen hundred men, led a desperate assault on the castle of Kawasaki, garrisoned by Sadato with four thousand picked soldiers. The attack was delivered during a heavy snow-storm, and in its sequel the Minamoto general found his force reduced to six men. Among these six, however, was his eldest son, Yoshiiye, one of the most skilful bowmen Japan ever produced. Yoshiiye's mother was a Taira. When she became enceinte her husband dreamed that the sacred sword of the war deity, Hachiman, had been given to him, and the boy came to be called Hachiman Tarô. This name grew to be a terror to the enemy, and it was mainly through his prowess that his father and their scanty remnant of troops escaped over roads where the snow lay several feet deep.

On a subsequent occasion in the same campaign, Yoshiiye had Sadato at his mercy and, while fixing an arrow to shoot him, composed the first line of a couplet, "The surcoat's warp at last is torn." Sadatō, without a moment's hesitation, capped the line, "The threads at last are frayed and worn," and Yoshiiye, charmed by such a display of ready wit,-lowered his bow. Nine years were needed to finish the campaign, and, in its sequel, Yoriyoshi was appointed governor of Iyo, and Yoshiiye, governor of Mutsu, while Kiyowara Takenori, without whose timely aid Sadato could scarcely have been subdued, received the high post of chinju-fu shoggun (commandant of the local Government office). Yoshiiye's magnanimity towards Sadatō at the fortress of Koromo-gawa has always been held worthy of a true bushi.

Sadatō was ultimately killed, but his younger brother Munetō had the affection and full confidence of Yoshiiye. Munetō, however, remembered his brother's fate and cherished a desire to take vengeance on Yoshiiye, which mood also was recognized as becoming to a model bushi. One night, the two men went out together, and Munetō deeided that the opportunity for vengeance had come. Drawing his sword, he looked into the ox-carriage containing

two great families who occupy such a large space in the pages of Japanese history are spoken of together as "Gen-Pei," and independently as "Genji" and "Heishi," or "Minamoto" and "Taira."]

[ ${ }^{1}$ The point of this couplet is altogether lost in English. It turns upon the fact that the word tate used by Yoshiiye means either a fortress or the vertical threads in woven stuff, and that koromo was the name of the fortress where the encounter took place and had also the significance of "surcoat."] 
Yoshiiye and found him sound asleep. The idea of behaving treacherously in the face of such trust was unendurable, and thereafter Munetō served Yoshiiye with faith and friendship. The confidence that the Minamoto hero reposed in the brother of his old enemy and the way it was requited - these; too, are claimed as traits of the bushi.

Yet another canon is furnished by Yoshiiye's career - the canon of humility. Oye no Masafusa was overheard remarking that Yoshilye had some high qualities but was unfortunately ignorant of strategy. This being repeated to Yoshiiye, he showed no resentment but begged to become Masafusa's pupil. Yet he was already conqueror of the Abe and governor of Dewa.

\section{THE GÖ-SANNEN CAMPAIGN}

Thereafter the provinees of Mutsu and Dewa were again the scene of another fierce struggle which, since it began in the third year (1089) of the Kwanji era and ended in the fifth year (1091), was called the "After Three-years War." With regard to the nature of this commotion, no enumeration of names is necessary. It was a family quarrel between the scions of Kiyowara Takenori, a magnate of Mutsu who had rendered conclusive assistance to Yoshiiye in the Nine-years' War; and as a great landowner of Dewa, Kimiko Hidetake, took part, the whole north of Japan may be said to have been involved. It fell to Yoshiiye, as governor of Mutsu, to quell the disturbance, and very difficult the task proved, so difficult that the issue might have been different had not Fujiwara Kiyohira - who will be presently spoken of - espoused the Minamoto cause.

When news of the struggle reached Kyōto, Yoshiiye's younger Brother, Yoshimitsu, who held the much coveted post of kebiishi, applied for permission to proceed at once to his brother's assistance. The Court refused his application, whereupon he resigned his office and, like a true bushi, hastened to the war. Yoshimitsu was a skilled performer upon a musical instrument called the sho. He had studied under a celebrated master, Toyohara Tokimoto, now no more, and, on setting out for the field of battle in the far north, he became apprehensive lest the secrets imparted to him by his teacher should die with him. He therefore invited Tokimoto's son, Tokiaki, to bear him company during the first part of his journey, and to him he conveyed all the knowledge he possessed. The spectacle of this renowned soldier giving instruction in the art of music to the son of his deceased teacher on moonlit nights as he travelled towards the battlefield, has always appealed strongly to Japanese conception of a perfect samurai, and has been the motive of many a picture.

This Go-sannen struggle furnished also another topic for frequent pictorial representation. When about to attack the fortress of Kanazawa, to which the approaches were very difficult, Yoshiiye observed a flock of geese rising in confusion, and rightly inferred an ambuscade of the enemy. His comment was, "Had not Ōye Masafusa taught me strategy, many brave men had been killed to-night." Yet one more typical bushi may be mentioned in connexion with this war. Kamakura Gongoro, a youth of sixteen, always fought in the van of Yoshiiye's forces and did great execution. A general on the enemy's side succeeded in discharging a shaft which entered the boy's eye. Gongorō, breaking the arrow, rode straight at the archer and cut him down. A shrine in Kamakura was erected to the memory of this intrepid lad.

When Yoshiiye reported to the Throne the issue of this sanguinary struggle, Kyōto replied that the war had been a private feud and that no reward or 
distinctions would be conferred. Yoshiiye therefore devoted the greater part of his own manors to recompensing those that had followed his standard. $\mathrm{He}$ thus won universal respect throughout the Kwantō. Men competed to place their sons and younger brothers as kenin (retainers) in his service and the name of Hachiman-kō was on all lips. But Yoshiiye died (1108) in a comparatively low rank. It is easy to comprehend that in the Kwanto it became a common saying, "Better serve the Minamoto than the sovereign."

\section{THE FUJIWARA OF THE NORTH}

Fujiwara Kiyohira, who is mentioned above as having espoused the cause of the Minamoto in the Go-sannen, was descended from Hidesato, the conqueror of Masakado. After the Go-sannen outbreak he succeeded to the six districts of Mutsu which had been held by the insurgent chiefs. This vast domain descended to his son Motohira, and to the latter's son, Hidehira, whose name we shall presently find in large letters on a page of Japanese history.

The Mutsu branch of the Fujiwara wielded paramount sway in the north for several generations. Near Hiraizumi, in the province of Rikuchū, may still be seen four buildings forming the monastery Chūson-ji. In one of these edifices repose the remains of Kiyohira, Motohira, and Hidehira. "The ceiling, floor and four walls of this Konjiki-do (golden hall) were originally covered with powdered gold, and its interior pillars are inlaid with mother-of-pearl on which are traced the outlines of twelve Arhats. In the days of Kiyohira the monastery consisted of forty buildings and was inhabited by three hundred priests.

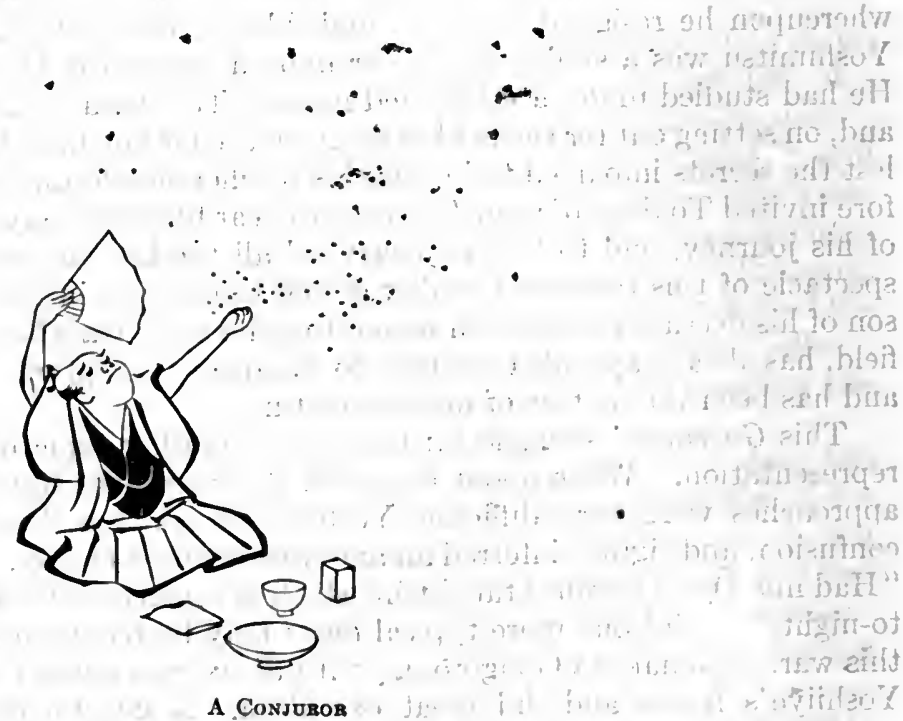




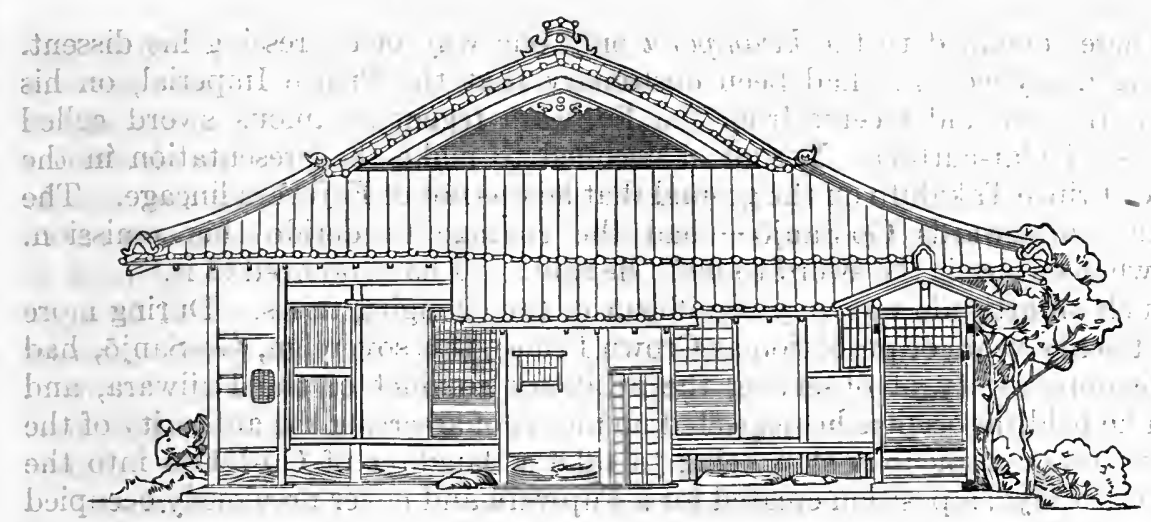

Side View of the "Kohö-AN" of DaItokU-Ji, at KYõto

\section{CHAPTER XXII}

\section{RECOVERY OF ADMINISTRATIVE AUTHORITY BY THE THRONE}

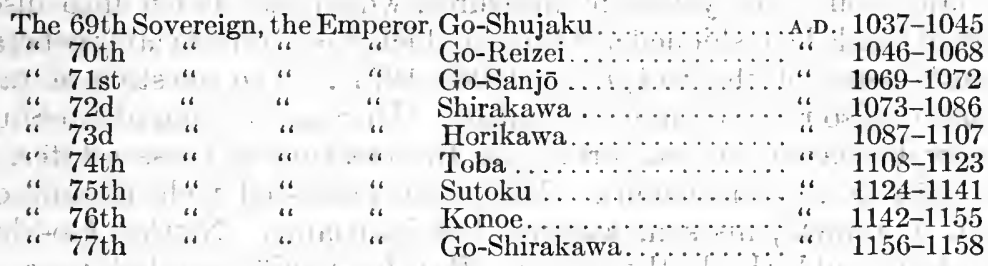

\section{DECADENCE OF FUJIWARA AUTOCRACY}

During two centuries the administrative power remained in the hands of the Fujiwara. They lost it by their own timidity rather than through the machinations of their enemies. When the Emperor Go-Shujaku was mortally ill, he appointed his eldest son, Go-Reizei, to be his successor, and signified his desire that the latter's half-brother, Takahito, should be nominated Crown Prince. Fujiwara Yorimichi, was then regent (kwampaku), To him, also, the dying sovereign made known his wishes: Now Takahito had not been born of a Fujiwara mother. The regent, therefore, while complying at once in Go-Reizei's case, said that the matter of the Crown Prince might be deferred, his purpose being to wait until a Fujiwara lady should bear a son to Go-Reizei.

In thus acting, Yorimichi obeyed the policy from which his family had never swerved through many generations, and which had now become an unwritten law of the State. :But his brother, Yoshinobu, read the signs of the times in a sinister light. He argued that the real power had passed to the military magnates, and that by attempting to stem the current the Fujiwara might be swept away altogether. He therefore repaired to the palace, and simulating ignorance of what had passed between the late sovereign and the kwampaku, inquired whether it was intended that Prince Takahito should enter a monastery. GoReizei replied emphatically in the negative and related the facts, whereupon Yoshinobu declared that the prince should be nominated forthwith. It was done, and thus for the first time in a long series of years a successor to the throne was proclaimed who had not the qualification of a Fujiwara mother. 
There remained to the kwampaku only one way of expressing his dissent. During many years it had been customary that the Prince Imperial, on his nomination, should receive from the Fujiwara regent a famous sword called T'subo-kiri (Jar-cutter). Yorimichi declined to make the presentation in the case of Prince Takahito on the ground that he was not of Fujiwara lineage. The prince - afterwards Go-Sanjo - had the courage to deride this omission. "Of what scrvice is the sword to me?" he said. "I have no need of it."

Such an attitude was very significant of the changing times. During more than twenty years of probation as Crown Prince, this sovereign, Go-Sanjō, had ample opportunity of observing the arbitrary conduct of the Fujiwara, and when he held the sceptre he neglected no means of asserting the authority of the Crown, one conspicuous step being to take a daughter of Go-Ichijo into the palace as $\operatorname{ch} \bar{u} \bar{u}$, a position created for a Fujiwara and never previously occupied by any save a Fujiwara.

Altogether, Go-Sanjō stands an imposing figure in the annals of his country. Erudition he possessed in no small degree, and it was supplemented by diligence, high moral courage and a sincere love of justice. He also set to his people an example of frugality. It is related that, observing as he passed through the streets one day, an ox-carriage with gold mountings, he stopped his cortège and caused the gold to be stripped off. Side by side with this record may be placed his solicitude about the system of measures, which had fallen into disorder. With his own hands he fashioned a standard which wasknown to later generations as the senshi-masu of the Enkyzu era (1069-1074). The question of tax-free manors (shōen) also received much attention. During the reign of Go-Shujaku, decrees were frequently issued forbidding the creation of these estates. The Fujiwara shōen were conspicuous. Michinaga possessed wide manors everywhere, and Yorimichi, his son, was not less insatiable. Neither Go-Shujaku nor Go-Reizei could check the abuse. But Go-Sanjo resorted to a really practical measure. He established a legislative office where all titles to shōen had to be examined and recorded, the Daihō system of State ownership being restored, so that all rights of private property required official sanction, the Court also becoming the judge in all disputes as to validity of tenure.

These orders came like a clap of thunder in a blue sky. Many great personages had acquired vast manorial tracts by processes that could not endure the scrutiny of the Kiroku-jo (registrar's office). Yorimichi, the kwampaku, was a conspicuous example. On receipt of the order to register, he could only reply that he had succeeded to his estates as they stood and that no documentary evidence was available. Nevertheless, he frankly added that, if his titles were found invalid, he was prepared to surrender his estates, since the position he occupied required him to be an administrator of law, not an obstacle to its administration. This was the same noble who had refused to present the sword, Tsubo-kiri, to Go-Sanjō when the latter was nominated Crown Prince. The Emperor might now have exacted heavy reparation. But his Majesty shrank from anything like spoliation. A special decree was issued exempting from proof of title all manors held by chancellors, regents, or their descendants.

\section{SALE OF OFFICES AND RANKS}

Another abuse with which Go-Sanjo sought to deal drastically was the sale of offices and ranks. This was an evil of old standing. Whenever special funds were required for temple building or palace construction, it had become 
customary to invite contributions from local magnates, who; in return, received, or were renewed in their tenure of, the post of provincial governor. Official ranks, were similarly disposed of. At what time this practice had its origin the records do not show, but during the reign of Kwammu (782-805,) the bestowal of rank in return for a money payment was interdicted, and Miyoshi Kiyotsura, in his celebrated memorial to Daigo (898-930), urged that the important office of kebiishi should never be conferred in consideration of money. But in the days of Ichijo, the acquisition of tax-free manors increased rapidly and the treasury's income diminished correspondingly, so that it became inevitable, in times of State need, that recourse should be had to private contributions, the contributors being held to have shown "merit" entitling them to rank or office or both.

Go-Sanjō strictly interdicted all such transactions. But this action brought him into sharp collision with the then kwampaku, Fujiwara Norimichi. The latter built within the enclosure of Kofuku-ji at Nara an octagonal edifice containing two colossal images of Kwannon. On this nanen-do the regent spent a large sum, part of which was contributed by the governor of the province. Norimichi therefore applied to the Emperor for an extension of the governor's term of office. Go-Sanjō refused his assent. But Norimichi insisted. Finally the Emperor, growing indignant, declared that the kwampaku's sole title to respect being derived from his maternal relationship to the sovereign, he deserved no consideration at the hands of an Emperor whose mother was not a Fujiwara. It was a supreme moment in the fortunes of the Fujiwara. Norimichi angrily swept out of the presence, crying aloud: "The divine influence of Kasuga Daimyōjin ${ }^{1}$ ceases from to-day. Let every Fujiwara official follow me." Thereat all the Fujiwara courtiers flocked out of the palace, and the Emperor had no choice but to yield. Victory rested with the Fujiwara, but it was purchased at the loss of some prestige.

\section{CAMERA SOVEREIGNTY}

Their obviously selfish device of seating a minor on the throne and replacing him as soon as he reached years of discretion, had been gradually invested by the Fujiwara with an element of spurious altruism. They had suggested the principle that the tenure of sovereign power should not be exercised exclusively. Go-Sanjo held, however, that such a system not only impaired the Imperial authority but also was unnatural. No father, he argued, could be content to divest himself of all practical interest in the affairs of his family, and to condemn the occupant of the throne to sit with folded hands was to reduce him to the rank of a puppet. Therefore, even though a-sovereign abdicated, he should continue to take an active part in the administration of State affairs. This was, in short, Go-Sanjō's plan for rendering the regent a superfluity. $\mathrm{He}$ proposed to substitute camera government (Insei) for control by a kwampaku. But fate willed that he should not carry his project into practice. He abdicated, owing to ill health, in 1073, and died the following year.

\section{SHIRAKAWA}

Go-Sanjo was succeeded by his eldest son, Shirakawa. He had taken for consort the daughter of Fujiwara Yorimichi. This lady, Kenko, had been 
adopted into the family of Fujiwara Morozane, and it is recorded that Yorimichi and Morozane shed tears of delight when they heard of her seleetion by the Crown Prince - so greatly had the influence of the Fujiwara declined. "Shirakawa modelled himself on his father. He personally administered affairs of State, displaying assiduity and ability but not justice. Unlike his father he allowed himself to be swayed by favour and affection, arbitrarily ignored timehonoured rules, and was guilty of great extravagance in matters of religion. But he carried into full effect the camera (or cloistered) system of government, thereafter known as Insei. ' For, in 1086, after thirteen years' reign, he resigned the sceptre to an eight-year-old boy, Horikawa, his son by the chügū, Kenko. The untimely death of the latter, for whom he entertained a strong affection, was the proximate cause of Shirakawa's abdication, but there can be little doubt that he had always contemplated such a-step. He took the tonsure and the religious title of $H \bar{o}-\bar{o}$ (pontiff), but in the Toba palace, his new residence, he organized an administrative machine on the exact lines of that of the Court.

Theneeforth the functions of Imperialism were limited to matters of etiquette and ceremony, all important State business being transacted by the $H \bar{o}=\bar{o}$ and

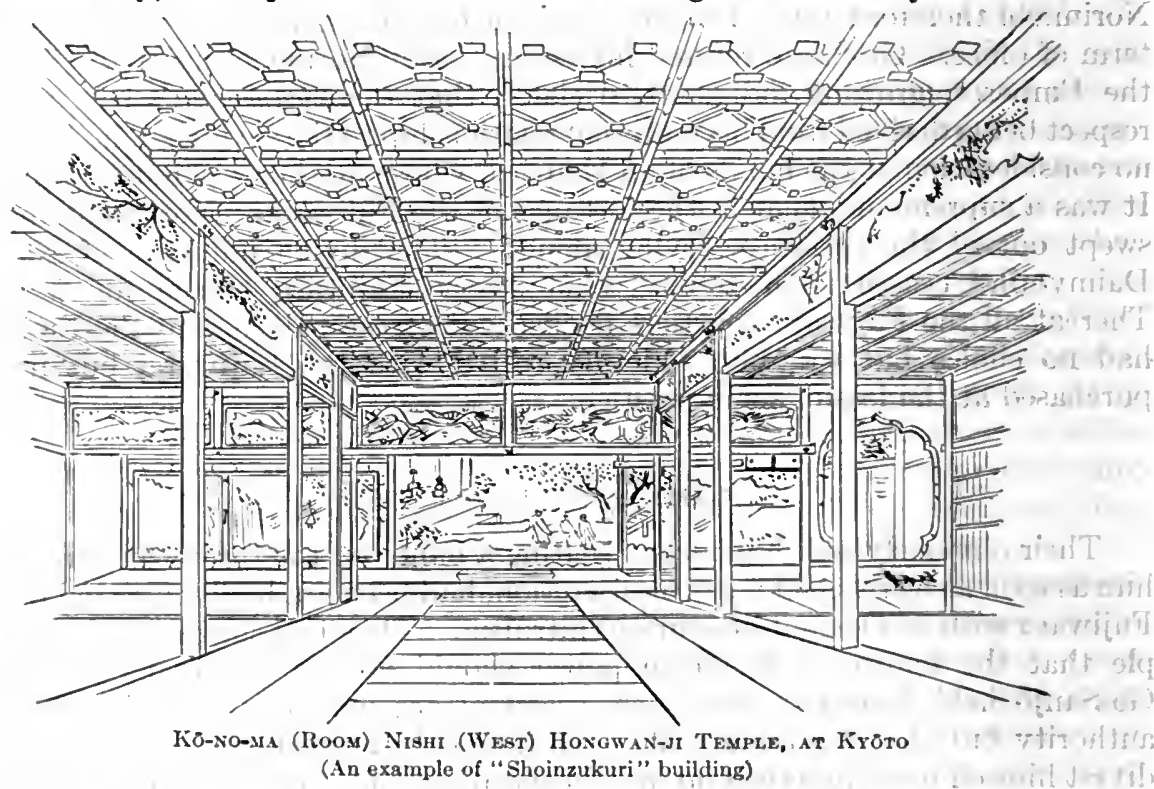

his eamera entourage. If the decrees of the Court clashed with those of the cloister, as was occasionally inevitable, the former had to give way. Thus, it can searcely be said that there was any division of authority. But neither was there any progress. The earnest efforts made by Go-Sanjo to eheck the abuse of sales of rank and office as well as the alienation of State lands into private manors, were rendered wholly abortive under the sway of Shirakawa. The cloistered Emperor was a slave of superstition. He caused no less than six temples $^{1}$ to be built of special grandeur, and to the principal of these (Hōshō-ji) he made frequent visits in state, on which occasions gorgeous ceremonies were performed. He ereeted the Temple of the 33,333 Images of Kwannon (the

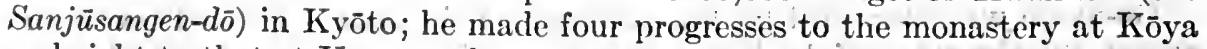
and eight to that at Kumano; he commissioned artists to paint 5470 Buddhist 
pictures, sculptors to cast 127 statues each sixteen feet high; 3150 life-size, and 2930 of three feet or less, and he raised twenty-one large pagodas and 446,630 small ones:

His respect for Buddhism was so extreme that he strictly interdicted the taking of lifein any form, a veto which involved the destruction of eight thousand fishing nets and the loss of their means of sustenance to innumerable fishermen, as well as the release of all falcons kept for hawking., It has even been suggested that Shirakawa's piety amounted to a species of insanity, for, on one occasion, when rain prevented a contemplated progress to $H \bar{o}$ shō-ji, he sentenced the rain to imprisonment and caused a quantity to be confined in a vessel.1. To the nation, however, all this meant something very much more than a mere freak. It meant that the treasury was depleted and that revenue had to be obtained by recourse to the abuses which Go-Sanjō, had struggled so earnestly to check, the sale of offices and ranks, even in perpetuity, and the inclusion of great tracts of State land in private manors.

TOBA

Horikawa died in 1107 , after a reign of twenty years, and was succeeded by his son Toba, a child of five. Affairs of State continued to be directed by the cloistered sovereign, and he chose for his grandson's consort Taiken-mon-in, who bore to him a son, the future Emperor Sutoku. Toba abdicated, after a reign of fifteen years, on the very day of Sutoku's nomination as heir apparent, and, six years later, Shirakawa died (1128), having administered the empire from the cloister during a space of forty-three years.

As a device to wrest the governing power from the grasp of the Fujiwara, Go-Sanjō's plan was certainly successful, and had he lived to put it into operation himself, the results must have been different. But in the greatly inferior hands of: Shirakawa this new division of Imperial authority and the segregation of its source undoubtedly conspired to prepare the path for military feudalism and for curtained Emperors.

Toba, with the title of $H \bar{o}-\bar{o}$, took the tonsure and administered from the cloister after Shirakawa's death.' One of his first acts after abdication was to take another consort, a daughter of Fujiwara Tadazane, whom he made Empress under the name of Kaya-no-in; but as she bore him no offspring, he placed in the Toba palace a second Fujiwara lady, Bifuku-mon-in, daughter of Nagazane. By her he had (1139) a son whom he caused to be adopted by the Empress, preparatory to placing him on the throne as Emperor Konoe, at the age of three. Thus, the cloistered sovereigns followed faithfully in the footsteps of the Fujiwara.

\section{SOLDIER-PRIESTS}

A phenomenon which became conspicuous during the reign of Shirakawa was recourse to violence by Buddhist priests. This abuse had its origin in the acquisition of large manors by temples and the consequent employment of soldiers to act as guards. Ultimately, great monasteries like Kōfuku-ji,.Onjō-ji, and Enryaku-ji came to possess thousands of these armed men, and consequently wielded temporal power. Shirakawa's absorbing belief in Buddhism created opportunities for the exercise of this influence. Keenly anxious that a son should be born of his union with Kenko, the daughter of Fujiwara Yorimichi, his Majesty bespoke the prayers of Raigō, lord-abbot of Onjō-ji. It happened

[' This silliness was spoken of by the people as ame-kingoku (the incarceration of the rain).] 
that unsuccessful application had frequently been made by the Onjō-ji monks for an important religious privilege. Raigo informed the Emperor that, if this favour were promised, the prayer for a prince would certainly be heard. Shirakawa made the promise, and Kenko gave birth to Prinee Atsubumi. But when the Emperor would have fulfilled his pledge, the priests of Enryaku-ji (Hiei-zan), jealous that a privilege which they alone possessed should be granted to priests of another monastery, repaired to the Court en masse to protest. Shirakawa: yielded to this representation and despatehed Ōye no Masafusa to placate Raigō. But the abbot refused to listen. He starved himself to death, passing day and night in devotion, and shortly after his demise the little prince, born in answer: to his prayers, died of small-pox.

In an age when superstition prevailed widely the death of the child was, of course, attributed to the incantations of the abbot. From that time a fierce feud raged between Onjō-ji and Enryaku-ji. In the year 1081, the priest-soldiers of the latter set the torch to the former, and, flocking to Kyōto in thousands, threw the capital into disorder. Order was with difficulty restored through the exertions of the kebiishi and the two Minamoto magnates, Yoshiiye and Yoshitsuna, but it was deemed expedient to guard the palace and the person of the Emperor with bushi. Twelve years later (1093), thousands of cenobites, carrying the sacred tree of the Kasuga shrine, marched from Nara to Kyōto, clamouring for vengeance on the governor of $\overline{O m i}$, whom they charged with arresting and killing the officials of the shrine.: This became a precedent. Thereafter, when-: ever the priests had a grievance, they flocked to the palace carrying the sacred tree of some temple or shrine. The soldier cenobites of Enryaku-ji-yama$h \overline{o s h}$, as they were called-showed themselves notably turbulent. ' They inaugurated the device of replacing the sacred tree with the "divine car,") against which none dare raise a hand or shoot an arrow. If their petition were rejected, they would abandon the ear in the streets of the capital, thus placing the city under a curse.

A notable instance occurred, in 1095, when these yama-hōshi of i Hiyoshi preferred a charge of blood-guiltiness against Minamoto Yoshitsuna, governor of Mino. They flocked to the palace in a truculent mob; but the bushi on duty, being under the command of a Minamoto, did not hesitate to use their bows. Thereupon the yama-hoshi discarded the divine car, hastened back to the temple; and assembling all the priests, held a solemn service invoking the wrath of heaven on the State. In an age of profound superstition sueh action threw the Court into consternation, and infinite pains were taken to persuade Shinto officials of an independent shrine to carry the divine car back to Hici-zan.

Instances of such turbulence were not infrequent, and they account in part for the reckless prodigality shown by Shirakawa in building and furnishing temples. The cenobites did not confine themselves to demonstrations at the palace; they had their own quarrels also. Kōfuku-ji's hand was against Kimbusen and Todai-ji, and not a few priests doffed the stole and cassock to engage in temporary brigandage. The great Taira leader, Tadamori, and his son, Kiyomori - one of the most prominent figures on the stage of medieval Japan dealt strongly with the Shintō communities at Hiyoshi and Gion, and drove the Kofuku-ji priests out of the streets of Kyōto, the result being that this great military family became an object of execration at Kōfuku-ji and Enryaku-ji alike. With difficulty the Court kept peace between them. It is related of Shirakawa $H \bar{o}-\bar{o}$ that the three things which he declared to defy his control were the waters of the Kamo River, the fall of the dice, and the yama-hoshi. 


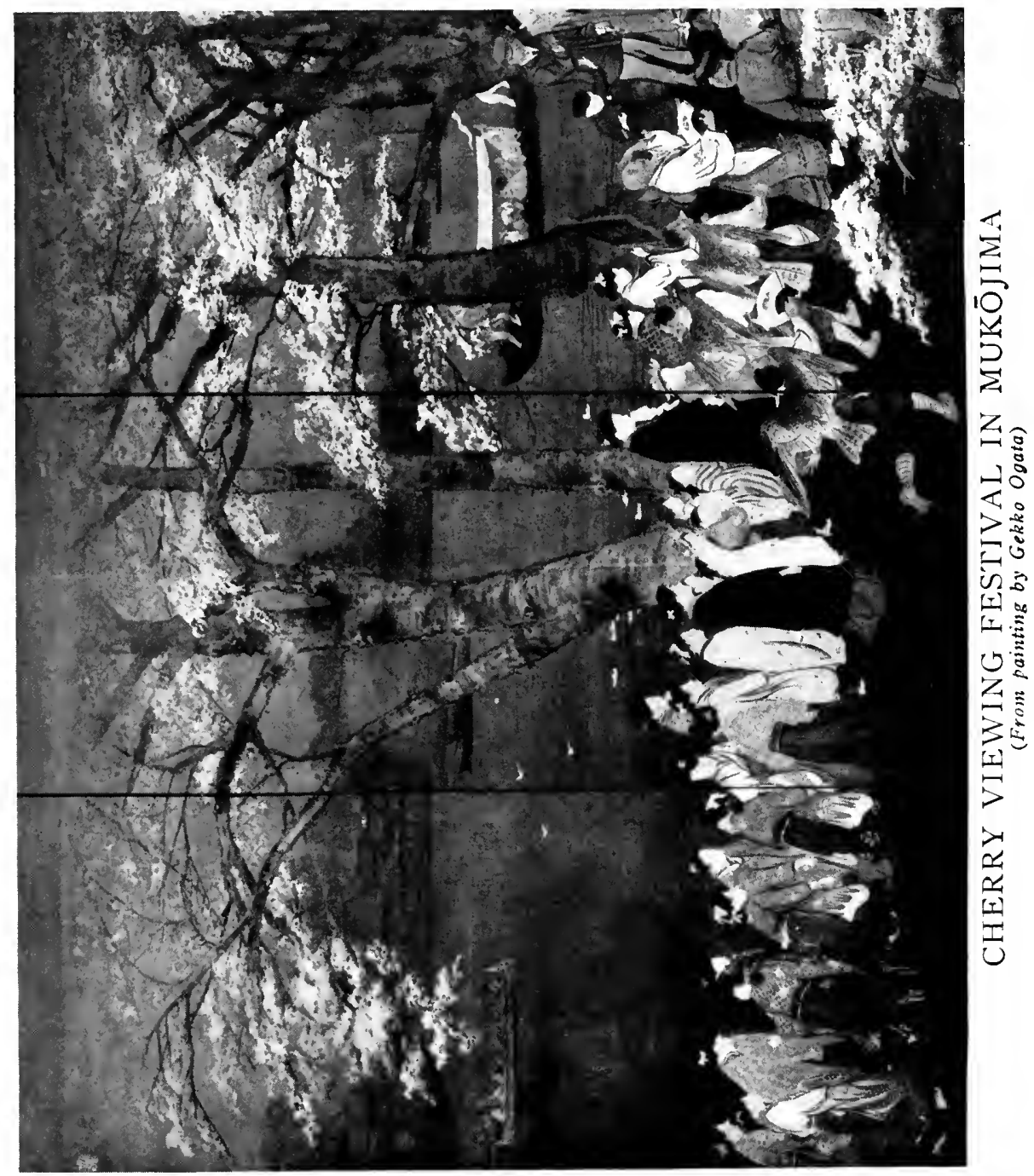




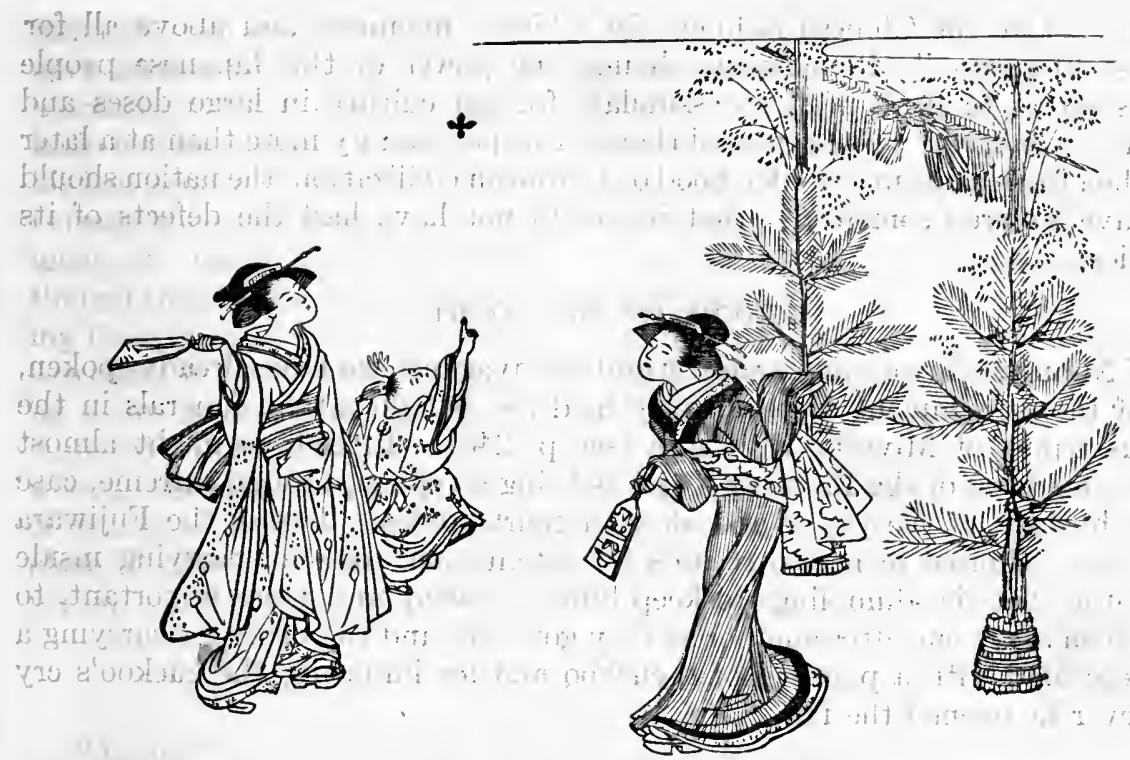

Praying Battledore and Shuttlecock

(From a painting)

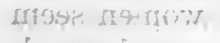

\section{CHAPTER XXIII}

\section{MANNERS AND CUSTOMS OF THE HEIAN EPOCH}

\section{GENERAL SUMMARY}

The period we are considering is a long one which owes its unity to the sole fact that the capitol was at Kyōto. It is, therefore, unsafe to generalize on its manners and customs. But we may say with a degree of accuracy that the epoch was marked by an increasing luxury and artificiality, due largely to the adoption of Chinese customs. The capital city was built on a Chinese pattern and the salient characteristics of the Court during the period named from the new capital are on the Chinese pattern too. The Chinese idea of a civil service in which worth was tested by examinations was carried to a pedantic extreme both in administration and in society. In these examinations the important paper was in Chinese prose composition, which was much as if Latin prose were the main subject to prove the fitness of a candidate for an English or American administrative post! And the tests of social standing and the means of gaining fame at Court were skill in verse-writing, in music and dancing, in calligraphy and other forms of drawing, and in taste in landscape gardening.

Ichijō was famed as a musician and a prose writer, and Saga as a calligraphist. The Akō incident (see p. 240) illustrates the lengths to which pedantry was carried in matters of administration. And the story of the ill-success at the capital of the young soldier Taira Masakado, contrasted with the popularity. of his showily vicious kinsman Sadabumi (see p. 253); illustrate what Murdoch means when he says that the early emperors of the Heian epoch had an "un- 
balanced craze for Chinese fashions, for Chinese manners, and above all for Chinese literature." Remarkable though the power of the Japanese people always seems to have been to assimilate foreign culture in large doses and speedily, it is hardly to be expected that at this period, any more than at a later one when there came in a sudden flood of European civilization, the nation should not have suffered somewhat - that it should not have had the defects of its qualities.

\section{LUXURY OF THE COURT}

Of Nimmyō's luxury and architectural extravagànce we have already spoken, and of the arraignment of prodigality in dress, banquets, and funerals in the famous report of Miyoshi Kiyotsura (see p. 246). Indeed; we might almost cite the madness of the Eimperor Yozei as being a typical, though extreme, case of the hysteria of the young and affected court nobles. Two of the Fujiwara have been pilloried in native records for ostentation: one for carrying inside his clothes hot rice-dumplings to keep himself warm, and, more important, to fling them away one after another as they got cold; and the other for carrying a fan decorated with a painting of a cuckoo and for imitating the cuckoo's cry whenever he opened the fan.

\section{CONVENTION AND MORALITY}

If the men of the period were effeminate and emotional, the women seem to have sunk to a lower stage of morals than in any other era, and sexual moral-

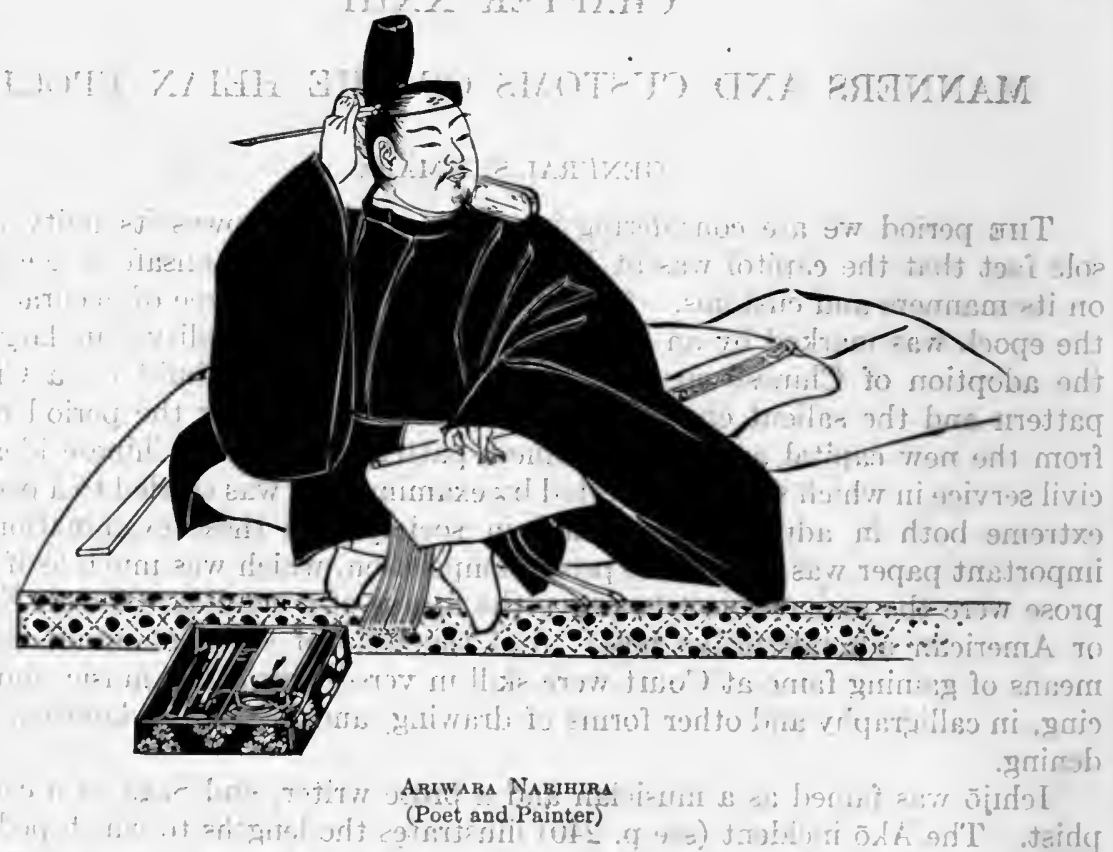

ity and wifely fidelity to have been abnormally bad and lightly esteemed., The story of Ariwara Narihira, prince, poet, painter and Jon Juan; and of Taka and her rise to power (see p. 238) has already been told; and it is to be-noted that the Fujiwara working for the control of the Throne through Imperial consorts 
induced, even forced; the Emperors to set a bad ex.mple in such matters. : But over all this vice there was a veneer of elaborate etiquette. Even in the field a breach of etiquette was a deadly insult: as we have seen (p. 254) Taira Masakado lost the aid of a great lieutenant in his revolt because he forgot to bind up his hair properly before he received a visitor.- At Court, etiquette and ceremony became the only functions of the nominal monarch after the camera government of the cloistered ex-Emperors had begun. And-aristocratic women, though they might be notoriously unfaithful, kept up a show of modesty, covering their faces in public, refusing to speak to a stranger, going abroad in closed carriages or heavily veiled with hoods, and talking to men with their faces hid by a fan, a screen, or a sliding door, these degrees of intimacy being nicely adjusted to the rank and station of the person addressed. Love-making and wooing were governed by strict and conventional etiquette, and an interchange of letters of a very literary and artificial type and of poems usually took the place of personal meetings. Indeed, literary skill and appreciation of Chinese poetry and art were the main things sought for in a wife.

\section{AMUSEMENTS}

The pastimes of Court society, in these years differed not so much in kind as in degree from those of the Nara epoch. In amusement; as in all else, there was extravagance and elaboration. What has already been said of the passion for literature would lead us to expect to find in the period an extreme development of the couplet-tournament (uta awase) which had had a certain vogue in the Nara epoch and was now a furore at Court. The Emperor Kōkō and other Emperors in the first half of the Heian epoch gave splendid versemaking parties, when the palace was richly decorated, often with beautiful flowers. In this earlier part of the period the gentlemen and ladies of the Court were separated, sitting on opposite sides of the room in which the party was held. Iater in the Heian epoch the composition of love letters was a favorite competitive amusement, and although canons of elegant phraseology were implicitly followed, the actual contents of these fictitious letters were frankly indecent.

Other literary pastimes were: "incense-comparing," a combination of poetical dilletantism and skill in recognizing the fragrance of different kinds of incense burned separately or in different combinations; supplying famous stanzas of which only a word or so was given; making riddles in verse; writing verse or drawing pictures on fans, testing literary and artistic skill; and making up lists of related ideographs. The love of flowers was carried to extravagant lengths. "The camera Court in particular organized magnificent picnics to see the cherry-trees of Hosho-ji and the snowy forest at Koya. There were spring festivals of sunrise at Sagano and autumn moonlight excursions to the Öi River. The taste of the time was typified in such vagaries as covering trees with artificial flowers in' winter and in piling up'snow so that some traces of snowy landscapes might still be seen in spring or summer. Such excess reminds the student of decadent Rome as portrayed by the great Latin satirists.

Other favorite amusements at Court were: gathering sweet-flag in summer and comparing the length of its? roots, hawking, fan-lotteries, a kind of backgammon called sugoroku, and different forms of gambling. Football was played, a Chinese game in which the winner was he who kicked the ball highest and kept it longest from touching the ground.

Another rage was keeping animals as pets, especially cats and dogs, which 
received human names and official titles and, when they died, elaborate funerals. Kittens born at the palace at the elose of the tenth century were treated with consideration comparable to that bestowed on Imperial infants. To the cat-

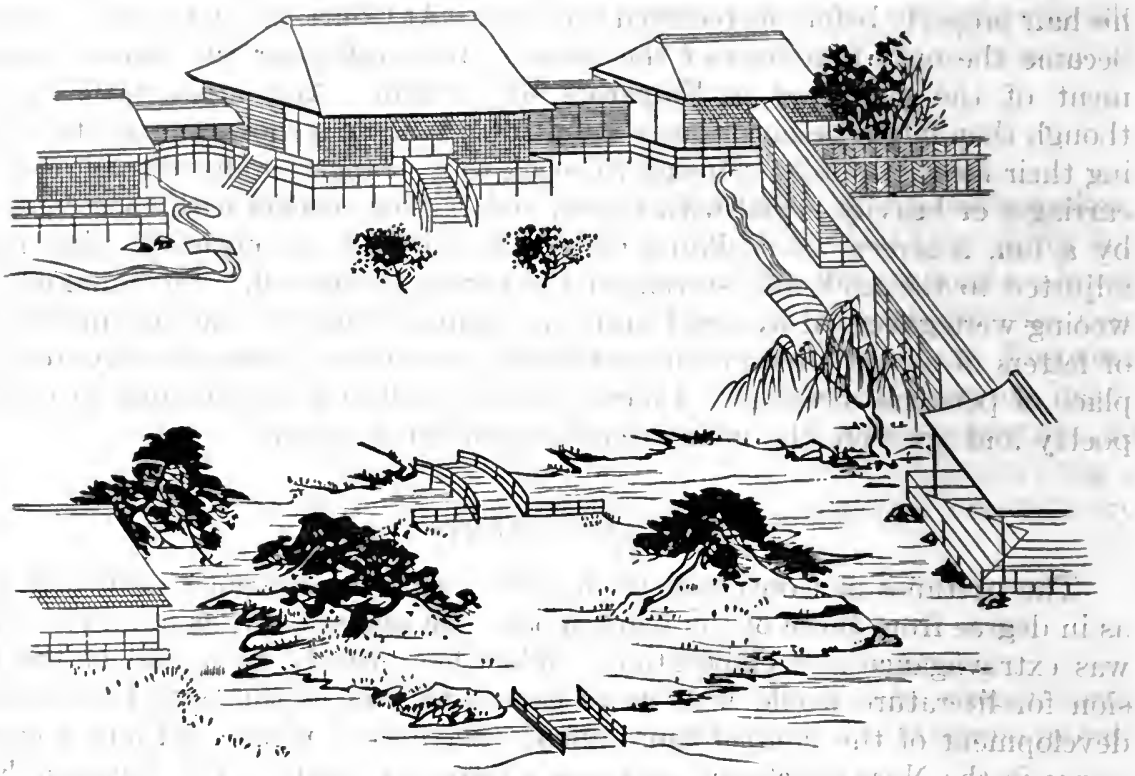

SKetch OF "ShindenzUKURI"

(Style of Dwelling House of Nobles in the Heian Epoch)

mother the courtiers sent the ceremonial presents after childbirth, and one of the ladies-in-waiting was honoured by an appointment as guardian to the young kittens.

\section{MUSIC AND DANCING}

With the growth of luxury in the Heian epoch and the inerease of extravagant entertainment and amusement, there was a remarkable development of music and the dance: Besides the six-stringed harp or wagon, much more complex harps or lutes of thirteen or twenty-five strings were used, and in general there was a great increase in the number and variety of instruments. Indeed, we may list as many as twenty kinds of musical instruments and three or four times as many varieties of dance in the Heian epoch. Most of the dances were foreign in their origin, some being Hindu, more Korean, and still more Chinese, according to the usual classification. But imported dances, adaptations of foreign dances, and the older native styles were all more or less pantomimic.

\section{ARCHITECTURE AND LANDSCAPE GARDENING}

Except in the new eapital city with its formal plan there were no great innovations in architecture. Parks around, large houses and willows and cherry-trees planted along the streets of Kyoto relieved this stiffness of the great city. Landscape-gardening became an art. Gardens were laid out in front of the row of buildings that made up the home of each noble or Court official. 
Convention was nearly as rigid here as it was in Court etiquette. In the centre of this formal garden was a miniature lake with bridges leading to an island; there was a waterfall feeding the lake, usually at its southern end; and at the eastern and western limits of the garden, respectively, a grotto for angling and a "hermitage of spring water" - a sort of picnic ground frequented on summer evenings.: The great artist, Kanaoka, of the end of the ninth century worked at laying out these rockeries and tiny parks. A native school of architects, or more correctly carpenters, had arisen in the province of Hida. There was less temple building than in the Nara epoch and more attention was given to the construction of elegant palaces for court officials and nobles. But these were built of wood and were far from being massive or imposing. As in other periods of Japanese architecture, the exterior was sacrificed to the interior where there were choice woodworking and joinery in beautiful woods, and occasionally screen- or wall-painting as decoration. There was still little house-furnishing. Mats (tatami), fitted together so as to cover the floor evenly, were not used until the very close of the period; and then, too, sliding doors began to be used as partitions. The coverings of these doors, silk or "paper, were the "walls" for Japanese mural paintings of the period. As the tatami came into more general use, the bedstead of the earlier period, which was itself a low dais covered with mats and with posts on which curtains and nets might be hung, went out of use, being replaced by silken quilts spread on the floor-mats. Cushions and arm-rests were the only other important pieces of furniture.

\section{COSTUME}

In the Heian epoch, Court costume was marked by the two characteristics that we have seen elsewhere in the period - extravagance and convention. Indeed, it may be said that Chinese dress and etiquette, introduced after the time of Kwammu were the main source of the luxury of the period. Costume was extreme, not alone in being rich and costly, but in amount of material used. Princely and military head-dresses were costly, jewelled, and enormously tall, and women wore their hair, if possible, so that it trailed below their elaborate skirts. Men's sleeves and trousers were cut absurdly large and full; and women's dress was not merely baggy but voluminous. At a palace fête in 1117 the extreme of elegance was reached by ladies each wearing a score or so of different coloured robes: In this period the use of costly and gorgeous brocades and silks with beautiful patterns and splendid embroideries began.

Women at Court, and the Court dandies who imitated them, painted artificial eye-brows high on the forehead, shaving or plucking out the real brows, powdered and rouged their faces and stained their teeth black.

\section{ART}

Ceramics did not advance in the Heian epoch, but in all other branches of art there were rapid strides forward. The development of interior decoration in temples, monasteries, and palaces was due to progress on the part of lacquerers and painters. Gold lacquer, lacquer with a gold-dust surface (called nashi-ji), and lacquer inlaid with mother-of-pearl were increasingly used. Thanks in part to the painters bureau (E-dokoro) in the palace, Japanese painters began to be ranked with their Chinese teachers. Koze Kanaoka was the first to be thus honored, and it is on record that he was engaged to paint figures of arhats 
on the sliding doors of the palace. The epoch also boasted Fujiwara Tameuji, founder of the 'Takuma family of artists, and Fujiwara Motomitsu, founder of the Tosa academy. The sculpture of the time showed greater iskill, but less grandeur of eonception, than the work of the: Nara masters. Sculpture in wood

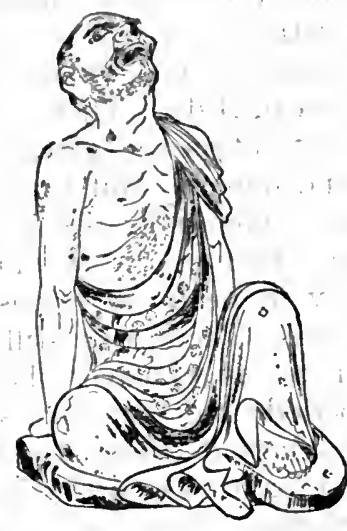

Rakax (Buddhist Disctple) (Carving in Stone at Horiuji)

was important, dating especially from the 11th century: Jōchō, possibly the greatest of the workers in this medium, followed Chinese models, and earved a famous Buddhar for Michinaga's temple of Hosho-ji (1022)! [qu Jöehō's descendant Unkei was the ancestor of many busshi or sculptors of Buddhist statues; and Kwaikei, a pupil of Unkei's brother Jōka$\mathrm{ku}$, is supposed to have collaborated with Unkei on the great gate-guardians of $/$ the Todai-ji temple. It is important to note that, especially in the latter half of the Heian cpoch, painters and sculptors were usually men of good family. Art had become fashionable.ro

Two minor forms of sculpture call for special attention. The decoration of armour reached a high pitch of elaboration; and the beautiful armour of Minamoto Yoshitsune is still preserved at Kasuga, Nara. And masks to be used in mimetic dances, such as the $N \bar{o}$, received attention from many great glyptic artists.

\section{AGRICULTURE}

In the year 799, cotton-seed, earried by an Indian junk which drifted to the coast of Mikawa, was sown in the provinces of Nankai-dō and Saikai-dō, and fifteen years later, when Saga reigned, tea plants were brought: from overseas and were set out in several provinces. The Emperor Nimmyo :(834-850) had buckwheat sown in the home provinces (Kinai), and the same savereign encouraged the cultivation of sorghum, panic-grass, barley; wheat; large white beans, small red beans, and sesame. It was at this time that the ina-hata (paddy-loom) was devised for drying sheaves of rice before winnowing $\mathrm{Al}$ though it was a very simple implement, it nevertheless proved of such great value that an Imperial command was issued urging its wide use. In short, in the early years of the Heian epoch, the Throne took an active part in promoting agriculture, but this wholesome interest gradually declined in proportion to the extension of tax-free manors (shöen).

\section{TRADE}

The story of trade resembled that of agriculture - prosperous development at the beginning of the era, followed by stagnation and decline. Under Kwammu (782-805) and his immediate successors, canals and roads were opened, irrigation works were undertaken, and coins were frequently cast. But coins were slow in finding their way into circulation, and taxes were generally paid in kind. Nevertheless, for purposes of trade, prices of staples were fixed in terms of coin. Thus in the year 996, a koku (about 5 bushels) of rice was the equivalent of 1000 cash ( $i k-k a n-m o n)$; a koku of barley was valued at 2500 cash, 
and a hiki (25 yards) of silk at 2000 cash. Yet in actual practice, commodities were often assessed in terms of silk or rice. Goods were packed in stores (kura) or disposed on shelves in shops (machi-ya), and at ports where merchantmen assembled there were houses called tsuya (afterwards toiya) where wholesale transactions were conducted on the commission system.

a's The city of Kyōto wảs divided into two parts, an eastern capital (Tōkyō) and a western capital (Saikyō). During the first half of every month all commercial transactions were conducted in the eastern capital, where fifty-one kinds "of commodities were sold in fifty-one shops; and during the second half the western capital alone was frequented, with its thirty-three shops and thirtythree classes of goods. After the abolition of embassies to China, at the close of the ninth century, oversea trade declined for a time. But the inhabitants of Tsukushi and Naniwa, which were favourably located for voyages, continued to visit China and Korea, whence they are reported to have obtained articles of value. Other ports frequented by foreign-going ships were Kanzaki, Eguchi, Kaya, Otsu, and Hakata.

\section{SUPERSTITION}

Turning to the inner life of the people in the Heian epoch, we may say with little fear of exaggeration that the most notable thing was the increase of superstition. This was due in part at least to the growth in Japan of the power of Buddhism, and, be it understood, of Buddhism of a degraded and debased form. The effort to combine Buddhism and Shinto probably robbed the latter of any power it might otherwise have had to withstand superstition. Although men of the greatest ability went into the Buddhist monasteries, including many Imperial princes, their eminence did not make them better leaders and guides of the people, but rather aided them in misleading and befooling the laity. Murdoch in speaking of the beginning of the 12th century says: "At this date, Buddhism in Japan from a moral point of view was in not a whit better case than was the Church of Rome between the death of Sylvester II and the election of Leo IX." An interesting parallel might be drawn between Japanese and European superstition, as each was consequent on the low standards of the clergy of the times. The famous report of Miyoshi Kiyotsura, to which we have so often alluded, spoke in no measured terms of the greed and vice of the Buddhist priests. And the character of these hireling shepherds goes far to explain the gross superstition of the time. We have told (p. 274) the story of the abbot Raigo and how the Court was forced to purchase from him intercessory prayers for the birth of an heir, and of the death of the heir in apparent consequence of Raigo's displeasure. Near the end of the ninth century one Emperor made a gift of 500,000 yen for prayers that seemed to have saved the life of a favourite minister. Prayers for rain, for prolonged life, for victory over an enemy, were implicitly believed to be efficient; and priests received large bribes to make these prayers., Or they received other rewards: the privilege of coming to Court in a carriage was granted to one priest for bringing rain after a long drought and to another for saving the life of a.sick prince-in 981. As men got along in years they had masses said for the prolongation of their lives, - with an increase in the premium each year for such life insurance. Thus, at forty, a man had masses said in forty shrines, but ten years later at fifty shrines in all.

In this matter, as in others, the influence of the. Fujiwara was great. They were in a close alliance with the priests, and they controlled the Throne through consorts and kept the people in check through priests and superstitions. 
With the widespread belief in the power of priestly prayer there was prevalent a fear of spirits and demons. Oda received a promise in a dream that he would become Emperor. In the next generation the Emperor Daigo exiled Sugawara Michizane to Kyūshū, where the exile died in two years. Soon afterwards the Emperor fell sick; and this, the disaster of 930 when a thunderstorm killed many nobles in the Imperial palace, and the sudden death of Michizane's accusers and of the Crown Prince were explained as due to the ill-will of the injured man's spirit. His titles were restored and everything possible was done to placate the ghost (see p. 244). To an earlier period belongs the similar story

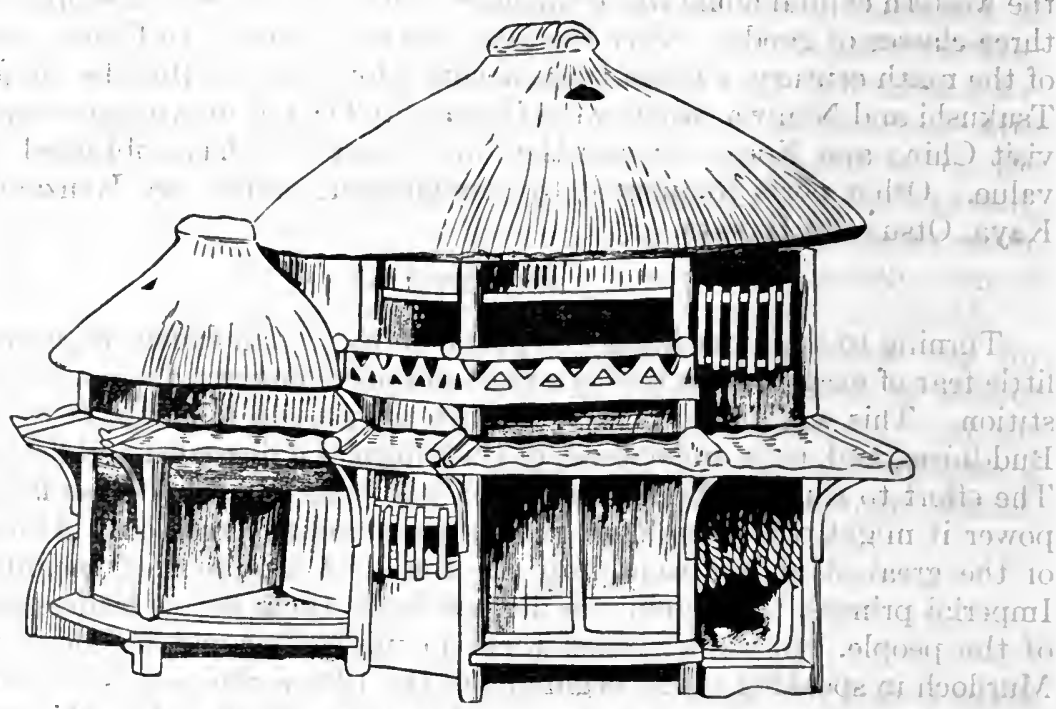

Earthen-Ware Houge for Ornament

of Kwammu and his efforts to placate the spirit of his younger brother whom he had exiled and killed. Kwammu, fearing that death was coming upon him, built a temple to the shade of this brother. A cloud over the palace of another Emperor was interpreted as a portentous monster, half monkey and half snake, and one of the Minamoto warriors won fame for his daring in shooting an arrow at the cloud, which then vanished. Equally foolhardy and marvellous was the deed of Fujiwara Michinaga, who alone of a band of courtiers in the palace dared one dark night to go unattended and without lights from one end of the palace to the other.

When the new city of Kyōto was built, a Buddhist temple was put near the northeast gate to protect the capital from demons, since the northeast quarter of the sky belonged to the demons; and on a hill a clay statue was ereeted, eight feet high and armed with bow, arrows and cuirass, to guard the city. So implicit was the belief in the power of this colossal charm that it was said that it moved and shouted to warn the city of danger.

\section{EDUCATION}

There was, of course, no organized system of sehools in this period, but education was not neglected. A university was established in the newly built capital, and there were five family schools or academies for the youth of the 
separate $u j i$. A school and hospital, founded by Fujiwara Fuyutsugu in 825, received an Imperial endowment. At almost exactly the same time (823) the Bunsho-in was founded by Sugawara. The Sogaku-in was founded in 831 by Arihara Yukihara. In 850 the consort of the emperor Saga built the Gakkwan-in for the Tachibana family; and in 841 the palace of Junna became a school. And there was one quasi-public school, opened in 828, in the Tōji monastery south of the capital, which was not limited to any family and was open to commoners.

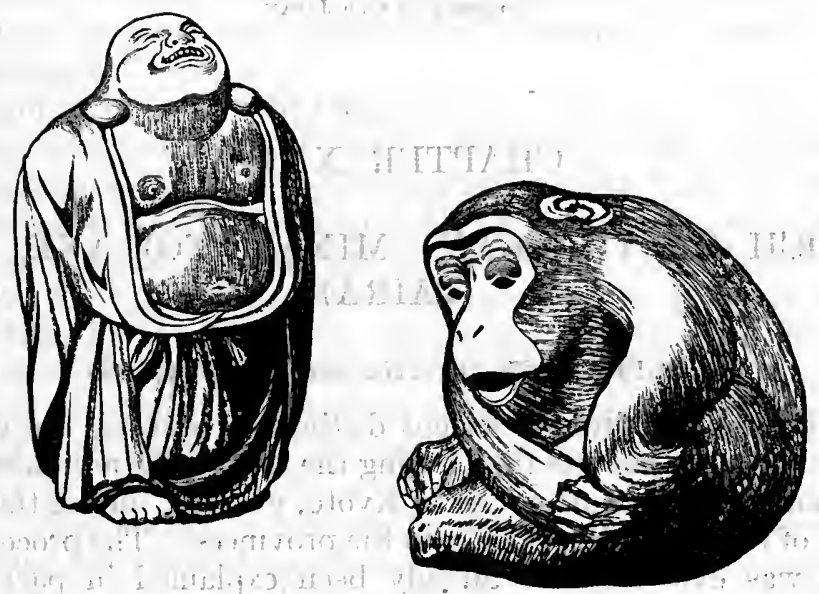

Netsuke

(Hand-carvings in Ivory) 


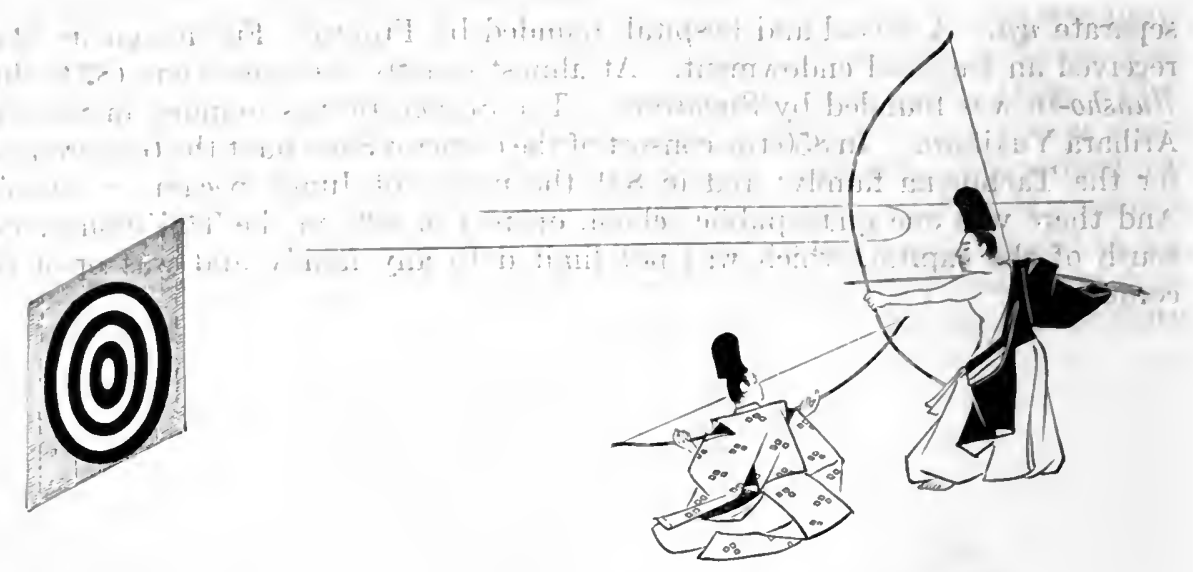

Archery IN Old Japan

\section{CHAPTER XXIV}

\section{THE EPOCH OF THE GEN (MINAMOTO) AND THE HEI}

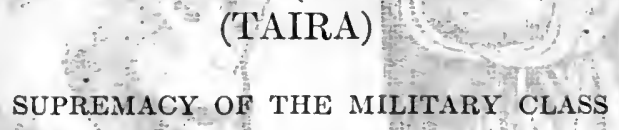

Described superficially, the salient distinction between the epochs of the Fujiwara and the Gen-pei was that during the former the administrative power lay in the hands of the Court nobles in Kyoto, whereas, during the latter, it lay in the hands of the military magnates in the provinces. The processes by which this change was evolved have already been explained in part and will be further elucidated as we advance. Here, however, it is advisable to note that this transfer of authority was, in one sense, a substitution of native civilization for foreign, and, in another, a reversion to the conditions that had existed at the time of the Yamato conquest. It was a substitution of native civilization for foreign, because the exotic culture imported from China and Korea had found its chief field of growth in the capital and had never extended largely to the provinces; and it was a reversion to the conditions existing at the time of the Yamato conquest, because at that time the sword and the sceptre had been one.

The Mononobe and the Ötomo families constituted the pillars of the State under the early Emperors. Their respective ancestors were Umashimade no Mikoto and Michi no Omi no Mikoto. The Japanese term monobe (or monono$f u$ ) was expressed by Chinese ideographs having the sound, bushi. Thus, though it is not possible to fix the exact date when the expression, bushi, came into general use, it is possible to be sure that the thing itself existed from time immemorial. When the Yamato sovereign undertook his eastward expedition, Umashimade with his monobe subdued the central districts, and Michi no Omi with his ótomo and Ōkume-be consolidated these conquests. Thereafter the monobe were organized into the konoe-fu (palace guards) and the otomo into the emon-fu (gate guards). Not military matters alone, but also criminal jurisdiction, belonged to the functions of these two $f u$. 
The earliest type of the Yamato race having thus been military, it becomes important to inquire what tenets constituted the soldier's code in old Japan. Our first guide is the celebrated anthology, Many $\bar{o}-s h \bar{u}$, compiled in the ninth century and containing some poems that date from the sixth. From this we learn that the Yamato monono-fu believed himself to have inherited the duty of dying for his sovereign if occasion required. In that cause he must be prepared at all times to find a grave, whether upon the desolate moor or in the stormy sea. The dictates of filial piety ranked next in the ethical scale. The soldier was required to remember that his body had been given to him by his parents; and that he must never bring disgrace upon his family name or ever disregard the dictates of honour. Loyalty to the Throne, however, took precedence among moral obligations. Parent, wife, and child must all be abandoned at the call of patriotism. Such, as revealed in the pages of the Myriad Leaves, were the simple ethics of the early Japanese soldier. And it was largely from the Mononobe and Ōtomo families that high officials and responsible administrators were chosen at the outset.

When Buddhism arrived in the sixth century, we have seen that it encountered resolute opposition at the hands of Moriya, the $\bar{o}$-muraji of the Mononobe family. That was natural. The elevation of an alien deity to a pedestal above the head of the ancestral Kami seemed specially shocking to the soldier class. But the tendency of the time was against conservatism. The Mononobe and the O'tomo forfeited their position, and the Soga stepped into their place, only to be succeeded in turn by the Fujiwara. These last, earnest disciples of Chinese civilization, looked down on the soldier, and delegated to him alone the use of brute force and control of the criminal classes, reserving for themselves the management of civil government and the pursuit of literature, and even leaving politics and law in the hands of the schoolmen.

In these circumstances the military families of Minamoto (Gen) and Taira (Hei), performing the duties of guards and of police, gradually acquired influence; were trusted by the Court on all occasions demanding an appeal to force, and spared no pains to develop the qualities that distinguished them-the qualities of the bushi. Thus, as we turn the pages of history, we find the ethics of the soldier developing into a recognized code. His sword becomes an object of profound veneration from the days of Minamoto Mitsunaka, who summons a skilled swordsmith to the capital and entrusts to him the task of forging two blades, which, after seven days of fasting and prayer and sixty days of tempering, emerge so trenchant that they are thereafter handed down from generation to generation of the Minamoto as treasured heirlooms.'

That the bushi's word must be sacred and irrevocable is established by the conduct of Minamoto Yorinobu who, having promised to save the life of a bandit if the latter restore a child taken as a hostage, refuses subsequently to inflict any punishment whatever on the robber. That a bushi must prefer death to surrender is a principle observed in thousands of cases, and that his family name must be carefully guarded against every shadow of reproach is proved by his habit of prefacing a duel on the battle-field with a recitation of the titles and deeds of his ancestors. To hold to his purpose in spite of evil report; to rise superior to poverty and hardship; not to rest until vengeance is exacted for wrong done to

['The swords were named "Knee-cutter" and "Beard-cutter," because when tested for decapitating criminals, they severed not only the necks but also the beard and the knees.] 
a benefactor or a relation; never to draw his sword except in deadly earnest these are all familiar features of the bushi's praetice, though the order and times of their evolution cannot be precisely traced.

Even more characteristic is the quality called fudoshin, or immobility of heart. That this existed in practice from an early era cannot be doubted, but its cultivation by a reeognized system of training dates from the beginning of the thirteenth century, when the introspective tenet (kwanshin-hö) of the Zen seet of Buddhism taught believers to divest themselves wholly of passion and emotion and to educate a mind unmoved by its environment, so that, in the storm and stress of battle, the bushi remains as calm and as self-possessed as in the quietude of the council chamber or the sacred stillness of the cloister. The erown of all his qualities was self-respeet. He rated himself too high to descend to petty quarrels, or to make the acquisition of rank his purpose; or to have any regard for money.

THE MILITARY ART

As for tactics, individual prowess was the beginning and the end of all contests, and strategy consisted mainly of deceptions, surprises, and ambushes. There were, indeed, certain reeognized principles derived from treatises compiled by Sung and ' $\mathrm{Ng}$, two Chinese generals of the third century A.D. "These laid down that troops for offensive operations in the field must be twice as numerous as the enemy; those for investing a fortress should be to the garrison as ten to one, and those for escalade as five to one. Outflanking methods were always to be pursued against an adversary holding high ground, and the aim should be to sever the communications of an army having a mountain or a river on its rear. When the enemy selected a position involving vietory or death, he was to be held, not attacked, and when it was possible to surround a foe, one avenue of escape should always be left to him, sinee desperate men fight fiercely. In crossing a river, much space should separate the van from the rear of the crossing army, and an enemy crossing was not to be attacked until his forces had become well engaged in the operation. Birds soaring in alarm should suggest an ambush", and beasts breaking cover, an approaching attack. There was much spying. A soldier who could win the trust of the enemy; sojourn in his midst, and create dissensions in his camp; was called a hero.

Judged by this code of precepts, the old-time soldier of the East has been denounced by some critics as representing the lowest type of military ethics. But such a criticism is romantic. The secret-intelligence department of a twentieth-century army employs and creates opportunities just as zealously as did the disciples of Sung and 'Ng. It is not here that the defects in the bushi's ethies must be sought. The most prominent of those defects was indifference to the rights of the individual. Bushido taught a vassal to sacrifice his own interest and his own life on the altar of loyalty, but it did not teach a ruler to reeognize and respect the rights of the ruled. It taught a wife to efface herself for her husband's sake, but it did not teach a husband any corresponding obligation towards a wife. In a word, it expounded the relation of the whole to its parts, but left unexpounded the relation of the parts to one another.

A correlated fault was excessive reverence for rank and rigid exclusiveness of class. There was practically no ladder for the commoner - the farmer, the 
artisan, and the merchant - to ascend into the circle of the samurai. It resulted that, in the thirteenth and fourteenth centuries, gifted men of the despised grades sought in the cloister an arena for the exercise of their talents, and thus, while the bushi received no recruits, the commoners lost their better elements, and Buddhism became a stage for secular ambition. It can not be doubted that by closing the door of rank in the face of merit, bushido checked the development of the nation. Another defect in the bushido was indifference to intellectual investigation. The schoolmen of Kyōto, who alone received honour for their moral attainments, were not investigators but imitators, not scientists but classicists. Had not Chinese conservatism been imported into Japan and had it not received the homage of the bushi, independent development of original Japanese thought and of intellectual investigation might have distinguished the Yamato race. By a learned Japanese philosopher (Dr. Inouye Tetsujirō) the ethics of the bushi are charged with inculcating the principles of private morality only and ignoring those of public morality.

\section{MILITARY FAMILES AND THEIR RETAINERS}

It has been noticed that the disposition of the Central Government was to leave the provincial nobles severely alone, treating their feuds and conflicts as wholly private affairs. Thus, these nobles being cast upon their own resources for the protection of their lives and properties, retained the services of bushi, arming them well and drilling them assiduously, to serve as guards in time of peace and as soldiers in war. One result of this demand for military material was that the helots of former days were relieved from the badge of slavery and became hereditary retainers of provincial nobles, nothing of their old bondage remaining except that their lives were at the mercy of their masters.

\section{FIEFS AND TERRITORIAL NAMES}

As the provincial families grew in numbers and influence they naturally extended their estates, so that the landed property of a great sept sometimes stretched over parts, or even the whole, of several provinces. In these circumstances it became convenient to distinguish branches of a sept by the names of their respective localities and thus, in addition to the sept name (uji or sei), there came into existence a territorial name (myōji or shi). For example, when the descendants of Minamoto no Yoshiiye acquired great properties at Nitta and Ashikaga in the provinces of Kōtsuke and Shimotsuke, they took the territorial names of Nitta and Ashikaga, remaining always Minamoto; and when the descendants of Yoshimitsu, younger brother of Yoshiiye, acquired estates in the province of Kai, they began to call themselves Takeda.

It is unnecessary to pursue the subject further than to note that, while the names of the great septs (uji) were few, the territorial cognomens were, very numerous; and that while the use of myōji (or shi) was common in the case of the Fujiwara, the Taira, and the Minamoto septs, the $u j i$ alone was employed by the Abe, the Ono, the Takahashi, the Kusakabe, the Ban, the Hata, and certain others. It will readily be conceived that although the territorial sections of the same sept sometimes quarrelled among themselves, the general practice was that all claiming common descent supported each other in war. The Minamoto (Gen) bushi recognized as the principal family line that of Tsunemoto from whom were descended the following illustrious chiefs:- 
Minamoto (Gen) no Tsunemoto, commander-in-chief of local Governments

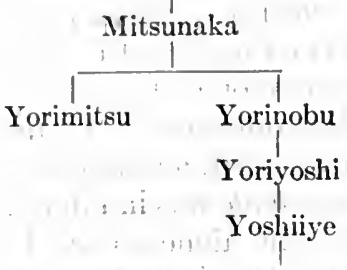

Yoshimune Yoshichika Yoshikuni Yoshitada Yoshitoki Yoshitaka

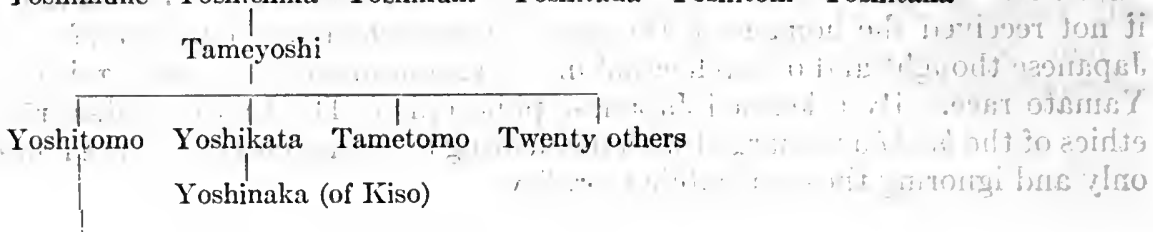

Yoritomo Noriyori Yoshitsune Six others

A similar table for the Taira (Hei) runs thus:-

Taira (Hei) no Sadamori (quelled the Masakado revolt).

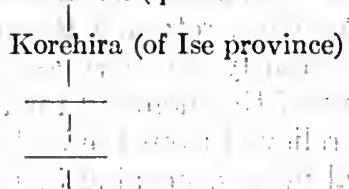

Masamori (governed Ise, Inaba, Sanuki, etc.; quelled the rebellion of Minamoto Yoshichika).

Tadamasa Tadamori (served the Emperors Shirakawa, Horikawa, and Toba; 1 subdued the pirates of Sanyō-dō and Nankai-dō)

Kiyomori (crushed the Minamoto and temporarily established the

Shigemori supremacy of the Taira):

In its attitude towards these two families the Court showed short-sighted shrewdness. It pitted one against the other. If the Taira showed turbulence, the aid of the Minamoto was enlisted; and when a Minamoto rebelled, a Taira received a commission to deal with him. Thus, the Throne purchased peace for a time at the cost of sowing, between the two great military clans, seeds of discord destined to shake even the Crown. In the capital the bushi served as palace guards; in the provinees they were practically independent. "Such was the state of affairs on the eve of a frerce struggle known in history as the tumult of the Hogen and Heiji eras (1150-1160).

[2]It is of this noble that history records an incident illustrative of the superstitions of the eleventh century. The cloistered Emperor Shirakawa kept Tadamori constantly by his side. One night, Shirakawa, accompanied by Tadamori, went to visit a lady fayourite in adetached palace near the shrine of Gion. Suddenly the two men saw an apparition of a demon covered with wirelike hair and having a luminous body! The Emperor ordered Tadamori to use his bow. ' But Tadamori advanced boldly and, seizing the demon, found that it was an old man wearing straw headgear as a protection against the rain, and carrying a lamp to kindle the light at the shrine: 'This valiant deed on Tadamori's part elicited universal applause, as indeed it might in an era of such faith in the supernatural.] 


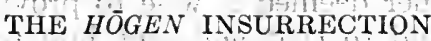

It has been related in Chapter XXII that Taiken-mon-in, consort of the Emperor Toba, was chosen for the latter by his grandfather, the cloistered Emperor Shirakawa, and that she bore to Toba a son who ultimately ascended the throne as Sutoku. But; rightly or wrongly; Toba learned to suspect that before she became his wife, the lady's relations with' Shirakawa had been overintimate and that Sutoku was illegitimate. Therefore, immediately after Shirakawa's demise, Toba took to himself an Empress, Kaya-no-in, daughter of Fujiwara Tadazane; and failing offspring by hèr, chose another Fujiwara lady, Bifuku-mon-in, daughter of Nagazane. For this, his third consort, he conceived a strong affection, and when she bore to him a prince, Toba placed the latter on the throne at the age of three, compelling Sutoku to resign. This happened in the year 1141, and there were thenceforth two cloistered Emperors, Toba and Sutoku, standing to each other in the relation of grandfather and grandson. The baby sovereign was called Konoe, and Fujiwara Tadamichi, brother of Bifuku-mon-in, became kwampaku.

Between this Tadamichi and his younger brother, Yorinaga, who held the post of sa-daijin, there existed acute rivalry. The kwampaku had the knack of composing a deft couplet and tracing a graceful ideograph. The sa-daijin, a profound scholar and an able economist, ridiculed penmanship and poetry as mere ornament. Their father's sympathies were wholly with Yorinaga, and he ultimately went so far as to depose Tadamichi from his hereditary position as $\bar{o}$-uji of the Fujiwara. Thus, the enmity between Tadamichi and Yorinaga needed only an opportunity to burst into flame, and that opportunity was soon furnished:

The Emperor Konoe died (1155) at the early age of seventeen, and the cloistered sovereign, Sútoku, sought to secure the throne for his son Shigehito, whom Toba's suspicions had disqualified. But Bifuku-mon-in, believing, or pretending to believe, that the premature death of her son had been caused by Sutoku's incantations, persuaded the cloistered Emperor, Toba, in that sense, and having secured the co-operation of the kwampaku; Tadamichi, she set upon the throne Toba's fourth son, under the name of Go-Shirakawa (1156-1158), the latter's son, Morihito, being nominated Crown Prince, to the complete exclusion of Sutoku's offspring. $t$ So long as Toba lived the arrangement remained undisturbed, but on his death in the-following year (1156), Sutoku, supported by the sa-daijin, Yorinaga, planned to ascend the throne again, and there ensued a desperate struggle. Stated thus briefly, the complication suggests merely a quarrel for the succession, but, regarded more closely; it is seen to derive rancour chiefly from the jealousies of the Fujiwara brothers, Yorinaga and Tadamichi, and importance from the association of the Minamoto and the Taira families. For when Sutoku appealed to arms against the Go-Shirakawa faction, he was incited by Fujiwara Yorinaga and his father Tadazane, and supported by Taira Tadamasa as well as by the two Minamoto, Tameyoshi and Tametomo; while Go-Shirakawa's cause wás espoused by Fujiwara Tadamichi, by Taira no Kiyomori, and by Minamoto Yoshitomó:

Among this group of notables the most memorable in a historical sense are Minamoto Tametomo and Taira Kiyomori. of the latter there will presently be occasion to speak again. The former was one of those born warriors illustrated by Yamato-dake, Saká-no-ye no Tamura-maro, and Minamoto no Yoshiiye. Eighth son of Minamoto Tameyoshi, he showed himself so masterful, physically 
and morally, that his father decmed it wise to provide a distant field for the exereise of his energies and to that end sent him to Bungo in the island of Kyüshū. Tametomo was then only thirteen. In two years he had established his sway over nearly the whole island, and the ceaseless excursions and alarms caused by his doings having attraeted the attention of the Court, orders for his chastisement were issued to the Dazai-fu. in Chikuzen - futile orders illustrating only Kyōto's ignorance. Tameyoshi, his father, was then removed from office as a punishment for his son's contumacy, and thereupon Tametomo, esteeming filial piety as one of the bushi's first obligations, hastened to the capital, taking with him only twenty-five of his principal retainers. His age was then seventeen; his height seven feet; his muscular development enormous, and he could draw a bow eight feet nine inches in length. His intention was to purchase his father's pardon by his own surrender, but on reaching Kyoto he found the Hōgen tumult just breaking out, and, of course, he joined his father's party.

The relationship of the opposing nobles deserves to be studied, as this was probably one of the most unnatural struggles on record

THE CLOISTERED EMPEROR'S

SIDE

Sutoku (the $J \bar{o}-\bar{o})$

Fujiwara Yorinaga

Fujiwara Tadazane

Minamoto Tameyoshi

Minamoto Tametomo

Taira no Tadamasa
THE REIGNING EMPEROR'S

\section{SIDE}

Go-Shirakawa, younger brother of Sutoku.

Fujıwara Tadamichi, son of Tadazane and brother of Yorinaga.

Minamoto Yoshitomo, son of Tameyoshi and brother of Tametomo.

Taira no Kiyomori, nephew of Tadamasa

Sutoku's party oceupied the Shirakawa palace. Unfortunately for the ex-Emperor the conduct of the struggle was entrusted to Fujiwara Yorinaga, and he, in defiance of Tametomo's advice, decided to remain on the defensive; an evil choice, since it entailed the tenure of wooden buildings highly inflammable. Yoshitomo and Kiyomori took full advantage of this strategical error. They forced the Shirakawa palace, and after a desperate struggle, ${ }^{1}$ the defenders took to flight. Thus far, except for the important issues involved and the unnatural division of the forces engaged, this Hoggen tumult would not have differed materially from many previous conflucts. But its sequel acquired terrible notoriety from the eruel conduct of the victors. Sutoku was exiled to Sanuki, and there, during three years, he applied himself continuously to copying a Buddhist Sutra, using his own blood for ink. The doctrine of the Zen sect had not yet prevailed in Japan, and to obtain compensation in future happiness for the pains he had suffered in life, it was essential that the exile's laboriously traced Sutra should be solemnly offered to the Buddha." He sent it to Kyōto," praying that the necessary step should be taken. But by the orders of his own brother, the Emperor, the request was refused, and the manuscript returned. Superstition ultimately succeeded where natural affection had failed; for the ex-Emperor, having inscribed maledictions on each of the five volumes of the

1 One incident of the fight has been admiringly handed down to posterity. The duty of holding the west gate of the Shirakawa palace fell to Tametomo and his handful of followers. The duty of attacking it happened to devolve on his brother, Yoshitomo. To avert such an unnatural conflict, Tamctomo, having proclaimed his identity, as was usual among bushi, drew his bow with such unerring aim that the arrow shore off an ornament from Yoshitomo's helmet without injuring him in any way. Yoshitomo withdrew, and the Taira took up the attack:]. 
Sutra with blood obtained by biting his tongue, and having hastened his demise by self-inflicted privations, - he died (1164) eight years after being sent into exile - the evils of the time were attributed to his unquiet spirit and a shrine was built to his memory.

Not less heartless was the treatment of the vanquished nobles. The Fujiwara alone escaped. Yorinaga had the good fortune to fall on the field of battle, and his father, Tadazane, was saved by the intercession of his elder son, Tadamichi, of whose dislike he had long been a victim. But this was the sole spot of light on the sombre page. By the Emperor's: orders, the Taira chief, Kiyomori, executed his uncle, Tadamasa; by the Emperor's orders, though not without protest; the Minamoto chief, Yoshitomo, put to death his father, Tameyoshi; by the Emperor's orders all the relatives of Yorinaga were sent into exile; by the Emperor's orders his nephew, Prince Shigehito, was compelled to take the tonsure, and by the Emperor's orders the sinews of Tametomo's bow-arm were cut and he was banished to the Izu island: ${ }^{1}$ In justice it has to be noted that Go-Shirakawa did not himself conceive these merciless measures. He was prompted thereto by Fujiwara Michinori, commonly known as Shinzei, whose counsels were all-powerful at the Court in those days.

\section{GO-SHIRAKAWA}

Go-Shirakawa, the seventy-seventh sovereign, occupied the throne during two years only $(1156-1158)$, but he made his influence felt from the cloister throughout the long period of thirty-four years (1158 to 1192), directing the administration from his "camera palace" (Inch $\bar{u})$ during the reigns of five Emperors. Ambition impelled him to tread in the footsteps of Go-Sanjō. He re-opened the Office of Records (Kiroku-jo), which that great sovereign had established for the purpose of centralizing the powers of the State, and he sought to recover for the Throne its administrative functions. But his independence was purely nominal, for in everything he took counsel of Fujiwara Michinori (Shinzei) and obeyed that statesman's guidance. Michinori's character is not to be implicitly inferred from the cruel courses suggested by him after the Hoggen tumult. He was a man of keen intelligence and profound learning, as learning went in those days: that is to say, he knew the classics by heart, had an intimate acquaintance with Buddhism and astrology, and was able to act as interpreter of the Chinese language. With his name is associated the origin of the shirabyoshi, or "white measure-markers"-girls clad in white, who, by posture and gesture, beat time to music, and, in after ages, became the celebrated geisha of Japan. To the practice of such arts and accomplishments Michinori devoted a great part of his life, and when, in 1140, that is to say, sixteen years before the Hoggen disturbance, he received the tonsure, all prospect of an official career seemed to be closed to him. But the accession of Go-Shirakawa gave him an opportunity. The Emperor trusted him, and he abused the trust to the further unhappiness of the nation.

\section{THE HEIJI TUMULT}

Go-Shirakawa's son, Morihito, ascended the throne in 1159 and is known in history as Nijo, the seventy-eighth sovereign of Japan. From the very outset

[1. The celebrated litterateur, Bakin, adduced many proofs that Tametomo ultimately made his way to Ryūkyū and that his descendants ruled the island. The great soldier himself died ultimately by his own hand in the sequel' of an unsuccessful engagement with the forces of the vice-governor of Izu.] 
he resented the ex-Emperor's attempt to interfere in the administration of affairs, and the two Courts fell into a state of discord, Fujiwara Shinzei inciting the cloistered Emperor to assert himself, and two other Fujiwara nobles, Tsunemune and Korekata, prompting Nijō to resist. These two, observing that another noble of their clan, Fujiwara Nobuyori; was on bad terms with Shinzei, approached Nobuyori and proposed a union against their common enemy. Shinzei had committed one great error; he had alienated the Minamoto family. In the Hoggen struggle, Yoshitomo, the Minamoto chief, an able captain and a brave soldier, had suggested the strategy: which secured victory for Go-Shirakawa's forces. But in the subsequent distribution of rewards, Y'oshitomo's claims received scant consideration, his merits being underrated by Shinzei.

This had been followed by a still more painful slight. To Yoshitomo's formal proposal of a marriage between his daughter and Shinzei's son, not only had a refusal been given, but also the nuptials of the youth with the daughter of the Taira chief, Kiyomori,-had been subsequently celebrated with much éclat. In short, Shinzei chose between the two great military clans, and though such discrimination was neither inconsistent with the previous practice of the Fujiwara nor ill-judged so far as the relative strength of the Minamoto and the Taira was coneerned for the moment, it erred egregiously in failing to recognize that the day had passed when the military clans could be thus employed as Fujiwara tools. Approached by Nobuyori, Yoshitomo joined hands with the plotters, and the Minamoto troops, forcing their way into the Sanjo palace, set fire to the edifice and killed Shinzei (1159). "The Taira chief, Kiyomori, happened to be then absent in Kumano, and Yoshitomo's plan was to attack him on his way back to Kyoto before the Taira forces had mustered.' But just as Fujiwara Yorinaga had wrecked his cause in the Hogen tumult by ignoring Minamoto Tametomo's advice, so in the Heiji disturbance; Fujiwara Nobuyori courted defeat by rejecting Minamoto Yoshitomo's strategy. The Taira, thus accorded leisure to assemble their troops, wön süch a signal victory that during many years the Minamoto disappeared almost completely from the political stage, and the Taira held the empire in the hollow of their hands.

Japanese historians regard Fujiwara Shinzei as chiefly responsible for these untoward events. Shinzei's record shows him to have been cruel, jealous, and self-seeking, but it has to be admitted that the conditions of the time were calculated to educate men of his type, as is shown by the story of the Hogen insurrection. For when Sutoku's partisans assembled at the palace of Shirakawa, Minamoto Tametomo addressed them thus: "I fought twenty battles and two hundred minor engagements to win Kyūshū, and I say that when an enemy is outnumbered, its best plan is a night attack. If we fire the Takamatsu palace on three sides to-night and assault it from the fourth, the foe will surely be broken. I see on the other side only one man worthy to be called an enemy. It is my brother Yoshitomo, and with a single arrow I can lay him low. As for Taira Kiyomori, he will fall if I do but shake the sleeve of my armour. 'Before dawn we shall be victors."

Fujiwara Yorinaga's reply to this counsel was: "Tametomo's method of fighting is rustic. There are here two Emperors competing for the throne, and the combat must be conducted in a fair and dignified manner." To such silliness the Minamoto hero made apt answer." "War," he said, "is not an affair of official ceremony and decorum. Its management were better left to the bushi whose business it is. My brother Yoshitomo has eyes to see an opportunity. To-night, he will attack us." .It is true that Tametomo afterwards refrained 
from taking his brother's life, but the above proves that he would not have exercised any such forbearance had victory been attainable by ruthlessness. History does not often repeat itself so exactly as it did in these Hōgen and Heiji struggles. Fujiwara Yorinaga's refusal to follow' Tametomo's advice and Fujiwara Nobuyori's rejection of Yoshitomo's counsels were wholly responsible for the disasters that ensued, and were also illustrative of the contempt in which the Fujiwara held the military magnates, who, in turn, were well aware of the impotence of the Court nobles on the battle-field.

The manner of Yoshitomo's death, too, reveals something of the ethics of the bush $i$ in the twelfth century. Accompanied by Kamada Masaie and a fow others, the Minamoto chief escaped from the fight and took refuge in the house of his concubine, Enju, at Awobaka in Owari. There they were surrounded and attacked by the Taira partisans. The end seemed inevitable. Respite was obtained, however, by: one of those heroic acts of self-sacrifice that stand so numerously to the eredit of the Japanese samurai. Minamoto Shigenari, proclaiming himself to be Yoshitomo, fought with desperate valour, killing ten of the enemy. Finally, hacking his own face so that it became unrecognizable, he committed suicide. Meanwhile, Yoshitomo had ridden away to the house of Osada Tadamune, father of his comrade Masaie's wife. There he found a hospitable reception. But when he would have pushed on at once to the east, where the Minamoto had many partisans, Tadamune, pointing out that it was New Year's eve, persuaded him to remain until the 3d of the first month.

Whether this was done of fell purpose or out of hospitality is not on record, but it is certain that Tadamune and his son, Kagemune, soon determined to kill Yoshitomo, thus avoiding a charge of complicity and earning favour at Court. Their plan was to conceal three men in a bathroom, whither Yoshitomo should be led after he had been plied with sake at a banquet. The scheme succeeded in part, but as Yoshitomo's squire, Konnō, a noted swordsman, accompanied his chief to the bath, the assassins dared not attack. Presently, however, Konnō went to seek a bath-robe, and thereupon the three men leaped out. Yoshitomo hurled one assailant from the room, but was stabbed to death by the other two, who, in their turn, were slaughtered by the squire. Meanwhile, Masaie was sitting, unsuspicious, at the wine-party in a distant chamber. Hearing the tumult he sprang to his feet, but was immediately cut down by. Tadamune and Kagemune. At this juncture Masaie's wife ran in, and crying, "I am not faithless and evil like my father and my brother; my death shall show my sincerity,"' seized her husband's sword and committed suicide, at which sight the dying man smiled contentedly. As for Konnō, after a futile attempt to lay. hands on Tadamune and Kagemune, he cut his way through their retainers and rode off safely. The heads of Yoshitomo and Masaie were carried to Kyōto by Tadamune and Kagemune, but they made so much of their exploit and clamoured for such high reward that Kiyomori threatened to punish them for the murder of a close connexion - Kiyomori, be it observed, on whose hands the blood of his uncle was still wet.

Yoshitomo had many sons ${ }^{1}$ but only four of them escaped from the Heiji tumult. The eldest of these was Yoritomo; then only fourteen. After killing two men who attempted to intercept his flight, he fell into the hands of Taira

[' One of these sons, Tomonaga, fell by his father's hand. Accompanying Yoshitomo's retreat, he had been severely wounded, and he asked his father to kill him rather than leave him at A wobake to fall into the hands of the Taira. Yoshitomo consented, though the lad was only fifteen years of age.] 
Munekiyo, who, pitying his youth, induced Kiyomori's step-mother to intercede for his life, and he was finally banished to Izu, whence, a few years later, he emerged to the destruction of the Taira. A still younger son, Yoshitsune; was destined to prove the most renowned warrior Japan ever produced. His mother, Tokiwa, one of Yoshitomo's mistresses, a woman of rare beauty; fled from the Minamoto mansion during a snow-storm after the Heiji disaster, and, with her three children, succeeded in reaching a village in Yamato, where she might have lain concealed had not her mother fallen into the hands of Kiyomori's agents. Tokiwa was then required to choose between giving herself up and suffering her mother to be executed. Her beauty saved the situation. Kiyomori had no sooner seen her face than he offered to have mercy if she entered his household and if she consented to have her three sons educated for the priesthood. Thus, Yoshitsune survived, and in after ages people were wont to say of Kiyomori's passion and its result that his blissful dream of one night had brought ruin on his house.

\section{THE TAIRA AND THE FUJIWARA}

In human affairs many events ascribed by onlookers to design are really the outcome of accident or unforseen opportunity. Historians, tracing the career of Taira no Kiyomori, ascribe to him singular astuteness in creating occasions and marked promptness in utilizing them. But Kiyomori was not a man of original or brilliant conceptions. He had not even the imperturbability essential to military leadership. The most prominent features of his character were unbridled ambition, intolerance of opposition, and unscrupulous pursuit of visible ends. He did not initiate anything but was content to follow in the footsteps of the Fujiwara. It has been recorded that in 1158 - after the Hogen tumult; but before that of Heiji - he married his daughter to a son of Fujiwara Shinzei. In that transaction, however, Shinzei's will dominated. Two years later, the Minamoto's power having been shattered, Kiyomori gave another of his daughters to be the mistress of the kwampaku, Fujiwara Motozane. There was no offspring of this union, and when, in 1166, Motozane died, he left a five-year-old son, Motomichi, born of his wife, a Fujiwara lady. This boy was too young to succeed to the office of regent, and therefore had no title to any of the property accruing to the holder of that post, who had always been recognized as de jure head of the Fujiwara family. Nevertheless, Kiyomori, having contrived that the child should be entrusted to his daughter's care, asserted its claims so strenuously that many of the Fujiwara manors and all the heirlooms were handed over to it, the result being a visible weakening of the great family's influence. ${ }^{1}$

\section{RESULTS OF THE HŌGEN AND HEIJI INSURRECTIONS}

The most signal result of the Hōgen and Heiji insurrections was to transfer the administrative power from the Court nobles to the military chiefs. In no country were class distinctions more scrupulously observed than in Japan. All officials of the fifth rank and upwards must belong to the families of the Court nobility, and no office carrying with it rank higher than the sixth might be oceupied by a military man. In all the history of the empire down to the twelfth century there had been only one departure from this rule, and that was in the case of the illustrious General Saka-no-ye no Tamura-maro, who had been raised to the third rank and made dainagon. 
The social positions of the two groups were even more rigidly differentiated; those of the fifth rank and upwards being termed tenjo-bito, or men having the privilege of entré to the palace and to the Imperial presence; while the lower group (from the sixth downwards) had no such privilege and were consequently

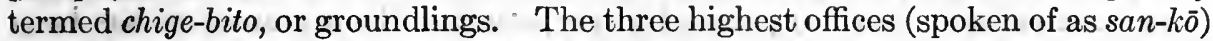
could not be held by any save members of the Fujiwara or Kuga families; and for officès carrying fifth rank upwards (designated taifu) the range of eligible tamilies extended to only four others, the Ariwara, the Ki, the Ōye, and the Kiyowara. All this was changed after the Heiji commotion. The Fujiwara had used the military leaders for their own ends; Kiyomori supplemented his military strength with Fujiwara methods. He caused himself to be appointed sangi (councillor of State) and to be raised to the first grade of the third rank, and he procured for his friends and relations posts as provincial governors, so that they were able to organize throughout the empire military forces devoted to the Taira cause.

These steps were mere preludes to his ambitious programme. He married his wife's elder sister to the ex-Emperor, Go-Shirakawa, and the fruit of this union was a prince who subsequently ascended the throne as Takakura. The Emperor Nijō had died in 1166, after five years of effort, only partially successful, to restrain his father, Go-Shirakawa's, interference in the administration. Nijō was succeeded by his son, Rokujō, a baby of two years; and, a few months later, Takakura, then in his seventh year, was proclaimed Prince Imperial. Rokujo (the seventy-ninth sovereign) was not given time to learn the meaning of the title "Emperor:" In three years he was deposed by Go-Shirakawa with Kiyomori's co-operation, and Takakura (eightieth sovereign) ascended the throne in 1169, occupying it until 1180. Thus, Kiyomori found himself uncle of an Emperor only ten years of age. Whatever may have been the Taira leader's defects, failure to make the most of an opportunity was not among them. The influence he exercised in the palace through his sister-in-law was far more exacting and imperious than that exercised by Go-Shirakawa himself, and the latter, while bitterly resenting this state of affairs, found himself powerless to correct it. Finally, to evince his discontent, he entered the priesthood, a demonstration which afforded Kiyomori more pleasure than pain. On the nomination of Takakura to be Crown. Prince the Taira leader was appointed - appointed himself would be a more accurate form of speech - to the office of nai-daijin, and within a very -brief period he ascended to the chancellorship, overleaping the two intervening posts of $u$-daijin and sa-daijin. This was in the fiftieth year of his life. At fifty-one, he fell seriously ill and took the tonsure by way of soliciting heaven's aid. People spoke of him as Dajō Nyūdō, or the "lay-priest chancellor." Recovering, he developed a mood of increased arrogance. His residence at Rokuhara was a magnificent pile of building, as architecture then went, standing in a park of great extent and beauty. There he administered State affairs with all the pomp and circumstance of an Imperial court. He introduced his daughter, Toku, into the Household and very soon she was made Empress, under the name of Kenrei-mon-in.

Thus completely were the Fujiwara beaten at their own game and the traditions of centuries set at naught. A majority of the highest posts were filled by Kiyomori's kinsmen. Fifteen of his family were of, or above; the third rank, and thirty were tenjo-bito. " "Akitsushima (Japan) was divided into sixty-six provinces. : Of these thirty were governed by Taira partisans. Their manors were to be found in five hundred places, and their fields were innumerable. 
Their mansions were full of splendid garments and rieh robes like flowers', and the spaces before their portals were so thronged with ox-carriages and horses that markets were often held there. Not to be a Taira was not to be a man."'

It is necessary to note, too, with regard to these manors, that many of them were tax-free lands (kōden) granted in perpetuity. Such grants, as has been already shown, were not infrequent. But they had been made, for the most part, to civilian officials, by whose serfs they were farmed, the proceeds being forwarded to Kyōto for the support of their owners; whereas the kōden bestowed on Taira officers were, in effeet, military fiefs. It is true that similar fiefs existed in the north and in the south, but their number was so greatly increased in the days of Taira ascendancy as almost to constitute a new departure. Kiyomori was; in truth, one of the most despotic rulers that ever held sway in Japan. He organized a band of three hundred youths whose business was to go about Kyoto and listen to the citizens' talk. If anyone was reported by these spies as having spoken ill of the Taira, he was seized and punished. One day Kiyomori's grandson, Sukemori, met the regent, Fujiwara Motofusa, and failing to alight from his carriage, as etiquette required, was compelled by the regent's retinue to do so. On learning of this incident, Kiyomori ordered three hundred men to lie in wait for the regent, drag him from his car and cut off his cue.

\section{PLOTS AGAINST THE TAIRA: KIYOMORI'S LAST YEARS}

All these arbitrary ${ }_{n}$ acts provoked indignation among every class of the people. A conspiracy known in history as the "Shishi-ga-tani plot," from the name of the place where the conspirators met to consult, was organized in 1177 , having for object a general uprising against the Taira.: At the Court of the cloistered Emperor the post of gon-dainagon was filled by Fujiwara Nariehika, who harboured resentment against Kiyomori's two sons, Shigemori and Munemori, inasmuch as they held positions for which he had striven in vain, the Left and Right generals of the guards. There was also a bonze, Saikō, who enjoyed the full confidence of Go-Shirakawa. In those days any cause was legitimized if its advocates could show an Imperial edict or point to the preserice of the sovereign in their midst. Thus, in the Heiji insurrection, the Minamoto received their severest blow when Fujiwara Korekata contrived that, under cover of darkness, the Emperor, disguised as a maid-of-honour in the household of the Empress, should be transported in her. Majesty's suite, from the Kurodo palace to the Taira mansion at Rokuhara. The Minamoto were thus transformedinto rebels, and the Taira became the representatives of Imperial authority. Therefore, in the Shishi-ga-tani plot the part assigned to the priest Saiko was to induce Go-Shirakawa to take active interest in the conspiracy and to issue a mandate to the Minamoto bushi throughout the country. No such mandate was issued, nor does it appear that the ex-Emperor attended any of the meetings in Shishiga-tani, but there can be no doubt that he had full cognizance of, and sympathized with, what was in progress.

The conspiracy never matured. It was betrayed by Minamoto Yukitsuna. Saiko and his two sons were beheaded; Narichika was exiled and subsequéntly put to death, and all the rest were banished. The great question was, how to deal with Go-Shirakawa. Kiyomori was for leading troops to arrest his Majesty, and to escort him as a prisoner to the Toba palace or the Taira mansion. None of the despot's kinsmen or adherents ventured to gainsay this purpose until 
Kiyomori's eldest: son, Shigemori, appeared upon the scene. Shigemori had contributed much to the signal success of the Taira. Dowered with all the strategical skill and political sagacity which his father lacked, he had won victories for the family arms, and again and again had restrained the rash exercise of Kiyomori's impetuous arrogance. The Taira chief had learned to stand in awe of his son's reproaches, and when Shigemori declared that he would not survive any violence done to Go-Shirákaiwa'; Kiyomori left the council chamber, bidding Shigemori to manage the matter as he thought fit. Thus, GoShirakawa escaped all the consequences of his association with the conspirators. But Kiyomori took care that a copy of the bonze Saikō's confession, extracted under torture and fully incriminating his Majesty, should come into the Imperial hands.

A final rupture between the ex-Emperor and the Taira leader became daily imminent Two events contributed to precipitate it One was that in the year following the Shishi-ga-tani conspiracy, Kiyomori's daughter, Toku, bore to Takakura a prince - the future Emperor Antoku (eighty-first sovereign). The Taira chief thus found himself grandfather of an heir to the throne, a fact which did not tend to abate his arrogance. The second was the death of Shigemori, which took place in 1179 .

the Shigemori's record shows him to have been at once a statesman and a general. He never hesitated to check his father's extravagances; and it has to be recorded

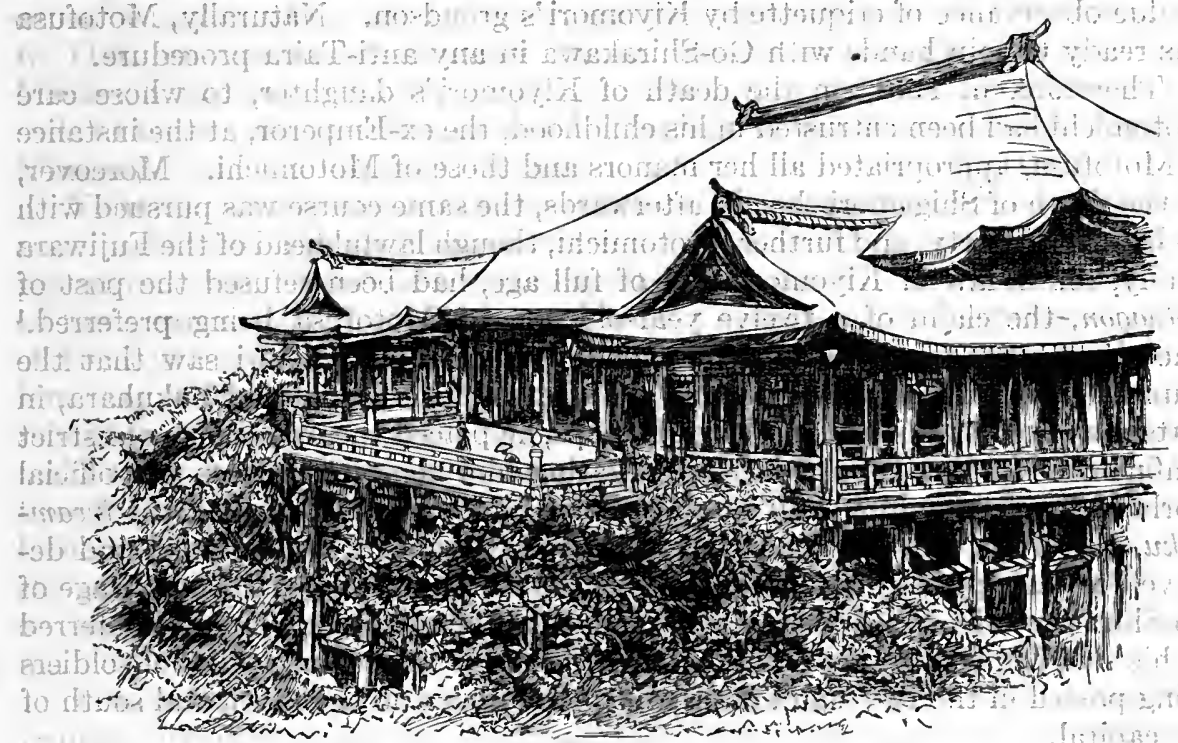

KiYomize-dera Temple, at KYôto

in Kiyomori's favour that, however intolerant of advice or opposition he habitually showed himself; his eldest son's remonstrances were seldom ignored. Yet, though many untoward issues were thus averted, there was no sign that growing responsibility brought to Kiyomori any access of circumspection. From first to last he remained the same short-sighted, passion-driven, impetuous despot and finally the evil possibilities of the sifuation weighed so heavily on Shigemori's

[ ${ }^{1}$ It is recorded that; on this occasion, Kiyomori, learning of his son.'s approach, attempted unsuccessfully to conceal under priestly robes the armour he had donned to go to the arrest of Go-Shirakawa.] 
nerves that he publicly repaired to a temple to pray for release from life. As though in answer to his prayer he was attacked by a disease which carried him off at the age of forty-two. There is a tradition that he installed forty-eight images of Buddha in his mansion, and for their services employed many beautiful women, so that sensual excesses contributed to the semi-hysterical condition into which he eventually fell. That is not impossible, but certainly a sense of impotence to save his father and his family from the calamities he clearly saw approaching was the proximate cause of his breakdown.

Results soon became apparent. The ex-Emperor, who had truly estimated Shigemori's value as a pillar of Taira power, judged that an opportunity for revolt had now arrived, and the Taira chief, deprived of his son's restraining influence, became less competent than ever to manage the great machine which fortune had entrusted to his direction. The first challenge came from the exEmperor's side. It has been related above that one of Kiyomori's politic acts after the Heiji insurrection was to give his daughter to the regent; that; on the latter's death, his child, Motomichi, by a Fujiwara, was entrusted to the care of the Taira lady; that a large part of the Fujiwara estates were diverted from the regent and settled upon Motomichi, and that the latter was taken into a Taira mansion. The regent who suffered by this arbitrary procedure was Fujiwara Motofusa, the same noble whom, a few years later, Kiyomori caused to be dragged from his car and docked of his queue because Motofusa had insisted on due observance of etiquette by Kiyomori's grandson. Naturally, Motofusa was ready to join hands with Go-Shirakawa in any anti-Taira procedure.

Therefore, in 1179, on the death of Kiyomori's daughter, to whose care Motomichi had been entrusted in his childhood, the ex-Emperor, at the instance of Motofusa, appropriated all her manors and those of Motomichi. Moreover, on the death of Shigemori shortly afterwards, the same course was pursued with his landed property, and further, Motomichi, though lawful head of the Fujiwara family, son-in-law of Kiyomori, and of full age, had been refused the post of chūnagon, the claim of a twelve year-old son of Motofusa being preferred.' The significance of these doings was unmistakable. "Kiyomori saw that the gauntlet had been thrown in his face. Hastening from his villa of Fukuhara, in Settsu, at the head of a large force of troops, he placed the ex-Emperor in strict confinement in the Toba palace, segregating him completely from the official world and depriving him of all administrative functions; he banished the kwampaku, Motofusa, and the chancellor, Fujiwara Moronaga; he degraded and deprived of their posts thirty-nine high officials who had formed the entourage of Go-Shirakawa; he raised Motomichi to the office of kwampaku, and he conferred on his son, Munemori, the function of guarding Kyōto, strong bodies of soldiers being posted in the two Taira mansions of Rokuhara on the north and south of the capital.

\section{THE YORIMASA CONSPIRACY}

In 1180, at the instance of Kiyomori and partly, no doubt, because of the difficult position in which he found himself placed with regard to his imprisoned father, the Emperor Takakura, then in his twentieth year, resigned the throne in favour of Kiyomori's grandson, Antoku (eighty-first sovereign), a child of three. This was the culmination of the Taira's fortunes. There was at that time among the Kyotto officials a Minamoto named Yorimasa, sixth in descent from Minamoto Mitsunaka, who flourished in the tenth century and by whose order the 
heirloom swords, Hige-kiri and Hiza-kiri, were forged. This Yorimasa was an expert bowman, a skilled soldier, and an adept versifier, accomplishments not infrequently combined in one person during the Heian epoch. Go-Shirakawa, appreciating Yorimasa's abilities, nominated him director of the Imperial Estates Bureau (Kurando) and afterwards made hin governor of Hyōgo.

But it was not until he had reached the age of seventy-five that, on Kiyomori's recommendation, he received promotion, in 1178, to the second grade of the third rank (ju-sammi), thus for the first time obtaining the privilege of access to the Imperial presence. The explanation of this tardy recognition is, perhaps, to be sought in Yorimasa's preference of prudence to loyalty. In the year. of Heiji, he held his little band of bushi in the leash until the issue of the battle could be clearly forseen, and then he threw in his lot with the Taira. Such shallow fealty seldom wins its way to high place.: Men did not forget Yorimasa's record. His belated admission to the ranks of the tenjo-bito provoked some derision and he was commonly spoken of as Gen-sammi (the-Minamoto third rank).

But even for one constitutionally so cautious, the pretensions of the Taira became intolerable. Yorimasa determined to strike a blow for the Minamoto cause, and looking round for a figure-head, he fixed upon Prince Mochihito, elder brother of Takakura. This prince, being the son of a concubine, had never reached Imperial rank, though he was thirty years of age, but he possessed some capacity, and a noted physiognomist had recognized in him a future : Emperor. In 1170, at Yorimasa's instance, Prince Mochihito secretly sent to all the Minamoto families throughout the empire, especially to Yoritomo at his place of exile in Izu, a document impeaching the conduct of the Taira and exhorting the Minamoto to muster and attack them.

Yorimasa's story shows that he would not have embarked upon this enterprise had he not seen solid hope of success. But one of the aids he counted on proved unsound. That aid was the Buddhist priesthood. Kiyomori had offended the great monasteries by bestowing special favour on the insignificant shrine of Itsukushima-Myojjin. $\mathbf{A}$ revelation received in a dream having persuaded him that his fortunes were intimately connected with this shrine, he not only rebuilt it on a scale of much magnificence, but also persuaded Go-Shirakawa to make three solemn progresses thither. This partiality reached its acme at the time of Takakura's abdication (1180); for instead of complying with the custom hitherto observed on such occasions - the custom of worshipping at one or more shrines of the three great monasteries - Enryaku (Hiei-zan), Kōfuku (Nara), or Onjo (Miidera) - Takakura, prompted by Kiyomori, proceeded to Itsukushima. 1

A monster demonstration on the part of the offended monasteries was temporarily quieted, but deep umbrage rankled in the bosoms of the priests, and Yorimasa counted on their co-operation with his insurrection. $\mathrm{He}$ forgot, however, that no bond could be trusted to hold them permanently together in the face of their habitual rivalry, and it was here that his scheme ultimately broke down. At an early stage, some vague news of the plot reached Kiyomori's ears and he hastened from his Fukuhara villa to Kyōto. But it soon became evident that his information was incomplete. He knew, indeed, that Prince Mochihito was involved, but he suspected Go-Shirakawa also, and he entertained no conception of Yorimasa's complicity. Thus, while removing Go-Shirakawa to Rokuhara and despatching a force to seize Mochihito, he entrusted the 
direction of the latter measure to Yorimasa's son, Kanetsuna, who, it need scareely be said, failed to apprehend the prince or to elicit any information from his followers.

Presently Kiyomori learned that the prince had escaped to Onjō-ji (Miidera): Thereupon secret negotiations were opened between Rokuhara and Enryaku-ji (Hiei-zan), not that the Taira chief suspected the latter, but because he appreciated that if Hiei-zan joined Miidera; the situation would become formidable. Meanwhile, his trust in Yorimasa remaining still unshaken, he sent him to attack Onjō-ji, which mission the old Minamoto warrior fulfilled by entering the monastery and joining forces with the prince. Yorimasa took this step in the belief that immediate aid would be furnished from Hiei-zan. But before his appeal reached the latter; Kiyomori's overtures had been accepted!r Nothing now remained for Yorimasa and Mochihito except to make a desperate rush on Kyōto or to ride away south to Nara, where temporary refuge offered The latter course was chosen, in spite of Yorimasa's advice. On the banks of the Uji River in a dense fog they were overtaken by the Taira force, the latter numbering twenty thousand, the fugitives three or four hundred. The Minamoto made a gallant and skilful resistance, and finally Yorimasa rode off with a handful of followers, hoping to carry Mochihito to a place of safety. Before they passed out of range an arrow struck the old warrior. Struggling back to Byōdō-in, where the fight was still in progress, he seated himself on his iron warfan and, having calmly composed his death-song; committed suicide:

\section{CHANGE OF CAPITAL AND DEATH OF KIYOMORI}

These things happened in May, 1180, and in the following month Kiyomori earried out a design entertained by him for some time. He transferred the capital from Kyōto to Fukuhára, in Settsu, where the modern town of Kōbe stands. Originally the Taira mansions were at the two Fukuhara, one on the north of Kyoto, the other on the south,-the eity being dominated from these positions. But Kiyomori seems to have thought that as the centres of 'Taira strength lay in the south and west of the empire, the province of Settsu would be a more convenient citadel than Kyōto. Hence he built at: Fukuhara a spacious villa and took various steps to improve the harbour - then called Muko - as well as to provide maritime facilities, among whieh may be mentioned the opening of the strait, Ondo no Seto. But Fukuhara is fifty iniles from Kyoto, and to reach the latter quickly from the former in an "emergency was a serious task in the twelfth century. Moreover, Kyôto was devastated in 1177 by a conflagration which reduced one-third of the eity to ashes, and in April of 1180 by a tornado of most destructive foree, so that superstitious folk, who abounded in that age, began to speak ominously of the eity's doom.

What weighed most with the Taira leader, however,'was the propinquity of the three great monasteries; Hiei-zan on the north; Miidera on the east; and Nara on the south. In fact, the eity lay at the mercy of the soldier-priests. At any moment they might combine, descend upon the eapital, and burn it before adequate succour could be marshalled. That such a peril should have been dreaded from such a source seems strange; but the Buddhist priests had shown a very dangerous temper more than onee, and from Kiyomori's point of view the possibility of their rising to restore the fortunes of the Fujiwara was never remote.

Kiyomori carried with him to Fukuhara the boy-Emperor (Antoku), the 
ex-Emperor (Takakura), the cloistered Emperor (Go-Shirakawa), the kwampaku (Motomichi), and all the high Court officials with rare exceptions. "The work of construction at Fukuhara not being yet complete, Go-Shirakawa had to be lodged in a building thirty feet square, to which men gave the name of the "jail palace." Kyōto, of course, was thrown into a state of consternation. Remonstrances, petitions, and complaints poured into the Fukuhara mansion. Meanwhile the Minamoto rose. In August of 1180, their white flag was hoisted, and though it looked very insignificant on the wide horizon of Taira power, Kiyomori did not underrate its meaning. At the close of the year, he decided to abandon the Fukuhara scheme and carry the Court back to.Kyoto. On the eve of his return he found an opportunity of dealing a heavy blow to the monasteries of Miidera and Nara. For, it having been discovered that they were in collusion with the newly risen Minamoto, Kiyomori sent his sons, Tomomori and Shigehira, at the head of aforce which sacked and burned Onjō-ji, Tōdai-ji, and Kōfuku-ji.

Thereafter a terrible time ensued for Kyōto, for the home provinces (Kinai), and for the west of the empire. During the greater part of three years, from 1180 to 1182 inclusive, the people suffered, first from famine and afterwards from pestilence. Pitiful accounts are given by contemporary writers. Men were reduced to the direst straits. Hundreds perished of starvation in the streets of Kyōto, and as, in many cases, the corpses lay unburied, pestilence of course ensued. It is stated that in Kyōto allone during two months there were forty-two thousand deaths. The eastern and western regions, however, enjoyed comparative immunity. By the priests and the political enemies of the Taira these cruel calamities were attributed to the evil deeds of Kiyomori and his fellow clansmen, so that the once omnipotent family gradually became an object of popular execration. Kiyomori, however, did not live to witness the ruin of his house. He expired at the age of sixty in March, 1181, just three months after the restoration of Kyōto to metropolitan rank. Since August of the preceding year, the Minamoto had shown signs of troublesome activity, but as yet it seemed hardly possible that their puny onsets should shake, still less pull down; the imposing edifice of power raisea by the Taira during twenty years of unprecedented suceess. Nevertheless, Kiyomori, impatient of all reverses, bitterly upbraided his sons and his officers for incompetence, and when, after seven days' sickness, he saw the end approaching, his last commission was that neither tomb nor temple should be raised to his memory until Yoritomo's head had been placed on his grave.?

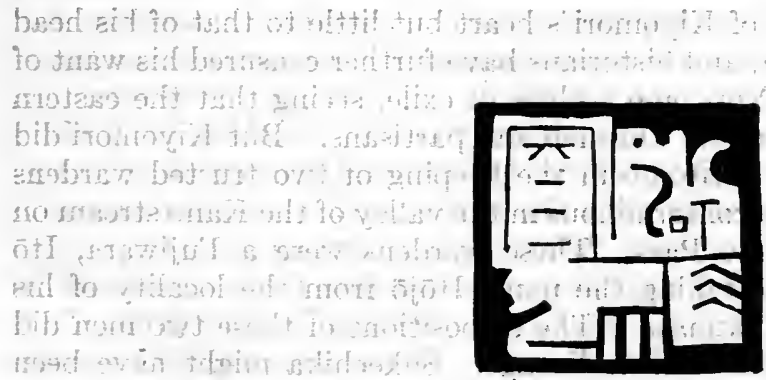

Artist's Seal 


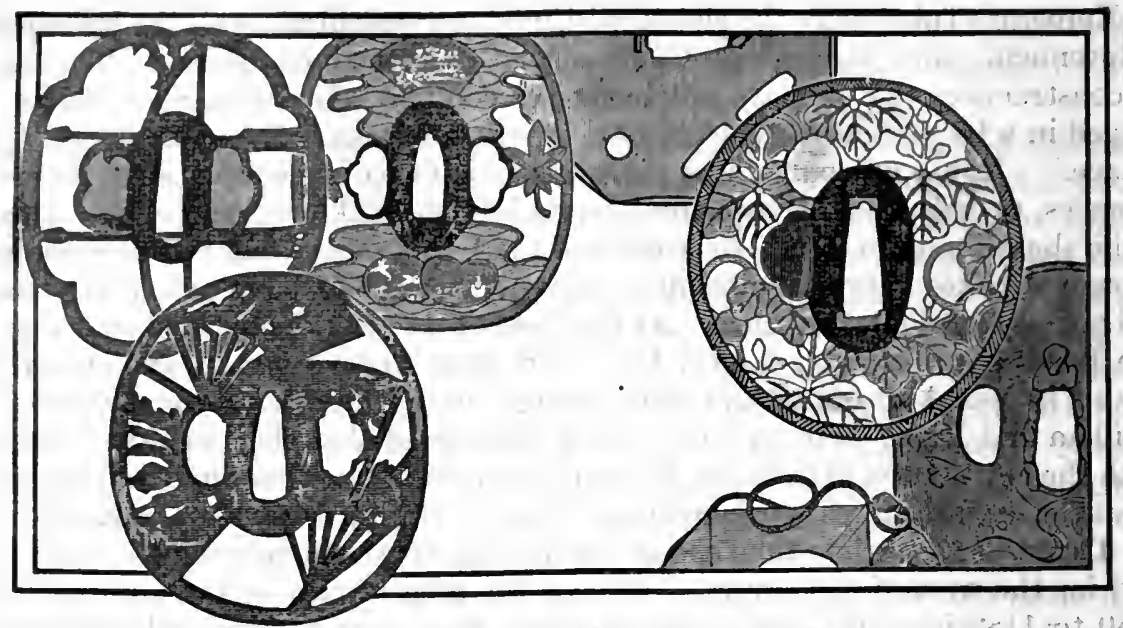

Sword-Guards (Tsuba) Havd-Carved in Brovze

\section{CHAPTER XXV}

\section{THE EPOCH OF THE GEN AND THE HEI (Continued)}

\section{OPENING OF THE CONFLICT}

When, after the great struggle of 1160, Yoritomo, the eldest of Yoshitomo's surviving sons, fell into the hands of Taira Munekiyo and was carried by the latter to Kyōto, for execution, as all supposed, and as would have been in strict accord with the canons of the time, the lad, then in his fourteenth year, won the sympathy of Munekiyo by his nobly calm demeanour in the presence of death, and still more by answering, when asked whether he did not wish to live, "Yes, since I alone remain to pray for the memories of my father and my elder brothers." Munekiyo then determined to save the boy if possible, and he succeeded through the co-operation of Kiyomori's step-mother, whom he persuaded that her own son, lost in his infancy, would have grown up to resemble closely Yoritomo.

It was much to the credit of Kiyomori's heart but little to that of his head that he listened to such a plea, and historians have further censured his want of sagacity in choosing Izu for Yoritomo's place of exile, seeing that the eastern regions were infested by Minamoto kinsmen and partisans. But Kiyomori did not act blindly. He placed Yoritomo in the keeping of two trusted wardens whose manors were practically conterminous in the valley of the Kano stream on the immediate west of Hakone Pass. These wardens were a Fujiwara, Itō Sukechika, and a Taira, who, taking the name Hōjo from the locality of his manor, called himself Hōjō Tokimasa. The dispositions of these two men did not agree with the suggestions of their lineage: Sukechika might have been expected to sympathize with his ward in consideration of the sufferings of the Fujiwara at Kiyomori's hands. Tokimasa, as a Taira, should have been wholly antipathetic. Yet had Tokimasa shared Sukechika's mood, the Minamoto's sun would never have risen over the Kwantō. 
The explanation is that Tokimasa belonged to a large group of provincial Taira who were at once discontented because their claims to promotion had been ignored; and deeply resentful of indignities and ridicule to which their rustic manners and customs had exposed them at the hands of their upstart kinsmen in Kyōto. Moreover, it is not extravagant to suppose, in view of the extraordinary abilities subsequently shown by Tokimasa, that he presaged the instability of the Taira edifice long before any ominous symptoms became outwardly visible. At any rate, while remaining Yoritomo's ostensible warden, he became his confidant and abettor.

This did not happen immediately, however. Yoritomo was placed originally under Sukechika's care, and during the latter's absence in Kyōto a liaison was established between his daughter and the Minamoto captive, with the result that a son was born. Sukechika, on his return, caused the child to be thrown into a cataract, married its mother to Ema Kotarō, and swore to have the life of his ward. But Yoritomo, warned of what was pending, effected his escape to Tokimasa's manor. It is recorded that on the way thither he prayed at the shrine of Hachiman, the tutelary deity of his family: "Grant me to become sei-ishogun and to guard the Imperial Court. Or, if I may not achieve so much, grant me to become governor of Izu, so that I may be revenged on Sukechika. Or, if that may not be, grant me death." "With Tokimasa he found security. But here again, though now a man over thirty, he established relations with Masa, his warden's eldest daughter. . In all Yoritomo's career there is not one instance of a sacrifice of expediency or ambition on the altar of sentiment or affection. He was a cold, calculating man. No cruelty shocked him nor did he shrink from any severity dictated by policy. It is in the last degree improbable that he risked his political hopes for the sake of a trivial amour. At any rate the event suggests crafty deliberation rather than a passing passion. For though Tokimasa simulated ignorance of the liaison and publicly proceeded with his previous engagement to wed Masa to Taira Kanetaka, lieutenant-governor of Izu, he privately connived at her flight and subsequent concealment.

This incident is said to have determined Yoritomo. He disclosed all his ambitions to Hōjō Tokimasa, and found in him an able coadjutor. Yoritomo now began to open secret communications with several of the military families in Izu and the neighbouring provinces. In making these selections and approaches, the Minamoto exile was guided and assisted by Tokimasa. Confidences were not by any means confined to men of Minamoto lineage. The kith and kin of the Fujiwara, and even of the Taira themselves, were drawn into the conspiracy, and although the struggle finally resolved itself into a duel $a$ l'outrance between the Taira and the Minamoto, it had no such exclusive character at the outset.

In May, or June, 1180, the mandate of Prince Mochihito reached Yoritomo, carried by his uncle, Minamoto Yukiiye, whose figure thenceforth appears frequently upon the scene. Yoritomo showed the mandate to Tokimasa, and the two men were taking measures to obey when they received intelligence of the deaths of Mochihito and Yorimasa and of the fatal battle on the banks of the Uji.

Yoritomo would probably: have deferred conclusive action in such circumstances had there not reached him from Miyoshi Yasunobu in Kyōto a warning that the Taira were planning to exterminate the remnant of the Minamoto and that Yoritomo's name stood first on the black-list. Moreover, the advisability of taking the field at once was strongly and incessantly urged by a priest, Mongaku, who, after a brief acquaintance, had impressed Yoritomo favourably. 
This bonze had been the leading figure in an extraordinary romance of real life. Originally Endō Moritō, an officer of the guards in Kyōto, he fell in love. with his cousin, Kesa, ${ }^{1}$ the wife of a comrade called Minamoto Wataru. ${ }_{0} \mathrm{His}$ addresses being resolutely rejected, he swore that if Kesa remained obdurate, he would kill her mother. From this dilemma the brave woman determined that self-sacrifice offered the only effective exit: She promised to marry Morito after he had killed her husband, Wataru; to which end she engaged to ply Wataru with wine until he fell asleep. She would then wet his head; so that Morito, entering by an unfastened door and feeling for the damp hair, might consummate his purpose surely. Morito readily agreed, but Kesa, having dressed her own hair in male fashion and wet her head, lay down in her husband's place.

When Morito found that he had killed the object of his passionate affection, he hastened to confess his crime and invited Wataru to slay him. But. Wataru, sympathizing with his remorse, proposed that they should both enter religion and pray for the rest of Kesa's spirit. ' It is related that one of the acts of penance performed by Mongaku — the monastic name taken by: Moritō - was to stand for twenty-one days under a waterfall in the depth of winter. Subsequently he devoted himself to collecting funds for reconstructing the temple of Takao, but his zeal having betrayed him into a breach of etiquette at the palace of Go-Shirakawa, he was banished to Izu, where he obtained access to Yoritomo and counselled him to put his fortune to the test. ${ }^{2}$

\section{THE FIRST STAGE OF THE STRUGGLE}

The campaign was opened by Hōjō Tokimasa on the 8th of September, 1180 . He attacked the residence of the lieutenant-governor of Izu, Taira Kanetaka, burned the mansion, and killed Kanetaka, whose abortive nuptials with the lady Masa had been celebrated a few months previously. Yoritomo himself at the head of a force of three hundred men, crossed the Hakone Pass three days later en route for Sagami, and encamped at Ishibashi-yama. This first essay of the Minamoto showed no military caution whatever. It was a march into space. Yoritomo left in his rear Itō Sukechika, who had slain his infant son and sworn his own destruction, and he had in his front a Taira force of three thousand under Ōba Kagechika. It is true that many Taira magnates of the Kwanto were pledged to draw the sword in the Minamoto cause. They had found the selfish tyranny of Kiyomori not at all to their taste or their profit: It is also true that the Ōba brothers had fought staunchly on the side of Yoritomo's father, Yoshitomo, in the Heiji war. Yoritomo may possibly have entertained some hope that the Ōba army would not prove a serious menace.

Whatever the explanation may be, the little Minamoto band were attacked in front and rear simultaneously during a stormy night. They suffered a crushing defeat. It seemed as though the white flag ${ }^{3}$ was to be lowered permanently, ere it had been fully shaken out to the wind. The remnants of the Minamoto sought shelter in a cryptomeria grove, where Yoritomo proved himself a powerful bowman. But when he had time to take stock of his followers, he found them reduced to six men. These, at the suggestion of Doi Sanehira, he ordered to

[1 Generally spoken of as "Kesa Gozen," but the latter word signifies "lady..']

[2 Tradition says that among the means employed by Mongaku to move Yoritomo was the exhibition of Yoshitomo's bones.]

[ ${ }^{3}$ The Taira flew a red ensign; the Minamoto, a white.] 
scatter and seek safety in flight, while he himself with Sanehira hid in a hollow tree. Their hiding-place was discovered by Kajiwara Kagetoki, a member of the Ōba family, whose sympathies were with the Minamoto. He placed himself before the tree and signalled that the fugitives had taken another direction. Presently,, $\bar{O}$ ba Kagechika; riding up, thrust his bow into the hollow tree, and as two pigeons flew out, he concluded that there was no hưman being within.

sil From the time of this hairbreadth escape, Yoritomo's fortunes rose rapidly. After some days of concealment among the Hakone mountains, he reached the shore of Yedo Bay, and crossing from Izu to Awa; was joined by Tokimasa and

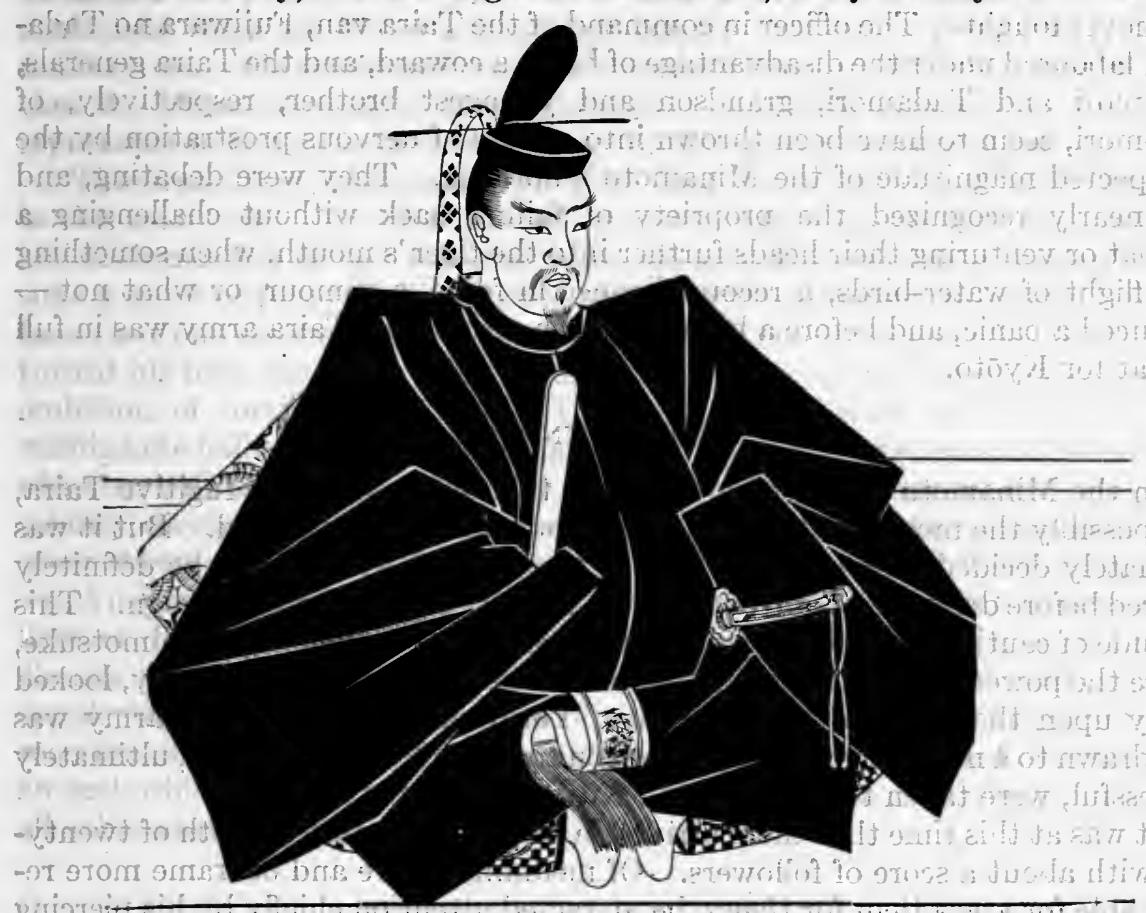

ast bo

MIINAMOTO YoRITOMO

others. Manifestoes were then despatched in all directions, and sympathizers began to flock in Entering Kazusa, the Minamoto leader secured the cooperation of Taira Hirotsune and Chiba Tsunetane, while Tokimasa went to canvass in Kai. 9 In short, eight provinces of the Kwantō responded like an echo to Yoritomo's call, and; by the time he had made his circuit of Yedo Bay; some twenty-five thousand men were marshalled under his standard. Kamakura, on the seacoast a few miles south of the present Yokohama, was chosen for headquarters, and one of the first steps taken was to establish there, on the hill of Tsurugaoka, a grand shrine to Hachiman; the god of War and tutelary deity of the Minamoto.

7 Meanwhile, Tokimasa had secured the allegiance of the Takeda family of Kai, and was about to send a strong force to join Yoritomo's army. But by this time the Taira were in motion. Kiyomori had despatched a body of fifty 
thousand men under Koremori, and Yoritomo had decided to meet this army on the banks of the Fuji river. It became necessary, therefore; to remove all potential focs from the Minamoto rear, and accordingly Hōjō Tokimasa received orders to overrun Suruga and then to direet his movements with a view to concentration on the Fuji. Thither Yoritomo marched from Kamakura, and by the beginning of November, 1180, fifty thousand Taira troops were encamped on the south bank of the river and twenty-seven thousand Minamoto on the north. A decisive battle must be fought in the space of a few days. In fact, the 13th of November had been indicated as the probable date. But the battle was never fought. The officer in command of the Taira van, Fujiwara no Tadakiyo, laboured under the disadvantage of being a coward, and the Taira generals, Koremori and Tadamori, grandson and youngest brother, respectively, of Kiyomori, seem to have been thrown into a state of nervous prostration by the unexpected magnitude of the Minamoto's uprising. They were debating, and had nearly recognized the propriety of falling back without challenging a combat or venturing their heads further into the tiger's mouth, when something - a flight of water-birds, a reconnaissance in force, a rumour, or what not produced a panic, and before a blow had been struck, the Taira army was in full retreat for Kyōto.

\section{YOSHITSUNE}

In the Minamoto camp there was some talk of pursuing the fugitive Taira, and possibly the most rapid results would thus have been attained. But it was ultimately decided that the allegiance of the whole $\mathrm{K}$ wanto must be definitely secured before denuding it of troops for the purpose of a western eampaign. This attitude of caution pointed specially to the provinees of Hitachi and Shimotsuke, where the powerful Minamoto families of Satake and Nitta, respectivcly, looked coldly upon the cause of their kinsman, Yoritomo. Therefore the army was withdrawn to a more convenient position on the Kiso River, and steps, ultimately successful, were taken to win over the Nitta and the Satake.

It was at this time that there arrived in Yoritomo's camp a youth of twentyone with about a score of followers. Of medium stature and of frame more remarkable for grace than for thews, he attracted attention chiefly by his piereing eyes and by the dignified intelligence of his countenance. This was Yoshitsune, the youngest son of Yoshitomo. His life, as already stated, had been saved in the Heiji disturbance, first, by the intrepidity of his mother, Tokiwa, and, afterwards, by the impression her dazzling beauty produced upon the Taira leader. Placed in the monastery of Kurama, as stipulated by Kiyomori, Yoshitsune had no sooner learned to think than he became inspired with an absorbing desire to restore the fortunes of his family. Tradition has surrounded the early days of this, the future Bayard of Japan, with many romantic legends, among which it is difficult to distinguish the true from the false. What is certain, however, is that at the age of fifteen he managed to effect his eseape to the north of Japan. The agent of his flight was an iron-merchant who habitually visited the monastery on matters of business; and whose dealings took him occasionally to Mutsu.

At the time of Yoshitsune's novitiate in the Kurama temple, the political power in Japan may be said to have been divided between the Taira, the provincial Minamoto, the Buddhist priests, and the Fujiwara, and of the last the only branch that had suffered no eclipse during the storms of Hoggen and Heiji had been the Fujiwara of Mutsu. It has been shown in the story of the Three Years' 
War, and specially in the paragraph entitled "The Fujiwara of the North," that the troops of Fujiwara Kiyohira and Minamoto Yoshiiye had fought side by side, and that, after the war, Kiyohira succeeded to the six districts of Mutsu, which constituted the largest estate in the hands of any one Japanese noble. That estate was in the possession of Hidehira, grandson of Kiyohira, at the time when the Minamoto family suffered its heavy reverses. Yoshitsune expected, therefore, that at least an asylum would be assured, could he find his way to Mutsu. He was not mistaken. Hidehira received him with all hospitality, and as Mutsu was practically beyond the control of Kyōto, the Minamoto fugitive could lead there the life of a bushi, and openly study everything pertaining to military art. He made such excellent use of these opportunities that, by the time the Minamoto standard was raised anew in Izu; Yoshitsune had earned the reputation of being the best swordsman in the whole of northern Japan.

This was the stripling who rode into Yoritomo's camp on a November day in the year 1180.; The brothers had never previously seen each other's faces, and their meeting in such circumstances was a dramatic event. Among Yoshitsune's score of followers there were several who subsequently earned undying fame, but one déserves special mention here. Benkei, the giant halberdier, had turned his back upon the priesthood, and, becoming a free lance, conceived the ambition of forcibly collecting a thousand swords from their wearers. $\mathrm{He}$ wielded the halberd with extraordinary skill, and such a huge weapon in the hand of a man with seven feet of stalwart stature constituted a menace before which a solitary wayfarer did not hesitate to surrender his sword. "One evening, Benkei observed an armed acolyte approaching the Gojō bridge in Kyōto. The acolyte was Yoshitsune, and the time, the eve of his departure for Mutsu. Benkei made light of disarming a lad of tendèr years and seemingly slender strength. But already in his acolyte days Yoshitsune had studied swordsmanship, and he supplemented his knowledge by activity almost supernatural. The giant Benkei soon found himself praying for life and swearing allegiance to his boy conqueror, an oath which he kept so faithfully as to become the type of soldierly fidelity for all subsequent generations of his countrymen.

\section{KISO YOSHINAKA}

Looking at the map of central Japan, it is seen that the seven provinces of Suruga, Izu, Awa, Kai, Sagami, Musashi, and Kazusa are grouped approximately in the shape of a Japanese fan (uchiwa), having Izu for the handle. Along the Pacific coast, eastward of this fan, lie the provinces of Shimōsa and Hitachi, where the Nitta and the Satake, respectively, gave employment for some time to the diplomatic and military resources of the Minamoto. Running inland from the circumference of the fan are Shinano and Kōtsuke, in which two provinces, also, a powerful Minamoto resurrection synchronized with, but was independent of, the Yoritomo movement.

The hero of the Shinano-Kōtsuke drama was Minamoto no Yoshinaka, commonly called Kiso Yoshinaka, because his youth was passed among the mountains where the Kiso River has its source. In the year 1155, Yoshitomo's eldest son, Yoshihira, ${ }^{1}$ was sent to Musashi to fight against his uncle, Yoshika-

[ 1 This Yoshihira was a giant in stature. He shares with Tametomo the fame of having exhibited the greatest prowess in the Hoggen and Heiji struggles. It was he who offered to attack Kyōto from Kumano - a measure which, in all probability, would have reversed the result of the Heiji war.] 
ta. The latter fell, and his son, Yoshinaka, a baby of two, was handed to Saito Sanemori to be executed; but the latter sent the child to Shinano, where it was brought up by Nakahara Kanetō, the husband of its nurse.:Yoshinaka attained an immense stature as well as signal skill in archery and horsemanship. Like Yoritomo and Yoshitsune, he brooded much on the evil fortunes of the Minamoto, and paid frequent visits to Kyōto to observe the course of events. In the year 1180, the mandate of Prince Mochihito reached him; and learning that Yoritomo had taken the field, he gathered a force in Shinano. Between the two leaders there could be no final forgetfulness of the fact that Yoritomo's brother had killed Yoshinaka's father, and had ordered the slaying of Yoshinaka himself. But this evil memory did not obtrude itself at the outset. They: worked independently. Yoshinaka gained a signal victory over the Taira forces marshalled against him by the governor of Shinano, and pushing thence eastivard into Kotsuke, obtained the allegiance of the Ashikaga of Shimotsuke and of the Takeda of Kai. Thus, the year 1180 closed upon a disastrous state of affairs for the Taira, no less than ten provinces in the east having fallen practically. under Minamoto sway.

\section{CONTINUATION OF THE CAMPAIGN}

Kiyomori expired in March, 1181, as already related. His last behest, that the head of Yoritomo should be laid on his grave, nerved his successors to fresh efforts. But the stars in their courses seemed to be fighting against the Taira. Kiyomori's son, Munemori, upon whom devolved the direction of the great clan's affairs, was wholly incompetent for such a trust. One gleam of sunshine; however, illumined the fortunes of the Heike. Two months after Kiyomori's' death; a Taira army under Shigehira attacked Yukiiye, Yoritomo's uncle, who had pushed westward as far as Owari. This Yukiiye never showed any qualities of generalship. He was repeatedly defeated, the only redeeming feature of his campaigns being that he himself always escaped destruction. On this occasion. he was driven out of Owari and forced to retire within the confines of the Kwantō.

But now the home provinces and the west fell into the horrors of famine and pestilenee, as described above; and in such circumstances to place armies in the field and to maintain them there became impossible. The Taira had to desist from all warlike enterprises until the summer of 1182 , when a great effort was? made to crush the rapidly growing power of the Minamoto. Commissions of provincial governor were sent to Jō no Nagashige, a puissant Taira magnate of Echigo; to Taira no Chikafusa, of Etchū, and to Fujiwara Hidehira, of Mutsu, who were all ordered to attack Yoritomo and Yoshinaka. Hidehira made no response, but Nagashige set in motion against Yoshinaka a strong force, swelled by a contingent from Kyōto under Michimori. The results were signal defeat for the Taira and the carrying of the white flag by Yoshinaka into Echigo; Etchū, Noto, and Kaga.

DISSENSIONS AMONG THE MINAMOTO

Meanwhile discord had declared itself between Yoritomo and Yoshinaka. It has been shown that the records of the two families afforded no basis of mutual confidence, and it has also been shown that the Takeda clan of Kai province were among the earliest adherents of the Minamoto cause. In view of 
Yoshinaka's brilliant successes, Takeda Nobumitsu proposed a marriage between his daughter and Yoshinaka's son, 'Yoshitaka. This union was declined by Yoshinaka, whereupon Nobumitsu suggested to Yoritomo that Yoshinaka's real purpose was to ally his house with the Taira by marriage. Whether Nobumitsu believed this, or whether his idea had its origin in pique, history does not indicate. But there can be no hesitation in concluding that a rupture between the itwo Minamoto chiefs was presaged by Yoritomo's entourage, who judged that two Richmonds could not remain permanently in the field.

19 Things gradually shaped themselves in accordance with that forecast. The malcontents in Yoritomo's camp or his discomfited opponents began to transfer their allegiance to Yoshinaka; a tendency which culminated when Yoritomo's uncle, Yukiiye, taking umbrage because a provincial governorship was not given to him, rode off at the head of a thousand cavalry to join Yoshinaka. The reception given by Yoshinaka to these deserters was in itself sufficient to suggest doubts of his: motives. Early in the year 1183, Yoritomo sent a force into Shinano with orders to exterminate Yoshinaka. But the latter declined the combat. Quoting a popular saying that the worst enemies of the Minamoto were their own dissensions, he directed his troops to withdraw into Echigo, leaving to Yoritomo a free hand in 'Shinano. 'When this was reported to Yoritomo, he recalled his troops from Shinano, and asked Yoshinaka to send a hostage Yoshinaka replied by sending his son Yoshitaka, the same youth to whom Takeda Nobumitsu had proposed to marry his daughter. He was now wedded to Yoritomo's daughter, and the two Minamoto chiefs seemed to have been effectually reconciled.

\section{ADVANCE OF YOSHINAKA ON KYŌTO}

Yoshinaka's desire to avoid conflict with Yoritomo had been partly due to the fact that the Taira leaders were known to be just then straining every nerve to beat back the westward-rolling tide of Minamoto conquest. They had massed all their available forces in Echizen, and at that supreme moment Yoritomo's active hostility would have completely marred Yoshinaka's great opportunity. In May, 1183, this decisive phase of the contest was opened; Koremori, Tamemori, and Tomonori being in supreme command of the Taira troops, which are said to have mustered one hundred thousand strong. At first, things fared badly with the Minamoto. They lost an important fortress at Hiuchi-yama, and Yukiiye was driven from Kaga into Noto. But when the main army of the Minamoto came into action, the complexion of affairs changed at once. In a great battle fought at Tonami-yama in Echizen, Yoshinaka won a signal victory by the manœuvre of launching at the Taira a herd of oxen having torches fastened to their horns. Thousands of the Taira perished, including many leaders.

Tother victories at Kurikara and Shinowara opened the road to Kyōto. Yoshinaka pushed on and, in August, reached Hiei-zan; while Yukiiye, the pressure on whose front in Noto had been relieved, moved towards Yamato; Minamoto no Yukitsuna occupied Settsu and Kawachi, and Ashikaga Yoshikiyo advanced to Tamba. Thus, the capital lay at the merey of Yoshinaka's armies. The latter stages of the Minamoto march had been unopposed. Munemori, after a vain attempt to secure the alliance of the Hiei-zan monks, had recalled his generals and decided to retire westward, abandoning Kyōto. He, would have taken with him the cloistered Emperor, but Go-Shirakawa secretly made 
his way to Hiei-zan and placed himself under the protection of Yoshinaka, rejoicing at the opportunity to shake off the.Taira yoke.

\section{RETREAT OF THE TAIRA}

On August 14, 1183, the evacuation of Kyōto took place. Munemori; refusing to listen to the counsels of the more resolute among his officers, applied the torch to the Taira mansions at northern and southern Rokuhara, and, taking with him the Emperor Antoku, then in his sixth year, his Majesty's younger brother, and their mother, together with the regalia - the mirror, the sword, and the gem - retired westward, followed by the whole remnant of his clan. Arrived at Fukuhara, they devoted a night to praying, making sacred music, and reading Sutras at Kiyomori's tomb, whereafter they set fire to all the Taira palaces, mansions, and official buildings, and embarked for the Dazai-fu in Chikuzen. They reckoned on the allegiance of the whole of Kyūshu and of at least one-half of Shikoku.

\section{EIGHTY-SECOND SOVEREIGN, THE EMPEROR GO-TOBA (A.D. 1184-1198)}

The Taira leaders having carried off the Emperor Antoku, there was no actually reigning sovereign in Kyōto, whither the cloistered Emperor now returned, an imposing guard of honour being furnished by Yoshinaka. GoShirakawa therefore resumed the administration of State affairs, Yoshinaka being given the privilege of access to the Presence and entrusted with the duty of guarding the capital. The distribution of rewards oceupied attention in the first place. Out of the five hundred manors of the Taira, one hundred and fifty were given to Yoshinaka and Yukiiye, and over two hundred prominent Taira officials were stripped of their posts and their Court ranks. Yoritomo received more gracious treatment than Yoshinaka, although the Kamakura chief could not yet venture to absent himself from the Kwanto for the purpose of paying his respects at Court. For the rest, in spite of Yoshinaka's brilliant success, he was granted only the fifth official rank and the governorship of the province of Iyo.

These things could not fail to engender some discontent, and presently a much graver cause for dissatisfaction presented itself. Fujiwara Kanezane, minister of the Right, memorialized the Court in the sense that, as Antoku had left the capital, another occupant to the throne should be appointed, in spite of the absence of the regalia. He pointed out that a precedent for dispensing with these tokens of Imperialism had been furnished in the ease of the Emperor Keitai (507-531). No valid reason existed for such a precipitate step. Antoku had not abdicated. His will had not been consulted at all by the Taira when they earried him off; nor would the will of a child of six have possessed any validity in such a matter. It is plain that the proposal made by the minister of the Right had for motive the convenience of the Minamoto, whose cause lacked legitimacy so long as the sovereign and the regalia were in the camp of the Taira.

But the minister's advice had a disastrous sequel. Yoshinaka was resolutely bent on securing the succession for the son of Prince Mochihito, who had been killed in the Yorimasa émeute. It was practically to Mochihito that the Court owed its reseue from the Taira tyranny, and his son - now a youth of seventeen, known as Prince Hokuriku, because he had founded an asylum at a monastery in Hokuriku-dō after his father's death - had been conducted to Kyōto by 
Yoshinaka, under a promise to secure the succession for him. But Go-Shirakawa would not pay any attention to these representations. He held that Prince Hokuriku was ineligible, since his father had been born out of wedlock, and since the prince himself had taken the tonsure; the truth being that the exEmperor had determined to obtain the crown for one of his own grandsons, younger brothers of Antoku. It is said that his Majesty's manner of choosing between the two lads was most capricious. He had them brought into his presence, whereupon the elder began to cry, the younger to laugh, and GoShirakawa at once selected the latter, who thenceforth became the Emperor Go-Toba.

\section{FALI OF YOSHINAKA}

Yoshinaka's fortunes began to ebb from the time of his failure to obtain the nomination of Prince Hokuriku. A force despatched to Bitchū with the object of arresting the abduction of Antoku and recovering possession of the regalia, had the misfortune to be confronted by Taira no Noritsune, one of the stoutest warriors on the side of the Heike. Ashikaga Yoshikiyo, who commanded the pursuers, was killed, and his men, were driven back pêle-mêle. This event impaired the prestige of Yoshinaka's troops, while he himself and his officers found that their rustic ways and illiterate education exposed them constantly to the thinly veiled sneers of the dilettanti and pundits who gave the tone to metropolitan society. The soldiers resented these insults with increasing roughness and recourse to violence, so that the coming of Yoritomo began to be much desired. Go-Shirakawa sent two messages at a brief interval to invite the Kamakura chief's presence in the capital. Yoritomo replied with a memorial which won for him golden opinions, but he showed no sign of visiting Kyōto. His absorbing purpose was to consolidate his base in the east, and he had already begun to appreciate that the military and the Imperial capitals should be distinct.

Naturally, when the fact of these pressing invitations to Yoritomo reached Yoshinaka's ears, 'he felt some resentment, and this was reflected in the demeanour of his soldiers, outrages against the lives and properties of the citizens becoming more and more frequent. Even the private domains of the cloistered Emperor himself, to say nothing of the manors of the courtiers, were freely entered and plundered, so that public indignation reached a high pitch. The umbrage thus engendered was accentuated by treachery. Driven from Kyūshū, the Taira chiefs had obtained a footing in Shikoku and had built fortifications at Yashima in Sanuki, which became thenceforth their headquarters. They had also collected on the opposite coast of the Inland Sea a following which seemed likely to grow in dimensions, and, with the idea of checking that result, it was proposed to send troops to the Sanyō-dō under Minamoto Yukiiye, who had been named governor of Bizen. Taught, however, by experience that disaster was likely to be the outcome of Yukiiye's generalship, Yoshinaka interfered to prevent his appointment, and Yukiiye, resenting this slight, became thenceforth a secret foe of Yoshinaka.

In analyzing the factors that go to the making of this complicated chapter of Japanese history, a place must be given to Yukiiye. He seems to have been an unscrupulous schemer. Serving originally under Yoritomo, who quickly took his measure, he concluded that nothing substantial was to be gained in that quarter. Therefore, he passed over to Yoshinaka, who welcomed him, not as an enemy of Yoritomo, but as a Minamoto. Thenceforth Yukiiye's aim was to cause a collision between the two cousins and to raise his own house on the ruins 
of both. He contributed materially to the former result; but as to the latter, the sixth year of his appearance upon the stage as Prince Mochihito's mandate bearer saw his own head pilloried in Kyōto.

Yoshinaka, however, had too frank a disposition to be suspicious. ${ }^{3 e}$ believed until the end that Yukiiye's heart was in the Minamoto cause? Then, when it beeame necessary to choose, between taking stupendous risks in the west or making a timely withdrawal to the east, he took Yukiiye into' his confidence. That was the traitor's opportunity. He secretly informed the exEmperor that Yoshinaka had planned a retreat to the east, carrying his Majesty with him, and this information, at a time when the excesses committed by Yoshinaka's troops had provoked much indignation, induced Go-Shirakawa to obtain from Hiei-zan and Miidera armed monks to form a palace-guard under the command of the kebiishi; Taira Tomoyasu, a declared enemy of Yoshinaka. At once Yoshinaka took a decisive step. He despatehed a force to the palace; seized the persons of Go-Shirakawa and Go-Toba; removed Motomichi from the regeney, appointing Moroie, a boy of twelve, in his place, and dismissed a number of Court officials.

In this strait, Go-Shirakawa, whose record is one long series of undignified manœuvres to keep his own head above water, applied himself to placaté Yoshinaka while privately relying on Yoritomo. His Majesty granted to the former the control of all the domains previously held by the Taira; appointed him to the high office of sei-i tai-shoggun (barbarian-subduing generalissimo); and commissioned him to attack Yoritomo while, at the same time, the latter was secretly encouraged to destroy his cousin. At that moment (February, 1184), Yoritomo's two younger brothers, Yoshitsune and Noriyori, 'were en route for Kyōto, where they had been ordered to convey the Kwanto taxes. They had a force of five hundred men only, but these were quickly transformed into the van of an army of fifty or sixty thousand, which Yoritomo, with extraordinary expedition, sent from Kamakura to attack Yoshinaka.

The "Morning Sun shōgun". (Asahi shōgun), as Yoshinaka was commonly called with reference to his brilliant career, now at last saw himself confronted by the peril which had long disturbed his thoughts. At a distance of three hundred miles from his own base, with powerful foes on either flank and in a city whose population was hostile.to him, his situation seémed almost desperate. He took a step dictated by dire necessity - made overtures to the Taira, asking that a daughter of the house of Kiyomori be given him for wife Munemori refused. The fortunes of the Taira at that moment appeared to be again in the ascendant. They were once more supreme in Kyūshü; the west of the main island from coast to coast was in their hands; they had re-established themselves in Fukuhara, and at any moment they might move against Kyōto. They could afford, therefore, to await the issue of the conflict pending between the Minamoto eousins, sure that it must end in disaster for one side and temporary weakness for the other.

In fact, the situation was almost hopeless for Yoshinaka. There had not been time to recall the main body of his troops which were confronting the Taira. All that he could do was to arrest momentarily the tide of onset by planting handfuls of men to guard the chief avenues at $\mathrm{Uji}$ and Seta where, four years previously, Yorimasa had died for the Minamoto cause, and Seta, where a long bridge spans the waters of Lake Biwa as they narrow to form the Setagawa. To the Uji bridge, Nenoi Yukichika was sent with three hundred men; to the Seta bridge, Imai Kanehira with five hundred. The names of these men 
and of their brothers, Higuchi Kanemitsu and Tate Chikatada, are immortal in Japanese history. They were the four sons of Nakahara Kanetō, by whom Yoshinaka had been reared, and their constant attendance on his person, their splendid devotion to him, and their military prowess caused people to speak of them as Yoshinaka's Shi-tenno- the four guardian deities of Buddhist temples. Their sister, Tomoe, is even more famous. Strong and brave as she was beautiful, she became the consort of Yoshinaka, with whom she had been brought up, and she accompanied him in all his campaigns, fighting by his side and leading a body of troops, in all his battles. She was with him when he made his final retreat and she killed a gigantic warrior, Uchida Ieyoshi, who attempted to seize her on that occasion. Yoshinaka compelled her to leave him at the supreme moment; being unwilling that she should fall into the enemy's hands; and after his death she became a nun, devoting the rest of her days to prayers for his spirit.

But it is not to be supposed that Yoshinaka repaid this noble devotion with equal sincerity. On the contrary, the closing scene of his career was disfigured by passion for another woman, daughter of the kwampaku, Fujiwara Motofusa. Attracted by rumours of her beauty after his arrival in Kyōto, he compelled her to enter his household, and when news came that the armies of Yoshitsune and Noriyori were approaching the capital, this great captain, for such he certainly was, instead of marshalling his forces and making dispositions for defence, went to bid farewell to the beautiful girl who resided in his Gojo mansion. Hours of invaluable time passed, and still Asahi shōgun remained by the lady's side. Finally, two of his faithful comrades, Echigo Chūta and Tsuwata Saburō, seated themselves in front of the mansion and committed suicide to recall their leader to his senses. Yoshinaka emerged, but it was too late. He could not muster more than three hundred men; and in a short time Yoshitsune rode into the city at the head of a large body of cavalry.

- Yoshitsune had approached by way of Uji. He was not at all deterred by the fact that the enemy had destroyed the bridge. His mounted bowmen dashed into the river ${ }^{1}$ and crossed it with little loss: A few hours brought them to Kyōto, where they made small account of the feeble resistance that Yoshinaka was able to offer. Wounded and: with little more than half a score of followers, Yoshinaka rode off, and reaching the plain of Awazu, met Imai Kanehira with the remnant of his five hundred men who had gallantly resisted Noriyori's army: of thirty thousand. Imai counselled instant flight eastward. In Shinano, Yoshinaka would find safety and a dominion, while to cover his retreat, Imai would sacrifice his own life. Such noble: deeds were the normal duty of every true bushi. Yoshinaka galloped away, but, riding into a marsh, disabled his horse and was shot down. Meanwhile Imai, in whose quiver there remained only eight arrows, had killed as many of the pursuing horsemen, and then placing the point of his sword in his mouth, had thrown himself headlong from his horse. One incident, shocking but not inconsistent with the canons of the time, remains to be included in this chapter of Japanese history. It has been related that Yoshinaka's son, Yoshitaka, was sent by his father to Kamakura as a hostage, and was married to Yoritomo's daughter. After the events above related Yoshitaka was put to death at Kamakura, apparently without Yoritomo's orders, and his widow; when pressed by her brother to marry again, committed suicide.

[ ${ }^{1}$ Japanese tradition loves to tell of a contest between Sasaki Takatsuna and Kajiwara Kagesue as to which should cross the river first. Kagesue was the son of that Kajiwara who had saved Yoritomo's life in the episode of the hollow tree.] 


\section{BATTLE OF ICHI-NO-TANI}

The victory of the armies led by Noriyori and Yoshitsune brought Kamakura and Fukuhara into direct conflict, and it was speedity decided that these armies should at once move westward to attack the Taira. A notable feature of the military operations of that era was celerity. Less than a month sufficed to mobilize an army of fifty thousand men and to march it from Kamakura to Kyotto, a distance of three hundred miles, and within ten days of the death of Yoshinaka this same army, augmented to seventy-six thou'sand, began to move westward from Kyōto (March 19, 1184). The explanation of this rapidity is furnished, in part, by simplicity of commisariat, and by the fact that neither artillery nor heavy munitions of war had to be transported. Every man carried with him a supply of cooked rice, specially prepared so as to occupy. little space while sufficing for several days' food, and this supply was constantly replenished by requisitions levied upon the districts traversed. 'Moreover, every man carried his own implements of war - bow and arrows, sword, spear, or halberd - and the footgear consisted of straw sandals which never hurt the feet, and in which a man could easily march twenty miles a day continuously.

These remarks apply to all the fighting men of whatever part of Japan, but as to the Kwantō bushi, their special characteristics are thus described by a writer of the twelfth century: "Their ponderous bows require three men or five to bend them. Their quivers, which match these bows, hold fourteen or fifteen bundles of arrows. They are very quick in releasing their shafts, and each arrow kills or wounds two or three foemen, the impact being powerful enough to pierce two or three thicknesses of armour at a time, and they never fail to hit the mark. Every daimyo (owner of a great estate) has at least twenty or thirty of such mounted archers, and even the owner of a small barren estate has two or three. Their horses are very excellent, for they are carefully selected, while as yet in pasture, and then trained after their own peculiar fashion With five or ten such excellent mounts each, they go out hunting deer or foxes and gallop up and down mountains and forests. Trained in these wild methods, they are all splendid horsemen who know how to ride but never how to fall. It is the habit of the Kwanto bushi that if in the field of battle a father be killed, the son will not retreat, or if a son be slain the father will not yield, but stepping over the dead, they will fight to the death."1

The Taira, as noted above, had by this time largely recovered from the disasters suffered in their first encounters with Yoshinaka's forces. In the western provinces of the main island, in Shikoku, and in Kyūshū, scions of the clan had served as governors in former times, so that ties of close intimacy had been established with the inhabitants. Since the first flight to Kyūshu in August, 1183, their generals, Shigehira, Michimori, Noritsune, and others had defeated the forces of Yoshinaka at Mizushima and those of Yukiiye at Muroyama, so that no less than fourteen provinces of the Sanyō-dō and the Nankai-dō owned Taira sway, and by the beginning of 1184 they had re-occupied the Fukuhara district, establishing themselves at a position of great natural strength called Ichi-no-tani in the province of Harima. Their lines extended several miles, over which space one hundred thousand men were distributed. They lay within a semi-circle of mountains supposed to be inaccessible from the north; their camp was washed on the south by the sea where a thousand war-vessels 
were assembled; the east flank rested on a forest, and the west was strongly fortified.

On March 21, 1184, the Kamakura armies delivered their assault on this position; Noriyori with fifty-six thousand men against the east flank at Ikuta; Yoshitsune's lieutenants with twenty thousand men against the west at Suma. Little progress was made. Defence and attack were equally obstinate, and the advantage of position as well as of numbers was with the former. But Yoshitsune himself had foreseen this and had determined that the best, if not the only, hope of victory lay in delivering an assault by descending the northern rampart of mountains at Hiyodori Pass. Access from that side being counted impracticable, no dispositions had been made by the Taira to guard the defile. Yoshitsune selected for the venture seventy-five men, among them being Benkei, Hatakeyama Shigetada, and others of his most trusted comrades. They succeeded in riding down the steep declivity, and they rushed at the Taira position, setting fire to everything inflammable.

What ensued is soon told. Taken completely by surprise, the Taira weakened, and the Minamoto, pouring in at either flank, completed the rout which had already commenced. Munemori was among the first of the fugitives. He embarked with the Emperor Antoku and the regalia, and steered for Yashima, whither he was quickly followed by the remnants of his force. Shigehira, Kiyomori's fifth son, was taken prisoner. Michimori, Tadanori; and Atsumori were killed. Several illustrative incidents marked this great fight. Michimori's wife threw herself into the sea when she heard of her husband's death. Tomoakira, the seventeen-year-old son of Tomomori, deliberately sacrificed himself to save his father, and the latter, describing the incident subsequently to his brother, Munemori, said with tears: "A son died to save his father; a father fled, leaving his son to die. Were it done by another man, I should spit in his face: But I have done it myself. What will the world call me?" This same Tomomori afterwards proved himself the greatest general on the Taira side. Okabe Tadazumi, a Minamoto captain, took the head of Tadanori but could not identify it. In the lining of the helmet, however, was found a roll of poems and among them one signed "Tadanori:"

Twilight upon my path,

And for mine inn to-night

The shadow of a tree,

And for mine host, a flower.

This little gem of thought has gleamed on Tadanori's memory through all the centuries and has brought vicarious fame even to his slayer, Tadazumi. Still more profoundly is Japanese sympathy moved by the episode of Taira no Atsumori and Kumagaye Naozane. Atsumori, a stripling of fifteen, was seized by Naozane, a stalwart warrior on the Minamoto side. When Naozane tore off the boy's helmet; preparatory to beheading him, and saw a young face vividly recalling his own son who had perished early in the fight, he was moved with compassion and would fain have stayed his hand. To have done so, however; would merely have been to reserve Atsumori for a crueller death. He explained his scruples and his sorrows to the boy, who submitted to his fate with calm courage. But Naozane vowed never to wield weapon again. He sent Atsumori's head and a flute found on his person to the youth's father, Tsunemori, and he himself entered the priesthood, devoting the remaining years of his life to prayers for the soul of the ill-fated lad. Such incidents do not find a 
usual place in the pages of history, but they contribute to the interpretation of a nation's character.

\section{BATTLE OF YASHIMA}

The battle of Ichi-no-tani was not by any means conclusive. It drove the Taira out of Harima and the four provinces on the immediate west of the latter, but it did not disturb them in Shikoku or Kyūshū, nor did it in any way cripple the great fleet which gave them a signal advantage. In these newly won provinces Yoritomo placed military governors and nominated to these posts Doi Sanehira and Kajiwara Kagetoki, heroes, respectively, of the cryptomeria forest and the hollow tree. But this contributed little to the solution of the vital problem, how to get at the Taira in Shikoku and in Kyūshū. Noriyori returned to Kamakura to consult Yoritomo, but the latter and his military advisers could not plan anything except the obvious course of marching an army from Harima westward to the Strait of Shimonoseki, and thereafter collecting boats to carry it across to Kyūshū. That, however, was plainly defective strategy. It left the flank of the westward-marching troops constantly exposed to attack from the coast where the Taira fleet had full command of the sea; it invited enterprises against the rear of the troops from the enemy's position at Yashima in Shikoku, and it assumed the possibility of erossing the Strait of Shimonoseki in the presence of a greatly superior naval force.

Yet no other plan of operations suggested itself to the Kamakura stratégists. Yoshitsune was not consulted. He remained in Kyōto instead of repairing to Kamakura, and he thereby roused the suspicion of Yoritomo, who began to see in him a second Yoshinaka. Hence, in presenting a list of names for reward in connexion with the eampaign against the "Morning Sun shögun," Yoritomo made no mention of Yoshitsune, and the brilliant soldier would have remained entirely without recognition had not the cloistered Emperor specially appointed him to the post of kebiishi. Thus; when the largely augmented Minamoto force began to move westward from Harima in October, 1184, under the command of Noriyori, no part was assigned to Yoshitsune. He remained unemployed in Kyöto.

Noriyori pushed westward steadily, but not without difficulty. He halted for a time in the province of Suwō; and finally, in March, 1185, five months after moving out of Harima, he contrived to transfer the main part of his foree across Shimonoseki Strait and to marshall them in Bungo in the north of Kyūshū. The position then was this: first, a Taira army strongly posted at Yashima in Sanuki (Shikoku), due east of Noriyori's van in Bungo, and threatening his line of communications throughout its entire length from Harima to the Strait of Shimonoseki; secondly, another Taira army strongly posted on Hikoshima, an island west of Shimonoseki Strait, which army menaced the communication's between Noriyori's van across the water in Bungo and his advaneed base in Suwō, and thirdly, the command of the whole Inland Sea in the hands of the Taira.

Evidently, in such conditions no advance, into Kyūshū could be made by Noriyori without inviting capital risks. The key of the situation for the Minamoto was to wrest the command of the sea from the Taira and to drive them from Shikoku preparatory to the final assault upon Kyūshū. This was recognized after a time, and Kajiwara Kagetoki received orders to collect or construct a fleet with all possible expedition, which orders he applied himself to carry out at Watanabe, in Settsu, near the eastern entrance to the Inland Sea. In justice to Yoritomo's strategy it must be noted that these orders were given almost 
simultaneously with the departure of the Minamoto army westward from Harima, so that by the time of Noriyori's arrival in Bungo, the military governor, Kagetoki; had got together some four hundred vessels at Watanabe.

Meanwhile, Yoshitsune had been chafing in Kyōto. To a man of his temperament enforced passivity on the eve of such epoch-making events must have been intolerable. He saw plainly that to drive the Taira from Shikoku was an essential preliminary to their ultimate defeat; and he saw; too, that for such an enterprise a larger measure of resolution and daring was needed than Kajiwara Kagetoki seemed disposed to employ. He therefore obtained from the cloistered Emperor the commission of tai-shogun (great general) and hastened to Settsu to take command. Complications ensued at once. Kagetoki objected to be relegated to a secondary place, and Go-Shirakawa was induced to recall Yoshitsune. But the latter refused to return to Kyoto, and, of course, his relations with Kagetoki were not cordial. The situation was complicated by an unpleasant incident. Kagetoki wished to equip the war-junks with sakaro. Yoshitsune asked what that meant; and being informed that sakaro signified oars at the bow of a boat for use in the event of going astern; he said that such a provision could tend only to suggest a movement fatal to success.

vef "Do you contemplate retiring?" he asked Kagetoki. "So far as I am concerned, I desire only to be equipped for advancing:" Kagetoki indignantly replied: "A skilful general advances at the right moment and retires at the right moment. You know only the tactics of a wild boar." "Yoshitsune angrily retorted, "I know not whether I am a boar or whether I am a deer, but I do know that I take pleasure in crushing a foe by attacking him:". From that moment the relations between the two generals were distinctly strained; and it will presently be seen that the consequences of their estrangement became historical.

E. The 21st of March, 1185, was a day of tempest. Yoshitsune saw his opportunity. He proposed to run over to the opposite coast and attack Yashima under cover of the storm. Kagetoki objected that no vessel could live in such weather. Yoshitsune then called for volunteers. About one hundred and fifty daring spirits responded. They embarked in five war-junks, some of the sailors being ordered to choose between manning the vessels or dying by the sword. : Sweeping over the Harima Nada: with the storm astern, Yoshitsune and his little band of heroic men landed safely on the Awa coast, and dashed at once to the assault of the Taira, who were taken wholly by surprise, never imagining that any forces could have essayed such an enterprise in such a tempest. Some fought resolutely, tbut ultimately all that had not perished under the: swords of the Minamoto obeyed Munemori's orders to embark, and the evening of the 23rd of March saw the Taira fleet congregated in Shido. Bay and erowded with fugitives. There they were attacked at dawn on the 24th by Yoshitsune; to whom there had arrived on the previous evening a re-enforcement of thirty war-junks; sent, not by Kagetoki, but by a Minamoto supporter who had been driven from the province of Iyo some time previously by the Taira.

As usual, the impetuosity of Yoshitsune's onset carried everything before it. Soon the Taira fleet was flying down the Inland Sea, and when Kajiwara Kageto$\mathrm{ki}$, having at length completed his preparations, arrived off Yashima on the 25th of March with some four hundred war-vessels, he found only the ashes of the Taira palaces and palisades. Munemori, with the boy Emperor and all the survivors of the Taira, had fled by sea to join Tomomori at Hikoshima. This enterprise : was even more brilliant and much more conclusive than that of 
Ichi-no-tani. During three consecutive days, with a mere handful of one hundred and fifty followers, Yoshitsune had engaged a powerful Taira army on shore, and on the fourth day he had attacked and routed them at sea, where the disparity of foree must have been evident and where no adventitious natural aids were available.

When every allowance is made for the incompetence of the Taira commander, Munemori, and for the crippling necessity of securing the safety of the childsovereign, Antoku, the battle of Yashima still remains one of the most extraordinary military feats on record. Among the incidents of the battle, it is recorded that Yoshitsune himself was in imminent peril at one time, and the details illustrate the manner of fighting in that era. He dropped his bow into the sea during the naval engagement, and when he essayed to pick it up; some Taira soldiers hooked his armour with a grapnel. Yoshitsune severed the haft of the grapnel with his sword and deliberately picked up the bow. Asked why he had imperilled his person for a mere bow, he replied, "Had it been a bow such as my uncle Tametomo bent, its falling into the enemy's possession would not matter; but a weak bow like mine would give them something to laugh at." Observing this incident, Noritsune, one of the best fighters and most skilled archers among the Taira, made Yoshitsune the target of his shafts. 'But Sato Tsuginobu, member of the band of trusted comrades who had accompanied the Minamoto hero from Mutsu, interposed his body and received the arrow destined for Yoshitsune. Kikuō, Noritsune's squire, leaped from his boat to decapitate the wounded Tsuginobu, but was shot down by the latter's younger brother. Yoshitsune pillowed Tsuginobu's head on his knees and asked the dying man whether he had any last message. The answer was: "To die for my lord is not death. I have longed for such an end ever since we took the field. My only regret is that I eannot live to see the annihilation of the Taira." Yoshitsune, weeping, said, "To annihilate the Taira is a mere matter of days, but all time would not suffice to repay your devotion."

\section{BATTLE OF DAN-NO-URA}

The fight at Yashima was followed by a month's interval of comparatively minor operations, undertaken for the purpose of bringing Shikoku completely under Minamoto sway. During that time the two clans prepared for final action. The Taira would have withdrawn altogether into Kyūshū, but such a course must have been preceded by the dislodging of Noriyori, with his army of thirty thousand men, from Bungo province, which they had occupied since the beginning of March. It is true that Noriyori himself was unable to make any further ineursion into Kyūshū so long as his maritime communications with his advaneed base in Suwo remained at the mercy of the Taira fleet. But it is equally true that the Taira generals dared not enter Kyūshū so long as a strong Minamoto force was planted on the left flank of their route.

Thus, a peculiar situation existed at the beginning of April, 1185. Of the two provinces at the extreme south of the main island, one, the eastern (Suwō), was in Minamoto oceupation; the other, the western (Nagato), was mainly.held by the Taira; and of the three provinees forming the northern littoral of Kyūshū, two, the western (Chikuzen and Buzen), were in Taira hands, and the third, the eastern (Bungo), was the camp of Noriyori with his thirty thousand men. Finally, the Strait of Shimonoseki between Chikuzen and Buzen was in Taira possession. Evidently the aim of the Taira must be to eliminate Noriyori from 
the battle now pending, and to that end they selected for arena Dan-no-ura, that is to say, the littoral of Nagato province immediately east of the Shimonoseki Strait.

We have seen that ever since the Ichi-no-tani fight, the Minamoto generals, especially Kajiwara Kagetoki, had been actively engaged in building, or otherwise acquiring, war-junks. By April, 1185, they had brought together a squadron of seven to eight hundred; whereas, in the sequel of Yashima and minor engagements, the Taira fleet had been reduced to some five hundred. The warjunk of those days was not a complicated machine. Propelled by oars, it had no fighting capacities of its own, its main purpose being to carry its occupants within bow-range or sword-reach of their adversaries. . Naval tactics consisted solely in getting the wind-gage for archery purposes.

By the 22nd of April, 1185, the whole of the Minamoto fleet had assembled at Ōshima, an island lying off the southeast of Suwō, the Taira vessels, with the exception of the Hikoshima contingent, being anchored at Dan-no-ura. On that day, a strong squadron, sent out by Yoshitsune for reconnoitring purposes; marshalled itself at a distance of about two miles from the Taira array, and this fact having been signalled to the Taira general, Tomomori, at Hikoshima, he at once passed the strait and joined forces with the main fleet at Dan-no-ura. Yoshitsune's design had been to deliver a general attack immediately after the despatch of the reconnoitring squadron, but this was prevented by a deluge of blinding rain which lasted until the night of the 24 th.

Thus; it was not until the 25th that the battle took place. It commenced with an inconclusive archery duel at long range, whereafter the two fleets closed up and a desperate hand-to-hand struggle ensued. Neither side could claim any decisive advantage until Taguchi Shigeyoshi deserted from the Taira and passed over with all his ships to the Minamoto. This Taguchi had been originally an influential magnate of Iyo in Shikoku, whence he had accompanied the Taira retreat to Nagato, leaving his son with three thousand men to defend the family manors in Iyo. The son was so generously treated by the Minamoto that he threw in his lot with them and sent letters urging his father to adopt the same cause. Taguchi not only followed his son's advice but also chose the moment most disastrous for the Taira.

His defection was followed quickly by the complete rout of the Heike. A resolute attempt was made to defend the ship containing the young Emperor, his mother, his grandmother; and several other Taira ladies; but the vessel finally passed into Minamoto possession. Not before: she had been the scene of a terrible tragedy, however. Kiyomori's widow, the Ni-i-no-ama, grandmother of Antoku, took the six-year old child in her arms and jumped into the sea, followed by Antoku's mother, the Empress Dowager (Kenrei-mon-in), carrying the regalia, and by other court ladies. The Empress Dowager was rescued, as were also the sacred mirror and the gem, but the sword was irrevocably lost.

The Taira leader, Munemori, and his son, Kiyomune, were taken prisoner, but Tomomori; Noritsune, and seven other Taira generals were drowned. Noritsune distinguished himself conspicuously. He singled out Yoshitsune for the object of his attack, but being unable to reach him, he seized two Minamoto bushi and sprang into the sea with them. Tomomori, Munemori's brother, who had proved himself a most able general, leaped overboard carrying an anchor. : Yoshitsune spoke in strongly laudatory terms' of Noritsune and ascribed to him much of the power hitherto wielded by the Taira. Munemori 
and his son were executed finally at Ōmi. Shigehira, in response to a petition from the Nara priests whose fanes he had destroyed by Kiyomori's orders, was handed over to the monks and put to death by them at Narasaka. But.Kiyomori's brother, who had interceded for the life of Yoritomo after the Heiji émeute, was pardoned, his rank and property being restored to him; and Taira no Munekiyo, who also had acted an important part in saving. Yoritomo at that time, was invited to visit Kamakura where he would have been received with honour; but he declined the invitation, declaring that a change of allegiance at such a moment would be unworthy of a bushi.

It may here be noted that, although several of the Taira leaders who took the field against the Minamoto were killed in the campaign or exeeuted or exiled after it, the punitory measures adopted by Yoritomo were not by: any means wholesale. To be a Taira did not necessarily involve Kamakura's enmity: On the contrary, not only was clemency extended to several prominent members of Kiyomori's kith and kin, but also many local magnates of Taira origin whose estates lay in the Kwantō were from first to last staunch supporters and friends of the Minamoto. After Dan-no-ura, the Heike's sun permanently ceased to dominate the political firmament, but not: a few Heike stars rose subsequently from time to time above the horizon.

\section{MUNEMORI AND ANTOKU}

The record of Munemori, whose leadership proved fatal to the Taira cause, stamps him as something very, rare among Japanese bushi - a coward. If was the first to fly from every battle-field, 1 and at Dan-no-ura he preferred surrender to death. Tradition alleges that in this final fight Munemori's reputed mother, $\mathrm{Ni}$-i-no-ama, before throwing herself into the sea with the Emperor in her arms, confessed that, Munemori was not her son. After she had borne Shigemori she became enceinte and her husband, Kiyomori, looked eagerly for the birth of another boy. But a girl was born. Just at that time the wife of a man who combined the occupations of bonze and umbrella-maker, bore a son; and the two ehildren were surreptitiously exchanged. This story does not rest upon infallible testimony. Nor does another narrative, with regard to the motives which induced Kiyomori's widow to drown the young Emperor. Those motives are said to have been two. One was to fix upon the Minamoto the heinous crime of having done a sovereign to death, so that some avenger might rise in future years; the other was to hide the fact that Antoku was in reality a girl whose sex had been concealed in the interest of the child's maternal grandfather, Kiyomori.

\section{YOSHITSUNE'S FATE}

Yoshitsune's signal victories, were at Ichi-no-tani and at Yashima. The fight at Dan-no-ura eould not have made him famous, for its issue was determined by defection in the enemy's ranks, not by any strategieal device or opportune coup on the side of the victors. Yet Japan aceords to Yoshitsune the first place among her great captains. Undoubtedly this estimate is influenced by sympathy. Pursued by the relentless anger of his own brother, whose cause he had so splendidly championed, he was forced to fly for refuge to the north, and was ultimately done to death. This most cruel return for glorious deeds has.invested his memory with a mist of tears tending to obscure the true outlines of events, so that while Yoritomo is execrated as an inhuman, selfish tyrant; Yoshitsune is 
worshipped as a faultless hero. Yet, when examined closely, the situation undergoes some modifications. Yoritomo's keen insight discerned in his half-brother's attitude something more than mere rivalry. He discovered the possible establishment of special relations between the Imperial Court and a section of the Minamoto.

Yoshitsune's failure to repair to Kamakura after the battle of Ichi-no-tani inspired Yoritomo's first doubts. Japanese annals offer no explanation of Yoshitsune's procedure on that occasion. It would have been in the reasonable sequence of events that the military genius which planned and carried out the great coup at Ichi-no-tani should have been available at the subsequent council of strategists in Kamakura, and it would have been natural that the younger brother should have repaired, as did his elder brother, Noriyori, to the headquarters of the clan's chief. Yet Yoshitsune remained at Kyōto, and that by so doing he should have suggested some suspicions to Yoritomo was unavoidable. The secret of the Court noble's' ability to exclude the military magnates from any share in State administration was no secret in Yoritomo's eyes: He saw clearly that this differentiation had been effected by playing off one military party against the other, or by dividing the same party against itself; and he saw clearly that opportunities for such measures had been furnished by subjecting the military leaders to constant contact with the Court nobility.

Therefore, the determined to keep two aims always in view. One was to establish a military and executive capital entirely apart from, and independent of, the Imperial and administrative metropolis; the other, to preserve the unity of the Minamoto clan in all circumstances. Both of these aims seemed to be threatened with failure when Yoshitsune preferred the Court in Kyōto to the camp in Kamakura; still more so when he accepted from Go-Shirakawa rank and office for which Yoritomo had not recommended him, and yet further when he obtained from the ex-Emperor a commission to lead the Minamoto armies westward without any reference to, and in despite of, the obvious intention of the Minamoto chief at Kamakura.

All these acts could scarcely fail to be interpreted by Yoritomo as preluding the very results which he particularly desired to avert, namely, a house of Minamoto divided against itself and the re-establishment of Court influence over a strong military party in Kyōto. His apprehensions received confirmation from reports furnished by Kajiwara Kagetoki. Yoritomo trusted this man implicitly. Never forgetting that Kajiwara had saved his life in the affair of the hollow tree, he appointed him to the post of military governor and to the command of the army destined to drive the Taira from Shikoku after the battle of Ichi-no-tani. In that command Kajiwara had been superseded by Yoshitsune, and had moreover been brought into ridicule in connexion not only with the shipbuilding incident but also, and in a far more flagrant manner, with the great fight at Yashima. He seems from the first to have entertained doubts of Yoshitsune's loyalty to Yoritomo, and his own bitter experiences may well have helped to convert those doubts into certainties. He warned Kamakura in very strong terms against the brilliant young general who was then the idol of Kyotto, and thus, when Yoshitsune, in June, 1185, repaired to Kamakura to hand over the prisoners taken in the battle of Dan-no-ura and to pay his respects to Yoritomo, he was met at Koshigoe, a village in the vicinity, by Hōjō Tokimasa, who conveyed to him. Yoritomo's veto against his entry to Kamakura. A letter addressed by Yoshitsune to his brother on that occasion ran, in part, as follows:- 
Here am I, weeping erimson tears in vain at thy displeasure. Well was it said that good medicine tastes bitter in the moutll, and true words ring harsh in the ear. This is why the slanders that men speak of me reniain unproved, why I am kept out of Kamakura unable to lay bare my heart. These many days I have lain here and could not gaze upon my brother's face. The bond of our blood-brotherhood is sundered.

But a short season after I was born, my honoured sire passed to another world, and I was left fatherless. Clasped in my mother's bosom, I was earried down to Yamato, and since that day I have not known a moment free from care and danger. Though it was but to drag out a useless life, we wandered round the eapital suffering hardship, hid in all manner of rustic spots, dwelt in remote and distant provinces, whose rough inhabitants did treat us with contumely. But at last I was summoned to assist in overthrowing the Taira house, and in this confliet I first laid Kiso Yoshinaka low. Then, so that I might demolish the Taira men, I spurred my steed on frowning precipices. Careless of death in the face of the foe, I braved the dangers of wind and wave, not reeking that my body might sink to the bottom of the sea, and be devoured by monsters of the deep. My pillow was my harness, arms my trade. by W. G. Aston.]

This letter breathes the spirit of sincerity. . But its perusal did not soften Yoritomo, if it ever reached his eyes. He steadily refused to cancel his veto, and after an abortive sojourn of twenty days at Koshigoe, Yoshitsune returned to Kyōto where his conduct won for him increasing popularity. Three months later, Yoritomo appointed him governor of Iyo. It is possible that had not the situation been complieated by a new factor, the feud between the brothers might have ended there. But Minamoto Yukiiye, learning of these strained relations, emerged from hiding and applied himself to win the friendship of Yoshitsune, who received his advances graciously. Yoritomo, much incensed at this development, sent the son of Kajiwara Kagetoki to Yoshitsune with a mandate for Yukiiye's execution. Such a choice of messenger was ill calculated to promote concord. Yoshitsune, pleading illness, declined to receive the envoy, and it was determined at Kamakura that extreme measures must be employed. Volunteers were called for to make away with Yoshitsune, and, in response, a Nara bonze, Tosabō Shōshun, whose physical endowments had brought him into prominence at Kamakura, undertook the task on condition that a substantial reward be given him beforehand.

Shōshun did not waste any time. On the eighth night after his departure from Kamakura, he, with sixty followers, attacked Yoshitsune's mansion at Horikawa in Kyõto. By wholesale oaths, sworn in the most solemn manner, he had endeavoured to disarm the suspicions of his intended victim, and he so far succeeded that, when the attack was delivered, Yoshitsune had only seven men to hold the mansion against sixty. But these seven were the trusty and stalwart comrades who had accompanied Yoshitsune from Mutsu and had shared all the vicissitudes of his career. They held their assailants at bay until Yukiiye, roused by the tumult, came to the rescue, and the issue of Shōshun's essay was that his own head appeared on the pillory in Kyoto. Yoshitsune was awakened and hastily armed on this oceasion by his beautiful mistress, Shizuka, who, originally a danseuse of Kyōto, followed him for love's sake in weal and in woe. Tokiwa, Tomoe, Kesa, and Shizuka - these four heroines will always occupy a prominent place in Japanese history of the twelfth century.

After this event there could be no concealments between the two brothers. With difficulty and not without some menaces, Yoshitsune obtained from Go-Shirakawa a formal commission to proceed against Yoritomo by force of arms. Matters now moved with great rapidity. Yoritomo, always prescient, had fully foreseen the course of events. Shōshun's abortive attack on the Horikawa mansion took place on November 10, 1185, and before the close of the month three strong columns of Kamakura troops were converging on Kyöto. In that interval, Yoshitsune, failing to muster any considerable 
force in the capital or its environs, had decided to turn his back on Kyōto and proceed westward; he himself to Kyūshū, and Yukiiye to Shikoku. They embarked on November 29th, but scarcely had they put to sea when they encountered a gale which shattered their squadron. Yoshitsune and Yukiiye both landed on the Izumi coast, each ignorant of the other's fate. The latter was captured and beheaded a few months later, but the former made his way to. Yamato and found hiding-places among the valleys and mountains of Yoshino. The hero of Ichi-no-tani and Yashima was now a proscribed fugitive. Go-Shirakawa, whose fate was always to obey circumstances rather than to control them, had issued a new mandate on the arrival of Yoritomo's forces at Kyōto, and Kamakura was now: authorized to exterminate Yoshitsune with all his partisans, wherever they could be found.

Almost simultaneously with the capture of Yukiiye, whose fate excites no pity, the fair girl, Shizuka, was apprehended and brought before Hōjō Tokimasa, who governed Kyōto as Yoritomo's lieutenant. Little more than a year had elapsed since she first met Yoshitsune after his return from Dan-no-ura, and her separation from him now had been insisted on by him as the only means of saving her life. Indifferent to her own fate, she quickly fell into the hands of Tokimasa's emissaries and was by them subjected to a fruitless examination, repeated with equally, abortive results on her arrival at Kamakura. There, in spite of her vehement resistance; she was constrained to dance before Yoritomo and his wife, Masa, but instead of confining herself to stereotyped formulae, she utilized the occasion to chant to the accompaniment of her dance a stanza of sorrow for separation from her lover. It is related that Yoritomo's wrath would have involved serious consequences for Shizuka had not the lady Masa intervened. The beautiful danseuse, being enceinte at the time, was kept in prison until her confinement. - She had the misfortune to give birth to a son, and the child was killed by Yoritomo's order, the mother being released. The slaughter of an innocent baby sounds very shocking in modern ears, but it is just to remember that the Kamakura chief and his three younger brothers would all have been executed by Kiyomori had not their escape been contrived by special agencies. The Confucian doctrine, which had passed into the bushi's code, forbade a man to live under the same sky with his father's slayer. Deeds like the killing of Yoshitsune's son were the natural consequence of that doctrine.

Meanwhile, Yoshitsune had been passing from one place of concealment to another in the three contiguous provinces of Izumi, Yamato, and Kii. He escaped deadly peril in the Yoshino region through the devotion of : Satō Tadanobu, whose brother, Tsuginobu, had died to save Yoshitsune's life in the battle of Yashima. Attacked by the monks of Z̄ō-ō-dō in overwhelming force, Yoshitsune had prepared to meet death when Tadanobu offered to personify him and hold the position while Yoshitsune escaped. With much difficulty Yoshitsune was induced to consent.: Tadanobu not only succeeded in covering the retreat of his chief, but also managed himself to escape to Kyoto where, being discovered, he died by his own hand. Finally, in the spring of 1187, Yoshitsune and his followers, disguised as mendicant friars, made their way up the west coast, and, after hairbreadth escapes, found asylum in the domain of Fujiwara Hidehira, who had protected Yoshitsune in his youth. Hidehira owned and administered the whole of the two provinces of Mutsu and Dewa, which in those days covered some thirty thousand square miles and could easily furnish an army of a hundred thousand men.

The attitude of this great fief had always been an object of keen solicitude to 
Yoritomo. At one time there were rumours that Hidehira intended to throw. in his lot with Yoshinaka; at another, that he was about to join hands with the Taira. Yoritomo could never be certain that if the Kwanto were denuded of troops for some westward expedition, an overwhelming attack might not be delivered against Kamakura from the north. Thus, when he learned that Yoshitsune had escaped to Mutsu, all his apprehensions were roused. By that time Hidehira had died, in his ninety-first year, but he had committed to his son, Yasuhira, the duty of guarding Yoshitsune. Hence, when, in the spring of 1188, Kamakura became aware of Yoshitsune's presence in Mutsu, two consecutive inessages were sent thither, one from Yoritomo, the other from the Court; ordering Yoshitsune's execution. Yasuhira paid no attention, and Go-Shirakawa commissioned Yoritomo to punish the northern chief's contumacy. Yasuhira now became alarmed. He sent a large force to attack Yoshitsune at Koromo-gawa. Benkei and the little band of comrades who had followed Yoshitsune's fortunes continuously during eight years, died to a man fighting for him, and Yoshitsune, having killed his wife and children, committed suicide. His head was sent to Kamakura.

But this did not satisfy Yoritomo. He wanted something more than Yoshitsune's head; he wanted the great northern fief, and he had no idea of losing his opportunity. Three armies soon marched northward. They are said to have aggregated 284,000 of all arms. One moved up the western littoral; another up the eastern, and the third, under Yoritomo himself, marched by the inland route. The men of Mutsu fought stoutly, but after a campaign of some two months, Yasuhira, finding himself in a hopeless position, opened negotiations for surrender. His overtures being incontinently rejected, he appreciated the truth, namely, that Yoritomo was bent upon exterminating the Fujiwara of the north and taking possession of their vast estates. Then Yasuhira fled to Ezo; where, shortly afterwards, one of his own soldiers assassinated him and carried his head to Yoritomo, who, instead of rewarding the man $r$ beheaded him for treachery. Thus, from 1189, Yoritomo's sway may be said to have extended throughout the length and breadth of Japan. In the storehouses of the Fujiwara, who, since the days of Kiyohira had ruled for a hundred years in the north, there were found piles of gold, silver, and precious stuffs with which Yoritomo recompensed his troops.

\section{YORITOMO'S' SYSTEM}

The system of government established by Yoritomo towards the close of the twelfth century and kept in continuous operation thereafter unitil the middle of the nineteenth, was known as the Bakufu, a word literally signifying "camp office," and intended to convey the fact that the affairs of the empire were in the hands of the military.' None of the great Japanese captains prior to Yoritomo recognized that if their authority was to be permanent; it must be exereised independently of the Court and must be derived from some source outside the Court. The Taira chief, in the zenith of his career, had sufficient strength to do as Yoritomo did, and at one moment, that is to say, when he established his headquarters at Fukuhara, he appears to have had a partial inspiration. But he never recognized that whatever share he obtained in the administration of State affairs was derived solely from the nature of the office conferred on him by the Court, and could never exceed the functions of that office or survive its loss: The Fujiwara were astuter politicians. By their plan of hereditary offices and by their device of supplying maidens of their own blood to be Imperial consorts, 
they created a system having some elements of permanency and some measure of independence.

To But it was reserved for Yoritomo to appreciate the problem in all its bearings and to solve it radically. The selection of Kamakura for capital was the first step towards solution. Kamakura certainly has topographical advantages. It is surrounded by mountains except on one face, which is washed by the sea: But this feature does not seem to have counted so much in Yoritomo's eyes as the fact that his father, Yoshitomo, had chosen Kamakura as a place of residence when he exercised military sway in the Kwanto, and Yoritomo wished to preserve the tradition of Minamoto power. He wished, also, to select a site so far from Kyōto that the debilitating and demoralizing influence of the Imperial metropolitan society might be powerless to reach the military capital. Kamakura was then only a fishing hamlet, but at the zenith of its prosperity it had grown to be a city of at least $\mathbf{a}$ quarter of a million of inhabitants. During a period of one hundred and fifty years it remained the centre of military society and the focus

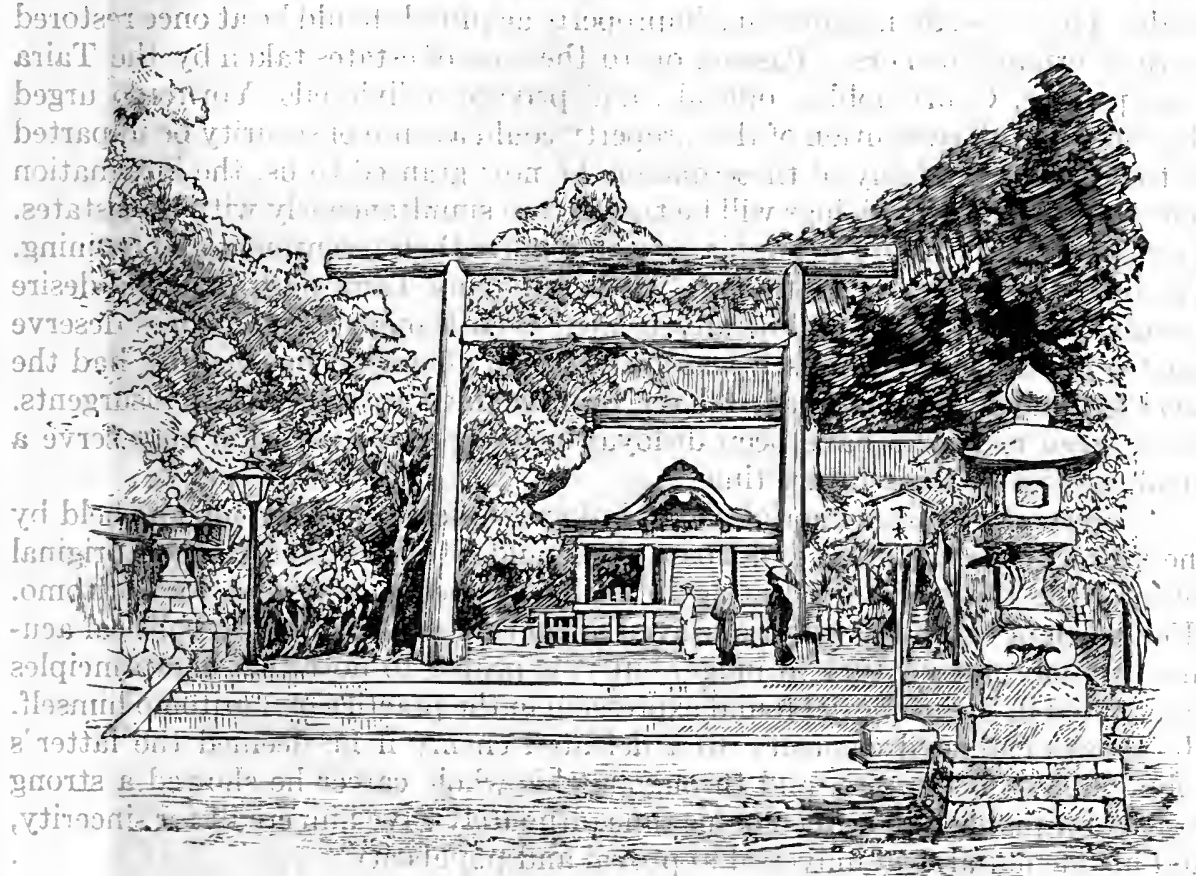

Hachiman Shrine at Kamakura

of a civilization radically different from that of Kyôto. The Taira had invited their own ruin by assimilating the ways of the Fujiwara and of the courtiers; the Minamoto aimed at preserving and developing at Kamakura the special characteristics of the buke:

\section{POLICY TOWARDS RELIGION}

Yoritomo seems to have believed that the Taira had owed their downfall largely to divine wrath, in that they had warred against the monasteries and confiscated manors belonging to shrines and temples. He himself adopted the policy of extending the utmost consideration to religion, whether Shinto or Buddhism, and to its devotees and their possessions. At Kamakura, though it 
has well-nigh reverted to its original rank as a fishing hamlet, there exist to-day. eloquent evidences of the Minamoto chief's reverent mood; among them being the temple of Hachiman; a colossal bronze image of Buddha which, in majesty of conception and execution, is not surpassed by any idol in the world; 1 a temple of Kwannon, and several other religious edifices, though the tomb of Yoritomo himself is "a modest little monument covered with creepers."

\section{YORITOMO'S MEMORIAL}

It has been stated above that, after the retreat of the Taira from Fukuhara, in 1183, Go-Shirakawa sent an envoy to Kamakura inviting Yoritomo's presence in Kyōto. Restrained, however, by a sense of insecurity, ${ }^{2}$ the Minamoto chief declined to leave Kamakura, and sent in his stead a memorial to the Throne. This document commenced with a statement that the ruin of the Taira had been due not to human prowess but to divine anger.against the plunderers of sacred lands. Therefore, all manors thus improperly acquired should be at once restored to their original owners. Passing on to the case of estates taken by the Taira from princes, Court nobles, officials, and private individuals, Yoritomo urged that only by full restitution of this property could a sense of security be imparted to the people. "If any of these manors be now granted to us, the indignation roused by the Taira's doings will be transferred simultaneously with the estates. To change men's misery to happiness is to remove their resentment and repining. Finally," the memorial continued, "if there be any Taira partisans who desire to submit, they should be liberally treated even though their offences deserve capital punishment. I myself was formerly an offender, ${ }^{3}$ but having had the good fortune to be pardoned, I have been enabled to subdue the insurgents. Thus, even men who have been disloyal on the present occasion may serve a loyal purpose at some future time.".

On receipt of this memorial, Go-Shirakawa ordered that the manors held by the Taira in the Tōkai-dō and Tōsan-dō should all be restored to their original owners, the duty of adjudicating in each case being delegated to Yoritomo. How much of this admirably conceived document was inspired by political acumen we may not venture to judge, but it is proper to note that the principles enunciated in the memorial found expression in the practice of Yoritomo himself. He always extended clemeney to a defeated enemy if he deemed the latter's submission to be sineere, and throughout his whole career he showed a strong respect for justice. The men of his time ultimately gave him credit for sincerity, and his memorial won universal approval and popularity.

\section{POLITY OF THE KAMAKURA BAKUFU}

Under the Daika (A.D. 645) system, various administrative organs were created in accordance with Tang models, and a polity at once imposing and elaborate eame into existence. But when the capital was overtaken by an era of literary effeminacy and luxurious abandonment, the Imperial exchequer fell into such a state of exhaustion that administrative posts began to be treated as

[1 This image was not actually erected by Yoritomo, but the project is attributed to him.]

[ ${ }^{2}$ Kamakura was always exposed to pressure from the north. It had long been proverbial that while the eight provinees of the Kwantō could defy the whole empire, Ō-U (Ōshu and Usha-Mutsa and Dewa) could defy the eight provinces.]

[ ${ }^{3}$ In allusion to the fact that owing to the Emperor's presence in the camp of the Taira during the émeute, the Minamoto occupied the position of rebels.] 


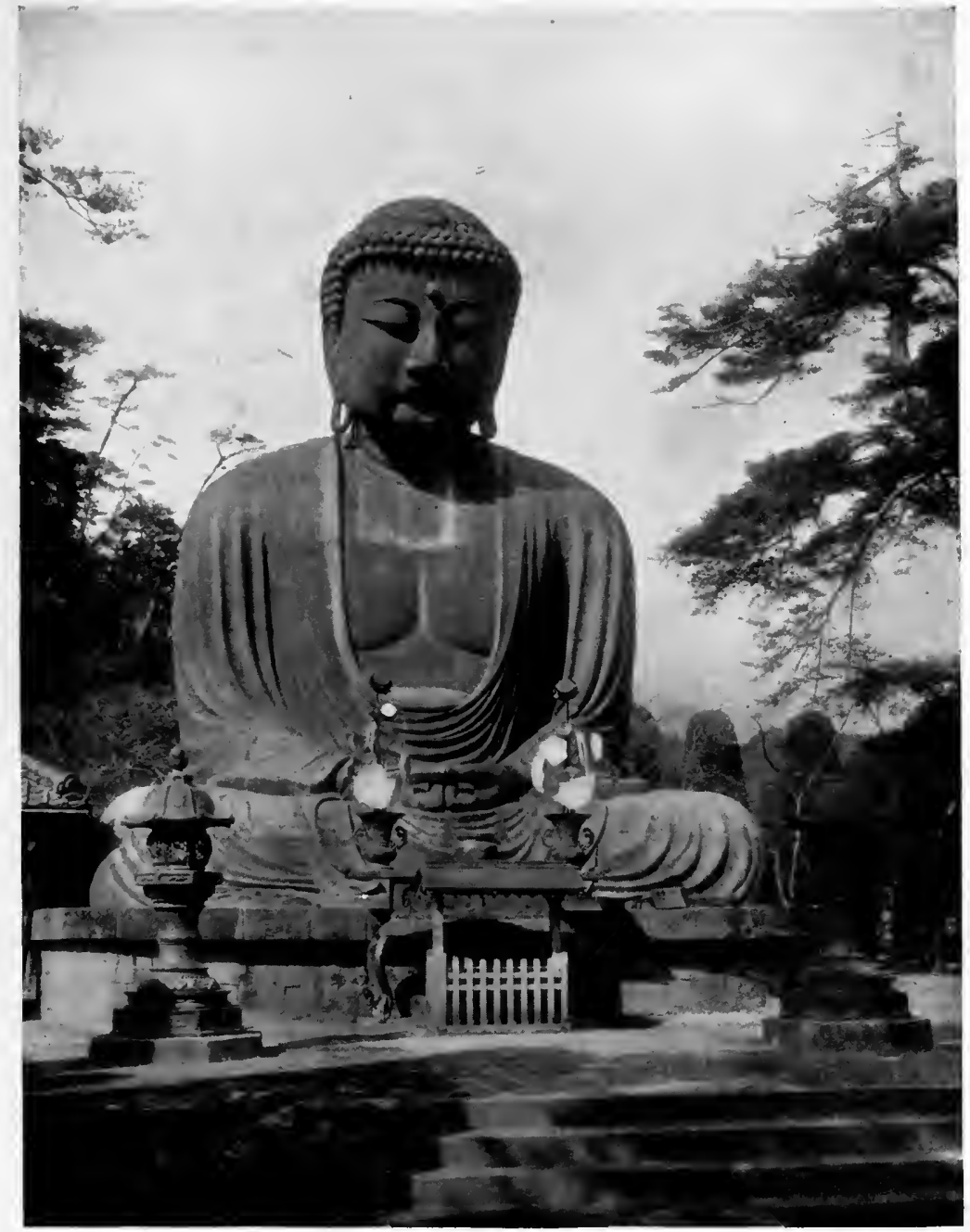

KAMAKURA DAIBUTSU, OR IMAGE OF BUDDHA (Cast in brontec, 1252 A. D.; height 47 feet) 

State assets and bought and sold like commercial chattels, the discharge of the functions connected with them becoming illusory, and the constant tendency being in the direction of multiplication of offices with a corresponding increase of red tape. Yoritomo and his councillors appreciated the evils of such a system and were careful not to imitate it at Kamakura. They took brevity and simpli city for guiding principles, and constructed a polity in marked contrast with that of Kyōto.

At the head of the whole stood the shogun, or commander-in-chief of the entire body of bushi, and then followed three sections. They were, first, the Samuraidokoro, which term, according to its literal rendering, signified "samurai place," and may be appropriately designated "Central Staff Officè." Established in 1180 , its functions were to promote or degrade military men; to form a council of war; to direct police duties so far as they concerned bushi; to punish crime, and to select men for guards and escorts. The president (bettō) obviously occupied a post of prime importance, as he practically controlled all the retainers (kenin) of the Minamoto clan and its allied houses. Its first occupant was Wada Yoshimori, representative of a famous family in the Kwantō, who had greatly distinguished himself in the Gen-Hei War. He held the post until the year 1213, when, taking up arms against Höjō Yoshitoki, he was defeated and killed. Thereafter, it being deemed inadvisable that the functions of such an important office should be delegated independently, they were made supplementary to those of the military regent (shikken), to be presently spoken of.

\section{MAN-DOKORO}

The second of the three great sections of the Bakufu polity was the Mandokoro (literally, "place of administration"), which, at the time of its establishment in 1184, was designated Kumon-jo, the change of name to Man-dokoro being made after Yoritomo's first visit to Kyōto (1190), when he was nominated gon-dainagon as well as general of the Right division of the guards (u-kon-e taishö)... In fact, the office $M a n$-dokoro had long existed in the establishment of the civil regent (kwampaku) at the Imperial capital, and a concession to Kyōto usages in the matter of nomenclature appealed to Yoritomo's taste for simplicity. The Man-dokoro had to discharge the duties and general business of the Bakufu. Its president was called bettō; its vice-president, $r e i$; there were secretaries, a manager (shitsuji), whose functions were mainly financial, and certain minor officials. Oye no Hiromoto was the first president, and the office of shitsuji became hereditary in the Nikaido family.

It will be seen that the bettō of the Man-dokoro corresponded to the regent in the Kyoto polity, the only difference being that the former officiated in military government, the latter in civil. The betto of the Man-dokoro was, in fact, designated by the alternative name of shikken (literally, "holder of authority") Thus there were two regents, one in Kyōto, one in Kamakura. In succession to Ōye no Hiromoto, the military regency fell to Hōjō Tokimasa, and subsequently to his son Yoshitoki, who, as shown above, held the post of betto of the Samuraidokoro. In short, both offices became hereditary in the Hōjo family, who thus acquired virtually, all the power of the Bakufu. The shikken, standing at the head of the Samurai-dokoro and the Man-dokoro simultaneously, came to wield such authority that even the appointment of the shogun depended upon his will, and though a subject of the Emperor, he administered functions far exceeding those of the Imperial Court. In the year 1225, a reorganization of the Man- 
dokoro was effected. An administrative council was added (Hyōjōshō), the councillors, fifteen or sixteen in number, being composed; in about equal parts, of men of science and members of the great clans. The regent (shikken) presided ex-officio.

\section{MONJÜ-DOKORO}

The third of the Bakufu offices was the Monjü-dokoro, or "place for recording judicial inquiries;" in other words, a high court of justice and State legislature. Suits at law were heard there and were either decided finally or transferred to other offices for approval. This office was established in 1184:? Its president was called shitsuji (manager), indicating that he ranked equally with the Man-dokoro official having the same appellation. The first occupant of the post was Miyoshi Yasunobu. He not only presided over the Monjū-dokoro in a judicial capacity but also attended the meetings of the Man-dokoro council (Hyōjōshü) ex-officio.

This Miyoshi Yasunobu, 1 as well as the representative of the Nikaido who occupied the post of shitsuji in the Man-dokoro; the Ōyefamily; who furnished the president of the latter, and the Nakahara, who served as the secretaries; were all men of erudition whom Yoritomo invited from Kyōto to: fill posts in his administrative system at Kamakura. In these unquiet and aristocratically: exclusive times, official promotion in the Imperial capital had largely ceased to be within reach of scholastic attainments, and Yoritomo saw an opportunity to attract to Kamakura men of learning and of competence. He offered to them careers which were not open in Kyōto, and their ready response to his invitations was a principal cause of the success and efficacy that attended the operation of the Bakufu system in the early days.

\section{HIGH CONSTABLES AND LAND-STEWARDS}

The most far-reaching change effected by Yoritomo was promptel by Ōye no Hiromoto, at the close of 1185, when, Yoshitsune and Yukiiye having gone westward from Kyōto, the Kamakura chief entertained an apprehension that they might succeed in raising a revolt in the Sanyō-dō, in Shikoku, and in Kyūshū. He sought advice from the high officials of the Bakufu as to the best preventive measures, and Ōye no Hiromoto presented a memorial urging that the Emperor's sanction be obtained for appointing in each province a high constable (shugo) and a land-steward ( $j i t \bar{o})$, these officials being nominated from Kamakura, while Yoritomo himself became chief land-steward $(s \overline{0}-j i t \bar{o})$ and subsequently lord high constable (sō-tsuihoshi) for the sixty-six provinces. The object of these appointments was to insure that the control of local affairs should be everywhere in the hands of the Bakufu, whose nominees would thus be in a position to check all hostile movements or preparations.

Yoritomo recognized the important bearings of this project. He at once sent Hōjō Tokimasa to guard Kyōto and to submit to the Court a statement thăt it would be far more effective and economical to prevent acts of insurrection than to deal with them after their full development, and that, to the former end, trustworthy local officials should be appointed; the necessary funds being ob-

['Miyoshi Yasunobu held the office of chügü no sakan in Kyōto. He was personally known to Yoritomo, and he was instrumental in securing the services of the astute Oyeno Hiromoto, whose younger brother, Chikayoshi, was governor of Aki at the time of receiving Yoritomo's invitation. His descendants reeeived the $u j i$ of Nagai and Morri; those of Yasunobu, the $u j i$ of Öta and Machino, and those of Chikayoshi, the uji of Settsu and Otomo.] 
tained by levying from the twenty-six provinces of the Go-Kinai, Sanin, Sanyō, Nankai, and Saikai a tax of five sho of rice per tan (two bushels per acre). GoShirakawa seems to have perceived the radical character of the proposed measure. He evinced much reluctance to sanction it. But Yoritomo was too strong to be defied. The Court agreed, and from that moment military feudalism may be said to have been established in Japan.

It has been shown that the land system fixed by the Daih $\bar{o}-r y \bar{o}$ had fallen into confusion. Private manors existed everywhere, yielding incomes to all classes from princes to soldiers: - In the days of the Fujiwara and the Taira more than one-half of the arable land throughout the empire was absorbed into such estates, which paid no taxes to anyone except their direct owners. The provincial governor appointed by the Court gradually ceased to exercise control over the shōen in his district, unless he happened to be a military man with a sufficient force of armed retainers (kenin) to assert his authority. Hence it became customary for provincial governors not to proceed in person to the place of their function. They appointed deputies (mokudai), and these limited their duties to the collection of taxes from manors. Lands constituting the domains of great, families, were under the complete control of their holders, and there being no one responsible for the preservation of general peace and order, bandits and other lawbreakers abounded.

This state of affairs was remedied by the appointment of high constables and land-stewards. The high constable had to arrest insurgents, assassins, and robbers wherever he found them, and to muster the soldiers for service in the Kyōto guards. The land-steward was to collect taxes from all private manors. Soon, however, these functions were extended, so that the high constables exercised judicial and administrative powers, and the land-stewards not only collected taxes, and, after deducting their own salaries, handed the remainder to those entitled to receive it, but also were responsible for the maintenance of peace and order within the manors entrusted to their charge.: High constables and land-stewards alike were responsible to Kamakura alone; they were beyond the jurisdiction of the Imperial Court. Thus, the sway of the Minamoto extended throughout the whole country. It may be stated at once here that the landsteward system did not work altogether satisfactorily. The acts of these officials created friction in several quarters, and they were soon withdrawn from all manors other than those owned or administered by Taira. The high constables remained, however, and were in full control of local military affairs, the Kamakura chief controlling the whole in his capacity of lord high constable.

\section{EXEMPTION OF SHRINES AND TEMPLES FROM THE SHUGO SYSTEM}

In pursuance of his policy of special benevolence towards religious institutions, Yoritomo exempted the manors of temples and shrines from the jurisdiction of high constables. Thus military men were not permitted to make an arrest within the enclosure of a fane, or to trespass in any way on its domains, these being tax-free.

\section{REFORM OF THE COURT}

Yoritomo did not confine himself to re-casting the system of provincial administration. He extended his reforms to the Court, also. Thrice within the short space of five years he had been proscribed as a rebel by Imperial decree once at the instance of the Taira; once at the instance of Yoshinaka, and once at 
the instance of Yoshitsune. In short; the Court, being entirely without military power of its own, was constrained to bow to any display of force from without. As a means of correcting this state of affairs, Hōjo Tokimasa was despatehed to the Imperial capital at the close of 1185 , to officiate there as high constable and representative of the Bakufu. A strong force of troops was placed at his disposal, and efficient means of speedy communications between the east and the west were organized. Moreover, a new office, that of scrutator (nairan), was instituted, and to him were transferred some of the powers hitherto wielded by the regent (kwampaku). Fujiwara Kanezane was the first occupant of this post. Further, a body of twelve councillors ( $g i s \bar{o})$, headed by Kanezane, were organized in the cloistered Emperor's Court (Inch $\bar{u}$ ), and to this council was entrusted the duty of discussing and deciding all State affairs. These important steps were taken early in 1186 .

Simultaneously, a number of Court officials, including all that had been connected with Yoshitsune and Yukiie, lost their posts, and, shortly afterwards, Kanezane, becoming regent (kwampaku) in place of Fujiwara Motomichi, co-operated with Ōye no Hiromoto in effecting many important changes, the latter operating at Kamakura, the former at Kyōto. It may be noted here that Kanezane's descendants received the name of Kujo, those of Motomichi being called Konoe, and the custom of appointing the kwampaku alternately from these two families came in to vogue from that time. All the above reforms having been effected during the year 1186, the Bakufu recalled Hōjō Tokimasa and appointed Nakahara Chikayoshi to succeed him. But, as the latter was not a scion of a military family, the Court desired to have a Hōjo appointed, and Yoritomo acceded by sending Hōjō Tokisada.

\section{PALACES AND FANES}

Yoritomo maintained from first to last a reverential attitude towards the Throne and towards religion. It has already been shown how generously he legislated in the matter of estates belonging to temples and shrines, and we may add that his munificence in that respect was stimulated by a terrible earthquake which visited Kyōto in the autumn of 1185 . While the city trembled under repeated shocks, the citizens told each other that this was the work of vengeful spirits of the Taira who, having fallen in the great sea-fight, were still without full rites of sepulture. The Kamakura chief seems to have accepted that view, for he not only gave substantial encouragement to the burning of incense and intoning of memorial Sutras, but he also desisted largely from his pursuit of the Taira survivors. Two years later (1187), he sent Oye no Hiromoto to the Imperial capital with authority and ample competence to repair the palaces there. The city was then infested with bandits, a not unnatural product of the warlike era. Chiba Tsunetane, specially despatched from Kamakura, dealt drastically with this nuisance, and good order was finally restored.

\section{YORITOMO VISTS KYŌTO}

During the early years of his signal triumphs Yoritomo was invited to Kyōto on several occasions. Various considerations deterred him. He wished, in the first place, to dispel the popular illusion that the Imperial capital was the centre of all dignity and power. People must be taught to recognize that, although Kyoto might be the ultimate source of authority, Kamakura was its 
place of practical exercise. He wished, in the second place, not to absent himself from Kamakura until he could be absolutely assured that his absence would not afford an opportunity to his enemies; which sense of security was not fully reached until the death of Yoshitsune and Fujiwara no Yasuhira, and the complete subjugation of the great northern fief of Ōshu in the year 1189. Finally, hë wished to appear in Kyōto, not merely as the representative of military power, but also as a benefactor who had rebuilt the fanes and restored the palaces.

On the 2nd of November, in the year 1190, he set out from Kamakura and reached Kyōto on December 5th. His armies had shown that, for the purpose of a campaign, the distance would be traversed in little more than half of that time. But Yoritomo's journey was a kind of Imperial progress. Attended by a retinue designed to surprise even the citizens of the Imperial metropolis, he travelled at a leisurely pace and made a pause of some duration in Owari to worship at his father's tomb. The Court received him with all consideration. He had already been honoured with the first grade of the second rank, so that he enjoyed the right of access to the Presence, and the cloistered Emperor held with him long conversations, sometimes lasting a whole day. But Yoritomo did not achieve his: purpose. It is true that he received the appointments of gondainagon and general of the Right division of the guards. These posts, however, were more objectionable on account of their limitations than acceptable as marks of honour. Their bestowal was a mere formality, and Yoritomo resigned them in a few days, preferring to be nominated sō-tsuihoshi.

What he really desired, however, was the office of sei-i tai-shoggun (barbariansubduing great general). This high title had been conferred more than once previously, but only for the purpose of some finite and clearly indicated purpose, on the attainment of which the office had to be surrendered. The Kamakura chief's plan was to remove these limitations, and to make the appointment not only for life but also general in the scope of its functions and hereditary in his own family, reserving to the sovereign the formal right of investiture alone. Go-Shirakawa, however, appreciated the far-reaching effects of such an arrangement and refused to sanction it. Thus, Yoritomo had to content himself with the post of lord high constable of the empire (sō-tsuihoshi), an office of immense importance, but differing radically from that of sei-i tai-shoggun in that, whereas the latter had competence to adopt every measure he pleased without reference to any superior authority, the former was required to consult the Imperial Court before taking any step of a serious nature. The Minamoto chief returned quietly to Kamakura, but he left many powerful friends to promote his interests in Kyōto, and when Go-Shirakawa died, in 1192, his grandson and successor, Go-Toba, a boy of thirteen, had not occupied the throne more than three months before the commission of sei-i tai-shogun was conveyed to Yoritomo by special envoys. Thereafter it became the unwritten law of the empire that the holder of this high post must be either the head of the principal Minamoto family or an Imperial prince.

Never before had there been such encroachment upon the prerogatives of the Crown. We have seen that, in the centuries antecedent to the Daika (A.D. 645) reforms, the sovereign's contact with his subjects had been solely through the medium of the $\bar{o}$-omi or the $\bar{o}$-muraji. By these, the Imperial commands were transmitted and enforced, with such modifications as circumstances might suggest, nor did the prerogative of nominating the $\bar{o}$-omi or the $\bar{o}$-muraji belong practically to the Throne. The Daika reforms, copying the Tang polity called 
into existence a cabinet and a body of officials appointable or removable by the sovereign at will, each entrusted with definite functions. But almost before that centralized system had time to take root, the Fujiwara grafted on it a modification which, in effect, substituted their own family for the ö-omi and the $\bar{o}$-muraji of previous times. And now, finally, came the Minamoto with their separate capital and their sei-i tai-shogun, who exercised the military and administrative powers of the empire with practically no reference to the Emperor. Yoritomo himself was always willing and even careful to envelop his own personality in a shadow of profound reverence towards the occupant of the throne, but he was equally careful to preserve for Kamakura the substance of power.

\section{DEATH OF YORITOMO}

Yoritomo lived only seven years after he had reached the summit of his ambition. He received the commission of 'sei-i tai-shoggun in the spring of 1192 ; and, early in 1199, he was thrown from his horse and killed, at the age of fiftythree. He had proceeded to the pageant of opening a new bridge over the Sagami River, and it was popularly rumoured that he had fallen from his horse in a swoon caused by the apparition of Yoshitsune and Yukiiye on the Yamato plain and that of the Emperor Antoku at Inamura promontory. Just twenty years had elapsed since he raised the Minamoto standard in Sagami. His career was short but meteoric, and he ranks among the three greatest statesmen Japan has ever produced, his compeers being Hideyoshi and Ieyasu.

\section{YORITOMO'S CHARACTER}

Japanese historians have written much about this illustrious man. Their views may be condensed into the following: Yoritomo was short in stature with a disproportionately large head. He had a ringing voice, gentle manners, an intrepid and magnanimous heart, profound insight, and extraordinary caution. The power of imposing his will upon others was one of his notable characteristics, as was also munificence to those that served him. Retainers of the Taira or of the Minamoto - he made no distinction. All that swore fealty to him were frankly regarded as go-kenin of the Bakufu. Estates were given to them, whether restored or newly bestowed; and they were treated much as were the hatamoto of the Yedo shōgunate in later times. He" spared no pains to preserve Kamakura against the taint of Kyōto's demoralizing influences. The bushi of the Kwantō were made the centre of society; were encouraged to observe the canons of their caste - frugality, loyalty; truth, valour, and generosity - canons daily becoming crystallized into inflexible laws. When Toshikane, lord of Chikugo, appeared at the Kamakura Court in a magnificent costume, Yoritomo evinced his displeasure by slashing the sleeves of the nobleman's surcoat. Skill in archery or equestrianism was so much valued that it brought quick preferment and even secured pardon for a criminal.

On the other hand, neglect of these arts, or conduct unbecoming a samurai, was mereilessly punished. When Hayama Muneyori retired to his province without accompanying the army sent to attack $\bar{O}-U$, he was severely censured and deprived of his estates. : Cognate instances might be multiplied. In the year 1193, the first case of the vendetta occurred in Japan. Yoritomo organized a grand hunting party on the moors at the southern base of Fuji-yama. Among those that accompanied him was Kudo Suketsune, who had done to death Soga 
no Sukeyasu. The latter's sons, Sukenari (commonly called Jūrō) and Tokimune (Gorō), having sworn to avenge their father, broke into Yoritomo's camp and took the head of their enemy. The elder was killed in the enterprise; the younger, captured and beheaded. Yoritomo would fain have saved Gorō's life, though the youth declared his resolve not to survive his brother. But the Kamakura chief was constrained to yield to the demands of Suketsune's son. He, however, marked his appreciation of Jūrō and Gorō's filial piety by carefully observing their last testament; and by exonerating the Soga estate from the duty of paying taxes in order that funds might be available for religious rites on account of the spirits of the brothers.

ant This encouragement of fidelity may well have been dictated by selfish policy rather than by moral convietion. Yet that Yoritomo took every conspicuous opportunity of asserting the principle must be recorded. Thus; he publicly declared Yasuhira a traitor for having done to death his guest, Yoshitsune, though in so doing Yasuhira obeyed the orders of Yoritomo himself; he executed the disloyal retainer who took Yasuhira's head, though the latter was then a fugitive from the pursuit of the Kamakura armies, and he pardoned Yuri Hachirō, one of Yasuhira's officers, because he defended Yasuhira's reputation in defiance of Yoritomo's anger.

Gratitude Yoritomo never failed to practise within the limit of policy. Rumour said that he had fallen in his first battle at Ishibashi-yama. Thereupon, Miura Yoshiaki, a man of eighty-nine, sent out all his sons to search for Yoritomo's body, and closing his castle in the face of the Taira forces, fell fighting. Yoritomo repaid this loyal service by appointing Yoshiaki's son, Wada Yoshimori, to be bettō of the Samurai-dokoro, one of the very highest posts in the gift of the Kamakura Government. Again, it will be remembered that when, as a boy of fourteen, Yoritomo had been condemned to death by Kiyomori, the lad's life was saved through the intercession of Kiyomori's step-mother, Ike, who had been prompted by Taira no Munekiyo. After the fall of the Taira, Yoritomo prayed the Court to release Ike's son, Yorimori, and to restore his rank and estates, while in Munekiyo's case he made similar offers but they were rejected.

Towards his own kith and kin, however, he showed himself implacable. In Yoshitsune's case it has been indicated that there was much to awaken Yoritomo's suspicions. But his brother Noriyori had no qualities at all likely to be dangerously exercised. A commonplace, simple-hearted man, he was living quietly on his estate in Izu when false news came that Yoritomo had perished under the sword of the Soga brothers. Yoritomo's wife being prostrated by the intelligence, Noriyori bade her be reassured since he, Noriyori, survived. When this came to Yoritomo's ears, doubtless in a very exaggerated form, he sent a band of assassins who killed Noriyori. Assassination was a device from which the Kamakura chief did not shrink at all. It has been shown how he sent Tosabō Shōshun to make away with Yoshitsune in Kyōto, and we now see him employing a similar instrument against Noriyori, as he did also against his halfbrother, Zensei. It would seem to have been his deliberate policy to remove every potential obstacle to the accession of his own sons. Many historians agree in ascribing these cruelties to jealousy. But though Yoritomo might have been jealous of Yoshitsune, he could not possibly have experienced any access of such a sentiment with regard to Noriyori or Zensei.

Towards religion, it would seem that his attitude was sincere. Not in Kyōto and Kamakura alone did he adopt drastic measures for the restoration or erection of temples and shrines, but also throughout the provinces he exerted his all- 
powerful influence in the same cause. He himself contributed large sums for the purpose, and at his instance the Courts of the Emperor and of the Bakufu granted special rights and privileges to bonzes who went about the country collecting subscriptions. Thus encouraged, the priests worked with conspicuous zeal, and by men like Mongaku, Jūgen, Eisai, and their comrades not only were many imposing fanes erected and many images cast, but also roads were opened, harbours constructed, and bridges built. Yoritomo knew what an important part religion had contributed in past ages to the country's national development, and he did not neglect to utilize its services in the interests, first, of the nation's prosperity and, secondly, of the Bakufu's popularity. Incidentally all this building of fanes and restoration of palaces promoted in no small degree the development of art, pure and applied. Experts in every line made their appearance, and many masterpieces of architecture and sculpture enriched the era. These reflected the change which the spirit of the nation was undergoing in its passage from the delicacy and weakness of the Fujiwara type to the strength, directness, and dignity of the bushi's code.

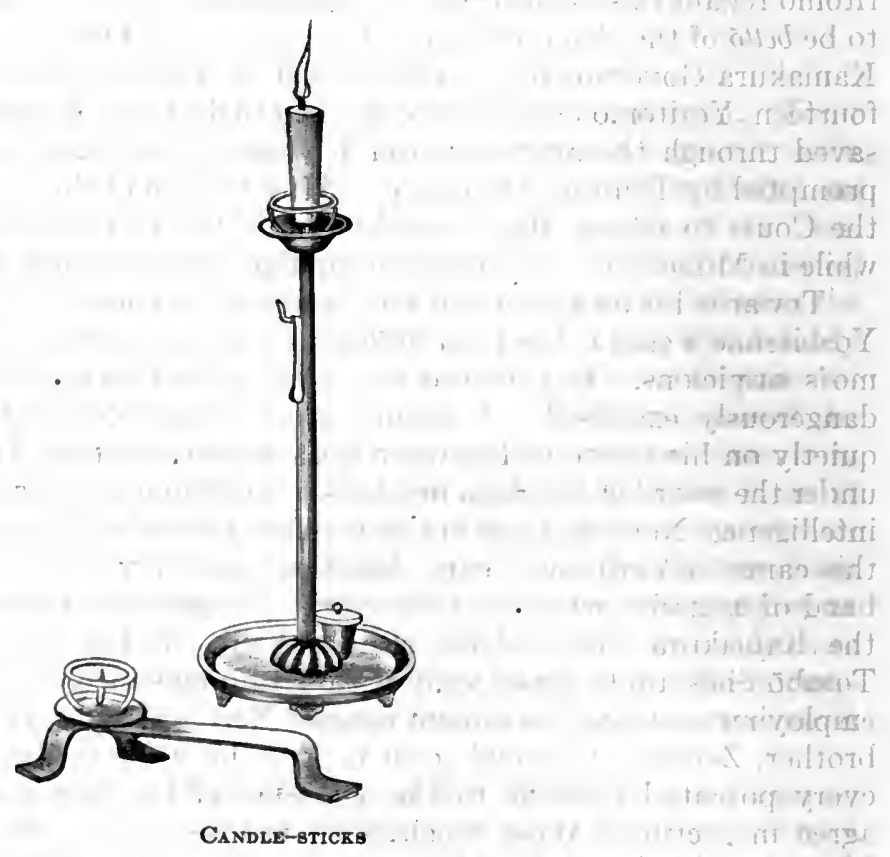




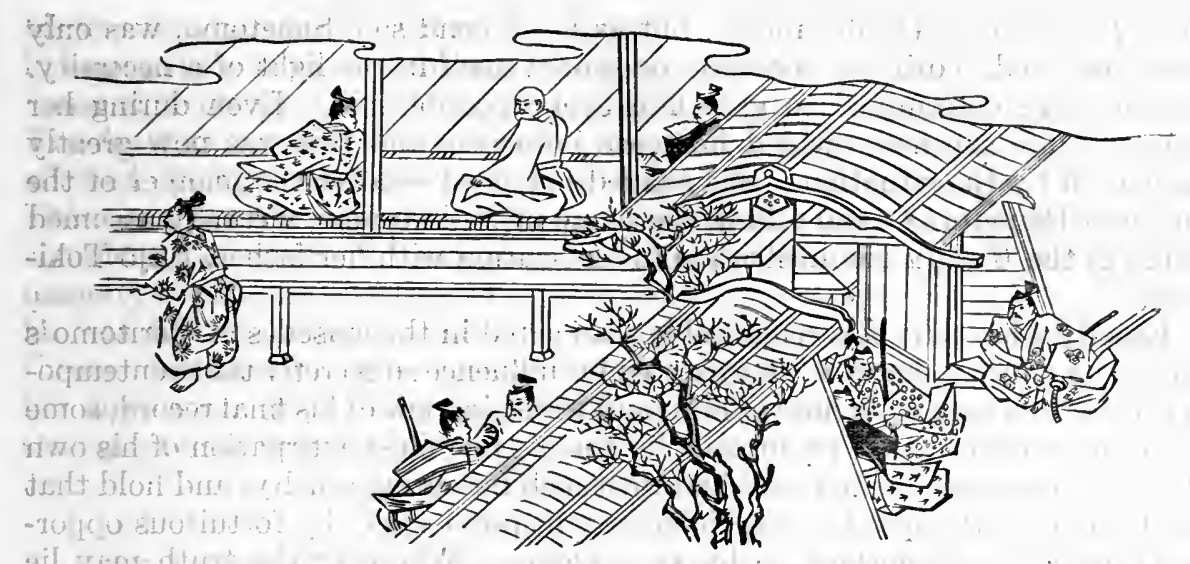

Samuray's Residence in the Kamakdra Period

\section{CHAPTER XXVI}

\section{THE KAMAKURA $B A K U F U$}

\section{ABDICATION OF GO-TOBA}

In the year 1198, the Emperor Go-Toba abdicated the throne in favour of his son, who reigned during twelve years (1199-1210) under the name of Tsuchimikado, eighty-third sovereign. Of Go-Toba much will be said by and by. It will suffice to note here, however, that his abdication was altogether voluntary. Ascending the throne in 1184, at the age of four, he had passed the next eight years as a mere puppet manipulated by his grandfather, Go-Shirakawa, the cloistered Emperor, and on the latter's death in 1192, Go-Toba fell into many of the faults of youth. But at eighteen he became ambitious of governing in fact as well as in name, and as he judged that this could be accomplished better from the Inch $\bar{u}$ (retired palace) than from the throne, he abdicated without consulting the Kamakura Bakufu. It is more than probable that Yoritomo would have made his influence felt on this occasion had any irregularity furnished a pretext. But the advisers of the Kyoto Court were careful that everything should be in order, and the Kamakura chief saw no reason to depart from his habitually reverent attitude towards the Throne.

\section{YORIIYE, THE LADY MASA, AND HŌJŌ TOKIMASA}

On the demise of Yoritomo (1199), his eldest son, Yoriiye, succeeded to the compound office of lord high constable and chief land-steward (sō-shugo-jitō), his investiture as shōgun being deferred until Kyōto's sanction could be obtained. Yoriiye was then in his eighteenth year, and he had for chief adviser Hatakeyama Shigetada, appointed to the post by Yoritomo's will. He inherited nothing of his father's sagacity. On the contrary, he did not possess even average ability, and his thoughts were occupied almost uniquely with physical pleasures. His mother, Masa, astute, crafty, resourceful, and heroic, well understood the de- 
ficiency of his moral endowments, but as her second son, Sanetomo, was only seven years old, Yoriiye's accession presented itself in the light of a necessity. She therefore determined to give him every possible aid. Even during her husband's life she had wielded immense influence, and this was now greatly augmented by the situation. She shaved her head - after the manner of the cloistered Emperors - and taking the name of Ni-i-no-ama, virtually assumed charge of the Bakufu administration in association with her father, Hōjo-Tokimasa.

Exactly what part this remarkable man acted in the episodes of Yoritomo's career, can never be known. He exerted his influence so secretly that contemporary historians took little note of him; and while, in view of his final record, some see in him the spirit that prompted Yoritomo's merciless extirpation of his own relatives, others decline to credit him with such far-seeing cruelty, and hold that his ultimately attempted usurpations were inspired solely by fortuitous opportunity which owed nothing to his contrivance. Wherever the truth may lie as between these views, it is certain that after Yoritomo's death, Hōjō Tokimasa conspired to remove the Minamoto from the scene and to replace them with the Hōịo.

\section{THE DELIBERATIVE COUNCIL}

The whole coterie of illustrious men - legislators, administrators, and generals - whom Yoritomo had assembled at Kamakura, was formed into a council of thirteen members to discuss the affairs of the Bakufu after his death. This body of councillors included Tokimasa and his son, Yoshitoki; $\bar{O}$ ye no Hiromoto, Miyoshi Yasunobu, Nakahara Chikayoshi, Miura Yoshizumi, Wada Yoshimori,Hiki Yoshikazu, and five others. But though they deliberated, they did not decide. All final decision required the endorsement of the lady Masa and her fäther, Hōjō Tokimasá.

\section{DEATH OF YORIIYE}

4) iftua llin jI

Yoriiye had been at the head of the'Bakuf $u$ for three years before his commission of shōgun came from Kyōto, and in the following yeàr (1203), he was attacked by a malady which threatened to end fatally. The question of the succession thus acquired immediate importance. Yoriiye's eldest son, Ichiman the natural heir, was only three years old, and Yoritomo's second son, Sanetomo, was in his eleventh year. In this balance of claims, Höjó Tokimasa saw his opportunity. He would divide the Minamoto power by way of preliminary to supplanting it? Marshalling arguments' based chiefly on the advisability of averting an armed struggle, he persuaded the lady Masa to endorse a compromise, namely; that to Sanetomo should be given the office of land-steward in thirty-eight provinces of the Kwansai; while to Ichiman should be secured the title of shog un and the offices of lord high constable and land-steward in twenty-eight provinces of the Kwantō.

Now the maternal grandfather of Ichiman was Hiki Yoshikazu, a captain who had won high renown in the days of Yoritomo. Learning of the projected partition and appreciating the grave effect it must produce on the fortunes of his grandson, Hiki commissioned his daughter to relate the whole story to Yoriiye, and applied himself to organize a plot for the destruction of the Hôjo facts came to the lady Masa's ears, and she lost no time in communicating them to Tokimasa, who, with characteristic promptitude, invited Hiki to a conference and had him assassinated." Thereipon, Hiki's son, Munetomo, assembled all 
his retainers and entrenched himself in Ichimän's mansion, where, being presently besieged by an overwhelming force of Tokimasa's partisans, he set fire to the house and perished, with the child, Ichiman, and with many brave soldiers. The death of his son, of his father-in-law, and of his brother-in-law profoundly affected Yoriiye. He attempted to take vengeance upon his grandfather, Tokimasa; but his emissaries suffered a signal defeat, and he himself, being now completely discredited, was constrained to follow his mother, Masa's, advice, namely, to take the tonsure and retire to the monastery Shüzen-ji in Izu. There he Iwas followed and murdered by Tokimasa's agents. It is apparent that throughout these intrigues the lady Masa made no resolute attempt to support her first-born. She recognized in him a source of weakness rather than of strength to the Minamoto.

\section{SANETOMO}

After Yoriiye's retirement, in 1204, to the monastery in Izu, Masa, with the concurrence of her father, Tokimasa, decided on the accession of her second son, Sanetomo, then in his twelfth year, and application for his appointment to the office of shögun having been duly made, a favourable and speedy reply was received from Kyōto. The most important feature of the arrangement was that Hōjo Tokimaśa became shikken, or military regent, and thus wielded greater powers than ever - powers which he quickly proceeded to abuse for revolutionary purposes. His policy was to remove from his path, by any and every measure,-all potential obstacles to the consummation of his ambition.

9 Among these obstacles were the lady Masa and the new shogun, Sanetomo. So long as these two lived, the Yoritomo family could count on the allegiance of the Kwantō, and so long as that allegiance remained intact, the elevation of the Hojō to the seats of supreme authority could not be compassed. Further, the substitution of $\mathrm{Ho} j \bar{o}$ for Minamoto must be gradual. Nothing abrupt would be tolerable. Now the Hōjo chief's second wife, Maki, had borne to him a daughter who married Minamoto Tomomasa, governor of Musashi and lord constable of Kyōto, in which city he was serving when history first takes prominent notice of him. This lady Maki seems to have been of the same type as her step-daughter, Masa. Both possessed high courage and intellectual endowments of an extraordinary order, and both were profoundly ambitious. Maki sấ no reason why her husband, Hōjō Tokimasa, should lend all his great influence to support the degenerate scions of one of his family in preference to the able and distinguished representative of the other branch. Tomomasa was both able and distinguished. By a prompt and vigorous exercise of military talent he had crushed a Heike rising in Ise, which had threatened for a time to become perilously formidable. His mother may well have believed herself justified in representing to Hōjō Tokimasa that such a man would make a much better Minamoto shōgun than the half-witted libertine, Yoriiye, or the untried boy, Sanetomo. It has been inferred that her pleading was in Tokimasa's ears when he sent a band of assassins to murder Yoriiye in the Shüzen-ji monastery: However that may be, there can be little doubt that the Hōjo chief, in the closing episodes of his career, favoured the progeny of his second wife, Maki, in preference to that of his daughter, Masa.

Having "removed" Yoriiye, he extended the same fate to Hatakeyama Shigetada, one of the most loyal and trusted servants of Yoritomo. Shigetada would never have connived at any measure inimical to the interests of his deceased master. Therefore, he was put out of the way. Then the conspirators 
fixed their eyes upon Sanetomo. The twelve-year-old boy was to be invited to Minamoto 'Tomomasa's mansion and there destroyed. This was the lády Maki's plan. The lady Masa discovered it, and hastened to secure Sanetomo's safety by carrying him to the house of her brother, Yoshitoki. The political eareer of Hōjo Tokimasa ended here. He had to take the tonsure, surrender his post of regent and go into exile in Izu, where he died, in 1215, after a decade of obscurity. As for Minamoto Tomomasa, he was killed in Kyōto by troops despatched for the purpose. This eonflict in 1205, though Hōjō Tokimasa and Minamoto Tomomasa figured so largely in it, is by some historians regarded as simply a conflict between the ladies Maki and Masa. These two women certainly oceupied a prominent place on the stage of events, but the figure behind the scenes was the white-haired intriguer, Tokimasa. Had the lady Maki's son-inlaw suceeeded Sanetomo, the former would have been the next vietim of Tokimasa's ambition, whereafter the field would have been open for the grand climacterie, the supremacy of the Hōjō.

\section{HŌJŌ YOSHITOKI}

Crafty and astute as was Hōjō Tokimasa, his son Yoshitoki excelled him in both of those attributes as well as in prescience. It was to the mansion of Yoshitoki that Sanetomo was carried for safety when his life was menaced by the wiles of Tokimasa. Yet in thus espousing the cause of his sister, Masa, and his nephew, Sanetomo, against his father, Tokimasa, and his brother-in-law, Tomomasa, it is not to be supposed that Yoshitoki's motive was loyalty to the house of Yoritomo. On the contrary, everything goes to show that he would have associated himself with his father's conspiracy had he not deemed the time premature and the method clumsy.: He waited patiently, and when the occasion arrived, he "covered his tracks" with infinite skill while marching always towards the goal of Tokimasa's ambition.

The first to be "removed" was Wada Yoshimori, whom Yoritomo had gratefully appointed bettō of the Samurai-dokoro. Yoritomo's eldest son, Yoriiye, had left two sons, Kugyō and Senju-maru. The former had taken the tonsure after his father's and elder brother's deaths, in 1204, but the cause of the latter was espoused with arms by a Shinano magnate, Izumi Chikahira, in 1213. On Wada Yoshimori, as betto of the Samurai-dokoro, devolved the duty of quelling this revolt. He did so effectually, but in the disposition of the insurgents? property, the shikken, Yoshitoki, contrived to drive Wada to open rebellion. He attacked the mansion of the shogun and the shikken, eaptured and burned the former, chiefly through the prowess of his giant son, Asahina Saburō; but was defeated and ultimately killed, Senju-maru, though only thirteen years old, being condemned to death on the pretext that his name had been used to foment the insurrection! After this convenient episode, Yoshitoki supplemented his office of shikken with that of betto of the Samurai-dokoro, thus becoming supreme in military and civil affairs alike.

\section{DEATH OF SANETOMO}

How far Sanetomo appreciated the situation thus created there is much difficulty in determining. The sentiment of pity evoked by his tragic fate has been projecterl too strongly upon the pages of his annals to leave them quite legible. He had seen his elder brother and two of the latter's three sons done to 
death. He had seen the "removal" of several of his father's most trusted lieutenants. He had seen the gradual upbuilding of the Hōjō power on this hecatomb of victims. That he perceived something of his own danger would seem to be a natural inference. Yet if he entertained such apprehensions, he never communicated them to his mother, Masa, who, from her place of high prestige and commanding intellect, could have reshaped the issue:

The fact would appear to be that Hōjo Yoshitoki's intrigues were too subtle for the perception of Sanetomo or even of the lady Masa. Yoshitoki had learned all the lessons of craft and cunning that his father could teach and had supplemented them from the resources of his own marvellously fertile mind. His uniformly successful practice was to sacrifice the agents of his crimes in order to hide his own connexion with them, and never to seize an opportunity until its possibilities were fully developed. Tokimasa had feigned ignorance of his daughter's liaison with Yoritomo, but had made it the occasion to raise an army which could be directed either against Yoritomo or in his support, as events ordered. There are strong reasons to think that the vendetta of the Soga brothers was instigated by Tokimasa and Yoshitoki, and that Yoritomo was intended to be the ultimate victim.

This was the beginning of a long series of intrigues which led to the deaths of Yoriiye and two of his sons, of Hatakeyama Shigetada, of Minamoto Tomomasa, of Wada Yoshimori, and of many a minor partisan of the Yoritomo family. In the pursuit of his sinister design, there came a time when Yoshitoki had to choose between his father and his sister. He sacrificed the former unhesitatingly, and it is very probable that such a choice helped materially to hide from the lady Masa the true purport of his doings. For that it did remain hidden from her till the end is proved by her failure to guard the life of Sanetomo, her own son, and by her subsequent co-operation with his slayer, Yoshitoki, her brother. A mother's heart would never wittingly have prompted such a course.

There is a tradition that Sanetomo provoked the resentment of Masa and Yoshitoki by accepting high officés conferred on him by Kyōto - chūnagon, and general of the Left division of the guards - in defiance of Yoritomo's motto, "Wield power in fact but never in name," and contrary to remonstrances addressed to him through the agency of Ōye no Hiromoto. There is also a tradition that, under pretense of visiting China in the company of a Chinese bonze, Chen Hosiang, he planned escape to the Kinai or Chügoku (central Japan), there to organize armed resistance to the Hojo designs. But it is very doubtful whether these pages of history, especially the latter, should not be regarded in the main as fiction. Sanetomo was too much of a litterateur to be an astute politician, and what eluded the observation of his lynx-eyed mother might well escape his perception.

In 1217, Yoshitoki invited Kugyō from Kyōto and appointed him to be betto of the shrine of Hachiman (the god of War) which stood on the hill of Tsurugaoka overlooking the town of Kamakura. Kugyo was the second and only remaining legitimate son of Yoriiye. He had seen his father and his two brothers done to death; and he himself had been obliged to enter religion, all of which misfortunes he had been taught by Yoshitoki's agents to ascribe to the partisans of his uncle, Sanetomo. Longing for revenge, the young friar waited. His opportunity came early in 1219 . Sanetomo, having been nominated minister of the Left by the Kyoto Court, had to repair to the Tsurugaoka shrine to render thanks to the patron deity of his family. The time was fixed for ten o'clock on the night of February 12th. Ōye no Hiromoto, who had cognizance 
of the plot, hid his guilty knowledge by offering counsels of caution. He advised that the function should be deferred until daylight, or, at any rate, that the shögun should wear armour. Minamoto Nakaakira combatted both proposals and they were rejected. Sanetomo had a vague presentiment of peril. $\mathrm{He}$ gave a lock of his hair to one of his squires and composed a couplet:- Ysinest

Though I am forth and gone,

And tenantless my home;

Forget not thou the Spring,

Oh! plum tree by the eaves.

Then he set out, escorted by a thousand troopers, his sword of State borne by the regent, Yoshitoki. But at the entrance to the shrine Yoshitoki turned back, pretending to be sick and giving the sword to Nakaakira. Nothing untoward occurred until, the ceremony being concluded, Sanetomo had begun to descend a broad flight of stone steps that led from the summit of the hill. Then suddenly Kugyõ sprang out, killed Sanetomo and Nakaakira, carrying off the head of the former, and, having announced himself as his father's avenger, succeeded in effecting his escape. But he had been the agent of Yoshitoki's crime, and his survival would have been inconvenient. Therefore, when he appealed to the Miura mansion for aid, emissaries were sent by the regent's order to welcome and to slay him. Sanetomo perished in his twenty-eighth year. All accounts agree that he was not a mere poet - though his skill in that line was remarkable - but that he also possessed administrative talent; that he strove earnestly to live up, and make his officers live up, to the ideals of his father, Yoritomo, and that he never wittingly committed an injustice.

\section{ESTABLISHMENT OF THE HŌJŌ REGENCY}

Thus, after three generations occupying a period of only forty years, the Minamoto family was ruined, and the reins of power were effectually transferred to Hōjo hands. It would seem natural, in the sequence of events, that the office of shoggun should now descend to the Hōjō. But Yoshitoki understood that such a measure would convict him of having contrived the downfall of Yoritomo's progeny in Höjö interests. Therefore a step was taken, worthy of the sagacity of the lady Masa and her brother, the regent. The Bakufu petitioned the Kyōto Court to appoint an Imperial prince to the post of shogun. That would have invested the Kamakura Government with new dignity in the eyes of the nation! But the ex-Emperor, Go-Toba, upon whom it devolved to decide the fate of this petition, rejected it incontinently.

His Majesty, as will presently be seen, was seeking to contrive the downfall of the Bakufu, and the idea of associating one of his own sons with its fortunes must have revolted him. In the face of this rebuff, nothing remained for the Bakufu except recourse to the descendants of the Minamoto in the female line. Yoritomo's elder sister had married into the Fujiwara family, and her greatgrandson, Yoritsune, a child of two, was carried to Kamakura and installed as the head of the Minamoto. Not until 1226, however, was he invested with the title of shōgun, and in that interval of seven years a momentous chapter was added to the history of Japan.

THE SHŌKYŪ STRUGGLE

The Shōky ū era (1219-1222) gave its name to a memorable conflict between Kyōto and Kamakura. Affairs in the Imperial capital were ruled at that time 
by the ex-Emperor, Go-Toba. We have seen how, in 1198, he abdicated in favour of his eldest son, Tsuchimikado. It is not impossible that the idea of rebelling, sooner or later, against the Bakufu had begun to germinate in the mind of Go-Toba at that date, but the probability is that, in laying aside the sceptre, his dominant aim was to enjoy the sweets of power without its responsibilities, and to obtain leisure for pursuing polite accomplishments in which he excelled. His procedure, however, constituted a slight to the Bakufu, for the change of sovereign was accomplished without any reference whatever to Kamakura. Tsuchimikado was a baby of three at the time of his aceession. He had been chosen by lot from among three sons of Go-Toba, but the ehoice displeased the latter, and in 1210, Tsuchimikado, then in his fifteenth year, was compelled to abdieate in favour of his younger brother, Juntoku, aged thirteen, the eighty-fourth oceupant of the throne. Again, Kamakura was not consulted; but the neglect evoked no remonstranee, for Sanetomo held the post of shōgun at the time, and Sanetomo always maintained an attitude of deference towards the Imperial Court which had nominated him to high office.

Juntoku held the sceptre eleven years, and then (1221) he, too, abdicated at his father's request. Very different considerations, however, were operative on this oceasion. Go-Toba had now definitely resolved to try armed eonclusions with the Bakufu, and he desired to have the assistance of his favourite son, Juntoku. Thus three cloistered Emperors had their palaces in Kyōto simultaneously. They were distinguished as Hon-in (Go-Toba), Chü-in (Tsuehimikado) and Shin-in ${ }^{1}$ (Juntoku). As for the oecupant of the throne, Chūkyo (eightyfifth sovereign) he was a boy of two, the son of Juntoku. Much has been written about Go-Toba by romantieists and little by sober historians. The pathos of his fate tends to obseure his true character. That he was gifted with exceptional versatility is scarcely questionable; but that he lacked all the qualities making for greatness appears equally certain. That his instincts were so eruel as to make him derive pleasure from scenes of human suffering, such as the torture of a prisoner, may have been due to a neurotic condition induced by early excesses, but it must always stand to his discredit that he had neither judgment to estimate opportunities nor ability to ereate them.

Briefly summarized, the conditions which eontributed mainly to the Shōky $\bar{u}$ struggle had their origin in the system of land supervision instituted by Yoritomo at theinstance of Ōye no Hiromoto. The constables and the stewards despatehed by the Bakufu to the provinees interfered irksomely with private rights of property, and thus there was gradually engendered a sentiment of discontent, especially among those who owed their estates to Imperial benevolenee. A well-known record (Tai-hei-ki) says: "In early morn the stars that linger in the firmament gradually lose their brillianey, even though the sun has not yet appeared above the horizon. The military families did not wantonly show contempt towards the Court. But in some distriets the stewards were more powerful than the owners of the estates, and the constables were more respected than the provineial governors. Thus insensibly the influence of the Court waned day by day and that of the military waxed."

There were other causes also at work. They are thus summarized by the Kamakura Jidaishi: "The conditions of the time ealled two parties into existence: the Kyotto party and the military party. To the former belonged not only many officials of Shinto shrines, priests of Buddhist temples, and managers

\footnotetext{
["Hon-in signifies the "original recluse;" Chit-in, the "middle recluse;" and Shin-in "the
} new recluse."] 
of private manors, but also a few nominal retainers of the'Bakufu. These last included men who, having occupied posts in the Imperial capital for a long time; had learned to regard the Court with gratitude; others who had special grievances against the Bakufu, and yet others who, having lost their estates, were ready to adopt any means of recovering them. The family system of the time paid ino heed to primogeniture. Parents fixed the succession by favouritism; and made such divisions as seemed expedient in their eyes. During a parent's lifetime there could be no appeal nor any remonstrance. But no sooner was a father's tombstone about to be erected, than his children engaged in disputes or appealed to the courts. Therefore the Bakufu, seeking to correct this evil state of affairs, issued an order that the members of a family should be subservient to the directions of the eldest son; which order was followed, in 1202 , by a law providing that disputes between brothers must be compromised, and by another, in 1214, ruling that applications for official posts must have the approval of the members of the applicants' family in conclave instead of being submitted direct, as theretofore. Under such a system of family autocracy it frequently happened that men were ousted from all share in their paternal estates, and these men, carrying their genealogical tables constantly in their pockets, were ready to join in any enterprise that might better their circumstances. Hence the Shōkyü struggle may be said to have been, politically, a collision between the Imperial Court and the Bakufu, and, socially, a protest against family autocracy."

The murder of Sanetomo inspired the Court with strong hope that a suicidal feud had commenced at Kamakura, and when the Fujiwara baby, Yoritsune, was sent thither, peace-loving politicians entertained an idea that the civil and the military administration would soon be found co-operating. But neither event made any change in the situation. The lady Masa and her brother remained as powerful as ever and as careless of the Court's dignity. lemeir(ges's?

Two events now occurred which materially hastened a rupture. One was connected with an estate, in the province of Settsu, conferred by Go-Toba on a favourite - a shirabyōshi, "white measure-marker," as a danseuse of those days was called. The land-steward of this estate treated its new owner, Kamegiku, with contumely, and Go-Toba was sufficiently infatuated to lodge a protest, which elicited from Kamakura an unceremonious negative. One of the flagrant abuses of the time was the sale of offices to Court ladies, and the Bakufu's attitude in the affair of the Settsu estates amounted to an indirect condemnation of such evil practices. But Go-Toba, profoundly incensed, applied himself from that day to mustering soldiers and practising military tactics. The second incident which precipitated an appeal to arms was the confiscation of a manor owned by a bushi named Nishina Morito,, who, though a retainer (kenin) of the Bakufu, had taken service at the Imperial Court." Go-Toba asked that the estate should be restored, but Yoshitoki flatly refused. ' It was then (1221) that Go-Toba contrived the abdication of his son, Juntoku, a young man of tiventyfour, possessing, apparently, all the qualities that make for success in war, and thereafter an Imperial decree deprived Yoshitoki of his offices and declared him a rebel. The die was now cast. Troops were summoned from all parts of the Empire to attack Kamakura, and a motley crowd mustered in Kyōto.

STEPS TAKEN BY THE BAKUFU

It was on June 6, 1221, that the Imperial decree outlawing Hōjō Yoshitoki appeared, and three days later Kamakura was informed of the event. The lady 
Masa at once summoned the leading generals of the Bakufu to her presence and addressed them thus: "To-day the time of parting has come. "You know well what kind of work the late shoggn, my husband, accomplished. But slanderers have misled the sovereign and are seeking to destroy the Kwantō institutions. If you have not forgotten the favours of the deceased shogun, you will join hearts and hands to punish the traducers and to preserve the old order. But if any of you wish to proceed to the west, you are free to do so."

bre This astute appeal is said to have moved the generals greatly. There was not one instance of disaffection; a sufficiently notable fact when we remember that the choice lay between the Throne and the Bakufu: A military council was at once convened by Yoshitoki to discuss a plan of campaign, and the view held by the great majority was that a defensive attitude should be adopted by guarding the Ashigara and Hakone passes:

Alone, Oye no Hiromoto opposed that programme. Regarding the situation from a political, not a strategical, standpoint; he saw that every day they remained unmolested must bring an access of strength to the Imperial forces, and he strenuously urged that a dash should be made for Kyōto at once. Even the lady Masa did not rise to Hiromoto's height of discernment; she advocated a delay until the arrival of the Musashi contingent. Another council was convened, but Hiromoto remained inflexible: He went so far as to urge that the Musashi chief - Yoshitoki's eldest son, Yasutoki - ought to advance alone, trusting his troops to follow. Then the lady Masa summoned Miyoshi Yasunobu and asked his opinion. He said: "The fate of the Kwanto is at stake. Strike at once!" Thereupon Hōjö Yoshitoki ordered Yasutoki, his son, to set out forthwith from Kamakura, though his following consisted of only eighteen troopers.

Thereafter, other forces mustered in rapid succession. They are said to have totalled 190,000. Tokifusa, younger brother of Yasutoki, was adjutant-general, and the army moved by three routes, the Tōkai-dō, the Tōsan-dō, and the Hokuriku-do, all converging upon the Imperial capital On the night of his departure from Kamakura; Yasutoki galloped back all alone and, hastening to his father's presence; said: "I have my orders for the disposition of the forces and for their destination. But if the Emperor in person commands the western army, I have no orders to guide me." "Hōjo Yoshitoki reflected for a time and then answered: "The sovereign cannot be opposed. If his Majesty be in personal command, then strip off your armour, cut your bow-strings, and assume the mien of low officials. But if the Emperor be not in command, then fight to the death. Should you be defeated.I will never see your face again."

git? gis mond

\section{THE STRUGGLE}

When they learned that a great army was advancing from the Kwanto, the courtiers in Kyōto lost heart at once. There was no talk of Go-Toba or of Juntoku taking the field. "Defensive measures were alone thought of." The Imperialist forces moved out to Mino, Owari, and Etchū. Their plan was to shatter the Bakufu columns separately, or, if that might not be, to fall back and cover the capital. It was a most unequal contest. The Kyoto troops were a mere mob without intelligence or coherence. They broke everywhere under the onset of the Kwantō veterans. At the river U.ji, where their last stand was made, they fought gallantly and obstinately. But their efforts only deferred the result by a few hours. On the twenty-fifth day (July 6, 1221) after he had 
marched out of Kamakura, Yasutoki entered Kyōto. The Thronel had no hesitation as to the course to be pursued in such circumstances.' From the palace of the Shin-in a decree was issued restoring the official titles of the Hôjō chief, and cancelling the edict for his destruction, while, through an envoy sent to meet him, he was informed that the campaign against the Bakufu had been the work of irresponsible subjects; that the sovereign did not sanction it, and that any request preferred by. Kamakura would be favourably considered.

Yasutoki received these gracious overtures with a silent obeisance, - and taking up his quarters at Rokuhara, proceeded to arrest the leaders of the antiBakufu enterprise; to execute or exile the courtiers that had participated in it, and to confiscate all their estates. In thus acting, Yasutoki obeyed instructions from his implacable father in Kamakura. He himself evinced a disposition to be mereiful, especially in the case of the Court nobles. These he sent eastivard to the Bakufu capital, which place, however, very few of them reached alive, their deaths being variously compassed on the way.

To the Imperial family no pity was shown. Even the baby Emperor ${ }^{1}$ was dethroned, and his place given to Go-Horikawa (1221-1232), the eighty-sixth sovereign, then a boy. of ten, son of Morisada, Go-Toba's elder brother. GoToba, himself was banished to the island of Oki, and Juntoku to Sado; while Tsuchimikado, who had essayed to check the movement against the Bakufu, might have remained in Kyōto had not the exile of his father and brother rendered the city intolerable. At his own request he was transferred, first; to Tosa, and then, to Awa. The three ex-Emperors died in exile. Go-Toba seems to have suffered specially from his reverse of fortunes. He lived in a thatched hut barely impervious to rain, and his lot is said to have been pitiful, even from the point of view of the lower orders.

\section{YASUTOKI'S EXPLANATION}

There had not been any previous instance of such treatment of the Imperial family by a subject, and public opinion was not unnaturally somewhat shocked: No little interest attaches, therefore, to an explanation given by Yasutoki himself and recorded in the Biography of Saint Myōe (Myōe Shönin-den). Visiting the temple after his victory, Yasutoki was thus addressed by Myōe:-

The ancients used to say, "When men are in multitude they may overcome heaven for a moment, but heaven in the end triumphs." Though a country be subdued by military force, calamities will soon overtake it unless it be virtuously governed. From time immemorial in both Japan and China sway founded on foree has never been permanent. " In this country, since the Age of Deities down to the present reign, the Imperial line has been unbroken through ninety generations. No prince of alien blood has aseended the throne. Everything in the realm is the property of the Crown. Whatever the Throne may appropriate, the subject must aequiesce. Even life must be sacrificed if the cause of good government demands it. But you have broken an Imperial army; destroyed Imperial palaces; seized the persons of sovereigns; banished them to remote regions, and exiled Empresses and princes of the Blood. Such acts are contrary to propriety. Heaven will infliet punishment.

These words are said to have profoundly moved Yasutoki. He replied:

I desire to express my sincere views. The late shogun (Yoritomo) broke the power of the Heike; restored peace of mind to the Court; removed the sufferings of the people, and rendered loyal service to the sovereign. Among those that served the shogun there was none that did not reverence the Emperor. It seems that his Majesty reeognized these meritorious deeds, for he bestowed ranks and titles. Yoritomo was not only appointed dainagon and taishö, but also given the post of $s \bar{o}$-tsuihoshi with powers extending to all parts of the empire. Whenever

$\left[{ }^{1}\right.$ To this child, Kanenari, who lived a virtual prisoner in Kyoto for thirteen years subsequently, the Bakufu declined to give the title of Emperor. Not until the Meiji Restoration (1870) was he enrolled in the list of sovereigns under the name of Chükyō.] 
such honours were offered, he firmly declined to be their recipient, his contention being that not for personal reward but for the sake of the Throne he had striven to subdue the insurgents and to govern the people mercifully. Pressed again and again, however, he had been constrained finally to accede, and thus his relatives also had benefitted, as my grandfather, Tokimasa, and my father, Yoshitoki, who owed their prosperity to the beneficence of the cloistered Emperor:

Dil But after the demise of his Majesty and of the shögun, the Court's administration degenerated. The loyal and the faithful were not recognized and often the innocent were punished. When it was reported that an Imperial army numbering tens of thousands was advancing against the Kwantō, my father, Yoshitoki, asked my views as to dealing with it. I replied: "The Kwantō has been loyal and has erred in nothing. Yet we are now to be punished. Surely the Court is in error? Still the whole country belongs; to the sovereign. What is now threatened must take its course. There is nothing for us but to bow our heads, fold our hands, and supplicate for mercy. If, nevertheless, death be our portion, it will be lighter than to live disloyal. "If we be pardoned, we can end our lives in mountain forests." My father, after reflecting for a space, answered: "What you say may be right, but it applies only when the sovereign has properly administered the country. During the present reign, however, the provinces under Imperial sway are in confusion; the peace is disturbed, and the people are in misery; whereas those under the Bakufu are peaceful and prosperous. If the administration of the Court be extended to all the land; misrule and unhappiness will be universal. . I do not resist the mandate for selfish reasons. I resist it in the cause of the people. "For them I sacrifice my life if heaven be not propitious. There are precedents. Wu of Chou and Kao-tsu of Han acted similarly, but, when victorious, they themselves ascended the throne, whereas if we succeed, we shall merely set up another prince of the same dynasty. Amaterasu and Hachiman will not reproach us. We will punish only the evil councillors who have led the Throne astray. You will set out with all expedition."?

Thus instructed, I took the road to Kyöto. But before departing, I went to worship at the shrine of Hachiman. There I prayed that if my taking the field was improper, I might be struck dead forthwith; but that if my enterprise could in any wise aid the country, bring peace to the people, and contribute to the prosperity of the shrines and temples, then might I receive the pity and sympathy of heaven. I took oath before the shrine of Mishima Myojin, also; that my purpose was free from all selfish ambition. Thus, having placed my life in the hand of heaven, I awaited my fate. If to this day' I have survived all peril, may I not regard it as an answer to my prayer?

A difference will be detected between the views here attributed to Yoshitoki and his previously narrated instructions to his son, Yasutoki. There can be little doubt that the record in the Myoe Shonin-den is the correct version. Yoshitoki obeyed the Chinese political ethics; he held that a sovereign had to answer for his deeds at the bar of public opinion. Yasutoki's loyalty was of a much more whole-hearted type: he recognized the occupant of the throne as altogether sacrosanct. If he obeyed his father's instructions in dealing with the Court, he condemned himself to the constant companionship of regret, which was reflected in the excellence of his subsequent administration.

\section{ADMINISTRATIVE CHANGES}

By the Shōkyū war the camera system of administration (Insei) at the Court was destroyed; and a great change took place in the relations of the Throne to the Bakufu. For, whereas the latter's authority in Kyōto had hitherto been largely nominal, it now became a supreme reality. Kamakura had been represented in the Imperial capital by a high constable only, whereas two special officials, called "inquisitors" (tandai) were now appointed, and the importance attaching to the office becomes apparent when we observe that the first tandai were Yasutoki himself and his uncle, Tokifusa. They presided over administrative machinery at the two Rokuhara - in the northern and southern suburbs of the city - organized exactly on the lines of the Kamakura polity; namely, a Samurai-dokoro, a Man-dokoro, and a Monju-dokoro. Further, in spite of imposing arrangements in Kyōto, no question was finally decided without previous reference to Kamakura, which thus became, in very truth, the administrative metropolis of the empire. 


\section{THE SHIMPO-JITÓ}

When Yoritomo appointed retainers of his own to be land-stewards in the various manors, these officials did not own the estates where they were stationed; they merely collected the taxes and exercised general supervision. After the Shōkyu struggle, however, some three thousand manors, hitherto owned by courtiers hostile to the Bakufu, were confiscated by the latter and distributed among the Minamoto, the Hōjo, and their partisans. The recipients of these estates were appointed also to be their land-stewards, and thus there came into existence a new class of manor-holders, who were at once owners and $j i t \bar{t}$, and who were designated shimpo-jito, or "newly appointed land-stewards," to distinguish them from the hompo-jito, or "originally appointed."

These shimpo-jito, in whom were vested at once the rights of ownership and of management, were the first genuine feudal chiefs in Japan - prototypes of the future daimyō and shomyo. It should be here noted that, in the distribution of these confiseated estates, the Kamakura regent, Yoshitoki, did not benefit to the smallest extent; and that the grants made to the two tandai in Kyoto barely sufficed to defray the charges of their administrative posts. Yoshitoki is in truth, one of the rare figures to whom history can assign the credit of coveting neither wealth nor station. Out of the three thousand manors that came into his hands as spolia opima of the Shokyū war, he might have transferred as many as he pleased to his own name; and wielding absolute authority in Kyöto, he could have obtained any title he desired. Yet he did not take a rood of land, and his official status at the time of his death was no higher than the fourth rank.

\section{THE BUILDERS OF THE, BAKUFU}

grollib) di

The great statesmen, legislators, and judges who contributed so much to the creation of the Bakufu did not long survive the Shōkyü struggle. Miyoshi Yasunobu, who presided over the Department of Justice (Monjü-dokoro) from the time of its establishment, had been attacked by mortal sickness before the Imperial army commenced its march eastward. His last advice was given to the lady Masa when he counselled an immediate advance against Kyōto. Soon afterwards he died at the age of eighty-two. The great Oye no Hiromoto, who contributed more than any other man to the conception and organization of the Kamakura system, and of whom history says that without him the Minamoto had never risen to fame, survived his colleague by' only four years, dying, in 1225, at the age of seventy-eight. The lady Masa, one of the world's heroines, expired in the same year; and 1224 had seen the sudden demise of the regent; Hōjo Yoshitoki. Fortunately for the-Bakufu; the regent's son, Yasutoki; proved himself a ruler of the highest ability, and his immediate successors weré not less worthy of the exalted office they filled.

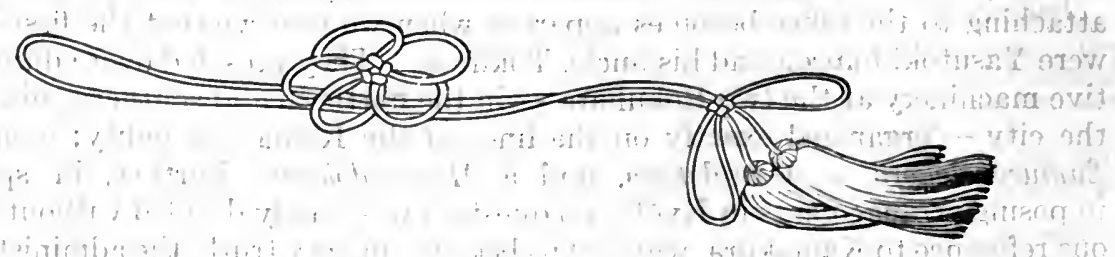




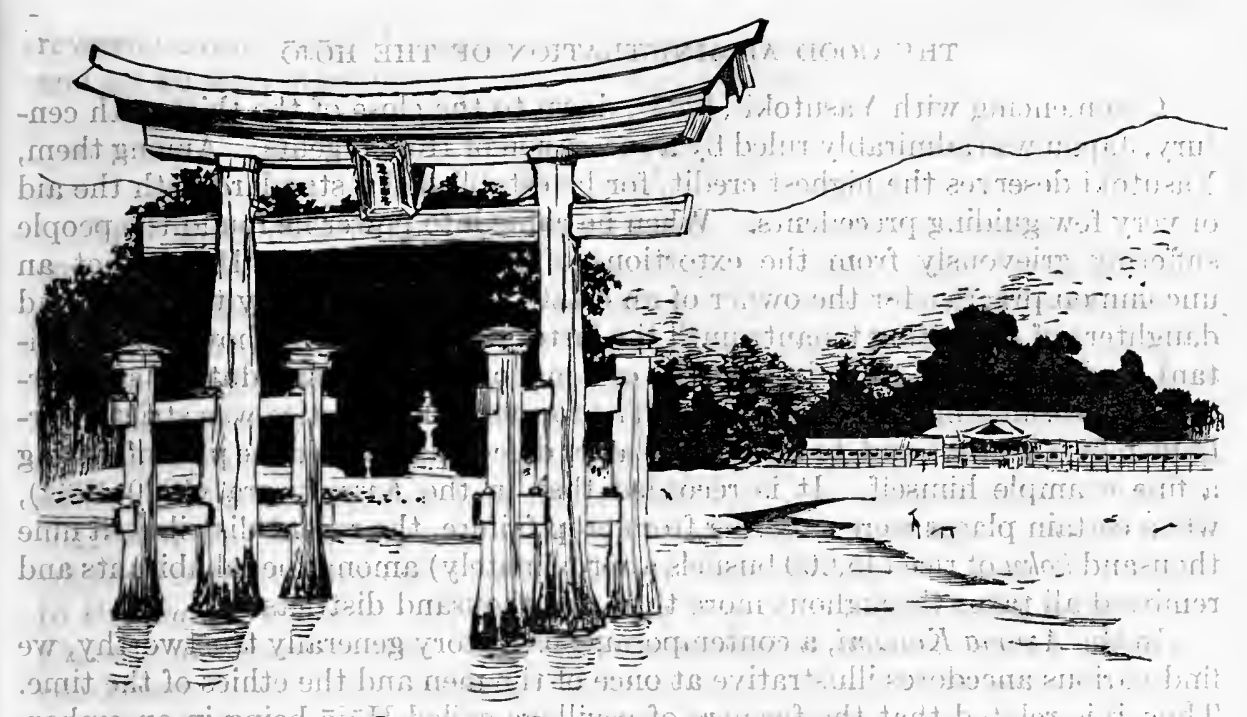

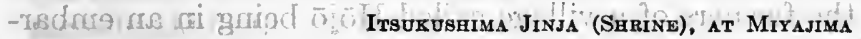

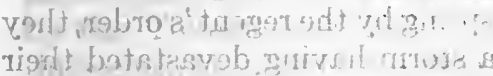

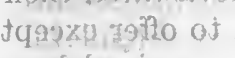

motit horissat

riants ni bourud sis

\section{CHAPTER 'XXVII}

\section{THE HOJO}

- $90 \mathrm{~m}$ ?

THE HŌJŌ IN KYŌTO

b) Le Therewas nothing perfunctory in the administration of the "Two Rokuhara" $($ Ryō-Rokuhara $)$ in Kyōto.s The northern and the southern offices were presided over by the most prominent members of the Hōjo family, men destined to fill the post of regent (shikken) subsequently in Kamakura. Thus, when Hōjō Yoshitoki died suddenly; in 1224, his son, Yasutoki, returned at once to Kamakura to succeed to the regency, transferring to his son,: Tokiuji, the charge of northern Rokuhara, and al short time afterwards the control of southern Rokuhara was similarly transferred from Yoshitoki is brother, Tokifusa, to the latter's son, Tokimori. Nominally, the jurisdiction of the two Rokuhara was confined to military affairs, but in reality their influence extended to every sphere within Kyōto and to the Kinai and the Saikai-dō without.

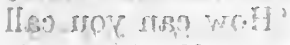




\section{THE GOOD ADMINISTRATION OF THE HŌJŌ}

Commencing with Yasutoki (1225), down to the close of the thirteenth century, Japan was admirably ruled by a succession of Hojō regents. Among them, Y asutoki deserves the highest credit, for he established a standard with the aid of very few guiding precedents. When he came into power he found the people suffering grievously from the extortions of manorial chiefs. It was not an uncommon practice for the owner of an estate to hold in custody the wives and daughters of defaulting tenants until the latter paid their rents, however exorbitant, and seldom indeed did the holder of a manor recognize any duty of succouring the peasants in time of distress. The former eruel practice was strictly forbidden by Yasutoli, and, to correct the latter defect, he adopted the plan of setting a fine example himself. It is recorded that in the $K$ wanki era $(1229-1232)$, when certain places were suffering from crop failure, the regent distributed nine thousand koku of rice (45,000 bushels approximately) among the inhabitants and remitted all taxes throughout more than one thousand districts.

In the Azuma Kagami, a contemporaneous history generally trustworthy, we find various anecdotes illustrative at once of the men and the ethics of the time. Thus, it is related that the farmers of a village called Hōjō being in an embarrassed condition, seed-rice was lent to them in the spring by the regent's order, they undertaking to repay it in the autumn. But a storm having devastated their fields, they were unable to keep their pledge. Nothing seemed to offer except flight. When they were on the eve of decamping, however, they received from Yasutoki an invitation to a feast at which their bonds were burned in their presence and every debtor was given half a bushel of rice. Elsewhere, we read that the regent himself lived in a house so unpretentious that the interior was visible from the highroad, owing to the rude nature of the surrounding fence. Urged to make the fence solid, if only as a protection against fire, his reply was: "However economically: a new wall and fence be eonstructed, the outlay would be at the cost of the people. As for me, if I do my duty to the State, my life and my house will be safe. If I fail, the strongest fence will not avail:",

In estimating what his bountiful assistance to the farmers meant, it is necessary to remember that he was very poor. The greater part of the comparatively small estates bequeathed to him by his father he divided among his half-brothers by a Fujiwara mother, reserving to himself only a little, for, said he: "I am the regent. What more do I-desire?" One day, while attending a meeting of the Hyōjoshu, helreceived news that the house of his brother, Tomotoki, was attacked. Immediately he hastened to the rescue with a small band of followers. Subsequently, one of his principal retainers remonstrated with him for risking his life in an affair so insignificant. Yasutoki answered: "How can you call an incident insignificant when my brother's safety was concerned? To me it seemed as important as the Shōkyī struggle. If I had lost my brother, what consolation would my rank have furnished?",

Yasutoki never made his rank a pretext for avoiding military service; he kept his watch in turn with the other guards, remaining up all night and attending to all his duties. When he periodically visited the temple of Yoritomo, he always worshipped without ascending to the aisle, his reason being that, were the shögun, Yoritomo, alive, the regent would not venture to sit on the dais by his side. Thrifty and eminently practical, he ridiculed a priest who proposed to tranquillize the nation by building fanes. "How can peace be brought to the people," he asked, "by tormenting them to subscribe for such a purpose?" 
revered learning, regarded administration as a literary art/rather than a military, and set no store whatever by his own ability or competence.

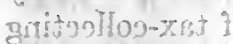

ad Jor tor

THE JŌEI CODE

slint:

The most memorable achievement during Yasutoki's regency was the compilation of a code of law called the Joei Shikimoku ${ }^{1}$ after the name of the era (Joei, 1232-1233) when it was promulgated. What rendered this legislation essentially necessary was that the Daiho code of the eighth century and all the laws founded on: it were inspired primarily by the purpose of centralizing the administrative power and establishing the Throne's title of ownership in all the land throughout the realm, a system diametrically opposed to the spirit of feudalism. This incongruity had made itself felt in Yoritomo's time, and had suggested the compilation of certain "Rules for Decisions" (Hanketsu-rei), which became the basis of the Jöei code in Yasutoki's days. Another objection to the Daih $\bar{o}$ code and its correlated enactments was that, being written with Chinese ideographs solely, they were unintelligible to the bulk of those they concerned. Confucius laid down as a fundamental maxim of government that men should be taught to obey, not to understand, and that principle was adopted by the Tokugawa in the seventeenth and eighteenth centuries. But in the thirteenth, the aim of Yasutoki and his fellow legislators was to render the laws intelligible to all, and with that object they were indited mostly in the kana syllabary.

The actual work of compilation was done by Hokkyō Enzen (a rénowned bonze), but the idea originated with Hōjō Yasutoki and Miyoshi Yasutsura, and every provision was carefully scanned and debated by the Bakufu's State council $($ Hyōjōshiu $)$. There was no intention of suppressing the Daihō code. The latter was to remain operative in all regions to which the sway of the Kyoto Court extended direct. But in proportion as the influence of the Bakufu grew, the $J \bar{o} e i$ laws received new adherents and finally became universally effective. A great modern authority, Dr. Ariga, has opined that the motive of the Bakufu legislation was not solely right for right's sake. He thinks that political expediency figured in the business, the Kamakura rulers being shrewd enough to foresee that a reputation for administering justice would prove a potent factor in extending their influence. If so, the scheme was admirably worked out, for every member of the council had to sign a pledge, inserted at the end of the Shikimoku, invoking? the vengeance of heaven on his head if he departed from the laws or violated their spirit in rendering judgment. Nothing, indeed, stands more signally to the credit of the Bakufu rulers from the days of Yoritomo and his ivife, Masa, downwards, than their constant endeavour to do justice between man and man.

\section{NATURE OF THE CODE}

The $J$ oei Shikimoku is not a voluminous document: it contains only fifty-one brief articles, which the poet Bashō eompares to the luminosity of the full moon. It has been excellently translated and annotated by Mr. Consul-General J. C. Hall in the "Transactions of the Asiatic Society of Japan" (Vol. XXXIV, Part

[' Called also the Kwantō Goseibai Shikimoku.]

(6) "This oath indicates, among other things, the deep sense of the importance of unanimity, of a united front, of the individual sharing fully in the collective responsibility, that was cherished by the Bakufu councillors. This was, -indeed, one of the chief secrets of the wonderful stability and efficiency of the machine." (Murdoch.)] 
I), and Mr. J. Murdoch, in his admirable History of Japan, summarizes its provisions lucidly. We learn that slavery still existed in the thirteenth century in Japan; but the farmer was guarded against cruel processes of tax-collecting and enjoyed freedom of domicile when his dues were paid. Fiefs might not be sold, but a peasant might dispose of his holding. "Village headmen, while held to a strict discharge of their duties and severely punished for various malpractices, were: safeguarded against all aggression or undue interference on the part of the jito. The law of property was almost entirely synonymous with that of fiefs. These, if originally conferred for public services rendered by the grantee, could not be sold. On the death of the holder it was not necessarily the eldest son - even though legitimate - that succeeded. The only provision affecting the father's complete liberty of bequest or gift to his widow or concubine, in one article - or children, was that a thoroughly deserving eldest son, whether of wife or concubine, could claim one-fifth of the estate.

"Not only could women be dowered with, or inherit, fiefs, and transmit a legal title to them to their own children, but a childless woman was even fully empowered to adopt an heir. Yoritomo had been the first to sanction this broadminded and liberal principle. In Kamakura, an adulterer was stripped of half of his fief if he held one; and if he had none, he was banished. For an adulteress the punishment was no severer, except that if she possessed a fief, the whole of it was confiscated. '. A good many sections of the code deal with legal procedure and the conduct and duty of magistrates, the great objects being to make the administration of justice simple, prompt, and pure, while repressing everything in the shape of pettifogging or factious litigation.

"The penalties were neither cruel nor ferocious. Death for the worst offences - among which theft is specially mentioned - confiscation of fief; and banishment, these exhaust the list. The only other punishment mentioned is that of branding on the face, inflicted on a commoner for the crime of forgery, a bushi's punishment in this case being banishment, or simply confiscation of his fief, if possessed of one.

"Bakufu vassals were strictly forbidden directly to solicit the Imperial Court for rank or office; they must be provided with a special recommendation from Kamakura. But once invested with Court rank, they might be promoted in grade without any further recommendation, while they were frce to accept the position of kebiishi. Analogous restrictions were placed on the Kwantō clergy, who were to be summarily removed from their benefices if found appealing to Kyōto for promotion, the only exception being in favour of Zen-shü priests. In thcir case the erring brother guilty of such an offence got off comparatively lightly - 'an influential member of the same sect will be directed to administer a gentle admonition.' The clergy within the Bakufu domains were to be kept strictly in hand; if they squandered the revenues of their incumbency and neglected the fabric and the established services therein, they were to be displaced. As regards the monasteries and priests outside the Bakufu domain, the case was entirely different; they were virtually independent, and Kamakura interfered there only when instructed to do so by Imperial decree."

It is not to be supposed that the Joei Shikimoku represents the whole outcome of Kamakura legislation. Many additions were made to the code during the 
fourteenth century, but they were all in the nature of amplifications or modifications. Kyōto also was busy with enactments in those times - busier, indeed, than Kamakura, but with smaller practical results:

\section{FALL OF THE MIURA}

Yasutoki died in 1242, having held the regency (shikken) for eighteen years. His two sons had preceded him to the grave, and therefore his grandson, Tsunetoki, became shikken. Tsunetoki resembled his grandfather in many respects, but, as he died in 1246, he had little opportunity of distinguishing himself. Nevertheless, during his brief tenure of power, he took a step which had momentous consequences. It will be remembered that after the murder of Minamoto Sanetomo by his nephew Kūgyō, in 1219, some difficulty was experienced in persuading the Imperial Court to appoint a successor to the shogunate, and finally the choice fell upon Fujiwara Yoritsune, then a child of two, who was not actually nominated shōgun until 1226. This noble, when (1244) in the twentyseventh year of his age and the eighteenth of his shogunate, was induced by the regent, Tsunetoki, to resign, the alleged reason being portents in the sky, and a successor was found for him in his son, Yoritsugu.

Iu Now, for many years past the Miura family had ranked next to the Hojōo in power and above it in wealth, but the two had always been loyal friends. Some umbrage was given to the Miura at this time, however, owing to the favours enjoyed at the regency by the Adachi family, one of whose ladies was the mother of the two shikken, Tsunetoki and Tokiyori. The situation thus created had its issue in a plot to kill Tokiyori, and to replace him by an uncle unconnected with the Adachi. Whether the Miura family were really involved in this plot, history gives no definite indication; but certainly the ex-shōgun, Yoritsune, was involved, and his very marked friendship with Miura Mitsumura could scarcely fail to bring the latter under suspicion. In the end, the Miura mansion was suddenly invested by a Hōjō force. Mitsumura and his elder brother, Yasumura, escaped to a temple where, after a stubborn resistance, they and 270 of their vassals committed suicide. No mercy was shown. The Miura were hunted and slaughtered everywhere, their wide, landed estates being confiscated and divided among the Bakufu, the fanes, and the courtiers at Kyōto.

The terribly drastic sequel of this affair illustrates the vast power wielded by the Hōjō throughout the empire in the thirteenth century. Yoritomo's system of high constables and land-stewards brought almost every part of the country under the effective sway of Kamakura. It is not to be supposed, however, that these high constables and land-stewards were suffered to subject the people within their jurisdiction to arbitrary or extortionate treatment. Not only could complaints of any such abuses count on a fair hearing and prompt redress at the hands of the Bakufu, but also inspectors were'despatched; periodically or at uncertain dates, to scrutinize with the utmost vigilance the conduct of the shugo and jito, who, in their turn, had a staff of specially trained men to examine the land survey and adjust the assessment and incidence of taxation:

\section{HŌJŌ TOKIYORI}

Tokiyori, younger brother of Tsunetoki, held the post of shikken at the time of the Miura tragedy: He had succeeded to the position; in 1246, on the death of Tsunetoki, and he nominally abdicated in 1256, when; in the sequel of a severe 
illness, he took the tonsure. A zealous believer, from his youth upwards; in the: doctrines of the Zen sect of Buddhism, he built a temple called Saimyō-ji among: the hills of Kamakura, and retired thither to tend his health - entrusting the office of shikken to a relative, Nagatoki, as his own son, Tokimune, was still of tender age - but continuing himself to administer military and judicial affairs,

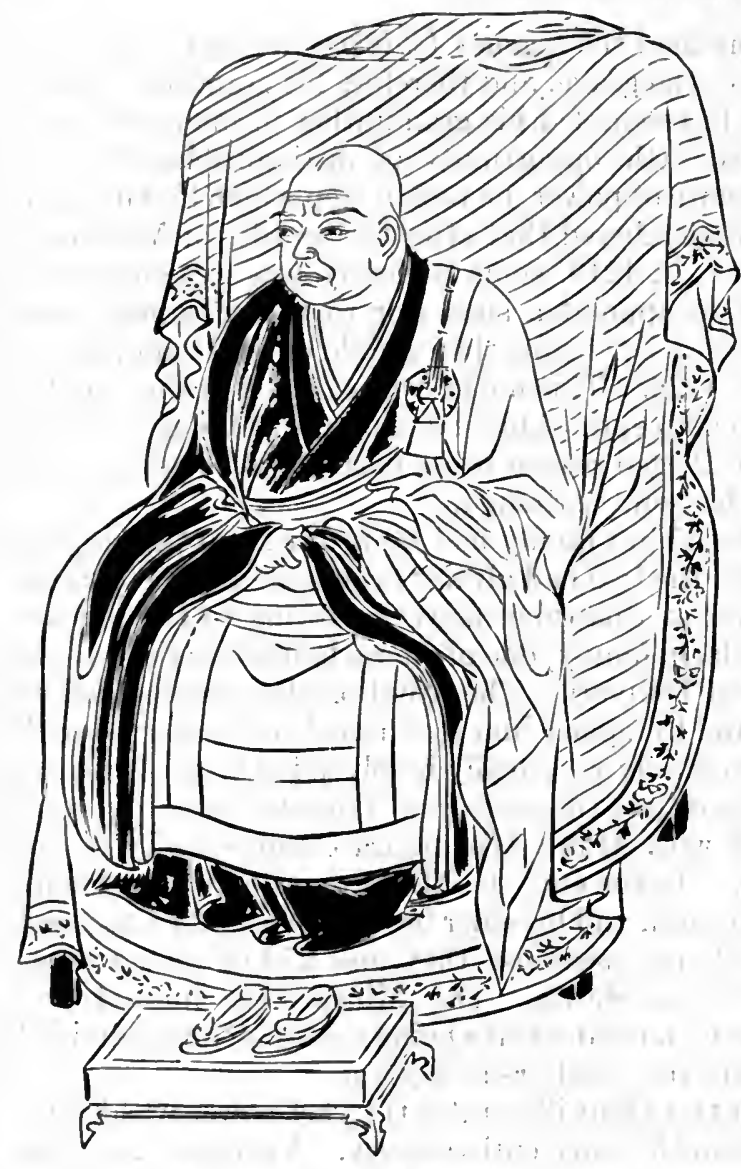

Hō Tơ TokiYonI especially when any criminal or civil case of a complicated or difficult nature occurred. Thus, there was a cloistered regent at Kamakura, just as there had so often been a cloistered Emperor in Kyōto.

Tradition has busied itself much with Tokiyori's life. He carried to extreme lengths the virtue of economy so greatly: extolled by his grandfather, Yasutoki. Such was the frugality of his mode of life that we read of him searching for fragments of food among the remnants of a meal, so that he might serve them to a friend, and we read, also, of his mother repairing with her own hands the paper covering of a shöji in expectation of a visit from him. He is further said to have disguised himself as an itinerent bonze and to have travelled about the provinces, observing the state of the people and learning their com:plaints. His experienees, on this pilgrimage read like a romance. Lodging at one time with an aged widow, he learns that she has been robbed of

her estate and reduced to painful poverty, a wrong which Tokiyori hastens to redress; at another time his host is an old samurai whose loyal record comes thus to the knowledge of the shikken and is subsequently recognized.

But it must be confessed that these tales rest on very slender evidence. Better attested is the story of Aoto Fujitsuna, which illustrates at once the character of Tokiyori and the customs of the time. This Fujitsuna was a man of humble origin but considerable learning. One year, the country being visited I by drought, Tokiyori gave rice and money to priests for religious services, and himself worshipped at the shrine of Mishima. These measures were vehemently criticized by Fujitsuna, who described them as enriching the wealthy to help the impoverished. When informed of this, Tokiyori, instead of resenting it, sent for Fujitsuna and nominated him a member of the Court of Recorders, ${ }^{1}$, where

[1' The Hikitsuke-shu, a body of men who kept the archives of the Man-dokoro and conducted 
he earned the reputation of being one of Japan's greatest judges. ${ }^{1}$ It is related of him that he devoted his whole fortune to objects of charity, and that when Tokiyori, claiming a revelation from heaven, proposed to increase his endowments, his : answer was, "Supposing heaven revealed to you that you should put me to death, would you obey?",

Tokiyori, as already related, though he nominally resigned and entered religion in 1256, really held the reins of power until his death, in 1263 . Thus the Insei (camera administration) came into being in Kamakura, as it had done previously in Kyōto. There were altogether nine of the Hōjö regents, as shown below:-
(1) Tokimasa 1203-1205
(2) Yoshitoki $1205-1224$
(3) Yasutoki 1224-1242
(4) Tsunetoki 1242-1246
(5) Tokiyori 1246-1256
(6) Tokimune 1256-1284
(7) Sadatoki 1284-1301
(8) Morotoki 1301-1311
(9) Takatoki 1311-1333

Retired in 1256 , but ruled in camera till 1263

Retired in 1301, but ruled in camera till 1311

The first six of these were men of genius, but neither Tokimasa nor Yoshitoki can be called really great administrators, if in the science of administration its moral aspects be included. The next four, however, from Yasutoki down to Tokimune, are distinctly entitled to a high place in the pages of history. Throughout the sixty years of their sway (1224-1284), the Japanese nation was governed with justice ${ }^{3}$ and clemency rarely found in the records of any medieval State, and it is a strange fact that Japan's debt to these Hōjō rulers remained unrecognized until modern times.

\section{THE SHŌGUNS IN KAMAKURA}

In the Minamoto's original scheme of government the office of shōgun was an administrative reality. Its purpose was to invest the Bakufu chief with permanent authority to command all the military and naval forces throughout the empire for the defence and tranquillization of the country. In that light the shoggunate was regarded while it remained in the hands of Yoritomo and his two sons, Yoriie and Sanetomo. But with the death of Sanetomo, in 1219, and the political extinction of the Minamoto family, the shoggunate assumed a different character in the eyes of the Minamoto's successors, the Hōjō. "These latter, not qualified to hold the office themselves, regarded it as a link between Kamakura and Kyōto, and even as a source from which might be derived lawful sanction for opposing the Throne should occasion arise. Therefore they asked the Emperor Go-Toba to nominate one of his younger sons, and on receiving a

preliminary judicial investigations. It was organized in Tokiyori's, time and from its members the $H y \overline{o j} \overline{o s h} \bar{u}$ was recruited.]

10 [t The other was Ooka Tadasuke of the Tokugawa period.]

$I^{2}$ It is related of this Aoto Fujitsuna that, having dropped a few cash into the Namera River at night, he expended many times the amount in paying torch-bearers to recover the lost coins, his argument being that the money thus expended was merely put into circulation, whereas the dropped money would have been irrevocably lost.]

b. [ [ ${ }^{3}$ it is recorded that the first half of every month in Kamakura was devoted to judicial proceedings, and that at the gate of the Record Office there was hung a bell, by striking. which a suitor or petitioner could count on immediate attention.] 
refusal, they were fain to be content with a member of the Fujiwara family; who had long held the Court in the hollow of their hands. This nomination was. never intended to carry with it any real authority. The shöguns were mere puppets. During the interval of 114 years between the death of Sanetomo (1219) and the fall of the Hōjo (1333), there were six of these fainéant officials:

Fujiwara Yoritsune

Age, at Age at
Depos'n Yoritsugu

Prince Munetaka, elder brother of Go-Fukakusa

Prince Koreyasu, son of Munetaka

Appn't

Prince Hisaakira, son of Go-Fukakusa

Prince Morikuni, son of Hisaakira

$\begin{array}{ccc}1219-1244 & 2 & 27 \\ 1244-1252 & 5 & 13 \\ 1252-1266 & 10 & 24 \\ 1266-1289 & 3 & 26 \\ 1289-1308 & 13 & 32 \\ 1308-1333 & 7 & 32\end{array}$

The record shows that all these officials were appointed at an age when independent thought had not yet become possible, and that they were removed as soon as they began to think for themselves. It will be observed that there is a palpable break in the uniformity of the list. Yoritsugu alone was stripped of office while still in his teens. That was because his father, the ex-shogun, engaged in a plot to overthrow the Hojō. But the incident was also opportune. It occurred just at the time when other circumstances combined to promote the ambition of the Hōjō in the matter of obtaining an Imperial prince for shōgun. The throne was then occupied by Go-Fukakusa (the eighty-ninth sóvereign), a son of Go-Saga (the eighty-eighth sovereign), who, as we shall see, owed his elevation to the influence exercised by Hōjo Yasutoki after the Shōkyū war. Now it happened that, in 1252, a conspiracy against Go-Saga was found to have been fomented by the head of that branch of the Fujiwara family from which the Kamakura shoguns were taken. The conspiracy was a thing of the past and so were its principal fomenters, but it served as a conclusive reason for not creating another Fujiwara shōgun. Prince Munetaka, an elder brother of the reigning Emperor, was chosen, and thus the last four Bakufu shöguns were all of Imperial blood.

Their lineage, however, did not avail much as against Bakufu arbitrariness. The Hōjō adopted towards the shōguns the same policy as that previously pursued by the Fujiwara towards the sovereigns - appointment during the years of childhood and removal on reaching full manhood. ${ }^{1}$ But the shoguns were not unavenged.

It was owing to the social influence exercised by their entourage that the frugal and industrious habits of the bushi at Kamakura were gradually replaced by the effeminate pastimes and enervating accomplishments of the Imperial capital. For the personnel and equipage of a shōgun's palace at Kamakura differed essentially from those of Hōjo regents (shikken) like Yasutoki and his three immediate successors. In the former were seen a multitude of highly paid officials whose duties did not extend to anything more serious than the conservation of forms of etiquette; the custody of gates, doors, and shutters; the care of pavilions and villas; the practice and teaching of polite accomplishments, such as music and versification; dancing, handball, and football; the cultivation of refined archery and equestrianism, and the guarding of the shögun's person. ${ }^{2}$

[ ${ }^{1}$ It is related that when the regent, Sadatoki, in 1289, removed Prince Koreyasu from the office of shogun, he ordered that the bamboo palanquin in which the prince journeyed to Kyöt o should be carried with the back in front. The people said that the prince was banished to Kyōto.]

[2 The officials of the shögun's court were collectively called banshiu.] 
At the regency, on the other hand, functions of the most arduous character were continuously discharged by a small staff of earnest, unpretentious men, strangers to luxury or leisure and solicitous, primarily, to promote the cause of justice and to satisfy the canons of efficiency. The contrast could not but be demoralizing. Not rapidly or without a struggle, but slowly and inevitably, the poison of bad example permeated Kamakura society, and the sinecures in the shogun's household came to be coveted by the veterans of the Bakufu, who, throughout the peaceful times secured by Hōjo rule, found no means of gaining honours or riches in the field, and who saw themselves obliged to mortgage their estates in order to meet the cost of living, augmented by extravagant banquets, fine buildings, and rich garments. Eight times between 1252 and 1330, edicts were issued by the Bakufu fixing the prices of commodities, vetoing costly residences, prohibiting expensive garments, censuring neglect of military arts, and ordering resumption of the old-time sports and exercises. These attempts to check the evil had only very partial successs. The vices spread, and "in the complex of factors that led to the downfall of the Bakufu, the ultimate ascendancy of Kyōto's social standards in Kamakura must probably be regarded as the most important:"

\section{THE TWO LINES OF EMPERORS}

It is necessary now to turn for a moment to the story of the Imperial city, which, since the appearance of the Bakufu upon the scene, has occupied a very subordinate place in these pages, as it did in fact. Not that there was any outward or visible sign of diminishing importance. All the old administrative machinery remained operative, the old codes of etiquette continued to claim strict observance, and the old functions of government were discharged. But only the shadow of authority existed at Kyoto; the substance had passed effectually to Kamakura. As for the throne, its chiefly remarkable feature was the brevity of its occupation by successive sovereigns:

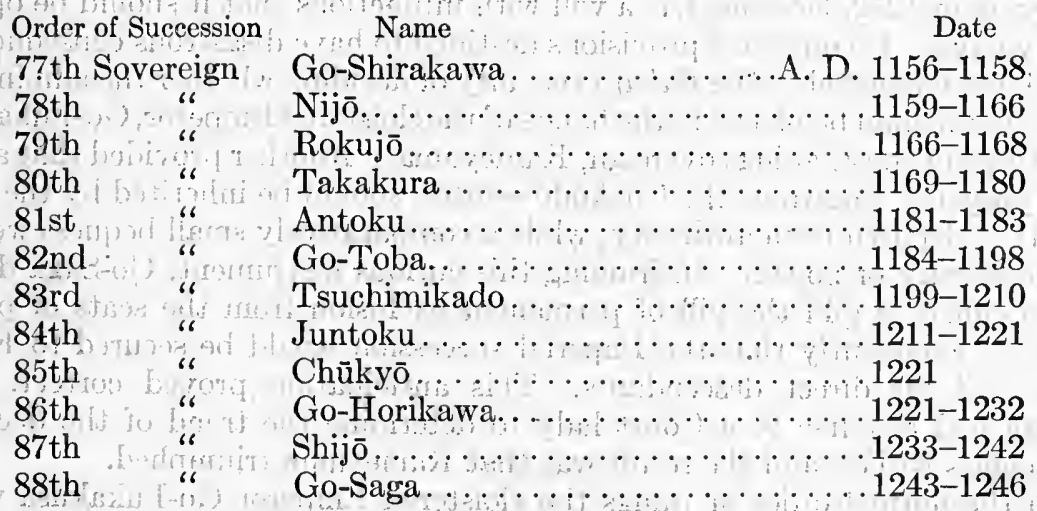

Here are seen twelve consecutive Emperors whose united reigns covered a period of ninety-one years, being an average of seven and one-half years, approximately. It has been shown that Go-Horikawa received the purple practically from the hands of the Hōjo in the sequel of the Shōky $\bar{u}$ disturbance, and the same is true of Go-Saga; he having been nominated from Kamakura in preference to a son of 'Juntoku, whose complicity in that disturbance had been notorious. Hence Go-Saga's attitude towards Kamakura was always one of deference, 
increased by the fact that his eldest son, Munetaka, went to Kamakura as shoggun, in 1252. Vacating the throne in 1246, he named his second son, Go-Fukakusa, to succeed; and his third, Kameyama, to be Prince. Imperial. The former was only three years old when (1246) he beeame nominal sovereign, and, after a reign of thirteen years, he was compelled (1259) to make way for his father's favourite, Kameyama, who reigned from 1259 to 1274.

To understand what followed, a short genealogical table will assist:

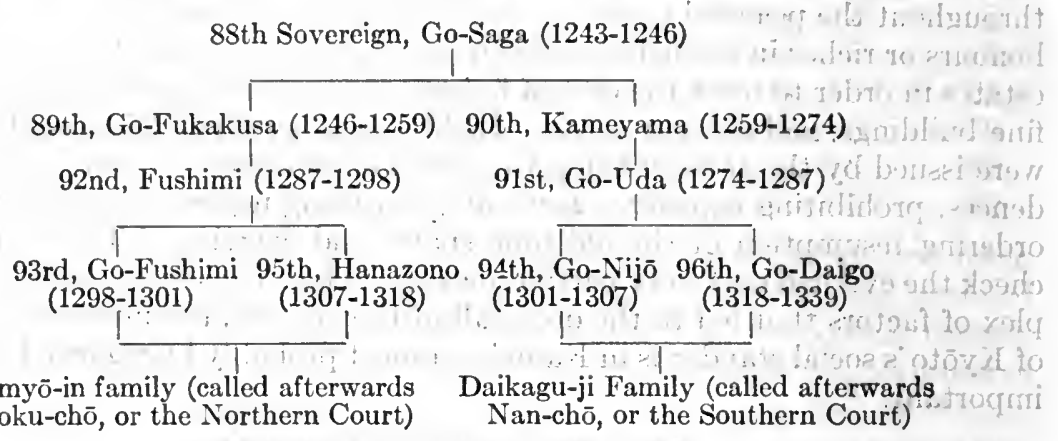

The cloistered Emperor, Go-Saga, abdicating after a reign of four years, conducted the administration according to the camera system during twentysix years. It will be observed from the above table that he essayed to hold the balance equally between the families of his two sons, the occupant of the throne being chosen from each alternately. But everything goes to show that he favoured the Kameyama branch. Like Go-Toba, he eherished the hope of seeing the Imperial Court released from the Bakufu shackles, and to that end the alert, enterprising Kameyama seemed better suited than the dull, resourceless Takakura, just as in Go-Toba's eyes Juntoku had appeared preferable to Tsuchimikado.

Dying in 1272, Go-Saga left a will with injunctions that it should be opened in fifty days. It contained provisions destined to have disastrous consequences. One clause entrusted to the Bakufu the duty of deciding whether the administrative power should be placed in the hands of the eloistered Emperor, Go-Fukakusa, or in those of the reigning sovereign, Kameyama. Another provided that a very large property, known as the Chōkōdo estates, should be inherited by the monarch thus deposed from authority; while a comparatively small bequest went to the depository of power. In framing this curious instrument, Go-Saga doubtless designed to gild the pill of permanent exclusion from the seats of power, believing confidently that the Imperial suecession would be secured to Kameyama and his direct descendants. This anticipation proved correct. The Bakufu had recourse to a Court lady to determine the trend of the deceased sovereign's wishes, and the result was that Kameyama triumphed.

In the normal order of things the cloistered Emperor Go-Fukakusa would have succeeded to the administrative place occupied by Go-Saga, and a large body of courtiers, whose chances of promotion and emolument depended upon that arrangement, bitterly resented the innovation. The palace became divided into two parties, the Naiho (interior seetion) and the Inhō (camera section), a division which grew more aceentuated when Kameyama's son ascended the throne as Go-Uda, in 1274. Go-Fukakusa declared that he would leave his palace and enter a monastery were such a wrong done to his children. Thereupon Kameyama - now cloistered Emperor - submitted the matter to the Bakufu, 
who, after grave deliberation, decided that Go-Fukakusa's son should be named Crown Prince and should reign in succession to Go-Uda. This ruler is known in history as Fushimi.

- Shortly after his accession a sensational event occurred. A bandit made his way during the night into the palace and seizing one of the court ladies, ordered her to disclose the Emperor's whereabouts. The sagacious woman misdirected him, and then hastened to inform the sovereign, who disguised himself as a female and escaped. Arrested by the guards, the bandit committed suicide with a sword which proved to be a precious heirloom of the Sanjo family. Sanjō Sanemori, a former councillor of State, was arrested on suspicion, but his examination disclosed nothing. Then a grand councillor (dainagon) charged the cloistered Emperor, Kameyama, with being privy to the attempt, and Fushimi showed a disposition to credit the charge. Kameyama, however, conveyed to the Bakufu a solemn oath of innocence, with which Fushimi was fain to be ostensibly content. But his Majesty remained unconvinced at heart. He sent to Kamakura a secret envoy with instructions to attribute to Kameyama an abiding desire to avenge the wrongs of Go-Toba and wipe out the Shōkyu humiliation. This vengeful mood might find practical expression at any time, and Fushimi, warned the Bakufu to be on their guard. "As for me," he concluded, "I leave my descendant's entirely in the hands of the Hōjō. With Kamakura we stand or fall.".

How much of this was sincere, how much diplomatic, it is not possible to determine. In Kamakura, however, it found credence. Sadatoki, then regent (shikken), 'took prompt measures to have Fushimi's son proclaimed Prince Imperial, and, in 1298, he was enthroned as Go-Fushimi. ' This evoked an indignant protest from the then cloistered Emperor, Go-Uda, and after some consideration the Kamakura regent, Sadatoki, suggested - "directed" would perhaps be a more correct form of speech - that thenceforth the succession to the throne should alternate between the two families descended from Go-Fukakusa and Kameyama, the length of a reign being. limited to ten years. Nominally, this arrangement was a mark of deference to the testament of Go-Saga, but in reality it was an astute device to weaken the authority of the Court by dividing it into rival factions. Kamakura's fiat received peaceful acquiescence at first. Go-Uda's eldest son took the sceptre in 1301, under the name of Go-Nijō, and, after seven years, he was succeeded by Fushimi's son, Hanazono, who, in twelve years, made way for Go-Uda's second son, Go-Daigo.

The descendants of Kameyama were called the "Daigaku-ji family," and the descendants of Go-Fukakusa received the name of the "Jimyō-in family." When a member of the latter occupied the throne, the Court enjoyed opulence, owing to its possession of the extensive Chōkōdō estates; but when the sovereign was of the Daigaku-ji line comparative penury was experienced. There can be little doubt that, throughout the complications antecedent to this dual system, the Fushimi princes acted practically as spies for the Bakufu. After all, the two Imperial families were descended from a common ancestor and should have shrunk from the disgrace of publishing their rivalries. It is true, as we shall presently see, that the resulting complications involved the destruction of the Hōjō; but it is also true that they plunged the nation into a fifty years' war.

It has already been related how, by Yoritomo's contrivance, the post of regent (kwampaku) in Kyōto came to be held alternately by scions of the Kujo 
family - descended from Fujiwara Kanezane - and scions of the Konoe family - descended from Fujiwara Motomichi. This system was subsequently extended at the instance of the Hōjō. The second and third sons of Michiiye, grandson of Kanezane, founded the houses of Nijō and Ichijo, respectively; while Kanehira, the second of two grandsons of Motomichi, established the house of Takatsukasa. These five families - Konoe, Kujō, Nijō, Ichijō, and Takatsukisa - were collectively ealled Go-sekke (the Five Regent Houses) in recognition of the fact that the regent in Kyoto was supposed to be taken from them in succession. The arrangement led to frequent strife with resulting weakness, thus excellently achieving the purpose of its contrivers, the Hōjō.

\section{THE FIRST MONGOL INVASION}

The rule of the Hojjo synchronized with two events of prime importancethe invasion of Japan by a: Mongolian army, first in 1274, and subsequently in 1281. Early in the twelfth century, the Emperor of China, which was then under the sway of the Sung dynasty, invited the Golden Tatars to deal with the Khitan Tatars, who held Manchuria, and who, in spite of heavy tribute paid annually by the Sung Court, continually raided northeastern China. The Golden Tatars responded to the invitation by not only expelling the Khitans but also taking their place in Manchuria and subsequently overrunning China, where they established a dynasty of their own from 1115 to 1234 .

These struggles and dynastic changes did not sensibly affect Japan. Her intercourse with the Asiatic continent in those ages was confined mainly to an interchange of visits by Buddhist priests, to industrial enterprise, and to a fitful exchange of commodities. It does not appear that any branch of the Tatars concerned themselves practically about Japan or the Japanese. Ultimately, however, in the first part of the thirteenth century, the Mongols began to sweep down on the Middle Kingdom under the leadership of Jenghiz Khan. They crushed the Golden Tatars, transferred (1264) the Mongol capital from central Asia to Peking (Cambalue), and, in 1279, under Kublai, completely conquered China. Nearly thirty years before the transfer of the capital to Peking, the Mongols invaded the Korean peninsula, and brought it completely under their sway in 1263, receiving the final submission of the kingdom of Koma, which alone had offered any stubborn resistance.

It is probable that Kublai's ambition, whetted by extensive conquests, would have turned in the direction of Japan sooner or later, but tradition indicates that the idea of obtaining the homage of the Island Empire was suggested to the great Khan by a Korean traveller in 1265. Kublai immediately acted on the suggestion. He sent an embassy by way of Korea, ordering the Koma sovereign to make arrangements for the transport of the envoys and to re-enforce them with a Korean colleague. . A tempest interrupted this essay, and it was not repeated until 1268, when the Khan's messengers, accompanied by a Korean suite, crossed safely to Chikuzen and delivered to the Dazai-fu a letter from Kublai with a covering despatch from the Korean King. The Korean sovereign's despatch was plainly inspired by a desire to avert responsibility from himself. He explained that in transporting the embassy he acted unavoidably; but that, in sending it, the Khan was not actuated by any hostile feeling, his sole purpose being to include Japan in the circle of his friendly tributaries.

In short, the Koma prince - he no longer could properly be called a monarch - would have been only too pleased to see Japan pass under the Mongol yoke 
as his own kingdom had already done. Kublai's letter, however, though not deliberately arrogant, could not be construed in any sense except as a summons to send tribute-bearing envoys to Peking. He called himself "Emperor" and addressed the Japanese ruler as "King;": instanced, for fitting example, the relation between China and Korea, which he described at once as that of lord and vassal and that of parent and child, and predicated that refusal of intercourse would "lead to war."

The Japanese interpreted this to be an offer of suzerainty or subjugation. Two courses were advocated; one by Kyōto, the other by Kamakura. The former favoured a policy of conciliation and delay; the latter, an attitude of contemptuous silence. Kamakura, of course, triumphed. After six months' retention the envoys were sent away without so much as a written acknowledgment. The records contain nothing to show whether this bold course on the part of the Bakufu had its origin in ignorance of the Mongol's might or in a conviction of the bushi's fighting superiority. Probably both factors were operative; for Japan's knowledge of Jenghiz and his resources reached her chiefly through religious channels, and the fact that Koreans were associated with Mongols in the mission must have tended to lower the affair in her estimation. Further, the Japanese had been taught by experience the immense difficulties of conducting oversea campaigns, and if they understood anything about the Mongols, it should have been the essentially non-maritime character of the midAsian conquerors.

By-Kublai himself that defect was well appreciated. He saw that to carry a body of troops to Japan, the seagoing resources of the Koreans must be requisitioned, and on the bootless return of his first embassy, he immediately issued orders to the Koma King to build one thousand ships and mobilize forty thousand troops. In vain the recipient of these orders pleaded inability to execute them. The Khan insisted, and supplemented his first command with instructions that agricultural operations should be undertaken on a large scale in the peninsula to supply food for the projected army of invasion. Meanwhile he despatched embassy after embassy to Japan, evidently being desirous of carrying his point by persuasion rather than by force. The envoys invariably returned re infectâ. On one occasion (1269), a Korean vessel carried off two Japanese from Tsushima and sent them to Peking. There, Kublai treated them kindly, showed them his palace as well as a parade of his troops, and sent them. home to tell what they had seen. But the Japanese remained obdurate, and finally the Khan sent an ultimatum, to which Tokimune, the Hojo regent, replied by dismissing the envoys forthwith.

War was now inevitable. Kublai massed 25,000 Mongol braves in Korea, supplemented them with 15,000 Korean troops, and embarking them in a flotilla, of 900 vessels manned by 8000 Koreans, launched this paltry army against Japan in November, 1274. The armada began by attacking. Tsushima and Iki, islands lying in the strait that separates the Korean peninsula from Japan. In Tsushima, the governor, So Sukekuni, ${ }^{1}$ could not muster more than two hundred bushi. But these two hundred fought to the death, as did also the still smaller garrison of Iki. Before the passage of the narrow strait was achieved, the invaders must have lost something of their faith in the whole cnterprise. On November 20th, they landed at Hakozaki Gulf in the province of Chikuzen: There they were immediately assailed by the troops of five Kyūshū chieftains: What force the latter represented there is no record, but they were certainly less.

[' Grandson of Taira no Tomomori, admiral of the Hei fleet in the battle of Dan-no-ura.] 
numerous than the enemy. Moreover, the Yuan army possessed a greatly superior tactical system. By a Japanese bushi the battle-field was regarded as an arena for the display of individual prowess, not of combined force. 19 The Mongols, on the contrary, fought in solid co-operation, their movements directed by sound of drum from some eminence where the commander-in-chief / watched the progress of the fight. If a Japanese approached to defy one of them to single combat, they enveloped and slew him. Further, at close quarters they used

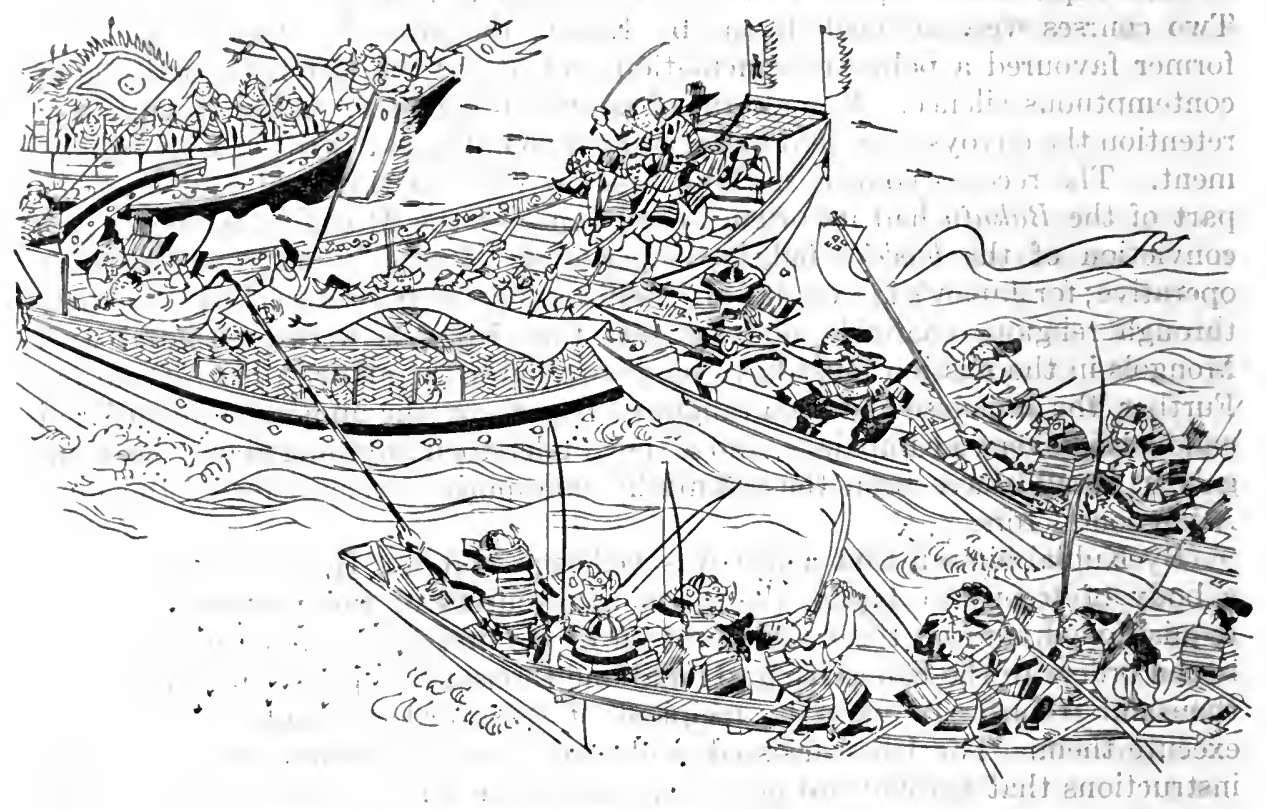

REPULAE OF THE Mongól INVADERS

(From a scroll painting in possession of the Imperial Household)

light arms dipped in poison, and for long-range purposes they had powerful crossbows, which quite outclassed the Japanese weapons. They were equipped also with explosives which they fired from metal tubes, inflicting heavy loss on the Japanese, who were demoralized by such an unwontcd weapon. "Finally, they were incomparable horsemen, and in the carly encounters they put the Japanese cavalry out of action by raising with drums and gongs a din that terrified the latter's horses. But, in spite of all these disadvantages, the Japanese fought stubbornly. Whenever they got within striking distance of the foe, they struck desperately, and towards evening they were able to retire in good order into cover "behind the primitive fortifications of Mizuki raised for Tenchi Tennō by Korean engineers six centuries before."

That night the west coast of Kyūshũ was menaced by one of those fierce gales that rage from time to time in sub-tropical zoncs. The Korean pilots knew that their ships could find safety in the open sea only. But what was to be done with the troops which had debarked? Had their commanders seen any certain hope of victory, they would not have hesitated to part temporarily from the ships. The day's fighting, however, appears to have inspircd a new estimate of the bushi's combatant qualities. It was decided to embark the Yuan forces and start out to sea. For the purpose of covering this movement, the Hakozaki shrine and some adjacent hamlets were fired, and when morning dawned the 
invaders' flotilla was seen beating out of the bay. One of their vessels ran aground on Shiga spit at the north of the haven and several others foundered at sea, so that when a tally was finally called, 13;200 men did not answer to their names. As to what the Japanese casualties were, there is no information.

\section{THE SECOND MONGOL INVASION}

Of course Kublai did not acknowledge this as a defeat at the hands of the Japanese. On the contrary, he seems to have imagined that the fight had struck terror into the hearts of the islanders by disclosing their faulty tactics and inferior weapons. He therefore sent another embassy, which was charged to summon the King of Japan to Peking; there to do obeisance to the Yuan Emperor. Kamakura's answer was to decapitate the five leaders of the mission and to pillory their heads outside the city. Nothing, indeed; is more remarkable than the calm confidence shown at this crisis by the Bakufu regent, Tokimune. His country's annalists ascribe that mood to faith in the doctrines of the Zen sect of Buddhism; faith which he shared with his father, Tokiyori, during the latter's life. The Zen priests taught an introspective philosophy. "They preached that life springs from not-living, indestructibility from destruction, and that existence and non-existence are one in reality. No creed coúld better inspire a soldier.

It has been suggested that Tokimune was not guided in this matter solely by religious instincts: he used the Zen-sh $\bar{u}$ bonzes as a channel for obtaining information about China. Some plausibility is given to that theory by the fact that he sat, first, at the feet of Dōryū, originally a Chinese priest named Tao Lung; and that on Dōryū's death he invited (1278) from China a famous bonze, Chu Yuan (Japanese, Sogen), for whose ministrations the afterwards celebrated temple Yengaku-ji was erected. Sogen himself, when officiating at the temple of Nengjen, in Wenchow, had barely escaped massacre at the hands of the Mongols; and he may not have been averse to acting as a medium of information between China and Kamakura.

Tokimune's religious fervour, however, did not interfere with his secular preparations.t In 1280, he issued an injunetion exhorting local officials and vassals (go-kenin) to compose all their dissensions and work in unison. There could be no greater crime, the document declared, then to sacrifice the country's interests on the altar of personal enmities at? a time of national crisis. Loyal obedience on the part of vassals, and strict impartiality on the side of high constables these were the virtues which the safety of the State demanded; and any neglect to practise them should be punished with the utmost severity. This injunction was issued in 1280, and already steps had been taken to construct defensive works at all places where the Mongols might effect a landing - at Hakozaki Bay in K̇yūshū; at Nagato, on the northern side of the Shimonoseki Strait; at Harima, on the southern shore of the Inland Sea; and at Tsuruga, on the northwest of the main island. Among these places,

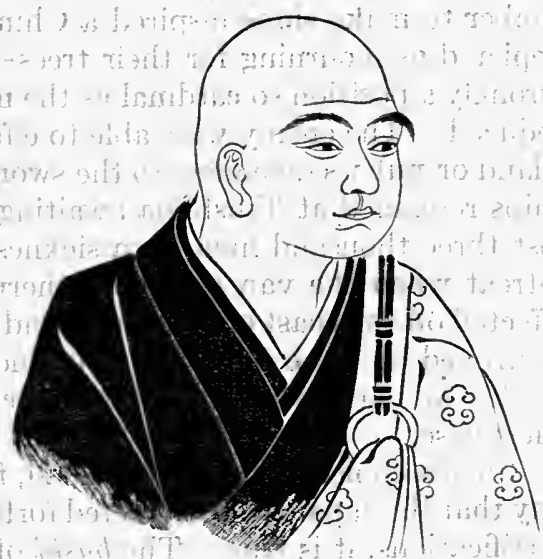

Hо̆о TOKIMUNe 
Hakozaki and Nagato were judged to be the most menaced, and special offices, after the nature of the Kyoto tandai, were established there.

Seven years separated the first invasion from the second. It was not of deliberate choice that Kublai allowed so long an interval to elapse. The subjugation of the last supporters of the Sung dynasty in southern China had engrossed his attention, and with their fall he acquired new competence to prosecute this expedition to Japan, because while the Mongolian boats were fit only for plying on inland waters; the ships of the southern Chinese were large, ocean-going craft. It was arranged that an army of 100,000 Chinese and Mongols should embark at a port in Fuhkien opposite the island of Formosa, and should ultimately form a junction in Tsushima Strait with an armada of 1000 Korean ships, carrying, in addition to their crews, a force of 50,000 Mongols and 20,000 Koreans.

But before launching this formidable host, Kublai made a final effort to compass his end without fighting. In 1280 , he sent another embassy to Japan, announcing the complete overthrow of the Sung dynasty, and summoning the Island Empire to enter into friendly relations. 'Kamakura's answer wàs to order the execution of the envoys at the place where they had landed, Hakata in Chikuzen. Nothing now remained except an appeal to force. $A$ weak point in the Yuan strategy was that the two armadas were not operated in unison: The Korean fleet sailed nearly a month before that from China. It would seem that the tardiness of the latter was not due wholly to its larger dimensions, but must be attributed in part to its composition. A great portion of the troops transported from China were not Mongols, but Chinese; who had been reeently fighting against the Yuan, and whose despatch on a foreign campaign in the service of their victors suggested itself as a politic measure. These men were probably not averse to delay and certainly cannot have been very enthusiastic.

In May, 1281, the flotilla from Korea appeared off Tsushima. Unfortunately, the annals of medieval Japan are singularly reticent as to the details of battles. There are no materials for constructing a story of the events that occurred on the Tsushima shores, more than six centuries ago. We do not even know what force the defenders of the island mustered. But that they were much more numerous than on the previous occasion, seven years before, is certain. Already, in 1280, Tokimune had obtained from Buddhist sources information of the Mongol preparations - preparations so extensive that the felling of timber to make ships inspired a Chinese poem in which the green hills were depicted as mourning for their trees - and he would not have failed to garrison strongly a position so cardinal as the midchannel island of Tsushima. It was not reduced. The enemy were able to effect a lodgement, but could not overrun the island or put its defenders to the sword, as had been done in 1274. The Korean ships remained at Tsushima awaiting the arrival of the Chinese flotilla. They lost three thousand men from sickness during this interval, and were talking of retreat when the van of the southern armada hove in sight. A junction was effected off the coast of Iki island, and the garrison of this little place having been destroyed on June 10th, the combined forces stood over towards Kyüshü and landed at various places along the coast of Chikuzen, Imaking Hakozaki Bay their base.

Such a choice of locality was bad, for it was precisely along the shores of this bay that the Japanese had erected fortifications. They were not very formidable fortifications, it is true. The bushi of these days knew nothing about bastions; curtains, glacis, or cognate refinements of military: engineering. They simply: 
built a stone wall to block the foe's advance, and did not even adopt the precaution of protecting their flanks. But neither did they fall into the error of acting entirely on the defensive. On the contrary, they attacked alike, on shore and at sea, Their boats were much smaller than those of the invaders, but the advantage in dash and daring was all on the side of the Japanese. So furious were their onsets, and so deadly was the execution they wrought with their trenchant swords at close quarters, that the enemy were fain to lash their ships together and lay planks between them for purposes of speedy concentration. It is most improbable that either the Korean or the Chinese elements of the invading army had any heart for the work, whereas on the side of the defenders there are records of whole families volunteering to serve at the front. During fifty-three days the campaign continued; that is to say, from June 23rd, when the first landing was effected, until August 14th, when a tornado swept off the face of the sea the main part of the Yuan armada.

No account has been preserved, either traditionally or historically, of the incidents or phases of the long fight. We know that the invaders occupied the island of Hirado and landed in Hizen a strong force intended to turn the flank of the Hakozaki Bay parapet. We know, inferentially, that they never succeeded in turning it. We know that, after nearly two months of incessant combat, the Yuan armies had made no sensible impression on the Japanese resistance or established any footing upon Japanese soil. We know that, on August the 14th and 15th, there burst on the shores of Kyūshū a tempest which shattered nearly the whole of the Chinese flotilla. And we know that the brunt of the loss fell on the Chinese contingent, some twelve thousand of whom were made slaves. But no such momentous chapter of history has ever been traced in rougher outlines. The annalist is compelled to confine himself to marshalling general results. It was certainly a stupendous disaster for the Yuan arms. Yet Kublai was not content; he would have essayed the task again had not trouble nearer home diverted his attention from Japan. The Island Empire had thus the honour of being practically the only state in the Orient that did not present tribute to the all-conquering Mongols.

But, by a strangely wayward fate, these victories over a foreign invader brought embarrassment to the Hôjo rulers rather than renown. In the first place, there could not be any relaxation of the extraordinary preparations which such incidents dictated. Kublai's successor, Timur, lost no time in countermanding all measures for a renewed attack on Japan, and even adopted the plan of commissioning Buddhist priests to persuade the Bakufu of China's pacific intentions. One of these emissaries, Nei-issan (Chinese pronunciation, Ning I-shan), settled permanently in Japan, and his holy ministrations as a $Z e n-s h \bar{u}$ propagandist won universal respect. But the Bakufu did not relax their precautions, and for more than a score of years a heavy burden of expense had to be borne on this account.

Further, when the wave of invasion broke on the shores of Kyūshū, the Court in Kyoto set the example of appealing to the assistance of heaven. Prayers were offered, liturgies were chanted, and incense was burned at many temples and shrines throughout the empire. Several of the priests did not hesitate to assert that their supplications had elicited signs and portents indicating supernatural aid. Rich rewards were bestowed in recognition of these services, whereas, on the contrary, the recompense given to the soldiers who had fought so gallantly and doggedly to beat off a foreign foe was comparatively petty. Mearts of recompensing them were scant. When Yoritomo overthrew the Taira, 
the estates of the latter were divided among his followers and co-operators. After the Shōkyz disturbance, the property of the Court nobles served a similar purpose. But the repulse of the Mongols brought no access of wealth to the victors, and for the first time military merit had to go unrequited while substantial grants were made to the servants of religion." The Bakufu, fully conscious of this dangerous discrepancy, saw no resource except to order that strict surveys should be made of many of the great estates, with a view to their delimitation and reduction, if possible. This, however, was a slow progress, and the ümbrage that it caused was more than commensurate with the results that accrued. Thus, to the Bakufu the consequences of a war which should have strengthened allegiance and gratitude were, on the contrary, injurious and weakening.

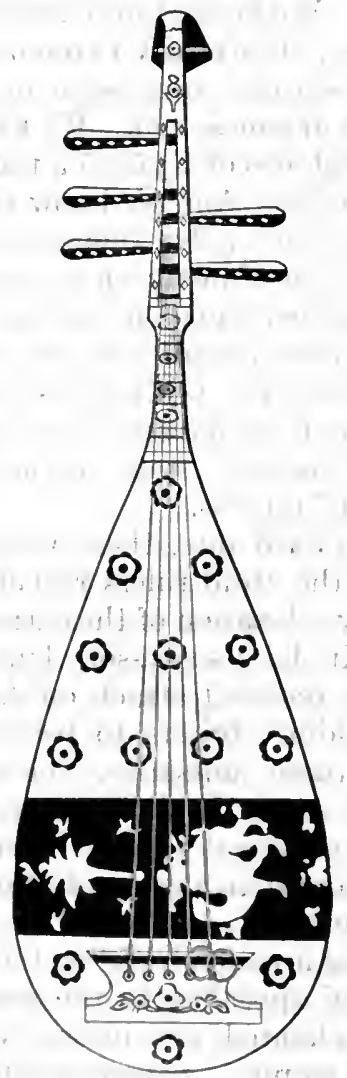

Five String Biwa (Japanebe Mandown) 


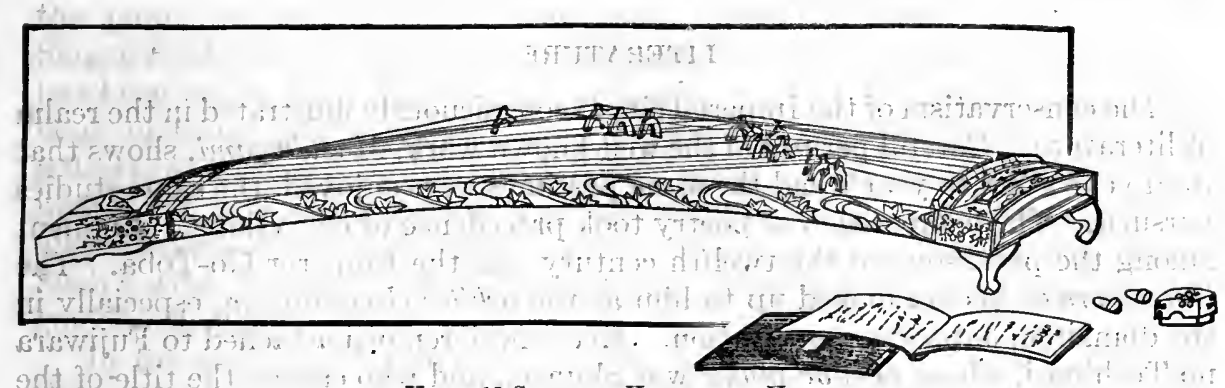

Koto, 13-Stringed HoRizontal Harp

\title{
CHAPTER XXVIII
}

\section{ART, RELIGION, LITERATURE, CUSTOMS, AND COM- MERCE IN THE KAMAKURA PERIOD}

\author{
ART
}

From the establishment of the Bakufu, Japanese art separated into two schools, that of Kamakura and that of Kyōto. The latter centered in the Imperial Court, the former in the Court of the Hōjo. Taken originally from Chinese masters of the Sui and Tang dynasties, the Kyoto art ultimately developed into the Japanese national school, whereas the Kamakura art, borrowed from the academies of Sung and Yuan, became the favourite of the literary classes and preserved its Chinese traditions. Speaking broadly, the art of Kyōto showed a decorative tendency, whereas that of Kamakura took landscape and 'seascape chiefly for motives' and, delighting in the melancholy aspects of nature, appealed most to the student and the cenobite. This distinction could be traced in calligraphy, painting, architecture, and horticulture. Hitherto penmanship in Kyōto had taken for models the style of Kōbō Daishi and Ono no Töfū. This was called $o-i e-f \bar{u}$ (domestic fashion), and had a graceful and cursive character. But the-Kamakura calligraphists followed the pure Chinese mode (karayō); as exemplified by the Buddhist priests; Sogen (Chu Yuan), and Ichinei (I Ning):

In Kyotto, painting was represented by the schools of Koze, Kasuga, Sumiyoshi, and Tosa; in Kamakura, its masters were Ma Yuan, Hsia Kwei, and Mu Hsi, who represented the pure Southern Academy of China, and who were followed by Sesshū, Kaō, and Shūbun.: So, too, the art of horticulture, though there the change was a transition from the stiff and comparatively artificial fashion of the no-niwa (moor garden) to the pure landscape park, ultimately developed into a Japanese specialty. Tradition ascribes to a Chinese bonze, who called himself Nei-issan (or Ichinei), the planning of the first landscape garden, properly so designated in Japan. He arrived in Kyūshū, under the name of I Ning, as a delegate from Kublai Khan in the days of Hōjo Sadatoki, and was banished, at first, to the province of Izu. Subsequently, however, the Bakufu invited him to Kamakura and assigned the temple Kenchö-ji for his residence and -place of ministrations. It was there that he designed the first landscape garden, furnishing suggestions which are still regarded as models. 


\section{LITERATURE}

The conservatism of the Imperial city is conspicuously illustrated in the realm of literature. Careful perusal of the well-known work, Masukagami, shows that from year's end to year's end the same pastimes were enjoyed, the same studies pursued. The composition of poetry took precedence of everything. Eminent among the poetasters of the twelfth century was the Emperor Go-Toba. The litterateurs of his era looked up to him as the arbiter elegantiarum, especially in the domain of Japanese versification. Even more renown attached to Fujiwara no Toshinari, whose nom de plume was Shunzei, and who earned the title of the "Matchless Master." His son, Sadaiye, was well-nigh equally famous under the name of Teika.

After the Shōkyū disturbance (1221), the empire enjoyed a long spell of peace under the able and upright sway of the Hojjo, and during that time it became the custom to compile anthologies. The first to essay that task was Teika. Grieving that the poets of his time had begun to prefer affectation and elegance to sineerity and simplicity, he withdrew to a secluded villa on Mount Ogura, and there selected a hundred poems by as many of the ancient authors. These he gave to the world; calling the collection Hyakunin-isshu, and succeeding generations endorsed his choice so that the book remains a classic to this day. Teika's son, Tameiye, won such favour in the eyes of the Kamakura shögun, Sanetomo, that the latter conferred on him the manor of Hosokawa, in Harima. Mying, Tameiye bequeathed this property to his son; Tamesuke, but he, being robbed of it by his step-brother, fell into a stato of miserable poverty which was shared by his mother, herself well known as an authoress under the name of Abutsu-ni. This intrepid lady, leaving her five sons in Kyoto, repaired to Kamakura to bring suit against the usurper, and the journal she kept en route $\rightarrow$ the Izayoi nikki - is still regarded as a model of style and sentiment. It bears witness to the fact that students of poetry in that era fell into two elasses: one adhering to the pure Japanese style of the Heian epoch; the others borrowing freely from Chinese literature.

Meanwhile, at Kamakura, the Bakufu regents, Yasutoki, Tokiyori and Tokimune, earnest disciples of Buddhism, were building temples and assigning them to Chinese priests of the Sung and Yuan eras, who reached Japan af official envoys or as frank propagandists. Five great temples thus came into existence in the Bakufu capital, and as the Chinese bonzes planned and superintended their construction, these buildings and their surroundings reflected the art-canons at once of China, of Japan, and of the priests themselves. The same foreign influence made itself felt in the region of literature. But we shotild probably. be wrong in assuming that either religion or art or literature for their own sakes constituted the sole motive of the Hōjo regents in thus acting. It hás already been shown that they welcomed the foreign priests as channels for obtaining information about the neighbouring empire's polities, and there is reason to think that their astute programme included a desire to endow Kamakura with an artistic and literary atmosphere of its own, wholly independent of Kyōto and purged of the enervating elements that permeated the latter.

This separation of the civilizations of the east (Kwantō) and the west (Kyōto) resulted ultimately in producing asceticism and religious reform The former, beeause men of really noble instincts were insensible to the ambition which alone absorbed a Kyotto littérateur - the ambition of figuring prominently in an approved anthology - and had, at the same time; no inclination to follow 
the purely military creed of Kamakura. Such recluses as Kamo Chōmei, Saigyō $H \bar{o} s$ shi and Yoshida Kenkō were an outcome of these conditions. Chōmei has been called the "Wordsworth of Japan." He is immortalized by a little book of thirty pages; called Hōjōki (Annals of a Cell.) It is a volume of reflections suggested by life in a hut measuring ten feet square and seven feet high, built in a valley remote from the stir of life. The style is pellucid and absolutely unaffected; the ideas are instinct with humanity and love of nature. Such a work, so widely admired, reveals an author and an audience instinct with graceful thoughts.

In the career of Saigyo - "the reverend," as his title "hoshi", signifies there were episodes vividly illustrating the manners and customs of the time. Originally an officer of the guards in Kyotto, he attained considerable skill in military science and archery, but his poetic heart rebelling against such pursuits, he resigned office, took the tonsure, and turning his back upon his wife and children, became a wandering bard. Yoritomo encountered him one day, and was so struck by his venerable appearance that he invited him to his mansion and would have had him remain there permanently. But Saigyō declined. On parting, the Minamoto chief gave him as souvenir a cat chiselled in silver, which the old ascetic held in such light esteem that he bestowed it on the first child he met. Yoshida Kenkō, who became a recluse in 1324, is counted among the "four kings." of Japanese poetry - Ton-a, Jōben, Keiun, and Kenkō. He has been called the "Horace of Japan." In his celebrated prose work, Weeds of Tedium (Tsure-zure-gusa), he seems to reveal a lurking love for the vices he satirizes. These three authors were all pessimistic. They reflected the tendeney of the time.

\section{RELIGION}

The earliest Buddhist sect established in Japan was the Hossō. It crossed from China in A.D. 653, and its principal place of worship was the temple Kofukuji at Nara. Then (736) followed the Kegon sect, having its headquarters in the Tódai-ji, where stands the colossal Daibutsu of Nara. Next in order was the Tendai, introduced from China by Dengyo in 805, and established at Hiei-zan in the temple Enryaku-ji; while fourth and last in the early group of important sects came the Shingon, brought from China in 809 by Kükai, and having its principal metropolitan place of worship at Gokoku-ji (or Tō-ji) in Kyōto, and its principal provincial at Kongōbō-ji on Kōya-san. These four sects and some smaller ones were all introduced during a period of 156 years. Thereafter, for a space of 387 years, there was no addition to the number: things remained stationary until 1196, when Honen began to preach the doctrines of the Jödo sect, and in the space of fifty-six years; between 1196 and 1252, three other sects were established, namely, the Zen, the Shin, and the Nichiren."

\section{THE TWO GIOUPS OF SECTS}

In what did the teachings of the early groups of sects differ from those of the later groups, and why did such a long interval separate the two? Evidently the answers to these questions must have an important bearing on Japanese moral culture. From the time of its first introduction (A.D. 522) into Japan until the days of Shōtoku Taishi (572-621), Japanese Buddhism followed the lines indicated in the land of its provenance, Korea. Prince Shōtoku was the first to appreciate China as the true source of religious learning, and by him priests were sent across 
the sea to study. But the first sect of any importance - the Hosso - that resulted from this movement does not seem to have risen above the level of idolatry and polytheism. It was a "system built up on the worship of certain perfected human beings converted into personal gods; it affirmed the eternal permanence of such beings in some state or other, and it gave them divine attributes."' Some of these were companions and disciples of Shaka (Sakiya Muni); others, pure ereations of fancy, or borrowed from the mythological systems of India. It is unnecessary here to enter into any enumeration of these deities further than to say that, as helpers of persons in trouble, as patrons of little children, as healers of the sick, and as dispensers of merey, they acted an important part in the life of the people. But they did little or nothing to improve men's moral and spiritual condition, and the same is true of a multitude of arhats, devas, and other supernatural beings that go to make up a numerous pantheon.

It was not until the end of the eighth century that Japanese Buddhism rose to a higher level, and the agent of its elevation was Dengyo Daishi, whom the Emperor Kwammu sent to China to study the later developments of the Indian faith. Dengyō and his companions in 802 found their way to the monastery of Tientai (Japanese, Tendai), and acquired there a perception of the true road to Saving Knowledge, a middle route "which includes all and rejects none, and in which alone the soul ean be satisfied." Meditation and wisdom were declared to be the stepping-stones to this route, and to reach them various rules had to be followed, namely, "the accomplishment of external means" - such as observing the precepts, regulating raiment and food, freedom from all worldly concerns and influences, promotion of all virtuous desires, and so forth; "chiding of evil desires" - such as the lust after beauty, the lust of sound, of perfumes, of taste, and of touch; "casting away hindrances;" "harmonizing the faculties," and "meditating upon absolute truth."

Now first we meet with the Buddhas of Contemplation, and with a creed which seems to embody a Father, a Son, and a Holy Spirit. Such, in briefest outline, was the doctrine taught at the close of the sixth century by a Chinese bonze at the monastery of Tientai, and earried thence to Japan two hundred years later by Dengyō, who established the Tendai sect on Mount Hiei near Kyōto. Dengyo did not borrow blindly; he adapted, and thus the Tendai creed, as taught at Hiei-zan, became in reality "a system of Japanese education, fitting the disciplinary and meditative methods of the Chinese propagandist on the pre-existing foundations of earlier sects."

"The comprehensiveness of the Tendai system caused it to be the parent of many schisms. Out of it came all the large seets, with the exception of the Shingon," to be presently spoken of. "On the other hand, this comprehensiveness ensured the suceess of the Tendai sect. With the conception of the Buddhas of Contemplation came the idea that these personages had frequently been inearnated for the welfare of mankind; that the ancient gods whom the Japanese worshipped were but manifestations of these same mystical beings, and that the Buddhist faith had come, not to destroy the native Shintō, but to embody it into a higher and more universal system." 2

[' Lloyd's Developments of Japanese Buddhism, "Transactions of the Asiatic Society of Japan," Vol. XXII; and Shinran and His Work, by the same author.]

["The Buddhists reeognized that the Shinlo gods were incarnations of some of the many Buddhas and Bodhisattvas brought from India and China, and then the two faiths amalgamated and for centuries comfortably shared the same places of worship."-Every-Day Japan, by Lloyd.] 


\section{THE SHINGON SECT}

It was not to Dengyō, however, that Japan owed her most mysterious form of Buddhism, but to his contemporary, Kūkai, remembered by posterity as Kōbo Daishi. The traditions that have been handed down with reference to this great teacher's life and personality reveal one of those saints whose preaching and ministration have bestowed a perpetual blessing on humanity. Here, it must suffice to say that he found no peace of mind until a visit to China brought comprehension of a Sutra which he had vainly studied in Japan. On his return, in 806, he appeared before the emperor and many bonzes, and "astonished all by his eloquence and his knowledge.

There are three "vehicles" in Buddhism, but only two of them need be mentioned here - the Hina-yâna, or Small Vehicle, and the Mahâ-yâna, or Great Vehicle. The term "vehicle" signifies a body of doctrine on which "a believer may ride to the perfect consummation of his humanity." The difference between these two requires many words to explain fully, whereas only a few can be devoted to the purpose here. "The Hina-yâna Sutra is intended for beginners; the Mahâ-yâna for those more advanced in the path of the law:" The teaching in the former is negative; in the latter, positive. In the Hina-yâna the perfect path is to abstain from four things - women, palaces, beautiful objects, and riches. In the Mahâ-yâna perfect virtue is the presence of four things - the spirit of wisdom, the love of virtue, patience and firmness, and the retired life. By the "spirit of wisdom" is meant the constant desire for the truth; by the "love of virtue" is signified the abhorrence of evil; by "patience and firmness" are indicated perfect manliness as exhibited towards the weak; by "the retired life" is designated humility and self-effacement.

"There is nothing in the world like the Chinese scriptures of the Mahâa-yâna. The canon in China is seven hundred times the amount of the New Testament," and, of course, this vast extent means that there is a correspondingly wide field for eclecticism. "The Hina-yâna did not trouble itself 'with metaphysical speculation; that was reserved for the Mahâ-yâna, and Kūkai was the greatest Japanese teacher of the arcana of Buddhism. How much of his system he owed to studies conducted in China, how much to his own inspiration, research has not yet determined. An essentially esoteric system; it conceived a world of ideas," grouped logically and systematically according to genera and species, forming a planetary cosmos, the members of which, with their satellites, revolved not only on their own axes but also round a central sun.

This was the "world of golden effulgence" - a world permeated by the light of truth. The sect was called the Shingon (True Word); and the central body was Dainichi (Great Sun), the Spirit of Truth, anterior to Shaka and greater than him. "To reach the realization of the Truth that Dainichi is omnipresent and that everything exists only in him, a disciple must ascend by a double ladder, each half of which has ten steps, namely, the intellectual ladder and the moral ladder." These ladders constitute, in fact, a series of precepts, warnings, and exhortations; some easily comprehensible, others demanding profound thought, and the whole calculated to educate an absorbing aspiration for the "transcendental virtues;" to possess which is to attain to perfect Buddhahood. Unquestionably the offspring of a great mind, this Shingon system, with its mysterious possibilities and its lofty morality, appealed strongly to the educated and leisured classes in Kyōto during the peaceful Heian epoch, while for the illiterate and the lower orders the simpler canons of the Tendai had to suffice. 


\section{THE JŌDO SECT}

It has been shown, however, that the preachers of these seets, one and all, were readily prone to resort to violence and bloodshed in pursuit of worldly interests, not even the exponents of the exalted "True Word" creed being exempt from the reproach. Teachers of a doctrine having for cardinal tenet the sacredness of life, the inmates of the great monasteries nevertheless did not hesitate to appeal to arms, at any time, in defence of their temporal privileges or in pursuit of their ambitious designs. Yet the discredit attaching to such a flagrant discrepancy between precept and practice might not have produced very signal result had not the twelfth century brought the Gen-Hei struggle; which plunged the empire into a state of turbulence and reduced the lower orders to a condition of pitiable misery.

For this distress neither the Tendai doctrines nor the Shingon conceptions were sufficiently simple to supply a remedy. Something more tangible and less recondite was needed, and it came (1196), in the sequel of twenty-five years' meditation and study, to Genkū - posthumously ealled Hōnen Shōnin "a priest of the Tendai sect. The leading characteristies of the Jodo (pure land) system introduced by him are easily stated. "Salvation is by faith, but it is a faith ritually expressed. The virtue that saves comes, not from imitation of $\mathrm{f}^{\prime}$ and conformity to, the person and character of the saviour, Amida, but from blind trust in his efforts and from ceaseless repetition of pious formula. It does. not necessitate any conversion or change of heart. It is really a religion of despair rather than of hope. It says to the believer: 'The world is so very evil that you can not possibly reach to Buddha-ship here. Your best plan, therefore, is to give up all such hope and simply set your mind upon being born in Amida's paradise after death." "1

\section{THE SHIN SECT}

An immediate offspring of the Jọdo, though not directly following it in the chronological sequence of sects, was the Shin, established (1224) under the name of $J \bar{o} d o$ Shin-sh $\bar{u}^{2}$ (True Sect of Jōdo), and owing its ineeption to Shinran, a pupil of Genkū. It was even simpler and less exacting than its parent, the Jōdo-sh $\bar{u}$, for it logically argued that if faith alone was necessary to salvation, the believer need not trouble himself about metaphysical subtleties and profound speculations; nor need he perform acts of religion and devotion; nor need he keep a multitude of eommandments; nor need he leave his home, renounce matrimony, or live by rule. Only he must not worship any save Amida, or pray for anything that does not concern his salvation. As for the time of attaining salvation, the Jodo seet taught that if the mercy of Amida be ealled to remembranee, he would meet the believer at the hour of death and conduct him to paradise; whereas Shin-shu preaches that the coming of Amida was present and immediate; in other words, that "Buddha dwelt in the heart now by faith.":

\section{THE ZEN SECT}

In the Jodo and the Shin sects an ample spiritual rest was provided for the weary in mind or body, for the illiterate, and for the oppressed.. But there was for a time no ereed which appealed specially to the military men; no body of 
doctrine which, while strengthening him for the fight, could bring to him peace of mind. The Zen-shü ultimately satisfied that want. Zen is the Japanese equivalent of the Indian term dhyanâ, which signifies "meditation." In fact, the Zen is a contemplative sect. Its disciples believe that, "knowledge can be transmitted from heart to heart without the intervention of words." But though purely a contemplative rite at the time of its introduction into Japan, 1168; it was subsequently modified - from 1223 - by two teachers, in whose hands it took the form known as the Sōtō' sect. This "joined scholarship and research to contemplation," and taught that, when the highest wisdom and most perfect enlightenment are attained, all the elements of phenomenal existence are seen to be empty, vain, and unreal. "Form does not differ from space or space from form; all things. surrounding us are stripped of their qualities, so that in this highest state of enlightenment, there can be no longer birth or death, defile-

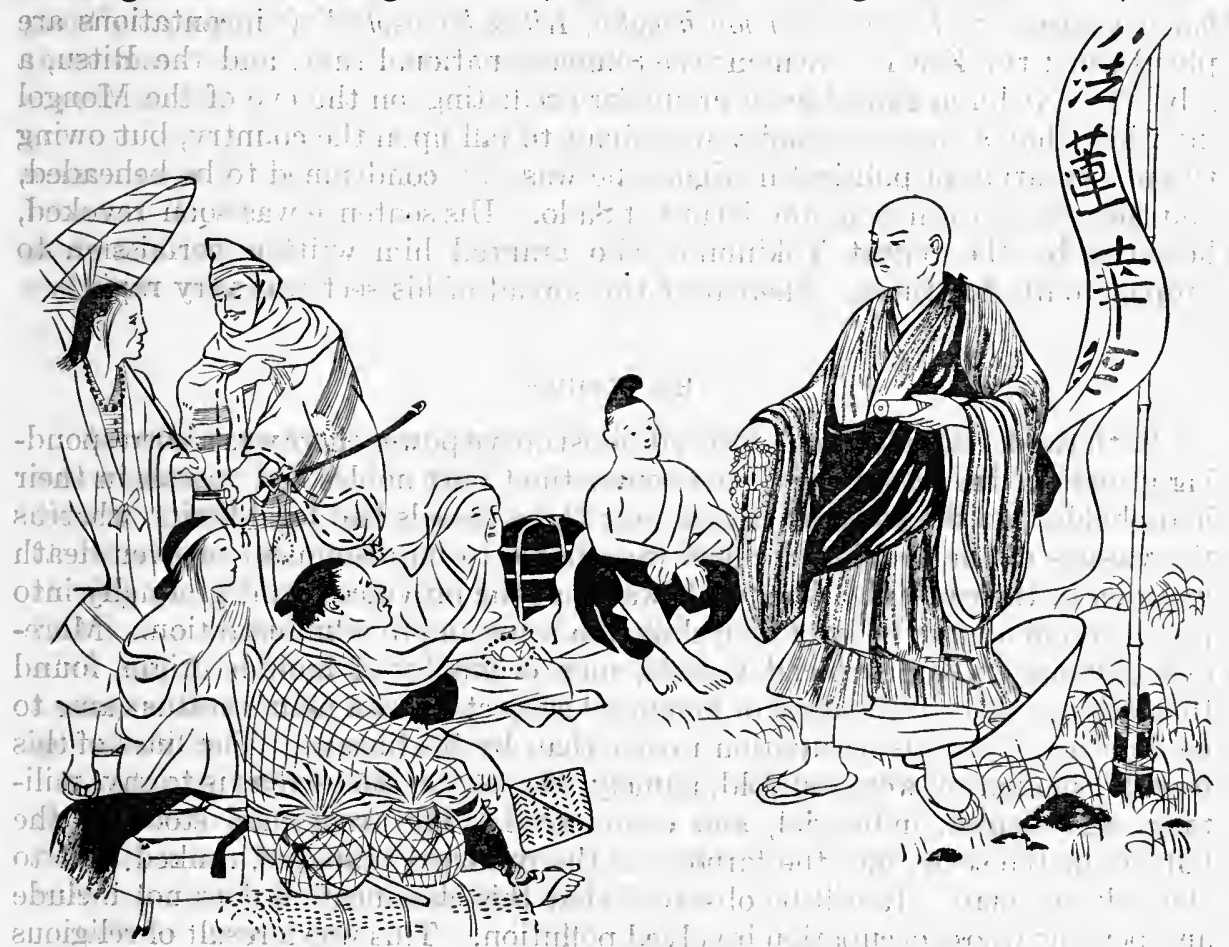

Nichiren Preaching in the Street

ment or purity, addition or destruction. There is, therefore, no such thing as ignorance, and therefore none of the miseries that result from it. If there is no misery, decay, or death, there is no such thing as wisdom, and no such thing as attaining to happiness or rest. Hence, to arrive at perfect emancipation we must grasp the fact of utter and entire void." Such a creed effectually fortified the heart of a soldier. Death ceased to have any terrors for him or the grave any reality.

\section{THE NICHIREN SECT}

This is the only one among Japanese sects of Buddhism that derives its name from that of its founder. And justly so, for Nichiren's personality pervades it. 
The son of a fisherman, from youth he applied himself to the study of Buddhism, became a bonze of the Shingon sect, and took the name of Nichiren (lotus of the sun). He, too, studied originally at Hiei-zan under Tendai tutors, but he ultimately followed an eclectic path of his own, which led him to the "Seripture of the Lotus of Good Law," and he taught that salvation could be attained merely by chaunting the formula, "namu myō hō renge ky'ö" ("hail to the Scripture of the Lotus of Good Law") with sufficient fervour and iteration. In fact, Nichiren's methods partook of those of the modern Salvation Army. He was distinguished, also, by the fanatical character of his propagandism: Up to his time, Japanese Buddhism had been nothing if not tolerant The friars were quick to take up arms for temporal purposes, but sectarian aggressiveness was virtually unknown until Nichiren undertook to denounce everyone differing from his views. ${ }^{1} \quad$ His favourite formula for denouncing other sects was; if nembutsu mugen, Zen temma, Shingon bōkoku, Ritsu kokuzoku" ("incantations are phantasms; the Zen is a demon; the Shingon, national ruin; and the Ritsu, a rebel"). Nichiren gained great credit for predicting, on the eve of the Mongol invasion, that a heavy ealamity was about to fall upon the country, but owing to an accusation of political intrigues, he was first condemned to be beheaded, and then was banished to the island of Sado. His sentence was soon revoked, however, by the regent Tokimune, who granted him written permission to propagate his doctrines. Thereafter the spread of his sect was very rapid.

\section{THE PEOPLE}

With the decentralization of the administrative power there was a corresponding growth of the vassal class. Of course the Court nobles had vassals in their households, but the power exercised over these vassals had legal limits, whereas the vassals of the provincial chiefs were liable to imprisonment or even death by order of their chiefs. One result was that the provinees came gradually into possession of a large body of men skilled in arms and in administration. Moreover, among these provincial vassals, men originally of humble origin, found themselves raised to the level of honoured subjects, and a man's status came to be determined by his occupation rather than by his lineage. The lines of this

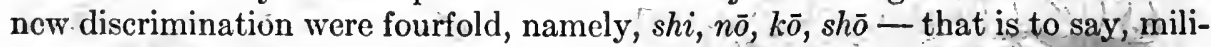
tary, agricultural, industrial, and commereial. The tradesman stood at the bottom of the seale, and the farmer, as the principal taxpayer, ranked next to the military man. It will be observed that this classification does not include any persons whose occupation involved pollution. This was a result of religious prejudice. Degradation attended every profession that required contact with the sick, the dead, or offal of any kind. Persons practising such callings were designated eta (men of many impurities). All belonging to the class inferior to tradesmen were originally regarded as outlaws, but subsequently, when soeicty was reorganized on a military basis, an official was specially entrusted with absolute control over persons excluded from the quadruple classification of soldier, farmer, mechanic, and merehant. Beggars constituted an important section of the outcasts (hinin). Next to them were professional caterers for amusement, from dog-trainers, snake-charmers, riddle-readers, acrobats, and trainers of animals, to brothel-keepers and executioners.

[ ${ }^{1}$ Out of some 72,000 temples in Japan to-day, 20,000, approximately, belong to the Shin sect; an equal number to the Zen; 13,000 to the Shingon; 8000 to the Jodo, and smaller numbers to the rest.] 


\section{DWELLING-HOUSES}

During the two centuries from the middle of the twelfth, aristocratic dwellings in the capital underwent little change. Military residences, however, developed some special features, though, in general, their architecture was of the simplest character. They had two enclosures, each surrounded by a boarded fence, and the whole:was encircled by a fosse crossed by outer and inner gates. There were ranges for archery and there were watch-towers, but the dwelling itself was small and plain. It consisted mainly of a hall, having a dais with a lacquered chair for important visitors; an apartment for women; a servants' room, and a kitchen, heat being obtained from a hearth sunk in the floor. Austere simplicity was everywhere aimed at, and it is related that great provincial chiefs did not think the veranda too lowly for a sleeping-place. The use of the tatami was greatly extended after the twelfth century. No longer laid on the dais only, these mats were used to cover the whole of the floors, and presently they were supplemented by cushions made of silk crêpe stuffed with cotton-wool. In the great majority of cases, roofs were covered with boards. Only in the houses of magnates was recourse had to tiles imported from China or slates of copperbronze. In the better class of house, the roof-boards were held in place by girders; but humble folks used logs of timber, or stones; to prevent wind-stripping, and these weights imparted an untidy, rude appearance to the structure.

vlont ra. It ragitis

\section{COSTUME}

A notable feature of costume in this era was that the skirt of an official's couter garment had to be long in proportion to his rank. But military men I did not observe this rule. It was followed only by the comparatively effeminate Court nobles and civil officials, who shaved their eyebrows, painted their cheeks, and blackened their teeth, as women did. While the soldiers of the Kamakura period wore their hair short and shaved the top of the head,- possibly for greater comfort when they were accoutred in heavy helmets, - the Court noble and the exquisite of the day wore their hair long and gathered in a queue, which was bound with paper.

As for women, long hair was counted a beauty, and when a lady of rank left the house, her tresses were gathered in a box carried by an attendant who walked behind; and when she seated herself, this attendant's duty was to spread the hair symmetrically on the ground like a skirt. Girls in their teens had a pretty fashion of wearing their hair in three clearly distinguished lengths - a short fringe over the forehead, two cascades falling below the shoulders, and a long lock behind. Women's hairdressing was simple in one respect: they wore no ornaments in the hair: Aristocratic ladies continued to wear loose trousers, but robes with skirts began to form a part of the costume of the lower classes and of unmarried girls. The girdle, so characteristic of Japanese habiliments in later days, had not yet come into use. Its predecessor was a narrow belt of silk encircling the waist and knotted in front, the outer garment being a long flowing robe, reaching from the neck to the heels and having voluminous sleeves. Female headgear was various. A woman walking abroad wore a large hat like an inverted bowl, and when she rode on horseback, she suspended from the rim of this hat a curtain from three to four feet long.

There were other fashions, but only one of them need be mentioned, namely, a hood to envelop the face so that the eyes alone remained visible. In the 
city streets women of the town wore a distinctive.costume as courtesans did in certain parts of Europe in the Middle Ages. The badge in Japan was a spirally twisted pyramidal eap of linen, about a foot and a half high. The materials of which clothing were made varied from rich Chinese brocade to coarse homespun; but, in general, the use of brocade was forbidden except to persons who had received it as a gift from the Court in Kyotto or Kamakura. Historical mention is first made of badges during the war of the Minamoto and the Taira. Their use was originally confined to purposes of distinction, and ultimately they came to be employed as a family crest by military men. A chrysanthemum flower with sixteen petals and a bunch of Paulownia leaves and buds constituted the Imperial badges, the use of which was interdieted to all subjects. It is not to be supposed, however, that badges were necessarily a mark of aristocracy: they might be woven or dyed on the garments of tradespeople or manufacturers. Footgear, also, offered opportunities for embellishment. Common people wore brown-leather socks, but those of position used blue leather having decorative designs embroidered in white thread.

\section{BRAZIERS, ETC.}

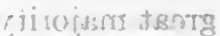

cen weylengen

Braziers now came into general use, and quickly became objects of ornament as well as of utility. Manufactured of brass or bronze, and sometimes even of silver, they had decorative designs repoussé or chiselled, and sometimes they took the shape of a metal receptacle inserted in a ease of finely grained or richly laequered wood. Another important warming utensil was the kotatsu, a latticed wooden frame enclosing a brazier and covered by a quilt. Lanterns were also employed. They consisted of a candle fixed in a skeleton frame on whieh an envelope of thin paper was stretehed. Their introduction was quickly followed by that of a kind of match which took the form of a thin piece of wood tipped with sulphur.

\section{DIET}

The military class did not allow themselves to be influenced by any religious scruples in their choice of viands. They ate everything except the flesh of oxen or horses. In serving meals, tables of Chinese form ceased altogether to be used, edibles being placed on a tray which stood about four inches high. : These trays and eups, and the bowls and plates ranged on them, showed great refinement, rich lacquer, silver, and gold being freely used in aristocratic dwellings.

\section{AGRICULTURE AND INDUSTRY}

Agriculture was, of course, greatly interrupted by the long continuance of military eampaigns; but, on the other hand, it received every encouragement from the Minamoto and the Hōjō. "The most important incident of the era in this context was the introduction of the tea-shrub from China in 1191. As for industrial pursuits, signal progress took place in the art of tempering steel. The Japanese swordsmith forged the most trenchant weapon ever produced by any nation. The ceramic industry, also; underwent great development from the thirteenth century onwards. It may be said to have owed its artistic beginning to Katō Shirōzaemon Kagemasa, who visited China at that time; and "learned the art of applying glaze to pottery biscuit; a feat not previously achieved in Japan." Another profession carried to high excellence was the sculpturing of 
Buddhist images. This reached its acme in a celebrated bronze Buddha which was set up at Kamakura, in 1252, and which remains to this day "one of the most majestic creations of art in any country."

\section{SUMPTUARY EDICTS}

The laws enacted by the Hōjo regents bear ample testimony to their desire of enforcing frugality. In the middle of the thirteenth century, they went so far as to interdict the brewing of sake throughout the empire, and another ordinance vetoed the serving of cakes at meals. Such interdicts could not possibly be strictly enforced, but they undoubtedly exercised much influence, so that the samurai limited themselves to two meals a day and partook only of the coarsest fare.

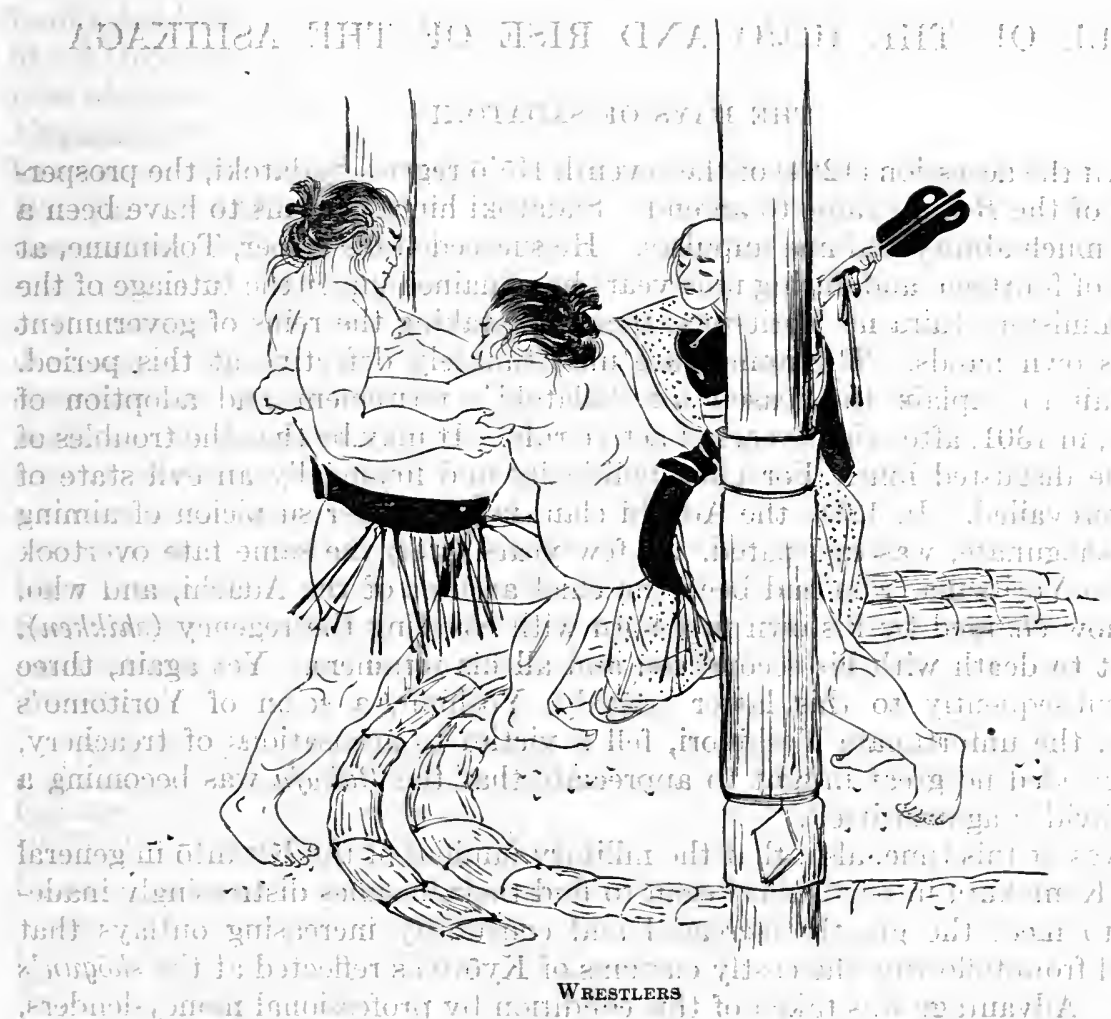

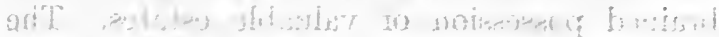




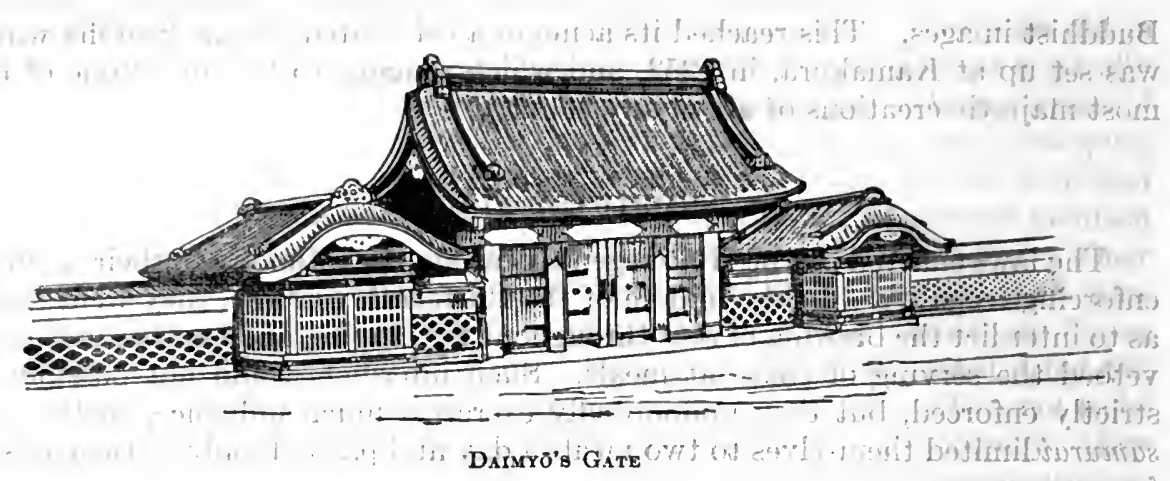

CHAPTER XXIX

\section{FALL OF THE HŌJO AND RISE OF THE ASHIKAGA}

\section{THE DAYS OF SADATOKI}

Wiтн the accession (1284) of the seventh Hōjō regent, Sadatoki, the prosperous era of the Bakufu came to an end. Sadatoki himself seems to have been a man of much ability and fine impulses. He succeeded his father, Tokimune, at the age of fourteen, and during nine years he remained under the tutelage of the prime minister, Taira no Yoritsuna, thereafter taking the reins of government into his own hands. The annals are unfortunately defective at this period. They fail to explain the reason for Sadatoki's retirement and adoption of religion, in 1301, after eight years of active rule. It may be that the troubles of the time disgusted him. For alike politically and financially an evil state of affairs prevailed. In 1286, the Adachi clan, falling under suspicion of aiming at the shōgunate, was extirpated. A few years later, the same fate overtook Taira no Yoritsuna, who had been the chief accuser of the Adachi, and who, being now charged by his own first-born with coveting the regency (shikken); was put to death with his second son and all his retainers. Yet again, three years subsequently to this latter tragedy, Yoshimi, a scion of Yoritomo's brother, the unfortunate Yoshinori, fell a victim to accusations of treachery, and it needed no great insight to appreciate that the Bakufu was becoming a house divided against itself.

It was at this time, also, that the military families of the Kwantō in general and of Kamakura in particular began to find their incomes distressingly inadequate to meet the greatly increased and constantly increasing outlays that resulted from following the costly customs of Kyōto as reflected at the shögun's palace. Advantage was taken of this condition by professional money-lenders, by ambitious nobles, and even by wealthy farmers, who, supplying funds at exorbitant rates of interest, obtained possession of valuable estates. The Bakufu made several futile legislative essays to amend this state of affairs, and finally, in the year 1297, they resorted to a ruinous device called tokusei, or the "benevolent policy." This consisted in enacting a law which vetoed all suits for the recovery of interest, cancelled all mortgages, and interdicted the pledging of military men's property. 
Of course, such legislation proved disastrous. Whatever temporary relief it afforded to indigent and improvident debtors, was far outweighed by the blow given to credit generally, and by the indignation excited among creditors. The Bakufu owed much of the stability of their influence to the frugality of their lives and to their unsullied administration of justice. But now the Kwantō bushi rivalled:the Kyōto gallants in extravagance; the Kamakura tribunals forfeited the confidence of the people, and the needy samurai began to wish for the return of troublous times, when fortunes could be won with the sword. Amid such conditions Sadatoki took the tonsure in 1300, and was succeeded nominally by his cousin Morotoki, who, however, administered affairs in consultation with the retired regent. In 1303, a son was born to Sadatoki, and the latter, dying in 1311, bequeathed the office of regent to this boy when he should reach years of discretion, entrusting him, meanwhile, to the guardianship of two officials, the more active of whom was a lay priest, Nagasaki Enki.

An idea of the confusion existing at that time in Kamakura may be gathered from the fact that, during the five years between the death of Sadatoki and the accession of his son Takatoki (1316), no less than four members of the Hōjo family held the regency in succession. Takatoki was destined to be the last of the Hōjo regents. : Coming into power at the age of thirteen, his natural giddiness of character is said to have been deliberately encouraged by his guardian, Nagasaki, but even had he been a stronger man it is doubtful whether he could have saved the: situation. Corruption had eaten deeply into the heart of the Bakufu. In 1323, a question concerning right of succession to the Ando estate was carried to Kamakura for adjudication, and the chief judge, Nagasaki Takasuke, son of the oId lay priest mentioned above, having taken bribes from both of the litigants, delivered an inscrutable opinion. Save for its sequel, this incident would merely have to be catalogued with many cognate injustices which disfigured the epoch. But the Ando family being one of the most powerful in northern Japan, its rival representatives appealed to arms in support of their respective claims, and the province of $\bar{O}$ shü was thrown into such confusion that a force had to be sent from Kamakura to restore order. This expedition failed, and with its failure the prestige of the Hōjo fell in a region where hitherto it had been untarnished - the arena of arms. The great Japanese historian; Rai Sanyō, compared the Bakufu of that time to a tree beautiful outwardlybut wormeaten at the core, and in the classical work, Taiheiki, the state of affairs is thus described:-

The Dengaku mime was then in vogue among all classes in Kyōto. Takatoki, hearing of this, summoned two rival troupes of Dengaku players to Kamakura and witnessed their performances without regard to the passage of time. He distributed the members of the troupes among the noble families related to the Hojō, and made these nobles compete to furnish the performers with mánificent costumes. At a banquet when a Derigaku mime was acted, the regent and his guests vied with one another in pulling off their robes and throwing them into a heap, to be redeemed afterwards for heavy sums which were given to the actors. The custom thus inaugurated became perpetual. One day, a number of dogs gathered in the garden of Takatoki's mansion'and had a fight. This so amused the regent that'orders were despatched to collect dogs by way of taxes; the result being that many people in the provinces took steps to breed dogs and presented them by tens or scores to Kamakura, where they were fed on fish and fowl, kept in kennels having gold and silver ornaments, and carried in palanquins to take the air. When these distinguished animals were borne along the public thoroughfares, people hastening hither and thither on business had to dismount and kneel in obeisance, and farmers, instead of cultivating the fields, had to act as bearers of the dogs' sedan-chairs. Thus, the city of Kamakura presented the curious spectacle of a town filled with well-fed dogs, clothed in tinsel and brocades, and totalling from four to five thousand. Twelve days in every month used to be devoted to dog-fights, and on these occasions, the regent, the nobles, and the people inside and outside the mansion used to assemble as spectators, sitting on the verandas or the ground. 


\section{THE COURT IN KYŌTO}

All these things were watehed with keen interest in Kyōto. It has been shown in Chapter XXVI that the Imperial family had been divided into two branches ever since the days of Go-Saga (1242-1246), one descended from his elder son, Go-Fukakusa, the other from his younger, Kameyama. These two branches may be conveniently distinguished as the senior and the junior, irespectively. It has also been shown that the princes of the senior branch uniformly relied on Kamakura and kept the Bakufu informed of all intrigues devised in Kyōto, whereas those of the junior branch constantly cherished the hope of reasserting the independence of the throne. A representative of the junior branch, Go-Daigo (1318-1339), happened to be on the throne when Takatoki, holding the regency at.Kainakura, scandalized the nation by his excesses and discredited the Hōjō by his incompetence.

Go-Daigo was an able sovereign. He dispensed justice scrupulously and made the good of the country his prime aim. It appeared to him that the time had come for Kyoto to shake off the fetters of Kamakura. With that object he took into his confidence two Fujiwara nobles, Suketomo, a councillor of State, and Toshimoto, minister of Finance. These he despatched on a secret tour of inspection through the provinces, instructing them at the same time to canvass for adherents among the local samurai. They met with considerable' 'success. Among the provincial families there were some of Taira origin who cherished traditional hatred towards the Minamoto; there were some of Minamoto blood who chafed at the supremacy of the Hōjo, and there were some who, independently of lineage, longed for a struggle and its contingent possibilities. Leading representatives of these classes began to hold conclaves in Kyōto. The meetings were marked by complete absence of ceremony, their object being to promote free interchange of ideas. Presently, suspicions were suggested to. Kamakura. The regent, Takatoki, who, though a careless libertine in his habits, living in the society of his thirty concubines, his troops of dancing mimes; and his packs of fighting dogs, was capable of stern resolution on occasions, threatened to dethrone the Emperor.

In this sore strait, Go-Daigo did not hesitate to make solemn avowal of the innocence of his purpose, and. Kamakura refrained from any harsh action towards the Throne. : But it fared ill with the sovereign's chief confidant, Fujiwara no Suketomo. He was exiled to Sado Island and there killed by Tákatoki's instructions. . This happened in 1325. Connected with it was an incident which illustrates the temper of the bushi. In spite of his mother.'s tearful remonstrances; Kunimitsu, the thirteen-year-old son of the exiled noble, set out from Kyōto for Sado to bid his father farewell. The governor of the island was much moved by the boy's affection, but, fearful of Kamakura, he refused to sanction a meeting and commissioned one Homma Saburō, a member of his family, to kill the prisoner. Kunimitsu determined to avenge his father, even at the expense of his own life. During a stormy night, he effected an entry into the governor's mansion, and, penctrating to Saburō's chamber, killed him. The child then turned his weapon against his own bosom. But, reflecting that he had his mother to care for, his sovereign to serve, and his father's will to carry out, he determincd to escape if possible. The mansion was surrounded by a deep moat which he could not cross.. But a bamboo grew on the margin, and climbing up this, he found that it bent with his weight so as to form a bridge. He reached Kyōto in safety. and ultimately attained the high post (chünagon) which his father had held. 


\section{THE SUCCESSION TO THE THRONE}

The year 1326 witnessed the decease of the Crown Prince, Kuninaga, who represented the senior branch of the Imperial family. Thereupon, Go-Daigo conceived the project of appointing his own son, Morinaga, to be Prince Imperial. That would have given the sceptre twice in succession to the junior branch, and the Bakufu regent, insisting that the rule of alternate succession must be followed, proposed to nominate Prince Kazuhito, a son of the cloistered Emperor, Go-Fushimi, who belonged to the senior branch. The question was vehemently discussed at Kamakura, Go-Daigo being represented by-Fujiwara no Fujifusa, and Go-Fushimi by another noble. The former contended that never since the days of Jimmu had any subject dared to impose his will on the Imperial family. Go-Saga's testament had clearly provided the order of succession to the throne, yet the Bakufu had ventured to set that testament aside and had dictated the system of alternate succession.: Thus, the princes of the elder branch not only became eligible for the throne, but also enjoyed great revenues from the Chōkōdō estate, though it had been bequeathed as a solatium for exclusion from the succession; whereas the princes of the junior branch, when not occupying the throne, were without a foot of land or the smallest source of income. Fujifusa was instructed to claim that the usufruct of the Chōkōdo estate should alternate in the same manner as the succession, or that the latter should be perpetually vested in the junior branch. To this just demand the regent, Takatoki, refused to accede. Kazuhito was named Prince Imperial, and thus the seeds of a sanguinary struggle were sown.

\section{CONSPIRACY IN KYŌTO}

Go-Daigo now conspired actively for the overthrow of the Hōjō. He took Prince Morinaga into his confidence, and, under the name Ōtō no Miya, made him lord-abbot of the great monastery of Hiei-zan, thus securing at once a large force of soldier cenobites. To the same end other religious establishments were successfully approached. During the space of five years this plot escaped Kamakura's attention. But, in 1331, the Bakufu, becoming suspicious, laid hands on several of the plotters and, subjecting them to judicial examination after the merciless fashion of the age, soon elicited a part, at any rate, of the truth. Yet Kamakura does not appear to have appreciated the situation until, Go-Daigo having summoned the Enryaku monks to his assistance, the cloistered Emperor of the senior branch, Go-Fushimi, despatched an urgent message to the Bakufu, declaring that unless prompt action were taken the situation would elude control.

To Hasty council was now held in Kamakura. Nagasaki Takasuke, the corrupt $k w a n r y \bar{o}$, advised that Go-Daigo should be dethroned and sent into exile, together with Ôtō no Miya, and that all implicated in the plot should be severely punished. This violent course was opposed by Nikaido Sadafusa, who pleaded eloquently for the respect due to the Throne, and contended that without the sovereign's favour the Bakufu could not exist. But Takasuke's advice prevailed, re-enforced as it was by reference to the Shökyū disturbance when vigorous dáring had won the day. With all possible expedition an army under the command of Sadafusa marched from Kamakura for Kyōto. Advised of these doings; Prince Morinaga persuaded the Emperor to change costumes with Fujiwara Morokata; whereafter the latter, riding in the Imperial palanquin, took ostensible refuge at 
Hiei-zan, and the sovereign, travelling in a Court lady's ox-ear, made his way, first, to Nara and thence to Kasagi in Yamato, guarded by the troops of Fujiwara Fujifusa. Rokuhara was then under the command of Hōjo Nakatoki, and upon him devolved the duty of seizing the Emperor's person. "He directed an army. against Hiei-zan, where Go-Daigo was believed to have found asylum. But Fujiwara Morokata, who personified the sovereign, managed to escape, as did also Prince Morinaga (Ōtō no Miya). Go-Daigo then sent to Kusunoki Masashige a mandate to raise troops and move against the "rebels," for to that category the Hojjo now belonged in the absence of an Imperial commission.

This Kusunoki Masashige (ealled Nankō) is one of Japan's ideal types of loyalty and courage. He and Nitta Yoshisada are the central figures in the long campaign upon which Japan now entered: Masashige belonged to the Tachibana family, which stood second among the four great septs of Japanthe Fujiwara, the Tachibana, the Minamoto, and the Taira - and Yoshisadar claimed kinship with the Minamoto. Receiving Go-Daigo's order, Kusunoki Masashige quickly collected a troop of local bush $i$ and constructed entrenchments at Akasaka, a naturally strong position in his native province of Kawachi. Takatoki now caused Prince Kazuhito to be proclaimed 'sovereign under the' name of Kōgon. But this monarch was not destined to find a place among the recognized occupants of the throne. For a time, indeed; fortune smiled on the Hōjō. Within a few days after Kōgon's assumption of the sceptre; Go-Daigo's retreat at Kasagi became untenable, and he fled, still escorted by the faithful Fujiwara Fujifusa. It must be reeognized that, whatever the Fujiwara family's usurpations in the past, their loyalty to the Throne throughout this era of cruel vicissitudes redeems a multitude of sins.

During his flight from Kasagi, the Emperor was without food for three days, and had to sleep with a rock for pillow. Overtaken by the Rokuhara troops, his Majesty was placed in a bamboo palanquin and carried to the temple Byôdoin, where, after the battle of the Uji Bridge, the aged statesman and general, Yorimasa, had fallen by his own hand, a century and a half previously. Here Go-Daigo received a peremptory order to surrender the Imperial insignia to the Hōjō nominee, Kōgon. He ref used. The mirror and gem, he alleged, had been lost, and there remained only the sacred sword, which he kept to defend himself against the traitors; when they fell upon him.: The high courage of this answer would have been finer had Go-Daigo's statement been true; but in reality' the three insignia were intact. It was then announced to his Majesty that he should be removed to Rokuhara where he would be entirely in the power of the Hōjo. Nevertheless, he maintained his lofty bearing, and refused to make the journey. unless all appropriate forms of etiquette were observed. At Rokuhara the demand for the insignia was repeated and the Emperor handed over duplicates, secretly retaining the genuine articles himself. Takatoki now issued orders for Go-Daigo to be removed to the island of Oki, sent all the members of his family into exile elsewhere, and banished or killed his principal supporters.

\section{RAISING OF A, LOYAL ARMY}

Kusunoki Masashige had but five hundred men under his command when he entrenched himself at Akasaka. There for twenty days he held out ágainst the attacks of the greatly superior Hōjō forces, until finally, no help arriving and his provisions being exhausted, he would have committed suicide had he not realized that his life belonged to the Imperial cause. He contrived to escape 
through the enemy's lines, and thus the only organized loyal force that remained in the field was that operating in Bingo under the command of Sakurayama Koretoshi. Thither a false rumour of Masashige's death having been carried, Koretoshi's troops dispersed and he himself committed suicide. Kojima Takanori, too, commonly known as Bingo no Saburō, was about to raise the banner of loyalty when the false news of Masashige's death reached him. This Takanori is the hero of an incident which appeals strongly to the Japanese love of the romantic ruluearning that the Emperor was being transported into exile in the island of Oki, and having essayed to rescue him en route, he made his way during the night into the enclosure of the inn where the Imperial party had halted, and having scraped off part of the bark of a cherry tree, he inscribed on the trunk the couplet:

Heaven destroy not Kou Chien,

$\mathrm{He}$ is not without a Fan ' $\mathrm{Li}$ '

This alluded to an old-time Chinese king (Kou Chien) who, after twenty years of exile, was restored to power by the efforts of a vassal (Fan Li). : The Emperor's guards, being too illiterate to comprehend the reference, 'showed the writing to Go-Daigo, who thus learned that friends were at hand. 'But Takanori could not accomplish anything more, and for a season the fortunes of the Throne were at a very low ebb, while at Kamakura the regent resumed his life of debauchery. Neither Prince Morinaga nor Masashige was idle, however. By skilful co-operation they recovered the entrenchments at Akasaka and overran the two provinces of Izumi and Kawachi, gaining many adherents. The fall of 1332 saw Masashige strongly postëd at the Chihaya fortress on Kongō Mountain; his lieutenants holding Akasaka; Prince Morinaga in possession of Yoshino Castle, and Akamatsu Norimura of Harima blocking the two highways called the Sanindō and the Sanyōdō.

In other words, the Imperialists held the group of provinces forming the northern littoral of the Inland Sea and commanded the approaches from the south. But now again Kamakura put forth its strength. At the close of February; 1333, a numerous force under the Hōjō banners attacked Yoshino and its fall became inevitable. Prince-Morinaga, wounded in several places; had resolved to make the castle his " death-pillow," when he was saved by one of those acts of heroic devotion so frequently recorded in the annals of the Japanese bushi. Murakami Yoshiteru insisted on donning the prince's armour and personating him so as to cover his retreat. At the supreme moment, Yoshiteru ascended the tower of the entrenchments and loudly proclaiming himself the prince, committed suicide. His son would fain have shared his fate, but Yoshiteru bade him live for Ifurther service. Subsequently"' he fell fighting against Morinaga's pursuers; but the prince escaped safely to the great monastery: of Kōya in Kishū. ${ }^{1}$ The victorious Hōjō then turned their arms against Akasaka, and having carried that position; attacked Chihaya where Masashige commanded in person. But the great soldier held his foes successfully at bay and inflicted heavy losses on them. Thus, the early months of 1333 witnessed a brighter state of affairs for the Imperial cause. "It was supported by Kusunoki Masashige, in Yamato, with Chihaya for headquarters; Prince Morinaga; at Kōya-san in Kishū; Akamatsu Norimura, in Harima and Settsu, whence his

[1 Yoshiteru's loyal sacrifice received official recognition, in 1908, on the accasion of military manœuvies in the neighbourhood of the scene of the tragedy. "The Emperor honoured his memory by bestowing on him high posthumous rank.] 
fortress of Maya menaced Rokuhara, and by Doi Michiharu and Tokunō Michikoto, in Iyo, whence, crossing to Nagato, they had attacked and defeated Hōjo Tokinao, the tandai of the province.

\section{ESCAPE OF THE EMPEROR FROM OKI}

The Oki group of islands lie in the Sea of Japan forty miles from the coast of the provinces Izumo and Hōki. Beppu, in Nishi-no-shima, one of the smallest of the group, was Go-Daigo's place of exile. By employing the services of a fishing-boat, Prince Morinaga succeeded in eonveying to his Majesty some intelligence of the efforts that were being made in the Imperial cause. This was early in 1333, and when the news spread among the guards at Beppu, they began to talk of the duties of loyalty. Narita Kosaburō and the Nawa brothers, Yasunaga and Nagataka - the name of the last was afterwards changed by the Emperor to Nagatoshi - thus became associated in a scheme for assisting the exile to recover his freedom. To remove him from Nishi-no-Shima was not difficult to contrive, but to traverse the provinees of Izumo or Hōki en route for a safe asylum seemed at first impossible, for in Izumo not only the governor but also the chief official of the great Shintō shrine were hostile, and in Hōki the strietest watehfulness had been enjoined from Rokuhara.

Nevertheless, it became necessary to make the attempt at once or refrain altogether. On the 8th of April, 1333, the guards at Beppu were given a quantity of sake on the plea that the accouchement of a Court lady was imminent. Custom preseribed that in such a case the lady should be removed to a different house, and therefore when the guards had well drunk, a palanquin was carried out, bearing ostensibly this lady only, but in reality freighted with the sovereign also. The night was passed in the village, and at daybreak the little party, leaving the lady behind, set out on foot for the nearest seaport, Chiba: The Emperor could seareely walk, but happily a man was encountered leading a pack-horse, and on this Go-Daigo rode. The next three days were devoted to seeking a safe landing in Izumo and endeavouring to procure provisions. On one oceasion, being pursued by servants of the great shrine, they had to re-embark and put out to sea, the Emperor and his sole attendant, Tadaaki, lying hid in the bottom of the boat beneath a quantity of seaweed and under the feet of the sailors. Finally, on the 13th of April, they made Katami port in the province of Hōki, and, being cordially weleomed by Nawa Nagataka, Go-Daigo was ultimately taken to a mountain called Funanoe, which offered excellent defensive: facilities. It is recorded that on the first stage of this journey from Nagataka's residence to the mountain, the Emperor had to be carried on the back of Nagataka's brother, Nagashige, no palanquin being available: Very soon many bushi flocked to the Imperial standard and Funanoe was strongly entrenched. It was on this occasion that Go-Daigo changed Nagataka's name to Nagatoshi, and conferred on him the title of "captain of the Left guards" (saemon-no-jō).

\section{DOWNFALL OF THE HŌJŌ}

When the Emperor's eseape from Oki beeame known, loyal samurai in great numbers espoused the Imperial cause, and a heavy blow was given to the prestige of the Hōjō by Akamatsu Norimura who, after several successful engagements with the Rokuhara army in Settsu, pushed northward from the fortress of Maya, where his forees were almost within sight of Kyōto. Takatoki, appre- 
ciating that a crisis had now arisen in the fortunes of the Hōjō, ordered Ashikaga Takauji to lead a powerful army westward. Takauji represented a junior branch of the Minamoto family. He was descended from the great Yoshiiye, and when Yoritomo rose against the Taira, in 1180 , he had been immediately joined by the then Ashikaga chieftain, who was his brother-in-law. Takauji, therefore, had ambitions of his own, and his mood towards the Hōjo had been embittered by two recent events; the first, that, though in mourning for the death of his father, he had been required to join the attack on Masashige's fortress at Kasagi; the second, that his own illness after returning from that campaign had not availed to save him from frequent summonses to conference with Takatoki.

Thus, this second order to take the field found him disposed to join in the overthrow of the Hōjo rather than in their support. Learning something of

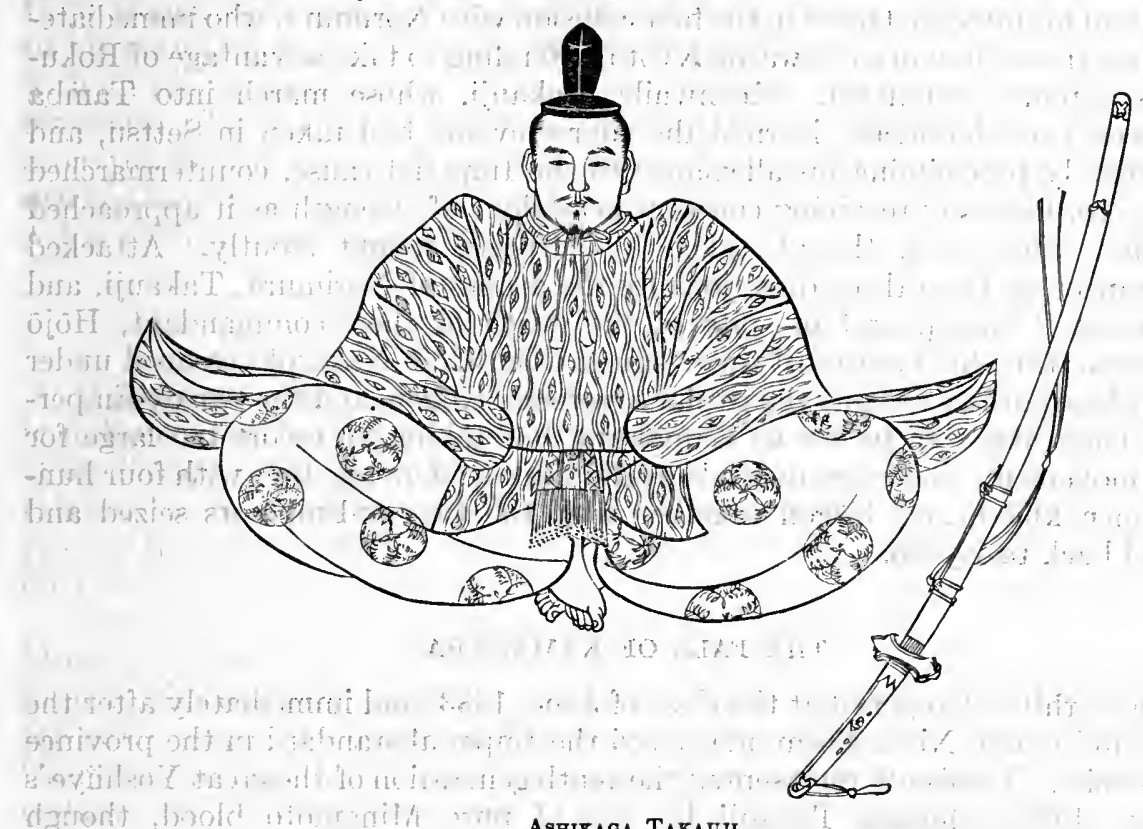

this mood, Takatoki demanded that the Ashikaga chief, before commencing his march, should hand in a written oath of loyalty, and further, should leave his wife, his children, and his brother-in-law as hostages in Kamakura. Takauji, who shrunk from no sacrifice on the altar of his ambition, complied readily, and the confidence of the Bakufu having thus been restored, a parting banquet was given in his honour, at which the Hōjō representative presented him with a steed, a suit of armour, a gold-mounted sword, and a white flag, this last being an heirloom from the time of Hachiman (Yoshiiye), transmitted through the hands of Yoritomo's spouse, Masa.

All these things did not turn Takauji by a hair's-breadth from his purpose. His army had not marched many miles westward before he despatched a message to the entrenchments in Hoki offering his services to the Emperor, who welcomed this signal accession of strength and commissioned Takauji to attack the Bakufu forces. Entirely ignorant of these things, Hōjō Takaiye, who commanded at Rokuhara, made dispositions to move against the Hōki fortress in co-operation with Takauji. The plan of campaign was that Takaiye's army should march 
southward through Settsu, and, having crushed Akamatsu Norimura, who occupied that provinee, should advance through Harima and Mimasaka into Hōki; while 'Takauji, moving northward at first by the Tamba highway, should ultimately turn westward and reach Hoki by the littoral road of the Japan Sea. In addition to these two armies, the Hojō had a powerful force engaged in beleaguering the fortress of Chihaya, in Yamato, where Kusunoki Masashige commanded in person.

It will thus be seen that, at this time (May, 1333), the Imperialists were everywhere standing on the defensive, and the Bakufu armies were attacking on the southeast, south, and north of Kyōto. Nothing seemed less probable than that the Imperial capital itself should become the object of an assault by the partisans of Go-Daigo. But the unexpected took place. HōjōTakaiye was killed and his force shattered in the first collision with Norimura, who immediately set his troops in motion towards Kyōto, intending to take advantage of Rokuhara's denuded condition. Meanwhile, Takauji, whose march into Tamba had been very deliberate, learned the course events had taken in Settsu, and immediately proclaiming his allegiance to the Imperial eause, countermarched for Kyōto, his army receiving constant accessions of strength as it approached the eity. Rokuhara, though taken by surprise, fought stoutly. Attacked simultaneously from three directions by the armies of Norimura, Takauji, and Minamoto Tadaaki, and in spite of the death of their commandant, Hōjō Tokimasu, they held out until the evening, when Hōjō Nakatoki escaped under cover of darkness, escorting the titular sovereign, Koggon,.and the two ex-Emperors. Their idea was to flee to Kamakura, but taking an escort too large for rapid movement, they were overtaken; the three leaders together with four hundred men killed, and Koggon together with the two ex-Emperors seized and carried back to Kyōto.

\section{THE FALL OF KAMAKURA}

These things happened at the close of June, 1333, and immediately after the fall of Rokuhara, Nitta Yoshisada raised the Imperial standard in the province of Kōtsuke. Yoshisada represented the tenth generation of the great Yoshiiye's family. Like Ashikaga Takauji he was of pure Minamoto blood, though Takauji belonged to a junior branch. The Nitta estates were in the district of that name in the province of Kotsuke; that is to say, in the very heart of the Kwanto. Hitherto, the whole of the eastern region had remained loyal to the Hōjō; but the people were growing weary of the heavy taxes and requisitions entailed by this three-years' struggle, and when Nitta Yoshisada declared against the Hōjō, his ranks soon swelled to formidable dimensions. It has been stated by some historians that Yoshisada's resolve was first taken on receipt of news that Rokuhara was lost to the Hōjō. But there can be no doubt that, like others of his sept, he had long resented the comparatively subordinate position occupied by Yoritomo's descendants, and the most trustworthy annals show that already while engaged in besieging Masashige in Chihaya fortress, he conceived the idea of deserting the Hōjō's eause. Through one of his officers, Funada Yoshimasa, he obtained a mandate from Prince Morinaga, and then, feigning sickness, he left the camp in Yamato and returned to Kōtsuke, where he lost no time in making preparations for revolt.

This actual declaration did not come, however, until the arrival of an officer from Kamakura, carrying a requisition for a great quantity of provisions to 
victual an army which the Hōjō were hastily equipping to recover Rokuhara. The officer was put to death, and Yoshisada with his brother, Yoshisuke, set their forces in motion for Kamakura. Menaced thus closely, the Hōjō made a supreme effort. They put into the field an army said to have numbered one hundred thousand of all arms. But their ranks were perpetually reduced by defections, whereas those of the Imperialists received constant accessions. The campaign lasted only a fortnight. For the final attack Yoshisada divided his army into three corps and advanced against Kamakura from the north, the east, and the west. The eastern column was repulsed and its general slain, but the western onset, commanded by Yoshisada himself, succeeded. Taking advantage of a low tide, he led his men over the sands and round the base of a steep cliff, 1 and carried the city by storm, setting fire to the buildings everywhere. The Hồjō troops were shattered and slaughtered relentlessly. Takatoki retreated to his ancestral cemetery at the temple Tōshō-ji, and there committed suicide with all the members of his family and some eight hundred officers and men of his army. Thus, Kamakura fell on the 5th of July, 1333, a century and a half after the establishment of the Bakufu by Yoritomo. Many heroic incidents marked the catastrophe and showed the spirit animating the bushi of that epoch. A few of them will find a fitting place here.

\section{HEROIC DEATHS}

It has been related above that, when Ashikaga Takauji marched westward from Kamakura, he left his family and his brother-in-law as hostages in the hands of the Bakufu. Subsequently, on the occasion of the assault by Nitta Yoshisada, this brother-in-law (Akabashi Moritoki) resisted stoutly but was defeated at the pass of Kobukoro. He committed suicide, remarking calmly, "It is better to die trusted than to live doubted."

Osaragi Sadanao, one of the Hōjō generals, was in danger of defeat by Ōdate Muneuji at the defence of Kamakura, when Homma Saemon, a retainer of the former, who was under arrest for an offence, broke his arrest and galloping into the field, restored the situation by killing the enemy's general, Ōdate Muneuji. Carrying the head of Muneuji, Saemon presented it to his chief and then disembowelled himself in expiation of his disobedience. Sadanao, crying that his faithful follower should not go unaccompanied to the grave, dashed into the enemy's ranks and fell, covered with wounds.

'Andō Shōshū, returning from the successful defence of the eastern approaches to Kamakura on the 5th of July, 1333, found the Government buildings a mass of charred ruins, and being ignorant of the multitude of suicides that had taken place in the cemetery at Tōshō-ji, cried out: "The end of a hundred years! How is it that none was found to die the death of fidelity?" Dismounting he prepared to take his own life when a messenger arrived carrying a letter from his niece, the wife of Nitta Yoshisada. This letter counselled surrender. Shōshū exclaimed furiously: "My niece is a samurai's daughter. How could she venture to insult me with words so shameless? "And how was it that Yoshi"sada allowed her to do such a thing?" Then, wrapping the letter round the hilt of his sword, he disembowelled himself.

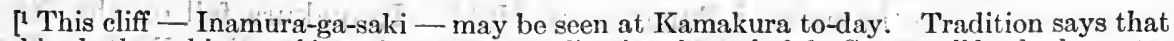
Yoshisada threw his sword into the waves, supplicating the god of the Sea to roll back the water and open a path for the loyal army. At dawn on the following day the tide was found to have receded sufficiently.] 


\section{THE LAST SCENE}

The last act of the Hōjo tragedy, which took place in the cemetery of the temple 'Tōshō-ji, showed the fidelity of the samurai character at its best. Among the Kamakura warriors was one Takashige, son of that Nagasaki Takasuke who had madc himself notorious by corrupt administration of justice. Takashige, a skilled soldier of enormous physical power, returned from the battle, when all hope of beating back Nitta Yoshisada's army had disappeared, and having warned the regent, Takatoki, that the bushi's last resource alone remained, asked for a few moments' respite to strike a final stroke. Followed by a hundred desperate men, he plunged into the thick of the fight and had almost come within reach of Yoshisada, when he was forced back. Galloping to Töshō-ji, he found Takatoki and his comrades drinking their farewell cup of sake. Takatoki handed the cup to Takashige, and he, after draining it thrice, as was the samurai's wont, passed it to Settsu Dōjun; disembowelled himself, and tore out his intestines. "That gives a fine relish to the wine," cried Dōjun, following Takashige's example. Takatoki, being of highest rank, was the last to kill himself.

Eight hundred suicides bore witness to the strength of the creed held by the Kamakura bushi. An eminent Japanese author" writes: "Yoritomo, convinced by observation and experience that the beautiful and the splendid appeal most to human nature, made it his aim to inculcate frugality, to promote military exercises, to encourage loyalty, and to dignify simplieity. Moral education he set before physical. The precepts of bushido he engraved on the heart of the nation and gave to them the honour of a precious heirloom. The Hojō, by exalting bushido, followed the invaluable teaching of the Genji, and supplemented it with the doctrines of Shintō, Confucianism, and Buddhism. Thus every bushi came to believe that the country's fate depended on the spirit of the samurai." Another and more renowned annalist ${ }^{2}$ wrote: "The Hōjō, rising from a subordinate position, flourished for nine generations. Their success was due to observing frugality, treating the people with kindness, meting out strict justice, and faithfully obeying the ancestral behest to abstain from seeking high titles." They took the substance and discarded the shadow. The bushido that they developed became a model in later ages, especially in the sixteenth century.

\section{LAST HŌJŌ ARMY}

molitas

When Kamakura fell the only Hōjo force remaining in the ficld was that which had been engaged for months in the siege of Chihaya, where Kusunoki Masashige held his own stoutly. This army had retired to Nara on receipt of the news of Rokuhara's capture, and when Kamakura met with the same fate, the leaders of the last Hōjō force surrendered at the summons of Ashikaga Takauji's emissaries. Subsequently, fifteen of these leaders were led out at midnight and behcaded.

THE RESTORATION OF THE KEMMU ERA

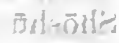

The conditions that now resulted are spoken of in Japanese history as "the Restoration of the Kemmu era" (1334-1336). It will be presently seen that the term is partly misleading. After his escape from Oki, Go-Daigo remained for some time in the fortress of Funanoe, in Hoki. Kamakura fell on the 5th of July, and his Majesty entered Kyōto on the 17th of that month. While in Hōki 
he issued various rescripts having special significance. They may be summarized as follows:

From bush $i$ down to priests, any man who performs meritorious deeds in battle will be duly recompensed, in addition to being confirmed in the possession of his previously held domain, and that possession will be continued in perpetuity to his descendants. In the case of persons killed in fight, suitable successors to their domains will be selected from their kith and kin.

With regard to Court officials and bushi down to temple priests and functionaries of Shinto shrines, any that come immediately to join the Imperial forces will be rewarded, in addition to being confirmed in the tenure of their original estates.

तr7 Similar consideration will be shown to all who, though unable to come in person, supply provisions or military necessaries, submit suggestions with loyal intent, or otherwise work in the interests of the Imperial army. Men surrendering in battle will be pardoned for their previous offences, and will be rewarded for services subsequently rendered.

The fate of the eastern outlaws (i.e. the Hōjo) being sealed, their destruction is imminent. They have slain many innocent people; plundered the property of all classes, despoiled temples, burned houses, and conducted themselves with extreme wickedness. Unless they be punished, public peace cannot be restored. Our army has to remove those evils, and therefore all in its ranks, while uniting to attack the rebels, will be careful not to inflict any suffering on the people or to plunder them and will treat them with all benevolence. If prisoners be common soldiers, they shall be released at once, and if officers, they shall be held in custody pending Imperial instructions. They shall not be punished without judgment. No buildings except the enemy's fortresses and castles shall be burned, unless the conditions of a battle dictate such a course, and it is strictly forbidden to set fire to shrines and temples. When the Imperial forces enter a city and have to be quartered in private houses, the owners of the latter shall be duly recompensed. If these injunctions be obeyed, the deities of heaven and earth and the ancestral Kami will protect the virtuous army in its assault upon the wicked traitors.

These edicts make it clear that in one most important respect, namely, the terms of land tenure, there was no idea of reverting to the old-time system which recognized the right of property to be vested in the Throne and limited the period of occupation to the sovereign's will.

\section{THE NEW GOVERNMENT}

When Go-Daigo entered Kyōto on the 17th of July, 1333, it was suggested by some of his advisers that a ceremony of coronation should be again held. But the sa-daijin, Nijō Michihira, opposed that course. He argued that although his Majesty had not resided in the capital for some time, the sacred insignia had been always in his possession; and that his re-entering the capital should be treated as returning from a journey.: This counsel was adopted. It involved the exclusion of Kogon from the roll of sovereigns, though the title of "retired Emperor" was accorded to him.

There were thus three ex-Emperors at the same time. Go-Daigo assigned the Chōkōdo estates for their support, retaining for himself only the provincial taxes of Harima. The Bakufu no longer having any official existence, the machinery of the Government in Kyoto was organized on the hypothesis of genuine administrative efficiency. There was no chancellor (dajō daijin) or any regent (kwampaku). These were dispensed with, in deference to the "Restoration" theory, namely, that the Emperor himself should rule, as he had done in the eras of Engi and Tenryaku (901-957). But for the rest, the old offices were resuscitated and filled with men who had deserved well in the recent erisis or who possessed hereditary claims. Prince Morinaga, the sometime lord-abbot of Hiei-zan, was nominated commander-in-chief (tai-shögun); and for the sake of historical lucidity hereafter the following appointments should be noted:

Prince Narinaga to be governor-general (kwanryō) of the Kwantō, with his headquarters at. Kamakura, and with Ashikaga Tadayoshi (brother of Takauji) for second in command. 
Prince Yoshinaga to be governor-general of Ō-U (Mutsu and Dewa), assisted by Kitabatake Chikafusa (an able statesman and a historian), and the latter's son, Akiiye, as well as by the renowned warrior, Yüki Munehiro.

Nijō Michihira to be sa-daijin.

Kuga Nagamichi to be u-daijin.

Dōin Kinkata to be nai-daijin.

It is observable that the occupants of all these great offices were Court nobles. The creed of the Kemmu era was that the usurping buke (military families) had been crushed and that the kuge (Court nobility) had come to their own again. As for the provinces, the main purpose kept in view by the new Govermment was to efface the traces of the shugo system. Apparently the simplest method of achieving that end would have been to appoint civilian governors (kokushi) everywhere. But in many cases civilian governors would have been powerless in the face of the conditions that had arisen under military rule, and thus the newly nominated governors included -

Ashikaga Takauji, governor of Musashi, Hitachi, and Shimōsa.

Ashikaga Tadayoshi (brother of Takauji), governor of Tōtōmi.

Kusunoki Masashige, governor of Settsu, Kawachi, and Izumi.

Nawa Nagatoshi, governor of Inaba and Hōki.

Nitta Yoshisada, governor of Kōtsuke and Harima.

Nitta Yoshiaki (son of Yoshisada), governor of Echigo.

Wakiya Yoshisuke (brother of Yoshisada), governor of Suruga.

One name left out of this list was that of Akamatsu Norimura, who had taken the leading part in driving the Hōjo from Rokuhara, and who had been faithful to the Imperial eause throughout. He now became as implacable an enemy as he had previously been a loyal friend. The fact is significant. Money as money was despised by the bushi of the Kamakura epoch. He was educated to despise it, and his nature prepared him to receive such education. But of power he was supremely ambitious - power represented by a formidable army of fully equipped followers, by fortified castles, and by widely recognized authority. The prime essential of all these things was an ample landed estate To command the allegiance of the great military families without placing them under an obligation by the grant of extensive manors would have been futile. On the other hand, to grant such manors in perpetuity meant the creation of practically independent feudal chiefs.

The trouble with the restored Government of Go-Daigo was that it halted between these two alternatives. Appreciating that its return to power had been due to the efforts of certain military magnates, it rewarded these in a measure; but imagining that its own administrative authority had been replaced on the ancient basis, it allowed itself to be guided, at the same time, by capricious favouritism. Even in recognizing the services of the military leaders, justice was not observed. The records clearly show that on the roll of merit the first place, after Prince Morinaga, should have been given to Kusunoki Masashige's name.' When Kasagi fell and when the Emperor was exiled, Masashige, alone among the feudatories of sixty provinces, continued to fight stoutly at the head of a small foree, thus setting an example of steadfast loyalty which ultimately produced many imitators. Nitta Yoshisada ought to have stood next in order; then Akamatsu Norimura; then Nawa Nagatoshi, and finally Ashikaga Takauji.: In the case of Takauji, there was comparatively little merit. He had taken up arms against the Imperial cause at the outset, and even in the assault on Roku- 
hara he had been of little serivce. Yet to him the Crown allotted the greatest honour and the richest rewards. Some excuse may be found in Takauji's lineage, but in that respect he was inferior to Nitta Yoshisada.

Still more flagrant partiality was displayed in other directions. Relying on the promises of the Funanoe edicts epitomized above, thousands of military officers thronged the Court in Kyōto, clamouring for recognition of their services. Judges were appointed to examine their pleas, but that proved a tedious task, and in the meanwhile all the best lands had been given away by favour or affection. Go-Daigo himself appropriated the manors of Höjo Takatoki; those of Hōjō Yasuie were assigned to Prince Morinaga; those of Osaragi Sadanao went to the Imperial consort, Renko. The immediate attendants of the sovereign, priests, nuns, musicians, liltérateurs - all obtained broad acres by the Imperial fiat, and when, in the tardy sequel of judicial procedure, awards were made to military men, no spoil remained to be divided. Soon a cry went up, and gained constantly in volume and vehemence, a cry for the restoration of the military régime. As for Go-Daigo, whatever ability he had shown in misfortune seemed to desert him in prosperity. He neglected his administrative duties, became luxurious and arrogant, and fell more and more under the influence of the lady Ren. Of Fujiwara lineage, this lady had shared the Emperor's exile and assisted his escape from Oki. It had long been her ambition to have her son, Tsunenaga, nominated Crown Prince, but as Prince Morinaga was older and had established a paramount title by his merits, his removal must precede the accomplishment of her purpose. Fate furnished a powerful ally. Prince Morinaga, detecting that Ashikaga Takauji concealed a treacherous purpose under a smooth demeanour, solicited the Emperor's mandate to deal with him. Go-Daigo refused, and thereafter the lady Ren and the Ashikaga chief, whose influence increased daily, entered into a league for the overthrow of Prince Morinaga.

It was at this time, when symptoms of disorder were growing more and more apparent, that Fujiwara Fujifusa, a high dignitary of the Court and one of the great statesmen of his era, addressed a solemn warning to Go-Daigo. The immediate occasion was curious. "There had been presented to the Court by the governor of Izumo a horse of extraordinary endurance, capable of travelling from Tomita, in that province, to Kyōto, a distance of one hundred and sixty miles, between dawn and darkness. The courtiers welcomed the appearance of this horse as an omen of peace and prosperity, but Fujiwara Fujifusa interpreted it as indicating that occasion to solicit speedy aid from remote provinces would soon arise. He plainly told the Emperor that the officials were steeped in debauchery; that whereas, in the early days of the restoration, the palace gates had been thronged with warriors, to-day'none could be seen, thousands upon thousands having left the capital disgusted and indignant to see Court favourites enriched with the rewards which should have fallen to the military; that the already distressed people were subjected to further heavy exactions for building or beautifying Imperial palaces; that grave injustice had been done to Akamatsu Norimura, and that unless the sovereign refrained from self-indulgence and sought to govern benevolently, a catastrophe could not be averted. But Go-Daigo was not moved, and finally, after repeating his admonition on several occasions, Fujifusa left the Court and took the tonsure. It says much for the nobility of the Emperor's disposition that he commissioned Nobufusa, father of Fujifusa, to seek out the persistent critic and offer him a greatly higher office if he would consent to return, and it says much for Fujifusa's sincerity that, 
hoping to give weight to his counsels, he embraced the life of a recluse and was never seen in public again.

\section{DEATH OF PRINCE MORINAGA}

Things now went from bad to worse in Kyoto, while in the provinces the remnants of the Hōjō's partisans began to raise their heads. The ever-loyal Kusunoki Masashige and Nawa Nagatoshi entered the capital to sccure it against surprise; Ashikaga Takauji, ostensibly for the same purpose, summoned large forces from the provinces, and Prince Morinaga occupied Nawa with a strong army. Takauji saw that the time had come to remove the prince, in whom he recognized the great obstacle to the consummation of his ambitious designs. Securing the co-operation of the lady Ren by a promise that her son, Narinaga, should be named Crown Prince and commander-in-chief (shōgun) in succession to Morinaga, he informed the Emperor that Prince Morinaga was plotting Go-Daigo's deposition and the elevation of his own son to the throne. The Emperor credited the accusation, summoned the usurping Morinaga to the palace, and caused him to be arrested. This happened in November, 1334. Morinaga vehemently declared his innocence. In a memorial to the Throne he recounted the loyal service he had rendered to his sovereign and father, and concluded with these words:-

In spite of all this I have unwittingly offended. I would appeal to heaven, but the sun and moon have no favour for an unfilial son. I would bow my head and cry to the earth for help, but the mountains and the rivers do not harbour a disloyal subject. The tie between father and son is severed, and I am cast away. I have no longer anything to hope in the world: If I may be pardoned, stripped of my rank, and permitted to enter religion, there will be no cause for regret. In my deep sorrow I cannot say more.

Had this piteous appeal reached Go-Daigo, he might have relented But just as the memorial addressed by Yoshitsune to his brother, Yoritomo, was suppressed by Hiromoto, so the chamberlain to whom Prince Morinaga entrusted his protest feared to carry it to the sovereign. Before the close of the year, the prince was exiled to Kamakura, and there placed in charge of Takauji's brother, Tadayoshi, who confined him in a cave dug for the purpose. He never emerged alive. Seven months later, Tadayoshi, on the eve of evacuating Kamakura before the attack of Hōjō Tokiyuki, sent an emissary to assassinate Morinaga in the cave: The unfortunate prince was in his twenty-eighth year. His name must be added to the long list of noble men who fell victims to slander in Japan. A Japanese annalist ${ }^{1}$ contends that Morinaga owed his fate as much to his own tactlessness as to the wiles of his enemies, and claims that in accusing Takauji to the throne, the prince forgot the Emperor's helplessness against such a military magnate as the Ashikaga chief. However that may have been, subsequent events clearly justified the prince's suspicions of Takauji's disloyalty. It must also be concluded that Go-Daigo deliberately contemplated his son's death when he placed him in charge of Takauji's brother.

\section{ASHIKAGA TAKAUJI OCCUPIES KAMAKURA}

The course of events has been somewhat anticipated above in order to relate the end of Prince Morinaga's eareer. It is necessary, now, to revert to the incident which precipitated his fate, namely, the capture of Kamakura by Hōjō Tokiyuki. This Tokiyuki was a son of Takatoki. He escaped to Shinano 
province at the time of the Hōjo downfall, and being joined there by many of his family's vassals, he found himself strong enough to take the field openly' in July, 1335, and sweeping away all opposition; he entered Kamakura in August. Ashikaga Takauji's brother was then in command at Kamakura. It seemed, indeed, as though the Emperor deliberately contemplated the restoration of the old administrative machinery in the Kwantō, changing only the personnel; for his Majesty appointed his tenth son, Prince Narinaga, a boy of ten, to be shōgun at Kamakura, and placed Ashikaga Tadayoshi in a position amounting, in fact though not in name, to that of regent (shikken). Probably these measures were merely intended to placate the Kwanto." Before there had been time to test their efficacy, the Hōjō swept down on Kamakura, and Tadayoshi and the young shōgun found themselves fugitives. Meanwhile, Ashikaga Takauji in Kyōto had been secretly fanning the discontent of the unrecompensed bushi, and had assured himself that a reversion to the military system would be widely welcomed. He now applied for a commission to quell the Hōjō insurrection, and on the eve of setting out for that purpose, he asked to be nominated shögun, which request being rejected, he left the capital without paying final respects to the Throne, an omission astutely calculated to attract partisans.

The Hōjō's resistance was feëble, and in a few weeks the Ashikaga banners were waving again over Kamakura. The question of returning to Kyōto had now to be considered. 'Takauji's brother, Tadayoshi, strongly opposed such a step. He compared it to putting one's head into a tiger's mouth, and in fact information had already reached Kamakura in the sense that the enemies of the Ashikaga were busily slandering the victorious general. It may fairly be assumed, however, that Takauji had never intended to return to Kyōto except as dictator. He assumed the title of shogun; established his mansion on the site of Yoritomo's old yashiki; undertook control of the whole Kwantö; confiscated manors of his enemies; recompensed meritorious deeds liberally, and granted pardons readily. In fact, he presented to public gaze precisely the figure he desired to present, the strong ruler who would unravel the perplexities of a distraught age. From all quarters the malcontent bushi flocked to his flag.

\section{TAKAUJI AND YOSHISADA}

A serious obstacle to the achievement of the Ashikaga chief's purpose was Nitta Yoshisada. Both men were of the Minamoto family, but Yoshisada's kinship was the closer and his connexion with the Hōjō had always been less intimate. Further, he had never borne arms against Go-Daigo's cause, as Takauji had done, and his unswerving loyalty made him an inconvenient rival. Therefore, the Ashikaga leader took an extreme step. He seized the domains of the Nitta family in the Kwanto and distributed them among his own followers; he caused his brother, Tadayoshi, to send letters inviting the adherence of many bushi; he addressed to the Throne a memorial impeaching Yoshisada on the ground that, whereas the latter's military successes had been the outcome entirely of opportunities furnished by the prowess of the Ashikaga, he did not hesitate to slander Takauji to the sovereign, and he asked for an Imperial commission to destroy the Nitta leader, whom he dubbed a "national thief."

Yoshisada, when he learned of the presentation of this memorial, seized the Ashikaga manors within his jurisdiction and addressed to the Throne a countermemorial in which he conclusively proved the falsehood of Takauji's assertion with reference to military affairs; charged him with usurping the titles of 
governor-general of the Kiwantō, and shōgun; declared that Prince Morinaga, the mainstay of the restoration, had become the victim of Takauji's slanders, and asked for an Imperial mandate to punish Takauji and his brother, Tadayoshi. It is significant that the leal and gallant Yoshisada did not hesitate thus openly to assert the innocence and merits of Prince Morinaga, though only a few months had elapsed since the Emperor himself had credited his most unhappy son's guilt. While Go-Daigo hesitated, news from various provinces: disclosed the fact that Takauji had been tampering with the bushi in his own interests. This settled the question. Takauji and Tadayoshi were proclaimed rebels, and to Nitta Yoshisada was entrusted the task of chastising them under the nominal leadership of Prince Takanaga, the Emperor's second son, to whom the title of shögun was granted.

\section{TAKAUJI ENTERS KYŌTO}

In the beginning of November, 1335, the Imperial force moved eastward. It was divided into two armies. One, under Yoshisada's direct orders, marched by the Tokaidō, or eastern littoral road; the other, under Yoshisada's brother, Wakiya Yoshisuke, with Prince Takanaga for titular general, advanced along the Nakasen-dō, or inland mountain-road. The littoral army, carrying everything before it, pushed on to the capital of Izu, and had it forced its attack home at once, might have captured Kamakura. But the Nitta chief decided to await the arrival of the Nakasen-do army, and the respite thus, afforded enabled the Ashikaga forces to rally. Tadayoshi reached the Hakone Pass and posted his troops on its western slopes in a position of immense natural vantage, while Takauji himself occupied the routes on the north, his van being at Takenoshita.

The Imperialists attacked both positions simultaneously. Takauji not only held his ground, but also, being joined by a large contingent of the Kyoto men who, under the leadership of Enya Takasada, had deserted in the thick of the fight, he shattered his opponents, and when this news reached Hakone on the following morning, a panic seized Yoshisada's troops so that they either fled or surrendered. The Nitta chieftain himself retired rapidly to Kyōto with a mere remnant of his army, and effected a union with the forces of the ever-loyal Kusunoki Masashige and Nawa Nagatoshi, who had given asylum to Go-Daigo at the time of the escape from Oki. The cenobites of Hiei-zan also took the field in the Imperial eause. Meanwhile, Takauji and Tadayoshi, utilizing their vietories, pushed rapidly towards Kyôto. The heart of the samurai was with them, and they constantly received large accessions of strength. Fierce fighting now took place on the south and east of the capital. It lasted for several days and, though the advantage was with the Ashikaga, their victory was not decisive.

An unlooked-for event turned the scale. It has been related above that, in the struggle which ended in the restoration of Go-Daigo, Akamatsu Norimura was chiefly instrumental in driving the Hojo from Rokuhara; and it has also been related that, in the subsequent distribution of rewards, his name was omitted for the slight reason that he had, at one period, entered religion. He now moved up from Harima at the head of a strong force and, attacking from the south, effected an entry into Kyōto, just as he had done three years previously. Go-Daigo fled to Hiei, carrying the sacred insignia with him, and on the 24th of February, 1336, the Ashikaga armies marched into the Imperial capital. 


\section{TAKAUJI RETIRES TO KY ŪSHU}

At this stage succour arrived for the Imperialists from the extreme north. In the arrangement of the local administration after Go-Daigo re-occupied the throne, the two northern provinces of Mutsu and Dewa had been separated from the Kwantō and placed under the control of Prince Yoshinaga, with Kitabatake Akiiye for lieutenant. The latter, a son of the renowned Chikafusa, was in his nineteenth year when the Ashikaga revolted. He quickly organized a powerful army with the intention of joining Yoshisada's attack upon Kamakura, but not being in time to carry out that programme, he changed the direction of his march and hastened towards Kyotto. He arrived there when the Ashikaga troops were laying siege to Hiei-zan, and effecting a union with the Imperialists, he succeeded in raising the siege and recovering the city.

- It is unnecessary to follow in detail the vicissitudes that ensued. Stratagems were frequent. At one time we find a number of Yoshisada's men; officers and privates alike, disguising themselves, mingling with the Ashikaga army, and turning their arms against the latter at a critical moment. At another, Kusunoki Masashige spreads a rumour of Yoshisada's death in battle, and having thus induced Takauji to detach large forces in pursuit of the deceased's troops, falls on him, and drives him to Hyōgo, where, after a heavy defeat, he has to flee to Bingo. Now, for a second time, the Ashikaga cause seemed hopeless when Akamatsu Norimura again played a most important rôle. He provided an asylum for Takauji and Tadayoshi; counselled them to go to the west for the purpose of mustering and equipping their numerous partisans; advised them to obtain secretly a mandate from the senior branch of the Imperial family so that they too, as well as their opponents, might be entitled to fly the brocade banner, and having furnished them with means to effect their escape, returned to Harima and occupied the fortress of Shirahata with the object of checking pursuit. At this point there is a break in the unrelenting continuity of the operations. It should obviously have been the aim of the Imperialists to strike a conclusive blow before the Ashikaga leaders had time to assemble and organize their multitudinous supporters in Shikoku, Kyūshü, and the provinces on the north of the Inland Sea. This must have been fully apparent to Kusunoki Masashige, an able strategist. 'Yet a delay of some weeks occurred.

A quasi-historical record, the Taiheiki, ascribes this to Yoshinaga's infatuated reluctance to quit the company of a Court beauty whom the Emperor had bestowed on him. Probably the truth is that the Imperialists were seriously in want of rest and that Yoshisada fell ill with fever. Something must also be attributed to a clever ruse on the part of Akamatsu Norimura. He sent to Yoshisảda's headquarters a message promising to give his support to the Imperialists if he was appointed high constable of Harima. Ten days were needed to obtain the commission from Kyōto, and Norimura utilized the interval to place the defenses of Shirahata fortress in a thoroughly secure condition. Thus, when his patent of high constable arrived, he rejected it with disdain, saying that he had already received a patent from the shogun, Takauji, and was in no need of an Imperial grant which "could be altered as easily as turning one's hand:"

To Yoshisada, enraged at having been duped, laid siege to Shirahata but found it almost invulnérable. It was on March 11, 1336, that Takauji went westward from Bingo; it, was on the 2nd of April that Yoshisada invested Shirahata, and it was on the 3 rd of July that the siege was raised The Ashikaga brothers had 
enjoyed a respite of more than three months, and had utilized it vigorously. They were at the Dazai-fu in Chikuzen in June when a message reached them that Shirahata could not hold out much longer. Immediately they set their forees in motion, advancing by land and water with an army said to have numbered twenty thousand and a fleet of transports and war-junks totalling seven thousand. At the island, Itsukushima, they were met by a Buddhist priest, Kenshun, bearer of a mandate signed by the ex-Emperor Kögon of the senior branch, and thus, in his final advance, the Ashikaga chief was able to fly the brocade banner. In the face of this formidable force the Imperialists fell back to Hyōgo - the present Kōbe - and it became necessary to determine a line of strategy.

\section{DEATH OF MASASHIGE}

Go-Daigo, in Kyōto, summoned Kusunoki Masashige to a conference. That able general spoke in definite tones. He declared it hopeless for the Imperialists

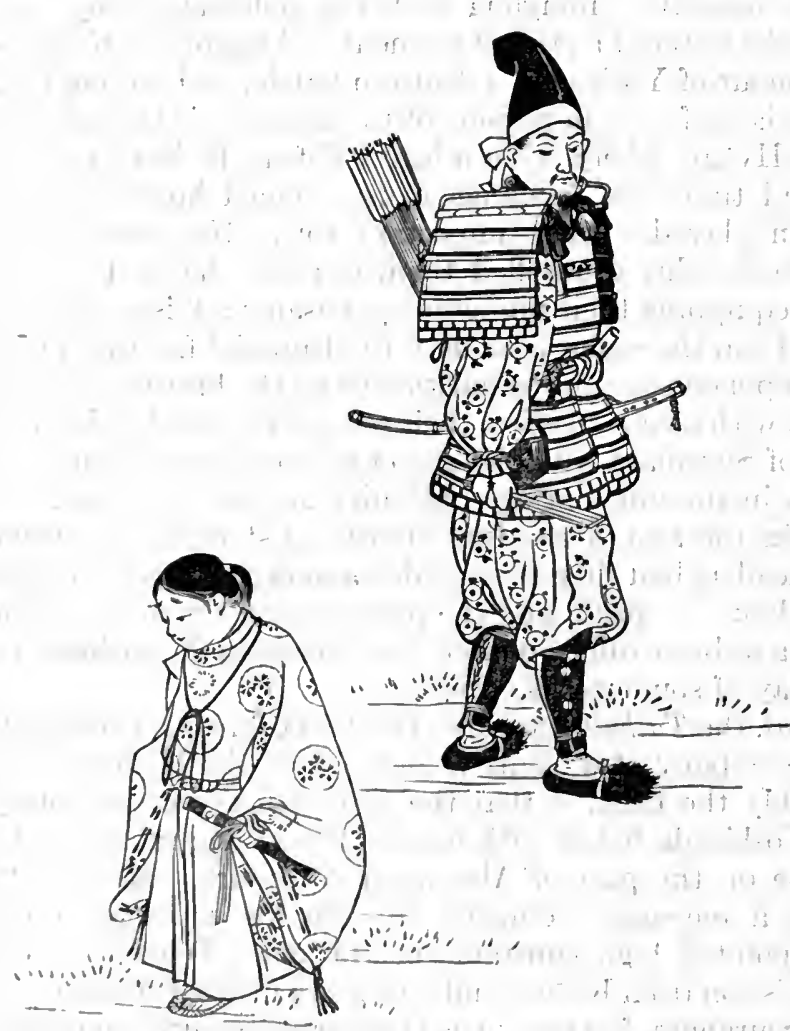

The Parting of Kogunoki Masabhige and his Son Masatguga with their comparatively petty force of worn-out warriors to make head against the great Ashikaga host of fresh fighters. The only wise course was to suffer the enemy: to enter Kyōto; and then, while the sovereign took refuge at Hiei-zan, to muster his Majesty's partisans in the home provinces for an uncéasing war upon the Ashikaga's long line of commúnications - a war culminating in an attack from the front and the rear simultaneously. Thus; out of temporary defeat, final victory would be wrested.

All present at the conference, with one exception, endorsed Masashige's view as that of a proved strategist.' The exception was a councillor, Fujiwara Kiyotada? He showed himself a veritable example of "those whom the gods wish to destroy." Declaring that all previous successes had been achieved by divine aid, which took no count of numerical disparity, he urged that if the sovereign quitted the capital before his troops had struck a blow, officers and men alike would be disheartened; and if refuge was again taken at Hiei-zan, the Imperial prestige would suffer. To these light words the Emperor hearkened. Masashige uttered no remon- 
strance. The time for controversy had passed. He hastened to the camp and bid farewell to his son, Masatsura: "I do not think that I shall see you again in life. If I fall to-day, the country will pass under the sway of the Ashikaga. It will be for you to judge in which direction your real welfare lies. Do not sully your father's loyalty by forgetting the right and remembering only the expedient. So long as a single member of our family remains alive, or so much as one of our rétainers, you will defend the old castle of Kongō-zan and give your life for your native land."

He then handed to his son a sword which he himself had received from the Emperor. Passing thence to Hyōgo, Masashige joined Nitta Yoshisada, and the two leaders devoted the night to a farewell banquet. The issue of the next? day's combat was a foregone conclusion. . Masashige had but seven hundred men under his command. He posted this little band at Minato-gawa, near the modern Kōbe, and with desperate courage attacked the van of the Ashikaga army. Gradually he was enveloped, and being wounded in ten places he, with his brother and sixty followers, entered the precincts of a temple and dicd by their own hands. ${ }^{1}$ Takauji and his captains, lamenting the brave bushi's death, sent his head to his family; and history recognizes that his example exercised an ennobling influence not only on the men of his era but also on subsequent generations. After Masashige's fall a similar fate must have overtaken Yoshisada, had not one of those sacrifices familiar on a Japanese field of battle been made for his sake. Oyamada Takaiye gave his horse to the Nitta general and fell fighting in his stead, while Yoshisada rode away. At first sight these sacrifices seem to debase the saved as much as they exalt the saver. But, according to Japanese ethics, an institution was always more precious than the person of its representative, and a principle than the life of its exponent. Men sacrificed themselves in battle not so much to save the life of a commanding officer, as to avert the loss his cause would suffer by his death. Parity of reasoning dictated acceptance of the sacrifice.

$\left[{ }^{1}\right.$ Kusunoki Masashige is the Japanese type of a loyal and true soldier. He was forty-three at the time of his death. Three hundred and fifty-six years later (1692), Minamoto Mitsukuni, feudal chief of Mito, caused a monument to be erected to his memory at the place of his last fight. It bore the simple epitaph "The Tomb of Kusunoki, a loyal subject."]

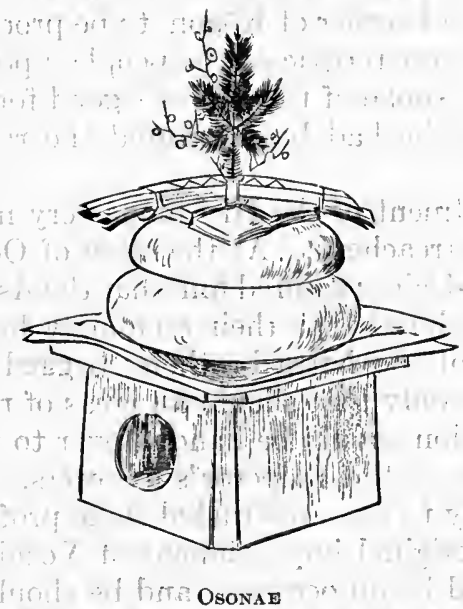




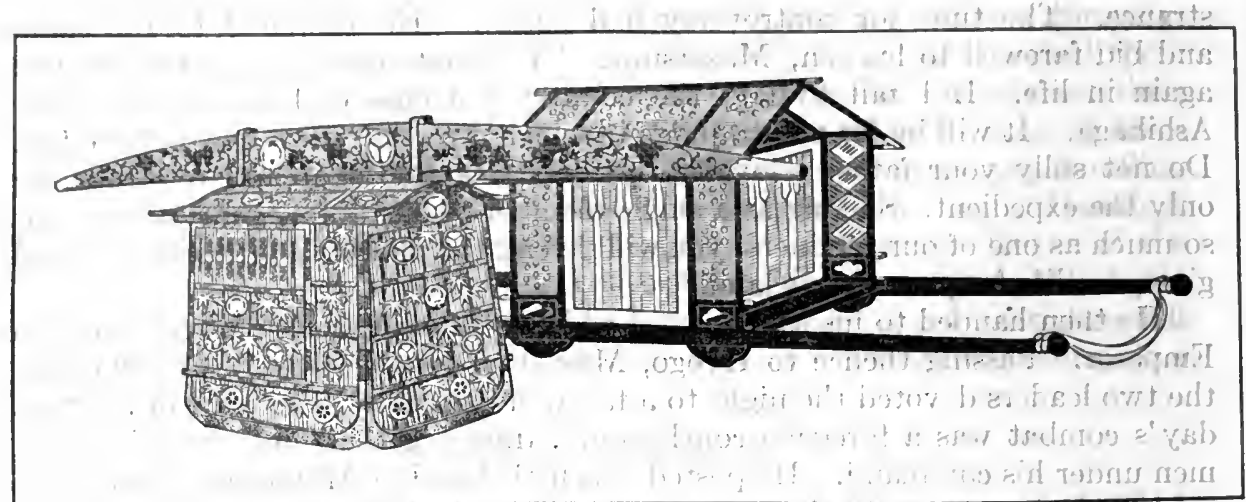

Palanguing

(U'sed in Old Japan Only by the Nobility)

\section{CHAPTER XXX}

\section{THE WAR OF THE DYNASTIES}

\section{OCCUPATION OF KYŌTO BY ASHIKAGA}

In July, 1336, Takauji entered Kyōto and established his headquarters at the temple Higashi-dera. Go-Daigo had previously taken refuge at the Hiei-zan monastery, the ex-Emperors, Hanazono and Kogon, remaining in the capital where they looked for the restoration of their branch of the Imperial family. The Ashikaga leader lost no time in despatching a force to attack Hiei-zan, but the Imperialists, supported by the cenobites, resisted stoutly, and no impression was made on the defences for a considerable time. In one of the engagements, however, Nawa Nagatoshi, who had harboured Go-Daigo after the flight ifrom Oki, met his death, and the Imperialist forces gradually dwindled. Towards the close of August, Takauji caused Prince Yutahito (or Toyohito, according to some authorities), younger brother of Kōgon, to be proclaimed Emperor, and he is known as Kōmyō. Characteristic of the people's political ignorance at that time is the fact that men spoke of the prince's good fortune since, without any special merit of his own, he had been granted the rank of sovereign by the shōgun.

Meanwhile, the investment of the Hiei monastery made little progress, and Takauji had recourse to treachery. At the close of October he opened secret communications with Go-Daigo; assured him that the Ashikaga did not entertain any disloyal purpose; declared that their seemingly hostile attitude had been inspired by the enmity of the Nitta brothers; begged Go-Daigo to return to Kyoto, and promised not only that should all ideas of revenge be foregone, but also that the administration should be handed over to the Court, and all their ranks and estates restored to the Emperor's followers.

Go-Daigo ought surely to have distrusted these professions. He must have learned from Takauji's original impeachment of Yoshisada how unscrupulous the Ashikaga leader could be on occasion, and he should have well understood the impossibility of peace between these two men." "Yet his Majesty relied on 
Takauji's assurances. It was in vain that Horiguchi Sadamitsu recounted Yoshisada's services, detailed the immense sacrifices he had made in the Imperial cause, and declared that if the Emperor were determined to place himself in Takauji's hands, he should prepare his departure from Hiei-zan by summoning to his presence Yoshisada with the other Nitta leaders and sentencing them to death. Go-Daigo was not to be moved from his purpose. He gave Yoshisada fair words indeed: "I profoundly praise your loyal services. $\mathrm{My}$ wish is to pacify the country by the assistance of your family, but heaven has not yet vouchsafed its aid. Our troops are worn out and the hour is unpropitious. Therefore, I make peace for the moment and bide my time: Do you repair to Echizen and use your best endeavours to promote the cause of the restoration. Lest you be called a rebel after my return to Kyōto, I order the Crown Prince. tolaccompany you."'s

Thus /Go-Daigo, truly faithful neither to the one side nor to the other, set out for the capital. That night, Yoshisada prayed at the shrine of Hiyoshi: "Look down on my loyalty and help me to perform my journey safely so that I may raise an army to destroy the insurgents. If that is not to be, let one of my descendants achieve my aim." Two hundred and six years later, there was born in Mikawa of the stock of Yoshisada one of the greatest generals and altogether the greatest ruler that Japan has ever produced, Minamoto Ieyasu. Heaven answered Yoshisada's prayer tardily but signally.

sitt endisis on to

Jushngroluit

\section{TAKAUJI'S FAITH}

Not one of Takauji's promises did he respect. He imprisoned Go-Daigo; he stripped all the courtiers of their ranks and titles; he placed in confinement all the generals and officers of the Imperial forces, and he ordered the transfer of the insignia to the sovereign of his own nomination, Kōmyō:? Tradition has it that Go-Daigo, victim of so many treacheries, practised one successful deception himself: he reserved the original of the sacred sword and seal and handed counterfeits to Kōmyō. This took place on November 12,1336. Some two months later, January 23, 1337, Go-Daigo, disguised as a woman for the second time in his career, fled from his place of detention through a broken fence, and reached Yoshino in Yamato, where he was received by Masatsura, son of Kusunoki Masashige, and by Kitabatake Chikafusa.

Yoshino now became the rendez-vous of Imperialists from the home provinces, and Go-Daigo sent a rescript to Yoshisada in Echizen, authorizing him to work for the restoration.

Thus commenced the War of the Dynasties, known in history as the Conflict of the Northern and Southern Courts, terms borrowed from the fact that Yoshino, where Go-Daigo had his headquarters, lay to the south of Kyōto. Hereafter, then, the junior branch of the Imperial Family will be designated the Southern Court and the senior branch will be spoken of as the Northern Court.

The struggle lasted from 1337 to 1392, a period of fifty-five years. Much has been written and said about the relative legitimacy of the two Courts. It does not appear that there is any substantial material for doubt. Go-Daigo neyer abdicated voluntarily; or ever surrendered the regalia. Before his time many occupants of the throne had stepped down at the suggestion of a Fujiwara or a Hōjō. But always the semblance of free-will had been preserved. Moreover, the transfer of the true regalia constituted the very essence of legitimate succession. But these remained always in Go-Daigo's possession. Therefore, 
although in the matter of lineage no distinction could be justly set up between the Northern and the Southern Courts, the collaterals of legitimacy were all with the latter.

Of course each complied with all the forms of Imperialism. Thus, whereas the Southern Court used the year-name Engen for 1336-1339, the North kept the year-name $K e m m u$ for two years, and as there were different nerigo names for half a century, a new element of confusion was added to the already perplexing chronology of Japan. In administrative methods there was a difference. The Northern Court adhered to the camera system: that is to say, the actual occupant of the throne was a mere figurehead, the praetical functions of Government being discharged by the cloistered sovereign. In the Southern Court the Emperor himself, nominally at all events, directed the business of administration. Further, the office of shogun in the Southern Court was held generally: by an Imperial Prince, whereas in the Northern Court its holder was an Ashikaga. In brief, the supporters of the Northern Court followed the military polity of the Bakufu while the Southern adopted Imperialism.

\section{NATURE OF THE WAR}

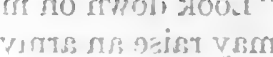

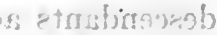

As the question at issue lay solely between two claimants to the succession, readers of history naturally expect to find the war resolve itself into a campaign, or a succession of campaigns, between two armies. Such was by no means the case. Virtually the whole empire was drawn into the turmoil, and independent fighting went on at several places simultaneously. The two Courts perpetually made Kyöto their objective. Regardless of its strategical disadvantages; they deemed its possession cardinal. Takauji had been more highly lauded and more generously rewarded than Yoshisada, because the former had recovered Kyōto whereas the latter had only destroyed Kamakura. Thus, while Go-Daigo constantly struggled to eapture Kyōto, Kōmyō's absorbing aim was to retáin it.

This obsession in favour of the Imperial metropolis left its mark upon many campaigns; as when, in the spring operations of 1336 , Yoshisada, instead of being allowed to pursue and annihilate Takauji, was recalled to guard Kyoto; and when, in July of the same year, Kusunoki Masashige was sent to his death rather than temporarily vacate the capital. It must have been fully apparent to the great captains of the fourteenth century that Kyoto was easy to take and hard to hold. Lake Biwa and the river Yodo are natural bulwarks of Yamato, not of Yamashiro. Hiei-zan looks down on the lake, and Kyōto lies on the great plain at the foot of the hill. If, during thirteen generations, the Ashikaga family struggled for Kyōto, they maintained, the while, their ultimate base and rallying-place at Kamakura, and thus, even when shattered in the west, they could recuperate in the east. The Southern Court had no such depot and recruiting-ground. They had, indeed, a tolerable place of arms in the province of Kawachi, but in the end they succumbed to topographical disadvantages. ${ }^{\prime}$ )

\section{DEATHS OF YOSHISADA AND AKIIYE}

In the fact that he possessed a number of sons, Go-Daigo had an advantage over his fourteen-year-old rival, Kōmyō, for these Imperial princes were sent out to various districts to stimulate the loyal efforts of local bushi. With Yoshisada to Echizen went the Crown Prince and his brother Takanaga. They entrenched themselves at Kana-ga-saki, on the seacoast, whence Yoshisada's 
eldest son; Yoshiaki, was despatched to Echigo to collect troops, and a younger brother, YYoshisuke, to Soma-yama on a similar errand. Almost immediately, Ashikaga Takatsune with an army of twenty thousand men laid siege to Kanaga-saki. But Yoshiaki and Yoshisuke turned in their tracks and delivered a rear attack which scattered the besiegers. This success; however, proved only temporary. The Ashikaga leader's deep resentment against Yoshisada inspired a supreme effort to crush him, and the Kana-ga-saki fortress was soon invested by an overwhelming force on sea and on shore. . Famine necessitated surrender. Yoshiaki and Prince Takanaga committed suicide, the latter following the former's example and using his blood-stained sword. The Crown Prince was made prisoner and subsequently poisoned by Takauji's orders. Yoshisada and his brother Yoshisuke escaped to Soma-yama and rallied their partisans to the number of three thousand.

grt The fall of Kana-ga-saki occurred in April; 1338, and, two months later, Go-Daigo took the very: exceptional course of sending an autograph letter to Yoshisadais The events which prompted his Majesty were of prime moment to the cause of the Southern Court. Kitabatake Akiiye, the youthful governor of Mutsu and son of the celebrated Chikafusa, marched southward at the close of 1337, his daring project being the capture, first, of Kamakura, and next, of Kyōtō The nature of this gallant enterprise may be appreciated by observing that Mutsu lies at the extreme north of the main island, is distant some five hundred miles from Kyōto, and is separated from the latter by several regions hostile to the cause which Akiiye represented. Nevertheless, the brilliant captain, then in his twenty-first year, seized Kamakura in January, 1338, and marched thence in February for Yoshino. He gained three victories on the way, and had nearly reached his objective when, at Ishizu, he encountered a great army of Ashikaga troops under an able leader, Kō no Moronao, and after a fierce engagement the Southern forces were shattered, Akiiye himself falling in the fight. This disaster occurred on June 11, 1338. A brave rally was made by Akiiye's younger brother, Akinobu. He gathered the remnants of the Mutsu army and occupied Otokoyama, which commands Kyōto.

It was at this stage of the campaign that Go-Daigo resorted to the exceptional measure of sending an autograph letter to Yoshisada, then entrenched at Somayama, in Echizen. His Majesty conjured the Nitta leader to march to the assistance of Akinobu at Otoko-yama. Yoshisada responded at once. He despatched his brother, Yoshisuke, with twenty thousand men, remaining himself to cover the rear of the expedition. But Otoko-yama surrendered before this succour reached it, and the Nitta brothers then combined their forces to operate against the Ashikaga. Nothing decisive resulted, and in September, 1338, Yoshisada fell in an insignificant combat near the fortress of Fujishima in Echizen. He caused a comrade to behead him and carry off the head, but the enemy identified him by means of the Imperial letter found on his person.

Yoshisada was only thirty-eight at the time of his death (September, 1338). Rai Sanyo (1780-1832), the great Japanese historian, says: "I saw a letter written by Yoshisada with his own hand for the purpose of admonishing the members of his family. In it he wrote: "An officer in command of an army should respect the sovereign; treat his subordinates with clemency: but decision; leave his fate in heaven's hands, and not blame others.' Yoshisada is open to criticism for not pursuing the Ashikaga when they fled westward from Kyōto; yet it must be remembered that he had no firm base, being hurried from one quarter to another. : The strategy he used was not his own free choice nor were 
the battles he fought contrived by himself. But his devotion to the Imperial, cause, his unfailing loyalty, and his indifference to self-interest have kept his: memory fresh and will always keep it fresh. If, two hundred years after his death, a chieftain was born of his blood to carry the Minamoto name to the pinnacle of glory, who shall say that heaven did not thus answer the prayer put up by Yoshisada at the shrine of Hiyoshi?"

\section{DEATH OF GO-DAIGO}

During these events, Go-Daigo sojourned at Yoshino, which was protected by Kusunoki Masatsura, Wada Masatomo, and others. At the close of August, 1339, his Majesty falling ill, and feeling that his end was near, resigned the throne to his twelve-year-old son, the Crown Prince Yoshinaga; whose historical name is Go-Murakami. Go-Daigo's will declared that his only regret in leaving the world was his failure to effect the restoration, and that though his body was buried at Yoshino, his spirit would always yearn for Kyōto. Tradition says that he expired holding a sword in his right hand, the Hokke-kyō-sutra in his left, and that Kitabatake Chikafusa spoke of the event as a dream within a dream.

It is recorded to Ashikaga Takauji's credit that, when the news reached Kyōto, he ordered five days' mourning; that he himself undertook to transcribe a sacred volume by way of supplieation for the repose of Go-Daigo's spirit, and that he caused a temple to be built for the same purpose. Of course, these events cast a cloud over the fortunes of the Southern Court, but its adherents did not abate their activities. Everywhere they mustered in greater or less force. The clearest conception of their strength may be obtained by tabulating the names of their families and of the latter's localities:- -

\section{FAMILIES}

Kitabatake

Nitta

Kusunoki

Kojima, Sakurayama, Arii, and Yoshikawa

Nawa and Misumi

Kikuchi, Matsura, and Kusano

Doi, Tokunō, Yuasa, and Yamamoto

Ii

Neo

Shintō officials

\section{Provinces}

Mutsu and Ise

Musashi, Shimotsuke, Echizen

Kawachi

Sanyō-dō

Sanin-dō

Saikai-dō

Nankai-dō

Tōtōmi

Mino

Atsuta

This table suggests that partisans of the Southern Court existed in almost, every part of the empire. So; in truth, they did. But friends of the Northern Court existed also, and thus it resulted that at no time throughout the fifty-five years of the struggle were the provinces free from strife. It resulted also that frequent changes of allegiance took place, for a family had often to choose between total ruin, on the one hand, and comparative prosperity at the sacrifice of eonstancy, on the other. Some historians have adduced the incidents of this cra as illustrating the shallowness of Japanese loyalty. But it can scarcely be said that loyalty was ever seriously at stake. In point of legitimacy there was nothing to choose between the rival branches of the Imperial family. A samurai 
might pass from the service of the one to that of the other without doing any violence to his reverence for the Throne.

What was certainly born of the troubled era, however, was a sentiment of contempt for central authority and a disposition to rely on one's own right arm. It could not have been otherwise. In several provinces official nominees of both Courts administered simultaneously, and men were requisitioned for aid, to-day, to the Northern cause, to-morrow, to the Southern. . To be strong enough to resist one or the other was the only way to avoid ruinous exactions. From that to asserting one's strength at the expense of a neighbour who followed a different flag was a short step, if not a duty, and thus purely selfish considerations dictated a fierce quarrel and inspired many an act of unscrupulous spoliation. A few cases are on record of families which resorted to the device of dividing themselves into two branches, each declaring for a different cause and each warring nominally: with the other. Thus the sept as a whole preserved its possessions, in part at any rate, whichever Court triumphed. But such double-faced schemes were very rare. A much commoner outcome of the situation was the growth of powerful families which regulated their affairs by means of a council of leading members without reference to Kamakura, Kyōto, or Yoshino. At the same time, minor septs in the neighbourhood saw the advantage of subscribing to the decisions of these councils and deferring to their judgments.

"This was an important step in the development of the feudal system. Another was the abolition of feudal fiefs, as well as of the succession of women to real estate, and a curtailment of the inheritance, not so much of younger sons, as of all sons except the one selected as lord of the clan."' The shugo (high constables) also became a salient element of feudalism. : Originally liable to frequent transfers of locality, some of them subsequently came to hold their office hereditarily, and these, together with the great majority of their confrères who had been appointed by the Bakufu, espoused the Ashikaga cause; a choice which impelled many of the military families in their jurisdiction to declare for the Southern Court. The Ashikaga shugo ultimately became leading magnates, for they wielded twofold authority, namely, that derived from their power as owners of broad estates, and that derived from their commission as shōgun's delégates entitled to levy taxes locally. The provincial governors, at the outset purély civil officials, occasionally developed military capacity and rivalled the hereditary: shugo in armed influence, but such instances were rare.

\section{THE COURSE OF THE WAR}

After the death of Kusunoki Masashige, of Nitta Yoshisada, and of Kitabatake Akiiye, the strategical direction of the war devolved mainly upon Kitabatake Chikafusa, so far as the Southern Court was concerned. The greater part of the nation may be said to have been in arms, but only a small section took actual part in the main campaign, the troops in the distant provinces being occupied with local struggles. Chikafusa's general plan was to menace Kyōto and Kamakura simultaneously. "Just as the eight provinces of the Kwanto formed the base of the Ashikaga armies, so the eight provinces constituting the Kii peninsula - Yamate, Kawachi, Izumi, Ise, Iga, Shima, Kii (in part), and Ōmi (in part) - served as bases for the partisans of the South. To strike at Kyōto from this base required the previous subjugation of Settsu, and, on the other hand, a strong army in Settsu menaced Yoshino. 
Chikafusa's plan, then, was to marshal in Kawachi force sufficient to threaten, if not to overrun, Settsu, and then to push on into the metropolitan province from. Oni and Iga, the Ashikaga having been previously induced to uncover Kyotto by the necessity of guarding Kamakura. From the Kii peninsula the obvious route to the Kwanto is by sea. Therefore, the Southerners established a naval base at Shingū, on the east coast of the peninsula, and used it for the purpose not only of despatehing a force northward, but also of maintaining communications with Shikoku and Kyūshū, where they had many partisans. Chikafusa himself led the oversea expedition to the Kwantō, but the flotilla was wrecked by a storm, and he reached Yedo Bay with only a small following. Nevertheless, he established himself at Oda, in Hitachi, and being there joined by many of the Ashikaga's enemies, he managed, not indeed to seriously menace. Kamakura, but at all events to give occupation to a large force of the Northerners. Driven out at last (1343), after more than four years' operations, he returned to Yoshino, where he found Kusunoki Masatsura, son of Masashige, fcarrying on from Kawachi a vigorous campaign against the Ashikaga in Settsu.

After many minor engagements, in all of which he was suecessful, Masatsura inflicted such a severe defeat on his opponents at Sumiyoshi that the Bakufu became alarmed, and mustering an army of sixty thousand men, sent it under Ko Moronao and his brother, Moroyasu, to attack Masatsura. This was in December, 1347. Then Masatsura and his younger brother, Masatoki, together with Wada Katahide and other bushi, to the number of 140 , made oath to conquer in fight or to die. They repaired to Yoshino, and having taken leave of the Emperor, Go-Murakami, they worshipped at the shrine of the late sovereign, Go-Daigo, inscribed their names upon the wall, and wrote under them:

We that our bows here
Swear nevermore to slacken
Till in the land of life we
Cease to be counted,
Our names now record.

It was in February, 1348, that the battle took place at Shijo-nawate in Kawaehi. Moronao had sixty thousand men at his disposal; Masatsura only three thousand.' The combat raged during six hours, the Kusunoki brothers leading thirty charges, until finally they were both covered with wounds, and only fifty men remained out of the sworn band. Then this remnant committed suicide. Moronao, following up his victory, marched into Yamato, and set fire to the palace there. Go-Murakami escaped to Kanao, and presently the Nitta family in the east and the Kitabatake in the west showed such aetivity that the Southern cause recovered its vitality, a turn of events largely promoted by dissensions in the Northern camp and by the consequent return of Moronao's forees to Kyōto. It is necessary, therefore, to direct our eyes for a moment to the course of affairs on the side of the Ashikaga.

\section{THE ASHIKAGA POLITY}

Ashikaga Takauji's original idea was to follow the system of Yoritomo in everything. Kamakura was to be his capital and he assumed the title of shögun. This was in 1335 . Three years later he received the shoggunate in due form from the Northern sovereign, Kōmyō. But he now discovered that Kyoto must be his headquarters so long as the War of the Dynasties lasted, and he therefore established the Bakufu at Muromachi in that city, modelling it on the 


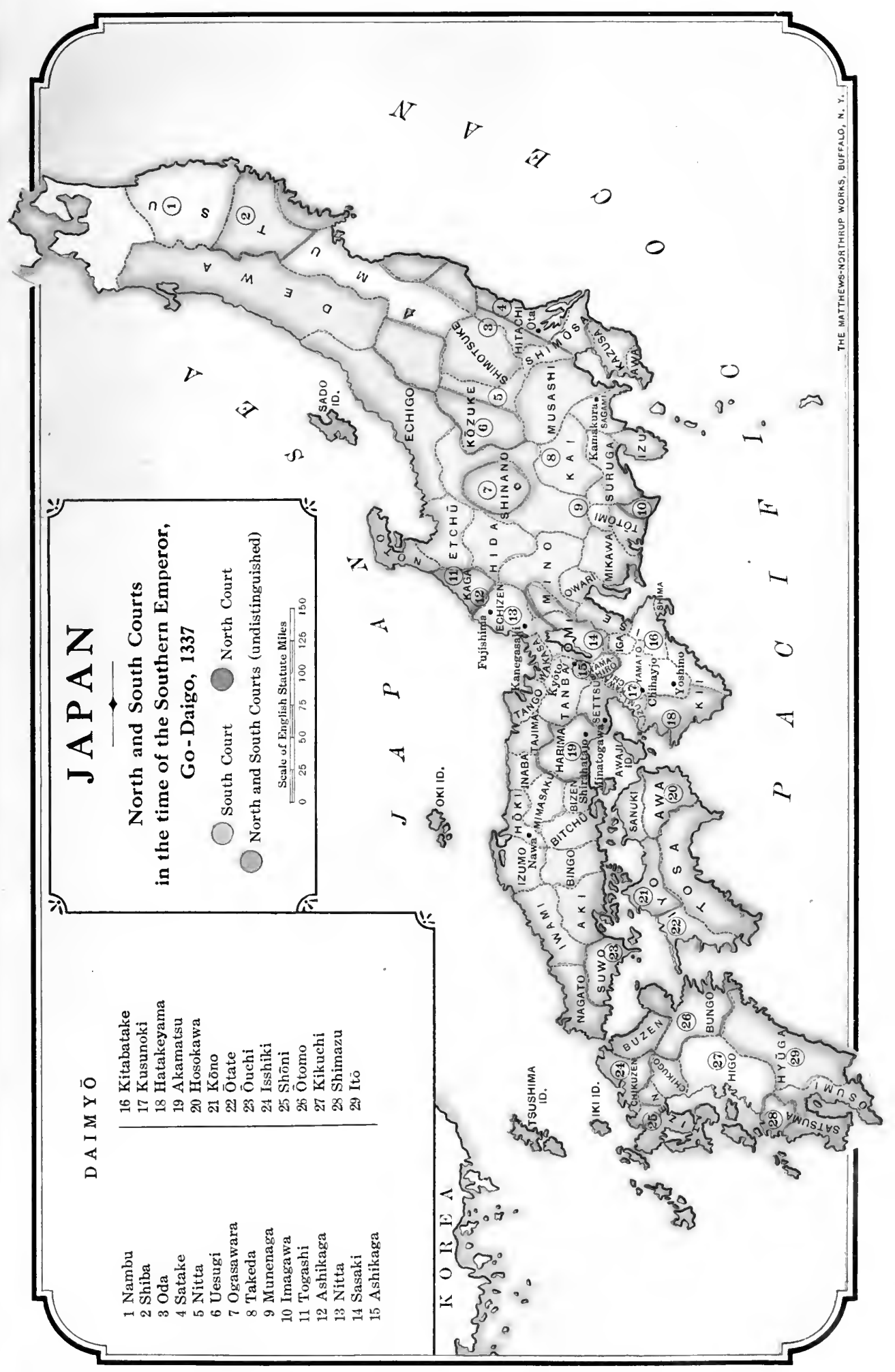



lines of Yoritomo's institution, but dispensing with a regent (shikken) and substituting for him a second shitsuji. The first two shitsuji at, Muromachi were Kō Moronao, the great general, and Uesugi Tomosada, a, connexion of Takauji. Kamakura was not neglected, however. It became a secondary basis, Takauji's eight-year-old son, Yoshiakira, being installed there as governorgenerál (kwanryō) of the Kwantō under the guardianship of Uesugi Noriaki as shitsuji, and the old administrative machinery of the Hōjo was revived in the main. Takauji's brother, Tadayoshi, became chief of the general staff in Kyōto, and:"several Kamakura literati - descendants of Öye, Nakahara, Miyoshi, and others - - were brought up to fill positions on the various boards, the services of some of the ablest priests of the time being enlisted in the work of drafting laws and regulations."'

To these priests and literati was entrusted the task of compiling a code based on the Jöei: Shikimoku of the Hōjo regents, and there resulted the Kemmu Shikimoku, promulgated in $1337 . .^{2}$. This was not a law, properly so called, but rather a body of precepts contained in seventeen articles. They have much interest as embodying the ethics of the time in political circles. " Economy must be universally practised. Drinking parties and wanton frolics must be suppressed. Crimes of violence and outrage must be quelled. The practice of entering the private dwellings of the people and making inquisitions into their affairs must be given up." Then follow two articles dealing with the ownership of vacant plots and rebuilding of houses and fireproof godowns in the devastated sections of the capital. The subsequent paragraphs provide that men of special ability for government work should be chosen for the office of shugo; that a stop must be put to the practice of influential nobles and women of all sorts and Buddhist ecclesiastics making interested recommendations (to the sovereign); that persons holding public posts must be liable to reprimand for negligence and idleness; that bribery must be firmly put down; that presents made from all quarters to those attached to the palace, whether of the inside or outside service, must be sent back; that those who are to be in personal attendance on the rulers must be selected for that duty; that ceremonial etiquette should be the predominant principle; that men noted for probity and adhèrence to high principle should be rewarded by more than ordinary distinction; that the petitions and complaints of the poor and lowly should be heard and redress granted; that the petitions of temples and shrines should be dealt with on their merits, and that certain fixed days should be appointed for the rendering of decisions and the issue of government orders. ${ }^{3}$

\section{THE 'JINNŌ: SHŌTŌKI}

Before proceeding with the history of this troubled era, it is advisable to speak of a great political brochure which was compiled by Kitabatake Chikafusa during the period (1340-1343) of his attempt to harass the Ashikaga from the direction of Hitachi. This was a work: designed to establish the divine claim of the sovereign of the Southern Court. Hence the title of the treatise, Correct Genealogy (Shōtōki) of the Divine Emperor (Jinnō). The reader knows that when, in the eighth century, Japan went to Chinese sources for jurisprudential inspiration, she had to eliminate the Confucian and Mencian doctrine that the 
sceptre may not be wielded by anyone whose virtues do not qualify him for the task in the eyes of the nation. This same doctrine permeated by construction the commentaries that accompanied the articles of the Kemmu Shikimoku as quoted above, and in that fact Chikafusa saw an opportunity of winning adherents for the Southern Court by proclaiming its heaven-conferred rights. I

"Great Yamato," Kitabatake wrote, " is a divine country." It is only our land whose foundations were first laid by the divine ancestor. It alone has been transmitted by the Sun goddess to a long line of her descendants.: There: is nothing of this kind in foreign countries. Therefore it is called the divine land: . - It is only our country which from the time when the heaven and earth were first unfolded, has preserved the succession to the throne intact in one single family. Even when, as sometimes naturally happened, it descended to a lateral branch, it was held according to just principles. This shows that the oath of the gods (to preserve the succession) is ever renewed in a way which distinguishes Japan from all other countries. . . . It is the duty of every man born on the Imperial soil to yield devoted loyalty to his sovereign, even to the sacrifice of his own life. Let no one suppose for a moment that there is any credit due to him for doing so. Nevertheless, in order to stimulate the zeal of those who came after, and in loving memory of the dead, it is the business of the ruler to grant rewards in sueh cases (to the children). Those who are in an inferior position should not enter into rivalry with them. Still more should those who have done no specially meritorious service abstain from inordinate ambitions I have already touched on the principles of statesmanship. They are based on justice and mercy, in the dispensing of which firm action is requisite. Such is the clear instruction vouchsafed to us by the Sun goddess."'

It is not to be supposed that these doctrines produced any wide-spread influence on public opinion at the time of their promulgation. In the first place they were not generally accessible; for not until the year 1649 was'Kitabatake's brochure printed. That it remained in manuscript during three centuries after its compilation is not attributable to technical difficulties. The art of blockprinting came to Japan from China in very early times, and it is on record that, in 770, the Empress Shōtokú caused a million Buddhist amulets to be printed. But the Jinnō Shōtōki did not fall on fruitful soil. Either its teaching was superfluous or men were too much engrossed with fighting to listen to academical disquisitions. Chikafusa's work was destined to produce great and lasting effects in future ages, but, for the moment, it accomplished little.

\section{DISCORD IN THE CAMP OF THE ASHIKAGA}

A prominent feature of the Ashikaga family's annals was continuity of internecine strife. The Hōjō's era had been conspicuously free from any such blemish; the Ashikaga's was markedly disfigured by it, so much so that by the debilitating effects of this discord the supremacy of the sept was long deferred. The first outward indications of the trouble were seen in 1348, when the able general, Kō Moronao, instead of following up his victory over the Southern Court after the death of Kusunoki Masatsura, turned suddenly northward from Yamato and hastened back to Kyōto:. His own safety dictated that step. For during his absence from the capital on campaign, a plot to effect his overthrow had matured under the leadership of Ashikaga Tadayoshi and Uesugi Shigeyoshi. The latter held the office of shitsuji, and was therefore Moronao's comrade, while 
Tadayoshi, as already stated, had the title of commander-in-chief of the general staff and virtually directed administrative affairs, subject; of course, to Takauji's approval. Moronao undoubtedly possessed high strategical ability, and being assisted by his almost equally competent brother, Moroyasu, rendered sterling military service to the Ashikaga cause. But the two brothers were arrogant, dissipated, and passionate. It is recorded of Moronao that he abducted the wife of Enya Takasada, and of Moroyasu that he desecrated the grave of Sugawara in order to enclose its site within his mansion, both outrages being condoned by the shogun, Takauji. In truth, even in the days of Taira overlordship, Kyōto was never so completely under the heel of the military as it was in early Ashikaga times.

Rokuhara did not by any means arrogate such universal authority as did Muromachi. The Court nobles in the middle of the fourteenth century had no functions except those of a ceremonial nature and were frankly despised by the haughty bushi. It is on record that Doki Yoritō, meeting the cortège of the retired Emperor Kōgon, pretended to mistake the escorts' cry of "In" (camera sovereign) for "inu". (dog), and actually discharged an arrow at the Imperial vehicle. Yorito suffered capital punishment, but the incident illustrates the demeanour of the military class.

The two Ko brothers were conspicuously masterful and made many enemies. But the proximate cause of the plot alluded to above was jealousy on the part of Ashikaga Tadayoshi and Uesugi Shigeyoshi, who resented the trust reposed by Takauji in Moronao and Moroyasu. The conspirators underestimated Moronás's character. Reaching Kyōto by forced marches from Yamato, he laid siege to Tadayoshi's mansion, and presently Tadayoshi had to save himself by taking the tonsure, while Shigeyoshi was exiled to Echizen, whither Moronao sent an assassin to make away with him. The Ashikaga chief, whose trust in Moronao was not at all shaken by these events, summoned from Kamakura his eldest son, Yoshiakira, and entrusted to him the functions hitherto discharged by his uncle, Tadayoshi, replacing him in Kamakura by a younger son, Motouji.

Yoshiakira was not Takauji's eldest son; he. was his eldest legitimateison. An illegitimate son, four years older, had been left in Kamakura as a priest, but was recognized as the possessor of such abilities that, although his father refused to meet him, his uncle, Tadayoshi, summoned him to Kyōto and procured for him the high office of tandai of the west. This Tadafuyu was discharging his military duties in Bingo when news reached him of Moronao's coup d'état in Kyōto and of his own patron, Tadayoshi's discomfiture. At once Tadafuyu crossed the sea to Higo in Kyūshū, where a large number of discontented samurai rallied to his banner, and Shōni, the Ashikaga tandai of Kyūshū, soon found himself vigorously attacked. The struggle presently assumed such importance that Kyōto's attention was attracted. The normal course would have been for Moronao to take the field against Tadafuyu. But Moronao was looking always for an opportunity to compass the death of his enemy, Tadayoshi, and thinking that his chance had now come, he persuaded Takauji to take personal command of the expedition to Kyūshū, the idea being to finally dispose of Tadayoshi during the absence of the Ashikaga shogun from Kyōto. 'Tadayoshi, however, obtained timely information of this design and escaping to Yamato, offered to surrender to the Southern Court. This was in January, 1350.

The advisers of the Emperor Go-Murakami differed radically in their counsels, but it was finally decided that every effort should be made to widen the rift in the Ashikaga lute, and the Court commissioned Tadayoshi to attack 
Takauji and recover Kyōto. Thus was presented the spectacle of a father (Takauji) fighting against his son (Tadafuyu), and a brother (Tadayoshi) fighting against a brother (Takauji). Tadayoshi was joined by many men of note and puissance whom the arrogance of the two Kō, Moronao and Móroyasu, had offended. A desperate struggle ensued, and the Kō generals had to retreat to Harima, where they joined with Takauji, the latter having abandoned his expedition to Kyūshū. Meanwhile, Yoshiakira, Takauji's eldest son, had escaped from Kyōto and entered his father's camp. After a time negotiations for peace were concluded (1351), one of the conditions being that Moronao and Moroyasu should lay down their. offices and enter the priesthood.I. But the blood of the shitsuji, Uesugi Shigeyoshi, was still fresh on Moronao's hands. Shigeyoshi's son, Akiyoshi, waylaid the two Kō on their route to Kyōto to take the tonsure, and Moronao and Moroyasu were both killed.

\section{YEAR-PERIODS AND COURTS}

Three years before the death of Moronao, that is to say, in 1348, the sovereign of the Northern Court, Kōmyō, abdicated in favour of Sukō. Ever since 1332 there had been a dual year-period, outcome of the divided Imperialism, and history was thus not a little complicated. It will be convenient here to tabulate, side by side, the lines of the two dynasties:-

Southern Court

96 th Sovereign, Go-Daigo .....

97 th" "Go-Murakami.

98th " Chōkei.......

99th " Go-Kameyama

$1318-1339$

$1339-1368$

$1368-1372$

$1372-1392$

\section{0th " Go-Komatsu.. 1392-1412}

It is observable that the average duration of a Southern sovereign's reign was eighteen years, whereas that of a Northern sovereign was only thirteen years.

\section{DEATH OF TADAYOSHI}

The peace concluded between the Ashikaga chief and his brother, Tadayoshi, was of brief duration; their respective partisans distrusted one another too much. The Nikki, the Hosokawa, the Doki, and the Sasaki, all followed Takauji,-but the Ishidō, the Uesugi, and the Momonoi adhered to Tadayoshi. At last the situation became so strained that Tadayoshi withdrew to Echizen and from thence made his way to Kamakura. In these circumstances, Takauji desired to take the field himself, but since to do so would have exposed Kyōto to danger from the south, he attempted to delude the Court at Yoshino into crediting his loyalty and his willingness to dethrone Sukō by way of preliminary to welcoming the return of Go-Murakami to Kyöto.

Takauji's professions were now appraised at their true value, however. The Court at Yoshino commissioned him to punish his rebellious brother, but took steps, as will presently be seen, to turn the resulting situation to its own advantage. 'Takauji now placed himself at the head of a strong army, and moving eastward, marched to Kamakura practically unopposed:- Tadayoshi escaped to Izu, where he took poison, or was given it. Takauji remained in the Kwanto 
during the greater part of two years (1352-1353). The task of restoring order and re-establishing the Ashikaga supremacy demanded all his ability and resources. "In the Kwantō.alone, during these two years, more battles were fought - some of considerable magnitude - than during the thirty years between 1455 and 1485 in England."

\section{THE SOUTHERN COURT IN KYŌTO}

In this state of affairs the Southern Court found its opportunity. In accepting Takauji's overtures, Kitabatake Chikafusa, who directed the politics and strategy of the Southern Court, had designed to dethrone Sukō, to adopt the year name, Shōhei, solely, and to establish an administrative council in Kyōto under his own presidency. He knew well that Takauji's surrender had not been sincere, but he counted on an access of strength from the partisans of Tadayoshi, and he looked for some occasion capable of being turned to advantage. Yoshiakira, who ruled Kyōto in the absence of his father, Takauji, made no difficulty about dethroning Sukō and requesting the return of the Southern sovereign, Go-Murakami. Neither did he hesitate to hand over the false insignia which had been given by Go-Daigo to the Northern Court. In February, 1352, Go-Murakami paid a visit to Otoko-yama on the southeast of Kyōto, and ordered a number of officials, under Kitabatake Chikafusa and Kusunoki Masanori, to enter the capital and conduct affairs. But his Majesty did not trust his own person into the city. He waited until his plans were mature, and then a strong force of Southern troops was launched against Kyōto, while a powerful army of Kwantō bushi, led by the Nitta brothers, Yoshioki and Yoshimune; as well as by Wakiya Yoshiharu, marched into Musashi and defeated Takauji on the Kotesashi moor.

The invaders actually got possession of Kamakura, but the superior strategy of the Ashikaga chief ultimately reversed the situation. Yoshimune had to fly to Echigo with a petty remnant of followers, and Yoshioki and Yoshiharu, evacuating .Kamakura, took refuge in the Kawamura fortress. Meanwhile, in Kyōto, things had fared in a somewhat similar manner. The Southern generals carried everything before them at the outset, and Yoshiakira had to fly to Ōmi. But, after a brief period of quiet, the Northern troops rallied and expelled the Southern. Yoshiakira found himself again supreme. A strange dilemma presented itself, however. There was no sovereign. The retired sovereigns, Kōgon, Kōmyō, and Sukō, had all been carried to a place well within the Southern lines, and even the false regalia were not available. Nevertheless, Yoshiakira, regardless of forms, raised to the throne the younger brother of Suko, who is known in history as Go-Kōgon. Thenceforth, on the accession of a Northern sovereign a merely nominal ceremony of transferring the sacred regalia sufficed. As for the ex-Emperors Kōgon and Kōmyō, they turned their backs finally on the world and became priests of the Zen sect of Buddhism.

\section{CAPTURE AND RE-CAPTURE OF KYŌTO}

In 1353, the Southern court received a signal accession of strength in the allegiance of the Yamana family and of Tadafuyu. The latter has already been spoken of as an illegitimate son of Takauji, who, through the influence of his uncle, Tadayoshi, was appointed tandai of the western provinces. The death of 
his patron inclined this able captain to join the Southern Court; and his inclination was trauslated into action early in 1353 , owing to need of support-against the partisans of the Ashikaga in the island of Kyūshū and the western provinces. As for the Yamana, they were of Minamoto lineage; their influence was supreme in Hōki and Inaba, and they faithfully espoused the Ashikaga cause until an unfulfilled promise of a manor alienated their good-will. For to such considerations of self-interest men not infrequently sacrificed their duty of allegiance in the troublous times of the fourteenth century.

Thus re-enforced, the Southern troops, under the supreme command of Tadafuyu, marched against Kyōto in July, 1353, and captured the city: Yoshia: kira; guarding the young sovereign, Go-Kōgon, effected his eseape, and the Southern Emperor, Go-Murakami, issued a decree depriving of their/offieial ranks and possessions all Court nobles who had assisted at the eeremony of the fugitive monarch's eoronation. But the supremacy of the South did not last long. In August, Yoshiakira was strong enough to countermarch against the capital and to drive out Tadafuyu. Moreover, Takauji himself now found it safe to leave the Kwantō. ' Placing his son Motouji in eharge at Kamakura, he returned to Kyōto accompanying the Emperor Go-Kōgon, and thenceforth during nearly two years the supremacy of the North was practically undisputed.

\section{DEATH OF CHIKAFUSA}

Fate willed that while his enemies were thus triumphant, death should overtake the great statesman, strategist, and historian, Kitabatake Chikafusa. He died in 1354, at the age of sixty-two. Japanese annalists say of Chikafusa: "It was through his ability that the Southern forees were co-ordinated/and kept active in all parts of the empire. It was due to his clever strategy that Kyōto lay under constant menace from the south. If the first great protagonists in the struggle between the Northern and the Southern Courts were Prince Morinaga and Takauji, and those of the next were Nitta Yoshisada and Takauji, the third couple was Kitabatake Chikafusa and Takauji." Chikafusa was of wide erudition; he had a wonderful memory, and his perpetual guides were justice and righteousness. After his death the Southern Court fell into a state of division against itself; and its spirit sensibly declined.

\section{DEATH OF TAKAUJI}

Takauji survived Chikafusa by only four years; he expired in 1358. Undoubtedly his figure is projected in very imposing dimensions on the pages of his country's history, and as the high mountain in the Chinese proverb is gilded by the sunbeams and beaten by the storm, so eondemnation and eulogy have been poured upon his head by posterity. An annalist of his time says: "Yoritomo was impartial in bestowing rewards, but so severe in meting out punishments as to seem almost inhuman. Takauji, however, in addition to being humane and just, is strong-minded, for no peril ever summons terror to his eye or banishes the smile from his lip; mereiful, for he knows no hatred and treats his foes as his sons; magnanimous, for he counts gold and silver as stones or sand, and generous, for he never compares the gift with the recipient; but gives away everything ás it comes to hand. It is the eustom for people to carry many presents to the shoggu on the first day of the eighth month, but so freely are those things given away that nothing remains by the evening, I am told." 
A later historian, Rai Sanyō (1780-1832), wrote: "There were as brave men and as clever in the days of the Minamoto as in the days of the Ashikaga. Why, then, did the former never dare to take up arms against the Bakufu, whereas the latter never ceased to assault the Ashikaga? It was because the Minamoto and the Hōjo understood the expediency of not entrusting too much power to potential rivals; 1 whereas the Ashikaga gave away lands so rashly that some families - as the Akamatsu, the Hosokawa, and the Hatakeyama - eame into the possession of three or four provinces, and in an extreme case one family that of Yamana - controlled ten provinces, or one-sixth of the whole empire. These septs; finding themselves so powerful; became unmanageable $\therefore$ Then the division of the Ashikaga into the Muromachi magnates and the Kamakura chiefs brought two sets of rulers upon the same stage, and naturally intrigue and distrust were born, so that, in the end, Muromachi was shaken by Hosokawa, and Kamakura was overthrown by Uesugi. An animal with too ponderous a tail cannot wag it, and a stick too heavy at one end is apt to break. The Ashikaga angled with such valuable bait that they ultimately lost both fish and bait. During the thirteen generations of their sway there was no respite from struggle between family and family or between chief and vassal." Takauji's record plainly shows that deception was one of his weapons. He was absolutely unscrupulous. He knew also how to entice men with gain, but he forgot that those who came for gain will go also for gain. It would seem, too, that he sacrificed justice to the fear of alienating his supportors. Not otherwise can we account for his leniency towards the Kō brothers, who were guilty of such violations of propriety.

\section{THE SECOND ASHIKAGA SHOOGUN}

Takauji was succeeded in the shōgunate by his eldest son, Yoshiakira, of whom so much has already been heard. The fortunes of the Southern Court were now at low ebb. During the year (1359) after Takauji's death, Kamakura contributed materially to the support of the Ashikaga cause. The Kwanto was then under the sway of Takauji's fourth son, Motouji, one of the ablest men of his time. He had just succeeded in quelling the defection of the Nitta family, and his military power was so great that his captains conceived the ambition of marching to Kyōto and supplanting Yoshiakira by Motouji. But the latter, instead of adopting this disloyal counsel; despatched a large army under Hatakeyama Kunikiyo to attack the Southern Court: Marching by the two highways of Settsu and Kawachi, this army attacked Yoshino and gained some important successes. But the fruits of the victories were not gathered. The Hatakeyama chief developed ambitions of his own, and; on returning to the Kwantō, was crushed by:Motouji and deprived of his office of shitsuji; that post being given again to Uesugi Noriaki, "who had been in exile since the death of Tadayoshi in 1352. At, or shortly after, this time; Kai and Izu and, later on, Mutsu, were put under Kamakura jurisdiction, and their peaceful and orderly condition formed a marked contrast to the general state of the rest of the empire."'

The next event of cardinal importance in this much disturbed period was the defection of Hosokawa Kiyouji, one of the shitsuji in Kyōto. This powerful chief, disappointed in his expectations of reward, went over to the Southern Court in 1361, and the result was that the Ashikaga shogun had to flee from Kyōto, escorting Go-Kōgon. The situation soon changed however. Hosokawa 
Kiyouji, returning to his native province, Awa; essayed to bring the whole of Shikoku into allegiance to the Southern Court, but was signally worsted by his cousin, Hosokawa Yoriyuki - afterwards very famous -, and scarcely a month had elapsed before Yoshiakira was back in the capital. In the same year (1362), the Northerners received a marked increase of strength by the accession of the Yamana family, which was at that time supreme in the five central provinces of eastern Japan - namely, Tamba, Inaba, Bizen, Bitchü, and Mimasaka. il During ten years this family had supported the Southern Court, but its chief, Tokiuji, now yielded to the persuasion of Yoshiakira's emissaries, and' espoused the Ashikaga cause on condition that he, Tokiuji, should be named high constable of the above five provinces.

Meanwhile, the partisans of the late Tadayoshi - the Kira, the Ishidô, the Momonoi; the Nikki, and others - constituted a source of perpetual menace, and even among the Ashikaga themselves there was a rebel (Takatsune): Yoshiakira became weary of the unceasing strife. He addressed overtures to the Southern Court and they were accepted on condition that he made formal act of surrender. This the shogun refused to do, but he treated Go-Murakami's envoy with every mark of respect, and though the pourparlers proved finally abortive, they had continued for five months, an evidence that both sides were anxious to find a path to peace. Yoshiakira died in the same year, 1367

\section{THE SOUTHERN COURT}

Previously to this event, a new trouble had occurred in the Southern Court. The Emperor Go-Murakami signified his desire to abdicate, and thereupon the Court nobles who had followed the three ex-Emperors into the Southern lines in 1352 fell into two cliques, each advocating the nomination of a different successor. This discord exercised a debilitating influence, and when Go-Murakami died (1368), the Southerners found themselves in a parlous condition. For his son and successor, Chökei, failing to appreciate the situation; immediately planned an extensive campaign against Kyöto-from the east and the south simultaneously.: Then Kusunoki Masanori passed into the Northern camp. Few events have received wider historical comment in Japan. The Kusunoki family stood for'everything loyal and devoted in the bushi's record, and Masanori was a worthy chief of the sept. So conspicuous were his virtues and so attractive was his personality that a samurai of the Akamatsu family, who had planned a vendetta against him, committed suicide himself rather than raise his hand to slay such a hero.

How, then; are we to account for Masanori's infidelity to the cause he had embraced? The answer of his country's most credible annalists is that his motive was to save the Southern Court. He saw that if the young Emperor, Chōkei, persisted in his design of a general campaign against Kyōto, a crushing defeat must be the outcome, and since the sovereign would not pay heed to his remonstrances, he concluded that the only way to arrest the mad enterprise was his own defection, which would weaken the South too much to permit offensive action. Ashikaga Yoshimitsu was then shögun at Muromachi. $\mathrm{He}$ had succeeded to that office in 1367 , at the age of nine, and his father, then within a year of death, had entrusted him to the care of Hosokawa Yoriyuki; one of the ablest men of his own or any generation. There are strong reasons for thinking that between this statesman and Masanori an understanding existed. So long as Yoriyuki remained in power there was nothing worthy of the name of war 
between the two Courts, and when, after his retirement in 1379 , the struggle re-opened under the direction of his successor (a Yamana chief), Masanori returned to his old allegiance and took the field once more in the Southern cause. His action in temporarily changing his allegiance had given ten years' respite to the Southérners.

\section{PEACE BETWEEN THE TWO COURTS}

The Southern Emperor, Chōkei, coming to the throne in 1368, abdicated in 1372 in favour of his brother, known in history as Go-Kameyama. During his brief tenure of power Chōkei's extensive plans for the capture of Kyōto did not mature, but he had the satisfaction of seeing the.whole island of Kyūshū wrested from Ashikaga hands: It is true that under the able administration of Imagawa Sadayo (Ryoshun), a tandai appointed by: the Ashikaga, this state of affairs was largely remedied during the next ten years, but as the last substantial triumph of the Yoshino arms the record of Chōkei's reign is memorable.; It was, in truth, the final success. The decade of comparative quiet that ensued on the main island proved to be the calm before the storm:

- $\mathrm{ri}_{2}$ The most prominent figures in the closing chapter of the great dynastic struggle are Hosokawa Yoriyuki and Yamana Mitsuyuki. When the second Ashikaga shōgun, Yoshiakira, recognized that his days were numbered, he summoned his trusted councillor, Hosokawa Yoriyuki, and his son Yoshimitsu, and said to the latter, "I give you a father," and to the former, "I give you a son." Yoriyuki faithfully discharged the trust thus reposed in him. He surrounded his youthful charge with literary and military experts, and secured to him every advantage that education could confer. Moreover, this astute statesman seems to have apprehended that if the cause of the Southern Court were not actually opposed, it would die of inanition; and he therefore employed all his influence to preserve peace. He endeavoured also to enforce strict obedience to the economical precepts of the Kemmu code, and altogether the ethics he favoured were out of harmony with the social conditions of Kyoto at the time and with the natural proclivities of the young shoggun himself! In fine, he had to leave the capital, too full of his enemies; and to retire to his native province, Awa.

During ten years he remained in seclusion. . But, in 1389, a journey made by the shogun to Miya-jima revealed so many evidences of Yoriyuki's loyalty that he was invited to return to Kyoto, and with his assistance the organization of the Ashikaga forces at Muromachi was brought to a high state of efficiency, partly because the astute Yoriyuki foresaw trouble with the Yamana family, which was then supreme in no less than ten provinces, or nearly one-sixth of all Japan. In 1391 Yamana Ujikiyo and his kinsman Mitsuyuki took the field against Kyōto under the standard of the Southern Court. He commanded a great army, and there resulted a desperate struggle known in history as the Meitoku War, after the name of the year-period when it occurred. The Yamana leader was killed and his army completely routed. In the following year, the great Hosokawa Yoriyuki died.. He had lived to see the ten provinces recovered from Yamana rule and partitioned among the Muromachi generals.

But he expired just before the final triumph to which his genius had so materially contributed For within a few month of his demise the War of the Dynasties came at last to a close. The proximate cause was the fall of the Kusunoki stronghold, which had been built by Masashige, and during sixty years 
had remained unconquered. With its reduction; preceded as it had been by the annihilation of the Yamana, the fortunes of the Southern Court had become hopeless, and overtures carried from Kyōto by one of the most distinguished of the Muromachi generals, Ōuchi Yoshihiro, were accepted. Go-Komatsu then occupied the Northern throne. He had succeeded Go-Enyū, in 1382, and the latter, had succeeded Go-Kōgon, in 1371. Go-Komatsu, having been only six years of age at the time of his accession, was in his sixteenth year when the two Courts came to an agreement

For a time the terms proved very difficult of adjustment, but ultimately it was decided that the Southern sovereign, Go-Kameyama, should abdicate in favour of the Northern, the former being thenceforth treated as the latter's father. This compact having been concluded, the sacred insignia were, transported from Yoshino to:Kyōto with all solemnity. Six Court nobles accompanied them from the South; twenty went out from the North to receive them, and a numerous body of troops formed the escort. The retiring Emperor spent ten days at the palace in Kyōto, throughout which time a magnificent banquet was held to celebrate the conclusion of the fifty-five years'war. Yoshino and other districts were assigned for the support of the ex-Emperor, and pensions ordomains were conferred on the Court nobles of the South, some of whom, however, declining to compromise their sense of honour by accepting favours from the North, withdrew to the provinces; and their exile was shared by several of the military leaders who had remained true to the South throughout. There can be little doubt that among these apparent implacables were some of a selfishly calculating disposition, who, anticipating a reversion to the system of alternate succession, as instituted by the Hōjō interpreters of Go-Saga's testament; looked for greater personal advantage when the Crown should come to the Southern branch than anything that could be hoped for by submitting to the Northern. They were mistaken. That testament, which had done so much mischicf in its time, was ignored from the close of the War of the Dynasties. It did not fall into total abeyance, however, without some further bloodshed, and the facts may be interpolated here so as to dispose finally of the subject.

In 1412 , the abdication of Go-Komatsu should have been followed by the accession of a Southern prince had the principle of alternation been pursued. It was not so followed. On the contrary, the sceptre fell to Shōkō -101 st sovereign - son of Go-Komatsu. Hence, in 1413, Date Yasumune, in Mútsu, and, in 1414, Kitabatake Mitsumasa, in Ise, made armed protests; gallant but ineffective. Again, in 1428, on the childless death of Shōkō, the claims of the Southern line were tacitly ignored in favour of Go-Hanazono, grandson of the third Northern Emperor, Sukō. . The same Mitsumasa now took the field; aided this time by Masahide, head of the ever loyal house of Kusunoki, but signal failure ensued. The last struggle in behalf of the Southern line took place in 1443, when " a band of determined men under Kusunoki Jirō and the Court noble, Hino Arimitsu, suddenly assailed the palace from two directions; all but succeeded in killing or capturing the Emperor, and actually got possession of the regalia. They were soon driven out, however, and in their flight to Hiei-zan, where one body of them entrenched themselves, the mirror and the sword were dropped and recovered by the pursuers.: The other body made good their escape to the wilds of Odai-ga-hara, carrying with them the seal; and it was not till a year later that it found its way back to Kyoto, when the rebels had been destroyed."1 

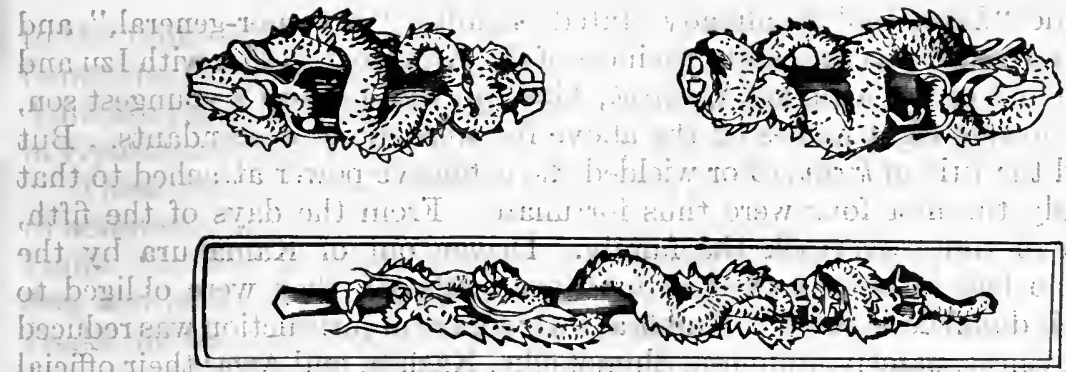

KozuKa and Meviki (Sword Furniture)

\section{CHAPTER XXXI}

\section{THE FALL OF THE ASHIKAGA}

\section{TWO BRANCHES OF THE ASHIKAGA}

THE Ashikaga family was divided into two main branches, both descended from Takauji. The representatives of one, the senior, branch had their headquarters at Muromachi in Kyōto and held the office of shōgun as a hereditary right. There were fifteen generations:-

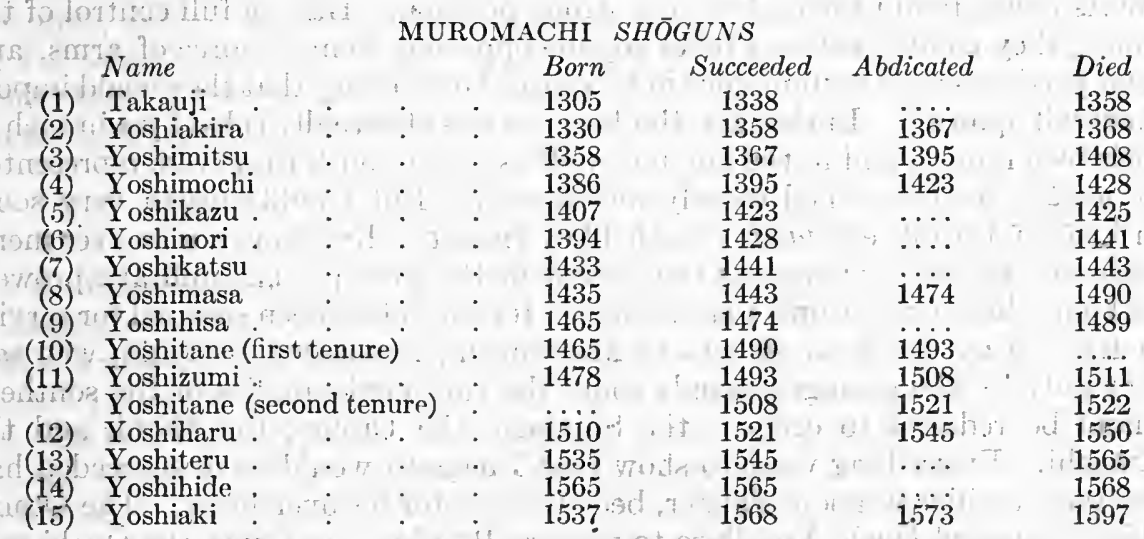

The apparent clashing of dates in the case of the fourth and fifth shoguns, Yoshimochi and Yoshikazu, is due to the fact that on the death of the latter, in 1425, the former resumed the office and held it until his own death, in 1428 .

\section{THE KAMAKURA KWANRYŌ AND KUBŌ}
(1) Motouji .
(2) Ujimitsu
(3) Mitsukane
(4) Mochiuji
(5) Shigeuji .
(6) Masatomo
(7) Takamoto
(8) Haruuji
(9) 5 Yoshiuji:

\section{Born}

1340

1357

1376

1398

1434

... 
The title "kwanryō," as already stated, signifies "governor-general," and the region governed was the eight provinces of the Kwantō; together with Izu and Kai. The first of the Ashikaga kwanryo, Motouji, was Takauji's youngest son, and the following eight names on the above list were direct descendants. But not all had the title of kwanryo or wielded the extensive power attached to that office. Only the first four were thus fortunate. From the days of the fifth, Shigeuji, evil times overtook the family. Driven out of Kamakura by the Uesugi, who had hitherto served as manager (shitsuji), they were obliged to change their domicile to Koga in Shimōsa; their sphere of jurisdiction was reduced to four provinces, namely, Shimōsa, Shimotsuke, Kazusa, and Awa; their official title was altered to gosho or $k u b \bar{o}$, and their former title of kwanryo passed to the Uesugi family who also replaced them at Kamakura. These things fell out in 1439, when Mochiuji died. To avoid confusion it is necessary to note that the chief official in the shögun's court at Muromachi in Kyōto was also called kwanryō. He had originally been termed "manager" (shitsuji), but, in 1367, this was changed to "governor-general," and the corresponding functions were practically those discharged by the regent (shikken) in the polity of the old Baku$f u$. The first Muromachi kwanryo was Shiba Yoshimasa, and it became the ultimate custom to give the post to a member of one of three families, the Shiba, the Hosokawa, and the Hatakeyama.

\section{STATE OF THE PROVINCES}

When swords were sheathed after the long and wasting War of the Dynasties, the Ashikaga found themselves in a strong position. Having full control of the Court, they could treat as a rebel anyone opposing them by force of arms, and their partisans were so numerous in Kyōto and its vicinity that they could impose their will upon all. In the east, the Kwanto was effectually ruled by a branch of their own family, and in the north as well as in the south they were represented by tandai, who governed stoutly and loyally. But trouble began very soon. In Kyūshū the office of tandai was held by Imagawa Ryoshun, a man ever memorable in Japanese history as the author of the precept that military prowess without education is worse than useless. Ryōshun had been selected for service in Kyūshū by the great shitsuji of Muromachi, Hosokawa Yoriyuki, who saw that only by the strongest hands could the turbulent families of the southern island be reduced to order - the Shimazu, the Ōtomo, the Shoni, and the Kikuchi. Everything went to show that Imagawa would have succéeded had not that familiar weapon, slander, been utilized for his overthrow. The Ötomo chief persuaded Ōuchi Yoshihiro to traduce Ryōshun, and since the Ōuchi sept exercised great influence in the central provinces and had taken a prominent part in composing the War of the Dynasties, the shogun, Yoshimitsu, could not choose but listen to charges coming from such a source. Imagawa Ryōshun was recalled (1396), and thenceforth Kyūshū became the scene of almost perpetual warfare which the Muromachi authorities were powerless to check.

\section{THE ŌUCHI FAMILY}

It was to the same Ōuchi family that the Muromachi shōgun owed his first serious trouble after the close of the War of the Dynasties. The ancestor of the family had been a Korean prince who migrated to Japan early in the seventh century, and whose descendants, five and a half centuries later, were admitted 
to the ranks of the samurai. The outbreak of the War of the Dynasties had found the Ouchi ranged on the Southern side, but presently they espoused the Ashikaga cause, and distinguished themselves conspicuously against the Kikuchi in Kyūshū and, abóve all, in promoting the conclusion of the dynastic struggle. 11 These eminent services were recognized by. Ouchi Yoshihiro's appointment to administer no less than six provinces - Nagato, Suwō; Aki, Buzen, Kii; and Izumi. In fact he guarded the western and eastern entrances of the Inland Sea, and held the overlordship of western Japan. At his castle in Sakai, near Ōsäka, he' amassed wealth by foreign trade, and there he received and harboured representatives of the Kusunoki and Kikuchi families, while at the same time he carried on friendly communications / with the Doki, the Ikeda, and the Yamana. In short, he grew too powerful to receive mandates from Muromachi, especially when they came through a kwanryo of the Hatakeyama family who had just risen to that distinction.

Suddenly, in November, 1399, the Ōuchi chief appeared in Izumi at the head of a force of twenty-three thousand men, a force which received rapid and numerous accessions. His grounds of disaffection were that he suspected the shōgun of a design to deprive him of the two provinces of Kii and Izumi, which were far remote from the other five provinces in his jurisdiction and which plàced him within arm's length of Kyōto, and, further, that no sufficient reward had been given to the family of his younger brother, who fell in battle. There were minor grievances, but evidently all were pretexts: the real object was to overthrow Muromachi. The shogun, Yoshimitsu, acted with great promptitude. He placed Hatakeyama Mitsuiye at the head of a powerful army, and on January 18, 1400, Sakai fell and Yoshihiro committed suicide. Thereafter the province of Kii was placed under the jurisdiction of the Hatakeyama family, and Izumi under that of Hosokawa, while the Shiba ruled in Echizen, Owari, and Tōtōmi. In short, these three families became the bulwarks of the Ashikaga.

\section{KAMAKURA AND MUROMACHI}

An important episode of the Ouchi struggle was that Mitsukane, the third Kamakura kivanryō of the Ashikaga line, moved an army into Musashi to render indirect assistance to the Ōuchi cause. In truth, from an early period of Kamakura's tenure by an Ashikaga governor-general of the Kwantō, there had been an ambition to transfer the office of shogun from the Kyōto to the Kamakura branch of the family. The matter was not mooted during Takauji's lifetime, but when, on his demise, the comparatively incompetent Yoshiakira came into power at Muromachi, certain military magnates of the eastern provinces urged the Kamakura kwanrȳo, Motouji, to usurp his brother's position. Motouji, essentially as loyal as he was astute, spurned the proposition. But it was not so with his son and successor, Ujimitsu. To him the ambition of winning the shōgunate presented itself strongly, and was only abandoned when Uesugi Noriharu committed suicide to add weight to a protest against such an essay.

Japanese annals contain many records of lives thus sacrificed on the altar of devotion and loyalty. From the outset the Uesugi family were the pillars of the Ashikaga kwanryō in Kamakura. Uesugi-Noriaki served as shitsuji in the time of the first kwariryō, and the same service was rendered by Noriaki's son, Yoshinori, and by the latter's nephew, Tomomune, in the time of the second kwanryō, Ujimitsu. Confusing as are the multitude of names that confront the foreign student of Japanese history, it is necessary to note that from the time of 
their appointment as shitsuji at Kamakura, Yoshinori took the family name of Yamanouchi, and Tomomune that of Ögigayatsu. Balked in his design against Kyōto, Ujimitsu turned his hand against the Nitta, old enemies of his family, and crushing them, placed the Ashikaga power on a very firm basis in the Kwantō. His son, Mitsukane, had the gift of handling troops with great skill, and in his time the prestige of the Kamakura kwanryō reached its highest point;

In the eyes of the military men of the eastern provinces, the shogun in distant Kyōto counted for little compared with the governor-general in adjacent Kamakura! The latter's mansion was called gosho (palace); its occupant was termed $k u b \bar{o}$, an epithet hitherto applied to the shögun only, and the elder and younger branches of the Uesugi family, in which the office of kwanryo of Muromachi was hereditary, were designated Ryō U'esugi (the Two Uesugi). Mitsukane, when he abetted the Ōuchi's attempt to overthrow the Kyōto shōgun, persuaded himself that he was only carrying out his father's unachieved purpose, and the shōgun, Yoshimitsu, took no step to punish him, preferring to accept his overtures - made through Uesugi Tomomune.

\section{THE EXTRAVAGANCE OF YOSHIMITSU}

There is little question that whatever applause history can extend to the administration of the third Ashikaga shogun, Yoshimitsu, was won for him by his profoundly sagacious guardian and chief minister, Hosokawa Yoriyuki. After

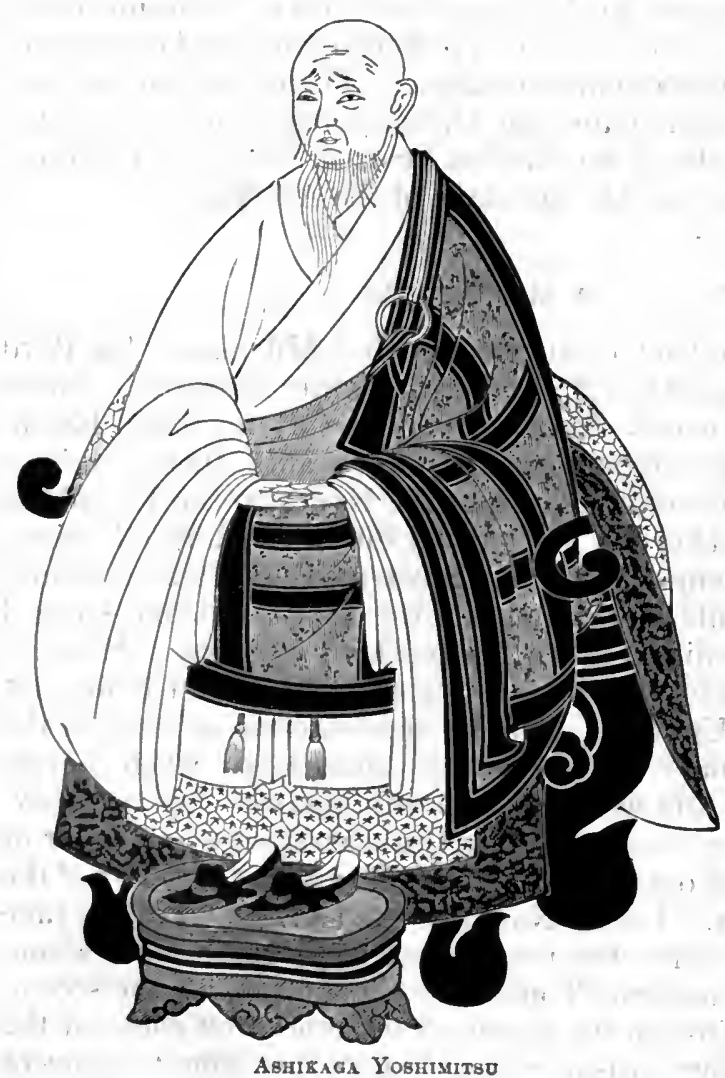
the latter's death, in 1392, many abuses and few meritorious acts appear in the shögun's record. Alike, the wise selfeffacement and the admirable frugality which distinguished the Hōjo rule were wholly foreign to the mood of Yoshimitsu. He insisted on being raised to the post of chancellor of the empire, and he openly spoke of himself as "king," designating as Go-sekke (Five Regent Houses) the familes of Shiba, Hosokawa, Hatakeyama, Rokkaku, and Yamana. At the ceremony of his investiture as chancellor (dajo daijin) he presented to the Throne a sword forged by Kunimitsu; one hundred pieces of white silk; one thousand silver coins; ten tigers' skins, and fifty pounds of dyed silk. To the ex-Emperor he gave a thousand silver coins; fifty pieces of white silk, and a sword, and among the Imperial princes 
and Court nobles he distributed ten thousand pieces of silver. Such was his parade of opulence.

The chief obstacle to conferring on him the title of chancellor had been that the records contained only one instance of a military man's appointment to that exalted post. That instance was Taira no Kiyomori, whose example should have been deterrent to a Minamoto. Yoshimitsu overcame the difficulty by nominally transferring his military functions to his son Yoshimochi (1423), and constituting himself the patron of literature. It was now that his love of luxury and splendour assumed its full dimensions. He had already beautified his Muromachi mansion by constructing there a park so spacious and so brilliant at all seasons that it went by the name of Hana no Gosho (Palace of Flowers)." This he now assigned as a residenee for his son and successor, Yoshimochi, transferring his own place of abode to the site occupied by the Saionji family, to whom was given in exchange an extensive manor in Kawachi. Here the Ashikaga chancellor built a palace of such dimensions that sixteen superintendents and twenty assistant superintendents were required to oversee the work. Most conspicuous was the Kinkaku-ji, or golden pavilion shrine, so called because its interior was gilt, the gold foil being thickly superposed on lacquer varnish. On this edifice, on the adjacent palace, and on a park where deer roamed and noble pine trees hung over their own shadows in a picturesque lake, immense sums were expended. Works of art were collected from all quarters to enhance the charm of a palace concerning which the bonze Sekkei declared that it could not be exchanged for paradise.

Yoshimitsu prayed the Emperor to visit this unprecedentedly beautiful retreat and Go-Komatsu complied. During twenty days a perpetual round of pastimes was devised for the entertainment of the sovereign and the Court nobles - couplet composing, music, football, boating, dancing, and feasting. All this was typical of the life Yoshimitsu led after his resignation of the shogun's office. Pleasure trips engrossed his attention - trips to Ise, to Yamato, to Hyogo, to Wakasa, and so forth. He set the example of luxury, and it found followers on the part of all who aimed at being counted fashionable, with the inevitable result that the producing classes were taxed beyond endurance. It has to be noted, too, that although Yoshimitsu lived in nominal retirement at his Kita-yama palace, he really continued to administer the affairs of the empire.

\section{INTERNATIONAL HUMILIATION}

It is not for arrogance, or yet for extravagance, that Japanese historians chiefly reproach Yoshimitsu. His unpardonable sin in their eyes is that he humiliated his country. From the accession of the Ming dynasty (1368) China made friendly overtures to Japan, especially desiring the latter to check the raids of her corsairs who, as in the days of the Hojō after the repulse of the Mongol armada, so also in the times of the Ashikaga, were a constant menace to the coastwise population of the neighbouring continent. Upon the attitude of the shog towards these remonstrances and overtures depended the prosecution of commerce with the Middle Kingdom, and the profits accruing from that commerce were too considerable to be neglected by a ruler like Yoshimitsu, whose extravagance required constant accessions of revenue. Moreover, the-Muromachi shögun was a disciple and patron of the Zen sect of Buddhism, and the priests of that sect always advocated peaceful intercourse with China, the source of philosophic and literary learning. 
All these considerations induced the Ashikaga chief not only to issue orders for the restraint of the corsairs, but also to receive from the Chinese Court despatches in which he was plainly designated the king of a country tributary to China, and to make answer in language unequivocally endorsing the propriety of such terminology. In one despatch, dated February, 1403, Yoshimitsu described himself as a "subject of Ming" and, "prostrate, begged to present twenty horses, ten thousand catties of sulphur, thirty-two pieces of agate, three gold-foil folding screens, one thousand lances, one hundred swords, a suit of armour, and an ink-stone." It is recorded that he even humbled himself so far as to ask for supplies of Chinese coins, and certainly these comparatively pure copper tokens remained largely in circulation in Japan down to Tokugawa times, under the name of Eiraku-tsūhō, Eiraku being the Japanese sound of the Chinese year-period, Y unglo (1403-1422).

\section{DEATH OF YOSHIMITSU}

Yoshimitsu died in 1408. He was accorded by the Court the posthumous rank of Dajō Tennō (ex-Emperor), a proof of the extraordinary confusion of etiquette caused by his arrogant pretensions. The Chinese sovereign, :Yunglo, sent a message of sympathy to the Japanese potentate's son, Yoshimochi; in which the deceased was designated "Prince Kung-hsien," but Yoshimochi, though not distinguished for ability, had sufficient wisdom ultimately to adopt the advice of the kwanrȳo, ShibaYoshimasa, and to decline the rank of Dajō Tennō, as well as to break off relations with the Ming ruler. Yoshimochi also handed over the magnificent edifice at Kita-yama to the Buddhist priesthood.

\section{THE EMPEROR SHŌKŌ}

In 1412, the Emperor Go-Komatsu abdicated in favour of his son Shōkō (101st sovereign), then twelve years old. This sovereign abandoned himself to the profligacy of the era. It is doubtful whether his reason was not unhinged. Some accounts say that he fell into a state of lunacy; others, that he practised magic arts At all events he died childless in 1428, and was succeeded by a grandson of the Emperor Sukō, Go-Hanazono, then in his tenth year. Thus, the claims of the Southern dynasty were ignored twice consecutively, and its partisans made armed protests in the provinces, as has been already noted. But these struggles proved abortive, and thereafter history is no more troubled with such episodes. The Daikagu-ji line disappears altogether from view, and the throne is occupied solely by representatives of the Jimyō-in. There can be very little doubt that the former was the legitimate branch; but fortune, was against it.

\section{YOSHIMOCHI, YOSHIKAZU, AND YOSHINORI}

Yoshimochi, son of Yoshimitsu, became shōgun (1395) at the age of nine, and the administration was conducted by Hosokawa Mitsumoto, Shiba Yoshishige, and Hatakeyama Mitsuiye. Twenty-eight years later, that is to say, in 1423, he abdicated in favour of his son, Yoshikazu. The cause of that step deserves notice. Yoshimitsu had intended to pass over Yoshimochi, his first-born, in favour of his second son, Yoshitsugu, but death prevented the consummation of that design. Yoshimochi, however, knew that it had been entertained. Therefore, after the death of their father, he seized Yoshitsugu, threw him into 


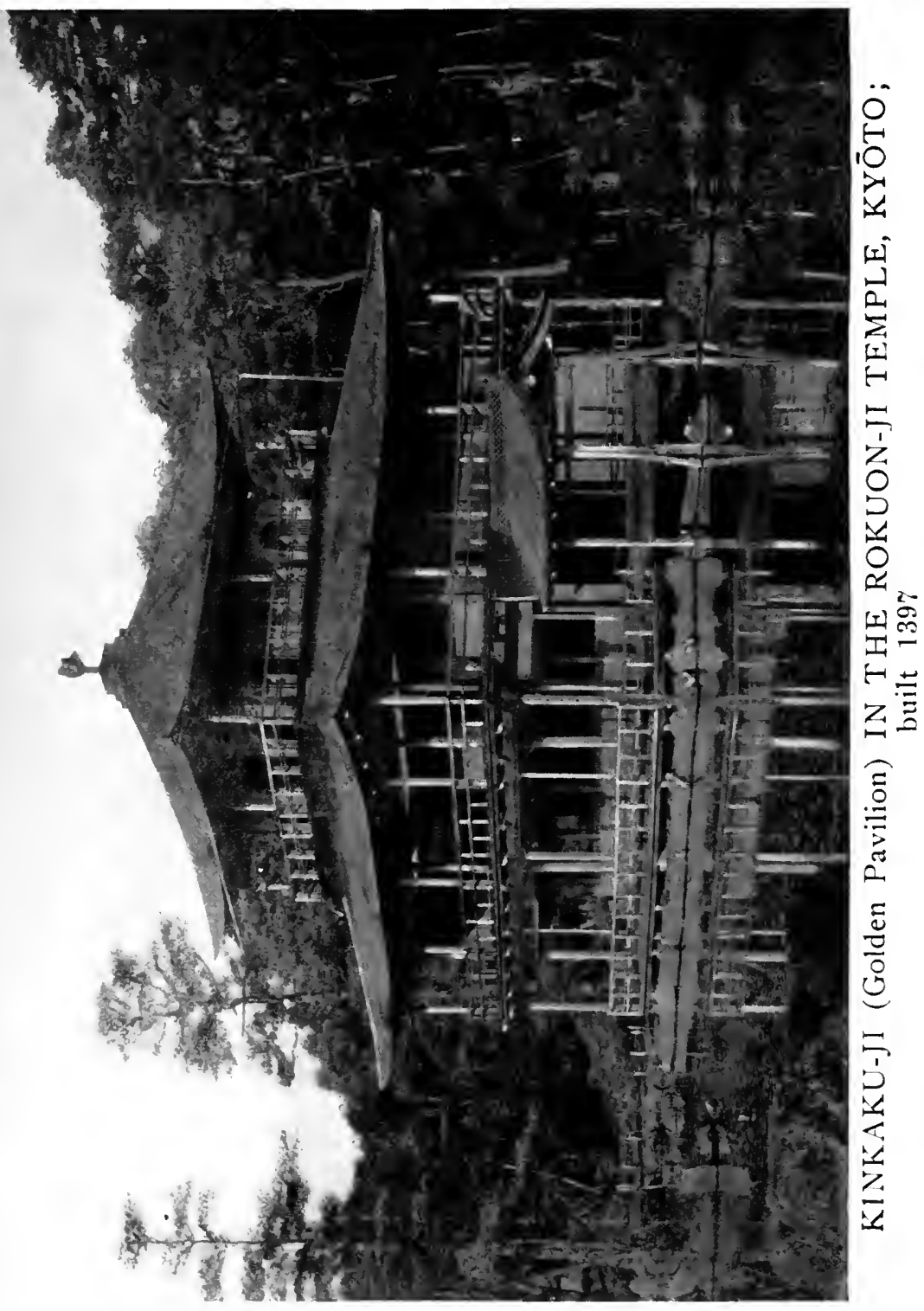



prison, and ultimately caused him to be killed. With the blood of his younger brother on his hands he abdicated in favour of his own sixteen-year-old son, Yoshikazu. But the latter died - some historians say that dissipation destroyed him - in two years, and having no second son to succeed, Yoshimochi himself resumed the office of shogun; holding it until his death, in 1428.

9'D During his thirty-three years' tenure of power this ruler seems to have aimed solely at enjoying the sweets of ease and tranquillity. He left the provinces severely alone and thought only of the peace of the metropolis." Turbulent displays on the part of self-appointed partisans of the Southern Court; intrigues in the Kwanto ; revolts among his own immediate followers - all these things were treated by Yoshimochi with gloved hands so long as the atmosphere of Kyoto wás not troubled. In 1428 , he fell sick, and, the end being in sight; he ordered his advisers to consult about his successor. Some advocated the appointment of his kinsman, Mochiuji, governor-general of the Kwantō, and $\mathrm{Mo}^{-}$ chiuji himself prayed that it should be so. But the choice ultimately fell on Yoshimochi's younger brother, Gien, who had embraced religion and was then serving as abbot of the temple Shoren-in.

This man, then in his thirty-fourth year, hesitated to accept the nomination, but was induced to do so. He changed his name to Yoshinori, and assuming the office in 1428 , showed high talents and great intrepidity. "He was, in truth, a ruler as efficient as his predecessor had been perfunctory. One of the most important events of his time was the ruin of the Ashikaga Bakufu at Kamakura. Between Kamakura and Muromachi there had been friction from an early date. We have seen the second and third governors-general of the Kwantō, Ujimitsu and Mitsukane, plotting to supplant the elder branch of their family in Kyōto, and we have seen how the accession of the priest, Yoshinori, had disappointed the ambition of the fourth governor-general, Mochiuji, who, if unable to become shögun himself; would fain have obtained that high office for his son; Yoshihisa. Several years previously, namely, in 1417 , there had occurred a feud! between the Yamanouchi and the Ögigayatsu branches of the Uesugi family in the Kwanto, the former represented by Norimoto, the latter by Ujinori. The Uesugi stood next to the Ashikaga at Kamakura, the important office of manager (shitsuji) being invariably held by the head of the former house.' It would have been well-nigh impossible therefore for the governor-general to view such a feud with indifference. Mochiuji, then in his twentieth year, sympathized with Norimoto, and in the sequel, Ujinori, with whom was allied Mochiuji's younger brother, Mochinaka, took the field at the head of such a force that the governorgeneral must have succumbed had not the shog un, Yoshimochi, rendered aid.

This should have placed Kamakura under a heavy debt of gratitude to Muromachi! But Mochiuji was not subject to such emotions. He rebelled vehemently against the lenient treatment accorded to Ujinori's son after their father's death, and the shog un had difficulty in placating him. So long, however, as Yoshimochi ruled in Kyōto, the Kamakura kwanryō abstained from further intrigues; but on the accession of the sometime bonze, Yoshinori, to the shoggnate, all sense of restraint was removed. The governor-general now made no attempt to conceal his hostility to the Muromachi shoggun. Certain family rights imperatively demanding reference to the shogun were not so referred, and Mochiuji not only spurned the remonstrances of the manager (shitsuji), Uesugi Norimoto, but even attempted to kill the latter's son, Norizane. All efforts to reconcile the Kwanto and the shitsuji proved futile, and Norizane had to flee to Kōtsuke. No sooner did these things come to the ears of the shogun, 
Yoshinori, than he obtained an Imperial commission to quell the insurgents, and placing an army under the orders of Mochifusa, a son of Ujinori, directed him to march against Kamakura.

At first it seemed as if the Kamakura men would emerge victorious. At the easily defended passes of Hakone they inflicted several successive though not signal defeats upon Mochifusa's army. But the appearance of Norizane in the field quickly changed the complexion of the campaign. Very soon the Kamakura force was shattered, and Mochiuji himself fled to the temple Shomyōo-ji in Kanazawa, where be begged to be allowed to retire from the world. But the shogun declined to pardon him and remained obdurate in spite of earnest and repeated petitions from Norizane, praying that Mochiuji should be forgiven and allowed to retire in favour of his son, Yoshihisa. In the end, Mochiuji, his son; his uncle, and many others all died by their own hands. These things happened in 1439. The redeeming feature of the sombre family feud was the fine loyalty of Norizane. Though it had been against him chiefly that Mochiuji raged, and though his death was certain had he fallen under the power of the Kamakura kwanryō, Mochiuji's fate caused him such remorse that he attempted to commit suicide and finally became a priest. Thenceforth, the title of governor-general of the Kwanto passed to the Uesugi, two of whom were appointed to act simultaneously. As for the Kamakura Ashikaga, the three remaining sons of Mochiuji fled to Koga in Shimōsa, where two of them, were subsequently killed by a Kamakura army, and the third, Shigeuji, fared as has already been described.

\section{ASSASSINATION OF THE SHŌGUN}

It has been shown that Akamatsu Norimura was among the captains who, contributed most to the triumph of the Ashikaga cause. In recognition of his distinguished services the offices of high constable in the five provinces of Settsu, Inaba, Harima, Mimasaka, and Bizen were given to his three sons? Mitsusuke, grandson of the eldest of these, administered three of the above provinces in the days of the fourth Ashikaga shōgun, Yoshimochi. A puny man of contemptible presence, Mitsusuke received little consideration at Muromachi, and the shoggun was induced to promise his office of high constable to a handsome kinsman, Mochisada. Enraged at such partiality, Mitsusuke set fire to his mansion in Kyōto and withdrew to his castle at Shirahata in Harima: When; however, the shoggun would have sent an army against him, none was found to take command, Mochisada having given universal offence by his haughty arrogance. In the sequel, Mitsusuke had to be pardoned and Mochisada ordered to kill himself.

After the death of the shoggun, Yoshimochi, Mitsusuke fell into fresh trouble. The new shögun, Yoshinori, belonged to a very different category of men from his immediate predecessors. He conquered the Kitabatake family in Ise; repressed the remnants of the Southern Court league; crushed the military monks by capturing Nara and Hiei-zan; put an end finally to Kamakura!s intrigues; obtained control of the west, and quelled his enemies in all directions. It now became his task to bend to his will the overstrong and over-presumptuous among the concerted families of the Ashikaga., Foremost of these were the Akamatsu, their chief, a man whose personality invited contumely: The shōgun disliked Mitsusuke, and found it an agreeable occupation to slight him. Gradually the Akamatsu leader became bitterly estranged. Moreover, he saw his younger sister executed for disobedience though she was the shögun's mistress; 
he saw the nephew of his old enemy, Mochisada, treated with marked favour by the Muromachi potentate, and he learned, truly or untruly, that his own office of high constable was destined to be bestowed on this favourite.

It was now the time when Kamakura's mischievous potentialities had been finally destroyed, and to commemorate the event, entertainments in the shoggun's honour were organized by the heads of the great military families. On the 6th of August, 1441, it fell to Akamatsu Mitsusuke to act as his.host. So soon as the shogun and his personal attendants had passed the portals of the Akamatsu mansion, the horses in the stables were set free as though by accident; the gates were closed to prevent the escape of the animals; Yoshinori with his small retinue, being thus caught in a trap, were butchered; the mansion was fired, and Mitsusuke with seven hundred followers rode off in broad daylight to his castle in Harima, whence, assisted by the monk, Gison, he sent circulars in all directions inciting to revolt. Thus miserably perished a ruler whose strong hand, active brain, and fearless measures, had he been spared a few years longer, might have saved his country from some of the terrible suffering she was destined to undergo in the century and a half subsequent to his death. He did not live long enough to reach a high place in history. But all his measures were designed to make for the eradication of immorality and corruption, and for the restoration of law and order throughout the country. His fault seems to have been precipitancy. So many suffered by his reforms, and in such quick succession, that the hatred he provoked could scarcely have been kept within control. In the matter of finance, too, he resorted, as will be presently seen, to devices quite irreconcilable with just administration.

\section{YOSHIKATSU AND YOSHIMASA}

The murder of Yoshinori left the shoggun's office without any designate occupant, but the heads of the great military families lost no time in electing Yoshikatsu ${ }^{1}$, the eight-year-old son of Yoshinori, and at the latter's nominal instance the Emperor ordered him to attack his father's assassin. The three Yamana chiefs, Mochitoyo (called also Sozzen, or the "Red Monk," one of the ablest captains of his country), Noriyuki, and Norikiyo; the Hosokawa chief, Mochitsune; and Sadamura, representing the Akamatsu family, all joined forces for the expedition, and presently an army of fifty thousand men sat down before Shirahata Castle. In October, 1441, the stronghold fell. Mitsusuke perished, and the three provinces he had administered were transferred to the Yamana Harima to Mochitoyo, Mimasaka to Norikiyo, and Bizen to Noriyuki.

We have seen how, in 1392, the Yamana family was shattered in a revolt against the authority of the shogun, Yoshimitsu. We now see the fortunes of the family thoroughly rehabilitated. The young shogun, however, did not long survive the punishment of his father's murderers. He died in 1443, at the age of ten, and was succeeded by his brother Yoshimasa, then in his eighth year. During the latter's minority, the administration fell into the hands of Hatakeyama Mochikuni and Hosokawa Katsumoto, who held the office of Muromachi kwanryo alternately. The country now began to experience the consequences of Yoshinori's death before his plans to limit the power of the great military septs had matured. Disorder became the normal condition in the provinces. The island of Kyūshū took the lead. There the Shōni, the Kikuchi, the Ōtomo, and the Shiba had always defied a central authority, and now Norishige, a young-

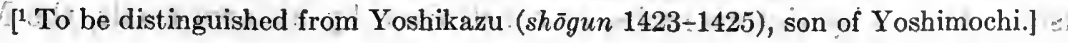


er brother of the assassin, Akamatsu Mitsusuke, found among them supporters of a scheme to restore the fortunes of his house. In the Kwantō partisans of the late kwanryō, Mochiuji, raised their heads. In the home provinces the warriorpriests of Nara sought to avenge the chastisement they had suffered at Yoshinori's hands, and among the immediate entourage of Muromachi, the Hosokawa, the Hatakeyama, the Shiba, and others engaged in desperate struggles about questions of succession.

Even when he reached man's estate, Yoshimasa proved wholly incompetent to deal with these complications. He abandoned himself to dissipation and left everything, great or small, to be managed by his wife, Fujiwara Tomiko, and

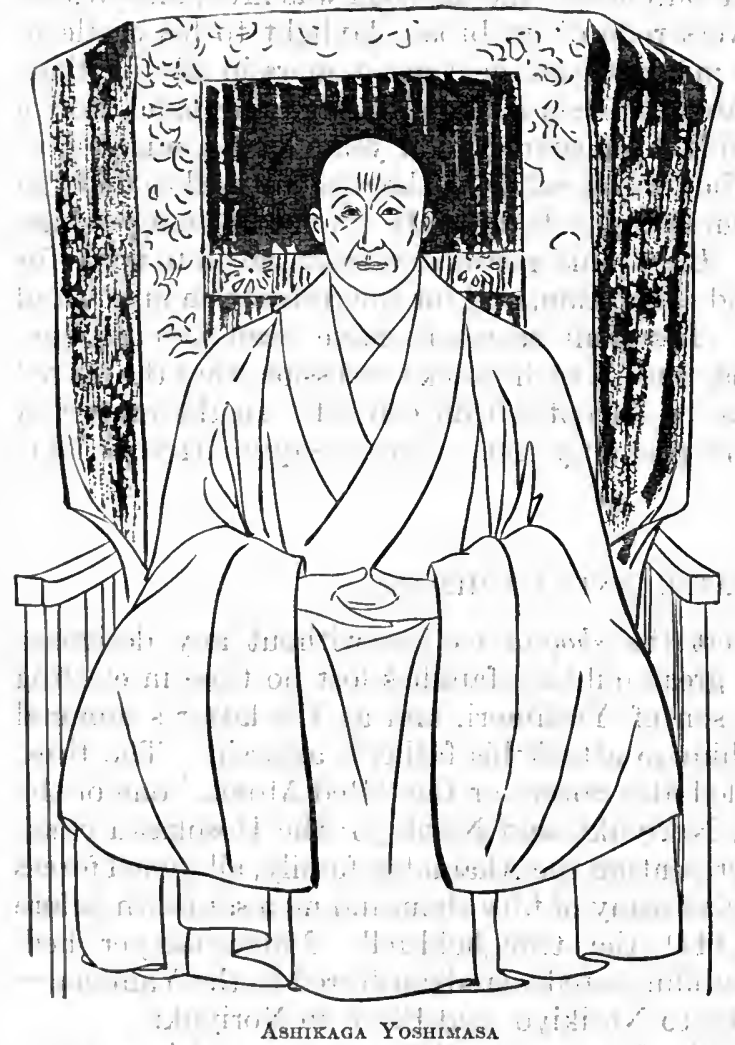
by his consort, Kasuga no Tsubone Bribery and corruption were the motive forces of the time. The innocent were punished; the unworthy rewarded. The shogin remained indifferent even when his mandates were neglected or contravened. The building of splendid residences, the laying out of spacious parks, the gratification of luxurious tastes, and the procuring of funds to defray the cost of his vast extravagance - these things occupied his entire attention.

\section{THE TOKUSEI}

Associated with the Ashikaga shōgunate is a financial device known in history as tokusei, a - term signifying "virtu ous administration." Originally imported from China; the tokusei meant nothing more than a temporary remission of taxes in times of

distress. But during the financial straits to which the country was reduced after the Mongol invasion, the Hōjō deemed it necessáry to afford relief to landowners who had mortgaged their property, and thus, in 1297 , a law tokusei-rei - was enacted, providing that eviction for debt must not be enforced. Under the Ashikaga, the tokusei received a still wider import. It was interpreted as including all debts and pecuniary obligations of any kind. In other'words; the promulgation of a tokusei ordinance meant that all debtors; then and there; obtained complete relief. The law was not construed exactly alike everywhere. Thus, in Nara a debtor must discharge one-third of his obligation before claiming exemption, and elsewhere a nominal sum had to be paid for release. Naturally, legislation so opposed to the fundamental principles of integrity. led to flagrant abuses: Forced by riotous mobs, or constrained by his own needs, the Muro- 
machi shōgun issued tokusei edicts again and again, incurring the hot indignation of the creditor class and disturbing the whole economic basis of society. Yoshimasa was conspicuously reckless; he put the tokusei system into force thirteen times.

\section{EXTRAVAGANCE AND INCOMPETENCE OF YOSHIMASA}

ho It is stated in the records of the $\bar{O}$ nin era (1467-1469) that Yoshimasa subordinated his duties altogether to his pleasures, and that his thoughts seemed to turn wholly on banquets and fêtes. His favourites, 'especially females, had the control of affairs and were the final arbiters in all important matters. Thus, a domain which had been in the undisputed possession of a family for generations might be alienated in favour of any claimant sufficiently unscrupulous and sufficiently rich to "commend" his title, and a judgment delivered by a court of law in the morning was liable to be reversed in the evening by the fiat of the ladies in the Muromachi "palace." Stability of policy had no existence. In a period of twenty-four years $(1444-1468)$, three sentences each of punishment and pardon were pronounced in the case of the Hatakeyama family; and in twenty years, Yoshikado and Yoshitoshi of the Shiba sept were each punished and pardoned three times. In Kyoto it became a current saying that loyal acts; not evil deeds, were penalized; and the truth of the comment found confirmation in the case of an official, Kumagaya, who was dismissed from his post and deprived of his property for venturing to memorialize the shogun in a critical manner.

Lire'These same records of the $\bar{O}$ nin year-period also make clear that one of the factors chiefly responsible for the disturbance was Yoshimasa's curious lack of sympathy with the burdens of the people. Even one grand ceremony in the course of from five to six years sufficed to empty the citizens' pockets. But in Yoshimasa's time there were nine of such fêtes in five years, and four of them had no warrant whatever except pleasure seeking - as a performance of the Sarugaku mime on an immense scale; a flower-viewing party; an al-fresco entertainment, and a visit to the cherry blossoms. On each of these occasions the court officials and the military men had to pawn their estates and sell their heirlooms in order to supply themselves with sufficiently gorgeous robes, and the sequel was the imposition of house taxes and land taxes so heavy that the provincial farmers often found vagrancy more lucrative than agricultural industry. Pawnshops were mercilessly mulcted. In the days of Yoshimitsu, they were taxed at each of the four seasons; in Yoshinori's time the same imposts were levied once a month, and under Yoshimasa's rule the pawnbrokers had to pay nine times in November, 1466 , and eight times in December of the same year.

Even after full allowance has been made for exaggeration, natural in the presence of such extravagance, there remains enough to convict Yoshimasa of something like a mania for luxury. He built for himself a residence so splendid that it went by the name of the Palace of Flowers (Hana no Gosho) and of materials so costly that the outlay totalled six hundred thousand strings of cash $;^{1}$ and he built for his mother, Shigeko, a mansion concerning which it is recorded that two of the sliding doors for the interior cost fwenty thousand" strings. ${ }^{2}$ Yet at times this same Yoshimasa was reduced to such straits for money that we read of him borrowing five hundred "strings" on the security of his armour, to pay for a parturition chamber.

The Palace of Flowers came into existence in 1459 , just on the eve of a period 
of natural calamitics which culminated in famine and pestilence. In 1462, these conditions were at their worst. From various provinces people flocked to the capital seeking food, and deaths from starvation became frequent in the city: A Buddhist priest, Gwana, constructed grass huts to which the famished sufferers were carried on bamboo stretchers to be fed with soft, boiled millet. It is recorded that, during the first two months of 1462 , the number of persons thus relieved totalled eighty-two thousand. Another Buddhist priest erected a monument to the dead found in the bed of the river below the bridge, Gojō. They aggregated twelve hundred. Scores of corpses received no burial, and the atmosphere of the city was pervaded with a shocking effluvium.

But even the presence of these horrors does not seem to have sobered the Muromachi profligate. The costly edifices were pushed on and the pcople's resources continued to be squandered. Even the Emperor, Go-Hanazono, was sufficiently. shocked to compose a couplet indirectly censuring Yoshimasa, and a momentary sense of shame visited the sybarite. But only momentary. We find him presently constructing in the mansion of his favourite retainer, Ise Sadachika, a bath-house which was the wonder of the time, a bath-house where the bathers were expected to come robed in the most magnificent costumes. One of the edifices that formed part of his palace after his retirement from active life, in 1474, was a "Silver Pavilion" intended to rival the "Golden Pavilion" of his ancestor, Yoshimitsu. During the last sixteen years of his life $\rightarrow$ he died in 1490 - he patronized art with a degree of liberality that atones for much of his previous profligacy. In the halls of the Jishō-ji monastery, constructed on a grand scale as his retreat in old age, he collected chefs d'cuvre of China and Japan, so that the district - Higashi-yama - where the building stood became to all ages a synonym for choice specimens, and there, too, he instituted the tea ceremonial whose votaries were thenceforth recognized as the nation's arbitri elegantiarum. Landscape gardens also occupied his attention. Wherever, in province or in capital, in shrine, in temple, in private house, or in official residence,

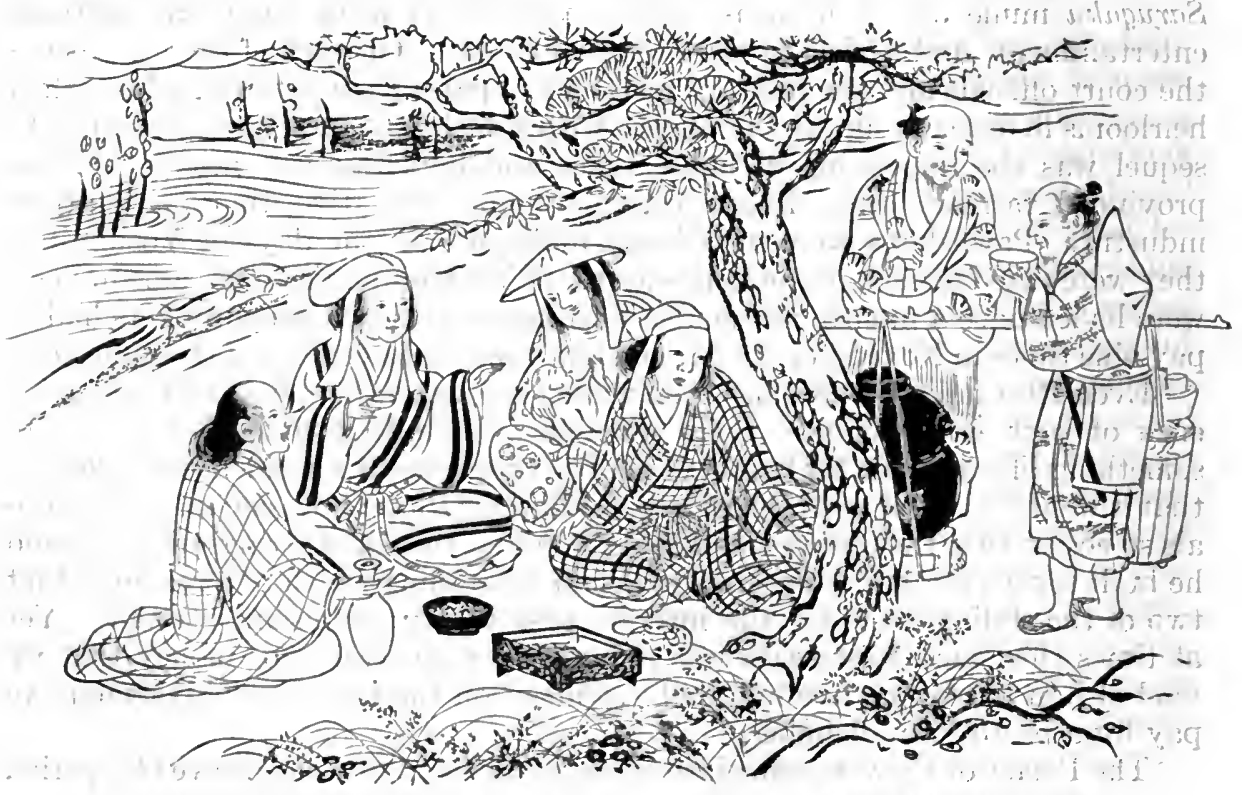

A Picnic duriso the Flower Season in the Ashikaga Period 
any quaintly shaped rock or picturesque tree was found, it was immediately requisitioned for the park of Higashi-yama-dono, as men then called Yoshimasa, and under the direction of a trio of great artists, Sō-ami, Gei-ami, and Nō-ami, there grew up a plaisance of unprecedented beauty, concerning which a poet of the time wrote that "every breeze coming thence wafted the perfume of tea." The pastimes of "listening to incense," of floral arrangement, of the dramatic mime, and of the parlour farce were all practised with a zest which provoked the astonishment even of contemporary annalists.

All this contributed materially to educate the nation's artistic faculties, but the cost was enormous and the burden of taxation correspondingly heavy. It was under this financial pressure that Yoshimasa approached the Ming emperor seeking pecuniary aid. Thrice the shögun's applications were successful, and the amounts thus obtained are said to have totalled three hundred thousand strings of eash (equivalent of $£ 450,000$, or $\$ 2,200,000$ ). His requests are said to have assumed the guise of appeals in behalf of famine-stricken people, but there is no evidence that any of the presents were devoted to that purpose. Partial apologists for Yoshimasa's infatuation are not wanting. Thus, it is alleged that he was weary of failure to reform the administration; that the corruption and confusion of society induced him to seek consolation in art; that outside the precincts of his palace he was restrained by the provincial magnates, and inside he had to obey the dictation of his wife, Tomi, of her brother, Katsumitsu, and of 'his own favourite page, Ise Sadachika, so that only in his tea reunions and his private theatricals could a semblance of independence be obtained; that his orders were not obeyed or his injunctions respected by any save the artists he had gathered around him, and that in gratifying his luxurious tastes, he followed the example of his grandfather, Yoshimitsu. But such exculpations amount to saying that he. was an essentially weak man, the slave of his surroundings.

\section{THE KWANTŌ TUMULT}

The lawlessness of the time and the indifference with which the shogun's mandates were treated find illustration in the story of the Kwanto . When (1439) Mochiuji perished, the only member of his family that survived was his five-year-old son, Shigeuji. This child placed himself under the protection of Muromachi. It will be remembered that Uésugi Norizane, lamenting his unwilling share in Mochiuji's destruction, had entered religion. His son', Noritada, was then appointed to act as manager (shitsuji) to Shigeuji, his colleague being Uesugi Akifusa (Ōgigayatsu Uesugi). But the Yùki familý, who had given shelter to two sons of Mochiuji, objected to bow their heads to the Uesugi, and persuaded Shigeuji to have Noritada killed.: Therefore, the partisans of the murdered man placed themselves under the banner of his brother, Fusaaki, and having received a commission from Muromachi as well as a powerful contingent of troops under Tmagawa Noritada, they marched in great force against Kamakura from Kōtsuke, Kazusa, and Echigo.

Kamakura was well-nigh reduced to ruins, but Shigeuji retired to the fortress of Koga in Shimōsa, and his cause against the Uesugi was espoused by the eight families of Chiba, Koyama, Satomi, Satake, Oda, Yũki, Utsunomiya, and Nasu, thenceforth known as the "eight generals" of the Kwantō." Against such a league it was difficult to operate suceessfully. Masatomo, a younger brother of Yoshimasa, built for himself a fortress at Horigoe, in Izu, which was thereafter known as Horigoe Gosho (the Horigoe Palace); Shigeuji in his castle of Koga being 
designated Koga Kubō (the.Koga shōgun). Castle building acquired from this time greatly increased vogue. Uesugi Mochitomo fortified Kawagoe in Musashi; Ōta Sukenaga (called also Dōkan), a vassal of the Ōgigayatsu Uesugi, built at Yedo a fort destined to have world-wide celebrity, and his father, Sukekiyo, entrenched Iwatsuki in the same province of Musashi. Thus the Kwantō became the arena of warring factions.

\section{PREFACE TO THE ONIN WAR}

We now arrive at a chapter of Japanese history infinitely perplexing to the reader. It is generally called the $\bar{O}$ nin War because the struggle described commenced in the year-period of that name, but whereas the Onin period lasted only two years (1467-1469), the $\bar{O}$ nin War continued for eleven years and caused shocking destruetion of life and property. When war is spoken of the mind naturally conjectures a struggle between two or perhaps three powers for a cause that is respectable from some points of view. But in the Önin War a score of combatants were engaged, and the motive was invariably personal ambition. It has been described above that when the Ashikaga chief; Takauji, undertook to re-establish the Minamoto Bakufu, he essayed to overcome opposition by persuasion rather than by force. Pursuing that policy, he bestowed immense estates upon those that yielded to him, so that in time there came into existence holders of lands more extensive than those belonging to the shogun himself.: Thus, while the landed estates of the Muromachi shogun measured only $15,798 \mathrm{ch} \bar{o}^{1}$ there were no less than eight daimyō more richly endowed. They were:-

\section{Daimyo}

(1) Yanada Takasuke

(2) Uesugi Akisada.

(3) Ōuchi Mochiyo.

(4) Hosokawa Katsumoto

(5) Shiba Mochitane.

(6) Sasaki Takayori.

(7) Hatakeyama Yoshinari

(8) Sasaki Mochikiyo.
Area of Estates in chō (3 acres) 32,083

$$
27,239
$$

25,435

24,465

23,576

16,872

16,801

16,725

If we examine the list still more minutely, we find no less than twenty-two families, each of whose estates was equal to, or larger than, one-half of the Muromachi manors. Some families consisted of several branches whose aggregate properties represented an immense area. This was notably the case of the Yamana; their five branches held lands totalling 45,788 cho. The owners of such estates must not be confounded with the high constables (shugo). Thus Yamana Sōzen, as the high constable of Harima province, held administrative authority in fourteen districts covering an area of 10,414 cho, and if to this be added the expanse of his ficf, namely, $8016 \mathrm{ch} \bar{o}$, we get a total nearly equal to the manors of Hosokawa Katsumoto. Again, Shiba Yoshitoshi, in addition to owning 10,816 chō, officiated as tandai of Kyūshū, which gave him jurisdiction over another extent of $106,553 \mathrm{ch} \bar{o}$, though it is true that his authority was defied in the provinces of Satsuma and Ösumi. The military owner of one of these great estates levied a revenue on a scale which will be presently discussed, but the high constable was nominally empowered to collect and transmit only such taxes as were payable to the Bakufu, namely, the "military dues" (buke-yaku) and the "farmers' dues"' (hyakushō-yaku), whereof the former were originally assessed 
at two per cent., and subsequently raised to five per cent., of a family income; and the latter varied from one to two per cent of a homestead's earnings. So long as a high constable or a tandai was loyal to the Bakufu, the latter received the appointed quota of imposts; but in times of insurrection, the shugo or tandai appropriated to his own purposes the proceeds alike of the buke-yaku and the hyaküshō-yaku.

Not merely inequalities of wealth operated to produce political unrest. It has also to be noted that each great military family supported a body of armed. retainers whose services were at all times available; further; we must remember that the long War of the Dynasties had educated a wide-spread spirit of fighting; which the debility of the Ashikaga Bakufu encouraged to action. The Ōnin disturbance had its origin in disputes about inheritance. It has been recorded that the high post of kwanryo (governor-general) in the Muromachi polity was filled by a member of one of three families; the Hosokawa; the Hatakeyama, and the Shiba. The Hosokawa were the most powerful, and had for representative in the middle of the fifteenth century an administrator, Katsumoto, who to extensive erudition and a profound knowledge of medicine added very exceptional gifts of statecraft and organizing ability... The Hatakeyama had for head Mochikuni, called also Tokuhon, a man of parts; and it happened that the rival family of Yamanalwas led by Mochitoyo, or Sōzen, who, on account of his powerful physique, shaved head, and peculiar complexion, sometimes received the name of the "Red Monk" (Aka-nyūdō).

Tokuhon being without a legitimate son, adopted his nephew, Masanaga, but subsequently desired to secure the succession to Yoshinari, a son borne to him by a concubine. This change was not viewed with equanimity by all the vassals of Tokuhon, and to solve the problem the latter appealed to the shogun, Yoshimasa; who authorized the death of Masanaga. Tokuhon, in his capacity of kwanryō, naturally had much weight with the shogun, but Yoshimasa's conduct on that occasion must be attributed mainly to a laisser-aller mood which he had then developed, and which impelled him to follow the example set by the Imperial Court in earlier times by leaving the military families in the provinces tolfight their own battles. Masanaga sought succour from Hosokawa Katsumoto, and that magnate, welcoming the opportunity of avenging an old injury at the hands of the Hatakeyama, laid siege to the mansion of Tokuhon; who barely escaped with his life, his son, Yoshinari, fleeing to the fortress of Wakae, in Kawachi; whence he was presently driven by the forces of Katsumoto and Sơzen, then acting in conjunction but destined afterwards to become bitter enemies.

Yfishe shōgun, true to his complacent policy, now recognized Masanaga as head of the house of Hatakeyama, Tokuhon having just died (1455). But Yoshinari did not acquiesce. In 1456, he marched with a Kawachi army against Masanaga, and a deadly struggle was barely prevented by the intervention of the shogun. Thenceforth, the Hatakeyama became divided into two families; Masanaga's branch being the more powerful, but Yoshinari obtaining favour at Muromachi and being nominated kwanry $\bar{o}_{\text {.t. }}$ Owing, however, to some petty causes, the shogun's good-will was subsequently estranged, and Yoshinari had to flee from Kyōto, pursued by Masanaga, who now held a commission from Muromachi to kill him: A seven-years' fight (1460-1467) ensued in Kawachi and Yamato. Yoshinari displayed greatly superior skill as a strategist, and finally Yamana Sōzen, who had always entertained a good opinion of him even while opposing his succession at the outset, openly espoused Yoshinari's eause. 
The immediate result was that Masanaga, who had béen named kwanryō in 1464, had to give way to Sōzen's nominee, Shiba' Yoshikado, and found himself in deadly peril.

It is necessary hore to recall the murder of the shogun Yoshinori, in 1441 . That crime had resulted in the fall of the Akamatsu family, the direct agent of its overthrow being the united forees of Hosokawa, Takeda, and Yamana. There were no bonds of genuine friendship between the Hosokawa chief, Katsumoto, and Yamana Sōzen. 'Their union was primarily due to Katsumoto's ambition. He desired to break the power of Hatakeyama Tokuhon, and with that ultimate object he courted the alliance of Sozzen, giving his own daughter to the latter in marriage and himself adopting Sōzen's son, Koretoyo: Thus, the two chiefs were subsequently found aeting together against Tokuhon's attempt to substitute his son, albeit illegitimate, for his nephew, as heir to the Hatakeyama estates. Neither Katsumoto nor Sōzen cared anything about the succession itself. Their object was simply to crush the Hatakeyama; and Sōzen, who never relied on argument where force was applicable, lost no time in attacking Tokuhon and driving him from his burning mansion, as has been already stated. From the legal consequences of that violence, Sōzen was 'saved by Katsumoto's intercession at Muromachi, and the alliance (1454) between the Hosokawa and the Yamana seemed stronger than ever. But Sōzen did not greatly trust his crafty ally, with whose gifts of political strategy he was well acquainted. He suspected Katsumoto of a design to restore the fortunes of the once powerful Akamatsu family, and he began to muster forces for the great struggle which he anticipated. Therefore it was that, in 1467 , as shown above, he not only espoused the cause of Hatakeyama Yoshinari, in whom he recognized an able captain, but also championed Shiba Yoshikado.

With regard to this latter, it is necessary to recognize that he also figured in a succession dispute. : The great family of Shiba being without a direet heir; a relative was appointed to the headship in 1452. This successor, Yoshitoshi; attempting to enforce the acquiescence of one of his vassals, was defeated and became a fugitive, a suceessor, Yoshikado, being nominated by the Shiba vassals? But a sister of the fugitive subsequently married the shogun's favourite, Ise Sadachika, and through her influence the shogun was induced (1466) to recall Yoshitoshi and to declare him rightful head of the Shiba family: Yamana Sozen, who had given his daughter in marriage to Yoshitoshi's rival, Yoshikado, immediately set a powerful army in motion for Kyōto; and the alarmed shōgun (Yoshimasa) not only recognized Yoshikado and drove out Yoshitoshi, but also nominated the former to be kwanryō.

From this grievously complicated story the facts which emerge essentially and conspicuously are: first, that Yamana Sozzen now occupied the position of champion to representatives of the two great families of Hatakeyama and Shiba; secondly, that the rival successors of these families looked to Hosokawa Katsumoto for aid; thirdly, that the relations between Sozzen and Katsumoto had become very strained, and fourthly, that the issue at stake in every case was never more lofty than personal ambition.. The succession to the shoggunate also was in dispute. Yoshimasa, being childless, desired to adopt as his heir his younger brother who had entered religion under the name of Gijin. The latter deelined the honour until Yoshimasa swore that were a son subsequently born to him, it should be made a priest but never a shögun. Gijin then took the name of Yoshimi, and was for a time recognized as heir-apparent, Hosokawa Kátsumoto being appointed manager" (shitsuji). Presently, however, the shogun's 
consort, Tomi, gave birth to a boy, Yoshihisa, and the mother persuaded Yoshimasa to contrive that her son should supplant the sometime priest. 'Of necéssity, the aid of Sōzen was sought to accomplish this scheme, Katsumoto being already officially attached to Yoshimi. The Yamana chief readily assented, and thus the situation received its final element, a claimant whose right rested on a deliberately violated oath.

\section{THE $\bar{O} N I N$ WAR}

By the close of 1466 , the two great protagonists, Katsumoto and Sozzen, had quietly collected in Kyōto armies estimated at 160,000 and 110,000 men; respectively. The shogun attempted to limit the area of disturbance by ordering that the various rival inheritors should be left to fight their own battles, and by announcing that whoever struck the first blow in their behalf would be proclaimed a rebel Such injunctions were powerless, however, to restrain men like Sōzen. In February, 1467, his followers attacked the former kwanrȳo, Hatakeyama Masanaga, and drove him from the capital. Katsumoto made no move, however; he remained on the watch, confident that thus the legitimacy of his caise would obtain recognition. In fact, the shögn was actually under guard of the Hosokawa troops, who, being encamped on the east and north of Muromachi, received the name of the Eastern Army; the Yamana forces, which were massed on the west and south, being distinguished as the Western Army.

II It It was evident that if either side retreated, the other would perforce be acknowledged by the Bakufu, and both were reluctant to put their fortunes to the final test. At length, early in July, 1467, a petty skirmish precipitated a general engagement. It was inconclusive, and the attitude of mutual observation was resumed. Two months later re-enforcements reached the Western Army, and thereafter, for nearly two years, victory rested with the Yamana. But Katsumoto clung desperately to his position. Kyōto wàs reduced almost completely to ruins, the Imperial palace, Buddhist temples, and other mansions being laid in ashes, countless rare works of art being destroyed, and the Court nobles and other eivil officials being compelled to flee to the provinces for shelter. A celebrated poet of the time said that the evening lark soared over moors where formerly there had been palaces, and in the $\bar{O}$ nin Records it is stated that the metropolis became a den for foxes and wolves, and that Imperial mandates and religious doctrines were alike unheeded.

At one time things looked as though the ultimate triumph must be with Sōzen. But what Katsumoto lacked in military ability he more than compensated in statecraft. From the outset he took care to legalize his cause by inducing the Emperor and the ex-Emperor to remove to Muromachi, where they were guarded by the Hosokawa troops, and the defections to which this must ultimately expose Sōzen's ranks were supplemented by fomenting in the domains of the Yamana and their allies intrigues which necessitated a diversion of strength from the Kyotto campaign. Curious and intricate was the attitude of the Hosokawa towards the rival aspirants to the 'shōgunate. Sōzen's aid, as related above, had originally been invoked and exercised in behalf of Yoshimasa, the shogrun's son by the lady Tomi.

Hence, it is not surprising to find the Yamana leader turning his back upon the sometime bonze, Yoshimi, in October, 1469. But it is surprising to see him openly espouse this same Yoshimi's cause two months later. The fact was that Sozzen might not choose. He had been outmanœuvered by his astute 
opponent, who now held complete control of the shogun, and who not only obtained an Imperial decree depriving Yoshimi of his offices, but also contrived that, early in 1469, the lady. Tomi's four-year-old son, Yoshihisa, should be officially declared heir to the shogunate. 'In this matter, Katsumoto's volteface had been nearly as signal as Sōzen's, for the former was Yoshimi 's champion at the beginning. Henceforth the war assumed the character of a struggle; for the succession to the shōgunate. The crude diplomacy of the Yamana leader was unable to devise any effective reply to the spectacular pageant of two sovereigns, a shōgun, and a duly-elected heir to the shōgunate all marshalled on the Hosokawa side. Nothing better was conceived than a revival of the Southern dynasty, which had ceased to be an active factor seventy-eight years previously. But this farce did little service to the cause of the Yamana: By degrees the hostile forces withdrew from the capital, of which the western half (called Saikyō) alone remained intact, and the strategy of the hostile leaders became concerned chiefly about preserving their own commissariat or depriving the enemy of his.

In 1472, a new feature was introduced: Hatakeyama joined the Eastern Army by order of the shögun, Yoshimasa. This was not merely a great accession of numerical strength, it also opened the road to the north where the Hatakeyama estates lay, and thus the Eastern Army found a solution of the problem which dominated the situation at Kyoto - the problem of provisions: The scale of success now swung in the direction of Hosokawa and his allies. But still no crushing victory was won, and meanwhile the war had continued seven years, with immense loss of life and treasure. : There is evidence that alike Katsumoto and Sōzen were fain to sheathe the sword in 1472, but during the long struggle conditions had developed which rendered peace difficult. In May, 1473, Sọzen died and was followed to the grave in less than a month by Katsumoto. Still the struggle went on in a desultory way until December; 1477, when the Yamana forces burned their cantonments and withdrew, Yoshimi coming to terms with Muromachi and retiring to Mino. Peace at length dawned for Kyoto. But not yet for the provinces. There the sword was not immediately sheathed. In Echizen, Owari, and Tōtomi the great Shiba family was subjected to weakening onsets by the Asakura, the Oda, and the Imagawa: In Kaga, the Togashi house was divided against itself. In Kyüshū there were bitter struggles between the Shimazu and the Itō, the Sagara and the Nawa, and the Ōtomo, the Shoni, and the Ōuchi. Finally, Shinano, Suruga, Mikawa were all more or less convulsed.

\section{YOSHIHISA}

In 1474, Yoshimasa retired from office and, at the close of the year, his nineyear-old son, Yoshihisa, succeeded him as shogun, the kwanryo being that Hatakeyama Yoshinari whose appearance in the field practically terminated the Ōnin War. The shogun Yoshimasa was in his thirty-ninth year at the time of this abdication, and he survived for sixteen years, not the least dissipated of his life, in which he instituted costly art reunions and carried self-indulgence to its extreme. During these years Tomi and her younger brother, Ise Sadachika, acquired such influence as to interfere in the administration, and under the pretext of procuring funds to rebuild the palace destroyed during the $\vec{O}$ nin War, they restored the toll-gates which had previously stood at the seven chief entrances to Kyōto, appropriating all the proceeds. 
J The young Yoshihisa could scarcely fail to be tainted by such an environment. Much to his credit, however, he showed sagacity and diligence, eschewing his father's luxurious habits, studying literature and military art, and taking lessons in statecraft from the ex-regent, Ichijō Kaneyoshi: Very early he became familiar with scenes of violence, for, goaded to madness by the taxes exacted at the seven toll-gates, a mob of the metropolitan citizens rose in arms, beat off the troops sent to quell them and threatened to sack the city; when, they were appeased by the issue of a tokusei ordinance, which, as already explained, meant the remission of all debts and the cancellation of all financial obligations. Socialism in such a genial form appealed not only to the masses but also to bushi, who had pledged their property as security for loans to meet warlike outlays or the demands of luxurious extravagance.

Alike in the home provinces and in distant Kaga, Noto, Etchū, and the south, tokusei riots took place. Notably incompatible with any efficient exercise of Muromachi authority was the independence which the provincial magnates had now learned to display. They levied what taxes they pleased; employed the proceeds as seemed good to them; enacted and administered their own laws; made war or peace as they wished, and granted estates or revenues to their vassals at will. In short, the bushi had gradually constructed for themselves a full suit of feudal garments, and to bring them once again under the effective control of the sovereign or the shogun was almost a hopeless task. Yoshihisa might perhaps have refrained from attempting it had the empire been at peace. But, in truth, the empire was on the threshold of a century-long struggle compared with which the $\bar{O}$ nin War proved a bagatelle. The mutterings of the coming storm made themselves very audible during the years of Yoshihisa's early manhood. The Uesugi septs, and the Hōjō and the Satomi, were fighting in the Kwantō; the western provinces, the central provinces, and Kyūshū were the scenes of constant conflicts, and no prospect of tranquillity presented itself. Yoshihisa determined to undertake the work of subjugating the whole country as Yoritomo had done effectually and as Takauji had done partially. But he died in his twenty-fifth year when engaged in conducting a campaign against the Rokkaku branch of the Sasaki family, in Ōmi province; a campaign which but for his death would certainly have been successful.

\section{YOSHITANE}

Yoshihisa, whose death took place in 1489 , left no son, and his father, the ex-shōgun Yoshimasa, made tardy atonement to his brother, Yoshimi, the sometime priest, by obtaining the high office of shōgun for the latter's son, Yoshitane, a youth of twenty-five. : In the following year Yoshimasa died, and, two years later (1492), Yoshitane placed himself at the head of an army to resume the Omi campaign which Yoshihisa's death had interrupted. His opponent was of Minamoto lineage, head of the Rokkaku branch of the Sasaki family, whose representative in the days of the Kamakura Bakufu had been high constable of four provinces, . $\overline{\mathrm{O}} \mathrm{mi}$, Izumo, Aki, and Iwami.

b) That the shogun, Yoshihisa, and his successor, Yoshitane, turned their -weapons so resolutely against this magnate was due to a cause illustrative of the abuses of the era. From the outset the Ashikaga sway over the provinces had been a vanishing quantity, and had disappeared almost entirely during the $\bar{O}$ nin War. Not alone did the writ of the sovereign or the shogun cease to run in regions outside Kyōto and its immediate vicinity, but also the taxes, though duly 
collected, did not find their way to the coffers of either Muromachi or the Court. Shugo there still existed, and jitō and kokushi; but neither high constable nor land-steward nor civil governor acted as practical representative of any Central Government: each functioned for his own hand; swallowing up for his own use, or for inclusion in some local fief, the manors which had once been the property of the State or of the Court nobility.

It was evidently of prime necessity from the Muromachi point of view that a state of affairs which crippled the shogun by impoverishing him should be remedied. Sasaki Takayori, head of the Rokkaku house, was a conspicuous product of his time. He had seized the manors of nearly fifty landowners in the province of $\bar{O} \mathrm{mi}$, and to punish his aggressions signally would furnish a useful object lesson. That was done effectually by Yoshitane's generals, and Sásaki had to flee from Ōmi. But the young shögun's triumph was short lived. $\mathrm{He}$ allowed himself to be drawn by Hatakeyama Masanaga into a private feud. We have already seen this Masanaga engaged with Yoshinari in a struggle for the Hatakeyama succession on the eve of the Ōnin War. Yoshinari was no longer alive, but he had bequeathed to his son, Yoshitoyo, a heritage of resentment against Masanaga, and the latter, who now held the post of kwanryo for the fourth time, induced the shogun to order an attack upon Yoshitoyo in the provinces of Kii and Kawachi. But Yoshitoyo managed to enlist the aid of the recently discomfited Sasaki, of the soldier-monks of Kōfuku-ji,; and, above all, of Hosokawa Masamoto, son of Hatakeyama Masanaga's old opponent, Hosokawa Katsumoto. With these co-operated the Yamana; the Isshiki, and other septs, so that Yoshitane found himself between two powerful armies, one in Kyōto, the other in Kii. In the sequel, Masanaga committed suicide, and the shōgun; Yoshitane, escaped to Șuwō.

\section{YOSHIZUMI AND YOSHIHARU}

Hosokawa Masamoto was now master of the situation in. Kyōto. It was for him to nominate a new shögun in lieu of the fugitive Yoshitane. He went to the Kwanto for a candidate. In 1461, Masatomo, brother of Yoshimása, had been nominated governor-general (kwanry $\bar{o})$ of the eight eastern provinces. His son, Yoshizumi, was chosen by Hosokawa to rule at Muromachi, and Hosokawa himself became kwanryō. The new shōgun held office in name only; all administrative power was usurped by the kwanryō and his nominees. Now, as Hosokawa Masamoto practised asceticism for the better pursuit of necromancy, in which he was a believer, he had no offspring. Therefore he adopted three sons: the first, Sumiyuki, being the child of the regent, Fujiwara-Masamoto; the second and third, Sumimoto and Takakuni, being kinsmen of his own. The first of these three was entrusted to Kasai Motochika; the last two ivere placed in the care of Miyoshi Nagateru. These guardians were Hosokawa's principal vassals in Shikoku; where they presently became deadly rivals. Motochika, believing that Hosokawa's ultimate intention was to elevate Sumimoto to the shōgunate, in which event the latter's guardian, Nagateru, woụld obtain a large access of power, compassed the murder of Hosokawa, the kwanryo, and proclaimed Sumiyuki head of the Hosokawa house. Thereupon Miyoshi Nagateru moved up from Shikoku at the head of a strong army, and, after a fierce conflict, Motochika and Sumiyuki were killed, and Sumimoto, then in his eleventh year; became chief of the Hosokawa family; receiving also the office of kwanryō. 
The Motochika faction, however, though defeated, were not destroyed. They conceived the plan of reinstating the shogun, Yoshitane, then a fugitive in the province of Suwo, and of securing the office of kwanryō for Takakuni, third son (by adoption) of the late Hosokawa Masamoto... The powerful Ouchi sept, which had its manors in Suwō, espoused the conspiracy, and escorted Yoshitane to Kyōto with a great army, the result being that the shōgun, Yoshizumi, had to flee to Ōmi; that Yoshitane took his place, and that Ouchi Yoshioki became deputy kwanryō.

These things happened in 1508. Thenceforth, the great protagonists in the Kyoto arena were the two factions of the Hosokawa house, led by Sumimoto and Takakuni, respectively; the former championing the cause of the shogun, Yoshizumi, and in alliance with the Miyoshi; the latter supporting the shoggun, Yoshitane, and aided by the Ōuchi: One reverse befell the Yoshitane-Ōuchi combination, but they quickly recovered from it; and from 1508 until 1518 a gleam of peace and prosperity shone once more in Kyōto under the administration of Ouchi Yoshioki, who governed with skill and impartiality, and whose influence seemed likely to restore the best days of the Bakufu. But, in 1518, he was recalled to his province by an attack from the shugo of Izumo, and by financial embarrassment resulting from his own generosity in supplying funds to the Crown and the shōgun.

Hosokawa Takakuni now became kwanryō, exercising his authority with a high hand. Then the Sumimoto branch of the Hosokawa, taking advantage of Ouchi's absence, mustered a force in Shikoku and moved against Kyōto. Takakuni found himself in a difficult position. In the capital his overbearing conduct had alienated the shogun, Yoshitane, and from the south a hostile army was approaching. He chose Hyogo for battle-field, and, after a stout fight, was discomfited and fled to Ōmi, the position of kwanryō being bestowed on his rival, Sumimoto, by the shögun. In a few months, however, Takakuni, in alliance with the Rokkaku branch of the Sasaki family under Sadayori, marched into Kyōto in overwhelming force. Miyoshi Nagateru retired to Chion-in, where he committed suicide; Sumimoto fled to Awa, dying there a few months later, and Yoshitane, after brief refuge in the island of Awaji, died in Awa, in 1523. Thus, Hosokawa Takakuni found himself supreme in Kyōto,.. and he proceeded to appoint a shogun, without awaiting the demise of Yoshitane. Yoshizumi, the eleventh shogun, who, as related above, fled from Kyōto in 1508 , dying three years later in exile, left two sons: Yoshiharu, whom he committed to the charge of Akamatsu Yoshimura, and Yoshikore, whom he entrusted to Hosokawa Sumimoto. In 1521, Takakuni invited Yoshiharu, then eleven years old; to the capital and procured his nomination to the shogunate.

\section{ANARCHY}

From this time forward the confusion grows worse confounded. The Miyoshi of Awa are found in co-operation with Yanamoto Kataharu espousing the cause of the shoggun's younger brother, Yoshikore, and of Harumoto, a son of Hosokawa Sumimoto. We see this combination expelling. Yoshiharu and Takakuni from Kyōto, and we see the fugitives vainly essaying to reverse the situation. Thereafter, during several years, there is practically no government in the capital. Riot and insurrection are daily features, and brigandage prevails unchecked. Kataharu, though not holding the office of kwanryo, usurps its functions so ostentatiously that the assassin's dagger is turned against him. 
Again the two Hosokawa chiefs, Takakuni and Harumoto, fight for power, and, in 1531, Takakuni is killed, Harumoto becoming supreme. Soon the Miyoshi brothers, Motonaga and Masanaga, engage in a fierce quarrel about their inheritance, and the former, with Yoshikore as candidate for the shogunate and Hatakeyama as auxiliary, raises the standard against Harumoto; who, aided by the soldier-priests of Hongwan-ji, kills both Yoshitaka and Motonaga and takes Yoshikore prisoner. 'Thereafter, Harumoto quarrels with the Hongwan-jibonzes, and being attacked by them, obtains the aid of Rokkaku Sadayori and the Nichiren priests, with the result that the splendid fane of Hongwan-ji is reduced to ashes. A reconciliation is then effected between Harumoto and the shogun, Yoshiharu, while Miyoshi Masanaga is appointed to high office. 'Yet once more the untiring Takakuni, aided by Miyoshi Norinaga, Motonaga's son, called also Chōkei," drives Yoshiharu and Harumoto from the metropolis, and presently a reconciliation is effected by the good offices of Rokkaku Sadayori, the real power of the $k w a n r y \bar{o}$ being thenceforth exercised by the Miyoshi family. Japanese historians have well called it an age of anarchy.

\section{YOSHITERU}

In 1545, the shogun, Yoshiharu, resigned in favour of his son, Yoshiteru. Two years of quiet ensued in Kyōto, and then the old feud broke out once more. The Hosokawa, represented by Harumoto, and the Miyoshi, by Chōkei, fought for supremacy. : Victory rested with the Miyoshi. The Hosokawa's power was shattered, and Chōkei ruled in Kyōto through his vassal, Matsunaga Hisahide. The era is memorable for the assassination of a shogun. Yoshiteru had become reconciled with Chōkei and was suffered to live quietly at Muromachi. But after Chōkei's death (he was poisoned by Hisahide), Yoshiteru's cousin, Yoshihide, a son of Yoshikore, sought to be nominated successor to the shōgunate through the aid of Masanaga and Hisahide. "In 1565, this plot matured. Hisahide suddenly sent a force which attacked Yoshiteru's palace and killed the shogun. "Yoshihide replaced the murdered potentate, and the Matsunaga family succeeded to the power previously wielded by the Miyoshi. Yoshiteru's younger brother, Yoshiaki, fled to Ōmi, but afterwards made his way to Owari, where Oda Nobunaga took him by the hand and ultimately placed him in the shögün's seat at Kyōto.

\section{REVIEW OF THE ASHIKAGA}

Among the fifteen representatives of the Ashikaga, two were slain by their own vassals, five died in exile, and one had to commit suicide. From the accession of Takauji, in 1338, to the death of Yoshiaki, in 1597, a period of 259 years, there was not so much as one decade of signal success and efficient government. With justice the story of the time has been summed up in the epithet "ge-koku-jo," or the overthrow of the upper by the lower. The appreciation of the eminent historian, Rai Sanyo, is most faithful. Every great conflict throughout the era was marked by similar features. It is a weary record of broken promises, violated allegiances, and family feuds. If the Hatakeyama, the Hosokawa, and the Miyoshi set their own interests above those of the shogun, the Ashikaga, in türn, sacrificed the interests of the Throne on the altar of their own ambition. A river cannot be purer than its source. If the Miyoshi vassals plotted against their chiefs, so did the latter against the Hosokawa; so 
did the Hosokawa against the Ashikaga; so did the Ashikaga against the Imperial family, and so did one-branch of the Imperial family against another. Everywhere there was lack of loyalty.

The loyalty wanting among masters was equally deficient among servants. There is no more treacherous episode in the Middle Ages than Matsunaga Hisahide's poisoning of his liege lord to compass the downfall of the Miyoshi family and slaying the shogun, Yoshiteru, to overthrow the Ashikaga, though he enjoyed the confidence of both. The Dai Nihon-rekishi (History of Great Japan) observes that the ethical primers, with which a literary education had formerly familiarized the nation, lost their influence in this military era. There was no inordinate desire for landed property until the Gen-Hei epoch, when a manor became the principal reward of a successful soldier. Thereafter, greed for domains acquired strength every year. Again, when Yoritomo became sō-tsuihoshi (commander-in-chief) and sō-jitōo (general steward) of the whole country, and his meritorious vassals were appointed shugo and jitō in each province, local authority passed from the Throne to the military families, and when, after the Shökyn struggle, the shugo and the jito came into actual possession of the estates they had previously administered, military feudalism was practically established. The Hōjō, by their just administration and astute measures, brought this system into esteem, but under the Ashikaga régime the reality of landed possession grew to be the unique aim of existence, and, to achieve it, sons forgot their paternal relation and vassals lost sight of fealty. The nation engaged in an armed scramble; individualism became paramount, and social obligations were ignored. This is the more noteworthy because loyalty is so typical a) Japanese virtue.

\section{THE ADMINISTRATION OF THE ASHIKAGA}

The common saying that the Kamakura Bakufu brought the entire country under one administrative control requires modification. It was not until Tokugawa days in the seventeenth century that the whole sixty provinces passed under one feudal ruler. Still as between the Kamakura Bakufu and the Muromachi, the latter, though its military supremacy was less complete, may be said to have extended its influence theoretically over the whole of the lands throughout the empire, except the Chōkōdō estates.

In another respect, also, the advantage lay with the Muromachi shõgunate. During the Kamakura era, the Court magnates continued to despise the Bakufu adherents; and the distance between the capital and Kamakura imparted to the latter an element of rusticity. But with the establishment of the Muromachi shōgunate a change took place. The Bakufu, the visible repository of power; stood side by side with the Court, and opportunities for close relations existed constantly. Moreover, the Court nobles, notably antagonistic to the military régime, followed the fortunes of the Southern dynasty, those alone remaining in the capital who were on more or less intimate terms with the military. Such were the Nijo, the Saionji, the Hino, and so forth. These observed the behests of the Bakufu; sought to acquire the latter's confidence, and always paid respect to the Hana no Gasho, as the shögun was called. So close were the relations that for ceremonial purposes at the Bakufu, it was customary to employ Court officials; and witty writers of the time discourse amusingly on the often clumsy efforts made by the courtiers to ape the customs and acquire the dialects of the provincial soldiers. 


\section{THE ORGANIZATION OF THE CENTRAL BAKUFU}

The administrative power having been transferred from the Court to the Bakufu, it may be said that the sei-i tai-shogun exercised supreme authority throughout the empire. But the shogun himself did not actually discharge administrative duties. That was done by the "kwanryo with the shöun's consent. Originally this official was called shitsuji (manager), and his functions were to look after the affairs of a provincial magnate's establishment. Dúring the Kamakura era, the Ashikaga family occupied a high place: Of Minamoto origin, it was connected with the Hōjo by marriage, and for generations its shitsuji had been a member of the Kō family. Ashikaga Takauji made Kō nó Moronao his shitsuji, and a highly competent captain he proved himself. Subsequently, in 1362, Shiba Yoshimasa was appointed shitsuji, but soon his title was changed to kwanryō (governor-general), and it thenceforth became customary for the latter position to be occupied by a member of one of the three families, Shiba, Hosokawa, and Hatakeyama, in succession.

Speaking broadly, the kwanryo corresponded to the skikken (regent) of Kamakura days. But whereas, the Kamakura shikken exercised virtually autocratic authority, the shögun being a minor, the Muromachi kwanryō, nominally, at all events, was under the control of an adult shōgun. In fact, the kwanryo in the Muromachi polity resembled the betto of the Man-dokoro in Yoritomo's time. For the rest, the Muromachi Bakufu was organized on practically the same lines as its Kamakura prototype. There was a Man-dokoro, a Monjudokoro, and a Samurai-dokoro, and the staff of these offices was taken originally, as far as possible, from the families of men who had distinguished themselves as legislators and administrators at Kamakura. There were also officials called bugyō (commissioners) who directed the enforcement of laws and ordinances. These commissioners numbered thirty-six, and each had his own sphere of duties: as the shōnin bugyō, who controlled judicial affairs; the tōsen bugyō, who dealt with affairs of foreign trade; the jisha bugyo, who superintended temples and shrines; the onshō bugyō, who had to do with official rewards' etc.

\section{ORGANIZATION OF PROVINCIAL GOVERNMENTS}

At Kamakura, also, there was a kwanryo to guard the eastern provinces (Kwantō). In Takauji's time, his second son, Motouji, was appointed to this office, and it was thenceforth inherited for some generations, the Uesugi family furnishing a shitsuji. Ultimately the Kamakura kuanryo became a powerfúl military satrap, hostile to the Muromachi shōgun. The holder of the office thén: received the title of $k u b \bar{o}$, and the hitherto shitsuji became kwanryō. In other respects the Kamakura polity retained the form it had under Yoritomo:a Hyōjō-shū (Council), a Hikitsuke-shū; a Morjū-dokoro, a Samurai-dokoro, and various bugyō. In Kyũshũ and. Dewa, the principal officer was called shugo, that post being of special importance; while in the other provinees shugo: and $\ddot{j i t} \bar{o}$ (high constables and land-stewards) continued to officiate as before.

The jurisdiction of these high constables - great military magnates or relatives of the shögun-extended to two or more provinces, and the shugo were then called kuni-mochi-sh $\bar{u}$. (province-holder). A daimyō (great name, i.e. feudal lord), in communicating with Muromachi, had to make a kuni-mochi his medium: For the Kwanto and Shikoku, the Hosokawa house was the kunimochi; for Shinano; Etchü; Echigo, and Kaga, the Hatakeyama; for-Ise, Kai, and Suruga, the Yamana; and for Kyūshū, the tandai. After the power of the 
tandai had declined, the Öuchi family took its place. In the days of Yoshinori's shoggunate, there were twenty-two shugo in the country, and seven of them administered three provinces or more, each. The provincial governors appointed by the Southern Court disappeared, for the most part, during the War of the Dynasties, and on the restoration of peace the only one of these high officials that remained was Kitabatake of Ise.

\section{SHUGO AND JITŌ}

Originally appointed for administrative and fiscal purposes only, the shugo and jito acquired titles of land-ownership from the beginning of the:Ashikaga era. To plunder and annex a neighbouring province became thenceforth a common feat on the part of these officials. In 1390, tracts of land measuring from onehalf of a province to two or three provinces are found to have been converted from the shugo's jurisdictional areas into military domains. Such magnates as Yamana Tokiuji held from five to eleven provinces. These puissant captains had castles and armies of their own. At first, they respected the requisitions of the Bakufu. Thus, in 1463, when an elaborate Buddhist ceremony had to be performed on the decease of Yoshimasa's mother, a tax in the form of cotton cloth was levied from the shugo, a ruler of three provinces contributing ten thousand pieces; a ruler of two provinices, five thousand, and so on. ${ }^{1}$

But after the Önin War (1467-1469), military magnates resided wholly on their own domains and paid no attention to requisitions from the Bakufu. Further, these magnates compelled all jito and go-kenin within their jurisdiction to serve as their vassals. Previously to the $\bar{O}_{\text {nin }}$ era the shugo had resided, for the most part, in Kyōto, delegating the discharge of their provincial functions to deputies (shugo-dai), chosen by the shugo and approved by the Bakufu. Presently, the process of selection was dispensed with, and the office became hereditary. Thus, Yusa of the Hatakeyama, Oda of the Shiba, Uragami of the Akamatsu, and so forth are examples of deputies who resided permanently in the provinces concerned and acquired influence there superior even to that of their principals. The deputies, in turn, had their vice-deputies (ko-shugo-dai), to whom the name daikwan (another term for "deputy") was often given. These daikwan were selected from among the members or vassals of a shugo's family to act provisionally as shugo-dai. As for the jito, from the middle of the Kamakura epoch their posts became mere sinecures, the emoluments going to support their families, or being paid over to a temple or shrine. Occasionally the office was sold or pawned. The comparatively small areas of land within which the jito officiated soon came to be recognized as their private domains, but after the Onin commotion this system underwent a change, the jito becoming vassals of the shugo. Many, however, held their original position until the middle of the sixteenth century. In the days of Toyotomi Hideyoshi and Oda Nobunaga namely, 'the second half of the sixteenth century - the name jito was given to the headman of a village or district, who served as the immcdiate representative of authority.

\section{FINANCE}

Cultivated land $(k \bar{o} d e n)$ was the great source of official revenue. The area under rice - the principal staple of production - in the middle of the fifteenth

"[ ${ }^{1}$ " "piece" was 40 feet, approximately. When the castle of Edo was built in Tokugawa days - seventeenth century - each daimy o had to contribute "aid" (otetsudai), after the Ashikaga custom.] 
century was about a million of $c h \bar{o},{ }^{1}$ or two and a half million acres; and this was owned by the Court, the Court nobles, the military magnates, the temples, and the shrines. From an uncertain date, but probably the close of the Kamakura $B a k u f u$, the area of a domain ceased to be calculated in terms of $c h \bar{o}$ and tan and was expressed in kwan (one thousand cash, or mon): The use of the kwan for this purpose had reference to the military service leviable upon the land. Thus; when land of one hundred kwan-mon was mentioned, an area capable of supporting military service valued at one hundred kwan-mon was understood. The calculation was very simple: one tsubo corresponded to one mon, so that one $k w a n-m o n$ represented one thousand tsubo for the purposes of this assessment. ${ }^{2}$

From various documents it appears that the three grades of land - best, medium, and inferior - were taxed at the rate of sixty, forty, and thirty per cent., respectively, of the yield: In other words, the average land-tax was forty per cent. of the yield-called shi-ko roku-min - or four parts to the Government and six to the farmer. If we consider the rates between the current price of land and the tax, there is a record, dated 1418, which shows that the tax levied by a temple - Myōkō-ji - was twenty per cent. of the market price of the land. But it would seem that the ratio in the case of Government taxation was much smaller, being only one and a half per cent. of the market value. There were, however, other imposts, which, though not accurately stated, must have brought the land-tax to much more than forty per cent. of the yield.

Turning to the Imperial Court, we find it supported by domains hereditarily held; by contributions from the seizei (expediency taxes, that is to say, taxes set aside for extraordinary State requirements); by occasional presents, and by revenues from kugoden (private Imperial land). The Court nobles had their own domains, usually small. All these estates, those of the Crown, of princes, and of Court nobles, were subject to a system called hansai. That is to say, one-half of their revenues were leviable for military purposes.' Originally this impost was understood to be a loan to the Bakufu, but ultimately it came to be regarded as a normal levy, though its practical effect was to reduce the revenue from such domains by one-half." Moreover, as the arrogance of the military magnates in the provinees grew more insistent, and as the'Bakufu's ability to oppose them became less effective, the domain of the Court nobles suffered frequent encroachments.

\section{REVENUES OF THE BAKUFU}

One source of revenue for the Bakufu was its domains in various places; another was the buke-yaku, or military-house dues. These were at first two per cent. of the land-tax of the house concerned, but afterwards they increased to

[ ${ }^{1}$ The $c h \bar{o}$ was equal to 10 tan, and the tan comprised 360 tsubo, the $t s u b o$ being a square of 6 feet side. At present the area under cultivation is some 3 millions of $\operatorname{ch} \bar{o}(71 / 2$ millions of acres).]

[ In the Ashikaga era the unit of currency may be said to have been the copper cash of China-called Eiraku-sen after the name (Chinese, Yunglo) of the Chinese year period when it was issued. Gold and silver coins were also in use; namely, the gold $r y \bar{o}$, which was equivalent to 10 silver ryō; but their circulation was comparatively small. The gold ryo was equal to 2000 mon of copper coins, and as 100 mon purchased 1 to (one-tenth part of a koku) of rice, it follows that the gold ryo represented 2 koku, or 30 yen of modern currency, the silver ryo representing 3 yen ( 1 yen $=2$ shillings -50 cents). It follows also that 10 strings of cash (one kwan) were worth a koku of rice, or 15 yen. As for silk piece-goods, 1 roll (hiki=48 yards) of the best kind was worth 45 yen, and the second and third-class kinds ranged from 33 to $221 / 2$ yen. Finally, in the year 1498, the records show that the daily wage of a labourer was some 16 sen of modern money (about 4 pence or 8 cents).] 
five per cent. Thus an estate paying one hundred koku in the form of land-tax, had to pay a further five koku as buke-yaku, the latter proceeds being sent to Kyōto for the use of the shögun's household. Another important levy was the tansen, which, as its name implies, was a land-rate levied at so much per tan (onequarter of an acre), the proceeds being devoted to special purposes, as, for example, to defray the cost of grand ceremonials or of new edifices. The records show one payment of tansen which works out at fifty mon per tan. Another document indicates that the monthly expenses of the Man-dokoro were some sixty kwanmon:and that they were defrayed by levying taxes upon pawnbrokers and sakedealers in Kyōto and in Ōmi province. The latter tax (shuko-zei) is shown to have been, on one occasion, two kwan eight hundred mon per house. The Bakufu collected dues on foreign commerce, also, and miscellaneous imposts of an irregular character made no small addition to its income.

\section{REVENUE OF SHRINES AND TEMPLES}

Temples and shrines derived part of their income from port-dues and barriertolls. Thus, the Hachiman temple of Iwashimizu received tolls from all traffic passing the Yamazaki bärrier; Kōfuku-ji levied duties on vessels entering Hyōgo port, and Engaku-ji of Kamakura collected tolls at the Hakone barrier (sekisho). Such taxes proving very prolific and easy to levy, the number of barriers increased rapidly, to the no small obstruction of tradeland travel. Further, the priests were constantly enriched with donations of land and money, in addition to the rents and taxes obtained from their own domains, and thus it resulted that several of the great monasteries possessed much wealth. To that fact is to be attributed the numerous establishments of soldier-priests maintained at Enryakuji, on Hiei-zan, and at Kōfuku-ji, in Nara. To that also is to be ascribed in part the signal development of literature among the friars, and the influence wielded by the Shintō officials of Kitano and the betto of Hachiman.

\section{REVENUE OF JITŌ}

A special tax levied by the jito was the hyakishō-yaku, or farmers' dues. These were one per cent. of the land-tax originally, but the rate was subsequently doubled. Other heavy imposts were frequently and arbitrarily enacted, and there can be no doubt that financial disorder contributed materially to bringing about the terrible calamities of the Battle era (Sengoku Jidai), as the period of eleven decades ending in 1600 is called. For, if the fiscal system was thus defective during the comparatively prosperous age of the Ashikaga, it fell into measureless confusion at a later date. It has been stated above that the area under rice cultivation at the middle of the fifteenth century was about one million $c h \bar{o}$; at the close of that century the figure was found to have decreased by more than fifty thousands of $c h \bar{o}$. From such a result, opposed as it is to all records of normal development, the unhappy plight of the agricultural classes may be inferred.

\section{TOKENS OF CURRENCY}

Minting operations also were discontinued under the Ashikaga. Cotton cloth and rice served as principal media of exchange. Fortunately, commerce with China in the days of the Ming rulers, and Yoshimasa's undignified though practical requests, brought a large supply of Yunglo (Japanese, Eiraku) copper 
cash, which, with other Chinese coins of the Tang and Sung dynasties, served the Japanese as media. This fortuitous element was conspicuous in all the domain of finance, especially after the $\bar{O}$ nin. War, when the territorial magnates fixed the taxes at their own convenience and without any thought of uniformity: One of the only sincere and statesmanlike efforts of reform was made; in 1491, by Hōjō Sōun. He reduced the rate then ruling, namely, equal parts to the taxcollector and to the taxpayer, and made it forty per cent. to the former and sixty to the latter, and he ordained that any jito collecting so much as a mon in exeess of the official figure, should be severely punished. How the people fared elsewhere it is not possible to say accurately, but the records show that extraordinary imposts were levied frequently, and that the tansen was exacted /again and again, as also were taxes on trades. As for the Imperial houschold, such was its condition that it barely subsisted on presents made by certain military magnates, so complete was the decentralization of the empire in this period.

\section{ATTITUDE OF THE ASHIKAGA TOWARDS THE THRONE}

The policy of the Ashikaga towards the Daikagu-ji line (the Southern Court) of the Imperial house was evidently one of complete elimination at the outset: But the impossibility of achieving such a programme soon came to be recognized and reconciliation was substituted. Thenceforth, in appearance at all events; the representatives of the Daikagu-ji line received due consideration and were sufficiently provided with incomes, as witness the treatment of the ex-Emperor Go-Kameyama by Yoshimitsu. But subsequent and repeated neglect of the elaims of the Southern branch in regard to the vital matter of the succession betrayed the insincerity of the Ashikaga, and provoked frequent appeals to arms.

The situation may be said to have been saved by the habit inaugurated at the close of the Heian epoch. From that time princes and nobles who saw no prospect of secular distinction began to take the tonsure, and this retirement to the cloister was assiduously encouraged by the Muromachi shoguns. A similar policy commended itself in the case of princes of the Jimyo-in branch (the Northern Court). It is true that; from the first, the representatives of this line had relied on the Bakufu, whether of Kamakura or of Muromachi. But in their hearts they deeply resented the usurpation of the shogunate; and the latter, fully cognisant of that sentiment; guarded against its effective display by providing only meagre allowances for the support of the Imperial household (Kinri) and the ex-Emperor's houschold (Send̄), and by contriving that only young and delicate princes should succeed to the throne. Thus, of seven sovereigns who reigned between 1336 and 1464, the oldest was only sixteen at the time of his succession and the youngest was six. When an Emperor reached maturity, it was * usual that he should abdicate and administer thenceforth from the Inch $\bar{u}$. Thus the influence of the Court was divided between the Kinri and the Sendōthe reigning sovereign and the retired. But the real depository of power was the shikken (regent) of the Inchu, to which office a member of the Hino family, maternal relatives of the Bakufu, was habitually appointed. When Yoshinori was shögun, he himself acted as shikken of the Inchü. As for the Court officials properly so called, from the kwampaku downwards, they were mere figureheads. Holding their posts, indeed, as of old; they constituted, not administrative actors, but an audience. 


\section{YOSHIMITSU AND THE THRONE}

The shogrn Yoshimitsu instituted the custom of inviting the sovereign to his mansion, and thenceforth such visits became a recognized feature of the relations between the Imperial and the Muromachi Courts. Yoshimitsu himself frequently repaired to the Kinri and the Sendo, and frequently accompanied the Empresses and their ladies on social visits or pleasure excursions. $\mathrm{He}$ is said to have gone in and out at the Imperial palaces without the slightest reserve, and on more than one occasion history accuses him of flagrantly transgressing the limits of decency in his intercourse with Suken-mon-in, mother of the Emperor Go-Enyū. - As a subverter of public morals, however, the palm belongs, not to Yoshimitsu, but to his immediate successor, Yoshimochi. He is said to have visited the Kinri and the Sendō six or seven times every month, and to have there indulged in all kinds of licence. History says, indeed, that he was often unable to appear at Court owing to illness resulting from intoxication.

\section{PRINCES AND PRIESTS}

As to the fact that, from the close of the Heian epoch, the cloister often proved a prison for Imperial princes whose ambition might have been troublesome had they remained at large, the following figures are eloquent:-

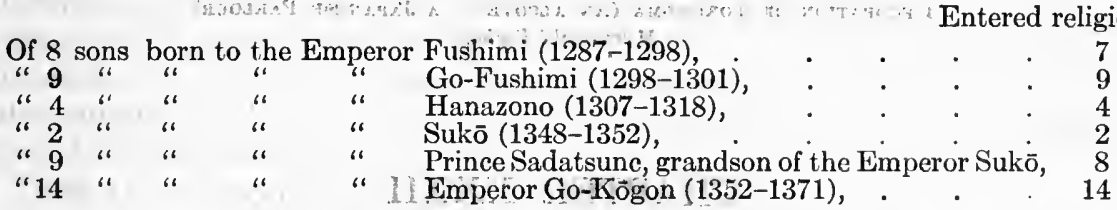

Absolute accuracy is not claimed for these figures, but they are certainly close approximations In fact, under the Muromachi Bakufu, every son of a sovereign, except the Prince Imperial, was expected to become a monk. The Ashikaga adopted a similar system and applied it ruthlessly in their own families. In truth, the Ashikaga epoch was notorious for neglect of the obligations of consanguinity. Father is found pitted against son, uncle against nephew, and brother against brother.

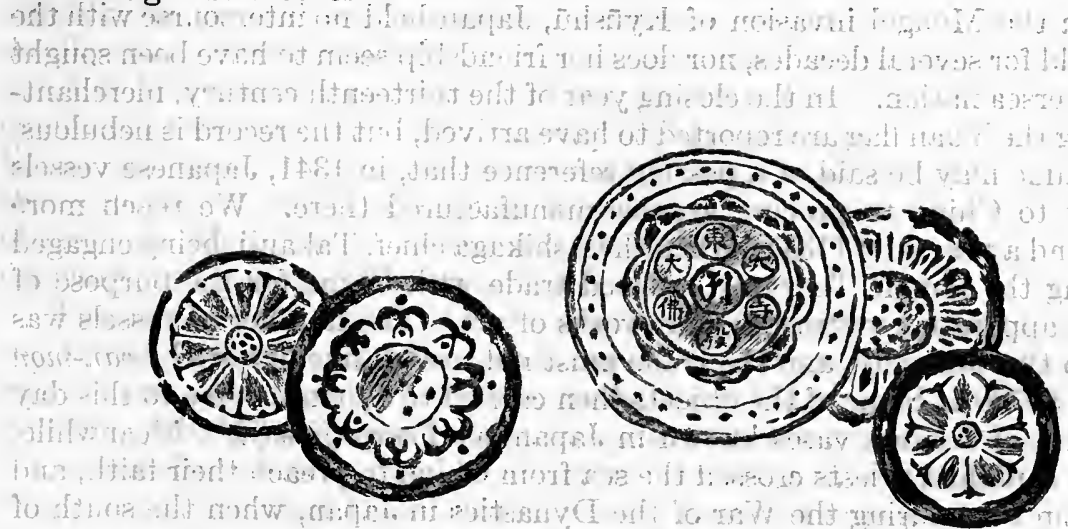

Tiles of the Daibutsuden of Tōdai-jt 


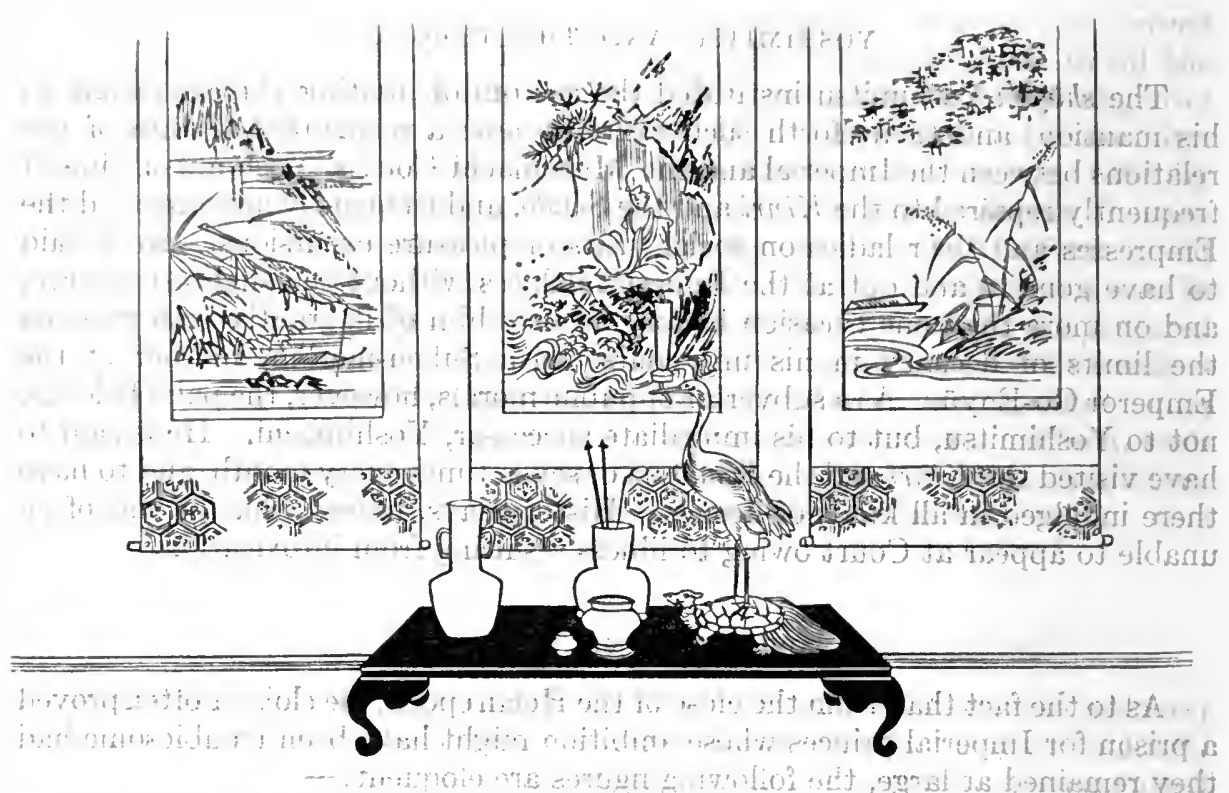

Decoration of Tokonoma (An alcove in a Japanese Parlour)

Muromachi Period

\section{CHAPTER XXXII}

\section{FOREIGN INTERCOURSE, LITERATURE, ART, RELIGION, MANNERS, AND CUSTOMS IN THE MURO- Tgisyo?

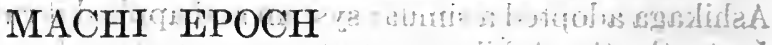

\section{FOREIGN INTERCOURSE \\ FORLIGN TNTERCOURS}

uit ittimi al

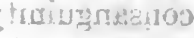

AfTer the Mongol invasion of Kyūshū, Japan held no intercourse with the outer world for several decades, nor does her friendship seem to have been sought by any oversea nation. In the elosing year of the thirteenth century, merchantmen flying the Yuan flag are reported to have arrived, but the record is nebulous, and the same may be said of a passing reference that, in 1341, Japanese vessels were sent to China to procure articles manufactured there. We reach more solid ground a yearlater (1342), when the Ashikaga chief, Takauji, being engaged in building the temple Tenryū-ji, opened trade with China for the purpose of obtaining apparatus, vestments, and works of art. The number of vessels was limited to two annually, and the trade must not exeeed five hundred kwan-mon $(£ 750$, or $\$ 3700$ ). Some of the objects then earried to Japan survive to this day in the form of celadon vases known in Japan as Tenryüji-seiji. Meanwhile, not a few Buddhist priests crossed the sea from China to preach their faith, and it is certain that during the War of the Dynasties in Japan, when the south of the country was in a state of anarchy, privateering in-Korean waters was freely resorted to by Japanese adventurers. A Korean envoy arrived at Fukuhara,

['The merchantmen received the name of Tenryüji-bune (bune signifies "ship").] 
in Settsu, in 1367 , bearer of a strong protest against this marauding, and declaring that for a decade past assassination and plunder had been freely practised by Japanese subjects on the inhabitants of the Korean littoral. China and Korea were then in a troubled condition.

In the year (1368) after the arrival of this envoy, the Yuan dynasty went down in China before the Ming, and in Korea the kingdom of Koma was overthrown, the $\mathrm{Yi}$ dynasty rising on its ruins and calling the peninsula Chōsen. The Ming sovereign immediately attempted to establish tradal intercourse with Japan, but the negotiations failed, and not until 1392 is there any record of oversea relations. Then, at length, Korea's protest elicited a reply from Japan. The shōgun, Yoshimitsu, sent to Chōsen a despateh, signifying that piracy had been interdicted, that all captives would be returned, and that he desired to establish friendly relations. It appears that at that time China also suffered from the depredations of Japanese corsairs, for the annals say that she repeatedly remonstrated, and that, in 1401; Yoshimitsu despatched to China an envoy carrying presents and escorting some Chinese subjects who had been cast away

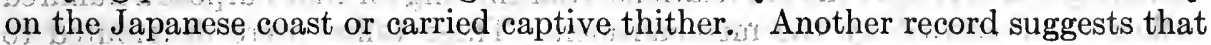
the Chinese Emperor was perplexed between the two warring Courts in Japan. At the time of his accession; a body of Mongol fugitives established themselves in Shantung, where they received assistance from some Japanese adventurers. The Ming sovereign opened communiçations on the subject with Prince Kanenaga, who held Kyūshū in the interests of the Southern Court, but the tone of the Chinese monarch was so arrogant that Prince Kanenaga made no reply: Then Taitsu employed a Buddhist priest, but the character of this bonze having been detected, he was thrown into prison.

These things happened in 1380 . In the following year Taitsu despatched a duly credited envoy who used menacing language and was sent back with a defiance from Prince Kanenaga. The priest, however, was set free in 1382, and having learned while in Japan that two Courts were disputing the title to the Crown, he informed the Chinese sovereign in that sense, and the latter subsequently addressed himself to Kyọto, with the result noted above, namely, that Yoshimitsu opened friendly relations (1401). It was to the Ouchi family of Suwo that the management of intercourse with Chōsen was entrusted, the latter sending its envoys to Yamaguchi Subsequently, after Ōuchi Yoshihiro's disaffection and disaster, a Buddhist priest and well-known artist, Sōami, acted as Muromachi's envoy to the Ming Court, being accompanied by a merchant, Koetomi, who is described as thoroughly conversant with Chinese conditions. By these two the first commercial treaty was negotiated. It provided that an envoy should be sent by each of the contracting parties in every period of ten years, the suite of this envoy to be limited to two hundred, and any ship carrying arms to be regarded as a pirate.

The first envoy from the Ming Court under this treaty was met by Yoshimitsu himself at Hyōgo, and being escorted to Kyōto, was hospitably lodged in a hotel there. Instructions were also issued from Muromachi to the officials in Kyūshū, peremptorily interdicting piracy and ordering the arrest of any that contravened the veto. Further, the high constables in several provinces were enjoined to encourage trade with China by sending the best products of their localities. In fact, Yoshimitsu showed himself thoroughly earnest in promoting oversea commerce, and a considerable measure of success attended his efforts. Unfortunately; an interruption was caused in 1419; when some seventeen thousand Koreans, Mongolians, and "southern barbarians" - a name given 
promiscuously to aliens - in 227 ships, bore down on Tsushima one midsummer clay and were not driven off until the great families of Kyüshu - the Ötomó, the Shoni, the Kikuchi, and the Shiba - had joined forces to attack the invaders. The origin of this incident is wrapped in mystery, but probably the prohibition of Japanese pirates was not enforced for the protection of Chōsen, and the assault on Tsushima was a desperate attempt at retaliation:

Yoshimochi, however, who was then šoggun, seems to have associated China with the invasion, for a Ming envoy, arriving just at the time of the contest, was indignantly refused audience. Thereafter, the tandai appointed from Muromachi to administer the affairs of Kyūshū was driven out by the Shoni family, and the shogun's policy of checking piracy ceased to be enforced, so that the coasts of China and Chösen were much harried; all legitimate commerce being suspended. When Yoshinori became shogun, however, this was one of the directions in which he turned his reforming hand. $A$ Buddhist priest, Dón, proceeded to the Ming Court as Muromachi's delegate, and the Chinese sovereign agreed to restore the old relations, transmitting for that purpose a hundred tallies to be carried by the merchantmen. These tallies were distributed to several high constables, to five great temples, and to merchants in Hyogo and Sakai, the corresponding tallies ${ }^{1}$ 'being entrusted to the Ouchi family, which, having now recovered its power, was charged with the duty of superintending the trade with China. Meanwhile, Sō Sadamori of 'Tsushima' had estáblished commercial relations with Chồsen, and received from thence a yearly consignment of two hundred koku of soy beans, the vessel that carried the staple being guarded by boats known as Tsushima-buine.

Thus, it fell out that the right of supervising the trade with China and Korea eame into the exclusive possession of the Öuchi and the Sō, respectively, and being liberally encouraged, brought great wealth to them as well as to other territorial magnates of the central and southern provinces. The records show that large profits were realized. Four or five hundred per cent. is spoken of, and, further, the Ming sovereign, in Yoshimasa's time, responded generously; as has been already shown, to the shogun's appeal for supplies of copper cash. One Japanese fan could be exchanged for a copy of a valuable book, and a sword costing one kwan-mon in Japan fetched five kwan-mon in China. Such prices were paid, howéver, for rare goods only, notably for Japanese raw silk, fifty catties (sixty-seven lbs.) of which sold for ten kwan-mon ( $£ 15$, or $\$ 75$, approximately). Gold, too, was much more valuable in China than in Japan. Ten ryō of the yellow metal could be obtained in Japan for from twenty to thirty kwan-mon and sold in China for 130. Sealskins, swords, spears, pepper, sulphur, fans, lacquer, raw silk, etc. were the chief staples of exports; and velvet, musk, silk fabrics, porcelains, etc., constituted the bulk of the imports. The metropolis being Kyōto, with its population of some 900,000 , Hyōgo was the most important harbour for the trade, and after it came Hakata, ${ }^{2}$ in Chikuzen; Bōnotsu, in Satsuma; Obi, in Hyūga, and Anotsu, in Ise. The customs duties at Hyōgo alone are said to have amounted to the equivalent of $£ 15,000$, or $\$ 75,000$, annually.

In China, Ningpo was the chief port. It had a mercantile-marine office and an inn for foreign guests. The tribute levied on the trade was sent thence to Nanking. In size the vessels employed were-from 50 to 130 tons, greater

[1 The tallies were cards on which a line of ideographs were inscribed. The card was then cut along the line, and a moiety was given to the trader, the corresponding moiety being kept by the superintendent.]

[ ${ }^{2}$ Hakata's place was subsequently taken by Hirado.] 
dimensions being eschewed through fear of loss.: An invoice shows that the goods carried by a ship in 1458 were: sulphur (410,750 lbs.); copper (206,000 lbs.); spears (11); fans (1250); swords (9500); lacquered wares (634 packages), and sapan-wood (141,333 lbs:). During the days of Yoshimasa's shoggunate such profits were realized that overtrading took place, and there resulted a temporary cessation. Fifty years later, when Yoshiharu ruled at Muromachi (1529), a Buddhist priest, Zuisa, sent by the shogun to China, and an envoy, Sōsetsu, despatched by the Öuchi family, came into collision at Ningpo. ${ }_{71}$ It was a mere question of precedence, but in the sequel Zuisa was seized, Ningpo was sacked; and its governor was murdered. The arm of the shogun at that time could not reach the Öuchi family, and a demand for the surrender of Sōsetsu was in vain preferred at Muromachi through the medium of the King of Ryūkyū. Yoshiharu could only keep silence.

The Ming sovereign subsequently (1531) attempted to exact redress by sending a squadron to Tsushima, but the deputy high constable of the Ōuchi compelled these ships to fly, defeated, and thereafter all friendly intercourse between Japan and China was interrupted, piratical raids by the Japanese taking its place. This estrangement continued for seventeen years, until (1548) Ouchi Yoshitaka ré-established friendly relations with Chösen and, at the same time, made overtures to China, which, being seconded by the despatch of an envoy - a Buddhist priest, Shūryō - from Muromachi, evoked a favourable response. Once more tallies were issued, 'but the number of vessels being limited to three and their crews to three hundred, the resulting commerce was comparatively small. Just at this epoch, too, Occidental merchantmen arrived in China, and the complexion of the latter's oversea trade underwent alteration. Thereafter, the Ashikaga fell, and their successor, Oda Nobunaga, made no attempt to re-open commerce with China, while his successor, Toyotomi Hideyoshi, planned the invasion of the Middle Kingdom, so that the sword was more in evidence than the soroban.

\section{JAPANESE PIRACY}

It is difficult to trace the beginnings of Japanese piracy in Far Eastern waters, but certainly it dated from a remote past and reached its extreme in the middle of the sixteenth century. The records show that Murakami Yoshihiro, of Iyo province, obtained control of all the corsairs in neighbouring seas and developed great puissance. Nor did any measure of opprobrium attach to his acts, for on his death he was succeeded by Morokiyo, a scion of the illustrious Kitabatake family. Numbers flocked to his standard during the disordered era of the War of the Dynasties, and from Korea in the north to Formosa and Amoy in the south the whole littoral was raided by them.

For purposes of protection the Ming rulers divided the coast into five sections, Pehchihli, Shantung, Chekiang, Fuhkien, and Liangkwang, appointing a governor to each, building fortresses and enrolling soldiers. All this proving inefficacious, the Emperor Taitsu, as already stated, addressed to Ashikaga Yoshimitsu a remonstrance which moved the shoggun to issue a strict injunction against the marauders. It was a mere formality. Chinese annals show that under its provisions some twenty pirates were handed over by the Japanese and were executed by boiling in kettles. No such international refinement as extra-territorial jurisdiction existed in those days, and the Japanese shogun felt no shame in delivering his countrymen to be punished by an alien State. It is 
not wonderful that when Yoshimitsu died, the Chinese Emperor bestowed on him the posthumous title Kung-hsien-wang, or "the faithful and obedient king."

But boiling a seore of the $W_{0 k o u}{ }^{1}$ in copper kettles did not at all intimidate the corsairs. On nearly all the main islands of the Inland Sea and in the Kyūshū waters they had their quarters. In fact, the gavernors of islands and a majority of the military magnates having littoral estates, took part in the profitable pursuit. No less than fourteen illustrious families were so engaged, and four of them openly bore the title of kaizoku tai-shögun (commander-in-chief of pirates). Moreover, they all obeyed the orders of the Ouchi family. $\quad$ It is on record that Ouehi Masahiro led them in an incursion into Cholladō, the southern province of Korea, and exacted from the sovereign of Chösen a promise of yearly. tribute to the Ouchi. This was only one of several profitable raids: The goods appropriated in Korea were sometimes carried to China for sale, the pirates assuming, now the character of peaceful traders, now that of ruthless plunderers. The apparition of these Pahan ${ }^{2}$ ships seems to have inspired the Chinese with consternation. They do not appear to have made any effective resistance. The deeade between 1553 and 1563 was evidently their time of greatest suffering; and their annals of that era repay perusal, not only for their direet interest but also for their collateral bearing on the story of the invasion of Korea at the close of the century.

On the $23 \mathrm{~d}$ of the fifth month of 1553 , twenty-seven Japanese vessels arrived at Lungwangtang. They looked like so many hills and their white sails were as clouds in the sky... On the fifth day of the fourth month of 1554, there appeared on the horizon a large ship which presently reached Lungwang-tang. Her crew numbered 562. They blew conches after the manner of trumpets, marshalled themselves in battle array, and surrounding the castle with flying banners, attacked it. On the fourth day of the ninth month of 1555, a two-masted ship carrying a crew of some hundreds came to Kinshan-hai, and on the next day she was followed by eight five-masted vessels with crews totalling some thousands. They all went on shore and looted in succession. On the $23 \mathrm{~d}$ of the second month of 1556 , pirate ships arrived at the entrance to Kinshan-hai. Their masts were like a dense forest of bamboo.

Further records show that in 1556 the pirates entered Yang-chou, looted and burned the city; that in 1559 they attacked Chekiang; that in 1560, they made their way to Taitsang, and thence pushed on towards Shanghai, Sungteh, etc., looting towns almost daily. There was no effective resistance. We find also the following appreciation of Japanese ships:-

The largest of the Japanese vessels can carry about three hundred men; the medium-sized, from one to two hundred, and the smallest from fifty to eighty. They are constructed low and narrow. Thus, when they meet a big ship they have to look up to attack her. The sails are not rigged like those of our ships which can be navigated in any wind. But wicked people on the coast of Fuhkien sold their ships to the foreigners; and the buyers, having fitted them with double bottoms and keels shaped so as to cleave the waves, came to our shores in them.

Evidently the Chinese were better skilled in the art of shipbuilding than the Japanese. As for the defensive measures of the Chinese the following is recorded:

The Government troops on sea and on land made every effort to keep off the pirates. They flew banners at morn and eve and fired guns seaward, so that the enemy, understanding by the flash and the detonation that we were prepared to resist, abstained from landing. But when the pirates handled their swords skilfully, their attack was fearful. Our countrymen when they saw these swordsmen, trembled and fled. Their fear of the Japanese was fear of the swords.' The pirates' firearms were only guns such as men use in pursuit of game. 'They did not range over one hundred paces. But their skill in using their guns was such that they never missed. We could not defeat them. They rise early in the morning and take their breakfast kneeling down. Afterwards their chief ascends an eminence and they gather below to hear his orders: He tells them off in detachments not exceeding thirty men, and attaching

[ 1 Yamato enemies.]

[2 Chinese pronunciation of the ideographs read by the Japanese "Hachiman" (god of War). The pirates inscribed on their sails the legend Hachiman Dai-bosatsu.] 
them to officers, sends them to loot places. The detachments operate at distances of from five hundred' to a thousand yards, but unite at the sound of a conch.

To re-enforce a detachment in case of emcrgency, small sections of three or four swordsmen move about. At the sight of them our men flee. Towards dark the detachments return to headquarters and hand in their loot, never making any concealment. It is then distributed. They always abduct' women, and at night they indulge in drinking and debauchery. They always advance in single rank at a slow pace, and thus their extension is miles long. For tens of days they can run without showing fatigue. In camping, they divide into many companies, and thus they can make a siege effective. Against our positions they begin by sending a few men who by swift and deceptive movements cause our troops to exhaust all their projectiles fruitlessly, and then the assault is delivered. They are clever in using ambushes, and often when they, seem to be worsted, their hidden forces spring up in our rear and throw our army into a panic.

briu

-ili There is no reason to doubt the truth of these records, naïve as are some of the descriptions Unquestionably the Wokou were a terrible scourge to the Chinese on the eastern littoral:

\section{INTERCOURSE WITH RYÜKYŪ}

Japanese annals say that the royal family of Ryūkyū was descended from the hero Minamoto Tametomo who was banished to the island in 1156, and certainly the inhabitants of the archipelago are a race closely allied to the Japanese. But in 1373 , the then ruler, Chūzan, sent an envoy to the Ming Court and became a tributary of the latter. In 1416, however, an ambassador from the islands presented himself at the Muromachi shọgunate, and twenty-five years later (1441), the shōgun: Yoshinori, just before his death, bestowed Ryūkyū on Shimazu Tadakuni, lord of Satsuma, in recognition of meritorious services. : Subsequently (1471) the shogun Yoshimasa, in compliance with a request from the Shimazu family, forbade the sailing of any vessel to Ryūkyu without a Shimazu permit, and when, a few years later, Miyake Kunihide attempted to invade Ryūky $\bar{u}$, the Shimazu received Muromachi's (Yoshitane's) commission to punish him. Historically, therefore, Ryūkyu formed part of Japan, but its rulers maintained a tributary attitude towards China until recent times, as will presently be seen:

\section{IITERATURE DURING THE MUROMACHI PERIOD}

Throughout the Muromachi period of two and a half centuries a group of military men held the administration and reaped all rewards and emoluments of office: so that literary pursuits ranked in comparatively small esteem. Some education was necessary, indeed, for men of position, but eminent scholars were exceptional. Noteworthy among the latter were Nijo Yoshimoto, Ichijō Fuyuyoshi, Dōin Kinsada, Sanjōnishi Sanetaka, and Kiyowara Naritada. Most renowned was Ichijo Kaneyoshi. Equally versed in the classies of China and Japan, as well as in Buddhism and Confucianism, he composed several works of high merit. A feature of the period was the erudition of the priests. Gen-e, a bonze of the temple Hiei-zan, adopted the commentaries of the Sung savants, Chengtzu and Chutsu, rejecting those of the earlier Han and Tang writers. In other words; he adopted the eclectic system of Buddhism and Confucianism as compounded by the scholars of the Sung and the Yuan epochs, in preference to the system of earlier pundits. The Emperor Go-Daigo invited Gen-e to Court and directed him to expound the Sutras. Thereafter, the Sung philosophy obtained wide allegiance, being preached by the priests of the Five Great Temples in Kyōto, and by all their provincial branches. On the other hand, the 
hereditary schools of Ōye and Sugawara, adhering to their old dogmas, fell behind the times and declined in influence.

The feature of the age in point of learning was that scholarship became a priestly specialty. From the Five Temples (Go-zan) students constantly flocked to China, where they received instruetions in the exoteries and esoterics of Buddhism, as modified by the creed of Confucius, laying the foundations of systems upon which philosophers of later ages, as Razan and Seiga, built fair edifices. These priests of the Five Temples were more than religious propagandists: they were ministers of State, as Tenkai and Sōden were in after times under the Tokugawa, and they practically commanded the shogins. One reason operating to produce this result was that, in an age when lineage or military prowess was the sole secular step to fortune, men of eivil talent but humble birth had to choose between remaining in hopeless insignificance or entering the priesthood where knowledge and virtue were sure passports to distinction. It was thus that in nearly every monastery there were found men of superior intellect and erudition. The fact was recognized. When Ashikaga Takauji desired to take counsel of Musō Kolushi, he repaired to that renowned priest's temple and treated him as a respected parent; and Yoshimitsu, the third of the Ashikaga shöguns, showed equal respect towards Gidō, Zekkai and Jorin, whose advice he constantly sought.

It was strange, indeed, that in an age when the sword was the paramount tribunal, the highest dignitaries in the land revered the exponents of ethics and literature. Takauji and his younger brother, Tadayoshi, sat at the feet of Gen-e as their preceptor. Yoshimitsu appointed Sugawara Hidenaga to be Court lecturer. Ujimitsu, the Kamakura kwanryo, took Sugawara Toyonaga for preacher. Yoshimasa's love of poetry impelled him to publish the Kinshüdan'? Above all, Yoshihisa was an earnest scholar. He had a thorough knowledge of Chinese and Japanese classics; he was himself a poetaster of no mean ability; he read canonical books even as he sat in his palanquin; under his patronage Ichijō Kaneyoshi wrote the Shödan-chiyō and ${ }^{2}$ the Bummei Ittōki; Fujiwara Noritane compiled the Teiö-keizu; Otsuki Masabumi lectured on the analects and Urabe Kanetomo expounded the standard literature of the East.

Yet, side by side with these patrons of learning stood a general public too ignorant to write its own name. Military men, who formed the bulk of the nation, were engrossed with the art of war and the science of intrigue to the exclusion of all erudition. The priests were always available to supply any need, and the priests utilized the occasion. Nevertheless, it stands to the credit of these bonzes that they made no attempt to monopolize erudition. Their aim was to popularize it. 'They opened temple-seminaries (tera-koya) and exercise halls $(d \bar{o} j \bar{o})$ where youths of all classes could obtain instruction and where an excellent series of text-books was used, the Iroha-uta ${ }^{3}$ the Dōji-kyō, the Teikin-orai, and the Goseibai-shikimoku. ${ }^{5}$ The Dōji-kyō has been translated by Professor Chamberlain (in Vol.VIII of the "Transactions of the Asiatic Society of Japan"). A few extracts will serve to show the nature of the ethical teaching given to Japanese children in medieval days:-

Let nothing lead thee into breaking faith with thy friend, and depart not from thy word.

[1 The Embroidered Brocade. Discourse.]

[2 Rustic Ideals of Government.]

[3 A syllabary of moral precepts like the ethical copy-books of Occidentals.]

[ ${ }^{4}$ A model letter-writer.]

[5 The criminal laws of Hōjō Yasutoki. All these text-books remained in use until the Meiji era.] 
It is the tongue that is the root of misfortunes; if the mouth were made like unto the nose, a man would have no trouble till his life's. end. In the house where virtue is accumulated there will surely be superabundant joy. No man' is worthy of honour from his birth; 'tis the garnering-up of virtue that bringeth him wisdom and virtue; the rich man may not be worthy of honour. - In thin raiment on a winter's night, brave the cold and be reading the whole night through; with scanty fare on a summer's day, repel hunger and be learning the whole day long. $\quad$ A father's loving kindness is higher than the mountains; a mother's bounty is deeper than the sea. . ... He that receiveth benefits and is not grateful is like unto the birds that despoil the branches of the trees they perch on. ${ }^{\circ}$. Above all things, men must practise charity; it is by almsgiving that wisdom is fed; less than all things, men must grudge money; it is by riches that wisdom is hindered. . . . The merit of an alms given with a compassionate heart to one poor man is like unto the ocean; the recompense of alms given to a multitude for their own sake is like unto a grain of poppy-seed.

This text-book, the $D \bar{o} j i-k y \bar{o}$, was compiled by a priest; Annen, who lived in the second half of the ninth century... Its origin belongs, therefore, to a much more remote era than that of the Muromachi shoguns, but, in common with the other text-books enumerated above, its extensive use is first mentioned in the Ashikaga epoch. The Five Temples of Kyoto - to be spoken of presently were seats of learning; and many names of the litterateurs that flourished there have been handed down. Not the least celebrated were Gido and Zekkai; who paid several visits to China, the fountain-head of ideographic lore. But these conditions were not permanent. The Önin War created a serious interruption. Kyôto was laid in ruins, and rare books lay on the roadside, no one caring to pick them up.

\section{PRIVATE SCHOOLS AND LIBRARIES}

Throughout the Ashikaga period the Kyōto university existed in name only, and students: of Japanese literature in the provinces disappeared. A few courtiers, as Nakahara, Ōye, Sugawara, Miyoshi, etc., still kept up the form of lecturing but they did not receive students at large. Nevertheless, a few military magnates, retaining some appreciation of the value of erudition, established schools and libraries. Among these, the Kanazawa-bunko and the Ashikaga-gakkō were the most famous. The former had its origin in the closing years of the Kamakura Bakufu. It was founded during the reign of Kameyama (1260-1274): by Sanetoki, grandson of Hōjō Yoshitoki. A large collection of Chinese and Japanese works filled its shelves, and all desirous of studying had free access. Akitoki, son of Sanetoki, adopted Kanazawa as his family name and added largely to the library. He caused the ideographs Kanazawa-bunko to be stamped in black on all Confucian works, and in red on Buddhist.

It is recorded in the $H \bar{o} j \bar{o}$ Kudaiki that men of all classes, laymen and priests alike, were shut up daily in this library where they studied gratis, and that Akitoki's son, Sadaaki, was as ardent a student as his father, so that men spoke of him as well fitted to be regent (shikken); thus showing that literary skill was counted a qualification for high office. Fire, the destroyer of so many fine relics of Japanese civilization, visited this library more than once, but during the reign of Go-Hanazono (1429-1464) it was restored and extended by the Uesugi family, who also rebuilt and endowed schools for the study of Japanese literature in the province of Kōtsuke. Among these schools was the Ashikaga-gakkō, under the presidency of a priest, Kaigen, in the day of whose ninth successor, Kyüka, the pupils attending the schools totalled three thousand. A few great families patronized literature without recourse to priests. This was notably the case with the $\bar{O}$ uchi, whose tradal connexions gave them special access to Chinese books. Ōuchi Yoshitaka, in particular, distinguished himself as an author. He established a library which remained for many generations; he sent 
officials to China to procure rare volumes, and it is incidentally mentioned that he had several manuscripts printed in the Middle Kingdom, although the art of block-printing had been practised in Japan since the close of the eighth century. A composition which had its origin at this epoch was the yōkyoku, a special kind of libretto for mimetic dances.: Books on art also were inspired by the Higashiyama craze for choice specimens of painting, porcelain, and lacquer. Commentarics, too, made their appearance, as did some histories, romances, and anthologies.

\section{PICTORIAL ART}

As Japan during the Ashikaga period sat at the feet of the Sung masters in philosophy and literature, so it was in the realm of art. There is, indeed, a much closer relation between literature and pictorial art in China than in any Occidental country, for the two pursuits have a common starting-point - calligraphy. The ideograph is a picture, and to trace it in such a manner as to satisfy the highest canons is a veritábly artistic achievement. It has been shown above that in the Muromachi era the priests of Buddha were the channels through which the literature and the philosophy of Sung reached Japan, and it will presently be seen that the particular priests who imported and interpreted this culture were those of the Zen sect. There is natural sequence, therefore, in the facts that these same priests excelled in calligraphy and introduced Japan to the pictorial art of the immortal Sung painters.

There were in China, at the time of the Ashikaga, two schools of painters: a Northern and a Southern." The term is misleading, for the distinction was really not one of geography but one of method.' What distinguished the Southern school was delicacy of conception, directness of execution, and lightness of tone. To produce a maximum of effect with a minimum of effort; to suggest as much as to depict, and to avoid all recourse to heavy colours - these were the cardinal tenets of the Southern school." They were revealed to Japan by a priest named Kañ, who, during the reign of Go-Daigo (1318-1339), passed ten years in China, and returning to Kyōto, opened a studio in the temple Kennin-ji, where he taught the methods of Li/Lungmin of the Sung dynasty and Yen Hui of the Yuan.' He revolutionized Japanese art.- After him Minchō is eminent: Under the name of Chō Densu - the Abbot Chō - he acquired perpetual fame by his paintings of Buddhist saints.

But Minchō's religious pictures did not help to introduce the Sung academy to Japan. That task was reserved for Josetsu - a priest of Chinese or Japanese origin - who, during the second half of the fourteenth century, became the teacher of many students at the temple Shōkoku-ji, in Kyōto. Among his pupils was Shūbun, and the latter's followers included such illustrious names as Sōtan, Sesshū, Shinnō; Masanobu, and Motonobu. It is to this day a question whether Japan ever produced greater artists than Sesshū and Motonobu. 'To' the same galaxy belongs Tosa no Mitsunobu, the founder of the Tosa school as Motonobu was of the Kanō. That official patronage was extended to these great men is proved by the fact that Mitsunobu was named president of the $E$-dokoro, or Court Academy of Painting; and Motonobu received the priestly rank of hōgen.

APPLIED ART

Industries in general suffered from the continual wars of the Ashikaga epoch, but the art of forging swords flourished beyonci all precedent. Already Awada- 
guchi, Bizen, Osafune, and others had attained celebrity, but for Okazaki Masamune, of Kamakura, who worked during the reign of Go-Daigo (1318-1339) was reserved the renown of peerlessness. His long travels to investigate the methods of other masters so as to assimilate their best features, are historically recorded, and at the head of the great trinity of Japanese swordsmiths his name is placed by universal acclaim, his companions being Gô no Yoshihiro and Fujiwara Yoshimitsu. ${ }^{1}$ In Muromachi days so much depended on the sword that military men thought it worthy of all honour. A present of a fine blade was counted more munificent than a gift of a choice steed, and on the decoration of the scabbard, the guard, and the hilt extraordinary skill was expended. Towards the close of the fifteenth century, a wonderful expert in metals, Gotō Yūjō, devoted himself to the production of these ornaments, and his descendants perpetuated his fame down to the middle of the nineteenth century. The Gotos, however, constitute but a small section of the host of masters who will always be remembered in this branch of art. In the Muromachi period alone we have such names as Aoki Kaneiye, Myocchin Nobuiye, Umetada Akihisa and others. Armour making also was carried to a point of high achievement during the epoch, especially by Nobuiye. ${ }^{3}$

\section{LACQUER}

It is generally conceded that the Japanese surpass all nations in the art of making lacquer. They not only developed the processes to a degree unknown to their original teacher, China, but they also introduced artistic features of great beauty. Unfortunately, history transmits the names of few masters in this line. We can only say that in the days of Yoshimasa's shoggunate, that is, during the second half of the fifteenth century, several choice varieties began to be manufactured, as the nashiji, the togidashi, the negoro-nuri, the konrinjinuri, the shunkei-nuri, the tsuishu, and the tsuikoku. Choice specimens received from later generations the general epithet Higashiyama-mono, in reference to the fact that they owed so much to the patronage of Yoshimasa in his mansion at Higashi-yama.

\section{PORCELAIN AND FAIENCE}

To the Muromachi epoch belongs also the first manufacture of faience, as distinguished from unglazed pottery, and of porcelain, as distinguished from earthenware. The former innovation is ascribed - as already noted - to Katō Shirōzaemon, a native of Owari, who visited China in 1223 and studied under the Sung ceramists; the latter, to Shonzui, who also repaired to China in 1510, and, on his return, set up a kiln at Arita, in Hizen, where he produced a small quantity of porcelain, using materials obtained from China, as the existence of Japanese supplies was not yet known. The faience industry found many followers, but its products all bore the somewhat sombre impress of the cha-no-yu (tea ceremonial) canons.

[ ${ }^{1}$ Chamberlain in Things Japanese says: "Japanese swords excel even the vaunted products. of Damascus and Toledo. To cut through a pile of copper coins without nicking the blade is, or was, a common feat. History, tradition, and romance alike re recho" with the exploits of this wonderful weapon."]

['For an exhaustive analysis see Brinkley's China and Japan.]

[ ${ }^{3}$ See Conder's History of Japanese Costume; Vol. IX. of the "Transactions of the Asiatic Society of Japan."] 
The architectural feature of the time was the erection of tea-parlours according to the severe type of the cha-no-yu cult. 'Such edifices were remarkable for simplicity and narrow dimensions. They partook of the nature of toys rather than of practical residences, being, in fact, nothing more than little chambers, entirely undecorated, where a few devotees of the tea ceremonial could meet and forget the world. "As for grand structures like the "Silver Pavilion" of Yoshimasa and the "Golden Pavilion" of "Yoshimitsu, they showed distinct traces of Ming influence, but with the exception of elaborate interior decoration they do not call for special comment.

A large part of the work of the Japanese architect consisted in selecting rare woods and uniquely grown timber, in exquisite joinery, and in fine plastering. Display and ornament in dwelling-houses were not exterior but interior; and beginning with the twelfth century, interior decoration became an art which occupied the attention of the great schools of Japanese painters. The peculiar nature of Japanese interior division of the house with screens or light partitions instead of walls lent itself to a style of decoration which was quite as different in its exigencies and character from Occidental mural decorations as was Japanese architecture from Gothic or Renaissance. The first native school of decorative artists was the Yamato-ryu , founded in the eleventh century by Fujiwara Motomitsu and reaching the height of its powers in the twelfth century. In the thirteenth century Fujiwara Tsunetaka, a great painter of this school, took the title of Tosa. Under him the Tosa-ry $\bar{u}$ became the successor of tbe Yamato-ry $\vec{u}$ and carried on its work with more richness and charm. The Tosa school was to a degree replaced after the fifteenth century in interior painting by the schools of Sesshü and Kanō.

\section{RELIGION}

As one of Yoritomo's first acts when he organized the Kamakura Bakufu had been to establish at Tsurugaoka a shrine to Hachiman (the god of War), patron deity of the Minamotos' great ancestor, Yoshiiye, so when Takauji, himself a Minamoto, organized the Muromachi Bakufu, he worshipped at the Iwashimizu shrine of Hachiman, and all his successors in the shögunate followed his example. Of this shrine Tanaka Harukiyo was named superintendent (bettō), and with the Ashikaga leader's assistance, he rebuilt the shrine on a sumptuous scale, departing conspicuously from the austere fashion of pure Shintō. ${ }^{2}$. It may, indeed, be affirmed that Shintō had never been regarded as a religion in Japan until, in the days of the Nara Court, it was amalgamated with Buddhism to form what was called Ryöbu-shintō. It derived a further character of religion from the theory of Kitabatake Chikafusa, who contended that Shintō, Buddhism, and Confucianism were all capable of being welded into one whole. Moreover, in the Muromachi period, the eminent scholar, Ichijō Kaneyoshi (1402-81), wrote a thesis which gave some support to the views of Chikafusa.

But, during the reign of Go-Tsuchimikado (1465-1500), Urabe Kanetomo, professing to interpret his ancestor, Kanenobu, enunciated the doctrine of Yuiitsu-shintō (unique Shintō), namely, that as between three creeds, Shintō

[ 1 The shrine covered a space of 400 square yards and had a golden gutter, 80 feet long, 13 feet wide, and over 1 inch thick.] 
was the root; Confucianism, the branches; and Buddhism, the fruit. This was the first explicit differentiation of Shinto. It found favour, and its propounder's son; Yoshida, asserted the principles still more strenuously. The fact is notable in the history of religion in Japan. Yoshida was the forerunner of Motoori, Hirata, and other comparatively modern philosophers who contended for the revival of "Pure Shinto.". Many Japanese annalists allege that Shintö owes its religious character solely to the suggestions of Buddhism, and point to the fact that the Shinto cult has never been able to inspire a great exponent.

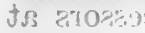

\section{BUDDHISM}

The attitude of the Ashikaga towards Buddhism was even more reverential. They honoured the Zen sect almost exclusively. Takauji built the temple Tenryū-ji, in Kyōto, and planned to establish a group of provincial temples

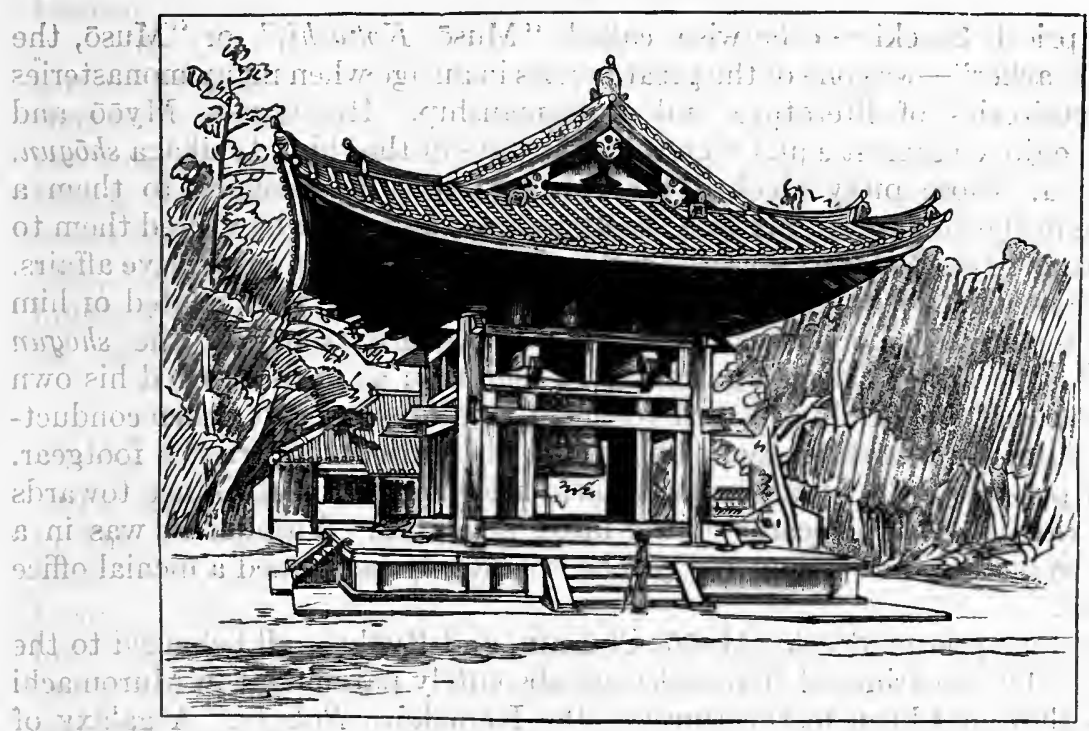

BELL-TOWER OF TŌDAI-JI

under the name of Ankoku-ji. There can be little doubt that his animating purpose in thus acting was to create a counterpoise to the overwhelming strength of the monasteries of Nara and Hiei-zan. The latter comprised three thousand buildings - temples and seminaries - and housed a host of soldier-monks who held Kyōto at their mercy and who had often terrorized the city and the palace. In the eighth century; when the great temple, Tödai-ji, was established at Nara, affiliated temples were built throughout the provinces, under the name of Kokubun-ji.

It was in emulation of this system that Takauji erected the Tenryu-ji and planned a provincial net-work of Ankoku-ji. His zeal in the matter assumed striking dimensions. On the one hand, he levied heavy imposts to procure funds; on the other; he sent to Ghina ships - hence called Tenryũji-bune-? to obtain furniture and fittings. Thus, in the space of five years, the great edifice was completed (1345), and there remained a substantial sum in the Muromachi treasury. The monks of Enryaku-ji (Hiei-zan) fathomed Takauji's purpose. 
They flocked down to the capital, halberd in hand and sacred car on shoulder, and truculently demanded of the Emperor that Soseki, high priest of the new monastery, should be exiled and the edifice destroyed. But the Ashikaga leader stood firm. He announced that if the soldier-monks persisted, their lord-abbot should be banished and their property confiscated; before which evidently earnest menaces the mob of friars turned their faces homeward. Thereafter, Takauji, and his brother Tadayoshi celebrated with great pomp the ceremony of opening the new temple, and the Ashikaga leader addressed to the priést, Soseki, a document pledging his own reverence and the reverence of all his successors at Muromachi. But that part of his programme which related to the provincial branch temples was left incomplete. At no time, indeed, were the provinces sufficiently peaceful and sufficiently subservient for the carrying out of. such a plan by the Ashikaga.

\section{GREAT PRIESTS}

The priest Soseki - otherwise called "Musō Kokushi," or "Musō, the national teacher"-was one of the great bonzes in an age when many monasteries were repositories of literature and statesmanship. His pupils, Myōō and Chūshin, enjoyed almost equal renown in the days of the third Ashikaga shögun, Yoshimitsu, whose piety rivalled that of Takauji. He assigned to them a residence in the Rokuon-ji, his own family temple, and there he visited them to hear discourses on Buddhist doctrine and to consult about administrative affairs. A still more illustrious bonze was Ryōken, of Nanzen-ji. It is related of him that he repaired, on one occasion, to the Kita-yama palace of the shogun Yosh mitsu, wearing a ragged garment. Yoshimitsu at once changed his own brocade surcoat for the abbot's torn vestment, and subsequently, when conducting his visitor on a boating excursion, the shogun carried the priest's footgear. It is not possible for a Japanese to perform a lowlier act of obeisance towards another than to be the bearer of the latter's sandals. Yoshimitsu was in a position to dictate to the Emperor, yet he voluntarily performed a menial office for a friar.

These four priests, Soseki, Myōō, Chūshin, and Ryōken, all belonged to the Zen sect. The doctrines of that sect were absolutely paramount in Muromachi days, as they had been in the times of the Kamakura Bakufu. A galaxy of distinguished names confronts us on the pages of history - Myōchō of Daitokuji; Gen-e of Myöshin-ji; Ikkyū Zenji of Daitoku-ji, a descendant of the Emperor Go-Komatsu; Tokusō of Nanzen-ji; Shiren of Tơfuku-ji; Shūshin of Nanżen-ji; Juō of Myōshin-ji; Tetsuō of Daitoku-ji, and Gazan of Sōji-ji. All these were propagandists of Zen-shu doctrine. It has been well said that the torch of religion burns brightest among dark surroundings. In circumstances of tumultuous disorder and sanguinary ambition, these great divines preached a creed which taught that all worldly things are vain and valueless. Moreover, the priests themselves did not practise the virtues they inculcated. They openly disregarded their vow of chastity; bequeathed their temples and manors to their children; employed hosts of stoled soldiers; engaged freely in the fights of the era, and waxed rich on the spoils of their arms.

It is recorded of Kenju (called also Rennyo Shōnin), eighth successor of Shinran, that his eloquence brought him not only a crowd of disciples but also wealth comparable with that of a great territorial magnate; that he employed a large force of armed men, and that by dispensing with prohibitions he made his doctrine popular." This was at the close of the fifteenth century when Yoshimasa 
-practised dilettanteism at Higashi-yama It became in that age a common habit that a man should shave his head and wear priest's vestments while still taking part in worldly affairs. The distinction between bonze and layman disappeared. "Some administrative officials became monks; some daimyō fought wearing sacerdotal vestments over their armour, and some priests led troops into battle. If a bonze earned a reputation for eloquence or piety, he often became the target of jealous violence at the hands of rival sectarians and had to fly for his life from the ruins of a burning temple. Not until the advent of Christianity, in the middle of the sixteenth century, did these outrages cease.

\section{THE FIVE TEMPLES OF KYŌTO}

The Zen sect had been almost equally popular during the epoch of the Hōjō. They built for it five great temples in Kamakura, and that example was followed by the Ashikaga in Kyoto. The five fanes in the capital were called collectively, Go-zan. They were Kennin-ji, Tōfuku-ji, Nanzen-ji, Tenryū-ji, and Shōkokuji. After the conclusion of peace between the Northern and Southern Courts the temple Shōkoku-ji was destroyed by fire and it remained in ashes until the time of Yoshimasa, when the priest, Chūshin, persuaded the shōgun to undertake the work of reconstruction. A heavy imposition of land-tax in the form of tansen, and extensive requisitions for timber and stones brought funds and materials sufficient not only to restore the edifice and to erect a pagoda 360 feet high, but also to replenish the empty treasury of the shogun. Thus, templebuilding enterprises on the part of Japanese rulers were not prompted wholly by religious motives.

\section{MANNERS AND CUSTOMS}

The frugal austerity of life under the rule of the Hōjō was changed to lavish extravagance under the Ashikaga. Yet things should have been otherwise, for in Takauji's time there was enacted and promulgated the code of regulations already referred to as the Kemmu Shikimoku, wherein were strictly forbidden basara, debauchery, gambling, reunions for tea drinking and couplet composing, lotteries, and other excesses. Basara is a Sanskrit term for costly luxuries of every description, and the compilers of the code were doubtless sincere in their desire to popularize frugality. But the Ashikaga rulers themselves did not confirm their precepts by example. They seemed, indeed, to live principally for sensuous indulgence.

A Japanese writer of the fifteenth century, in a rhapsodical account of the Kyoto of his day, dwells on the wonderful majesty of the "sky-piercing roofs" and "cloud-topping balconies" of the Imperial palace. And he points with evident pride to the fact that this splendor - a splendor only a little less - was to be found besides in many other elegant residences which displayed their owners taste and wealth. The chronicler notes that even those who were not noble, including some who had made their money by fortunetelling or by the practice of medicine, were sometimes able to make such display, to live in pretentious houses and have many servants. So could the provincial nobles, who it seems did not in other periods make much of a showing at the capital.

The dwellers in these mansions lived up to their environment. The degree of their refinement may be inferred from the fact that cooking became a science; they had two principal academies and numerous rules to determine the sizes and 
shapes of every implement and utensil, as well as the exact manner of manipulating them. The nomenelature was not less elaborate. In short, to become a master of polite accomplishments and the cuisine in the military era of Japan demanded patient and industrious study.

\section{MODE OF TRAVELLING}

The fashions of the Heian epoch in the manner of travelling underwent little change during the military age. The principal conveyance continued to be an ox-carriage or a palanquin. The only notable addition made was the kago, a kind of palanquin slung on a single pole instead of on two shafts. The kago accommodated one person and was carried by two. Great pomp and elaborate organization attended the outgoing of a nobleman, and to interrupt a procession was counted a deadly crime, while all persons of lowly degree were required to kneel with their hands on the ground and their heads resting on them as a nobleman and his retinue passed.

\section{LANDSCAPE GARDENING}

Great progress was made in the art of landscape gardening during the Muromachi epoch, but this is a subject requiring a volume to itself. Here it will suffice to note that, although still trammelled by its Chinese origin, the art received signal extension, and was converted into something like an exact science, the pervading aim being to produce landscapes and water-scapes within the limits of a comparatively small park without conveying any sense of undue restriction. Buddhist monks developed signal skill in this braneh of esthetics, and nothing could exceed the delightful harmony which they achieved between nature and art. It may be mentioned that the first treatise on the art of landscape gardening appeared from the pen of Gokyogoku Yoshitsune in the beginning of the thirteenth century. It has been well said that the chief difference between the parks of Japan and the parks of Europe is that, whereas the latter are planned solely with reference to a geometrical scale of comeliness or in pure and faithful obedience to nature's indications, the former are intended to appeal to some particular mood or to evoke special emotion, while, at the same time, preserving a likeness to the landscapes and water-scapes of the world about us.

\section{MINIATURE LANDSCAPE GARDENING}

By observing the principles and practical rules of landscape gardening while reducing the scale of construction so that a landscape or a water-scape, complete in all details and perfeetly balanced as to its parts, is produced within an area of two or three square feet, the Japanese obtained a charming development of the gardener's art. Admirable, however, as are these miniature reproductions of natural seenery and consummate as is the skill displayed in bringing all their parts into exact proportion with the scale of the design, they are usually marred by a suggestion of triviality. - In this respect, greater beauty is achieved on an even smaller scale by dwarfing trees and shrubs so that, in every respect except in dimensions, they shall be an accurate facsimile of what they would have been had they grown for cycles unrestrained in the forest. The Japanese gardener "dwarfs trees" so that they remain measurable only by inches after their age has reached scores, even hundreds, of years, and the proportions of leaf, branch 
and stem are preserved with fidelity. The pots in which these wonders of patient skill are grown have to be themselves fine specimens of the keramist's craft, and as much as $£ 200$ is sometimes paid for a notably well-trained tree." 1

\section{TEA CEREMONIAL}

The tea ceremonial (cha-no-yu) is essentially Japanese in its developments though its origin came from China. It has been well described as "a mirror in which the extraordinary elaborations of Japanese social etiquette may be seen vividly reflected." In fact, the use of tea as a beverage had very little to do with the refined amusement to which it was ultimately elevated. The term "tasting": would apply more accurately to the pastime than "drinking." But even the two combined convey no idea of the labyrinth of observances which constituted the ceremonial. The development of the cha-no-yu is mainly due to Shukō, a priest of the Zen sect of Buddhism, who seems to have conceived that tea drinking might be utilized to promote the moral conditions which he associated with its practice Prof. H. B. Chamberlain notes that "It is still considered proper for tea enthusiasts to join the Zen sect of Buddhism, and it is from the abbot of Daitokuji at Kyọto that diplomas of proficiency are obtained." The bases of Shukō's system were the four virtues - urbanity, purity, courtesy, and imperturbability - and little as such a cult seemed adapted to the practices of military men, it nevertheless received its full elaboration under the feudal system. But although this general description is easy, enough to formulate, the etiquette and the canons of the cha-no-yu would require a whole volume for an exhaustive description.

\section{INCENSE COMPARING}

The Muromachi epoch contributed to aristocratic pastimes the growth of another amusement known as ko-awase, "comparing of incense," a contest which tested both the player's ability to recognize from their odour different varieties of incense and his knowledge of ancient literature. As early: as the seventh century the use of incense had attained a wide vogue in Japan. But it was not until the beginning of the sixteenth century that Shino Soshin converted the pastime into something like a philosophy. From his days no less than sixty-six distinct kinds of incense were recognized and distinguished by names derived from literary allusions. This pastime is not so elaborate as the cha-noyu, nor does it furnish, like the latter, a series of criteria of art-objects. But it shows abundant evidence of the elaborate care bestowed upon it by generation after generation of Japanese dilettanti.

\section{$I K E-B A N A$}

The English language furnishes no accurate equivalent for what the Japanese call ike-bana. The literal meaning of the term is "living flower," and this name well explains the fundamental principle of the art, namely, the arrangement of flowers so as to suggest natural life. In fact, the blossoms must look as though they were actually growing and not as though they were cut from the stems. It is here that the fundamental difference between the Occidental and the Japanese method of flower arrangement becomes apparent; the former appeals

[1 Encyclopaedia Britannica, 11th Edition, article "Japan," Brinkley.] 
solely to the sense of colour, whereas the latter holds that the beauty of a plant is not derived from the colour of its blossoms more than from the manner of their growth. In fact, harmony of colour rather than symmetry of outline was the thing desired in a Japanese floral composition. It might be said that Western art, in general, and more particularly the decorative art of India, Persia and Greece - the last coming to Japan through India and with certain Hindu modifications - all aim at symmetry of poise; but that Japanese floral arrangement and decorative art in general have for their fundamental aim a symmetry by suggestion, - a balance, but a balance of inequalities. The ike-bana as conceived and practised in Japan is a science to which ladies, and gentlemen also, devote absorbing attention.

\section{OTHER PASTIMES}

viong bluort

It will be understood that to the pastimes mentioned above as originating in military times must be added others bequeathed from previous eras." Principal among these was "flower viewing" at all seasons; couplet composing; chess; draughts; football; mushroom picking; and maple-gathering parties, as well as other minor pursuits. Gambling, also, prevailed widely during the Muromachi epoch and was carried sometimes to great excesses, so that samurai actually staked their arms and armour on a cast of the dice. ' It is said that this vice had the effect of encouraging robbery, for a gambler staked things not in his possession, pledging himself to steal the articles if the dice went against him.

\section{SINGING AND DANCING}

One of the chief contributions of the military era to the art of singing was a musical recitative performed by blind men using the four-stringed Chinese lute, the libretto being based on some episode of military history. The performers were known as biwa-bōzu, the name " $b \bar{o} z u$ " (Buddhist priest) being derived from the fact that they shaved their heads after the manner of bonzes. These musicians developed remarkable skill of elocution, and simulated passion so that in succeeding ages they never lost their popularity. Sharing the vogue of the biwa-bōzu, but differing from it in the nature of the story recited as well as in that of the instrument employed, was the jöruri, which derived its name from the fact that it was originally founded on the tragedy. of Yoshitsune's favourite mistress, Joruri. In this the performer was generally a woman, and the instrument on which she accompanied herself was the samisen. These two dances may be called pre-eminently the martial music of Japan, both by reason of the subject and the nature of the musical movement.

The most aristocratic performance of all, however, was the yojkyoku, which ultimately grew into the $n \bar{o}$. This was largely of dramatic character and it owed its gravity and softness of tone to priestly influence, for the monopoly of learning possessed in those ages by the Buddhist friars necessarily made them pre-eminent in all literary accomplishments. The no, which is held in just as high esteem to-day as it was in medieval times, was performed on a stage in the open air and its theme was largely historical. At the back of the stage was seated a row of musicians who served as chorus, accompanying the performance with various instruments, chiefly the flute and the drum, and from time to time intoning the words of the drama. An ajunct of the $n \bar{o}$ was the kyogen. The no was solemn and stately; the kyōgen comic and sprightly. In fact, the latter 
was designed to relieve the heaviness of the former, just as on modern stages the drama is often relieved by the farce. It is a fact of sober history that the shogun Yoshimasa officially invested the $n \bar{o}$ dance with the character of a ceremonious accomplishment of military men and that Hideyoshi himself often joined the dancers on the stage.
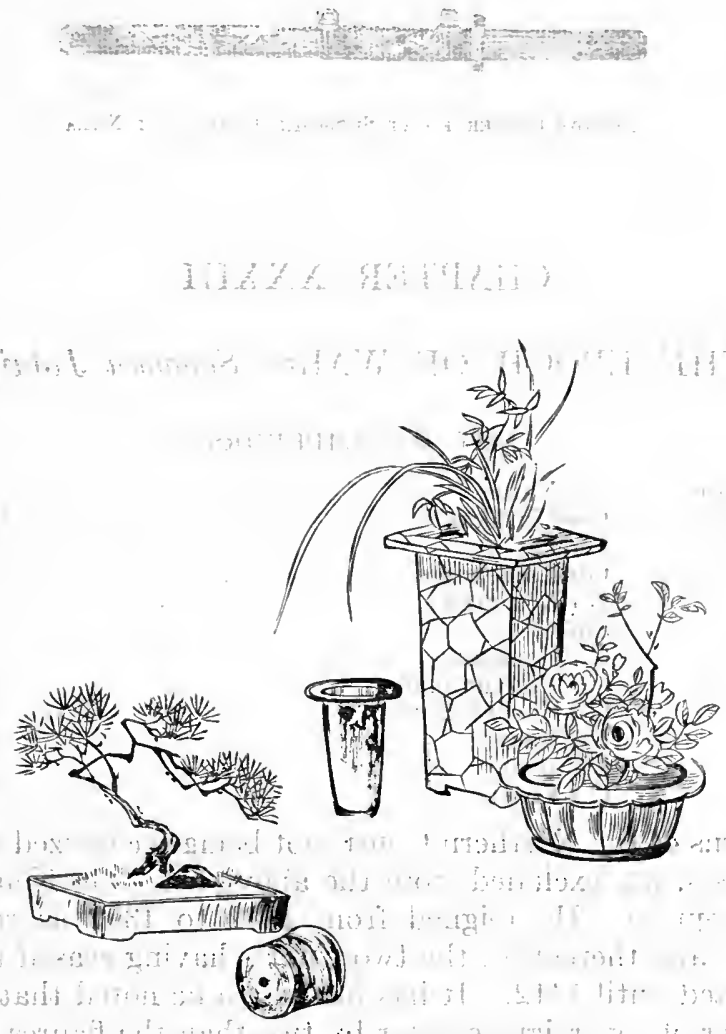

Flower Pots and Dware Trege

How 

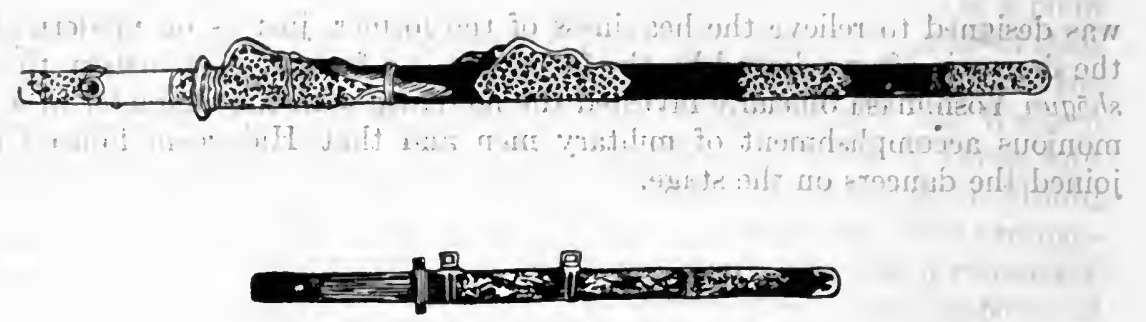

Swords Preserved at Shōsō-in Temple, at Nara

\section{CHAPTER XXXIII}

\section{THE EPOCH OF WARS (Sengoku Jidai)}

\begin{tabular}{|c|c|}
\hline \multicolumn{2}{|c|}{$\begin{array}{c}\text { Order of Succession } \\
\text { 97th Sovereign }\end{array}$} \\
\hline 98th & \\
\hline $99 \mathrm{th}$ & " \\
\hline 100th & " \\
\hline $101 \mathrm{st}$ & " \\
\hline $102 \mathrm{~d}$ & " \\
\hline $103 d$ & " \\
\hline 104 th & " \\
\hline 105th & " \\
\hline 106th & " \\
\hline 107th & " \\
\hline
\end{tabular}

\section{LIST OF' EMPERORS}

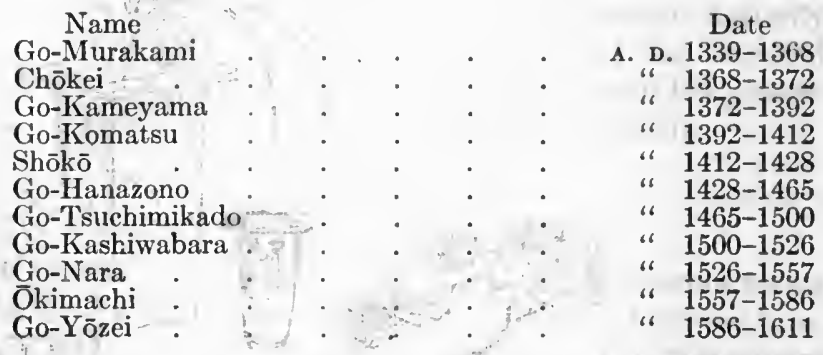

The sovereigns of the Northern Court, not being recognized as legitimate by Japanese annalists, are excluded from the above list. Go-Komatsu, however, is made an exception. He reigned from 1382 to 1392 as representing the Northern Court, and thereafter, the two Courts having ceased their rivalry, he reigned undisputed until 1412. It has further to be noted that many histories make the number of sovereigns greater by two than the figures recorded in the lists of this volume. That is because the histories in question count as two the Empresses Kōgyoku (642-645) and Saimei (655-661), although they represent the same sovereign under different names, and because they adopt a similar method of reckoning in the case of the Empresses Kōken (749-758) and Shōtoku (765-770), whereas in this volume the actual number of sovereigns is alone recorded.

\section{THE COURT}

The interval between the close of the fifteenth century and the end of the sixteenth is set apart by Japanese annalists as the most disturbed period of the country's history and is distinguished by the term Sengoku Jidai, or the Epoch of Wars. It would be more accurate to date the beginning of that evil time from the Ōnin year-period (1467-1469); for in the Ōnin era practical recognition was extended to the prineiple that the right of suecession to a family estate justifies appeal to arms, and that such combats are beyond the purview of the central authority. There ensued disturbances constantly increasing in area and intensity, and not only involving finally the ruin of the Ashikaga shōgunate but 
allso subverting all law, order, and morality. Sons turned their hand against fathers, brothers against brothers, and vassals against chiefs. Nevertheless, amid this subversion of ethics and supremacy of the sword, there remained always some who reverenced the Throne and supported the institutions of the State; a noteworthy feature in the context of the fact that, except during brief intervals, the wielder of the sceptre in Japan never possessed competence to enforce his mandates but was always dependent in that respect on the voluntary co-operation of influential subjects.

tIf In the Sengoku period the fortunes of the Imperial Court fell to their lowest ebb. The Crown lands lay in the provinces of Noto, Kaga, Echizen, Tamba, Mino, and so forth, and when the wave of warfare spread over the country, these estates passed into the hands of military magnates who absorbed the taxes into their own treasuries, and the collectors sent by the Court could not obtain more than a small percentage of the proper amount. The exchequer of the Muromachi Bakifu suffered from a similar cause, and was further depleted by extravagance, so that no aid could be obtained from that source. Even worse was the case with the provincial manors of the Court nobles; who were ultimately driven to leave the capital and establish direct connexion with their properties. Thus, the I'chijo family went to Tosa; the Ane-no-kōji to Hida, and when Ōuchi Yoshioki retired to Suwō on resigning his office (kwanryō), many Court magnates who had benefitted by his generosity in Kyōto followed him southward.

So impoverished was the Imperial exchequer that, in the year 1500, when the Emperor Go-Tsuchimikado died, the corpse lay for forty days in a darkened room of the palace, funds to conduct the funeral rites not being available. Money was finally provided by Sasaki Takayori, and in recognition of his munificence he was authorized to use the Imperial crest (chrysanthemum and Paulownia); was granted the right of entrée to the palace, and received an autographic volume from the pen of the Emperor Go-Kōgon. If there was no money to bury Go-Tsuchimikado; neither were any funds available to perform the coronation of his successer, Go-Kashiwabara. Muromachi made a futile attempt to levy contributions from the daimyō, and the kwanry $\bar{o}$, Hosokawa Masamoto, is recorded to have brusquely said, in effect, that the country could be administered without crowning any sovereign. Twenty years passed before the ceremony could be performed, and means were ultimately (1520) furnished by the Buddhist priest Kōken - son of the celebrated Rennyo Shōnin, prelate of the Shin sect - who, out of the abundant gifts of his disciples, placed at the disposal of the Court a sum of ten thousand gold ryo ${ }^{1}{ }^{1}$ being moved to that munificence by the urging of Fujiwara Sanetaka, a former nai-daijin. In recognition of this service, Kōken was raised to high ecclesiastical rank.

It: will be remembered that, early in this sixteenth century, Yoshioki, deputy kwanryō and head of the great Ouchi house, had contributed large sums to the Muromachi treasury; had contrived the restoration of several of the Court nobles' domains to their impoverished owners', and had assisted with open hand to relieve the penury of the throne. The task exhausted his resources, and when recalled to his province by local troubles in 1518 , the temporary alleviation his generosity had brought was succeeded by hopeless penury. From time immemorial it had been the universal rule to rebuild the two great shrines at Ise every twentieth year, but nothing of the kind had been possible in the case of the Naigu (inner shrine) since 1462 , and in the case of the Geg $\bar{u}$ (outer shrine) since 1434 Such neglect insulted the sanctity of the Throne; yet appeals to the 
Bakufu produced no result. ' In 1526, the Emperor Go-Kashiwabara died. It is on record that his ashes were carried from the crematorium in a box slung from the neck of a gencral officer, and that the funeral train consisted of only twenty-six officials. For the purposes of the coronation ceremony of this sovereign's successor, subseriptions had to be solicited from the provincial magnates, and it was not until 1536 that the repairs of the palace could'be undertaken, so that the Emperor Go-Nara was able to write in'his diary?" "All that I desired to have done has been accomplished, and I am much gratified." On this occasion the Ouchi family again showed its generosity and its loyalty to the Throne.

The extremity of distress was reached during the Kyöroku era (1528-1531), when the struggle between the two branches of the Hosokawa family converted Kyotto once more into a battle-field and reduced a large part of the city to ashes. The Court nobles, with their wives and children, had to seek shelter and refuge within the Imperial palace, the fences of which were broken down and the buildings sadly dilapidated.

A contemporary record tells with much detail the story of the decay of the capital and the pitiful plight of the Throne. The Emperor Go-Nara (15271557) was reduced to earning his own living. This he did by his skill as a calligrapher - at least one instance of something useful resulting from the penchant of the Court for the niceties of Chinese art and letters. Any one might leave at the palace' a few coins for payment and order a fair copy of this or that excerpt from a famous classic. The palace was overrun, the ehronicler says. Its garden became a resort for tea-drinking:among the lower classes and children made it a play-ground. It was no longer walled in, but merely fenced with bamboo. The whole city was in a similar desolation; things having become worse and worse beginning with the $\bar{O}$ nin disturbance of 1467 and the gencral exodus of the samurai from the capital at that time. At this time the military nobles came to the city only to fight, and the city's population melted away. All was disorder." The city was flooded and the dike which was built to cheek the flooded rivers came to be thought a fine residence place in comparison with lower parts of the town.

It was at this time that men might be observed begging for rice in the streets of the eapital. They carried bags to receive contributions which were designated kwampaku-ryō (regent's money). "Some of the bags thus used are preserved by the noble family of Nijō to this day. Another record says that the stewardéss of the Imperial household service during this reign (Go-Nara), on being asked how summer garments were to be supplied for the ladies-in-waiting, replied that winter robes with their wadded linings removed should be used. The annals go so far as to allege that deaths from cold and starvation occurred among the courtiers. An important fact is that one of the provineial magnates who contributed to the succour of the Court at this period was Oda Nobuhide of Owari, father of the celebrated Oda Nobunaga.

\section{BUDLHIST, VIOLENCE}

The decline of the Muromachi Bakufu's authority encouraged the monks as well as the samurai to become a law to themselves. Incidental references have already been made to this subject, but the religious commotions of the Sengoku period invite special attention. The Buddhists of the Shin sect, founded by Shinran Shonin (1184-1268), which had for headquarters the great temple 


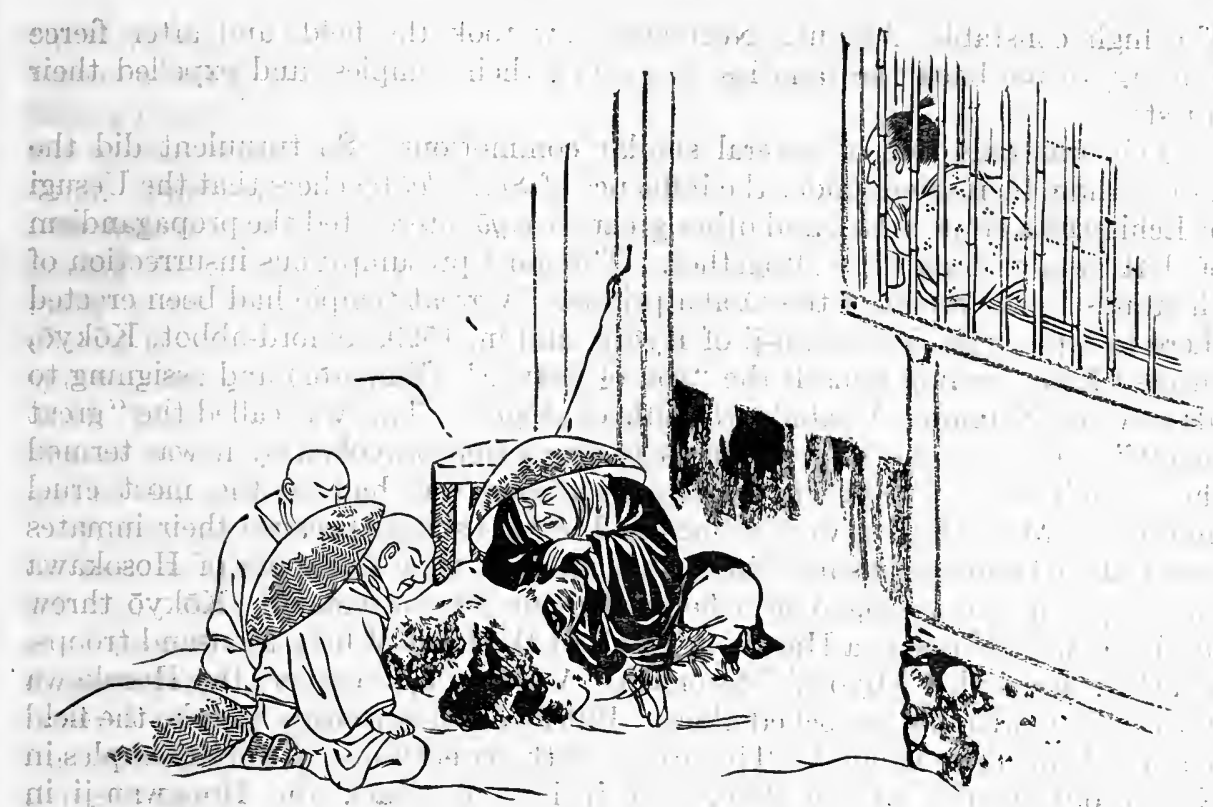

SHINRAN Shönin

Hongwan-ji in Kyoto, were from the outset hostile to the monks of Enryaku-ji. Religious doctrine was not so much concerned in this feud as rivalry. Shinran had been educated in the Tendai tenets at Enryaku-ji. Therefore, from the latter's point of view he was a renegade, and while vehemently attacking the creed of his youth, he had acquired power and influence that placed the Hongwanji almost on a level with the great Hiei-zan. In the days of Kenju, popularly called Rennyo Shonin (1415-1479), seventh in descent from the founder, Shinran, the Ikkō - by which name the Shin sect was known - developed conspicuous strength. Kenju possessed extraordinary eloquence. Extracts from his sermons were printed on an amulet and distributed among worshippers, who grew so numerous and so zealous that the wealth of the sect became enormous, and its leaders did not hesitate to provide themselves with an armed following. Finally the monks of Hiei-zan swept down on Hongwan-ji, applied the torch to the great temple, and compelled the abbot, Kenju, to fly for his life.

It is significant of the time that this outrage received no punishment. Kenju escaped through Ömi to Echizen, where the high constable, an Asakura, combining with the high constable, a Togashi, of the neighbouring province of Kaga, erected a temple for the fugitive abbot, whose favour was well worth courting. The Ikkō-shu, however, had its own internal dissensions. . In the province of Kaga, a sub-sect, the Takata, endeavoured to oust the Hongwan disciples, and rising in their might, attacked (1488) the high constable; compelled him to flee; drove out their Takata rivals; invaded Etchū; raided Noto, routing the forces of the high constable, Hatakeyama Yoshizumi; seized the three provinces Kaga, Noto, and Etch $\bar{u}$ - and attempted to take possession of Echizen. This wholesale campaign was spoken of as the $I k k \bar{o}-i k k i$ (revolt of Ikkō). A few years later, the Shin believers in Echizen joined these revolters, and marched through the province, looting and burning wherever they passed. . No measure of secular-warfare had been more ruthless than were the ways of these monks. 
The high constable, Asakura Norikage, now took the field, and after fierce fighting, drove back the fanaties, destroyed their temples, and expelled their priests.

This was only one of several similar commotions. So turbulent did the monks show themselves under the influence of :Shin-shu teachers that the Uesugi of Echigo, the Hōjō of Izu, and other great daimyō interdicted the propagandism of that form of Buddhism altogether. The most presumptuous insurrection of all stands to the eredit of the Ōsaka priests. A great temple had been erected there to replace the Hongwan-ji of Kyōto, and in, 1529, its lord-abbot, Kōkyō, entered Kaga, calling himself the "son of heaven" (Emperor) and assigning to his steward, Shimoma Yorihide, the title of shogun. This was called the "great revolt" (dai-ikki), and the movement of opposition provoked by it was termed the "small revolt" (shō-ikki). Again recourse was had to the most cruel methods. Men's houses were robbed and burned simply beeause their inmates stood aloof from the insurrection. Just at that time the septs of Hosokawa and Miyoshi were engaged in a fierce struggle for supremacy. Kōkyō threw in his lot with Hosokawa Harumoto, and, at the head of fifty thousand troops, attacked and killed Miyoshi Motonaga. Very soon, however, the Hosokawa chief fell out with his cassocked allies. But he did not venture to take the field against them single handed. The priests of the twenty-one Nichiren temples in Kyoto, old enemies of the Ikko, were incited to attack the Hongwan-ji in Osaka. This is known in history as the Hokke-ikki, Hokke-shü being the name of the Nichiren sect. Hiei-zan was involved in the attack, but the warlike monks of Enryaku-ji replied by pouring down into the capital, burning the twenty-one temples of the Nichiren and butchering three thousand of their priests. Such were the ways of the Buddhists in the Sengoku period.

\section{THE KWANTŌ}

During the-Sengoku period (1490-1600) the Japanese empire may be compared to a seething cauldron, the bubbles that unceasingly rose to the surface disappearing almost as soon as they emerged, or uniting into groups with more or less semblance of permanence. To follow in detail these superficial changes would be a task equally interminable and fruitless. They will therefore be traced here in the merest outline, except in cases where large results or national effects are concerned. The group of eight provinces called collectively Kwantō first claims attention as the region where all the great captains and statesmen of the age had their origin and found their chief sphere of action. It has been seen that the fifth Ashikaga kwanryō, Shigeuji, driven out of Kamakura, took refuge at Koga in Shimotsuke; that he was thenceforth known as Koga Kubō; that the Muromachi shoggun, Yoshimasa, then sent his younger brother, Masatomo, to rule in the Kwantō; that he established his headquarters at Horigoe in Izu, and that he was officially termed Horigoe Gosho. His chief retainers, were the two Uesugi families - distinguished as Ōgigayatsu Uesugi and Yamanouchi Uesugi, after the names of the palaces where their mansions were situated $\rightarrow$ both of whom held the office of kwanryo hereditarily.

These Uesugi families soon engaged in hostile rivalry, and the Ōgigayatsu branch, being allied with Ōta Dōkwan, the founder of Yedo Castle, gained the upper hand, until the assassination of Dōkwan, when the Yamanouchi became powerful. It was at this time - close of the fifteenth century - that there occurred in the Horigoe house one of those succession quarrels so common since 
the Ōnin era. Ashikaga Masatomo, seeking to disinherit his eldest son, Chachamaru, in favour of his second son, Yoshimichi, was killed by the former, the latter taking refuge with the Imagawa family in Suruga, by whom he was escorted to the capital, where he became the Muromachi shogun under the name of Yoshizumi Parricides and fratricides were too common in that disturbed age for Chachamaru's crime to cause any moral commotion. But it chanced that among the rear vassals of the Imagawa there was one, Nagauji, who, during many years, had harboured designis of large ambition. Seizing the occasion offered by Chachamaru's crime, he constituted himself Masatomo's avenger, and marching into Izu, destroyed the Horigoe mansion, and killed Chachamaru. Then (1491) Nagauji quietly took possession of the province of Izu, building for himself a castle at Hōjō. He had no legal authority of any kind for the act, neither coinmand from the Throne nor commission from the shogun.

It was an act of unqualified usurpation. Yet its perpetrator showed that he had carefully studied all the essentials of stable government - careful selection of official instruments; strict administration of justice; benevolent treatment of the people, and the practice of frugality: Being descended from the Taira of Ise and having occupied the domains long held by the Hōjō, he adopted the uji name of "Hōjōo," and having extended his conquests to Sagami province, built a strong castle at Odawara. He is often spoken of as Sōun, the name he adopted in taking the tonsure, which step did not in any degree interfere with his secular activities. A profoundly skilled tactician, he never met with a military reverse, and his fame attracted adherents from many provinces. $\mathrm{His}$

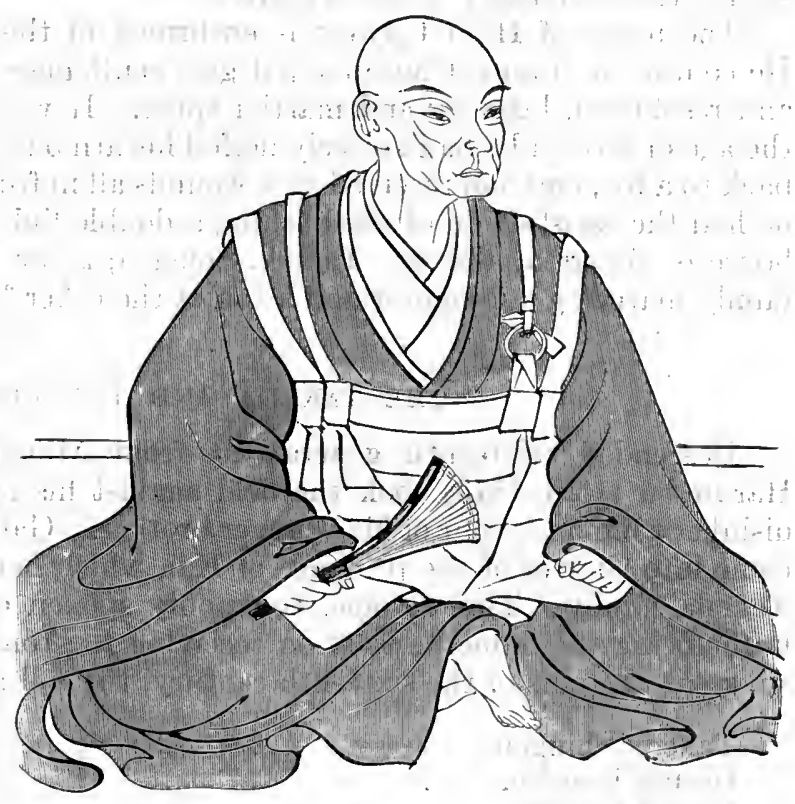
instructions to his son Ujitsuna were characteristic. Side by side with an injunction to hold himself in perpetual readiness for establishing the Hōjō sway over the whole of the Kwantō, as soon as the growing debility of the Uesugi family offered favourable opportunity, stood a series of rules elementary almost to affectation: to believe in the Kami; to rise early in the morning; to go to bed while the night is still young, and other counsels of cognate simplicity formed the ethical thesaurus of a philosopher wise enough to formulate the astute maxim that a ruler, in choosing his instruments, must remember that they, too, choose him. 
Ujitsuna proved himself a worthy son of Sōun, but much had still to be accomplished before the Kwantō was fully won: Among the eight provinces, two, Awa and Kazusa, which looked across the sea to Odawara, were under the firm sway of the Satomi family - one of the "eight generals" of the Kwantō and not until 1538 could the Hōjō chief find an opportunity to crush this strong sept. The fruits of his victory had hardly been gathered when death overtook him, in 1543. His.sword descended, however; to a still greater leader, his son Ujiyasu, who pushed westward into Suruga; stood opposed to Kai in the north, and threatened the Uesugi in the east. The two branches of the Uesugi had joined hands in the presence of the Hōjo menace, and a powerful league including the Imagawa and the Ashikaga of Koga, had been formed to attack the Họjo. So long did they hesitate in view of the might of Odawara, that the expression "Odawara-hyogi". passed into the language as a synonym for reluctance; and when at length they moved to the attack with eighty thousand men, Hojjo Ujiyasu, at the head of a mere fraction of that number, inflicted a defeat which settled the supremacy of the Kwantō.

The name of Hōjo Ujiyasu is enshrined in the hearts of Japanese bushi. He combined in an extraordinary degree gentlemess and bravery, magnanimity and resolution, learning and martial spirit. It was commonly said that from the age of sixteen he had scarcely doffed his armour; had never once showed his back to a foe, and had received nine wounds all in front. ${ }_{1}$ : Before he died (1570) he had the satisfaction of establishing a double link between the Hojo and the house of the great warrior, Takeda Shingen, a son and a daughter from each family marrying a daughter and a son of the other. ${ }^{2}$

\section{THE TAKEDA AND THE UESUGI}

Descended (sixteenth generation) from Minamoto Yoshimitsu, Takeda Harunobu (1521-1573) took the field against his father, who had planned to disinherit him in favour of his younger brother: Gaining the vietory, Harunobu came into control of the province of Kai, which had long been the seat of the Takeda family. This daimyō, commonly spoken of as Takeda Shingen, the latter being the name he took on receiving the tonsure, ranks among Japan's six great captains of the sixteenth century, the roll reading thus: $-\frac{1}{x+2}$

Takeda Shingen

Uesugi Kenshin

(1521-1573)

Hōjō Ujimasa

Oda Nobunaga

Toyotomi Hideyoshi

Tokugawa Ieyasu

$(1530-1578)$

$(1538-1590)$

(1534-1582)

(1536-1598)

$(1542-1616)$

The second of the above, Uesugi Kenshin, was not a member of the great Uesugi family which took such an important part in the affairs of the Kwantō. He belonged to the Nagao, which originally stood in a relation of vassalage to the Yamanouchi branch of the Uesugi in Echigo, and his father attained an independent position. Kagetora, as Kenshin was ealled in his youth, found himself engaged in his twenty-first year in a contest with his elder brother, whom he killed, and, by way of penanee for the fratricide, he took the tonsure under the name of Kenshin and would have retired from the world had not his generals 

insisted on his remaining in command. It was at this time that Kenshin became a member of the Uesugi sept. In 1505, the two branches of the Kwanto Uesugi joined hands against their common enemy, Hōjō Sōun, and from that time the contest was continued until 1551, when Ujiyasu, grandson of Soun, drove Uesugi Norimasa from his castle of Hirai in Kōtsuke. The vanquished general fled to Echigo to seek succour from his family's old-time vassal, Nagao Kagetora, already renowned under the name of Kenshin. Norimasa bestowed the office of kwanryo as well as the uji of Uesugi on Kenshin, who thenceforth became known as Uesugi Kenshin, and who thus constituted himself the foe of the Hōjō. At a somewhat earlier date, Kenshin had been similarly supplicated by Murakami Yoshikiyo, whose castle was at Kuzuo in Shinano, whence he had been driven by Takeda Shingen.

It thus fell out that Uesugi Kenshin had for enemies the two captains of highest renown in his era, Hōjō Ujimasa and Takeda Shingen. This order of an-
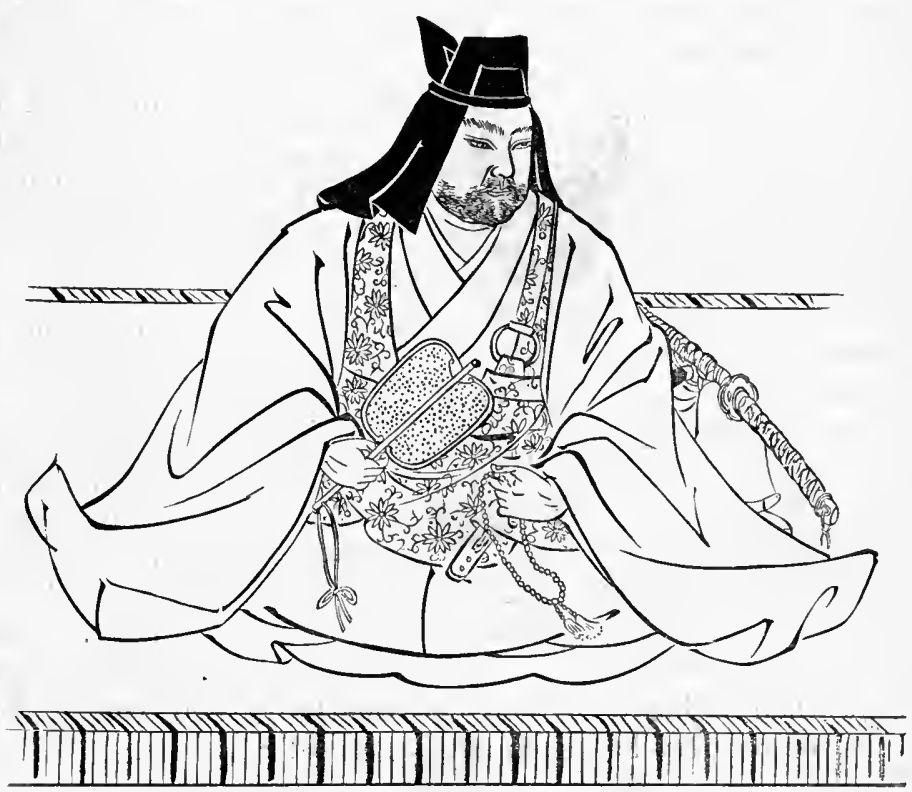

Uesugi Kenshin

tagonism had far-reaching effects. For Kenshin's ambition was to become master of the whole Kwantō, under pretence of re-establishing the original Uesugi, but his expansion southward from Echigo was barred by Shingen in Shinano and Kai, and his expansion eastward by the Hōjō in Sagami and Musashi. The place of the struggle between Shingen-and Kenshin was Kawanaka-jima, an arena often pictured by artists of later generations and viewed to-day by pilgrims to the venerable temple, Zenkō-ji. There the two generals, recognized as the two greatest strategists of that epoch, met four times in fierce strife, and though a Japanese historlan compares the struggle to the eruption of volcanoes or the blowing of gales of blood, victory never rested on either standard.

Peace.having been at length restored for a moment, in 1558, Kenshin visited Kyoto in the following year. There he was received with distinction. The Emperor - Ōkimachi - bestowed on him a sword, and the shōgun, Yoshiteru, entitled him to incorporate the ideograph "teru" in his name, which was thus changed from Kagetora to Terutora. He was also granted the office of kwanryō. On his return to Echigo, Kenshin proceeded to assert his new title. Mustering an army said to have been 110,000 strong, he attacked the Hōjō in Odawara. But Ujiyasu would not be tempted into the open. He remained always behind 
the ramparts, and, in the meanwhile incited Shingen to invade Echigo, so that Kenshin had to raise the siege of Odawara and hasten to the defence of his home provinee. There followed another indecisive battle at Kawanaka-jima, and thereafter renewed attacks upon the Hōjō, whose expulsion from the Kwantō devolved on Kenshin as kwanryō. But the results were always vague: the Hōjo refrained from final resistance, and Shingen created a diversion. The chief sufferers were the provinces of the Kwanto, a scene of perpetual bat-

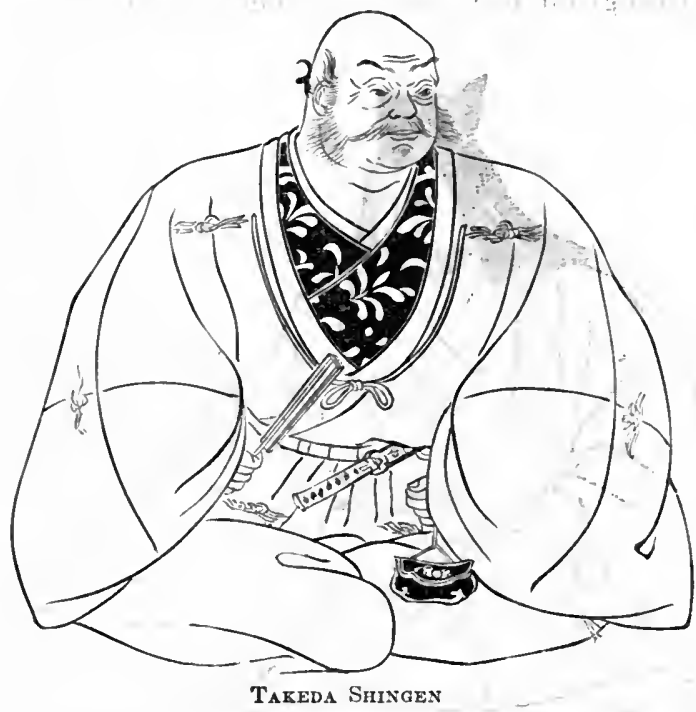

tle. In the end, after 'Etchū and Kōtsuke had been brought under Kenshin s'sway, peace was concluded between him and the Hōjo, and he turned his full strength against his perennial foe, Shingen. But at this stage the situation was entirely changed by the appearance of Oda Nobunaga on the scene, as will be presently narrated. It is recorded that, on the eve of his death, Shingen advised his son to place himself and his domains in Kenshin's keeping, for, said he, "Kenshin now stands unrivalled, and $\wedge$ Kenshin will never break faith with you," and it is recorded of Kenshin that when he heard of Shingen's death, he shed tears and exclaimed, "Would that the country had such another hero!'”

THE IMAGAWA, THE KITABATAKE, THE SAITŌ, AND THE ODA FAMULIES

The Imagawa, a branch of the Ashikaga, served as the latter's bulwark in Suruga province during many generations. In the middle of the sixteenth century the head of the family was Yoshimoto. His sway extended over the three provinces of Suruga, Tötomi, and Mikawa, which formed the littoral between Owari Bay and the Izu promontory. On the opposite side of Owari Bay lay Ise province, the site of the principal Shinto shrine and the original domain of the Taira family, where, too, the remnants of the Southern Court had their home. Its hereditary governor was a Kitabatake, and even after the union of the two Courts that great family, descendants of the immortal historian and philosopher, Chikafusa, continued to exereise sway. But, in 1560 , discord among the chief retainers of the sept furnished a pretext for the armed intervention of Oda Nobunaga, who invested his son, Nobukatsu," with the rights of government. On the northern littoral of Owari Bay, and therefore separating Ise and Mikarva, was situated the province of Owari, which, in turn, opened on the north into Mino. In this latter province the Doki family wás destroyed by the Saitō, and these in turn were crushed by the Oda, in 1561, who, from their headquarters in Owari, shattered the Imagawa of Mikawa and the Saito in Mino, thereafter sweeping over Isie. 
THE ROKKAKÜ, THE ASAI, THE ASAKURA, AND THE HATAKEYAMA FAMILIES

The province of Ōmi had special importance as commanding the approaches to Kyōto from the east. Hence it became the scene of much disturbance, in which the Hosokawa, the Kyogoku; the Rokkaku, and the Asai families all took part. Finally, in the middle of the sixteenth century, the Asai gained the ascendancy by obtaining the assistance of the Asakura of Echizen. This latter province, conterminous with the north of Ömi, was originally under the control of the Shiba family, but the Asakura subsequently: obtained the office of ingh constable, and acquired a great access of power at the time of the Ikko revolt by driving the turbulent priests from the province. At that era, or a little later, the provinces of Kii, Kawachi, Izumi, and Yamato were all the scenes of fierce fighting, but the pages of history need not be burdened with details of the clash of purely private ambitions.

\section{THE MŌRI AND THE AMAKO FAMILIES}

The Ouchi family was very powerfully situated. Descended from a Korean Crown Prince who migrated to Japan early in the seventh century, its representative, Yoshioki (1477-1528), controlled the southern provinces of the main island - Iwami, Aki, Suwo, and Nagato - as well as the two northern provinces of Kyüshū-Chikuzen and Buzen. This was the chieftain who, in 1508, marched to Kyōto at the head of a great army, and restored the Ashikaga shogun. Yoshitane, himself receiving the office of kwanryō. Eleven years later, on his return to the south, he was followed by many nobles from Kyōto, and his chief provincial town,.Yamaguchi, on the Shimonoseki Strait, prospered greatly. But his son Yoshitaka proved a weakling, and being defeated by his vassal, Suye Harukata - called also Zenkyō - he committed suicide, having conjured another vassal, Mōri Motonari, to avenge him.

The Móri family ${ }^{1}$ had for ancestor the great statesman and legislator of Yoritomo's time, Oye Hiromoto, and its re-

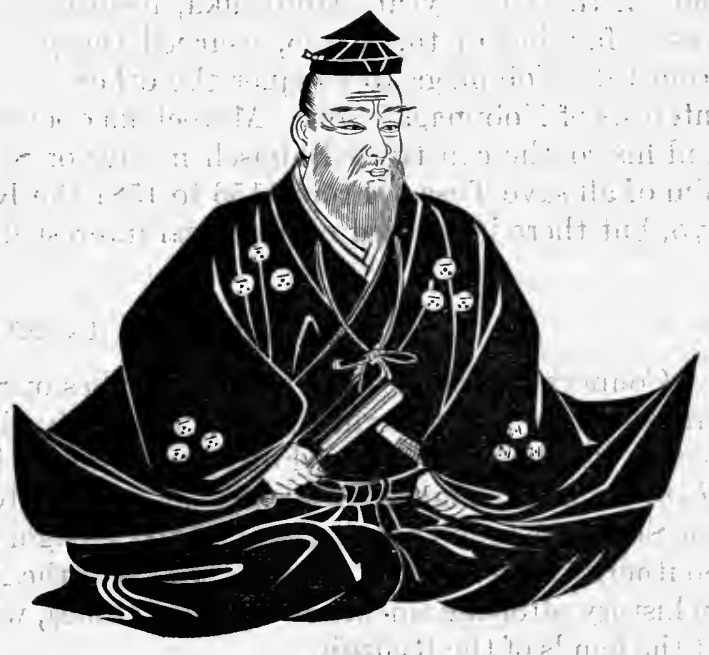

Möri Motonara presentative, Motonari (1497$157 \mathrm{~N}$, had two sons scarcely. inferior to himself in strategical ability, Kikkawa Motoharu and Kohayakawa Takakage. A commission having been obtained from, Kyōto, Motonari took the field in 1555, and with only three thousand men succeeded, by a daring feat, in shattering Harukata with twenty thousand. Thus far, Mōri Motonari had obeyed the behest of his late chief. But thereafter he made no attempt to restore the Ouchi family. On the contrary, he relentlessly prosecuted the campaign against Suye Harukata, with whom was associated 
Ōuchi Yoshinaga, representing the Ōuchi house by adoption, until ultimately Yoshinaga committed suicide and, the Ouchi family becoming extinct, Motonari succeeded to all its domains.

At that time the province of Izumo, which is conterminous with Iwami along its western frontier, was under the control of the high constable, Amako Tsunehisa (1458-1540), who, profiting by the fall of the great Yamana sept, had obtained possession of the provinces Bingo and Hoki as well as of the Oki Islands: This daimyō was a puissant rival of the Ouchi family, and on the downfall of the latter he soon came into collision with Möri Motonari. Tsunehisa's grandson, Yoshihisa (1545-1610), inherited this feud, which ended with the extinction of the Amako family and the absorption of its domains by the Morri, the latter thus becoming supreme in no less than thirteen provinces of the Sanyō-dō and the Sanin-dō.

THE MIYOSHI, THE ICHIJŌ, THE CHŌSOKABE, AND THE KŌNO FAMILIES

With the island of Shikoku (four provinces) are connected the names of the Hosokawa, the Miyoshi, the Iehijo, the Chōsokabe, and the Kono families. Early in the fourteenth century, the celebrated Hosokawa Yoriyuki was banished to Sanuki, and in the middle of the fifteenth century we find nearly the whole of the island under the sway of Hosokawa Katsumoto. Then, in the Daiei era (1521-1528), the Miyoshi, vassals of the Hosokawa, came upon the scene in Awa. From 1470 to 1573 , the province of Tosa was governed by the Ichijo, but, in the latter year, Motochika, head of the Chōsokabe, one of the seven vassal families of the Ichijo, usurped the province, and then received orders from Oda Nobunaga to conquer the other three provinces of the island in the interests of Nobunaga's son. Motochika obeyed, but on the death of Nobunaga and his son he constituted himself master of Shikoku until Hideyoshi deprived him of all save Tosa. From 1156 to 1581 the Kono family held the province of Iyo, but there is nothing of historical interest in their career.

\section{THE DAIMYŌ IN KYŪSHŪ}

Connected with Kyūshū are the families of Shōni, Ōtomo, Ryūzōji, Kikuchi and Shimazu. The term "shōn " originally signified vice-governor. Its first bearer was Mutō Sukeyori (Fujiwara), who received the commission of Dazai no shōni from Minamoto Yoritomo. Subsequently it became a family name, and the Shōni are found fighting against the Mongol invaders; stoutly supporting the Southern Court; passing over to the side of the Ashikaga; and losing their places in history after the suicide of Tokihisa (1559), who had suffered repeated defeats at the hands of the Ryūzōji.

The Otomo family was a branch of the.Fujiwara. One of its members, Nakahara Chikayoshi, received from Minamoto Yoritomo the office of high constable of the Dazai-fu, and to his son, Yoshinao, was given the uji of Ōtomo, which, as the reader knows, belonged'originally to Michi no Omi, a general of the Emperor Jimmu. In Kyūshū, the Ōtomo espoused the cause of the Northern Court, and made themselves masters of Buzen, Bungo, Chikuzen, Chikugo, Hizen, and Higo. In 1396, the head of the family - Chikayo - held the office of tandai of Kyūshū. Yoshishige, commonly called Sōrin (1530-1587), fought successfully with the Kikuchi and the Akizuki, and the closing years of his life were devoted to a futile struggle against the Shimazu, the Ryūzōji, and the 
Akizuki He escaped disaster by obtaining succour from Hideyoshi, but the $\bar{O}$ tomo: domain was reduced to the single province of Bungo.

The Ryūzōji first appear in historyl as vassals of the Shōni, under whose banner they fought against the Ōtomo; in 1506. Subsequently they became independent and established a stronghold in Hizen, which province was granted to them in fief by Hideyoshi.

The:Kikuchi, a branch of the Fujiwara, held office in Kyūshū from the tenth century. They are chiefly noteworthy for their gallant defence of the cause of the Southern Court. After many vicissitudes the family disappeared from history in the middle of the sixteenth century.

dos The ancestor of the Shimazu family was Tadahisa, an illegitimate son of Minamoto Yoritomo. His mother, to escape the resentment of Yoritomo's wife, Masa, fled to Kyūshū, and Tadahisa; having been named governor of Satsuma, proceeded thither, in 1196, and by conquest added to it the two provinces, Hy üga and $\bar{O}$ sumi.' The Shimazu family emerged victorious from all campaigns until Hideyoshi in person took the field against them, as will be presently related: ${ }^{1}$

\section{THE $\bar{O}-U$ REGION}

The $\bar{O}-U$ region (Mutsu-Dewa) was the home of many septs which fought among themselves for supremacy. Of these the most influential were the Mogami of Yamagata, the Date of Yonezawa, and the Ashina of Aizu. In the extreme north were the Nambu who, however, lived too remote from the political centres to occupy historical attention. The Date maintained friendly relations with the

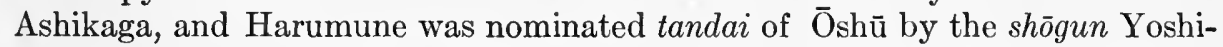
haru, of whose name one ideograph (haru) was given to the Date chief. The family attained its greater distinction in the time of Masamune (1566-1636), and was fortunate in being able to stand aloof from some of the internecine strife of the sixteenth century. Nevertheless, the region was sufficiently disturbed. Thus, the Tsugaru and the Nambu struggled in the north, while the Date, further north, shattered the power of the Nikaido, the Nihonmatsu, the Ashina, and the Tamura, or fought less decisively against the Satake (of Hitachi), and in Ushū (Dewà) the Mogami were confronted by the Uesugi of Echigo.

\section{DATE MASAMUNE}

The most renowned of the Date family was Masamune, who to great military skill added artistic instincts and considerable poetic ability. Tradition has handed down some incidents which illustrate the ethics of that time as well as the character of the man. It is stated that Masamune came into possession of a scroll on which were inscribed a hundred selected poems copied by the celebrated Fujiwara Ietaka. Of this anthology Masamune was much enamoured, for the sake alike of its contents and of its calligraphy. But learning accidentally that the scroll had been pawned to the merchant from whom he had obtained it, he instituted inquiries as to its owner, and ultimately restored the scroll to him with the addition of five gold ryō. The owner was a knight-errant (rōnin) named Imagawa Motome, who thereafter entered Masamune's service and ultimately rose to be a general of infantry (ashigaru). The sympathy which taught Masamune to estimate the pain with which the owner of the scroll must have parted with it was a fine trait of character. Another incident in this 
remarkable man's career happened at an entertainment where he accidentally trod on the robe of one Kanematsu, a vassal of the Tokugawa.: Enraged by an act of carelessness which amounted almost to a deliberate insult; Kanematsu struck Masamune. A commotion at once arose, the probable outcome being that Masamune would return the blow with his sword. But he remained pertly cool, making no remark except that he had been paid for his want of care, and that, at any rate, Kanematsu was not an adversary worthy of his resentment.

\section{THE FIVE CENTRES}

Among the welter of warring regions glanced at above, five sections detach themselves as centres of disturbance. The first is the Court in Kyoto and the Muromachi Bakufu, where the Hosokawa, the Miyoshi, and the Matsunaga deluged the streets with blood and reduced the city to ashes. "The second is the Hojō of Odawara, who compassed the destruction of the kubo at Koga and of the two original Uesugi families. The third is Takeda of Kai, who struggled on one side with the Uesugi of Echigo and on the other with the Imagawa of Suruga. The fourth is Oda Nobunaga, who escorted the shoggun to the capital. And the fifth is the great Mori family, who, after crushing the Oưchi and the Amako, finally came into collision with the armies of Oda under the leadership of Hideyoshi.

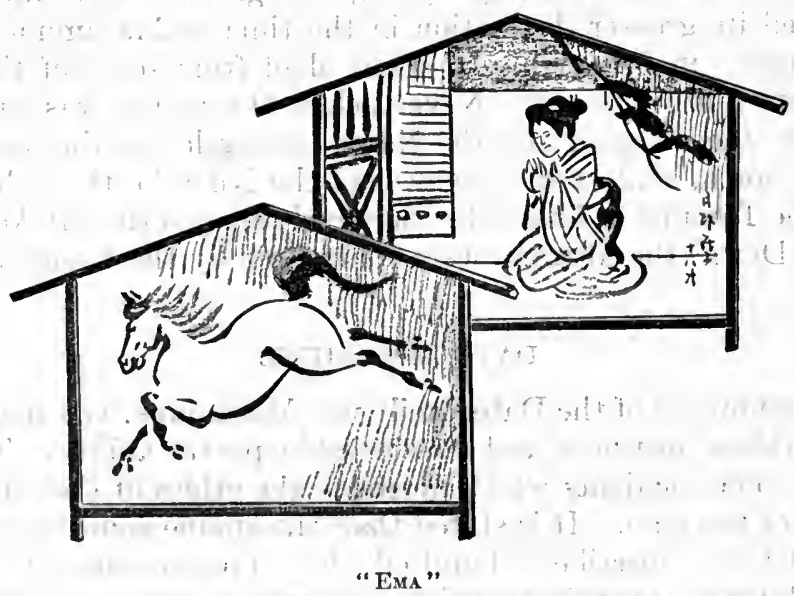

(Pictures Painted on Wood, Especially of Horses, Hung up in the Temple as Motive Offerings) 


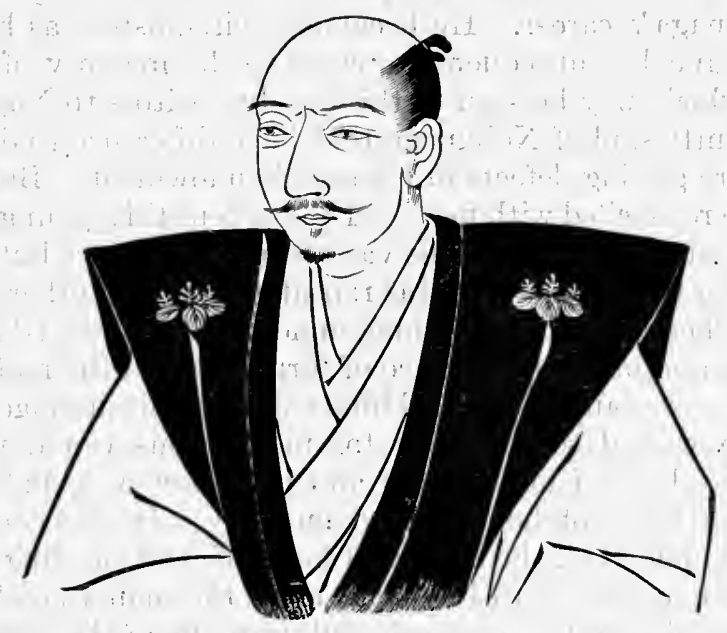

OdA NoBÜnaga

\section{CHAPTER : XXXIV}

\section{NOBUNAGA, HIDEYOSHI, AND IEYASU}

\section{ODA NOBUNAGA}

When the Taira sept was shattered finally at Dan-no-ura, a baby grandson of Kiyomori was carried by its mother to the hamlet of Tsuda, in Ömi provinee. Subsequently this child, Chikazane, was adopted by a Shintō official of Oda, in Echizen, and thus acquired the name of Oda. For generations the family served uneventfully at the shrine in Ōmi, but in the disturbed days of the Ashikaga shöguns, the representative of the eighth generation from Chikazane emerged from the obscurity of Shinto services and was appointed steward (karō) of the Shiba family, which appointment involved removal of his residence to Owari. From that time the fortunes of the family beeame brighter. Nobuhide, its representative at the beginning of the sixteenth century, acquired sufficient power to dispute the Imagawa's sway'over the provinee of Mikawa, and sufficient wealth to contribute funds to the exhausted coffers of the Court in Kyōto.

This man's son was Nobunaga. Born in 1534, and destined to bequeath to his country a name that will never die; Nobunaga, as a boy, showed much of the eccentrieity of genius. He totally despised the eanons of the time as to costume and etiquette. One of his peculiarities was a love of long swords, and it is related that on a visit to Kyōto in his youth he carried in his girdle a sword which trailed on the ground as he.walked. Rough and careless, without any apparent dignity, he caused so much solicitude to his tutor and guardian, Hirate Masahide, and showed so much indifferenee to the latter's remonstranees, that finally Masahide had recourse to the faithful vassal's last expedient - he committed suicide, 
leaving a letter in which the explanation of his act was aecompanied by a stirring appeal to the better instincts of his pupil and ward. This proved the turningpoint in Nobunaga's career. He became as cireumspect as he had previously been careless, and he subsequently erected to the memory of his brave monitor a temple which may be seen to this day by visitors to Nagoya.

It is frequently said of Nobunaga that his indifference to detail and his lack of patience were glaring defects in his moral endowment. But that accusation can scarcely be reconeiled with facts. Thus, when still a young man, it is related of him that he summoned one of his vassals to his presence but, giving no order, allowed the man to retire. This was repeated with two others, when the third, believing that there must be something in need of care, looked about attentively before retiring, and observing a piece of torn paper on the mats, took it up and earried it away. Nobunaga recalled him, eulogized his intelligence, and declared that men who waited scrupulously for instructions would never accomplish much. The faculties of observation and initiation were not more valued by Nobunaga than those of honesty and modesty. It is recorded that on one oceasion he summoned all the officers of his staff, and showing them a sword by a famous maker, promised to bestow it upon the man who should guess most correctly the number of threads in the silk frapping of the hilt. All the officers wrote down their guesses with one exception, that of Mori Rammaru. Asked for the reason of his abstention, Mori replied that he happened to know the exact number of threads, having counted them on a previous occasion when admiring the sword. Nubunaga at once placed the weapon in his hands, thus recognizing his honesty. Again, after the construction of the famous castle at Azuchi, to which reference will be made hereafter, Nobunaga, desiring to have a record compiled in commemoration of the event, asked a celebrated priest, Sakugen, to undertake the composition and penning of the document. Sakugen deelared the task to be beyond his literary ability, and recommended that it should be entrusted to his rival, Nankwa. Nobunaga had no recourse but to adopt this counsel, and Nankwa performed the task admirably, as the document, which is still in existence, shows. In recognition of this success, Nobunaga gave the compiler one hundred pieces of silver, but at the same time bestowed two hundred on Sakugen for his magnanimity in recommending a rival.

Nobunaga unquestionably had the gift of endearing himself to his retainers, though there are records which show that he was subject to outbursts of fieree anger. Even his most trusted generals were not exempt from bitter words or even blows, and we shall presently see that to this fault in his character. was approximately due his tragic end. Nevertheless, he did not lack the faculty of pity. On the occasion of a dispute between two of his vassals about the boundaries of a manor, the defeated litigant bribed one of Nobunaga's principal staff-officers to appeal for reversal of the judgment. This officer adduced reasons of a sufficiently specious character, but Nobunaga deteeted their fallacy, and appeared about to take some precipitate action when he happened to observe the wrinkles which time had written on the suppliant's face. He recovered his sang-froid and contented himself with sending the officer from his presence and subsequently causing to be handed to him a couplet setting forth the evils of bribery and corruption. He forgave the guilty man in consideration of his advanced age, and the incident is said to have closed with the suicide of the old officer. Frugality was another trait of Nobunaga's character. But he did not save money for money's sake. He spent with lavish hand when the occasion called for munificence; as when he contributed a great sum for the rebuilding of 
the Ise shrines. Perhaps nothing constitutes a better clue to his disposition than the verses he habitually quoted:-

Life is short; the world is a mere dream to the idle.

Only the fool fears death, for what is there of life that does

Not die once, 'sooner or later?

Man has to die once and once only;

He should make his death glorious.

It is recorded that Nobunaga's demeanour in battle truly reflected the spirit of these verses.

\section{HIDEYOSHI'}

Nobunaga certainly deserved the success he achieved, but that he achieved it must be attributed in part to accident. That accident was his association with Hideyoshi. ${ }^{1}$ It has been sometimes said that circumstances beget the men to

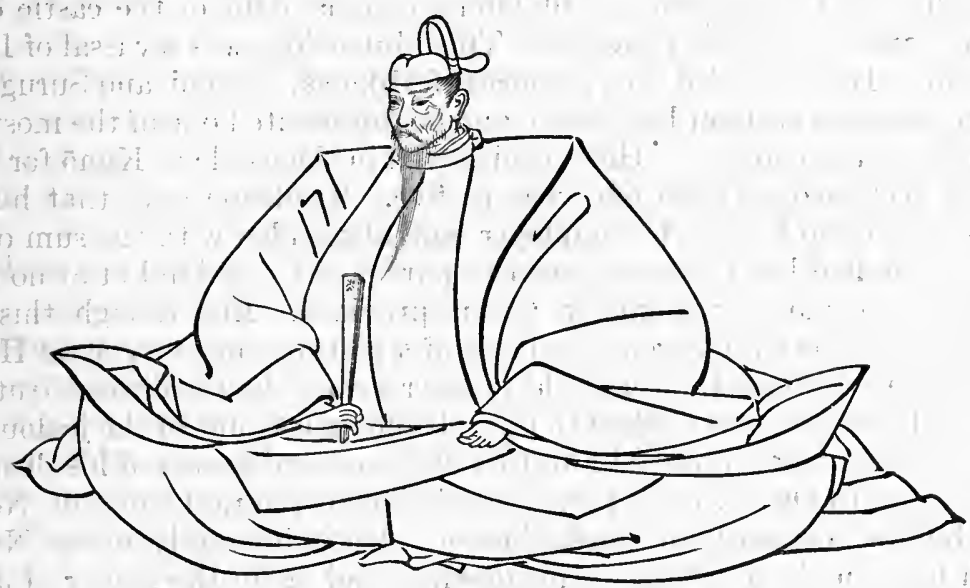

Tототомi Hideyoshi

deal with them. Fallacious as such a doctrine is, it almost compels belief when we observe that the second half of the sixteenth century in Japan produced three of the greatest men the world has ever seen, and that they joined hands to accomplish the stupendous task of restoring peace and order to an empire which had been almost continuously torn by war throughout five consecutive centuries. These three men were born within an interval of eight years: Nobunaga, in 1534; Hideyoshi, in 1536, and Ieyasu, in 1542.

There are many stories about Hideyoshi's early days, but the details are obscured by a record called the Taikōki, which undoubtedly makes many excursions into the region of romance. The plain facts appear to be that Hideyoshi was the son of a humble farmer named Kinoshita Yaemon, who lived in the Aichi district of Owari province, and who preferred the life of a footsoldier (ashigaru) to the pursuit of agriculture. Yaemon served the Oda family, and died when Hideyoshi was still a youth. In Owari province, at a homestead called Ichō-mura from the name of the tree (maiden-hair tree) that flourishes

[ ${ }^{1}$ To avoid needless difficulty the name "Hideyoshi"' is used solely throughout this history. But, as a matter of fact, the great statesman and general was called in his childhood Nakamura Hiyoshi; his adult name was Tōkichi; afterwards he changed this to Hashiba and ultimately, he was known as Toyotomi Hideyoshi.] 
there in abundance, there stands a temple built in the year 1616 on the site of the house where Hideyoshi was born. . This temple is known as Taikō-zan "Tait $\bar{o}$ " having been the title of Hideyoshi in the latter years of his life-and in the grounds of the temple may be seen the well from which water was drawn to wash the newly born baby. The child grew up to be a youth of dimunitive stature, monkey-like face, extraordinary precocity, and boundless ambition. Everything was against him - personal appearance, obscurity of lineage, and absence of scholarship. Yet he nëver seems to have doubted that a great future lay before him.

Many curious legends are grouped about his childhood. They are for the most part clumsily constructed and unconvincing, though probably we shall be justified in accepting the evidence they bear of a mind singularly well ordered and resourceful." At the age of sixteen he was employed by a Buddhist priest to assist in clistributing amulets, and by the agency of this priest he obtained an introduction to Matsushita Yukitsuna, commandant of the castle of Kunō at Hamamatsu, in Tōtomi province. This Matsushita was a vassal of Imagawa Yoshimoto. He controlled the provinces of Mikawa, Tōtōmi, and Suruga, which lie along the coast eastward of Owari, and he represented one of the most powerful families in the country. "Hideyoshi served in the castle of Kunō for a period variously reckoned at from one year to five. Tradition says that he abused the trust placed in him by his employer, and absconded with the sum of six ryo wherewith he had been commissioned to purchase a new kind of armour which had recently come into vogue in Owari province. But though this alleged theft becomes in certain annals the basis of a picturesque story as to Hideyoshi repaying Matsushita a thousandfold in later years, the unadorned truth seems to be that Hideyoshi was obliged to leave Kunō on account of the jealousy of his fellow retainers, who slandered him to Yukitsuna and procured his dismissal.

Returning to Owari, he obtained admission to the ranks of Oda Nobunaga in the humble capacity of sandal-bearer. He deliberately chose Nobunaga through faith in the greatness of his destiny, and again the reader of Japanese history is confronted by ingenious tales as to Hideyoshi's devices for obtaining admission to Nobunaga's house. But the most credible explanation is, at the same time; the simplest, namely, that Hideyoshi's father, having been borne on the military roll of Nobunaga's father, little difficulty offered in obtaining a similar favour for Hideyoshi.

Nobunaga was then on the threshold of his brilliant career. In those days of perpetual war and tumult; the supreme ambition of each great territorial baron in Japan was to fight his way to the capital, there to obtain from the sovereign and the Muromachi Bakufu a commission to subdue the whole country and to administer it as their lieutenant. Nobunaga seems to have cherished that hope from his early ycars, though several much more powerful military magnates would surely oppose anything like his pre-eminence. Moreover, in addition to comparative weakness, he was hampered by local inconvenience. The province of Owari was guarded on the south by sea, but on the east it was menaced directly by the Imagawa family and indirectly by the celebrated Takeda Shingen, while on the north it was threatened by the Saito and on the west by the Asai, the Sasaki, and the Kitabatake. Any one of these puissant feudatories would have been more than a match for the Owari chieftain, and that Imagawa Yoshimoto harboured designs against Owari was well known to Nobunaga, for in those days spying, slander, forgery, and deceit of every kind had the approval of the Chinese writers on military ethics whose 
books were regarded as classics by the Japanese. Hideyoshi himself figures at this very time as the instigator and director of a series of acts of extreme treachery, by which the death of one of the principal Imagawa vassals was compassed; and the same Hideyoshi was the means of discovering a plot by Imagawa emissaries to delay the,repair of the castle of Kiyosu, Nobunaga's headquarters, where a heavy fall of rain had caused a landslide. Nobunaga did not venture to assume the offensive against the Imagawa chief. He chose as a matter of necessity to stand on the defensive, and when it became certain that Imagawa Yoshimoto had taken the field, a general impression prevailed that the destruction of the Oda family was unavoidable.

\section{BATTLE OF OKEHAZAMA}

In the month of June, 1560, Imagawa Yoshimoto crossed the border into Owari at the head of a force stated by the annals to have been forty-six thousand strong. Just two years had elapsed since-Hideyoshi's admission to the service of the Owari baron in the office of sandal-bearer. Nevertheless, some generally credible records do not hesitate to represent Hideyoshi as taking a prominent part in the great battle against the Imagawa, and as openly advising Nobunaga with regard to the strategy best adapted to the situation. It is incredible that a private soldier, and a mere youth of twenty-two at that, should have risen in such a short time to occupy a place of equality with the great generals of Nobunaga's army. But that Hideyoshi contributed more or less to the result of the fight may be confidently asserted.

The battle itself, though the forces engaged were not large, must be counted one of the great combats of the world, for had not Nobunaga emerged victorious the whole course of Japanese history might have been changed. At the outset, no definite programme seems to have been conceived on Nobunaga's side. He had no allies, and the numerical inferiority of his troops was overwhelming. The latter defect was remedied in a very partial degree by the resourcefulness of Hideyoshi. In his boyhood he had served for some time under a celebrated chief of freebooters, by name Hachisuka Koroku, ${ }^{1}$ and he persuaded that chieftain with his fifteen hundred followers to march to the aid of the Owari army, armour and weapons having been furnished by Sasaki Shōtei, of Ōmi province. Sasaki regarded Nobunaga's plight as too hopeless to warrant direct aid, but he was willing to equip Hachisuka's men for the purpose, although the addition of fifteen hundred soldiers could make very little difference in the face of such a disparity as existed between the combatants.

Shortly before these events, Owari had been invaded from the west by the Kitabatake baron, whose domain lay in Ise, and the invaders had been beaten back by a bold offensive movement on Nobunaga's part. The ultimate result had not been conclusive, as Nobunaga advisedly refrained from carrying the war into Ise and thus leaving his own territory unguarded. But the affair had taught the superiority of offensive tactics, and thus Nobunaga's impulse was to attack the army of Imagawa, instead of waiting to be crushed by preponderate force. His most trusted generals, Shibata Katsuiye, Sakuma Nobumori, and Hayashi, Mitsukatsu, strenuously opposed this plan. They saw no prospect whatever of success in assuming the offensive against strength so superior, and they urged the advisability of yielding temporarily and awaiting an opportunity to recover independence. Here, Hideyoshi is reputed to have shown 
conspicuous wisdom at the council-table. He pointed out that there could be no such thing as temporary surrender. The Imagawa would certainly insist on hostages sufficiently valuable to insure permanent good faith, and he further declared that it was a mistake to credit the Imagawa with possessing the good-will of any of the other great feudatories, since they were all equally jealous of one another.

Finally, it was resolved that seven forts should be built and garrisoned, and that five of them should be allowed to fall into the enemy's hands if resistance proved hopeless. In the remaining two forts the garrisons were to be composed of the best troops in the Owari army, and over these strongholds were to be flown the flags of Nobunaga himself and of his chief general. It was hoped that by their success in five of the forts the Imagawa army would be at once physically wearied and morally encouraged to concentrate their entire strength and attention on the capture of the last two fortresses. Meanwhile, Nobunaga himself, with a select body of troops, was to march by mountain roads to the rear of the invading forces and deliver a furious attack when such a manœuvre was least expected. The brave men who engaged in this perilous enterprise were strengthened by worshipping at the shrine of Hachiman in the village of Atsuta, and their prayers evoked appearances which were interpreted as manifestations of divine assistance. Most fortunately for the Owari troops, their movements were shrouded by a heavy rainfall, and they succeeded in inflicting serious loss on the invading army, driving it pêle-mêle across the border and killing its chief, Yoshimoto. No attempt was made to pursue the fugitives into Mikawa. Nobunaga was prudently content with his signal victory. It raised him at once to a level with the greatest provincial barons in the empire, and placed him in the foremost rank of the aspirants for an Imperial commission:

\section{TOKUGAWA IEYASU}

The battle of Okehazama led to another incident of prime importance in Japanese history. It brought about an alliance between Oda Nobunaga and Tokugawa Ieyasu. Among the small barons subject to the Imagawa there was one called Matsudaira Motoyasu. He had taken the name, Motoyasu, by

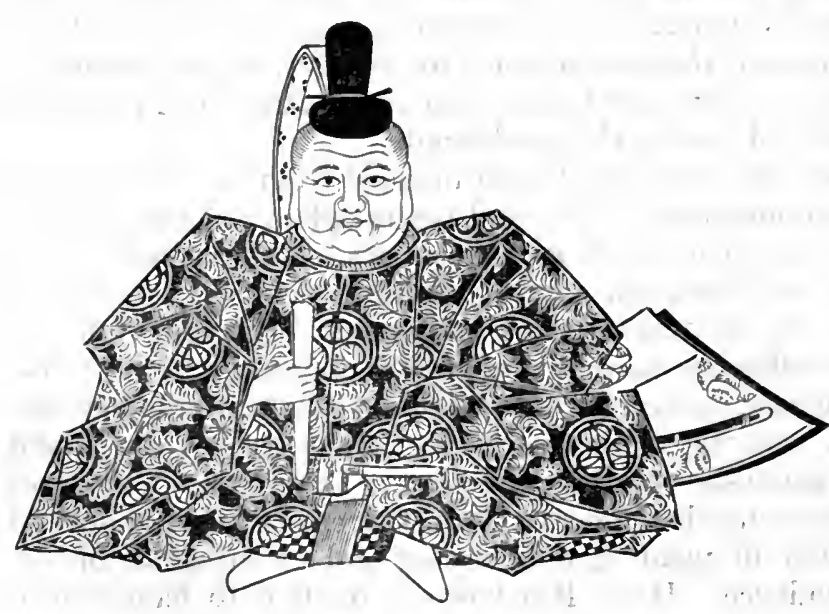

TORUGAWA IEYABU adopting one of the ideographs of Yoshimoto's appellation. His fámily; long in alliance with the Imagawa, were at a variance with the Oda, and in the battle of Okehazama this Motoyasu had captured one of the Owari forts. But on the defeat and death of $\mathrm{Yo}$ shimoto, the Matsudaira chieftain retired at once to his own eastle of Okazaki, in the province of Mikawa. He had then to consider his position; for by the death of Yo- 
shimoto, the headship of the Imagawa family had fallen to his eldest son, Ujizane, a man altogether inferior in intellect to his gifted father. Nobunaga himself appreciated the character of the new ruler, and saw that the wisest plan would be to cement a union with Matsudaira Motoyasu. Accordingly he despatched an envoy to Okazaki Castle to consult the wishes of Motoyasu. The latter agreed to the Owari chief's proposals, and in February, 1562, proceeded to the castle of Kiyosu, where he contracted with Oda Nobunaga an alliance which endured throughout the latter's lifetime. In the following year, Motoyasu changed his name to Ieyasu, and subsequently he took the uji of Tokugawa. The alliance was strengthened by intermarriage, Nobuyasu, the êldest son of Ieyasu, being betrothed to a daughter of Nobunaga.

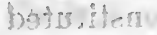

\section{NOBUNAGA'S POSITION}

It was at this time, according to Japanese annalists, that Nobunaga seriously conceived the ambition of making Kyōto his goal. The situation offered indueements. In the presence of a practically acknowledged conviction that no territorial baron of that era might venture to engage in an enterprise which denuded his territory of a protecting army, it was necessary to look around carefully before embarking upon the Kyōto project. Nobunaga had crushed the Imagawa, for though his victory had not been conclusive from a military point of view; it had placed the Imagawa under incompetent leadership and had thus freed Owari from all menace from the littoral provinces on the east. Again, in the direction of Echigo and Shinano, the great captain, Uesugi Kenshin, dared not strike at Nobunaga's province without exposing himself to attack from Takeda Shingen. But Shingen was not reciprocally hampered. His potentialities were always an unknown quality. He was universally recognized as the greatest strategist of his time, and if Nobunaga ventured to move westward, the Kai baron would probably seize the occasion to lay hands upon Owari. It is true that the alliance with Tokugawa Ieyasu constituted some protection. But Ieyasu was no match for Shingen in the field. Some other check must be devised, and Nobunaga found it in the marriage of his adopted daughter to Shingen's son, Katsuyori.

\section{THE COURT APPEALS TO NOBUNAGA}

In Kyōto, at this time, a state of great confusion existed. The Emperor Ōkimachi had ascended the throne in 1557. But in the presence of the violent usurpations of the Miyoshi and others, neither the sovereign nor the shogun could exercise any authority, and, as has been shown already, the Throne was constantly in pecuniarily embarassed circumstances. Nobunaga's father, Nobuhide, had distinguished himself by subscribing liberally to aid the Court financially, and this fact being now recalled in the context of Nobunaga's rapidly rising power, the Emperor, in the year 1562, despatched Tachiri Munetsugu nominally to worship at the shrine of Atsuta, but in reality to convey to Nobunaga an Imperial message directing him to restore order in the capital. The Owari baron received this envoy with marked respect. It is recorded that he solemnly performed the ceremony of lustration and clothed himself in hitherto unworn garments on the occasion of his interview with the envoy. It was not in his power, however, to make any definite arrangement as to time. He could only proféss his humble determination to obey the Imperial behest, and promise 
the utmost expedition. But there can be no doubt that the arrival of this envoy decided the question of a march to Kyōto, though some years were destined to elapse before the project could be carried out.

Two things were necessary, however, namely, a feasible route and a plausible pretext. Even in those times, when wars were often undertaken merely for the purpose of deciding personal supremacy, there remained sufficient public morality to condemn any baron who suffered himself to be guided openly by ambition alone. Some reasonably decent cause had to be found. Now the Emperor, though, as above stated, communicating his will verbally to Nobunaga, had not sent him any written commission. The necessary pretext was furnished, however, by the relations between the members of the Saito family of Mino province, which lay upon the immediate north of Owari, and constituted the most convenient road to Kyōto. Hidetatsu, the head of that family, had fought against Nobunaga's father; Nobuhide, and one of the conditions of peace had been that the daughter of Hidetatsu should become the wife of Nobunaga.

Subsequently, the Saito household was disturbed by one of the family, feuds so common during the fifteenth and sixteenth centuries in Japan.r. Hidetatsu, desiring to disinherit his eldest son, Yoshitatsu, had been attacked and killed by the latter, and Nobunaga announced his intention of avenging the death of his father-in-law: But before this intention could be carried out; Yoshitatsu died (1561), and his son, Tatsuoki, a man of little resource or ability, had to bear the onset from Owari. Nobunaga, at the head of a large foree; crossed the Kiso River into Mino. But he found that, even under the leadership of Tatsuoki, the Mino men were too strong for him', and he was ultimately compelled to adopt the device of erecting on the Mino side of the river a fortress which should serve at once as a basis of military operations and as a pläce for establishing relations with the minor families in the province. The building of this fort proved a very difficult task, but it was finally accomplished by a clever device on the part of Hidcyoshi, who, a master of intrigue as well as of military strategy, subsequently won over to Nobunaga's cause many of the principal vassals of the Saito family, among them being Takenaka Shigeharu, who afterwards proved a most capable lieutenant to Hideyoshi.

These preliminaries arranged, Nobunaga once more crossed the Kiso (1564) at the head of a large army, and after many days of severe fighting, captured the castle of Inaba-yama, which had been strongly fortified by Yoshitatsu, and was deemed impregnable. Nobunaga established his headquarters at this castle, changing its name to. Gifu, and thus extending his dominion over the province of Mino as well as Owari. He had now to consider whether he would push on at once into the province of $\bar{O} \mathrm{mi}$, which alone lay between him and Kyōto, or whether he would first provide against the danger of a possible attack on the western littoral of Owari from the direction of Ise. $1: \mathrm{He}$ chose the:latter course, and invaded Ise at the head of a considerable force. But he. here met with a repulse at the hands of Kusunoki Masatomo, who to the courage and loyalty of his immortal ancestor, Masashige, added no small measure of strategical ability. He succeeded in defending his castle of Yada against Nobunaga's attacks, and finally the Owari general, deceived by a rumour to the effect that Takeda Shingen had reached the neighbourhood of Gifu with a strong army, retired hurriedly from-Ise.

It may here be mentioned that three years later, in 1568 , Hideyoshi succeeded in inducing all the territorial nobles of northern Ise, except Kusunoki Masatomo; to place themselves peacefully under Nobunaga's sway. Hideyoshi's history 
shows him to have been a constant believer in the theory that a conquered foe generally remains an enemy, whereas a conciliated enemy often becomes a friend. Acting on this conviction and aided by an extraordinary gift of persuasive eloquence, he often won great victories without any bloodshed. Thus he succeeded in convincing the Ise barons that Nobunaga was not swayed by personal ambition; but that his ruling desire was to put an end to the 'wars which had devastated Japan continuously for more than a century. It is right to record that the failures made by Nobunaga himself in his Ise campaign were in the sequel of measures taken in opposition to Hideyoshi's advice, and indeed the annals show that this was true of nearly all the disasters that overtook Nobunaga throughout his career, whereas his many and brilliant successes were generally the outcome of Hideyoshi's counsels.

\section{ANOTHER SUMMONS FROM THE EMPEROR}

In November, 1567, the Emperor again sent Tachiri Munetsugu to invite Nobunaga's presence in Kyōto. His Majesty still refrained from the dangerous step of giving a written commission to Nobunaga, but he-instructed Munetsugu to carry to the Owari chieftain a suit of armour and a sword. Two years previously to this event, the tumult in Kyōto had culminated in an attack on the palace of the shoggun Yoshiteru, the conflagration of the building, and the suicide of the shogun amid the blazing ruins. Yoshiteru's younger brother; Yoshiaki, effected his escape from the capital, and wandered about the country during three years, supplicating one baron after another to take up his cause. This was in 1568 , just nine months after the Emperor's second message to Nobunaga, and the latter, acting upon Hideyoshi's advice, determined to become Yoshiaki's champion, since by so doing he would represent not only the sovereign but also the shogun in the eyes of the nation. Meanwhile - and this step also was undertaken under Hideyoshi's advice - a friendly contract had been concluded with Asai Nagamasa, the most powerful baron in Ōmi, and the agreement had been cemented by the marriage of Nobunaga's sister to Nagamasa.

\section{NOBUNAGA PROCEEDS TO KYŌTO}

In October, 1568, Nobunaga set out for Kyōto at the head of an army said to have numbered thirty thousand. He did not encounter any serious resistance on the way, but the coming of his troops threw the city into consternation, the general apprehension being-that the advent of these provincial warriors would preface a series of depredations such as the people were only too well accustomed to. But Nobunaga lost no time in issuing reassuring proclamations, which, in the sequel, his officers proved themselves thoroughly capable of enforcing, and before the year closed peace and order were restored in the capital, Yoshiaki being nominated shōgun and all the ceremonies of Court life being restored. Subsequently, the forces of the Miyoshi sept made armed attempts to recover the control of the city, and the shogun asked Nobunaga to appoint one of his most trusted generals and ablest administrators to maintain peace. It was fully expected that Nobunaga would respond to this appeal by nominating Shibata, Sakuma, or Niwa, who had served under his banner's from the; outset; and in whose eyes Hideyoshi was a mere upstart. But Nobunaga selected Hideyoshi, and the result justified his choice; for during Hideyoshi's sway Kyōto enjoyed such tranquillity, as it had not known for a century. 
Nobunaga omitted nothing that could make for the dignity and comfort of the new shoggun. He caused a palace to be erected for him on the site of the former Nijō Castle, contributions being levied for the purpose on the five provinces of the Kinai as well as on six others; and Nobunaga himself personally supervised the work, which was completed in May, 1569. But it may fairly be doubted whether Nobunaga acted in all this matter with sincerity. At the outset his attitude towards the shoggun was so respectful and so considerate that Yoshiaki learned to regard and speak of him as a father. But presently Nobunaga presented a memorial, charging the shogun with faults which were set forth in seventeen articles. In this impeachment, Yoshiaki was accused of neglecting his duties at Court; of failing to propitiate the territorial nobles; of partiality in meting out rewards and punishments; of arbitrarily confiscating private property; of squandering money on needless enterprises; of listening to flatterers; of going abroad in the disguise of a private person, and so forth. It is claimed by some of Nobunaga's biographers that he was perfectly honest in presenting this memorial, but others, whose judgment appears to be more perspicacious, consider that his chief object was to discredit Yoshiaki and thus make room for his own subsequent succession to the shōgunate.

At all events Yoshiaki interpreted the memorial in that sense. He became openly hostile to Nobunaga, and ultimately took up arms. Nobunaga mademany. attempts to conciliate him. He even sent Hideyoshi to solicit Yoshiaki's return to Kyōto from Kawachi whither the shoggun had fled. But Yoshiaki, declining to be placated, placed himself under the protection of the Mori family, and thus from the year 1573, Nobunaga became actual wielder of the shogun's authority. Ten years later, Yoshiaki returned to the capital, took the tonsure and changed his name to Shōzan. At the suggestion of Hideyoshi a title and a yearly income of ten thousand koku were conferred on him. He died in Ōsaka and thus ended the Ashikaga shōgunate.

\section{SAKAI}

One of the incidents connected with Hideyoshi's administration in Kyōto illustrates the customs of his time. Within eight miles of the city of Ōsaka lies Sakai, a great manufacturing mart. This latter town, though originally forming part of the Ashikaga domain, nevertheless assisted the Miyoshi in their attack upon the shoggunate. Nobunaga, much enraged at such action, proposed to sack the town, but Hideyoshi asked to have the matter left in his hands. This request being granted, he sent messengers to Sakai, who informed the citizens that Nobunaga contemplated the destruction of the town by fire. Thereupon the citizens, preferring to die sword in hand rather than to be cremated, built forts and made preparations for resistance.

This was just what Hideyoshi designed. Disguising himself, he repaired to Sakai and asked to be informed as to the object of these military preparations. Learning the apprehensions of the people, he ridiculed their fears; declared that Nobunaga had for prime object the safety and peace of the realm, and that by giving ear to such wild rumours and assuming a defiant attitude, they had committed a fault not to be lightly condoned. Delegates were then sent from Sakai at Hideyoshi's suggestion to explain the facts to Nobunaga, who acted his part in the drama by ordering the deputies to be thrown into prison and promising to execute them as well as their fellow townsmen. In this strait the people of Sakai appealed to a celebrated Buddhist priest named Kennyo, 
and through his intercession Hideyoshi agreed to ransom the town for a payment of twenty thousand ryō. The funds thus obtained were devoted to the repair of the palaces of the Emperor and the shogun, a measure which won for Nobunaga the applause of the whole of Kyöto.

\section{NOBUNAGA'S SITUATION}

Oda Nobunaga was now in fact shōgun. So far as concerned legalized power he had no equal in the empire, but his military strength was by no means proportionate. In the north, in the east, in the west, and in the south, there were great territorial nobles who could put into the field armies much larger than all the Owari chief's troops. Takeda Shingen, in the Kwantō, was the most formidable of these opponents. In the year 1570, when the events now to be related occurred, the Hōjō sept was under the rule of Ujimasa, and with him Shingen had concluded an alliance which rendered the latter secure against attack on the rear in the event of movement against Kyōto. The better to ensure himself against Hōjo designs, Shingen joined hands with the Satomi family in Awa, and the Satake family in Hitachi; while to provide against irruptions by the Uesugi family he enlisted the co-operation of the priests in Kaga, Echizen, and Noto. Shingen further established relations of friendship with Matsunaga Hisahide in the far west. It was this baron that had attacked the palace of Nijo when Yoshiteru, the shögun, had to commit suicide, and Shingen's object in approaching him was to sow seeds of discord between the shōgunate and Nobunaga. Most imminent of all perils, however, was the menace of the Asai family, in Ōmi, and the Asakura family in Echizen. A glance at the map shows that the Asai were in a position to sever Nobunaga's communications with his base in Mino, and that the Asakura were in a position to cut off his communications with Kyōto. In this perilous situation Nobunaga's sole resource lay in Tokugawa Ieyasu and in the latter's alliance with the Uesugi, which compact the Owari chief spared no pains to solidify. But from a military point of view Ieyasu was incomparably weaker than Shingen.

\section{THE STRUGGLE WITH THE ASAKURA AND THE ASAI}

In 1570 , Nobunaga determined to put his fortunes to a final test. Having concentrated a large body of troops in Kyōto, he declared war against Asakura Yoshikage, who had refused to recognize the new shōgun. Success crowned the early efforts of the Owari forces in this war, but the whole situation was changed by Asai Nagamasa, who suddenly marched out of ${ }_{i} \mathrm{mi}$ and threatened to attack Nobunaga's rear. It is true that before setting out for Kyōto originally; Nobunaga had given his sister in marriage to Nagamasa, and had thus invited the latter's friendship. But Nagamasa had always been on terms of close amity with Yoshikage, and, indeed, had stipulated from the outset that Nobunaga should not make war against the latter. It cannot be said, therefore, that Nagamasa's move constituted a surprise. Nobunaga should have been well prepared for such contingencies. He was not prepared, however, and the result was that he found himself menaced by Yoshikage's army in front and by Nagamasa's in rear. Tokugawa Ieyasu, who had associated himself by invitation with this expedition into Echizen, advised Nobunaga to countermarch with all rapidity for Kyōto, and it was so determined. Hideyoshi was left with three thousand men to hold Yoshikage's forces in some degree of check. 
The situation at that moment was well-nigh desperate. There seemed to be no hope for either Nobunaga or Hideyoshi: But Nobunaga was saved by the slowness of Nagamasa, who, had he moved with any rapidity, must have reached Kyōto in advance of Nobunaga's forces; and Hideyoshi was saved by an exereise of the wonderful resourcefulness which peril always awoke in this great man. Calculating that Yoshikage's army would reach Kanagasaki Castle at nightfall, Hideyoshi, by means of thousands of lanterns and banners gave to a few scores of men a semblance of a numerous army. Yoshikage, who believed that Nobunaga had retired, was visited by doubts at the aspect of this great array, and instead of advancing to attack at onee, he decided to await the morning. Meanwhile, Hideyoshi with his little band of troops, moved round Yoshikage's flank, and delivering a fierce attack at midnight, completely defeated the Echizen forces. ${ }^{1}$

This episode was, of course, not conclusive. It merely showed that so long as Nagamasa and Yoshikage worked in combination, Nobunaga's position in Kyoto and his communications with his base in Mino must remain insecure. He himself would have directed his forces at once against Nagamasa, but Hideyoshi contended that the wiser plan would be to endeavour to win over some of the minor barons whose strongholds lay on the confines of Ömi and Mino. This was gradually accomplished, and after an unsuccessful attempt upon the part of Sasaki Shōtei of Ōmi to capture a castle (Chōkō-ji) which was under the command of Nobunaga's chief general, Katsuiye, the Owari forces were put in motion against Nagamasa's principal strongholds, Otani and Yoko-yama. The former was attacked first, Nobunaga being assisted by a contingent of five thousand men under the command of Ieyasu. Three days of repeated assaults failed to reduce the castle, and during that interval Nagamasa and Yoshikage were able to enter the field at the head of a force which greatly outnumbered the Owari army.

In midsummer, 1570, there was fought, on the banks of the Ane-gawa, one of the great battles of Japanese history. It resulted in the complete discomfiture of the Echizen chieftains. The records say that three thousand of their followers were killed and that among them were ten general officers. The castle of Otani, however, remained in Nagamasa's hands. Nobunaga now retired to his headquarters in Gifu to rest his forees.

But he was quickly summoned again to the field by a revolt on the part of the Buddhist priests in the province of Settsu, under the banner of Miyoshi Yoshitsugu and Saitō Tatsuoki. Nobunaga's attempt to quell this insurrection was unsuccessful, and immediately Nagamasa and Yoshikage seized the occasion to march upon Kyöto. The priests of Hiei-zan reeeived them with open arms, and they occupied on the monastery's commanding site, a position well-nigh impregnable, from which they constantly menaced the capital. It was now the commencement of winter. For the invading troops to hold their own upon Hiei-zan throughout the winter would have been even more difficult than for Nobunaga's army to cut off their avenues of retreat and supply.

In these circumstances peace presented itself to both sides as the most feasible plan, and the forces of Nagamasa and Yoshikage were allowed to march away unmolested to $\overline{\mathrm{O}} \mathrm{mi}$ and Echizen, respectively. This result was intensely mortifying to Hideyoshi, who had dévoted his whole energies to the destruction of these dangerous enemies. But the final issue was only postponed. By contrivances, which need not be related in detail, Nagamasa was again induced 
to take the field, and, in 1573 , the Owari forces found themselves once more confronted by the allied armies of Echizen and $\overline{0} \mathrm{mi}$. By clever strategy the Echizen baron was induced to take the fatal step of separating himself from his Ōmi colleague, and at Tone-yama he sustained a crushing defeat, leaving two thousand of his men and twenty-three of his captains dead upon the field. $\mathrm{He}$ himself fled and for a time remained concealed, but ultimately, being closely menaced with capture, he committed : suicide. Meanwhile, Nagamasa had withdrawn to his stronghold of Otani, where he was besieged by -Nobunaga. The castle ultimately fell, Nagamasa and his son dying by their own hands.

This year witnessed also the death of Takeda Shingen, and thus Nobunaga not only established his sway over the whole of the provinces of Ōmi and Echizen but also was relieved from the constant menace of a formidable attack by a captain to whom public opinion justly attributed the leading place among Japanese strategists. The whole of Nagamasa's estates, yielding an annual return of $180,000 \mathrm{koku}$, was given to Hideyoshi, and he was ordered to assume the command of Otani Castle, whence, however, he moved shortly afterwards to Nagahaima:

\section{HIEI-ZAN}

It was now possible for Nobunaga to devote his entire attention to the soldierpriests who had allied themselves with his enemies. It has been shown that the monastery: of Hiei-zan had afforded shelter and sustenance to the forces of Echizen and Ōmi during the winter of 1570-1571, and it has been shown also that Nobunaga; underrating the strength of the priests in the province of Settsu, sustained defeat at their hands. He now (1574) sent an army to hold the soldiermonks of Settsu in check while he himself dealt with Hiei-zan. This great monastery, as already shown, was erected in the ninth century in obedience to the Buddhist superstition that the northeastern quarter of the heavens is the "Demon's Gate;" and that a temple must be erected there to afford security against evil influences. . The temple on Hiei-zan had received the munificent patronage of monarch after monarch; and had grown to be a huge monastery, containing some three thousand priests. This miniature city completely commanded Kyōto, and was guarded in front by a great lake. But, above all, it was sanctified by the superstition of the people, and when Nobunaga invested it, he found the greatest reluctance on the part of his generals to proceed to extremities. Nevertheless, he overcame these scruples, and drawing a cordon of troops round the great monastery, he applied the torch to the buildings, burnt to death nearly all its inmates, including women, confiscated its estates, and built, for purposes of future prevention, a castle at Sakamoto, which was placed under the command of Akechi Mitsuhide." When, in after years, this same Mitsuhide treacherously compassed Nobunaga's death, men said that the opening of the Demon's Gate had entailed its due penalty.

\section{OTHER PRIESTLY DISTURBANCES}

to It was not in Settsu and at Hiei-zan only that the Buddhist soldiers turned their weapons against Nobunaga. The. Asai sept received assistance from no less than ten temples in $\bar{O} \mathrm{mi}$; the Asakura family had the ranks of its soldiers recruited from monasteries in Echizen and Kaga; the Saitō clan received aid from the bonzes in Izumi and Iga, and the priests of the great temple Hongwan$\mathrm{ji}$ in Ōsaka were in friendly communication with the Móri sept in the west, with 
the Takeda in Kai, and with the Hōjō in Sagami. In fact, the difficulties encountered by Nobunaga in his attempts to bring the whole empirel under the affective sway of the 'Throne were incalculably aceentuated by the hostility of the great Shin sect of Buddhism. He dealt effectually with all except the monastery at Ishi-yama in Osaka. The immense natural strength of the position and the strategical ability of its lord-abbot, Kōsa, enabled it to defy all the assaults of the Owari chief, and it was not until 1588 - six years after Nobunaga's death - that, through the intervention of the Emperor, peace was finally restored. After eleven years of almost incessant struggle, his Majesty's envoy, Konoe Sakihisa, succeeded in inducing the Ikkō priests to lay down their arms. It will be presently seen that the inveterate hostility shown by the Buddhists to Nobunaga was largely responsible for his favourable attitude towards Christianity.

\section{THE CASTLE OF AZUCHI}

The lightness and flimsiness of construction in Japanese houses has been noted already several times. Even though there was continual warfare in the provinces of family against family, the character of the fighting and of the weapons used was such that there was little need for the building of elaborate defenses, and there was practically nothing worthy the name of a castle. Watchtowers had been built and roofs and walls were sometimes protected by putting nails in the building points outward,- a sort of chevaux de frise. But a system of outlying defenses, diteh, earthen wall and wooden palisade, was all that was used so long as fighting was either hand-to-hand or with missiles no more penetrating than arrows. But when fire-arms were introduced in 1542, massively constructed castles began to be built. These were in general patterned after Western models, but with many minor modifications.

The first of these fortresses was built at Azuchi, in Ōmi, under the auspices of Oda Nobunaga. Commenced in 1576, the work was completed in 1579 . In the centre of the castle rose a tower ninety feet high, standing on a massive stone basement seventy-two feet in height, the whole forming a structure absolutely without precedent in Japan. The tower was of wood, and had, therefore; no capacity for resisting cannon. But, as a matter of fact, artillery can scarcely be said to have been used in Japan until modern days. Nobunaga's castle is stated by some historians to have been partially attributable to Christianity, but this theory seems to rest solely upon the fact that the central tower.was known as Tenshi-kaku, or the "tower of the lord of Heaven." There were more numerous indications that the spirit of Buddhism influenced the architect, for in one of the highest storeys of the tower, the four "guardian kings". were placed, and in the lower ehamber stood an effigy of Tamon (Ananda). The cost of eonstrueting this colossal edifice was very heavy, and funds had to be collected from the whole of the eleven provinces then under Nobunaga's sway.

\section{NOBUNAGA AND IEYASU}

It has already been noted that Ieyasu was Nobunaga's sole ally in the east of Japan at the time of the fall of the Imagawa clan. It has also been noted that Ujizane, the son of Imagawa Yoshimoto, was a negligible quantity. During many years, however, Ieyasu had to stand constantly on the defensive against Takeda Shingen. But, in 1572, Shingen and Ieyasu made a compact against the Imagawa, and this was followed by a successful campaign on the part of the 
Tokugawa leader aginst Ujizane. The agreement between Shingen and Ieyasu lasted only a short time. In November, 1572, Shingen led a large force and seized two of the Tokugawa castles, menacing the third and most important at Hamamatsu, where Ieyasu himself was in command. Nobunaga thereupon despatched an army to succour his ally, and in January, 1573, a series of bloody engagements took place outside Hamamatsu. One of Nobunaga's generals fled; another died in battle, and Ieyasu barely escaped into the castle, which he saved by a desperate device - leaving the gates open and thus suggesting to the enemy that they would be ambushed if they entered. This battle, known in history as the War of Mikata-ga-hara, was the greatest calamity that ever befell Ieyasu, and that he would have suffered worse things at the hands of Takeda Shingen cannot be doubted, had not Shingen's death taken place in May, 1573.

Various traditions have been handed down about the demise of this celebrated captain, undoubtedly one of the greatest strategists Japan ever possessed. Some say that he was shot by a soldier of Ieyasu; others that he was hit by a stray bullet, but the best authorities agree that he died of illness. His son, Katsuyori, inherited none of his father's great qualities except his bravery. Immediately on coming into power, he moved a large army against the castle of Nagashino in the province of Mikawa, one of Ieyasu's strongholds. . This was in June, 1575 , and on the news reaching Nobunaga, the latter lost no time in setting out to succour his ally. On the way a samurai named Torii Suneemon arrived from the garrison of Nagashino with news that unless succour were. speedily given the fortress could not hold out. This message reached Ieyasu, who was awaiting the arrival of Nobunaga before marching to the relief of the beleagured fortress. Ieyasu assured the messenger that help would come on the morrow, and urged Suneemon not to essay to re-enter the fortress. But the man declared that he must, carry the tidings to his hard-set comrades. He was taken prisoner by the enemy and led into the presence of Katsuyori, who assured him that his life would be spared if he informed the inmates of the castle that no aid could be hoped for. Suneemon simulated consent. Despatched under escort to the neighbourhood of the fort, he was permitted to address the garrison, and in a loud voice he shouted to his comrades that within a short time they might look for succour. He was immediately killed by his escort.

This dramatic episode became a household tradition in Japan. Side by side with it may be set the fact that Hideyoshi, who accompanied Nobunaga in this: campaign; employed successfully against the enemy one of the devices recommended by the Chinese strategists, whose books on the method of conducting warfare were closely studied in those days by the Japanese. Sakuma Nobumori; one of Nobunaga's captains, was openly, and of set purpose, insulted and beaten by orders of his general, and thereafter he escaped to the camp of the Takeda army, pretending that the evil treatment he had undergone was too much for his loyalty. Katsuyori, the Takeda commander, received the fugitive with open arms, and acting in accordance with his advice, disposed his troops in such a manner as to forfeit all the advantages of the position. The battle that ensued is memorable as the first historical instance of the use of firearms on any considerable scale in a Japanese campaign. Nobunaga's men took shelter themselves behind palisades and fusilladed the enemy so hotly that the old-fashioned hand-to-hand fighting became almost impossible. The losses of the Takeda men were enormous, and it may be said that the tactics of the era underwent radical 
alteration from that time, so that the fight at Takinosawa is memorable in Japanese history. Hideyoshi urged the advisability of pushing on at once to Katsuyori's capital, but Nobunaga hesitated to make such a call upon the energies of his troops, and the final overthrow of the Takeda chief was postponed.

\section{MILITARY TACTICS}

The Mongol invasion should have taught to the Japanese the great advantages of co-operating military units, but individual prowess continued to be the guiding factor of field tactics in Japan down to the second half of the sixteenth century, when the introduction of firearms inspired new methods: Japanese historians have not much to sáy upon this subject. Indeed Rai Sanyō, in the Nihon-gwaishi, may almost be said to be the sole authority. $\mathrm{He}$ writes as follows: "The generalship of Takeda Shingen and Uesugi Kenshin was something quite new in the country at their time: Prior to their day the art of manœuvring troops had been little studied. 'Armies met, but each individual that composed them relied on his personal prowess and strength for victory. These two barons, however, made a special study of strategy and military tacties, with the result that they became authorities on the various methods of handling troops. In reference to the employment of cavalry, the Genji warriors and the first of the Ashikaga shōguns made use of horses largely, but in later days the Ashikaga did not move away from Kyōto and had no use for horsès . Nobunaga, being near Kyōto, and most of the wars in which he engaged involving no very long marches, relied almost solely on infantry. Both Takeda and Uesugi were well supplied with mounted troops, but owing to the hilly nature of their territories, they made no special study of cavalry exercises and, almost invariably, the soldiers employed their horses solely for rapid movement from one place to another; when a battle commenced they alighted and fought on foot. It is therefore correct to say that at this time cavalry had gone out of use. Bows and arrows were, of course; superseded when firearms came into use.

"Thenceforth, the gun and the long spear were the chicf weapons relied on. Peasants did not rank as soldiers, but their services were variously utilized in time of war. They were trained in the use of muskets, and of bows and arrows on hunting expeditions, and thus, when hostilities broke out, they were able to render considerable assistance in the defense of their houses. Highwaymen were frequently employed as spies and scouts. Both Takeda and Uesugi sanctioned this practice. These two generals also agreed in approving the following tactical arrangement: the van-guard, consisting of musketeers, artillerymen', and archers, was followed by companies of infantry armed with long spears. Then came the cavalry; and after them the main body, attached to which were drummers and conch-blowers. The whole army was divided into right and left wings, and a body of men was kept in reserve. At the opening of the battle, the horsemen dismounted and advanced on foot. This order was occasionally modified to suit altered circumstances, but as a rule, it was strictly followe."

The artillery mentioned in the above quotation must be taken in a strictly limited sense. Indeed, it would be more correct to speak of heavy muskets, for cannon, properly so called; may scarcely be said to have formed any part of the equipment of a Japanese army until modern times. When the Portuguese discovered Japan, in 1542, they introduced the musket to the Japanese, and the weapon was long known as Tanegashima, that being the name of the island 
where the Portuguese ship first touched. Thenceforth, the manufacture of firearms was carried on with more or less success at various places, especially Sakai in Izumi and Negoro in Kii. "Small guns" (kozutsu) and "large guns" (özutsu) are mentioned in the annals of the time, but by ozutsu we must understand muskets of large ealibre rather than cannon.

\section{INVASION OF CHÜGOKU}

At this time nearly the whole of central Japan (Chūgoku) was under the sway of Mōri Terumoto, who succeeded his grandfather, Motonari, head of the great Mōri family and ancestor of the present Prince Mōri. One of these central provinces, namely, Harima, had just been the scene of a revolt which Hideyoshi crushed by his wonted combination of cajolery and conquest. The ease with which this feat was accomplished and the expediency of maintaining the sequence of successes induced Hideyoshi to propose that the subjugation of the whole of central Japan should be entrusted to him and that he should be allowed to adopt Nobunaga's second son; Hidekatsu, to whom the rule of Chūgoku should: be entrusted, Hideyoshi keeping for himself only the outlying portions. "Nobunaga readily agreed, and, in 1577 , Hideyoshi set out on this important expedition, with a force of some ten thousand men, all fully equipped and highly trained. It is noteworthy that, before leaving Azuchi, Hideyoshi declared to Nobunaga his intention of conquering Kyūshū after, the reduction of Chūgoku, and thereafter he announced his purpose of crossing to Korea and making that country the basis of a campaign against China. "When that is effected," Hideyoshi is quoted as saying, "the three countries, China, Korea, and Japan," will be one. I shall do it all as easily as a man rolls up a piece of matting and carries it under his arm."

-5 It is evident from these words that the project of invading Korea and China was entertained by. Hideyoshi.nearly twenty years before-as will presently be seen - he attempted to carry it into practice Hideyoshi marched in the first place to Harima, where his operations were so vigorous and iso successful that Ukita Naoiye, who held the neighbouring provinces of Bizen and Mimasaka under the suzerainty of Mōri Terumoto, espoused Nobunaga's cause without fighting.? It is unnecessary to follow the details of the campaign that ensued. It lasted for fiveyears, and ended in the subjection of as many provinces, namely, Harima, Tamba, sango, Tajima, and Inaba. Hideyoshi then returned to Azuchi and presented to Nobunaga an immense quantity of spolia opima which are said to have exceeded five thousand in number and to have covered all the ground: around the castle.

\section{DESTRUCTION OF THE TAKEDA}

Shortly before Hideyoshi's triumphant return from his first brilliant campaign in the central provinces, a memorable event occurred in Kai. Nobunaga's. eldest son, Nobutada, uniting his forces with those of Ieyasu; completely' destroyed the army of Takeda Katsuyori at Temmoku-zan, in the province of Kai. So thorough was the victory that Katsuyori and his son both committed suicide. Nobunaga then gave the province of Suruga to Ieyasu, and divided Shinano and Kōtsuke into manors, which were distributed among the Owari generals as rewards. Takigawa Kazumasu was nominated kwanryō of the Kwantō, chiefly in order to watch and restrain the movements of the Hōjō family; now the only formidable enemy of Nobunaga in the east. 


\section{RESUMPTION OF THE CHŪGOKU CAMPAIGN}

After a brief rest, Hideyoshi again left Kyōto for the central provinces. He commenced operations on this second occasion by invading the island of Awaji, and having reduced it, he passed on to Bitchū, where he invested the important castle of Takamatsu, then under the command of Shimizu Muneharu. This stronghold was so well planned and had such great natural advantages that Hideyoshi abstained from any attempt to carry it by assault, and had recourse to the device of damming and banking a river so as to flood the fortress. About two miles and a half of embankment had to be made, and during the progress of the work, Mōri Terumoto, who had been conducting a campaign elsewhere, found time to march a strong army to the relief of Takamatsu. But.Terumoto; acting on the advice of his best generals, refrained from attacking Hideyoshi's army. He sought rather to invite an onset from Hideyoshi, so that, during the progress of the combat, the garrison might find an opportunity to destroy: the embankment. Hideyoshi, however, was much too astute to be tempted by such tacties. He saw that the fate of the castle must be sealed in a few days, and he refrained from any offensive movement. But, in order to gratify Nobunaga by simulating need of his assistance, a despatch was sent to Azuchi begging him to come and personally direct the capture of the fort and the shattering of Terumoto's army.

\section{ASSASSINATION OF NOBUNAGA}

Among Nobunaga's vassal barons at that time was Akechi Mitsuhide. A scion of the illustrious family of Seiwa Genji, Mitsuhide had served under several suzerains prior to 1566, when he repaired to Gifu and offered his sword to Nobunaga. Five years afterwards he received a fief of one hundred thousand $k o k u$ and the title of Hyüga no Kami. . This rapid promotion made him Nobunaga's debtor, but a shocking event, which occurred in 1577, seems to have inspired him with the deepest resentment against his patron. Mitsuhide, besieging the castle of Yakami in Tamba province, promised quarter to the brothers Hatano, who commanded its defence, and gave his own mother as hostage. But Nobunaga, disregarding this promise, put the Hatano brothers to the sword, and the latter's adherents avenged themselves by slaughtering Mitsuhide's mother. The best informed belief is that this incident converted Mitsuhide into Nobunaga's bitter enemy, and that the spirit of revenge was fostered by insults to which Nobunaga, always passionate and rough, publicly subjected Mitsuhide. At all events, when, as stated above, Hideyoshi's message of invitation reached Nobunaga at Azuchi, the latter gave orders for the despateh of a strong force to Takamatsu, one body, consisting of some thirty thousand men, being placed under the command of Mitsuhide. Nobunaga himself repaired to Kyōto and took up his quarters at the temple Honnō-ji, whence he intended to follow his armies to the central provinces.

Mitsuhide concluded that his opportunity had now come. He determined to kill Nobunaga, and then to join hands with Mōri Terumoto. He made known his design to a few of his retainers, and these attempted fruitlessly to dissuade him, but, seeing that his resolution was irrevocable, they agreed to assist him. The troops were duly assembled and put in motion, but instead of taking the road westward, they reeeived an unexpected intimation, "The enemy is in Honnō-ji," and their route was altered accordingly. Nobunaga defended himself valiantly. But being at last severely wounded and recognizing the 
hopelessness of resistance, he set fire to the temple and committed suicide, his fourteen-year-old son, Katsunaga, perishing with him. His eldest son, Nobutada; who had just returned from the campaign in the east, followed his father to Kyōto, and was sojourning in the temple Myōgaku-ji when news reached him of Mitsuhide's treachery. He attempted to succour his father, but arrived too late. Then he repaired to the Nijo palace and, having entrusted his infant son to the care of Maeda Gen-i with instructions to carry him to Kiyosu, he made preparation for defence against Mitsuhide. Finally, overwhelmed by numbers, he killed himself, and his example was followed by ninety of his retainers. Mitsuhide then proceeded to Azuchi and having pillaged the castle, returned to Kyōto, where he was received in audience by the Emperor, and he then took the title of shōgun.

\section{AFTER THE ASSASSINATION}

Nobunaga was assassinated on the second day of the sixth month, according to Japanese reckoning. News of the event reached the camp of the besiegers of Takamatsu almost immediately, but a messenger sent by Mitsuhide to convey the intelligence to Mōri and to solicit his alliance was intercepted by Hideyoshi's men. A great deal of historical confusion envelops immediately subsequent events, but the facts seem simple enough. Hideyoshi found himself in a position of great difficulty. His presence in Kyōto was almost a necessity, yet he could not withdraw from Takamatsu without sacrificing all the fruits of the campaign in the west and exposing himself to a probably disastrous attack by Mōri's army. In this emergency he acted with his usual talent. Summoning a famous priest, Ekei, of a temple in Aki, who enjoyed the confidence of all parties, he despatched him to Mōri's camp with proposals for peace and for the delimitation of the frontiers of Mōri and Nobunaga, on condition that the castle of Takamatsu should be surrendered and the head of its commander, Shimizu Muneharu, presented to his conquerer.

Mōri was acting entirely by the advice of his two uncles, Kikkawa and Kohayakawa, both men of profound insight. They fully admitted the desirability of peace, since Hideyoshi's army effectually commanded the communications between the eastern and western parts of Chūgoku, but they resolutely rejected the notion of sacrificing the life of Shimizu on the altar of any compact. When the priest carried this answer to Hideyoshi, the latter suggested; as the only recourse, that Shimizu himself should be consulted. Ekei accordingly repaired to the castle and explained the situation to its commandant. Shimizu had not a moment's hesitation. He declared himself more than willing to die for the sake of his liege-lord and his comrades, and he asked only that fish and wine, to give the garrison the rare treat of a good meal, should be furnished. On the 5 th of the sixth month this agreement was carried into effect. Shimizu committed suicide the compact between Mōri and Hideyoshi was signed, and the latter, striking his camp, prepared to set out for Kyōto. It was then for the first time that Mōri and his generals learned of the death of Nobunaga. Immediately there was an outcry in favour of disregarding the compact and falling upon the enemy in his retreat; but Kikkawa and Kohayakawa stubbornly opposed anything of the kind. They declared that such a course would disgrace the house of Mōri, whereas, by keeping faith, the friendship of Hideyoshi and his fellow barons would be secured. Accordingly the withdrawal was allowed to take place unmolested. 


\section{IEYASU}

The life of the Tokugawa chieftain was placed in great jeopardy by the Mitsuhide incident. After being brilliantly received by Nobunaga at Azuchi, Ieyasu, at his host's suggestion, had made a sightsceing excursion to Kyōto, whence he prolonged his journey to Osaka and finally to Sakai. The news of the catastrophe reached him at the last-named place, and his immediate impulse was to be avenged upon the assassin. But it was pointed out to him that his following was much too small for such an enterprise, and he therefore decided to set out for the east immediately. Mitsuhide, well aware of the Tokugáwa baron's unfriendliness, made strenuous efforts to waylay Ieyasu on the way, and with great difficulty the journey eastward was accomplished by avoiding all the highroads.

\section{NOBUNAGA}

Nobunaga perished at the age of forty-nine. The great faults of his character seem to have been want of discrimination in the treatment of his allies and his retainers, and want of patience in the conduct of affairs. In his eyes, a baron of high rank deserved no more consideration than a humble retainer, and he often gave offence which disturbed the achievement of his plans. As for his impetuousness, his character has been well depicted side by side with that of Hideyoshi and Ieyasu in three couplets familiar to all Japanese. These couplets represent Nobunaga as saying:-

Nakaneba korosu
Hototogisu.
(I'll kill the cuckoo
If it won't sing.)

By Hideyoshi the same idea is conveyed thus:-

Nakashite miyō

Hototogisu.

(I'll try to make the cuckoo sing.)

Whereas, Ieyasu puts the matter thus:-

Nakumade matō

Holotogisu.

(I'll wait till the cuckoo does sing.)

Nevertheless, whatever Nobunaga may have lost by these defects, the fact remains that in the three decades of his military career he brought under his sway thirty-three provinces, or one-half of the whole country, and at the time of his death he contemplated the further conquest of Shikoku, Chūgoku, and Kyūshū. To that end he had appointed Hideyoshi to be Chikuzen no Kami; -Kawajiri Shigeyoshi to be Hizen no Kami, while his own son, Nobutaka, with Niwa Nagahide for chief of staff, had been sent to subdue Shikoku. Even admitting that his ambition was self-aggrandizement in the first place, it is undeniable that he made the peace of the realm, the welfare of the people, and the stability of the throne his second purposes, and that he pursued them with ardour. Thus, one of his earliest acts when he obtained the control in Kyoto was to appoint officials for impartially administering justice, to reduce the citizens' taxes; to succour widows and orphans, and to extend to all the blessings of - security and tranquillity. In 1572 , we find him sending messengers to the provinces with instructions to put in hand the making of roads having a width of 
from twenty-one to twelve feet; to set up milestones and plant trees along these roads; to build bridges; to remove barriers, and generally to facilitate communications.

Towards the Throne he adopted a demeanour emphatically loyal. In this respect, he followed the example of his father, Nobuhide, and departed radically from that of his predecessors, whether Fujiwara, Taira, or Ashikaga. "As concrete examples may be cited the facts that he restored the shrines of Ise, and reinstituted the custom of renovating them every twenty years; that, in the year following his entry into the capital, he undertook extensive repairs of the palace; that he granted considerable estates for the support of the Imperial household, and that he organized a commission to repurchase all the properties which had been alienated from the Court:" Finally, it is on record that when, in recognition of all this, the sovereign proposed to confer on him the rank of minister of the Left, he declined the honour, and suggested that titles of lower grade should be given to those of his subordinates who had shown conspicuous merit.

\section{DEATH OF MITSUHIDE}

It was plainly in Hideyoshi's interests that he should figure publicly as the avenger of Nobunaga's murder, and to this end his speedy arrival in Kyōto was essential. He therefore set out at once, after the fall of Takamatsu, with only a small number of immediate followers. Mitsuhide attempted to destroy him on the way; and the details of this attempt have been magnified by tradition to incredible dimensions. All that can be said with certainty is that Hideyoshi was, for a moment; in extreme danger but that he escaped 'scathless.' Immediately on arriving in Kyōto; he issued an appeal to all Nobunaga's vassal-barons, inviting them to join in exterminating Mitsuhide, whose heinous crime "provoked both heaven and earth."

ris But it was no part of Hideyoshi's policy to await the arrival of these barons. $\mathrm{He}$ had already at his command an army of some thirty thousand men, and with this he moved out, challenging Mitsuhide to fight on the plains of Yamazaki. Mitsuhide did not hesitate to put his fortunes to the supreme test. He accepted Hideyoshi's challenge, and, on the 12th of June, a great battle was fought, the issue of which was decided by two things; first, the defection of Tsutsui Junkei, who refrained from striking until the superior strength of Hideyoshi had been manifested, and secondly, the able strategy of Hideyoshi, who anticipated Mitsuhide's attempt to occupy the position of Tenno-zan, which commanded the field. From the carnage that ensued Mitsuhide himself escaped, but while passing through a wood he received from a bamboo spear in the hands of a peasant a thrust which disabled him, and he presently committed suicide. Thus, on the thirteenth day after Nobunaga's death, the head of his assassin was exposed in Kyōto in front of the temple of Honno-ji where the murder had taken place, and Mitsuhide's name went down in history as the "Three days' shögun" $($ Mikkakubō) ?

\section{CONFERENCE AT KIYOSU}

By this time the principal of Nobunaga's vassal-barons were on their way at the head of contingents to attack Mitsuhide. On learning of the assassin's death, these barons all directed their march to Kiyosu, and in the castle from which Nobunaga had moved to his early conquests thirty years previously, a momentous council was held for the purpose of determining his successor. The 
choice would have fallen naturally on Sambōshi, eldest son of Nobunaga's first-born, Nobutada, who, as already described, met his death in the Mitsuhide affair. But Hideyoshi was well understood to favour Sambōshi's suecession; and this sufficed to array in opposition several of the barons habitually hóstile to Hideyoshi. Thus, in spite of the fact that both were illegitimate and had already been adopted into other families, Nobunaga's two sons, Nobukatsu and Nobutaka, were put forward as proper candidates, the former supported by Ikeda Nobuteru and Gamō Katahide; the latter, by. Shibata Katsuiye and Takigawa Kazumasu.

At one moment it seemed as though this question would be solved by an appeal to violence, but ultimately, at the suggestion of Tsutsui Junkei, it was agreed that Sambōshi should be nominated Nobunaga's successor; that Nobukatsu and Nobutaka should be appointed his guardians, and that the administrative duties should be entrusted to a council consisting of Shibata Katsuiye, Niwa Nagahide, Ikeda Nobuteru, and Hideyoshi, each taking it in turn to discharge these functions and each residing for that purpose in Kyoto three months during the year. An income of one hundred thousand koku in the province of Ōmi was assigned to Sambōshi pending the attainment of his majority, when he should be placed in possession of much larger estates, which were to be entrusted in the meanwhile to the keeping of one of the four barons mentioned above. Nobukatsu received the province of Owari, and Nobutaka that of Mino, the remainder of Nobunaga's dominions being apportioned to his generals, with the exception of Hideyoshi, to whom were assigned the provinces recently: overrun by him in the midlands - Tajima, Harima, Inaba, and Tamba.

Such an arrangement had no elements of stability. The four councillors could not possibly be expected to work in harmony, and it was certain that Katsuiye, Sakuma Morimasa, and Takigawa Kazumasu would lose no opportunity of quarrelling with Hideyoshi. Indeed, that result was averted solely by Hideyoshi's tact and long suffering, for when; a few days later, the barons again met at Kiyosu for the purpose of discussing territorial questions, every: possible effort was made to find a pretext for killing him. But Hịdeyoshi's astuteneśs and patience led him successfully through this maze of intrigues and complications. He even went so far as to hand over his castle of Nagahama to Katsuiye, and to endure insults which in ordinary circumstances must have been resented: with the sword. Tradition deseribes a grand memorial ceremony organized in Kyōto by Hideyoshi in honour of Nobunaga, and, on that occasion, incidents are said to have occurred which bear the impress of romance It is, at all events, certain that the immediate issue of this dangerous time was a large increase of Hideyoshi's authority, and his nomination by the Court to the second grade of the fourth rank as well as to the position of major-general: 1 , Moreover, the three barons who had been appointed with Hideyoshi to administer affairs in Kyōto in turn, saw that Hideyoshi's power was too great to permit the peaceful: working of such a programme. They therefore abandoned their functions, and Hideyoshi remained in sole charge of the Imperial Court and of the administration in the capital.

\section{DEATH OF SHIBATA KATSUIYE}

It has been already stated that Nobunaga's sons, Nobutaka and Nobukatsu, were bitter enemies and that Nobutaka had the support of Takigawa Kazumasu as well as of Shibata Katsuiye. Thus, Hideyoshi was virtually, compelled to 
espouse the cause of Nobukatsu. In January, 1583, he took the field at the head of seventy-five thousand men, and marched into Ise to attack Kazumasu, whom herbesieged in his castle at Kuwana. The castle fell, but.Kazumasu managed to effect his escape, and in the mean while Katsuiye entered Ōmi in command of a great body of troops, said to number sixty-five thousand. At the last moment, however, he had failed to secure the co-operation of Maeda Toshiiye, an important ally, and his campaign therefore assumed a defensive character: Hideyoshi himself, on reconnoitring the position, concluded that he had neither numerical preponderance nor strategical superiority sufficient to warrant immediate assumption of the offensive along the whole front. He therefore distributed his army on a line of thirteen redoubts, keeping a reserve of fifteen thousand men under his own direct command, his object being to hold the enemy's forces in check while he attacked Gifu, which place he assaulted with such vigour that the garrison made urgent appeals to Katsuiye for succour.

on In this situation it was imperative that some attempt should be made to break the line of redoubts, but it was equally imperative that this attempt should not furnish to the enemy a point of concentration. Accordingly, having ascertained that the weakest point in the line was at Shizugatake, where only fifteen : hundred men were posted, Katsuiye instructed his principal general, Sakuma Morimasa, to lead the reserve force of fifteen thousand men against that position, but instructed him at the same time to be content with any success, however partial, and not to be betrayed into pushing an advantage, since by so doing he would certainly furnish a fatal opportunity to the enemy. Morimasa neglected this caution. Having successfully surprised the detachment at Shizugatake, and having inflicted heavy carnage on the defenders of the redoubt, who lost virtually all their officers, he not only sat down to besiege the redoubt, whose decimated garrison held out bravely, but he also allowed his movements to be hampered by a small body of only two score men under Niwa Nagahide, who took up a position in the immediate neighbourhood, and displaying their leader's flag, deceived Morimasa into imagining that they had a powerful backing. These things happened during the night of April 19, 1583. Katsuiye, on receipt of the intelligence, sent repeated orders to Morimasa requiring him to withdraw forthwith; but Morimasa, elated by his partial victory, neglected these orders.

On the following day, the facts were communicated to Hideyoshi, at Ōgaki, distant about thirty miles from Shizugatake, who immediately appreciated the opportunity thus: furnished. 'He set out at the head of his reserves, and in less than twenty-four hours his men crossed swords with Morimasa's force. The result was the practical extermination of the latter, including three thousand men under Katsuiye's adopted son; Gonroku. The latter had been sent to insist strenuously on Morimasa's retreat; but learning that Morimasa had determined to die fighting, Gonroku announced a similar intention on his own part. This incident was characteristic of samurai canons. Hideyoshi's victory cost the enemy five thousand men, and demoralized Katsuiye's army so completely that he subsequently found himself able to muster a total force of three thousand only. Nothing remained but flight, and in order to withdraw from the field, Katsuiye was obliged to allow his chief retainer, Menju Shōsuke, to impersonate him; a feat which, of course; cost Shōsuke's life.

Katsuiye's end is one of the most dramatic incidents in Japanese history. He decided to retire to his castle of Kitanoshō, and, on the way thither, he visited his old friend, Maeda Toshiiye, at the latter's castle of Fuchü, in Echizen. 
Thanking Toshiiye for all the assistance he had rendered, and urging him to cultivate friendship with Hideyoshi, he obtained a remount from Toshiiye's stable, and, followed by about a hundred samurai, pushed on to Kitanoshō. Arrived there, he sent away all who might be suspected of sympathizing with Hideyoshi, and would also have sent away his wife and her three daughters. This lady was a sister of Nobunaga. She had been given, as already stated, to Asai Nagamasa, and to him she bore three children. But after Nagamasa's destruction she was married to Katsuiye, and was living at the latter's castle of Kitanoshō when the above incidents occurred. She declined to entertain the idea of leaving the castle, declaring that, as a' samurai's daughter, she should have shared her first husband's fate, and that nothing would induce her to repeat that error. Her three daughters were accordingly sent away, and she herself joined in the night-long feast which Katsuiye and his principal retainers held while Hideyoshi's forces were marching to the attack. When the sun rose, the whole party, including the ladies, committed suicide, having first set fire to the castle.

\section{YODOGIMI}

One of the three daughters of Asai Nagamasa afterwards became the concubine of Hideyoshi and bore to him a son; Hideyori; who, by her advice, subsequently acted in defiance of Ieyasu, thus involving the fall of the house of Hideyoshi and unconsciously avenging the fate of Nobunaga.

\section{NOBUTAKA}

Nobunaga's son, Nobutaka, who had been allied with Katsuiye, escaped, at first, to Owari on the latter's downfall, but ultimately followed Katsuiye's example by committing suicide. As for Sambōshi, Nobunaga's grandson and nominal heir, he attained his majority at this time, but proving to be a man of marked incompetence, the eminent position for which he had been destined was withheld: He took the name of Oda Hidenobu, and with an income of three hundred thousand koku settled down contentedly as Hideyoshi's vassal.

\section{ŌSAKA CASTLE}

Hideyoshi left behind him a striking monument of his greatness of thought

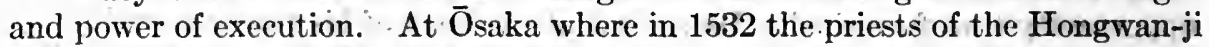
temple had built a castle which Nobunaga captured in 1580 only after a long and severe siege, Hideyoshi built what is called The Castle of $\bar{O}_{\text {saka. }}$ It is a colossal fortress, which is still used as military headquarters for garrison and arsenal, and the dimensions of which are still a wonder, though only a portion of the building survives. Materials for the work were requisitioned from thirty provinces, their principal components being immense granite rocks, many of which measured fourteen feet in length and breadth, and some were forty feet long and ten feet wide. These huge stones had to be carried by water from a distance of several miles. The outlying protection of this great castle con'sisted of triple moats and escarpments. The moats were twenty feet deep, with six to ten feet of water. The total enclosed space was about one hundred acres, but only one-eighth of this was the hommaru, or keep, inside the third moat.

It will be seen that the plan of the castle was to have it divided into spaces 
separately defensible, so that an enemy had to establish his footing by a series of repeated efforts.

And the second respect in which it was a novelty in Japanese defensive warfare was that the castle donjon was heavily built and armoured after a fashion! The three-storey donjon was framed in huge timbers, quite unlike the flimsy structure of most Japanese buildings, and the timbers were protected against fire by a heavy coat of plaster. Roof and gates were covered with a sort of armor-plate; for there was a copper covering to the roof and the gates were faced with iron sheets and studs. In earlier "castles" there had been a thin covering of plaster which a musket ball could easily penetrate; and stone had been used only in building foundations.

\section{THE KOMAKI WAR}

After the suicide of nis brother, Nobutaka, and when he saw that his nephew, Sambōshi (Hidenobu), was relegated to the place of a vassal of Hideyoshi, Nobukatsu seems to have concluded that the time had come to strike a final blow in assertion of the administrative supremacy of the Oda family. He began, therefore, to plot with that object. Hideyoshi, who was well served by spies, soon learned of these plots, and thinking to persuade Nobukatsu of their hopeléssness, he established close relations with the latter's three most trusted retainers. No sooner did this come to the cognizance of Nobukatsu than he caused these three retainers to be assassinated, and applied to Ieyasu for assistance. Ieyasu consented. This action on the part of the Tokugawa baron has been much commented on and variously interpreted by historians, but it has always to be remembered that Ieyasu had been Oda Nobunaga's ally; that the two had fought more than once side by side, and that had the Tokugawa leader rejected Nobukatsu's appeal, he would not only have suffered in public estimation, but would also have virtually accepted a position inferior to that evidently claimed by Hideyoshi.

I.) The course of subsequent $\in$ vents seems to prove that Ieyasu, in taking the field on this occasion, aimed simply at asserting his own potentiality and had no thought of plunging the empire into a new civil war. In March, 1584, he set out from Hamamatsu and joined Nobukatsu at Kiyosu, in Owari. The scheme of campaign was extensive Ieyasu placed himself in communication with Sasa'Narimasa, in Echizen; with Chōsokabe Motochika, in Shikoku, and with the military monks in the province of Kii: The programme was that Narimasa should raise his standard in Echizen and Kaga, and that Motochika, with the monks of Kii, should move to the attack of Ōsaka, so that Hideyoshi would be compelled to carry on three wars at the same time. Hideyoshi met this combination with his usual astuteness. He commissioned Uesugi Kagekatsu to attack the Sasa troops in rear while Maeda Toshiiye menaced them from the front; he told off Hachisuka to oppose the soldier-monks of Kii; he posted Sengoku Hidehisa in Awaji to hold in check the forces of Chōsokabe Motochika, and he stationed Ukita Hideiye at Okayama to provide against the contingency of hostility on the part of the Mori family. Fighting commenced in the province of I'se, and success at the outset crowned the arms of Hideyoshi's generals. They captured two castles, and Ieyasu thereupon pushed his van to an isolated hill called Komaki-yama, nearly equidistant from the castles of Inu-yama and Kiyosu, in Owari; which he entrenched strongly, and there awaited the onset of the Ōsaka army. The war thus came to be known as that of Komak1. 
Hideyoshi himself would have set out for the field on the 19th of March, but he was obliged to postpone his departure for some days, until Kuroda and Hachisuka had broken the offensive strength of the monks of Kii. It thus fell out that he did not reach the province of Owari until the 27th of March. His army is said to have numbered one hundred and twenty thousand men. It is commonly alleged that this was the only war between Ieyasu and Hideyoshi, and that the latter suffered defeat at the hands of the former. But the fact is that two of Hideyoshi's generals, Ikeda Nobuteru and Mōri Nagayoshi, acted in direct contravention of his orders, and thus precipitated a catastrophe for which Hideyoshi cannot justly be held responsible. These two captains argued that as Ieyasu had massed a large force at Komaki and at the Obata entrenchments in the same district, he had probably left his base in Mikawa comparatively undefended. They proposed, therefore, to lead a force against Mikawa. Hideyoshi showed great reluctance to sanction this movement, but he allowed himself to be at last persuaded, with the explicit reservation that no success obtained in Mikawa province should be followed up; and that whatever the achievement of Nobukatsu's troops, they should at once rejoin the main army in Owari.

Unquestionably Hideyoshi had in vivid recollection the disaster which had overtaken Katsuiye at Shizugatake. Ieyasu, fully cognizant of the situation through the medium of a spy, knew the limitations set by Hideyoshi. On April the 7th, Nobuteru attacked the fortress of Iwasaki, in Mikawa, killed its commandant, and captured the castle. But elated by this victory, he neglected Hideyoshi's caution, and the generals of Ieyasu, closing in on him, inflicted a crushing defeat at a place called Nagakude. It is thus evident that Hideyoshi's share in the disaster was of a most indirect character. He immediately hastened to Nagakude, but only to find that Ieyasu had retired to Obata, and subsequently, when Hideyoshi returned to his headquarters, Ieyasu placed a still longer interval between the two armies by marching back to Komaki.

The war thenceforth may be said to have consisted of a series of menaces and evasions. Each general sought to entice his opponent out of an entrenched position, and each general showed an equal determination not to be so enticed: At last, Hideyoshi pushed a force into Mino and captured several castles in that province. But even this failed to change Ieyasu's attitude. The Tokugawa leader entered the fortress of Kiyosu, and Nobukatsu repaired to that of Nagashima, in Ise. After eight months of this comparatively fruitless manœuvring, a treaty was concluded, on December the 11th, between Hideyoshi and Nobukatsu, and subsequently between Hideyoshi and Ieyasu, the latter giving his son Ogimaru to be adopted by Hideyoshi. The boy was eleven years of age at the time. His name was changed to Hashiba Hideyasu, and he received the appointment of governor of Mikawa province.

The circumstances in which this treaty was concluded have provoked much historical discussion. Did the overtures come originally from Hideyoshi, or did they emanate from Ieyasu and Nobukatsu? Some annalists have endeavoured to prove that Hideyoshi assumed the attitude of a suppliant, while others have attributed that demeanour to the Tokugawa chieftain. The situation, however, presents one feature which is very significant. It was not until the month of November, 1584, that Chōsokabe Motochika effectually brought the island of Shikoku under his sway, and thus became free to lead a strong army, including the monks of Kii province, against Ōsaka. This formidable danger could not but influence Hideyoshi in the direction of clasping hands 
with his eastern foes, and it is therefore more than probable that a statesman who had never previously allowed considerations of personal dignity to interfere with the prosecution of a vital policy, did not hesitate to bow his head to Nobukatsu, in order to recover the free use of the great army assembled in Owari, Mino, and Ise. Most fortunate was it for Japan that events took this turn, for, had Ieyasu and Hideyoshi remained mutually hostile, the country would probably have been plunged into a repetition of the terrible struggle from which nothing enabled it to emerge except the combined labours of Nobunaga, Hideyoshi, and Ieyasu. It was not, however, until the early summer of 1586 that Hideyoshi and Ieyasu established genuinely friendly relations. During a year and a half subsequent to the conclusion of the treaty which ended the Komaki War, Ieyasu held severely aloof and refrained from visiting Kyōto. Finally, Hideyoshi despatched Asano Nagamasa to propose that leyasu should take into his household Hideyoshi's younger sister, and that Hideyoshi should send his mother as a hostage to Okazaki, to remain there during a visit by Ieyasu to Kyotto. Four months were needed by Ieyasu to consider this proposal, and in September, 1586 , he repaired to Ōsaka and thence accompanied Hideyoshi to Kyōto.

\section{HIDEYOSHI BECOMES REGENT}

In May, 1583, after the downfall of Katsuiye, the Emperor appointed Hideyoshi to be a councillor of State, and conferred on him the fourth order of rank. In November of the following year, he received another step of rank and was nominated gon-dainagon. The Emperor Ōkimachi at that time contemplated abdication, but the palace which he would have occupied as ex-Emperor had fallen into such a state of disrepair as to be virtually uninhabitable. Hideyoshi signalized his loyalty on this occasion by spending a large sum on the renovation of the palace, and in recognition of his services the Emperor raised him to the high post of nai-daijin. It was confidently expected that he would then become sa-daijin, but; owing to complications which need not be related here, the outcome of the matter was that he received the still higher post of kwampaku (regent). There can be no doubt that he himself had contemplated becoming shoggin. In fact, it is on record that he made proposals in that sense to Yoshiaki, the last of the Ashikaga shoguns. But it had come by that time to be recognized that only a scion of the Minamoto family could be eligible for the post of shogun, and thus Yoshiaki declined Hideyoshi's overtures, though to accept them would have materially altered the fallen fortunes of the Ashikaga sept. Hideyoshi ultimately became prime minister of State (dajo "daijin) and took the family name of Toyotomi. It is stated, but the evidence is not conclusive, that in order to reach these high posts, he had to be adopted into the house of a Fujiwara noble. He had been a Taira when he served under Nobunaga, and to become a Fujiwara for courtly purposes was not likely to cause him much compunction.

\section{THE MONKS, SHIKOKU, AND ETCHŪ}

Immediately on the termination of the Komaki War, Hideyoshi took steps to deal effectually with the three enemies by whom his movements had been so much hampered, namely, the Buddhist priests of Kii, the Chōsokabe clan in Shikoku, and the, Sasa in Etchū. It has already been stated that the priests of Kii had their headquarters at Negoro, where there stood the great monastery of Dai-Dembō-In, belonging to the Shingon sect and enjoying almost the repute 
of Kōya-san. Scarcely less important was the monastery of Sawaga in the same province. These two centres of religion had long been in possession of large bodies of trained soldiers whose ranks were from time to time swelled by the accession of wandering samurai (rōnin). . The army despatched from Ösaka in the spring of 1585 to deal with these warlike monks speedily captured the two monasteries, and, for purposes of intimidation, crucified a number of the leaders. For a time, Koya-san itself was in danger, several of the fugitive monks having taken refuge there. But finally Kōya-san was spared in consideration of surrendering estates yielding twenty-one thousand koku of rice, which properties had been violently seized by the monasteries in former years.

Three months later, Hideyoshi turned his arms against the Chōsokabe sept in Shikoku. This being an enterprise of large dimensions, he entrusted it's conduct to five of his most competent generals, namely, Ukita Hideiye, Hachisuka Iemasa, Kuroda Nagamasa, Kikkawa Motoharu, and Kohayakawa Takakagé. Hideyoshi himself would have assumed the direct command, and had actually set out for that purpose from Ōsaka, when couriers met him with intelligence that less than one month's fighting had brought the whole of the Island of the Four Provinces into subjection. He therefore turned eastward, and entering Etchū, directed the operations in progress there under the command of Maeda Toshiiye against Sasa Nárimasa. This campaign lasted seven days, and ended in the surrender of Narimasa, to whom Hideyoshi showed remarkable clemency, inasmuch as he suffered him to remain in possession of considerable estates in Etchū.

\section{THE UESUGI}

At this time Hideyoshi eemented relations of friendship with the Uesugi family of Echigo, whose potentialities had always been a subject of apprehension to Nobunaga. The powerful sept was then ruled by Kagekatsu, nephew of the eelebrated Kenshin. This daimyo had given evidence of good-will towards Hideyoshi during the Komaki War, but it was naturally a matter of great importance to establish really cordial relations with so powerful a baron. History relates that, on this occasion, Hideyoshi adopted a course which might well have involved him in serious peril. He entered Echigo with a mere handful of followers, and placed himself practically at the merey of Kagekatsu, judging justly that such trustful fearlessness would win the heart of the gallant Kagekat'su. Hideyoshi's insight was justified by the sequel. Several of the principal retainers of Kagekatsu advised that advantage should be taken of Hideyoshi's rashness; and that his victorious career should be finally terminated in Echigo. But this vindictive counsel was rejected by the Uesugi baron, and relations of a warmly friendly character were established between the two great captains.

\section{INVASION OF KYŪSHŪ}

There now remained only three really formidable enemies of Hideyoshi. These were Hōjō Ujimasa, in the Kwantō; Date Masamune, in Dewa and Mutsu, and Shimazu Yoshihisa, in Kyūshū. Of these, the Shimazu sept was probably the most powerful, and Hideyoshi determined that Kyūshū should be the scene of his next warlike enterprise. - The Island of the Nine Provinces was then under the rule of three great clans; the Shimazu, in the south; the Ōtomo, in Bungo, and the Ryūzōji, in Hizen. The most puissant of these had at one time been Ryũzōji Takanobu, but his cruel methods had alienated the sympathy of many 
of his vassals, among them being Arima Yoshizumi, who threw off his allegiance to Takanobu and joined hands with Shimazu Yoshihisa. Takanobu sent an army against Yoshizumi, but the Satsuma baron despatched Shimazu Masahisa to Yoshizumi's aid; and a sanguinary engagement at Shimabara in 1585 resulted in the rout of Takanobu's forces and his own death.

Takanobu's son and successor, who was named Masaiye, being still a boy; advantage was taken of the fact by Ōtomo Yoshishige, who invaded Hizen, so that Masaiye had to apply to the Shimazu family for succour. The Satsuma chieftain suggested that the matter might be settled by mutual withdrawal of forces, but Yoshishige declined this overture, and the result was a battle in which the Ōtomo troops were completely defeated. Ōtomo Yoshishige then (1586) had recourse to Hideyoshi for assistance, thus furnishing the opportunity of which Ōsaka was in search: Orders were immediately issued to Mōri, Kikkawa, Kohayakawa, and Chōsokabe Motochika to assemble their forces for an oversea expedition, and in the mean while,' Sengoku Hidehisa was despatched to Kyūshū bearing a letter in which Hideyoshi, writing over his title of kwampaku, censured the Shimazu baron for having failed to pay his respects to the Imperial Court in Kyōto, and called upon him to do so without delay. This mandate was treated with contempt. Shimazu Yoshihisa threw the document on the ground, declaring that his family had ruled in Satsuma for fourteen generations; that only one man in Japan, namely Prince Konoe, had competence to issue such an injunction, and that the head of the house of Shimazu would never kneel to a monkey-faced upstart.

Hideyoshi had foreseen something of this kind, and had warned Sengoku Hidehisa in the sense that whatever might be the action of the Satsuma baron, no.warlike measures were to be precipitately commenced. Hidehisa neglected this warning. Yielding to the anger of the moment, he directed the Ōtomo troops to attack the Satsuma forces, and the result was disastrous. When the fighting ended, the Satsuma baron had pushed into Bungo and taken sixteen forts there, so that fully one-half of Kyūshū was now under the sway of the Shimazu. Hideyoshi, on receiving news of these disasters, confiscated the estates of : Sengoku Hidehisa, and issued orders to thirty-seven provinces to provide commissariat for three hundred thousand men and twenty thousand horses for a period of one year. Soon an army of one hundred and fifty thousand men assembled at Ōsaka, and the van, numbering sixty thousand, embarked there on the 7 th of January, 1587, and landed at Yunoshima in Bungo on the 19th of the same month - dates which convey some idea of the very defective system of maritime transport then existing. In Bungo, the invading army was swelled by thirty thousand men under the leadership of Kohayakawa and Kikkawa, and the whole force, under the command-in-chief of Hidenaga, Hideyoshi's brother, moved to invest the castle of Takashiro.

It is unnecessary to follow the fighting in all its details. The salient facts are that Hideyoshi left Ōsaka with the main army of one hundred and thirty thousand men on the $22 \mathrm{~d}$ of January; 1587 , and, travelling by land, reached the Strait of Akamagasaki - now called Shimonoseki - on the 17th of February. He marched through Chikuzen, making friends of the local chieftains by forbearance and diplomacy, and fighting the first great battle of the campaign at Ōguchi on the Sendai-gawa. The Satsuma baron's younger brother, Iehisa, after a gallant resistance, surrendered to Hideyoshi, and was employed by the latter to communicate direct with his chief, Yoshihisa. It was generally supposed that Iehisa would never return from this mission, but would remain in 
the camp of Shimazu. He did return, however, his word of honour being of more importance in his estimation than the opportunity of recovering his liberty.

History states that Hideyoshi thereafter treated this noble man with the greatest consideration, but it is difficult to reconcile that account with the fact that Hideyoshi subsequently pressed Iehisa to guide the Ōsaka army through the mountains and rivers which constituted natural defences for the fief of Satsuma. Iehisa, of course, refused, and to Hideyoshi's credit it stands on record that he did not press the matter with any violence. This difficulty of invading an unknown country without any maps or any guides, a country celebrated for its topographical perplexities, was ultimately overcome by sending Buddhist priests to act as spies in the dominions of Shimazu. These spies were led by the abbot, Kennyo, with whose name the reader is already familiar, and as the Shimazu family were sincere believers in Buddhism, no obstacles were placed in the way of the treacherous monks. They were able ultimately to guide the Ōsaka army through the forests and mountains on the north : of Kagoshima, and Hideyoshi adopted the same strategy as that pursued in a similar case three hundred years later, namely, sending a force of fifty thousand men by sea with orders to advance against Kagoshima from the south. The Satsuma troops were completely defeated, and only the castle of Kagoshima remained in their hands.

At this stage of the campaign Hideyoshi behaved with remarkable magnanimity and foresight. Contrary to the advice of some of his principal retainers, he refused to proceed to extremities against the Shimazu clan, and agreed to make peace, on the basis that the clan should be left in possession of the provinees of Satsuma, Ōsumi, and Hyūga, the only further stipulation being that the then head of the house, Yoshihisa, should abdicate in favour of his younger brother, Yoshihiro. As for the Buddhist priests who had sacrificed their honour to their interests, those that had acted as guides to the invading army were subsequently crucified by order of the Satsuma baron, and the Shin sect, to which they belonged, was interdicted throughout the whole of the Shimazu fief. Yoshibiro was summoned to Kyōto by Hideyoshi to answer for this action, but he pleaded that such treachery amply deserved such punishment, and that he was prepared to bow to Hideyoshi's judgment in the matter. The defence was admitted by Hideyoshi, but the abbot Kennyo received such large rewards that he was able to erect the great temple Nishi Hongwan-ji, "which became the wonder of after-generations of men and which has often been erroneously referred to by foreign writers as a proof of the deep religious feelings of Buddhist converts three hundred years ago."1

\section{THE HŌJŌ}

From end to end of Japan there were now only two powerful barons whose allegiance had not been formally rendered to Hideyoshi and to the Emperor under the new régime. These were Date Masamune and Hōjō Ujimasa. $\uparrow$ The origin and eminence of the Hōjō family from the days of its founder, Nagauji, have already been described in these pages, and it need only be added here that Ujimasa enjoyed a reputation second to none of his predecessors. That he should stand aloof from all his brother barons seemed to the latter an intolerable evidence of pride, and they urged Hideyoshi to resort at once to extreme measures. There can be no doubt that this was the intention of Hideyoshi himself, but with characteristic prudence he had recourse at the outset to pacific 
devices. He therefore sent an envoy to the Hōjō's stronghold at Odawara, urging Ujimasa to lose no time in paying his respects to the Court at Kyōto. The Hōjo chief's reply was that Sanada Masayuki had encroached upon the Hojo ostates in Numata, and that if this encroachment were rectified, the desired obeisance to the Throne would be made.

Thereupon, Hideyoshi caused the restoration of Numata, but the Hōjō baron, instead of carrying out his part of the agreement, made this restoration the pretext for an unwarrantable act of aggression. Whatever sympathy might have been felt in Kyōto with the Hōjō family was forfeited by this procedure, and in March, 1590, an army of over two hundred thousand men was set in motion for the Kwantō. Hideyoshi's troops moved in three columns. One, commanded by Ieyasu, marched by the seacoast road, the Tōkaidō; another, under Uesugi Kagekatsu and Maeda Toshiiye, marched by the mountain road, the Tōsandō, and the third attacked from the sea. None of these armies encountered any very serious resistance. The first approached Odawara by the Hakone range and the second by way of the Usui pass. The castle at Odawara; however, was so strongly built and so stoutly held that its capture by storm seemed impossible, and Hideyoshi's forces were obliged to have recourse to a regular siege which lasted nearly four months. During the latter part of that time, Hideyoshi encouraged his soldiers to indulge in all sorts of amusements, and thus the camp of the besiegers constantly echoed the notes of musical performances and the shouts of dancers and saké drinkers. Finally, in July, 1590, the great fortress surrendered, and the Hōjö baron, Ujimasa, was put to death, his head being sent to Kyōto for exposure, but the life of his son, Ujinao, was spared on condition that he enter a monastery.

\section{HŌJŌ UJINORI}

One incident of this struggle is very characteristic of the ethics of the era. During the interchange of messages that preceded recourse to arms, the Hojōo baron sent his brother, Ujinori, to Kyōto as an envoy to discuss the situation with Hideyoshi. The latter received Ujinori with all courtesy and endeavoured to impress upon him the imperative necessity of his chief's acquiescence. Ujinori promised to contribute to that end as far as lay in his power, but history describes him as adding: "Should my brother fail to comply with your commands, and should it be necessary for you to send an army against the Kwantō, it must be clearly understood that this visit of mine to your Excellency shall not in any way prejudice my loyalty to my brother. On the contrary, if the peace be broken, I shall probably have to command the van of my brother's forces, and in that event I may have to offer to your Excellency a flight of my rusty arrows."

Hideyoshi is narrated to have laughingly replied that the peace was in no danger of being broken and that he trusted Ujinori to use his best endeavours to avert war. On his return to the Kwantō, Ujinori was ordered to defend the castle of Nira-yama with seven thousand men, and he soon found himself attacked by fifty thousand under seven of Hideyoshi's generals. Ujinori reminded. his comrades that Nira-yama had been the birthplace of the founder of the Hōjo family, and therefore it would be an eternal shame if even one of the entrenchments were lost. Not one was lost. Again and again assaults were delivered, but they were unsuccessful, and throughout the whole of the Kwantō, Nira-yama alone remained flying the Hōjō flag to the end. Ujinori surrendered 
in obedience to Ujimasa's instructions after the fall of Odawara, but Hideyoshi, instead of punishing him for the heavy losses he had inflicted on the Osaka army, lauded his fidelity and bravery, and presented him with an estate of ten thousand koku.

\section{DATE MASAMUNE}

When news reached Date Masamune of the fall of all the Hōjō's outlying forts and of the final investment of Odawara, he recognized, from his place in Mutsu and Dewa, that an attitude of aloofness could no longer be maintained with safety. Accordingly, braving considerable danger, he made his way with a small retinue to Odawara and signified his willingness to comply with any terms imposed by Hideyoshi. Thus, for the first time since the middle of the fifteenth century, the whole of the empire was pacified.

\section{YEDO}

It is historically related that, during the siege of Odawara; Hideyoshi invited Ieyasu to the former's headquarters on Ishigaki Hill, whence an uninterrupted view of the interior of the castle could be had. The Tokugawa baron was then asked whether, if the eight provinces of the Kwanto were handed over to him, he would choose Odawara for central stronghold. He replied in the affirmative. Hideyoshi pointed out the superior advantages of Yedo from a strategical and commercial point of view, and ultimately when he conferred the Kwantō on Ieyasu, he chose Yedo for the latter's capital, the accompanying revenue being about two and a half million koku. Hideyoshi further proposed to appoint Oda Nobukatsu to the lordship of the five provinces which had hitherto constituted the domain of Ieyasu, namely, Suruga, Tōtomi, Mikawa, Kai, and Shinano. Nobukatsu, however, alleging that he did not desire any large domain, asked to be allowed to retain his old estates in Owari and Ise.

This attitude angered Hideyoshi for reasons which will presently be apparent. He assigned to Nobukatsu a comparatively insignificant fief at Akitá, in the remote province of Dewa, and gave the estates in Owari and Ise to Hidetsugu, the nephew and adopted successor of Hideyoshi, while the five provinces hitherto under the sway of Ieyasu were divided among Hideyoshi's generals and retainers. In September, 1590, Ieyasu entered Yedo, and subdivided his extensive domain among his followers in order of merit, thus establishing the Tokugawa system of hereditary daimyō and founding a new Bakufu. All this was very significant. In such matters, Hideyoshi had repeatedly shown himself to be a man of great magnanimity, and had allowed even his enemies to retain possession of lands which would eertainly have been taken from them by other conquerors. Thus, in the case of the Mōri sept, fully half of the midland counties was left in their occupation, and; in the case of the Shimazu family, they were suffered to retain two and a half provinces.

With regard to Ieyasu, however, Hideyoshi behaved with marked caution. By granting to the Tokugawa chieftain the whole of the Kwantō, Hideyoshi made it appear as though he were conferring a signal favour; but in reality his object was to remove Ieyasu out of the zone of potential danger to Kyōto. Ieyasu fully recognized this manœuvre, but bowed to it as the less of two evils. As a further measure of precaution, Hideyoshi interposed one of his own family, Hidetsugu, between the Kwantō and Kyōto, and with the object of menacing the rear of Ieyasu and restraining the movements of the Date, he 
placed Gamō Ujisato at Aizu in Ōshū. He further posted Ishida Katsushige at Sawa-yama (now called Hikone) in the province of Ōmi, to cover the principal route to Kyoto, and for similar reasons with regard to the Yamato and Tamba roads he assigned to his brother, Hidenaga, the castle of Köri-yama, which commanded Izumi and Kii, and to his adopted son, Hidekatsu, the castle at Fúkuchi-yama in Tamba. . This plan of distributing their domains, so that the daimyō should be mutually repressive, was followed with still greater care by Ieyasu when he, in turn, became supreme.

\section{HIDEYOSHI AND BUDDHISM}

There are evidences that, from his childhood, Hideyoshi had little reverence for the Buddhist faith. When only twelve years of age he is said to have beaten and smashed an image of Amida because it remained always insensible to the offerings of food placed daily before it." Again, when on his way to Kyotto to avenge the assassination of Nobunaga, he saw an idol floating on a stream, and seizing the effigy he cut it into two pieces, saying that the deity Daikoku, having competence to succour one thousand persons only, could be of little use to him at such a crisis as he was now required to meet. Finally, on the occasion of his expedition against the Hojo of Odawara, when the sailors of Mishima; in Sagami, objected to carrying war-horses in their boats on the plea that the god of the sea, Ryūjin, hated everything equine; Hideyoshi did not hesitate to remove these scruples by addressing a despatch to the deity with orders to watch over the safety of the steeds.

Yet this same Hideyoshi evidently recognized that the Buddhist faith had great potentialities in Japan, and that its encouragement made for the peace and progress of the country. Buddhism suffered terribly at the hands of Nobunaga: The great monastery of Enryaku-ji was a mass of blackened ruins at the time of the Oda baron's death, and it has been shown that the monasteries of: Kii and Ōsáka fared almost equally badly at the hands of Hideyoshi: Nevertheless the latter had no sooner grasped the supreme administrative power than he showed himself a protector and promotor of Buddhism. Scattered throughout the empire and apparently crippled for all time, the monks of Hiei-zan very soon gave evidence of the vitality of their faith by commencing a vigorous propaganda for the restoration of the great monastery Many renowned priests, as Zensō, Gösei, and others, headed this movement; Prince Takatomo, adopted son of the Emperor Ōkimachi, agreed to become lord-abbot of the sect (Tendai), and the Imperial Court issued a proclamation exhorting the people to subscribe for the pious purpose. Hideyoshi, Ieyasu, and other great barons addressed their vassals in a similar sense, and in Hideyoshi's proclamation the imperative necessity of Enryaku-ji as a barrier at the "Demon's Gate" was distinctly stated: Under such auspices the monastery quickly rose from its ashes, though in point of size and magnificence it was inferior to its predecessor." At the same time Hideyoshi steadily pursued the policy of checking the military tendencies of the monks, and it may be said that, from his era, the soldier-priest ceased to be a fäctor in the political situation.

\section{THE KYÖTO DAIBUTSU}

The erection of a colossal image of the Buddha at Nara, in the eighth century, and at Kamakura, in the thirteenth century, marked the consummation of great political programmes in which religious influence acted a 
strong part. Hideyoshi determined to set up a still more imposing effigy in Kyoto, and, in 1586, the work was commenced under the superintendence of Maeda Gen-i. All the principal idol-makers were summoned to the capital, and among them were said to have been some Chinese experts. Hideyoshi declared that whereas the Nara Daibutsu had taken twenty-seven years to build, the Kyōto image should be finished in five. He kept his word. No less than twenty-one provinces were placed under requisition for labour and materials. The enclosure of the temple containing the image measured 260 yards by 274 , and the great hall had dimensions of 110 yards by 74 .

The original intention had been to make the idol of copper; but as the statue was to have a height of 160 feet, the quantity of metal required could not have been obtained within the time fixed, and lacquered wood was therefore substituted for copper. It is related that timbers of sufficient scantling could not be found anywhere except in the forests at the base of Fuji-yama, and Ieyasu employed fifty thousand labourers at a cost of a one thousand ryo in gold, for the purpose of felling the trees and transporting them to Kyoto. The operations furnished evidence of the curiously arbitrary methods practised officially in that age. Thus, when the building was interrupted owing to a lack of large stones for constructing the pedestal, messengers were sent to appropriate rocks standing in private gardens, without consulting the convenience of the owners, and many beautiful parks were thus deprived of their most picturesque elements. Moreover, on the plea of obtaining iron to make nails, elamps, and so forth, a proclamation was issued ealling upon the civilian section of the population at large to throw their swords, their spears, their muskets, and their armour into the melting-pot. This proclamation, though couched in terms of simulated benevolence, amounted in reality to a peremptory order. The people were told that they only wasted their substance and were impeded in the payment of their taxes by spending money upon weapons of war, whereas by giving these for a religious purpose, they would invoke the blessings of heaven and promote their own prospcrity. But, at the foot of these specious arguments, there was placed a brief command that the weapons must be surrendered and that those concerned should take due note of their duty in the matter. The import of such an injunction was not lost on the people, and general disarming of the agricultural and the artisan elasses marked the success of Hideyoshi's policy. It is on record that he himself actually joined in the manual labour of dragging stones and timbers into position, and that, clad in hempen garments, he led the labourers' chorus of "Kiyari.":

\section{THE JURAKU-TEI}

In the year 1586, the Emperor Ōkimachi resigned the throne to his grandson, Go-Yozzei. Like Nobunaga, Hideyoshi was essentially loyal to the Imperial Court. He not only provided for the renovation of the shrines of Ise, but also built a palace for the retiring Emperor's use. On the 11th of the seventh month of 1585 , he was appointed regant (kwampaku), and on the 13th of the same month he proceeded to the Court to render thanks. He himself, however, was without a residence in the capital, and to remedy that deficiency he built a palace called Juraku-tei (Mansion of Pleasure) which, according to the accounts transmitted by historians, was an edifice of exceptional magnificence. Thus, the Taikoki (Annals of the Taikō) speak of "gates guarded by iron pillars and copper doors; of high towers which shone like stars in the sky; of roof-tiles 
which roared in the wind, and of golden dragons which sang songs among the clouds." Nothing now remains of all this grandeur except some of the gates and other decorative parts of the structure, which were given to the builders of the temples of Hongwan-ji after the destruction of the Juraku-tei when Hidetsugu and his whole family died under the sword as traitors. There can be no doubt, however, that the edifice represented every possible feature of magnificence and refinement characteristic of the era.

Hideyoshi took up his abode there in 1587, and at the ensuing New Year's festival he prayed to be honoured by a visit from the Emperor. This request was complied with during the month of May in the same year. All the details of the ceremony were ordered in conformity with precedents set in the times of the Ashikaga shöguns, Yoshimitsu and Yoshimasa, but the greatly superior resources of Hideyoshi were enlisted to give éclat to the fête. The ceremonies were spread over five days. 'They included singing, dancing, couplet composing, and present giving. The last was on a scale of unprecedented dimensions. The presents to the Imperial household and to the Court Nobles varied from three hundred koku of rice to 5530 ryo of silver, and in the case of the Court ladies, the lowest was fifty koku and the highest three hundred.

The occasion was utilized by Hideyoshi for an important ceremony, which amounted to a public recognition of his own supremacy. A written oath was signed and sealed by six great barons, of whom the first four represented the Toyotomi (Hideyoshi's) family and the last two were Ieyasu and Nobukatsu. The signatories of this oath solemnly bound themselves to respect eternally the estates and possessions of the members of the Imperial house, of the Court nobles, and of the Imperial princes, and further to obey faithfully all commands issued by the regent. This obligation was guaranteed by invoking the curse of all the guardian deities of the empire on the head of anyone violating the engagement. A similar solemn pledge in writing was signed by twenty-two of the great military barons.

\section{THE KITANO FÊTE}

The esoterics of the tea ceremonial and the vogue it obtained in the days of the shogun Yoshimasa, have already been described. But note must be taken here of the extraordinary zeal displayed by Hideyoshi in this matter. Some claim that his motive was mainly political; others that he was influenced by purêly esthetic sentiments, and others, again, that both feelings were responsible in an equal degree. There is no material for an exact analysis. He doubtless appreciated the point of view of the historian who wrote that "between flogging a war-steed along the way to death and discussing esthetic canons over a cup of tea in a little chamber nine feet square, there was a radical difference." But it must also have appealed keenly to his fancy that he, a veritable upstart, by birth a plebeian and by habit a soldier, should ultimately set the lead in artistic fashions to the greatest aristocrats in the empire in a cult essentially pacific.

However these things may have been, the fact remains that on the 1st of November, 1587, there was organized by his orders on the Pine Plain (Matsubara) of Kitano a cha-no-yu fête of unprecedented magnitude. The date of the fête was placarded in Kyōto, Nara, Ōsaka, Sakai, and other towns of importance more than a month in advance; all lovers of the tea cult were invited, whether plebeian or patrician, whether rich or poor; frugality was enjoined, and the proclamations promised that the choicest among the objects of art collected by Hideyoshi during many decades should be exhibited. It is recorded that 
over 360 persons attended the fête. Some erected simple edifices under the pine trees; some set up a monster umbrella for a roof, and some brought portable pavilions. These various edifices are said to have occupied a space of isix square miles. Three pavilions were devoted to Hideyoshi's art-objects, and he himself served tea and exhibited his esthetic treasures to Ieyasu, Nobukatsu, Toshiiye, and other distinguished personages.

\section{HIDEYOSHI'S LARGESSE}

Hideyoshi's love of ostentation when political ends could be served thereby was strikingly illustrated by a colossal distribution of gold and silver. One morning in June, 1589 , the space within the main gate of the Juraku palace was seen to be occupied throughout a length of nearly three hundred yards with gold and silver coins heaped up on trays each containing one hundred and fifty pieces. Immediately within the gate sat Hideyoshi, and beside him was the Emperor's younger brother, Prince Roku. The mass of glittering treasure was guarded by officials under the superintendence of Maeda Gen-i, and presently the names of the personages who were to be recipients of Hideyoshi's largesse were read aloud, whereupon each of those indicated advanced and received a varying number of the precious trays. The members of Hideyoshi's family. were specially favoured in this distribution. His mother received 3000 ryō of gold and 10,000 ryo of silver; his brother, Hidenaga, 3000 ryo of gold and 20,000 of silver; and his nephew, Hidetsugu, 3000 of gold and 10,000 of silver. To Nobukatsu, to Ieyasu, to Mōri Terumoto, to Uesugi Kagekatsu, and to Maeda Toshiiye, great sums were given; varying from 3000 ryo of gold and 10,000 of silver to 1000 of gold and 10,000 of silver. It is said that the total of the coins thus bestowed amounted to 365,000 ryō, a vast sum in that era. A history of the time observes that the chief recipients of Hideyoshi's generosity . were the members of his own family, and that he would have shown better taste had he made these donations privately. Perhaps the deepest impression produced by this grand display was a sense of the vast treasure amassed by Hideyoshi; and possibly he contemplated something of the kind.

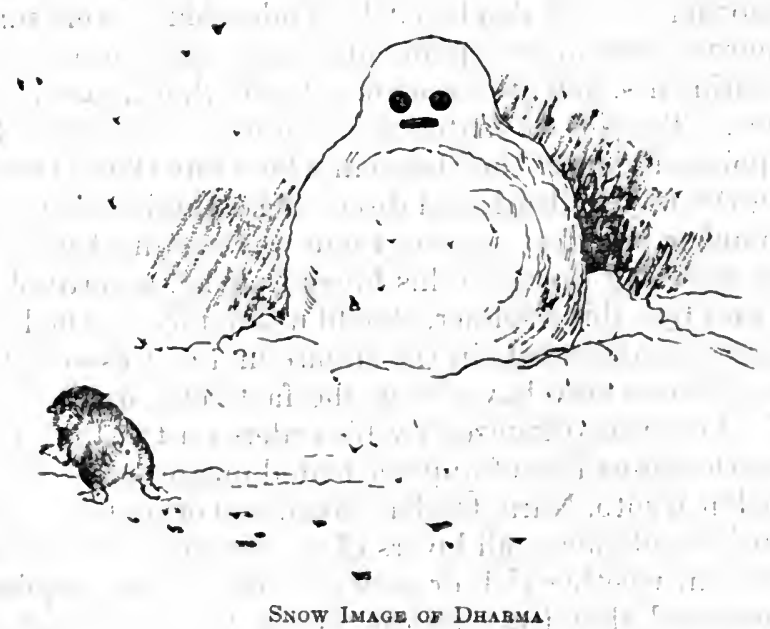




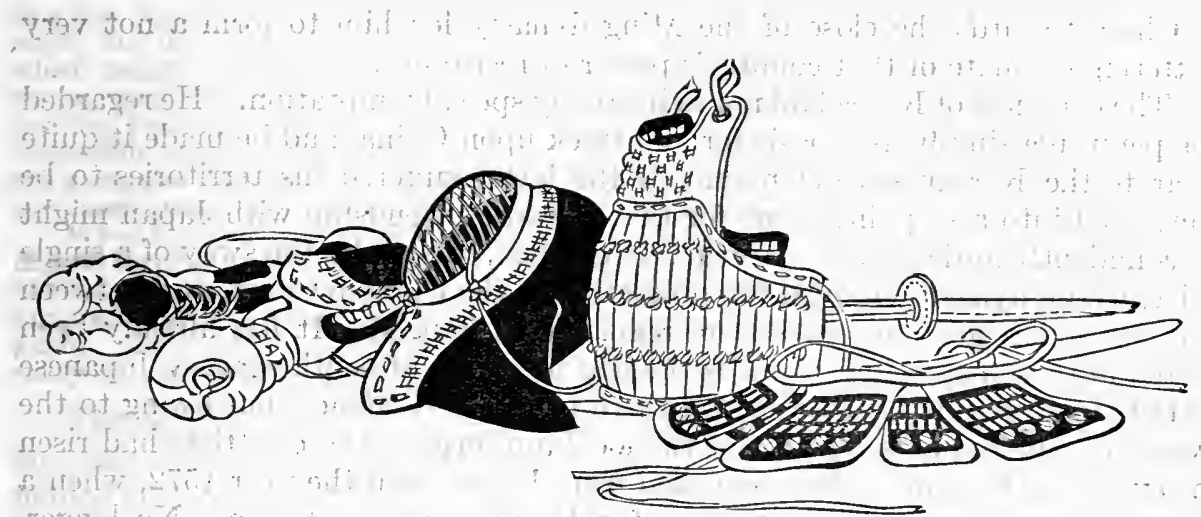

A Fencing Outfit

\section{CHAPTER XXXV}

\section{THE INVASION OF KOREA}

\section{CAUSES}

Having brought the whole of Japan under his control, Hideyoshi conceived the project of conquering China. That appears to be the simplest explanation of his action. His motive, however, has been variously interpreted. Some historians maintain that his prime purpose was to find occupation for the vast host of soldiers who had been called into existence in Japan by four centuries of almost continuous warfare. Others do not hesitate to allege that this oversea campaign was designed for the purpose of assisting to exterminate the Christian converts. Others, again, attempt to prove that personal ambition was Hideyoshi's sole incentive. It does not seem necessary to estimate the relative truth of these analyses, especially as the evidence adduced by their several supporters is more or less conjectural. As to the idea that Hideyoshi was influenced by anti-Christian sentiment, it is sufficient to observe that out of nearly a quarter of a million of Japanese soldiers who landed in Korea during the course of the campaign, not so much as ten per cent. were Christians, and with regard to the question of personal ambition, it may be conceded at once that if Hideyoshi's character lays him open to such a charge, his well-proven statecraft exonerates him from any suspicion of having acted without thought for his country's good.

One fact which does not seem to have been sufficiently considered by annalists is that during the sixteenth century the taste for foreign adventure had grown largely in Japan. Many persons had gone abroad in quest of fortune and had found it. It is on record that emigrants from the province of Hizen had established themselves in considerable numbers in China, and that their success induced their feudal lord; Nabeshima, to seek the Central Government's permission for returning his province to the latter and taking; in lieu, the district near Ningpo, where his vassals had settled. Hideyoshi doubtless shared the general belief that in oversea countries Japanese enterprise could find many profitable opportunities, and it is easy to believe that the weakened condition 
of China towards the close of the Ming dynasty led him to form a not very flattering estimate of that country's power of resistanee.

The conquest of Korea had not in itself any special temptation. He regarded the peninsula simply as a basis for an attack upon China, and he made it quite clear to the Korean sovereign that, if the latter suffered his territories to be converted into a stepping-stone for that purpose, friendship with Japan might be confidently anticipated. Korea, at that time, was under the sway of a single ruler, whose dynasty enjoyed the protection of the Chinese Court, and between the two sovereigns embassies were regularly exchanged. It has already been stated in these pages that towards the middle of the fifteenth century Japanese settlers in Korea had been assigned three places of residence, but owing to the exactions suffered at the hands of the local authorities, these settlers had risen in revolt and had finally been expelled from Korea until the year 1572, when a concession was once more set apart for Japanese use at Fusan. No longer, however, were envoys sent from Korea to Japan, and evidence of the outrages committed from time to time by Japanese pirates is furnished by a decree of the Korean Government that a Japanese subject landing anywhere except at Fusan would be treated as a corsair.

Such were the existing conditions when, in '1587, Hideyoshi called upon the Korean monarch to explain the cessation of the old-time custom of exchanging envoys. To this the King of Korea replied that he would willingly renew the ancient relations provided that the Japanese authorities seized and handed over a number of Korean renegades, who had been acting as guides to Japanese pirates in descents on the Korean coast. This stipulation having been complied with, a Korean embassy was duly despatched by Kyōto, and after some delay its members were received by Hideyoshi in the hall of audience. What happened on this occasion is described in Korean annals, translated as follows by $\mathrm{Mr}$. Aston ${ }^{1}$ :-

The ambassadors were allowed to enter the palace gate borne in their palanquins. They were preceded the whole way by a band of music. They ascended into the hall, where they. performed their obeisances. Hideyoshi is a mean and ignoble-looking man; his complexion is dark, and his features are wanting in distinction. But his'eyeballs send out fire in flashes enough to pierce one through. He sat upon a threefold cushion with his face to the south. He wore a gauze hat and a dark-coloured robe of State. His officers were ranged round him, each in his proper place. When the ambassadors were introduced and had taken their seats, the refreshments offered them were of the most frugal description. A tray was set before each, on which was one dish containing steamed mochi (rice-cake), and sake of an inferior quality was handed round a few times in earthenware eups and in a very unceremonious way. The civility of drinking to one another was not obscrved.

After a short interval, Hideyoshi retired behind a eurtain, but all his officers remained in their places. Soon after, a man came out dressed in ordinary clothes, with a baby in his arms, and strolled about the hall. This was no other than Hideyoshi himself, and everyone present bowed down his head to the ground. Looking out between the pillars of the hall, Hideyoshi espied the Korean musicians. He commanded them to strike up all together as loud as they could, and was listening to their music when he was reminded that babies could despise ceremonies as much as princes, and laughingly called one of his attendants tó take the child and bring him a change of clothing. He seemed to do exactly as he pleased, and was as unconcerned as if nobody else were present. The ambassadors, having made their obeisance, retired, and this audience was the only occasion on which they were admitted to Hideyoshi's presence.

After long delay Hideyoshi replied to the letter carried by the above envoys, and his language is important as clearly indicating the part which he designed for Korea in the pending war. The document is thus translated by Mr. Aston:-

This empire has of late years been brought to ruin by internal dissensions which allowed no opportunity for laying aside armour. This state of things roused me to indignation, and

['Hideyoshi's Invasion of Korea, by Aston: Japan," Vol. VI.]

"Transactions of the Asiatic Society of 
in a few years I restored peace to the country. I am the only remaining scion of a humble stock, but my mother once had a dream in which she saw the sun enter her bosom, after which she gave birth to me. There was then a soothsayer who said: "Wherever the sun shines, there will be no place which shall not be subject to him. It may not be doubted that one day his power will overspread the empire." It has therefore been my boast to lose no favourable opportunity, and taking wings like a dragon, I have subdued the east, chastised the west, punished the south, and smitten the north. Speedy and great success has attended my career, which has been like the rising sun illuminating the whole earth.

When I reflect that the life of man is less than one hundred years, why should I spend my days in sorrow for one thing only? I will assemble a mighty host, and, invading the country of the great Ming, I will fill with the hoar-frost from my sword the whole sky over the four hundred provinces. Should I carry out this purpose, I hope that Korea will be my vanguard. Let her not fail to do so, for my friendship with your honourable country depends solely on your conduct when I lead my army against China.

The Korean envoys entrusted with the delivery of the above despatch were accompanied by one of the chief vassals of the Tsushima baron, and a monk, named Genso, who acted in the capacity of interpreter. By these two Japanese the Korean Government was clearly informed that nothing was required of Korea beyond throwing open the roads to China, and that she would not be asked to give any other assistance whatever in the war against her northern neighbour." In the context of this explanation, the Seoul Government was reminded that, three centuries previously, Korea had permitted her territory to be made a basis of Mongolian operations against Japan, and therefore the peninsula might well allow itself to be now used as a basis of Japanese operations against China. From Korean annals we learn that the following despatch was ultimately sent by the Korean sovereign to Hideyoshi ${ }^{1}$ :-

Two letters have already passed between us, and the matter has been sufficiently discussed. What talk is this of our joining you against China? From the earliest times we have followed law and right: : From within and from without all lands are subject to China. If you have desired to send your envoys to China, how much more should we? When we have been unfortunate she has helped us. The relations which subsist between us are those of parent and child. This you know well. Can we desert both Emperor and parent and join with you? You doubtless: will be angry at this, and it is because you have not been admitted to the Court of China. Why is it that you are not willing to admit the suzerainty of the Emperor, instead of harbouring such hostile intents against him? This truly passes our comprehension.

The bitterness of this language was intensified by a comment made to the Japanese envoys when handing them the above despatch. His Majesty said that Japan's programme of conquering China resembled an attempt to bail out the ocean with a cockle-shell. From Korea's point of view her attitude was perfectly justifiable. The dynasty by which the peninsula was then ruled owed its very existence to China's aid, and during two centuries the peninsula had enjoyed peace and a certain measure of prosperity under that dynasty. On the other. hand, Korea was not in a position to think of resisting Japan on the battle-field. The only army which the former could boast of possessing consisted of men who were too indigent to purchase exemption from service with the colours, and thus she may be said to have been practically without any effcient military. organization. Moreover, her troops were not equipped with either artillery or match-locks. The only advantage which she possessed may be said to have been exceedingly difficult topographical features; which were practically unknown to the Japanese. Japan had not at that time even the elements of the organization which she was ultimately destined to carry to such a high point of perfection. She had no secret-service agents or any cartographers to furnish her generals with information essential to the success of an invasion; and from the moment that her troops landed in Korea, their environment would be absolutely strange. 


\section{JAPAN'S PREPARATIONS}

These considerations did not, however, deter Hideyoshi. Immediately on receipt of the above despatch from the Korean Court, preparations were commenced for an oversea expedition on a colossal scale. Nagoya, in the province of Hizen, was chosen for the home-basis of operations. It has been observed by several critics that if Hideyoshi, instead of moving by Korea, had struck at China direct oversea, he would in all probability have seen his flag waving over Peking in a few months, and the whole history of the Orient would have been altered. That may possibly be true. But we have to remember that the Korean peninsula lies almost within sight of the shores of Japan, whereas to reach China direct by water involves a voyage of several hundred miles over seas proverbially tempestuous and dangerous. Even in modern times, when maritime transport has been so greatly developed, a general might well hesitate between the choice of the Korean and the ocean routes to China from Japan, were he required to make a choice. In the face of the certainty of Korean hostility, however, Hideyoshi's selection was certainly open to criticism. Nevertheless, the event showed that he did not err in his calculations so far as the operations on shore were concerned.

He himself remained in Japan throughout the whole war. He went to Nagoya towards the close of 1592 and stayed there until the beginning of 1594 , and it was generally understood that he intended ultimately to assume direct command of the oversea armies. In fact, at a council held to consider this matter, he proposed to cross the water at the head of one hundred and fifty thousand men, handing over the administration of affairs in Japan to Ieyasu. On that occasion; one of his most trusted followers, Asano Nagamasa, provoked a violent outburst of temper on Hideyoshi's part by declaring that such a scheme would be an act of lunacy, since Hideyoshi's presence alone secured the empire against recurrence of domestic strife. The annals are not very clear at this point, but everything seems to indicate that Hideyoshi's purpose of leading the armies in person would have been carried into practice had it not become certain that the invasion of China would have to be abandoned. The time and the manner in which this failure became clear will be seen as we proceed:

\section{CONDITIONS FROM THE INVADER'S POINT OF VIEW}

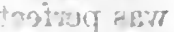

ati hi) 110

The sea which separates Japan from the Korean peninsula narrows on the south to a strait divided by the island of Tsushima into two channels of nearly equal width. Tsushima had, for centuries, been the Japanese outpost in this part of the empire. To reach the island from the Japanese side was always an easy and safe task, but in the fifty-six-mile channel that separates Tsushima from the peninsula of Korea an invading flotilla had to run the risk of an attack by Korean warships. ${ }^{1}$ The army assembled at Nagoya totalled over three hundred thousand men, whereof some seventy thousand constituted the first fighting line and eighty-seven thousand the second, the remainder forming a reserve to meet contingencies. The question of maritime transport presented some difficulty, but was solved by the expedient of ordering each maritime feudatory to furnish two large ships for every hundred thousand koku of the fief's assessment, and their crews were obtained by compelling each fishing village to furnish ten sailors for every hundred houses it contained.: These were not

['See the Encyclopadia Britannica, 11th edition; article "Japan," by Brinkley.] 
fighting vessels but mere transports. Fighting men to the number of ninetytwo hundred were, however, distributed among the ships, and were armed with match-locks, bows, and swords. The problem of commissariat was very formidable. This part of the enterprise was entrusted solely to Asano Nagamasa, minister of Justice, one of the five bugyo,-, that is to say, five officials called administrators, in whose intelligence and competence Hideyoshi placed signal reliance. In the records of the Asano family it is stated that an immense quantity of rice was shipped at the outset, but that on landing in Korea the army found ample supplies of grain in every castle throughout the peninsula. Nevertheless, the problem of provisions ultimately became exceedingly difficult, as might well have been predicted.

\section{PLAN OF CAMPAIGN}

As for the plan of campaign, it was precisely in accord with the principles of modern strategy. The van, consisting of three army corps, was to cross rapidly to Fusan on the south coast of the peninsula, whence a movement northward, towards the capital, Seoul, was to be immediately commenced, one corps marching by the eastern coast-road, one by the central route, and one by the western. "Thereafter the other four corps, which formed the first fighting line, together with the corps under the direct orders of the commander-in-chief, Ukita Hideiye, were to cross for the purpose of effectually subduing the regions through which the van had passed; and, finally, the two remaining corps of the second line were to be transported by sea up the west coast of the peninsula, to form a junction with the van which, by that time, should be preparing to pass into China over the northern boundary of Korea, namely, the Yalu River. For the landing-place of these re-enforcements the town of Pyong-yang was adopted, being easily accessible by the Tadong River from the coast. In later ages, Japanese armies were destined to move twice over these same regions, once to the invasion of China [in 1894]; once to the attack of Russia [in 1904], and they adopted almost the same strategical plan as that mapped out by Hideyoshi in the year 1592. The forecast was that the Koreans would offer their chief resistance, first, at the capital, Seoul; next at Pyong-yang, and finally at the Yalu, as the approaches to all these places constituted positions capable of being utilized to great advantage for defensive purposes." 1 ."

\section{THE MARCH TO SEOUL}

On the 24th of May, 1592, the first army corps (18,700 men), under the command of Konishi Yukinaga, crossed unmolested to the peninsula. So little did the Koreans anticipate an invasion that the earliest intelligence they had of the advent of the invaders was furnished by the commandant of Fusan, who happened that day to be hunting on Deer Island at the entrance to the harbour, and who sighted the approach of the hostile flotilla. On the 25th, Konishi's troops carried the castle of Fusan by storm, after a brave resistance by the garrison, and, on the $27 \mathrm{th}$, the same fate befell another and stronger fortress lying three miles inland and garrisoned by twenty, thousand picked soldiers. Four days after the landing of Konishi's army, the second corps (20,800 strong), under Katō Kiyomasa, reached Fusan, and immediately took the east-coast road, according to the programme of campaign.

[' Encyclopadia Britannica, 11th" edition; article "Japan," by Brinkley.] 
Thenceforth, however, it was really a race between the two armies as to which should form the van. At the pass of Cho-ryung a reunion was effected. This position offered exceptional facilities for defence, but owing to some unexplained reason no attempt was made by the Koreans to hold it. $\mathbf{A}$ few miles further north stood a castle reckoned the strongest fortress in the peninsula. Konishi and Katō continued the combination of their forces as they approached this position, but, contrary to expectation, the Koreans fought in the open and the castle fell without difficulty. Thereafter, the two corps separated; Kato taking the westerly road and Konishi the direct route to Seoul. In short, although the two generals have been accused of crippling themselves by jealous competition, the facts indicate that they co-operated effectively as far as the river Imjin, where a strenuous effort to check them was expected to be made by the Koreans.

From the landing place at Fusan to the gates of Seoul the distance is 267 miles. Konishi's corps covered that interval in nineteen days, storming two forts, carrying two positions, and fighting one pitched battle on the way. Katō's corps, travelling by a circuitous and more arduous road but not meeting with so much resistance, traversed the distance between Fusan and the capital in four days less. At Seoul, with its thirty thousand battlements and three times as many embrasures, requiring a garrison ninety thousand strong, only seven thousand were available, and nothing offered except flight, a course which the Royal Court adopted without hesitation, leaving the city to be looted and partially destroyed, not by the Japanese invaders but by the Korean inhabitants themselves.

The King did not halt until he had placed the Imjin River between himself and the enemy. Moreover, as soon as he there received news of the sack of the city, he renewed his flight northward and took up his quarters at Pyong-yang. It was on the 12th of June that the Korean capital fell, and by the 16 th four army corps had assembled there, while four others had effected a landing at Fusan. After a rest of fifteen days, the northern advance was resumed from Seoul, with the expectation that a great struggle would take place on the banks of the Imjin. The conditions were eminently favourable for defence, inasmuch as the approach to the river from the south was only by one narrow gulch, whereas, on the northern side, lay a long, sandy stretch where troops could easily be deployed. Moreover the Japanese had no boats wherewith to negotiate a broad and swiftly flowing river. During ten days the invaders remained helpless on the southern bank. Then the Koreans allowed themselves to be betrayed by the common device of a simulated retreat. They crossed in exultant pursuit, only to find that they had been trapped into an ambush. Konishi and Katō now again separated, the former continuing the direct advance northward, and the latter taking the northeastern route, which he ultimately followed along the whole of the coast as far as Kyong-sang; whence he turned inland and finally reached Hai-ryong, a place destined to acquire much importance in modern times as the point of junction of the Kilin-Korean railways.

The distance from Seoul to Pyong-yang on the Tadong is 130 miles, and it was traversed by the Japanese in eighteen days, ten of which had been occupied in forcing the passage of the Imjin. On the southern bank of the Tadong, the invaders found themselves in a position even more difficult than that which had confronted them at the Imjin. They had to pass a wide rapid river with a walled city of great strength on its northern bank and with all the boats in the 
possession of the Korean garrison, which was believed to be very numerous. Some parleying took place, and the issue of the situation seemed very doubtful when the Koreans lost patience and crossed the river, hoping to destroy the Japanese by a night attack. They miscalculated the time required for this operation, and daylight compelled them to abandon the enterprise when its only result had been to disclose to the invaders the whereabouts of the fords. Then ensued a disorderly retreat on the part of the Koreans, and there being no. time for the latter to fire the town, storehouses full of grain fell into the hands of the invaders. The Korean Court resumed its flight as far as Wi-ju, a few miles south of the Yalu River, whence messengers were sent to China to solicit succour.

\section{THE COMMAND OF THE SEA}

Thus far, everything had marched in perfect accord with the Japanese programme. A force of nearly two hundred thousand men had been carried over the sea and had overrun practically the whole of Korea. "At this point, however, the invasion suffered a check owing to a cause which in modern times has received much attention, though in Hideyoshi's days it had been little considered; the Japanese lost the command of the sea. The Japanese idea of sea fighting in those times was to use open boats propelled chiefly by oars. They closed as quickly as possible with the enemy and then fell on with the trenchant swords which they used so skilfully. Now, during the fifteenth century and part of the sixteenth, the Chinese had been so harassed by Japanese piratical raids that their inventive genius, quickened by suffering, suggested a device for coping with these formidable adversaries. Once allow the Japanese swordsman to come to close quarters and he carried all before him. To keep him at a distance, then, was the great desideratum, and the Chinese compassed this in maritime warfare by completely covering their boats with roofs of solid timber, so that those within were protected against missiles or other weapons, while loop-holes and ports enabled them to pour bullets and arrows on a foe.

"The Koreans learned this device from the Chinese and were the first to employ it in actual warfare. Their own history alleges that they improved upon the Chinese model by nailing sheet iron over the roofs and sides of the 'turtle-shell' craft and studding the whole surface with chevaux de frise, but Japanese annals indicate that in the great majority of cases timber alone was used. It seems strange that the Japanese should have been without any clear perception of the immense fighting superiority possessed by: such protected war-vessels over small open boats. But certainly they were either ignorant or indifferent. The fleet which they. provided to hold the command of Korean waters did not include one vessel of any magnitude; it consisted simply of some hundreds of row-boats manned by seven thousand men. Hideyoshi himself was perhaps not without misgivings. Six years previously, he had endeavoured to obtain two war-galleons from the Portuguese, and had he succeeded, the history of the Far East might have been radically different. Evidently, however, he committed, a blunder which his countrymen in modern times have conspicuously avoided; he drew the sword without having fully investigated his adversary's resources.

"Just about the time when the van of the Japanese army was entering Seoul, the Korean admiral; Yi Sun-sin, at the head of a fleet of eighty vessels, attacked the Japanese squadron which lay at anchor near the entrance to Fusan harbour, set twenty-six of the vessels on fire, and dispersed the rest. Four other engage- 
ments ensued in rapid succession. The last and most important took place shortly after the Japanese troops had seized Pyong-yang. It resulted in the sinking of over seventy Japanese vessels, transports and fighting ships combined, which formed the main part of a flotilla carrying reinforcements by sea to the van of the invading army. This despatch of troops and supplies by water had been a leading feature of Hideyoshi's plan of campaign, and the destruction of the flotilla to which the duty was entrusted may be said to have sealed the fate of the war by isolating the army in Korea from its home base.

"It is true that Konishi Yukinaga, who commanded the first division, desired to continue his northward march from Pyong-yang without delay. $\mathrm{He}$ argued that China was wholly unprepared, and that the best hope of ultimate victory lay in not giving her time to collect her forces. But the commanderin-chief, Ukita Hideiye, refused to endorse this plan. He took the view that since the Korean provinces were still offering desperate resistance, supplies could not be drawn from them, neither could the troops engaged in subjugating them be freed for service at the front. Therefore it was essential to await the consummation of the second phase of Hideyoshi's plan, namely, the despatch of re-enforcements and munitions by water to Pyong-yang. The reader has seen how that second phase fared. The Japanese commander at Pyong-yang never reeeived any accession of strength. His force suffered constant diminution from casualties, and the question of commissariat became daily more difficult: Japanese historians themselves admit the fact that no wise effort was made to conciliate the Korean people. They were treated so harshly that even the humble peasant took up arms, and thus the peninsula, instead of serving as a basis of supplies, had to be garrisoned perpetually by a strong army." 1 "' "Korean historians give long and minute accounts of the development and exploits of guerilla bands, which, though they did not obtain any signal victory over the invaders, harassed the latter perpetually, and compelled them to devote a large part of their force to guarding the lines of communication.

\section{CHINESE INTERFERENCE}

Having suffered for their loyalty to China, the Koreans naturally looked to her for succour. Peking should have understood the situation thoroughly. Even without any direct communication from Japan; the Peking Court had cognizance of Hideyoshi's intentions. A letter addressed by him in the year 1591 to the King of Ryūkyu stated clearly his intention of extending Japanese sovereignty throughout the whole Orient, and the ruler of Ryūkyū had lost no time in making this fact known to Peking. ${ }^{2}$. Yet it does not appear that the Chinese had any just appreciation of the situation. Their first response to Korea's appeal was to mobilize a force of five thousand men in the Liaotung peninsula, which force crossed the Yalu and moved against Pyong-yang, where the Japanese van had been lying idle for over two months. This occurred early in October, 1592. The ineident illustrated China's confidence in her own superiority. "The whole of the Korean forces had been driven northward throughout

["Encyclopodia Britannica, 11th edition; artiele "Japan," by Brinkley.]

[2 There is still extant a letter addressed by Hideyoshi in June, 1592, to Hidetsugu, his nephew, and then nominal suecessor. In this document it is distinetly stated that the attention of the Emperor of Japan should be directed to the Chinese eapital, inasmuch as the Japanese Court would pay a visit to Peking in 1594, on which occasion the ten provinces surrounding the Chinese capital would be presented to his Majesty, and out of this territory the Court nobles would receive estates.] 
the entire length of the peninsula by Japanese armies, yet Peking considered that five thousand Chinese braves would suffice to roll back this tide of invasion."

The result was a foregone conclusion. Three thousand of the Chinese were killed; and the rest fled pêle-mêle across the Yalu. China now began to be seriously alarmed. She despatched to Pyong-yang an envoy named Chen Weiching - known in Japanese history as Chin Ikei - who was instructed not to conclude peace but only to make such overtures as might induce the Japanese to agree to an armistice, thus enabling the Chinese authorities to mobilize a sufficient force. Konishi Yukinaga fell into this trap. He agreed to an armistice of fifty: days, during which the Japanese pledged themselves not to advance more than three miles northward of Pyong-yang while Chen proceeded to Peking to arrange terms of peace. It is very evident that had the Japanese seen any certain prospect of proceeding to the invasion of China, they would not have agreed to such an arrangement as this - an arrangement which guaranteed nothing except leisure for the mobilization of a strong Chinese army. It had, indeed, become plain to the Japanese commanders, after six months of operations in the peninsula, that the wisest course for them was to arrange a satisfactory peace.

The second force put in the field by China is estimated by the Jesuits and the Japanese at $200 ; 000$ men and at 51,000 by Korean history. Probably the truth lies midway between the two extremes. This powerful army moved across Manchuria in the dead of winter and hurled itself against Pyong-yang during the first week of February, 1593. The Japanese garrison at that place cannot have greatly exceeded twenty thousand men, for nearly one-half of its original number had been detached to hold a line of forts guarding the communications with Seoul. Neither Chinese nor Japanese history comments on the instructive fact that the arrival of this army under the walls of Pyong-yang was China's answer to her envoy's promise of a satisfactory peace, nor does it appear that any discredit attached to Chen Weiching for the deception he had practised; his competence as a negotiator was subsequently'admitted without cavil. The Chinese, though their swords were much inferior to the Japanese weapon, possessed great superiority in field artillery and cavalry, as well as in the fact that their troopers wore iron mail which defied the keenest blade. Thus, after a severe fight which cost the Japanese twenty-three hundred men, they had to evacuate Pyong-yang and retreat towards Seoul, the army under Katō Kiyomasa retiring at the same time from the northeast and fighting its way back to the central route. Orders were then issued by the commander-in-chief, Ukita, for the whole of the Japanese forces in the north of the peninsula to concentrate in Seoul, but Kohayakawa, one of Hideyoshi's most trusted generals, whose name has occurred more than once in these annals, conducted a splendid covering movement at a place a few miles northward of Seoul, the result of which was that the Chinese fled in haste over the Injin, losing ten thousand men in their retreat.

But, though the Japanese had thus shaken off the pursuit, it was impossible for them to continue in occupation of Seoul. The conditions existing there were shocking. Widespread famine menaced, with its usual concomitant, pestilence. According to Korean history, the streets of the city and the roads in the suburbs were piled with corpses to a height of ten feet above the wall. The Japanese, therefore, made proposals of peace, and the Chinese agreed, on condition that the Japanese gave up two Korean princes held captive by them, and retired to the south coast of the peninsula. These terms were accepted, 
and on May 9, 1593; that is to say, 360 days after the landing of the invaders' van at Fusan, the evacuation of the Korean capital took place. The Chinese commanders showed great lack of enterprise. They failed to utilize the situation, and in October of the same year they withdrew from the peninsula all their troops except ten thousand men. Negotiations for permanent peace now commenced between the Governments of Japan and China, but-while the pourparlers were in progress the most sanguinary incident of the whole war.took place. During the early part of the campaign a Japanese attack had been beaten back from Chinju, which was reckoned the strongest fortress in Korea. Hideyoshi now ordered that the Japanese troops, before sailing for home, should rehabilitate their reputation by capturing this place, where the Koreans had mustered a strong army. The order was obeyed. Continuous assaults were delivered against the fortress during the space of nine days, and when it passed into Japanese possession the Koreans are said to have lost between sixty and seventy thousand men and the casualties on the Japanese side must have been almost as numerous.

\section{THE NEGOTIATIONS}

After the fall of Chinju, all the Japanese troops, with the exception of Konishi's corps, were withdrawn from Korea, and the Japanese confined their operations to holding a cordon of twelve fortified camps along the southern coast of the peninsula. These camps were nothing more than bluffs overlooking the sea on the south, and protected on the land side by moats and earthworks. The action at Chinju had created some suspicion as to the integrity of Japan's designs, but mainly through the persistence and tact of the Chinese envoy, Chen Weiching, terms were agreed upon, and on October 21,1596 , a Chinese mission reached Japan and proceeded to Ōsaka. The island had just then been visited by a series of uniquely disastrous earthquakes, which had either overthrown or rendered uninhabitable all the great edifices in and around Kyōto. One corner of Ōsaka Castle alone remained intact, and there the mission was received. Hideyoshi refused to give audience to the Korean members of the mission, and welcomed the Chinese members only, from whom he expected to receive a document placing him on a royal pinnacle at least as high as that occupied by the Emperor of China. The document actually transmitted to him was of a very different significance as the following extract shows:

The Emperor, who respects and obeys heaven and is favoured by Providence, commands that he be honoured and loved wherever the heavens overhang and the earth upbears. The Imperial command is universal; even as far as the bounds of ocean where the sun rises, there are none who do not obey it. In ancient times our Imperial ancestors bestowed their favours on many lands: the Tortoise Knots and the Dragon Writing were sent to the limits of far Japan; the pure alabaster and the great-seal character were granted to the monarchs of the submissive country. Thereafter came billowy times when communications were interrupted, but an auspicious opportunity has now arrived when it has pleased us again to address you: You, Toyotomi Taira Hideyoshi, having established an Island kingdom and knowing the reverence due to the Central Land, sent to the west an envoy, and with gladness and affection offered your allegiance. On the north you knocked at the barrier of ten thousand $l i$, and earnestly requested to be admitted within our dominions. Your mind is already confirmed in reverent submissiveness. How can we grudge our favour to so great meekness? We do, therefore, specially invest you with the dignity of "King of Japan," and to that intent issue this our commission. Treasure it carefully. As a mark of our special favour towards you, we send you over the sea a robe and crown contained in a costly, case, so that you may follow our ancient custom as respects dress. Faithfully defend the frontier of our empire; let it be your study to act worthily of your position as our minister; practice moderation and selfrestraint; cherish gratitude for the Imperial favour so bountifully bestowed upon you; change not your fidelity; be humbly guided by our admonitions; continue always to follow our instruetions. ${ }^{1}$ 
of Hideyoshi had already donned the robe and crown mentioned in the above despatch, his belief being that they represented bis investiture as sovereign of Ming. " On learning the truth, he tore off the insignia and flung them on the ground in a fit of ungovernable wrath at the arrogance of the Chinese Emperor's tone. It had never been distinctly explained. how this extraordinary misunderstanding arose, but the most credible solution of the problem is that Naito, baron of Tamba, who had proceeded to Peking for the purpose of negotiating peace, was so overawed by the majesty and magnificence of the Chinese Court that,' instead of demanding Hideyoshi's investiture as monarch of China, he stated that nothing was needed except China's formal acknowledgement of the kwámpáku's real rank. Hideyoshi, in his natural anger, ordered the Chinese ambassadors to be dismissed without any written answer and without any of the gifts usual on such occasions according to the diplomatic custom of the Orient.

Wo $\mathrm{He}$ was, however, induced not to prosecute his quarrel with the Middle Kingdom, and he turned his anger entirely against Korea. Accordingly, on March 19, 1597, nine fresh corps were mobilized for oversea service, and these being thrown into Korea, brought the Japanese forces in that country to a total of 141,000 men. But the campaign was not at first resumed with activity proportionate to this great army. The Japanese commanders seem to have waited for some practical assurances that the command of the sea would not be again wrested from them; a natural precaution seeing that, after five years' war, Korea herself ${ }^{\text {was no }}$ longer in a position to make any contributions to the commissariat of the invaders. It is a very interesting fact that, on this occasion, the Japanese victories at sea were as signal as their defeats had been in 1592. The.Korean navy comprised the same vessels which were supposed to have proved so formidable five years previously, but the Japanese naval architects had risen to the level of the occasion, and the Korean fleet was well-nigh annihilated.

Meanwhile, the Chinese had sent a powerful army to southern Korea, and against these fresh forces the Japanese attacks were directed. Everywhere the invaders were victorious, and very soon the three southern provinces of the peninsula had been captured. No actual reverse was met with throughout, -but an indecisive victory near Chiksan, in the north of the metropolitan province, rendered it impossible for the Japanese to establish themselves in Seoul before the advent of winter, and they therefore judged it advisable to retire to their seaboard chain of entrenched camps. Early in 1598, a fresh army of forty thousand men reached Seoul from China, and for a moment the situation seemed to threaten disaster for the Japanese. . Their strategy and desperate valour proved invincible, however, and the Kagoshima samurai won, on October 30, 1598 , a victory so signal that the ears and noses of thirty-seven thousand Chinese heads were sent to Japan and buried under a tumulus near the temple of Daibutsu in Kyōto, where this terrible record, called Mimizuka (Mound of Ears), may be seen to-day.

Just about this time, intelligence of the death of Hideyoshi reached the Japanese commanders in Korea, and immediately an armistice was arranged. The withdrawal of the invading forces followed, not without some serious difficulties, and thus the six years' campaign terminated without any direct results except an immense loss of life and treasure and the reduction of the Korean peninsula to a state of desolation. It has been repeatedly pleaded that the ravages wrought by Hideyoshi's armies during this war amply account 
for the wholly unprogressive state into which Korea thenceforth fell. But to conclude that a nation could be reduced by a six-years' war to three centuries of hopelessness and helplessness is to credit that nation with a very small measure of resilient capacity.

\section{INDIRECT RESULTS}

The war was not altogether without indirect results of some value to Japan: Among these may be cited the fact that, a few decades later, when the Tsing dynasty destroyed the Ming in China, subjugated Korea, and assumed a position analogous to that previously held by the Yuan, no attempt was made to defy. Japan. The memory of her soldiers' achievements on the Korean battle-fields sufficed to protect her against foreign aggression. Another material-result was that, in compliance with Hideyoshi's orders, the returning Japanese generals brought back many Korean art-artisans who contributed largely to the develop' ment of the ceramic industry. On no less than seven different kinds of now well-known porcelain and pottery in Japan did these experts exercise marked influence, and their efforts were specially timely in view of the great vogue,then enjoyed by all utensils used in connexion with the tea ceremonial. It is not to be supposed, however, that these Korean artisans showed any superiority to the Japanese as artists. The improvements they introduced were almost entirely of a technical character. Another benefit: derived by Japan from her contact with Korea at this time was the introduction of movable type. Up to this time the art of printing had been in a very primitive condition in Japan, and the first book printed with movable type made its appearance in the Bunroku era (1592-1595).

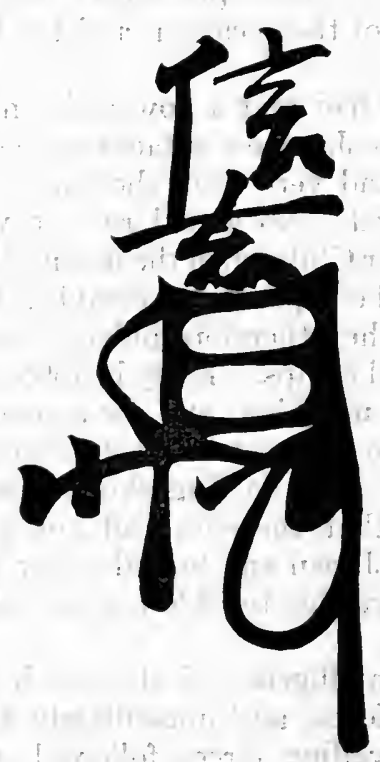

एकता 


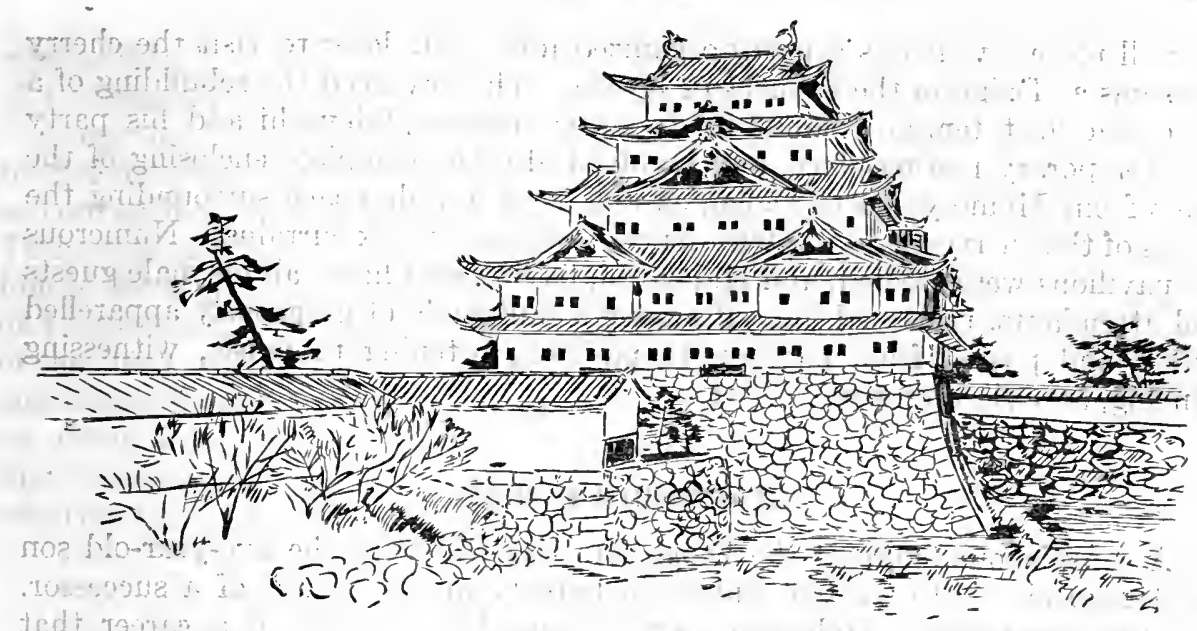

Nagoya Castle

\section{CHAPTER XXXVI}

\section{THE MOMO-YAMA EPOCH}

\section{MOMO-YAMA}

THE epochs of Japanese history from the eighth century until the fall of the Ashikaga shogunate are generally divided into the Nara, the Heian, the Kamakura, the Muromachi, and the Higashi-yama. To these has now to be added the Momo-yama (Peach Hill), a term derived from the name of a palatial residence built by Hideyoshi in the Fushimi suburb of Kyoto. The project was conceived in 1593, that is to say, during the course of the Korean campaign, and the business of collecting materials was managed on such a colossal scale that the foundations could be laid by September in the same year. Two months sufficed not only to construct a mansion of extraordinary magnificence and most elaborate interior decoration, but also to surrourd it with a spacious park presenting all the choicest features of Japanese landscape gardens. The annals state that fifty thousand men were engaged on the work, and the assertion ceases to seem extravagant when we consider the nature of the task and the singularly brief period devoted to its completion. It was Hideyoshi's foible to surpass all his predecessors and contemporaries alike in the magnitude of his designs and in the celerity of their achievement. Even his pastimes were conceived on the same stupendous scale. Thus, in 1594, at the very time when his armies in Korea were conducting an oversea campaign of unprecedented magnitude, he planned a flower-viewing fête which will live in the pages of history as more sumptuous and more magnificent than the hitherto unrivalled festivities of Yoshimasa. The places visited were the cherry-clad hills of Yoshino and the venerable monastery of Koya, and some idea of the scale of the fête may be gathered from the fact that to a shrine on Koya-san, dedicated to the memory of his mother, Hideyoshi presented a sum equivalent to $£ 14,000$ or $\$ 68,000$. 
Still more lavish was a party organized four years later to visit the cherry blossoms at Daigo in the suburbs of Kyöto. This involved the rebuilding of a large Buddhist temple (Sambō-in) to aceommodate Hideyoshi and his party as a temporary resting-place, and involved also the complete enelosing of the roads from Momo-yama to Daigo, as well as of a wide space surrounding the slopes of the cherry-elad hills, with fences festooned in silk curtains. Numerous tea pavilions were erected, and Hideyoshi, having sent home all his male guests and attendants, remained himself among a multitude of gorgeously apparelled ladies, and passed from pavilion to pavilion, listening to music, witnessing dancing, and viewing works of art.

\section{HIDEYOSHI'S FAMILY}

A conspicuous figure at the Daigo fête was Hideyori, the five-year-old son of Hideyoshi. Fate treated Hideyoshi harshly in the matter of a successor. His younger brother, Hidenaga, perished on the threshold of a career that promised to be illustrious; his infant son, Tsurumatsu, passed away in September, 1591 , and Hideyoshi, being then in his fifty-fourth year, saw little prospect of becoming again a father. He therefore adopted his nephew, Hidetsugu, ceding to him the office of regent (kwampaku), and thus himself taking the title of Taiko, which by usage attached to an ex-regent. ${ }^{1}$ Hidetsugu, then in his twentyfourth year, had literary gifts and polite accomplishments much above the average. But traditions - of somewhat doubtful veracity, it must be admitted - attributed to him an inhuman love of taking life, and tell of the indulgenee of that mood in shocking ways. On the other hand, if credence be due to these tales, it seems strange that they were not included in the accusations preferred finally against Hidetsugu by the Taik $\bar{o}$, when the former's overthrow became advisable in the latter's eyes. For it did so become. Within less than two years of Hidetsugu's elevation to the post of regent, another son was born to Hideyoshi by the same lady, Yodo, the demise of whose child, Tsurumatsu, had caused Hideyoshi to despair of being succeeded by an heir of his own lineage. A niece of Oda Nobunaga, this lady was the eldest of three daughters whose mother shared the suicide of her husband, the great general, Shibata Katsuiye. Hideyoshi placed her among his consorts, bestowing upon her the castle of Yodo, hence her name, Yodogimi. Her rare beauty captivated the veteran statesman and soldier, and won for her suggestions a measure of deferenee which they did not intrinsically deserve. Soon the court became divided into two cliques, distinguished as the "civil" and the "military." At the head of the latter stood Hideyoshi's wife, Yae, a lady gifted with large discernment, who had shared all the vicissitudes of her husband's fortunes, and acted as his shrewd and loyal adviser on many occasions. With her were Katō Kiyomasa and other generals and nobles of distinction. The civil party espoused the cause of the lady Yodo, and among its followers was Ishida Katsushige, to whom chiefly the ultimate catastrophe is attributed by history.

The birth of Hideyori on August 29, 1593, immediately actuated the dissensions among these two cliques. Ishida Katsushige, acting in Hideyori's interests, set himself to convince the Taikō that Hidetsugu harboured treacherous designs, and Hideyoshi, too readily allowing himself to credit tales which promised to remove the one obstacle to his son's suecession, ordered Hidetsugu to eommit suicide, and at the same time (August 8,1595 ), sentenced his concubines to be

[' It is by this title, "Taiko," that Hideyoshi is most frequently spoken of in History.] 
executed in the dry bed of the river Sanjō. Their heads, together with that of Hidetsugu himself, were buried in the same grave, over which was set a tablet bearing the inscription, "Tomb of the Traitor, Hidetsugu." To this day, historians remain uncertain as to Hidetsugu's guilt. If the evidence sufficed to convict him, it does not appear to have been transmitted to posterity. The Taikō was not by nature a cruel man. Occasionally fits of passion betrayed him to deeds of great violence. Thus, on one occasion he ordered the crucifixion of twenty youths whose sole offence consisted in scribbling on the gate-posts of the Juraku palace. But in cold blood he always showed himself forebearing, and letters written by his own hand to his mother, his wife, and others disclose an affectionate and sympathetic disposition. It would be unjust to assume that without full testimony such a man sentenced a whole family of his own relatives to be executed.

\section{HIDEYOSHI'S DEATH}

A few months after the Daigo fête, Hideyoshi was overtaken by mortal sickness. His last days were tormented by the thought that all his skill as an organizer and all his power as a ruler were incompetent to devise a system such as would secure the succession to his child. In June, 1596, he had procured the investiture of Hideyori, then three years old, with the title of regent, and when, just two years later, his own sickness began to develop alarming features, he resolved to place all his trust in Ieyasu. After much thought. three boards were ordered to be formed: one consisted of five "senior ministers" (dairōo), its personnel being Tokugawa Ieyasu, Mōri Terumoto; Ukita Hideiye, Maeda Toshiiye, and Uesugi Kagekatsu. By these five statesmen the great affairs of the empire were to be managed. The second board was formed with three nobles of lesser note. They were designated the "middle ministers" (chürō), "whose duty was to arbitrate between the board of senior ministers and the third board, namely that of five "administrators" (bugyō). This third board had been originally organized by Hideyoshi

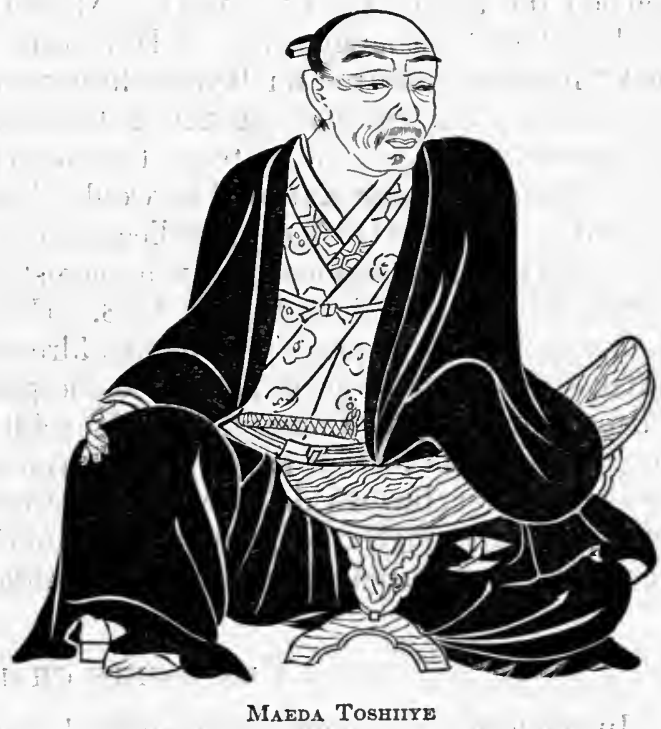
in 1585 , but it had not, of course, been associated with the other two boards which came into existence after Hideyoshi's death, though its personnel and its functions remained throughout the same as they had been originally. Again and again, with almost pitiable iteration, the Taiko conjured the thirteen nobles forming these boards to protect Hideyori and to ensure to him the heirship of his father's great fortunes. Each was required to subscribe a written oath of eight articles:-

(1) That they would serve Hideyori with the same single-minded loyalty they had shown to his father. 
(2) That the rules of Hideyoshi's house were not to be altered; and that if, in the administration of public affairs, the five bugyo were unable to determine a course of action, they shoild eonsult Hideyori through Ieyasu and Toshiie; or, if neessary before taking action, the Emperor was to be consulted.

(3) That there were to be no factions among them, personal considerations and partiality of every kind being excluded from their councils.

(4). That they must endeavour to work together in the discharge of their duties, suppressing all petty jealousies and differenees.

(5) That, in settling matters, the opinion of the majority was usually to be followed, but, at the same time, if the opinion of the minority showed no sign of being dietated by personal interests, it should be duly considered. That without permission from-Hideyori no administrator should dispose of any of his (the administrator's) territory to another person.

(6) That all accounts were to be kept in a manner above suspicion; that there were to be no irregularities and 'no pursuing of personal interests; that no questions concerning landed estates should be dealt with during the minority of Hideyori; that no petitions should be presented to him, and that leyasu himself would neither ask for changes to be made in the matter of land-ownership nor aceept any gift of land from 'Hideyori during the latter's minority.

(7) That whatever Hideyori desired to have kept secret, whether eonnected with his private life or with the Government, must on' no account be allowed to leak out.

(8) That if any of the administrators or their subordinates found that they had unwittingly acted contrary to orders, they should at once report the fact to their superiors, who would then deal leniently with them.

The above document was solemnly endorsed, the gods being called upon to punish any one violating its provisions. It was further ordered that Hidetada, son of Ieyasu, should give his daughter in marriage to Hideyori; that Ieyasu, residing in the Fushimi palace, should act as regent until Hideyori reached the age of fifteen, and that Maeda Toshiiye, governing the castle of Ōsaka, should act as guardian of Hideyori. 'It is recorded by some historians that the taiko conferred on Ieyasu diseretionary power in the matter of Hideyori's succession, authorizing the Tokugawa baron to be guided by his own estimate of Hideyori's character as to whether the latter might be safely trusted to diseharge the high duties that would devolve on him when he reached his majority. But the truth of this allegation is open to doubt. It may well have been invented, subsequently, by apologists for the line adopted by Icyasu. Hideyoshi died on September 18, 1598. His last thoughts were directed to the troops in Korea. He is said to have addressed to Asano Nagamasa and Ishida Katsushige orders to go in person to the peninsula, and to provide that "the spirits of one hundred thousand Japanese soldiers serving there should not become disembodied in a foreign land." For a time the death of the great statesman was kept secret, but within three months the newly created boards found themselves strong enough to cope with the situation, and the remains of Hideyoshi were publicly interred at the shrine of Amida-ga-mine, near Kyōto.

\section{HIDEYOSHI'S CHARACTER}

In modern times many distinguished Japanese historians have undertaken to analyze Hideyoshi's character and attainments. They are divided in their estimate of his literary capacity. Some point to his letters, which, while they display a not inconsiderable familiarity with Chinese ideographs, show also some flagrant neglect of the uses of that script. Others refer to his alleged fondness for composing Japanese poems and adduce a verselet said to have been written by him on his death-bed: 
It is not certain, however, that Hideyoshi composed this couplet, and probably the truth is that his labours as a soldier and a statesman prevented him from paying more than transitory attention to literature. But there can be no question that he possessed an almost marvellous power of reading character, and that in devising the best exit from serious dilemmas and the wisest means of utilizing great occasions, he has had few equals in the history of the world. He knew well, also, how to employ pomp and circumstance and when to dispense with all formalities. Above all, in his choice of agents he never allowed himself to be trammelled by questions of birth or lineage, but chose his officers solely for the sake of their ability and attainments, and neither tradition nor convention had any influence on the appointments he made. He was passionate but not resentful, and he possessed the noble quality of not shrinking from confession of error. As for his military genius and his statecraft, it is only necessary to consider his achievements. They entitle him to stand in the very front of the world's greatest men. Turning to his legislation, we find much that illustrates the ethics of the time. It was in 1585 that he organized the board of five administrators, and the gist of the regulations issued in the following year for their guidance was as follows:-

(1) No subordinate shall leave his liege lord without the latter's permission, nor shall anyone give employment to a violator of this rule.

(2) Farmers must remain on the land assigned to them and must never leave it untilled. On the other hand, landowners should visit their tenants and should investigate in company with the latter the actual amount of the harvest reaped. One-third of this should be left to the farmer and two-thirds should go to the owner of the land.

(3) If owing to natural ealamity the harvest be less than two bushels per acre, the whole of the yield shall go to the farmer. But if the harvest exceed that figure, it shall be divided in the proportions indicated in (2).

(4) No farmer shall move away from his' holding to avoid the land-tax or to escape forced labour. Anyone harbouring a violator of this rule shall expose to punishment not only himself but also the inhabitants of the entire village where he resides.

(5) The lord of a fief must issue such instructions as shall guarantee his agricultural vassals against trouble or annoyance, and shall himself investigate local affairs instead of entrusting that duty to a substitute. Landowners who issue unreasonable orders to farmers shall be punished.

(6) In calculating cubic contents, the regulated unit of measure shall be used, and two per cent. shall be the maximum allowance for shortage.

(7) Embankments injured by floods and other mischief wrought by natural calamities must be repaired during the first month of the year when agriculturists are at leisure. In the case, however, of damage which exceeds the farmers' capacity to repair, the facts should be reported to the taiko who will grant necessary assistance.

There follow various sumptuary regulations. We have next a series of interesting instructions known as "wall-writings" of the castle of Ōsaka:- -

(1) Intermarriages between daimyō's families require the previous consent of the Taikō.

(2) Neither daimyō nor shōmyō is permitted to enter into secret engagements or to exchange written oaths, or to give or take hostages.

(3) In a quarrel the one who forebears shall be recognized as having reason.

(4) No man, whatever his income, should keep a large number of concubines.

(5) The amount of sake imbibed should be limited to one's capacity.

(6) The use of sedan-chairs shall be confined to Ieyasu, Toshiie, Kagekatsu, Terumoto, Takakage, the court nobles, and high priests. Even a daimyō, when young, should ride on horseback. Those over fifty years of age may use a sedan-chair when they have to travel a distance of over one $r i$ (two and a half miles). Priests are exempted from this veto.

Very interesting, too, is the Taiko Shikimoku, consisting of seventy-three articles, of which thirteen are translated as follows: -

(1) Free yourself from the thraldom of passion.

(2). Avoid heavy drinking.

(3) Be on your guard against women.

(4) Be not contentious or disputatious. 
(5) Rise early.

(6) Beware of practical jokes.

(7) Think of your own future.

(8) Do not tire of things.

(9) Beware of thoughtless people.

(10) Beware of fire.

(11) Stand in awe of the law.

(12) Set up fences in your hearts against wandering or extravagant thoughts.

(13) Hold nobody in contempt.

The sumptuary rules referred to above were that, so far as a man's means permitted, all garments except those worn in winter should be lined with silk, and that this exception did not apply to the members of the Toyotomi family a strange provision showing that Hideyoshi did not expect his own kith and kin to set an example of economy, however desirable that virtue might be in the case of society at large. Further, it was provided that no wadded garment should be worn after the 1st of April-corresponding to about the 1st of May in the Gregorian calendar; that pantaloons and socks must not be lined; that men of inferior position must not wear leather socks, and that samurai must use only half-foot sandals, a specially inexpensive kind of footgear. Finally, no one was permitted to employ a crest composed with the chrysanthemum and the Paulownia imperialis unless specially permitted by the Taikō, who used this design himself, though originally it was limited to the members of the Imperial family. So strict was this injunction that even in the case of renovating a garment which carried the kiku-kiri crest by permission, the badge might not be repeated on the restored garment. Supplementary regulations enjoined members of the priesthood, whether Buddhist or Shinto, to devote themselves to the study of literature and science, and to practise what they preached. Moreover, men of small means were urged not to keep more than one concubine, and to assign for even this one a separate house. It was strictly forbidden that anyone should go about with face concealed, a custom which had prevailed largely in previous eras.

\section{MOTIVES OF LEGISLATION}

The 7th of August, 1595, was the day of the Hidetsugu tragedy, and the above regulations and instructions were promulgated for the most part early in September of the same year. It is not difficult to trace a connexion. The provision against secret alliances and unsanctioned marriages between great familics; the veto against passing from the service of one feudal chief to that of another without special permission, and the injunction against keeping many concubines were obviously inspired with the purpose of averting a repetition of the Hidetsugu catastrophe. Indirectly, the spirit of such legislation suggests that the signatories of these laws - Takakage, Terumoto, Toshiiye, Hideiye, and Ieyasu - attached some measure of credence to the indictment of treason preferred against Hidetsugu.

\section{AGRARIAN LAWS}

The agrarian legislation of Hideyoshi is worthy of special attention. It shows a marked departure from the days when the unit of rice measurement was a "handful" and when thirty-six handfuls made a "sheaf," the latter being the tenth part of the produce of a tan. In Hideyoshi's system, all cubic measurements were made by means of a box of accurately fixed capacity - 
$10 \mathrm{~g} \overline{0}$, which was the tenth part of a koku (5.13 bushels) - the allowance for short measure was limited to two per cent., and the rule of 360 tsubo to the tan (a quarter of an acre) was changed to 300 tsubo.

At the same time (1583), land surveyors (kendenshi) were appointed to compile a map of the entire country. A similar step had been taken by the Ashikaga shōgun, Yoshiteru, in 1553, but the processes adopted on that occasion were not by any means so accurate or scientific as those prescribed by the Taiko. The latter entrusted the work of survey to Nazuka Masaiye, with whom was associated the best mathematician of the era, Zejōbō, and it is recorded that owing to the minute measures pursued by these surveyors and to the system of taking two-thirds of the produce for the landlord instead of one-half or even less, and owing, finally, to estimating the tan at 300 tsubo instead of at 360 without altering its taxable liability, the official revenue derived from the land throughout the empire showed a total increase of eight million koku, equivalent to about $£ 11,000,000$ or $\$ 54,000,000$.

fry Hideyoshi has been charged with extortion on account of these innovations. Certainly, there is a striking contrast between the system of Tenchi and that of Toyotomi. The former, genuinely socialistic, divided the whole of the land throughout the empire in equal portions among the units of the nation, and imposed a land-tax not in any case exceeding five per cent. of the gross produce. The latter, frankly feudalistic, parcelled out the land into great estates held by feudal chiefs, who allotted it in small areas to farmers on condition that the latter paid sixty-six per cent. of the crops to the lord of the soil. But in justice to Hideyoshi, it must be owned that he did not devise this system. He was not even the originator of its new methods, namely, the abbreviation of the tan and the expansion of the rate. Both had already been put into practice by other daimy $\overline{0}$. It must further be noted that Hideyoshi's era was essentially one of war. The outlays that he was obliged to make were enormous and perpetual. $\mathrm{He}$ became accustomed, as did his contemporary barons, to look lightly at vast expenditure. Not otherwise can we account for the fact that, within the brief period of eleven years, he undertook and completed five great works involving enormous cost. These works were the Ōsaka Castle, in 1583; a palace for the retiring Emperor Ōkimachi, in 1586; the palace of Juraku, in 1587; the Kyōto Daibutsu, in 1586, and the Momo-yama Palace, in 1594. What sum these outlays aggregated no attempt has been made to calculate accurately, but the figure must have been immense. In fact, when Hideyoshi's financial measures are considered, it should always be in the context of his achievements and his necessities.

\section{COINS}

Another important feature of Hideyoshi's era was the use of coins. During the time of the Ashikaga shōgunate, two kinds of gold coins were minted, and both were called after the name of the era when they first went into circulation; they were known as the Shōchō koban (1428-1429) and the Tembun koban (15321555). . But these coins were so rare that they can scarcely be said to have been current. As tokens of exchange, copper coins were imported from China, and were known in Japan as Eiraku-sen, Eiraku being the Japanese pronunciation of the Chinese era, Yunglo. These were of pure metal, and side by side with them were circulated an essentially inferior iron coin struck in Japan and known as bita-sen. Oda Nobunaga, appreciating the disastrous effects produced by such currency confusion, had planned remedial measures when death overtook 
him, and the task thus devolved upon Hideyoshi. Fortunately, the production of gold and silver in Japan increased greatly at this epoch, owing to theintroduction of scientific metallurgical methods from Europe. The gold mines of Sado and the silver mines of Ikuno quadrupled or quintupled their output, and Hideyoshi caused an unprecedented quantity of gold and silver coins to be struck; the former known as the Tenshō koban and the Tensho óban, and the latter as the silver $b u$ (ichibu-gin) and the silver half-bu (nishu-gin.)

Gold and silver thenceforth became the standards of value, and as the mines at Sado and Ikuno belonged to the Government, that is to say, to Hideyoshi; his wealth suddenly received a conspicuous increase. That he did possess great riches is proved by the fact that when, in September, 1596, a terrible earthquake overthrew Momo-yama Castle and wrecked all the great structures referred to above, involving for Hideyoshi a loss of "three million pieces of gold," he is described as having treated the incident with the utmost indifference, merely directing that works of reparation should be taken in hand forthwith. The records say that Ōsaka Castle, which had suffered seriously: and been rendered quite uninhabitable, was put in order and sumptuously fitted up within the short space of six weeks. Of course, much of the resulting expense had to be borne by the great feudatories; but the share of Hideyoshi himself cannot have been inconsiderable.

\section{LITERATURE, ART, AND COMMERCE}

It has already been shown that in spite of the disorder and unrest which marked the military: era, that era saw the birth of a great art movement under the Ashikaga shogun, Yoshimasa. It has now to be noted that this movement was rapidly developed under the Taiko. "The latter it was whose practical genius did most to popularize art. Although his early training and the occupations of his life until a late period were not calculated to educate esthetic taiste', he devoted to the cause of art a considerable portion of the sovereign power that his great gifts as a military leader and a politician had brought him." His earnest patronage of the tea ceremonial involved the cultivation of literature, and although he himself did not excel in that line, he did much to promote the taste for it in others. In the field of industrial art, however, his influence was much more marked. "Not only did, he bestow munificent allowances on skilled artists and art artisans, but also he conferred on them distinctions which proved stronger incentives than any pecuniary remuneration, and when he built the celebrated mansions of Juraku and Momo-yama, so vast were the sums that he lavished on their decoration, and such a certain passport to his favour did artistic merit confer, that the little town of Fushimi quickly became the art capital of the empire, and many of the most skilful painters, lacquerers; metalworkers; and wood-carvers within the Four Seas congregated there.

Historians speak with profound regret of the dismantling and destruction of these splendid edifices a few years after the Taikō's death; but it is more than probable that the permanent possession of even such monuments of applied art could not have benefited the country nearly as much as did their destruction. For the immediate result was an exodus of all the experts who, settling at Fushimi, had become famous for the sake of their Momo-yama work. They scattered

$\left[{ }^{1}\right.$ The ōban was an oval plate measuring 7 inches by 4 , and weighing 53 ounces. It contained 63.84 per cent. of gold and 20 per cent. of silver. The koban was one-tenth of the value of the öban.] 
among the fiefs of the most powerful provincial nobles, who received them hospitably and granted them liberal revenues.-From that-time, namely, the close of the sixteenth century, there sprang up an inter-fief rivalry of artistic production which materially promoted the development of every branch of art and encouraged refinement of life and manners. Not less noteworthy in the history of this military epoch is the improvement that took place in the social status of the merchant during the sixteenth century. Much was due to the liberal views of the Taikō. "He encouraged commercial voyages by his countrymen to Macao and to Cambodia, to Annam, and to other places. Nine ships engaged in this trade every year. They carried licences bearing the Taikós vermilion stamp, and the ports of departure were Nagasaki, Ōsaka, and Sakai.

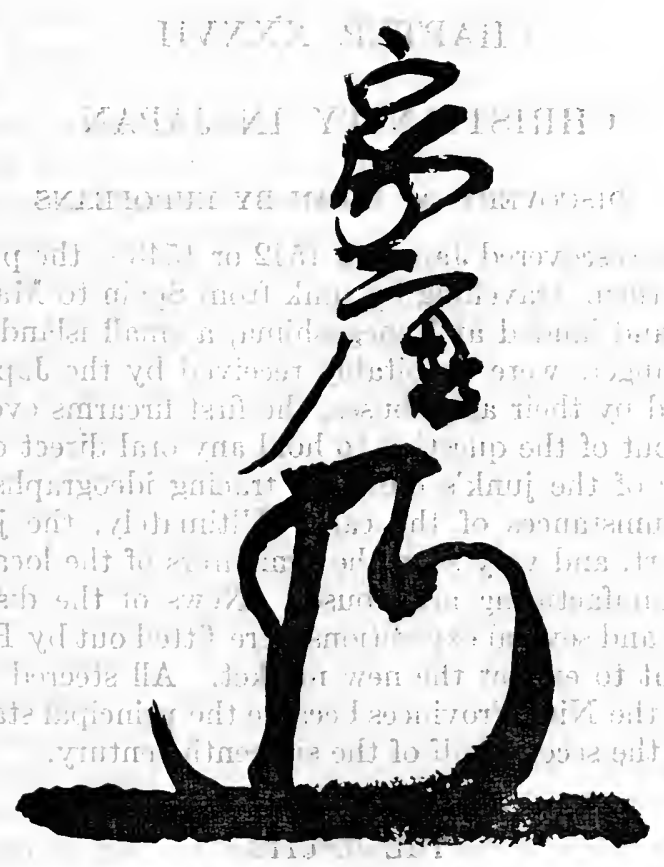

Signature of Tokugawa Ieyasu 


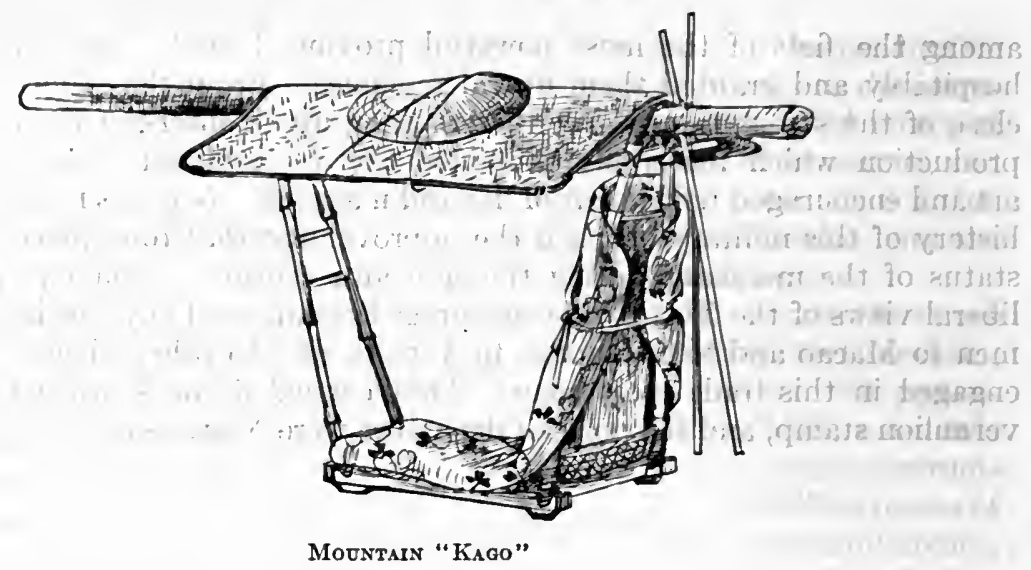

\section{CHAPTER XXXVII}

\section{CHRISTIANITY IN JAPAN}

\section{DISCOVERY OF JAPAN BY EUROPEANS}

The Portuguese discovered Japan in 1542 or 1543 - the precise date is not known. Three of them, travelling by junk from Spain to Macao, were driven from their course and landed at Tanegashima, a small island off the south of Kyūshū. The strangers were hospitably received by the Japanese, and great interest was excited by their arquebuses; the first firearms ever seen in Japan. It was, of course, out of the question to hold any oral direct conversation, but a Chinese member of the junk's crew, by tracing ideographs upon the sand, explained the circumstances of the case. Ultimately, the junk was piloted to a convenient port, and very soon the armourers of the local feudatory were busily engaged manufacturing arquebuses. News of the discovery of Japan circulated quickly, and several expeditions were fitted out by Portuguese settlements in the Orient to exploit the new market. All steered for Kyūshū, and thus the Island of the Nine Provinces became the principal stage for European intercourse during the second half of the sixteenth century.

\section{THE JESUITS}

There were, at that time, not a few Jesuits at Macao, Goa, and other outposts of Western commerce in the Far East. But not until 1549 was any attempt made to proselytize Japan. On August 15th of that year, Francis Xavięr, a Jesuit priest, landed at Kagoshima. Before his coming, the Portuguese traders had penetrated as far as Kyōto, which they reported to be a city of some ninetysix thousand houses, and their experience of the people had been very favourable, especially with regard to receptivity of instruction. Xavier was weary of attempting to convert the Indians, whom he had found "barbarous, vicious, and without inclination to virtue," and his mind had been turned towards Japan by a message from a Japanese daimy $\bar{o}$ (whose identity and reasons for 
inviting him have never been explained), and by a personal appeal from a Japanese," whose name appears in Portuguese annals as "Anjirō," and who, having committed a serious crime in Japan, had taken refuge in a Portuguese vessel, whose master advised him to repair to Malacca and confess his sins to Xaviër.

This man, Anjirō, already possessed some knowledge of the Portuguese language, and he soon became sufficiently proficient in it to act as interpreter, thus constituting a valuable aid to the Portuguese propagandists. Xavier, with two fellow countrymen and Anjiro, repaired to Kagoshima, where the Satsuma baron gave them unqualified permission to preach their doctrine. Not that he had any sympathy with Christianity, about which he knew nothing, but solely because he wished to secure a share in the oversea commerce which had brought so much wealth to his fellow barons on the main island. He thought, in short, that the Jesuits would be followed by merchant ships, and when Portuguese trading vessels did actually appear in the Satsumawaters, but; instead of making any stay there, passed on to the comparatively petty principality of Hirado, Xavier and his comrades were quickly ordered to leave Kagoshima. It seems, also, that Xavier's zeal had outrun his discretion. The Buddhist priests in Kagoshima were ready at first to listen respectfully to his doctrines, but were quickly alienated by his aggressive intolerance. . They urged upon the Satsuma baron the dangers that attended such propagandism, and he, already smarting from commercial disappointment; issued an edict, in 1550, declaring it a capital offence to embrace Christianity. The edict was not retrospective. About one hundred and fifty converts whom Xavier, aided by Anjiriō, had won during his two years' sojourn; were not molested, but Xavier himself passed on to the island of Hirado, where he, was received by salvos of artillery from Portuguese vessels lying in harbour. Matsuura, the Hirado baron, had already been captivated by the commerce of the newcomers, and seeing the marked reverence extended by them to Xavier, the baron issued orders that respectful attention should be paid to the teaching of the foreign propagandist. "Doubtless owing in large part to these orders, one hundred converts were made during the first ten days of Xavier's residence in Hirado.

It was, in fact; evident that the attitude of the official classes towards the new-comers was mainly influenced by the prospect of trade, and that the attitude of the non-official classes towards the foreign religion depended largely on the mood of their superiors. Xavier argued that "if the favour of such a small prince was so potent for the conversion of his subjects, it would be quite another thing if he (Xavier) could have the protection of the Emperor." He therefore resolved to visit Kyōto. His journey took him in the first place to Yamaguchi, capital of the Chōshū fief. : This town lay on the northern shore of Shimonoseki Strait, and had long been the principal emporium of trade' with China and Korea. But the ruler of the fief, though courteous to the new-comers, evinced no disposition to show any special cordiality towards humble missionaries unconnected with commerce. Therefore, finding that their preaching produced little effect, Xavier and his companion, Fernandez, continued their journey to Kyōto, which they reached after travelling for nearly two months on foot in the depth of winter. It happened, however, that the capital was then suffering sharply from the effects of internecine strife, and the two missionaries failed to obtain access to either the sovereign or the shogrun.

Nothing remained, therefore, but recourse to street preaching, and for this they were ill equipped, for Xavier, constitutionally: a bad linguist, knew very 
little of the Japanese language, and his companion, Fernandez; even less, while as for Anjirō, he had remained in Kagoshima. After devoting a few days to this unproductive task; Xavier returned to Yamaguchi. He had not made any converts in Kyōto, but he had learned a useful lesson, namely, that religious propagandism, to be successful in Japan, must be countenanced by the ruling classes. He therefore caused his canonicals to be sent to him from Hirado, together with his credentials from the viceroy of India, the governor of Malacca, and the bishop of Goa: These documents he submitted to the Choshū baron, accompanying them with certain rare objects of European manufacture, including a clock and a harpsicord. A permit to preach Christianity was now obtained without difficulty, and the Yamaguchi officials went so far as to issue a proclamation expressing approval of the. Western religion and granting entire liberty to embrace it. An empty Buddhist monastery was assigned as a residence for Xavier and his companions, and the fact is certainly an eloquent testimony to the magnanimity of the Buddhist priests.

Many converts were now made, and fresh proof was obtained that the road to-success lay in associating propagandism with commerce. It was nearly a decade: since the Portuguese had effected their first landing on Tanegashima, and throughout that interval trade had flourished in their hands. They had not sought any new markets on the main island; first, because their ignorance of the coasts rendered navigation risky; and, secondly, because internecine war raged throughout almost the whole of the main island, whereas Kyūshū enjoyed comparative tranquillity. Xavier now took advantage of a Portuguese vessel which called at Yamaguchi en route for Bungo, a province on the eastern littoral of Kyūshu. His intention was to return for a time to the Indies, but on reaching Bungo he learned that its ruler, Ōtomo, wielded exceptional power and showed a disposition to welcome the Jesuit father.

This Ōtomo was destined ultimately to act a leading part on the stage of Christianity in Japan. 'Xavier now had recourse to methods suggested by his recent experiences. On a visit to Ōtomo he caused himself to be escorted by a large number of the Portuguese crew, who wore rich garments, carried arms, and flaunted banners. This procedure seems to have weighed cogently with Ōtomo, who was keenly desirous of attracting foreign traders and obtaining from them not only wealth but also novel and effective weapons of war. Seeing that Xavier was almost deified by the Portuguese, Ōtomo naturally applied himself to win the good-will of the Jesuits, and for that purpose not only accorded to them entire liberty to teach and to preach, but also despatched a messenger to his younger brother (who had just succeeded to the lordship of Yamaguchi), advising him to protect the two Jesuits then residing there, namely, Torres and Fernandez. Xavier remained four months in Bungo and then set sail for Goa in February, 1552. He died in December of the same year, and thus his intention of returning to Japan was defeated. His stay in Japan had lasted twenty-seven months, and in that interval he and his comrades had won some 760 converts.

\section{RESULTS OF PROPAGANDISM}

It is worth while to recapitulate here the main events during this first epoch of Christian propagandism in Japan. 'It has been shown that in more than a year's labours in Kagoshima, Xavier, with the assistance of Anjiro as an interpreter, obtained 150 believers. Now, "no language lends itself with greater difficulty than Japanese to the discussion of theological questions. The terms 
necessary for such a purpose are not current among laymen, and only by special study, which; it need searcely: be said, must be preluded by accurate aequaintance with the-tongue itself, can a man hope to become duly equipped for the task of exposition and dissertation. It is open to grave doubt whether any foreigner has ever attained the requisite proficiency. Leaving Anjirō in Kagoshima, to care for the converts made there, Xavier pushed on to Hirado, where he baptized a hundred Japanese in a few days. Now, we have it on the authority of Xavier himself that, in this Hirado campaign, 'none of us knew Japanese.' How, then, did they proceed? - 'By reciting a semi-Japanese volume' (a trans: lation made by Anjirō of a treatise from Xavier's pen) 'and by delivering sermons; we brought several over to the Christian cult:'

gfci"Sermons preached in Portuguese or Latin to a Japanese audience on the island of Hirado in the year 1550 can scarcely have attracted intelligent interest. On his first visit to Yamaguchi, Xavier's means of access to the understanding of his hearers was confined to the rudimentary knowledge of Japanese which Fernandez had been able to acquire in fourteen months, a period of study which, in modern times with all the aids now procurable, would not suffice to carry a student beyond the margin of the colloquial. No converts were won. The people of Yamaguchi probably admired the splendid faith and devotion of these over-sea philosophers, but as for their doctrine, it was unintelligible. In Kyōto, the same experience was repeated with an addition of much physical hardship. But; when the Jesuits returned to Yamaguchi in the early autumn of 1551, they baptized five hundred persons, including several members of the military class. Still Fernandez with his broken Japanese was the only medium for communicating the profound doctrines of Christianity. It must be concluded that the teachings of the missionaries produced much less effect than the attitude of the local chieftain."' 1

But the Jesuits have not left any misgivings on record. They relate that during Xavier's sojourn in Bungo he had numerous public debates - one continuing for five days - with Buddhist priests, but even Fernandez not being available as an interpreter, these debates must have been either farcical or imaginary, though brilliant results are claimed for them by the Church historians. That Xavier himself was not satisfied is proved by his determination to transfer his ministrations to China, for he said, "if the Chinese adopt the Christian religion, the Japanese also will abandon the religions they have introduced from China."

\section{SECOND PERIOD OF PROPAGANDISM}

Torres and Fernandez remained in Japan after Xavier's departure and were there joined soon afterwards by three others. The new-comers landed at Kagoshima and found that the Satsuma baron was as keen as ever in welcoming foreign trade; although his attitude towards the alien religion continued antipathetic. Bungo now became the headquarters of the Jesuits in Japan. Local disturbances had compelled them to leave Yamaguchi, where their disputes with Buddhist priests had become so violent that an official proseription of the Western religion was pronounced. In Funai, the capital of the province of Bungo, they built their first church in Japan and also a hospital. From that piace, too, they began to send yearly reports known as the Annual Letters to their generals in Rome, and these Letters give an interesting insight into 
the conditions then existing in Japan. The: writers "describe a state of abject poverty among the lower orders - poverty so cruel that the destruction of children by their famishing parents : was an every-day occurrence." This terrible state of affairs was due to the civil wars: which had entered their most violent phase in the Ōnin era $(1467-1468)$, and had continued without intermission ever since. The trade carried on by the Portuguese did not, however, suffer any interruption. Their vessels repaired to Hirado as well as to Funai, and the masters and seamen of the ships appear to have treated the missionaries with such scrupulous respect that the Japanese formed an almost exaggerated conception of the civil influence wielded by the religionists. It further appears that in those early days the Portuguese seamen refrained from the riotous excesses which had already won for them a most unenviable reputation in China.'

In fact, their good conduct constituted an object lesson in the interests of Christianity. We learn, incidentally that, in 1557, two of the fathers, visiting Hirado at the instance of some Portuguese sailors who felt in want of religious ministrations, organized a kind of propagandism which anticipated the methods of the Salvation Army. They "sent brothers to parade the istreets, ringing bells, and chaunting litanies; they organized bands of boys for the same purpose; they caused the converts, and even children, to flagellate themselves at a model of Mount Calvary, and they worked miracles, healing the sick by contact with scourges or with a booklet in which Xavier had written litanies and prayers. It may well be imagined that such doings attracted surprised attention in Japan? They were supplemented by even more striking practices. For a sub-feudatory. of the Hirado chief, having been converted, showed his zeal by destroying Buddhist temples and throwing down the idols, thus inaugurating a campaign of violence destined to mark the progress of Christianity throughout the greater part of its history in Japan. There followed the overthrowing of a cross in the Christian cemetery, the burning of a temple in the town of Hirado, and a street riot, the sequel being that the Jesuit fathers were compelled to return once more to Bungo."'

All this conveys an idea of the guise under which Christianity was presented originally to the Japanese Meanwhile, the Portuguese traders did not allow their commerce to be interrupted by any misfortunes which overtook the Jesuits. Hirado continued to be frequented by Portuguese merchantmen, and news of the value of their trade induced Sumitada, feudatory of Ōmura, to invite the Jesuits in Bungo to his fief, offering them a free port for ten years, an extensive tract of land, a residence for the missionaries, and other privileges. This induced the Hirado feudatory to revoke the edict which he had issued against the Jesuits, and they were preparing to take advantage of his renewed hospitality when a Portuguese merchantman entered Hirado. Its appearance convinced the local chieftain that trade could be had without the accompaniment of religion, towards which he renewed his hostility.. When, however, this change of demeanour was communicated to Funai; the Jesuit leader, Torres, hastened thence to Hirado, and induced the master of the merchantman to leave the port on the ground that he could not remain in a country where they maltreated those who professed the same religion as himself. Thereafter, for some years, Hirado remained outside the pale of foreign trade: But ultimately three merchant vessels appeared in the offing and announced their willingness to put in provided that the anti-Christian ban was removed. This remonstrance proved effective.

["Encyclopædia Brilannica, 11th edition; : article .".Japan," by Brinkley.] 
'A parallel case occurred a few years later in the island of Amakusa. There a petty baron, avowedly for the purpose of attracting foreign trade, embraced Christianity and required all his vassals to follow his example. But when no Portuguese ship arrived, he apostatized; ordered his vassals to return to:their old faith, and expelled the missionaries.

"In fact, the competition for the patronage of Portuguese traders was so keen that the Hirado feudatory attempted to burn several of their vessels because they frequented the territorial waters of his neighbour and rival; Sumitada. The latter became a most stalwart Christian when his wish was gratified. $\mathrm{He}$ set himself to eradicate idolatry throughout his fief with the strong arm, and his fierce, intolerance provoked revolts which ended in the destruction of the Christian town at the newly opened free port. Sumitada; however, quickly reasserted his authority, and five years'later (1567), he took a step which had far-reaching consequences, namely, the building of a church at Nagasaki, in order that Portuguese commerce might have a centre and the Christians' an assured asylum. Nagasaki was then a little fishing village. In five years it grew to be a town of thirty thousand inhabitants, and Sumitada became one of the richest of the Kyūshū feudatories."'

This baron appears to have been sincere in his adoption of the foreign religion. "When in 1573, successful conflicts with neighbouring fiefs brought him an access of territory, he declared that he owed these victories to the influence of the Christian God, and shortly afterwards he proclaimed banishment for all who would not accept the foreign faith. There were then no Jesuits by his side, but immediately two hastened to join him, and 'these accompanied by a strong guard, but yet not without danger of their lives, went round causing the churches of the Gentiles, with their idols, to be thrown down to the ground, while three Japanese Christians went preaching the law of God everywhere.' "s They further record that three fathers who were in the neighbouring fief "all withdrew therefrom to work in this abundant harvest, and in the space of seven months twenty thousand persons were baptized, including the bonzes of about sixty monasteries." 1 The Jesuit vice-provincial (Francis Cabral), relating these events, speaks with marked satisfaction of the abasement of the Buddhist priests, and adds, "That these should now come to such a humility that they throw themselves on the ground before two ragged members of the Company is one of the miracles worked by the Divine Majesty."

In Funai things were by no means so satisfactory. The Jesuits, as stated above, had a hospital there, which had been built at the charges of a devout Portuguese. But Francis Cabral, writing from Bungo, in 1576, said: "Down to this hour the Christians have been so abject and vile that they have shown no desire to acknowledge themselves, partly from being few in the midst of so many Gentiles, partly because the said Christianity began in the hospital where we cure the people of low condition and those suffering from contagious diseases, like the French evil and such others. Whence the Gospel came to be of such little reputation that no man of position would dare to accept it (although it seemed good and true to him). merely lest he should be confounded with this rabble (con quella plebe). And although we gave much edification with such works, the thing nevertheless was a great obstacle to the spread of the holy faith. And thus, during the twenty years we have had a residence in Funai, one gentleman became a Christian, and this after having been cured of the said evil in his house; but as soon as he was cured he afterwards

['Encyclopedia Britannica, 11th edition;- article "Japan," by Brinkley.] 
thought it shame to acknowledge his Christianity in the presence of others."

This most disheartening record underwent a complete change in 1576, when the son of the Bungo feudatory, a youth of some sixteen years, and, two years later, the feudatory himsèlf, Otomo, embraced the Christian faith. In the first Annual Letter sent to Rome after these events a striking admission is made: "It is Otomo, next to God;, whom the Jesuits have to thank for their suceess in Japan." This appreciation looks somewhat exaggerated when placed side by side with the incidents that occurred in Sumitada's fief, as related above. Nevertheless, Ōtomo certainly did render powerful aid, not within his own fief alone but also through his influence elsewhere. Thus, he did not hesitate to have recourse to arms in order to obtain for the Jesuits access to the island of Amakusa, where one of the local barons, tempted originally by tradal prospects and afterwards urged by his wife, called upon his vassals: to choose between conversion or exile, and issued an order that any Buddhist priests refusing to accept Christianity would have their property confiscated and their persons banished.

Practically the whole population became converts under the pressure of these edicts, and it is thus seen that Christianity owed much of its success in Kyūshū to methods which recall Islam and the Inquisition. Another illustration of this is furnished by the Arima fief, which adjoined that of $\bar{O}$ mura where Sumitada ruled. The heads of these two fiefs were brothers; and thus when Sumitada embraced Christianity the. Jesuits received an invitation to visit Arima the ports of Kuchinotsu and Shimabara, where from that time Portuguese ships repaired frequently. In 1576, the Arima baron, seeing the prosperity and power which had followed the conversion of his brother Sumitada, raccepted baptism and became the "Prince Andrew" of missionary records. In those records we read that "the first thing Prince Andrew did after his baptism was to con" vert the chief temple of his capital into a church, its revenues being assigned for the maintenance of the building and the support of the missionaries. He then took measures to have the same thing done in the other towns of his fief, and he seconded the preachers of the Gospel so well in everything else that he could flatter himself that he soon would not have one single idolator in his states." This fanatical "Prince Andrew"' survived his baptism by two years only, but during that time twenty thousand converts were made in Arima. His successor, however, was a believer in Buddhism. He caused the Christian churches to be destroyed and the crosses to be thrown down; he ordered the Jesuits to quit his dominions, and he required the converts to return to Buddhism. Under this pressure about one-half of the converts apostatized, but the rest threatened to leave Kuchinotsu en masse. However this would have meant the loss of foreign trade, and as a result of this circumstance the anti-Christian ediets were radically modified.

Just at that time, also, a fortunate incident occurred. It had become the custom for a large vessel from Macao to visit Japan every year, and the advent of this ship had great importance from a commercial point of view. It chanced that she made the port of Kuchinotsu her place of call in 1578; and her presence suggested such a pleasing outcome that the feudatory embraced Christianity and allowed his vassals to do the same. By this "great ship from Maeao" the Jesuit vice-general, Valegnani was a passenger. A statesman as well as a preacher, this astute politician made such a clever use of the opportunity that, in 1580, "all the city was made Christian, and the people burned their idols and destroyed forty temples, reserving some materials to build churches." 


\section{RESULTS OF THE FIRST THREE DECADES OF PROPAGANDISM}

The record achieved by the Christian propagandists up to this time was distinctly: satisfactory. In the Annual Letter of 1582 we find it stated that, at the close of ' 1581 , that is to say, thirty-two years after Xavier's landing in Japan there were about 150,000 converts. Of these some 125,000 were in $K y u \overline{s h u}$; the remainder in Yamaguchi, Kyotto, and the vicinity of the latter city. As for the Jesuits in Japan; they then numbered seventy-five, but down to the year 1563 there had never been more than nine. "The harvest. was certainly great in proportion to the number of sowers. But it was a harvest mainly of artificial growth forced by despotic insistence of feudal chiefs. who possessed the power of life and death over their vassals, and were influenced by a desire to attract foreign trade.?

barlosorect:

raged bert (1)

\section{BUDDHISM AND CHRISTIANITY}

"To the Buddhist priests this movement of Christian propagandism had brought an experience hitherto almost unknown in Japan - persecution solely on account of creed. They had suffered for interfering in politics, but the cruel vehemence of the Christian fanatic may be said to have now become known for the first time to men themselves usually conspicuous for tolerance of heresy and for receptivity of instruction. They had had little previous experience of humanity in the garb of an Ötomo of Bungo, who, in the words of Crasset, "went to the chase of the bonzes as to that of wild beasts, and made it his singular pleasure to exterminate them from his states." "1

\section{JAPANESE 'EMBASSY TO EUROPE}

Another important result of the coming of Valegnani to Japan was that, in 1582, an embassy sailed from Nagasaki for Europe. It consisted of four young men, representing the fiefs of Arima, Ōmura, and Bungo, and it is related that at Lisbon, Madrid, and Rome they were received with an elaborate show of dazzling magnificence, so that they carried back to their island home a vivid impression of the might and wealth of Western countries.

\section{KYŌTO AND CHRISTIANITY}

It has already been shown that the visit to Kyōto by Xavier and Fernandez was wholly unsuccessful. Such was not the case, however, when another visit was made to the same city by Vilela, in the year 1559. This eminent missionary had been invited to Kyôto -by the abbot of the celebrated Buddhist monastery of Hiei-zan, who desired to investigate the Christian doctrine. It is to be noted that, at this time, Christian propagandism in Kyūshū had not yet begun to be disfigured by acts of violence. Vilela carried letters of introduction from the Bungo feudatory, but before he reached the capital the Buddhist abbot of Hiei-zan had died, and his successor did not show the same liberal spirit of inquiry. Still, Vilela was permitted to expound his doctrines in the presence of a gathering of priests in the great monastery, and afterwards the good offices of one of these bonzes, supplemented by the letter of the Bungo feudatory, procured for the Jesuit father the honour of being received by the shōgun, Yoshiteru, who treated him with müch consideration and assigned a house for his residence." 
Vilela does not seem to have allowed himself to be influenced in any degree by the aid that he received on this oceasion from his Buddhist friend, who is described as "one of the most respected men in the city." The Jesuit father seized the first opportunity to denounce Buddhism and its followers in unmeasured terms, and soon the bonzes began to intrigue with corresponding vehemence for the expulsion of the foreign propagandists. But the shogun extended his protection to Vilela, by issuing a decree which made it a capital punishment to injure the missionaries or obstruct their work The times, however, were very troublous, so that Vilela and his fellow workers had to encounter much difficulty and no little danger. Nothing, however, damped their ardour, and five years after their arrival in Kyōto they had not only obtained many converts but had organized churches in five towrs within a radius of fifty miles from the capital. Two ineidents may be specially mentioned illustrating the loyal spirit with which the Japanese of that time approached controversy. Among Vilela's converts were two Buddhist priests who had been nominated officially to investigate and report upon the novel doctrines, and who, in the sequel of their investigation, openly embraced Christianity though they had originally been vehemently opposed to it. The second incident was the conversion of a petty feudatory, Takayama, whose fief lay at Takatsuki in the vieinity of the capital. He challenged Vilela to a public discussion of the merits of the two creeds, and being vanquished, he frankly acknowledged his defeat,' adopted Christianity, and invited his vassals as well as his family to follow his example. His son, Yūsho, became one of the most loyal supporters of Christianity in all Japan. He is the "Don Justo Ukondono" of the Jesuits, annals.

\section{NOBUNAGA AND CHRISTIANITY}

At the time of Vilela's visit to Kyōto civil war was, raging. It led to the death of the shogun, Yoshiteru, and to the issue of an Imperial decree proscribing Christianity.: Vilela and his two comrades were obliged to take refuge in the town of Sakai, and they remained there during three years, when they were invited to an interview; with Oda Nobunaga, who, at this time, had risen almost to the pinnacle of his immense power? Had Nobunaga shown himself hostile to Christianity, the latter's fate in Japan would have been quickly sealed; but not only was he a man of wide and liberal views, but also he harboured a strong antipathy against the Buddhists, whose armed interference in politics had caused him much embarrassment. He welcomed Christianity largely as an opponent of Buddhism, and when Takayama conducted Froez from Sakai to Nobunaga's presence, the Jesuit received a cordial welcome. Theneeforth, during the fourteen remaining years of his life, Nobunaga steadily befriended the missionaries in partieular and foreign visitors to Japan in general $\mathrm{He}$ stood between the Jesuits and the Throne, when, in reply to an appeal from Buddhist priests, the Emperor Okimachi, for the seeond time, issued an antiChristian deeree (1568); he granted a site for a church and a residence at Azuchi on Lake Biwa, where his new castle stood; he addressed to various powerful feudatories letters signifying a desire for the spread of Christianity; he frequently made handsome presents to the fathers, and whenever they visited him he showed himself accessible and gracious. The Jesuits said of him: "This man seems to have been chosen by, God to open and prepare the way for our faith. In proportion to the intensity of his enmity to the bonzes and their seets is his good-will towards our fathers who preach the law of God, 
whence he has shown them so many favours that his subjects are amazed and unable to divine what he is aiming at in this. I will only say that, humanly speaking, what has above all given great credit and reputation to the fathers is the great favour Nobunaga has shown for the Company." It is not to be supposed, however, that Nobunaga's attitude towards the Jesuits signified any belief in their doctrines. In 1579, he took a step which showed plainly that policy as a statesman ranked much higher in his estimation than duty towards religion. For, in order to ensure the armed assistance of a certain feudatory, a professing Christian, Nobunaga seized the Jesuits in Kyoto, and threatened to ban their religion altogether unless they persuaded the feudatory to adopt Nobunaga's side. - Nevertheless, that Christianity benefited much by his patronage there can be no dissentient opinion.

(-ill 210 bucris

\section{HIDEYOSHI AND CHRISTIANITY}

After Nobunaga's death, in 1582, the supreme power fell into the hands of Hideyoshi, and had he chosen to exercise it, he could have easily undone the whole work hitherto achieved by the Jesuits' at the cost of much effort and devotion. But, at first; Hideyoshi followed Nobunaga's example. He not only accorded a friendly audience to Father Organtino, as representative of the fathers, but also he went in person to assign to the Company a site for a church and a residence in Ōsaka. At this time, "many Christian converts were serving in high positions, and in 1584, the Jesuits placed it on record that 'Hideyoshi was not only not opposed to the things of God, but he even showed that he made much account of them (the fathers) and preferred them to all the sects of the bonzes. . . . He is entrusting to Christians his treasures, his secrets, and his fortresses of most importance, and he shows himself well pleased that the sons of the great lords about him should adopt our customs and our law. Two years later in Ōsaka he received with every mark of cordiality and favour a Jesuit mission which had come from Nagasaki seeking audience, and on that occasion his visitors recorded that he spoke of an intention of christianizing one half of Japan." Nor did he confine himself to licensing the missionaries to preach throughout all Japan: he exempted not only churches from the billeting of soldiers but also the priests themselves from local burdens. "This' was in 1586, on the eve of his great military enterprise, the invasion of Kyūshū. : : He carried that difficult campaign to completion by the middle of 1587 , and throughout its course he maintained a uniformly friendly demeanour toward the Jesuits. But suddenly, when on the return journey he reached Hakata in the north of the island, his policy underwent a radical metamorphosis. Five questions were by his orders propounded to the vice-provincial of the Jesuits: 'Why and by what authority he and his fellow propagandists had constrained Japanese subjects to become Christians? Why they had induced their disciples and their sectaries to overthrow temples? Why they persecuted the bonzes? Why they and other Portuguese ate animals useful to men, such as oxen and cows? Why the vice-provincial allowed merchants of his nation to buy Japanese and make slaves of them in the Indies?' To these queries Coelho, the vice-provincial, made answer that the missionaries had never themselves resorted; or incited, to violence in their propagandism, or persecuted bonzes; that if their eating of beef was considered inadvisable, they would give up the practice, and that they were powerless to prevent or restrain the outrages perpetrated by their countrymen. Hideyoshi read the 
vice-provincial's reply and, without comment, sent him word to retire to Hirado, assemble all his followers there, and quit the country within six months. On the next day (July 25,1587 ) the following edict was published:

"Having learned from our faithful councillors that foreign priests have come into our estates, where they preach a law contrary to that of Japan, and that they have even had the audacity to destroy temples dedicated to our Kami and Hotoke; although the outrage merits the most extreme punishment, wishing nevertheless to show them mercy, we order them under pain of 'death to quit Japan within twenty days. 5 . Dung that space no harm or' hurt will be done to them. But at the expiration of that term, we order that if any of them be found in our estates, they should be seized and punished as the greatest criminals. As for the Portuguese mérchants, we permit them to enter our ports, there to continue their aceústomed trade, and to remain in our estates provided our. affairs need this. But we forbid them to bring any foreign priests into the country, under the penalty of the confiscation of their ships and goods." ",

How are we to account for this seemingly rapid change of mood on $\mathrm{Hi}$ deyoshi's part? A comparison of dates furnishes some assistance in replying to that question. The Kyūshū campaign took place in 1587, and it was in 1586 that Hideyoshi commenced the construction of the colossal image of Buddha in Kyōto. The Taikō was by no means a religious man: ${ }^{3}$ That is amply shown by the stories told in the previous pages. But his political sagacity taught him that to continue Nobunaga's crusade against Buddhism would not be wise statesmanship, and that if the bonzes could be disarmed and diverted from military pursuits, they would become useful agents of intellectual and moral progress. His idea of setting up a gigantic idol in the capital marked his final substitution of a conciliatory programme for the fercely destructive methods of Nobunaga. Of necessity he had, then, to reconsider his demeanour towards Christianity; and it is on record that before leaving Ōsaka for Kyūshū he publicly; stated, "I fear much that all the virtue of the European priests is merely a mask of hypocrisy and serves only to conceal pernicious designs against the empire." Then, in Kyūshū, two things influenced him strongly. One was that he now saw with his own eyes what militant Christianity really meant - ruined temples, overthrown idols, and coesced converts. Such excesses had not disgraced Christian propagandism in Kyōto or in the metropolitan provinces, but in Kyūshū the unsightly story was forced upon Hideyoshi's attention. The second special feature of the situation in Kyūshū was that relations of an altogether exceptional character were established between Hideyoshi and Kennyo, abbot of the Shin seet. By the contrivance of that prelate, Hideyoshi's troops were enabled to follow a secret road to the stronghold of the Satsuma baron, and in return for such valuable services Hideyoshi may well have been persuaded to proseribe Christianity. m?

Some importance, though probably of a less degree, attaches also to the last of the five questions propounded by Hideyoshi to the vice-provincial why the priests allowed merchants of their nation to buy Japanese subjects 'and carry them into slavery in the Indies. It was in Kyūshu only that these abuses were perpetrated. With respect to this matter the following passage appears in the archives of the Academy of History at Madrid: "Even the Lascars and scullions of the Portuguese purchase and carry slaves away. Hence it happens that many of them die on the voyage, because they are heaped up one upon the other, and if their master fall sick (these masters are sometimes Kaffirs and the negroes of the Portuguese); the slaves are not cared for. It even often happens that the Kaffirs cannot procure the necessary food for them. I here omit the excesses committed in the lands of pagans where the

['Encyclopódia Britannica, 11th edition; article "Japan," by Brinkley.] 
Portuguese spread themselves to recruit youth and girls, and where they live in such a fashion that the pagans themselves are stupefied atit." Nevertheless, the fact that the Taiko specially exempted the Portuguese merchants from his decree of banishment indicates that he did not attach cardinal importance to their evil doings in the matter of slaves. It seems rather to have been against the Jesuits that his resentment was idrected, for he did not fail to perceive that, whereas they could and did exact the utmost deference from their country;s sailors and traders when the ends of Christian propagandism were served thereby, they professed themselves powerless to dissuade these same traders and sailors from outrages which would have disgraced any religion. He cannot but have concluded that if these Portuguese merchants and seamen were to be regarded as specimens of the products of Christianity, then, indeed, that creed had not much to recommend it. All these things seem amply, sufficient to account for the change that manifested itself in Hideyoshi's attitude towards Christianity at the close of the Kyūshü campaign.

\section{SEQUEL OF THE EDICT OF BANISHMENT}

The Jesuits, of whom it must be said that they never consulted their own safety when the cause of their faith could be advanced by self-sacrifice, paid no attention to the Taik $\bar{o}$ 's edict. They did indeed assemble at Hirado to the number of 120 , but when they received orders to embark at once, they decided that only those needed for service in China should leave Japan. The rest remained and continued to perform their religious duties as, usual, under the protection of the converted feudatories. The latter also appear to have concluded that it was not. necessary to follow. Hideyoshi's injunctions strictly concerning the expulsion of the priests. It seemed, at first, as though nothing short of extermination was contemplated by the Taiko. He caused all the churches in Kyōto, Ōsaka, and Sakai to be pulled down, and he sent troops to raze the Christian places of -worship in Kyŭshū. But the troops accepted gifts offered to them by the feudatories and left the churches standing, while Hideyoshi not only failed to enforce his edict, but also allowed himself in the following year, 1588 , to be convinced by a Portuguese envoy that unless the missionaries were suffered to remain; oversea trade could not possibly be carried on in a peaceful and orderly manner. For the sake of that trade, Hideyoshi agreed to tolerate the Christian propagandists, and, for a time, the foreign faith continued to flourish in Kyūshü and found a favourable field even in Kyōto.

At this time, in response to a message from the Jesuits, the viceroy of the Indies sent an ambassador to thank Hideyoshi for the favours he had hitherto bestowed upon the missionaries, and in the train of this nominally secular embassy came a number of fresh Jesuits to labour in the Japanese. field. The ambassador was Valegnani, a man of profound tact. Acting upon the Taikō's unequivocal hints, Valegnani caused the missionaries to divest their work of all ostentatious features and to comport themselves with the utmost circumspection, so that official attention should not be attracted by any salient evidences of Christian propagandism. Indeed, at this very time, as stated above, Hideyoshi took a step which plainly showed that he valued the continuance of trade much more highly than the extirpation of Christianity. "Being assured that Portuguese merchants could not frequent Japan unless they found Christian priests there, he consented to sanction the presence of 
a limited number of Jesuits," though he was far too shrewd to imagine that their services could be limited to men of their own nationality, and to clever to forget that these very Portuguese, who professed to attach so much importance to religious ministrations, were the same men whose flagrant outrages the fathers declared themselves powerless to check. If any further evidence were needed of Hideyoshi's discrimination between trade and religion, it is furnished by his despatches to the viceroy of the Indies written in 1591:-

The fathers of the Company, as they are called, have come to these islands to teach another religion here; but as that of the Kami is too surely founded to be abolished, this new law ean serve only to introduce into Japan a diversity of cults prejudieial to the welfare of the State. It is for this reason that, by. Imperial edict, I have forbidden these foreign doetors to continue to preach their doctrine. I have even ordered them to quit Japan, and $I^{2}$ am resolved no longer to allow' any one of them to eome here to spread new opinions. I nevertheless desire that trade between you and us should always be on the same footing [as before]. I shall have every care that the ways are free by sea and land: I have freed them from all pirates and brigands. The Portuguese will be ableto traffic with my subjects and I will in no wise suffer any one to do them the least wrong.

The statistics of 1595 showed that there were then in Japan 137 Jesuit fathers with 300,000 native converts, including seventeen feudal chiefs and not a few bonzes.

\section{HIDEYOSHI'S FINAL ATTITUDE TOWARDS CHRISTIANITY}

For ten years after the issue of his anti-Christian decree at Hakata, Hideyoshi maintained a tolerant demeanour. But in 1597, his forbearance was changed to a mood of uncompromising severity. Various explanations have been given of this change; but the reasons are obscure. "Up to 1593 the Portuguese had possessed a monopoly of religious propagandism and oversea commerce in Japan. The privilege was secured to them by agreement between Spain and Portugal and by a papal bull. But the Spaniards in Manila had long looked with somewhat jealous eyes on this Jesuit reservation, and when news of the anti-Christian decree of 1587 reached the Philippines, the Dominicans and Franciscans residing there were fired with zeal to enter an arena where the crown of martyrdom seemed to be the least reward within reach. The papal buill, however, demanded obedience, and to overeome that difficulty a ruse was necessary: the governor of Manila agreed to send a party of Franciscans as ambassadors to Hideyoshi. In that guise, the friars, being neither traders nor propagandists, considered that they did not violate either the treaty or the bull. It was a technical subterfuge very unworthy of the object contemplated, and the friars supplemented it by swearing to Hideyoshi that the Philippines would submit to his sway. Thus they obtained permission - to visit Kyōto; Ōsaka, and Fushimi, but with the explicit proviso that they must not preach:": 1

How far they observed the terms and the spirit of this arrangement may be gathered from the facts that "very soon they had built a ehurch in Kyōto, consecrated it with' the utmost pomp, and were preaching sermons and chaunting litanies there in flaggrant defiance of Hideyoshi's veto. Presently, their number received an access of three friars who came bearing gifts from the governor of Manila , and now they not only established a convent in Ōsaka; but also seized a Jesuit church in Nagasaki and converted the circumspect worship hitherto conducted there by the fathers into services of the most publie character.

['Encyclopoedia Britannica, 11th edition; article "Japan," by Brinkley.] 
Officially cheoked in Nagasaki; they charged the Jesuits in Kyōto with having intrigued to impede them, and they further vaunted the courageous openness of their own ministrations as compared with the clandestine timidity of the methods which wise prudence had induced the Jesuits to adopt. Retribution would have followed quickly had not Hideyoshi's attention been engrossed by an attempt to invade China through Korea. At this stage, however; a memorable incident occurred. Driven out of her course by a storm, a great and richly laden Spanish galleon, bound for Acapulco from Manila; drifted to the coast of Tosa province, and running - or being purposely run - on a sand-bank as she was towed into port by Japanese boats, broke her back: She carried goods to the value of some six hundred thousand crowns, and certain officials urged Hideyoshi to confiscate her as, derelict, conveying to him, at the same time, a detailed account of the doings of the Franciscans and their open flouting of his orders. Hideyoshi, much incensed, commanded the arrest of the Franciscans and despatched officers to Tosa to confiscate the San Felipe. The pilot of the galleon sought to intimidate these officers by showing them, on a map of the world, the vast extent of Spain's dominions, and being asked how one country had acquired such wide sway, replied, ${ }^{1}$ 'Our kings begin by sending into the countries they wish to conquer missionaries who induce the people to embrace our religion, and when they have made considerable progress, troops are sent who combine. with the new Christians, and then our kings have not much trouble in accomplishing the rest." "2

\section{THE FIRST CHRISTIAN MARTYRS IN JAPAN}

The words of the San Felipe's master were immediately reported to Hideyoshi: They roused him to hot anger. $\mathrm{He}$ is reported to have cried: "What! my States are filled with traitors, and their numbers increase every day. I have proscribed the foreign doctors, but out of compassion for the age and infirmity of some among them, I have allowed their remaining in Japan. I shut my eyes to the presence of several others because $I$ fancied them to be quiet and incapable of forming bad designs, and they: are serpents I have been cherishing in my bosom. The traitors are entirely employed in making me enemies among my own subjects and perhaps in my own family. But they will learn what it is to play with me .... I am not anxious for myself. So long as the breath of life remains, $\mathbf{I}$ defy all the powers of the earth to attack me. But I am perhaps to leave the empire to a child, and how can he maintain himself against so many foes, domestic and foreign, if I do not provide for everything incessantly?".

Then, finally, the Franciscans were arrested and condemned to have their noses and ears cut off ${ }^{3}$ to be promenaded through Kyōto, Ōsaka, and Sakai, and to be crucified at Nagasaki. "I have" ordered these foreigners to be treated thus;" Hideyoshi is recorded to have stated, "because they have come from the Philippines to Japan, calling themselves ambassadors, although they were not so; because they have remained here for long without my permission; because in defiance of my prohibition they have built churches, preached their religion, and caused disorders:" These men were the first martyrs in Japan.

[1 Charlevoix, referring to this incident, says, "This unfortunate statement inflicted a wound on religion which is bleeding still after a century and a half. .']

[2 Encyclopodia Britannica, 11th edition; ' article "Japan," by Brinkley.]

[3 The mutilation was confined to the lobe of one ear.] 
They numbered twenty-six, namely, six Franciscans, three Jesuits, and seventeen native Christians who were chiefly domestic servants of the Franciscans. They met their fate with noble fortitude. Hideyoshi did not stop there. He took measures to have his edict of 1587 converted into a stern reality. The governor of Nagasaki received orders to send away all the Jesuits, permitting only two or three to remain for the service of Portuguese merchants.

The Jesuits, however, were not to be deterred by personal peril. There were 125 of them in Japan at that time, and of these only eleven left ,Nagasaki by sea in Oetober, 1597, though the same vessel carried a number of pretended Jesuits who were, in reality, disguised sailors. This deception was necessarily known to the local authorities; but their sympathies being with the Jesuits, they kept silence until early the following year, when, owing to a rumour that Hideyoshi himself contemplated a visit to Kyūshū, they took really efficient measures to expel all the fathers. No less than 137 churches throughout Kyūshū were thrown down, as well as several seminaries and residences of the fathers, and, at Nagasaki, all the Jesuits in Japan were assembled for deportation to. Macao in the following year when the "great ship" was expected to visit that port. But before her arrival Hideyoshi died, and a respite was thus gained for the Jesuits.

\section{FOREIGN POLICY OF THE TOKUGAWA FAMILY}

It has been confidently stated that Tokugawa Ieyasu regarded Christian nations and Christian propagandists with distrust not less profound than that harboured by Hideyoshi. But facts are opposed to that view. Within less than three months of the Taikō's death; the Tokugawa chief had his first interview with a Christian priest. The man was a Francisean, by name Jerome de Jesus. He had been a member of the fictitious embassy from Manila, and his story illustrates the zeal and courage that inspired the Christian fathers in those days. "Barely escaping the doom of crucifixion which overtook his companions, he had been deported from Japan to Manila at a time when death seem to be the certain penalty of remaining. But no sooner had he been landed in Manila than he took passage in a Chinese junk, and, returning to Nagasaki, made his way secretly from the far south of Japan to the province of Kii. There arrested, he was brought into the presence of Ieyasu, and his own record of what ensued is given in a letter subsequently sent to Manila:-

"When the Prince saw me he asked how I managed to eseape the previous persecution. I answered him that at that date God had delivered me in order that I might go to Manila and bring back new colleagues from there - preachers of the divine law - and that I had returned from Manila to encourage the Christians, cherishing the desire to die on the cross in order to go to enjoy eternal glory like my former colleagues. On hearing these words the Emperor began to smile, whether in his quality of a pagan of the sect. of Shaka which teaches that there is no future life, or whether from the thought that I was frightened at having to be put to death. Then, looking at me kindly, he said; "Be no' longer afraid and no longer conceal yourself and no longer ehange your habit, for I wish you well; and as for the Christians who every year pass within sight of Kwantō where my domains are, when they go to Mexico with their ships, I have a keen desire for them to visit the harbours of this island, to refresh themselves there, and to take what they wish, to trade with my vassals, and to teach them how to develop silver mines; and that my intentions may be accomplished before my death, I wish you to indicate-to me the means to take to realize them.".

'I answered that it was necessary that Spanish pilots should take the soundings of his harbours, so that ships might not be lost in future as the San Felipe had been, and that he should solicit this service from the governor of the Philippines. The Prince approved of my advice, and accordingly he has sent a Japanese gentleman, a native of Sakai, the bearer of this message.

It is essential to oppose no obstacle to the complete liberty offered by the Emperor to the Spaniards and to our holy order, for the preaching of the holy gospel. 
The same Prince (who is about to visit the Kwantō) invites me to accompany him to make choice of a house, and to visit the harbour which he promises to open to us; his desires in this respect are keener than I can express.' "'

Subsequent events confirm the accuracy of the above story. Father Jerome was allowed to build the first Christian church in Yedo and to officiate there. Moreover, Ieyasu sent "three embassies in succession to the Philippines, proposing reciprocal freedom of commerce, offering to open ports in the Kwantō, and asking for competent naval architects." These architects never came, and the trade that resulted from the Tokugawa chief's overtures was paltry in comparison with the number of friars that accompanied it to Japan. It has been suggested that Ieyasu designed these Spanish monks to serve as a counterpoise to the influence of the Jesuits. For he must have known that the Franciscans opened their mission in Yedo by "declaiming with violence against the fathers of the Company of Jesus,". and he must have understood that the Spanish monks assumed towards the Jesuits in Japan the same intolerent and abusive tone that the Jesuits themselves had previously assumed towards Buddhism.

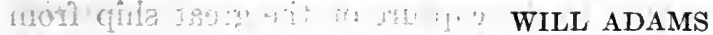

At about this time a Dutch merchant ship named the Liefde arrived in Japan. In 1598, a squadron of five ships sailed from Holland to exploit the sources of Portuguese commerce in the Orient, and of the five vessels only one,

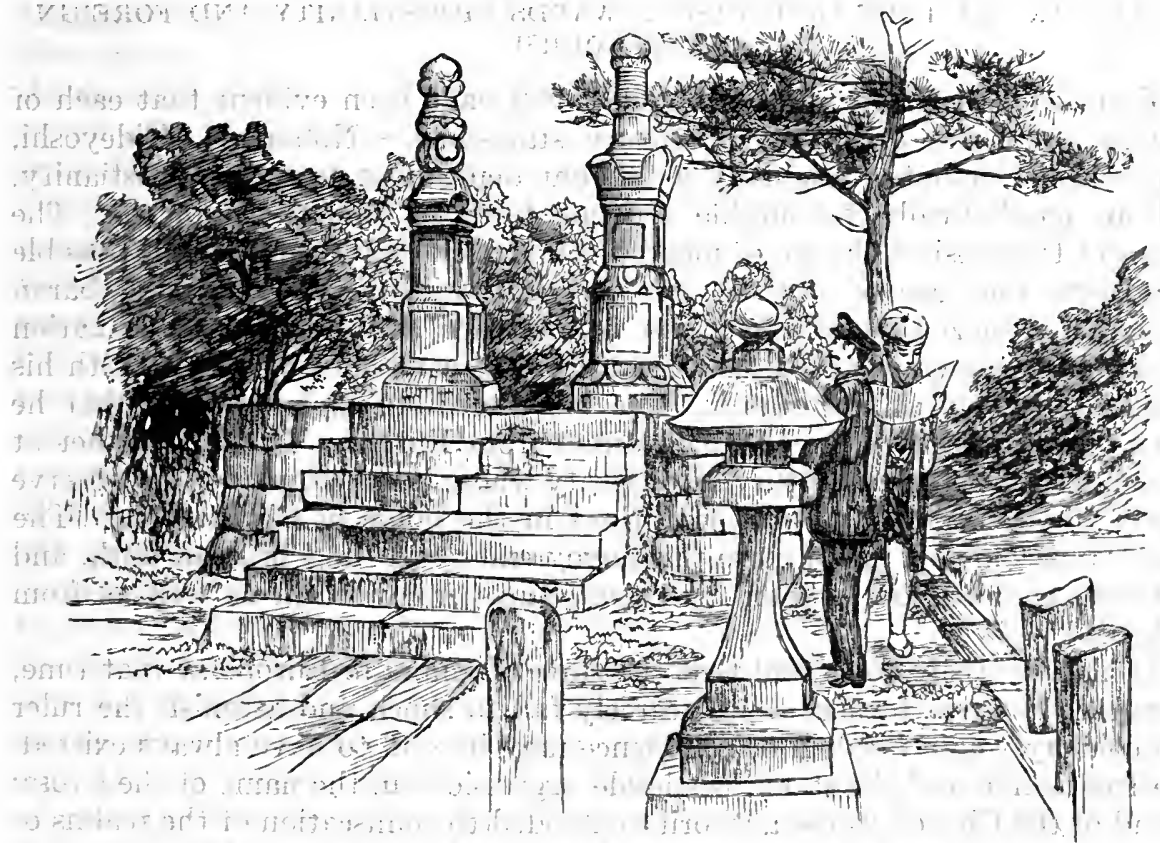

Anjin-zeka, near Yokoseka, the Tomb of Will Adams

the Liefde, was ever heard of again. She reached Japan in the spring of 1600 , with only four and twenty survivors of her original crew, numbering 110. Towed into the harbour of Funai, she was visited by Jesuits, who, on discovering her nationality, denounced her to the local authorities as a pirate. 
On board the Liefde, serving in the capacity of pilot major was an Englishman; Will Adams, of Gillingham in Kent. Icyasu summoned him to Ösaka, and between the rough English sailor and the Tokugawa chief there commenced a curiously friendly intercourse which was not interrupted until the death of Adams, twenty years later.

"The Englishman became master-shipbuilder to the Yedo Government; was employed as diplomatic agent when other traders' from his own country and from Holland arrived in Japan, received in perpetual gift a substantial estate, and from first to last possessed the implicit confidence of the shogun. Ieyasu quickly discerned the man's honesty; perceived that whatever benefits foreign commerce might confer would be increased by encouraging competition among the foreigners, and realized that English and Dutch trade presented the wholesome feature of complete dissociation from religious propagandism. On the other hand, he showed no intolerance to either Spaniards or Portuguese. He issued (1601) two official patents sanctioning the residence of the fathers in Kyōto, Ōsaka, and Nagasaki; he employed Father Rodriguez as interpretér at the Court in Yedo, and, in 1603 he gave munificent succour to the Jesuits who were reduced to dire straits owing to the capture of the great ship from Macae by the Dutch and the consequent loss of several years' supplies for the mission in Japan." 1

\section{ULTIMATE ATTITUDE OF IEYASU TOWARDS CHRISTIANITY AND FOREIGN INTERCOURSE}

From what has been written above it will have been evident that each of Japan's great trio of sixteenth century statesmen - Nobunaga, Hideyoshi, and Ieyasu - adopted originally a tolerant demeanour towards Christianity, and an emphatically favourable attitude towards foreign commerce. The causes of Hideyoshi's change of mood are tolerably clear, but it is not possible to analyse the case of Ieyasu with certainty. That the Tokugawa baron strongly patronized Buddhism might be regarded as a sufficient explanation of his ultimate hostility to the foreign faith, but cannot be reconciled with his amicable attitude at the outset. The more credible explanation is that he was guided by intelligence obtained direct from Europe. He sent thither at the end of the sixteenth century an emissary whose instructions were to observe closely the social and political conditions in the home of Christianity? The better to accomplish his purpose this envoy embraced the Christian faith, and was thus enabled to carry on his observations from within as well as from without.

It may be easily conceived that the state of affairs in Europe at that time, when recounted to Ieyasu, could scarcely fail to shock and astonish the ruler of a country where freedom of conscience may be said to have always existed. The Inquisition and the stake; wholesale aggressions in the name of the Cross; a head of the Church whose authority extended to confiscation of the realms of heretical sovereigns; religious wars, and profound fanaticism - these were the elements of the story told to Ieyasu by his returned envoy. The details could not fail to produce an evil impression. Already his own observation had disclosed to the Tokugawa chief abundant evidence of the spirit of strife engendered by Christian dogma in those times. No sooner had the Franciscans and the Dominicans arrived in Japan than a fierce quarrel broke out between 
them and the Jesuits - a quarrel which even community of suffering could not compose. "Not less repellent was an attempt on the part of the Spaniards to dictate: to Ieyasu the expulsion of all Hollanders from Japan, and an attempt on the part of the Jesuits to dictate the expulsion of the Spaniards. The former proposal ${ }_{i}$ couched almost in the form of a demand, was twice formulated, and accompanied on the second occasion by a scarcely less insulting offer, namely, that Spanish men-of-war would be sent to Japan to burn all Dutch ships found in the ports of the empire. If in the face of proposals so contumelious of his authority Ieyasu preserved a calm and dignified mein, merely replying that his country was open to all comers, and that, if other nations had quarrels among themselves, they must not take Japan for battle-ground, it is nevertheless unimaginable that he did not strongly resent such interference with his own independent foreign policy, and that he did not interpret it as foreshadowing a disturbance of the realm's peace by sectarian quarrels among Christians:"'

The repellent aspects under which Christianity thus presented itself to Ieyasu:were supplemented by an act of fraud and forgery perpetrated in the interest of a Christian feudatory by a trusted official, himself a Christian. This experience persuaded the Tokugawa ruler that it was unsafe to employ Christians at his Court. He not only dismissed all those so employed, but also banished them from Yedo and forbade: any feudal chief to harbour them. Another, incident, not without influence, was connected with the survey of the Japanese coast by a Spanish mariner and a Franciscan friar. An envoy from New Spain (Mexico) had obtained permission for this survey, but "when the mariner (Sebastian) and the friar (Sotelo) hastened to carry out the project, Ieyasu asked Will Adams to explain this display of industry. The Englishman replied that such a proceeding would be regarded in Europe as an act of hostility, especially on the part of the Spaniards or Portuguese, whose aggressions were notorious. He added, in reply to further questions, that 'the Roman priesthood had been expelled from many parts of Germany, from Sweden, Norway,.Denmark, Holland, and England, and that, although his own country preserved the pure form of the Christian faith from which Spain and Portugal had deviated, yet neither English nor Dutch considered that that fact afforded them any reason to war with; or to annex, States which were not Christian solely for the reason that they were non-Christian." " 1 Hearing these things from Will Adams, Ieyasu is said to have remarked, "If the sovereigns of Europe do not tolerate these priests, I do them no wrong if I refuse to tolerate them:"

Another incident, too complicated to describe in detail, may be summed up by saying that some Japanese Christians were discovered to have conspired for the overthrow of the Tokugawa Government by the aid of foreign troops. It was not an extensive plot, but it helped to demonstrate that the sympathy of the priests and their converts was plainly with the enemies of Tokugawa's supremacy. Ieyasu, however, abstained from extreme measures in the case of any of the foreign priests, and he might have been equally tolerant towards native Christians, also, had not the Tokugawa authority been openly defied in Yedo itself by a Franciscan father - the Sotelo mentioned above: "Then (1613) the first execution of Japanese converts took place, though the monk himself was released after a short incarceration. At that time . . . insignificant differences of custom sometimes induced serious misconceptions. A Christian who had violated a secular law was crucified in Nagasaki. Many 
of his fellow-believers kneeled around his eross and prayed for the peace of his soul. A party of converts were afterwards burnt to death in the same place for refusing to apostatize, and their Christian friends crowded to carry off portions of their bodies as holy relics. When these things were reported to Ieyasu, he said, 'Without doubt that must be a diabolic faith which persuades people not only to worship criminals condemned to death for their crimes; but also to honour those who have been burned or cut to pieces by the order of their.lord.' ',

\section{SUPPRESSION OF CHRISTIANITY}

The first prohibition of Christianity was issued by Ieyasu in September, 1612 , and was followed by another in April, 1613; but both bore-the character of warnings rather than of punitive regulations. It was on the 27 th of January, 1614 - that is to say, fifty-four years and five months after the landing of Xavier at Kagoshima - that an edict appeared ordering that all the foreign priests should be collected in Nagasaki preparatory to removal from Japan; that all churches should be pulled down, and that all converts should be compelled to abjure Christianity. There were then in Japan 156 ministers of Christianity, namely, 122 Jesuits, 14 Franciscans, 9 Dominicans, 4, Augustinians, and 17 secular priests. It is virtually eertain that if these men had obeyed the orders of the Japanese Government by leaving the country finally, not so much as one foreigner would have suffered for his faith in Japan, except the six Franciscans executed on the "Martyrs' Mount"' at Nagasaki by Hideyoshi's order, in 1597. But the missionaries did not obey. Suffering or even death counted for nothing with these men as against the possibility of saving souls. "Forty-seven of them evaded the edict, some by concealing themselves at the time of its issue, the rest by leaving their ships when the latter had passed out of sight of the shore of Japan, and returning by boats to the scene of their former labours. Moreover, in a few months, those that had actually crossed the sea re-crossed it.in various disguises." 1 The Japanese Government had then to consider whether it would suffer its authority to be thus defied by foreign visitors or whether it would resort to extréme measures:

\section{PERIOD SUBSEQUENT TO 1613}

Throughout a period of two years immediately following the issue of the anti-Christian edict of 1614, the attention of Ieyasu, and indeed of the whole Japanese nation, was concentrated on the struggle which took place between the adherents of the Tokugawa and the-supporters of Hideyori. That struggle

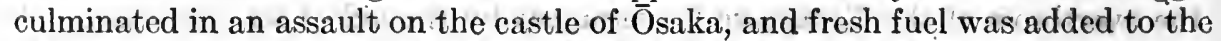
fire of anti-Christian resentment inasmuch as many Christian converts espoused Hideyori's cause, and in one part of the field the troops of Ieyasu had to fight against a foe whose banners were emblazoned with a cross and with images of Christ and of St. James, the patron saint of Spain. Nevertheless, the Christian converts possessed the sympathy of so many of the feudal chiefs that much reluctance was shown to inftict the extreme penalty of the law on men and women whose only crime was the adoption of an alien religion. "Some of the feudal chiefs; even at the risk of losing their estates, gave asylum to the converts; others falsely reported a complete absence of 'Christians in their dominions, and some endeavoured earnestly to protect the fanatics; while, as to the people at

['Encyclopadia Britannica, 11th edition; article "Japan,"' by Brinkley.] 


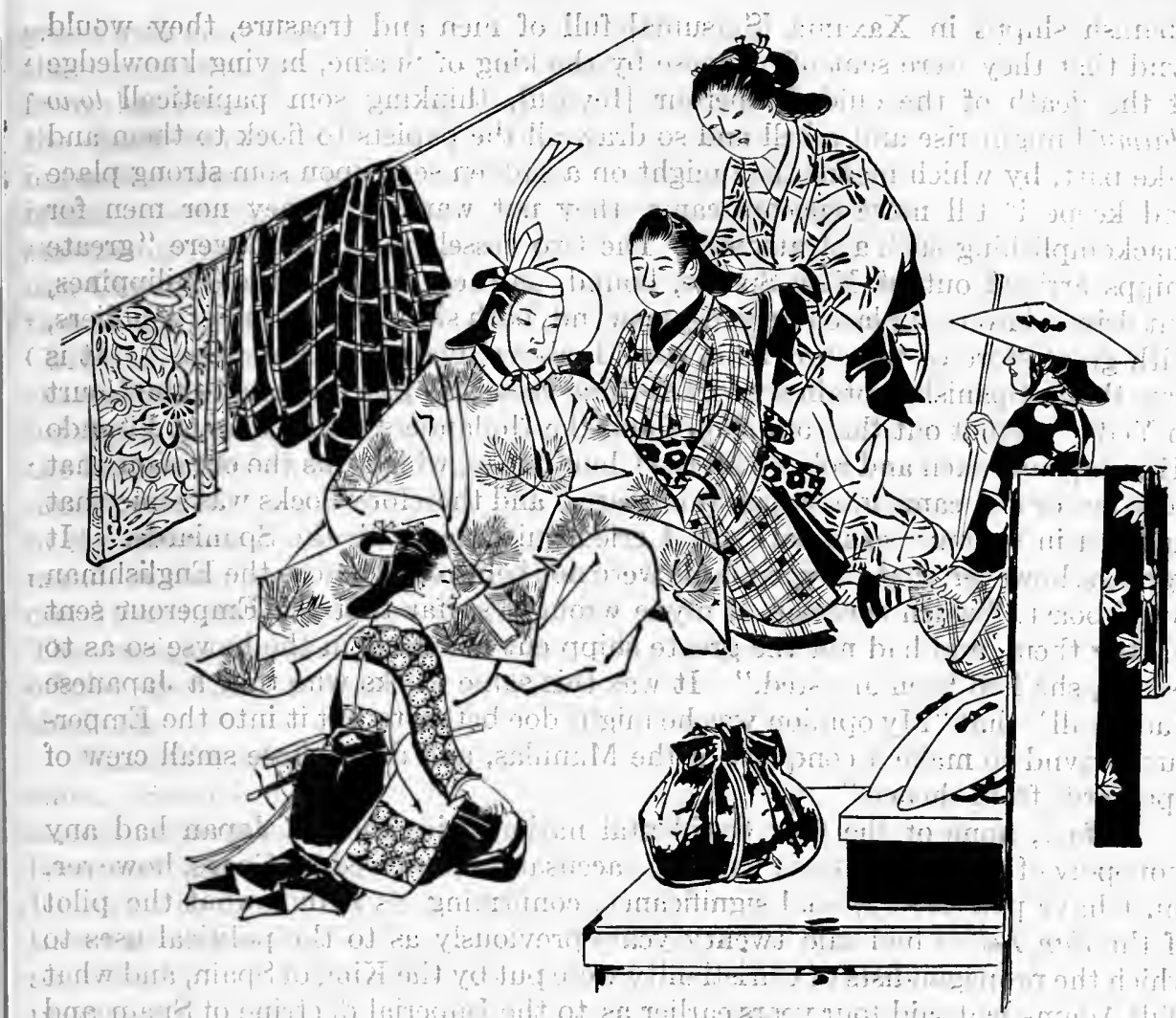

Green-room of a Theatre

(In the Middle of the Tokugawa Period)

large, their liberal spirit is shown in the fact that five priests who were in Ōsaka Castle at the time of its capture were able to make their way to distant refuges without any'risk of betrayal.

On the other hand, there were not wanting feudatories who, judging that zeal in obeying the edict would prove a passport to official reward, acted on that conviction. Notably was this true of Hasegawa, who received the fief of Arima by way of recompense for barbarous cruelty towards the Christians. Yet it is on record that when this baron sent out a mixed force of Hizen and Satsuma troops to harry the converts, these samurai warned the Christians to flee and then reported that they were not to be found anywhere During these events the death of Ieyasu took place (June 1,1616), and pending the dedication of his mausoleum the anti-Christian crusade was virtually suspended.

\section{ENGLISH AND DUTCH INTRIGUES AGAINST SPANIARDS AND PORTUGUESE}

It has been frequently alleged that if the Spaniards and the Portuguese endeavoured to bring the Hollanders into bad odour, the English and the Dutch intrigued equally against the Portuguese and the Spaniards. The accusation cannot be rebutted. Cocks, the factor of the English commercial mission to Japan, has himself left it on record that; being at the Yedo Court in the fall of 1616 , "I enformed the two secretaries that yf they lookt out well about these two 
Spanish shipps in Xaxama [Satsuma] full of men and treasure, they would fynd that they were sent off purpose by the king of Spaine, having knowledge of the death of the ould Emperour [Ieyasu], thinking som papisticall tono [daimyō might rise and rebell and so draw all the papists to flock to them and take part, by which means they might on a sudden seaz upon som strong place and kcepe it till more succors came, they not wanting money nor men for thackomplishing such a strattgin." The two vessels in question were "greate shipps arrived out of New Spaine, bound, as they said, for the Philippines, but driven into that place per contrary wynd, both shipps being full of souldiers, with great store of treasure, as it is said, above five millions of pezos. "It is true that a Spanish captain sent from these vessels to pay respects to the Court in Yedo "gave it out that our shipps and the Hollanders which were at Firando [Hirado] had taken and robbed all the China junks, which was the occasion that very few or non came into Japan this yeare," and therefore Cocks was somewhat justified in saying "so in this sort I cried quittance with the Spaniards." It appears, however, that the Spaniards were not belieyed, whereas the Englishman could boast, "which speeches of myne wrought so far that the Emperour sent to stay them, and had not the greate shipp cut her cable in the hawse so as to escape, she had been arrested." It was this same Cocks who told a Japanese "admirall" that "My opinion was he might doe better to put it into the Emperour's mynd to make a conquest of the Manillas, and drive those small crew of Spaniards from thence."

In fact, none of the four Occidental nationalities then in Japan had any monopoly of slandering its rivals $s_{s:}$ The accusation preferred by Cocks; however, must have possessed special significance, confirming, as it did, what the pilot of the San Felipe had said twenty years previously as to the political uses to which the propagandists of Christianity were put by the King of Spain, and what Will Adams had said four years earlicr as to the Imperial doctrine of Spain and Portugal that the annexation of a non-Christian country was always justifiable. The "greate shipps out of New Spaine," laden with soldiers and treasure and under orders to combine with any Christian converts willing to revolt against the Yedo Government, were concrete evidence of the truth of the Spanish sailor's revelation and of the English exile's charge. It has always to be remembered, too, that Kyūshū, the headquarters of Christianity in Japan, did not owe to the Tokugawa shoguns the same degree of allegiance that it had been forced to render to Hideyoshi. A colossal campaign such as the latter had conducted against the southern island, in 1587, never commended itself to the ambition of Ieyasu or to that of his comparatively feeble successor, Hidetada: Hence, the presence of Spanish or Portuguese ships in Satsuma suggested danger of an exceptional degree.

In the very month (September, 1616) when Cocks "cried quittance with the Spaniards," a new anti-Christian edict was promulgated by Hidetada, son and successor of Ieyasu. It pronounced sentence of exile against all Christian priests, not excluding even those whose presence had been sanctioned for the purpose of ministering to the Portuguese merchants; it forbade the Japanese, under penalty of being burned alive and having all their property confiscated, to connect themselves in any way: with the Christian propagandists or with their co-operators or servants; and above all, to show them any; hospitality. The same penalties were extended to women and children, and to the five neighbours on both sides of a convert's abode, unless these became informers. Every feudal chief was forbidden to keep Christians in his service, and the edict was promul- 
gated with more than usual severity, although its enforcement was deferred until the next year on account of the obsequies of Ieyasu. This edict of 1616 differed from that issued by: Ieyasu in 1614, since the latter did not explicitly prescribe the death-penalty for converts refusing to apostatize. But both agreed in indicating expulsion as the sole manner of dealing with the foreign priests. It is also noteworthy that, just as the edict of Ieyasu was immediately preceded by statements from Will Adams about the claim of Spain and Portugal to absorb all non-Christian countries, so the edict of Hidetada had for preface Cock's attribution of aggressive designs to the Spanish ships at Kagoshima in conjunction with Christian converts. Not without justice, therefore, have the English been charged, with some share of responsibility for the terrible things that ultimately befell the propagandists and the professors of Christianity in Japan. As for the shogun, Hidetada, and his advisers, it is probable that they did not foresee much occasion for actual recourse to violence. They knew that a great majority of the converts had joined the Christian Church at the instance, or by the command, of their local rulers, and nothing can have seemed less likely than that a creed thus lightly embraced would be adhered to in defiance of torture and death. The foreign propagandists also might have escaped all peril by obeying the official edict and leaving Japan. They suffered because they defied the laws of the land.

Some fifty of them happened to be in Nagasaki at the time of Hidetada's edict. Several of these were apprehended and deported, but a number returned almost immediately. This happened under the jurisdiction of Ōmura, who had been specially charged with the duty of sending away the bateren (padres). He seems to have concluded that a striking example must be furnished, and he therefore ordered the seizure and decapitation of two fathers, De l'Assumpcion and Machado. The result completely falsified his calculations, for so far from proving a deterrent; the fate of the two fathers appealed widely to the people's sense of heroism. Multitudes flocked to the grave in which the two coffins were buried.: The sick were carried thither to be restored to health; and the Christian converts derived new courage from the example of these martyrs. Numerous conversions and numerous returns of apostates took place everywhere:

While this enthusiasm was at its height, Navarette, vice-provincial of the Dominicans, and Ayala, vice-provincial of the Augustins, emerged from hiding, and robed in their full canonicals, commenced an open propaganda, heralding their approach by a letter addressed to Ōmura and couched in the most defiant terms. Thus challenged, Ōmura was obliged to act promptly; especially as Navarette declared that he (Navarette) did not recognize the Emperor of Japan but only the Emperor of Heaven. The two fanatics were seized, conveyed secretly to the island of Takashima, and there decapitated; their coffins being weighted with big stones and sunk in the sea, so as to prevent a repetition of the scenes witnessed at the tomb of the fathers mentioned above... Thereupon, the newly elected superior of the Dominicans:at once sent three of his priests to preach in Ōmura's territories, and two of them, having been seized, were cast into prison where they remained for five years. Even more directly defiant was the attitude of the next martyred priest, an old Franciscan monk; Juan de Santa Martha. He had for three years suffered all the horrors of a medieval Japanese prison, yet when it was proposed to release him and deport him to New Spain, his answer was that, if released, he would stay in Japan and preach there. $\mathrm{He}$ laid his head on the block in August, 1618.

Throughout the next four years, however, no other foreign missionary was 
capitally punished in Japan, though many arrived and continued their propagandism. During that interval, also, there occurred another incident calculated to fix upon the Christians still deeper suspicion of political designs. In a Portuguese ship, captured by the Dutch, a letter was found instigating Japanese converts to revolt, and promising that; when the number of disaffected became sufficient, men-of-war would be sent from Portugal to aid them. Another factor tending to invest the converts with political potentialities was the writing of pamphlets by apostates, attributing the zeal of foreign propagandists solely to traitorous motives. Further, the Spanish and Portuguese propagandists were indicted in a despatch addressed to the second Tokugawa shögun, in 1620 , by the admiral in command of the British and Dutch fleet of defence, then cruising in Oriental waters. The admiral unreservedly charged the friars with treacherous machinations, and warned the shogun against the aggressive designs of Philip of Spain.

This cumulative evidence dispelled the last doubts of the Japanese, and a time of sharp suffering ensued for the fathers and their converts. There were many shocking episodes. Among them may be mentioned the case of Zuñiga, son of the marquis of Villamanrica. He visited Japan as a Dominican in 1618, but the governor of Nagasaki persuaded him to withdraw. Yielding for the moment, he returned two years later, accompanied by Father Flores. They travelled in a vessel commanded by a Japanese Christian, and off Formosa she was overhauled by an English warship, which took off the two priests and handed them over to the Dutch at Hirado. There they were tortured and held in prison for sixteen months, when an armed attempt made by some Japanese Christians to reseue them precipitated their fate. By order from Yedo, Zuñiga, Flores, and the Japanese master of the vessel which bad carried them, were roasted to death in Nagasaki on August 19, 1622. Thus the measures adopted against the missionaries are seen to have gradually increased in severity. The first two fathers put to death; De l'Assumpcion and Machado, were beheaded in 1617, not by the common executioner but by one of the principal officers of the daimy $\bar{o}$. The next two, Navarette and Ayala, were decapitated by the executioner. Then, in 1618, Juan de Santa Martha was executed like a common criminal, his body being dismembered and his head exposed. Finally, in 1622 , Zuñiga and Flores; were burned alive.

The same year was marked by the "great martyrdom" at Nagasaki, when nine foreign priests went to the stake together with nineteen Japanese converts. Apprehension of a foreign invasion seems to have greatly troubled the shögun at this time. He had sent an envoy to Europe who, after seven years abroad, returned on the eve of the "great martyrdom,": and made a report thoroughly. unfavourable to Christianity. 1 Hidetada therefore refused to give audience to the Philippine embassy in 1624, and ordered that all Spaniards should be deported from Japan. It was further decreed that no Jápanese Christians should thenceforth be allowed to go to sea in search of commerce, and that although nonChristians or men who had apostatized might travel freely; they must not visit the Philippines:

Thus ended all intercourse between Japan and Spain. The two countries had been on friendly terms for thirty-two years; and during that time a widespread conviction that Christianity was an instrument of Spanish aggression had been engendered. .. Iemitsu, son of Hidetada, now ruled in Yedo, though Hidetada himself remained "the power behind the throne.". The year (1623) of the former's accession to the shoggunate had seen the re-issue of anti-Christian 
decrees and the martyrdom of some five hundred Christians within the Tokugawa domains, whither the tide of persecution now flowed for the first time. 'From that period onwards official attempts to eradicate Christianity in Japan were unceasing. Conspicuously active in this cause were two governors of Nagasaki, by name Mizuno and Takenaka, and the feudal chief of Shimabara, by name Matsukura. To this last is to be credited the terrible device of throwing converts into the solfataras at Unzen, and under him, also, the punishment of the "fosse" was resorted to." It consisted in suspension by the feet, head downwards in a pit until death ensued. By many this latter torture was heroically endured to the end, but in the case of a few the pains proved unendurable.

It is on record that the menace of a Spanish invasion seemed so imminent to Matsukura and Takenaka that they proposed an attack on the Philippines so as to deprive the Spaniards of their base in the East. This bold measure failed to obtain approval in Yedo. In proportion as the Christian converts proved invincible, the severity of the repressive measures increased. There are no accurate statistics showing the number of victims. Some annalists allege that two hundred and eighty thousand perished up to the year 1635, but that figure is probably exaggerated, for the converts do not seem to have aggregated more than three hundred thousand at any time, and it is probable that a majority of these, having embraced the alien creed for light reasons, discarded it readily under menace of destruction. "Every opportunity was given for apostatizing and for escaping death. Immunity could be secured by pointing out a fellow convert, and when it is observed that among the seven or eight feudatories who embraced Christianity only two or three died in that faith, we must conclude that not a few cases of recanting occurred among the vassals. Remarkable fortitude, however, is said to have been displayed." Caron, one of the Dutch traders of Hirado, writing in 1636, says:-

At first the believers in Christ were only beheaded and afterwards attached to a eross, which was considered as a sufficiently heavy punishment. But when many of them were seen' to die with emotions of joy and pleasure, some even to go singing to the place of execution; and when although thirty and sometimes one hundred were put to death at a time, and it was found that their numbers did not appear to diminish', it was then determined to use every exertion to change their joy into grief and their songs into tears and groans of misery. To effect this they, were tied to stakes and burned alive; were broiled on wooden gridirons, and thousands were thus wretchedly destroyed. But as the number of Christians was not perceptibly lessened by these cruel punishments, they became tired of putting them to death, and attempts were then made to make the Christians abandon their faith by the infliction of the most dreadful torments which the most diabolical invention could suggest. The Japanese Christians, however, endured these persecutions with a great deal of steadiness and courage; very few, in comparison with those who remained steadfast in the faith; were the number of those who fainted under the trials and abjured their religion. It is true that these people possess, on such occasions, a stoicism and an intrepidity of which no examples are to be met with in the bulk of other nations. = Neither men nor women are afraid of death. Yet an uncommon steadfastness in the faith must, at the same time, be requisite to continue in these trying circumstances.

The intrepidity of the native converts was rivalled by the courage of their foreign teachers. Again and again these latter defied the Japanese authorities by visiting Japan - not for the first time but occasionally even after having been deported. Contrary to the orders of the governors of Macao and Manila, nay of the King of Spain himself, the priests arrived, year after year, with the certainty of being apprehended and sent to the stake after brief periods of propagandism. In 1626, when the campaign of persecution was at its height, more than three thousand converts were baptized by these brave priests, of whom none is known to have escaped death except those that apostatized under torture, and they were very few; although not only could life be saved by abandoning 
the faith but also ample allowances of money could be obtained from the authori-, ties. Anyone denouncing a propagandist received large reward, and the people were required to prove their orthodoxy by trampling upon a picture of Christ.

\section{CONTINUATION OF THE FEUDS BETWEEN THE DUTCH AND THE}

PORTUGUESE

While the above events were in progress, the disputes between the Dutch, the Portuguese, and the Spaniards went on without cessation. In 1636, the Dutch discovered in a captured Portuguese vessel a report written by the governor of Macao, describing a festival which had just been held there in honour of Vieyra, who had been martyred in Japan. The Dutch transmitted this document to the Japanese "in order that his Majesty may see more clearly. what great honour the Portuguese pay to those he had forbidden his realm as traitors to the State and to his crown." It does not appear that this accusation added much to the resentment and distrust against the Portuguese. At any rate, the Bakufu in Yedo took no step distinctly hostile to Portuguese laymen until the following year (1637), when an edict was issued forbidding "any foreigners to travel in the empire lest Portuguese with passports bearing Dutch names might enter."

\section{THE SHIMABARA REVOLT}

At the close of 1637 , there occurred a rebellion, historically known as the "Christian Revolt of Shimabara," which put an end to Japan's foreign intercourse for over two hundred years. The Gulf of Nagasaki is bounded on the west by the island of Amakusa and by the promontory of Shimabara. In the early years of Jesuit propagandism in Japan, Shimabara and Amakusa had been the two most thoroughly Christianized regions, and in later days they were naturally the scene of the severest persecutions. Nevertheless, the people might have suffered in silence, as did their fellow believers elsewhere, had they not been taxed beyond endurance to supply funds for an extravagant feudatory. Japanese annalists, however, relegate the taxation grievance to an altogether secondary place, and attribute the revolt solely to the instigation of five samurai who led a roving life to avoid persecution for their adherence to Christianity. Whichever version be correct, it is certain that the outbreak attracted all the Christians from the surrounding regions, and was officially regarded as a Christian rising. The Amakusa insurgents passed over from that island to Shimabara, and on the 27th of January, 1638, the whole body - numbering; according to some authorities, twenty thousand fighting men with thirteen thousand women and children; according to others, little more than one-half of these figures took possession of the dilapidated castle of Hara, which stood on a plateau with three sides descending one hundred feet perpendicularly to the sea and with a swamp on the fourth side:

'The insurgents fought under flags inscribed with red crosses and their battle cries were "Jesus," "Maria," and "St. Iago." They defended the castle successfully against repeated assaults until the 12 th of April, when, their provisions and their ammunition alike being exhausted, they were overwhelmed and put, to the sword, with the exception of 105 prisoners. During this siege the Dutch gave practical proof of their enmity to the Christianity of the Spaniards and Portuguese. For, the guns in the possession of the besiegers being too light to accomplish anything effective, application was made to Koeckebacker, the 
Dutch factor at Hirado, to lend ships carrying heavier metal. He complied by despatching the De Ryp, and her twenty guns threw 426 shots into the castle in fifteen days. There has been handed down a letter carried by an arrow from the castle to the besiegers. It was not an appeal for mercy but a simple enumeration of reasons:-

For the sake of our people we have now resorted to this castle. You will no doubt think that we have done this with the hope of taking lands and houses. Such is by no means the case. It is simply because Christianity is not tolerated as a distinet sect, which is well known to you. Frequent prohibitions have been published by the shōgun, to our great distress. Some among us there are who consider the hope of future life as of the highest importance. For these there is no escape. Because they will not change their religion they incur various kinds of severe punishments, being inhumanly subjected to shame and extensive suffering, till at last for their devotion to the Lord of Heaven, they are tortured to death. Others, even men of resolution, solicitous for the sensitive body and dreading the torture, have, while hiding their grief, obeyed the royal will and recanted. Things continuing in this state, all the people have united in an uprising in an unaccountable and miraculous manner. Should we continue to live as heretofore and the above laws not be repealed, we must incur all sorts of punishments hard to be endured; we must, our bodies being weak and sensitive, sin against the infinite Lord of Heaven and from solicitude for our brief lives incur the loss of what we highly esteem. Thése things fill us with grief-beyond endurance. Hence we are in our present condition. It is not the result of a corrupt doctrine.

It seems probable that of the remaining Japanese Christians the great bulk perished at the massacre of Hara. "Thenceforth there were few martyrs, and though Christianity was not entirely extirpated in Japan, it survived only in remote places and by stealth.

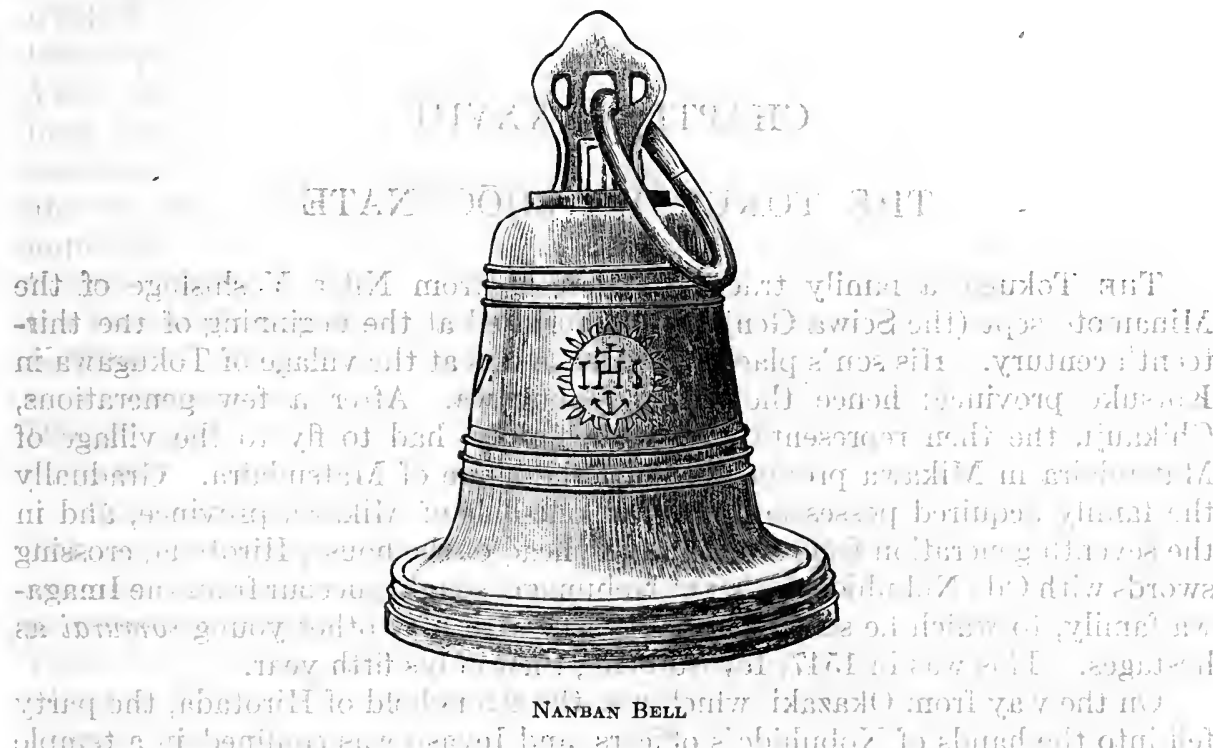




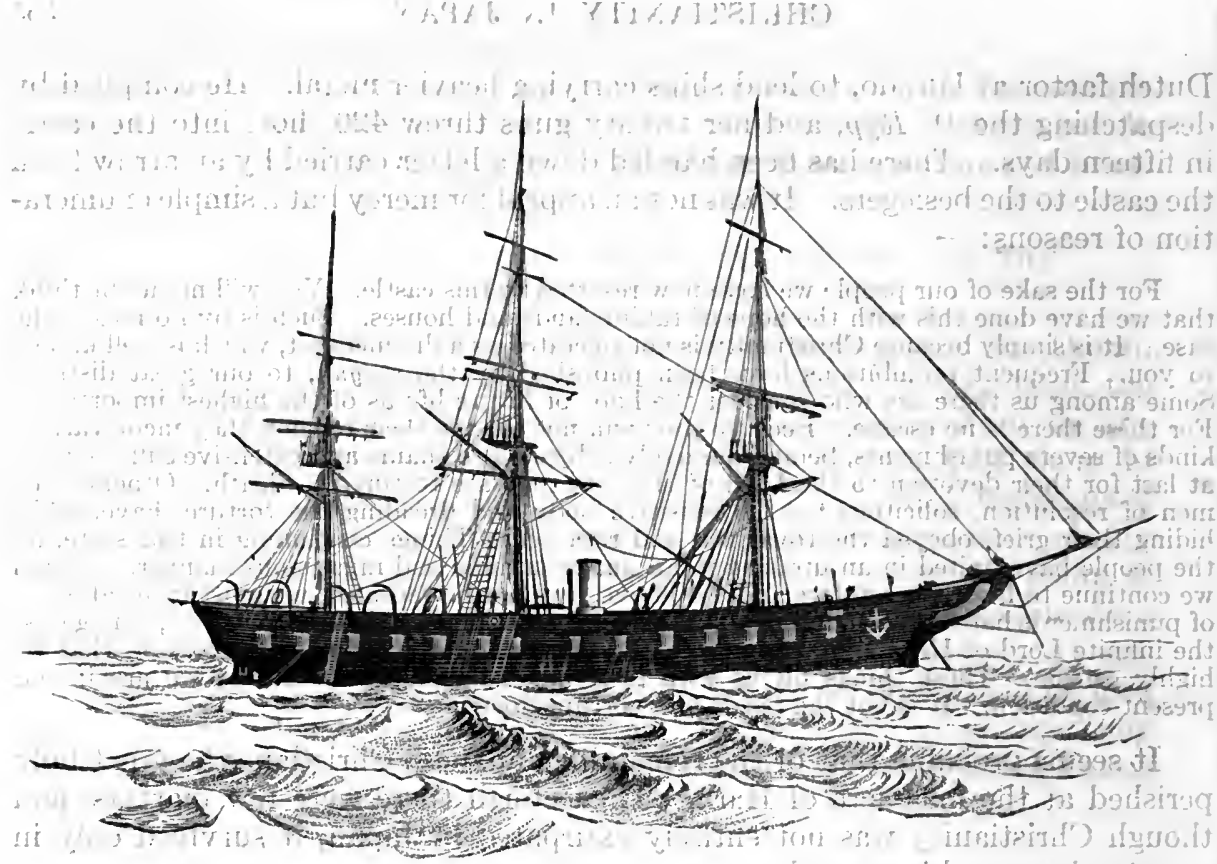

The "Kaiyo Kwan," the First Warship of Japay

(Built in Holland for the Tokugawa Feudal Government)

\section{CHAPTER XXXVIII}

\section{THE TOKUGAWA SHŌGUNATE}

The Tokugawa family traced its deseent from Nitta Yoshishige of the Minamoto sept (the Seiwa Genji) who flourished at the beginning of the thirteenth century. His son's place of residence was at the village of Tokugawa in Kotsuke province: hence the name, Tokugawa. After a few generations, Chikauji, the then representative of the family had to fly to the village of Matsudaira in Mikawa province, taking the name of Matsudaira. Gradually the family acquired possession of about one-half of Mikawa provinee, and in the seventh generation from Chikauji, the head of the house, Hirotada, crossing swords with Oda Nobuhide, father of Nobunaga, sought succour from the Imagawa family, to which he sent his son, Ieyasu, with fifty other young samurai as hostages. This was in 1547 , Ieyasu-being then in his fifth year.

On the way from Okazaki, which was the stronghold of Hirotada, the party fell into the hands of Nobuhide's officers, and Ieyasu was confined in a temple where he remained until 1559 , when he obtained permission to return to Okazaki, being then a vassal of the Imagawa family. But when (1569) the Imagawa suffered defeat in the battle of Okehazama, at the hands of Oda Nobunaga, Ieyasu allied himself with the latter. In 1570, he removed to Hamamatsu, having subjugated the provinees of Mikawa and Tōtommi. He was forty years old at the time of Nobunaga's murder, and it has been shown above that he espoused the cause of the Oda family in the campaign of Komak -yama. At 
forty-nine he became master of the Kwantō and was in his fifty-sixth year when Hideyoshi died. Ieyasu had nine sons: (1) Nobuyasu; (2) Hideyasu (daïmyō of Echizen); (3) Hidetada (second shögun); (4) Tadayoshì (daimyō of Kiyosu); (5) Nobuyoshi (daimyō of Mito); (6) Tadateru (daimyō of Echigo); (7) Yoshinao (daimyō of Owari); (8) Yorinobu (daimyä of Kii), and (9) Yorifusa (daimy $\overline{0}$ of Mito). He had also three daughters; the first married to Okudaira Masanobu; the second to Ikeda Terumasa, and the third to Asano Nagaakira. bivf

\section{EVENTS IMMEDIATELY PRIOR TO THE BATTLE OF SEKIGAHARA}

The political complications that followed the death of the Taiko are extremely difficult to unravel, and the result is not commensurate with the trouble." Several annalists have sought to prove that Ieyasu strenuously endeavoured to observe faithfully the oath of loyalty made by him to Hideyoshi on the latter's death-bed. They claim for him that until his hands were forced he steadfastly and faithfully worked in the interests of Hideyoshi. But his acts do not lend themselves to any such interpretation. The best that can be said of him is that he believed himself to have been entrusted by the Taik $\bar{o}$ with discretionary power to determine the expediency of Hideyori's succession, and that he exercised that power in the interests of the Tokugawa family; not of the Toyotomi.

Circumstances helped him as they do generally help great men. From the time of the birth of the lady Yodo's second son, the official world in Kyoto had been divided into two factions. The Hidetsugu catastrophe accentuated the lines of division, and the Korean campaign had a similar effect by affording a field for bitter rivalry between the forces of Konishi Yukinaga, who belonged to the Yodo faction, and Kato Kiyomasa, who was a protégé of Hideyoshi's wife, Yae. Further fuel was added to this fire of antagonism when the order went forth that the army should leave Korea, for the Kato faction protested against surrendering all the fruits of the campaign without any tangible recompense, and the Konishi party insisted that the Taikō's dying words must be obeyed implicitly. In this dispute; Ishida Katsushige, the chief actor in the Hidetsugu tragedy, took a prominent part. For, when in their capacity as belonging to the Board of Five Administrators, Ishida and Asano Nagamasa were sent to Kyüshū to superintend the evacuation of the Korean peninsula, they, too, fell into a controversy on the same subject. Ieyasu stood aloof from both parties. His policy was to let the feud develop and to step in himself at the supreme móment.

On the other hand, it was the aim of Ishida Katsushige to involve the Tokugawa chief, thus compassing his downfall and opening an avenue for the ascension of Ishida himself to the place of dictator. Allied with Ishida in this - plot was his colleague on the Board of Five Administrators, Masuda Nagamori. Their method was to create enmity between Ieyasu and Maeda Toshiiye, to whom the Taiko had entrusted the guardianship of Hideyori and of the $\overline{\text { Osaka }}$ Castle. This design was barely thwarted by the intervention of Hosokawa Tadaoki (ancestor of the present Marquis Hosokawa). Ieyasu was well informed as to Ishida's schemes on two other occasions; the first immediately before, the second just after, the death of the Taikō. In each case rumours of an armed outbreak were suddenly circulated in Fushimi for the purpose of creating confusion such as might furnish an opportunity to strike suddenly at Ieyasu: These essays failed in both instances, and the Tokugawa chief, instead of retaliating by direct impeachment of Ishida, applied himself to cementing close relations 
with certain great daimy $\bar{o}$ by matrimonial alliances. Such unions had been implicitly interdicted by the Taiko, and the procedure of Ieyasu elicited a written protest from the boards of the Five Senior Ministers and the Five Administrators. They threatened Ieyasu with dismissal from the former board unless he furnished a satisfactory explanation. This he declined to do and for some time a very strained situation existed in Kyōto, an armed struggle being ultimately averted by the good offices of the Three Middle Ministers.

It was evident, however, that the circumstances had become critical, and it was further evident that, as long as Ishida Katsushige's intrigues continued, a catastrophe might at any moment be precipitated. Sensible of these things, a party of loyal men, spoken of in history as the "seven generals" - Ikeda Terumasa (ancestor of the present Marquis Ikeda); Katō Kiyomasa; Kuroda Nagamasa (son of Kuroda Yoshitaka, and ancestor of the present Marquis Kuroda); Fukushima Masanori, Asano Yukinaga (son of Asano Nagamasa and ancestor of the present Marquis Asano); Hosokawa Tadaoki, and Katō Yoshiaki (ancestor of the present Viscount Katō) - vowed to take Ishida's life, while he was still in Ōsaka Castle, whither he had gone (1599) to attend the death-bed of his friend, Maeda Toshiiye. Ishida, finding himself powerless to resist such a combination after the death of Maeda, took an extraordinary step; he appealed to the protection of Ieyasu - that is to say, to the protection of the very man against, whom all his plots had been directed. And Ieyasu protected him.

We are here confronted by a riddle which has never been clearly interpreted. Why did Ishida seek asylum from Ieyasu whom he had persistently intrigued to overthrow, and why did Ieyasu, having full knowledge of these intrigues, grant asylum? Possibly an answer to the former question can be furnished by the fact that Ishida was in sore straits. Attending Maeda Toshiiye's death-bed, he had seen the partisans of the deceased baron transfer their allegiance to Ieyasu through the intervention of Hosokawa Tadaoki, and he had learned that his own life was immediately threatened by the seven generals.; Even if he succeeded (which was very problematical) in escaping from Ösaka to his own castle of Sawa-yama, in Ömi province, the respite could have been but brief and such a step would have been equivalent to abandoning the political arena. Only a very strong arm could save him; and with consummate insight he may have appreciated the Tokugawa chief's unreadiness to precipitate a crucial struggle by consenting to his death.

But what is to be said of Ieyasu? Unwilling to admit that his astuteness could ever have been at fault, some historians allege that the Tokugawa chief saved Ishida's life with the deliberate purpose of letting him discredit himself and his partisans by continued intrigues. These annalists allege, in fact, that Ieyasu, acting on the advice of Honda Masanobu, by whose profound shrewdness: he was largely guided, saved the life of Ishida in order that the latter's subsequent intrigues might furnish a pretext for destroying Hideyori. That, however, is scarcely conceivable, for Ishida had many powerful confederates, and the directoutcome of the leniency shown by Ieyasu on that occasion was an armed struggle: from which he barely emerged victorious. The truth seems to be that, for all his profound wisdom, Ieyasu erred in this instance. Ishida Kotsushige outwitted him. For, during the very days of his asylum in Fushimi, under the protection of Ieyasu, Ishida opened secret communication with Uesugi Kagekatsu and invited him to strike at the Tokugawa. Uesugi consented. It must be observed that the character of Ishida has been portrayed for posterity mainly, by historians, who were under Tokugawa influence. Modern and impartial 
annalists are by no means so condemnatory in their judgment of the man: In whatever arts of deception Ishida excelled; Ieyasu was at least his equal; while in the matter of loyalty to the Toyotomi family, Ishida's conduct compares favourably; with that of the Tokugawa leader; and if we look at the men who

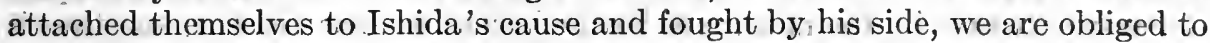
admit that he must have been highly esteemed by his contemporaries, or, at any rate, that they recognized in him the champion of Hideyori, at whose father's hands they had received such benefits.

\section{ORGANIZATION OF THE JAPANESE EMPIRE AT THE CLOSE OF THE SIXTEENTH CENTURY}

The realm of Japan was then held by 214 feudatories, each having an annual income of at least 10,000 koku (omitting minor landowners). These 214 estates yielded to their holders a total income of nearly nineteen million $k o k u$, and of that aggregate the domains of the five noblemen forming the Board of Senior Statesmen constituted one-third. Tokugawa Ieyasu was the wealthiest. His domains in the eight provinces forming the Kwanto yielded an income of 2,557,$000^{2}$ koku. Next on the list came Mōri Terumoto with 2,205,000 koku, and Uesugi Kagekatsu with 1,200,000 koku. The latter two were partisans of Ishida But direct communication between their forces was difficult, for while the Mōri domains covered the nine provinces on the extreme west of the main island, Uesugi's lay on the north of the Kwainto, whence they:stretched to the shore of the Japan Sea. Fourth and fifth on the Board of: Senior Statesmen were Maeda Toshiiye, whose fief $(835,000 \mathrm{koku})$ occupied Kaga and Etchū; and Ukita Hidéiye $(574,000 \mathrm{koku})$, whóse castle stood at. Oka-yama,-in Bizen. All these; except Maeda embraced the anti-Tokugawa cause of Ishida Katsushige, and it thus becomes easy to understand the desire of Ishida to win over Maeda Toshinaga, son of Toshiiye, to his camp. On the side of Ieyasu's foes were also marshalled Shimazu Yoshihisa, feudal chief of Satsuma $(700,000 \mathrm{koku})$; Satake Yoshinobu of Hitachi province $(545,700 \mathrm{koku})$; Konishi Yukinaga in Higo (200,000 koku), who was counted one of the greatest captains of the era, and, nominally, Kohayakawa Hideaki in Chikuzen $(522,500, k o k u)$. With Ieyasu were the powerful daimyō: Date Masamune of Sendai : $(580,000 \mathrm{koku})$; Kàtō Kiyomasa of Kumamoto (250,000 koku); Hosokawa Tadaoki of Tango $(230,000 \mathrm{koku})$; Ikeda Terumasa of Mikawa $(152,000 \mathrm{koku})$, and Kuroda Nagamasa of Chikuzen $(250,000$ koku). This analysis omits minor names.

\section{BATTLE OF SEKIGAHARA}

The plan of campaign formed by Ishida and his confederates was that Uesugi and Satake should attack the Kwanto from the north and the east simultaneously," while Mōri and Ukita should move against Fushimi and occupy Kyōto. In May, 1600, Ieyasu went through the form of requiring Uesugi to repair to Kyōto and explain his obviously disaffected preparations. The reply sent by Uesugi was defiant. Therefore, the Tokugawa chief proceeded to mobilize his own and his allies' forces. He seems to have clearly foreseen that if he himself moved eastward to Yedo, Momo-yama would be assaulted in his absence. But it being necessary to simulate trust in Mōri and Ukita, then nominally his supporters, he placed in Momo-yama Castle a garrison of only two thousand men under his old and staunch friend, Torii Mototada. Ieyasu planned that 
Uesugi should be attacked simultaneously from five direetions; namely from Sendai by Date; from Kaga by Maeda; from Dewa by Mogami; from Echigo by Hori, and from Hitachi by Satake. But among these five armies that of Satake declared for Ishida, while those of Maeda and Hori were constrained to adopt a defensive attitude by the menace of hostile barons in their vicinity and thus it fell out that Date and Mogami alone operated effectively in the cause of Ieyasu:

The Tokugawa chief himself lost no time in putting his troops in motion for Yedo, where, at the head of some sixty thousand men, he arrived in August, 1600, his second in command being his third son, Hidetada. Thence he pushed rapidly northward, with the intention of attacking Uesugi. But at Oyama in Shimotsuke news reached him that Ishida and his partisans had drawn the sword in the west, and had seized Ōsaka, together with the wives and families of several of the captains who were with Ieyasu's army. A council was immediately held and these captains were given the option of continuing to serve under Ieyasu or retiring to join the western army and thus ensuring the safety of their own families. : They chose the former, and the council further decided that, leaving Date and Mogami to deal with Uesugi and Satake, and posting for the same purpose at Utsunomiya, Hideyasu, second son of Ieyasu, the main army should countermarch to meet the western forces at some point remote from Yedo.

The Tokugawa battalions, following two routes - the Tōkaido and the Nakasendo - made rapid progress westward, and on September 21 st, the van of the division under Fukushima and Ikeda reached Kiyosu. But the Nakásendo column of thirty-eight thousand men under Hidetada encountered such desperate resistance before the castle of Ueda, at the hands of Sanada Masayuki, that it did not reach Sekigahara until the great battle was over. Meanwhile; the western army had pushed steadily eastward.: Its first exploit was to capture and burn the Momo-yama castle, which was splendidly defended by the veteran Torii Mototada, then in his sixty-second year. With a garrison of only two thousand men he held at bay during eleven days an investing force of forty thousand. The torch was set to the castle on the 8th of September by traitors in the garrison, and Mototada committed suicide. Thereafter, the van of the western army advanced to Gifu along the Nakasendo, and the main body, making a detour through Ise, ultimately pushed forward into Mino.

With this army were no less than forty-three generals of renown, and the number of feudal barons, great and small, who sent troops to swell its ranks was thirty-one. Undoubtedly these barons were partially influenced by the conception generally prevalent that the fortunes of the two great families of Toyotomi and Tokugawa depended on the issue of this struggle. But it must also be admitted that had Ishida Katsushige been as black as the Tokugawa historians paint him, he could never have served for the central figure of such an array. $\mathrm{He}$ is seen inciting the besiegers of Momo-yama Castle to their supreme and successful effort. He is seen winning over to the Toyotomi cause baron after baron. He is seen leading the advance of the western army's van. And he is seen fighting to the end in the great battle which closed the campaign some heroic qualities must have accompanied his gift of statesmanship. The nominal leader of the western army, which mustered 128,000 strong, was Mori Terumoto, and under him were ranged Ukita Hideiye, Mōri Hidemoto, Shimazu Yoshihiro, Konishi Yukinaga, and many other captains of repute. Under the Tokugawa banners there marched 75,000 men, their van led by Ii Naomasa and Honda Tadakatsu. 
(97. On October 21, 1600, the great battle of Sekigahara was fought. The strategy on the side of the western forces was excellent. Their units: were disposed along a crescent-shaped line recessed from the enemy, so that an attacking army, unless its numerical strength was greatly superior, had to incur the risk of being enveloped from both flanks - a risk much accentuated by the fact that these flanking troops occupied high ground: But on the side of the western army there was a feature of weakness which no strategy could remove: all the battalions constituting the right wing were pledged to espouse the cause of Ieyasu at the crisis of the struggle. There were six of these battalions, large or small, and they were commanded by Akakura, Ogawa, Kuchiki, Wakizaka; Kohayakawa; and Kikkawa. Thus, not only were the eastern troops able to deliver their attack in full force against the centre and left of their foes, but also the latter were exposed to the most demoralizing of all eventualities, treachery.

After a fierce fight the western army was completely defeated. Some accounts put its losses at 35,000 men; others, with greater probability, estimating that only 100,000 men were actually engaged on both sides - namely, 60,000 on the Tokugawa side, and 40,000 on the Toyotomi - conclude that the losses were 6000 and 9000, respectively. Shimazu of Satsuma, at the head of a handful of samurai, cut his way through the lines of Ieyasu, and reaching Osaka, embarked hastily for Kyūshū. Ishida Katsushige lay concealed in a cave fơr a fề days, but was ultimately seized and beheaded, in company with Konishi Yukinaga and Ankokuji Ekei, at the execution ground in Kyotto. This one battle ended the struggle: there was no rally. Punishment followed quickly for the feudatories who had fought against the Tokugawa. Thus Mōri Terumoto's domain, originally covering eight provinces and yielding a revenue of 1,205,000 koku, was reduced to the two provinces of Suwo and Nagato, yielding 300,000 koku. The three provinces of Ukita Hideiye were entirely forfeited, and he himself was banished to the island Hachijōshima. Oda Hidenobu, grandson of Nobunaga, Masuda Nagamori, and Sanada Masayuki, with his son, were ordered to take the tonsure and retire to the monastery of Koya-san. The fief of Uesugi Kagekatsu was reduced from 1,200,000 koku in Aizu to $300,000 \mathrm{koku}$ in Yonezawa; and the 800,000 koku of the Satake family in Hitachi were exchanged for 200,000 koku in Akita. Only the Shimazu family of Satsuma remained without loss. Secured by inaccessibility, it continued to hold the provinces of Satsuma, Ōsumi, and Hyuga, with a revenue of $700,000 \mathrm{koku}$.

\section{REDISTRIBUTION OF THE FIEFS}

These measures represented only a fraction of the readjustments then effected. Ieyasu, following the example set on a small scale by the Taikō, parcelled out the country in such a manner as to provide security against future trouble. Dividing the feudatories into hereditary vassals (fudai no kerai) and exterior nobles (tozama), he assigned to the former small but greatly increased estates situated so as to command the main highways as well as the great cities of central Japan, and he located the exterior nobles - many of them with largely reduced domains - in districts remote not only from Yedo and Kyōto but also from each other, wherever such method of distribution was possible. Moreover, in the most important places - as Ōsaka, Fushimi, Sakai, Nagasaki, Yamada (in Ise), and Sado (the gold mines), there were appointed administrators (bugyō), direct nominees of the Tokugawa; while Kyōto was put under the sway of a deputy of the shogun (shoshidai). Again, although the tozama daimyo received 
tolèrably munificent treatment in the matter of estates, their resources were seriously crippled by the imposition of costly public works. These works consisted mainly of restoring dilapidated castles or building new ones on a scale so colossal as to be exceeded by only the stronghold at Ōsaka. It is recorded that when Fukushima Masanori, lord of Kiyosu in Owari, complained of the crippling effects of these severe requisitions, Katō Kiyomasa told him that there was no alternative except to retire to his castle and defy Yedo. The most costly: of the edifices that came into existence in these circumstances was the castle of Nagoya, which is still one of the wonders of Japan. Twenty great barons took part in erecting it; the leading artists of the time were engaged in its interior decoration, and the roof of its donjon was crowned with two gold dolphins, measuring nearly nine feet in height.

\section{IEYASU: BECOMES SHŌGUN}

On the 28th of March, 1603, the Emperor nominated Ieyasu to be minister of the Right and sei-i tai-shogun, presenting to him at the same time the conventional ox-chariot and military baton. Nine days later, the Tokugawa chief repaired to the palace to return thanks for these honours. The Emperor with his own hands gave him the drinking-cup and expressed profound gratification that through his military skill the wars which had convulsed the nation were ended, and the foundations of the empire's peace securely laid. Ieyasu was then in his sixty-second year. In the following May, Hideyori was made nai-daijin, and in the same month a marriage was contracted betwcen him, then in his eleventh year, and Tenju-in, the seven-year-old daughter of Hidetada, son and successor of Ieyasu.

\section{YEDO AND KYŌTO}

Ieyasu now took up his residence at Momo-yama Castle and Hidetada was ordered to live in Yedo. But the former made it a custom to go eastward every autumn on the pretext of enjoying the sport of falconry, and to remain in Yedo until the next spring. In February, 1605, the Tokugawa chief's return to Kyoto from the Kwanto capital was made the occasion of a great military display. Both Ieyasu and Hidetada travelled at the same time with a following of 170,000 soldiers, who were encamped outside the city whence they marched in, ten thousand daily, during seventeen consecutive days. This martial parade is said to have produced a great effect upon the nobles of the Kinai and the western provinees. But Ieyasu did not long retain the office of shögun. In 1605, he conveyed to the Imperial Court his desire to be relieved of military functions, in favour of his son Hidetada, and the Emperor at once consented, so that Hidetada succeeded to all the offices of his father, and Ieyasu retired to the castle of Sumpu, the capital of Suruga. His income was thenceforth reduced to 120,000 koku annually, derived from estates in the provines of Mino, Ise, and Ōmi. "But this retirement was in form rather than in fact. All administrative affairs, great or small, were managed in Sumpu, the shögun in Yedo exercising merely the power of sanction. Ieyasu made frequent journeys to Yedo under the pretext of hawking but in reality for government purposes.

It was on the 30th of August, 1590, that Ieyasu made his first formal entry into Yedo from Sumpu. " Yedo Castle had previously been occupied by an agent 
of the Hōjō clán.: It was very small, and its surroundings consisted of barren plains and a few fishing villages. On the northwest was the moor of Musashi, and on the southeast a forest of reeds marked the littoral of Yedo Bay. The first task that devolved upon Ieyasu was the reclamation of land for building purposes. Some substantial work was done, yet the place did not suggest any fitness for the purpose of an administrative centre, and not until the battle of Sekigahara placed him in command of immense resources, did Ieyasu decide to make Yedo his capital. He then had large recourse to labour requisitioned from the feudatories. By these means hills were levelled, swamps reclaimed; and embankments built, so that the whole aspect of the region was changed, and sites were provided for the residences of various barons and for the establishment of shops and stores whose owners flocked to the new eity from Ōsaka; Kyōto, and other towns. Thereafter, a castle of colossal dimensions, exceeding even the Ōsaka fortress in magnitude and magnificence, was rapidly constructed, the feudatories being required to supply labour and materials in a measure which almost overtaxed their resources:

sily Historians differ as to the exact date of the establishment of the Yedo $B a k u f u$; but the best authorities are agreed that the event should be reckoned from the battle of Sekigahara, since then, for the first time, the administrative power came into the hand of the Tokugawa baron, he having previously been simply the head of a board instituted by the Taiko. There can be no doubt; that in choosing Yedo for his capital, Ieyasu was largely guided by: the example of Yoritomo and by the experience of the Ashikaga. Kamakura had been a success as signal as Muromachi had been a failure. In the former, Ieyasu had much to imitate; in the latter, much to avoid. We have seen that he distributed the estates of the feudatories so as to create a system automatically unfavourable to disturbance, in which contrivance he borrowed and extended the ideas of Nobunaga and Hideyoshi. It remains to note that what Hōjō Tokimasa and $\overline{0}$ ye Hiromoto were to Minamoto Yoritomo as advisers and organizers, and what Ashikaga Tadayoshi and Kōno Moronao were to Ashikaga Takauji in the same rôles, such, also, were Honda Masanobu and Honda Masazumi to Tokugawa Ieyasu.

\section{HIDEYORI AND IEYASU}

In May, 1605, Hideyori was nominated $u$-daijin.

At that time the nation was divided pretty evenly into two factors; one obedient to the Tokugawa, the other disposed to await Hideyori's coming of age; which event was expected to restore the authority of the Toyotomi family: Fukushima Masanori and Katō Kiyomasa were the most enthusiastic believers in the latter forecast. Up to that time Ieyasu had not given any definite indication of the attitude he intended to assume towards the Taiko's heir. It was not till the year 1611 that he found an opportunity of forming a first-hand estimate of Hideyori's character. $\mathrm{He}$ then had a meeting with the latter at Nijō Castle, and is said to have been much struck with the bearing and intelligence of Hideyori. In fact, whereas common report had spoken in very disparaging terms of the young man's capacities Hideyori was then seventeen years old - the Tokugawa chief found a dignified and alert lad whose aspect suggested that if he was suffered to remain in possession of Ōsaka a few years longer, Yedo would run the risk of being relegated to a secondary place.

Ieyasu after that interview is said to have felt like "a man who, having still a long distance to travel; finds himself enveloped in darkness.". He saw that 
the time for considering justice and humanity had passed, and he summoned Honda Masanobu to whom he stid: "I see that Hideyori is grown up to be a son worthy of his father. By and by it will be difficult for such a man to rendain subservient to another." Masanobu, whom history describes as the "Tokuga? wa's storehouse of wisdom,": is recorded to have replied: "So Is too, think, but there is no cause for anxiety: I have an idea.' What this idea was events soon disclosed. . Summoning one of the officials in the service of Hideyori's wife Hidetada's daughter - Masanobu spoke as follows: "Hideyori is the only son of the late Taiko and it is the desire of the $\bar{O}$-gosho": (the title given to Ieyasu after his retirement from the shōgunate) "that he, Hideyori, should have a numerous and thriving family. Therefore, if any woman takes his fancy, she must be enrolled among his attendants to whatever class she may belong. Moreover, if there be among these ladies any who show jealousiés or makè disturbances, no complaint need be preferred to the $\bar{O}$-gosho. I will undertake to settle the matter."

From that time Hideyori lived among women. $\mathbf{A}$ word may here be said about the marriage between Hideyori and the granddaughter of Ieyasu, the bride and the bridegroom alike being mere children. According to a recognized historical authority, writing in the Tokugawa Jidaishi, such marriages were inspired by one or more of the following motives: $(1)$ that the bride or bridegroom ishould serve as a hostage; (2) that the wedding should contribute to cement an alliance between the families of the bride and the bridegroom; (3) that the wedding should become a mean's of spying into the affairs of one of the families; (4) that it should be an instrument for sowing seeds of enmity between the two families: The objects' of Ieyasu in wedding his granddaughter at seven years of age to Hideyori at eleven were doubtless of the nature indicated in the third and fourth of the above definitions... On the one hand; he seemed to the Ōsaka party to be conforming to the will of the Taik $\overline{0}$; on the other, he was able to introduce into the household of Hideyori an unlimited number of spies among the retinue of his granddaughter.

\section{KATAGIRI KATSUMOTO}

Just before his death, Hideyoshi specially conjured Koide Hidemasa and Katagiri Katsumoto to labour for the safety of the Toyotomi family. Hidemasa soon followed his patron to the grave, and the duty of managing the affairs of the family devolved entirely upon Katsumoto in his capacity of administrator $($ bugy $\bar{o})$. He devoted himself to the task with the utmost sincerity and earnestness, and he made it the basic principle of his policy to preserve harmony between the Tokugawa and the Toyotomi. His belief was that Ieyasu had not many years more to live, and that on his demise the administrative power would revert wholly to Hideyori as a natural consequence. Hence the wisest course was to avoid any collision in the meanwhile:

\section{THE OATH OF FEALTY}

On the 14th of May, 1601, that is to say, shortly after the battle of Sekigahara, all the feudatories: were invited to subscribe a written oath of loyalty to the Tokugawa. This oath consisted of three articles. The first was a promise to observe strictly all instructions issued by the Bakufu in Yedo. The sceond was an engagement not to harbour or protect any person who had either violated or 
opposed the will of the shogun.: The third was a pledge not to give employment to any samurai reported to be a traitor or an assassin. By these stipulation's the signatories swore to abide strictly, and declared that any violation of the provisions of the oath would render the violator liable to severe punishment. Among the signatories there were not found any members of the Ösaka party. These put forward the last will of the Taiko as a reason for refusing to sign, and from that time it became evident that the situation must terminate in an armed struggle.

\section{ONNO HARUNAGA}

Among the Ōsaka partisans was one called Ōno Harunaga, the son of the lady Yodo's nurse. This youth led a life of great profligäcy, and although not wanting in any of the attributes of the samurai; he altogether lacked political insight." Thus, his relations with Katsumoto were strained, and Harunaga constantly essayed to undermine Katsumoto's influence. Hideyori himself did not want for ability, but acting by the advice of his mother, Yodo, and of his friend; Harunaga, he adopted a false policy of opposition to Ieyasu.

\section{STATE OF ŌSAKA}

The fact that the feudatories who called themselves friends of the $\overline{0}$ saka party had refused to sign the oath of fealty, and the fact that the lady Yodo and Harunaga threw their influence into the anti-Tokugawa scale, had the effect of isolating Ōsaka so far as the laws of the Bakufu were concerned. : Men who had broken those laws or otherwise offended against the shogun took refuge in Ōsaka. Such was the case with the son of Hosokawa Tadaoki; with Gotō Matabei, chief vassal of Kúroda Nagamasa, and with Nambu Saemon, principal retainer of Nambu Nobunao.: These three and many others repaired to the castle of $\bar{O}$ saka, and being there secure against any unarmed attempt of the Tokugawa to arrest them, they virtually defied Ieyasu's control. By degrees a constant stream of rōnin, or free-lances, flowed into that city; and a conspicuous element among its inhabitants consisted of Christian feudatories, who, regardless of the edicts of the Bakufu, openly preached their faith and were in no wise checked by the Toyotomi rulers. Even the Buddhist and Shinto priests in Ōsaka and its territories were independent of the Bakuf $u$ authority; and there were cases of boundary disputes in which the Tokugawa officials declined to give judgment since they were not in a position to enforce it. It may well be supposed that this state of affairs grew steadily more obnoxious to the Tokugawa. Ieyasu only awaited a pretext to assert the supremacy of his authority.

\section{INSCRIPTION ON THE BELL}

It has already been stated that in the year 1586 , a colossal image of Buddha was erected by Hideyoshi at the Hōkō-ji in Kyōto. This idol was made of wood, and the great earthquake of 1596 destroyed it. Subsequently, Ieyasu advised Hideyori to replace the wooden idol with a bronze one. Ōno Harunaga stood opposed to this idea, but Katagiri Katsumoto, constant to his policy of placating Ieyasu, threw his influence into the other scale. It is impossible to tell whether, in making this proposal, Ieyasu had already conceived the extraordinary scheme which he ultimately carried out. It would appear more probable, however, that his original policy was merely to impoverish the Toyotomi family by imposing 
upon it the heavy outlay necessary for constructing a huge bronze Buddha. Many thousands of ryo had to be spent, and the moncy was obtained by converting into coin a number of gold ingots in the form of horses, which Hideyoshi had stored in the treasury of the Ösaka castle as a war fund. Five years later; that is to say, in 1614, the great image was completed and an imposing ceremony of dedication was organized. A thousand priests were to take part, and all the people in the capital, as well as many from the surrounding provinces, assembled to witness the magnificent fête. Suddenly an order was issued in the name of Ieyasu, interdicting the consummation of the ceremony on the ground that the inscription carried by the bell for the idol's temple was designedly treasonable to the Tokugawa. This inscription had been composed and written by a high Buddhist prelate, Seikan, reputed to be one of the greatest scholars and most skilful calligraphists of his time.

It was inconceivable: that such a man should err flagrantly in the use of the ideographic script. I Ieyasu, however, despatched to Kyōto two rival prelates, Sōden and Tengai, with instructions to convoke a meeting of the priests of the Five Temples and invite them to express an opinion about the inscription. Sōden held the post of administrator of temples. This placed him officially at the head of all the other priests, and thus the opinions he expressed at the instance of Ieyasu possessed special weight. It was in vain that Seikan repudiated all intention of disrespect and pointed out that the inscription dia not for a moment lend itself to the interpretation read into it by the Tokugawa chief: Only one priest; Kaizan of Myōshin-ji, had sufficient courage to oppose Sōden's view, and the cause of the Tokugawa chief triumphed.

Without a full knowledge of the Chinese ideographic script it is impossible to clearly understand either the charges preferred by the Tokugawa or the arguments employed in rebuttal. Western readers may, however, confidently accept the unanimous verdict of all modern scholars, that the interpretation assigned to the inscription in the first place by the Tokugawa officials, and in the second by Hayashi Dōshun, representing the Confucianists, and Sōden and Tengai, representing the Buddhists, was grossly unreasonable. That many experts should be found to range themselves on the side of a ruler so powerful as Ieyasu was not wonderful, but it says little for the moral independence of the men of the time that only one Buddhist priest among many thousand had the courage to withhold his consent to a judgment which outraged truth and justice.

Naturally the news of the decision threw Ōsaka into a state of great excitement. Lady Yodo hastened to despatch to Sumpu her principal lady-in-waiting, Ōkura-no-Tsubone, accompanied by another dame of the chamber. These two were received by Acha-no-T subone at the court of Ieyasu, and through her they conveyed fervent apologies to the Tokugawa chief. Ieyasu treated the whole matter lightly. He granted an interview to the two ladies from Ōsaka and sent them on to Yedo to visit the wife of Hidetada, the lady Yodo's younger sister. The Ōsaka députies naturally drew favourable inferences from this courteous mood, and taking an opportunity to refer to the affair of the inscription on the bell, elicited from Ieyasu an assurance that the matter need not be regarded with concern.

Not for a moment suspecting any deception, Ōkura-no-T subone and hel companion took their way to Ōsaka. On the other hand, Honda Masanobu and the priest, Tengai, were instructed to inform Katsumoto that the umbrage of Ieyasu was deeply roused, and that some very strong measure would be necessary to restore the Bakufu's confidence in Hideyori. Katsumoto vainly sought some 
definite statement as to the nature of the reparation required. He was merely told to answer the question himself. He accordingly proposed one of three courses, nämely; that the lady Yodo should be sent to Yedo as a hostage; that Hideyori should leave Ōsaka and settle at some other castle; or, finally, that he should acknowledge himself a vassal of the Tokugawa. To these proposals the only reply that could be elicited from Ieyasu was that Yodo and her son should choose. whichever course they pleased, and, bearing that answer, the disquieting 'import of : which he well understood, 'Katsumoto set out from

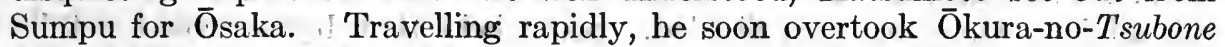
and explained to her the events and their import. But the lady was incredulous. She was more ready to suspect. Katsumoto's sincerity than to believe that Ieyasu had meant to deceive her.

Had Katsumoto been free to continue his journey to Ôsaka, reaching it in advance of Ōkura-no-Tsubone's party, the result might have been different. But Ieyasu did not contemplate any such sequence of events. He instructed Itakura Katsushige to invite Katsumoto to call at Kyōto on the way to Ōsaka with the object of discussing an important affair. Katsumoto had no choice but to delay his journey, and Katsushige took care that the delay should be long enough to afford time for Ōkura-no-Tsubone's party to.reach Ōsaka, and to present their report, together with their suspicions of Katsumoto's disloyalty. to Lady Yodo was incensed when she learned the terms that Katsumoto had offered. "I am Hideyori's mother," she is reported to have cried. "I will never bend my knee to the Kwantō. Rather will I and my son make this castle our death-pillow:". Then, with Ōno Harunaga, she formed a plot to kill Katsumoto and to draw the sword against the Tokugawa. Subsequently, when Katsumoto returned to Ōsaka and reported the result of his mission, he stated his conviction that the only exit from the dilemma was one of the three. courses indicated above. Yodogimi, on being informed of this opinion, intimated her desire to see Katsumoto. . But when the day named for the meeting came and Katsumoto was on the point of leaving his residence for the purpose of repairing to the conference, he received information that the intention was to kill him en route. He therefore fled to his domain in the remote province of Ibaraki. It is recorded that Katśumoto's plan was to offer to send Yodo as a hostage to Yedo. Then the question would arise as to a place of residence for her in the eastern capital, and the processes of preparing a site and building a house were to be supplemented by accidental conflagrations, so that the septuagenarian, Ieyasu, might easily pass away before the actual transfer of the hostage took place. Such was Katsumoto's device, but he had to flee from Ōsaka before he could carry it into effect.

\section{THE SIEGE OF ŌSAKA CASTLE}

In the year 1614, Ieyasu issued orders for the attack of Ōsaka Castle, on the ground that Katsumoto's promise had not been fulfilled. The Tokugawa chief set out from Sumpu and his son, Hidetada, from Yedo. Their armies, combined with the forces of several of the feudatories, are said to have aggregated one hundred and fifty thousánd men. In Ōsaka, also, a great host was assembled, and among its leaders were several renowned warriors, including Sanada. Yukimura, Gotō Matabei, Hanawa Naotsugu, and others; who, although not originally vassals of the Toyotomi, supported Hideyori loyally. As for the castle. its enormous strength rendered it well-nigh impregnable, and after weeks 
of effort the Tokugawa forces had nothing to show for their repeated attacks except a long list of casualties.

'Ieyasu now had recourse to intrigue. The mother of Kyōgoku Takatsugu, daimyo of Obama, in Wakasa, was the younger sister of the lady Yodo. Ieyasu induced her to open communications with Yodo, and to represent to the latter the advisability of concluding peace with the Tokugawa instead of remaining perpetually: beleaguered in a fortress, thus merely postponing an end which eould not be finally averted. ' A council was convened in' the castle to consider this advice. Opinions were divided. Some held that Ieyasu could not be believed, and that if the struggle were maintained for a few years, the face of affairs might change radically. Others urged that the loyalty of the garrison was not above suspicion, and that if the fight went on much longer, treachery: might be practised, to which risk a speedy peace, even at some cost, would be preferable: Ōno Harunaga was among the advocates of surrender, but Hideyóri himself showed that his character had not been mistaken by Ieyasu. $\mathrm{He}$ indignantly reminded Hārunaga and the latter's fellow thinkers that ảrms had been taken up by their advice and in opposition to the loyal efforts of Katsumoto in the cause of peace.

Lady Yodo, however, threw her influence into the scale with Ōno Harunaga, and finally peace was concluded on terms highly favourable to the Toyotomi. It was agreed that Hideyori should remain in the possession of the castle and of all his domains, and that the garrison, as well as the unattached samurai who formed part of it, should not be punished but should be provided for subsequently. It might have occurred to the leaders of the Osaka party that these lenient conditions covered some occult designs; nothing was less likely than that a statesman like Ieyasu would be content with/so signal a failure. But a shortsighted sentiment of confidence seems to have obscured the judgment of the Ōsaka folks. They actually gave heed to Ieyasu's complaint that ihe, the $\bar{o}+g o s h o$; and his son; the shoggun, must not be allowed to have taken so much trouble for nothing; that it was customary to give hostages to an army which agreed to raise a siege, and that at least a portion of the castle's defences should be destroyed. As to theslast point, the Tokugawa chief was kind enough to say that the work of demolition should not cost the garrison anything, since labour would be supplied gratis by the shōgun.

After considerable correspondence it was agreed that Harunaga's son should go to Yedo as a hostage, and that a portion of the outer moat of Ōsaka Castle should be filled up: Meyasu did not lose a moment in giving effect to this latter provision. He ordered some of the fudai daimyō of the Kwantō to proceed to Ōsaka with several thousands of men, who should go to work forthwith to tear down the parapets and fill up the moats of the castle. These orders were implicitly obeyed, and as Ieyasu had omitted to indicate any limit for the work of destruction, it went on without check, and presently the second line of parapets began to follow the first. The Ōsaka leaders protested and essayed to stay the destruction. But the officers who were in command of the operation said that without a direct mèssage from Honda Masazumi, who represented Ieyasu, they. could not suspend their task. - Efforts were then made to approach Honda, but he: was conveniently absent "on account of his health," and the ensuing correspondénce occupied several days, during which the pulling-down and filling-up went on by day and-by night. More than one-half of the'second moat had disappeared before Masazumi could be found His answer was that he had been merely told to fill up the moat. Possibly he had mistaken the scope of his 
instructions and he would refer the matter to Ieyasu. This involved further delay and more filling, until, finally, Masazumi acknowledged that he had made a mistake, declared himself prepared to undergo punishment; and withdrew his men to Fushimi:

Ieyasu supplied the sequel of the farce, When complaint was made against Masazumi, the Tokugawaleader simulated astonishment, expressed much regret, and said that he would condemn Masazumi to commit suicide were it permissible to mar this happy occasion by any capital sentence. "Peace," declared the astute old statesman," "has now been fortunately concluded. Let us not talk any more about the castle's moats or parapets:" Against such an attitude the $\bar{O}$ saka men could not enter any protest, and the farce ended there. Had the Ōsaka leaders possessed any measure of the wisdom that marked all the doings of -Ieyasu, they would not have suffered matters to rest at such a stage. But they foolishly imagined that some retaliation might be effected by calling upon the Tokugawa to supplement that part of the peace provisions which related to allowances for the samurai who had fought on the side of the garrison. A demand in that sense was preferred to Ieyasu. But he had now laid aside his transient suavity. The Ōsaka people were brusquely informed that they must look to the Toyotomi family for recompense, and that as for rewarding unattached samurai who had drawn the sword against the shogun, the $\overline{0}$ saka people, were they obedient to the dictates of loyalty,-would of their own account peremptorily reject such an unwarranted proposition, even though Ieyasu himself were disposed to consent to it.

ii Of course this answer profoundly enraged the $\bar{O}$ saka party. They appreciated for the first time that they had been deceived throughout, and that by a series of adroit manœuvres they had been removed from an almost impregnable position to a practically helpless plight. Not a few turned their backs on the castle, but a great majority determined to renew the conflict and to die at their posts. The circumstances, however, had now undergone a radical change. The castle had been converted from the strongest fortress in Japan into a mere semblance of strength, and no garrison, however brave and however resolute, could have defended it successfully, against the forces that the Tokugawa were able to marshal.

br As for Ieyasu, he knew that his task had been immensely lightened. On the 3rd of May, 1615, he started from Sumpu for Ōsaka at the head of an army numbering scarcely one-third of the force previously led against the castle. Nevertheless, one contingency presented itself in a dangerous light. : It was always possible that Hideyori himself should make a sortie from the fortress, and, in that event, the prestige attaching to the memory of his father, Hideyoshi, might have demoralized a large section of the Tokugawa troops. 'To avert this danger, Ieyasu had recourse to his wonted methods of deception. It has been shown that he held Harunaga's son as a hostage. This youth was required to write a letter to his father stating that collusion existed between parties within and without the fortress, i and that the traitors had plotted to induce:Hideyori to make a sortie, whereupon the cástle would be given up and Hideyori would be delivered into the hands of his enemies. Harunaga does not appear to have entertained any doubt as to the trustworthiness: of this letter $\mathrm{He}$ carried it hastily to Hideyori; who was in the act of preparing to sally out of the castle and throw himself upon the beleaguering forces.

The receipt of the letter naturally led to a change of plan, and although desperate fighting subsequently took place, the castle was finally set on fire by 
traitors and its fate was seen to be hopeless: Hideyori's wife, granddaughter of Ieyasu, repaired to the Tokugawa headquarters to plead for the life of her husband and his mother. But Ieyasu was inexorable. He granted asylum to his: granddaughter, but replied to her prayer by ordering a renewal of the attack upon the eastle. On June 4th, Hideyori committed suicide, and his mother, Yodo, was killed by one of his retainers. Some thirty men and women killed. themselves at the same time.

Men spoke of the first fruitless assault upon the castle as the "Winter Campaign," and of the second and successful assault as the "Summer Campaign." But the two operations were radieally different in their character. For, whereas in the first assault the garrison-numbering something like one: hundred and eighty thousand men - stood strictly on the defensive; wisely relying on the immense strength of the fortress, on the second occasion most of the fighting took place outside the walls, the garrison preferring to rely upon strategy and courage rather than on ruined parapets and half-filled moats. Thus, the details of the second campaign occupy a large space in Japanese histories, but these tedious features of strategy and tactics are abbreviated here. There ean be no doubt that Ieyasu, so far from seeking to save:Hideyori's life, deliberately planned his destruction. Moreover, when it became known that an illegitimate son of Hideyori, called Kunimatsu, had been carried from the castle by some common soldiers and secreted at a farmhouse in Fushimi, Ieyasu caused this child of six to be seized and beheaded by a common executioner at Sanjō-kawara in Kyōto. This episode reflects no eredit whatever on the Tokugawa leader. That he should extirpate every seion of the Toyotomi family was not inconsistent with the canons of the time or with the interests of his own security. But death at the hands of a common executioner ought, never to have been decreed for the son of the $u$-daijin, and the cruelty of the order finds no excuse. No tenet of bushido can be reconciled with such inhumanity.

To this ehapter of history belongs the attitude of Ieyasu towards the memory of his old friend and benefactor, Hideyoshi. He caused to be levelled with the ground the temple of Toyokuni Daimyō-jin, where the spirit of Hideyoshi was worshipped, and he ordered the removal of the tomb of the Taiko from Amidagamine to a remote corner of the Daibutsu enclosure. Finally, he sought and obtained the Emperor's sanction to revoke the sacred title conferred posthumous-? ly on Hideyoshi. One looks in vain for any fragment of magnanimity among such acts. Ieyasu is reported to have avowedly adopted for guidance the precept, "'Before taking any step propound to your heart the query, how about justice?" He certainly did not put any, such query to his own conseience in connexion with the castle of Ōsaka or its inmates.

\section{THE GENNA YEAR-PERIOD (1615-1623)}

The battle of Sekigahara is often spoken of as the last great interneeine campaign in Japanese history, but this is hardly borne out by the facts. Indeed, from what has been said above, it will be seen that Sekigahara was merely a prelude to Ōsaka, and that the former stood to the latter almost. in the relation of a preliminary skirmish. It is from August, 1615, that we must date the commencement of the long period of peace with which Japan was blessed under Tokugawa rule. The year-name was then changed to Genna. 


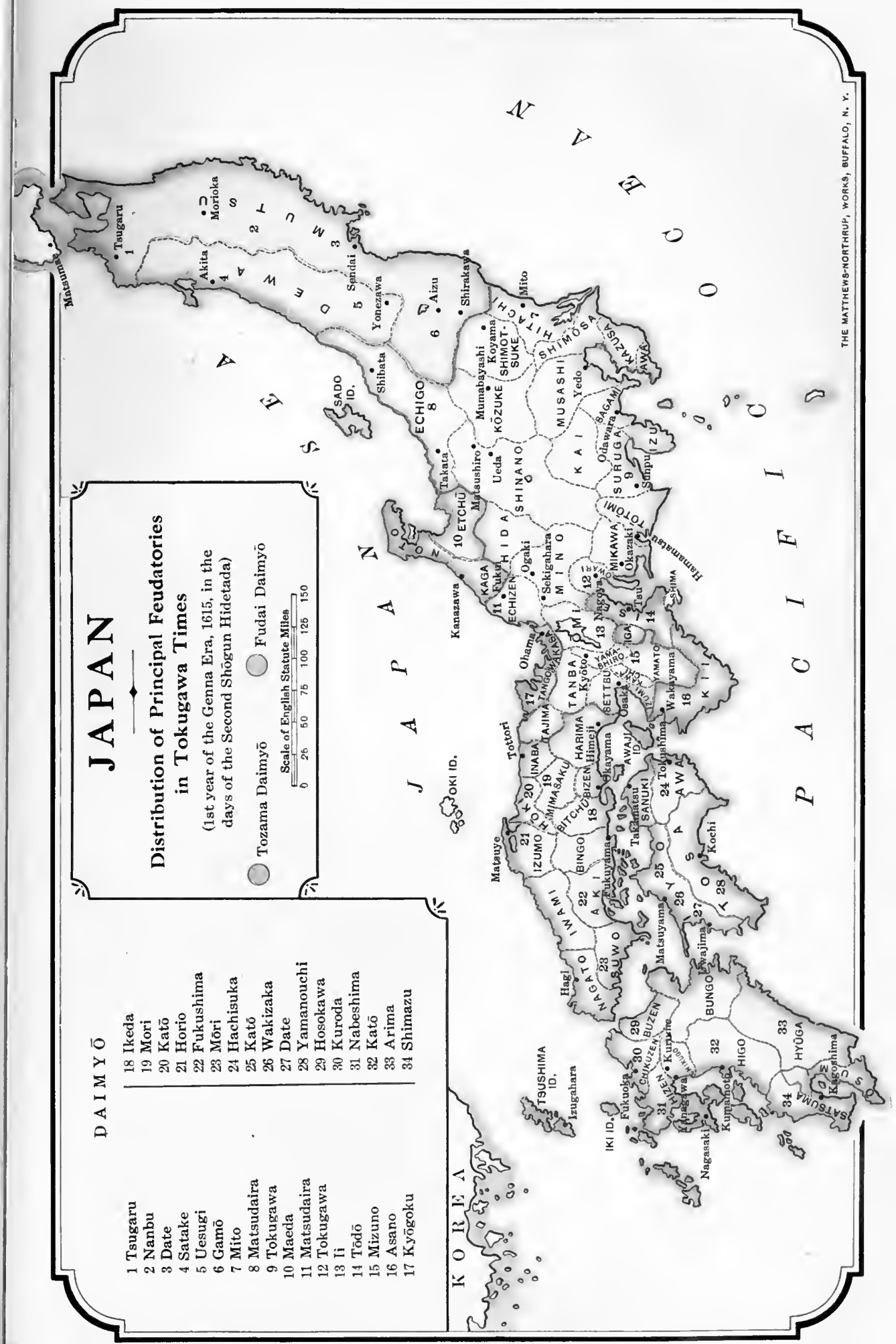


s 


\section{DEATH OF IEYASU}

In February, 1616, Ieyasu fell sick, and in April the Emperor sent an envoy to confer on him the title of dajo daijin. $\mathrm{He}$ expired a few days afterwards at the age of seventy-five and was apotheosized as Toshö Dai-Gongen (Light of the Fast and Great Incarnation) He was buried on the summit of Mount Kunō in Suruga; and ultimately his ashes were carried to Nikko for interment. It is recorded; though not on independent authority, that when his end was drawing near he spoke to those at his side in the following terms: "My death is now in sight; but happily the country is at peace, and Hidetada has already discharged the duties of shogun for several years. I have, therefore, no cause for anxiety. If : after I am gone, Hidetada should make any failure in his administration of public affairs, or if he should lose control of the people, any one of you to whom the Imperial order may be addressed, should assume the functions of shogun, for, as you well know, that post is not the property of this or that person in particular, nor will my rest in the grave be disturbed though such an event occurs."

Another record, however, represents Ieyasu as following the example of the Taiko and conjuring his most trusted retainers to devote their strength to the support of the Tokugawa family. To Hidetada he is said to have suggested the advisability of compelling the daimy $\bar{o}$ to remain in Yedo for three full years after his (Ieyasu's) demise, in order to test thoroughly their attitude. Hidetada replied that while most unwilling to reject his father's advice, his intention was to allow the feudatories to leave Yedo at once, and if any one of them evinced hostile feeling by shutting himself up in his castle, he, Hidetada, would follow him thither and level his parapets with the ground. Such an object lesson was, in his opinion, the best stepping-stone to supremacy. Ieyasu is reported to have received this answer with profound satisfaction, and to have declared that he was now assured of the permanence of peace. He then had all his sons called to his side and enjoined upon them the duty of serving the shogun faithfully. To his grandson, Iemitsu, he specially addressed himself, saying: "It will fall to your lot, some day, to govern the country. On that day remember that benevolence should be the first principle of a ruler."

\section{CHARACTER OF IEYASU}

Frugality is one of the virtues which Ieyasu certainly possessed. Striking example of its display is connected with Yedo Castle. This fortress, as built originally by Ōta Dōkwan, was not of imposing dimensions even as a military stronghold, and the dwelling-house in the keep presented most homely features, having a thatched roof and a porch of rough boat-planks. Yet Ieyasu was content to make this edifice his palace, and while he devoted much care to strengthening the fortifications, he bestowed none on the enlargement and adornment of the dwelling. The system he adopted to populate the city may be said to have been colonial. He encouraged his vassals to settle there, giving them lands to cultivate and breeding-grounds for horses, so that within a brief time the city obtained numerous inhabitants and developed a prosperous condition. It was in planning the details of all enterprises that he particularly excelled. To everything he brought an almost infinite capacity of patient study and minute examination; his principle being that to achieve success the first desideratum is to avoid mistakes. Doubtless he owed this faculty of profound 
painstaking to the vicissitudes of his early life. The years that he passed under the control of the Imagawa and afterwards under that of Oda taught him patience and self-restraint, and made the study of literature obligatory for him, at the same time begetting in his mind a feeling of reverence for the Buddhist faith.

Japanese historians generally credit him with the virtues of humanity, magnanimity, justice, and affability. That he was always pleased to receive advice from others and that he set an example of courtesy and zeal, there can be no doubt. Neither will anyone deny that his resourcefulness amounted to genius. On the other hand, his record shows that he waserupulous in utilizing opportunities, whether created by himself or made accéssible by fortune, and from the same record we are compelled to infer that he could be cruel and implacable on occasion. His favourite sayings afford perhaps the best index that we possess to his disposition:

Man's life is like a long journey toiling under a heavy burden.

Never be in a hurry.

He that regards destitution as his habitual lot will never feel the pressure of want.

When the spirit of ambition arises in your bosom, recall the days of your distress.

To forbear is the source of harmlessness and the road to success.

Regard anger as an enemy.

He that knows how to win only and does not know how to lose, will achieve nothing useful. Blame yourself and aequit others.

To fall short is better than to exceed.

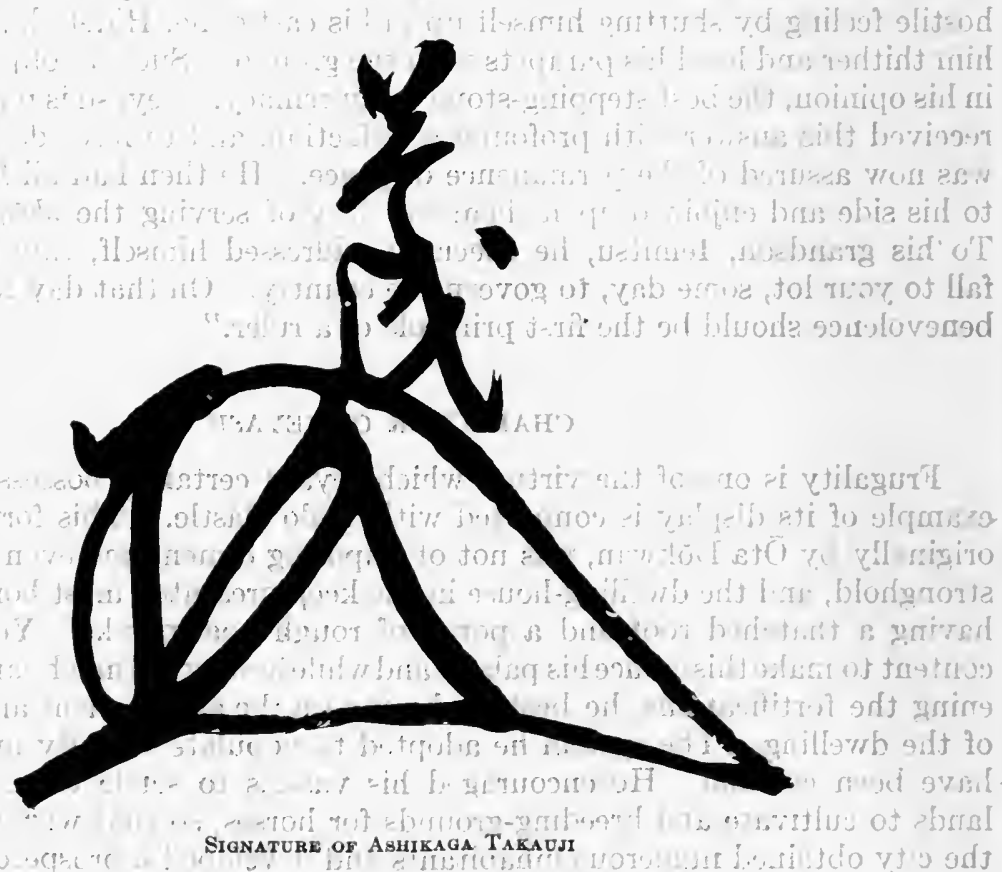




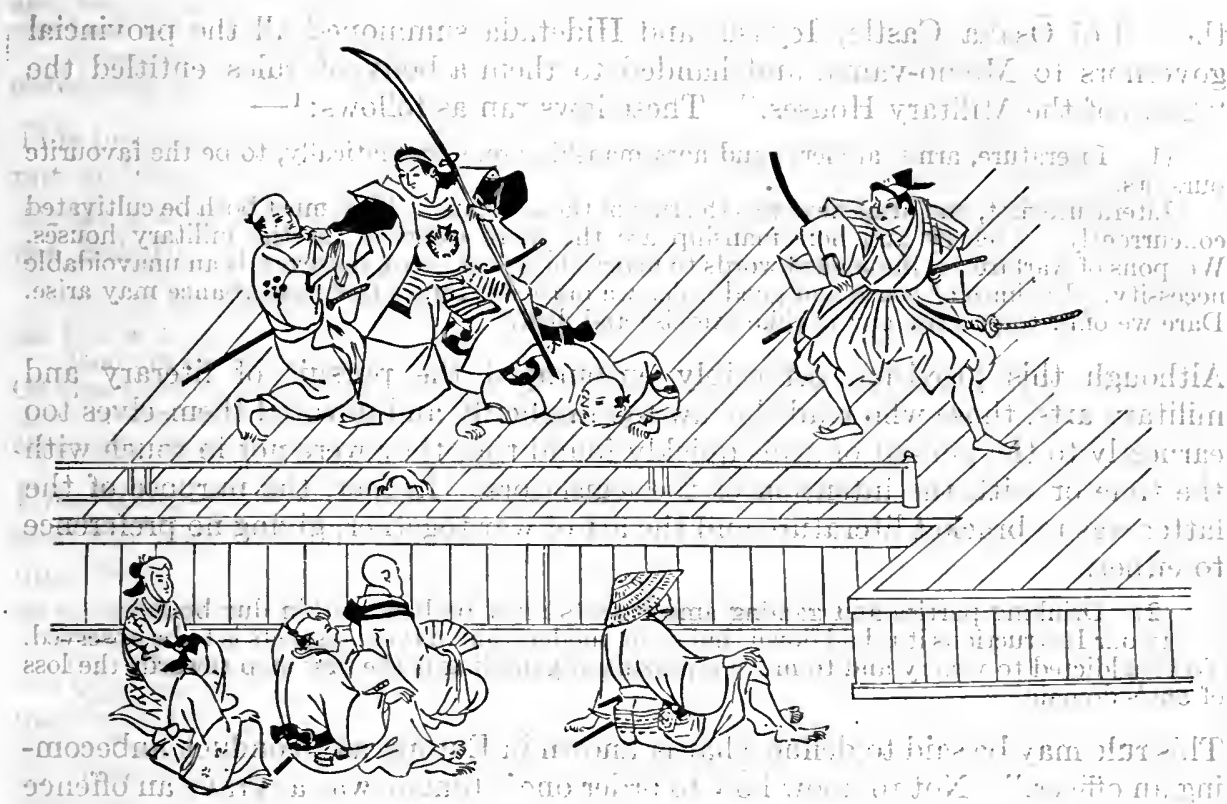

Theathical Play of Oli Jifan

\section{CHAPTER XXXIX}

\section{FIRST PERIOD OF THE TOKUGAWA BAKUFU; FROM THE FIRST TOKUGAWA SHŌGUN, IEYASU, TO THE FOURTH, IETSUNA $(1603-1680)$}

\section{LEGISLATION}

The Tokugawa family having brought the whole empire under its sway, Ieyasu applied himself to legislative work with $a$ degree of thoroughness and earnestness that far exceeded anything in the history of his prediecessors. The terms of the oath of allegiance that he dictated to the feudatories after the battle of Sekigahara have been already referred to. Ten years later, that is to say, in 1611 , he required all the provincial governors to subscribe this same oath; and, in 1613, he enacted a law for the Court nobles (kugeshu-hatto), to which the Imperial assent was obtained. This was the first instance of a military man legislating for the nobles of the capital; but it must be noted that the latter by: their own misconduct furnished an opportunity for such interference. $A$ Court scandal assumed such dimensions, in 1607, that the Emperor ordered the Bakufu to investigate the matter and to inflict suitable punishment. Ieyasu summoned a number of the offenders to Sumpu, where he subjected fourteen of them to severe examination. Ultimately some were sentenced to exile and others were deprived of their ranks, while the principal malefactor, Inokuma, general of the Left, was condemned to death. This affair demonstrated that the effective power was in the hands of the military, and throughout the Tokugawa rule they never failed to exereise it. In September of the year that witnessed 
the fall of Ōsaka Castle, Ieyasu and Hidetada summoned all the provincial governors to Momo-yama, and handed to them a body of rules entitled the "Laws of the Military Houses." These laws ran as follows: ${ }^{1}$ -

(1) Literature, arms, archery, and horsemanship are, systematically, to be the favourite pursuits.

Literature first, and arms next was the rule of the ancients. They must both be cultivated concurrently. Archery and horsemanship are the more essential for the military houses. Weapons of warfare are ill-omened words to utter; the use of them, however, is an unavoidable necessity. In times of peace and good order we must not forget that disturbance may arise. Dare we omit to practise our warlike exereise and drill?

Although this provision ostensibly encouraged the pursuit of literary and military arts, those who read the law too implicitly and devoted themselves too earnestly to the pursuit of arms quickly found that they were not in touch with the time or with the intention of the legislators. In fact, the purpose of the latter was to bracket literature and the art of war together, giving no preference to either.

(2) Drinking parties and gaming amusements must be kept within due bounds.

In our Instructions it is laid down that strict moderation in these respeets is to be observed. To be addicted to venery and to make a pursuit of gambling is the first step towards the loss of one's domain.

This rule may be said to define what is known in Europe as "conduct unbecoming an officer." Not to know how to order one's tongue was as grave an offence as debauchery, according to the canons of the samurai.

(3) Offenders against the law are not to be harboured in feudal domains.

Law is the very foundation of ceremonial decorum and of social order. To infringe the law in the name of reason is as bad as to outrage reason in the name of law. To disregard the law (laid down by us) is an offence which will not be treated with leniency.

This provision was directly suggested by the Government's desire to suppress Christianity.

(4) Throughout the domains whether of the greater or lesser barons (daimyō and shōmyō) or of the "holders of ininor benefits, if 'any ' of the gentry or soldiers (shi and sotsu) in their service be guilty of rebellion or murder, such offenders must be at once expelled from their domain.

Fellows of savage disposition (being retainers) are an apt weapon for overthrowing the domain or the family employing them, and a deadly instrument for cutting off the common people. How can such be tolerated?

In the early days of the Yedo Bakufu it was not uncommon for a feudatory to enrol among his vassals refugee samurai who had blood on their hands. These would often be pursued into the fiefs where they had taken refuge, and much disorder resulted. The above provision removed these murderers from the protection of the feudatory in whose, service they had enlisted.

(5) Henceforth no social intercourse is to be permitted outside of 'one's own domain with the people (gentry and commoners) of another domain.

In general, the customs of the various domains are all different from one another, each having its own peculiarities. "To'divulge the secrets of one's own domain is a sure indication of an intent to curry favour.

It has been shown that by the Chinese masters of strategy whose works were studied in Japan the art of espionage was placed on a high pinnacle. This teaching appears to have produced such evil results that the Tokugawa legislated against it.

(6). The residential castles in the domains may be repaired; but the matter must invari-5

[ ${ }^{1}$ The translation of these laws is taken from a paper read by Mr. Consul-General J. C. Hall and recorded in the "Transactions of the Asiatic Society of Japan" for 1911.] 
ably be reported. Still more imperative is it that the planning of structural innovations of any kind must be absolutely avoided.

fir A castle with a parapet exceeding three thousand feet by ten is a bane to a domain. Crenelated walls and deep moats (of castles) are causes of anarchy.

This provision was important as a means of enfeebling the barons. They were not at liberty to repair even a fence of the most insignificant character or to dredge a moat, much more to erect a parapet, without previous sanction from the Bakufu.

(7) If, in a neighbouring domain, innovations are being hatched or cliques being formea, the fact is to be reported without delay.

Men are always forming groups; whilst, on the other hand, few ever come to anything. On this account; they fail to follow their lords or fathers, and soon come into collision with those of neighbouring villages. If the ancient prohibitions are not maintained, somehow or other innovating schemes will be formed.

Everything in the form of combination, whether nominally for good or for evil, was regarded with suspicion by the Bakufu, and all unions were therefore interdicted. Of course, the most important incident which the law was intended to prevent took the form of alliances between barons of adjacent provinces.

(8) Marriages must not be contracted at private convenience.

Now; the marriage union is a result of the harmonious blending of the $I n$ and $Y o$ (i.e. the Yin and Yang of Chinese metaphysies, the female and male principles of nature). It is therefore not a matter to be lightly undertaken. It is said in the "Scowling" passage of the (Chow) Book of Changes, "Not being enemies they unite in marriage." "Whilst (the elders are) thinking of making advances to the opponent (family), the proper time (for the marriage of "the young couple) is allowed to slip by. In the "Peach Young" poem of the Book of Odes it is said, "If the man and woman, duly observing what is eorrect, marry at the proper time of life, there will be no widows in the land." "To form cliques (political parties) by means of matrimonial connexions is a source of pernicious stratagems.

This provision was, in fact, a codification of the veto pronounced by Hideyoshi on his death-bed against marriages between the families "of different daimyō: Ieyasu himself had been the first to violate the veto, and he was the first to place it subsequently on the statute book. The third Tokugawa shogun, Iemitsu, extended the restriction by ordering that even families having estates of only three thousand koku should not intermarry without 'Yedo's previous consent. (9) As to the rule that the daimyo shall come (to the shogun's court at Y edo) to do service-

On the Shoku Nihongi (The Continuation of the Chronicles of Japan) it is recorded amongst the enactments,

"Except when entrusted with some official duty to assemble, no one (dignitary) is allowed at his own pleasure to assemble his tribe within the limits of the capital, no one is to gó about attended by more than twenty horsemen, etc.".

honce it is not permissible to lead about a large force of soldiers. For daimyo whose revenues range from $1,000,000$ koko down to 200,000 koku, the number of twenty horsemen is not to be exceeded. For those whose revenues are 100,000 koku and under, the number is to be in the same proportion.

On occasions of official service, however $(i . e$ in time of warfare), the number of followers is to be in proportion to the social standing of each daimyo.

The above rule of repairing to the capital to pay respects (go-sankin) was an old fashion, and barons were accustomed to go with large retinues. Thus, it often happened that collisions occurred between the cortèges of hostile feudatories, and it was to prevent these sanguinary encounters that the Tokugawa set strict limits to the number of samurai accompanying a military chief.

(10) There must be no confusion in respect of dress uniforms, as regards the materials thereof:

The distinction between lord and vassal, between superior and inferior, must be clearly marked by the apparel. Retainers may not, except in rare cases by special favour of their lords, indiscriminately wear silk stuffs, such as shiro-aya. (undyed silk with woven patterns), 
shiro-kosode (white wadded silk coats), murasaki-awase (purple silk coats, lined), murasaki-nira (silk coats lined with purple); nori (white gloss silk), mumon (silk coat without the wearer's badge dyed on it), kosode (a coloured silk-wadded coat). In recent times, retainers and henchmen (soldiers) have taken to wearing rich damasks and silk brocade. This elaborate display was not allowed by the ancient laws and it must be severely kept within bounds.

(11) Miscellaneous persons are not at their pleasure to ride in palanquins.

There are families who for special reasons from of old have (inherited) the privilege of riding in palanquins without permission from the authorities; and there are others who by permission of the authorities exercise that privilege. But, latterly, even sub-vassals and henchmen of no rank have taken to so riding. This is a flagrant impertinence. Henceforward the daimyō of the provinees, and such of their kinsfolk as are men of distinction subordinate to them, may ride without applying for Government permission. Besides those, the following have permission, viz., vassals and retainers of high position about their lords; doctors and astrologers; persons of over sixty years of age, and sick persons and invalids. If ordinary retainers; or inferior henchmen (sotsu): are allowed to ride in palanquins, it will be considered to be the fault of their lords:

This proviso, however, docs not apply to Court nobles, abbots, or ecclesiastics in general.

(12) The samurai throughout the provinces are to practise frugality.

Those who are rich like to make a display, whilst those who are poor are ashamed of not being on a par with the others. There is no other influence so pernicious to social obseryances as this; and it must be strictly kept in check.

Frugality always occupied a prominent place in the Bakufu's list of essentials. Frequent and strenuous efforts were made by successive shōguns to encourage people in this virtue, but with the long peace enjoyed by the country under Tokugawa rule, a tendency to increasing luxury constantly prevailed, and the Government's aims in this respect were not realized except for brief periods. During the administration of the first three Tokugawa shoguns, and under the eighth shogun (Yoshimune), some success attended official injunctions of economy, but on the whole a steady growth of extravagance characterized the era.

(13) The lords of domain (kokushu, masters of provinces) must select men of capacity. for office.

The way to govern is to get hold of the proper men. The merits and demerits (of retainers) whould be closely scanned, and reward or reproof unflinchingly distributed accordingly: If there be capable men in the administration, that domain is sure to flourish; if there be not capable men, then the domain is sure to go to ruin. This is an admonition which the wise ones of antiquity all agree in giving forth.

The tenor of the foregoing rules must be obeyed.

Keichō, 20th year, $7 \mathrm{th}$ month (September 23, 1615).

The above body of laws may be regarded as the Tokugawa Constitution. They were re-enacted by each shoggun in succession on assuming office. The custom was to summon all the daimyo to Yedo, and to require their attendance at the Tokugawa palace, where, in the presence of the incoming shogun, they listened with faces bowed on the mats to the reading of the laws. Modifications and additions were, of course, made on each occasion, but the provisions quated above remained unaltered in their essentials. $U_{p}$ to the time of the third shogun (Iemitsu), the duty of reading aloud the laws at the solemn ceremonal of the new shoggun's investiture devolved on a high Buddhist priest; but it was thereafter transferred to the representative of the Hayashi family (to be presently spoken of). Any infraction of the laws was punished mercilessly, and as their occasionally loose phraseology left room for arbitrary interpretation; the provisions were sometimes utilized in the interest of the shogun and at the expense of his enemies.

\section{RULES FOR THE IMPERIAL COURT AND COURT NOBLES}

In the same month of the same year there was promulgated a body of laws called the "Rules of the Imperial Court, and the Court Nobles" (Kinchu narabi ni Kugeshū Sho-hatto). This, enactment bore the signatures of the 
kwampaku and the shogun and had the Imperial sanction. It consisted of sevienteen articles, but only five of them had any special importance:-

rs: (1) Learning is the most essential of all accomplishments. Not to study is to be ignorant of the doctrines of the ancient sages, and an ignorant ruler has never governed a nation peacefully.

This specious precept was not intended to be literally obeyed. The shogguns had no desire for an erudite Emperor. Their conception of learning on the part of the sovereign was limited to the composition of Japanese verselets. A close study of the doctrines of the ancient Chinese sages might have exposed the illegitimacy of the Bakufu administration. Therefore, Yedo would have been content that the Mikado should think only of spring flowers and autumn moonlight, and should not torment his mind by too close attention to the classics.

(2) A man lacking in ability must not be appointed to the post of regent or minister of State even though he belong to the Go-sekke (Five Designated Families), and it is needless to say that none but a member of those families may serve in such a position.

(3) A man of ability, even though he be old, shall not be allowed to resign the post of regent or minister of State in favour of another. If he attempts to resign, his resignation should be refused again and again.

The above two provisions practically conferred on the Bakufu the power of not only appointing the regent and ministers of State but also of keeping them in office. For, as the law had been framed in Yedo, in Yedo also was vested competence to judge the ability or disability of a candidate. Hence, when the Emperor proposed to appoint a regent or a minister, the Bakufu had merely to intimate want of confidence in the nominee's ability; and similarly, if the sovereign desired to dismiss one of those high officials, the shog un could interfere effectually by reference to the letter of the law. Thus, the power of appointing and dismissing the great officials in Kyotto, which is one of the important prerogatives of the crown, was practically usurped by the shogun.

(4) An adopted son shall always be chosen from the family of his adopter; and a female shall never be adopted to be the head of a family, no such custom having existed in Japan at any time.

This provision had two main objects. The first was to avert adoptions having the effect of combinations; the second, to prevent adoption of Imperial princes into other families. The Bakufu sought, as far as possible, to bring about the taking of the tonsure by all princes of the Blood who were not in the direct line of the succession, and to keep these princes from attaining to the posts of regents or ministers of State.

(5) All reports shall be submitted to the Emperor by the regent, the densō, or an administrator (bugyō). Any other person who, in disregard of this rule, attempts to address the Throne direct, shall be sent into exile, whatever his rank.

The denso mentioned in this provision was an official appointed by the Bakufu for that special purpose: The: whole arrangement as to communication with the Throne constituted a powerful buttress of Bakufu influence. Generally, the latter could contrive, as has been shown above, to control the appointment and continuance in office of a regent or a minister, while as for the administrators $($ bugyo $)$, they were nominees of Yedo. - It thus resulted that the Throne was approachable through the channel of the Bakufu only.

The above laws remained unchanged throughout the Tokugawa era. A special law was also enacted with reference to Buddhist sects and the principal 
Buddhist temples. Ieyasu secured to these temples the possession of their manors by granting title-deeds bearing what was ealled the: "go-shuinji," or "vermilion signature." The term was not really applicable in the case of Ieyasu. It is true that Hideyoshi, doubtless in imitation of Chinese custom, stamped a vermilion seal upon documents of this character; but the Tokugawa shoguns employed a black signature written with a pen. Nevertheless, the term" "goshuinji" continued to be used from the time of the Taiko downwards. It was an outcome of Ieyasu's astuteness that the great Hong wan temple was divided into two branches, eastern and western, by which process its influence was prevented from becoming excessive. During the administration of the third shogun, every daimyō was required to adhere to a definite sect of Buddhism, and to the Buddhist and Shintō temples was entrusted the duty of keeping an accurate census of their parishioners. The direct purpose of these latter laws was to facilitate the extermination of Christianity. Anyone whose name was not enrolled on one of the above lists fell under suspicion of embracing the foreign faith.

\section{A JAPANESE HISTORIAN'S OPINION}

Referring to the above lars the Tokugawa Jidaishi says: -

The above laws and regulations were the Constitution of the Tokugawa Bakufu. By the aid of their provisions the influence of Yedo was extended to every part of the nation from the Imperial Court to the world of religion. No such codes had ever previpusly, existed in Japan. Any unit of the nation, whether a Court noble, a great feudatory, a priest, or a common samurai, had to yield implieit obedience or to suffer condign punishment. "Thus, it fell out that everybody being anxious to conform with the rules, the universal tendency was to share in preserving the peace. From the point of view of this system, Ieyasu was eminently above all modern and ancient heroes. Hideyoshi won brilliant victories in war, but he saw no better method of maintaining peace at home than to send the country's armies' to fight abroad. He seems to have conceived a hope that his generals would find goals for their ambition in Korea or China, and would exhaust their strength in endeavouring to realize their dreams. But his plan brought about the contrary result; for the generals formed fresh enmities among themselves, and thus the harvest that was subsequently reaped at Sekigahara found hands to sow it.

leyasu, however, prized literature above militarism. He himself became a pioneer of learning, and employed many scholars to assist in constructing a solid framework of peace. The territorial nobles had to follow his example. Even Katō Kiyomasa, Asano Yukinága, and Kuroda Nagamasa, each of whom during his lifetime was counted a divinely inspired general, found themselves constrained to study the Chinese classics under the giudance of Funabashi Hidekata and Fujiwara Seigwa.' How much more cogent, then, was the similar neeessity under which lesser men laboured. Thus, Ieyasu's love of literature may be regarded as a cause of the peace that prevailed under the Tokugawa for 260 years.

\section{REVIVAL OF LEARNING}

Ieyasu employed four instruments for educational purposes - the establishment of schools, the engagement of professors, the collection of ancient literary works, and the printing of books. In accordance with his last will his son Yoshinao, daimy of owari, built, in 1636, the Daiseiden College beside the temple of Kiyomizu in Ueno Park, near the villa of Hayashi Razan, the celebrated Confucian scholar; but, in 1691, the college was moved to the slope called Shōhei-zaka, where a bridge - Shöhei-bashi - was thrown àcross the river. "Shōhei" is the Japanese pronunciation of "Changping," Confucius's birthplace, and the school was known as the Shōhei-kō. It received uniform patronage at the hands of the Tokugawa, whose kinsmen and vassals were required to study there, their proficiency, as determined by its examinations, being counted a passport to office. Yoshinao laid the foundation of a great library at the school and the number of volumes was constantly increased. 


\section{Costumes}

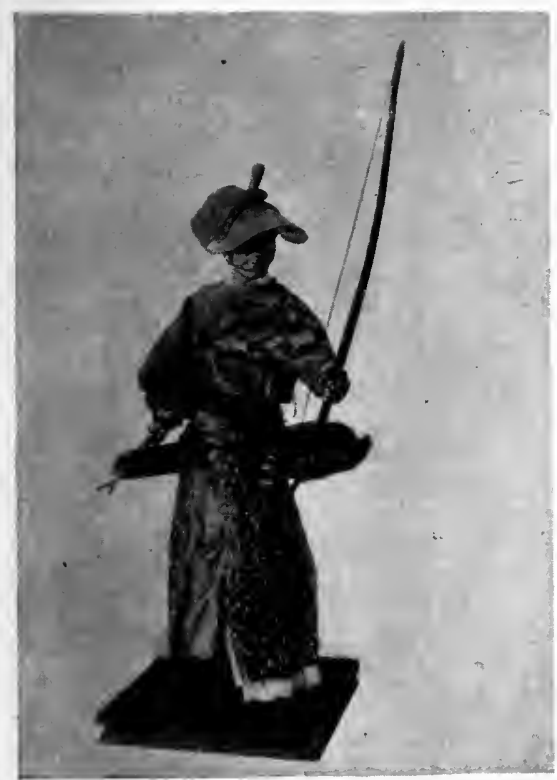

Samurai in Hunting Robe

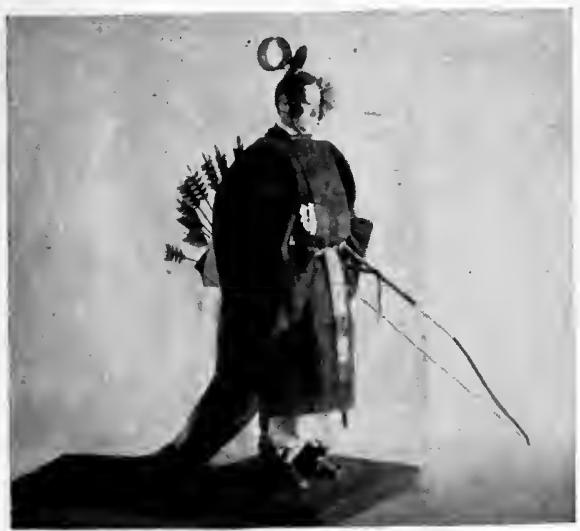

Imperial Court noble (FAnge)

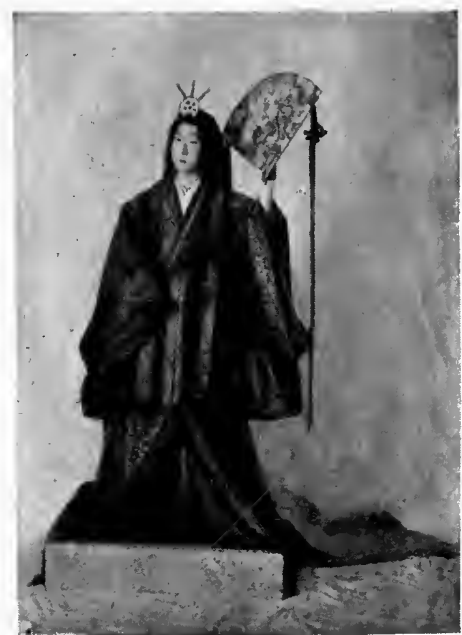

(Kwanjo) Court Attendant

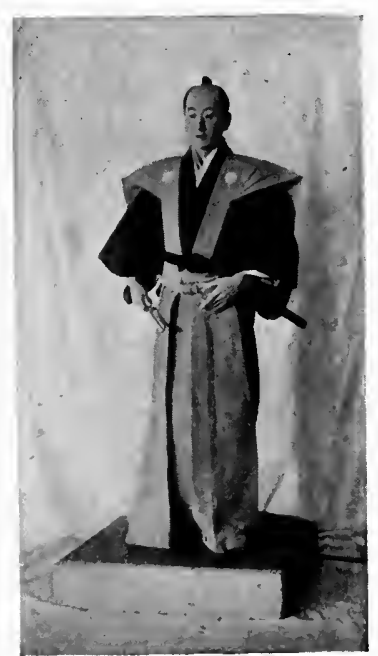

Samurai in Court Robe 

During the lifetime of Ieyasu, one of the most noted scholars was Fujiwara Seigwa. By the invitation of the Tokugawa chief he lectured on the classics in Kyoto, and it is recorded that Ieyasu, who had just (1600) arrived in that city, attended one of these lectures, wearing his ordinary garments. Seigwa is related to have fixed his eyes on Ieyasu and addressed him as follows:" The greatest work of Confucius teaches that to order oneself is the most essential of achievements. How shall a man who does not order himself be able to order his country? I am lecturing on ethics to one who behaves in a disorderly and discourteous manner. I believe that I preach in vain." Ieyasu immediately. changed his costume, and the event contributed materially to the reputation alike of the intrepid teacher and of the magnanimous student, as well as to the popularity of Seigwa's doctrines.

Hayashi Razan was a disciple of Seigwa 'whose reputation as a scholar he rivalled. Ieyasu employed him extensively in drafting laws; and many of his disciples subsequently served as teachers of the Chinese classics. The scripture of Hayashi's school of ethics was Chu Hi's commentary on the "Great Learning". of Confucius In this system, ethics become a branch of natural philosophy. "Corresponding to the regular change of the seasons in nature is right action in man (who is the crown of nature), in the relation of sovereign and subject, parent and child, elder brother and younger brother, husband and wife, friend and friend. To his sovereign, or lord, he is bound to be faithful; to his parents, dutiful, and to his elder brother, respectful." Affection should characterize the relations of husband and wife and trust those of friend with friend."

A moment's consideration of this ethical system shows that it cannot be reconciled with such a form of administration as that existing under the Bakufu. Genuine loyalty to the sovereign found no place in the practical code of Tokugawa: Whether Ieyasu appreciated that fact or whether he ignored it in consideration of the civilizing and tranquillizing influences of Confucianism; there is nothing to show. Ultimately, however, it was-to the ethics of the Chinese sage that the Tokugawa downfall became indirectly attributable.

Ieyasu showed much earnestness in searching for and collecting ancient books. Before and after the war of Ósaka, he ordered priests to copy old books and records preserved in Buddhist temples and noblemen's houses. 'Subsequently, during the Kwanei era - 1621-1643 - there was built within the castle of Yedo a library called Momijiyama Bunko where the books were stored. He was also instrumental in causing the compilation and publication of many volumes whose contents contribute materially to our historical knowledge. The writing of history in the Imperial Court had been abandoned for many years, and the scholars employed by Ieyasu had recourse to private diaries for materials. Hayashi Razan (Döshun) was entrusted with the duty of distinguishing between the true and the false in using these records, and there resulted two memorable works the second of these consisted in the main of genealogical tables. 'It extended to 372 volumes and subsequently became the Kwanei Shoke Keizu-den. The first, a national history, was originally called the Honchō Hennen-roku. Before its compilation Razan '(Dōshun) died, and the book was concluded by his son, Harukatsu, in the year 1635. It consisted of three hundred volumes in all, and covered the period from the age of the Gods to the year 1610. It is now known as the Honcho Tsügan. The two works having been published to the order and under the patronage of the Bakufu, their contents were by no means free from the stain of favour and affection, but they nevertheless possess inestimable historical value. 
THE SECOND TOKUGAWA SHŌGUN, HIDETADA

Hidetada, third son of Ieyasu, was born in 1579; succeeded to the shoggunate in 1605 ; abdicated in 1622, and died in 1632. His appearance on the historical stage was not very glorious, for, as already shown, when marching to join his father's army before the battle of Sekigahara, he allowed himself to be detained so long at the siege of Ueda. Castle that he failed to be present at the great combat, and Ieyasu, as a mark of displeasure, refused to meet him until Honda Masazumi pleaded Hidetada's cause. During the first eleven years of his shögunate he exercised little real authority, the administration being conducted by Ieyasu himself from his nominal place of retirement in Sumpu. Thus, the period of Hidetada's independent sway extended over six years only. But dưring the ten subsequent years he continued to exercise much camera influence over the Government, though his power was inferior to that which had been wielded by Ieyasu in nominal retirement. Honda Masazumi, who had befriended him at the critical time mentioned above; occupied the highest post in the administration, the second place being assigned to Sakai Tadayo, while in Kyōto the Tokugawa interests were guarded by Itakura Katsushige and Matsudaira Masatsuna.

The era of Hidetada was essentially one of organization, and by the exercise of sincerity and justice he contributed much to the stability of the Tokugawa rule. Not the least memorable step taken by him related to the fortress of Yedo. In the year following his succession, he ordered the feudatories of the east to construct the castle which remains to this day one of the marvels of the world. "Around it stretched a triple line of moats; the outermost measuring nine and a half miles in length, the innermost one and a half; their scarps constructed with blocks of granite nearly as colossal as those of the Ōsaka stronghold, though in the case of the Yedo fortification every stone had to be carried hundreds of miles over the sea. The gates were proportionately as huge as those at Osaka; well-nigh the most stupendous works ever undertaken, not excepting even the Pyramids of Egypt. There is not to be found elsewhere a more striking monument of military power, nor can anyone considering such a work, as well as its immediate predecessor, the Taiko's stronghold at Ōsaka, and its numerous contemporaries of lesser but still striking proportions in the principal fiefs, refuse to. credit the Japanese with eapacity for large conceptions and competence to carry them into practice."

CONJUGAL RELATIONS BETWEEN THE IMPERIAL FAMILY AND THE TOKUGAWA

It had been one of the most cherished wishes of Ieyasu to follow the Fujiwara precedent by establishing conjugal relations between the Imperial family and the Tokugawa. But the ex-Emperor, Go-Yozei, turned a deaf ear to this proposal on the ground that a lady born in a military house had never been chosen consort of a sovereign. Ieyasu, however, did not abandon his purpose. He entrusted its prosecution to Tōdo Takatora, and in 1616, the year of Ieyasu's death, Tōdo induced Konoe Nobuhiro, minister of the Right, to promote this undertaking. Nobuhiro, being the Emperor's younger brother, was able, to exert much influence, and finally the ex-Emperor gave his consent. In June, 1620, Kazuko, daughter of Hidetada, became first lady-in-waiting, and ultimately Empress under the name of Tofuku-mon-in. It is recorded that 1180 chests were required to carry her trousseau from Yedo, and that the costs of her outfit 
and of her journey to Kyōto aggregated more than a million sterling. . She gave birth to two princes and five princesses, and the house of Konoe, which had been instrumental in procuring her summons to the Court, became the leader of the Go-sekke.

\section{DEATH OF HIDETADA AND HIS CHARACTER}

After resigning the shogunate in 1622 , Hidetada retired to the inner castle (Nishi Maru) in Yedo and there continued to direct affairs. He died ten years later, at the age of fifty-eight, and was interred at the temple Zōjō-ji, in the Shiba distriet of the eastern capital. Japanese historians agree that Hidetada's character was adapted for the work of consolidation that fell to his lot. $\mathrm{He}$ resembled his father, Ieyasu, in decision and perseverance; he never dealt lightly with any affair, and while outwardly gentle and considerate, he was at heart subtle and uncompromising. An interesting illustration of the administrative canons of the time is afforded in the advice said to have been given by Hosokawa Tadaoki when consulted by Hidetada. "There is an old proverb," Tadaoki replied, "that if a round lid be put on a square vessel, those within will have ease; but if a square lid be used to cover a square vessel, there will result a feeling of distress."? Asked for a standard by which to judge qualifications for success, the same nobleman answered that an oyster shell found on the Akashi shore is the best type of a man qualified to succeed, for the shell has been deprived of all its angles by the beating of the waves. Of Hidetada himself there is told an anecdote which shows him to have been remarkably free from superstition. A comet made its appearance and was regarded with anxiety by the astrologists of Kyōto, who associated its advent with certain misfortune. Hidetada ridiculed these fears. "What can we tell,". he said, "about the situation of a solitary star in the wide universe, and how can we know that it has anything to do with this little world?".

\section{THE THIRD SHŌGUN, IEMITSU}

Iemitsu, son of Hidetada, was born in 1603; succeeded to the shoggunate in 1622 , and held that post until his death, in 1651. His principal ministers were Ii Naotaka (who had occupied the post of premier since the days of Ieyasu), Matsudaira Nobutsuna, and Abe Tadaaki, one of the ablest officers that served the Tokugawa. He devoted himself to consolidating the system founded by his grandfather, Ieyasu, and he achieved remarkable success by the exercise of exceptional sagacity and determination. In 1626, he proceeded to Kyoto at the head of a large army, simply for the purpose of conveying to the feudal nobles a significant intimation that he intended to enforce his authority without hesitation. Up to that time the feudal chiefs were not officially required to reside in Yedo for any fixed time or at any fixed interval. But now it was clearly enacted that the feudatories of the east and those of the west should repair to the Bakufu capital, at different seasons in the year; should remain there a twelvemonth, - in the case of feudal lords from the Kwanto only six months - and should leave their wives and families as hostages during the alternate period of their own absence from the shogun's city, which they spent in the provinces.

This system was technically called sankin kotai, that is " alternate residence in capital." From the point of view of the Tokugawa the plan was eminently 
wise, for it bound the feudal chiefs eloser to the shōgun, keeping them under his eye half the time and giving hostages for their good behaviour the other half; and it helped the growth of Yedo both in financial and political power, by bringing money into it and by making it more than before an administrative headquarters. On the other hand there was a corresponding drain on the provinces, all the greater since the standard of living at Yedo was higher than in rural districts and country nobles thus learned extravagance. To prevent other families from growing too rich and powerful seems to have been a part of Ieyasu's definite plan for holding in check possible rivals of the Tokugawa' so that it is not impossible that he foresaw this very result. At any rate it is known that in the instructions for government which he handed down to his successors he urged them to keep strict surveillance over their feudal lords and if any one of them seemed to be growing rich to impose upon him such a burden of public works as would cripple him.

In 1632, Iemitsu made another military demonstration at Kyōto, and on this occasion the Emperor would have conferred on him the post of prime minister (dajō daijin). But he refused to àcept it. This refusal was subsequently explained as a hint to the feudal chiefs that inordinate ambition should be banished from their bosoms; but in reality Iemitsu was influenced by the traditional principle that the Throne had no higher gift to bestow on a subject than the shōgunate.

\section{PROMINENT FEATURES OF THE ADMINISTRATION OF IEMITSU}

The prominent feature of this able ruler's administration was that he thoroughly consolidated the systems introduced by his grandfather and confirmed by his father. From the time of Iemitsu downwards, eardinal forms were never changed, alterations being confined to non-essentials: On his death-bed he desired that his prime minister, Hotta Masamori, and several other notables should accompany him to the tomb, and on the night of the 10th of June, 1651, Hotta Masamori (aged forty-six), Abe Shigetsugu (aged fifty-two), Uchida Masanobu (aged thirty-three), Masamori's mother (aged sixty-three), Saegusa Moriyoshi, and Okuyama Yasushige all committed suicide. Their tombs stand to this day in Nikkō.

\section{THE NIKKŌ SHRINE AND THE KWANEI TEMPLE}

It has been related how largely Ieysau was aided against the Ōsaka party by Tengai, abbot of Enryaku-ji. This priest it was that devised the singular accusation connected with the inscription on a bell at Hōkō-ji. He received from Ieyasu the diocese of Nikkō in Shimotsuke province, where he built a temple which ultimately served as the shrine of Ieyasu. But the first Tokugawa shōgun, faithful to his frugal habits, willed that the shrine should be simple and inexpensive, and when Hidetada died, his mausoleum (mitamaya) at the temple Zojjōji in Yedo presented by its magnificence such a contrast to the unpretending tomb at Nikkō, that Iemitsu ordered Akimoto Yasutomo to rebuild the latter, and issued instructions to various feudal chiefs to furnish labour and materials. The assistance of even Korea, Ryūkyū, and Holland was requisitioned, and the Bakufu treasury presented 700,000 ryō of gold. The shrine was finished in 1636 on a scale of grandeur and artistic beauty almost unsurpassed in any other country. The same priest, Tengai, was instrumental in building the tem- 
ple known as Kwanei-ji, and at his suggestion; Hidetada asked the Imperial Court to appoint a prince to the post of abbot (monsu).

This system already existed in the case of Enryaku-ji on Hiei-zan in Kyōto, and it was Tengai's ambition that his sect; the Tendai, should possess in Yedo a temple qualified to compete with the great monastery of the Imperial capital. Thus, Ueno hill on which the Yedo structure stood was designated "Tōei-zan," as the site of the Kyoto monastery was designated "Hiei-zan," and just as the temple on the latter received the name of "Enryaku-ji," after the era of its construction (Enryaku), so that in Yedo was named "Kwanei-ji," the name of the year period of its foundation being Kwanei. Finally, the Kwanei-ji was interided to guard the "Demon's Gate" of the Bakufu city as the Enryaku-ji guarded the Imperial capital. Doubtless, in furthering this plan, Iemitsu had for ultimate motive the association of an Imperial prince with the Tokugawa family, so that in no circumstances could the latter be stigmatized as "rebels:' Not until the day of the Tokugawa's downfall did this intention receive practical application, when the priest-prince of Ueno (Prince Kitashirakawa) was set up as their leader by the remnants of the Bakufu army.

\section{ISE AND NIKKŌ}

Through many centuries it had been the custom of the Imperial Court to worship at the great shrine of Ise and to offer suitable gifts.' This ceremony was long suspended, however, on account of continuous wars as well as the impecunious condition of the Court. Under the sway of the Oda and the Toyotomi, fitful efforts were made to renew the custom; but it was left for the Tokugawa to re-establish it. The third shoggun, Iemitsu, petitioned the Court in that sense, and assigned an estate in Yamashiro as a means of defraying the necessary expenses, the Fujinami family being appointed to perform the ceremony hereditarily. At the same time Iemitsu petitioned that the Court should send an envoy to worship at Nikko every year on the anniversary of the death of Ieyasu, and this request having been granted, Nikkō thenceforth became to the Tokugawa what Ise was to the Imperial Court.

\section{BUDDHISM AND CHRISTIANITY}

It has been shown that the Shimabara revolt finally induced the Bakufu Government to adopt the policy of international seclusion and to extirpate Christianity. In carrying out the latter purpose, extensive recourse was had to the aid of Buddhism. The chief temple of each sect of that religion was officially fixed, as were also the branch temples forming the parish of the sect; every unit of the nation was required to register his name in the archives of a temple, and the Government ordered that the priests should keep accurate lists of births and deaths. Anyone whose name did not appear on these lists was assumed to belong to the alien faith. This organization was completed in the time of Iemitsu.

\section{THE FOURTH SHŌGUN, IETSUNA}

Ietsuna, the fourth Tokugawa shōgun, eldest son of Iemitsu, was born in 1642 and succeeded to the office in 1651, holding it until his death in 1680 . In bequeathing the administrative power to youth in his tenth year, Iemitsu 
clearly foresaw that trouble was likely to arise. He therefore instructed his younger brother, Hoshina Masayuki, baron of Aizu, to render every assistance to his nephew, and he appointed Ii Naotaka to be prime minister, associäting with him Sakai Tadakatsu, Matsudaira Nobutsuna,; Abe Tadaali, and other statesmen of proved ability. : These precautions were soon seen to be necessary, for the partisans of the Toyotomi seized the occasion to attempt a coup. aithe country at that time swarmed with rönin:(wave-men); that is to say, samurai who were, for various reasons, roving free-lances. There seems to have been a large admixture of something very like. European chivalry in the make: up of these ronin, for some of them seem to have wandered about merely to right wrongs and defend the helpless. Others sought adventure for adventure's sake and for glory's, challenging the best swordsman in each place to which they came. Many seem to have taken up the lives of wanderers out of a notion of loyalty; the feudal lords to whom they had owed allegiance had been crushed by the Tokugawa and they refused to enter the service of the shogun. itsns to

The last-named reason seems to have been what prompted the revolt of 1651, when Ietsuna, aged ten; had just succeeded in the shōgunate his father Iemitsu who had exalted the power of the Tokugawa at the expense of their military houses. The rōnin headed by Yui Shōsetsu and Marubashi Chūya plotted to set fire to the city of Yedo and take the shogun's castle. The plot was discovered. Shōsetsu committed suicide, and Chūya was crucified In the following year (1652) another intrigue was forned under the leadership of Bekki Shōemon, also a rōnin. On this occasion the plan was to murder Ii Naotaka, the first minister of State, as well as his colleagues, and then to set fire to the temple Zōjō-ji on the occasion of a religious ceremony. But this plot, also, was discovered before it matured, and it proved to be the last attempt that was made to overthrow the Bakufu by force until more than two hundred years had passed.

\section{THE LEGISLATION OF IEMITSU AND IETSUNA}

On the 5th of August, 1635, a body of laws was issued by Iemitsu under the title of Buke Sho-hatto, and these laws were again promulgated on June 28, 1665 , by the fourth shoggun, Ietsuna, with a few alterations. The gist of the code of Iemitsu was as follows:- That literature and arms were to be the chief object of cultivation; that the great and small barons were to do service by turns in Yedo, strict limits being set to the number of their retainers; that all work on new castles was strictly interdicted, and that all repairs of existing castles must not be undertaken without sanction from the Yedo administration; that in the event of any unwonted occurrence, all barons present at the scene must remain and await the shogun's orders; that no person other than the officials in charge might be present at an execution; that there must be no scheming innovations, forming of parties, or taking of oaths; that private quarrels were strictly interdicted, and that all matters difficult of arrangement must be reported to the Yedo administration; that barons having an income of ten thousand koku or more, and their chief officials, must not form matrimonial alliances without the shogun's permission; that greater simplicity and economy must be obeyed in social observances, such as visits of ceremony, giving and receiving presents, celebrating marriages, entertaining at banquets, building residences, and general striving after elegance; that there must be no indiscriminate intermingling (of ranks); that, as regards the materials of dress, undyed silk with 
woven patterns (shiro aya) must be worn only by Court nobles (kuge) and others of the highest ranks; that wadded coats of undyed silk might be worn by daimyo and others of higher rank; that lined coats of purple silk, silk coats - with the lining of purple, white gloss silk, and coloured silk coats without the badge were not to be worn at random; that coming down to retainers, henchmen, and men-at-arms, the wearing by such persons of ornamental dresses such as silks, damask, brocade, or embroideries was quite unknown to the ancient laws, and a stop must be put to it; that all the old restrictions as to riding in palanquins must be observed; that retainers who had a disagreement with their original lord were not to be taken into employment by other daimyō; "that if any such was reported as having been guilty of rebellion or homicide, he was to be sent back (to his former lord); that any who manifests a refractory disposition must either be'sent back or expelled; that where the hostages given by sub-vassals to their mesne lords had committed an offence requiring punishment by banishment or death, a report in writing of the circumstances must be made to the administrators' office and their decision awaited; that in case the circumstances were such as to necessitate or justify the instant cutting-down of the offender, a personal account of the matter must be given to the administrator; that lesser feudatories must honestly discharge the duties of their position and refrain from giving unlawful or arbitrary orders (to the people of their fiefs); that they must take care not to impair the, resources or well-being of the province or district in which they are; that roads, relays of post-horses, boats, ferries, and bridges must be carefully attended to, so as to ensure that there should be no delays or impediments to quick communication; that no private toll-bars might be erected or "any existing ferry discontinued; that no vessels of over five hundred $k o k u$ burden were to be built; that the glebe lands of shrines and temples scattered throughout the provinces, having been attached to them from ancient times to the present day; were not to be taken from them; that the Christian sect: was to be strictly: prohibited in all the provinces and in all places; that in case of any unfilial conduct the offender should be dealt with under the penal law; that in all matters the example set by the laws of Yedo was to be followed in all the provinces and places.

As has been noted above, this same body of laws was re-enacted under the authority of Ietsuna, with the following slight alterations, namely, that the veto was removed from the wearing of costly ornamented dresses by retainers, henchmen, and men-at-arms; and that the restriction as to size should not apply to a cargo vessel. At the same time a prohibition of junshi (following in death) was issued in these terms:-

That the custom of following a master in death is wrong and unprofitable is a caution which has been at times given from of old; but owing to the fact that it has not actually been prohibited, the number of those who cut their belly to follow their lord on his decease has become very great. For the future, to those retainers who may be animated by such an idea, their respective lords should intimate, constantly and in very strong terms, their disapproval of the custom. If, notwithstanding this warning, any instance of the practice should occur, it will be deemed that the deceased lord was to blame for unreadiness. ${ }^{c}$ Henceforward, moreover, his son and successor will be held blameworthy, for incompetence, as not having prevented the suicides.?

\section{RELEASE OF HOSTAGES}

Another memorable step was taken during the administrative period of Ietsuna. It had been the custom to require that all the great nobles should

[" From a paper read by $\mathrm{Mr}$. Consul-General J.C. Hall and recorded in the "Transactions of the Asiatic Society of Japan" for 1911.] 
send a number of their chief retainers or the latter's fathers, brothers, and sons to Yedo, where they were held as hostages for the peaceful conduct of their feudal chiefs. But when the system of sankin kötai had been in operation for some time, and when the power of the Tokugawa Bakufu had been fully consolidated, this practice of exacting hostages became superfluous and vexatious. It was therefore abandoned in the year 1665 and the hostages were all suffered to leave Yedo.

\section{THE MING, DYNASTY}

The fall of the Ming dynasty in China took place in the thirteenth year of Ietsuna's succession, "and for a moment it seemed that Japan might possibly take the field against the conquering Tatars. A Chinese immigrant who had settled in the island of Hirado, in Hizen, married the daughter of a Japanese farmer, and had a son by her. The immigrant's name was Cheng Chi-lung, and when the partisans of the Ming dynasty made their last stand at Foochaw, they chose Cheng for general, through him soliciting aid from the Yedo Bakufu. Their request was earnestly discussed in Yedo, and it is possible that had the Ming officers held out a little longer, Japan might have sent an expedition across the sea. Cheng Chi-lung's son, Cheng Cheng-kung, resisted to the last, and when he fell fighting at Macao, his Japanese mother committed suicide. Other fugitives from China, notably an able scholar named Chu Chi-yu, settled in Japan at this time, and contributed not alittle to the promotion of art and literature."

\section{YEDO}

The influence of the sankin kôtai system upon the prosperity of Y Yedo, as well as upon the efficiency of the Tokugawa administration, has already been noticed. Indeed, Yedo in the middle of the seventeenth century was one of the most populous and prosperous cities in the world. - But very little intelligence had been exercised in planning it. The streets were narrow and there were no bridges across the main river. Thus, in 1657, a fire broke out which, being fanned by a violent wind, burned for two days, destroying the greater part of the city together with the residences of nearly all the daimyō. The calamity occurred in the month of February and was accompanied by a violent snowstorm, which greatly increased the sufferings of the citizens: Tradition says that 108,000 persons lost their lives, but that number is probably an exaggeration. In the following year,' another similar catastrophe occurred on almost the same scale, and it seemed as though Yedo could never rise from its ashes. Yet the result of these calamities was salutary. The Bakufu selected suitable situations for the residences of the daimyo, and issued a law requiring that the main thoroughfares must have a width of sixty feet and even the by-streets must not be narrower than from thirty to thirty-six feet. Moreover, three bridges, namely, the Ryogoku, the Eitai, and the Shin-ô, were thrown across the Sumida. This river, which formed the eastern boundary of the eity, had hitherto been left unbridged for military reasons, and the result was that on the occasion of the great conflagration thousands of pcople, caught between the flames and the river bank, had to choose death by burning or by drowning. Nevertheless, some officials opposed the building of bridges, and were only silenced by the astute remark of Sakai-Tadakatsu that if Yedo was ever to be a great city, the convenience of its inhabitants must be first consulted, for, after all, the people themselves constituted the best stronghold. This may be re- 

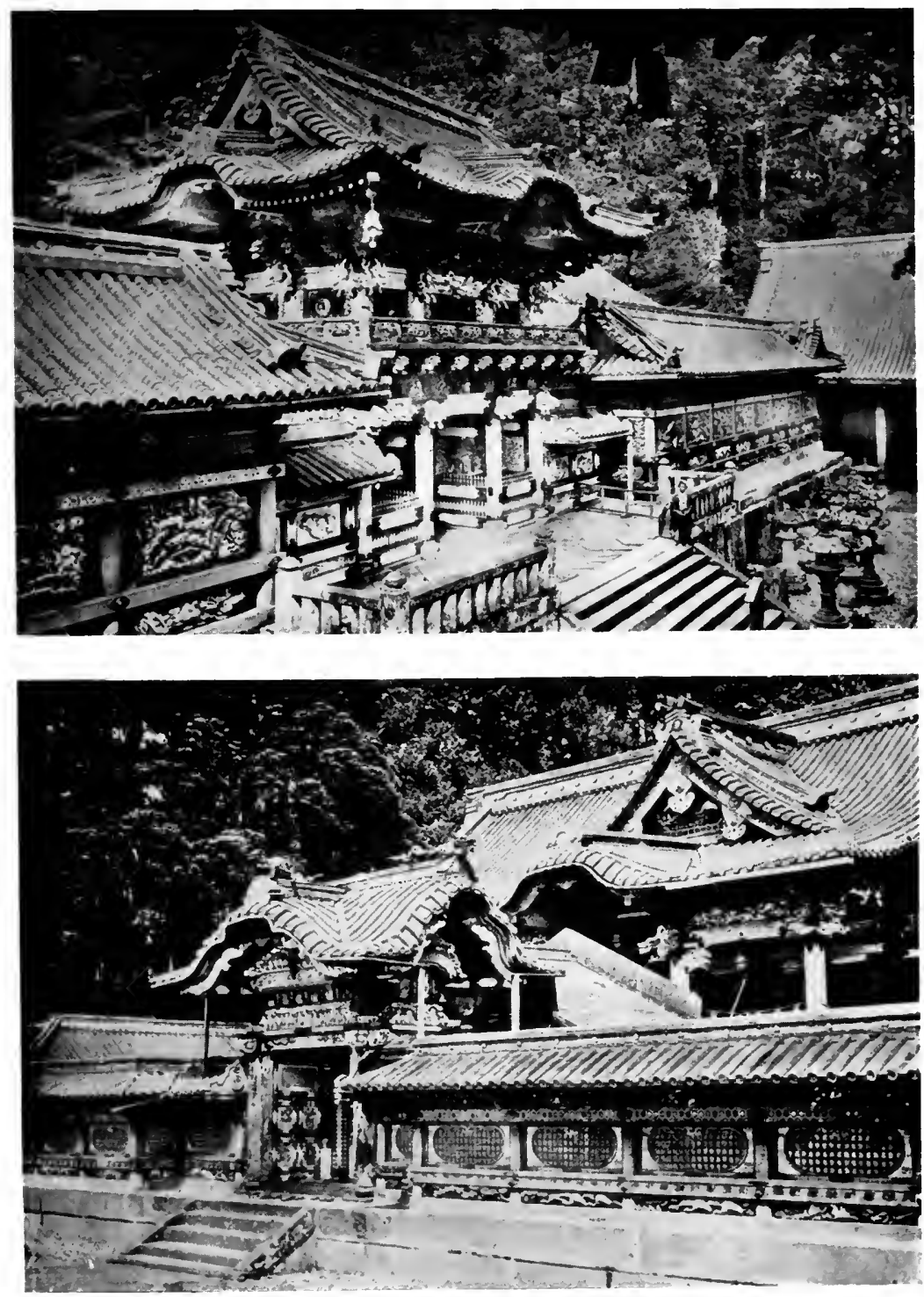

TOKUGAWA SHRINE AT NIKKO 

garded as an evidence of the deference that was beginning then to be paid to the non-military classes by the samurai.

It was at this time (1658), also, that the city of Yedo obtained its first supply of good water. There was already an aquaduct from Inokashira Lake to the Kanda district of the city, but it carried only a very small volume of water, and the idea of harnessing the Tama-gawa to supply the town was due to two citizens, Shöemon and Seiemon, who subsequently received the family name of Tamagawa. The Bakufu granted a sum of 7500 ryo towards the expense, and on the completion of the work within two years, gifts of 300 ryo were made to the two projectors. The water had to be carried through a distance of over thirty miles, and the enterprise did high credit to the engineering skill of the men of the time.

\section{DECADENCE OF THE BAKUFU ADMINISTRATION}

The era of this fourth Tokugawa shōgun, Ietsuna, was remarkable for things other than the lawlessness of the "wave-men." From that time the Tokugawa began to fare as nearly all great families of previous ages had fared: the substance of the administrative power passed into the hands of a minister, its shadow alone remaining to the shögun. . Sakai Tadakiyo was the chief author of this change. Secluded from contact with the outer world, Ietsuna saw and heard mainly through the eyes and ears of the ladies of his household. But Tadakiyo caused an order to be issued forbidding all access to the Court ladies except by ministerial permit, and thenceforth the shogun became practically deaf and dumb so far as events outside the castle were concerned. Some Japanese historians describe this event as an access of "weariness" on the shogun's part towards the duties of administration. This is a euphemism which can be interpreted by what has been set down above. From 1666, when he became prime minister in Yedo, Sakai Tadakiyo seems to have deliberately planned the relegation of his master to the position of a fainéant and the succession of the shogun's: son to supreme power. 'Tadakiyo's lust of authority was equalled only by his cupidity. "Everything went to the highest bidder. It had gradually become the fashion that the daimyo should invite to their Yedo residences all the leading administrators of the Bakufu. On these entertainments great sums were squandered and valuable presents were a feature of the fettes. It also became fashionable to pay constant visits at the mansions of the chief officials and these visits were always accompanied with costly gifts. It is recorded that the mansion of Tadakiyo was invariably so crowded by persons waiting to pay their respects that a man repairing thither at daybreak could scarcely count on obtaining access by evening-fall. The depraved state of affairs brought the administration of the Tokugawa into wide disrepute, and loyal vassals of the family sadly contrasted the evil time with the days of Ieyasu, seventy years previously.

\section{THE COURTS OF KYŌTO AND OF YEDO}

The great financial straits to which the Imperial Court was reduced during the time of the Muromachi shoguns have been already described. : Both Oda Nobunaga and Toyotomi Hideyoshi made some endeavours to correct this evil state of affairs, and when Tokugawa Ieyasu came into power he adopted still more liberal methods. In 1604, he increased the revenue of the Court by 
10,000 koku annually, and in the course of the next few years he caused the palace to be rebuilt on a scale of considerable grandeur. The same policy was pursued by the second shogun, Hidetada, who assigned to the ex-Emperor an income of $3000 \mathrm{koki}$ and made various allowances to princes and other members of the Imperial family. The recipients of these allowances totalled:140, anil it is on record that, in the year 1706, the revenues of the Imperial Court ag. gregated 29,000 koku; those of the ex-Emperor 15;000; those of the princes and Court nobles, 44,000; those of the Monzeki1 temples, 19,000 ; those of the Court ladies and Imperial nuns, 7500, and those of the Court officials 2300, the whole making a total of about $120,000 k o k u$. The income of the retired shoggun alone equalled that amount, and it was enormously surpassed by the revenues of many of the daimyo. It must be noted, however, that although the rice provided for the above purposes was made a charge upon the Kinai provinces as well as upon Tamba and Ōmi, neither to the Emperor nor to the Imperial princes nor to the Court nobles were estates granted directly. These incomes were collected and transmitted by officials of the Bakufu; but not a tsubo of land was under the control of either sovereign or prince.

Military affairs; civil administration, financial management, including the casting of coins, judicial and legislative affairs, the superintendence of temples, and so forth, were all in the hands of the Bakufu in Yedo or of provincial officials nominated by the shogun. : Nothing could have been more complete than the exclusion of the Kyoto Court from the whole realm of practical government; nor could any system have contrasted more flagrantly with the theory of the Daika reforms, according to which every acre of land throughout the length and breadth of the empire was the property of the sovereign. It might have been expeeted that the Tokugawa shogguns would at least have endeavoured to soften this administrative effacement by pecuniary generosity; but so little of that quality did they display that the Emperor and the ex-Emperor were perpetually in a state of financial embarrassment. As for the Court nobles, their incomes did not always suffice even for the needs of every-day life, and they were obliged to have recourse to various devices, such as marrying their daughters to provincial governors or selling professional diplomas, the right of conferring which was vested in their families.

\section{THE SEKKE, DENSÓ, AND SHOSHIDAI}

The sole functions left to the Imperial Court were those of appointing the shogun - which of course was only formal - eonferring ranks, fixing the name of year-periods, ordering the calendar, taking part in ceremonials, nominating priests and officials, and sanctioning the building of temples: Thus, the regent (kwampaku) was the sovereign's appointee $+\mathrm{He}$ had to be chosen in succession from one of the five families - Konoe, Takatsukasa, Kujō, Nijō, and Ichijo, to which the general name Go-sekke (the Five Regent Families) was given. But the regent was practically without power of any kind. Very different was the ease of the densī, who had direct access to the Throne. Appointed by the shoggun from one of seventeen fámilies closely related to the Tokugawa, a densō, before entering upon the duties of his office, was obliged to swear that he would minutely and unreservedly report to the Bakufu everything coming to his knowledge. His principal duty was to communicate direct with the Throne. There was also another Bakufu nominee called the gisō, who administered 
the affairs of the Imperial Court; and who held, in addition, the post of dai-nagon, chü-nagon; or shö-nagon, which offices were rescrved for members of the Tokugawa family. eiYet another official representing the Bakufu was the shoshidai, who managed all matters connected with the guarding of the Imperial Court and the Court nobles, at the same time transacting financial business. In the event of any disturbance occurring in Court circles in Kyōto, it was reported, first, to the shoshidai and, then, by him, to the senior officials in Yedo, while any disturbance occurring in Yedo was equally reported, first to the shoshidai and afterwards by the latter to the sovereign. The shoshidai was in fact a governor-general; with powers far superior to those of any Court noble, and his sway extended to the eight provinces in the neighbourhood of Kyoto. By means of the shoshidai all circumstances of the Imperial Court were fully conveyed to - the Bakufu in Yedo and complete control was exercised over the Imperial capital and its environs. The Bakufu were careful to choose for this post a man whose loyalty and ability stood beyond question. Finally, reference may be made to the administrator of the reigning sovereign's Court (Kinri-zuki bugyō) and the administrator of the ex-Emperor's court (Sendō-zuki bugyō), both of whom were Bakufu nominees.

\section{THE 107TH SOVEREIGN, THE EMPEROR GO-YÖZEI (A.D. 1586-1611)}

This Emperor held the sceptre throughout the memorable epoch from the death of Nobunaga till that of Ieyasu; and he continued to exercise power during six years after his abdication. It was the that conferred the post of shōgun on Ieyasu and gave him his posthumous title of $T \bar{o}$ shō Gongen. His Majesty was the eldest son of the Emperor Ōkimachi. He surrendered the throne to his third son in 1611, dying at the age of forty-seven; in 1617.

THE 108TH SOVEREIGN, THE EMPEROR GO-MIZU-NO-O (A.D. 1611-1629)

This sovereign had for consort a daughter of the shōgun Hidetada, as already described. The wedding took place in the year 1620 , and its magnificence offered a theme for enthusiastic comment by contemporary historians. The shogun was careful to surround the Imperial bride with officials of his own choosing, and these, joining hands with the shoshidai and the densō, constituted an entourage which ordered everything at Kyōto in strict accordance with the interests of the Tokugawa. The new Empress was dowered with an estate much larger than that of the Emperor himself, although the latter's allowance was increased by ten thousand koku. It is related that his Majesty's impecuniosity compelled the curtailment of various ceremonies and prevented the giving of presents in the ordinary routine of social conventions, so that it became necessary to replenish the Imperial purse by lending rice and money to the citizens at high rates of interest.

A serious collision occurred during Go-Mizu-no-o's reign between the Courts of Kyotto and Yedo. The Emperor, who inclined to literature andireligion, conceived a profound reverence for two Buddhist prelates of great learning and conspicuously holy lives. To these priests, Takuan and Gyokushitsu, his Majesty presented purple robes, a mark of the highest distinction, in apparently unwitting violation of the ecclesiastical laws promulgated by Ieyasu, which forbade the giving of such robes to any bonzes except those of Kennin-ji. On learning of the incident, the Bakufu summoned these prelates to Yedo, deprived 
them of the robes, and sent them into banishment. The Emperor, naturally much offended, declared that he would no longer occupy the throne, and in 1629 , the year of the two priests' transportation, 'he carried out his threat, abdicating in favour of the Imperial princess, Oki, his eldest daughter by the Tokugawa Empress.

\section{THE 109TH SOVEREIGN, THE EMPRESS'MYŌSHŌ (A.D. 1629-1643)}

The Princess Oki, eldest daughter of Tokufu-mon-in and the Emperor Go-Mizu-no-o, was only seven years of age when thus called on to occupy the throne. During eight hundred years no female bad wielded the sceptre of Japan, and the prineess was not without a brother older than herself, though born of a different mother. Thus, the announeement of the Emperor's intention created profound astonishment in the Imperial Court. The partisans of the Bakufu supported the project, but the friends of the Imperial farnily denounced it strenuously. Nothing moved the Emperor, however. His Majesty appears to have thought that to bestow the princess' hand on a subject and to elevate her elder brother to the throne would surely be productive of serious mischief, since the husband of the princess, supported by the Bakufu, would prove an invincible power in the State.

As for the Tokugawa statesmen, some accounts allege that they objected to the Emperor's project, but others say that when the matter was reported in Yedo, the shoggun signified that his Majesty: might consult his own judgment. What is certain is that the Bakufu sent to Kyōto the prime minister, Sakai Tadakiyo, with three other representatives, and that shortly after their arrival in the Imperial capital, arrangements were completed for the proposed change. The Imperial consort, Tófuku-mon-in, was declared ex-Empress with a revenue of 10,000 koku, and the little princess, who is known in history as Myōshō, received an income of $20,000 \mathrm{koku}$; while to the ex-Emperor, Go-Mizu-no-o, only 3000 koku were allotted. Not until 1634, on the occaston of a visit made by Iemitsu, was this glaring contrast corrected: the shogun then increased the ex-Emperor's allowance to $7000 \mathrm{koku}$, and his Majesty continued to administer public affairs from his place of retirement until 1680, when he died in his eighty-fifth year.

\section{THE 110TH SOVEREIGN, THE EMPEROR GO-KŌMYŌ (A.D. 1643-1654)}

This sovereign was a brother of the Empress Myōshō but of a different mother. He was brought up by Töfuku-mon-in as though he were her real child, until he succeeded to the throne at the age of eleven, occupying it for eleven years. Form his earliest youth he showed sagacity; magnanimity, and benevolence. His love of literature was absorbing, and he studied earnestly, taking the priests of the Five Temples as his teachers. He is said to have arrived at the conclusion that a sovereign should never study any useless branch of learning, and as he failed to see the utility of Buddhism, he turned to Confucianism in preference. Moreover, dissatisfied with the old-commentaries of the Han and Tang dynasties, he chose in their stead the new classics composed by Chengtsz and Chutsz; and as for Japanese literature, he condemned as grossly misleading works like the Genji Monogatari and the Ise Monogatari.

There can be no doubt that this sovereign conceived the ambition of recovering the administrative authority. His reign extended from the twenty-second 
year of Iemitsu's sway to the fifth of Ietsuna's, and in the troubles of that period he thought that he saw his opportunity. It is related that he devoted much attention to sword exercise, and the shoshidai Itakura Shigemune warned him that the study of military matters did not become the Imperial Court and would probably provoke a remonstrance from Yedo should the fact become known there. The Emperor taking no notice of this suggestion, Shigemune went so far as to declare his intention of committing suicide unless the fencing lessons were discontinued. Thereupon the young Emperor calmly observed: "I have never seen a military man kill himself, and the spectacle will be interesting. You had better have a platform erected in the palace grounds so that your exploit may be clearly witnessed." When this incident was reported by the shoshidai to Yedo, the Bakufu concluded that some decisive measure must be taken, but before their resolve had materialized and before the sovereign's plans had matured, he died of small-pox, in 1654, at the age of twenty-two, having accomplished nothing except the restoration and improvement of certain Court ceremonials, the enactment of a few sumptuary laws, and the abandonment of cremation in the case of Imperial personages.

THE 111TH SOVEREIGN, THE EMPEROR GO-SAIEN (A.D. 1654-1663) AND THE 112TH SOVEREIGN, THE EMPEROR REIGEN (A.D. 1663-1686)

nt Go-Saien was the sixth son of the Emperor Go-Mizu-no-o. His reign is remarkable in connexion with the attitude of the Yedo Bakufu towards the Throne. In 1657, as already related, Yedo was visited by a terrible conflagration, and another of scarcely less destructive violence occurred in the same city the following year, while, in 1661, the Imperial palace itself was burned to the ground, the same fate overtaking the principal Shintō shrine in Ise, and nearly every province suffering more or less from a similar cause. Moreover, in 1662, a series of earthquakes disturbed the country throughout a whole month, and the nation became almost demoralized in the face of these numerous calamities. Then the Bakufu took an extraordinary step. They declared that such visitations must be referred to the sovereign's want of virtue and that the only remedy lay in his abdication. The shogun, Ietsuna, was now ruling in Yedo. He sent envoys to Kyōto conveying an order for the dethronement of the Emperor, and although his Majesty was ostensibly allowed to abdicate of his own will, there could be no doubt as to the real circumstances of the case: His brother, Reigen, succeeded him, and after holding the sceptre for twentyfour years, continued to administer affairs from his place of retirement until his death, in 1732.

\section{SANKE AND SANKYŌ}

When Ieyasu, after the battle of Sekigahara, distributed the fiefs throughout the Empire, he gave four important estates to his own sons, namely, Echizen to Hideyasu; Owari to Tadayoshi; Mito to Nobuyoshi, and Echigo to Tadateru. Subsequently; after the deaths of Tadayoshi and Nobuyoshi, he assigned Owari to his sixth son, Yoshinao, and appointed his seventh son, Yorinobu, to: the Kii fief, while to his eighth son, Yorifusa, Mito was given. These last three were called the Sanke (the Three Families). From them the successor to the shōgunate was chósen in the event of failure of issue in the direct line. Afterwards this system was extended by the addition of three branch-families (San- 
$k y \overline{0})$, namely those of Tayasu and Hitotsubashi by, Munetake and Munetada, respectively, sons of the shogun Yoshimune; and that of Shimizu by Shigeyoshi, son of the shogun Ieshige. $:$ It was enacted that if no suitable heir to the shōgunate was furnished by the Sanke, the privilege of supplying one should devolve on the Sankyo, always, however, in default of an heir in the direct line. The representatives of the Sanke had their estates and castles, but no fiefs were assigned to the Sankyō; they resided in Yedo close to the shogun's palace, and received each an annual allowance from the Bakufu treasury.

\section{THE FEUDAL SYSTEM OF THE TOKUGAWA}

It has been shown that in distributing the fiefs Ieyasu aimed at paralyzing the power of the tozama daimyo and vitalizing that of the fuda $i$ barons. Whis he effected, as far as concerned the tozama feudatories, by isolating them from each other, or by placing those of equal strength in juxtaposition, so that they might become rivals; while in the case of fuda $i$ barons, he established an effective system of communications between them, so that co-operation and concentration of forces were facilitated. Broadly speaking, this method had for result the planting of the tozama daimyō in the west and of the fudai barons in the east, as well as along the main roads between the two capitals. The plan worked admirably during 270 years, but at the Restoration, in 1867, the western daimyo combined to overthrow the shōgunate.

Very noticeable were the steps taken to provide facilities for communication between Yedo and Kyōto.' No less than fifty-three posting stations were established along the road from the Bakufu capital to the Imperial city, and at several places barriers were set up. Among these latter, Hakone was considered specially important. The duty of guarding the barrier there was assigned to the Ōkubo family; who enjoyed the full confidence of the Tokugawa and who had their castle in Odawara. . No one could pass this barrier without a permit. Women were examined with signal strictness, they being regarded as part of the system which required that the wives of the daimy $\bar{o}$ should live in Yedo as hostages. Thus, whereas a man was granted ingress or egress if he carried a passport signed by his own feudal chief and addressed to the guards at the barrier, a woman might not pass unless she was provided with an order signed by a Bakufu official. Moreover, female searchers were constantly on duty whose business it was to subject women travellers to a scrutiny of the strictest character, involving, even, the loosening of the coiffure. All these precautions formed part of the sankin kotai system, which proved one of the strongest buttresses of Tokugawa power. But; from the days of Ietsuna, the wives and children of the daimyo were allowed to return to their provinces, and under the eighth shōgun, Yoshimune, the system of sankin kötai ceased to be binding. This was because the Tokugawa found themselves sufficiently powerful to dispense with such artificial aids.

\section{THE FIEES}

There were certain general divisions of the feudatories. Everyone possessing a fief of 10,000 koku or upwards was called a daimyó. The title included the Sanke, the Sankyō, the gokemon (governor of Echizen), the fudai (hereditary vassals), and the tozama. These. were again subdivided into three classes according to the sizes of their fiefs. In the first class stood the kokushu (called also kuni-mochi; or proyincial barons) who possessed revenues of at least 300,000 
koku. The second class consisted of the jōshu (called also shiro-mochi, or castleowning barons) whose incomes ranged between 100,000 and $300,000 \mathrm{koku}$. Finally, the third class was composed of the ryoshu (sometimes known as shironashi, or castleless barons), whose revenues ranged from 10,000 to $100,000 \mathrm{koku}$. These feudatories might be recommended by the shōgun for Court rank in Kyōto, but the highest office thus conferred was that of dainagon (great councillor), from which fact the attitude of the feudatories towards imperially conferred distinctions can be easily appreciated. Nevertheless, the rules of etiquette were strictly observed by provincial magnatcs attending Court functions. They had to conform carefully to the order of their precedence and with the sumptuary rules as to colour and quality of garments, and any departure from these conventions was severely punished.

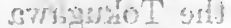

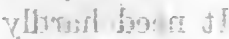 \\ SUCCESSION}

If a feudatory committed some crime or died childless, the law required that he should be transferred to another province, or that his successor should suffer a considerable reduction of revenue. Experience showed, however, that as many of the feudatories died childless, there were numerous losses of fiefs, and ultimately it was enacted that a baron might adopt, a successor by way of precaution, unless he deferred that step until he lay dying or sought permission to take it before he reached the age of seventeen. - Thismeant that if any feudal chief died before reaching his seventeenth year, his estate was lost to his family. By way of correcting such a hardship, the adoption of an heir was afterwards sanctioned without reference to the age of the adopter, and it was further decided that a man of fifty or upwards might adopt a son even on his death-bed. Finally, in the year 1704; all these restrictions were virtually abolished, and especially the rule that an adopted son must necessarily beiong to the family of his adopter.

\section{SEVERITY OF THE TOKUGAWA TOWARDS THE FEUDATORIES}

Although Ieyasu and his successors in the shōgunate did not fail to provide large estates for their own kith and kin, they never showed any leniency in dealing with the latter's offences. Ieyasu professed to believe in the potency of justice above all administrative instruments, and certainly he himself as well as his successors obeyed that doctrine unswervingly in so far as the treatment of their own families was concerned. They did not hesitate to confiscate fiefs, to pronounce sentence of exile, or even to condemn to death. Thus, in the year of Ieyasu's decease, his sixth son, Matsudaira Tadateru, was deprived of his fief - 610,000 koku - and removed from Echigo to Asama, in Ise. Tadateru's offence was that he had unjustly done a vassal of the shogun to death, and had not moved to the assistance of the Tokugawa in the Ōsaka War. Moreover, when his elder brother; the shog un Hidetada, repaired to the Imperial palace, Tadateru had pretended to be too ill to accompany him, though in reality he was engaged in a hunting expedition. This was the first instance of the Bakufu punishing one of their own relatives.

Another example was furnished in 1623 when Matsudaira Tadanao, lord of Echizen, was sentenced to confinement in his own house and was ordered to hand over his fief of 750,000 koku to his heir. This: Tadanao was a grandson of Ieyasu, and had-shown himself a strong soldier in the Ōsaka War. But 
subsequently he fell into habits of violence and lawlessness, culminating in neglect of the sankin'kōtai system. His uncle, the shögun Hidetada, sentenced him as above described. Under the administration of Iemitsu this unflinching attitude towards wrongdoers was maintained more relentlessly than ever. The dai nagon, Tadanaga, lord of Suruga and younger brother of Iemitsu by the same mother, received (1618) in Kai province a fief of $180,000 \mathrm{koku}$, and, seven years later, this was increased by Suruga and Tōtomi, bringing the whole estate up to 500,000 . koku. He resided in the castle of Sumpu and led an evil life, paying no attention whatever to the remonstrances of his vassals. In 1632 ; Iemitsu confiscated his fief and exiled him to Takasaki in Kōtsuke, where he was compelled to undergo confinement in the Yashiki of: Andö Shigenaga. Fourteen months later, sentence of death was pronounced against him at the early age of twenty-eight.

Other instances might be quoted showing how little mercy the Tokugawa shōguns extended to wrongdoers among their own relatives. It need hardly be said that outside clans fared no better. Anyone who gave trouble was promptly punished. Thus, in 1614, Ōkubo Tádachika, who had rendered good service to the Bakufu in early days, and who enjoyed the full confidence of the shogun, was deprived of his castle at Odawara and sentenced to confinement for the comparatively trifling offence of contracting a private marriage. Again, in 1622, the prime minister, Honda Masazumi, lord of Utsunomiya, lost his fief of 150,000 koku and was exiled to Dawe for the sin of rebuilding his castle without due permission, and killing a soldier of the Bakufu. To persons criticising this latter sentence as too severe, Doi Toshikatsu is recorded to have replied that any weakness shown at this early stage of the Tokugawa rule must ultimately prove fatal to the permanence of the Bakufu, and he expresised the conviction that none would approve the punishment more readily than Masazumi's dead father, 'Masanobu, were he still living to pass judgment.

Doubtless political expediency, not the dictates of justice, largely inspired the: conduct of the Bakufu in these matters, for in proportion as the material influence of the Tokugawa increased, that of the Toyotomi diminished. In 1632, when the second shogun, Hidetada, died, it is related that the feudal barons observed the conduct of his successor, Iemitsu, with close attention, and that a feeling of some uneasiness prevailed. Iemitsu, whether obeying his own instinct or in deference to the advice of his ministers, Sakai Tadakatsu and Matsudaira Nobutsuna, summoned the feudal chiefs to his castle in Yedo and addressed them as follows: "My father and my grandfather, with your assistance and after much hardship, achieved their great enterprise to which I; who have followed the profession of arms since my childhood, now succeed. It is my purpose to treat you all without distinction as my hereditary vassals. If any of you object to be so treated, let him return to his province and take the consequences.",

Date Masamune assumed the duty of replying to that very explicit statement. "There is none here," he said, "that is not grateful for the benevolence' he has received at the hands of the Tokugawa. If there be such a thankless and disloyal person, and if he conceive treacherous designs, I, Masamune, will be the first to attack him and strike him down. The shögun need not move so much as one soldier." With this spirited reply all the assembled daimyö expressed their concurrence, and Iemitsu proceeded to distribute his father's legacies to the various barons and their vassals. Very soon after his accession he had to order the execution of his own brother, Tadanaga, and the banishment of Katō Tadahiro, "son of the celebrated Katō Kiyomasa. The latter was 
punished on the ground that he sent away his family from Yedo during the time of mourning for the late shoggun, Hidetada. He was deprived of his estate at Kumamoto in Higo and was exiled to Dewa province.

The punishment of these two barons is said to have been in the sequel of a device planned by Iemitsu and carried out by Doi Toshikatsu. The latter, being accused of a simulated crime, was sentenced to confinement in his mansion. Thence he addressed to all the daimyo a secret circular, urging them to revolt and undertaking to make Tadanaga shōgun instead of Iemitsu. With two exceptions every baron to whose hands this circular came forwarded it to the Bakufu in Yedo. The exceptions were Tadanaga and Tadahiro, who consequently fell under the shögun's suspicion. Thereafter, it is related that some of the barons set themselves to deceive the Bakufu by various wiles. Thus, Maeda Toshinaga had recourse to the manœuvre of allowing the hair in his nostrils to grow long, a practice which speedily earned for him the reputation of insanity, and Date Masamune conceived the device of carrying a sword with a wooden blade. The apprehensions of which such acts were indicative cannot be considered surprising in view of the severe discipline exercised by the Bakufu. Thus, during the shōgunate of Hidetada, no less than forty changes are recorded to have been made among the feudatories, and in the time of Iemitsu there were thirty-five of such incidents. History relates that to be transferred from one fief to another, even without nominal loss of revenue, was regarded as a calamity of ten years' duration. All this was partly prompted by the Bakufu's policy of weakening the feudatories. To the same motive must be assigned constant orders for carrying out some costly public work.

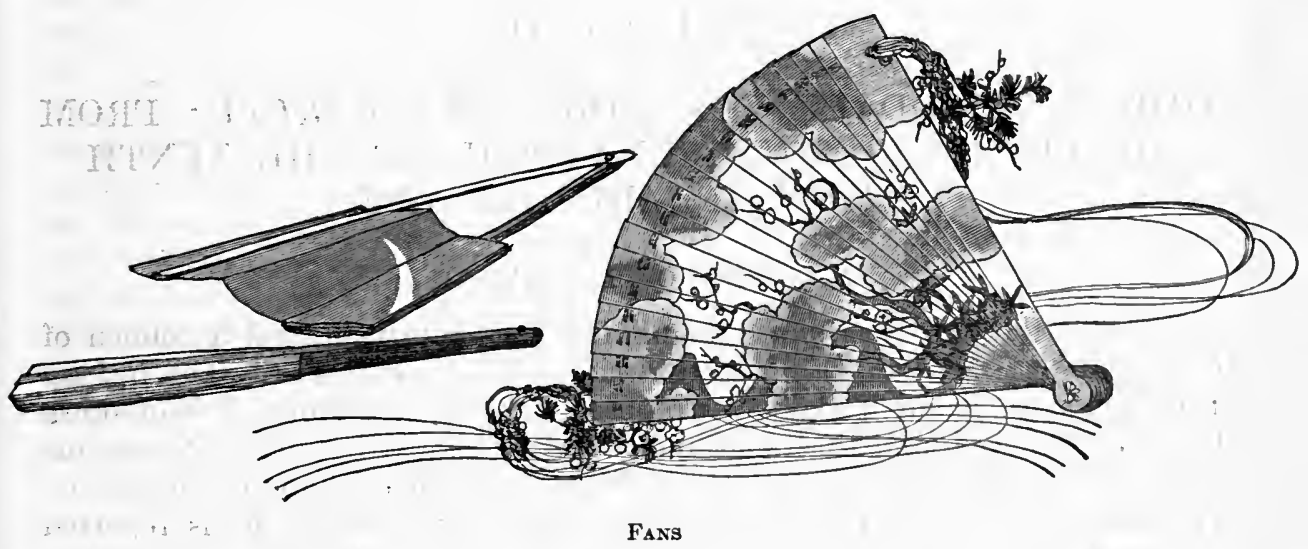




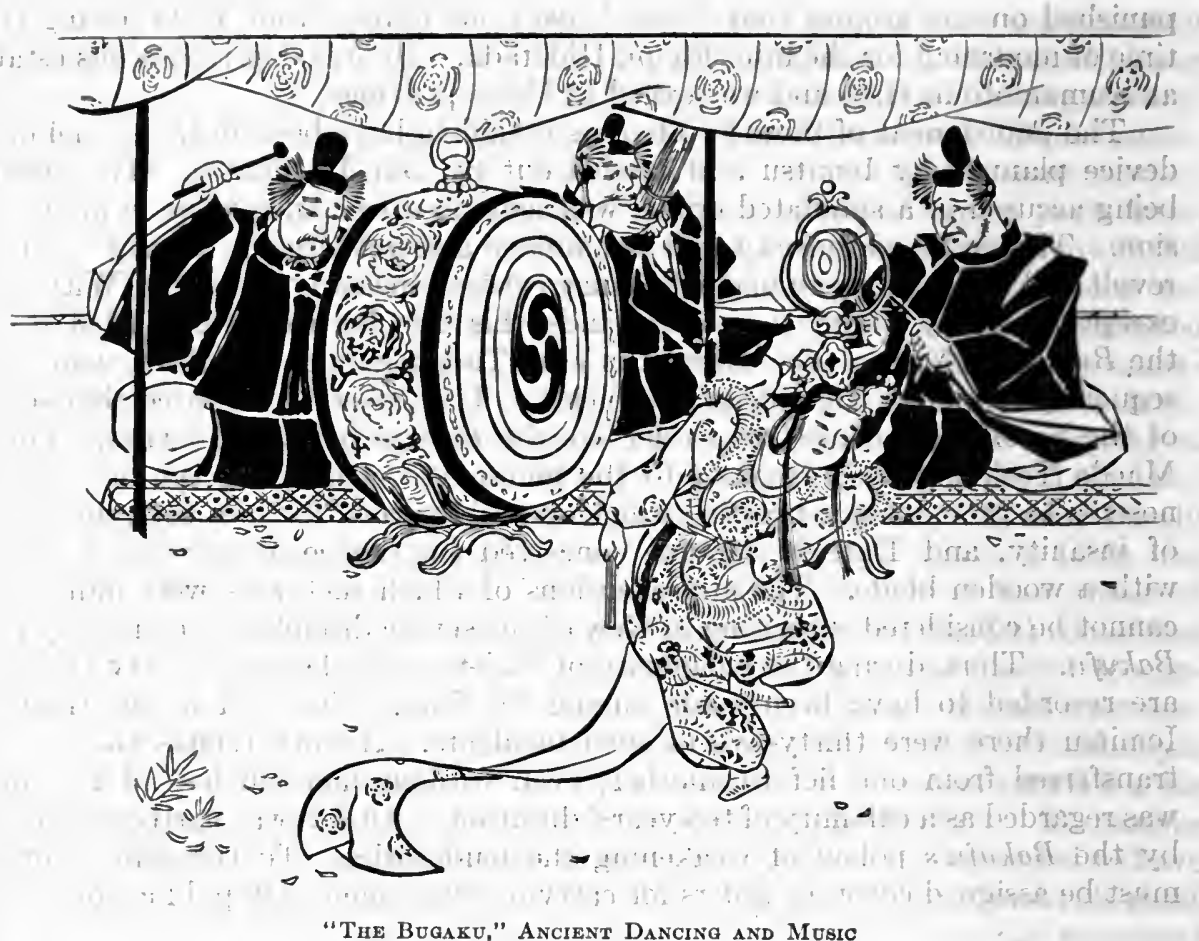

\section{CHAPTER XL}

\section{MIDDLE PERIOD OF THE TOKUGAWA BAKUFU; FROM THE FIFTH SHŌGUN, TSUNAYOSHI, TO THE TENTH SHŌGUN, IEHARU (1680-1786)}

\section{ACCESSION OF TSUNAYOSHI}

IN 1680, the fourth shoggun, Ietsuna, fell dangerously ill, and a council of the ehief Bakufu officials was held to decide upon his successor. The Bakufu prime minister, Sakai Tadakiyo, proposed that the example of Kamakura should be followed, and that an Imperial prince should be invited to assume the office of shoggun. Thereupon Hotta Masatoshi, one of the junior ministers, vehemently remonstrated. "Is the prime minister jesting?" he is reported to have asked. "There is no question whatever as to the succession. That dignity falls to Tsunayoshi and to Tsunayoshi alone. He is the legitimate son of the late shogun, Iemitsu, and the only brother of the present shogun, Ietsuna. If the minister is not jesting, his proposition is inexplicable." This bold utterance was received with profound silence, and after a few moments Sakai Tadakiyo retired from the council chamber.

It has to be remembered in connexion with this incident, that Tadakiyo exercised almost complete sway in the Bakufu Court at that time, and the fact 
that he yielded quietly to Hotta Masatoshi's remonstrance goes far to acquit him of any sinister design such as securing the whole administrative power for himself by setting up an Imperial prince as a mere figurehead. The more probable explanation is that as one of the consorts of the shoggun Ietsuna was enceinte at that time, the Bakufu prime minister desired to postpone any family decision until the birth of her child, since to dispense with an Imperial prince would be as easy to procure one, whereas if one of the shogun's lineage were nominated, he would be difficult to displace. There had been born to Iemitsu five sons, of whom the eldest; Ietsuna, had succeeded to the shogunate, and three others had died, the only one remaining alive being Tsunayoshi, who, having been born in 1646, was now (1680) in his thirty-fourth year.

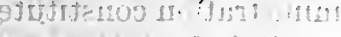

\section{HOTTA MASATOSHI}

On Tsunayoshi's accession the prime minister, Sakai Tadakiyo, was released from office, and Hotta Masatoshi became his successor. Naturally, as Masatoshi had been instrumental in obtaining the succession for Tsunayoshi; his influence with the latter was very great. But there can be no question that he deserves to rank as one of Japan's leading statesmen in any age, and that he devoted his signal abilities to the cause of progress and administrative purity. The result of his strenuous services was to check the corruption which had come to pervade every department of State in the closing years of the fourth shoggun's sway, and to infuse the duties of government with an atmosphere of diligence and uprightness.

grfintivinga te

\section{THE ECHIGO COMPLICATION}

For several years prior to the accession of Tsunayoshi, the province of Echigo had been disturbed by an intrigue in the family of Matsudaira Mitsunaga. It is unnecessary to enter into further details. The incident was typical of the conditions existing in many of the barons' households, and the history of Japan furnishes numerous parallel cases. But connected with this particular example is the remarkable fact that the shoggun himself finally undertook in the hall of justice to decide the issue, and that the rendering of justice by the chief of the Bakufu became thenceforth a not infrequently praetised habit. Instructed by his prime minister, the shogun swept aside all the obstacles placed in the path of justice by corruption and prejudice; sentenced the principal intriguer to death; confiscated the Mitsunaga family's estate of 250;000 koku on the ground of its chief's incompetence, and severely punished all the Bakufu officials who had been parties to the plot.

अriti

THE ATAKA MARU

Another act of Tsunayoshi stands to the credit of his acumen. Although the third shogun, Iemitsu, had vetoed the building of any vessels exceeding five hundred-koku capacity, his object being to prevent oversea enterprise, he caused to be constructed for the use of the Bakufu a great ship called the Ataka Maru, which required a crew several hundred strong and involved a yearly outlay figuring in the official accounts at one hundred thousand koku. One of Tsunayoshi's first orders was that this huge vessel should be broken up, and when his ministers remonstrated on the ground that she would be invaluable in case 
of emergency, he replied that if an insurrection could not be suppressed without such extraordinary instruments, the Bakufu might step down at once from the seats of power. "As for me," he added, "I have no desire to preserve such an evidence of constant apprehension and at such a charge on the coffers of the State."

\section{ENCOURAGEMENT OF VIRTUE}

Tsunayoshi also instructed his officials to search throughout the empire for persons of conspicuous filial piety and women of noted chastity. To these he caused to be distributed presents of money or pensions, and he directed the litterateurs of the Hayashi family to write the biographies of the recipients of such rewards. In fact, the early years of the shogun's administration constitute one of the brightest periods in the history of the Tokugawa Bakufu.

\section{ASSASSINATION ÓF HOTTA MASATOSHI}

On the 8 th of October, 1684, the Bakufu prime minister, Hotta Masatoshi, was assassinated in the shogun's palace by one of the junior ministers, Inaba Masayasu, who met his death immediately at the hands of the bystanders. This extraordinary affair remains shrouded in mystery until the present day. Hotta Masatoshi was the third son of Masamori, who died by his own hand to follow his master, Iemitsu, to the grave. Masatoshi, inheriting a part of his father's domain, received the title of Bitchu no Kami, and resided in the castle of Koga, ultimately (1680) becoming prime minister (dairō) with an annual revenue of $130,000 \mathrm{koku}$. His high qualities are recorded above, but everything goes to show that he had more than the ordinary reformer's stubbornness, and that tolerance of a subordinate's errors was wholly foreign to his disposition. Even to the shoggun himself he never yielded in the smallest degree; and by the majority of those under him he was cordially detested. The records say that on one occasion, when remonstrated with by his friend, the daimyō of Hirado, who warned him that his hardness and severity might involve him in trouble, Masatoshi replied, "I thank you for your advice, but so long as I am endeavouring to reform the country, I have no time to think of myself."

It is easy to understand that a man of such methods had enemies sufficiently numerous and sufficiently resolute to compass his death. On the other hand, Masayasu, his assassin, was related to him by marriage, and possessed an estate of $25,000 \mathrm{koku}$, as well as holding the position of junior minister of State. It is extremely unlikely that a man in such a position would have resorted to such a desperate act without great provocation, or ample sanction. The question is, was the shoggun himself privy to the deed?. It is recorded that there was found on Masayasu's person a document expressing deep gratitude for the favours he had received at the hands of the shoggun, and declaring that only by taking the life of Masatoshi could any adequate return be made. It is further recorded that the steward of the Bakufu, addressing the corpse of Masayasu, declared that the deceased had shown unparallelled loyalty. Again, history says that Mitsukuni, daimyō of Mito, repaired to the Inaba mansion after the incident, and expressed to. Masayasu's mother his condolences and his applause. Finally, after-Masatoshi's death, his son was degraded in rank and removed to a greatly reduced estate. All these things are difficult to explain except on the supposition that the shogun himself was privy to the assassination. 


\section{ENCOURAGEMENT OF CONFUCIANISM}

The third shögun, Iemitsu, addressing the mother of his son, Tsunayoshi, is said to have expressed profound regret that his own education had been confined to military science. "That is to me," he is reported to have said, "a source of perpetual sorrow, and care should be taken that Tsunayoshi, who seems to be a clever lad, should receive full instruction in literature." In compliance with this advice, stéps were taken to interest Tsunayoshi in letters, and he became so attached to this class of study that even when sick he found solace in his books. The doctrines of Confucius attracted him above all other systems of ethics. He fell into the habit of delivering lectures on the classics, and to show his reverence for the Chinese sages, he made it a rule to wear full dress on these occasions, and to worship after the manner of all Confucianists. It has already been related that a shrine of Confucius was built in Ueno Park by the Tokugawa daimyo of Owari, and that the third shogun, Iemitsu, visited this shrine in 1633 to offer prayer. Fifty years later, the fifth shogun, Tsunayoshi, followed that example, and also listened to lectures on the classics by Hayashi Nobuatsu. Subsequently (1691), a new shrine was erected at Yushima in the Hongo district of Yedo, and was endowed with an estate of one thousand koku to meet the expenses of the spring and autumn festivals. Further, the daimy $\bar{o}$ were required to contribute for the erection of a school in the vicinity of the shrine. At this school youths of ability, selected from among the sons of the Bakufu officials and of the daimyō, were educated, the doctrines of Confucius being thus rendered more and more popular.

Under 'Tsunayoshi's auspices, also, many books were published which remain to this day standard works of their. kind. Another step taken by the shoggun was to obtain from the Court in Kyoto the rank of junior fifth class for Hayashi Nobuatsu, the great Confucian scholar, who was also nominated minister of Education and chief instructor at Hongo College. Up to that time it had been the habit of Confucianists and of medical men to shave their heads and use titles corresponding to those of Buddhist priests. In these circumstances neither Confucianists nor physicians could be treated as samurai, and they were thus excluded from all State honours. The distinction conferred upon Hayashi Nobuatsu by the Imperial Court effectually changed these conditions. The Confucianists ceased to shave their heads and became eligible for official posts. Thereafter, ten of Hayashi's disciples were nominated among the shögun's retainers, and were required to deliver lectures periodically' at the court of the Bakufu. In short, in whatever related to learning, Tsunayoshi stands easily at the head of all the Tokugawa shōguns.

\section{CHANGE OF CALENDAR}

A noteworthy incident of Tsunayoshi's administration was a change of calendar, effected in the year 1683 . The credit of this achievement belongs to a mathematician called Shibukàwa Shunkai. A profound student, his researches had convinced him that the Hsuan-ming calendar, borrowed originally from China and used in Japan ever since the year A.D. 861, was defective. He pointed out some of its errors in a memorial addressed to the Bakufu under the sway of the fourth shogun, but the then prime minister, Sakai Tadakiyo, paid no attention to the document. Shunkai, however, did not desist. In 1683, an eclipse of the moon took pläce, and he demonstrated that it was erroneously 
calculated in the Chinese calendar. The fifth shögun, Tsunayoshi, was then in power, and the era of his reforming spirit had not yet passed away. He adopted Shunkai's suggestion and obtained the Imperial sanction for a change of calendar so that the Husan-ming system went out of force after 822 years of use in Japan.

\section{JAPANESE LITERATURE}

Tsunayoshi did not confine his patronage to Chinese literature; he devoted much energy to the encouragement of Japanese classical studies, also Thus, in 1689 , he invited to Yedo Kitamura Kigin and his son Shunchō and bestowed upon the former the title of $\mathrm{Ho}$ in together with a revenue of five hundred koku. This marked the commencement of a vigorous revival of Japanese literature in the Bakufu capital. Moreover, in Ōsaka a scholar named. Keichū Ajari published striking annotations of the celebrated anthologies, the Manyō-sh $\bar{u}$ and the Kokin-shi, which attracted the admiration of Tokugawa Mitsukuni, baron of Mito. He invited Keichū to his castle and trea ted him with marked consideration.; These littérateurs were the predecessors of the celebrated Kamo and Motoori, of whom there will be occasion to speak by and by.

\section{FINE ARTS}

Tsunayoshis patronage extended also to the field of the fine arts. The Tokugawa Bakufu had hitherto encouraged the Kano School only whereas the Tosa Academy was patronized by the Court at Kyōto. This partiality was corrected by Tsunayoshi. He invited Sumiyoshi Gukei - also called Hirozumi - the most distinguished pupil of Tosa Mitsuoki, bestowed on him a revenue of two hundred $k o k w$, and gave him the official position of chief artist of the Tosa-ryy, placing him on an equal footing with the chief of the Kan $\overline{0}-r y y \bar{u}$. It was at this time also that the ukiyoe (genre picture) may be said to have won popular favour. Contemporaneously there appeared some dramatic authors of high ability, and as the ukiyoe and the drama appealed mainly to the middle. and lower classes, the domain of literature and the fine arts received wide extension. Thus, Chikamatsu Monzaemon, of Ōsaka, the greatest dramatist that his country ever possessed, composed plays which have earned for him the title of the "Shakespeare of Japan;"; and as for the light literature of the era, though it was disfigured by erotic features, it faithfully reflected in other respects the social conditions and sentiments of the time.

\section{THE MERCANTILE CLASS}

From the commencement of Japanese history down to the second half of the seventeenth century, the canons and customs were dictated solely by the upper class, and neither merchants nor artisans were recognized as possessing any social or literary influence whatever. But in the middle period of the Tokugawa Bakufu - the Genroku period, as it is commonly called - the tradesman became a comparatively conspicuous figure. For example, in the realm of poetry, hitherto strictly reserved for the upper classes, the classic verse called renga (linked song) was considered to be sullied by the introduction of any common or every-day word, and therefore could be composed only by highly educated persons. This now found a substitute in the haikai, which admitted language taken from purely Japanese sources and could thus be produced with- 
out any exercise of special scholarship. Afterwards, by the addition of the hokku, an abbreviation of the already brief renga and haikai, which adapted itself to the capacities of anyone possessing a nimble wit or a sparkling thought, without any preparation of literary study, the range of poetry was still further extended. Matsuo Bashō was the father of the haikai and the hokku, and his mantle descended upon Kikaku, Ransetsu, Kyoriku, and other celebrities. They travelled round the country popularizing their art and immensely expanding the field of literature. The craft of penmanship flourished equally, and was graced by such masters as Hosoi Kōtaku and Kitamura Sessan.. Yedo, the metropolis of wealth and fashion, became also the capital of literature and the fine arts, and a characteristic of the era was the disappearance of charlatans, whether laymen or bonzes, who professed to teach the arcana of special accomplishments. In short, every branch of study passed out of the exclusive control of one or two masters and became common property, to the great advantage of original development.

\section{REMOVAL OF THE RŌJU}

What has thus far been written depicts the bright side of Tsunayoshi's administration. It is necessary now to look at the reverse of the picture. There we are first confronted by an important change of procedure. It had been the custom ever since the days of Ieyasu to conduct the debates of the council of ministers $(R \bar{o} j \bar{u})$ in a chamber adjoining the shōgun's sitting-room, so that he could hear every word of the discussion, and thus keep himself au courant of political issues. After the assassination of Hotta Masatoshi this arrangement was changed. The council chamber was removed to a distance, and guards were placed in the room where it had originally assembled, special officials being appointed for the purpose of maintaining communications between the shōgun and the $R \bar{o} j \bar{u}$. This innovation was nominally prompted by solicitude for the shog ${ }^{2}$ 's safety, but as its obvious result was to narrow his sources of-information and to bring him under the direct influence of the newly appointed officials, there is strong reason to believe that the measure was a reversion to the evil schemes of Sakai Tadakiyo, who plotted to usurp the shogun's authority.

\section{YANAGISAWA YASUAKI}

Tsunayoshi had at that time a favourite attendant on whom he conferred the rank of Dewa no Kami with an estate at Kawagoe which yielded 100,000 koku annually: :The friendship of the shogun for this most corrupt official had its origin in community of literary taste. Tsunayoshi lectured upon the "Doctrine of the Mean," and Yasuaki on the Confucian "Analects," and after these learned discourses a Sarugaku play, or some other form of light entertainment, was organized; The shōgun was a misogynist, and Yasuaki understood well that men who profess to hate women become the slave of the fair sex when their alleged repugnance is overcome. He therefore set himself to lead the shogun into licentious habits, and the lecture-meetings ultimately changed their complexion. Tsunayoshi, giving an ideograph from his name to Yasuaki, called him Yoshiyasu; and authorized him to assume, the family name of Matsudaira, conferring upon him at the same time a new domain in the province of Kai yielding $150,000, k o k u$. Thenceforth, the administration fell entirely into the hands of this schemer. No prime minister (dairō) was appointed after the assassination of Hotta Masatoshi; the council of ministers became 
a mere echo of Yoshiyasu's will and the affairs of the Bakufu were managed by one man alone.

THE DOG MANIA

Tsunayoshi lost his only son in childhood and no other being born to him, he invited a high Buddhist priest to pray for an heir to the shoggunate. This priest, Ryūkō by name, informed Tsunayoshi that his childless condition was a punishment for taking animal life in a previous state of existence, and that if he wished to be relieved of the curse, he must show mercy, particularly to dogs, as he had been born in the year whose zodiacal sign was that of the "Dog." It seems strange that such an earnest believer in the Confucian doctrine should have had recourse to Buddhism in this matter. But here also the influence of Yoshiyasu is discernible. At his suggestion the shögun built in Yedo two large temples, Gokoku-ji and Goji-in, and Ryūko was the prelate of the former. An order was accordingly issued against slaughtering dogs or taking life in any form, the result being that all wild animals multiplied enormously and wrought great damage to crops. Thereupon the Bakufu issued a further notice to the effect that in case wild animals committed ravages, they might be driven away by noise, or even by firing blank cartridges, provided that an oath were made not to kill them. Should these means prove defective, instructions must be sought from the judicial department. Moreover, if any animal's life was taken under proper sanction, the carcass must be buried without removing any part of its flesh or skin. Violations of this order were to be severely punished, and it was enacted that an accurate register must be kept of all dogs owned by the people, strict investigations being made in the event of the disappearance of a registered dog, and the officials were specially warned against permitting one animal to be substituted for another. Strange dogs were to be well fed, and any person neglecting this obligation was to be reported to the authorities.

At first these orders were not very seriously regarded, but by and by, when many persons had been banished to Hachijō-jima for killing dogs; when several others had been reproved publicly for not giving food to homeless animals, and when officials of the supreme court were condemned to confinement for having taken no steps to prevent dog-fights, the citizens began to appreciate that the shōgun was in grim earnest. A huge kennel was then constructed in the Nakano suburb of Yedo as a shelter for homeless dogs. It covered an area of about 138 acres, furnished accommodation for a thousand dogs, and was under the management of duly appointed officials, while the citizens had to contribute to a dogfund; concerning which it was said that a dog's ration for a day would suffice a man for a day and a half.

Tsunayoshi came to be spoken of as Inu-kubō (Dog-shōgun), but all his measures did not bring him a son; neither did their failure shake his superstitious credulity. Solemn prayers were offered again and again with stately pomp and profuse circumstance, and temple'after temple was built or endowed at enormous cost, while the laws against taking animal life continued in force more vigorously than ever. Birds and even shell-fish were included in the provisions, and thus not only were the nation's foodstuffs diminished, but also its crops lay at the mercy of destructive animals and birds. It is recorded that a peasant was exiled for throwing a stone at a pigeon, and that one man was put to death for catching fish with hook and line, while another met the same fate for injuring a dog, the head of the criminal being exposed on the public execution ground and a neighbour: who had reported the offence being rewarded with thirty ryo . 
We read, also, of officials sentenced to transportation for clipping a horse or furnishing bad provender. The annals relate a curious story connected with these legislative excesses. The Tokugawa baron of Mito, known in history as Kōmon Mitsukuni, on receiving evidence as to the monstrous severity with which the law protecting animals was administered, collected a large number of men and organized a hunting expedition on a grand scale. Out of the animals killed, twenty dogs of remarkable size were selected, and their skins having been dressed, were packed in a case for transmission to Yanagisawa Yoshiyasu, whom people regarded as chiefly responsible for the shogun's delirium. The messengers to whom the box was entrusted were ordered to travel with all speed, and, on arriving in Yedo, to repair forthwith to the Yanagisawa mansion, there handing over the skins with a written statement that the Mito baron, having found such articles useful in the cold season, availed himself of this opportunity to submit his experience together with a parcel of dressed hides to the shogun through Yoshiyasu. It is said that the recipient of this sarcastic gift conceived a suspicion of the Mito baron's sanity and sent a special envoy to examine his condition.

dxrาionture

\section{FINANCE}

In the sequel of this corrupt administration, this constant building of temples, and this profusion of costly ceremonials, the shögun's Government found itself seriously embarrassed for money. Ieyasu had always made frugality and economy his leading principles." He had escaped the heavy outlays to which his fellow barons were condemned in connexion with the Korean campaign, since his share in the affair did not extend beyond collecting a force in the province of Hizen.? Throughout his life he devoted much attention to amassing a reserve fund, and it is said that when he resigned the shogunate to his son, he left 150,000 gold ōban (one and a half million $r y \bar{o}$ ), and nearly two million ounces (troy) of silver in the treasury. Further, during his retirement at Sumpu, he saved a sum of one million ryo. The same economy was practised by the second shögun, although he was compelled to spend large sums in connexion with his daughter's promotion to be the Emperor's consort, as well as on the repairs of Yedo Castle and on his several progresses to Kyōto. On the occasion of these progresses, Hidetada is said to have distributed a total of $4,217,400$ ryō of gold and 182,000 ryo of silver among the barons throughout the empire. The third shögun, Iemitsu, was open handed. We find him making frequent donations of 5000 kwamme of silver to the citizens of Kyoto and Yedo; constructing the inner castle at Yedo twice; building a huge warship; entertaining the Korean ambassadors with much pomp; disbursing 400,000 ryō on account of the Shimabara insurrection, and devoting a million ryo to the construction and embellishment of the mausolea at Nikkō. Nevertheless, on the whole Iemitsu must be regarded as an economical ruler.

As for his successor, Ietsuna, he had to deal with several calamitous occurrences. After the great fire in Yedo, he contributed 160,000 ryo for the relief of the sufferers; he rebuilt Yedo Castle, and he reconstructed the Imperial palace of Kyōto twice. In the Empō era (1673-1680), the country was visited by repeated famines, which had the effect of reducing the yield of the taxes and calling for large measures of relief. In these circumstances, a proposal was formally submitted recommending the debasement of the gold coinage, but it failed to obtain official consent. It may be mentioned that, in the year 1659 , the treasury was reduced to-ashes, and a quantity of gold coin contained therein 
was melted. With this bullion a number of gold pieces not intended for ordinary circulation were cast, and stamped upon them were the words, "To be used only in cases of national emergency." The metal th us reserved is said to have amounted to 160,000 ryō. The register shorws that when the fifth shögun succeeded to power, there were 3,850,000 gold ryo in the treasury. But this enormous sum did not long. survive the extravagance of T sunayoshi.

After the assassination of Hotta Masatoshi, the administrative power fell entirely into the hands of Yanagisawa Yoshiyasu, and the example set by him for those under' his guidance, and by his master, the shōgun; soon found followers among all classes of the people. As an instance of ludicrous luxury it may be mentioned that the timbers intended for the repair of the castle in Yedo were wrapped in wadded quilts when transported to the city from the forest. Finally, the treasury became so empty that, when the shogun desired to repair to the mausolea at Nikkō, which would have involved a journey of ten days at the most, he was compelled to abandon the idea, as the officials of the treasury declared themselves unable to find the necessary funds. That sum was calculated at 100,000 ryō, or about as many pounds sterling, which fact is alone sufficient to convey an idea of the extravagance practised in everything connected with the Government.

The immediate outcome of this incident was the summoning of a council to diseuss the financial situation, and after much thought the suggestion of Hagiwara Shigehide, chief of the: Treasury, was accepted, namely, wholesale debasement of the gold, silver, and copper coins. The old pieces, distinguished as "Keicho coins,": that being the name of the year period (1596-1614) when they were minted, were replaced by greatly inferior "Genroku coins" (1688-1703), with the natural results - appreciation of commodities and much forging of counterfeit coins. Presently the Government is found levying a tax upon 27,200 sake brewers within the Kwantō, and, in 1703, fresh expedients became necessary to meet outlays incurred owing to a great earthquake and conflagration which destroyed a large part of Yedo Castle and of the daimyo' $s$ mansions. Further debasement of the currency was resorted to, the new coins being distinguished by the term ". Hōei," after the name of the year-period when they were minted.

About this time several of the feudatories found themselves in such straits that they began to issue paper currency within their dominions, and this practice having been interdicted by the Bakufu, the daimyo fell back upon the expedient of levying forced loans from wealthy merchants in Osaka. Meanwhile, the crime of forgery became so prevalent that, in the interval between 1688 and 1715 , no less than 541 counterfeiters were crucified within the districts under the direct control of the Bakufu. The feudatory of Satsuma is credited with having justly remarked that the victims of this cruel fate suffered for their social status rather than for their offence against the law, the real counterfeiters being Yanagisawa and Hagiwara, who were engaged continuously in uttering debased coins.

It must be admitted in behalf of the financiers of that era that their difficulties were much accentuated by natural calamities. The destructive earthquake of 1703 was followed, in 1707 , by an eruption of Fuji, with the result that in the three provinces of Musashi, Sagami, and Suruga, considerable districts were buried in ashes to the depth of ten feet, so that three years and a heavy expenditure of money were required to restore normal conditions Thenceforth the state of the Bakufu treasury went from bad to worse Once again Hagiwara 
Shigehide had recourse to adulteration of the coinage. This time he tampered mainly with the copper tokens, but owing to the unwieldy and impure character of these coins; very great difficulty was experienced in putting them into circulation; and the Bakufu financiers finally were obliged to fall back upon the reserve of gold kept in the treasury for special contingencies. There can be no doubt that Japan's foreign trade contributed materially to her financial embarrassment, but this subject will be subsequently dealt with.

\section{TSUNAYOSHI'S FAVOURITE}

When Tsunayoshi became shōgun, Yanagisawa Yoshiyasu occupied the position of a low-class squire in the shogun's household and was in receipt of a salàry of three hundred koku yearly. Four years later, he received the title of Dewa no Kami and his revenue was increased to 100,000 koku. Finally, in 1703, he was appointed daimyō of Kai province and came into the enjoyment of a total income of 150,000 koku. This was the more remarkable inasmuch as, owing to the strategical importance of Kai, it had been reserved as a fief for one of the Tokugawa family; and its bestowal on a complete outsider was equivalent to the admission of the latter into the Tokugawa circle. This remarkable promotion in rank and income shows how completely the shogun had fallen under the influence of his favourite, Yoshiyasu, who exhibited wonderful skill in appealing at once to the passions and to the intellect of his master. Some historians of the time relate that the shoggun's infatuation betrayed him into promising to raise Yoshiyasu's revenue to a million koku, and to nominate as successor to thershōgunate a son borne by Yos'iyasu's wife to Tsunayoshi; but according to tradition, these crowning extravagances were averted on the very night preceding the day of their intended consummation, the shogun being stabbed to death by his wife, who immediately committed suicide. This tale, however, has been shown to be an invention with no stronger foundation than the fact that Tsunayoshi's death took place very suddenly at a highly critical time. It is not to be doubted that many of the excesses and administrative blunders committed by the fifth Tokugawa shogun were due to the pernicious influence of Yanagisawa Yoshiyasu.

\section{DECLINE OF THE SAMURAI SPIRIT}

The no dance was among the indulgences which Tsunayoshi affected and among the accomplishments in which he himself excelled. He took into his service a number of skilled dancers of the $n \bar{o}$, and treated them as hereditary vassals, setting aside the chamber of the Paulownia for their use. These performers, whatever their origin, received the treatment of samurai, and their dainty posturing in the dance became a model for the lords of the Bakufu Court, so that the simple demeanour of military canons was replaced by $a$ mincing and meretricious mien. Another favourite dance in Yedo Castle was the füryü. A book of the period describes the latter performance in these terms: "Sixteen youths made their appearance; they all wore wide-sleeved robes and purple figured silk with embroidery of oak leaves in gold and silver threads. They carried two swords with gold mountings and scarlet tassels, so that when they danced in harmony with the flutes and drums the spectacle presented was one of dazzling brilliancy." Thenceforth this "Genroku dance," as it came to be called, obtained wide vogue. The same is true of the jôruri, which is one of the 
most emotional forms of chant. Hitherto the samisen had been regarded as a vulgar instrument, and its use had never received the sanction of aristocratic circles. But it now came into favour with all classes of women from the highest to the lowest; and the singing of the $j$ or ruri was counted a far more important accomplishment than any kind of domestic education.

Such an appeal to the emotional side of human nature could not fail to undermine the stoicism of the samurai and the morality of society in general. The practice of the military arts went out of fashion, and it became an object with the bushi not only to have his sword highly ornamented, but also to adapt its dimensions to the fashion of the moment, thus sacrificing utility to elegance. In short, the Genroku era (1688-1703) was essentially a time of luxury and extravagance, its literature abounding in theatrical plays, songs, verses; and jōruri, and its ideals involving the sacrifice of the noble to the elegant. Men were promoted in rank not merely because they could dance gracefully; but also because they made themselves conspicuous for kindness to dogs, in obedience to the shoggun's foible, and as many of these men had not learned to ride on horseback they petitioned for permission to use palanquins. This marked a signal departure from the severe rules of former days. Street palanquins ( machikago) ultimately came into use by all who could afford the luxury. In short, the ancient order of educational precedence was reversed, and polite accomplishments took the place of military science.

\section{THE AKŌ VENDETTA}

Nevertheless, this degenerate era produced one of the most remarkable acts of self-sacrificing loyalty that stand to the credit of Japanese samurai. On the 7 th of February, 1703, forty-seven bushi, under the leadership of Oishi Yoshio,

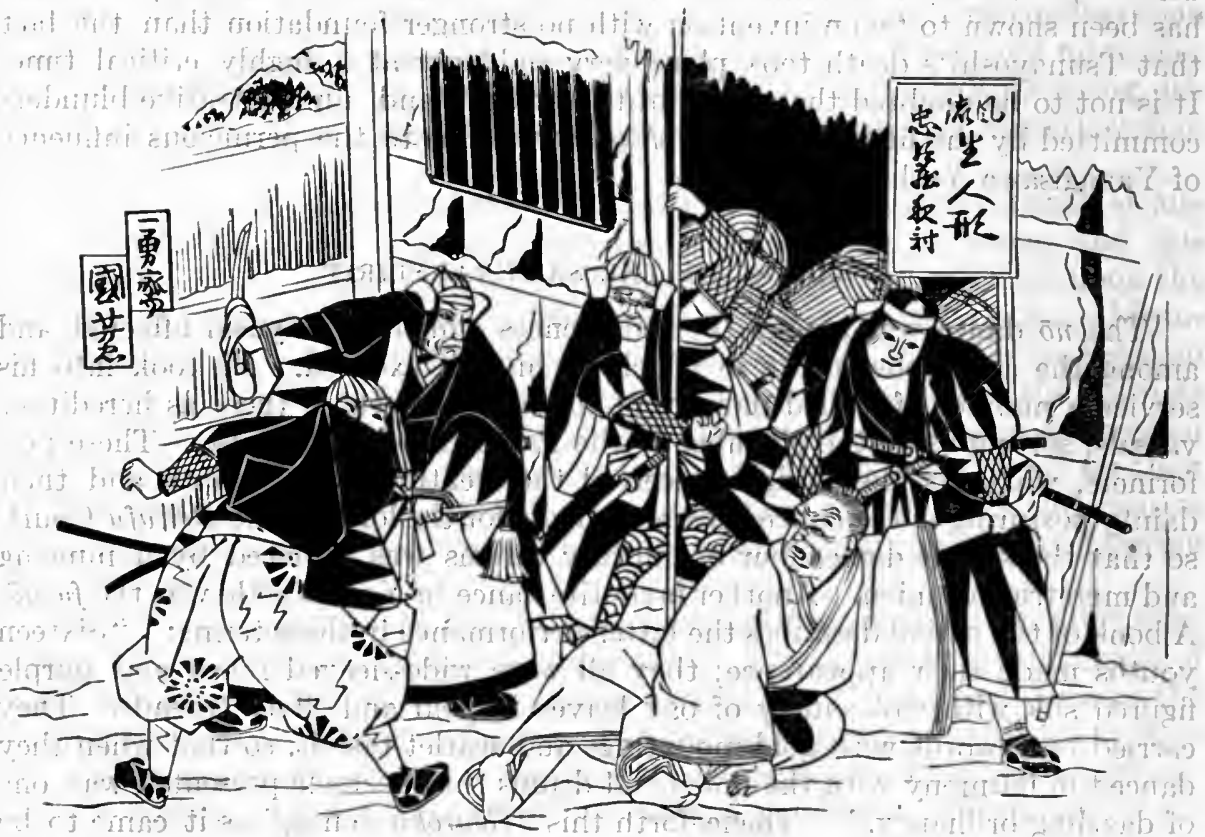


forced their way into the mansion of Kira Yoshihide; killed him in order to avenge the death of their feudal chief, Asano Naganori, daimy $\vec{o}$ of Akō; and then surrendered themselves to justice. Under the title of The Forty-seven Rōnins, this story has been told in history, on the stage, and in all forms of literature, so that its details need not be repeated here. It will suffice to say that, under great provocation, the Ako feudatory drew his sword in the precincts of Yedo Castle and cut down Kira Yoshihide, for which breach of court etiquette rather than for the deed of violence, the Akō baron was condemned to commit suicide and his estates were confiscated. Thereupon, forty-seven of his principal vassals pledged themselves to wreak vengeance, and, after nearly two years of planning and watching, they finally succeeded in achieving their purpose. Degenerate as was the spirit of the time, this bold deed aroused universal admiration. The vendetta was not illegal in Japan. It had been practised from medieval times and often with direct sanction of the authorities. But in no circumstances was it officially permissible within the cities of Kyōto, Yedo, Ōsaka, and Sumpu, or in the vicinity of the shogun's shrines. The forty-seven rōnins had therefore committed a capital crime. - Yet they had only obeyed the doctrine of Confucius, and the shōgun therefore endeavoured to save their lives. More than a year was spent discussing the issue, and it is recorded that Tsunayoshi appealed to the prince-abbot of Ueno in order to secure his intervention in the cause of leniency. The day was ultimately carried by the advocates of stern justice, and the forty-seven rōnins "were ordered to commit suicide.

They obeyed without a murmur. One of them, Terasaka Kichiemon by name, had been sent to carry the news to Akō immediately after the perpetration of the deed of vengeance. He returned when his comrades were condemned and gave himself up to the authorities, but they declined to punish him on the ground that the case had already been disposed of. The eminent Confucian scholar, Hayashi Nobuatsu, petitioned for the pardon of the ronins, and the scarcely less celebrated Muro Kyüsô compiled a book describing the incident; but, for some reason never fully explained, the noteworthy scholar, Ogyü Sorai, took the opposite side. One act of the authorities is eloquent as to the sentiment prevailing at the time.". They condemned Yoshihide's son, Yoshikata, to be deprived of his ancestral domain for not having died in company with his father. As for the feeling of the nation at large, it was abundantly manifested by many of the great feudatories, who vied with one another in conferring offices and revenues on the sons and grandsons of the "Forty-seven."

\section{YAMAGA SOKŌ}

The affair of the forty-seven rōnins helped to bring into eminence the name of Yamaga Sokō, a firm believer in Confucianism and an ardent follower of military science. Amid an environment of unfavourable conditions Sokō preached the cult of bushido, and was the first to embody that philosophy in a written system. His books - the Shi-do (Way of the Warrior) and Bukyō Shögaku (Military Primer) - contain minute instructions as to the practice and the morale of the samurai. Soko rejected the Chutsz interpretation, then in vogue, of the Chinese classics, and insisted on the pure doctrine of the ancient sages,'so that he found himself out of touch with the educational spirit of the time. Thus, falling under the displeasure of the Bakufu, he was charged with propagating heterodox views and was sent to Ako to be kept in custody by 
Asano Naganori, who treated him throughout with courtesy and respect. In return, Sokō devoted his whole energy during ninetcen years to the education of the Akō vassals, and the most prominent of the Forty-seven Rōnins wás among his pupils.

\section{THE SIXTH $S H O ̄ G U N$, IENOBU}

Tsunayoshi died of small-pox in 1709, after a brief illness. He had no son, and five years previously, his nephew Ienobu (third son of his deceased elder brother, Tsunashige) had been declared heir to the shōgunate. Having been born in 1662, Ienobu was in his forty-seventh year when he succeeded to the office of shogun. His first act was to abolish Tsunayoshi's legislation for the protection of animals. He is said to have offered the following explanation at the tomb of the deceased shōgun: "You desired to protect living animals and strictly interdicted the slaughter of any such. - You willed that even after your death the prohibition should be observed. But hundreds of thousands of human beings are suffering from the operation of your law. To repeal it is the only way of bringing peace to the nation.":

\section{ARAI HAKUSEKI}

Ienobu gave evidence of his sagacity by dismissing Yanagisawa Yoshiyasu, the corrupt favourite of the late shogun; by appointing in his stead Manabe Norifusa to the office of personal assistant (soba yōnin), and by reposing full confidence in Arai Hakuseki. This last is recognized by posterity as the most distinguished among Japanese Confucianists. He studied the literature of both the Tang and the Sung dynasties, and he laboured to apply the precepts of Chinese philosophy to the practical needs of his own country. Moreover, he devoted exceptional attention to the conditions existing in Occidental States, and he embodied his thoughts and researches on the latter subject in a book called Sairan Igen; the first treatise of its kind published in Japan.

A practical illustration of his knowledge was furnished in connexion with the reception of Korean envoys. It had been customary to convey to these officials an imposing conception of Japanese magnificence by treating them with lavish-hospitality. Hakuseki was able to detect that the conduct of the envoys violated in many respects the rules of Chinese etiquette, and having obtained the shoggun's nomination to receive the envoy, Cho, he convinced the latter that there must be no more neglect of due formalities. He then memorialized the shogun in the sense that these Korean ambassadors were merely Chinese spies, and that instead of receiving a lavish welcome, they should be required to limit their journey to the island of Tsushima, where only a very restricted ceremonia! should be performed in their honour. This shrewd; though somewhat conservative, suggestion elicited general approval, but was not carried into effect until the time of the eleventh shögun.

\section{ADJUSTMENT OF THE FINANCES}

It has been shown above that the fifth shogun bequeathed to his successor a much embarrassed treasury. In this realm, also, the advice of Arai Hakuseki proved invaluable. In his volume of reminiscences there is an interesting statement connected with finance. It quotes Hagiwara Shigehide; commissioner of the Treasury, as saying that the shogun's estate at that time yielded 
four million koku annually, in addition to which there accrued from 760,000 ry $\overline{0}$ to 770,000 ryô in money, representing the proceeds of dues and taxes. In this latter sum was included 40,000 ryō, customs duties collected at Nagasaki, and 6000 ryō yielded by a tax on sake. The same report mentions that a sum of 160 ,000 : ry $\bar{o}$ had been expended in clearing away the volcanic ashes which fell:in the three provinces of Musashi, Sagami, and Suruga after the great eruption of Fujisan. Arai Hakuseki was able to prove the erroneous character of this report, but his demonstration did not impugn any of the above figures. Incidentally it is mentioned in Arai's comments that 700,000 ryo were allotted for building an addition to Yedo Castle, and 200,000 ryo for the construction of the deceased shōgun's mausoleum, out of which total Hakuseki explicitly charges the officials, high and low alike, with diverting large sums to their own pockets in collusion with the contractors and tradesmen employed on the works. Another interesting investigation made by Arai Hakuseki is in connexion with the country's foreign trade. He showed that the amount of coins exported from Nagasaki alone, during one year, totalled $6,192,800$ ryo of gold; $1,122,687$ kwamme of silver and $228,000,000 \mathrm{kin}$ of copper. ${ }^{1} \mathrm{He}$ alleged that the greater part of this large outflow of specie produced nothing except luxuries with which

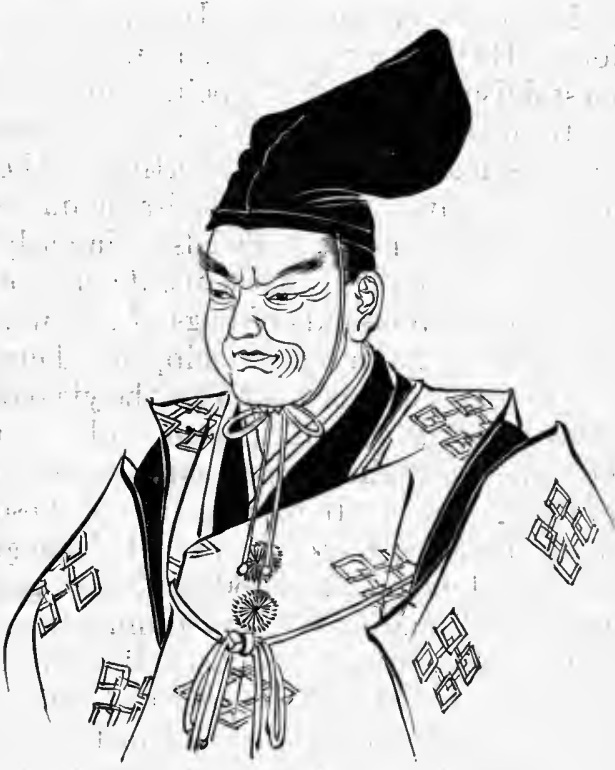

AraI HakUSekI the nation could very well dispense, and he therefore advised that the foreign trade of Nagasaki should be limited to thirteen Chinese junks and two Dutch vessels annually, while stringent measures should be adopted to prevent smuggling.

The ordinance based upon this advice consisted of two hundred articles, and is known in history as the "New Nagasaki Trade Rules of the Shotoku Era" (1711-1715). One portion of the document ran as follows: "During the Jokyo era (1684-1687), the trade with Chinese merchants was limited to 6000 kwamme of silver, and that with Dutch traders to 50,000 ryo of gold, while the number of Chinese vessels was not allowed to exceed seventy per annum. After a few years, however, copper coins came into use as media of exchange in addition to silver, and moreover there was much smuggling of foreign goods. Thus, it resulted that gold, silver, and copper flowed out of the country in great quantities. Comparing the aggregate thus exported during the 107 years since the Keicho era with the amount coined in Japan during the same interval, it is found that one-quarter of the gold coins and three-quarters of the silver left the country. If that state of affairs continue, it is obvious that after a hundred years from the present time one-half of the empire's gold will be carried away and there will be no silver at all left. As for copper, the sum remaining in the coun- 
try is insufficient, not only for purposes of trade but also for the needs of every: day life. It is most regrettable that the nation's treasure should thus be squandered upon foreign luxuries. The amount of currency needed at home and the amount produced by the mines should be investigated so as to obtain a basis for limiting the foreign trade at the open ports of Nagasaki, Tsushima, and Satsuma, and for fixing the maximum number of foreign vessels visiting those places." 1 !?

\section{IMPEACHMENT OF HAGIWARA SHIGEHIDE}

In connexion with Arai Hakuseki's impeachment of the Treasury commissioner, Hagiwara Shigehide, it was insisted that an auditor's office must be re-established, and it was pointed out that the yield of rice from the shōgun's estates had fallen to 28.9 per cent. of the total produce instead of being forty per cent., as fixed by law. Nevertheless, the condition of the farmers was by no means improved, and the inevitable inference was that the difference went into the pockets of the local officials. Similarly, enormous expenses were incurred for the repair of river banks without any corresponding diminution of floods, and hundreds of thousands of bags of rice went nominally to the bottom of the sea without ever having been shipped. During the year that followed the reconstruction of the auditor's office, the yield of the estates increased by 433,400 bags of rice, and the cost of riparian works decreased by 38,000 ryo of gold, while, at the same time, the item of shipwreeked cereals disappeared almost completely from the ledgers. In consequence of these charges the commissioner, Shigehide, was dismissed. History says that although his regular salary was only $3000 k o k u$ annually, he embezzled 260,000 ryō of gold by his debasement of the currency, and that ultimately he starved himself to death in token of repentance.

Ienobu and his able adviser, Hakuseki, desired to restore the currency to the system pursued in the Keicho era (1596-1614), but their purpose was thwarted by insufficiency of the precious metals. They were obliged to be content with improving the quality of the coins while decreasing their weight by one half. These new tokens were called kenji-kin, as they bore on the reverse the ideograpb ken, signifying. "great original." The issue of the new coins took place in the year 1710, and at the same time the daimyō were strictly forbidden to issue paper currency, which veto also was imposed at the suggestion of Arai Hakuseki.

\section{THE SEVENTH SHOGGUN, IETSUGU}

The seventh Tokugawa shôgun, Ietsugu, son of his predecessor, Ienobu, was born in 1709, succeeded to the shōgunate in April, 1713, and died in 1716. His father, Ienobu, died on the 13th of November, 1712, so that there was an interval of five months between the demise of the sixth shogun and the accession of the seventh. Of course, a child of four years who held the office of shogun for the brief period of three years could not take any part in the administration or have any voice in the appointment or dismissal of officials. Thus, Arai Hakuseki's tenure of office depended upon his relations with the other ministers, and as all of these did not approve his drastic reforms, he was obliged to retire, but Manabe Norifusa remained in office.

\section{THE EIGHTH SHŌGUN, YOSHIMUNE}

By the death of Ietsugu, in 1716, the Hidetada line of the Tokugawa family became extinct, and a successor to the shoggunate had to be sought from the 
Tokugawa of Kii province in the person of Yoshimune, grandson of Yorinobu and great-grandson of Ieyasu. Born in 1677, Yoshimune, the eighth Tokugawa shoggun, succeeded to office in 1716 , at the age of thirty-nine. The son of a concubine, he had been obliged to subsist on the proceeds of a very small estate, and he therefore well understood the uses of economy and the condition of the people. His habits were simple and plain; and he attached as much importance as Ieyasu himself had done to military arts and literary pursuits. It had become a custom on the occasion of each shögun's succession to issue a decree confirming, expanding, or altering the systems of the previous potentate. "Yoshimune's first decree

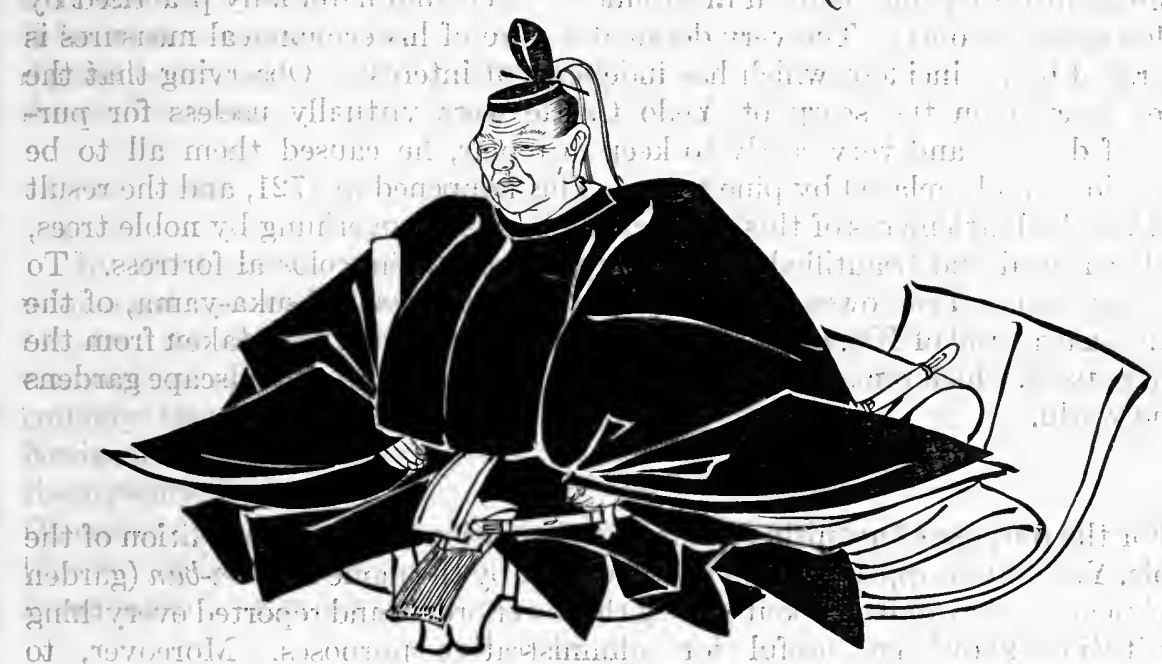

ToKUgawa Yoshimune

placed special emphasis on the necessity of diligence in the discharge of administrative functions and the eschewing of extravagance. Always he made it his unflagging aim to restore the martial spirit which had begun to fade from the samurai's bosom, and in the forefront of important reforms he placed frugality. The Bakufu had fallen into the habit of modelling their systems and their procedure after Kyōto examples. In fact, they aimed at converting Yedo into a replica of the Imperial capital. This, Yoshimune recognized as disadvantageous to the Bakufu themselves and an obstacle to the resuscitation of bushido. Therefore, he set himself to restore all the manners and customs of former days, and it became his habit to preface decrees and ordinances with the phrase "In pursuance of the methods, fixed by Gongen" (Ieyasu). His idea-was that only the decadence of bushido could result from imitating the habits of the Imperial Court, and as Manabe Norifusa did not endorse that view with sufficient zeal, the shogun relieved him of his office of minister of the Treasury.

One of Yoshimune's measures was to remodel the female department of the palace on the lines of simplicity and economy. All the ladies-in-waiting were required to furnish a written oath against extravagance and irregular conduct of every kind, and in the sixth year after his accession the shogun ordered that a list should be furnished setting forth the names and ages of such of these ladies as were conspicuously beautiful. Fifty were deemed worthy of inscription, and quite a tremor of joyful excitement was caused, the measure being regarded as prefacing the shögun's choice of consorts. But Yoshimune's purpose was very 
different: He discharged all these fair-faced ladies and kept only the ill-favoured ones, his assigned reason being that as ugly females find a difficulty in getting husbands, it would be only charitable to retain their services.

He revived the sport of hawking, after the manner of Ieyasu, for he counted it particularly suitable to soldiers; and he pursued the pastime so ardently that men gave him the name of the Taka-shōgun (Falcon shōgun). Healso inaugurated a new game called uma-gari (horse-hunting); and it is on record that he required the samurai to practise swimming in the sea. By way of giving point to his ordinances inculcating frugality, he himself made a habit of wearing cotton garments in winter and hempen in summer - a custom habitually practised by the lower orders only. The very detailed nature of his economical measures is illustrated by an incident which has independent interest. Observing that the fences erected on the scarp of Yedo Castle were virtually useless for purposes of defence and very costly to keep in repair, he eaused them all to be pulled down and replaced by pine trees. This happened in 1721, and the result was that the battlements of this great castle were soon overhung by noble trees, which softened and beautified the military aspect of the colossal fortress. To the same shogun Yedo owes the cherry and plum groves of Asuka-yama, of the Sumida-gawa, and of Koganei. The saplings of these trees were taken from the Fukiage park, which remains to-day one of the most attractive landscape gardens in the world.

\section{OTHER MEASURES}

For the purpose of acquiring accurate information about the condition of the people, Yoshimune appointed officials who went by the name of niwa-ban (garden watchmen). They moved about among the lower orders and reported everything constituting knowledge useful for administrative purposes. Moreover, to facilitate the ends of justice, the shögun revived the ancient device of petition-

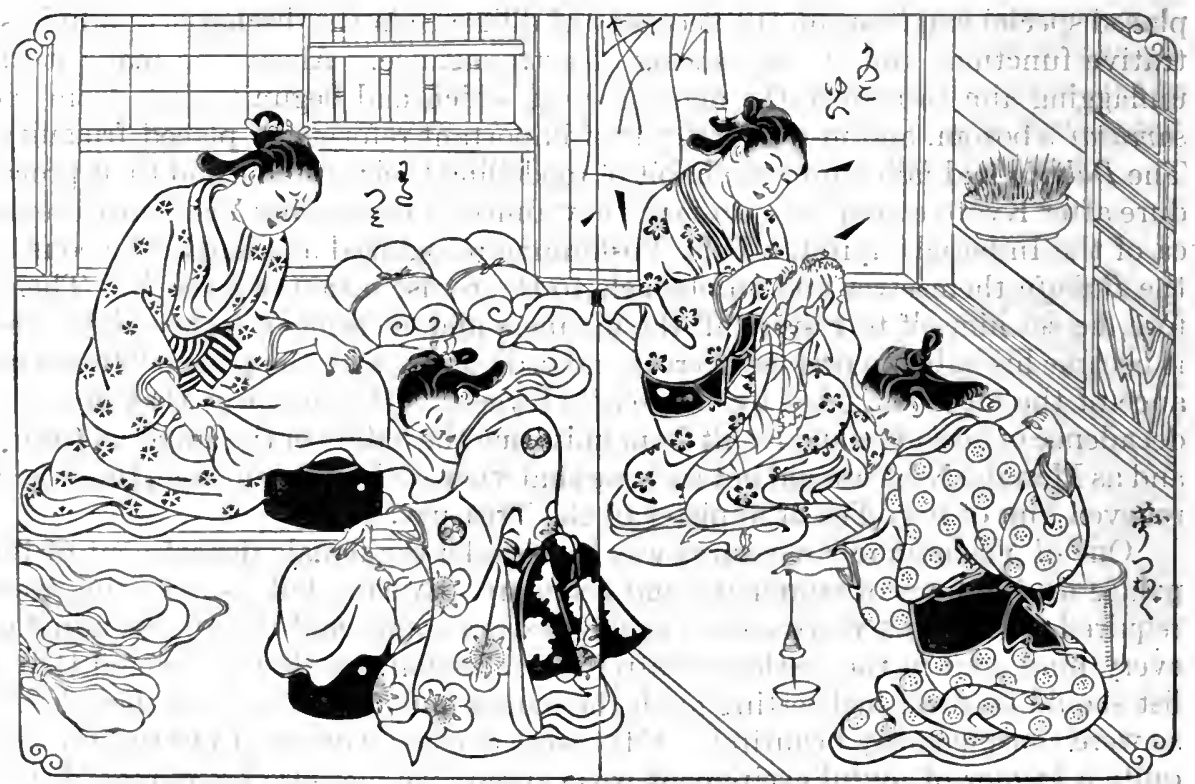


boxes (meyasu-bako), which were suspended in front of the courthouse in order that men might lodge there a written statement of all complaints. It was by Yoshimune, also, that the celebrated Ōoka Tadasuke, the "Solomon of Japan," was invited from Yamada and appointed chief justice in Yedo. The judgments delivered by him in that capacity will be famous as long as Japan exists. It has to be noted, however, that the progressive spirit awakened by Yoshimune's administration was not without untoward results. Extremists fell into the error of believing that everything pertaining to the canons of the immediate past must be abandoned, and they carried this conception into the realm of foreign trade, so that the restrictions imposed in the Shotoku era (1711-1715) were neglected. It became necessary to issue a special decree ordering the enforcement of these regulations, although, as will presently be seen, Yoshimune's disposition towards the civilization of the Occident was essentially liberal.

\section{CODES OF LAW}

By this time the miscarriages of justice liable to occur when the law is administered with regard to precedent only or mainly, began to be plainly observable, and the shogun, appreciating the necessity for written codes, appointed a commission to collect and collate the laws in operation from ancient times; to embody them in codes, and to illustrate them by precedents. Matsudaira Norimura, one of the ministers of State, was appointed chief commissioner, and there resulted, after four years of labour, the first genuine Japanese code (Oshioki Ojōmoku). W This body of laws was subsequently revised by Matsudaira Sadanobu, and under the name of Osadame Hyakkajō ("Hundred Articles of Law.".), it remained long in practice:

\section{LITERATURE}

Yoshimune was not behind any of his ancestors in appreciation of learning. In 1721, when his administrative reforms were still in their infancy, he invited to Yedo Kinoshita Torasuke (son of the celebrated Kinoshita Junan), Muro Nawokiyo, and other eminent men of letters, and appointed them to give periodical lectures. Nawokiyo was named "adviser to the shogun," who consulted him about administrative affairs, just as Arai Hakuseki had been consulted by Ienobu. In fact, it was by the advice of Arai Hakuseki that Nawokiyo (whose literary name was Kyŭsō), entered the service of Yoshimune Contemporaneous with these litterateurs was the renowned Ogyu Sorai, whose profound knowledge of finance and of administrative affairs in general made him of great value to the Bakufu.9 'He compiled a book called Seidan (Talks on Government) which immediately became a classic. Special favour was shown to the renowned Confucianist, Hayashi Nobuatsu. He and his son were asked to deliver regular lectures at the Shohei College, and these lectures were the occasion of a most important innovation, namely, the admission of all classes of people, whereas previously the audience at such discourses had been strictly limited to military mén.

It is to be observed that in the days of Yoshimune's shogunate the philosophy of Chutsz (Shu-shi) was preferred to all others. It received the official imprimatur, the philosophy of 'Wang Yang-ming ( $\mathrm{O}$ Yō-mei) being' set aside. - One consequence of this selection was that the Hayashi family came to be regarded as the sole depositories of true Confucianism. Yoshimune himself, however, was not disposed to set any dogmatic limits to the usefulness of men of learning. $\mathrm{He}$ 
assumed an absolutely impartial attitude towards all. schools; adopting the good wherever it was found, and employing talent to whatever school it belonged. Thus when Kwanno Chokuyō established a place of education in Yedo, and Nakai Seishi did the same.in Osaka, liberal grants of land were made by the:Bakufu to both men. Another step taken by the shogun was to institute a search for old books throughout the country, and to collect manuscripts which had been kept in various families for generations. By causing these to be copied or printed, many works which would otherwise have been destroyed or forgotten were preserved.

It is notable that all this admirable industry had one untoward result: Japanese literature came into vogue in the Imperial capital, and was accompanied by the development of a theory that loyalty to the sovereign was inconsistent with the administration of the Bakufu. The far-reaching consequences of this conception will be dealt with in a later chapter. Here, it is sufficient to say that one of the greatest and most truly patriotic of the Tokugawa shoguns himself unwittingly sowed the seeds of disaffection destined to prove fatal to his own family.

\section{ADOPTION OF WESTERN LEARNING}

Yoshimune was fond of astronomy. He erected a telescope in the observatory at Kanda, a sun-dial in the palace park, and a rain-gauge at the same place. By his orders a mathematician named Nakane Genkei translated the Gregorian calendar into Japanese, and Yoshimune, convinced of the superior accuracy of the foreign system, would have substituted it for the Chinese then used in Japan; had not his purpose excited such opposition that he judged it prudent to desist. It was at this time that the well-informed Nishikawa Masayasu and Shibukawa Noriyasu were appointed Government astronomers.

Previously the only sources of information about foreign affairs had been the masters of the Dutch ships, the Dutch merchants, and the Japanese interpreters at Nagasaki. The importation of books from the Occident having been strictly forbidden by the third shögun, Iemitsu, Yoshimune appreciated the disadvantage of : such a restriction, and being convineed of the benefits to be derived from the study of foreign science and art, he rescinded the veto except in the case of books relating to Christianity. Thus, for the first time, Japanese students were brought into direct contact with the products of Western intelligence. In 1744, Aoki Konyō received official orders to proceed to Nagasaki for the purpose of seeking instruction in Dutch from Dutch teachers. Shibukawa and Aoki are regarded as the pioneers of Occidental learning in Japan, and, in the year 1907, posthumous honours were conferred on them by the reigning Emperor of their country!

\section{THE SANKIN KŌTAI}

It has already been stated that the financial embarrassment of the Bakufu in Yoshimune's time was as serious as it had been in his predecessor's days. Moreover, in 1718, the country was swept by a terrible tornado, and in 1720 and 1721, conflagrations reduced large sections of Yedo to ashes. Funds to succour the distressed people being imperatively needed; the shogun called upon all the feudatories to subscribe one hundred koku of rice for every ten thousand koku of their estates. By way of compensation for this levy he reduced to half a year the time that each feudal chief had to reside in Yedo. This meant, of course, a substantial lessening of the great expenses entailed upon the feudatories by the 
sankin kōtai system, and the relief thus afforded proved most welcome to the daimy $\bar{o}$ and the shömyō alike. Yoshimune intended to extend this indulgence ultimately by releasing the barons from the necessity of coming to Yedo more than once in from three to five years, and, in return, he contemplated a corresponding increase of the special levy of rice. But his ministers opposed the project on the ground that it would dangerously loosen the ties between the feudatories and the Bakufu, and inasmuch as events proved that this result threatened to accrue from even the moderate indulgence granted by the shogun, not only was no extension made but also, in 1731, the system of sankin kōtai was restored to its original form. The experiment, indeed proved far from satisfactory. The feudatories did not confine themselves to assertions of independence; they also followed the example of the Bakufu by remitting some of the duties devolving on their retainers and requiring the latter to show.their gratitude for the remissions by monetary payments. Nominally, these payments took the form of loans, but in reality the amount was deducted from the salaries of vassals. This pernicious habit remained in vogue among a section of the feudatories, even after the sankin kōtai had been restored to its original form.

\section{OFFICIAL SALARIES}

From ancient times it had been the habit of the Bakufu to assign important offices to men who were in enjoyment of large hereditary incomes. This was mainly for financial reasons. Salaries were paid in the form of additions to the hereditary estates - in other words, the emoluments of office became permanent, and the charge upon the Bakufu being correspondingly increased, it was obviously expedient to fill high administrative posts with men already in possession of ample incomes. This system was radically changed by Yoshimune. He enacted that a clear distinction should be made between temporary salary and hereditary income. Thenceforth, salary was to be received only during the tenure of office and was to cease on laying down official functions. This reform had the effect not only of lightening the burden upon the Bakufu income, but also of opening high offices to able men without regard to their private fortunes'

\section{THE CURRENCY}

From the first day of assuming administrative power, Yoshimune gave earnest thought to reform of the eurrency. His ambition was to restore the gold and silver coins to the quality and sizes existing in the Keichö era. This he effected, though not on a sufficiently large scale. Each of the new coins was equal in intrinsic value to two of the corresponding kenji coins, and the circulation of the latter was suspended, the new coins being called Kyōho-kin after the year-name of the era (1716-1735) when they made their appearance. It was a thoroughly wholesome measure, but the quality of the precious metals available did not suffice. Thus, whereas the gold coins struck during ten years of the $K y \bar{o} h \bar{o}$ era totalled only $8,290,000$ ryō, a census taken in 1732 showed a total population of $26,921,816$. Therefore, the old coins could not be wholly withdrawn from circulation, and people developed a tendency to hoard the new and more valuable tokens.

Other untoward effects also were produced. The shoggun paid much attention to promoting agriculture and encouraging land reclamation, so that the yield of rice increased appreciably. But this proved by no means an unmixed blessing. 


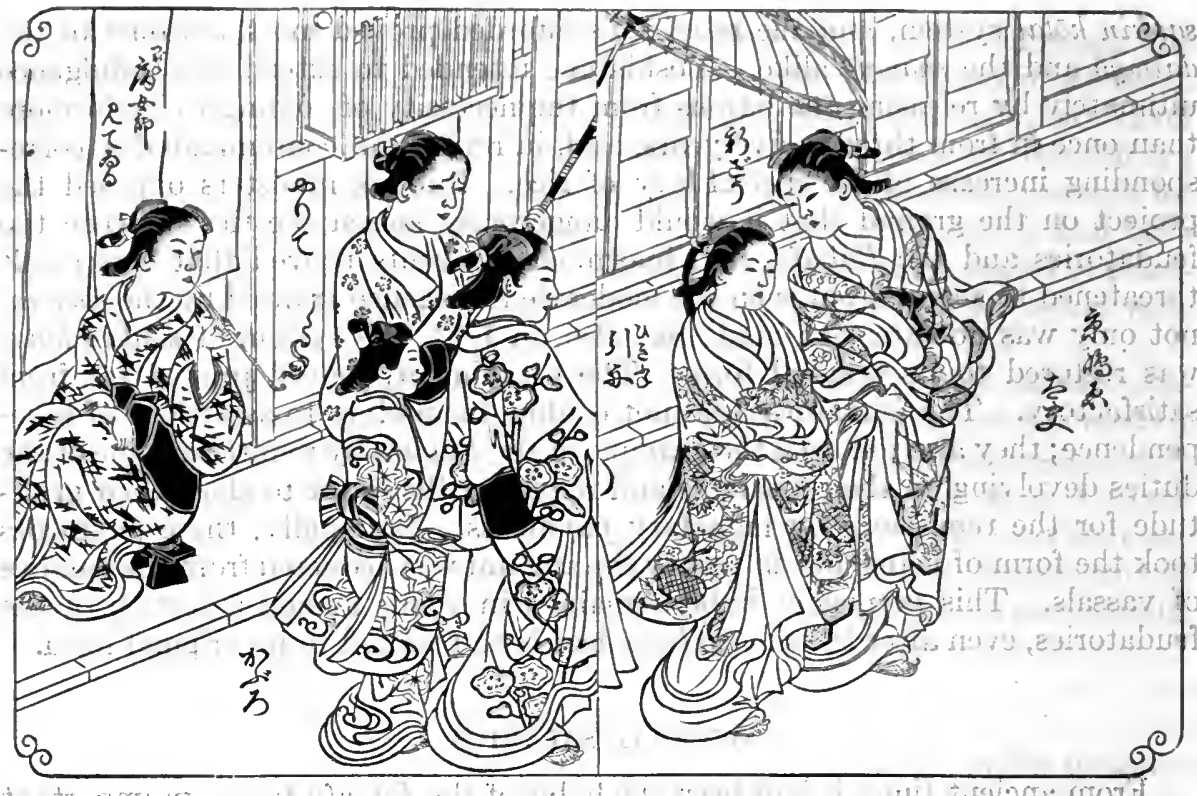

Varjous Occupations of Women, KYöhō ERa

Side by side with an increase in the quantity of rice appearing in the market, the operation of the new currency tended to depreciate prices, until a measure of grain which could not have been bought at one time for less than two ryō became purchasable for one. In fact, the records show that a producer considered himself fortunate if he obtained half a ryō of gold for a koku of rice. This meant an almost intolerable state of affairs for the samurai, who received his salary in grain and for the petty farmer. Thus, a man whose income was three rations of rice annually, and who consequently had to live on 5.4 koku for a whole year; found that when he set aside from three to four koku for food, there remained little more than one ryō of assets to pay for salt, fuel, clothes, and all the other necessaries of life.

So acute was the suffering of the samurai that a rice-exchange was established at Dojima, in Osaka, for the purpose of imparting some measure of stability to the price of the cereal. Just at this time (1732), the central and western provinces were visited by a famine, which caused seventeen thousand deaths and reduced multitudes to the verge of starvation. The Bakufu rendered aid on a munificent scale, but the price of rice naturally appreciated, and although this brought relief to the military class, it was misconstrued by the lower orders as a result of speculation on 'Change. Riots resulted, and rice-merchants fearing to make purchases, the market price of the cereal fell again, so that farmers and samurai alike were plunged into their old difficulties.

Ultimately, in 1735, the Bakufu inaugurated a system of officially fixed prices (osadame-sōba), according to which $1.4 \mathrm{koku}$ of rice had to be exchanged for one ryo of gold in Yedo, the Ôsaka rate being fixed at forty-two momme of silver for the same quantity of the cereal. Anyone violating this rule was fined ten momme of silver for each koku of rice purchased or sold by him. It is related that the osadame-sōba was operative in name only, and that the merchants secretly dealt in the cereal at much lower prices than those officially fixed. The Yedo financiers 
now concluded that the quantity of currency in circulation was insufficient and its quality too good. Accordingly, the gold and silver coins were once more reminted, smaller and less pure tokens being issued under the name of bunji-kin with reference to the Genbun era (1736-1740) of their issue. Thus, the reform of the currency, achieved with so much difficulty in the early years of Yoshimune's administration, had to be abandoned, and things reverted to their old plight.

If this difficulty operated so acutely under a ruler of Yoshimune's talent, the confusion and disorder experienced when he withdrew his able hand from the helm of State may be imagined. The feudatories were constantly distressed to find funds for supporting their Yedo mansions, as well as for carrying out the public works imposed on them from time to time, and for providing the costly presents which had become a recognized feature of ordinary and extraordinary intercourse. As an example of the luxury of the age, it may be mentioned that when the fffth shogun visited the Kaga baron, the latter had to find a sum of a million ryo to cover the expenses incidental to receiving such a guest. In these circumstances, there arose among the feudatories a habit of levying monetary contributions from wealthy persons in their fiefs, the accommodation thus afforded being repaid by permission to carry swords or by promotion in rank. The poorer classes of samurai being increasingly distressed, they, too, borrowed money at high rates of interest from merchants and weal thy farmers, which loans they were generally unable to repay. Ultimately, the Bakufu solved the situation partially by decreeing that no lawsuit for the recovery of borrowed money should be entertained a reversion to the tokusei system of the Ashikaga shoguns.

Of course, credit was completely undermined by the issue of this decree. It is strange that such conditions should have existed under such a ruler as Yoshimune. But even his strenuous influence did not suffice to stem the current of the time. The mercantile instinct pervaded all the transactions of every-day life. If a man desired to adopt a son, he attached much less importance to the latter's social status or personality than to the dimensions of his fortune, and thus it came about that the family names of petty feudatories were freely bought and sold. Yoshimune strictly interdicted this practice, but his veto had no efficiency; wealthy farmers or merchants freely purchased their way into titled families. From this abuse to extortion of money by threats the interval was not long, and the outcome, where farmers were victims, took the form of agrarian riots. It was to the merchants, who stood between the farmers and the samurai, that fortune offered conspicuously favourable opportunities in these circumstances. The tradesmen of the era became the centre of extravagance and luxury, so that in a certain sense the history of the Yedo Bakufu may be said to be the history of mercantile development.

\section{INDUSTRIAL PROGRESS}

Yoshimune devoted much attention to the encouragement of industrial progress. Deeming that a large import of drugs and sugar caused a ruinous drain of specie, he sent experts hither and thither through the country to encourage the domestic production of these staples as well as of vegetable wax. The feudatories, in compliance with his suggestion, took similar steps, and from this time tobacco growing in Sagami and Satsuma; the weaving industry in Kōtsuke and Shimotsuke; sericulture in Kōtsuke, Shinano, Mutsu, and Dewa; indigo cultivation in Awa; orange growing in Kii, and the curing of bonito in Tosa and 
Satsuma - all these began to flourish. Another feature of the time was the cultivation of the sweet potato at the suggestion of Aoki Konyo, who saw in this vegetable a unique provision against famine. Irrigation and drainage works also received official attention, as did the reclamation of rice-growing areas and the storing of cereals.

THE NINTH SHŌGUN,: IESHIGE

In 1745 , Yoshimune resigned his office to his son, Ieshige, who, having been born in 1702, was now in his forty-third year. Yoshimune had three sons, Ieshige, Munetake, and Munetada. Of these the most promising was the second, Munetake, whose taste for literature and military art almost equalled his father's. Matsudaira Norimura, prime minister, recognizing that Ieshige, who was weak, passionate, and self-willed, would not be able to fill worthily the high office of shögun, suggested to Yoshimune the advisability of nominating Munetake. But Yoshimune had his own programme. Ieshige's son, Ieharu, was a very gifted youth, and Yoshimune reckoned on himself retaining the direction of affairs for some years, so that Ieshige's functions would be merely nominal until Ieharu became old enough to succeed to the shōgunate.

Meanwhile, to prevent complications and avert dangerous rivalry, Yoshimune assigned to Munetake and Munetada residences within the Tayasu and $\mathrm{Hi}$ totsubashi gates of the castle, respectively, gave the names of these gates as family titles, and bestowed on each a revenue of one hundred thousand koku, together with the privilege of supplying an heir to the shogunate in the event of failure of issue in the principal house of Tokugawa or in one of the "Three Families." The shogun, Ieshige, followed the same plan with his son, Yoshishige, and as the latter's residence was fixed within the Shimizu gate, there came into existence "Three Branch Families" called the Sankyo, in supplement of the already existing Sanke. ${ }^{1}$

Of course, the addition of the Shimizu family had the approval of Yoshimune. In fact, the whole arrangement as to the Sankyo was an illustration of his faithful imitation of the institutions of Ieyasu. The latter had created the Sanke, and Yoshimune created the Sankyō; Ieyasu had resigned in favour of his son and had continued to administer affairs from Sumpu, calling himself $\bar{O}$-gosho; Yoshimune followed his great ancestor's example in all these respects except that he substituted the western part of Yedo Castle for Sumpu. Ieshige's most salient characteristic was a passionate disposition. Men called him the "short-tempered shōgun" (kanshaku kubō). He gave himself up to debauchery, and being of delicate physique, his self-indulgence quickly undermined his constitution. "So long as Yoshimune lived, his strong hand held things straight, but after his death, in 1751, the incompetence of his son became very marked. He allowed himself to fall completely under the sway of his immediate attendants, and, among these, Tanuma Okitsugu succeeded in monopolizing the evil opportunity thus offered. During nearly ten years the reforms effected by Yoshimune steadily ceased to be operative, and when Ieshige resigned in 1760, the country had fallen into many of the bad customs of the Genroku era.

\section{THE TENTH SHŌGUN, IEHARU}

After his abdication in 1760, Ieshige survived only fourteen months, dying, in 1761, at the age of fifty-one. He was succeeded, in 1760, by his son, Ieharu;

$\left[{ }^{1}\right.$ The present Princes Tokugawa are the representatives of the main line of the shogun; the Marquises Tokugawa, representatives of the Sanke, and the Counts Tokugawa, of the Sankyō.]. 
who, having been born in 1737, was twenty-three years old when he began to administer the country's affairs. - One of his first acts was to appoint Tanuma Okitsugu to be prime minister, bestowing on him a fief of fifty-seven thousand koku in the province of Tōtomi, and ordering him to construct a fortress there. At the same time Okitsugu's son, Okitomo, received the rank of Yamato no Kami and the office of junior minister. These two men became thenceforth the central figures in an era of maladministration and corruption. So powerful and allreaching was their influence that people were wont to say, "Even a bird on the wing could not escape the Tanuma." The shögun was not morally incapable, but his intelligence was completely overshadowed by the devices of Okitsugu, who took care that Ieharu should remain entirely ignorant of popular sentiment. Anyone attempting to let light into this state of darkness was immediately dismissed. It is related of a vassal of Okitsugu that he was found one day with three high officials of the shogun's court busily engaged in applying a moxa to his foot. The three officials knew that their places depended on currying favour with this vassal; how much more, then, with his master, Okitsúgu! Everything went by bribery. Justice and injustice were openly bought and sold. Tanuma Okitsugu was wont to say that human life was not so precious as gold and silver; that by the liberality of a man's gifts his sincerity might truly be gauged, and that the best solace for the trouble of conducting State affairs was for their administrator to find his house always full of presents.

Ieharu, however, knew nothing of all this, or anything of the natural calamities that befell the country under his sway - the eruption of the Mihara volcano, in 1779 , when twenty feet of ashes were piled over the adjacent country through an area of several miles; the volcanic disturbance at Sakura-jima, in Ōsumi, which took place about the same time and ended in the creation of several new islands; the outbreak of the Asama crater, in 1783, when half the provinces of the Kwantō were covered with ashes; and the loss of forty thousand lives by a flood in the Tone-gawa. Of all these visitations the shogun remained uninformed, and, in spite of them, luxury and extravagance marked the lives of the upper classes. Many, however, were constrained to seek loans from wealthy merchants in Ōsaka, and these tradesmen, admonished by past incidents, refused to lend anything. At last the intolerable situation culminated in a deed of violence. In April, 1784, Sano Masakoto, a hereditary vassal of the shogun, drew his sword upon Okitsugu within the precincts. of the castle in Yedo and wounded him severely. Masakoto was seized and sentenced to commit suicide, but the justice of his attempt being recognized, the influence of Okitsugu and his son began to decline. Two years later (1786), there appeared a decree in the name of the Bakufu, ordering that the temples in all the provinces, the farmers, the artisans, and the merchants should send their gold and silver every spring to the Central Government, to the end that the latter might lend this treasure to the feudatories, who would pledge themselves to pay it back after five years. ${ }^{1}$

There is reason to believe that the shögun himself knew nothing; of this ordinance until a multitude of complaints and remonstrances found their way, in part, to his ears. At all events, the extraordinary decree proved to be the last act of Okitsugu's official life. He was dismissed from office, though whether the credit of that step belongs to the Sanke and the elder officials or to the shoggun, is not certain, for Ieharu is said to have died just before the final disgrace of the corrupt statesman was consummated. The Yedo upon which he closed his eyes in October, 1786, presented features of demoralization unsurpassed in 
any previous era. In fact, during the period of forty-one years between the accession of the ninth shogun, Ieshige, in 1745, and the death of the tenth; Ieharu, in 1786, the manners and customs of the citizens developed along very evil lines. It was in this time that the city Phryne (machi-geisha) made her appearance; it was in this time that the theatre; which had hitherto been elosed to the better classes, began to be frequented by them; it was in this time that gambling became universal; it was in this time that parents learned to think it an honour to see their daughters winning favour as dancing girls, and it was in this time that the samurai's noble contempt for money gave place to the omnipotence of gold in military and civil circles alike.

THE IMPERIAL COURT. THE 113TH SOVEREIGN, THE EMPEROR HIGASHIYAMA (A. D. $1687-1710)$

In 1687, the Emperor Reigen abdicated in favour of Higashiyama, then a boy of thirteen, Reigen continuing to administer affairs from behind the curtain as was usual. Tsunayoshi was then the shogun in Yedo. He showed great consideration for the interests of the Imperial Court. Thus, he increased his Majesty's allowance by ten thousand koku of rice annually, and he granted an income of three thousand koku to the ex-Emperor. Moreover, all the Court ceremonies, which had been interrupted for want of funds, were resumed, and steps were taken to repair or rebuild the sepulchres of the sovereigns throughout the empire.

\section{RELATIONS BETWEEN THE FEUDATORIES AND THE COURT NOBLES}

According to a rule made in the beginning of the Tokugawa dynasty, a lady of Tokugawa lineage was forbidden to marry a Court noble; but the shogin himself was expected to take a consort from one of the noble houses in the Imperial capital. From the days of Iemitsu this latter custom was steadily maintained, and gradually the feudatories came to follow the shogun's example, so that marriages between military magnates and noble ladies of Kyoto were frequent. To these unions the Court nobles were impelled by financial reasons and the military men by ambition. The result was the gradual formation of an Imperial party and of a Bakufu party in Kyoto, and at times there ensued sharp rivalry between the two cliques. In the days of the seventh shogun, Ietsugu, the Emperor Reigen would have given his daughter Yaso to be the shōgun's consort for the purpose of restoring real friendship between the two Courts, but the death of the shoggun in his boyhood interrupted the project.

THE 114TH SOVEREIGN, THE EMPEROR NAKANOMIKADÖ (A. D. 1710-1735)

Higashiyama abdicated (1710) in favour of Nakanomikado, who reigned for twenty-five years. This reign is remarkable for a change in the system hitherto uniformly pursued, namely, that all Imperial princes with the exception of the direet heir should become Buddhist priests $(h \bar{o}-$-shinnō), and all princesses except those chosen as consorts of the shöguns, should become Buddhist nuns (bikuni-gosho). It has already been shown that this custom found many followers in the days of Ashikaga administration, and it was observed with almost equal strictness under the Tokugawa, who certainly aimed at the gradual weakening of the Imperial household's influence. Arai Hakuseki remonstrated 
with the shögun, Ienobu, on the subject. He contended that however humble a man's lot may be, his natural desire is to see his children prosper, whereas in the case of Imperial princes, they were condemned to the ascetic career of Buddhist priests. He denounced such a system as opposed to the instincts of humanity, and he advised not only that certain prinees should be allowed to form families of their own, but also that Imperial princesses should marry into branches of the Tökugawa. Ienobu is said to have acknowledged the wisdom of this advice, and its immediate result was the establishment of the princely house of Kanin, which, with the houses of Fushimi, Kyoggoku (afterwards Katsura); and Arisugawa, became the four Shinnōke. Among other privileges these were designated to furnish an heir to the throne in the event of the failure of direct issue. When Yoshimune succeeded to the headship of the Bakufu, and after Arai Hakuseki was no longer in office, this far-seeing policy was gradually abandoned, and all the relations between the Imperial Court and the Bakufu became somewhat strained.

THE 115TH SOVEREIGN, THE EMPEROR SAKURAMACHI (A. D, 1732-1735), AND THE 116TH SOVEREIGN, THE EMPEROR MOMOZONO (A. D. 1735-1762)

After the death of the ex-Emperor Reigen (1732), the Emperor Nakanomikado administered affairs himself during three years, and then abdicated in 1735 in favour of Sakuramachi, who was sixteen years of age, and who reigned until 1747, when he abdicated in favour of Momozono, then seven years of age. It was in this reign that there appeared an eminent scholar, Yamazaki Ansai, who, with his scarcely less famous pupil, Takenouchi Shikibu, expounded the Chinese classics according to the interpretation of Chutsz. They sought to combine the cults of Confucianism and Shinto, and to demonstrate that the Mikados were descendants of gods; that everything possessed by a subject belonged primarily to the sovereign, and that anyone opposing his Majesty's will must be killed, though his brothers or his parents were his slayers. The obvious effect of such doctrines was to discredit the Bakufu shöguns, and information having ultimately been lodged in Yedo through an enemy of Takenouchi, seventeen Court nobles together with others were arrested and punished, some capitally and some by exile. Among those executed the most remarkable was Yamagata Daini, a master of military science, who, having endured the torture without confession, was finally put to death on the ground that in teaching the method of attacking a fortress he used drawings of Yedo Castle. This incident is remarkable as indicating the first potent appearance of a doctrine to the prevalence of which the fall of the Tokugawa Bakufu was ultimately referable.

THE 117TH SOVEREIGN, THE EMPRESS GO-SAKURAMACHI (A. D. 1762-1770), AND THE 118TH SOVEREIGN, THE EMPEROR GO-MOMOZONO (A. D. 1770-1780)

The Emperor Momozono died in 1762 after having administered the Government for sixteen years. His eldest son, Prince Hidehito, being a mere baby, it was decided that Princess Tomo, Momozono's elder sister, should occupy the throne, Prince Hidehito becoming the Crown Prince. Her Majesty is known in history as Go-Sakuramachi. Her reign lasted only eight years, and in 1770 she abdicated in favour of her nephew, Hidehito, who ascended the throne as the Emperor Go-Momozono and died after a reign of nine years. This exhausted the lineal descendants of the Emperor Nakanomikado. 
THE 119TH SOVEREIGN, THE EMPEROR KŌKAKU' (A. D. 1780-1816)

In default of a direct heir it became necessary to have recourse to one of the "Four Princely Families," and the choice fell upon Prince Tomohito, representing the Kanin house. He succeeded as Kōkaku, and a Japanese hiștorian remarks with regard to the event and to the growth of the spirit fostered by Yamazaki Ansai, Takenouchi Shikibu, and Yamagata Daini, that "the first string of the Meiji Restoration lyre vibrated at this time in Japan." Kōkaku's reign will be referred to again later on.

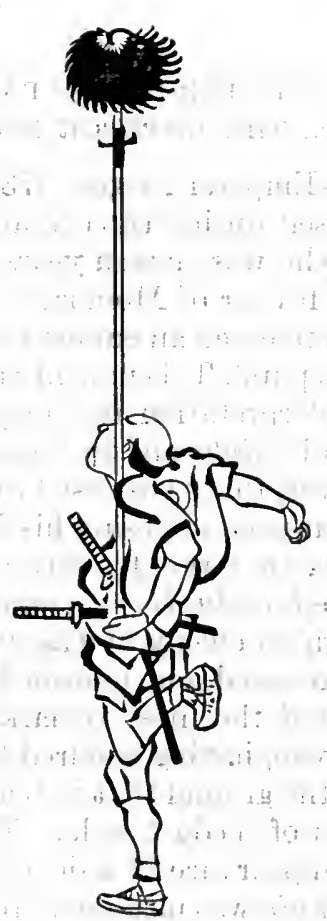

beysriguta

(Keyati) Spear Carrier (One of a Daimyō's Procession) 


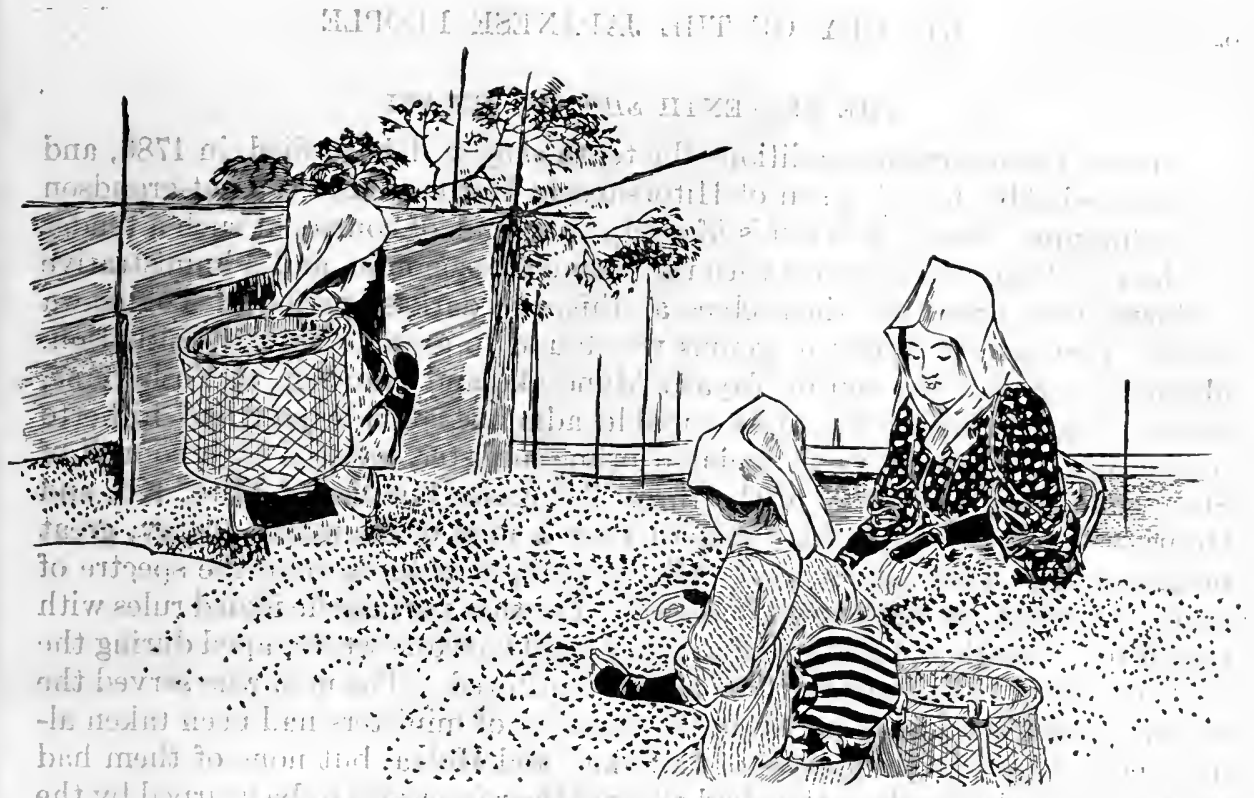

Picking Tea leaveg in Uji, a Celebrated Tea District

\section{CHAPTER XLI}

\section{Gr THE LATE PERIOD OF THE TOKUGAWA BAKUFU. THE ELEVENTH SHŌGUN, IENARI. (1786-1838)}

\section{NATURAL CALAMITIES}

THE misgovernment of Tanuma and his son was not the only calamity that befell the country during the closing years of the tenth shogun, Ieharu's, administration. The land was also visited by famine and pestilence of unparallelled dimensions. The evil period began in 1783 and lasted almost without intermission for four years. It is recorded that when the famine was at its height, rice could not be obtained in some parts of the country for less than forty ryo a koku. Sanguinary riots took place in Yedo, Kyōto, Ōsaka, and elsewhere. The stores of rice-merchants and the residences of wealthy folks were plundered and, in many cases, destroyed. To such extremities were people driven that cakes made from pine-tree bark served as almost the sole means of subsistence in some districts, and the Government is found gravely proclaiming that cakes made of straw were more nutritious. There are records of men deserting their families, wandering into other provinces in search of food and dying by thousands on the way. An official who had been sent to Matsumae, in the province of Mutsu; to observe the state of affairs, reported that the villages to the east of Nambu had been practically depopulated and the once fertile fields converted into barren plains. "Although farmhouses stood in the hamlets, not a solitary person was to be seen on the road; not a human voice was to be heard. Looking through a window, one saw dead bodies lying without anyone to bury them, and sometimes skeletons covered with quilts reposed on the mats, while among the weeds countless corpses were scattered." 


\section{THE ELEVENTH SHÖGUN, IENARI}

Among these terrible conditions the tenth shoggun, Ieharu died, in 1786, and was succeeded by Ienari, a son of Hitotsubashi Harunari and a great-grandson of Yoshimune. Ienari was in his fifteenth year, and, of course, at such a tender age he could not possibly deal with the financial, economic, and administrative problems that presented themselves at this, the darkest period of Tokugawa sway. Fortunately a man of genius was found to grapple with the situation. Matsudaira Sadanobu, son of Tayasu Munetake and grandson of Yoshimune, proved himself one of the most capable administrators Japan had hitherto produced. In 1788, he was appointed prime minister, assisted by a council of State comprising the heads of the three Tokugawa families of Mito, Kil, and Owari. Sadanobu was in his thirtieth year, a man of boundless energy, great insight, and unflixehing courage. His first step was to exorcise the spectre of famine by which the nation was obsessed. For that purpose he issued rules with regard to the storing of grain, and as fairly good harvests were reaped during the next few years, confidence was in a measure restored. The men who served the Bakufu during its middle period in the capacity of ministers had been taken almost entirely from the families of Ii, Sakai, and Hotta; but none of them had shown any marked ability; they had allowed their functions to be usurped by the personal attendants of the shogun. This abuse was remedied by the appointment of the heads of the three Tokugawa families to the post of ministers, and for a time Sadanobu received loyal and efficient support from his colleagues.

\section{CONFLAGRATION IN KYŌTO}

The series of calamities which commenced with the tempests, floods, and famines of 1788 eulminated in a fire such as never previously had swept Kyōto. It reduced to ashes the Imperial palace, Nijō Castle, 220 Shintō shrines, 128 Buddhist temples, and 183,000 houses.' The loss of life (2600) was not by any means as severe as that in the great fire of Yedo, but the Imperial city was practically destroyed. Ishikawa Jinshiro, who commanded at Nijô Castle, immediately distributed a thousand koku of rice from the Government's store to relieve the distressed citizens. He acted in this matter without waiting to seek sanction from the Bakufu, and his diseretion was rewarded by appointment to the high office of inspector-general of police (ō-metsuke).

The problem of restoring the palace presented much difficulty in the impoverished state of the country, but the Bakufu did not hesitate to take the task in hand, and to issue the necessary requisitions to the feudatories of the home provinces. Sadanobu himself repaired to Kyoto to superintend the work, and took the opportunity to travel throughout a large part of the country. During his tour all that had any grievances were invited to present petitions, and munificent rewards were bestowed on persons who had distinguished themselves by acts of filial piety or by lives of chastity. Such administrative measures presented a vivid contrast with the corrupt oppression practised by the Tanuma family, and it is recorded that men and women kneeled on the road as Sadanobu passed and blessed him with tears. 
dealt with almost every form of expenditure. He himself made a practice of attending at the castle wearing garments of the coarsest possible materials, and the minute character of his ordinances against extravagance almost taxes credulity.

Thus, he forbade the custom of exchanging presents between official colleagues; ordered that everyone possessing an income of less than ten thousand koku should refrain from purchasing anything new; whether clothing, utensils, or furniture; interdicted the wearing of white robes except on occasions of ceremony; ordained that wedding presents should henceforth be reduced by one-half, advised that dried lobsters should be substituted for fresh fish in making presents; prohibited the wearing of brocade or embroidered silk by ladies not of the highest class; enjoined simplicity in costumes for the $n \bar{o}$ dance, in children's toys, in women's pipes, or tobacco-pouches, and in ladies' hairpins or hairdress; forbade gold lacquer in any form except to delineate family crests; limited the size of dolls; vetoed banquets, musical entertainments, and all idle pleasures except such as were justified by social status, and actually went to the length of ordering

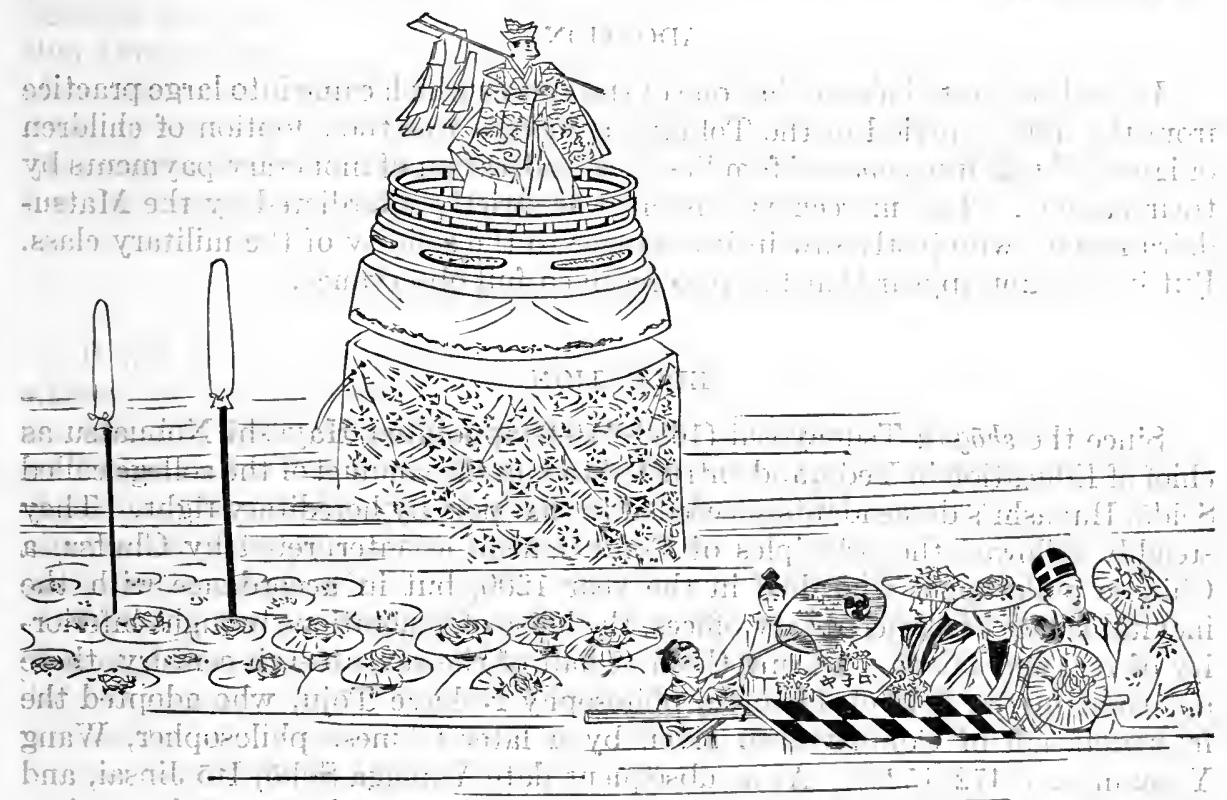

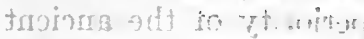

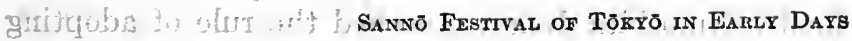

women to dress their own hair, dispensing entirely with professional hairdressers, who were bade to change their occupation for tailoring or laundry work.

ur This remarkable'statesman laboured for the ethical improvement of his countrymen as well as for their frugality of life. In 1789 , we find him legislating against the multiplication of brothels, and, two years later, he vetoed mixed bathing of men and women. One of the fashions of the time was that vassals left in charge of their lords' mansions in Yedo used to organize mutual entertainments by way of promoting good-fellowship, but in reality for purposes of dissipation. These gatherings were strictly interdicted. Simultaneously with the issue of this mass of negative legislation, Sadanobu took care to bestow rewards 
and publish eulogies. Whoever distinguished himself by diligent service, by chastity, by filial piety, or by loyalty, could count on honourable notice.

\section{THE KWANSEI VAGABONDS}

During the Kwansei era (1789-1800), Yedo was infested by vagabonds, who, having been deprived of their livelihood by the famine during the years immediately previous, made a habit of going about the town in groups of from three to five men committing deeds of theft or incendiarism. Sadanobu, acting on the advice of the judicial officials, dealt with this evil by establishing a house of correction on Ishikawa Island. There homeless vagrants were detained and provided with work, those ignorant of any handicraft being employed as labourers. The inmates were fed and elothed by the Government, and set free after three years, their savings being handed to them to serve as capital for some occupation. The institution was placed under the care of Hasegawa Heizō; five hundred bags of rice and five hundred ryō being granted annually by the Bakufu for its support.

\section{ADOPTION}

It has been stated above that one of the abuses which came into large practice from the middle period of the Tokugawa Bakufu was the adoption of children of ignoble birth into samurai families in consideration of monetary payments by their parents. This mercenary custom was strictly interdicted by the Matsudaira regent, who justly saw in it a danger to the solidity of the military class. But it does not appear that his veto received full observance.

\section{EDUCATION}

Since the shoggun Tsunayoshi (1680-1709) appointed Hayashi Nobuatsu as chief of Education in Yedo, and entrusted to him the conduct of the college called Seidō, Hayashi's descendants suceeeded to that post by hereditary right. - They steadily followed the principles of Confucianism as interpreted by Chutsz, a Chinese philosopher who died in the year 1200, but in accordance with the inevitable fate of all hereditary offices, the lapse of generations brought inferiority of zeal and talent. During the first half of the seventeenth century, there appeared in the field of Japanese philosophy Nakaye Tōju, who adopted the interpretation of Confucianism given by a later Chinese philosopher, Wang Yang-ming (1472-1529). At a subsequent date Yamaga Sokō, Itō Jinsai, and Ogyū Sorai (called also Butsu Sorai) asserted the superiority of the ancient Chinese teaching; and finally Kinoshita Junan preached the rule of adopting whatever was good, without distinction of Tang or Sung.

These four schools engaged in vehement controversy, and showed such passion in their statements and such intolerance in their contradictions, that they seemed to have altogether forgotten the ethical principles underlying their own doctrines. In the last quarter of the eighteenth century, other schools came into being, one calling itself the "eclectic school," another the "inductive school,", and so forth, so that in the end one and the same passage of the Confucian Analects received some twenty different interpretations, all advanced with more or less abuse and injury to the spirit of politeness.

In these cireumstances the educational chief in Yedo lost control of the situation. Even among his own students there were some who rejected the teachings 
of Chutsi, and Confucianism threatened to become a stumbling-block rather than an aid to ethics. The prime minister, Sadanobu, now appointed four philosophers of note to assist the Hayashi family, and these famous teachers attended in turn at the Seidō to lecture, commoners as well as samurai being allowed to attend. Sadanobu further directed that the heads of Government departments should send in a list of those best educated among their subordinates, and the men thus recommended were promoted after examination. Moreover, the prime minister himself, attended by his colleagues and the administrators, made a habit of inspecting personally, from time to time, the manner of teaching at the college, and finally, in 1795, the Seido was definitely invested with the character of a Government college, a yearly grant of 1130 koku being apportioned to meet the expenses, and an income of 1500 koku being bestowed upon the Hayashi family.

In the same year, it was decreed that no one should be eligible for a post in the civil service unless he was an avowed follower of the Chutsz philosophy. This bigoted measure, spoken of as the "prohibition of heterodoxy," did not produce the desired effect. It tended rather to accentuate the differences between the various schools, and a petition was presented to the Bakufu urging that the invidious veto should be rescinded. The petitioners contended that although the schools differed from each other, their differences were not material, since all stood on common foundations, namely, the doctrines of Confucius and Mencius, and all agreed in inculcating the virtues of filial piety, brotherly love, loyalty, humanity, righteousness, politeness, and general tranquillity.

\section{THE PHILOSOPHIES OF CHUTSZ AND WANG YANG-MING}

It will be interesting to pause here a moment in order to inquire briefly the nature of the philosophies which occupied Japanese thought throughout the seventeenth and the eighteenth centuries. We need not go beyond the schools of Chutsz and Wang Yang-ming, for the third, or "ancient," school adopted the teachings of Confucius and Menciusin their purity, rejecting all subsequent deductions from the actual words used by these sages. These two schools have been well distinguished as follows by a modern philosopher, Dr. Inouye Tetsujirō:-(1) " (1) Chutsz maintained that it is necessary to make an extensive investigation of the world and its laws before determining what is the moral law. Wang held that man's knowledge of moral law precedes all study and that a man's knowledge of himself: is the very highest kind of learning. Chutsz's method may be said to be inductive; Wang's, deductive.

“(2) The cosmogony of Chutsz was dualistic. All nature owed its existence to the $R i$ and $K i$, the determining principle and the vital force of primordial aura that produces and modifies motion. Wang held that these two were inseparable: His teáching was therefore monistic.

7. " (3) Chutsz taught that the primary principle, $R i$, and the mind of man were quite separate, and that the latter was attached to the $K i$. Wang held that the mind of man and the principle of the universe were one and the same, and argued that no study of external nature was required in order to find out nature's laws. To discover these, man had only to look within his own heart. He that understands his own heart understands nature, says Wang.

"(4) Chutsz's system makes experience necessary in order to understand the laws of the universe, but Wang's idealism dispenses with it altogether as a teacher. 
"(5). Chutsz taught that knowledge must come first and right conduct after. Wang contended that knowledge and conduct cannot be separated. One is part of the other. Chutsz may be said to exalt learned theories and principles, and Wang to extol practice.

"The moral results of the systems briefly stated were as follows: Chutsz's teaching produced many learned men in this country, but not infrequently these men were inferior, being narrow-minded, prejudiced, and behind the age. Wang's doctrines, on the other hand, while they cannot escape the charge of shallowness on all occasions, serve the moral purpose for which they were propagated better than those of the rival school. Though in the ranks of the Japanese followers of Chutsz there were numbers of insignificant, bigoted traditionalists, the same cannot be said of those who adopted Wang's views. They were as a class fine specimens of humanity, abreast, if not ahead, of the age in which they lived. No system of teaching has produced anything approaching!such a number of remarkable men. If a tree is to be judged by its fruit, Wang's philosophy in Japan must be pronounced one of the greatest benefits that she received from the neighbouring continent, though not a little of its power in this country is to be traced to the personality: of the man who was the first to make it thoroughly known to his fellow countrymen, Nakaye Tōju." 1

Dr. Inouye adds: "By exclusive attention to the dictates of conscience and by sheer force of will the Wang school of philosophers succeeded in reaching a standard of attainment that served to make them models for posterity: The integrity of heart preached by his followers in Japan has become a national heritage of which all Japanese are proud. In the West, ethics has become too exclusively a subject of intellectual inquiry, a question as to which of rival theories is the most logical. By the Japanese, practical virtue has been exalted to the pedestal of the highest honour."

The same authority, discussing the merits of the Chutsz school, says: "To the question which has so often been asked during the past few years, whence comes the Japanese fine ethical standard, the answer is that it undoubtedly originated with the teaching of Chutsz as explained, modified, and carried into practice in Japan. The moral philosophy of the Chutsz school in Japan compared with that of the other two sehools was moderatein tone, free from eccentricities, and practical in a rare degree. In the enormous importance it attached to self-culture and what is known in modern terminology as self-realization, the teaching of the Chutsz school of Japanese moralists differed in no material respects from the doctrines of the New Kantians in England."

sgipolmond

\section{RETIREMENT OF SADANOBU}

After six years of most enlightened service; Matsudaira Sadanobu resigned office in 1793 to the surprise and consternation of all truly patriotic Japanese. History is uncertain as to the exact cause of his retirement, but the explanation seems to be, first, that his uncompromising zeal of reform had earned him many enemies who watched constantly for an opportunity to attack him, and found it during his absence on a visit to inspect the coasts of the empire with a view to enforcing the 'veto against foreign trade; and secondly, that a question of prime importance having arisen between the Courts of Kyōto and Yedo, Sadanobu's influence was exercised in a manner deeply resented by the sovereign as well as by the loyalists throughout the empire. This important incident will be present- 
ly referred to in detail. Here it will suffice to state that Sadanobu did not retire in disgrace. He was promoted to the rank of general of the Left, which honour was supplemented by an invitation to attend at the castle on: State occasions. He chose, however, to live in retirement, devoting himself to the administration of his own domain and to literary pursuits. The author of several well-known books, he is remembered by his pen-name, Rakuo, almost as constantly as by his historical, Sadanobu. He died in 1829, at the age of seventytwo.

\section{HITOTSUBASHI HARUNARI}

After Sadanobu's resignation of the post of prime minister, the shōgun's father, Hitotsubashi Harunari, moved into the western citadel of Yedo Castle, and thenceforth the great reforms which Sadanobu had effected by the force of genius and unflagging assiduity; were quickly replaced by an age of retrogression, so that posterity learned to speak of the prodigality of the Bunka and Bunsei eras (1804-1829), instead of the frugality of the Kwansei (1789-1800). As for the shogun, Ienari; he received from the Throne the highest rank attainable by a subject, together with the office of daijo-daijin. Such honour. was without precedent since the time of Ieyasu. Ienari had more than fifty daughters, all born of different mothers, from which fact the dimensions of his harem may be inferred:

THE 119TH SOVEREIGN, THE EMPEROR KŌKAKU (A. D. 1780-1816)

The Emperor Kōkaku ascended the throne in 1780 and abdicated in 1816 . He was undoubtedly a wise sovereign and as a classical scholar he won considerable renown: After reigning for thirty-six years, he administered State affairs from the Palace of Retirement during twenty-four, and throughout that long interval of sixty years, the country enjoyed profound peace. The period of Sadanobu's service as prime minister of the Bakufu coincided with the middle of Kōkáku's reign, and in those days of happiness and prosperity men were wont to say that with a wise sovereign in the west a wise subject had appeared in the east. Up to that time the relations between Kyoto and Yedo were excellent, but Sadanobu's resignation and the cause that led to it produced between the two Courts a breach which contributed materially, though indirectly, to the ultimate fall of the Tokugawa.

\section{REBUILDING OF THE IMPERIAL PALACE}

It has already been noted that after the great fire of 1788 ; the Bakufu, acting, of course, at the instance of their prime minister; ordered Sadanobu to supervise the work of reconstructing the Imperial palace. Since the days of Oda and Toyotomi, the palace had been rebuilt or extensively repaired on several oceasions; but always the plans had been too small for the requirements of the orthodox ceremonials. Sadanobu determined to correct this fault. He called for plans and elevations upon the bases of those of the tenth century, and from the gates to the roofs he took care that everything should be modelled on the old lines. The edifices are said to have been at once chaste and magnificent, the internal decorations being from the brushes of the best artists of the Tosa and Sumiyoshi Academies. Sealed estimates had been required from several leading architects, and Sadanobu surprised -his colleagues by awarding the work to the highest bidder, on the ground that cheapness could not consist with true merit 
in such a case, and that any thought of cost would evince a want of reverence towards the Imperial Court. The buildings were finished in two years, and the two Emperors, the reigning and the retired; took up their residence there. His Majesty Kōkaku rewarded the shögun with an autograph letter of thanks as well as a verse of poetry composed by himself, and on Sadanobu he conferred a sword and an album of poems. The shogun Ienari is said to have been profoundly gratified by this mark of Imperial favour. Heopenly attributed it to Sadanobu's exertions, and he presented to the latter a facsimile of the autograph letter.

\section{THE TITLE TROUBLE}

In the very year (1791) following the Emperor's entry into the new palace, a most untoward incident occurred. Up to that time the relations between the Courts of Kyōto and Yedo had left nothing to be desired, but now a permanent breach of amity took place. The sovereign was the son of Prince Tsunehito, head of the Kanin family..: This prince, in spite of his high title, was required by Court etiquette to sit below the ministers of State on ceremonial occasions in the palace. Such an order of precedence offended the sovereign; and his Majesty proposed that the rank of dajo tenno should be given to his father, thus placing him in the position of a retired Emperor. Of course it was within the prerogative of the Emperor to confer titles. The normal procedure would have been to give the desired rank to Prince Tsunehito, and then to inform the Bakufu of the accomplished fact. But, in consideration of the very friendly relations existing between the two Courts, the sovercign seems to have been univilling to act on his own initiative in a matter of such importance:

Yedo was consulted, and to the surprise of Kyōto, the Bakufu prime minister assumed an attitude hostile to the Court's desire. The explanation of this singular act on Sadanobu's part was that a precisely analogous problem perplexed Yedo simultaneously. When Ienari was nominated shōgun, his father, Hitotsubashi Harunari, fully expected to be appointed guardian of the new potentate, and being disappointed in that hope, he expressed his desire to receive the title of $\bar{o}$-gosho (retired shogin), so that he might enter the western citadel of Yedo Castle and thence administer affairs as had been done by ex-Emperors in Kyōto for hundreds of years, and by ex-shöguns on several occasions under the Tokugawa. Disappointed in this aspiration, Harunari, after some hesitation; invited the attention of the shogun to the fact that filial piety is the basis of all moral virtues, and that, whereas the shoggun's duty required him to set a good example to the people, he subjected his own father to unbecoming humiliation. Ienari referred the matter to the State council, but the councillors hesitated to establish the precedent of conferring the rank of $\bar{o}$-gosho on the head of one of the Sankyo families - Tayasu, Shimizu, and Hitotsubashi - who had never discharged the duties of shögun.

The prime minister, Sadanobu,' however, had not a moment's hesitation in opposing Harunari's project. He did, indeed, order a well-known Confucian scholar to search the annals in order to find whether any precedent existed for the proposed procedure, either in Japan or in China, but he himself declared that if such an example were set in the shoggn's family, it might be the cause of grave inconvenience among the people. In other words, a man whose son had been adopted into another family might claim to be regarded as the head of that family in the event of the death of the foster-father. It is certain, however, that other and stronger reasons influenced the Bakufu prime minister. Hitotsubashi 
Harunari was generally known as Wagamama Inkyo (the Wayward Recluse ${ }^{1}$ ). His most intimate friends were the shogun's father-in-law, Shimazu Ei- $\overline{0}$, and Ikeda Isshinsai. The latter two were also inkyo and shared the tastes and foibles of Harunari. One of their greatest pleasures was to startle society. Thus, when Sadanobu was legislating with infinite care against prodigality of any kind, the above three old gentlemen loved to organize parties on an ostentatiously extravagant scale, and Sadanobu naturally shrank from seeing the title of $\bar{o}$-gosho conferred on such a character, thus investing him with competence to interfere arbitrarily in the conduct of State affairs.

Just at this time, the Court in Kyōto preferred its application, and Sadanobu at once appreciated that if the rank of dajo tenno were conferred on Prince Tsunehito, it would be impossible to withhold that of $\bar{o}$-gosho from Harunari. Consequently the Bakufu prime minister wrote privately to the Kyōto prime minister, Takatsukasa Sukehira, pointing out the inadvisability of the proposed step. This letter, though not actually an official communication, had the effect of shelving the matter for a time, but, in 1791, the Emperor re-opened the question, and summoned a council in the palace to discuss it. The result was that sixty-five officials, headed by the prime minister and the minister of the Right, supported the sovereign's views, but the ex-premier, Takatsukasa Sukehira, and his son, the minister of the Left, with a few others, opposed them.

The proceedings of this council with an autograph covering-letter from the sovereign were sent to the Bakufu, in 1792, but for a long time no answer was given. Meanwhile Prince Tsunehito, already an old man, showed signs of declining health, and the Imperial Court pressed Yedo to reply. Ultimately the Bakufu officially disapproved the project. No statement of reasons accompanied the refusal, but it was softened by a suggestion that an increase of revenue might be conferred on the sovereign's father. This already sufficiently contumelious act was supplemented by a request from the Bakufu that the Imperial Court should send to Yedo the high secretary and the chief of the Household: Unwillingly the Court complied, and after hearing the arguments advanced by these two officials, Sadanobu sentenced them to be placed in confinement for a hundred days, and fifty days, respectively, which sentence was carried out at the temple Seishō-ji in Yedo, and the two high officials were thereafter sent back to Kyōto under police escort. Ultimately they were both dismissed from office, and all the Court dignitaries who had supported the sovereign's wishes were cautioned not to associate themselves again with such "rash and unbecoming acts.". It can scarcely be denied that Sadanobu exercised his power in an extreme and unwise manner on this occasion. A little recourse to tact might have settled the matter with equal facility and without open disrespect to the Throne. But the Bakufu prime minister behaved after the manner of the deer-stalker of the Japanese proverb who does not see the mountain, and he thus placed in the hands of the Imperialist party a weapon which contributed materially to the overthrow of the Bakufu seventy years later.

[ ${ }^{1}$ It has always been a common custom in Japan for the head of a family to retire nominally from active life af ter he attains his fiftieth year. He is thenceforth known as inkyo (or recluse). The same is true of women.] 


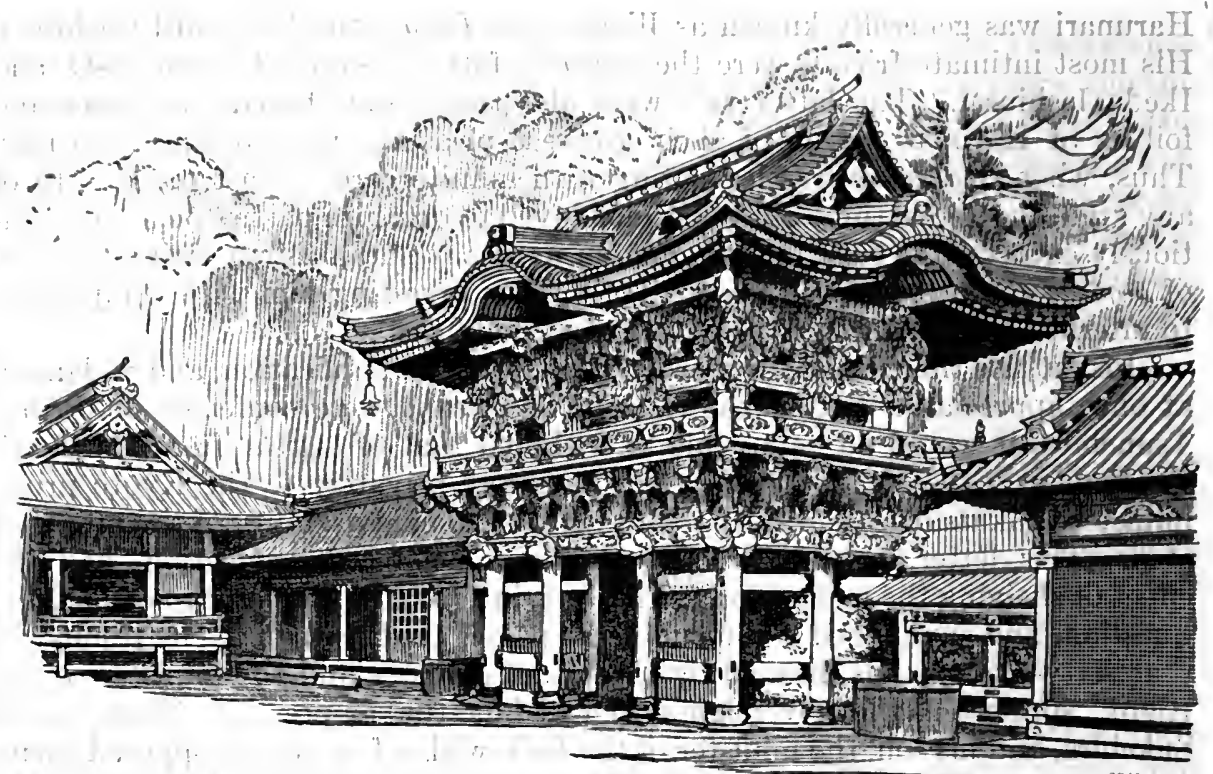

Yómei-Mon Gate, at NikEó

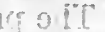

roistion

\section{CHAPTER XLII}

\section{ORGANIZATION, CENTRAL AND LOCAL; CURRENCY AND THE LAWS OF THE TOKUGAWA $B A K A F U$}

\section{THE ORGANIZATION OF THE TOKUGAWA BAKUFU}

THE organization of the Tokugawa Bakufu cannot be referred to any earlier period than that of the third shōgun, Iemitsu. The foundations indeed were laid after the battle of Sekigahara, when the administrative functions eame into the hands of Ieyasu. By him a shoshidai (governor) was established in Kyōto together with municipal administrators (machi bugyō). But it was résérved for Iemitsu to develop these initial creations into a competent and consistent whole. There was, first, what may be regarded as a cabinet, though the name of its members ( $r \bar{o} j \bar{u}$, or seniors) does not suggest the functions generally discharged by ministers of State. One of the rōju was appointed to the post of dairo (great senior). He corresponded to the prime minister in a Western Cábinet, and the other rōju may be counted as ministers. Then there were junior ministers, and after them came administrators of accounts, inspectors, administrators of shrines and temples, and municipal administrators. The place where State business was discharged went by the name of $G o-Y \bar{o}$-beya. There, the senior and junior ministers assembled to transact affairs, and the chamber being situated in the immediate vicinity of the shoggun's sitting-room, he was able to keep himself au courant of important administrative affairs. During the time of the fifth shoggun, however, as already related, this useful arrangement underwent radical alteration. As for judicial business, there did not originally exist 
any special place for its transaction. A chamber in the official residence was temporarily assigned for the purpose, but at a later date a court of justice $(H y o j o-s h o)$ was established at Tatsunokuchi in Yedo. This organization, though carried within sight of completion in the days of the third shốgun, required to be supplemented by the eighth, and was not actually perfected until the time of the eleventh.

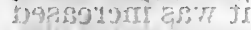

$9 \mathrm{~d} T$

THE DAIRŌ

The duties of the dairō sometimes called karō or $\bar{o}$-doshiyori - were to preside over the roju and to handle important administrative affairs. In many respects his functions resembled those discharged by the regent (shikken) of the Kamakura Bakufu. To the office of dairō a specially distinguished member of the roju was appointed, and if no one possessing the necessary qualifications was available, that post had to be left vacant. Generally the Ii, the Hotta, or the Sakai family supplied candidates for the office.

\section{THE $R \bar{O} J \bar{U}$}

The rōju or senior ministers - called also toshiyori - discharged the administration. They resembled the kwanry of the Muromachi Government. There were five of these ministers and they exercised control over all matters relating to the Imperial palace, the palace of the ex-Emperor (Sendo), the Imperial princes, the princely abbots (monzeki) and all the daimyo. It was customary to choose the rōju from among officials who had previously served as governors of Ōsaka or Kyōto or as sōshaban, who will be presently spoken of at greater length.

\section{THE WAKA-DOSHIYORI}

There were five junior ministers (waka-doshiyori) whose principal functions were to exercise jurisdiction over the hatamoto and the kenin. These latter names have already been alluded to, but for the sake of clearness it may be well to explain that whereas the fudai daimyo consisted of the one hundred and seventysix barons who joined the standard of Ieyasu before the battle of Sekigahara; the hatamoto (bannerets), while equally direct vassals of the shōgun, were lower than the daimy $\bar{o}$ though higher than the go-kenin, who comprised the bulk of the Tokugawa samurai. Members of the waka-doshiyori might at any time be promoted to the post of $r \bar{o} j \bar{u}$. Their functions were wide as well as numerous, and resembled those performed by the hyojōo-shu and the hikitsuke-shu of the Kamakura and Muromachi Governments... A junior minister must previously have occupied the post of administrator of temples and shrines (jisha-bugyō) or that of chamberlain $(\bar{o}-s o b a-s h \bar{u})$ or that of chief guard $(\bar{o}-b a n)$. The offices of minister and junior minister were necessarily filled by daimy $\bar{a}$ wo were hereditary vassals of the shōgun.

\section{SECRETARIES}

There were two secretariats, the oku-yunhitsu (domestic secretariat) and the omote-yunitsu (external secretariat). They discharged, on account of the senior ministers, the duties of scribes, and were presided over by a todori, who, in later days, wielded large influence. 
THE JISHA-BUGYO

The jisha-bugyō, as their name suggests, supervised all affairs relating to shrines, temples, Shintō officials, bonzes, and nuns as well as persons residing within the domains of shrines and temples. They also discharged judicial functions in the case of these various classes. The number of these administrators of shrines and temples was originally three, but afterwards it was increased to four, who transacted business for a month at a time in succession. The sosshaban, who were entitled to make direct reports to the shogun, had to fill the office of jisha-bugyo in addition to their other functions, which were connected with the management of matters relating to ceremony and etiquette.

At first there were only two of these soshaban, but subsequently their number was increased to twenty-four, and it became customary for one of them to keep watch in the castle at night. They were generally ex-governors of Ōsaka and Fushimi, and they were necessarily daimyō who had the qualification of direct vassalage to the shōgun. The jisha-bugyō performed their judicial functions in their own residences, each administrator employing his own vassals for subordinate purposes, and these vassals, when so employed, were distinguished as jisha-yaku or toritsugi. Further, officiating in conjunction with the jisha-bugyō, were chief inspectors (daikenshi), and assistant inspectors (shökenshi) whose duties require no description. "The classes of people' to whom the jisha-bugyó's jurisdiction extended were numerous: they embraced the cemetery-keepers at Momiji-yama, the bonzes, the fire-watchmen, the musicians, the Shinto officials, the poets, the players at go or chess, and so forth.

\section{THE $M A C H I-B U G Y O \bar{O}$}

The municipal administrator (machi-bugyō) controlled affairs relating to the citizens in general. This was among the oldest institutions of the Tokugawa, and existed also in the Toyotomi organization. At first there were three machibugyō, but when the Tokugawa moved to Yedo, the number was decreased to one, and subsequently increased again to two in the days of Iemitsu. Judicial businessoccupied the major part of the machi-bugyō's time. His law-court was in his own residence, and under his direction constables (yoriki or doshin) patrolled the city. He also transacted business relating to prisons and the municipal elders of Yedo (machi-doshiyori) referred to him all questions of a difficult or serious nature.

\section{THE KANJÖ-BUGYO}

The financial administrator (kanjō-bugyō) received also the appellation of kitchen administrator (daidokoro-bugyō), and his duties embraced everything relating to the finance of the Bakufu, including, of course, their estates and the persons residing on those estates. The eight provinces of the $\mathbf{K}$ wanto were under the direct control of this bugyō, but other districts were administered by a daikwan (deputy). There were two kinds of kanjō-bugyō, namely, the kuji-kata and the katte-kata (public and private), the latter of whom had to adjudicate all financial questions directly affecting the Bakufu, and the former had to perform a similar function in cases where outsiders were concerned. Various officials served as subordinates of these important bugyō, who were usually taken from the rōju or the waka-doshiyori, and, in the days of the sixth shogun, it was found necessary to appoint an auditor of accounts (kanjo-gimmiyaku), who, although 
nominally of the same rank as the kanjo-bugyō, really acted in a supervisory capacity. The Bakufu court of law was the Hyōjo-sho. Suits involving issues that lay entirely within the jurisdiction of one bugyo were tried by him in his own residence, but where wider interests were concerned the three bugyo had to conduct the case at the $H y \bar{o} j \bar{o}-s h o$, where they formed a collegiate court. On such occasions the presence of the censors was compulsory. Sometimes, also, the three bugyō met at the Hyōjō-sho merely for purposes of consultation.

\section{THE CENSORS}

An important figure in the Tokugawa organization was the censor (metsuke), especially the great censor ( $\overline{0}$-metsuke). The holder of the latter office served as the eyes and ears of the rōju and supervised the feudal barons. There were four or five great censors. One of them held the additional office of administrator of roads (dōchü-bugyō), and had to oversee matters relating to the villages, the townis, and the postal stations along the five principal highways. Another had to inspect matters relating to religious sects and firearms - a strange combination. Under the great censors were placed administrators of confiscated estates. The ordinary censors had to exercise surveillance over the samurai of the hatamoto and were under the jurisdiction of the waka-doshiyori. There were altogether sixty metsuke, and they travelled constantly throughout the empire obtaining materials for reports which were submitted to the wakadoshiyori. Among them are found censors who performed the duties of coroners. ${ }^{1}$

\section{THE CHAMBERLAINS}

Even more important than the censors were the chamberlains (soba yōnin) who had to communicate to the shoggun all reports submitted by the rōju, and to offer advice as to the manner of dealing with them. They also noted the shoggun's decisions and appended them to documents. The exercise of these functions afforded opportunities for interfering in administrative affairs, and such opportunities were fully utilized, to the great detriment of public interest. There were also pages $(k o s h \bar{o})$; castle accountants (nando); literati to the shōgun (oku-jusha), and physicians (oku-isha).

\section{MASTERS OF CEREMONIES}

The duty of transmitting messages from the shōgun to the Emperor and of regulating all matters of ceremony connected with the castle was discharged by fifteen masters of ceremonies ( $k \bar{o} k e)$ presided over by four chiefs (the office of chief being hereditary in such families as the Ōsawa and the Kira) who, although their fiefs were comparatively small, possessed influence not inferior to that of the daimyo.. A koke was usually on watch in the castle by day. These masters of ceremonies are not to be confounded with the chamberlains (sōshaban) already spoken of. The latter numbered twenty-four. They regulated affairs connected with ceremonies in which all Government officials were concerned, and they kept:watch at the castle by night. Subordinate to the kōke and the chamberlains

[1 The employment of censors by the Bakufu has been severely criticized as indicating a system of espionage. It scarcely seems necessary to observe that the same criticism applies to all highly organized Occidental Governments with their secret services, their detectives and their inquiry agencies.] 
were various officials who conveyed presents from the feudal lords to the shogin; directed matters of decoration and furniture, had charge of miscellaneous works in the castle, and supervised all persons, male or female, entering or leaving the shoggun's harem. Officials of this lasticlass were under the command of a functionary called $\bar{o}$-rusui who had general charge of the business of the harem; directed the issue of passports to men and women of the samurai class or to commoners, and had the care of all military stores in the castle. The name rusui signifies a person in charge during the absence of his master, and was applied in this case since the $\bar{o}-r$ sui had to guard the castle when the shōgun was not present. The multifarious duties entrusted to officials over whom the $\bar{o}$-rusui presided required a large number and a great variety of persons to discharge them, but these need not be enumerated in dëtail here.

\section{THE TAMARIZUME}

Characteristic of the elaborate etiquette observed at the shögun's castle was the existence of semi-officials called tamarizume, whose chief duty in ordinary times was to repair to the castle once every five days, and to inquire through the rōjo as to the state of the shogun's health. On occasions of emergency they participated in the administration, taking precedence of the $r \bar{o} j \bar{u}$ and the other feudatories. The Matsudaira of Aizu, Takamatsu, and Matsuyama; the Ii of Hikone, and the Sakai of Himeji - these were the families which performed the functions of tamarizume as a hereditary right. It is unnecessary to describe the organization and duties of the military guards to whom the safety of the castle was entrusted, but the fact has to be noted that both men and officers were invariably taken from the hatamoto class.

\section{THE WOMEN'S APARTMENTS}

In the ō-oku, or innermost buildings of the shogun's castle, the harem was situated. Its chief official was a woman called the o-toshiyori (great elder), under whom were a number of ladies-in-waiting, namely; the toshiyori, the rōjo, the chūro, the kojōrō, and others. There were also ladies who attended solely to visitors; others who kept the keys; others who carried messages to public officers, and others who acted as secretaries. All this part of the organization would take pages to describe in detail, ${ }^{1}$ and is necessarily abbreviated here. We may add, however, that there were official falconers, sailors, grooms, gardeners, and every kind of artist or mechanician.

\section{THE LOCAL GOVERNMENT SYSTEM.}

In organizing a system of local government the Tokugawa Bakufu began by appointing a shoshidai in Kyōto to guard the Imperial palácé, to supervise Court officials, and to oversee financial measures as well as to hear suits-at-law, and to have control over temples and shrines. The shoshidai enjoyed a high measure of respect. He had to visit Yedo once in every five or six years for the purpose of making a report to the shoun in person. The municipal administrator of Kyōto and the administrators of Nara and Fushimi, the Kyōto deputy (daikwan), and all the officials of the Nijo palace were under the jurisdiction of

['For fuller particulars of the manner of daily life at the shōgun's court, see Chapter 1 . Vol. IV, of Brinkley's "Oriental Series."] 
the shoshidain (To qualify for this high office a man must have served as governor of $\bar{O}$ saka. In the Imperial city the municipal administrator heard suits-at-law presented by citizens, managed the affairs of temples and shrines, and was responsible for collecting the taxes in the home provinces. "There were two of these officials in Kyōto and, like their namesakes in Yedo, they had a force of constables (yoriki) and policemen (döshin) under their command.

\section{THE JODDAI}

Regarded with scarcely less importance than that attaching to the shoshidai was an official called the $j \bar{o} d a i$ of Ōsaka, on whom devolved the responsibility of guarding the Kwansei. For this office a hereditary däimyo of the Tokugawa family was selected, and he must previously have occupied the offices of sosishaban and jisha-bugyō. The routine of promotion was from the jödai of Ōsaka to the shoshidai of Kyōto and from thence to the rōju. Originally there were six jōdai but their number was ultimately reduced to one. Sumpu also had a jōdai, who discharged duties similar to those devolving on his Osaka namesake. In Nagasaki; Sado, Hakodate, Niigata, and other important localities, bugyō were stationed, and in districts under the direct control of the Bakufu the chief official was the daikwan:

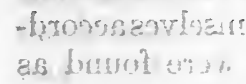

geadt 7 llast

\section{ADMINISTRATION IN FIEFS}

- dis The governmental system in the fiefs closely resembled the system of the Bakufu. The daimyō exercised almost unlimited power, and the business of their fiefs was transacted by factors $(\operatorname{karo})$. Twenty-one provinces consisted entirely of fiefs, and in the remaining provinces public and private estates were intermixed.

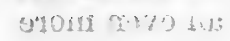

LOCAL AUTONOMY

Both the Bakufu and the feudatories were careful to allow a maximum of autonomy to the lower classes. Thus the farmers elected a village chief - called nanushi or shōya - who held his post for life or for one year, and who exercised powers scarcely inferior to those of a governor. There were also heads of guilds (kumi-gashira) and representatives of farmers (hyakushōdai) who participated in administering the affairs of a village. Cities and towns had municipal elders (machi-doshiyori), under whom also nanushi officiated. The guilds constituted a most important feature of this local autonomic system. They consisted of five householders each; being therefore called gonin-gumi, and their main functions were to render mutual aid in all times of distress, and to see that there were no evasions of the taxes or violations of the law. In fact, the Bakufu interfered as little as possible in the administrative systems of the agricultural, manufacturing, and commercial classes, and the feudatories followed the same rule.

\section{FINANCE}

The subject of finance in the Bakufu days is exceedingly complicated, and a very bare outline will suffice. It has already been noted that the unit of landmeasurement varied from time to time and was never uniform throughout the empire. That topic need not be further discussed. Rice-fields were divided into five classes, in accordance with which division the rates of taxation were 
fixed. Further, in determining the amount of the land-tax, two methods were followed; one by inspection, the other by average. In the case of the former, the daikwan repaired in the fall of each year to the locality concerned, and having ascertained the nature of the crop harvested, proceeded to determine the rate of tax. This arrangement lent itself so readily to abuse that the system of averages was substituted as far as possible. That is to say, the average yield of crops for the preceding ten or twenty years served as a standard.

The miscellaneous taxes were numerous. Thus, there were taxes on business; taxes for post-horses and post-carriers; taxes in the form of labour, which were generally fixed at the rate of fifty men per hundred koku, the object in view being work on river banks, roads, and other public institutions; tixes to meet the cost of collecting taxes, and taxes to cover defalcations. Sometimes the above taxes were levied in kind or in actual labour, and sometimes they were collected in money. To facilitate collection in cities, merchants were required to form guilds according to their respective businesses, and the head of each guild had to collect the tax payable by the members. Thus, upon a guild of sake-brewers a tax of a thousand gold $r y \bar{o}$ was imposed, and a guild of wholesale dealers in cotton had to pay five hundred ryō. There was a house-tax which was assessed by measuring the area of the land on which a building stood, and there was.a tax on expert labour such as that of carpenters and matmakers. In order to facilitate the levy of this last-named tax the, citizens were required to locate themselves according to the nature of their employment, and thus such names were found as "Carpenter's street;" "Matmaker's street," and so forth. Originally these imposts were defrayed by actual labour, but afterwards money came to be substituted.

An important feature of the taxation system was the imposition of buke-yaku, (military dues). For these the feudatories were liable, and as the amount was arbitrarily fixed by the Bakufu, though always with due regard to the value of the fief, such dues were often very onerous. "The same is true in an even more marked degree as to taxes in labour, materials, or money, which were levied upon the feudatories for the purposes of any great work projected by the Bakufu. These imposts were called aids (otetsudai).

\section{MANNER OF PAYING TAXES}

The manner of paying taxes varied accordingly to localities. Thus, in the Kwantō, payment was generally made in rice for wet fields and in money for uplands, at the rate of one gold $r y \bar{o}$ per two and a half koku of rice. In the Kinai and western provinces as well as in the Nankai-do, on the other hand, the total tax on wet fields and uplands was divided into three parts, two of which were paid with rice and one with money, the value of a koku of rice being fixed at forty-eight mon of silver (four-fifths of a gold $r y \bar{o}$ ). As a general rule, taxes imposed on estates under the direct control of the Bakufu were levied in rice, which was handed over to the daikwan of each province, and by him transported to Yedo, Kyōto, or Ōsaka, where it was placed in stores under the control of store-administrators (kura-bugyō).

In the case of cash payments the money was transported to the castle of Yedo or Osaka, where it came under the care of the finance administrator (kanebugy $\bar{o})$. Finally, the accounts connected with such receipts of cash were compiled and rendered by the administrator of accounts (kane-bugyō), and were subsequently audited by officials named katte-kata, over which office a member of the 
rōjū or waká-doshiyori presided. Statistics compiled in 1836 show that the revenue annually collected from the Tokugawa estates in rice and money amounted to 807,068 koku and 93,961 gold ryō respectively. As for the rate of the land-tax, it varied in different parts of the provinces, from seventy per cent. for the landlord and thirty for the tenant to thirty for the landlord and seventy for the tenant.

\section{CURRENCY}

It has been shown above that, from the time of the fifth shoggun, debasement of the coins of the realm took place frequently. Indeed it may be said that whenever the State fell into financial difficulty, debasement of the current coins was regarded as a legitimate device. Much confusion was caused among the people by repeated changes in the quality of the coins. Thus, in the days of the eighth shögun, no less than four varieties of a single silver token were in circulation. When the country renewed its foreign intercourse in the middle of the nineteenth century, there were no less than eight kinds of gold coin in circulation, nine of silver, and four of copper or iron. The limits within which the intrinsic value of gold coins varied will be understood when we say that whereas the gold oban. of the Keicho era (1596-1614) contained, approximately, 291/2 parts of gold to 13 of silver and was worth about seventy-five yen. The corresponding coin of the Man-en era (1860) contained 101/3 parts of pure gold to $191 / 4$ of silver, and was worth only twenty-eight yen.

\section{PAPER CURRENCY}

The earliest existing record of the use of paper currency dates from 1661, when the feudal chief of Echizen obtained permission from the Bakufu to employ. this medium of exchange, provided that its circulation was limited to the fief where the issue took place. These paper tokens were called hansatsu (fief notes), and one result of their issue was that moneys accruing from the sale of cereals and other products of a fief were preserved within that fief. The example of Echizen in this matter found several followers, but the system never became universal.

\section{JUDICIAL PROCEDURE}

The administration of justice in the Tokugawa days was based solely on ethical principles. Laws were not promulgated for prospective application. They were compiled whenever an occasion arose, and in their drafting the prime aim was always to make their provisions consonant with the dictates of humanity. Once; indeed, during the time of the second shogun, Hidetada, a municipal administrator, Shimada Y ùya, having held the office for more than twenty years, and having come to be regarded as conspicuously expert in rendering justice, it was proposed to the shogun that the judgments delivered by this administrator should be recorded for the guidance of future judges. Hidetada,' however, objected that human affairs change so radically as to render it impossible to establish universally recognizable precedents, and that if the judgments delivered in any particular era were transmitted as guides for future generations, the result would probably be slavish sacrifice of ethical principles on the altar of stereotyped practice.

In 1631 , when the third shoggun, Iemitsu, ruled in.Yedo, a public courthouse $(H y \bar{o} j \bar{o}-s h o)$ was for the first time established. Up to that time the shogun him- 
self had served as a court of appeal in important cases. These were first brought before a bugyo, and subsequently, if specially vital issues were at 'stake; the shoggun personally sat as judge, the duty of executing his judgments being entrusted to the bugyo and other officials.

Thenceforth, the custom came to be this: Where comparatively minor interests were involved and where the matter lay wholly within the jurisdiction of one administrator, that offieial sat as judge in a chamber of his own mansion; but in graver cases and where the interests concerned were not limited to one jurisdietion, the $H y \bar{o} j \bar{o}$-sho beeame the judicial court, and the three administrators, the rōju, together with the censors; formed a collegiate tribunal. There were fixed days each month for holding this collegiate court, and there were also days when the three administrators alone met at one of their residences for purposes of private conference. The hearing by the shogun was the last recourse, and before submission to him the facts had to be investigated by the chamberlains (sobash $\bar{u})$, who thus exereised great influencen A lawsuit instituted by a plebeian had to be submitted to the feudatory of the region, or to the administrator, or to the deputy (daikwan), but might never be made the subject of a direct petition to the shogun. If the feudatory or the deputy were held to be acting contrary to the dictates of integrity and reason, the suitor might change his domicile for: the purpose of submitting a petition to the authorities in Yedo; and the law provided that no obstruetion should be placed in the way of such change. $\mathrm{M}$ git

\section{LAW}

As stated above, the original principle of the Bakufu was to avoid compiling any written criminal code: But from the days of the sixth and the seventh shōguns, Ienobu and Ietsugu, such provisions of criminal law as related to ordinary offences eame to be written in the most intelligible style and placarded throughout the city of Yedo and provincial towns or villages. On such a placard $(k \overline{o s a t s u})$ posted up, in the year 1711, at seven places in Yedo, it was enjoined on parents, sons, daughters, brothers' 'husbands, wives, and other relatives that they must maintain intimate and friendly relations among themselves; and that, whereas servants must be faithful and industrious, their masters should have compassion and should obey the dictates, of right in dealing with them; that everyone should be hard working and painstaking; that people should not transgress the limits of their social status; that all deceptions should be carefully avoided; that everyone should make it a rule of life to avoid doing injury or causing loss' to others; that gambling should be eschewed; that quarrels and disputes of every kind should be avoided; that asylum should not be given to wounded: persons; that firearms should not be used without cause; that no one should conceal an offender; that the sale or purchase of human being, should be strictly: prohibited except in cases where men or women offered their services for a fixed: term of years or as apprentices; or in cases of hereditary servitude; finally, that; though hereditary servants went to other places and changed their domicile, it: should not be lawful to compel their return.

In the days of the eighth shōgun, Yoshimune, it being held that crimes were often due to ignorance of law, the-feudatories and deputies were directed to make arrangements for conveying to the people under their jurisdiction some knowledge of the nature of the statutes; and the result was that the mayors (nanushi) of provincial towns and villages had to read the laws once a month atla meeting of citizens or villagers convened for the purpose. Previously to this time, 
namely; in the days of the fourth shogun, Ietsugu, the office of recorder (tome$y \dot{a} k u$ ) was instituted in the $H y \bar{o} j \bar{o}-$ sho for the purpose of committing to writing all judgments given in lawsuits. But in the days of Yoshimune, the rules and regulations issued by the Bakufu from the time of Ieyasu downwards were found to have fallen into such confusion that the difficulty of following them was practically insuperable.

10 Therefore, in 1742 , Matsudaira Norimura, one of the rōju, together with the three administrators, was commissioned to compile a body of laws, and the result was a fifteen volume book called the Hatto-gaki (Prohibitory Writings). The shögun himself evinced keen interest in this undertaking.: He frequently consulted with the veteran officials of his court, and during a period of several years he revised "The Rules for Judicial Procedure." Associated with him in this work were Kada Arimaro, Ogyū Sorai, and the celebrated judge, Ōoka Tadasuke, and not only the Ming laws of China, but also the ancient Japanese Daihō-ritsu were consulted:

This valuable legislation, which showed a great advance in the matter of leniency; except in the case of disloyal or unfilial conduct, was followed, in 1767, by reforms under the shōoun, Ieharu, when all the laws and regulations placarded or otherwise promulgated since the days of Ieyasu were collected and collated to form a prefatory volume to the above-mentioned "Rules for Judicial Procedure," the two being thenceforth regarded as a single enactment under the title of Kajō-ruiten. "The Rules for Judicial Procedureistr originally comprised 103 articles; but, in 17.90, Matsudaira Sad a nob u revised this code, reducing the number of articles to one hundred, and calling it Tokugawa Hyakkajo, or " One Hundred Laws and Regulations of the Tokugawa."

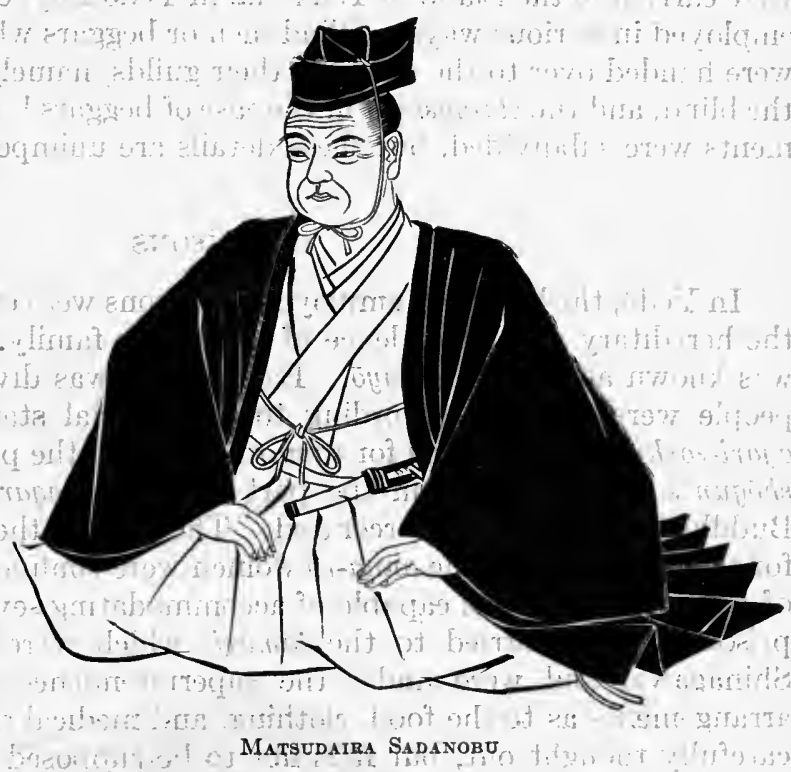
This completed the legislative work of the Yedo Bakufu. But it must not be supposed that these laws were disclosed to the general public. They served simply for purposes of official reference. The Tokugawa in this respect strictly followed the Confucian maxim, "Make the people obey but do not make them know."

\section{CRIMES AND PUNISHMENTS}

In Tokugawa days the principal punishments were six; namely, reprimand (shikari), confinement (oshikome), flogging (tataki), banishment (tsuihó), exile to an island (entō), and death (shikei). The last named was divided into five kinds, namely, deprivation of life (shizai), exposing the head after decapitation 
(gokumon), burning at the stake (hiaburi), crucifixion (haritsuke), and sawing to death (nokogiri-biki). There were also subsidiary penalties, such as public exposure (sarashi), tattooing (irezumi) - which was resorted to not less for purposes of subsequent identification than as a disgrace - confiscation of a an estate (kessho), and degradation to a status below the hinin (hininteshita).

The above penalties were applicable to common, folk. ... In the case of samurai the chief punishments were detention (hissoku), confinement (heimon or chikkyo), deprivation of status (kaieki), placing in the custody of a feudatory (azuke), suicide (seppuku), and decapitation (zanzai). Among these, seppuku was counted the most honourable. As a rule only samurai of the fifth official rank and upwards were permitted thus to expiate a crime, and the procedure was spoken of as "granting death" (shi wo tamau). The plebeian classes, that is to say, the farmers, the artisans, and the tradesmen, were generally punished by fines, by confinement, or by handcuffing (tegusari). Priests were sentenced to exposure (sarashi), to expulsion from a temple (tsui-in), or to exile (kamai).

For women the worst punishment was to be handed over as servants (yakko) or condemned to shave their heads (teihatsu). Criminals who had no fixed domicile and who repeated their evil acts after expiration of a first sentence, were carried to the island of Tsukuda, in Yedo Bay, or to Sado, where they were employed in various ways. Blind men or beggars who offended against the law were handed over to the chiefs of their guilds, namely, the soroku in the case of the blind, and the eta-gashira in the case of beggars. ${ }^{1}$ Some of the above punishments were subdivided, but these details are unimportant.

\section{PRISONS}

In Yedo, the buildings employed as prisons were erected at Demmachō under the hereditary superintendence of the Ishide family. The governor of prisons was known as the rôya-bugyō. Each prison was divided into five parts where people were confined according to their social status. The part called the agari-zashiki was reserved for samurai who had the privilege of admission to the shoggun's presence; and in the part called the agariya common, samurai and Buddhist priests were incarcerated. The ō ${ }^{\circ} \bar{o}$ and the hyakushō-rō were reserved for plebeians, and in the onna-rō women were confined. Each section consisted of ten rooms and was capable of accommodating seven hundred persons. Sick prisoners were carried to the tamari, which were situated at Asakusa and Shinagawa, and were under the superintendence of the hinin-gashira. All arrangements as to the food, clothing, and medical treatment of prisoners were carefully thought out, but it is not to be supposed that these Bakufu prisons presented many of the features on which modern eriminology insists. On the contrary, a prisoner was exposed to serious suffering from heat and cold, while the coarseness of the fare provided for him often caused disease and sometimes death. Nevertheless, the Japanese prisons in Tokugawa days were little, if anything, inferior to the corresponding institutions in Anglo-Saxon countries at the same period.

\section{LOYALTY AND FILIAL PIETY}

In the eyes of the Tokugawa legislators the cardinal virtues were loyalty and filial piety, and in the inculcation of these, even justice was relegated to an

[1 For fuller information about these degraded classes see Brinl-ley's "Oriental Series," Vol. II.] 
inferior place. Thus, it was provided that if a son preferred any public charge against his father, or if a servant opened a lawsuit against his master, the guilt of the son or of the servant must be assumed at the outset as an ethical principle. To such a length was this ethical principle carried that in regulations issued by Itakura Suō no Kami for the use of the Kyōto citizens, we find the following provision: "In a suit-at-law between parent and son judgment should be given for the parent without regard to the pleading of the son. Even though a parent act with extreme injustice, it is a gross breach of filial duty that a son should institute a suit-at-law against a parent. There can be no greater immorality, and penalty of death should be meted out to the son unless the parent petitions for his life." In an action between uncle and nephew a similar principle applied. Further, we find that in nearly every body of law promulgated throughout the whole of the Tokugawa period, loyalty and filial piety are placed at the head of ethical virtues; the practice of etiquette, propriety, and military and literary accomplishments standing next, while justice and deference for tradition occupy lower places in the schedule.

A kōsatsu (placard) set up in 1682, has the following inscription: "Strive to be always loyal and filial. Preserve affection between husbands and wives, brothers, and all relatives; extend sympathy and compassion to servants." Further, in a street notice posted in Yedo during the year 1656, we find it ordained that should any disobey a parent's directions, or reject advice given by a municipal elder or by the head of a five-households guild, such a person must be brought before the administrator, who, in the first place, will imprison him; whereafter, should the malefactor not amend his conduct, he shall be banished forever; while for anyone showing malice against his father, arrest and capital punishment should follow immediately.

In these various regulations very little allusion is made to the subject of female rights. But there is one significant provision, namely, that a divorced woman is entitled to have immediately restored to her all her gold and silver ornaments as well as her dresses; and at the same time husbands are warned that they must not fail to make due provision for a former wife. The impression conveyed by careful perusal of all Tokugawa edicts is that their compilers obeyed, from first to last, a high code of ethical principles.

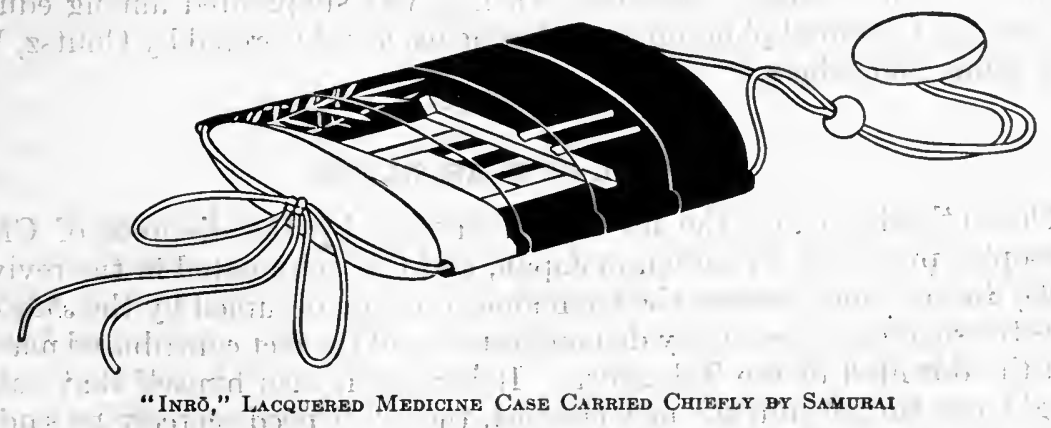




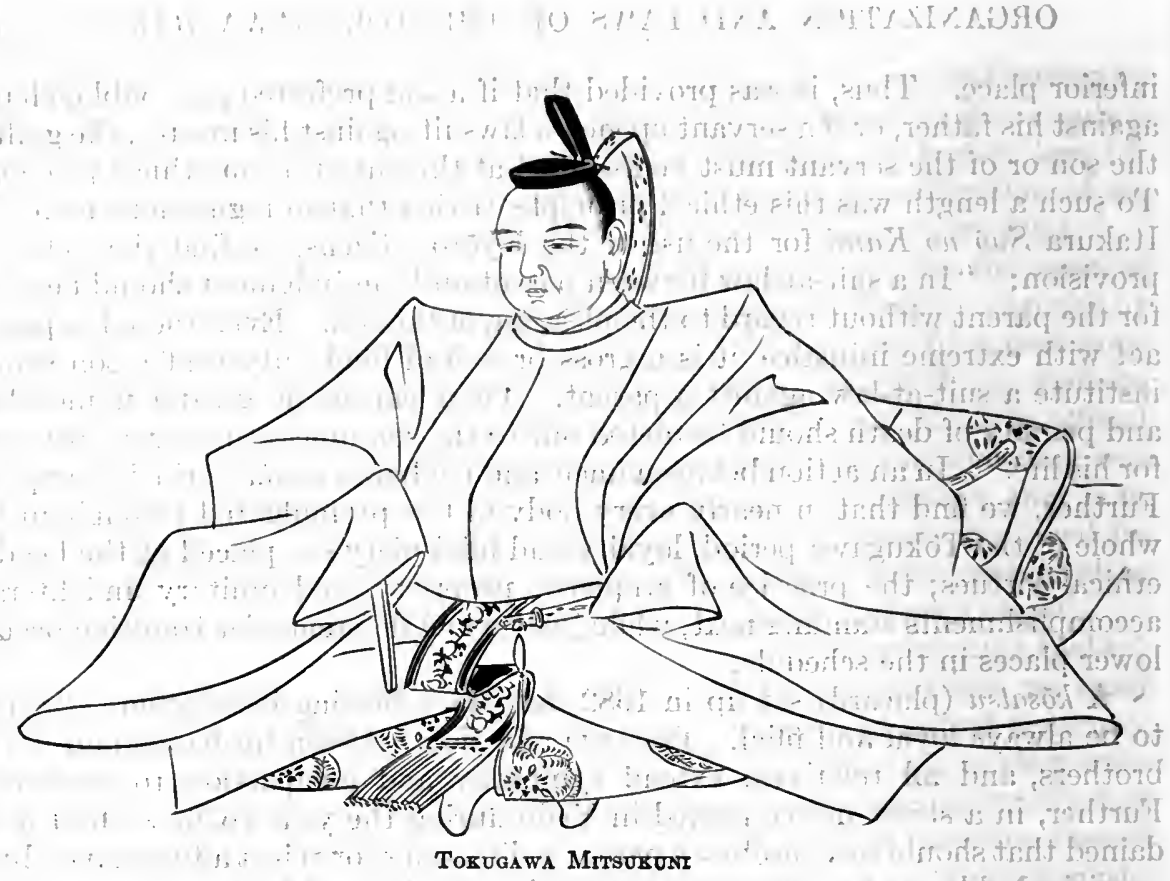

CHAPTER XLIII

\section{REVIVAL OF THE SHINTO CULT}

\section{$R Y \overline{O B}$ SHINTŌ}

THE reader is aware that early in the ninth century the celebrated Buddhist priest, Kūkai (Kōbō Daishi), compounded out of Buddhism and Shintō a system of doctrine called Ryōbu Shintō. The salient feature of this mixed creed was the theory that the Shintō deities were transmigrations of Buddhist divinities. Thereafter, Buddhism became the national religion, which position it held until the days of the Tokugawa shoguns, when it was supplanted among educated Japanese by the moral philosophy of Confucius, as interpreted by Chutsz, Wang Yang-ming, and others:

\section{REVIVAL OF PURE SHINTŌ}

The enthusiasm and the intolerance showed by the disciples of Chinese philosophy produced a reaction in Japan, and this culminated in the revival of Shintō, during which process the anomalous position occupied by the shögun towards the sovereign was clearly demonstrated, and the fact contributed materially to the downfall of the Tokugawa. It was by Ieyasu himself that national thought was turned into the new channel, though it need scarcely be said that the founder of the Tokugawa shōgunate had no premonition of any results injurious to the sway of his own house.

After the battle of Sekigahara had established his administrative supremacy, and after he had retired from the shōgunate in favour of Hidetada, Ieyasu 
applied himself during his residence at Sumpu to collecting old manuscripts, and shortly before his death he directed that the Japanese section of the library thus formed should be handed over to his eighth son, the baron of Owari, and the Chinese portion to his ninth son, the baron of Kii. Another great library was subsequently brought together by a grandson of Ieyasu, the celebrated Mitsukuni $(1628-1700)$, baron of Mito, who, from his youthful days, devoted attention to Japanese learning, and, assembling a number of eminent scholars, composed the Dai Nihon-shi (History of Great Japan), which consisted of 240 volumes and became thenceforth the standard history of the country. It is stated that the expenditures involved in producing this history, together with a five-hundredvolume work on the ceremonies of the Imperial Court, amounted to one-third of the Mito revenues, a sum of about 700,000 ry $\overline{0}$. There can be little doubt that Mitsukuni's proximate purpose in undertaking the colossal work was to controvert a theory advanced by Hayashi Razan that the Emperor of Japan was descended from the Chinese prince, Tai Peh, of $\mathrm{Wu}$, of the Yin dynasty.

Chiefly concerned in the compilation of the Dai Nihon-shi were Asaka Kaku, Kuriyama Gen, and Miyake Atsuaki. They excluded the Empress Jingo from the successive dynasties; they included the Emperor Kọbun in the history proper, and they declared the legitimacy of the Southern Court as against the Northern. But in the volume devoted to enumeration of the constituents of the empire, they omitted the islands of Ezo and Ryūkyü. This profound study of ancient history could not fail to expose the fact that the shogunate usurped powers which properly belonged to the sovereign and to the sovereign alone. But Mitsukuni and his collaborators did not give prominence to this feature. They confined themselves rather to historical details.

It was reserved for four other men to lay bare the facts of the Mikado's divine right and to rehabilitate the Shintō cult. These men were Kada Azumamaro (1668-1736), Kamo Mabuchi (1697-1769), Motoori Norinaga (17301801), and Hirata Atsutane (17761834). Associated with them were other scholars of less note, but these are overshadowed by the four great masters. Kada, indeed, did notachieve much more than the restoration of pure Japanese literature to the pedestal upon which it deserved to stand. That in itself was no insignificant task, for during the five centuries that separated the Gen-Hei struggle from the establishment of the Tokugawa family, Japanese books had shared the destruction that overtook everything in this

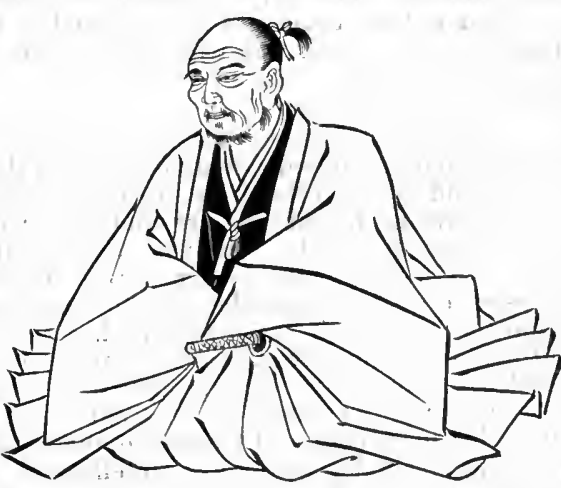

Kamo MaBUCHI period of wasting warfare, and the Japanese language itself had undergone such change that to read and understand ancient books, like the Kojiki and the Manyō-shì, demanded a special course of study. To make that study and to prepare the path for others was Kada's task, and he performed it so conscientiously that his successors were at once able to obtain access to the treasures of ancient literature." It was reserved for Mabuchi to take the lead in championing. Japanese ethical systems as against Chinese. By his writings we are taught the nature of the struggle waged throughout the Tokugawa period be- 
tween Chinese philosophy and Japanese ethics, and we are enabled, also, to réach a lucid understanding of the Shinto cult as understood by the Japanese themselves. The simplest route to that understanding is to let the four masters speak briefly, each for himself:

Learning is a matter in which the highest interests of the empire are involved, and no man ought to be vain enough to imagine that he is able by himself to develop it thoroughly.

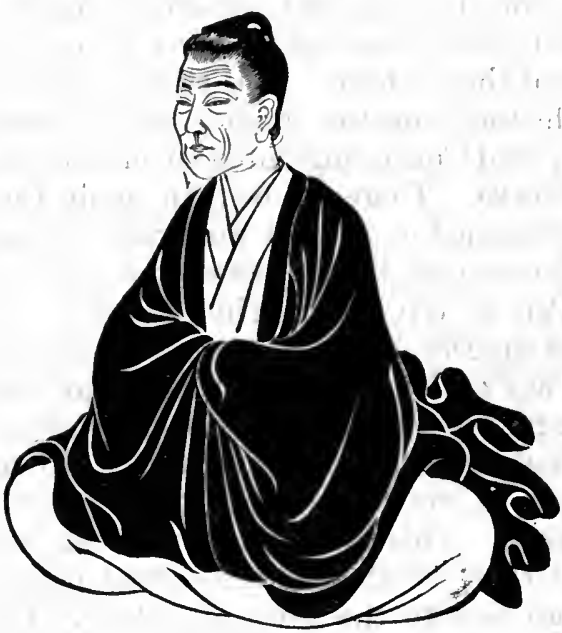

Motoori Norinaga

Nor should the student blindly adhere to the opinions of his teacher. : Anyone who desires to study Japanese literature should first àcquire a good knowledge of Chinese, and then pass over to the Manyo-shu, from which he may discover the ancient principles of the divine age. If he resolve bravely to love and admire antiquity, there is no reason why he should fail to acquire the ancient style in poetry as well as in other things. In ancient times, as the poet expressed only the genuine sentiments of his heart, his style was naturally direct, but since the practice of writing upon subjects chosen by lot came into vogue, the language of poetry has become ornate and the ideas forced. The expression of fictitious sentiment about the relations of the sexes and miscellaneous subjects is not genuine poetry. [Kada Azumamaro.]

Wherein lies the value of a rule of conduct? In its conducing to the good order of the State. The Chinese for ages past have had a succession of different dynasties to rule over them, but Japan has been faithful to one uninterrupted line of sovereigns. Every Chinese dynasty was founded upon rebellion and parricide. Sometimes, a powerful ruler was able to transmit his authority to his son and grandson, but they, in their turn, were inevitably deposed and murdered, and the country was in a perpetual state of civil war. A philosophy which produces such effects must be founded on a false system. When Confucianism was first introduced into Japan, the simple-minded people, deceived by its plausible appearance, accepted it with eagerness and allowed it to spread its influence everywhere. The consequence was the civil war which broke out immediately after the death of Tenji Tenno, in A.D. 671, between that Emperor's brother and son, which only came to an end in 672 by the suicide of the latter.

In the eighth century, the Chinese costume and etiquette were adopted by the Court. This foreign pomp and splendour covered the rapid depravation of men's hearts, and created a wide gulf between the Mikado and his people. So long as the sovereign maintains a simple style of living, the subjects are contented with their own hard lot. Their wants are few and they are easily ruled. But if a sovereign has a magnificent palace, gorgeous clothing, and crowds of finely dressed women to wait on him, the sight of these things must cause in others a desire to possess themselves of the same luxuries; and if they are not strong enough to take them by force, their envy is excited. Had the Mikado continued to live in a house roofed with shingles and having walls of mud, to carry his sword in a scabbard wound round with the tendrils of some creeping plant, and to go to the chase carrying his bow and arrows, as was the ancient custom, the present state of things would never have come about. ${ }^{[21}$ But since the introduction of Chinese manners, the sovereign, while occupying a highly dignified place, has been degraded to the intellectual level of a woman. The power fell into the hands of servants, and although they never actually assumed the title, they were sovereigns in fact, while the Mikado became an utter nullity.

In ancient times, when men's dispositions were straightforward, a complicated system of morals was unnecessary. It would naturally happen that bad acts might occasionally be committed, but the integrity of men's dispositions would prevent the evil from being concealed and growing in extent. In these days, therefore, it was unnecessary to have a doctrine of right and wrong. But the Chinese, being bad at heart, were only good externally, in spite of the teaching they received, and their evil acts became of such magnitude that society was thrown into disorder. The Japanese, being straightforward, could do without teaching. It has been alleged that, as the Japanese had no names for "benevolence," "righteousness," "propriety," "sagacity," and "truth," they must have been without these principles. But these things exist in every country, in the same way as the four seasons which make their annual rounds. In the spring, the weather does not become mild all at once, or in the summer, hot. Nature proceeds by gradual steps. According to the view of the Chinese, it is not 
summer or spring unless it becomes hot or mild all of a sudden. Their principles sound very plausible but are unpractical. [Kamo Mabuchi.]

Japan is the country which gave birth to the goddess of the Sun, which fact proves its superiority over all other countries that also enjoy her favours. The goddess having endowed her grandson with the Three Sacred Treasures, proclaimed him sovereign of Japan for ever and ever. His descendants shall continue to rule it as long as the heavens and earth endure. Being invested with this complete authority, all the gods under heaven and all mankind submitted to him, with the exception of a few wretches who were quickly subdued. To the end of time each Mikado is the son of the goddess. His mind is in perfect harmony of thought and feeling with hers. He does not seek out new inventions but rules in accordance with precedents which date from the Age of the Gods, and if he is ever in doubt, he has recourse to divination, which reveals to him the mind of the great goddess. In this way the Age of the Gods and the present age are not two ages, but one, for not only the Mikado but also his ministers and people act up to the tradition of the divine age. Hence, in ancient times, the idea of michi, or way, (ethies) was applied to ordinary thoroughfares only, and its application to systems of philosophy, government, morals, religion, and so forth is a foreign notion.

As foreign' countries (China and India, particularly the former) are not the special domain of the Sun goddess, they, have no permanent rulers, and evil spirits, finding a field of action there, have corrupted mankind. In those countries, any bad man who could manage to seize the power became a sovereign. Those who had the upper hand were constantly scheming to maintain their positions, while their inferiors were as constantly on the watch for opportunities to oust them. The most powerful and cunning of these rulers succeeded in taming their subjects, and having secured their position, became an example for others to imitate. In China the name of "holy men" has been given to these persons. But it is an error to count these "holy men" as in themselves supernatural and good beings, superior to the rest of the world as are the gods. The principles they established are called michi (ethics), and may be reduced to two simple rules, namely, to take other people's territory and to keep fast hold of it.

The Chinese "holy men" also invented the Book of Changes, by which they pretended to discover the workings of the universe; a vain attempt, since it is impossible for man with his limited intelligence to discover the principles which govern the acts of the gods. In imitation of them, the Chinese nation has since given itself up to philosophizing, to which are to be attributed its constant internal dissensions. 'When things go right of themselves, it is best to leave them alone. In ancient times, although there was no prosy system in Japan, there were no popular disturbances, and the empire was peacefully ruled. It is because the Japanese were truly moral in their practice that they required no theory of morals, and the fuss made by the Chinese about theoretical morals is owing to their laxity in practice. It is not wonderful that students of Chinese literature should despise their own country for being without a system of morals, but that the Japanese, who were acquainted with their own ancient literature, should pretend that Japan too had such a system, simply out of a feeling of envy, is ridiculous.

When Chinese literature was imported into Japan, the people adopted many Chinese ideas, laws, customs, and practices, which they so mixed up with their own that it became necessary to adopt a special name for the ancient native customs, which were in consequence called Kami no michi or Shintō, the word "michi" being applied in the same sense as the Chinese $T a o$, and Kami because of their divine origin. These native customs survived only in ceremonies with which the native gods are worshipped. Every event in the universe is the act of the gods. They direct the changes of the seasons, the wind and the rain, the good and bad fortune of States and individuals. Some of the gods are good, others bad, and their acts "partake of "their own natures. Buddhists attribute events to "retribution" (Inga), while the Chinese ascribe them to be the "decree of heaven" (Tien ming). This latter is a phrase invented by the so-called "holy men" to justify murdering sovereigns and seizing their dominions. As neither heaven nor earth has a mind, they cannot issue decrees. If heaven really could issue decrees, it would certainly protect the good rulers and take care to prevent bad men from seizing the power, and, in general, while the good would prosper,' the bad would suffer misfortune. But in reality we find many instances of the reverse. Whenever anything goes wrong in the world, it is to be attributed to the action of the evil gods called "gods of crookedness," whose power is so great that the Sun goddess and the Creatorgods are sometimes unable to restrain them; much less are human beings able to resist their influence. The prosperity of the wicked and the misfortunes of the good, which seem opposed to ordinary juistice, are their doing. The Chinese, not possessing the traditions of the Divine Age, were ignorant of this truth, and were driven to invent the theory of heaven's decrees.

The eternal endurance of the dynasty of the Mikado is a complete proof that the "way," called Kami no michi or Shintō, infinitely surpasses the systems of all other countries. The "holy men" of China were merely unsuccessful rebels. The Mikado is the sovereign appointed by the pair of deities, Izanagi and Izanami, who created this country. The Sun. goddess never said, "Disobey the Mikado if he be bad," and therefore, whether he be good or bad, no one attempts to deprive him of his authority. He is the Immovable Ruler who must endure to the end of time, as long as the sun and moon continue to shine. In ancient language the Mikado was called a'god, and that is his real character. Duty, therefore, consists in obey- 
ing him implieitly without questioning his acts. During the Middle Ages, such men as Hōjō Yoshitoki, Hojo Yasutoki, Ashikaga Takauji; and others, violated this duty (michi) and took up arms against him. Their disobedience to the Mikado is attributable to the influence of the Chinese learning. "This "way" was established by Izanagi and Izanami and delivered by them to the Sun goddess, who handed it down, and this is why it is called the "way of the gods."

The nature of this "way" is to be learned by studying the Kojiki and ancient writings, but mankind has been turned aside from it, by the spirits, of crookedness, to Buddhism and Chinese philosophy. The various doctrines taught under the name of Shintō are without authority. Human beings, having been produced by the spirit of the two ereative deities, are naturally endowed with the knowledge of what they ought to do, and what they ought to refrain from doing. It is unnecessary for them to trouble their heads with systems of morality. If a system of morals were necessary, men would be inferior to animals, all of whom are endowed with the knowledge of what they ought to do, only in an inferior degree to man. If wliat the Chinese call benevolence, modesty, filial piety, propriety, love, fidelity, and truth really constituted the duty of man, they would be so recognized and practised without any teaching; but since they were invented by the so-called "holy men" as instruments for ruling a viciously inclined population, it became necessary to insist on more than the aetual duty of man. Consequently, although plenty of men profess these doctrines, the number of those that practise them is very small. Violations of this teaching were attributed to human lusts. As human lusts are a part of man's nature, they must be a part of the harmony of the universe, and cannot be wrong according to the Chinese theory. It was the vicious nature of the Chinese that necessitated such strict rules, as, for instance, that persons descended from a common ancestor, no matter how distantly related, should not intermarry. These rules, not being founded on the harmony of the universe, were not in accordanee with human feelings and were therefore seldom obeved.

In. ancient times, Japanese refrained from intermarriage among children of the same mother, but the distance between the noble and the mean was duly preserved." Thus, the country was spontaneously well governed, in accordance with the "way" established by the gods. Just as the Mikado worshipped the gods in heaven and earth, so his people pray, to the good gods in order to obtain blessings, and perform rites in honour of the bad gods in order to avert their displeasure. If they committed crimes or defiled themselves, they employed the usual methods of purification tauglit them by their own hearts. Since there are bad as well as good gods, it is neessary to propitiate them with offerings of agrecable food; playing the lute, blowing the flute, singing and dancing, and whatever else is likely to put them in good humour.

It has been asked whether the Kami no michi is not the same as the Taoism of Laotzu. Laotzu hated the vain conceits of the Chinese scholars, and honoured naturalness, from which a resemblance may be argued; but as he was born in a dirty country not under special proteetion of the Sun goddess, he had heard only the theories of the succession of so-called "holy" men," and what he believed to be naturalness was simply what they called natural. He did not know that the gods are the authors of every human aetion, and this-ignorance constituted a cause of radical difference. To have acquired the knowledge that there is no michi (ethics)' to be learned and practised is really to have learned to practise the "way of the gods."

Many miracles occurred in the Age of the Gods, the truth of which was not disputed until men were taught by the Chinese philosophy to analyse the acts of the gods by the aid of their own feeble intelligence. The reason assigned for disbelieving in miracles is that they cannot be explained; but in fact, although the Age of the Gods has passed away, wondrous miracles surround us on all sides. For instance, is the earth suspended in space or does it, rest upon something else? If it be said that the earth rests upon something else, then what is it that supports that something else? According to one Chinese theory, the earth is a globe suspended in space with the heavens revolving round it: But even if we suppose the heavens to be full of air, no ordinary principles will account for the land and sea being suspended in space withont moving. The explanation offered is as miraculous as the supposition previously made. It seems plausible enough to say that the heavens, are merely air and are without any definite form. If this be true, there is nothing but air outside the earth, and this air must be infinite or finite in extent. If it is infinite in extent, we cannot fix any point, as its centre, so that it is impossible to understand why the earth should be at rest; for if it, be not in the centre it eannot be at rest. If it be finite, what eauses the air to condense in one particular spot, and what position shall we assign to it?

In any case all these things are miraculous and strange. How absurd to take these miracles for granted, and at the same time to disbelieve in the wonders of the Divine Age! Think again of the human body. Seeing with the eyes, hearing with the ears, speaking with the mouth, walking on the feet, and performing all manner of acts with the hands are strange, things; so also the flight of birds and inseets through the air, the blossoming of plants and trees, the ripening of their fruits and seeds are strange; and the strangest of all is the transformation of the fox and the badger into human form. If rats, weasels, and certain birds see in the dark, why should not the gods have been endowed with a similar faculty?

The facts that many: of the gods are invisible now and have never been visible furnish no argument against their existence. Existence ean be made known to us by other senses than. 
those of sight, such as odour or sound; while the wind, which is neither seen, heard, nor smelt is recognized by the impression which it makes upon our bodies. [Motoori Norinaga]:

จ Although numbers of Japanese cannot state with any certainty from what gods they are descended; all of them have tribal names (kabaine), which were originally bestowed by the Mikado, and those who make it their province to study genealogies, can tell from a man's ordinary surname who his remotest ancestor must have becn. "From the fact of the divine descent of the Jápanese people proceeds their immeasurable superiority to the natives of other countries in courage and intelligence. ${ }^{1}$

The accounts given in other countries, whether by Buddhism or by Chinese philosophy, of the form of the heavens and earth and the manner in which they came into existence, are all inventions of men who exercised all their ingenuity over the problem; and inferred that -such things must actually be the case: As for the Indian account, it is nonsense fit only to deceive women and children, and I do not think it worthy of reflection. 'The Chinese theories, on the other hand; are based upon profound philosophical speculations and sound extremely plausible, but what they call the absolute and the finite, the positive and negative essences, the eight diagrams, and the five elements, are not real existences, but are fictitious names invented by the philosophers and freely applied in every direction. They say that the whole universe was produced by agencies, and that nothing exists which independent of them. But all these statements are nonsense. The principles which animate the universe are beyond the power of analysis, nor can they be fathomed by human intelligence, and all statements founded upon pretended explanations of them are to be rejected. $\rightarrow$ All that man can think and know is limited by the powers of sight, feeling, and calculation, and what goes beyond these powers, cannot be known by any amount of thinking.

The Chinese accounts sound as if based upon profound principles, and one fancies that they must be right, while the Japanese accounts sound shallow and utterly unfounded in reason. But the former are lies while the latter are the truth, so that as time goes on and thought attains greater accuracy, the erroneous nature of these falsehoods becomes even more apparent while the true tradition remains intact. In modern times, men from countries lying far off in the West have voyaged all round the seas as their inclinations prompted them, and have ascertained the actual shape of the earth. They have discovered that the earth is round and that the sun and the moon revolve round it in a vertical direction, and it may thus be conjectured how full of errors are all the ancient Chinese accounts, and how impossible it is to believe anything that professes to be determined a priori. But when we come to compare our ancient traditions as to the origin of a thing in the midst of space and its subsequent development, with what has been ascertained to be the actual shape of the earth, we find that there is not the slightest error, and this result confirms the truth of our ancient traditions. But although accurate discoveries made by the men of the Far West as to the actual shape of the earth and its position in space infinitely surpass the theories of the Chinese, still that is only a matter of calculation. There are many other things actually known to exist which cannot be solved by that means; and still less is it possible to solve the question of how the earth, sun, and moon came to assume their form. Probably those countries possess theories of their own, but whatever they may be, they can but be guesses after the event, and probably resemble the Indian and the Chinese theories.

The most fearful crimes which a man commits go unpunished by society so long as they are undiscovered, but they draw down on him the hatred of the invisible gods. The attainment of happiness by performing good acts is regulated by the same law. Even if the gods do not punish secret sins by the usual penalties of law, they inflict diseases, misfortunes, short life, and extermination of the race. Never mind the praise or blame of fellow men, but act so that you need not be ashamed before the gods of the Unseen. If you desire to practise true virtue, learn to stand in awe of the Unseen, and that will prevent you from doing wrong. Make a vow to the god who rules over the Unseen and eultivate the conscience implanted in you, and then you will never wander from the way. You cannot hope to live more than one hundred years in the most favourable circumstances, but as you will go to the unscen realm of Okuninushi after death and be subject to his rule, learn betimes to bow down before heaven. The spirit's of the dead continue to exist in the unseen world which is everywhere about us, and they all become gods of varying character and degrees of influence. Some reside in temples built in their honour; others hover near their tombs, and they continue to render service to their princes, parents, wives, and children as when in their body. [Hirata Atsutane. $]^{2}$

The great loyalist of the eleventh century, Kitabatake Chikafusa, had fully demonstrated the divine title of the sovereigns of Japan, but his work reached only a narrow circle of readers, and his arguments were not re-enforced by the sentiment of the era. Very different was the case in the days of the four literati

[ ${ }^{1}$ Although Hirata claims the superiority for his own countrymen, he frankly acknowledges the achievements of the Dutch in natural science.]

[ ${ }^{2}$ The above extracts are all taken from Sir Ernest Satow's Revival of Pure Shintō. in the appendix to Vol. III. of the "Transactions of the Asiatic Society of Japan."] 
quoted above. The arrogant and intolerant demeanour of Japanese students of Chinese philosophy who elevated the Middle Kingdom on a pedestal far above the head of their own country, gradually provoked bitter resentment among patriotic Japanese, thus lending collateral strength to the movement which took place in the seventeenth and eighteenth centuries in favour of reversion to the customs and canons of old times.

As soon as attention was intelligently concentrated on the history of the past, it was clearly perceived that, in remote antiquity, the empire had always been administered from the Throne, and, further, that the functions arrogated to themselves by the Hojōo, the Oda, the Toyotomi, and the Tokugawa were pure usurpations, which deprived the Imperial Court of the place properly belonging to it in the State polity. Just when this reaction was developing strength, the dispute about the title of the ex-Emperor occurred in Kyoto, and furnished an object lesson more eloquent than any written thesis. 'The situation was complicated by the question of foreign intercourse, but this will be treated separately.

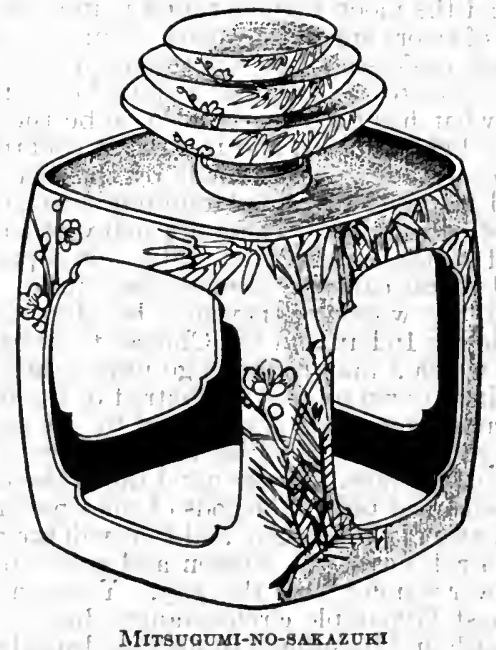

(Sake Cups used only on Happy Occasions such as. Weddings and Now Year Days) 


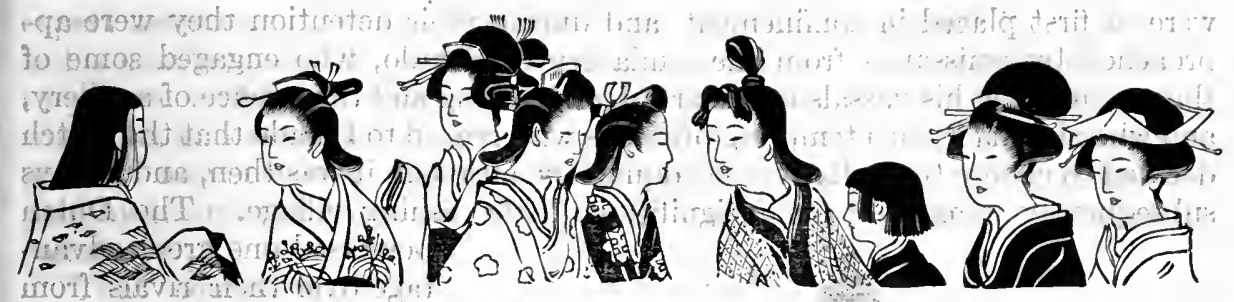

Difrerent Styles of Coiffure

CHAPTER XLIV

\section{FOREIGN RELATIONS AND THE DECLINE OF THE TOKUGAWA}

\section{FOREIGN TRADE IN THE SEVENTEENTH CENTURY}

From what has been stated in previous chapters, it is clearly understood that Nobunaga, Hideyoshi, and Ieyasu were all well disposed towards foreign intercourse and trade, and that the Tokugawa chief made even more earnest endeavours than Hideyoshi to differentiate between Christianity and commerce, so that the fate of the former might not overtake the latter. Ieyasu, indeed, seems to have kept three objects steadfastly in view, namely, the development of oversea trade, the acquisition of a mercantile marine, and the prosecution of mining enterprise. To the Spaniards, to the Portuguese, to the English, and to the Dutch, he offered a site for a settlement in a suburb of Yedo, and had the offer been accepted, Japan might never have been closed to foreign intercoursc. At that time the policy of the empire was free trade. There were no customs dues, though it was expected that the foreign merchants would make liberal presents to the feudatory into whose port they carried their wares. The Tokugawa baron gave plain evidence that he regarded commerce with the outer world as a source of wealth, and that he wished to attract it to his own domains. On more than one occasion he sent an envoy to Manila to urge the opening of trade with the regions in the vicinity of Yedo, and to ask the Spaniards for expert naval architects. His attitude is well shown by a law enacted in 1602:

If any foreign vessel by stress of weather is obliged to touch at any principality or to put into any harbour of Japan, we order that, whoever these foreigners may be, absolutely nothing whatever that belongs to them, or that they may have brought in their ship, shall be taken from them. Likewise, we rigorously prohibit the use of any violence in the purchase or sale of any of the commodities brought by their ship, and if it is not convenient for the merchants of the ship to remain in the port they have entered, they may pass to any other port that may suit them, and therein buy and sell in full freedom. Likewise, we order, in a general manner, that foreigners may freely reside in any part of Japan they choose, but we rigorously forbid them to propagate their faith.

In the year 1605 , the Tokugawa chief granted a permit to the Dutch for trade in Japan, his expectation being that the ships which they undertook to send every year would make Uraga, or some other place, near Yedo, their port of entry. In this he was disappointed. The first Hollanders that set foot in Japan were eighteen survivors of the crew of the wrecked Liefde. These men 
were at first placed in confinement, and during their detention they were approached by emissaries from the feudatory of Hirado, who engaged some of them to instruct his vassals in the art of gun casting and the science of artillery, and who also made such tempting promises with regard to Hirado that the Dutch decided to choose that place for headquarters, although it was then, and always subsequently remained, an insignificant little fishing village. The Duteh possessed one great advàntage over their rivals from Manila and Macao: they were prepared to carry on commerce while eschewing religious propagandism. It was this element of the situation that the Hirado feudatory shrewdly appreciated / when he enticed the Dutchmen to make Hirado their port of entry.

With regard to the desire of Ieyasu to exploit the mining resources of his country, the fact is demonstrated by an incident which occurred at the time. The governor-general of the Philippines (Rodrigo Vivero y Velasco), whose ship had been cast away on the coast of Japan while en route for Acapulco, had an interview with Ieyasu, and in response to the latter's application for fifty mining experts, the spaniards made a proposal, to the terms of which, onerous as they were, Ieyasu agrecd; namely that one-half of the produce of the mines should go to the miners; that the other half should be divided equally between I ey asu and the King of Spain; that the latter might send officials to Japan to protect his mining interests, and that these officials might be accompanied by priests; who would have the right to erect public churches and to hold religious services there. ${ }^{1}$ These things happened in 1609. Previous to that time, the Tokugawa chief had repeatedly impósed a strict veto on Christian propagandism; yet we now find him removing that veto partially, for the sake of obtaining foreign

['. It is to be understood, of course, that these ministrations were intended to be limited to Spaniards resident in Japan.] 
expert assistance Like Hideyoshi, Ieyasu had full confidence in himself and in his countrymen. He did not doubt his ability to deal with emergencies if they arose, and he made no sacrifice to timidity. But his courageous policy,died with him, and the miners never came. Moreover, the Spaniards seemed incapable of any successful effort to establish trade with Japan. "Fitful visits were paid by their vessels at Uraga, but the Portuguese continued to monopolize the commerce.

That commerce, however, was not without rude interruptions. One, especially memorable, occurred at the very time when Rodrigo's vessel was cast away. "In a quarrel at Macao some Japanese sailors lost their lives, and their comrades were compelled by the commandant, Pessoa, to sign a declaration exonerating the Portuguese. The signatories, however, told a different tale when they returned to Japan, and their feudal chief, the daimyo of Arima, was much incensed, as also was leyasu In the following year (1609), this same Pessoa arrived at Nagasaki in command of the Madre de Dios, carrying twelve Jesuits and a cargo worth a million crowns. Ieyasu ordered the Arima feudatory to seize her. 1 Surrounded by an attacking force of twelve hundred men in boats, Pessoa fought his ship for three days, and then, exploding her magazine, sent her to the ibottom with her crew, her passenger-priests, and her cargo.".

no Fifty-eight years before the date of this occurrence, Xavier had conveyed to Charles V a warning that if ships from New Spain "attempted to conquer the Japanese by force of arms, they would have to do with a people no less covetous than warlike, who seem likely to capture any hostile fleet, however strong." It was a just appreciation. The Portuguese naturally sought to obtain satisfaction for the fate of Pessoa, but Ieyasu would not even reply to their demands, though he made no attempt to prevent the resumption of trade with Macao.

\section{OPENING OF ENGLISH AND DUTCH TRADE}

In the year 1609 , Ieyasu had reason to expect that the Spaniards and the Dutch would both open trade with Japan. His expectation was disappointed in the case of the Spaniards, but, two years later, the Dutch flag was seen in Japanese waters. It was flown by the Brach, a merchantman which, sailing from Patani, reached Hirado with a cargo of pepper, cloth, ivory, silk, and lead. Two envoys were on board the vessel, and her arrival in Japan nearly synchronized with the coming of the Spanish embassy from Manila, which had been despatched expressly for the purpose of "settling the matter regarding the Hollanders." Nevertheless, the Dutch obtained a liberal patent from Ieyasu.

Twelve years previously, the merchants of London, stimulated by a spirit of rivalry with the Dutch, had organized the East India Company, which at once began to send ships eastward. As soon as news came that the Dutch were about to establish a trading station in Japan, the East India Company: issued orders that the Clove, commanded by Saris, should proceed to the Far Eastern islands. The Clove reached Hirado on the 11th of June, 1613. Her master, Saris, soon proved that he did not possess the capacity essential to success. He was self-opinionated, suspicious, and of shallow judgment. Though strongly urged by Will Adams to make Uraga the seat of the new trade; though convinced of the excellence of the harbour there, and though instructed as to the great advantage of proximity to the shōgun's capital, he appears to have harboured some distrust of Adams, for he finally selected Hirado in preference to Uraga, "which was much as though a German going to England to open trade should prefer to 
establish himself at Dover or Folkestone rather than in the vicinity of London." Nevertheless he received from Ieyasu a charter so liberal that it plainly displayed the mood of the Tokugawa shōgun towards foreign trade:-

(1) The ship that has now come for the first time from England over the sea to Japan may carry on trade of all kinds without hindrance. With regard to future visits (of English ships), permission will be given in regard to all matters.

(2) With regard to the cargoes of ships, requisition will be made by list according to the requirements of the shōgunate.

(3) English ships are free to visit any port in Japan. If disabled by storms they may put' into any harbour.

(4) Ground in Yedo in the place which they may desire shall be given to the English; and they may erect houses and reside and trade there. They shall be at liberty to return to their country whenever they wish to do so, and to dispose as they like of the houses they have ereeted.

(5) If an Englishman dies in Japan of disease or any other cause, his effects shall be handed over without fail.

(6) Forced sales of cargo and violence shall not take place.

(7) If one of the English should commit an offence, he should be sentenced by the English general according to the gravity of his offence. ${ }^{1}$

The terms of the above show that Saris was expected to make Yedo his headquarters. Had he done so he would have been practically freelfrom competition; would have had the eastern capital of the empire for market, and would have avoided many expenses and inconveniences connected with residence elsewhere. But he did not rise to the occasion, and the result of his mistaken

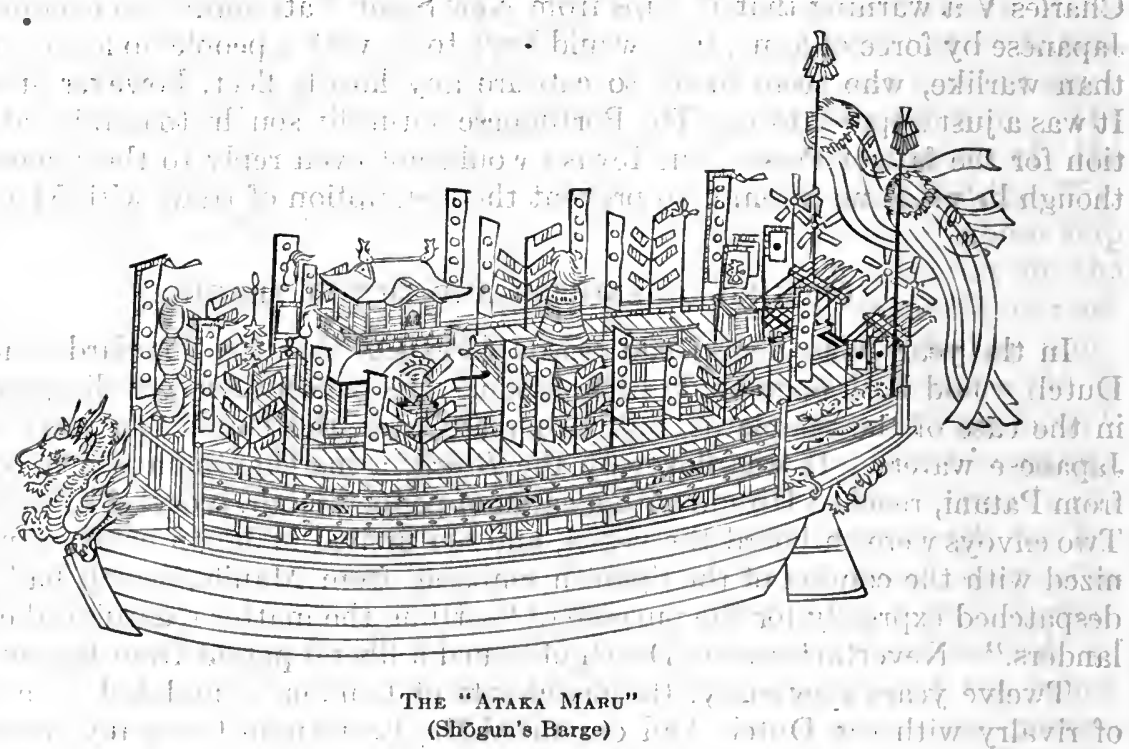

choice as well as of bad management was that, ten years later (1623), the English factory at Hirado had to be closed, the losses incurred there' having aggregated $£ 2000-\$ 10,000$. It has to be noted that, a few months after the death of Ieyasu, the above charter underwent a radical modification. The original document threw open to the English every port in Japan; the revised document limited them to Hirado. But this restriction may be indirectly traced to the blunder of not accepting a settlement in Yedo and a port at Uraga. For the foreign policy of the Tokugawa was largely swayed by an apprehension that the Kyūshü feudatories, many of whom were not over-well disposed to the rule of

[' In this article, Ieyasu recognizes the principle of extra-territorial jurisdiction.] 
the Bakufu, might derive from the assistance of foreign trade such a fleet and such an armament as would ultimately enable them to overthrow the Tokugawa. Therefore, the precaution was adopted of confining the English and the Dutch to Hirado, the domain of a feudatory too petty to become formidable, and to Nagasaki, which was one of the four Imperial cities, the other three being Yedo, Kyōto, and Ōsaka:

It is easy to see that an English factory in Yedo and English ships at Uraga would have strengthened the Tokugawa ruler's hand instead of supplying engines of war to his political foes; and it must further be noted that the question of locality had another injurious outcome. For alike at Hirado and at Nagasaki, the foreign traders "were exposed to a crippling competition at the hands of rich Ōsaka monopolists, who, as representing an Imperial city and therefore being pledged to the Tokugawa interests, enjoyed special indulgences from the Bakufu. These shrewd traders who were then, as they are now, the merchantprinces of Japan, not only drew a ring around Hirado, but also sent vessels on their own account to Cochin China, Siam, Tonkin, Cambodia, and other foreign lands with which the English and the Dutch carried on trade." One can scarcely be surprised that Cocks, the successor of Saris, wrote, in 1620, "which maketh me altogether aweary of Japan."

It is, however, certain that the closure of the English factory at Hirado was voluntary; from the beginning to the end no serious friction had occurred between the English and the Japanese. When the former withdrew from the Japanese trade, their houses and stores at Hirado were not sold, but were left in the safekeeping of the local feudatory, who promised to restore them to their original owners should the English company desire to re-open business in Japan. The company did think of doing so on more than one occasion, but the idea did not mature until the year 1673, when a merchantman, the Return, was sent to obtain permission. "The Japanese authorities, after mature reflection, made answer that as the king of England was married to a Portuguese princess, British subjects could not be permitted to visit Japan. That this reply was suggested by the Dutch is very probable; that it truly reflected the feeling of the Japanese Government towards Roman Catholics is certain."

\section{END OF THE PORTUGUESE TRADE WITH JAPAN}

In the year 1624, the expulsion of the Spaniards from Japan took place, and in 1638 the Portuguese met the same fate. Two years prior to the latter event, the Yedo Bakufu adopted a measure which effectually terminated foreign intercourse: They ruled that to leave the country, or to attempt to do so, should constitute a capital crime; that any Japanese subject residing abroad should be executed if he returned; that the entire kith and kin of the Spaniards in Japan should be expelled, and that no ships of ocean-going dimensions should be built in Japan. This meant not only the driving out of all professing Christians, but also the imprisonment of the entire nation within the limits of the Japanese islands, as well as an effectual veto on the growth of the mercantile marine. It is worth noting that no act of spoliation was practised against these tabooed people. Thus, when those indicated by the edict - to the number of 287 left the country for Macao, they were allowed to carry: away with them their whole fortunes.

The expulsion of the Spaniards did not leave the Portuguese in an improved [' Encyclopoedia Britannica (11th Edition); article "Japan," by Brinkley.] 
condition. Humiliating restrictions continued to be imposed upon them. If a foreign priest were found upon any galleon bound for Japan; such priest and the whole of the crew of the galleon were liable to be executed, and many other irksome conditions were instituted for the control of the trade. Nor had the aliens even the satisfaction of an open market, for all the goods carried in their galleons had to be sold at a fixed price to a ring of licensed Japanese merchants from Ōsaka. In spite of all these deterrents, however, the Portuguese continued to send galleons to Nagasaki until the year 1637, when their alleged connexion with the Shimabara rebellion induced the Japanese to issue the final edict that heneeforth any Portuguese ship coming to Japan should be burned, together with her cargo, and everyone on board should be executed.

This law was not enforced with any undue haste; ample time was given for compliance with its provisions. Possibly misled by this procrastination, the Portuguese at Macao continued to strive for the re-establishment of commercial relations until 1640, when a very sad event put an end finally to all intercourse. Four aged men, selected from among the most respected citizens of Macao, were sent to Nagasaki as ambassadors. Their ships carried rich presents and an earnest petition for the renewal of commercial intercourse. They were at once imprisoned, and having declined to save their lives by abjuring the Christian faith, the four old men and fifty-seven of their companions were decapitated, thirteen only being left alive for the purpose of conveying the facts to Macao. To these thirteen there was handed at their departure a document setting forth that, "So long as the sun warms the earth, any Christian bold enough to come to Japan, even if he be King Philip himself or the God of the Christians, shall pay for it with his head." One more effort to restore the old intimacy: was made by the Portuguese in 1647, but it failed signally, and would certainly have entailed sanguinary résults had not the two Portuguese vessels beat a timely retreat.

\section{THE DUTCH AT DESHIMA}

In 1609, the Dutch made their appearance in Japan, and received an excellent welcome. Ieyasu gave them a written promise that "no man should do them any wrong and that they should be maintained and defended as his own vassals." $\mathrm{He}$ also granted them a charter that wherever their ships entered, they should be shown "all manner of help, favour, and assistance." Left free to choose their own trading port, they made the mistake of selecting Hirado, which was eminently unsuited to be a permanent emporium of interstate commerce." Neverthèless, owing partly to their shrewdness, partly to their exclusive possession of the Spice Islands, and partly to their belligerent co-operation with the English against the Spaniards, they succeeded in faring prosperously for a time.

The day came, however, when, being deprived of freedom of trade and limited to dealings with a guild of Nagasaki and Ōsaka merchants, they found their gains seriously affected. Other vicissitudes overtook them, and finally the Japanese concluded that the safest course was to confine the Dutch to some position where, in a moment of emergency, they could easily be brought under Japanese control. Nagasaki was chosen as suitable, and there a Dutch factory was established which, for a time, flourished satisfactorily. From seven to ten Dutch vessels used to enter the port annually - their cargoes valued at some eighty thousand pounds ( $a v d p$.) of silver, and the chief staples of import being silk and piece-goods. Customs duties amounting to five per cent. were levied; 495 pounds of silver had to be paid annually as a rent for the little island of 
Deshima, and every year a mission had to proceed to Yedo from the factory, carrying presents for the chief Bakufu officials, which presents are said to have aggregated some 550 pounds of silver on each occasion. The Dutch traders, nevertheless, found their business profitable owing to purchases of gold and copper, which metals could be procured in Japan at much lower rates than they commanded in Europe. Thus, the now familiar question of an outflow of specie was forced upon Japanese attention at that early date, and, by way of remedy, the Government adopted, in 1790 , the policy of restricting to one vessel annually the Dutch ships entering Nagasaki, and forbidding that vessel to carry away more than 350 tons of copper.

boteverats

\section{EFFECTS PRODUCED UPON JAPAN BY THE POLICY OF EXCLUSION}

Whatever losses Japan's policy of seclusion caused to the nations which were its victims, there can be no doubt that she herself was the chief sufferer. During two and a half centuries she remained without breathing the atmosphere of international competition, or deriving inspiration from an exchange of ideas with other countries. While the world moved steadily forward, Japan stood practically unchanging, and when ultimately she emerged into contact with the Occident, she found herself separated by an immense interval from the material civilization it had developed.

The contrast between the Japan of the middle of the sixteenth and that of the middle of the seventeenth century has often been made by the historian of foreign influence. In 1541 the country was open to foreign trade, foreign civilization and foreign ideas and these were welcomed eagerly and, in accordance with the remarkable natural aptitude of the Japanese for adaptation, were readily assimilated: Not only were foreign traders allowed to come to Japan, but Japanese were allowed to go abroad. And all this was in the line of a long-continued Japanese policy - the policy thanks to which Chinese influence had made itself so strongly felt in Japan, and which had brought in Buddhism and Confucianism, not to speak of arts and letters of foreign provenance.

At the close of the hundred years, in 1641,'all was changed. Japan was absolutely isolated. Foreigners were forbidden to enter, except the Dutch traders who were confined to the little island of Deshima. And natives were forbidden to go out, or to accept at home the religious teachings of foreigners. Only ships suited for the coastwise trade might be built. The nation's intercourse with Occidental civilization was shut off, and its natural power of change and growth through foreign influences was thus held in check. The wonder is that it was not destroyed by this inhibition. The whole story of foreign intercourse as it has so far been told makes it plain that the reason why it was prohibited was in the nature of foreign propaganda and not in any unreadiness of the Japanese for western civilization.

\section{SECOND ERA OF FOREIGN TRADE}

Japan's seclusion was maintained unflinchingly: But, though her goods found a market in China, only during her period of self-effacement, the reputation of her people for military prowess was such that no outside nation thought of forcing her to open her ports. A British seaman, Sir Edward Michelborne, in the sequel of a fight between his two ships and a Japanese junk near Singapore, left' $a$ record that "The Japanese are not allowed to land in any part of India 
with weapons, being a people so desperate and daring that they are feared in all places where they come." Nevertheless, Russian subjects, their shores being contiguous with those of Japan, occasionally found their way as sailors or colonists into the waters of Saghalien, the Kuriles, and Yezo. The Japanese did not then exercise effective control over Yezo, although the island was nominally under their jurisdiction. Its government changed from one hand to another in the centuries that separated the Kamakura epoch from the Tokugawa, and in the latter epoch we find the Matsumae daimy $\bar{o}_{\text {r }}$ ruling all the islands northward of the Tsugaru Straits. But the Matsumae administration contented itself with imposing taxes and left the people severely alone. Thus, when in 1778, a small party of Russians appeared at Nemuro seeking trade, no preparations existed to impose the local government's will on the strangers. They were simply promised an answer in the following year, and that answer proved to be that all Japan's oversea trade must by law be confined to Nagasaki.

The Russians did not attempt to dispute this ruling. They retired quietly: But their two visits had shown them that Yezo was capable of much development, and they gradually began to flock thither as colonists. Officials sent from Japan proper to make an investigation reported that Kamchatka, hitherto a dependency of Japan, had been taken possession of by Russians, who had established themselves in the island of Urup and at other places. The report added that the situation would be altogether lost unless resolute steps were taken to restore it. Unfortunately, the death of the tenth shogun having just then occurred, the Yedo Court found it inconvenient to take action in remote Yezo. Thus, Russian immigration and Japanese inaction continued for some time, and not until 1792 were commissions again despatched from Yedo to inquire and report. They made an exhaustive investigation, and just as it reached the hands of the Bakufu, a large Russian vessel arrived off Nemuro, carrying some shipwrecked Japanese sailors whom her commander offered to restore to their country, accompanying this offer with an application for the opening of trade between Russia and Japan. Negotiations ensued, the result being that Nagasaki was again referred to as the only port where foreign trade might be lawfully conducted, and the Russians, therefore, declared their intention of proceeding thither, a passport being handed to them for the purpose. It does not appear, however, that they availed themselves of this permit, and in the mean while the Yedo commissioners pursued their journey northward, and pulled up a number of boundary posts which had been erected by the Russians in Urup.

The Bakufu now began to appreciate the situation more fully. They took under their own immediate control the eastern half of Yezo, entrusting the western half to Matsumae. The next incident of note was a survey of the northern islands, made in 1800 by the famous mathematician, Ino Tadayoshi, and the despatch of another party of Bakufu investigators. Nothing practical was done, however, and, in 1804, a Russian ship arrived at Nagasaki carrying a number of Japanese castaways and again applying for permission to trade. But it soon appeared that the Bakufu were playing fast and loose with their visitors and that they had no intention of sanctioning general foreign commerce, even at Nagasaki. Incensed by such treatment, the Russians, in 1806, invaded Saghalien, carried away several Japanese soldiers, and partially raided Etorop and other places. They threatened further violence in the following year unless international trade was sanctioned.

The Bakufu had now a serious problem to solve, and their ideas of its solution were almost comical. Thus, one statesman recommended the organization 
of a special force recruited from the ranks of vagrants and criminals and stationed permanently in the northern islands. A more practical programme was the formation of a local militia. But neither of these suggestions obtained approval, nor was anything done beyond removing the Matsumae feudatory and placing the whole of the islands under the direct sway of the Bakufu.

For a period of five years after these events the Russians. made no further attempt to establish relations with Japan, and their next essay, namely, the despatch of a warship - the Diana - to survey the Yezo coasts, was unceremoniously interrupted by the Japanese. Another vessel flying the Russian flag visited Kunajiri, in 1814. On that occasion the Japanese managed to seize some members of the Russian crew, who were ultimately saved by the shrewdness of one of their officers. These events imparted fresh vigour to Japan's prejudices against foreign intercourse, but, as for the Russians, not a few of them found their way to Saghalien and settled there without any resolute attempt on the part of the Bakufu to expel them.

\section{COAST DEFENCE}

One effect of the events related above was to direct Japanese attention to the necessity of coast defence, a subject which derived much importance from information filtering through the Dutch door at Nagasaki. Under the latter influence a remarkable book (Kai-koku Hei-dan) was compiled by Hayashi Shibei, who had associated for some time with the Dutch at Deshima. He urged frankly that Japan must remain helpless for naval purposes if her people were forbidden to build ocean-going vessels while foreigners sailed the high seas, and he further urged that attention should be paid to coast defence, so that the country might not be wholly at the mercy of foreign adventurers. The brave author was thrown into prison and the printing-blocks of his book were destroyed, but his enlightenment bore some fruit, for immediately afterwards the Bakufu prime minister made a journey along the coasts of the empire to select points for the erection of fortifications, and to encourage the feudatories to take steps for guarding these important positions.

\section{FOREIGN LITERATURE}

It has already been stated that in the days of the shogun Yoshimune (17161745 ) the veto against studying foreign books was removed. But for some time this liberal measure produced no practical effect, since there did not exist even a Dutch-Japanese vocabulary to open the pages of foreign literature for Japanese study. Indeed, very few books were procurable from the Dutch at Deshima. The most accessible were treatises on medicine and anatomy, and the illustrations in these volumes served as a guide for interpreting their contents. Earnestness well-nigh incredible was shown by Japanese students in deciphering the strange terms, and presently the country was placed in possession of The History of Russia, Notes on the Northern Islands, Universal Geography, A Compendium of Dutch Literature, Treatises on the Art of Translation, a Dutch-Japanese Dictionary and so forth, the immediate result being a nascent public conviction of the necessity of opening the country, - a conviction which, though not widely held, contributed materially to the ultimate fall of the Bakufu.

The Yedo Court, however, clung tenaciously to its hereditary conservatism. Thus, in 1825, the Bakufu issued a general order that any foreign vessel coming 
within range of the coast batteries should at once be fired upon, and not until 1842 was this harsh command modified in the sense that a ship driven into a Japanese port by stress of weather might be given food, water, and provisions, but should be warned to resume her voyage immediately. Mean while, strenuous: efforts were made to strengthen the littoral defences, and a very active revival of the study of the military art took place throughout the empire, though, at the same time, the number of patriots sufficiently brave and clear-sighted to condemn the policy of seclusion grew steadily.

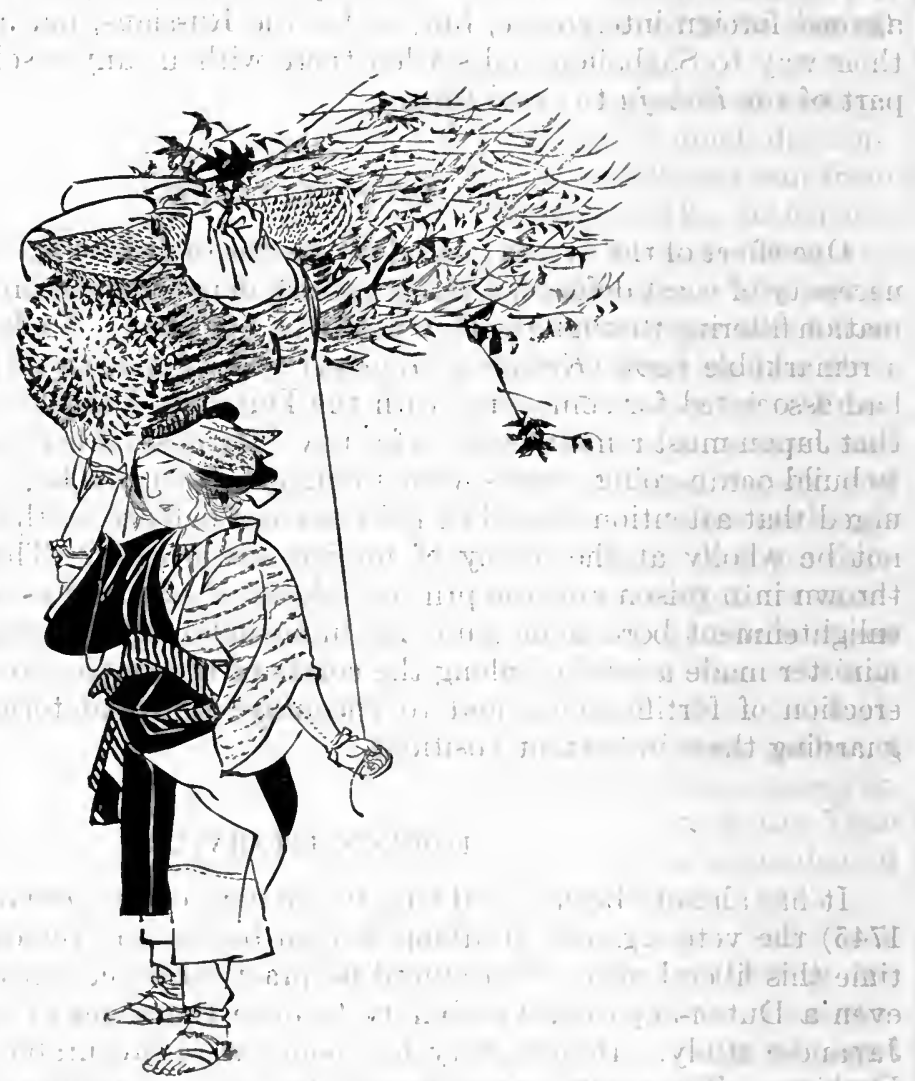

“Oharame"' (A Female Labodrer in the Subugbs of KYōto) 


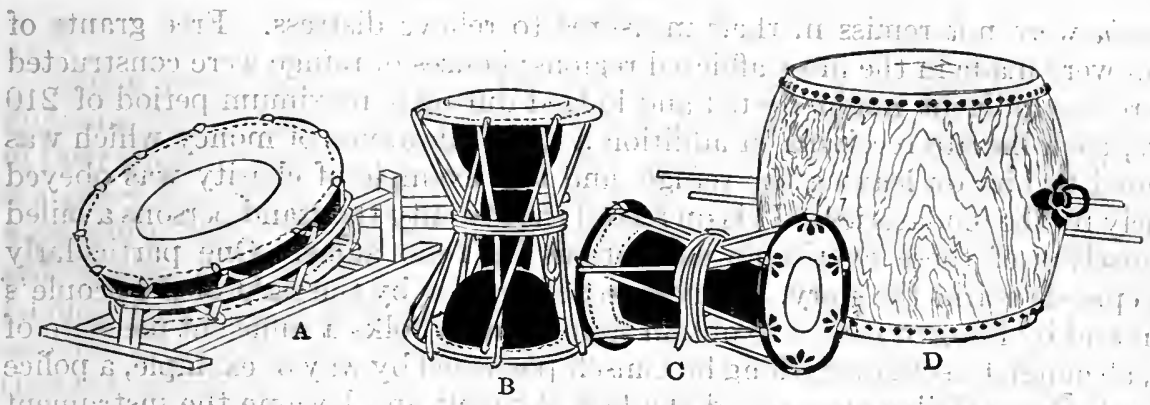

Two Drums and Tsuzumi

$A$ and D. are Drums; $B$ and $C$ are Tsuzumi.

\section{CHAPTER XLV}

\section{FOREIGN RELATIONS AND THE DECLINE OF THE TOKUGAWA (Continued)}

\section{THE TWELFTH SHŌGUN, IEYOSHI (1838-1853).}

From the period of this shogun the strength of the Bakufu began to wane steadily, and the restoration of the administrative power to the sovereign came to be discussed, with bated breath at first, but gradually with increased freedom. It is undeniable, however, that the decline of the Tokugawa was due as much to an empty treasury as to the complications of foreign intercourse. The financial situation in the first half of the nineteenth century may be briefly described as one of expenditures constantly exceeding income, and of repeated recourse by the Bakufu to the fatal expedient of debasing the currency. Public respect was steadily undermined by these displays of impecuniosity, and the feudatories in the west of the empire - that is to say, the tozama daimyo, whose loyalty to the Bakufu was weak at the best - found an opportunity to assert themselves against the Yedo administration, while the appreciation of commodities rendered the burden of living constantly more severe and thus helped to alienate the people.

\section{SUMPTUARY LAWS}

While with one hand scattering abroad debased tokens of exchange, the Bakufu legislators laboured strenuously with the other to check luxury and extravagance. Conspicuous among the statesmen who sought to restore the economical habit of former days was Mizuno Echizen no Kami, who, in 1826 and the immediately subsequent years, promulgated decree after decree vetoing everything in the nature of needless expenditures. It fared with his attempt as it always does with such legislation. People admired the vetoes in theory but paid little attention to them in practice.

\section{FAMINE IN THE TEMPŌ ERA (1830-1844)}

From 1836 onward, through successive years, one bad harvest followed another until the prices of rice and other cereals rose to unprecedented figures. The 
Bakufu were not remiss in their measures to relieve distress. Free grants of grain were made in the most afflicted regions; houses of refuge were constructed where the indigent might be fed and lodged during a maximum period of 210 days, each inmate recciving in addition a daily allowance of money which was handed to him on leaving the refuge, and this example of charity was obeyed widely by the feudatories. It is on record that twenty thousand persons availed themselves of these charitable institutions in Yedo alone. One particularly sad episode marks the story. Driven to desperation by the sight of the people's pain and by his own failure to obtain from wealthy folks a sufficient measure of aid, although he sold everything he himself possessed by way of example, a police official, Ôshio Heihachiro, raised the flag of revolt and became the instrument of starting a tumult in which eighteen thousand buildings were destroyed in Ōsaka. In a manifesto issued before committing suicide in company with his son, Heihachiro charged the whole body of officials with corrupt motives, and declared that the sovereign was treated as a recluse without any practical authority; that the people did not know where to make complaint; that the displeasure of heaven was evinced by a succession of natural calamities, and that the men in power paid no attention to these warnings.

The eleventh shögun, Ienari; after fifty-one years of office, resigned in favour of his son, Ieyoshi, who ruled from 1838 to 1853. Ienari survived his resignation by four years, during which he resided in the western castle, and, under the title of $\bar{o}$-gosho, continued to take part in the administration. As for Ieyoshi, his tenure of power is chiefly notable for the strenuous efforts made by his prime minister, Mizuno Echizen no Kami, to substitute economy for the costly luxury that prevailed. Reference has already been made to this eminent official's policy, and it will suffice here to add that his aim was to restore the austere fashions of former times. The schedule of reforms was practically endless. Expensive costumes were seized and burned; theatres were relegated to a remote suburb of the city; actors were ostracized; a censorship of publications checked under severe penalties the compilation of all anti-foreign or immoral literature, and even children's toys were legislated for.

At first these laws alarmed people, but it was soon found that competence to enforce was not commensurate with ability to compile, and the only result achieved was that splendour and extravagance were more or less concealed. Yet the Bakufu officials did not hesitate to resort to force. It is recorded that storehouses and residences were sealed and their inmates banished; that no less than 570 restaurants were removed from the most populous part of the city, and that the maidservants employed in them were all degraded to the class of "licensed prostitutes." This drastic effort went down in the pages of history as the "Tempo Reformation." It ended in the resignation of its author and the complete defeat of its purpose.

\section{TOKUGAWA NARIAKI}

Contemporaneous with the wholesale reformer, Mizuno, was Tokugawa Nariaki (1800-1860), daimyo of Mito, who opposed the conciliatory foreign policy, soon to be described, of Ii Naosuke (Kamon no Kami). Nariaki inherited the literary tastes of his ancestor, Mitsukuni, and at his court a number of earnest students and loyal soldiers assembled. Among them were Fujita Tōko (1806-1855) and Toda Tadanori, who are not less remarkable as scholars and historians than as administrators. 


\section{RELATIONS WITH THE INITED STATES}

Japan now began to make the acquaintance of American citizens, who, pursuing the whaling industry in the seas off Alaska and China, passed frequently in their ships within easy sight of the island of Yezo. Occasionally, one of these schooners was cast away on Japan's shores, and as a rule, her people were treated with consideration and sent to Deshima for shipment to Batavia. Japanese sailors, also, were occasionally swept by hurricanes and currents to the Aleutian Islands, to Oregon, or to California, and in several cases these mariners were sent back to Japan by. American vessels. It was on such an errand of mercy that the sailing ship Morrison entered Yedo Bay, in 1837, and being required to repair to Kagoshima, was driven from the latter place by cannon shot. It was on such an errand, also, that the Manhattan reached Uraga and lay there four days before she was compelled to take her departure. It would seem that the experiences collected by Cooper, master of the latter vessel, and published after his return to the United States, induced the Washington Government to essay the opening of Japan. A ninety-gun ship of the line and a sloop, sent on this errand, anchored off Uraga in 1846, and their commander, Commodore Biddle, applied for the sanction of trade. He received a positive refusal, and in pursuance of his instructions to abstain from any act calculated to excite hostility or distrust, he weighed anchor and sailed away.

\section{GREAT BRITAIN AND OTHER POWERS}

In this same year, 1846, a French ship touched at the Ryūkyū archipelago, and attempted to persuade the islanders that if they wished for security against British aggression, they must place themselves under the protection of France. England, indeed, was now.much in evidence in the seas of southern China, and the Dutch at Deshima, obeying the instincts of commercial rivalry, warned Japan that she must be prepared for a visit from an English squadron at any moment. The King of Holland now (1847) intervened. He sent to Yedo a number of books together with a map of the world and a despatch urging Japan to open her ports. This was not done for Japan's sake. The apparent explanation is that the trade at Deshima having ceased to be worth pursuing, the Dutch East India Company had surrendered its monopoly to the Netherlands Government, so that the latter's advice to Japan is explained. But his Majesty's efforts had no immediate result, though they doubtless augmented Japan's feeling of anxiety.

Twelve months later, the Preble, an American brig under Commander Glynn, anchored off Nagasaki and threatened to bombard the town unless immediate delivery was made of fifteen foreign seamen held by the Japanese for shipment to Batavia. The castaways were surrendered, and Commander Glynn found evidence to prove that Japan was by no means ignorant of American doings in Mexico, and that she was beginning to comprehend how close the world was approaching her shores. Once again in the following year (1849), the King of Holland wrote, telling the Japanese to expect an American fleet in their waters twelve months later, and to look for war unless they agreed to international commerce This was no empty threat. The.Washington Government had actually addressed to European nations a memorandum justifying an expedition to Japan on the ground that it would inure to the advantage of all, and the King of Holland appended to his letter a draft of the treaty which would be presented 
in Yedo. "All these things render it obvious that in the matter of renewing their relations with the outer world, the Japanese were not required to make any sudden decision under stress of unexpected menace; they had ample notice of the course events were taking."

\section{THE 121ST SOVEREIGN, THE EMPERỌ KŌMEI (A. D. 1846-1867)}

The Emperor Ninkō died in 1846 and was succeeded by his son, Kômei, the 121 st sovereign. The country's foreign relations soon 'bccame 'a source of profound concern to the new ruler. Among the Court nobles there had developed in Ninkō's reign a strong desire to make theirinfluence felt in the administration of the empire, and thus to emerge from the insignificant position to which the Bakufu system condemned them. In obedience to their suggestions, the Emperor Ninkō established a special college for the education of Court nobles, from the age of fifteen to that of forty. This step does not seem to have caused any concern to the Bakufu officials. The college was duly organized under the name of Gakushü-jo (afterwards changed to Gakushu-in). The Yedo treasury went so far as to contribute a substantial sum to the support of the institution, and early in the reign of Komei the nobles began to look at life with eyes changed by the teaching thus afforded. Instructors at the college were chosen among the descendants of the immortal scholars, Abe no Seimei, Sugawara no Michizane, and others scarcely less renowned. The Emperor Ninkō had left instructions that four precepts should be inscribed conspicuously in the halls of the college, namely:-

Walk in the paths trodden by the feet of the great sages.

Revere the righteous canons of the empire.

He that has not learned the sacred doctrines, how can he govern himself?

He that is ignorant of the classics, how can he regulate his own conduct?

A manifest sign of the times, the portals of this college were soon thronged by Court nobles, and the Imperial capital began to awake from its sleep of centuries. The Emperor himself evinced his solicitude about foreign relations by fasting and by praying at the shrines of the national deities, his Majesty's constant formula of worship being a supplication that his life might be accepted as a substitute for the safety of his country. The fact was that the overthrow of the Yedo Bakufu had begun to constitute an absorbing object with many of the high officials in Kyōto. It had hitherto been an invariable rule that any policy contemplated in Yedo became an accomplished fact before a report was presented in the Imperial capital. But very soon after his coronation, the Emperor Komei departed from this time-honoured sequence of procedure and formally instructed the Bakufu that the traditional policy of the empire in foreign affairs must be strictly maintained. The early Tokugawa shöguns would have strongly resented such interference, but times had changed, and Ieyoshi bowed his head quietly to the new order. Thenceforth the Bakufu submitted all questions of foreign policy to the Imperial Court before final decision.

\section{COMMODORE PERRY}

In the year 1853, Commodore Perry of the United States Navy appeared in Uraga Bay with a squadron of four warships and $560 \mathrm{men}$. The advent of such a force created much perturbation in Yedo. Instead of dealing with the affair on their own absolute authority, the Bakufu summoned a council of the feuda- 
tories to discuss the necessary steps. Meanwhile, the shoggun, who had been ill for some time, died, and his decease was pleaded as a pretext for postponing discussion with the Americans. Perry being without authority to resort to force, did not press his point. $\mathrm{He}$ transmitted the President's letter to the sovereign of Japan, and steamed away on the 17 th of July, declaring his intention to return in the following year. This letter was circulated among the feudatories, who were invited to express their opinions on the document. Their replies are worthy of perusal as presenting a clear idea of Japanese views at that time with regard to foreign intercourse. The gist of the replies may be summarized as follows:-

The ultimate purpose of foreigners in visiting Japan is to reconnoitre the country. This is proved by the action of the Russians in the north. What has been done by Western States in India and China would doubtless be done in Japan also if opportunity offered. Even the Dutch are not free from suspicion of acting the part of spies.

Foreign trade, so far from benefitting the nation, cannot fail to impoverish it, inasmuch as oversea commerce simply means that, whereas Japan receives a number of unnecessary luxuries, she has to give in exchange quantities of precious metals.

To permit foreign intercourse would be to revoke the law of exclusion which has been enforced for centuries, and which was the outcome of practical experience.

These opinions were subscribed by a great majority of the feudatories. few; however, had sufficient foresight and courage to advocate foreign intercourse. The leaders of this small minority were, Ii Naosuke, baron of Hikone, historically remembered as Ii Kamon no Kami; Toda Izu no Kami, bugyō of Uraga ; Takashima Kihei (called also Shirōdayū, or Shūhan); Egawa Tarozaemon, bugyō of Nirayama; and Otsuki Heiji, a vassal of the baron of Sendai. The views of these statesmen may be briefly summarized as follows:

It is not to be denied that many illustrious and patriotic men, anticipating injury to the country's fortunes and perversion of the nation's moral canons, are implacably opposed to foreign intercourse. But the circumstances of the time render it impossible to maintain the integrity of the empire side by side with the policy of seclusion. The coasts are virtually unprotected. The country is practically without a navy. Throughout a period of nearly two and a half centuries the building of any ship having a capacity of over one hundred koku has been forbidden, and in the absence of war-vessels there is no means of defence except coast batteries, which are practically non-existent.

When inaugurating the policy of seclusion, the Bakufu Government took care to leave China and Holland as a bridge between Japan and the rest of the world. It will be wise to utilize that bridge for dealing with foreign States, so as to gain time for preparations of defence, instead of rushing blindly into battle without any supply of effective weapons. If the Americans have need of coal, there is an abundant supply in Kyūshū. If they require provisions and water, their needs can easily be satisfied. As for returning distressed foreign seamen, that has hitherto been done voluntarily, and an arrangement on this subject can be made through the medium of the Dutch. As for foreign trade, the times have changed radically since a veto was imposed on all commercial transactions, and it by no means follows that what was wise then is expedient now. Japan must have ocean-going vessels, and these cannot be procured in a moment. Her best way is to avail herself of the services of the Dutch as middlemen in trade, and to lose no time in furnishing herself with powerful men-of-war and with sailors and gunners capable of navigating and fighting these vessels.

In short, the wisest plan is to make a show of commerce and intercourse, and thus gain time to equip the country with a knowledge of naval architecture and warfare. The two things most essential are that Christianity should not be admitted in the train of foreign trade, and that the strictest economy should be exercised by all classes of the people so as to provide funds for the building of a navy and the fortification of the coasts.

The question alluded to at the close of the above, namely, the question of finance, was a paramount difficulty for the Bakufu. In the very year of Perry's coming, a member of the Cabinet in Yedo wrote as follows to Fujita Tóko, chief adviser of the Mito feudatory: "Unless I tell you frankly about the condition of the treasury you cannot appreciate the situation. If you saw the accounts you would be startled; and would learn at a glance the hopelessness of 
going to war. The country could not hold out even for a twelvemonth, and there is nothing for it except that everyone should join in saving money for purposes of equipment. - If we keep the peace now and toil unremittingly for ten years, we may hope to restore the situation." In truth, the Bakufu had practically no choice. "On one hand, thousands of publicists, who believed themselves patriotic, clamoured for the policy of seclusion, even at the cost of war; on the other, the Yedo Government knew that to fight must be to incur crushing defeat." The Bakufu then issued the following temporizing decree:

With regard to the despatch from the United States Government, the views of competent men have been taken and have been carefully considered by the shogun:- The views expressed are variously worded but they advocate either peace or war. Everyone has pointed out that we are without a navy and that our coasts are undefended. Meanwhile, the Americans will be here again next year. Our policy shall be to evade any definite answer to their request; while at the same time maintaining a peaceful demeanour. It may be, however, that they will have recourse to violence. For that contingency we must be prepared lest the country suffer disgrace. Therefore every possible effort will be made to prepare means of defence. Above all it is imperative that everyone should practise patience, refrain from anger, and carefully observe the conduct of the foreigners. Should they open hostilities, all must at once take up arms and fight strenuously for the country.

A less vertebrate policy could scarcely have been formulated, but the conduct of the Bakufu statesmen was more stalwart than their language. Under the guidance of Abe Masahiro, one of the ablest statesmen that Yedo ever possessed; batteries were built at Shinagawa to guard the approaches to Yedo; defensive preparations were made along the coasts of Musashi, Sagami, Awa, and Kazusa; the veto against the construction of ocean-going ships was rescinded, and the feudatories 'were invited to build and arm large vessels; a commission was given to the Dutch at Deshima to procure from Europe a library of useful books; cannon were cast; troops were drilled, and everyone who had acquired expert knowledge through the medium of the Dutch was taken into official favour.

But all these efforts tended only to expose their own feebleness, and on the 2nd of November, 1853, instructions were issued that if the Americans returned; they were to be dealt with peacefully. "In short, the sight of Perry's steampropelled ships, their powerful armament, and the specimens they carried of Western wonders had practically broken down the barriers of Japan's isolation without any need of treaties or conventions." Thus, when the American commodore returned in the following February with ten ships and crews numbering two thousand, he easily obtained a treaty by which Japan promised kind treatment to shipwrecked sailors; permission to foreign vessels to obtain stores and provisions within her territory, and an engagement that American vessels might anchor in the ports of Shimoda and Hakata. Much has been written about Perry's judicious display of force and about his sagacious tact in dealing with the Japanese, but it may be doubted whether the consequences of his exploit did not invest its methods with extravagant lustre.

\section{TREATIES OF COMMERCE}

Russia, Holland, and England speedily obtained treaties similar to that concluded by Commodore Perry in 1854 . These, however, were not commercial conventions. It was reserved for Mr. Townsend Harris, American consulgeneral in Japan, to open the country to trade. Arriving in August, 1856, he concluded in March, 1857, a treaty securing to United States citizens the right of permanent residence at Shimoda and Hakodate, as well as that of carrying on trade at Nagasaki and establishing consular jurisdiction. Nevertheless, 
nothing worthy to be called commercial intercourse was allowed by the Bakufu, and it was not until Mr. Harris, with infinite patience and tact, had gone to Yedo after ten months' delay that he secured the opening of ports other than Nagasaki to international commerce. In this achievement he was assisted by Hotta Masamutsu, successor to the great Masahiro, and, like most of his colleagues, a sincere advocate of opening the country.

Japan has been much blamed for her reluctance in this matter, but when we recall the danger to which the Yedo administration was exposed by its own weakness, and when we observe that a strong sentiment was growing up in favour of abolishing the dual form of government, we can easily appreciate that to sanction commercial relations might well have shaken the Bakufu to their foundations. It was possible to construe the Perry convention and the first Harris convention as:mere acts of benevolence towards strangers, but a commercial treaty would not have lent itself to any such construction. We cannot wonder that the shōgun's ministers hesitated to take an apparently suicidal step. They again consulted the feudatories and again received an almost unanimously unfavourable answer.

In fact, history has preserved only one unequivocal expression of consent. It was formulated by Matsudaira Yoshinaga, baron of Echizen. He had been among the most ardent exclusionists in the first council of feudatories; but his views had subsequently undergone a radical change, owing to the arguments of one of his vassals, Hashimoto Sanae - elder brother of Viscount Hashimoto Tsunatsune, president of the Red Cross Hospital, who died in 1909. "Not only did this remarkable man frankly advocate foreign trade for its own sake and as a means of enriching the nation, thus developing its capacity for independence, but he also recommended the fostering of industries, the purchase of ships and firearms, the study of foreign arts and sciences, and the despatch of students and publicists to Western countries for purposes of instruction. Finally, he laid down the principle that probity is essential to commercial success." Such doctrines were then much in advance of the time. Nevertheless, Harris achieved his purpose. He had audience of the shoggun in November, 1857, and, on the 29th of the following July, a treaty was concluded opening Yokohama, from the 1st of July, 1858, to commerce between the United States and Japan.

This treaty was concluded in spite of the failure of two attempts to obtain the sanction of the Throne. Plainly the Bakufu shrank from openly adopting a policy which, while recognizing its necessity, they distrusted their own ability to force upon the nation. They had, however, promised Mr. Harris that the treaty should be signed, and they kept their word at a risk, of whose magnitude the American consul-general had no conception. Mr. Harris had brought to this conference exceptional diplomatic skill and winning tact, but it cannot be denied that he derived assistance from contemporaneous events in China, where the Peiho forts had just been captured and the Chinese forced to sign a treaty. He was thus able to warn the Japanese that the British and the French fleets might be expected at any moment to enter Yedo Bay, and that the best way to avert irksome demands at the hands of the British was to establish a comparatively moderate precedent by yielding to the American proposals.

THE THIRTEENTH SHŌGUN, IESADA (1853-1858)

Between the conclusion of the Harris commercial treaty and its signature, the Bakufu prime minister visited Kyōto, for the purpose of persuading the 
Imperial Court to abandon its anti-foreign attitude. His mission was quite unsuccessful, the utmost concession obtained by him being that the problem of the treaty should be submitted to the feudatories. Another question raised on this occasion in Kyōto was the succession to the shōgunate. The tivelfth shōgun, Ieyoshi, had died in 1853; and was succeeded by Iesada, a physically incompetent ruler. Iesada had been married to the daughter of the Satsuma feudatory, as planned by the former Bakufu premier, Abe, who hoped thus to cement friendly relations with the great southern baron, a hereditary enemy of the Tokugawa. There was no issue of the marriage, and it being certain that there could be no issue, two candidates for the shogunate: were proposed. They were Keiki, son of Nariaki of Mito a man of matured intellect and high capacities, and Iemochi, son of Nariyuki of Kii, a boy of thirteen. Public opinion supported the former, and his connexion with the house of Mito seemed to assure an antiforeign bias. Chiefly for the latter reason; the Court in Kyöto favoured his nomination.

But Keiki was not really an advocate of national seclusion. Had the succession been given to him then, he would doubtless have adopted a liberal policy. On the other hand, his appointment would have been equivalent to the abdication of Iesada, and in order to avert that catastrophe, the shogun's entourage contrived to obtain the appointment of Ii Kamon no Kami to the post of prime minister in Yedo. This baron was not less capable than courageous. He immediately caused the young daimy $\bar{o}$ of Kii to be nominated successor to the shoggunate, and he signed the Harris treaty. A vehement outcry ensued. It was claimed that the will of the Imperial Court had been set at nought by signing the treaty without the sovereign's sanction, and that unconditional yiclding to foreign demands was intolerable. The Mito baron headed this opposition. But it is observable that even he did not insist upon the maintenance of absolute seclusion. All that he and his followers demanded was that a delay should be imposed in order to obtain time for definite preparation, whereas the premier, Ii, was for the immediate opening of the country.

\section{THE FOURTEENTH SHŌGUN, IEMOCHI (1858-1866)}

Iesada died in 1858, and the reluctance of the Imperial Court to sanction the succession of Iemochi was evidenced by a long delay in the transmission of the necessary Imperial document. During that interval, the feudatories of Mito and Echizen had a memorable interview with the premier, Ii, whose life seemed at that time to hang by a thread, but who, nevertheless, advanced unflinchingly towards his goal. The three feudatories offered to compromise; in other words, they declared their willingness to subscribe the commereial convention provided that Keiki was appointed shogun; the important fact being thus established that domestic politics had taken precedence of foreign. Ii not only declined this offer, but also did not hesitate to punish the leaders of the opposition by confinement and by temporary exclusion from the Court.

\section{FOREIGN MILITARY SCIENCE}

It was during the days of the thirteenth shogun that Japan may be said to have commenced her practical study of foreign military science. Instructors were imported from Holland, and a college was established at Nagasaki. Among its graduates were several historical characters, notably Katsu Rintarō, after 
wards Count Katsu, minister of Marine in the Meiji Government. A naval college (Gunkan Kyōjujo) also was organized at Tsukiji, in Yedo; while at Akunoura, in Nagasaki, an iron-foundry was erected. There, the first attempt at shipbuilding on foreign lines was made, and there, also, is now situated the premier private dockyard in Japan, namely, that of the Mitsubishi Company. Already, in 1854, the Dutch Government had presented to Japan her first steamship; the Kanko Maru.

\section{FOREIGN REPRESENTATIVES AND THE BAKUFU}

An indirect consequence of these disputes between the Throne and the Court nobles, on one side, and the Bakufu officials, on the other, was to perplex the foreign representatives who were now residing in Yedo. These representatives learned to believe that the shogun's ministers were determined either to avoid making treaties or to evade them when made. However natural this suspicion may have been, it lacked solid foundation. That is proved by a memorial which the Yedo statesmen addressed to the Throne after the negotiation of the Harris treaty. They made it quite plain that they were acting in perfect good faith, the only doubtful point in the memorial being that, after the organization of a competent army and navy, the problem of peace or war might be decided. "If peaceful relations be maintained by ratifying the treaty," they wrote, "the avaricious aliens will definitely see that there is not much wealth in the country, and thus, abandoning the idea of gain, they will approach us with friendly feelings only and ultimately will pass under our Emperor's grace. They may then be induced to make grateful offerings to his Majesty, and it will no longer be a question of trade but of tribute." . Something of sinister intention seems to present itself between the lines of this document. But we have to remember that it was addressed ultimately to the Kyōto nobles, whose resentment would have been at once excited by the use of friendly or self-effacing language.

There is also on record correspondence that passed between the Bakufu premier, Ii, and certain friends of his in the Imperial capital. From these letters it appears that Yedo was advised by the far-seeing section of the Kyōto statesmen to simulate the policy of bringing aliens under Japanese influence, and of using for purposes of military and naval development the wealth that would accrue from oversea trade. In a word, the Bakufu had to disguise their policy in terms such as might placate the Kyōto conservatives, and this deception was once carried so far that an envoy sent to Kyōto from Yedo represented the shōgun as hostile at heart to foreigners, though tolerating them temporarily as a matter. of prudence. It cannot be wondered at that the foreign representatives found much to perplex them in these conditions, or that at the legations in Yedo, as well as among the peoples of Europe and America, an uneasy feeling grew up that Japan waited only for an opportunity to repudiate her treaty engagements.

\section{INTRIGUES IN KYŌTO}

About this time there began to assemble in the Imperial capital a number of men who, though without social or official status, were at once talented; patriotic, and conservative. At their head stood Umeda Genjiro, who practised as a physician and wrote political brochures under the nom de plume of Umpin. He soon became the centre of a circle of loyalists whose motto was Son- $\bar{O} J \bar{o}-I$ (Revere the sovereign, expel the barbarians); and associated with him were 
Rai Miki, a son of Rai Sanyō; Yanagawa Seigan; Yoshida Shōin; Saigō Kichinosuke - better known as Saigo Takamori, the leader of the Satsuma rebellion of 1877,- Hashimoto Sanae, and others who have been not unjustly described as the real motive force that brought about the Restoration of 1867 .

These men soon came to exercise great influence over the Court nobles especially Konoe, Takatsukasa, Ichijō, Nijō, and Sanjō - and were consequently able to suggest subjects for the sovereign's rescripts. Thus his Majesty was induced to issue an edict which conveyed a reprimand to the shōgun for concluding a treaty without previously referring it to the feudatories, and which suggested that the Mito and Owari feudatories should be released from the sentence of confinement passed on them by Ii Kamon no-Kami. This edict startled the Bakufu. They at once sent from Yedo envoys to remonstrate with

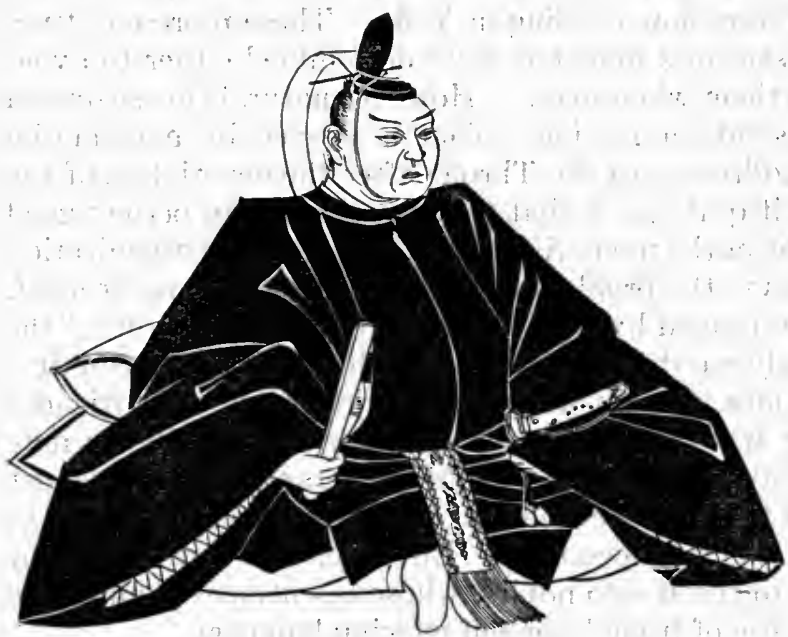

II NAOSCKE

the conscrvatives; and after a controversy lasting four months; a compromise was effected by, which the sovereign postponed any action for the expulsion of foreigners and the shógun declared that his tolerance of international commerce was only: temporary. This was regarded as: a victory for the shogunate. But the Yedo envoys, during their stay in Kyōto, discovered evidences of a plot to overthrow the Bakufu. Great severity was shown in dealing with this conspiracy.

The leaders were beheaded, banished, or ordered to commit suicide; the Mito feudatory being sentenced to perpetual confinement in his fief; the daimy $\bar{o}_{\text {: }}$ of Owari, to permanent retirement; and Keiki, former candidate for the succession to the shōgunate, being deprived of office and directed to live in seclusion. Many other notable men were subjected to various penalties, and this" "Great Judgment of Ansei" - the name: of the era - caused a profound sensation throughout the empire. The nation mourned for many sincere patriots who had been sentenced on the flimsiest evidence, and the whole incident tended to accentuate the unpopularity of foreign intercourse.

\section{THE SECRET EDICT}

The compromise mentioned above as having been effected between Yedo and Kyotto had the effect of stultifying the previously drafted edict which condemned the shoggun for concluding a treaty without consulting the feudatories. The edict had not been publicly promulgated, but it had come into the possession of the Mito feudatory, and by his orders had been enclosed in the family tomb, where it was guarded night and day by a strong troop of samurai. The Bakufu insisted that to convey such a document direct from the Throne to a feudatory was a plain trespass upon the shögun's authority? 'Mito, however, refused to surrender it. The most uncompromising conservatives of the fief issued a 
manifesto justifying their refusal, and, as evidence of their sincerity, committed suicide.

\section{ASSASSINATION OF II}

Nariaki, the Mito baron, now instructed his vassals to surrender the edict. He may have shared the views of his retainers, but he was not prepared to assert them by taking up arms against his own family. In the face of this instruction the conservative samurai had no choice but to disperse or commit suicide. Some twenty of them, however, made their way to Yedo bent upon killing Ii Kamon no Kami, whom they regarded as the head and front of the evils of the time. The deed was consummated on the morning of the 24th of March, 1860, as Ii was on his way to the shogun's castle. All the assassins lost their lives or committed suicide.

\section{sqit. oj tosit:

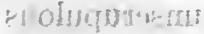

\section{ATTITUDE OF THE JAPANESE SAMURAI}

The slaying of Ii was followed by several similar acts, a few against foreigners and several against Japanese leaders of progress. Many evil things have been said of the men by whom these deeds of blood were perpetrated. But we have always to remember, that in their own eyes they obeyed the teachings of hereditary conviction and the dictates of patriotism towards their country as well as loyalty towards their sovereign. It has been abundantly shown in these pages that the original attitude of the Japanese towards foreigners was hospitable and liberal. It has also been shown how, in the presence of unwelcome facts, this mood was changed for one of distrust and dislike. Every Japanese patriot believed when he refused to admit foreigners to his country in the nineteenth century that he was obeying the injunctions handed down from the lips of his most illustrious countrymen, Hideyoshi, Ieyasu, and Iemitsu - believed, in short, that to re-admit aliens would be to expose the realm to extreme peril and to connive at its loss of independence. He was prepared to obey this conviction at the cost of his own life, and that sacrifice seemed a sufficient guarantee of his sincerity:

\section{THE FIRST FOREIGNERS}

It must be conceded; too, that the nineteenth-century foreigner did not present himself to Japan in a very lovable light. His demeanour was marked by all the arrogance habitually shown by the Occidental towards the Oriental, and though the general average of the oversea comers reached a high standard, they approached the solution of all Japanese problems with a degree of suspicion which could not fail to be intensely irksome to a proud nation. Even the foreign representatives made it their habit to seek for trickery or abuse in all Japanese doings, official or private, and though they doubtless had much warrant for this mood, its display did not tend to conciliate the Japanese. Many instances might be cited from the pages of official records and from the columns of local newspapers, but they need not be detailed here.

Moreover, there were difficulties connected with trade. The framers of the treaties had found it necessary to deal with the currency question, and their manner of dealing with it was to stipulate that foreign coins should be exchangeable with Japanese, weight for weight. This stipulation did not take into any account the ratio between the precious metals; and as that ratio was fifteen to one in Europe and five to one in Japan, it is obvious that, by the mere process of 
exchange, a foreign merchant could reap a rich harvest. Of course this was never. intended by the framers of the treaty, and when the Japanese saw the yellow metal flowing away rapidly from the realm, they adopted the obvious expedient of changing the relative weights of the gold and silver coins.

It may be doubted whether any state would have hesitated to apply that remedy. Yet by the foreigner it was censured as a "gross violation of treaty right" and as "a deliberate attempt on the part of the Japanese authorities to raise all the prices of the native produce two hundred per cent. against the foreign purchaser." The British representative, Sir Rutherford Alcock, in a despatch written to his Government, at the close of 1859 , penned some very caustic comments on the conduct of his countrymen, and did not hesitate to declare that "in estimating the difficulties to be overcome in any attempt to improve the aspect of affairs, if the ill-disguised enmity of the governing classes and the indisposition of the Executive Government to give partial effect to the treaties be classed among the first and principal of these, the unscrupulous character and dealings of foreigners who frequent the ports for purposes of trade are only second and-scarcely inferior in importance, from the sinister character of the influence they exercise."

It is only just, however, to note the other side of the picture, and to observe that the foreign merchant had many causes of legitimate dissatisfaction; that his business was constantly hampered and interrupted by Japanése official interference; that the ready recourse which Japanese samurai had to deeds of blood against peaceful strangers seemed revoltingly cruel; that he appeared to be surrounded by an atmosphere of perplexity and double dealing, and that the large majority of the Anglo-Saxon tradesmen visiting Japan in the early days of her renewed intercourse had nothing whatever in common with the men described in the above despatch.

\section{KYŌTO}

In order to follow the sequence of events, it is necessary to revert to Kyōto, which, as the reader will have perceived, was the centre of national politics in this troublous era. An incident apparently of the greatest importance to the Bakufu occurred in 1861. The shoggun received the Emperor's sister in marriage. But the auspicious event had to be heavily paid for, since the Bakufu officials were obliged to pledge themselves to expel foreigners within ten years. This inspired new efforts on the part of the conservatives. A number of samurai visited Yokohama, and promised death to any Japanese merchant entering into transactions with the aliens. These conservatives further announced the doctrine that the shoggun's title of sei-i (barbarian-expelling) indicated explicitly that to expel foreigners was his duty, and the shogun's principal officials were so craven that they advised him to apologize for failing to discharge that duty instead of wholly repudiating the extravagant interpretation of the anti-foreign party.

Encouraged by these successes, the extremists in Kyōto induced the sovereign to issue an cdict in which, after speaking of the "insufferable and contumelious behaviour of foreigners;" of "the loss of prestige and of honour constantly menacing the country," and of the sovereign's "profound solicitude," his Majesty openly eited the shogun's engagement to drive out the aliens within ten years, and explicitly affirmed that the grant of an Imperial princess' hand to the shogin had been intended to secure the unity required for that achievement. Such an edict was in effect an exhortation to every Japanese subject to organize an 
anti-foreign crusade, and it "publicly: committed the Bakufu Court to a policy. which the latter had neither the power to carry out nor any intention of attempting to carry out."

But at this juncture something like a reaction took place in the Imperial capital. A party of able men, led by Princes Konoe and Iwakura, had the courage to denounce the unwisdom of the extremists, at whose head stood Princes Arisugawa and Sanjō. At that time the most powerful fiefs in Japan were Satsuma and Chōshū. Both were hereditarily hostile to the Tokugawa, but were mutually separated by a difference of opinion in the matter of foreign policy, so that when the above two cabals were organized in Kyōto, the Chōshū men attached themselves to the extremists, the Satsuma to the moderates. The latter contrived to have an Imperial rescript sent to Yedo by the hands of the Satsuma feudatory; Shimazu Hisamitsu. This rescript indicated three courses, one of which the shogun was asked to choose: namely, first, that he himself should proceed to Kyoto for the purpose of therc conferring with the principal feudatories as to the best means of tranquillizing the nation; secondly, that the five principal littoral fiefs should be ordered to prepare coast defences, and, thirdly, that Keiki of Mito and the feudatory of Echizen should be appointed to high office, in the Bakufu administration.

To obey this rescript was to violate the fundamental law of the Bakufu, namely, that all interference in administrative affairs was forbidden to the Kyōto Court. The only dignified course for the shōgun to take was to refuse compliance or to resign, and probably had he done so he would have recovered the power of which he had gradually been deprived by the interference of Kyōto. But his advisers lacked courage to recommend such a course. At their suggestion the shogun signified his willingness to comply with the first and the third of the conditions embodied in the edict. The Satsuma feudatory strongly counselled that the shōgun should decline to proceed to Kyōto and should reject all proposals for the expulsion of foreigners, but the Bakufu ignored his advice.

\section{THE NAMAMUGI INCIDENT}

At this time there occurred an incident which had the most far-reaching consequences. A party of British subjects, three gentlemen and a lady, met, at Namamugi on the Tōkaidō, the cortège of the Satsuma feudatory as he was returning from Yedo. Unacquainted with the strict etiquette enforced in Japan in such situations, the foreigners attempted to ride through the procession, the result being that one, Mr. Richardson, was killed, and two of the others were wounded. The upshot of this affair was that the British Government, having demanded the surrender of the samurai implicated in the murder, and having been refused, sent a naval squadron to bombard Kagoshima, the capital of the Satsuma baron. In this engagement, the Satsuma men learned for the first time the utter helplessness of their old weapons and old manner of fighting, and their conversion to progressive ideas was thoroughly effected.

\section{CONTINUED INTRIGUES IN KYŌTO}

The submissive attitude of the Bakufu towards the Imperial Court encouraged the extremists in Kyōto to prefer fresh demands. Instead of waiting for the shōgun to repair to Kyōto, as he had pledged himself to do in compliance with the edict mentioned above, they contrived the issue of another rescript, requiring 
the Bakufu to proclaim openly the adoption of the alien-expelling policy, and to fix a date for its practical inception. Again the Bakufu yielded. They did not, indeed, actually take the steps indicated in the reseript, but they promised to consider its contents as soon as the shögun arrived in Kyotto. The extremists, however, could not reconcile themselves to even that delay. "In the spring of 1863, they constrained Keiki, who had been appointed guardian to the shogun and who was then in Kyōto, to give an engagement that on the shōgun's return to Yedo decisive measures to put an end to foreign intercourse should be begun.

This engagement the shogun found awaiting him on his arrival in the Imperial capital, and at the same time messages daily reached him from Yedo, declaring that unless he returned at once to Yedo to settle the Namamugi affair; war with Great Britain would be inevitable. But the conservatives would not allow him to return. They proeured the issue of yet another Imperial decree directing that "if the English barbarians wanted a conference, they should repair to Ôsaka Harbour and receive a point-blank refusal; that the shoggn should remain in Kyoto to direct defensive operations, and that he should accompany the Emperor to the shrine of the god of War where a "barbarian-quelling sword' would be handed to him." Illness saved the shog gun from some of his perplexities and, in his absence, the Yedo statesmen paid the indemnity required by Great Britain for the Namamugi outrage and left her to exact whatever further redress she desired. Accordingly, in July, 1863, a British squadron proceeded to Kagoshima and bombarded it as already described.

\section{THE SHIMONOSEKI COMPLICATION}

If the Satsuma men thus received a conclusive lesson as to the superiority of Western armaments, the Chōshū fief was destined to be similarly instructed not long afterwards. It will have been perceived that at this epoch the Imperial Court was very prolific in anti-foreign ediets. One of these actually appointed the 11th of May, 1863, as the date for commencing the barbarian-expelling campaign, and copies of the edict were sent direct to the feudatories without previous reference to the shōgun. 'The Chōshū daimyō found the edict so congenial that, without waiting for the appointed day; he opened fire on American, Freneh, and Dutch merchantmen passing the Strait of Shimonoseki, which his batteries commanded. The ships suffered no injury, but, of course, such an act could not be condoned, and the Bakufu Government being unwilling or unable to give full reparation, the three powers whose vessels had been fired on joined hands with England for the purpose of despatching a squadron to destroy the Chōshū forts, which result was attained with the greatest ease. This "Shimonoseki : Expedition," as it was. called, enormously strengthened the conviction which the bombardment of Kagoshima had established. The nation thoroughly appreciated its own belligerent incapacity when foreign powers entered the lists, and patriotic men began to say unhesitatingly that their country was fatally weakened by the dual system of government.

\section{CHANGE OF OPINION IN KYŌTO}

The sway exercised by the extremists in Kyōto now received a check owing to their excessive zeal. They proeured the drafting of an Imperial edict which declared the Emperor's resolve to drive out the foreigners, and announced a visit by his Majesty to the great shrines to pray for success. This edict never 
received the Imperial seal. The extremists appear to have overrated their influence at Court. They counted erroneously on his Majesty's post facto compliance, and they thus created an opportunity of which the moderates took immediate advantage. At the instance of the latter and in consideration of the fictitious edict, Mōri Motonori of Chōshū, leader of the extremists, was ordered to leave the capital with all the nobles who shared his opinions. Doubtless the bombardment of Kagoshima contributed not a little to this measure, but the ostensible cause was the irregularity of the edict. There was no open disavowal of conservatism, but, on the other hand, there was no attempt to enforce it. The situation for the extremists was further impaired by an appeal to force on the part of the Chōshū samurai. They essayed to enter Kyōto under arms, for the ostensible purpose of presenting a petition to the Throne but really to make away with the moderate-leaders. This political coup failed signally, and from that time the ardent advocates of the anti-foreign policy began to be regarded as rebels. Just at this time the Shimonoseki expedition gave an object lesson to the nation, and helped to deprive the barbarian-expelling agitation of any semblance of Imperial sanction.

\section{CHŌSHŪ AND THE BAKUFU}

When the Chōshū feudatory attempted to close the Shimonoseki Strait by means of cannon, the Bakufu sent a commissioner to remonstrate. But the Chōshū samurai insisted that they had merely obeyed the sovereign's order, and the better to demonstrate their resolution, they put the commissioner to death. Thus directly challenged, the Bakufu mustered a powerful force and launched it against Chōshū. But by this time the two great southern clans, having learned the madness of appealing to force for the purpose of keeping the country closed, had agreed to work together in the interests of the State. Thus, when the Bakufu army, comprising contingents from thirty-six feudatories, reached Chōshü, the latter appealed to the clemency of the invading generals, among. whom the Satsuma baron was the most powerful, and the appeal resulted in the withdrawal of the punitory expedition without the imposition of any conditions. The Bakufu were naturally much incensed.' Another formidable force was organized to attack Chōshū, but it halted at Ōsaka and sent envoys to announce the punishment of the rebellious fief; to which announcements the fief paid not the least attention.

\section{THE HYŌGO DEMONSTRATION}

While things were at this stage, Sir Harry Parkes, representative of Great Britain, arrived upon the scene in the Far East. A man of remarkably luminous judgment and military methods, this distinguished diplomatist appreciated almost immediately that the ratification of the treaties by the sovereign was essential to their validity, and that by investing the ratification with all possible formality, the Emperor's recovery of administrative power might be accelerated. $\mathrm{He}$ therefore conceived the idea of repairing to Hyōgo with a powerful naval squadron for the purpose of seeking, first, the ratification of the treaty; secondly, the reduction of the import tariff from an average of fifteen per cent. ad valorem (at which figure it had been fixed by the original treaty) to five per cent., and, thirdly, the opening of the ports of Hyōgo and Ōsaka at once, instead of nearly two years hence, as previously agreed.

Among the penalties imposed upon Chōshu by the four powers which com- 
bined to destroy the forts at Shimonoseki was a fine of three million dollars; and the Bakufu, being unable to collect this money from Chōshū, had taken upon themselves the duty of paying it and had already paid one million. Sir Harry Parkes's plan was to remit the remaining two millions in consideration of the Government endorsing the three demands formulated above." It need hardly be said that the appearance of a powerful squadron of foreign warships at the very portals of the Imperial palace threw the nation into a ferment. The eight vessels east anchor off Hyōgo in November, 1866, and it seemed to the nation that the problem of foreign intercourse had been revived in an aggravated form.

Once again the anti-foreign agitators recovered their influence, and inveighed against the Bakufu's incompetence to avert such trespasses even from the sacred city. Under the pressure brought to bear by these conservatives;, the Emperor dismissed from office or otherwise punished the ministers appointed by the shögun to negotiate with the foreign representatives, and in the face of this humiliating disavowal of Bakufu authority, the shogun had no alternative except to resign. He did so. But the Imperial Court hesitated to accept the responsibilities that would have resulted from sanctioning his resignation. The Bakufu were informed that the Emperor sanctioned the treaties and that the shogun was authorized to deal with them, but that steps must be taken to revise them in consultation with the feudatories, and that Hyōgo and Ōsaka must not be opened, though the proposed change of tariff-rate would be permitted. 1 Nothing definite was said about remitting the two million dollars remaining from the Chōshū fine, and Sir Harry Parkes was able to say triumphantly that he had obtained two out of three concessions demanded by him without having given any quid pro whatever.

\section{THE LAST OF THE TOKUGAWA SHŌGUNS}

The measures against Chōshū were now recommenced, but with complete unsuccess, and thus a final blow was given to the prestige of the Yedo Government. It was at this time (1866) that the fourteenth shogun, Iemochi, passed away and was succeeded by Yoshinobu, better known as Keiki. Whatever the political views of this nobleman may have been when he was put forward by the conservatives, in 1857, as a candidate for succession to the shōgunate, he no sooner attained that dignity, in 1866, than he became an ardent advocate of progress. French experts were engaged to remodel the army, and English officers to organize the navy; the shogun's brother was sent to the Paris Exposition, and Occidental fashions were.introduced at the ceremonies of the Bakufu Court.

\section{SATSUMA AND CHŌSHŪ}

When Keiki assumed office he had to deal speedily with two problems; that is to say, the complication with Chōshū, and the opening of Hyōgo. The Emperor's reluctant consent to the latter was obtained for the beginning of 1868 , and an edict was also issued for the punishment of Chōshū. The result was twofold: fresh life was imparted to the anti-foreign agitation, and the Satsuma and Chōshū feudatories were induced to join hands against the Tokugawa. Alike in Satsuma and in Chōshū, there were a number of clever men who had long laboured to combine the forces of the two fiefs in order to unite the whole empire under the sway of the Kyōto Court. Saigo and Ōkubo on the Satsuma side, 
Kido and Sanjō on the Chōshũ became leading figures on the stage of their country's new career. Through their influence, aided by that of Itō, afterwards prince, and Inouye, afterwards marquis, the two great clans were brought into alliance, and when, in 1867, the shoggun, Keiki, sought and obtained Imperial sanction for the punishment of Chōshū, Satsuma agreed to enter the lists on the latter's side.

\section{TOSA MEMORIAL}

An incident of a most striking and unexpected nature now occurred. Yōdõ, the Tosa feudatory, addressed to the shogun a memorial exposing the helpless condition of the Bakufu and strongly urging that the administration should be restored to the Emperor in order that the nation might be united to face the dangers of its new career. It is necessary to note here that, although the feudatories have been frequently referred to in these pages as prominent figures in this or that public drama, the feudal chiefs themselves exercised, in Tokugawa days, very little influence on the current of events. A modern historian speaks justly when he says:-

"In this respect the descendants of the great Tokugawa statesman found themselves reduced to a position precisely analogous to that of the emperor in Kyōto. Sovereign and shögun were alike mere abstractions so far as the practical work of the government was concerned. With the great mass of the feudal chiefs things fared similarly. These men who, in the days of Nobunaga, Hideyoshi and Ieyasu, had directed the policies of their ficfs and led their armies in the field, were gradually transformed, during the lone peace of the Tokugawa era, into voluptuous fainéants or, at best, thoughtless dilettanti, willing to abandon the direction of their affairs to seneschals and mayors; who, while on the whole their administration was able and loyal, found their account in contriving and perpetuating the effacement of their chiefs. Thus, in effect, the government of the country, taken out of the hands of the shogun and the feudatories, fell into those of their vassals. There were exceptions, of course, but so rare as to be mere accidental.

The revolution which involved the fall of the shogunate, and ultimately of feudalism, mav be called democratic with regard to the personnel of those who planned and directed it. They were, for the most part, men without either rank or social standing.". 1

Keiki himself, although the memorial was directed against him, may fairly be reckoned among these longsighted patriots. The Tosa memorial appealed so forcibly to the convictions he entertained that he at once summoned a council of all feudatories and high officials then in Kyōto; informed them of his resolve to adopt the advice of the memorialist, and, on the following day, handed in his resignation to the Emperor. This memorable event took place on the 14th of October, 1867; and the answer of the Emperor before the assembly of December 15th marked the end of the shogunate.

\section{THE 122ND SOVEREIGN, THE EMPEROR MUTSUHITO (A.D. 1867-1912)}

The throne was occupied at this time by Mutsuhito, who had succeeded on the 13th of February, 1867, at the death of his father, Kōmei, and who himself died on the 29th day of July 1912. At the time of his accession, the new monarch was in his fifteenth year, having been born on the 3rd of November, 1852.

[1 Encyclopaedia Britannica, 11th Edition; article "Japan," by Brinkley.] 


\section{IMMEDIATE CONSEQUENCE OF THE RESIGNATION}

Undoubtedly Keiki's resignation was presented in all good faith. It deserves to rank among the most memorable ineidents of the world's history, for such a sacrifice has seldom been made by any ruler in the interests of his nation. But by the Satsuma and Chōshū feudatories, the sincerity of the shōgun was not recognized. Through their influence the youthful Emperor was induced to issue an edict calling Keiki a traitor, accusing him of arrogance and disloyalty, declaring that he had not hesitated to violate the commands of the late Emperor, and directing that he should be destroyed. In obedience to this reseript the Tokugawa officials were treated with such harshness that Keiki found it impossible to ealm their indignation; it culminated in an abortive attack upon Kyōto. Thereupon, Keiki retired to Yedo, which eity he subsequently surrendered unconditionally. But all his former adherents did not show themselves equally placable.: An attempt was made to set up a rival candidate for the throne in the person of the Imperial lord-abbot of the Ueno monastery in Yedo; the Aizu clan made a gallant and unsuccessful resistance in the northern provinees, and the shōgun's admiral, Yenomoto (afterwards viscount), essayed to establish a republic in Yezo, whither he had retired with the Tokugawa warships: But these petty incidents were altogether insignificant compared with the great event of which thcy were a sequel.

\section{THE MEIJI GOVERNMENT AND FOREIGN INTERCOURSE}

The year-name was now ehanged to Meiji (Enlightened Government), from January 1, 1868, a term fully justified by events. One of the earliest acts of the new Government was to invite the foreign representatives to the Imperial city,-where the Emperor himself received them in audienee, an act of extreme condescension according to Japanese canons of etiquette. Thereafter, an Imperial decree announced the sovereign's determination to cement amicable relations with foreign nations, and declared that any Japanese subject guilty of violence to a foreigner would be: acting in contravention of his sovereign's commands, as well as injuriously to the dignity and good faith of the country in the eyes of the powers with which his Majesty had pledged himself to maintain friendship. So signal was the change that had taken place in the demeanour of the nation's leaders towards foreign intercourse! Only two years earlier, the advent of a squadron of foreign war-vessels at Hyogo had created almost a panic and had caused men to cry out that the precincts of the sacred eity of Kyōto were in danger of desecration by barbarian feet. But now the Emperor invited the once hated aliens to his presence, treated them with the utmost courtesy, and publicly greeted them as welcome guests. Such a metamorphosis has greatly perplexed some students of Japanese history. Yet the explanation is simple. The Kagoshima and Shimonoseki expeditions had taught Japan that she was powerless in the face of Western armaments; she had learned that national effacement must be the sequel of seclusion, and, above all, she had come to an understanding that her divided form of government paralyzed her for purposes of resistance to aggression from abroad. 


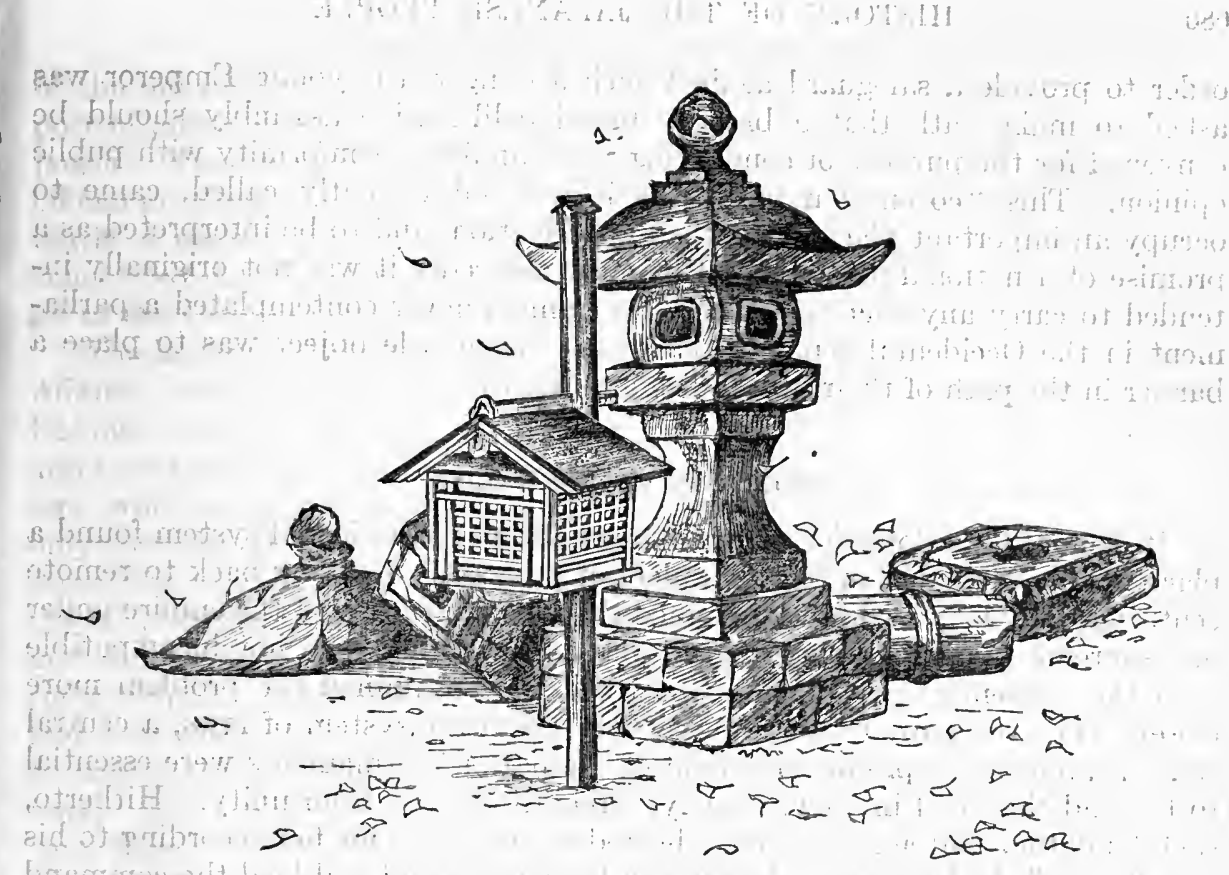

Stone and Wooden Lanterns Erected in Front of Shrines

\section{CHAPTER XLVI}

\section{THE MEIJI GOVERNMENT}

\section{THE LEADERS OF REFÖRM}

In describing the events that culminated in the fall of the Tokugawa, frequent references have been made to the feudatories. But it should be clearly understood that the feudal chiefs themselves had very little to do with the consummation of this great change. "The men that conceived and achieved the Revolution of 1867 , were chiefly samurai of inferior grade." They numbered fifty-five in all, and of these only thirteen were aristocrats, namely, five feudal barons and eight court nobles. The average age of these fifty-five did not exceed thirty years.

\section{THE EMPEROR'S OATH}

The great clans which took part in bringing about this restoration of the administrative power to the Emperor did not altogether trust one another. Hitherto, all political commotions had been planned for the sake of some prominent family or eminent leader, and had resulted merely in altering the personnel of those occupying the seats of power. It was not unnatural that history should have been expected to repeat itself in 1867, especially since the clan mainly responsible, Satsuma, overshadowed all its associates with one exception. Therefore, to many onlookers it seemed that the Tokugawa Government had been overthrown to make room for the all-powerful southern feudatory. In 
order to provide a safeguard against such a danger, the young Emperor was asked to make oath that a broadly based deliberative assembly should be convened for the purpose of conducting State affairs in conformity with public opinion. This "coronation oath," as it was subsequently called, came to occupy an important place in political appreciation, and to be interpreted as a promise of a national assembly. But most assuredly it was not originally intended to carry any such meaning. Its framers never contemplated a parliament in the Occidental sense of the term. Their sole object was to place a barrier in the path of their own selfish ambitions.

\section{ABOLITION OF FEUDALISM}

It is more than doubtful whether the abolition of the feudal system found a place in the original plan of the leaders of progress. Looking back to remote centuries, they may well have imagined that the unification of the empire under one supreme ruler, administering as well as governing, was not incompatible with the existence of the fiefs. But when they. examined the problem more closely, they recognized that a universally operative system of laws, a central treasury, and the supreme command of the nation's armaments were essential to the end they had in view, namely, strength derived from unity. Hitherto, each feudatory had assessed and collected taxes within his fief according to his own free-will, had exercised the right of legislation, and had held the command of all troops within his territories.

The continuance of such conditions would have defeated the purpose of the reformers. This they recognized. But how were these prescriptive privileges to be abolished? An Imperial mandate might indeed have been issued, but even an Imperial mandate without the means of enforcing it would probably have proved futile. In fact, compulsion in any form could not be employed: the only resource was persuasion. The feudatories of Satsuma, Chōshū, Tosa, and Hizen were the four most puissant in the empire. They were persuaded to surrender their fiefs to the Throne and to ask for reorganization under a uniform system of law. This example found many imitators. Out of the whole 276 feudatories only seventeen failed to make a similar surrender. It was a wonderful display of patriotic altruism in the case of some, at any rate, of the daimyō. But, at the same time, many undoubtedly obeyed the suggestions of their chief vassals without fully appreciating the cost of obedience. - It had long been their habit to abandon the management of their affairs to seneschals (karō), and they followed the custom on this occasion without profound reflection.

With the samurai at large, however, the case was different. For them, the preservation of the fief had always been the prime object of interest and fealty: To uphold it concerned their honour; to preserve it, their means of livelihood. Nothing could have been more remarkable than that these men should have quietly acquiesced in the surrender of legislative and financial autonomy by their chiefs. The most credible explanation is that on this great occasion the samurai obeyed their habitual custom of associating some form of self-immolation with every signal deed.

\section{THE NEW ORGANIZATION}

The total abolition of feudalism may be said to have now come in sight, but the leading progressists adopted all precautions to consummate their programme without disturbance. They resolved to preserve, at the outset, the semblance 
of the old system, and to that end the ex-feudatories were nominated to the post of governor in the districts where they had formerly exercised autonomic power The samurai, however, were left in possession of their incomes and official positions: It was enacted that each governor should receive yearly onetenth of the revenue of his former fief; that the emoluments of the samurai should be taken in full from the same source, and that the surplus, if any, should go to the Central Government.

fro The latter was organized with seven departments, namely, Religion, Home Affairs, Foreign Affairs, Army and Navy, Finance, Justice, and Law. This Gabinet was presided over by a premier - necessarily an Imperial princeand by a vice-premier.: Moreover, it was assisted by a body of eighteen councillors, who comprised the leaders of reform. Evidently, however, all this was only partial. It is true that the fiefs ( $h a n$ ) had been converted into prefectures (ken ), and it is also true that the daimyo had become mere governors. But, on the other hand, the local revenues continued to pass through the hands of the governors, and in the same hands remained the control of the samurai and the right of appointing and dismissing prefectural officials. A substantial beginning had been made, however, and presently another appeal being addressed to the ex-daimy $\bar{o}$, they were induced to petition for the surrender of their lccal autonomy. The same plan was pursued in the case of the samurai. It was essential that these should cease to be hereditary soldiers and officials and should be reabsorbed into the mass of the people from whom they had sprung originally. Following the course which had proved so successful with the feudatories, a number of samurai were induced to memorialize for permission to lay aside their swords and revert to agriculture. But neither in the case of the feudatories nor in that of the samurai were these self-sacrificing petitions carried into immediate practice. They merely served as models.

\section{CLAN REPRESENTATION}

It may well be supposed that the ambitions of the great clans by which this revolution has been effected proved somewhat difficult to reconcile. The Satsuma feudatory was the first to take umbrage. He contended that, in selecting the high officials of the new organization, sufficient account had not been taken of the services of his fief. With considerable difficulty he was satisfied by his own appointment to an office second only to that of prime minister. This incident led, however, to an agreement under which each of the great clans, Sätsuma, Chōshū, Hizen, and Tosa, should be equally represented in the Government. Thus, the "principle of clan-representation received practical recognition in the organization of the Government. It continued to be recognized for many years, and ultimately became the chief target of attack by partypoliticians:" It was further arranged, at this time, that each of the above four clans should furnish a contingent of troops to guard the sovereign's person and to form the nucleus of a national army.

\section{ABOLITION OF LOCAL AUTONOMY}

It being now considered safe to advance to the next stage of the mediatization of the fiefs, the Emperor issued an edict abolishing local autonomy; removing the sometime daimy $\bar{o}$ from their post of prefectural governor; providing that the local revenues should thereafter be sent into the central treasury; declaring 
the appointment and dismissal of officials to be among the prerogatives of the Imperial Government; directing that the ex-feudatories should continue to receive one-tenth of their former incomes but that they should make Tökyō ${ }_{1}^{1}$ their place of permanent residence, and ordaining that the samurai should be left in continued and undisturbed possession of all their hereditary pensions and allowances.

These changes were not so momentous as might be supposed at first sight. It is true that the ex-feudatories.were reduced to the position of private gentlemen without even a patent of nobility. But, as a matter of fact, the substance of administrative power had never been possessed by them: it had been left in most eases to their seneschals. Thus, the loss of what they had never fully. enjoyed did not greatly distress them.- Moreover, they were left in possession of the accumulated funds of their former fiefs, and, at the same time, an income of one-tenth of their feudal revenues was guaranteed to them-a sum which generally exceeded their former incomes when from the latter had been deducted all charges on account of the maintenance of the fiefs. Therefore, the sacrifice they were required to make was not so bitter after all, but that it was a very substantial sacrifice there can be no question.

\section{THE SAMURAI'S POSITION}

The above edict was promulgated on August 29,1871; that is to say, nearly four years after the fall of the Tokugawa. The samurai, however, remained to be dealt with. Feudalism could not be said to have been abolished so long as the samurai continued to be a class apart. These men numbered four hundred thousand and with their families represented a total of about two million souls. They were the empire's soldiers, and in return for devoting their lives to military service they held incomes, some for life, others hereditary, and these enoluments aggregated two millions sterling annually. No reformer, however radical, would have suggested the sudden disestablishment of the samurai system or advocated the wholesale deprivation of incomes won by their forefathers as a reward for loyal service to the State or to the fiefs.

The Government dealt with this problem much as it had done with the problem of the feudatories. In 1873 , an Imperial decree announced that the treasury was ready to commute the samurai's incomes on the basis of six-years purchase in the place of hereditary pensions and four years for life-pensions, half of the money to be paid in eash and the remainder in bonds carrying eight per cent. interest. This measure was. in no sense compulsory; the samurai were free to accept or reject it. Not a few chose the former course, but a large majority continued to wear their swords and draw their pensions as of old. The Government, however, felt that there could be no paltering with the situation. Shortly after the issue of the above edict a conscription law was enacted, by which every adult male became liable for military service, whatever his social status. Naturally, this law shocked the samurai. The heavy diminution of their incomes hurt them less, perhaps, than the necessity of laying aside their swords and of giving up their traditional title to represent their country in arms. They had imagined that service in the army and navy would be reserved exclusively for them and their sons, whereas by the conscription law the commonest unit of the people became equally eligible.

1 Yedo was now called Tōkyō, or "Eastern Capital;" and Kyōto was named Saikyō, or "Western Capital."] 


\section{FRICTION AMONG THE LEADERS OF REFORM}

It could not have been expected that this manner of treating the samurai would obtain universal approval. Already, too, the strain of constructive statesmanship had developed friction among the progressist leaders who had easily marched abreast for destructive purposes. They differed about the subject of a national assembly, some being inclined to attach more practical importance than others to the Emperor's coronation oath that a broadly based deliberative assembly should be convened: A small number of zealous reformers wished to regard this as a promise of a national assembly, but the great majority of the progressist leaders interpreted it merely as a guarantee against the undue preponderance of any one clan. In fact, according to the view of the latter party the broadly based deliberative assembly was regarded solely as an instrument for eliciting the views of the samurai, and

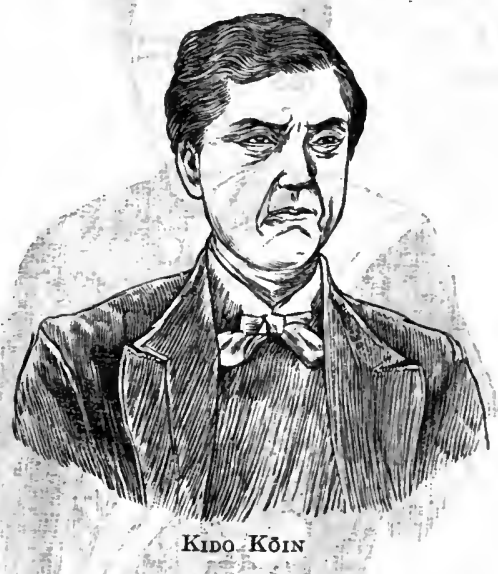
entirely without legislative power. Such an assembly was actually convened in the early years of the:Meiji era, but its second session proved it to be nothing

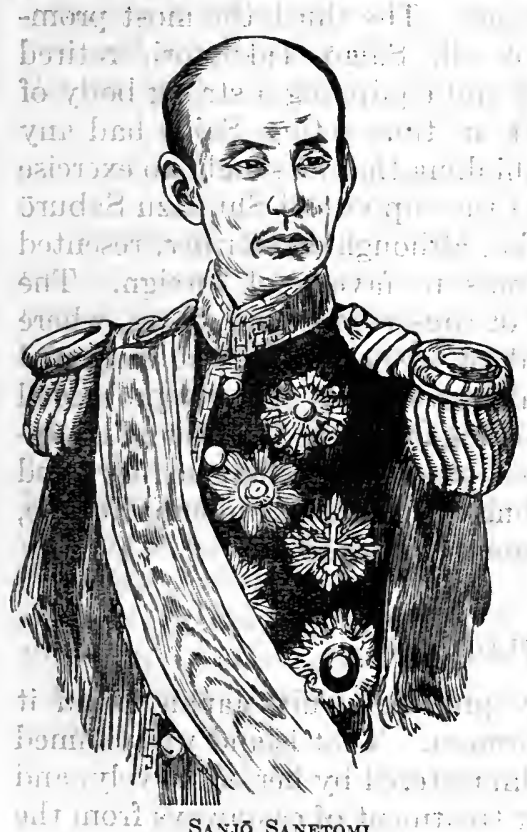

SANJó SATEToMi more than a debating club and it was suffered to lapse out of existence.

A more perplexing problem now (1873) presented itself, however. The Korean Court deliberately abandoned the custom followed by it since the time of Hideyoshi's invasion - the custom of sending a presentbearing embassy to felicitate the accession of each shōgun. Moreover, this step was accompanied by an offensive despatch announcing a determination to cease all relations: with a renegade from the civilization of the Orient. : It may well be imagined how indignantly this attitude of the neighbouring kingdom was resented by Japan. The prominent leaders of national reform at that time were Sanjō and Iwakura, originally Court nobles;' Saigō and Ōkubo, samurai of Satsuma, and Kido, a samurai of Chōshū. In the second rank: were several men destined afterwards to attain great celebrity - the late Prince Itō, Marquis Inouye, Count Ōkuma, Count Itagaki "-often spoken of as the "Rousseau of Japan" - and several others.

The first five; however, were pre-eminent at the moment when Korea sent her offensive message. They were not, however, absolutely united as to policy: Saigo Takamori held some conservative opinions, the chief of which was that

[ ${ }^{1}$ The distinction between Court nobles and territorial nobles had been abolished in 1871.] 
he wished to preserve the military class in their old position of the empire's only soldiers. He had, therefore, greatly resented the eonscription law, and while his discontent was 'still fresh' the Korean problem presented itself for

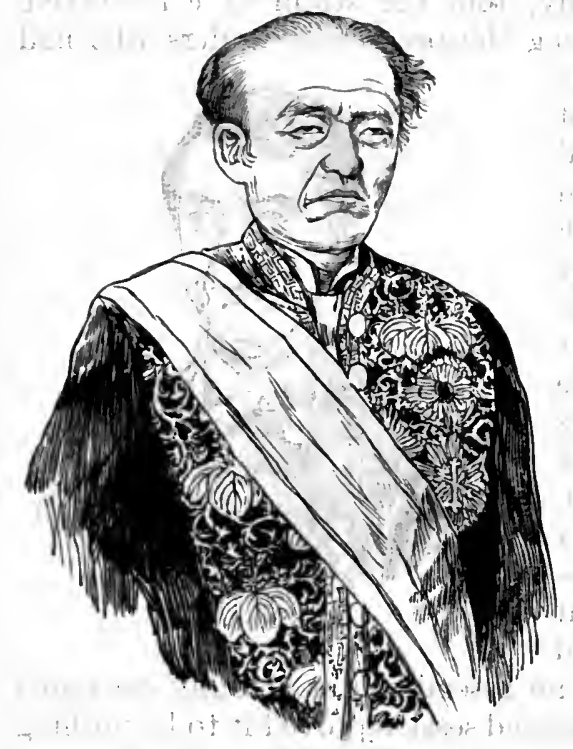

IWAKURA Tomóosmi

solution. In Saigō's eyes an oversea war. offered the only chance of saving the samurai, since the conscription law had not yet produced any trustworthy soldiers. He therefore voted to draw the sword at once, and in this he obtained the support of several influential men who burned to avenge the nation's disgrace... On the other hand, those in favour of peace insisted that the country must not venture to engage in a foreign war during the era of radical transition.

The discussion was carried to the Emperor's presence; the peace-party prevailed, and Saigo with three other Cabinet ministers resigned. One of the seceders, Etō Shimpéi, had recourse to arıns, but was speedily crushed. Another, Itagaki Taisuke; from thíat moment stood forth as the champion of representative institutions. The third, the most prominent? of all, Saigo Takamori, retired to Satsuma and devoted himself to organizing and equipping a strong body of samurai. It is not by any means clear that, in thus acting, Saigo had any revolutionary intention. Posterity agrees in thinking that he sought to exercise control rather than to inspire revolt. He had the support of Shimazu Saburō (Hisamitsu), former feudatory of Satsuma, who, although a reformer, resented a : wholesale abandonment of Japanese customs in favour of foreign. The province of Satsuma thus became a seed-plot of conservative influences, where "Saigō and his constantly augmenting band of samiurai found a congenial environment." On the one hand, the Central Government steadily proceeded with the organization of a conscript army, teaching it foreign tacties and equipping it with foreign arms. On the other, the southern clan cherished its band of samurai, arming them with the rifle and drilling them in the manner of Europe, but leaving them always in posession of the samurai's sword.

\section{THE FORMOSAN EXPEDITION}

Before these curious conditions bore any practical fruit, Japan found it necessary to send a military expedition to Formosa. That island was claimed as part of China's domains, but it was not administered by her effectively, and its inhabitants showed great barbarity in their treatment of castaways from the Ryūkyū, or Loochoo, Islands. The Chinese Government's plain function was to punish these acts of eruelty, but as the Peking statesmen showed no disposition to discharge their duty in that respect, Japan took the law. into her own hands. A double purpose was thus served. For the expedition to Formosa furnished employment for the Satsuma samurai, and, at the same time, assured the Ryūkyū islanders that Japan was prepared to protect them. 
The campaign in Formosa proved a very tame affair. It amounted to the shooting-down of a few semi-savages. No attempt was made to penetrate into the interior of the island, where, as modern experience shows, many great difficulties would have had to be overcome. Peking took serious umbrage on account of Japan's high-handed conduct - for such it seemed to Chinese eyes. In the first place, the statesmen of the Middle Kingdom contended that the Ryūkyū Islands could not properly be regarded as an integral part of the Japanese empire; and the second place, they claimed that, in attacking Formosa, Japan had invaded Chinese territory. After a long interchange of despatches the Tōkyō Government sent an ambassador to Peking, and a peaceful solution was found in the payment by China of a small indemnity, and the recognition of Formosa as a part of the Middle Kingdom. ${ }^{1}$

\section{THE KOREAN QUESTION AGAIN}

The Formosan expedition took place in 1874, and, in the fall of 1875, a Korean fort opened fire on a Japanese warship which was engaged in surveying the coast. Such an insult could not be tamely endured. Japan marshalled an imposing number of warships and transports; but, following the example set in her own case by. Commodore Perry, she employed this flotilla to intimidate Korea into signing a treaty of amity and commerce and opening certain ports to foreign trade. Thus, Korea was drawn from her hereditary isolation, and to Japan fell the credit of having become an instrument for extending the principle of universal intercourse which she had herself so stoutly opposed during two and a half centuries. It was a clever coup, but it earned little credit with the samurai., They regarded such a settlement as derogatory to their country.

\section{ABOLITION OF THE SAMURAI}

It was at this stage that the Tōkyō Government felt itself strong enough to resort to conclusive measures in the cases of the samurai. Three years had now passed since the wearing of swords had been declared optional and since a scheme for the voluntary commutation of the samurai's pensions had been elaborated. The leaders of progress felt that the time had now come to make these measures compulsory, and, accordingly, two edicts were issued in that sense. The edicts, especially their financial provisions, imposed a heavy sacrifice. But it is very noticeable that the momentary question evoked no protests. It was to the loss of their swords that a number of samurai objected strenuously. Some scores of them, wearing old-fashioned armour and equipped with hereditary. weapons, attacked a castle, killed or wounded three hundred of the garrison, and then died by their own hands. Here and there throughout the empire a few: equally vain protests were raised, and finally the Satsuma samurai took the field.

\section{THE SATSUMA REBELLION}

This insurrection in the south severely taxed the resources of the Central Government. The Satsuma samurai were led by Saigo Takamori, but it has always been claimed for him that he undertook the command, not for the purpose of overthrowing the Meiji Government, but in the hope of restraining his followers. Ultimately, however, he seems to have been swept away by the

[1 The indemnity amounted to 500,000 dollars (Mexican).] 
tide of their enthusiasm. The insurgents numbered some forty thousand; they all belonged to the samurai class, were fully trained in Oceidental tactics, and were equipped with rifles and field-guns. Their avowed purpose was to restore

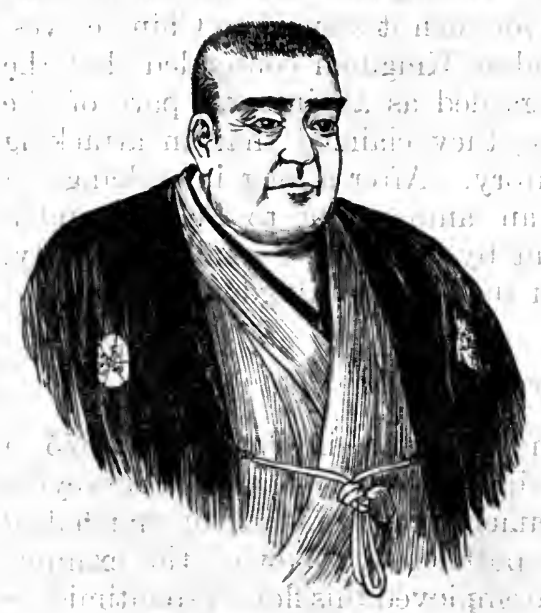

Saigo Takamori the military class to its old position'; and to insure to it: all the posts in the army and the navy.

Fighting began on January $29,187.7$, and ended on September 24 th of the same year. All the rebel leaders fell in battle or died by their own hands. During these eight months of warfare; the Government put sixty-six thousand men into the field, and the casualties on both sides totalled thirty-five thousand, or thirty-three per cent. of the whole. Apart from the great issue directly at stake, namely, whether Japan should have a permanent military cláss, a secondary problem of much interest found a solution in the result.- It was the problem whether an army of conscripts, supposed to be lacking in the fighting instinct and believed to be incapable of standing up to do battle with the samurai, could hold its own against the flower of the bushi, as the Satsuma men undoubtedly were. There really never was any substantial reason for doubt about such a subject. The samurai were not racially distinct from the bulk of the nation. They had originally been mere farmers, possessing no special military aptitude. Nevertheless, among all the reforms introduced during the Meiji era, none was counted so hazardous as the substitution of a conseript army for the nation's traditional soldiers. : The Satsuma rebellion disposed finally of the question.

\section{EDUCATION OF THE NATION}

Meanwhile the Government had been strenuously seeking to equip the people with the products of Western civilization. It has been shown that the men who sat in the seats of power during the first decade of the Meiji era owed their exalted position to their own intellectual superiority and far-seeing statesmanship. That such men should become the nation's teachers would have been natural anywhere. But in Japan there was a special reason for the people's need of official guidance. It had become a traditional habit of the Japanese to look to officialdom for example and direction in everything, and this habit naturally asserted itself with special force when there was question of assimilating a foreign civilization which for nearly three centuries had been an object of national repugnance. The Government, in short, had to inspire the reform movement and, at the same time, to furnish models of its working.

The task was approached with wholesale energy by those in power. In general the direction of the work was divided among foreigners of different nations. Frenchmen were employed in revising the criminal code and in teaching strategy and tactics to the Japanese army. The building of railways, the installation of telegraphs and of lighthouses, and the new navy were turned over to English engineers and sailors. Americans were employed in the formation 
of a postal service, in agricultural reforms; and in planning colonization and an educational system. $:$ In an attempt to introduce Occidental ideas of art Italian sculptors and painters were brought to Japan." And German experts were asked to develop a system of local government, to train Japanese physicians, and to educate army officers. Great misgivings were expressed by foreign onlookers at this juncture. They found it impossible to believe that such wholesale adoption of an alien civilization could not be attended with due eclecticism, and they constantly predieted a violent reaction. But all these pessimistic views were contradicted by results. There was no reaction; and the memory of the apprehensions then freely uttered finds nothing but ridicule to-day.

\section{FINANCE}

One of the chief difficulties with which the Meiji statesmen had to contend was finance. When they took over the treasury from the Bakufu there were absolutely no funds in hand, and for some years, as has. been shown above, all the revenues of the former fiefs were locally expended, no part of them, exeept a doubtful surplus, finding its way to the Imperial treasury. The only resource wàs an issue of paper money. Such tokens of exchange had been freely employed since the middle of the seventeenth century, and at the time of the mediatization of the fiefs, 1694 kinds of notes were in circulation.

The first business of the Government should have been to replace these unsecured tokens with uniform and sound media of exchange. But instead of performing that duty the Meiji statesmen saw themselves compelled to follow the evil example set by the fiefs in past times:- Government notes were issued. They fell at the outset to a discount of fifty per cent. and various devices, more or less despotic, were employed to compel their circulation at par. By degrees, however, the Government's credit improved, and thus, though the issues of inconvertible notes aggregated sixty million yen at the close of the first five years of the Meiji era, they passed freely from hand to hand without discount. . But, of course, the need for funds in connexion with the wholesale reforms and numerous enterprises inaugurated officially became more and more pressing, so that in the fourteenth year (1881) after the Restoration, the face value of the notes in circulation aggregated 180 million yen, and they stood at a heavy discount. $\rightarrow$ The Government, after various tentative and futile efforts to correct this state of depreciation, set themselves to deal radically with the problem. Chiefly by 'buying exporters' bills and further by reducing administrative expenditures as well as by taxing alcohol, a substantial specie reserve was gradually accumulated, and, by 1885 , the volume of fiduciary notes having been reduced to 119 millions, whereas the treasury vaults contained forty-five millions of precious metals, the resumption of specie payments was announced. As for the national debt, it had its origin in the commutation of the feudatories' incomes and the samurai's pensions. A small fraction of these outlays was defrayed with ready money, but the great part took the form of public loan-bonds. These bonds constituted the bulk of the-State's liabilities during the first half-cycle of the $M e i j i$ era, and when we add the debts of the fiefs, which the Central Government took over; two small foreign loans; the cost of quelling the Satsuma rebellion, and various debts incurred on account of public works, naval construction, and minor purposes, we arrive at the broad fact that the entire national debt of Japan did not exceed 305 million yen at the close of the twenty-eighth year of her new era. 
A war with China in 1894-1895 - to be presently spoken of - and a war with Russia in 1904-1905, together with the price paid for the nationalization of railways and for various undertakings, brought the whole debt of the nation to 2300 million yen in 1907, which is now being paid off at the rate of fifty million yen annually. It remains to be noted that, in 1897, Japan took the momentous step of adopting gold monometallism. The indemnity which she obtained from China after the war of $1894-1895$ brought to her treasury a stock of gold sufficient to form a substantial specie reserve. Moreover, gold had appreciated so that its value in terms of silver had exactly doubled during the first thirty years of the Meiji era. There was consequently no arithmetical complication connected with the adoption of the single gold standard. It was only necessary to double the denomination, leaving the silver subsidiary coins unchanged.

\section{EDUCATION}

In the field of education the Meiji statesmen effected speedy reforms. Comparatively little attention had been directed to this subject by the rulers of medieval Japan, and the fact that the Meiji leaders appreciated the necessity of studying the arts and sciences of the new civilization simultaneously with the adoption of its products, bears strong testimony to the insight of these remarkable men. Very shortly after the abolition of feudalism, an extensive system of public sehools was organized and education was made compulsory. "There were schools, colleges, and universities, all modelled on foreign lines with such alterations as the special customs of the nation dictated. These institutions grew steadily in public favour, and to-day over ninety per cent. of boys and girls who have attained the school age receive education in the common elementary schools, the average annual cost per child being about $8 s .6 \mathrm{~d} .(\$ 2.00)$, to which the parents contribute $13 / 4 d$. (31/2 cents) per month. Youths receiving education enjoy certain exemption from conscription, but as this is in strict.accordance with the Western system, it need not be dwelt upon here.

\section{LOCAL ADMINISTRATION}

For purposes of local administration the empire is divided into prefectures (ken), counties (gun), towns (shi), and districts (chō or son). The three metropolitan prefectures of Tökyō, Ōsaka, and Kyōto are called $f u$, and their districts are distinguished as "urban" (chō) and "rural" (son), according to the number of houses they contain. The prefectures derive their names from their chief towns. The prineiple of popular representation is strictly adhered to, every prefecture, every county, every town, and every district having its own local assembly, wherein the number of members is fixed in proportion to the population. These bodies are all elected. The enjoyment of the franchise depends upon a property qualification which; in the ease of prefectural and county assemblies, is an annual payment of direct national taxes to the amount of three yen (6s., \$1.50); in the ease of town and district assemblies two yen; and in the case of prefectural assemblies, ten yen. There arelother arrangements to secure the due representation of property, the electors being divided into classes according to their aggregate payment to the national treasury. Three, such classes exist, and each elects one-third of an assembly's mombers.. There is no payment for the members of an assembly; but all salaried officials, ministers of religion, and contractors for public works, as well as persons unable to write 
their own names and the names of the candidates for whom they vote, are denied the franchise.

A prefectural assembly holds one session of thirty days annually; and a county assembly, one session of not more than fourteen days; while the town and district assemblies are summoned by the mayor or the headman whenever recourse to their deliberation appears expedient. Each prefecture has a prefect (governor) and each county assembly has a headman. Both are appointed by the Central Administration, but an assembly has competence to appeal to the minister of Home Affairs from the prefect's decisions. In the districts, also, there are headmen, but their post is always elective and generally non-salaried. Other details of the local-government system are here omitted." It suffices to say that the system has been in operation for over thirty years and has been found satisfactory in practice. Moreover, these assemblies constitute excellent schools for the political education of the people.

\section{THE CONSTITUTION}

It has already been shown that the sovereign's so-called coronation oath did not contemplate a national assembly in the Western sense of the term: The first assembly convened in obedience to the oath consisted of nobles and samurai only; and was found to be a virtually useless body. Not till 1873, when Itagaki Taisuke, seceding from the Cabinet on account of the Korean complication, became a warm advocate of appealing national questions to an elective assembly, did the people at. large come to understand what was involved in such an institution. Thenceforth Itagaki became the centre of a more or less enthusiastic group of men advocating a parliamentary system, some from sincere motives, and others from a conviction that their failure to obtain posts was in a manner due to the oligarchical form of their country's polity.

When the Satsuma rebellion broke out, four years later, this band of Tosa agitators memorialized the Government, charging it with administering affairs in despite of public opinion; with ignoring popular rights, and with levelling down instead of up; since the samurai had been reduced to the class of commoners, whereas the latter should have been educated to the standard of the former. But the statesmen in power insisted that the nation was not yet ready to enjoy constitutionál privileges.: They did not, indeed, labour under any delusion as to the ultimate direction in which their reforms tended, but they were determined to move gradually, not precipitately. They had already (1874) arranged for the convention of an annual assembly of prefects who should act as channels of communication between the central authorities and the people in the provinces. This was designed to be the embryo of representative institutions, though obviously it bore that character in a very limited degree only.

In the following year (1875), the second step was taken by organizing a Senate (Genrō-in), which consisted of official nominees and was charged with the duty of discussing and revising laws and ordinances prior to their promulgation. But it had no power of initiative, and its credit in the eyes of thenation was more or less injured by the fact that its members consisted for the most part of men for whom no posts could be found in the administration and who, without some steadying influence, might have been drawn into the current of discontent.

At this stage, an event occurred which probably moved the Government to greater expedition. In the spring of 1878 , the great statesman, Ōkubo Toshimitsu, who had acted such a prominent part on the stage of the reformation drama, 
was assassinated. His slayers were avowedly sympathizers of Saigo, but in their statement of motives they assigned as their prineipal incentive the Government's failure to establish representative institutions. They belonged to a province

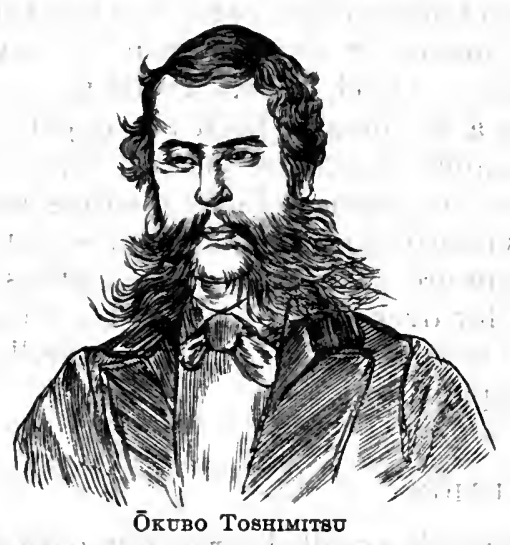
far removed from Satsuma, and their explanation of the murder showed that they had little" knowledge of Saigō's real sentiments. But the nation saw in them champions of a constitutional form of government, and the authorities appreciated the necessity of greater expedition. Thus, two months "after Ōkubo's death, the : establishment of elective assemblies in the prefectures and cities was proclaimed.

Reference has already been made to these and it will suffice here to note that their principal functions were to determine the amount and object of local taxes; to audit the accounts for the previous year; and to petition the Central Government, should that seem expedient. These assemblies represented the foundations of genuinely representative institutions, for although they lacked legislative power, they discharged parliamentary functions in other respects. In fact, they served as excellent training schools for the future Diet. But this did not at all satisfy Itagaki and his followers. They had now persuaded themselves that without a national assembly it would be impossible to oust the clique of elansmen who monopolized the prizes of power. Accordingly, Itagaki organized an association called $J i y \bar{u}-t \bar{o}$ (Liberals), the first political party in Japan. Between the men in office and these visionary agitators a time of friction, more or less severe, ensued. The Government withheld from the people the privileges of free speech and public meeting, so that the press and the platform found themselves in frequent collision with the police. Thus, little by little, the Liberals came to be regarded as victims of official tyranny, so that they constantly obtained fresh adherents.

Three years subsequently (1881), another political crisis occurred. Ōkuma Shigenobu resigned his portfolio, and was followed into private life by many able politicians and administrators. These organized themselves into a party ultimately called Progressists (Shimpo-tō), who, although they professed the same doctrine as the Liberals, were careful to maintain an independent attitude; thus showing that "Japan's first political parties were grouped, not about principles, but about persons."

It must not be supposed for a moment that the Progressists were conservative.' There was no such thing as real conservatism in Japan at that time. The whole nation exhaled the breath of progress. Ōkuma's secession was followed quickly by an edict promising the convention of a national assembly in ten years. Confronted by this engagement; the political parties might have been expected to lay down their arms. But a great majority of them aimed at ousting the clan-statesmen rather than at setting up a national assembly. Thus, having obtained a promise of a parliament, they applied themselves to exeiting antiofficial sentiments in the future electorates; and as the Government made no attempt to controvert the prejudices thus excited, it was evident that when the ['Encyclopadia Britannica (11th edition); article "Japan," by Brinkley.] 
promised parliament came into existence, it would become an arena for vehement attacks upon the Cabinet.

Of course, as might have been expected, the ten years of agitated waiting, between 1881 and 1891, were often disfigured by recourse to violence. Plots to assassinate ministers; attempts to employ dynamite; schemes to bring about an insurrection in Korea - such things were not infrequent. There were also repeated dispersions of political meetings by order of police inspectors, as well as suspensions or suppressions of newspapers by the fiat of the Home minister. Ultimately it became necessary to enact a law empowering the police to banish persons of doubitful character from Tōkyō without legal trial, and even to arrest and detain such persons on suspicion. In 1887, the Progressist leader, Ōkuma, rejoined the Cabinet for a time as minister of Foreign Affairs, but after a few months of office his leg was shattered by a bomb and he retired into private life and founded the Waseda University in Tōkyō.

by It may indeed be asserted that during the decade immediately prior to the opening of the national assembly, "an anti-Government propaganda was incessantly preached from the platform and in the press." The Tökyo statesmen, however, were not at all discouraged. They proceeded with their reforms unflinchingly. In 1885, the ministry was recast, Itō Hirobumi - the same Prince Ito who afterwards fell in Manchuria under the pistol of an assassin - being appointed premier and the departments of State being reorganized on European lines. Then a nobility was created, with five orders, prince, marquis, count, viscount, and baron. The civil and penal laws were codified. 'The finances were placed on a sound footing. A national bank with a network of subordinate institutions was established. Railway construction was pushed on steadily. Postal and telegraph services were extended. The foundations of a strong mercantile marine were laid. A system of postal savings-banks was instituted. Extensive schemes of harbour improvement, roads, and riparian works were planned and put into operation. The portals of the civil service were made accessible solely by competitive examination. A legion of students was sent westward to complete their education, and the country's foreign affairs were managed with comparative skill.'

\section{PROMULGATION OF THE CONSTITUTION}

On the 11th of February, 1889, the Constitution was promulgated amid signs of universal rejoicing. The day was signalized, however, by a terrible deed. Viscount Mori, one of Japan's most enlightened statesmen, was stabbed to death by Nishino Buntarō, a mere stripling, the motive being to avenge what the murderer regarded as a: sacrilegious act, namely, that the viscount, when visiting the shrine at Ise in the previous year, had partially raised one of the curtains with his cane. The explanation given of this extraordinary act by a modern historian is that "Japan was suffering at the time from an attack of hysterical loyalty, and the shrine at Ise being dedicated to the progenitrix of the country's sovereigns, it seemed to Nishino Buntarō that when high officials began to touch the sacred paraphernalia with walking-sticks, the foundations of "Imperialism were menaced." An interesting light is thrown upon the Japanese character in the sequel of this crime. During many subsequent years the tomb of Nishino received the homage of men and women who "worshipped achievement without regard to the nature of the thing achieved." There was a similar furore of enthusiasm over the would-be assassin of Ōkuma. 


\section{PROVISIONS OF THE CONSTITUTION}

The framers of the Constitution, chief among whom was Prince Itō, naturally took care not to make its provisions too liberal. The minimum age for electors and elected was fixed at twenty-five and the property qualification at payment of direct taxes aggregating not less than fifteen yen $(30$ s. \$7.20) annually.

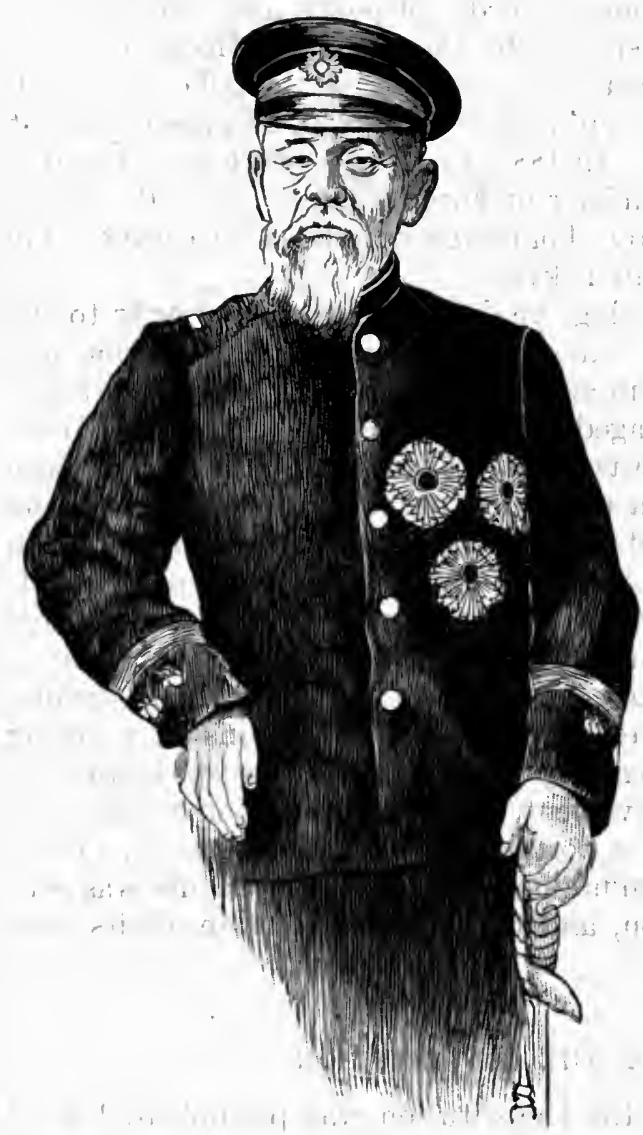

The Late Prince itō

A bicameral system was adopted: The House of Peers was in part hereditary, in part elective (one representative of the highest taxpayers in each prefecture), and in part nominated by the sovereign (from among:men of: signal attainments); while the House of Representatives consisted of three hundred elected members. In the eyes of party politicians this property qualifieation was much too high; it restrieted the number of franchiseholders to 460,000 in a pation of nearly fifty millions. A struggle for the extension of the franchise commenced immediately, and; after nearly ten years, the Government framed a bill lowering the qualifieation to ten yen for electors; dis= pensing with it altogether in the case of candidates; inaugurating secret ballots; extending the limits of the electorates so as to include the whole of a prefecture, and increasing the members of the lower house to 363 . By this change of qualification the number of franchise holders was nearly doubled.

As for the provisions of the Constitution, they differed in no respect from those of the most advaneed Western standard. One exception to this statement must be noted, however. The wording of the document lent itself to the interpretation that a ministry's tenure of office depended solely on the sovereign's ' will. In other words, a Cabinet received its mandate from the Throne, not from the Diet. This reservation immediately became an object of attack by party politicians. They did not venture to protest against the arrangement as an Imperial prerogative. The people would not have endured such a protest. The only course open for the party politicians was to prove practically that a ministry not responsible to the legislature is virtually impotent for legislation. 31?

Success has not attended this essay. The Throne continues, nominally at all events, to appoint and dismiss ministers. As for the proceedings of the diet, the most salient feature was that, from the very outset; the party politicians in the lower chamber engaged in successive attacks upon the holders of power. This 
had been fully anticipated; for during the whole period of probation antecedent to the meeting of the first Diet, the party politicians had been suffered to discredit the Cabinet by all possible means, whereas the Cabinet had made no effort to win for themselves partisans in the electorates. They relied wholly upon the sovereign's prerogative, and stood aloof from alliances of any kind, apparently indifferent to everything but their duty to their country. Fortunately, the House of Peers ranged itself steadfastly on the side of the Cabinet throughout this struggle, and thus the situation was often saved from apparently pressing danger. The war with China (1894-1895) greatly enhanced the Diet's reputation; for all the political parties, laying aside their differences, without a dissenting voice voted funds for the prosecution of the campaign.

\section{POLITICAL PARTIES}

During several years the House of Representatives continued to be divided into two great parties with nearly equally balanced power - the Liberals and the Progressists, together with a few minor coteries. But, in 1898, the Liberals and Progressists joined hands; thus coming to wield a large majority in the lower house. Forthwith, the Emperor, on the advice of Prince Itō, invited Counts Ōkuma and Itagaki to form a Cabinet. An opportunity was thus given to the parties to prove the practical possibility of the system they had so long lauded in theory. The united parties called themselves Constitutionists (Kensei-tō). Their union lasted barely six months, and then "the new links snapped under the tension of the old enmities."

A strange thing now happened. The Liberals invited Prince Itō to be their leader, and he agreed on condition that his followers should obey him implicitly. A new and powerful party was thus formed under the designation of Friends of the Constitution (Rikken Seiynukai). Thus, the Liberals not only enlisted under the statesmen whose overthrow' they had for nearly twenty years sought to effect, but also they practically expunged from their platform an essential article of faith-parliamentary cabinets. Another proof was here furnished that political combinations in Japan were based rather on persons than on principles.

As for the new party, even Prince Itō's wonderful talents and unequalled prestige failed to hold successfully the reins of the heterogeneous team which he had now undertaken to drive. The House of Peers opposed him on account of his association with political parties, and he at once resigned the premiership. The party he had formed did not, however, dissolve. Prince Itō, indeed, stepped out of its ranks, but he was' succeeded by his intimate friend, Marquis Saionji, one of Japan's blue-blooded aristocrats, and to him the Constitutionists have yielded implicit obedience ever'since. 'For the rest; it is impossible to foresee what the outcome of the parliamentary system will be in Japan. "Up to the present the principal lesson learned by politicians seems to have been the value of patience. The Constitutionists have shown that they are quite ready to support a Cabinet entirely independent of parties, where its measures seem conducive to the nation's good.' Such a Cabinet was that of Prince Katsura, who, in turn, after three years' tenure of office, stepped down quietly in August, 1911, to make way for the Constitutionists, under Marquis Saionji. In a word, the nation seems to have arrived at the conclusion that these parliamentary problems cannot be safely solved except by, long and deliberate experiment. ${ }^{1}$

[ ${ }^{1}$ For minute information about party politics, and parliamentary procedure see the "Oriental Series," Vol. IV.] 


\section{AGRICULTURE AND INDUSTRY}

The growth of agricultural and industrial enterprise is one of the most remarkable features of modern Japan. Up to the beginning of the Meiji era, agriculture almost monopolized attention, manufacturing industry being altogether of a domestic character. Speaking broadly, the gross area of land in Japan, exclusive of Saghalien, Korea, and Formosa is seventy-five million acres, and of this only some seventeen millions are arable. It may well be

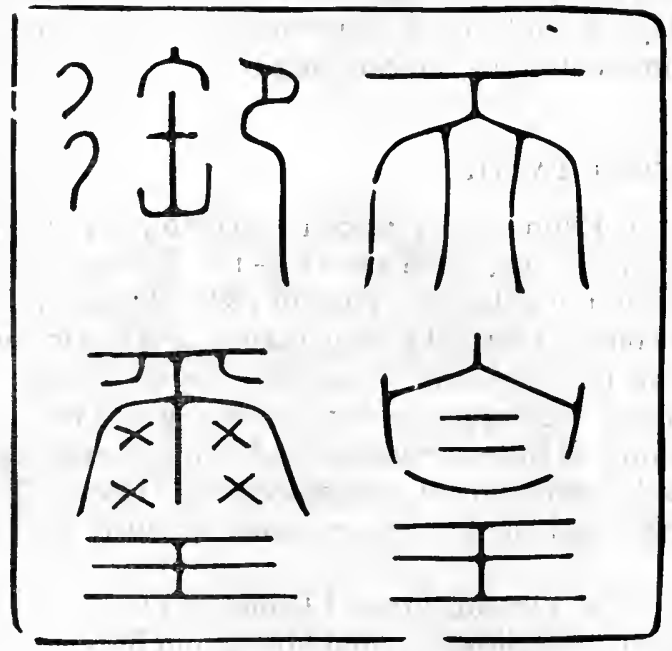

Seal of Mutsuhito, the late Emperor supposed that as rice is the principal staple of foodstuff, and as the area over which it can be produced is so limited, the farmers have learned to apply very intensive methods of cultivation. Thus, it is estimated that they spend annually twelve millions sterling $-\$ 60,000,000-$ on fertilizers. By unflinching industry and skilled processes, the total yield of rice has been raised to an annual average of about fifty million koku; that is to say, two hundred and fifty million bushels:

But the day cannot be far distant when the growth of the population will outstrip that of this essential staple, and unless the assistance of Korea and Formosa can be successfully enlisted, a problem of extreme difficulty may present itself. Meanwhile, manufacturing industry has increased by leaps and bounds. Thus, whereas at the opening of the Meiji era, every manufacture was of a domestic character, and such a thing as a joint-stock company did not exist, there are now fully 11,000 factories giving employment to 700,000 operatives, and the number of joint-stock companies aggregates 9000 . Eviclently, Japan threatens to become a keen competitor of Europe and America in all the markets of the Orient, for she possesses the advantage of propinquity, and as well an abundance of easily trained labour. But there are two important conditions that offset these advantages. In the first place Japanese wages have increased so rapidly that in the last fifteen years they have nearly doubled, and, secondly, it must be remembered that Japanese labour is not so effieient as that of Europe and America.

\section{RAILWAYS}

The work of railway construction, which may be said to have commenced with the $M e i j i$ era, has not advanced as rapidly as some other undertakings. The country has now only 5770 miles of lines open to traffic and 1079 miles under construction. All these railways may be said to have been built with domestic eapital. Nearly the whole was nationalized in 1907, so that the State has paid out altogether sixty-six million pounds sterling $-\$ 325,000,000-$ on account of railways, an investment which yields a net return of about three and a half millions sterling $-\$ 17,000,000-$ annually. 
THE MERCANTILE MARINE

Another direction in which Japanese progress has been very marked is in the development of a mercantile marine. At an early period of the country's modern history, her statesmen recognized that transports are as necessary to the safety of a State as are soldiers, and, in fact, that the latter cannot be utilized without the former. The Government, therefore, encouraged with liberal subsidies and grants-in-aid the purchase or construction of ships, the result being that whereas, in 1871, Japan's mercantile marine comprised only forty-six ships with a total tonnage of 17,948 , the corresponding figures in 1910 were 6436 and $1,564,443$ respectively. In the war with China in 1894-1895, as well as in that with Russia in 1904-1905, Japan was able to carry large armies to the Asiatic continent in her own vessels, thus demonstrating the wisdom of the policy pursued by the Government, although it had been habitually denounced by the enemies of subsidies in any circumstanees. . Shipbuilding yards had also been called into existence, and there are now four of them where vessels aggregating 87,495 tons have been built.

\section{THE ARMY}

It has been seen that the Satsuma rebellion of 1877 severely taxed the military resources of the empire. In fact, the organization of special brigades to supplement the conscripts was found necessary. Therefore, two years later, the conscription law was revised, the total term of service being increased from seven years to ten, with the result that the number of trained soldiers who could be called out in case of war became larger by fully one-half. Further, in 1882, another expansion of armaments was effected in obedience to an Imperial decree, so that when war with China broke out in 1894, Japan possessed an available force of seven divisions (including the guards), and these, raised to a war-footing, represented about 150,000 men. She had already learned that, however civilized the Occident might claim to be, all the great States of the West depended mainly on military and naval force, and that only by a demonstration of that force could international respect be won.

hif Of course, this creed was not publicly proclaimed. Firmly as Japanese statesmen believed it, they could not confess their conviction openly. in the Diet, and therefore much difficulty was experienced in inducing the two houses to endorse the Government's scheme of increased armaments. Indeed, the subject came to be a frequent topic of discussion between the Cabinet and the House of Representatives, and in the end Japan was obliged to go into war against China without a single line-of-battle ship, though her adversary possessed two. Nevertheless, the Island Empire emerged signally victorious.

It might have been supposed that she would then rest content with the assurance of safety her prowess had won. But; in the immediate sequel of the war, three of the great European powers, Russia, Germany, and France, joined hands to deprive Japan of the fruits of her victory by calling upon her to vacate the southern littoral of Manchuria from the mouth of the Yalu to the Liaotung peninsula. Japan thus acquired the conviction that her successes against China were not estimated by Western States as any great evidence of belligerent power, and that it would be necessary for her to fight again if she hoped to win any considerable measure of international respect. Prince Itō, then prime minister, keenly appreciated this necessity. He invited the Diet to vote for a substantial increment of land and sea forces, and after much opposition in the 
House of Representatives, funds were obtained for raising the army to thirteen divisions and for an increase of the navy which will be by and by spoken of.

The wisdom of these measures found full justification, in 1904, when swords had to be crossed with Russia. After that war, which raised Japan to aleading place among the nations, the old problem came up again for solution Once more the Elder Statesmen - as the Meiji leaders were called - asked the Diet to maintain the organization of the army at the point to which it had been carried during the war, and once more the lower house of the Diet proved very difficult to persuade. Ultimately, however, the law of military service was revised so that the fixed establishment became nineteen divisions, together with various special corps. It is not possible to speak with absolute accuracy of the force that Japan is now capable of mobilizing, but when the new system is in full working order, she will be able to put something like a million and a half of men into the fighting line. Her military budget amounts to only: seven millions sterling - $\$ 35,000,000-$ - wonderfully small sum considering the results obtained.

\section{THE NAVY}

It has been shown how, in the year 1636, the Bakufu Government strictly interdicted the building of all vessels of ocean-going capacity. The veto naturally precluded enterprise in the direction of naval expansion, and when Commodore Perry, at the head of a powerful squadron, arrived in Uraga Bay, two centuries afterwards, the Japanese were suddenly and vividly instrueted in the enormous power of a nation wielding such weapons of war. This object lesson having been most practically inculcated by the bombardments of Kagoshima and Shimonoseki, Japan saw that she must not lose one moment in equipping herself with a naval force. At first, she had to purchase all her ships from foreign countries, and so difficult was it to obtain parliamentary support for these acquisitions that, as already stated, when war with the neighbouring empire broke out in 1894, she did not possess a single ironclad, her strongest vessels being four second-elass cruisers; which, according to modern ideas, would not be worthy of a place in the fighting line.

During the next ten years the teachings of experience took deeper root, and when the great combat with Russia commenced, the Japanese navy included four ironclads and six armoured cruisers. The signal victories obtained by her in that war did not induce any sentiment of self-complacency. She has gone on ever since increasing her navy, and the present programme of her statesmen is that by the end of 1921, she will possess twenty-five units of the first fighting line; that figure being based on the principle that she should be competent to encounter the greatest force which any: foreign State, England excluded, will be able to mass in Far Eastern waters ten years hence. Her annual expenditure on account of the up-keep of her navy is at present three and one-quarter million pounds sterling - $\$ 17,000,000$. No feature is more remarkable than the fact that Japan can now build and equip in her own yards and arsenals warships of the largest size. She is no longer dependent on foreign countries for these essentials of safety. 
provoked opposition in Tōkyō, and not until 1875 was a final settlement reached, the eonditions being that Japan should recognize Russia's title to the whole of Saghalien and Russia should recognize Japan's title to the Kuriles. These latter islands had always been regarded as Japanese property, and therefore the arrangement now effected amounted to the purchase of an area of Japanese territory by Russia, who paid for it with a part of Japan's belongings. An interesting sequel to this chapter of history is that, thirty years later, Saghalien became the scene of a Japanese invasion and was ultimately divided between the two nations along the fiftieth parallel, which was precisely what the Bakufu statesmen had originally proposed.

\section{THE FORMOSAN EXPEDITION}

The expedition of Formosa in $\mathbf{1 8 7 4}$ has already been spoken of. Insignificant in itself, the incident derived vicarious interest from its effect upon the relations between Japan and China in connexion with the ownership of the Ryūkyū Islands. Lying a little south of Japan, these islands had for some eenturies been regarded as an appanage of the Satsuma fief, and the language spoken by their inhabitants showed unmistakable traces of affinity with the Japanese tongue. Therefore when, in 1873, the crew of a wrecked Ryūkyūan junk was barbarously. treated by the Formosan aborigines, the Yedo Government at once sought redress from Peking. But the Chinese paid no attention to this demand until a foree of Japanese troops had made a punitory visit to Formosa, and China, recognizing that her territory had been invaded, lodged a protest which would probably have involved the two empires in a war had not the British minister in Peking intervened. The arrangement made was that China should indemnify Japan to the extent of the expenses incurred by the latter in punishing the aborigines.

\section{THE RYŪKY'U COMPLICATION}

A fact collaterally established by the Formosan affair was that the Ryūkyū Islands belonged to Japan, and, in 1876, the system of local government already inaugurated in Japan proper was extended to Ryūkyū, the ruler of the latter being pensioned. China now formulated a protest. She claimed that Ryūkyû̃ had always been a tributary of her empire. But China's interpretation of "tribute" was essentially unpractical. "So long as her own advantage could be promoted, she regarded as a token of vassalage the presents periodically carried to her Court from neighbouring States, but so soon as there arose any question of discharging a suzerain's duties, she classed these offerings as an insignificant interchange of neighbourly courtesy." Undoubtedly Ryūkyū, from time to time, had followed the eustom of despatching gift-bearing envoys to Peking, just as Japan herself had done. But it was on clear record that Ryūkyū had been subdued by Satsuma without any attempt whatever on China's part to save the islands from that fate; that thereafter, during two centuries, they had been included in the Satsuma fief, and that China, in the settlement of the Formosan complieation, had constructively acknowledged Japan's title to the group. Each empire asserted its claims with equal assurance, and things remained thus until 1880, when General Grant, who visited Japan in the course of a tour round the world, suggested a peaceful compromise. A conference met in Peking, and it was agreed that the islands should be divided, Japan taking the northern part and China the southern. But at the moment of signing the 


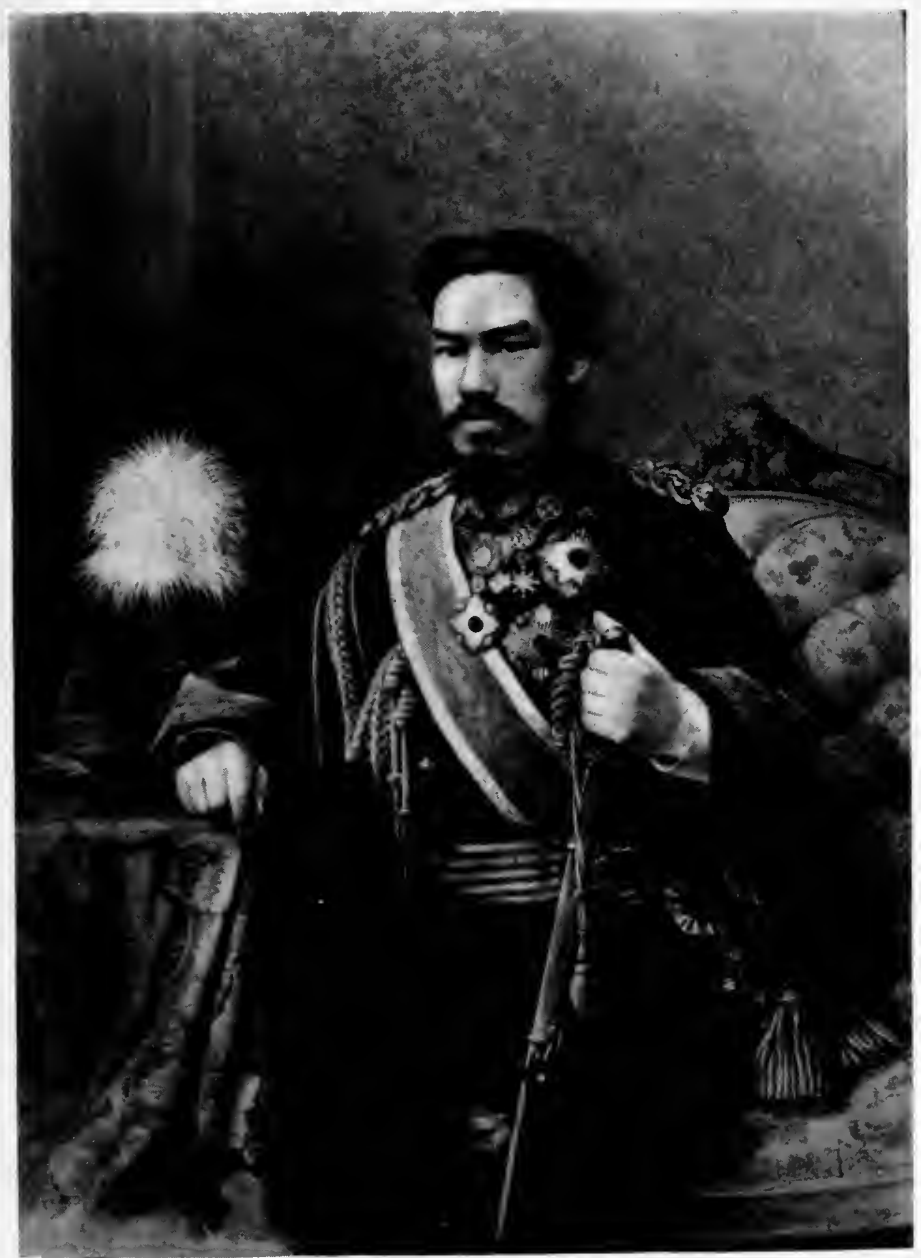

THÉ EMPEROR MEIJI (MUTSUHITO) 

convention, China drew back, and the discussion ended in Japan retaining the islands, China's protests being pigeonholed.

\section{KOREAN COMPLICATION}

Sufficient reference has already been made in these pages to the series of events that terminated in 1875 , when Japan, by a display of partly fictitious force, drew Korea out of international isolation and signed with the Peninsular Kingdom a treaty acknowledging the latter's independence.

\section{WAR WITH CHINA}

During the centuries when China occupied the undisputed position of first in might and first in civilization on the Asiatic continent, her habit was to use as buffer states the small countries lying immediately beyond her borders. But she always took care to avoid any responsibilities that might grow out of this arrangement: In a word, the tide of foreign aggression was to be checked by an understanding that these little countries shared the inviolability of great China, but it was understood, at the same time, that the consequences of their own acts must rest upon their own heads. Such a system, having no bases except sentiment and prestige, soon proved futile in the face of Occidental practicality. Burma, Siam, Annam, and Tonking, one by one, ceased to be dependent on China and independent towards all other nations.

'In Korea's case, however, the fiction proved more tenacious, since the peninsula furnished easy access to Manchuria, the cradle of the Manchu dynasty. But while seeking to maintain the old-time relations with Korea, Chinese statesmen clung uniformly to traditional methods. They refrained from declaring Korea a dependency of China; yet they sought to keep up "the romance of ultimate dependency and intermediate sovereignty." It was thus that, in 1876, Korea was allowed to conclude with Japan a treaty describing the former as "an independent State enjoying the same rights as Japan," nor did the Peking Government make any protest when the United States, Great Britain, and other powers concluded similar treaties.

To exercise independence in practice, however, was not permitted to Korea. A Chinese resident was stationed in Seoul, the Korean capital, and he quickly became an imperium in imperio. Thenceforth Japan, in all her dealings with the Peninsular :Kingdom, found the latter behaving as a Chinese dependency, obeying the Chinese resident in everything. Again and again, Japanese patience was tried by these anomalous conditions, and although nothing occurred of sufficient magnitude to warrant official protest, the Tōkyō Government became sensible of perpetual rebuffs and humiliating interferences at China's hands. Korea herself suffered seriously from this state of national irresponsibility. There was no security of life and property, or any effective desire to develop the country's resources. If the victims of oppression appealed to force, China readily lent military assistance to suppress them, and thus the royal family of Korea learned to regard its tenure of power as dependent on ability to conciliate China:

On Japan's side, also, the Korean question eaused much anxiety. It was impossible for the Tōkyō statesmen to ignore the fact that their country's safety' depended largely on preserving Korea from the grasp of 'a Western power. They saw plainly that such a result might at any moment be expected if Korea 
was suffered to drift into a state of administrative incompetence. Once, in 1882 , and again, in 1884, when Chinese soldiers were employed to suppréss réform movements which would have impaired the interests of the Korean monarch, the latter's people, counting Japan to be the source of progressive tendencies in the East, destroyed her legation in Scoul, driving its inmates out of the city. Japan was not yet prepared to assert herself forcibly in redress of such outrages, but in the ensuing negotiations she acquired titles' that "touched the core of China"s alleged suzerainty."... Thus, in 1882, Japan obtained recognition of her right to protect her legation with troops; and, in 1885, a convention; signed at Tientsin, pledged each of the contracting parties not to send a military force to Korea without notifying the other.

In spite of these agreements China's arbitrary and unfriendly interference in Korean affairs continued to be demonstrated to Japan. Efforts to obtain redress proved futile, and even provoked threats of Chinese armed intervention. Fimally, in the spring of 1894 , an insurrection of some magnitude broke out in Korea, and in response to an appeal from the Royal family; China sent twentyfive hundred troops, who went into camp at Asan, on the southwest coast of the peninsula. Notice was duly given to the Tökyo Government, which now decided that Japan's vital interests as well as the cause of civilization in the East required that an end must be put'to Korea's dangerous misrule and to China's arbitrary interference. Japan did not claim for herself anything that she was not willing to accord to China. But the Tokyō statesmen were sensible that to ask their conservative neighbour to promote in the Peninsular Kingdom a progressive programme which she had always steadily rejected and despised in her own case, must prove a chimerical attempt; if ordinary diplomatic methods alone were used. Accordingly, on receipt of Peking's notice as to the sending of troops to the peninsula, Japan gave corresponding notice on her own part, and thus July, 1894, saw a Chinese force encamped at Asan and a Japanese force in the vicinity of Seoul.

In having recourse to military aid, China's nominal purpose was to quell the Tonghak insurrection, and Japan's motive was to obtain a position such as would strengthen her demand for drastic treatment of Korea's malady. In giving notice of the despatch of troops, China described Korea as her "tributary State," thus emphasizing a contention which at once created an impossible situation. During nearly twenty years Japan had treated Korea as her own equal, in accordance with the terms of the treaty of 1876 , and she could not now agree that the Peninsular Kingdom should be officially classed as a tributary of China, Her protests, however, were contemptuously ignored, and Chinese statesmen continued to apply the offensive appellation to Korea, while at the same time they asserted the right of limiting the number of troops sent by Japan to the peninsula as well as the manner of their employment.

Still desirous of preserving the peace, Japan proposed a union between herself and China for the purpose of restoring order in Korea and amending that country's administration. China refused. "She even expressed supereilious surprise that Japan, while asserting Korea's independence, should suggest the idea of peremptorily reforming its administration. The Tokyō Cabinet now announced that the Japanese troops should not be withdrawn without "some understanding that would guarantee the future peace, order, and good government of Korea," and as China still refused to come to such an understanding, Japan undertook the work single-handed.

The Tonghak rebellion, which Chinese troops were originally sent to quell, 
had died of inanition before they landed. The troops, therefore, had been withdrawn. But China kept them in Korea, her avowed reason being the presence of the Japanese military force near Seoul. In these circumstances, Peking was notified that a despatch of re-enforcements on China's side must be construed as an act of hostility. Notwithstanding this notice, China not only sent a further body of troops by sea to encamp at Asan, but also despatched an army overland across the Yalu. These proceedings precipitated hostilities. Three Chinese warships, convoying a transport with twelve hundred soldiers on board, met and opened fire on two Japanese cruisers. The result was signal. One of the Chinese warships was captured; another was so riddled with shot that she had to be beached and abandoned; the third escaped in a dilapidated condition, and the transport, refusing to surrender, was sent to the bottom. These things happened on the 25th of July, 1894, and war was declared by'each empire six days subsequently.

The Japanese took the initiative.' They despatched from Seoul a column of troops and routed the Chinese entrenched at Asan, many of whom fled northward to Pyong-yang, a town on the Tadong River, memorable as the scene of a battle between a Chinese and a Japanese army in 1592. Pyong-yang offered great facilities for defence. The Chinese massed there a force of seventeen thousand men, and made preparations for a decisive contest, building parapets, mounting guns, and strengthening the position by every device of modern warfare. Their infantry had the advantage of being armed with repeating rifles, and the configuration of the ground offered little cover for an attacking army. Against this strong position the Japanese moved in two columns; one marching northward from Seoul, the other striking westward from Yuensan. Forty days elapsed before the Japanese forces came into action, and one day's fighting sufficed to carry all the Chinese positions, the attacking armies having only seven hundred casualties and the defenders, six thousand.

The next day, September 17 th, Japan achieved an equally conspicuous success at sea. Fourteen Chinese warships and six torpedo-boats, steering homeward after convoying a fleet of transports to the mouth of the Yalu River, fell in with eleven Japanese war-vessels cruising in the Yellow Sea. The Chinese squadron was not seeking an encounter. Their commanding officer did not appear to appreciate the value of sea-power. His fleet included two armoured battle-ships of over seven thousand tons' displacement,' whereas the Japanese had nothing stronger than belted cruisers of four thousand. Therefore a little enterprise on China's part might have severed Japan's maritime communications and compelled her to evacuate Korea. The:Chinese, however, used their warvessels as convoys only, keeping them carefully in port when no such duty was to be performed. It is evident that, as a matter of choice, they would have avoided the battle of the Yalu, though when compelled to fight they fought stoutly. After a sharp engagement, four of their vessels were sunk, and the remainder steamed into Weihaiwei, their retreat being covered by torpedo-boats.

By this victory the maritime route to China lay open to Japan. "She could now attack Talien, Port Arthur, and Weihaiwei, naval stations on the Liaotung and Shantung peninsulas, where strong permanent fortifications had been built under the direction of European experts. These forts fell one by one before the assaults of the Japanese troops as easily as the castle of Pyong-yang had fallen. Only by the remains of the Chinese fleet at Weihaiwei was a stubborn resistance made, under the command of Admiral Ting. But, after the entire squadron of torpedo craft had been captured, and after three of the largest Chinese ships 
had been sent to the bottom by Japanese torpedoes, and one had met the same fate by gunfire, the remainder surrendered, and their gallant commander, Admiral Ting, rejecting all overtures from the Japanese, committed suicide.

The fall of Weihaiwei ended the war. It had lasted seven and a half months, and during that time the Japanese had operated with five columns aggregating 120,000 men. "One of these columns marched northward from Seoul, won the battle of Pyong-yang, advanced to the Yalu, forced its way into Manchuria, and moved towards Mukden by Feng-hwang, fighting several minor engagements; and conducting the greater part of its operations amid deep snow in midwinter, The second column diverged westward from the Yalu, and, marching through southern Manchuria, reached Haicheng, whence it advanced to the capture of Niuchwang. The third landed on the Liaotung peninsula, and, turning southward, carried Talien and Port Arthur by assault. The fourth moved up the Liaotung peninsula, and, having seized Kaiping, advanced against Niuchwang, where it joined hands with the second column. The: fifth crossed from Port Arthur to Weihaiwei, which it captured." In all these operations the Japanese casualties totalled 1005 killed and 4922 wounded; the deaths from disease aggregated 16,866 , and the monetary expenditure amounted to twenty millions sterling, about $\$ 100,000,000$. It had been almost universally believed that, although Japan might have some success at the outset, she would ultimately be shattered by impact with the enormous mass and the overwhelming resources of China. Never was forecast more signally contradicted by events.

\section{CONCLUSION OF PEACE}

Li Hung-chang, viceroy of Pehchili, whose troops had been chiefly engaged during the war, and who had been mainly responsible for the diplomacy that had led up to it, was sent by China as plenipotentiary to discuss terms of peace. The conference took place at Shimonoseki, Japan being represented by Marquis (afterwards Prince) Itō, and on the 17th of April, 1895, the treaty was signed. It recognized the independence of Korea; ceded to Japan the littoral of Manchuria lying south of a line drawn from the mouth of the river Anping to the estuary of the Liao, together with the islands of Formosa and the Pescadores; pledged China to pay an indemnity of two hundred million taels; provided for the occupation of Weihaiwei by Japan pending payment of that sum; secured the opening of four new places to foreign trade and the right of foreigners to engage in manufacturing enterprises in China, and provided for a treaty of commerce and amity between the two empires, based on the lines of China's treaty. with Occidental powers.

\section{FOREIGN INTERFERENCE}

Scarcely was the ink dry upon this agreement when Russia, Germany, and France presented a joint note to the Tokyō. Government, urging that the permanent occupation of the Manchurian littoral by Japan would endanger peace. Japan had no choice but to bow to this mandate. The Chinese campaign had exhausted her treasury as well as her supplies of war material, and it would have been hopeless to oppose a coalition of three great European powers. She showed no sign of hesitation. On the very day of the ratified treaty's publication, the Emperor of Japan issued a rescript, in which, after avowing his devotion to the cause of peace, he "yielded to the dictates of magnanimity, and accepted the advice of the three powers." 
But although the Tōkyō Government sought to soften the situation by the grace of speedy acquiescence, the effect produced upon the nation was profound. There was no difficulty in appreciating the motives of Russia and France. It was natural that the former should object to the propinquity of a warlike people like the Japanese, and it was natural that France should remain true to her ally. But Germany's case defied interpretation. She had no interest in the ownership of Manchuria, and she professed herself a warm friend of Japan. It seemed, therefore, that she had joined in snatching from the lips of the Japanese the fruits of their victory simply for the sake of establishing some shadowy title to Russia's good-will.

\section{THE CHINESE CRISIS OF 1900}

In the second half of the year 1900 an anti-foreign outbreak, known as the "Boxer Rebellion," broke out in the province" of Shantung, and, spreading thence to Pehchili, produced a situation of imminent peril for the foreign communities of Peking and Tientsin. No Western power could intervene with sufficient promptness. Japan alone was within easy reach of the commotion. But Japan held back. She had fully fathomed the distrust with which the growth of her military strength had inspired some European nations, and she appreciated the wisdom of not seeming to grasp at an opportunity for armed display. In fact, she awaited a clear mandate from Europe and America, and, on receiving it, she rapidly sent a division $(20,000 \mathrm{men})$ to Pehchili. Tientsin was relieved first, and then a column of troops provided by several powers, the Japanese in the van, marched to the succour of Peking. In this campaign the Japanese greatly enhanced their belligerent reputation as they fought under the eyes of competent military critics. Moreover, after the relief of the legations in Peking, they withdrew one-half of their forces, and they subsequently cooperated heartily with Western powers in negotiating peace terms, thus disarming the suspicions with which they had been regarded at first.

\section{WAR WITH RUSSIA}

From the time (1895) when the three-power mandate dictated to Japan a cardinal alteration of the Shimonoseki treaty, Japanese statesmen concluded that their country must one day cross swords with Russia. Not a few Occidental publicists shared that view, but the great majority, arguing that the little Island Empire of the Far East would never risk annihilation by such an encounter, believed that forbearance sufficient to avert serious trouble would always be forthcoming on Japan's side: Yet neither geographical nor historical conditions warranted that confidence. The Sea of Japan, which, on the east; washes the shores of the Japanese islands and on the west those of Russia and Korea, has virtually only two routes communicating with the Pacific Ocean. One is in the north? namely, the Tsugaru Strait; the other is in the south, namely, the channel between the Korean peninsula and the Japanese island of Kyūshū. Tsugaru Strait is practically under Japan's complete control; she can close it at any moment with mines. But the channel between the Korean peninsula and Kyūshū has a width of 102 miles, and would therefore be a fine open seaway were it free from islands." Midway in this channel, however, lie the twin islands of Tsushima, and the space that separates them from Japan is narrowed by another island, Iki. Tsushima and Iki have belonged to Japan from time immemorial, and thus the avenues from the Pacific Ocean to the Sea of Japan are 
controlled by the Japanese empire. In other words, access to the Pacific from Korea's eastern and southern coasts, and access to the Pacific from Russia's Maritime Province depend upon Japan's good-will.

These geographical conditions had no great concern for Korea in former days. But with Russia the case was different. Vladivostok, the principal port in the Far East, lay at the southern extremity of the Maritime Province: Freedom of passage by the Tsushima Strait was therefore a matter of vital importance, and to secure it one of two things was essential, namely, that she herself should possess a fortified port on the Korean side, or that Japan should be restrained from acquiring such a port. Here, then, was a strong inducement, for Russian aggression in Korea. When the eastward movement of the great northern power brought it to the mouth of the Amur, the acquisition of Nikolaievsk for a naval basis was the immediate reward. But Nikolaievsk, lying in an inhospitable region, far away from all the main routes of the world's commerce, offered itself only as a stepping-stone to further acquisitions. To push southward from this new port became an immediate object.

There lay an obstacle in the way. The long strip of seacoast from the mouth of the Amur to the Korean frontier - an area then called the Usuri region because that river forms part of its western boundary - belonged to China, and she, having conceded much to Russia in the way of the Amur, showed no inclination to make further concessions in the matter of the Usuri. She was persuaded to agree, however, that the region should be regarded as common property, pending a convenient opportunity for clcar delimitation. That opportunity soon came. Seizing the moment (1860) when China had been, beaten to her knees by England and France, Russia secured the final cession of the Usuri region, which then became the Maritime Province of Siberia. Then Russia shifted hernaval basis in the Pacific to a point ten degrees south from Nikolaievsk, namely, Vladivostok. Immediately after this transfer an attempt was made to obtain possession of Tsushima. A Russian man-of-war proceeded thither, and quietly began to establish a settlement which would soon have constituted a title of ownership had not Great Britain interfered. The same instinct that led Russia from the mouth of the Amur to Vladivostok prompted the acquisition of Saghalien also, which, as already related, was accomplished in 1875 .

But all this effort did not procure for Russia an unobstructed avenue from Vladivostok to the Pacific or an ice-free port in the Far East. In Korea seemed to lie a facile hope of saving the maritime results of Russia's great trans-Asian march from Lake Baikal to the Maritime Province and to Saghalien. Korea seemed to offer every facility for such an enterprise. Her people were unprogressive; her resources undeveloped; her self-defensive capacities insignificant; her government corrupt. On the other hand, it could not be expected that Japan and China would acquiesce in any aggressions against their neighbour, Korea, and it became necessary that Russia should seek some other line of communication supplementing the Amur. waterway and the long ocean route. Therefore she set about the construction of a railway across Asia. This railway: had to be carried along the northern bank of the Amur where engineering and economic difficulties abound. Moreover, the, river makes a huge semicircular sweep northward, and a railway following its northern bank to Vladivostok must make the same detour. .If, on the contrary, the road could be carried south of the river along the diameter of the semicircle, it would be a straight, and therefore a shorter, line, technically easier and economically better. To follow this diameter, however,' would involve passing through Chinese territory, namely, 
Manchuria, and an excuse for soliciting China's permission was not in sight. In 1894, however, war broke out between Japan and China, and in its sequel Japan passed into possession of the southern littoral of Manchuria, which meant that Russia could never get nearer to the Pacific than Vladivostok, unless she swept Japan from her path. It is here, doubtless, that we must find Russia's true motive in inducing Germany and France to unite with her for the purpose of ousting Japan from Manchuria. The "notice to quit" gave for reasons that the tenure of the Manchurian littoral by Japan would menace the security of the Chinese capital, would render the independence of Korea illusory, and would constitute an obstacle to the peace of the Orient. Only one saving clause offered for Japan - to obtain from China a guarantee that no portion of Manchuria should thereafter be leased or ceded to a foreign State. But France warned the Tōkyo Government that to press for such a guarantee would offend Russia, and Russia declared that, for her part, she entertained no design of trespassing in Manchuria. Thus, Japan had no choice but to surrender quietly the main fruits of her victory. : She did so, and proceeded to double her army and treble her navy.

\section{RUSSIA'S AND GERMANY'S REWARDS}

As a recompense for the assistance nominally rendered to China in the above matter, Russia obtained permission in Peking to divert her trans-Asian railway from the huge bend of the Amur to the straight line through Manchuria. Neither Germany nor France received any immediate compensation. But three years later, by way of indemnity for the murder of two missionaries by a Chinese mob, Germany seized a portion of the province of Shantung, and forthwith Russia obtained a lease of the Liaotung peninsula, from which she had driven Japan in 1895. This act she followed by extorting from China permission to construct a branch of the trans-Asian railway from north to south, that is to say from Harbin through Mukden to Talien and Port Arthur. Russia's maritime aspirations had now assumed a radically altered phase. Hitherto her programme had been to push southward from Vladivostok along the coast of Korea, but she had now suddenly leaped Korea and found access to the Pacific by the Liaotung peninsula. Nothing was wanting to establish her as practical mistress of Manchuria except a plausible excuse for garrisoning the place. Such an excuse was furnished by the Boxer rising, in 1900. The conclusion of that complication found her in practical occupation of the whole region. But here her diplomacy fell somewhat from its usually high standard. Imagining that the Chinese could be persuaded, or intimidated, to any concession, she proposed a convention yirtually recognizing her title to Manchuria.

\section{JAPAN'S ATTITUDE}

Japan watched all these things with profound anxiety. If there were any reality in the dangers which Russia, Germany, and France had declared to be incidental to Japanese occupation of a part of Manchuria, the same dangers must be doubly incidental to Russian occupation of the whole of Manchuria. There were other considerations, also. The reasons already adduced show that the independence of Korea was an object of supreme solicitude to Japan. It was to establish that independence that she fought with China, in 1894, and the same motive led her after the war to annex the Manchurian littoral adjacent to Korea's northern frontier. If Russia came into possession of all Manchuria, her sub- 
sequent absorption of Korea would be almost inevitable. Manchuria is larger than France and the United Kingdom put together. The addition of such an immense area to Russia's East Asiatic dominions, together with its littoral on the Gulf of Pehchili and the Yellow Sea, would necessitate a corresponding expansion of her naval force in the Far East. With the exception of Port Arthur and Talien, however, the Manchurian coast does not offer any convenient naval base. It is only in the harbours of southern Korea that such bases can be found. In short, without Korea, Russia's East Asian extension would have been economically incomplete and strategically defective.

If it be asked why, apart from history and national sentiment, Japan should object to Russia in Korea, the answer is, first, because there would thus be planted almost within cannon-shot of her shores a power of enormous strength and traditional ambition; secondly, because whatever voice in Manchuria's destiny Russia derived from her railway, the same voice in Korea's destiny was possessed by Japan, as the sole owner of the railways in the Korean peninsula; thirdly, that whereas Russia had an altogether insignificant share in the foreign commerce of Korea and scarcely ten bona fide settlers, Japan did the greater part of the oversea trade and had tens of thousands of settlers; fourthly, that if Russia's dominions stretched uninterruptedly from the sea of Okhotsk to the Gulf of Pehchili, her ultimate absorption of northern China would be inevitable, and fifthly, that such domination and such absorption would involve the practical closure of all that immense region to the commerce and industry of every Western nation except Russia.

This last proposition did not rest solely on the fact that in opposing artificial barriers to free competition lies Russia's sole hope of utilizing, to her own benefit, any commercial opportunities brought within her reach. It rested, also, on the fact that Russia had objected to foreign settlement at the Manchurian marts recently opened, by Japan's treaty with China, to American and Japanese subjects. Without settlements, trade at those marts would be impossible, and thus Russia had constructively announced that there should be no trade but the Russian, if she could prevent it. Against such dangers Japan would have been justified in adopting any measure of self-protection. She had forescen them for six years and had been strengthening herself to avert them. But she wanted peace. She wanted to develop her material resources and to accumulate some measure of wealth without which she must remain insignificant among the nations.

Two pacific programmes offered and she adopted them both. Russia, instead of trusting time to consolidate her tenure of Manchuria, had made the mistake of pragmatically importuning China for a conventional title. If, then, Peking could be strengthened to resist this demand, some arrangement of a distinctly terminable nature might be made. The United States, Great Britain, and Japan, joining hands for that purpose, did succeed in so far stiffening China's backbone that her show of resolution finally induced Russia to sign a treaty pledging herself to withdraw her troops from Manchuria in three installments, each step of evacuation to be accomplished by a fixed date. That was one of the pacific programmes. The other suggested itself in connexion with the new commercial treaties which China had agreed to negotiate in the sequel of the Boxer troubles. These documents contained clauses providing for the opening of three places in Manchuria to foreign trade. It scemed a reasonable hope that the powers, having secured commercial access to Manchuria by covenant with its sovereign, would not allow Russia to restrict arbitrarily their privileges. Both of these 






hopes were disappointed. When the time came for evacuation, Russia behaved as though no promise had been given. She proposed new conditions which would have strengthened her grasp of Manchuria instead of loosening it.

\section{NEGOTIATION BETWEEN RUSSIA AND JAPAN}

China being powerless to offer any practical protest, and Japan's interest ranking next in order of importance, the Tōkyō Government approached Russia direct. They did not ask for anything that could hurt her pride or impair her position. Appreciating fully the economical status she had acquired in Manehuria by large outlays of capital, they offered to recognize that status, provided that Russia would extend similar recognition to Japan's status in Korea; would promise, in common with Japan, to respect the sovereignty and the territorial integrity of China and Korea, and would be a party to a mutual engagement that all nations should have equal commercial and industrial opportunities in Manchuria and in the Korean peninsula. In a word, they invited Russia to subscribe the policy originally enunciated by the United States and Great Britain, the policy of the open door and of the integrity of the Chinese and Korean empires.

Thus commenced negotiations which lasted five and a half months. Japan gradually reduced her demands to a minimum. Russia never made any appreeiable reduction of hers. She refused to listen to Japan for one moment about Manchuria. Eight years previously, Japan had been in military possession of the littoral of Manchuria when Russia, with the assistance of Germany and France, had expelled her for reasons which concerned Japan much more than they concerned any of these three powers. Now, Russia had the assurance to declare that none of these things concerned Japan at all. The utmost she would admit was Japan's partial right to be heard about Korea. At the same time, she herself commenced a series of aggressions in northern Korea. That was not all. While she studiously deferred her answers to Japan's proposals, and while she protracted the negotiations to an extent visibly contemptuous, she hastened to make substantial additions to her fleet and her army in far-eastern Asia. It was impossible to mistake her purpose. She intended to yield nothing, but to prepare such a parade of force that her obduracy would command submission. The only alternatives for Japan were war or permanent effacement in Asia. She chose war.

\section{EX'TRATERRITORIAL JURISDICTION}

Before passing to the story of this war, it is necessary to refer to two incidents of Japan's foreign relations, both of which preceded her struggle with Russia. The first was the restoration of her judicial autonomy. It has always been regarded as axiomatic that the subjects or citizens of Western countries, when they travel or reside in Oriental territories, should be exempted from the penalties and processes of the latter's criminal laws. In other words, there is reserved to a Christian the privilege, when within the territories of a pagan State, of being tried for penal offences by Christian judges. In civil cases the jurisdiction is divided, the question at issue being adjudicated by a tribunal of the defendant's nationality; but in criminal cases jurisdiction is wholly reserved. Therefore powers making treaties with Oriental nations establish within the latter's borders consular courts which exercise what is called "extraterritorial jurisdiction." This system was; of course, pursued in Japan's case. It involved the confine- 
ment of the foreign residents to settlements grouped around the sites of their consular courts; for it would plainly have been imprudent that such residents should have free access to provincial districts remote from the only tribunals

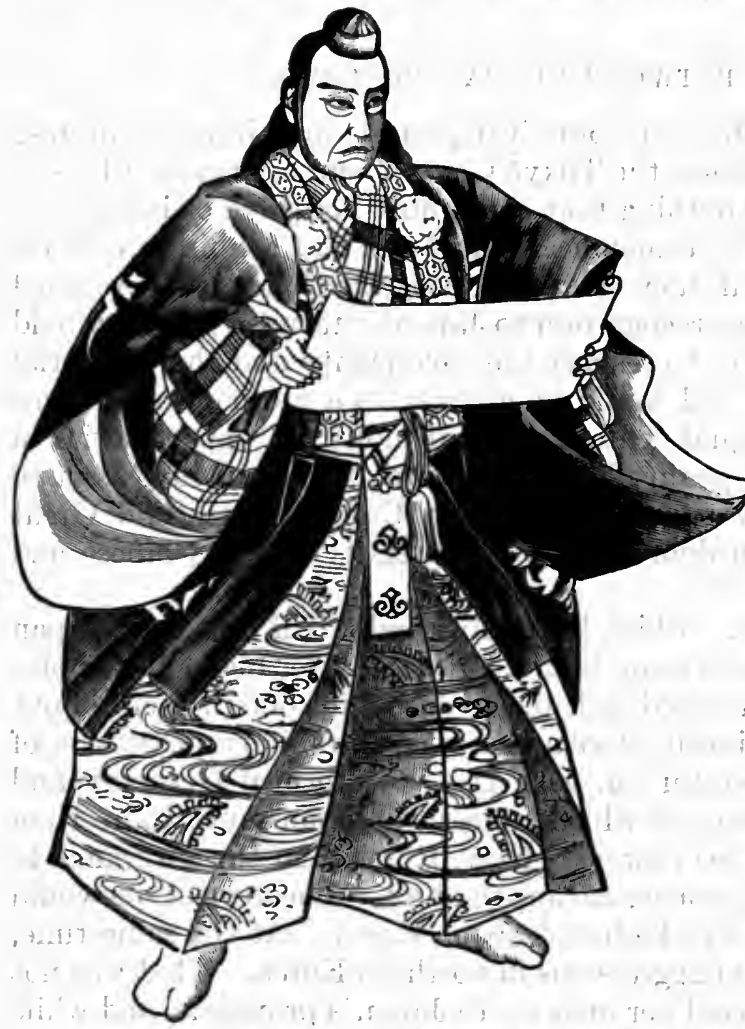

Danjoró, a Famous Actor, as Benkei in Kanjinchō (a play) competent to control them.

This provision, though inserted without difficulty in the early treaties with Japan, provoked much indignation among the conservative statesmen in Kyōto. Accordingly; no sooner had the Meiji Restoration been effected tlian an embassy: was despatched to the Occident to negotiate for: a revision of the treaties so as to remove the clause about consular jurisdiction, and to restore the customs tariff to the figure at which it had stood prior to 'Sir Harry Parkes' naval demonstration at Hyōgo. The Japanese Government was entitled to raise this question in 1871 , for the treaties were textually subject to revision in that year. . No time was lost in despatching the embassy. But its failure was a foregone conclusion. The conditions originally necessitating exträterritorial jurisdiction had not, by 1871 , undergone any change justifying its abolition. It is not to be denied, on the other hand, that the consular courts themselves invited criticism. Some of the great Western powers had organized competent tribunals with expert judicial officials, but others, whose trade with Japan was comparatively insignificant; were content? to entrust consular duties to merchants, who not only lacked legal training but were also themselves engaged in the commercial transactions upon which they might, at any moment, be required to adjudicate magisterially.:

It cannot be contended that this obviously imperfect system was disfigured by many abuses. On the whole, it worked passably well, and if its organic faults helped to discredit it, there is no denying that it saved the Japanese from complications which would inevitably have arisen had they been entrusted with jurisdiction which they were not prepared to exercise satisfactorily. Moreover, the system had vicarious usefulness; for the ardent desire of Japanese patriots to recover the judicial autonomy, which is a fundamental attribute of every sovereign State, impelled them to recast their laws and reorganize their' law courts with a degree of diligence which would otherwise have probably been less conspicuous. Twelve years of this work, carried on with the aid of thoroughly competent foreign jurists, placed Japan in possession of codes of criminal and civil law in which the best features of European jurisprudence were applied to 
the conditions and usages of Japan. Then, in 1883, Japan renewed her proposal for the abolition of consular jurisdiction, and by way of compensation she promised to throw the country completely open and to remove all restrictions hitherto imposed on foreign trade, travel, and residence within her realm.

But this was a problem against whose liberal solution the international prejudice of the West was strongly enlisted. No Oriental State had ever previously sought such recognition, and the Occident, without exception, was extremely reluctant to entrust the lives and properties of its subjects and citizens to the keeping of a "pagan" people. "Not unnaturally the foreigners resident:in Japan, who would have been directly affected by the change, protested against it with great vehemence. Many of them, though not averse to trusting Japan, saw that her reforms had been consummated with celerity amounting to haste, and a great majority fought simply for consular jurisdiction as a privilege of inestimable value, not to be surrendered without the utmost deliberation. The struggle that ensued between foreign distrust and Japanese aspirations often developed painful phases, and did much to intensify the feeling of antagonism which had existed between the Japanese and the foreign residents at the outset and which even to-day has not wholly disappeared. The Government and citizens of the United States of America never failed to show sympathy with Japanese aspirations in this matter, and; as a general rule, "foreign tourists and publicists discussed the problem liberally and fairly, perhaps because, unlike the foreign communities: resident in Japan, they had no direct interest in its solution.".

The end was not reached until 1894. Then Great Britain agreed that from July, 1899, jurisdiction over all British subjects within the confines of Japan should be entrusted to Japanese tribunals, provided that the new Japanese codes of law should have been in operation during at least one year before the surrender of jurisdiction. Japan, on her side, promised to throw the whole country open from the same date, removing all limitations upon trade, travel, and residence of foreigners.

Tariff autonomy had been an almost equal object of Japanese ambition, and it was arranged that she should recover it after a period of twelve years, an increased scale of import duties being applied in the interval. It will be observed that Great Britain took the lead in abandoning the old system. It was meet that she should do'so; for, in consequence of her preponderating commercial interests, she had stood at the head of the combination of powers by which the irksome conditions were originally imposed upon Japan. The other Occidental States followed her example with more or less celerity, and the foreign residents, now that nothing was to be gained by continuing the struggle, showed clearly that they intended to bow gracefully to the inevitable. 'The Japanese also took some conspicuous steps.

"An Imperial rescript declared in unequivocal terms that it was the sovereign's policy and desire to abolish all distinctions between natives and foreigners, and that, by fully carrying out the friendly purpose of the treaties, his people would best consult his, wishes, maintain the character of the nation, and promote its prestige. The premier and other ministers of State issued instructions to the effect that the responsibility now devolved on the Government, and the duty on the people, of enabling foreigners to reside confidently and contentedly in every part of the country. Even the chief Buddhist prelates addressed to the priests and parishioners of their dioceses injunctions pointing out that freedom of conscience being now guaranteed by the Constitution, men professing 
alien creeds must be treated as courteously as the disciples of Buddhism and must enjoy the same privileges."'

It may here be stated once for all that Japan's recovery of her judicial autonomy has not been attended by any of the disastrous results freely predicted at one time. Her laws are excellent, and her judieiary is competent and just.

\section{FIRST ANGLO-JAPANESE ALLIANCE}

The seeond of the two incidents alluded to above was an alliance between England and Japan, signed on January 30, 1902. The preamble of this agreement - the first of its kind ever concluded between . England and an Oriental power - affirmed that the contracting parties were solely actuated by a desire to preserve the status quo and the general peace of the Far East; that they were both speeially interested in maintaining the independence and territorial integrity of the empires of China and Korea, and in securing equal opportunities in these countries for all nations; that they mutually recognized it as admissible for either of the contracting parties to take such measures as might be indispensable to safeguard these interests against a threat of aggressive action by any other power, or against disturbances in China or Korea, and that, if one of the contracting parties became involved in war in defence of these interests, the other should maintain strict neutrality and endeavour to prevent any third power from joining in hostilities against its ally. Finally, should a third power join in such hostilities, then the other contracting party promised to come to the assistance of its ally, to conduct the war in common, and to make peace by mutual agreement only. The alliance was to hold good for five years from the date of signature, but if either:ally was engaged in war at such time, the alliance was to continue until the conelusion of peace.

It is unnecessary to dwell upon the influence exerted by this compact on the Russo-Japanese war. It kept the field clear for Japan and guaranteed her against a repetition of such a combination as that which must be regarded as the remote cause of the struggle.

\section{THE EARLY PHASES OF THE WAR}

Japan's great problem in crossing swords with Russia was to obtain a safe avenue for her troops over the sea. Russia might at once have gained an overwhelming advantage had she seized and controlled the lines of communication between the Japanese islands and the continent of Asia. Her strategists can scarcely have failed to appreciate that fact, and would doubtless have acted aceordingly had they obtained a few months' leisure to mass an overwhelmingly strong fleet in the seas of China and Japan. They had such a fleet actually in esse; for, at the moment when war broke out, the Russian squadrons assembled in the East, or en route thither, comprised no less than fifty-nine fighting ships, mounting 1350 guns and manned by 18,000 men. But these figures included the Mediterranean squadron which, surprised by the outbreak of hostilities, abandoned its journey to the Pacific: Obviously, Japan's wisest course was to anticipate the combination of Russia's sea forces, and consciousness of that faet operated to hasten the current of events.

IPortiArthur, where the bulk of the Russian Pacific squadron lay, is somewhat difficult of ingress and egress. On January 31,1904 , the operation of extracting griazstorn [1Brinkley, article "Japan," Encyelopaedia Britannica, 11th Edition.] 
the ships and parading them outside was commenced, being brought to a conclusion on February $3 \mathrm{rd}$, whereafter the squadron steamed out to sea, and, having made a short cruise off the coast of the Shantung promontory, returned to its position on the following day. The fleet taking part in this manœuvre consisted of twenty-six ships, and the whole Russian naval force then in eastern Asia comprised seven battle-ships; four armoured cruisers, seven protected cruisers, four gunboats, six sloops, twenty-five destroyers, two mining transports, and fourteen first-class torpedo-boats.

The Japanese, on their side, had six battle-ships, eight armoured cruisers, thirteen protected cruisers, fourteen small cruisers, nineteen destroyers, and eighty-five torpedo-boats. This enumeration "shows a numerical superiority on the Japanese side, but in fighting capacity the two fleets were nearly equal. For, though the Russians possessed seven battle-ships to six Japanese, the latter had better gun-protection and greater weight of broadside fire than the former; and though Japan could muster eight armoured cruisers against Russia's four, the latter were supplemented by five protected cruisers which ranked far above anything of the same class on the Japanese side.

\section{THE FIRST NAVAL OPERATION}

When the Russian ships returned on the 4th of February from their cruise off the Shantung promontory, they took up their stations outside Port Arthur, all the harbour lights and beacons being left in position, and no special precaution being taken except that a patrol of three torpedo-boats was sent out. Yet the Russians should have appreciated the presence of danger. For, on the 6th of February, Japan had broken off the negotiations in St. Petersburg, and had given official information of her intention to take measures for protecting her menaced interests. That signified war and nothing but war, and the "Official "Messenger" of the same evening published the intimation, which was immediately communicated to Admiral Alexieff at Port Arthur.

The Russian fleet was then divided into three squadrons. The largest body lay off Port Arthur, and two very much smaller squadrons were posted, one at Chemulpo on the west coast of Korea, and another at Vladivostok. It is obvious that such division of the fleet on the eve of hostilities should have been carefully avoided. The ships should all have been held together with an extensive network of scouts so as to enable them swiftly and strongly to fall upon any Japanese transports carrying troops to the mainland, or to meet effectually and crush any attempt of the Japanese squadrons to obtain command of the sea:

On the night of February 8th-9th, three Japanese squadrons of destroyers, aggregating ten vessels, steamed across a calm, moonlit sea and delivered a torpedo attack on the Russian squadron at Port Arthur, the result being that the battle-ships Retvisan and Tsarevitch together with the cruiser Pallada were holed. These battle-ships were the most powerful vessels in the Russian squadron, and the Pallada was a first-class protected cruiser of 6630 tons' displacement. The Japanese destroyers had left Sasebo on the 6th of February and they returned thither uninjured, having materially weakened the Russian fleet. On the day following this surprise, Admiral Tōgō, the Japanese commander-inchief, engaged the remains of the Russian squadron with the heavy guns of his battle-ships at a range of eight thousand yards, and succeeded in inflicting some injury on the battle-ship Poltava, the protected cruisers Diana and Askold, and a second-class cruiser Novik. The Russians ultimately retreated towards the 
harbour with the intention of drawing the Japanese under closer fire of the land batteries, but the Japanese fleet declined to follow after them, and, instead, steamed away. Three days later (February 11th) another disaster overtook the Russians. The Yenisei, one of the two mining-transports included in their fleet, struck a mine and sank so rapidly in Talien Bay that ninety-six of her crew perished. The Japanese had no part at all in this catastrophe. It was purely aecidental.

\section{THE CHEMULPO AFFAIR}

While these things were happening at Port Arthur, a squadron of the Japanese navy, under Admiral Uryū, escorted a number of transports to Chemulpo, the port of the Korean capital, Seoul. There the Russian protected cruiser Variag (6500 tons) together with the gunboat Korietz and the transport. Sungari were lying. It does not appear that Admiral Uryū's prime object was to engage these Russian ships. But Chemulpo having been ehosen as the principal landing-place of the Japanese army corps which was to operate in Korea, it was, of course, imperative that the harbour should be cleared of Russian war-vessels. On February 8th, the Russians at Chemulpo were surprised by a summons from Admiral Uryū to leave the port or undergo bombardment at their anchorage. The vessels stood out bravely to sea, and after an engagement lasting thirty-five minutes at ranges varying from five to ten thousand yards, they were so badly injured that they returned to the port and were sunk by their own crews, together with the transport Sungari. The moral effect of the destruction of these vessels was incalculable.

\section{DECLARATION OF WAR}

On the 10th of February, the Czar and the Mikado respectively issued declarations of war. The former laid stress upon Russia's pacific intentions in proposing revision of the agreements already existing between the two empires with regard to Korean affairs, and accused the Japanese of making a sudden attack on the Russian squadron at Port Arthur "without previously notifying that the rupture of diplomatic relations implied the beginning of warlike action." The Japanese declaration insisted that the integrity of Korea was a matter of the gravest concern to Japan, inasmuch as the separate existence of the former was essential to the safety of the latter, and charged that "Russia, in disrespect of her solemn treaty pledges to China and of her repeated assurances to other powers, was still in occupation of Manchuria, had consolidated and strengthened her hold upon those provinces, and was bent upon their final annexation." With regard to Russia's accusation against Japan of drawing the sword without due notice, a distinguished British publicist made the following comment in the columns of The Times (London):

"Far from thinking the Japanese attack on the night of February 8th, two full days after the announcement of the intention to take action, was an exception to, or a deviation from, tradition and precedent, we should rather count ourselves fortunate if our enemy, in the next naval war we have to wage, does not strike two days before blazoning forth his intention, instead of two days aiter. The tremendous and decisive results of success for the national cause are enough to break down all the restraining influences of the code of international law and Christian morality:" 
THE FIRST MILITARY OPERATIONS

From the moment when war became inevitable, the problem of absorbing interest was to determine Russia's strategy, and it was ultimately seen that the two main groups of her forces were to be posted at Port Arthur and on the Yalu; the latter to resist an advance from Korea, and the former to defend the Liaotung peninsula; which constituted the key of the Russian position. Between the mouth of the Yalu and the Liaotung peninsula, a distance of 120 miles, there were many points where raiding parties might have been landed to cut th' Russian railway. Against this danger, flying squadrons of Cossacks were employed. After the destruction of the three Russian vessels in Chemulpo and the crippling of the Port Arthur squadron, Japanese transports entered the former port and quietly landed some three thousand troops, which advanced immediately upon Seoul and took possession of it.

From that time there could be no doubt that the intention of the Japanese was to make their first attack upon the enemy by marching up the Korean peninsula, and that the capital of Korea was chosen for a base of operations because of climatic considerations. Chemulpo, however, was not the only landing-place. Fusan also served for that purpose, as subsequently did also Chinnampo, an inlet on the west coast of the peninsula. The distance from the port of Fusan to the Yalu River is four hundred miles, in round numbers, and the roads are very bad throughout the whole country. Hence the advance of the Japanese, which was made in a leisurely manner with the utmost circumspection and attention to detail, involved so much time that April had drawn to its close before the troops deployed on the banks of the Yalu. They consisted of three divisions constituting an army corps, and each division had a ration-strength of 19,000 men with a combatant strength of 14,000 sabres and rifles and thirtysix field-guns. It may be assumed, therefore, that when the Japanese First Army under General (afterwards Count) Kuroki reached the Yalu, it had a fighting-strength of between forty and fifty thousand men. There had practically been no collision during the interval of the advance from the southern extremity of the peninsula to its northern boundary. It is true that, on March 28th, a squadiron of Cossacks attempted to surprise the Japanese cavalry at Chong-ju, but the essay proved a failure, and the Cossacks were driven back upon Wiju, which they evacuated without any further struggle.

Vo The Russian plan of operations did not originally contemplate a serious stand at the Yalu. The idea was to retire gradually, drawing the Japanese into Manchuria towards the railway, and engaging them in the exceedingly difficult country crowned by the Motien Mountains. But at the last moment General Kuropatkin, Russian commander-in-chief in Manchuria, issued orders to General Sassulitch, commander of the Second Siberian Army Corps, to hold the line of the Yalu with all his strength. Sassulitch could muster for this purpose only five regiments and one battalion of infantry; forty field-guns; eight machine-guns, and some Cossacks - twenty thousand combatants, approximately. Kuroki disposed his troops so that their front extended some twenty miles along the Yalu, the centre being at Kiuliencheng, a walled town standing about 180 feet above the river. From this point southward, the right, or Manchurian, bank has a considerable command over the left; and at Kiuliencheng a tributary stream, called the Ai, joins the main river, "which thenceforth widens from 4000 to 7000 yards and runs in three channels between the islands and the mainland: The central channel is navigable by small craft, and the other chan- 
nels are fordable waist-deep. The Ai River is also fordable in many places during the spring." On the right bank of the Yalu, at the point of its junction with the $\mathrm{Ai}$, the ground rises so as to command the position taken by the Russians.

The plan of the Japanese commander was to threaten an attack on the lower radius of the river; to throw two divisions against Kiuliencheng, and to use the remaining division in a wide flanking movement, crosing the river higher up. The battle took place on Sunday, the 1st of May. During the preceding nights, the Japanese placed a strong force of artillery in cleverly masked batteries; and under cover of these guns, threw seven bridges across the river; the highest upstream being thirteen miles above Kiuliencheng and the lower two being directed to the centre of the Russian position. General Kuroki then telegraphed to Tōkyō that he proposed to attack at dawn on Sunday, his plan being to mareh one division across the fords of the Ai River, and to employ the other two; one in crumpling up the Russian left, the other in attacking Antung, where a large Russian force was in position. This programme was accuratcly carried out. The Japanese infantry forded the Ai breast-deep, and, swarming up the heights, drove the Russians from these strong positions. Meanwhile, the Japanese guards' division had crossed on the left and directed its march upon Antung; while the remaining division had completely turned the Russian left flank. The fiercest struggle occurred at Homutang, where a Russian regiment and a battery of artillery made a splendid stand to save their comrades at Antung from being cut off.

The casualties on the Japanese side were 318 killed, including five officers, and 783 wounded, including thirty-three officers. The Russian casualties numbered $1303 \mathrm{k}$ :lled and 613 prisoners, but the detail of wounded was not published. The Japanese captured twenty-one quick-firing field-guns, eight machine-guns, 1021 rifles and a quantity of ammunition, etc. The moral result of this battle can hardly be overestimated. It had never been seriously believed in Europe that a Russian army could be conquered by a Japanese in a fair fight, and probably that incredulity influenced Kuropatkin when he ordered Sassulitch to defy strategical principles by attempting to hold a radically defective position against a greatly superior force. In a moment, the Japanese were crowned with military laurels and placed on a pedestal for the world to admire. But the Japanese themselves were not deceived. They saw clearly that the contest had been between six battalions of Russians and two divisions of Japanese, a disparity of strength amply sufficient to account for the result in any circumstances.

\section{NAVAL OPERATIONS}

During the period of eleven weeks immediately subsequent to the battle of the Yalu, there were no military operations of a striking character. Japan was preparing to despatch a second army to Manchuria, and pending its shipment the chief duty to be discharged devolved upon the fleet, namely, the further crippling of the Port Arthur squadron in order to secure the transports against its enterprises. The object was promoted on the 13th of April by the loss of the Russian battle-ship Petropavlovsk. She struck one of the mines laid by the Japanese and sank in a few minutes, earrying the Russian admiral, Makaroff, together with about six hundred sailors, to the bottom.

This event, although it materially weakened the Port Arthur squadron, had nothing to do with the fixed programme of Admiral Tōgo,, which programme, was 
to block the narrow channel forming the entrance of Port Arthur by sinking merchant vessels in the fairway. Three attempts to accomplish this were made. The first was on February 24th; the second, on March 2nd-3rd. In the first essay, five steamers were employed, their crews consisting of seventy-seven volunteers. They failed. On the second occasion four steamers of at least two thousand tons each were sent in under the orders of Commander Hirose. On this occasion, again, the steamers failed to reach vital points in the channel, and their experience alone remained to compensate the loss of many lives. These two attempts were watched by the public with keen interest and high admiration. The courage and coolness displayed by officers and men alike elicited universal applause.

But it was generally believed that the successful prosecution of such a design was impossible and that no further essay would be made. The Japanese, however, are not easily deterred. On the night of May 2 nd, eight steamers, aggregating some 17;000 tons, were driven into the channel in the face of mines, batteries, and torpedoes, and five of them reached their allotted positions, so that the blocking of the harbour for the passage of large vessels was accomplished. The list of casualties proved very heavy. Out of 159 persons only eight officers and thirty-six men returned unhurt. The whole of the remainder, including twenty officers, were killed, wounded, or missing.

\section{LANDING OF THE SECOND ARMY}

On the very night after the accomplishment of this third blocking operation, a second Japanese army commenced to land at Pitszewo, eastward of the Liaotung peninsula. This was precisely the point chosen for a similar purpose by the Japanese in the war with China, ten years previously, and such close adherence to the former programme was condemned by some critics, especially as transports cannot get close to the shore at Pitszewo, but have to lie four miles distant, the intervening space consisting, for the most part, of mud flats. But the Japanese were perfectly familiar with every inch of the coast from the mouth of the Yalu to Port Arthur, and had the Russian commanders possessed equally accurate knowledge, they would have recognized that Pitszewo was designated by natural features as the best available landing-place, and knowing that, they might have made effective dispositions to oppose the Japanese there, whereas ten thousand men had been put on shore before any suspicion seems to have been roused in the Russian camp.

\section{BATTLE OF KINCHOU}

After its landing at Pitszewo, on May 5th and the following days, the Second Japanese Army, consisting of three divisions under General (afterwards Count) Oku, pushed westward, driving away the Russian detachments in the vicinity and securing the control of the Port Arthur railway. Then, at Kinchou, on the 26th of May, a great battle was fought. A little south of Kinchou lies a narrow neck of land connecting the Kwangtung promontory with the mainland. It is a neck only a mile and three-quarters broad, having Kinchou Bay on the northwest and Hand Bay on the southeast. On each side the ground near the sea is low, but along the centre of the neck a ridge rises, which culminates in a point about 350 feet above the sea. This point is known as Nanshan, and its commanding position is such that an army holding it blocks all access to the Kwangtung peninsula. 
The problem for the Japanese was to obtain possession of this neck as the sole road of access to Port Arthur; while General Stössel, who commanded the Russian troops, knew that if the neck fell into Japanese hands, Port Arthur would become unapproachable by land. "The Nanshan position offered unusual advantages for defenee, and had been diligently prepared for permanent ỏceupation during many weeks. Ten forts of semi-permanent character had been built, and their armament showed that, on this oceasion, the Russian artillery was vastly superior, both in calibre and in range, to the Japanese guns. Forts, trenches, and rifle-pits, covered by mines and wire entanglements, were constructed on every point of vantage and in separate tiers. Searchlights were also employed, and every advantage was taken of the proximity of a' great fortress and its ample plant."1

It will occur to the reader that war-vessels might have been advantageously used for the attack and defence of such a position, and, as a matter of fact, Russian gunboats manœuvred in Hand Bay on the southeastern shore of the neck. But, on the western side, the shoal waters of Kinchou Bay prevented access by Japanese vessels in the face of the heavy batteries erected by the Russians on dominating sites. This splendid position was held by a Russian army mustering ten thousand strong with fifty siege-guns and sixteen quickfirers. A frontal attack seemed suicidal but was deliberately chosen. At daybreak the battle commenced, and, after sixteen hours of incessant fighting, a Japanese infantry force turned the left flank of the Russian line and the day was won. Over seven hundred Russian dead were buried by the Japanese, and into the latter's hands fell sixty-eight cannon of all calibres with ten machineguns. The Japanese casualties totalled 4912.

This battle finally solved the problem as to whether Japanese infantry could hold its own against Russian. "With almost everything in its favour, a strong, fresh, and confident Russian army, solidly entrenched behind almost inaccessible fortifieations and supported by a formidable and superior artillery, was, in a single day, fairly swept out of its trenches."' The victorious Japanese pressed forward rapidly, and on the 30th of May obtained possession of Dalny; a base presenting incalculable advantages for the prosecution of an attack upon Port Arthur, which fortress it was now evident that the Japanese had determined to capture.

\section{THE BATTLE OF TELISSU}

To have left the Japanese in undisturbed possession of the neck of the Liaotung peninsula would have been to abandon Port Arthur to its fate. On the other hand, the Russians ought not to have entertained any hope of their own ability to carry such a position by assault after they had signally failed to hold it in the face of attack. Nevertheless, finding it intolerable, alike to their prestige and to their sense of camaraderie, to take no measure in behalf of the great fortress and its thirty thousand defenders, they determined to march at once to its assistance. To that end celerity was all important, and on June 14th; that is to say, only eighteen days after the battle of Kinchou, a Russian army of some thirty-five thousand combatants, under the command of General Baron Stackelberg, moving down the railway to recover Kinchou and Nanshan, came into collision with the Japanese and fought the battle of 'Telissu. The Russian general, clinging always to the railway, advanced with such a restricted front that the Japanese, under General Oku, outflanked him, and he was driven back 
with a loss of about ten thousand, killed and wounded, fourteen guns, and four hundred prisoners.

\section{NAVAL INCIDENTS}

On June 15 th, the very day after the Telissu victory, the Japanese met their only naval catastrophe. While their fleet was watching the enemy off Port Arthur, the battleships Hatsuse and Yashima struck mines and sank immediately. Moreover, on the same day, the cruisers Kasuga and Yoshino collided in a dense fog, and the latter vessel was sent to the bottom. As the Japanese possessed only six battle-ships, the loss of two was a serious blow, and might have emboldened the Russians to despatch a squadron from the Baltic to take the earliest possible advantage of this incident. Foreseeing this, the Japanese took care to conceal the loss of the Hatsuse and Yashima, and the fact did not become known until after the battle of Tsushima, a year later, when the Russian fleet had been practically annihilated.

Méanwhile, the Russian squadron at Vladivostok had accomplished little. This squadron consisted originally of three armoured cruisers, Gromovoi, Rossia, and Rurik, with one protected cruiser, Bogatyr. But the last-named ship ran on a rock near Vladivostok and became a total wreck in the middle of May, a month marked by many heavy losses. These cruisers made several excursions into the Sea of Japan, sinking or capturing a few Japanese merchantmen, and cleverly evading a Japanese squadron under Admiral Kamimura, detailed to watch them. But their only achievement of practical importance was the destruction of two large Japanese transports, the Hitachi Maru and the Sado Maru. In achieving this feat the Russians appeared off Tsushima in the Straits of Korea, on June 15th, and the transports which they sunk or disabled carried heavy guns for the bombardment of Port Arthur.

Of course, nothing was publicly known about the cargo of the Hitachi and her consort, but there could be no question that, in timing their attack with such remarkable accuracy, the Russians must have obtained secret information as to the movements of the transports and the nature of their cargo. Considerable criticism was uttered against Admiral Kamimura for failure to get into touch with the Vladivostok vessels during such a long interval. But much of the censure was superficial. Kamimura redeemed his reputation on the 14th of August when, in a running fight between Fusan and Vladivostok, the Rurik was sunk and the Gromovoi and Rossia were so seriously damaged as to be unable to take any further part in the war. On this occasion six hundred Russians were rescued by the Japanese from the sinking Rurik, and it was noted at the time that the Russians had made no attempt to save Japanese life at the sinking of the Hitachi Maru.

\section{THE JAPANESE FORCES}

Immediately after the landing of the army corps under General Oku and the capture of Dalny in the sequel of the battle of Kinchou, the Japanese began to pour troops into Dalny, and soon they had there three divisions under the command of General (afterwards Count) Nogi. This force was henceforth known as the Third Army, that of General Kuroki being the First, and that under General Oku, the Second. The next operation was to land another army at Takushan, which lies on the south coast of Manchuria, between Pitszewo and the estuary of the Yalu. This army was under the command of General (afterwards Count) Nozu, and its purpose was to fill the gap between the First 
Army and the Second. Nozu's corps thus became the Fourth Army. In fact, the Japanese repeated, in every respect, the plan of campaign pursued by them ten years previously in the war with China.

There was one ultimate difference, however. In the latter war, the force which captured Port Arthur was subsequently carried oversea to the Shantung province, where it assaulted and took the great Chinese naval port at Weihaiwei. But the army sent against Port Arthur, in 1904, was intended to march up the Liaotung peninsula after the capture of the fortress, so as to fall into line with the other three armies and to manœuvre on their left flank during the general, advance northward. Thus considered, the plan of campaign suggests that General Nogi and his three divisions were expected to capture Port Arthur without much delay, and indeed their early operations against the fortress were conducted on that hypothesis. But, as a matter of fact, in spite of heroic, efforts and unlimited bravery on the Japanese side, Port Arthur, with its garrison of thirty thousand men, its splendid fortifications, and its powerful artillery, backed by the indomitable resolution and stubborn resistance of Russian soldiers, did not fall until the last day of 1904 , and Nogi's army was unable to take part in the great field-battles which marked the advance of the three other. Japanese armies from the seacoast to the capital of Manchuria.

Step by step, however, though at heavy sacrifice of life, the Japanese fought their way through the outer lines of the Russian defences, and the end of July; saw the besiegers in such a position that they were able to mount guns partly, commanding the anchorage within the port. An intolerable situation being thus created for the Russian squadron, it determined to put to sea, and on August 10 th this was attempted. Without entering into details of the fight that ensued, it will suffice to state briefly that the result of the sortie was to deprive the Russian squadron of the services of one battle-ship, three cruisers, and five torpedo craft, leaving to Rear-Admiral Prince Ukhtonsky, who commanded the vessels in Port Arthur, only five battle-ships, two cruisers (of which one was injured), and three destroyers. On August 18th, a gunboat; on August 23d, another battle-ship, and on August 24th another destroyer were sunk or disabled by striking Japanese mines, and it may be said briefly that the Russian squadron thenceforth ceased to be a menace to the Japanese, and that only the land forces had to be counted with.

\section{FIELD OPERATIONS PRIOR TO BATTLE OF 'LIAOYANG}

By the close of June the three Japanese armies under Generals Kuroki, Nozu, and Oku were fully deployed and ready to advance in unison. The task before them was to clear the Russians from the littoral of the Korean Sen and force them through the mountains of Manchuria into the valley of the Liao River. In these operations the Japanese acted uniformly on the offensive, whereas the Russians occupied positions carefully chosen and strictly fortified, where they stood always on the defensive. Five heavy engagements, beginning with Fenshuiling on the 26th of June and ending with Yangtzuling on July 31st, were fought in these circumstances, and in every instance the Japanese emerged victorious. From the commencement of the land campaign until the end of July the invading army's casualties were 12,000, while the Russian losses, exclusive of those at Port Arthur, aggregated 28,000 killed and wounded, and 113 light siege- and field-guns, together, with eighteen machine-guns, captured. 


\section{THE BATTLE OF LIAOYANG}

The first great phase of the field-operations may be said to have terminated with the battle of Liaoyang, which commenced on August 25th and continued almost without interruption for nine days, terminating on the 3rd of September. In this historic contest the Russians had 220,000 men engaged. They were deployed over a front of about forty miles, every part of which had been entrenched and fortified with the utmost care and ingenuity. In fact, the position seemed impregnable, and as the Japanese could muster only some 200,000 men for the attack, their chances of success appeared very small. Desperate fighting ensued, but no sensible impression could be made on the Russian lines, and finally, as a last resource, a strong force of Kuroki's army was sent across the Taitsz River to turn the enemy's left flank. The Russian general, Kuropatkin, rightly estimated that the troops detached by General Kuroki for this purpose were not commensurate with the task assigned to them, whereas the Russians could meet this flanking movement with overwhelming strength. 'Therefore, Kuropatkin sent three army corps across the river, and by September 1st, the Japanese flanking forces were confronted by a powerful body.

Strategists are agreed that, had Kuropatkin's plans found competent agents to execute them, the Japanese advance would have been at least checked at Liaoyang. In fact, the Japanese, in drafting their original programme, had always expected that Nogi's army would be in a position on the left flank in the field long before there was any question of fighting at Liaoyang. It was thus due to the splendid defence made by the garrison of the great fortress that Kuropatkin found himself in such a favourable position at the end of August. But unfortunately for the Russians, one of their generals; Orloff, who had thirteen battalions under his command, showed incompetence, and falling into an ambuscade in the course of the counter-flanking operation, suffered defeat with heavy losses. The Japanese took full advantage of this error, and Kuropatkin, with perhaps excessive caution, decided to abandon his counter-movement and withdraw from Liaoyang. He effected his retreat in a manner that bore testimony to the excellence of his generalship. The casualties in this great battle were very heavy. From August 25th, when the preliminary operations may be said to have commenced, to September 3rd, when the field remained in the possession of the Japanese, their losses were 17,539, namely, 4866 in the First Army; 4992 in the Fourth, and 7681 in the Second, while the Russian casualties were estimated at 25,000 .

\section{BATTLES OF SHAHO AND OF HEIKAUTAI}

On the 2nd of October, General Kuropatkin issued from his headquarters in Mukden an order declaring that the "moment for the attack, ardently desired by the army, had at last arrived, and that the Japanese were now to be compelled to do Russia's will." Barely a month had elapsed since the great battle at Liaoyang, and it still remains uncertain what had happened in that interval to justify the issue of such an order. But the most probable explanation is that Kuropatkin had received re-enforcements, so that he could marshal 250,000 to 260,000 troops for the proposed offensive, and that his news from Port Arthur suggested the necessity of immediate and strenuous efforts to relieve the fortress. His plan was to throw forward his right so as to outflank the Japanese, recover possession of Liaoyang, and obtain command of the railway. 
He set his troops in motion on the 9th of October, but he was driven back after more than a week's fighting. No less than 13,333 Russian dead were left on the field, and at the lowest calculation, Kuropatkin's casualties must' have exceeded 60,000 men exclusive of prisoners. There can be no doubt whatever that the Russian army had suffered one of the most overwhelming defeats in its history, and that after a fortnight's hard marching and nine days' hard fighting, with little food or sleep, it had been reduced by terrible losses and depressing fatigues to a condition bordering on extermination. Such was the result of Kuropatkin's first attempt to assume the offensive. Thereafter, fully three months of complete inaction ensued, and the onlooking world occupied itself with conjectures as to the explanation of this apparent loss of time.

Yet the chief reason was very simple. The weather in central Manchuria at the close of the year is such as to render military manœuvres almost impossible on a large scale, and this difficulty is greatly accentuated by the almost complete absence of roads. In fact, the reasons which induced Kuropatkin to defy these obstacles, and renew his outflanking attempts after the beginning of the cold weather, have never been fully explained. The most probable theory is that held by Japanese strategists, namely, that he desired to find some opening for the vigorous campaign which he intended to pursue in the spring, and that his attention was naturally directed to the region between the Hun and the Liao rivers, a region unoccupied by either army and yet within striking distance of the bases of both. Moreover, he had received nearly three whole divisions from Europe, and he looked to these fresh troops with much confidence. He set his forees in motion on the 25th of January, 1905. Seven Russian divisions were engaged, and the brunt of the fighting was borne by two Japanese divisions and a brigade of cavalry. Two other divisions were engaged, but the part they acted in the fight was so subordinate that it need searcely be taken into account. The Russians were finally driven back with a loss of some twenty thousand killed; wounded, or prisoners. This battle of Heikautai was the last engagement that took place before the final encounter.

\section{PORT ARTHUR}

The relief of Port Arthur had ceased to be an important objective of Kuropat kin before he planned his Heikautai attack. The great fortress fell on the last day of 1904. It was not until the middle of May that the Kinchou isthmus and Dalny came into Japanese hands, nor was the siege army under General Nogi marshalled until the close of June. During that interval, General Stössel, who commanded, on the Russian side, availed himself of all possible means of defence, and the investing force had to fight for every inch of ground. The attack on the outlying positions occupied fully a month, and not till the end of July. had the Japanese advanced close enough to attempt a coup de main. There can be no doubt that they had contemplated suceess by that method of procedure, but they met with such a severe repulse, during August, that they recognized the necessity of recourse to the comparatively slow arts of the engineer. Thereafter, the story of the siege followed stereotyped lines except that the colossal nature of the fortifications entailed unprecedented sacrifice of life on the besiegers' part. The crucial point of the siege-operations was the capture of a position called 203-Metre Hill. This took place on November 30th after several days of the most terrible fighting ever witnessed, fighting which cost the Japanese ten thousand casualties. The importance of the hill iwas that it 
furnished a post of observation whence indications could be given to guide the heavy'Japanese artillery in its cannonade of the remaining. Russian ships in the harbour.

Nothing then remained for the Russians except to sink the ships, and this they did, so that Russia lost a squadron which, all told, represented an outlay of over thirty millions sterling $-\$ 150,000,000$; In a telegram despatched to his own Government on January 1st, General Stössel said: "Great Sovereign, forgive! We have done all that was humanly possible. Judge us; but be merciful. Eleven months have exhausted our strength. A quarter only of the defenders, and one-half of them invalids, occupy tiventy-seven versts of fortifications without supports and without intervals for even the briefest repose. The men are reduced to shadows!' On the previous day Stössel had written to General Nogi, declaring that further resistance would merely entail useless loss of life considering the conditions within the fortress. The total number of prisoners who surrendered at the fall of the fortress was 878 officers and $23,491 \mathrm{men}$, and the captured material included 546 guns; 35,252 rifles; 60 torpedoes; 30,000 kilograms of powder; 82,670 rounds of gun-ammunition; two and a quarter million rounds of small-arm ammunition; a number of wagons; 1,920 horses; four battle-ships; two cruisers; fourteen gunboats and torpedocraft; ten steamers; thirty-three steam launches, and various other vessels. These figures are worthy of study, as one of General Stössel's alleged reasons for surrendering was scarcity of ammunition.

\section{MISHCHENKO'S RAID}

The capture of Port Arthur meant something more than the fall of a fortress which had been counted impregnable and which had dominated the strategical situation for fully seven months. It meant, also, that General Nogi's army would now be free to join their comrades beyond the Liao River, and that Kuropatkin would find his opponents' strength increased by four divisions. It became, therefore, important to ascertain how soon this transfer was likely to be effected, and, if possible, to interrupt it by tearing up the railway. Accordingly, on January 8th, General Mishchenko's division of Cossacks, Caucasians, and Dragoons, mustering six thousand sabres, with six batteries of light artillery, crossed the Hun River and marched south on a five-mile front. Throughout the war the Cossacks, of whom a very large force was with the Russian army, had hitherto failed to demonstrate their usefulness, and this raid in force was regarded with much curiosity. It accomplished very little. Its leading squadrons penetrated as far south as Old Niuchwang, and five hundred metres of the railway north of Haicheng were destroyed, a bridge also being blown up. "But this damage was speedily restored, and as for the reconnoitring results of the raid, they seem to have been very trifling.

\section{THE BATTLE OF MUKDEN}

After the battle of Heikautai, which cost the Russians twenty thousand casualties and exposed the troops to terrible hardships, Kuropatkin's army did not number more than 260,000 effectives. On the other hand, he could rely upon a constant stream of re-enforcements from Europe, as the efficiency of the railway service had been enormously inereased by the genius and energy of Prince Khilkoff, Russian minister of Ways and Communications. In fact, 
when all the forees under orders for.Manchuria had reached their destination, Kuropatkin would have under his command twelve army corps, six rifle-brigades, and nine divisions of mounted troops, a total of something like half a million men. Evidently the Japanese would not have acted wisely in patiently awaiting the coming of these troops. Moreover, since the break-up of winter would soon render temporarily impossible all operations in the field, to have deferred any forward movement beyond the month of March would have merely facilitated the massing of Russian re-enforcements in the lines on the Shaho, where the enemy had taken up his position after his defeat at Heikautai. These considerations induced Marshal Oyama to deliver an attack with his whole force during the second half of February, and there resulted a conflict which, under the name of the "battle of Mukden," will go down in the pages of history as the greatest fight on record.

It has been claimied by the Russians that Kuropatkin was thinking of assuming the offensive when the Japanese forced his hand; but however that may be, the fact is that he fought on the defensive as he had done throughout the whole war with two exceptions. Nevertheless; we may confidently assert that at no, previous period had the Russians been so confident and so strong. According to the Japanese estimate, the accuracy of which may be trusted, Kuropatkin had 376 battalions, 171 batteries, and 178 squadrons; representing 300,000 rifles, 26,000 sabres and 1368 guns, while the defences behind which these troops were sheltered were of the most elaborate character, superior to anything that the Japanese had encountered during the previous battles of the fieldeampaign. On the other hand, the Japanese also were in unprecedented strength. Up to the battle of Heikautai, Kuropatkin had been confronted by only three armies, namely, the First, Second, and Fourth, under Generals Kuroki, Oku, and Nozu, respectively. In the middle of February, these numbered three, four, and two divisions, respectively. But there had now been added a considerable number of reserve brigades, bringing up the average strength of most of the divisions to from 22,000 to 25,000 men. Further, in addition to these armies, two others were in the field, namely, the Third, under General Nogi, and the Fifth, under General Kawamura. General Nogi's force had marched up from Port Arthur, but General Kawamura's was a new, army formed of special reservists and now put in the field for the first time.

The Russians oceupied a front forty-four miles in extent and from five to six miles in depth. They did not know, apparently, that General Kawamura's army had joined Oyama's forces, nor did they know. where Nogi's army was operating. The Japanese programme was to hold the Russian eentre; to attack their left flank with Kawamura's army, and to sweep round their right flank with Nogi's forces. The latter were therefore kept in the rear until Kawamura's attack had developed fully on the east and until the two centres were hotly: engaged. Then "under cover of the smoke and heat generated by the conflict of the other armies on an immense front, and specially screened by the violent activity of the Second Army, Nogi marehed in echelon of columns from the west on a wide, circling movement; swept up the Liao valley, and bending thence eastward, deseended on Mukden from the west and northwest, giving the finishing blow of this gigantic encounter; severing the enemy's main line of retreat, and foreing him to choose between surrender and flight. To launch, direct, and

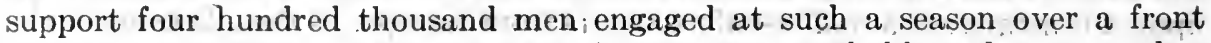
one hundred miles in length was one of the most remarkable tasks ever undertaken on the field of battle by a modern staff.": 


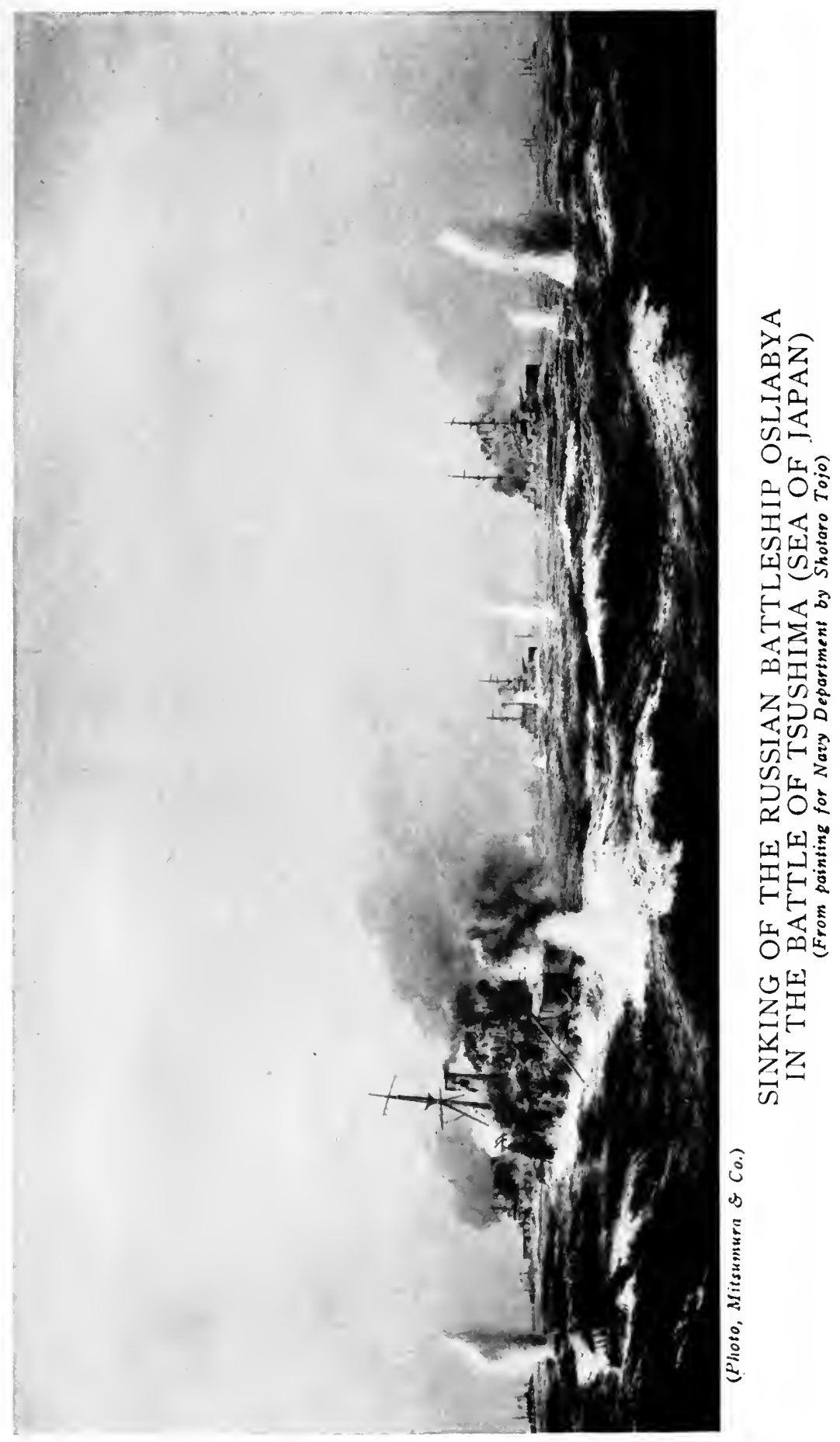



Of course, all these events did not move exactly as planned, but the main feature of the great fight was that Kuropatkin, deceived by Kawamura's movement, detached a large force to oppose him, and then recalled these troops too late for the purpose of checking General Nogi's flanking operation. The fighting was continuous for almost two weeks; and on the morning of March 16th, the Russians had been driven out of Mukden and forced northward beyond Tiehling. I In fact, they did not pause until March 20th; when Linievitch, who had succeeded Kuropatkin in the chief command, was able to order a halt at Supingchieh, seventy miles to the north of Mukden. "The. Russian losses in this most disastrous battle included, according to Marshal Öyama's reports, 27,700 killed and 110,000 wounded," while an immense quantity of war material fell into the hands of the victors. The Japanese losses, up to the morning of March 12th, were estimated at 41,222.

\section{THE BATTLE OF TSUSHIMA}

From the outset, both sides had appreciated the enormous preponderance that would be conferred by command of the sea. It was in obedience to this conviction that the Russian authorities were in the act of taking steps to increase largely their Pacific squadron when the outbreak of war compelled them to suspend the despatch of re-enforcements. They did not; however, relinquish their preparations. Evidently, any vessels sent to the scene of combat after fighting had begun must be competent to defend themselves against attack; which condition entailed strength to form an independent squadron. The preparations to acquire this competence involved a long delay, and it was not until the 16th of October, 1904, that Admiral Rozhdestvensky left Libau with some forty ships. . The world watched this adventure with astonished eyes: Thitherto Great Britain, equipped as she is with coaling-stations all round the globe, had been the only power thought capable of sending a large fleet on an ocean voyage. Rozhdestvensky's squadron consumed over three thousand tons of coal daily when steaming at a reduced speed, and how this supply was to be kept up in the absence of ports of call, no one was able to conjecture. The difficulty was ultimately overcome by the very benevolent character which the neutrality of certain powers assumed, and in May, 1905, the Baltic squadron; as the vessels under Rozhdestvensky were called, made its appearance in Far Eastern waters.

It had been supposed that the Russians would seek to envelop their movements in obscurity, but they; seem to have appreciated, from the outset, the absurdity of endeavouring to conceal the traces of a fleet of forty vessels steaming along the routes of the world's commerce. They therefore proceeded boldly on their way, slowly but indomitably overcoming all obstacles. It will be observed that the date of their departure from Libau was just two months after the last attempt of the Port Arthur squadron to escape to Vladivostok. Doubtless, this sortie, which ended so disastrously for the Russians, was prompted in part by anticipation of the Baltic fleet's approaching departure, and had the Port Arthur squadron, or any considerable portion of it, reached Vladivostok before Rozhdestvensky's coming, Admiral Tōgō might have been caught between two fires. The result of the sortie, however, dispelled that hope. Long before Rozhdestvensky reached the Far East, he fell into touch with Japanese scouts, and every movement of his ships was flashed to the enemy. That Vladivostok was his objective and that he would try to reach that place if possible without 
fighting, were unquestionable facts. But by what avenue would he enter the Sea of Japan? The query occupied attention in all the capitals of the world during several days, and conjectures were as numerous as they were conflicting. But Admiral Tōgō had no moment of hesitation. He knew that only two routes were possible, and that one of them, the Tsugaru Strait, could be strewn with mines at very brief notice.. The Russians dare not take that risk. Therefore Tö waited quietly at his base in the Korean Strait and on the 27th of Mayl his scouts reported by wireless telegraphy at 5 A.M., "Encmy's fleet sighted in 203 section. He seems to be steering for the east channel!".

In the historic action which ensued, Rozhdestvensky had under his command eight battle-ships, nine cruisers, three coast-defence ships, nine destroyers, an auxiliary cruiser, six special-service steamers, and two hospital ships.' cTogó's fleet consisted of five battle-ships (one of them practically valueless), one coastdefence vessel, eight armoured cruisers, ten protected cruisers, twenty destroyers, and sixty-seven torpedo-boats. Numerically, the advantage was on the Japanese side, although in first-class fighting material the disparity was not remarkable: : As for the result, it can only be called annihilation for the Russian squadron. Out of the thirty-eight ships composing it, twenty were surik; six captured; two went to the bottom or were shattered while escaping; six iwere disarmed and interned in neutral ports to which they had fled; one was released after capture, and of one the fate is unknown. Only two escaped out of the whole'squadron. This wonderful result justifies the comment of a competent authority:

"We can recognize that Tōgo is great - great in the patience he exercised in the face of much provocation to enter upon the fight under conditions less favourable to the success of his cause; great in his determination to give decisive battle despite advice offered to him to resort to methods of evasion, subtèrfuge, and finesse; great in his use of not one but every means in his power to crush his enemy, and great; greatest perhaps of all, in his moderation after victory. unparalleled in the annals of modern naval war.

"The attitude of the Japanese people in the presence of this epoch-making triumph is a sight for men and gods. They have the grand manner of the ancients, and their invariable attitude throughout the war, whether in the hour of victory or in that of disappointment, has been worthy of a great people. No noisy and vulgar clamour, no self-laudation, no triumph over a fallen enemy, but deep thankfulness, calm satisfaction, and reference of the cause of / victory to the illustrious virtue of their Emperor:"!

The Japanese losses in the two-days' fighting were three torpedo-boats, and they had 116 killed and 538 wounded.

\section{PEACE RESTORED}

After the battles of Mukden and Tsushima, which were great enough to terminate the greatest:war,-the Russians and the Japanese alike found themselves in a position which must either prelude another stupendous effort on both sides or be utilized to negotiate peace. Here the President of the United States of America intervened, and, on the 9th of June, 1905, the American minister in Tōkyō and the ambassador in St. Petersburg, instructed from Washington, handed an identical note to the Japanese and the Russian Governments respectively, urging the two countries to approach each other direct. : On the following 
day; Japan intimated her frank acquiescence, and Russia lost no time in taking a similar step. 'Two months nevertheless elapsed before the plenipotentiaries of the two powers met, on August 10th, at Portsmouth, New Hampshire. Russia sent M. (afterwards Count) de Witte and Baron Rosen; Japan, Baron (afterwards Marquis) Komura, who had held the portfolio of Foreign Affairs throughout the war, and Mr. (afterwards Baron) Takahira. The Japanese statesmen well understood that much of the credit accruing to them for their successful conduct of the war must be forfeited in the sequel of the negotiations. For the people of Japan had accustomed themselves to expect that Russia would recoup a great part, if not the whole, of the expenses incurred by their country in the contest, whereas the ministry in Tokyo knew that to look for payment of indemnity by great State whose territory has not been invaded effectively or its existence menaced must be futile.

Nevertheless, diplomacy required that this conviction should be concealed, and thus Russia carried to the conference a belief that the financial phase of the discussion would be crucial. Baron Komura's mandate was, however, that the only radically essential terms were those formulated by Japan prior to the war. She must insist on securing the ends for which she had fought, since she believed them to be indispensable to the peace of the Far East, but beyond that she would not go.' The Japanese plenipotentiaries, therefore, judged it wise to submit their terms in the order of the real importance, leaving their Russian colleagues to imagine, as they probably would, that the converse method had been adöpted, and that everything prefatory to questions of finance and territory was of minor consequence.

The negotiations, commencing on the 10th of August, were not concluded until the 5 th of September, when a treaty of peace was signed. There had been a moment when the onlooking world believed that unless Russia agreed to ransom the island of Saghalien by paying to Japan a sum of 120 millions sterling, $\longrightarrow 580,000,000$, the conference would be broken off. Nor did such an exchange seem unreasonable, for were Russia expelled from the northern part of Saghalien, which commands the estuary of the Amur, her position in Siberia would have been compromised: But Japan's statesmen were not disposed to make any display of territorial aggression. The southern half of Saghalien had originally belonged to Japan and had passed into Russia's possession by an arrangement which the Japanese nation strongly resented: To recover that portion of the island seemed, therefore, a legitimate ambition. Japan did not contemplate any larger demand, nor did she seriously insist on an indemnity. Thus, the negotiations were never in real danger of failure."

hre The Treaty of Portsmouth recognized Japan's "paramount political, military, and economic interests" in Korea; provided for the simultaneous evacuation of Manchuria by the contracting parties; transferred to Japan the lease of the Liaotung peninsula, held by Russia from China, together with that of the Russian railways south of Kwanchengtsz and all collateral mining or other privileges; ceded to Japan the southern half of Saghalien, the fiftieth parallel of latitude to be the boundary between the two parties; secured fishing-rights for Japanese subjects along the coasts of the seas of Japan, Okhotsk, and Bering; laid down that the expense incurred by the Japanese for the maintenance of the Russian prisoners during the war should be reimbursed by Russia, less the outlays made by the latter on account of Japanese prisoners, by which arrangement Japan obtainéd a payment of some four million sterling - $\$ 20,000,000$, and provided that the contracting parties, while withdrawing their military force 
from Manchuria, might maintain guards to protect their respective railways, the number of such guards not to exceed fifteen per kilometre of line. There were other important restrictions: first, the contracting parties were to abstain from taking, on the Russo-Korean frontier, any military measures which might menace the security of Russian or Korean territory; secondly, the two powers pledged themselves not to exploit the Manchurian railways for strategic purposes, and thirdly, they promised not to build on Saghalien or its adjacent islands any fortifications or other similar works, or to take any military measures which might impede the free navigation of the Strait of La Pérouse and the Gulf of Tatary.

The above provisions concerned the two contracting parties only. But China's interests also were considered. Thus, it was agreed to "restore entirely and completely to her exclusive administration" all portions of Manchuria then in the occupation, or under the control, of Japanese or Russian troops, except the leased territory; that her consent must be obtained for the transfer to Japan of the leases and concessions held by the Russians in Manchuria; that the Russian Government should disavow the possession of "any territorial advantages or preferential or exclusive concessions in impairment of Chinese sovereignty or inconsistent with the principle of equal opportunity in Manchuria," and that Japan and Russia "engaged reciprocally not to obstruct any general measures common to all countries which China might take for the development of the commerce and industry of Manchuria."

This distinction between the special interests of the contracting parties and the interests of China herself, as well as of foreign nations generally, is essential to clear understanding of a situation which subsequently attracted much attention. From the time of the Opium War (1857) to the Boxer rising (1900), each of the great Western powers struggled for its own hand in China, and each sought to gain for itself exclusive concessions and privileges with comparatively little regard for the interests of others and with no regard whatsoever for China's sovereign rights. The fruits of this period were permanently ceded territories (Hongkong and Macao); leases temporarily establishing foreign sovereignty in various districts (Kiao-chou, Weihaiwei, and Kwang-chow); railway and mining concessions, and the establishment of settlements at open ports where foreign jurisdiction was supreme. But when, in 1900, the Boxer rising forced all the powers into a common camp, they awoke to full appreciation of a principle which had been growing current for the past two or three years, namely, that concerted action on the lines of maintaining China's integrity and securing to all alike equality of opportunity and a similarly open door, was the only feasible method of preventing the partition of the Chinese empire and averting a clash of rival interests which might have disastrous results. This, of course, did not mean that there was to be any abandonment of special privileges already acquired or any surrender of existing concessions. The arrangement was not to be retrospective in any sense. Vested interests were to be strictly guarded until the lapse of the periods for which they had bcen granted, or until the maturity of China's competence to be really autonomous.

A curious situation was thus created. International professions of respect for China's sovereignty, for the integrity of her empire, and for the enforcement of the open door and equal opportunity co-existed with legacies from an entirely different past. Russia endorsed this now policy, but not unnaturally declined to abate any of the advantages previously enjoyed by her in Manchuria. Those advantages were very substantial. They included a twenty-five-year lease - 
with provision for renewal - of the Liaotung peninisula, within which area of 1220 square miles Chinese troops might not penetrate, whereas Russia would not only exercise full administrative authority, but also take military and naval action of any kind; they included the creation of a neutral territory on the immediate north of the former and still more extensive, which remained under Chinese administration, and where neither Chinese nor Russian troops might enter, nor might China, without Russia's consent, cede land, open trading marts, or grant concessions to any third nationality; and they included the right to build some sixteen hundred miles of railway (which China would have the opportunity of purchasing at cost price in the year 1938, and would be entitled to receive gratis in 1982), as well as the right to hold extensive zones on either side of the railway, to administer these zones in the fullest sense, : and to work all mines.lying along the lines:

Under the Portsmouth treaty these advantages were transferred to Japan by Russia, the railway, however, being divided so that only the portion (5211/2 miles) to the south of Kwanchengtsz fell to Japan's share, while the portion (1077. miles) to the north of that place remained in Russia's hands. China's consent to the above transfers and assignments was obtained in a treaty signed at Peking on the 22nd of December, 1905. Thus, Japan came to hold in Manchuria a position somewhat contradictory. On the one hand, she figured as the champion of the Chinese empire's integrity and as an exponent of the new principle of equal opportunity and the open door. On the other, she appeared as the legatee of many privileges more or less inconsistent with that principle. But, at the same time, nearly all the great powers of Europe were similarly circumstanced. ' In their cases, also, the same incongruity was observed between the newly professed policy and the aftermath of the old practice: It was scarcely to be expected that Japan alone should make a large sacrifice on the altar of a theory to which no other State thought of yielding any retrospective obedience whatever. She did, indeed, furnish a clear proof of deference to the open-door doctrine, for instead of reserving the railway zones to her own exclusive use, as she was fully entitled to do, she sought and obtained from China a pledge to open to foreign trade sixteen places within these zones.

For the rest, however, the inconsistency between the past and the present, though existing throughout the whole of China, was nowhere so conspicuous as in the three eastern provinces (Manchuria); not because there was any real difference of degree, but because Manchuria had been the scene of the greatest war of modern times; because that war had been fought by Japan in the cause of the new policy, and because the principles of the equally open door and of China's integrity had been the main bases of the Portsmouth treaty, of the Anglo-Japanese alliance, and of the subsequently concluded ententes with France and Russia. In short, the world's eyes were fixed on Manchuria and diverted from China proper, so that every act of Japan was subjected to an exceptionally rigorous scrutiny, and the nations behaved as though they expected her to live: up to a standard of almostideal altitude. China's mood, too, greatly complicated the situation. She had the choice between two moderate and natural courses; either to wait quietly until the various concessions granted by her to foreign powers in the evil past should lapse by maturity, or to qualify herself by earnest reforms and industrious developments for their earlier recovery. Nominally she adopted the latter course, but in reality she fell into a mood of much impatience. Under the name of a "rights-recovery campaign" her people began" to protest vehemently against the continuance of any conditions which impaired. 
her sovereignty, and as this temper coloured her attitude towards the various questions which inevitably grew out of the situation in Manchuria; her relations with Japan became somewhat strained in the early part of $1909.1079 \%$, vlro Jors

\section{JAPAN IN KOREA AFTER THE WAR WITH RUSSIA}

frrixt vers. To roitos

Having waged two wars on account of Korea Japan emerged from the second conflict with the conviction that the policy of maintaining the independ: ence of that country must be modified, and that since the identity: of Korean and Japanese interests in the Far East and the paramount character of Japanese interests in Korea would not permit Japan to leave Korea to the care of any third power, she must assume the charge herself. Europe and America ialso recognized that view of the situation, and consented to withdraw their/egations from Seoul, thus leaving the control of Korean foreign affairs entirely in the hands of Japan, who further undertook to assume military direction in the event of aggression from without or disturbance from within. "But in the matter of internal administration, she continued to limit herself to advisory supervision. Thus, though a Japanese resident-general in Seoul, with subordinate residents throughout the provinces, assumed the functions hitherto discharged by foreign ministers and consuls, the Korean Government was merely asked to employ. Japanese experts in the position of counsellors, the right to accept or reject their counsels being left to their employers.

Once again, however, the futility of looking for any real reforms under this optional system was demonstrated. Japan sent her most renowned statesman; Prince: Itō, to discharge the duties of resident-general; but even he, in spite of patience and tact, found that some less optional methods must be résorted to. Hence, on the 24 th of July, 1907, a new agreement was signed, by which the resident-general acquired initiative as well as consultative competence to enact and enforce laws and ordinances; to appoint and rémove Korean officials; ;and to place capable Japanese subjects' in the ranks of the administration. That this constituted a heavy blow to Korea's independence could not be gainsaid. That it was inevitable seemed to be equally obvious. For there existed in Korea nearly all the worst abuses of medieval systems. The administration of justice depended solely on favour or interest. The police contributed by corruption and incompetence to the insecurity of life and property: The troops were a body of useless mercenaries. Offices being allotted by sale, thousands of incapables thronged the ranks of the executive. The' Emperor's Court was crowded by diviners and plotters of all kinds; male and femalein The finances of the Throne and those of the State were hopelessly confused.ri: There was nothing like an organized judiciary." $A$ witness was in many cases considered particeps criminis; torture was commonly employed to obtain evidence, and defendants in eivil cases were placed under arrest. Imprisonment meant death or permanent disablement for a man of means.- Flogging so severe as to cripple; if not to kill, was a common punishment; every major offence from robbery upwards was capital, and female criminals were frequently executed by adminis:tering shockingly painful poisons." The currency was in a state of the utmost, confusion. Extreme corruption and extortion were practised in connexion with taxation. Finally, while nothing showed that the average Korean lacked the elementary virtue of patriotism, there had been repeated proofs that the safety and independence of the empire counted for little with political initriguers. Japan must step out of Korea altogether or effect drastic reforms there: 01 
niShe necessarily chose the latter alternative, and the things which she accomplished between the beginning of 1906 and the close of 1908 may be briefly described as the elaboration of a proper system of taxation; the organization of a staff to administer annual budgets; the re-assessment of taxable property; thefloating of public loans for productive enterprises; the reform of the currency; the establishment of banks of various kinds, including agricultural and commercial; the creation of associations for putting bank-notes into circulation; the introduction of a warehousing system to supply capital to farmers; the lighting and buoying of the coasts; the provision of posts; telegraphs, roads, and railways; the erection of public buildings; the starting of various industrial enterprises (such as printing, brick making, forestry and coal mining); the laying out of model farms; the beginning of cotton cultivation; the building and equipping of an industrial training school; the inauguration of sanitary works; the opening of hospitals and medical schools; the organization of an excellent educational system; the construction of waterworks in several towns; the complete remodelling of the Central Government; the differentiation of the Court and the executive, as Iwell as of the administrative and the judiciary; the formation of an efficient body of police; the organization of law-courts with a majority of Japanese jurists on the bench; the enactment of a new penal code, and draștic reforms in the taxation system.

In the summer of :1907; the resident-general advised the Throne to disband the standing army as an unserviceable and expensive force. The measure was doubtless desirable, but the docility of the troops had been overrated. Some of them resisted vehemently, and many became the nucleus of an insurrection which lassted in a desultory manner for nearly two years; cost the lives of 21,000 insurgents and 1300 Japanese, and entailed upon Japan an outlay of nearly a million sterling. Altogether, what with building 642 miles of railway; making loans to Korea, providing funds for useful purposes and quelling the insurrection; Japan was fifteen millions sterling $\$ 72,000,000$ - out of pocket on Korea's account by the end of 1909 . She had also lost the veteran statesman, Prince Itō, who was assassinated at Harbin by a Korean fanatic on the 26th of October, 1909.:

\section{ANNEXATION OF KOREA}

Japan finally resolved that nothing short of annexation would suit the situation, and that step was taken on August 22, 1910. At what precise moment this conviction forced itself upon Japan's judgment it is impossible to say; She knows how to keep her counsel. But it was certainly with great reluctance that she, hitherto the exponent and champion of Korean independence, accepted the rôle of annexation. The explanation given by her own Government is as follows:

In its solicitude to put an end to disturbing conditions, the Japanese Government made an arrangement, in 1905, for establishing a protectorate over Korea and they have ever since been assiduously engaged in works of reform, looking forward to the consummation of the desired end. But they have failed to find in the régime of a protectorate sufficient hope for a realization of the object which they had in view, and a condition of unrest and disquietude still prevails throughout the whole peninsula. In these circumstances, the necessity of introducing fundamental changes in the system of government in Korea has become entirely manifest, and an earnest and careful examination of the Korean problem has convincer the Japanese Government that the régime of a protectorate cannot be made to adapt itself to the actual condition of affairs in Korea, and that the responsibilities devolving upon Japan for the due administration' of the country cannot be justly fulfilled without the complete annexation of Korea to the: Empire.:

[ Encylopædia Britannica (11th Edition); article "Japan," by Brinkley.] 
"Thus the dynasty of sovereigns, which had continued in an unbroken' line from 1392, came to' an end with the independence of this country; whose national traditions and history had extended over four thousand years, whose foundation as a kingdom was coeval with that of the Assyrian empire; and the two last living representatives of the dynasty exchanged their positions as Imperial dignitaries for those of princes and pensioners of Japan." Since that drasticistep was taken, events seem to have fully justified it. Under the able management of Count Terauchi, the evil conditions inimical to the prosperity and happiness of the people are fast disappearing. Comparative peace and order reign; and: there appears to be no reason why the fruits of progressive civilization should not ultimately be gathered in Japan's new province as plentifully as they are in Japan herself.

\section{SITUATION IN 1911}

The unstable element of the East Asian situation to-day is the position occupied by Japan and Russia in Manchuria. Both powers possess privileges there which will not be easily surrendered, and which are likely; sooner or later, to prove incompatible with China's autonomy. It was apprehended at the outset that Russia would not long consent to occupy the place assigned to her by the Treaty of Portsmouth, and that she would quickly prepare for a war of revenge. Her statesmen, however,'showed as much magnanimity as wisdom. On July 30,1906 , they signed with Japan a convention pledging the contracting parties to respect all the rights accruing to one or the other under the Portsmouth Treaty: If international promises can be trusted, continuous peace is assured between the two powers. Russia, however, is not only doubling the track of her Siberian Railway; but is also building a second line along the Amur; while Japan will soon command access to central Manchuria by three linés; one from Dalny to Kwanchengtsz; another from Fusan viâ Wiju to Mukden, and a third from the northeastern coast of Korea via Hoiryong, on the Tumen, to Kilin. js ${ }^{2}$

These developments do not suggest that when the lease of Liaotung and the charter of the railways mature - in twenty-five years and thirty years, respectively, from the date of their signature - either Japan or Russia will be found ready to surrender these properties. Meanwhile, the United States of America is gradually constituting itself the guardian of China's integrity in Manchuria, and the citizens of the Pacific slope, under the influence of the labour question, are writing and speaking as though war'between the great republicland the Far Eastern empire were an inevitable outcome of the future. This chimera is unthinkable by anyone really familiar with the trend of Japanese' sentiment, but it may encourage in China a dangerous mood, and it helps always to foster an unquiet feeling. On the whole, when we add the chaotic condition into which China is apparently falling, it has to be admitted that the second decade of the twentieth century does not open a peaceful vista in the Far East.

\section{STEADY-POINTS}

There are, however, two steady-points upon the horizon. One is the AngloJapanese treaty: not the treaty of 1902 , spoken of already above, but a treaty which replaced it and which was concluded on August 12, 1905. The latter document goes much further than the former. For, whereas the treaty of 1902 merely pledged each of the contracting parties to observe neutrality in the event 


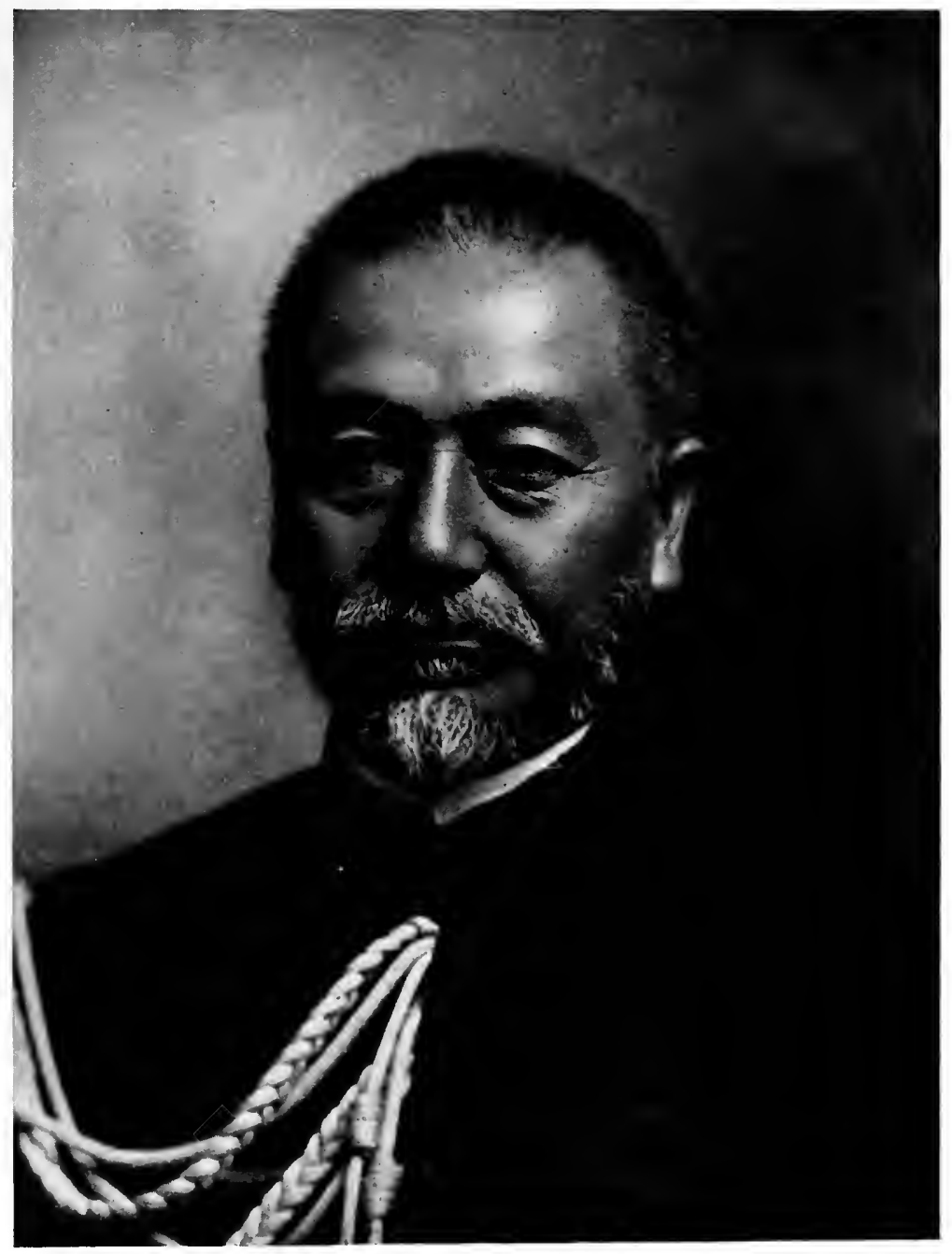

ADMIRAL TŌGŌ 

of the other being engaged in defence of its interests, and to come to that other's assistance in the event of any third power intervening belligerently, the treaty of 1905 provides that-

Whenever in the opinion of either Japan or Great Britain, any of the rights and interests referred to in the preamble of this agreement are in jeopardy, the two Governments will communicate with one another fully and frankly, and will consider in common the measures which should be taken to safeguard those menaced rights or interests.

If, by reason of unprovoked attack or aggressive action, wherever arising, on the part of any other power or powers, either contracting party should be involved in war in defence of its territorial rights or special interests mentioned in the preamble of this agreement, the other contracting party will at once come to the assistance of its ally, and will conduct the war in common, and make' peace in mutual agreement with it.

The "rights and interests" here referred to are defined as follows in the preamble:

The consolidation and maintenance of the general peace in the regions of eastern Asia and of India.

The preservation of the common interests of all powers in China by insuring the independence and integrity of the Chinese empire and the principle of equal opportunities for the commerce and industry of all nations in China.

The maintenance of the territorial rights of the high contracting parties in the regions of eastern Asia and of India, and the defence of their special interests in the said regions.

This remarkable agreement came into force from the date of its signature, and its period of duration was fixed at ten years. During its existence the two powèrs, England and Japan, are pledged to use all endeavours for maintaining - not only peace in the East, but also the independence and integrity of China! The significance of such a pledge is appreciated when we recall the dimensions of the British navy supplemented by the Japanese, and when we further recall that Japan, with her base of operations, within easy reach of the Asiatic continent, can place half a million of men in the field at any moment. The second steadypoint is China's financial condition. She is the debtor of several Western nations, and they may be trusted to avert from her any vicissitude that would impair her credit as a borrower. Prominent among such vicissitudes is the dismemberment of the country.

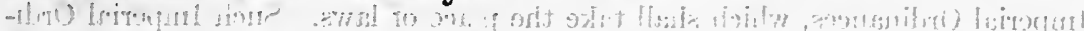

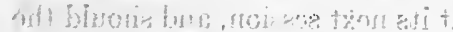

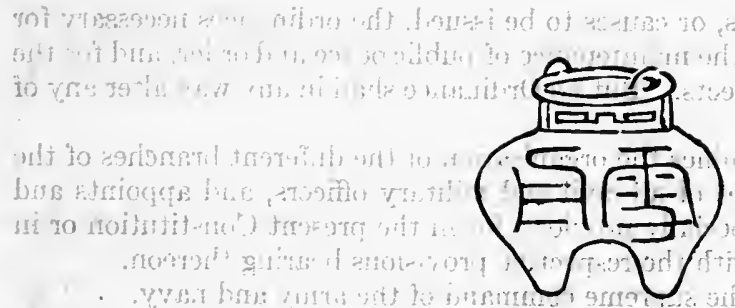

Seal of Sesseo, the Painter 


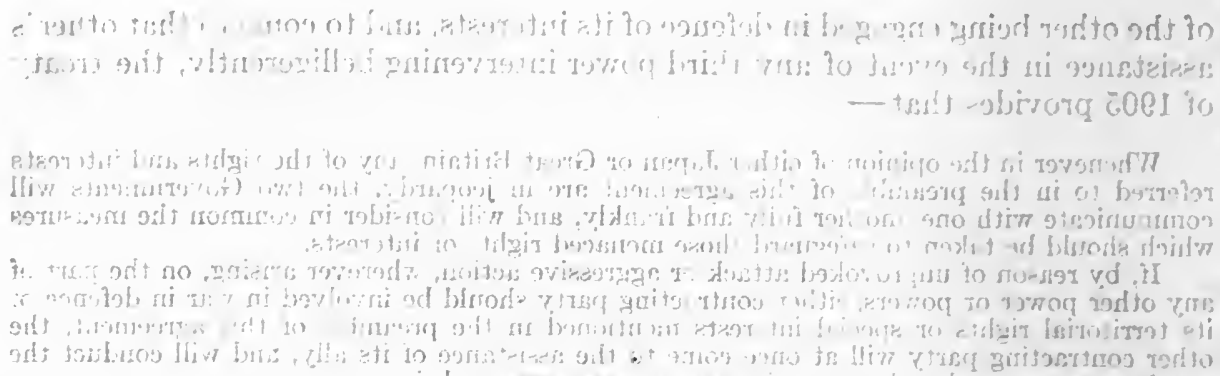

\section{APPENDIX}

linis florimos ni t:"

\section{1.-CONSTITUTION OF THE EMPIRE OF JAPAN}

\section{TŌKYŌ, FEBRUARY 11,..1889}

\section{Chapter I. THE EMPERor}

Article I. The Empire of Japan shall be ruled over by Emperors of the dynasty, which has reigned in an unbroken line of descent for ages past.

Article II. The succession to the throne shall devolve upon male deseendants of the

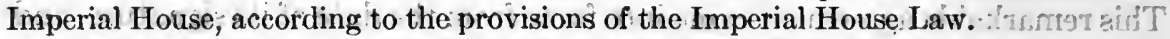
C'JArticle III." The person of the Emperor is sacred and inviolable.

yraticle IV: The Emperor being the Head of the Empire the rights of sovereignty are invested in him, and he exercises them in accordance with the provisions of the present Constitution.

Article $V$ The Emperor exercises the legislative power with the eonsent of the Imperial Diet.

Article Vi. The Emperor gives sanction to laws, and orders them to be promulgated and put into foree.

"Article VII. The Emperor convokes the Imperial Diet, opens, closes; and prorogues it, and dissolves the House of Representatives on Article /VIII. In ease of urgent necessity; when the Imperial Diet is not sitting, the Emperor; in order to maintain the public safety or to a vert a publie danger, has the power, to issue Imperial Ordinances, which shall take the place of laws. Sueh Imperial Ordinanees shall, however, be laid before the Imperial Diet at its next session, and should the Diet disapprove of the said Ordinances, the Government shall declare them to be henceforth invalid.

Article IX. The Emperor issues, or causes to be issued, the ordinanees necessary for the earrying out of the laws, or for the maintenance of publie peace and order, and for the promotion of the welfare of his subjects. But no Ordinance shall in any way alter any of the existing laws.

Article X. The Emperor determines the organisation of the different branches of the Administration; he fixes the salaries of all civil and military officers, and appoints and dismisses the same. Exceptions speciafly provided for in the present Constitution or in other laws shall be in accordance with the respective provisions bearing thereon.

Article XI. The Emperor has the supreme eommand of the army and navy.

Article XII. The Emperor determines the organisation and peace standing of the army and navy.

Article XIII. The Emperor declares war, makes peace, and concludes treaties.

Article XIV. The Emperor proclaims the law of siege. The conditions and operdtion of the law of siege shall be determined by law.

Artiele XV. The Emperor confers titles of nobility, rank, orders, and other marks of honour.

Article XVI. The Emperor orders amnesty, pardon, eommutation of punishments, and rehabilitation. 
od Article:XVII. The institution of a Regency shall take place in conformity with the provisions of the Imperial House Law. ${ }^{1}$

The Regent shall exercise the supreme powers which belong to the Emperor in his name.

\section{Chapter II. Rights and Dútes of Subjectís}

Article XVIII. The conditions necessary for being a Japanese subject shall be determined by law.

Article XIX. Japanese subjects shall all equally be eligible for civil and military appointments; and any other public offices, subject only to the conditions prescribed and Laws and Ordinances.

L. Article XX. Japanese subjects are amenable to service in the army or navy, according to the provisions of law.

to Artiele XXI. Japanese subjects are amenable to the duty of paying taxes, according to the provisions of law.

Article XXII. Subject to the limitations imposed by law, Japanese subjects shall enjoy full liberty in regard to residence and change of abode.

Article XXIII. No Japanese subject shall be arrested, detained, tried or punished, except àccording to law.

213 Article XXIV. No Japanese subject shall be deprived of his right of being tried by judges determined by law.

Article XXV. Except in the cases provided for in the law, the house of no Japanese subject shall be entered or searched without his permission.

orl Article XXVI. Except in cases provided for in the law, the secrecy of the letters of Japanese subjects shall not be violated.

Article XXVII. The rights of property of Japanese subjects shall not be violated; Such measures; however, as may be rendered necessary in the interests of the public welfare shall be taken in accordance with the provisions of the law.

Article XXVIII. Japanese subjects shall, within limits not prejudicial to peace and order, and not antagonistic to their duties as subjects, enjoy freedom of religious belief. Ir Article XXIX. Japanese subjects shall, within the limits of the law, enjoy liberty in regard to speech, writing, publication, public meetings, and associations.

- Article XXX. Japanese subjects may present petitions, provided that they observe the proper form of respect, and comply with the rules specially provided for such matters. -ivo Article XXXI. The provisions contained in the present chapter shall not interfere with the exercise, in times of war or in case of national emergency, of the supreme powers which belong to the Emperor.

Article XXXII Each and every one of the provisions contained in the preceding articles of the present chapter shall, in so far as they do not conflict with the laws or the rules and discipline of the army and navy, apply to the officers and men of the army and of the navy.

\section{Chapter III. The Imperial Diet}

Article XXXIII. The Imperial Diet shall consist of two Houses: the House of Peers and the House of Representatives.

Article XXXIV. The House of Peers shall, in accordance with the Ordinance concerning the House of Peers, be composed of members of the Imperial Family, of Nobles, and of Deputies who have been nominated by the Emperor.

Article XXXV. The House of Representatives shall be composed of members elected by the people, according to the provisions of the Law of Election.

Article XXXVI. No one can at one and the same time be a member of both Houses.

Article XXXVII. Every law requires the consent of the Imperial Diet:

Article XXXVIII. Both Houses shall vote upon projects of law brought forward by the Government, and may respectively bring forward projects of law. 
Article XXXIX. A bill which has been rejected by either of the Houses shall not be again brought in during the same session.

Article XL. Both Houses can make recommendations to the Government in regard to laws, or upon any other subject. When, however, such recommendations are not adopted, they cannot be made a second time during the same session.

Article XLI. The Imperial Diet shall be convoked every year.

Article XLII. A session of the Imperial Diet shall last during three months. In case of necessity, a duration of a session may be prolonged by Imperial order I I W

Article XLIII. When urgent necessity arises, an extraordinary sessión may be convoked, in addition to the ordinary one. The duration of an extraordinary sessionishall be determined by Imperial order.

"ions(riblu bre eves I

Article XLIV. With regard to the opening, closing, and prorogation of the Imperial Diet, and the prolongation of its sessions, these shall take place simultaneously in both Houses. Should the ${ }^{\prime}$ House of Representatives be ordered to dissolve, the House of Peers shall at the same time be prorogued.

Article XLV. When the House of Representatives has been ordered to dissolve, the election of new members shall be ordered by Imperial decree, and the new House shall be convoked within five months from the day of dissolution.

Article XLVI. No debate can be opened and no vote can be taken in either House of the Imperial Diet unless not less than one-third of the whole number of the members thereof is present.

Article XLVII. Votes shall be taken in both Houses by absolute majority. In the case of a tie vote, the President shall have the casting vote.

Article XLVIII. The deliberation of both Houses shall be held in public. The deliberations may, however, upon demand of the Government or by resolution of the House, be held in seeret sitting.

Article XLIX. Both Houses of the Imperial Diet may respectively present addresses to the Emperor.

Article L. Both Houses may receive petitions presented by subjects.

Article LI. Both Houses may enact, besides what is provided for in the present constitution and in the law of the Houses, rules necessary for the management of their internal affairs.

Article LII. No member of either House shall be held responsible outside the respective Houses for any opinion uttered or for any vote given by him in the House: When', however, a member himself has given publicity to his opinions, by public speech, by documents in print, or in writing, or by any other means, he shall, as regards such actions; be amenable to the general law.

Article LIII. The members of both Houses shall, during the session, be free from arrest, unless with the permission of the House, except in cases of flagrant delicts, or of offences connceted with civil war or foreign troubles.

Article LIV. The Ministers of State, and persons deputed for that purpose by the Government, may at any time take seats and speak in either House.

\section{Chapter IV. The Ministers of State and the Privy Council}

Article LV. The respective Ministers of State shall give their advice to the Emperor, and be responsible for it.

All laws, public ordinances, and imperial rescripts, of whatever kind, that relate to the affairs of the state, require the counter-signature of a Minister of State.

Article LVI. The Privy Council shall, in accordance with the provisions for the organisation of the Privy Council, deliberate upon the important matters of State, when they have been consulted by the Emperor.

\section{Chapter V. The Judioature}

Article LVII. Judicial powers shall be exercised by the courts of law, according to law, in the name of the Emperor. The organisation of the courts of law shall be determined by law. 
od Article LVIII. The judges shall be appointed from among those who possess the proper qualifications determined by law. No judge shall be dismissed from his post except on the ground of sentence having been passed upon him for a criminal act, or by reason of his having been subjected to punishment for disciplinary offence. Rules for disciplinary punishment shall be determined by law.

Article LIX. Trials shall be conducted and judgments rendered publicly. When, however, there exists any fear that such publicity may be prejudicial to peace and order, or to the maintenance of public morality; the public trial may be suspended, either in accordance with the law bearing on the subject or by the decision of the court concerned. Article LX. Matters' which fall within the competency of the special courts shall be specially determined by law.

30 Article LXI. The courts of law shall not take cognizance of any suits which arise out of the allegations that rights have been infringed by illegal action on the part of the executive authorities, and which fall within the competency of the court of administrative litigation, specially established by law.

\section{Chapter VI. Finance}

Article LXII. The imposition of a new tax or the modification of the rates (of an existing one) shall be determined by law.

However, all such administrative fees or other revenue as are in the nature of compensation for services rendered shall not fall within the category of the above clause.

The raising of national loans and the contracting of other liabilities to the charge of the National Treasury, except those that are provided in the Budget, shall require the consent of the Imperial Diet.

đ'Árticle LXIII. Existing taxes shall, in so far as they are not altered by new laws, continue to be collected as heretofore.

Article LXIV. The annual expenditure and revenue of the State shall, in the form of an annual Budget, receive the consent of the Imperial Diet. Any expenditure which exceeds the appropriations set forth under the various heads of the Budget, or those not provided for in the Budget, shall be referred subsequently to. the Imperial Diet for its approval:

Article LXV. The Budget shall be first laid before the House of Representatives.

w Article LXVI. The expenditure in respect of the Imperial House shall be defrayed every year out of the National Treasury, according to the present fixed amount for the same, and shall not hereafter require the consent thereto of the Imperial Diet, except in case an increase thereof is found necessary.

Article LXVII. The fixed expenditure based upon the supreme powers of the Emperor and set forth in this Constitution, and such expenditure as may have arisen by the effect of law, or as appertains to the legal obligations of the Government, shall be neither rejected nor reduced by the Imperial Diet, without the concurrence of the Government.

Article LXVIII. In order to meet special requirements the Government may ask the consent of the Imperial Diet to a certain amount as a continuing expenditure fund, for a previously fixed number of years.

Article LXIX. In order to supply unavoidable deficits in the Budget, and to meet requirements unprovided for in the same, a reserve fund shall be established.

Article LXX. When there is urgent need for the adoption of measures for the maintenance of the public safety; and when in consequence of the state either of the domestic affairs or of the foreign relations, the Imperial Diet cannot be convoked, the necessary financial measures may be taken by means of an Imperial Ordinance. In such cases as those mentioned in the preceding clause the matter shall be submitted to the Imperial Diet at its next session for its approval.

Article LXXI. When the Imperial Diet has not voted on the Budget, or when the Budget has not been brought into actual existence, the Government shall carry out the Budget of the preceding year. 
Article IXXXII. The final account of the expenditure and revenue of the State shall be verified and confirmed by the Board of Audit, and it shall be submitted by the Government to the Imperial Diet, together with the report of verification of the said Board.

The organisation and competency of the Board of Audit shall be determined by law. separately.

\section{Chapter VII. Supplementary Rules}

Article LXXIII. Should, hereafter, the necessity arise for the amendment of the provisions of the present Constitution, a project to that effect shall be submitted for the deliberation of the Imperial Diet by Imperial Order. In the above case, neither House ean open a debate, unless not less than two-thirds of the whole number of members are present; and no amendment can be passed unless a majority of not less than two-thirds of the members present is obtained.

Article LXXIV: No modification of the Imperial House Law shall be required to be submitted for the deliberation of the Imperial Diet." ${ }^{\prime}$ No provision of the present Constitution can be modified by the Imperial House Law.

Article LXXV. No modification ean be introduced into the Constitution, or into the Imperial House Law, during the time of a Regeney.

Article LXXVI. Existing legal enactments, such as laws, regulations, and ordinances, and all other such enactments, by whatever names they may be ealled, which do not conflict with the present constitution, shall continue in force. All existing contracts or orders which entail obligations upon the Government, and which are conneeted with the expenditure, shall come within the scope of Article LXVII.

\section{2.- AGREEMENT BETWEEN JAPAN AND THE UNITED KINGDOM, SIGNED} AT LONDON, AUGUST 12, 1905

Preamble. The Governments of Japan and Great Britain, being desirous of replaeing the agreement concluded between them on the 30th January, 1902, by fresh stipulations; have agreed upon the following articles, which have for their object:

(a) The consolidation and maintenance of the general peace in the regions of Eastern Asia and of India;

(b) The preservation of the common interests of all Powers in China by insuring the independence and integrity of the Chinese Empire and the principle of equal opportunities for the commerce and industry of all nations in China;

(c) The maintenance of the territorial rights of the High Contracting Parties in the regions of Eastern Asia and of India, and the defence of their special interests in the said regions:

Article I. It is agreed that whenever, in the opinion of either Great Britain or Japan, any of the rights and interests referred to in the preamble of this Agreement are in jeopardy, the two Governments will communicate with one another fully and frankly; and will consider in common the measures which should be taken to safeguard those menaced rights or interests. (671)

Article II. If by reason of unprovoked attack or aggressive action, wherever arising, on the part of any other Power or Powers either Contracting Party should be involved in war in defence of its territorial rights or special interests mentioned in the preamble of this Agreement, the other Contracting Party will at once come to the assistance of its ally, and will conduct the war in common, and make peace in mutual agreement with it. $(672)$

Article III. Japan possessing paramount political, military, and economic interests in Corea, Great Britain recognizes the right of Japan to take: such measures of guidance, control, and protection in Corea as she may deem proper and necessary to safeguard and advance those interests, provided always that such measures are not contrary to the principle of equal opportunities for the commerce and industry of all nations. (672) 
Article IV. Great Britain having a special interest in all that concerns the security of the Indian frontier, Japan recognizes her right to take such measures in the proximity of. that frontier as she may find necessary for safeguarding her Indian possessions. (672) vricticle V. The High Contracting Parties agree that neither of them will, without consulting the other, enter into separate arrangements with another Power to the prejudice of the objects described in the preamble of this Agreement. (672)

Article VI: As regards the present war between Japan and Russia, Great Britain will continue to maintain strict neutrality unless some other Power or Powers should join in hostilities against Japan, in which case Great Britain will come to the assistance of Japan, and will conduct the war in common, and make peace in mutual agreement with Japan. (672)

Article VII. The conditions under which armed assistance shall be afforded by either Power to the other in the circumstances mentioned in the present Agreement, and the means by which such assistance is to be made available, will be arranged by the Naval and Military authorities of the Contracting Parties, who will from time to time consult one another fully and freely upon all questions of mutual interest. ¿(673)

Article VIII. The present Agreement shall, subject to the provisions of Article VI, come into effect immediately after the date of its signature, and remain in force for ten years from that date.

In case neither of the High Contracting Parties should have notified twelve months before the expiration of the said ten years the intention of terminating it, it shall remain binding until the expiration of one year from the day on which either of the High Contracting Parties shall have denounced it. But, if when the date fixed for its expiration arrives, either ally is actually engaged in war, the alliance shall, ipso facto, continue until peace is conc̈lüded: (673)

In faith whereof the Undersigned, duly authorized by their respective Governments, have signed this Agreement and have affixed thereto their Seals.

Done in duplicate at London, the 12th day of August, 1905.

(L.S.) TADASU HAYASHI

Envoy Extraordinary and Minister Plenipotentiary of His Majesty the Emperor (L.S.) LANSDOWNE of Japan at the Court of St. James.

His Britannic Majesty's Principal Secretary of State for Foreign Affairs.

\section{3. - TREATY OF PEACE BETWEEN JAPAN AND RUSSIA SIGNED AT PORTS- MOUTH, SEPTEMBER 5, 1905}

Article I. There shall henceforth be peace and amity between Their Majesties the Emperor of Japan and the Emperor of all the Russias and between Their respective States and subjects. (783)

ro Article II. The Imperial Russian Government, acknowledging that Japan possesses in Corea páramount political, military and economical interests, engage neither to obstruct nor interfere with the measures of guidance, protection and control which the Imperial Government of Japan may find it necessary to take in Corea.

5) It is understood that Russian subjects in Corea shall be treated exactly in the same manner as the subjects or citizens of other foreign Powers, that is to say, they shall be placed on the same footing as the subjects or citizens of the most favoured nation.

It is also agreed that, in order to avoid all cause of misunderstanding, the two High Contracting Parties will abstain, on the Russo-Corean frontier; from taking any military measure which may menace the security: of Russian or Corean territory.

Article III. Japan and Russia mutually engage:

1. To evacuate completely and simultaneously Manchuria except the territory affected by the lease of the Iiao-tung Peninsula, in conformity with the provisions of additional Article I, annexed to this. Treaty: and 
2. To restore entirely and completely to the exclusive administration of China all portions of Manchuria now. in the occupation or under the control of the Japanese or Russian troops, with the exception of the territory above mentioned.

The Imperial Government of Russia declare that they have not in Manchuria any territorial advantages or preferential or exclusive concessions in impairment of Chinese sovereignty or inconsistent with the principle of equal opportunity. (784)

Article IV. Japan and Russia reciprocally engage not to obstruct any general measures common to all countries, which China may take for the development of the commerce, and industry of Manchuria. (784)

Article V. The Imperial Russian Government transfer and assign to the Imperial Government of Japan, with the consent of the Government of China, the lease of Port Arthur, Talien and adjacent territory, and territorial waters and all rights, privileges and concessions connected with or forming part of such lease and they also transfer and assign to the Imperial Government of Japan all public works and properties in the territory affected by the above mentioned lease.

The two High Contracting Parties mutually engage to obtain the consent of the Chinese Government mentioned in the foregoing stipulation:

The Imperial Government of Japan on their part undertake that the proprietary rights of Russian subjects in the territory above referred to shall be perfectly respected. (784)

Article VI. The Imperial Russian Government engage to transfer and assign to the Imperial Government of Japan, without compensation and with the consent of the Chinese Government, the railway between Chang-chun (Kuan-cheng-tzu) and Port Arthur and all its branches, together with all rights, privileges and properties appertaining thereto in that region, as well as all coal mines in the said region belonging to or worked for the benefit of the railway:

The two High Contracting Parties mutually engage to obtain the consent of the Government of China mentioned in the foregoing stipulation. I (785)

Article VII. Japan and Russia engage to exploit their respective railways in Manchuria exclusively for commercial and industrial pürposes and in no wise for strategic purposes.

It is understood that that restriction does not apply to the railway in theiterritory affected by the lease of the Liao-tung Peninsula. : (785)

Article VIII. The Imperial Governments of Japan and Russia, with a view to promote and facilitate intercourse and traffic, will, as soon as possible, conclude a separate convention for the regulation of their connecting railway services in Manchuria. (785)

Article IX. The Imperial Russian Government cede to the Imperial Government of Japan in perpetuity and full sovereignty, the southern portion of the Island of Saghalien and all islands adjacent thereto, and all public works and properties thereon. The fiftieth degree of north latitude is adopted as the northern boundary of the ceded territory. The exact alignment of such territory shall be determined in accordance with the provisions of additional Article II, annexed to this Treaty.

Japan and Russia mutually agree not to construct in their respective possessions on the Island of Saghalien or the adjacent islands, any fortifications or other similar military works. They also respectively engage not to take any military measures which may impede the free navigation of the Straits of La Perouse and Tartary. (785)

Article X. It is reserved to the Russian subjects; inhabitants of the territory ceded to Japan, to sell their real property and retire to their country; but, if they prefer to remain in the ceded territory, they will be maintained and protected in the full exercise of their industries and rights of property, on condition of submitting to Japanese laws and jurisdiction. Japan shall have full liberty to withdraw the right of residence in, or to deport from, such territory, any inhabitants who labour under political or administrative disability. She engages, however, that the proprietary rights of such individuals shall be fully respected. (786)

Article XI: Russia engages to arrange with Japan for granting to Japanese subjects rights of fishery along the coasts of the Russian possessions in the Japan, Okhotsk and Behring Seas. 
of It is agreed that the foregoing engagement shall not affect rights already belonging to Russian or foreign subjects in those regions.: (786)

Article XII The Treaty of Commerce and Navigation between Japan and Russia having been annulled by the war, the Imperial Governments of Japan and Russia engage. to adopt as the basis of their commercial relations, pending the conclusion of a new treaty: of commerce and navigation on the basis of the Treaty which was in force previous to the present war, the system of reciprocal treatment on the footing of the most favoured nation, in which are included import and export duties, customs formalities, transit and tonnage dues, and the admission and treatment of the agents, subjects and vessels of one country in the territories of the other. (786)

bu Article XIII. As soon as possible after the present Treaty comes into force, all prisoners of war shall be reciprocally restored. The Imperial Governments of Japan and Russia shall each appoint a special Commissioner to take charge of prisoners... All prisoners in the hands of the Government shall be delivered to and reeeived by the Commissioner of the other Government or by his duly authorized representative, in such convenient numbers and at such convenient ports of the delivering State as such delivering State shall notify in advance to the Commissioner of the receiving State.

The Governments of Japan and Russia shall present to each other, as soon as possible after the delivery of prisoners has been completed; a statement of the direct expenditures respectively incurred by them for the eare and maintainance of prisoners from the date of capture or surrender up to the time of death or delivery. Russia engages to repay Japan, as soon as possible after the exchange of the statements as above provided, the difference between the actual amount so expended by Japan and the actual amount similarly disbursed by Russia. (787)

Article XIV. The present Treaty shall be ratified by Their Majesties the Emperor of Japan and the Emperor of all the Russias. Such ratification shall;' with as little delay as possible and in any case not later than fifty days from the date of the signature of the Treaty, be announced to the Imperial Governments of Japan and Russia respectively through the French Minister in Tokio and the Ambassador of the United States in Saint Petersburg and from the date of the later of such announcements this Treaty shall in all its parts come into full force.

The formal exchange of the ratification shall take place at Washington as soon as possible. (787)

Article XV. The present Treaty shall be signed in duplicate in both the English and French languages. The texts are in absolute conformity, but in case of discrepancy in interpretation, the French text shall prevail.

In witness whereof, the respective Plenipotentiaries have signed and affixed their seals to the present Treaty of Peace. (788)

Done at Portsmouth (New Hampshire) this fifth day of the ninth month of the thirty-eighth year of Meiji, corresponding to the twenty-third day of August (fifth September), one thousand nine hundred and five.
(Signed) Jutaro Komura (L.S.)
(Signed) K. TaKahira (L.S.)
(Signed) Serge Witte (L.S.)
(Signed) Rosen (L.S.)

In conformity with the provisions of Articles III and IX of the Treaty of Peace between Japan and Russia of this date, the undersigned Plenipotentiaries have concluded the following additional Articles:

I. To Article III. The Imperial Governments of Japan and Russia mutually engage to commence the withdrawal of their military forces from the territory of Manchuria simultaneously and immediately after the Treaty of Peace comes into operation, and within a period of eighteen months from that date, the Armies of the two countries shall be completely withdrawn from Manchuria, except from the leased territory of the Liaotung Peninsula.

The forces of the two countries occupying the front positions shall be first withdrawn. 
The High Contracting Parties reserve to themselves the right to maintain guards to protect their respective railway lines in Manchuria. . The number of such guards shall not exceed fifteen per kilomètre and within that maximum number, the comminiders of the Japanese and Russian Armies shall, by common accord, fix the number of such guards to be employed, as small as possible having in view the actual requirements.

The Commanders of the Japanese and Russian forces in Manchuria shall agree upon the details of the evacuation in conformity with the above principles and shall take by common accord the measures necessary to carryl out the evacuation as soon as prissible and in any case not. later than the period of eighteen months. (789)

II. To Article IX. As soon as possible after the present Treaty comes into force, a Commission of Delimitation, composed of an equal number of members to be appointed respectively by the two High Contracting: Parties, shall on the spot mark in a permanent: manner' the exact boundary between the Japanese and Russian possessions on the Island of Saghalien. The Commissions shall be bound, so far as topographical considerations permit; to follow the fiftieth parallel of north latitude as the boundary line, and in case any deflections from that line at any points are, found to be necessary, compensation will be made by correlative deflections at other points. It shall also be the duty of the said Commission to prepare a list and description of the adjacent islands included in the cession and finally the Commission shall prepare and sign maps showing the boundaries of the ceded territory. The work of the Commission shall be subject to the approval of the High Contracting Parties.

The foregoing additional Articles are to be considered as ratified with the ratification of the Treaty of Peace to which they are annexed. (789).

Portsmouth the 5th day, 9th month, 38th year of Meiji corresponding to the $\frac{\text { 23rd August, }}{5 \text { th September }} 1905$.

(Signed) Jutaro Kovura (L.S.)

(Signed) K. TAKAHIRA (L.S.)

(Signed) Serge Witte (L.S.)

(Signed) Rosen' (I.S.)

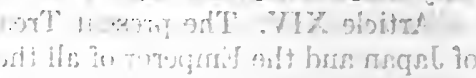

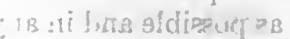

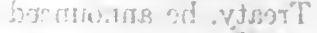

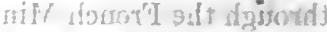

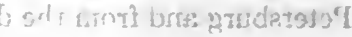
sri srison gitasi ati

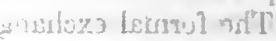
(TRT) .olfizaog ndT .Y/ olvima

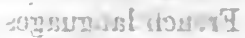

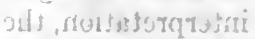

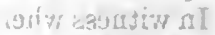

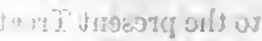

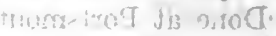

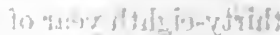

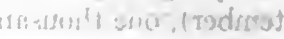

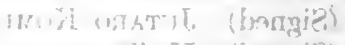

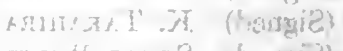
harmit) (Innpie) -r 


\section{INDEX}

Abdication, Shōmu,

Fujiwara policy, 237

Abe, Princess, becomes Empress Kōken, 197

Abe family and Nine Years' Commotion, 266; Minister of the Left, 160

- Kōzō on moral influence of Chinese classics, 104

- Masahiro, policy in 1853,

666 ; attempts to strengthen Tokugawa, 668.

- Munetō, brother of Sadatō, war in Mutsu, 266-7.

- Nakamaro (701-70), studies in China, 190

- Sadatō (1019-1062), in Nine

Years' Commotion, 266-7

- Seimei, astronomer, his descendants in Gakashujo, 664

- Shigetsugu (1600-51), 582

- Tadaaki (1583-1644), minister of Iemitsu, 581

Abutsu-ni (d. 1283), author of Izayoi-nikki, 366

Academies for youth of $u j i$, Gaku-in, 206, 282-3; templeschools, tera-koya, 448; established by Yoshinao, 578; the Hongo school, 599; schools in Yedo and Osaka, 614; for court nobles 664

Acha-no-Tsubone, 566

Achi, Chinese prince, migrates to Japan (289 A.D.) with weavers, 102; carpenters, 126 ; and Saka-no-ye no Tamuramaro, 221

Adachi family, connexion with Hōjō, Miura plot against, 351 ; crushed (1286), 376

Adahiko, son of Omi, befriends Ōke and Woke, 118

Adams, Will (d. 1520), English pilot on Liefde, adviser of Ieyasu, 546, 547, 550; Saris distrusts, 653 ; tomb (ill.), 545

Adoption, law of, in Court Laws, 577; in Tokugawa fiefs, 593 ; laws of, 626

After-Han dynasty (211-65) of China, 102
Aganoko, lands confiscated, 96

Agglutinative language, 57

Agriculture, early development of $47,70-1$; and religion, 66 ; encouraged by Sujin, 79,80 ; in reign of Suinin, 84; on state revenue lands, 96 ; in years $540-640$, 155 ; in Nara epoch, 207; in Heian, 279; in Kamakura period, $374 ;$; under Yoshimune, 615-16, 617-18; Americans in remodelling methods of, 686-7; growth in 19th century, 694

Ai river, fighting on, 713-14

Ainu, nature-worship of, 47 ; language, 56 ; subdivision of yellow race, 58 ; ill., 42 .

Aizu, meeting-plan of armies in Shidō shōgun campaign, 80; clan loyal to shogun at Restoration, 678

Akabashi Moritoki, 385

Akagashira, "red head," Akahige, "red beard," Yemishi leader in 8th century, 222

Akahito see Yamabe Akahito Akákura at Sekigahara, 561

Akamatsu, large land-holdings of, 409; Ashikaga Yoshinori plots against, $420-1$

- Mitsusuke. (1381-1441) rebels against Yoshimochi, 420; defeated, 421.

- Norimura

$(1277-1350)$ defender of Go-Daigo, 381, 382 , 384; turns against Crown, 388, 389; captures Kydto (1336), 392; and Ashikaga, 393

- Norishige, revolts in Kyūshū, 421-2

- Sadamura, among generals attacking Mitsusuke, 421

- Yoshimura, ... guardian of Ashikaga Yoshiharu, 433

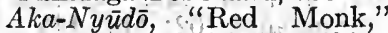
427; see Yamana Mochitoyo Akasaka taken by Hōjō, 381

Akazome Emon, authoress of Eigwa Monogatari, 261
Akechi Mitsuhide (1526-82), soldier under Nobunaga, 485 ; goes over to the Morri, 490; shogoun, 491; tries to kill Ieyasu, 492; death, 493

Aki, province, 491

Aki, daughter of Kiyo and Fujiwara Yoshifusa, Montoku's empress, 236

Akimoto Yasutomo - (1580 1642) rebuilds Ieyasu's shrine, 582

Akitoki see Kanazawa Akitoki Akizuki of Kyūshū, defeated by Ōtomo, 470

$A k \bar{k}$, "reliance on equity," quibble over word 240,275

Akō, vendetta of, 606-7.

Akunoura, foundry, 669

Akuro-ō, Yemishi leader in 8th century wars, possibly Ōro-o, i. e., Russian, 222

Alcock, Sir Rutherford (180997), on aliens in Japan, 672 Alderman, over homestead of 50 houses, 164

Alexieff, E. I., (b. 1843), Russian admiral, in command at Port Arthur, 711

Aliens, in prehistoric ban or bambetsu, 92; naturalized, skilled artisans, the tamibe, 94; see Extraterritorial Jurisdiction

Altaic myth, 26, 70; group of languages, 57

Amako family crushed in Izumo by the Mōri, 470 .

- Tsunehisa (1458-1540), rivalry with Ōuchi, 470

- Yoshihisa (1545-1610), de- feated by Mōri, 470

Amakusa, Portuguese trade and Christianity in, 535, 536; Shimabara revolt, ,554-5

Ama-no-Hihoko, prince of Shiragi, Korea, settles in Tajima, 84,88

Amaterasu-ō-mi-Kami, Sungoddess, 11, 12, 61, 62, 195

Amida, the Saviour, 370 ; Amida-ga-mine, shrine, near K yōto, tomb of Hideyoshi, 524 
Amur river, battle on, $(660 \mid$ Apotheosis, one class of Kami A.D.) with Sushen, 35; Russia's position on, 704

Amuscments, prehistoric, 75; in early historic times, 148, $157,213-14$; in Heian epoch, $277-8$; at Kamakura, 377 ; in Muromachi epoch, 457-9; (ills.), 92, 116, 268, 275

Anahobe, Prince, rival of Yōmei for throne, 135; to succeed Yōmei, 136

Anato now Nagato, 81

Ancestor-worship, apotheosis of distinguished mortals, 64 ; grafted on Buddhism, 193

Andō family revolt, 377

- Shōshū, suicide (1333), 385

Andrew, Prince, Arima Yoshisada, 536

Ane-gawa, battle (1570), 484

Ane-no-kōji family, 461

Animals, killing, forbidden in reign (741) of Kōken, 197, earlier, 212, in time of 'Tsunayoshi, 602, 608, result in stock farming, 268, 273; worship of, 65,128 , mythical and terrible beasts in early records, 70; pets, 277-8

Anjin-Zuka, tomb of Will Adams, 545 (ill.)

"Anjirō," Japanese interpreter of Xavier, 531, sqq.

Ankan, 27th Emperor (534535), 120

Ankō, 20th Emperor (454456), 111-12; palace, 126

Ankokuji Ekei see Ekei

Annam, trade with, 529

Annen, priest, compiles $D \bar{o} j i$ $k y \bar{o}, 449$

Annual Letter of Jesuits, 533, 537

Anotsu, Ise, China trade, 444

Anra, province Mimana, 83

Ansatsu-shi, inspectors of provincial government, 200

Anthology, first Japanese, "Myriad Leaves," 214; of poems in Chinese style, Kwaif $\bar{u}$-so , 214-15; the Kokin-shu, 10th century, 237; the three, of the Ho-en epoch, 251; the Hyakunin-isshu of Teika, 366; in the Kyōto school, 366

Antoku, 81st Emperor'(11811183), 297, 298, 310; drowned at Dan-no-ura, 319 ; perhaps a girl, 320

Antung, on Yalu, Russians defeated, 714

Aoki Kaneiye, metal-worker of Muromachi period, 451

- Konyō, scholar, studies Dutch (1744), 614; introduces sweet potato, 618

Aoto Fujitsuna criticizes

Hōjō Tokiyori, 352-3

Ape, worship of, 128 formed by, 64

Aqueducts in irrigation, 207

Arai Hakuseki (1656-1726)

Confucianist, author of Sairan Igen, 608-9 (ill.); retired, 610; opposes forcing Imperial princes into priesthood, $620-1$ Arakahi, defeats Iwai in Chikugo (528 A.D.), 123

Archaeological relics, 45-55

Archery, early devclopment of, $70,136-7$ in reign of Temmu, 171; equestrian, in Nara epoch, 214; 284 (ill.)

Architecture, in proto-historic times, 126; influenced by Buddhism, 153, 208; in Heian epoch, 278-9; Kamakura period, 373; Muromachi, 452 Are see Hiyeda Are

Ariga, Dr., on Korean influence on early relations with China, 84 f.n.; on supposed moral influence of Chinese classics, 104; on false attribution to Shotoku of estimate of Buddhism, 133; on Jöei code, 349

Arii, adherents of -Southern Court in Sanyō-dō, 400

Arima, in Settsu, thermal spring, 157; Jesuits and Buddhists in, 536; represented in embassy to Europe, 537 Arima Yoshisada (d. 1577), brother of Ōmura Sumitada, baptized as Andrew, 536

- Yoshizumi rebels, 501

Arisugawa, one of four princely houses, 621

- Prince (1835-95), leader of anti-foreign party, 673

Arita, porcelain manufacture, 451

Ariwara, $u j i$ of princely descent, 205; Takaoká's family in, 231 f.n.; academy, 283; eligible to high office, 295

- Narihira (825-882), poet, $236,237-8 ; 251,276$ (ill.)

- Yukihira (818-893), poet, 251 ; founds academy, (881), 206

Armour, Yamato, in sepulchral remains, 52 ; in Muromachi epoch, 451; early arms and armour, 69-70; after $D a i h \bar{o}$, 181 ; in Heian epoch, 280

Army see Military Affairs

Army and Navy, Department in Meiji government, 681

Army inspector, 181

Arrow-heads, 51

Artillery, early use, 488

Artisans, in prehistoric tamibe, 94; Korean and Chinese immigrants, $102 ; 113 ; 144$

Arts and Crafts, promoted by Yüryaku, 113, 128; Chinese and Korean influence, 153, in Kamakura period, 365 ; in
Heian epoch, 279; patronized by Yoshimasa, 424 ; first books on, 450; in Muromachi epoch, 450; in time of Hideyoshi, 5:3; patronized by Tsunayoshi, 600 Asahina Saburō (or Yoshihide), son of Wada Yoshimori, 338 Asai family control Ōmi province, 469; Nobunaga's struggle with, 483-5; helped by Buddhists, 485

- Nagamasa (1545-73), won over to Nobunaga, 481; joins Asakura, defeated, 483-5

Asaka Kaku, contributor to Dai Nihon-shi, 645

Asakura family in Echizen, 469; struggle with Nobunaga, 483-5; helped by "Buddhist priests, 485

- Yoshikage (1533-73), de-

feated by Hideyoshi, 484-5.

Asama, eruption (1783), 619

Asan,- Korea, - occupied ${ }^{\text {To }}$ by

Chinese (1894), 700

Asano Nagamasa (1546-1610), 512 ; in charge of commissariat 513 ; sent to Korea (1598), 524,557

- Naganori, daimyō of Akō, exile, suicide, avenged by "47 Rōnins," 607; 608

- Yukinaga (1576-1613), against Ishida, $558 ; 578$,

Ashikaga family favour Yoritomo, 308 ; 'revolt' of 1335 , 392-5; "shōgun of Northern court, 398; government, 402-3; internal quarrels, $404-$ 5; "estimate by Rai Sanyō, 409 ; fall of, $413-41$; government, $435-41$; scholarship, 448; school, 449 ; Buddhism, 453; against Hõjō, 466; end of shoggunate of, 482

- Chachamaru, kills his father Masatomo, 465

- gakkō, great school, under patronage of Uesugi, 449 ?

- Haruuji (d. 1560), kubō, 413

- Masatomo (1436-91), kubô, 413,432 ; builds fort at Horigoe, 425,464 ; suecession, 465

- Mitsukane' (1376-1409), kwanryō, 413 ; assists the Ouchi, 415, 416

- Mochinaka, brother of Mochiuji, sides with Ögigayatsu 419

- Mochisada, intrigue make him high constable, 420 - Mochiuji (1398-1439), kwanryō, 413, 419; sides with Yamanouchi branch of Uesugi, 419; suicide, 420

- Motouji (1340-67), son of Takauji, 408; kwanryō, 413; urged to become shögun, 415 - Shigeuji '(1434-97); kubō, $413,414,420,425-6$ 
Ashikaga Tadafuyu (13261400), s son of Takauji, rebels in Kyūshū, 405; joins Southern party in 1353,407 ; takes and loses Kyôto, 408

-Tadayoshi (1307-52), assistant governor-general of Kwantō, 387; governor of Tōtōmi, 388; kills Morinaga, 390 ; practically regent, 391 ; in Ashikaga revolt, 392 ; chief of general staff, 403 ; plots against the $\bar{K} \overline{0}$ brothers, defeated, joins Southern party, 404-5; suicide, 406.

- Takamoto, kubō, 413

- Takauji (1305-58), joins Go-Daigo, 383 (ill.)-4, 386; provincial governor, 388; plots against Morinaga, 38990; declares i himself shögun, 392; captures Kyōto 396-7; changes plans, 402-3; crushes Tadayoshi, 406-7; defeated, 407; death, estimate, 408-9; shōgun (1338-58), 413; distributes estates, 426 ; letters, 448; shrine of Hachiman, 452; Buddhist temples, 453; signature, 572 (ill.)

- Ujimitsu (1357 $\div 98)$, kwaninyo, 413 ; wishes to be shōgun, 415 ; strengthens family in Kwantō; 416 ; literature, 448 -Yoshiaki (1537-97), shōgun, 1568-73, 413, 434, 481; turns to Mōri, defeated, 482 ; Hideyöshi intrigues with, 499

\section{- Yoshiakira.} (1330-67),

kwanryō of Kwantō, 403; succeeds Tadayoshi, 405; dethrones Sukô, 407; defeats Tadafuyu, 408; shōgun, 409, 413; surrender and death, 410 ; plot against; 415

-Yoshiharu (1510-50), shō-gun 1521-45, 413, 433, 434

-Yoshihide (1565-8), shōgun, $413 ; 434$

- Yoshihisa (1465-89), shōgun (1474-89), 413; Önin war, 429; declared heir, 430; administration, 431 ; scholarship, 448

- Yoshikatsu (1433-43), shōgun, 413, 421

- Yoshikazu (1407-25), shōgiun (1423-5), 413, 418-19

- Yoshikiyo, advances

Tamba, 309; killed, 311

- Yoshikore, 433, 434

- Yoshìmasa (1435-90), shōgun, 413, 421-4,422 (ill.), succession, 428-9; retires 430; fosters letters, 448

- Yoshimi (1439-91), called Gijin, heir of Yoshimasa, 428; deserted by Yamana (1469), 429; retires (1477); 430 -Yoshimichi see Ashikaga
Ashikaga Yoshimitsu (1358(1367-95); 410, 413; extravagant administration, 416 (illi), 417; foreign " policy, 417-18; dies, receives rank of exEmperor,: 418 ; treatment of Crown, 441 ; and piracy, 443, 445; favours Zen priests, 454

-Yoshimochi (1386-1428), shōgun, 413, 418, 419; succeeds his father Yoshimitsu in military offices, 417 ; rebellion against, 420 ; excesses, 441

-Yoshinori (1394-41), shōgun $(1428-41)$; 413; abbot, called Gien, 419; rule, 420 ; killed, 421; relations with China, 444; grants Ryūkyū to Shimazu, 447

- Yoshitane

(1465-1523), shōgun 413; rule, 431-2; defeated by Hatakeyama Yoshitoyo, 432; death; 433

- Yoshiteru (1535-65), shōgun, (1545-65), 413, 434; suicide, 481 ; receives Vilela, 537 - Yoshitsugu, killed by his brother Yoshimochi, 418-19 - Yoshiuji, last $k u b \bar{o}, 413$

- Yoshizumi, originally Yoshimichi (1478-1511), shōgun 413; nominal rule, 432 ; death, 433

Ashina of Aizu, 471

Asiatic yellow race, 58

Askold, Russian protected cruiser at Port Arthur, 711

Asomaro, governor of Dazaifu, wins favor of Dōkyō, 199 Assumption, De l', martyrdom (1617), 551

Aston, W. G., on dates in "Chronicles," 6; Korean origin of Kumaso, 41 ; purification service, 64 f.n.; neolithic boats; 72 ; chronology, 81 f.n.; invasions of Korea, 89; Japanesé authority:in Korea, 90; local records, 109; 17-Article Constitution, 140-2; women in Heian epoch, 250; Yoshitsune's letter, 321-2; invasion of Korea, 510-11

Asuka, Empress Kōmyō, 18990

Asuka, capital moved to, 185 ; palace built by Kōgyoku, 154 Asuka-yáma, groves, 612

Asukara Norikige, high con-stable, crushes revolt, 464

Asylum established by Fujiwara Fuyutsugi, 233

Ata rebels against Sujin, 79

Ataka Maru, great ship of

Bakufu, broken up by Tsunayoshi, $597-8 ; 654$ (ill.)

Atalanta I zanagi, 25-6

Atogi, Korean scribe, 103

Atsumi Hirafu, defeated by

Chinese in Korea (662), 167
Atsunaga, brother of Atsunari, 260; see Go-Shujaku

Atsunari, Prince, son of Ichijō, 260; see Gō-Ichijō

Atsuta, Hachiman's shrine, 478

Auditor of accounts, 634-5

Auguries; 66.

Augustins in Japan, 551

Avatars of Buddha, Kami 193, 195-6; 228 .f.n.

Awa, mythical first island, 28; culture of mulberry and hemp in, 67 ; overrun by Taira Tadatsune, 263; invaded by Yoritomo, 305; won from Satomi by Hōjō Ujitsuna, 466; Miyoshi in, 470; indigo growing, 617

Awada, Mahito, on committee for Daihō laws (701), 176

Awadaguchi, swordsmith, 450-1

Awaji, island, in early myth, 28,29 ; Izanagi goddess of, 109; Sagara exiled to, 226 ; reduced by Hideyoshi, 490

Awo, Princess, sister of Woke, rules in interregnum, 118

Axe, in fire ordeal, 125

Ayala (d. : 1617), Augustin vice-provincial, executed, 551 Azuchi, in Ōmi, fort built by Nobunaga, 486; church and residence for priests, 538

Azuke, placing in custody of feudatory, 642

Azuma, eastern provinces, origin of name, 86

- Kagami, 13th century history, on Hōjō Yasutoki, 348 Azumi, temple of, 166

Babylonian myth, 25

Backgammon or sugoroku, 277 Badges, 374 ; and crests, 525

Baelz, Dr. E., on stature and race of Japanese, 57,58 ; on shape of eye, 59

Bakin, on last years of Minamoto Tametomo, 291 f.n.

Bakufu, camp government, military control, 'Y Yoritomo's system of shōgunate, 324330; three: divisions, 327 ; entrusted with choice of emperor (1272 \& 1274), 356; power weakened by Mongol invasion, 363-4; and rapidly fails, 378; :Go-Fushimi appeals to, 379; re-created at Kyōto by Takauji, 402-3; in Muromachi period, 436; at Yedo, 563; oath of loyalty, to 564-5;'Tokugawa $B ., 573-643$; appointing power, 577, and other powers; 588; exiles Yamaga Soko for heterodoxy, 607-8; power léssened by Chinese learning, 614; $B$. party in Kyōto, 620; relations with Court, 621 ; organ- 
ization, 632 sqq.; decline of power, 661-78; Court nobles and Empcror begin to oppose, 664; puts through Harris commercial treaty, 667; and forcign representatives, 669 ; pledged (1861) to drive out foreigners in 10 years, 672-3; further interference of Crown and Court. party, 673-4; power ended, 677 .

Baltic squadron, Russian, defeated by 'Tögō, 723-4

Bambetsu or Ban, aboriginal class, $92 ; 233$

Bandits commanded by Buddhist priests in 10 th century, 247 ; their outrages, 262.

Bandō or $K$ wantō provinees, army raised in, during 8th century, 223; see Kwantō.

Banishment, 641, 642; edict of 1587, against Christians, 5401,544

Banzai, "10,000 years," viva, 119 f.n.

Baptismal flags, 152 f.n.

Bärley, cultivation of, urged as substitute for rice, 207

Bashō see Matsuo Bashō

Batchelor, Rev. John, on pitdwellers, 43

Battering-engine, 211

Battle Era, Sengoku Jidai, 1490-1600, 439, 460

$\mathrm{Be}$, guilds or corporations, 71-2, 224; hereditary, not changed by Daika, 172 ; property of Crown, 124; of armourers, 85; fishermen, 99

Bekki Shōemon, in plot of 1652,584

Bell, of Hōkō-ji, "treasonable" inscription on, 566; on public-service horses, 162 f.n. bronze bells, $48-9,210,44$ (ill.); Nanban, 555 (ill.); bell-tower, 453 (ill.); suzu, 52, 53,218

Benkei, halberdier, 307, 315

Bettō, superintendent of $u j i$ schools, 206; president of samurai-dokoro, 327 ; regent, shikken, head of man-dokoro, office hereditary in Hojō family, 327 ; head of monjüdokoro, becomes finance minister of shōgun (1225), 347

Bidatsu, 30th Emperor (57285), 134-5

Biddle, James. (1783-1848), Commodore, U. S. N., in Japan (1846), 663

Bifuku-mon-in, eonsort of Toba, mother of Konoe, 273, 289

Bin,Buddhist priest, "national doctor" 160; death (654), 166 Bingo, woman ruler in, 85

Bingo, Saburō, see Kojima

Takanori

Birth customs, 73
Bison, fossil remains, $45 \mathrm{f}$. $\mathrm{n}$.

Bita-sen, copper coins, 527

Bitchū, provinee; Yoshinaka's force defeated in, 311 ; invaded by Hideyoshi, 490

Biwa, 4-stringed lute; biwabōzu, players, 458; (ill.) 364

Biwa, Lake, 170

Bizen, swordsmith, 450

Bizen transferred from Akamatsu to Yamana family, 421

Black, early colour of mourning, 213

Black Current. see Kuro-shio Boards of Religion and Privy Council under Daiho code, 178-9

Bogalyr, Russian protected cruiser wrecked, 717

Bondmen arid : Freemen, division by Daika, 161; by Jitō's edict, 173

Bonita, curing, industry, 617 Bōnotsu, Satsuma, 444

Borneo, possible souree of Kumaso, 39

Boxer Rebellion, : Japanese troops in China during, 703

Brach, Dutch ship, 653

Bramsen, William, on early dates in "Chronicles, " 6

Branding, 66, 125

Braziers, 374

Brewing, 69

Bribery and sale of office, attempts to abolish, $270-1$

Bridges, 8 (ill.), 697 (ill.)

Brine in cosmogony, 9,19

Brinkley, Capt. Frank (18411912), article in Encyclopadia Britannica quoted, 457, 512, $513,516,533,534,535,537$, $540,542,543,545,546,547$, $548,655,677,690,710,729$. Oriental Series referred to, $451,636,642,693$.

Bronze culture in South, 46 ; traces before the Yamato, 48; bells, 48.49; mirrors, bowls, vases in Yamato tombs,. 53; great statue of Buddha, 193

Buddha, early images of, 132 , 133, 134; copper images ordered in 605,$143 ;$ golden image of, from Shiragi (616 and 621) 151, 152; great bronze : Nara image. (750 A.D.), 193; Kami incarnations of, theory: of Mixed Shintō, 193, 195-6, 368; bronze image (1252) at $\mathrm{Ka}$ makura, 326 , 375; great image at Kyōto, 506, 565; replaced by bronze, 566

Buddhism introduced 552 A.D., 131-5; use of writing, 103; early politics, 140; rapid spread, 143; priests above law, 144: architecture, 153; music, 156; Empresses, 157; disasters and signs. check spread, 157; in Nara epoch, 190-6; abdications, $197 ; \mathrm{de}$ cline of Yamato, $\Omega 1200-1$; industry, 208; funeral " of Shomu, 212; time of IKwammu, 227; official advancement, 229; vices of priests, $230 ; \cdot 246,247$; superstition, 275 ; in Heian epoch, 276 ; in Yorinusa uprising, $299-300$; Hōjō regents, 366 ; sec̈ts, $367-$ 72 ; Korean and Chinese, 367 8; three Vehicles, 369 ; soldier priests; 379 ; crushed by Yoshinori, 420; amulets, 404; Chinede priests, 442 ; combined with Confucianism and Shinto, 452; Ashikaga,-453; wairs of monks; $462-4$; revolt in Settsu, 484 ; oppose Nobunaga, 485,6 ; in IKomaki war, 498; 500; spies in Kyūshū, 502; Hideyoshi, 505, 540; priests of Kagoshimá, 531; in Chôsh $\overline{\text {, }}$; 532 ; in Yamaguchi, 533; persecuted in Hirado by Christians, 534; 536,537 ; priests converted by Vilela, 538; Ieyasu's laws, 577-8; gains by suppression of Christiañity, 583 .

Bugyō, 36 commissioners of Muromachi, 436 ; 5 administrators under Hideyoshi, 513, 523,525 ; special appointees to rich fiefs, $561 ;$ - under Bakufu, 577; : in Emperor's and ex-Emperor's court, 589 Building-land, tenure, 182

Buke, see Military houses.

Bukyo Shögaku;" "Military Primer," by Yamaga Sok $\overrightarrow{0}, 607$ Bummei Ittōk; work of Ichijō IKaneyoshi, 448

Bungo, Tsuchi-gumo in; 42 ; Xavier. in, 532; Jesuit headquarters, 533; Christiain isuccess among nobles, 30 ; in embassy of $1582,537: 8,{ }^{5}$ Bunji-kin, debased coins of $1736-40 ; 617$

Bunka, period, $1804-17,629$

Bunroku, period, $1592-5,520$ :

Bunsei, period, 1818-29, 629

Bureaux, under Daika; 164

Burial, jars of Yamato, 49; primitive methods, 47 ; coffins, 74; honour of tombs, 118 , 119,213 ; mounds, 50 , limited in size, 163 ; funcral customs, $74,139,212-13$

Bushi, 129; $264 ; 284$; originated in N.E: Japan,86; name first used of guards, 248; virtues of, typified in leaders of : Nine Years' Commotion, 266-7; general deseription, 285-7; of IKwantō described, 314; fighting against Mongols, 359-60; outrages in provinces, 431 
Bushido, way of the warrior, 264, 286; cult 'developed by Yamaga Sokō, 607-8; and by Yoshimune, 611

Butsú Sorai see Ogyū Sorai

Butter, tribute to Court, 212

Buzen, Tsuchi-gumo in, 40

Byōdō-in, Tendai temple, 265

(ill.); prison of Go-Daigo, 380

Cabinet under Restoration rule, 681 ; crisis over Korea (1873), 684; of 1885,691 ; dependent on Crown, 692

Cabral; Francis (1529-1609), cuesuit Vice-provincial, on early missions, hospitals, Buddhists, 535-6

Calendar, Prince Shōtoku, 143; revision of $1683,599-$ 600 further revision planned by Yoshimune, 614

Calligraphy, 234, 251, 365, 601

Calthrop, Capt., on: Oriental tactics, $286 \mathrm{f}: \mathrm{n}$.

Cambodia, trade with, 529

Camera government, insei, proposed by. Go-Sanjō, 271; under Shirakawa, 272; GoShirakawa, 291; Yoritomo establishes giso at the Inchü, 330 ; the three recluses, 341 ; system destroyed by Shökyiu war, 345 ; in Kamakura regency; 352, 353 ; camera party at court; 1272,356 ; in Northern court, 398

Canals, 155, 282

Canonical names of emperors, 21,73

Capital changed at beginning of reign, 74, 78; Jimmu's change to Yamato, 76; Chūai's to far south, 88 ; to Nara (709) and previous changes, 185-6; changes helped road building, 210; change from Nara to Kyōto (792), 224-6; from Kyōto to Fukuhara, 1180,300

Capital Punishment, 125-6, $-641-2$

Caps, official, as insignia of rank, 146; effect of, i on hair dressing, 156; cap rank replaced by cap grade after Daika, 164; varnished gauze, $211 ; 373-4$; (ill.), 34

Car, of Enryaku-ji, 274

Caron, Francis, Dutch trader, on Japanese martyrs, 553

Cart, hunting, 126 ; compass cart;" 210; Heian epoch,' 280 Casting in Nara epoch, 208

Castles; 62, 220

Catapult, 181

Caterpillar; worship; of 158

Cats; pets in Heian epoch, 277 Cattle, not used for food in (early Japan, 69, killing forbidden, 197, 208, 212; Chris- tians accused of eating, 539
Cavalry, in capital, 180 ; in war, 488

Censor, 179; in Tokugawa organization, 635 ; as judge, 640 Census, reign of Sujin, 80; time of Daika; (645 A.D.), 161, 169; classifications, under Daihō, 181 ; by Buddhist and Shinto priests, 578

Central Department, under Daika, 164; under Daihō, 179 Centralization of government, 67,681

Ceramics, primitive, 47; $\mathrm{Ya}$ mato, 53-4, 69; Korean, 113; 520; Gyōgi, 195; Heiañ, 282; Kamakura, "374; Muromachi, 451.

Cereals, five, $63-71$; premiums for large crops, 207

Ceremonies, Department of, under Daika, 164; under Dai$h \bar{o}, 179 ; 15$ masters of; Koke, 635-6; lāw ? (927), 64

Chamberlain, Basil 'Hall, on dates in early "Chronicles," 6 ; meaning of Kami, 8 ; classification of language, 56 ; village communities, 67 ; ancient dress, $67 \leftarrow 8$; Altaic myth, 70; names, 73 ; education, 74 ; Dōji-kyō, 448-9; swords, 451 Chamberlain, 94, 171,633,635; pass on cases referred to shiogun, 640

Chancellor, dajō daijin, 169. 179; abolished, 387; Ashikaga Yoshimitsu, 416-17

Changan; Tang metropolis, Kyōto patterned after, 226

Chao Heng, Chineséname for Abe Nakamaro, 190

Charlevoix, quoted on Spanish galleon incident, $543 \mathrm{f} . \mathrm{n}$.

Chekiang, attacked by pirates (1559), , 446

Chemulpo, Russians in, attacked and defeated by Uryū, 712 ; landing-place for Japanese attack, 713

Cheng Cheng-kung, 586

Cheng Chi-lung, general of Ming dynasty, 586

Chengtsz, Confücian commentaries of, 590

Chen Hosiang, bonze, 339

Chen' Weiching (Chin Ikei); Chinese envoy to Japanese in Korea, 517; and negotiations for peace, 518

Cherry-trees, 1 groves, 612 ; festivals, 277,522

Chiba, branch of Taira, 265; one of " 8 Generals of Kwantō," 425

Chiba Tsunetane (1118-1201), favours Yoritomo, 305; sent to Kyōto, 330

Chichibu; copper in, (708), 186 Chichibu branch of Taira, 265 Chihaya in Hōjō war, : 381

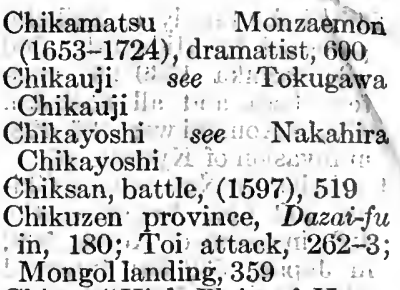

China, "High Plain of Heaven," 32," "Eternal Land," $60-84$; architecture, 126,452 ; bronze bells, 48 ; bronze mirrors, 52; Buddhism, 367-8; calendar, 599-600, ceramics, 451 chronology, 6, 7, 77, 81, 161 ; clay effigies; 50 ; coinage, 418; Crown, 128, 160, 165; divination, 66; government, 67; literature, 104, 214, 234, 578-9, 645-6; morality, 177 ; myth, 25-7; nobility, 153; painting, 452; promotion of officials, 146 ; relations and early intercourse; $78,: 101$, $113,144-5,152-3,165,190-1$, $227,241,417,442,443,446$; - scholars in Japan, 153, 361, 366; ' Hideyoshi's plan to conquer, 509-11, 516; interference in . Korea, 516-17; Ming dynasty, 586; trade, 609; Formosa, 684-5, 698; China-Japan war, 699-702, - Boxer rebellion, 703; Russia, 704-6; Treaty of Portsmouth, 726; of Peking, 727; finances,' 731

Chin Ikei see Chen Weiching

Chinju, fort in Korea, taken by Japanese, 518

Chinju-fu, "local government station in Korea, 83, 121

Chinnampo, landing-place for Japahese (1904), 713

Cho; Korean envoy, 608

Chō Densu see 1 Minehō

Chōkei, 98th Empéror (1368$72), 406,410,411,460$

Chơkei see Miyoshi Norinaga Chōkōdō estätes, 356,357 , $379,387,435$

Chōkō-ji, castle in Ōmi, 484

Cholladō, southern. Korea, attaoked by pirates, 446

Chōmei see Kamo Chōmei

Chong-ju, Korea, Cossacks defeated at, 713

Cho-ryung, pass in Korea, 514 Chösen, name of Korea, first use, 443

Chōshū, Xavier in, 531-2; feudatory of, opposes Tokugawa and joins extremists, 673; Shimonoseki complieation, 674; revolt of samurai, 675; joins Satsuma against Tokugawa, 676-7; fiefs surrender to Crown, 680; clan representation, 681 
Chōsokabe family in Shikoku punished by Hidey,oshi, 500 - Motochika (1539-99), masters Tosa and all : Shikoku, 470 ; in Komaki war, 497,498 ; in invasion of $\mathrm{Ky} u \bar{s} \mathrm{~s} \overline{\mathrm{u}}, 501$

Christianity, Nestorian in China, 192 f.n.; Azuchi castle; 486; invasion of Korea, 509; in Japan, 530-55; Imperial edict àgainst; 538 ; aid given by Nobunaga, 538-9; Hideyoshi's attitude towards, 53940 ; his edict of 1587,540 ; Ieyasu's treatment and his edicts, 544-9; Christians side with Hideyori, 548; , Hidetada's edict (1616), $1550-1$, (1624) 552 ; teaching in Ôsaka after edicts, 565 ; and Buddhist and Shinto census, 578 ; laws against $(1635,1665)$, 585; Ieyasu distinguishes between - commerce and, 651;

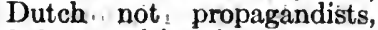
652 ; opposition in 1853,665 "Chronicles," Early Japanese, Nihongi, general character, 3 ; superior to Records, 4 ; accuracy of chronology, 6 ; contradicts Records, 77; Chinese colour in, 78; conquest of Korea, 89; stories from Korean history; 119-20

Chronology, 5-8; inaccuracy, 77,114 ; invasion of Korea, 90; reign of Nintoku, 104 Chrysanthemum, : Imperial badge, 374, 461, 525

Chu Chi-yu, Chinese scholar, 586

- Hi, Hayashi follows, 579

Chūai, 14th Emperor (192 200), 88, 40, 87, 90 f.n.

Chūgoku, central Japan, in vaded by Hideyoshi, 489-91 Chūkyō, 85th Emperor (1221), 341,344 and f.n.

Chīsan, Mimasaka, Kami of 128

Chūshin, Zen priest, pupil of Soseki, 454, 455

Chūson-ji, monastery, with graves of the Fujiwara of the North, 268

Chutsz, (Shu-shi), Confucian commentaries of, 590,644 ; rejected by Yamaga Sokō; 607; officially adopted, 613, 627; expounded by Japanese scholars, 621, 626; contrasted with Wang Yang-ming, 627-8 Chu Yuan see Sogen'

Chüzan, ruler of Ryūkyū (1373); 447

Cicada-shaped hair ornaments, 164

City administration, 179-180; municipal rulers, 62 ; administrators, 632,$634 ; 637$; elders, 634,637
Civil affairs and Civil Government, departments, 164,179 Clan representation under Meiji government, 681

Clay Effigies, haniwa, from neolithic sites; 47 ; substituted for human sacrifice at tomb, :50, 54, 74, 82

Clepsydra, Chinese, 209

Clocks, 209-10; 652 (ill.)

Cloistered monarchs, 341, 440; and see Camera

"Cloud chariot," war tower, 210

Clove, English ship, 653

Cock-fighting, 75

Cocks, Richard, English factor, warns Yedo Court against Spain $549-50 ;$ apparent cause of edict of 1616,551 ; successor of Saris, 655 .

Code, ryō, of Daih $\overline{0}$ (701 A.D.) and $Y \bar{o}$ ō (718 A.D.) 176; of $1742,613,641$; of $1790 ; 641$

Coelho, Gaspard :(d. 1590); vice-províncial of Jesuits, ordered (1587) i from Japan, $539-40$

Coinage, Wadō era (708-715), 155, 186; Nara epoch, 201; of Heian epoch, 281; Chinese, 418; Hideyoshi's time, $527+8$; plan to debase $(1673-80)$, 603; Genroku debased coin, 604; exports of metal from Nagasaki, 609-10; attempt to restore $(1710), 610,615-$ 16 ; again debased, 617,639 , 661 ; foreign :trade, 671

Colours of Court costume, grades, 211 ; indicating: social status, 281

Combs, ancient, 68

Commerce, early, 155; after - Daika, i64; . Nara epoch, 209; Heian, 281; Muromachi, 442-5; under Hideyoshi, 529, Portuguese, 530, 534; motive for permission to preach, 531, 532,541 ; Dutch, 545, 609; trade rules, 609,613 ; $\mathrm{com}^{-}$ 'mercial 'spirit in Yedo, 617; in Tokugáwa period, 651-60; exclusion; 657 ; coinage and European trade, 671-2

Commercial class, 372,600

Conception; miraculous, 192

Concubinage 73 ; classes at court, 110

Conder, J., on armour, 451

Confiscation of lands as : punishment, 96, or as expiation of offence, 117; 120; escheat at Daika, 162; punishment under Tokugawa, 642

Confucianism, Shōtoku on 132-3; modifying Buddhism, 447; in Tokugawa period, 578; favoured by Ko-Kömyō, 590, and Tsunayóshi, 599; Confucianists eligible for civil posts," 599; Yamaga Sokô, 607-8; combined with Shinto, 621 ; Japanese schools of, 626-8; hold 1 on educated class, 544 ; vendetta, 119,607 . Conscription, first ( 689 A:D.) in Japan, 174; 180; partial abolition of $(780,792), 218$ Constable, High, and lord high constable, in Yoritomo's land reform, 328; city constables, 634,637

Constitution, of Shōtoku (604 A.D.), text and comment; $140-2$; after Restoration (1889), 691-2, (text) 732-6

Constitutionist party, 693

Consular courts, 708 sqq

Cooking in ancient Japan, 69; in Muromachi epoch, 455-6:

Cooper, master of Mantiatlan, 663

Copper in Japan, 186-187; use for images of Buddha, 143-4, exhausts currency, 201; Chinese coins, $418,439-40,527$; in 15 th century trade, 445, debased Japanese coin, 527; exports of :Nagasaki, 609-10 Coronation Oath of 1867,679 80

Cosmogony, 8,25

Cost of living, 187 f.n., 616

Costume, : prehistoric, 68; in Inkyō's reign, 111; Chinese and Buddhist influence, 156 ; Nara epoch, 211; Heian', 279; Kamakura period, 373 ; laws of Military Houses, $575+6$; Sadanobu's laws, 625

Cotton first planted in Japan (799), 280; cloth; tax, 437; cloth as currency, 439

Council, Administrative, of Man-dokoro, 328-of Twelve, at camera Court, 330

Councillor, Sangi, establishment of office, 231 .

Couplet il Composing, is uta awase, 277, 127, court amusè ment, 115, 118; at "windingwater fête" and other festís vals, 213-14; mania for, 215, 234 ; tournaments, 250 ; in Heian epoch, 277, Kamakura 366 ; Tokugawa, 577

Court, costume, colours and kinds, 211; céremonial, 171 ; for Imperial power see Crown

Court houses or families, kuge, 256; come into power again at'restoration, 388 ; in Muromachi period, 435 ; driven to provinces, 461; Ieyasu's laws for, $573,576-7$; intermarriage with military; 620 ; college for, established by (Ninkō, 664; influenced by anti-foreign party, 670 ; in Restoration, 679 ; distinction between ter- 
ritorial and court nobles abolished (1871), $683 \mathrm{f}$.n.

Court of justice, $h y \bar{o} j \overline{0}-s h \bar{o}, 633$, 635; first, (1631), 639

Court, Northern and Southern, 356; and see Dynasties

Crasset on Christian persecu-

tion of Buddhists, 537

Creation, story of, $9,25$.

Cremation, introduced, 213

Crimes in ancient Japan, 66; classified in Daihō code, 178 ; see Penal Law

Crocodile myth, 20, 26, 33, 65

Crown; property of, 124,162 ,

164,182 ; shifts in power of,

$79,94,97,105,128,139,165$,

$182,232,387$; divine right,

403; Ashikaga, 440; in Sengo-

$k u$ period, 460-2; Nobunaga,

493; Ieyasu's Court Laws,

576-7; Tokugawa, 587-8;

Chinese classics strengthen,

614,621,644; Tsunayoshi,620;

loyalty, 647; American com-

mercial treaty, 667; rescript to shogun, 673; turns against extremists, 674; Restoration of 1867,677; growth of power 681-2; Cabinet dependent on, 692-3

Crown Prince, in proto-historic period, above the law, 125

Crucifixion, haritsuke, 642

Currency in Ashikaga period, 438 f.n., 439-40; see Coinage

Customs tariff, 708

Daian-ji temple, 191

Dai-Dembō-In, monastery of

Shingon sect in Kii,499-500

Daiei, year-period, $1521-8,470$

Daigo, 60th Emperor (898930), 241-53

Daigo, suburb of Kyōto, 522

Daihō (Taihō), year-period, 701-3, legislation of, 176-84; revision, 232, 641

Daijo-uji of Hitachi, branch of Taira, 265

Daika or Taikwa "Great Change," 645 A.D., 160-5; - name of first nengō or yearperiod, $645-9,161$; reforms, 170,326

Dàikagu-ji family, afterwards Nan-chō; the Southern Court, descendants : Kameyama, 356,357 ; passed over, 418 ; treatment by Ashikaga, 440 Daikwan, deputy or vice-deputy, 437, 634, 636; tax assessor, 638 ; judge, 640

Daimyō, "great name," holder of large estate, 253; holdings, 426; 436; Buddhism, 578; 10,000 koku or more, .592; powers, 637

Dai Nihon-shi, "History of Great Japan," 645 ; on military era, 435

Dairies under Daihō laws, 212
Dairō, 5 senior ministers, 523 ; prime minister, 598, 632, 633 Daiseiden College, or Shōheiko, founded by Tokugawa, 578

Daitoku-ji, Zen temple in Kyōto, 454; (ill.), 233, 269

Dajo, (Daijō) daijin, chancellor, prime minister, 671 A.D., 169; Privy Council Board, 179 ; office abolished, 387

Dajo Kwan, Privy Council, 171

Dalny occupied by Japanese, 716,717

Dance masks, 282

Dancing at funerals, 74; court, 110, 213; music, Korean influence, 156; pantomimic, of monkey Sarume in myth, 12,213 ; music and poetry, 215; development in Heian epoch, 278; white posture dance, shirabyőshi, 291 ; mimetic dance, libretto for, 450 , develops into $n \overline{0}, 458 ; n \bar{o}$ and fūryū, 605; 596 (ill.)

Dan-no-ura, defeat of Taira at, 318-20

Date family of Yonezawa in 16th century wars, 471

- Harumune, 471

- Masamune (1566-1636), $471-2$; surrenders to Hideyoshi, 504; favours Ieyasu, 559 ; against Uesugi, 560 ; loyal to Iemitsu, 594

- Yasumune rebels (1413) in Mutsu, 412

Dazai-fu, government station in Mimana (Kara, Korea) transferred to Kyūshū, 83, 180,258

Debt, slavery for, cancellation of interest, 173; legislation (tokusei) of 1297, in favour of military families, 376 , and under Ashikaga, 422

Decoration, Interior, 153

Defilement in Shint $\overline{0}_{1}$ code, 276

Degradation in rank, 642

Deluge myth, 26

Demmachō, prison at, 642

Demon's gate, N.E. entrance, 228,283 ; guarded by Hieizan, 485 , and, at Yedo by Tōei-zan, 583; I belief in demons, 282; dragon-headed devil, 91 (ill.)

Dengaku mime, 377

Dengyō Daishi, posthumous name of Saichō (q.v.)

Dening, W., Life of Toyotomi Hideyoshi, 484 f.n.; 488 f.n.; on Confucian philosophy, $628 \mathrm{f}$.n.

Departments, under Daika, 164; under Daihö; 179

Deputy, 437, 634 .

De Ryp, Dutch ship, cannonades Hara castle, 555
"Descent" upon Kyūshū, $18-19 ; 29-30$

Descent, Law of in Daihō legislation, 177-8

Deshima, island, Dutch factory on, 656-7

Dewa, Yemishi in, 219; GoSannen campaign, 267; (Ushū) part of $\bar{O}-U,-388 ; 16$ th century wars, 471 ; silk growing, 617

De Witte, Serge Julievitch, Count . (b. 1849), Russian peace commissioner at Portsmouth, 725

Diana, Russian ship, sent to survey Yezo, 659; Russian protected cruiser at Port Arthur, 711

Dickins, F. V., translation of Taketori Monogatari, 251 f.n. Diet;':Coronation oath promising, 679-80; reform leaders differ about, 683 ; development of, 689-91; Constitution promulgated, 691 ; bicameral system, 692

Dirges at funerals, 74, 212

District, gun or kồri (originally agata), Daika subdivision, smaller than province, 165; classification under Daih $\overline{0}$, 180; chief of, gunchō, 182 ; governors, gunshi, 200; district governors and title to uplands, 201; in Meiji administration, $\operatorname{ch} \bar{o}$, or son, 688

Divination, 27, 66

Doctors, national, 160

Dōen, Buddhist priest, envoy to China, 444

Dōgo, Iyo, thermal spring, 157 Dogs as pets, 277-8; dog fights, 377; Tsunayoshi's mania for, 602

Doi support Southern Court in Nankai-dō, 400

- Sanehira (d. 1220), Yoritomo's lieutenant, 304-5; military governor, 316

- Michiharu (d. 1337), defender of Go-Daigo, 382

- Toshikatsu (1573-1644),

enforces feudal laws, 594, 595

Dōin Kinkata (1291-1360), minister of Go-Daigo, 388

- Kinsada (1340-99), scholar: 447

Dōji; Sanron Buddhist, abbot of Daian-ji, 191

Dōjima, in Ōsaka, rice-exchange, 616

Dōjō, exercise halls, 448

Doki (Toki) family favour Takauji, 406; beaten by Saitō, 468.

- Yoritō (d. 1342), insults Kōgon, 405

Dōkyō see Yuge Dōkyō

Dolmen in Yamato sepulture, 49-50; compared with Chi- 
nese and Korean 50; precious metals in, 186

Dominicans, Ayala and other marytrs, 551

Döryū ' (Tao Iung), Chinese priest, teacher of Fujiwara Tokimune, 361

Dōshō, Buddhist priest, introduces cremation, 213

Double entendre, 266 f.n.

Drafts, game, prehistoric, 75

Dragon, early superstition, 128

Dragon-Fly Island, old name of Japan, 18 f.n:

Drama; yokyoku, mimetic dance, $450 ; n \tilde{o}, 458-9 ; k y o ̄ g e n$, 459 ; time of 'T'sunayoshi; 600 ; theatre in Yedo, 620; illustrations, 28, 56, 549, 573, 708 Drums, 55 (ill.), 661 (ill.)

Dualism of Shintō, 65

Dug-outs, maruki-bune, $126 \mathrm{f} . n$.

Duke, kimi, 73; mahito, 171

Dukes of the Presence, early official organization, 98

Dutch, trade in Japan, beginning 1600,545 , Spanish intrigues against, 547, 653; Dutch and English intrigues against Portuguese and Spaniards, 549-50, 552, 554; aid in reduction of Christian revolt in Shimabara, 554-5; trade at Nagasaki restricted, 609 ; Western learning, 614; refuse grant in Yedo, 651; choose Hirado as headquarters, 652, 653; the Brach, 653; at Deshima, 656-7; literature, 659; in 19th century, 663,666 ; teachers of military science, 668 ; 'give steamship, 669 ; at Shimonoseki, 674

Dwarf trees and miniature gardens, $456-7 ; 459$ (ill.)

Dwelling-Houses, primitive, 62; abandoned on death of owner, 74 ; general character in Nara epoch, 209; in Heian epoch, 279-80; Kamakura, 373; Muromachi,"455-6, (ill.), 335

Dyeing, 68

Dynasties, War of the (133792), 396-412; table, 406

Ears of enerny as spoil, 519

Earthquake, 416 A.D., 111; 599 A.D. drives people to appeal to Earthquake Kami, 157; in Kyōto (1185), 330, and (1596), 518; of 1662 charged to Lmperor's lack of virtue, 591 ; of 1703,604

Eastern Army, Hosokawa Ōnin War, 429

Eastern Tsin dynasty (317420) Chinese migration,' 102 East India Company, 653-5 Eben, Buddhist priest, 134

Ebisu, variant of Yemishi (q.v.)

Echigo, barrier settlement
(645) against Yemishi, 38; and Matsuduira, 597

- Chūta, suicide, 313

Echizen, paper money in, 639

Education, in ancient Japan, 74; in Nara epoch, 214, in Heian, 282-3; temple schools, 448; military foundations, 449; at Yedo, 626; in Meiji epoch, 688; see Academies

Egawa Tarozaemon advocates foreign intercourse, 665

Eight Generals of Kwantō, 425 Eigwa Monogatari, "Tales of Splendour," story of the Fujiwara, by Akazome Einon, 261 Eiraku, or Yunglo, Chinése year-period, 1403-22, $E$.tsūhō, Chinese coins, 418, 438 f.n., $439-40,527$

Eisai (1141-1215), priest, 334

Eitai, bridge in Yedo, 586

Ekei (d. 1600), priest, of Aki, 491,561

Elder Statesmen, 696

Elder, official over five households, under Daika, 164

Elephant, fossil 45 f.n.

Elixir, Hsa Fuh's quest, 78

Emishi see Soga Emishi

Emperors, long reigns of early, 77; see also Crown, Court, Posthumous Names, Camera government.

Empō, period, 1673-80, 603

Empress, Kōken first, to receive Crown except in trust, 197

Empress Dowager, $K w \bar{o}$-taikō, title given only to $K w \overline{o b e t s u}$ until Shömu's reign, 189

Encyclopodia Britanicica, quoted, $60,457,512,513,516$, $533,534,535,537,510,542$, $543,545,546,547,548,655$, $677,690,710,729$

Endō Moritō see Mongaku

Engaku-ji, temple, 439

Engen, period, 1336 9, 398

Engi, period, $901-23,245+251$; revision of Rules and Regilations, $177 ;$ overthrow of Sugawara Michizane, 242-4

English intrigue against Spanish and Portuguese, 549 50, 551,552 ; refuse grant in Yedo, 651; go to Hirado rather than Uraga, 653; early trade, $654-5$; end of trade, 655 ; fleet expected (1858); 667 ; Numamugi ineident and bombardment of Kagoshima, 673, 674; the Hyōgō demonstration, 675-6; employed in railway, telegraph and navy, 686 ; treaty of 1894 abólishes consular jurisdiction after 1899, 709; Anglo-Japanése alliance, 710,730 , (text) 736 Finkyü, period, 1069-74, 270 En no Ubasoku (Shōkaku;
Gyoja, the anchorite), founder of Yamabushi priests, 196

Enomoto see Yenomoto

Enryaku-ji, Téndai monastery on Hiei-zan, 276,367 ; cits armed men, yama-höshi, 1273 ; jealous of Onjo-ji monks, 274; in Yorimasa conspiraicy, 300 ; in Kyōto conspiracy, ${ }^{3} 379$ quarrel with Takauji, 453-4; feud with Hongwan-ji; 463 ; destroyed by Nobunaga, 485; rebuilt, 505 ; named " from year-period, $782 \div 805,583$

Envoys, Three, in early myth, $16+17$

Enya Takásada (d. 1338), Kō Moronxo abduets wife of, 40.5 Enyũ, 64th Emperor (970-84), 259

Eshi, Yamato no, painters, descendants of Shinki, 127.

Esoterie and Exoterie Buddhism, 132, $369=16,150,10$

Etchū, provinee, 468

"Eternal Land," 60, 84

Ethnologists, Japanese, on origins, $59-60$

Etorop raided by Russians (1806), 658

Eto Shimpei (1835-74), min-

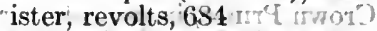
Euhemerist interpretation of myths, 29

Exoterie Buddhism, 132

Extraterritorial Jurisdiction, $707-10$

Eye, obliquity, fold, ete., 59

Eyebrows shaved, $279+(\{-2)(\}$

Ezo, Buddhist mission to, 194

Face-painting, $74-5,279$ orfes

Families, uji, rank in prehistoric times, 92-3; basis of empire before Daika; 161 , 165; family qualification for highest Court offices before Heiji tumult, 295; names sold in Yoshimurie's time, 617 Famine of 621 A.D.inturns people agáinst Buddhism, 157; of 1180-1, 301; of 1462, 424 ; of $1673-80,603$; of $1783-$ 6, 623; of $1836 s q q, ., 661$

Fans, 128; 595 (ill.); lotteries, 277 ; verses on, 277 ; trade', 445 Farmers, 142, 372; taxes, 426 , 439 ; representatives, 637 , 3 h Fenshuiling, Russians defeated at, 718

Fernandez, João (d. 1566), Portuguese Jesuit, companion of Xavier, 531, 532; 533

Festivals, ancient, 63; Buddhist, 144; flower, 214; Heian epoch, 277; Ashikaga, 423 ; Hideyoshi, 521-2; Sannō, 625 (ill.); dolls, 117 (ill.)

Feudal system, beginnings, 67 ; Sujin, 80; land-holding, 95-6; proto-historic, ... 128; , land grants, '172; Daihö laws, 178; 
11 th century wars, 264 ; territoriâl names, 287 ; constables and land-stewards, $329, J o e^{2}$ code, 350 ; war of dynasties, 401; 15th century, 431; Hideyoshi's land system, 527 ; fiefs (1600), -561; hereditary vasșals, 561 , $592,633,176 ;$ laws of 1635 and 1651,585 ; "under Tokugawa, 592-5; sankin kótdi, 614-15; taxes, 617 intermarriage with court nobles, 620 ; government, 637 ; tozama oppose Yedo, 661; in Restoration, 677,679 ; abolition, of, $680-2$

Filial piety, 285,643

Finance and administration, ancient, 67 ; in protohistoric times, .124; in Nara epoch, 201; in Muromachi epoch, $437+8$; under early Tokugawa, 603-5; pólicy of Arai Hakuseki, 608-9; "accommónation" system of 1786,619 ;'under Tokugawa, $637-8$; in early Meiji period, $687-8$; 691

Finance or Treasury Department, 164,179 ; in 19 th century, 681

Financial administrator, 634

Firearms first use, 487,4889 ,

530 ; commissioners, 635

Fish as food, 69, 212 .

Fishermen, revolt of, 99

Fishing in early times, 72 ; "laws regulating nets in" reign of Temmu; 171; keeping cormorants forbidden, 212 ; equipment, 99 (ill.)

Five Regent Houses, "sèe GoSekke-

Flesh-eating forbidden, 171; defilemerit, 276

Flores, Luis, Flemish Dominican, burned (1622), 552

Flowers, at funerals, 212 ; festivals, 214,424 (ill), in Heian pastimes, 277 a rangement of, $457-8,75$ (ill.); pots (ill), 459

Flutes, 234 (ill.)

Fo, dogs of 280

Folding paletot, 211

Food and drink, ancient, 68

69 ; in Nara-epoch, 212 ; in

Kamakura period, 374 ; Sada-

nobu's sumptiary laws, 625

Football, prehistoric, 75 ; in prota-historic period, "148, 157; in Heian epoch, 277

Forced labour, 181, 183-4, 224

Foreign Affairs, Department of, 681 ; earliest foreign "intercourse, 81, 83; 101; Ashikága, 417-18; Muromachi epoch, 442-5; foreign learning, 614 ; Tokugawa 652-76; military science, 668-9; Meiji era, 678; foreigners in making new
Japan, 686-7 ; consular jurisdiction abolished, 709 ; AngloJapanese alliance, 710; and see Christianity and names, of countries.

Forests of early Japan, 70

Formosa, expedition against (1874), 684-5, 698; ceded by China (1895), 702

Fortification, development, 486; feudal castles built only by permission of Tokugawa, $574-5,584 ;$ coast defence, 659,666

Fossil remains, 45 f.n.

Franchise, extension of, 692

Franciścans, Spanish, enter "Japan "as ambassadors," 542 ; intrigue against Portuguese 'Jesuits, "543," 546-7; punished by Hideyoshi, 543-4; favoured to offset Jesuit influence, 545

Freemen and bondmen, 161, 173

French in Ryūkū (1846), 663; Harris plays off English and French to get his commercial treaty, 667; at Shimonoseki, 674 ; in work on criminal law and army training, 686 ; in Manchuria note (1895), 702-3 Froez, Luis (d. 1597), Portuguese Jesuit, $538^{\circ}$

Fúdoki, Local Records, 3

Fuhi, Eight Trigrams of, 66

Fuhito see Fujiwara Fuhito

Fuhkien, Kublai at, 362

Fuji river, battle on, 306

Fuji; Mt., eruption of, (1707) 604; 1 (ill.)

Fujunami in Ise worship, 583 Fujita 'Töko (1806-55), adviser of Nariaki, 662,665

Fújitsuna see Aota Fujitsuna

Fujiwara, in Yamato, capital moved to, by Jitō, 185

Fujiwara, Shimbetsu family, influence after $670^{\circ}$ A.D., 128 ; Imperial consorts, 176 ; legislation, $177 ;^{-1}$ historiography, 188;" Asuka made Empress, 189-190; opposé Makibi and Gembō, 191; Buddhism, 192; abdication, 197, 237; family tree, 203; choose Emperors, 205 ; academy of, 206,283 ; increase of poiver, 236; policy of abdication, 237; depose Yōzei,- 238-9; “oppose Tachibana, 240; plot against Michizane, 243-4; interregnum, 245; war of Taira and Minamoto, 254 ; influence on Court, 257; oppose Tamehira, 258; family quarrels, 259; literature, 261; Minamoto, "claws" of, 265 ; provincial branches, 266; Mutsu, 268, 306 ; power wanes, 269 ; Im-
perial consorts 276 ; anti-mili- tary, 285; power weakened by Kiyomori, 294; Yoritomo's followers get their estates, 324 ; conspiracy of 1252,354 ; loyal to Throne (1331), 380; Hideyoshi adopted by, 499 .

- Fuhito, son of Kamatari,

Daihō and $Y \bar{o} r \bar{o}$ codes, $176^{\circ}$ builds Buddhist temple, 192 ; death $203 ; 189,190$

- Fujifusa aids Go-Daigo (1326), 379-80; retires 389-90 - Fusazaki (682-736), son of Fuhito, founds northern family, 203

- Fuyutsugu (775-826), 232-

233; Könin revision of Rules and Regulations, 177, 232; minister founds academy, 200 - Hidehira (1096-1187), son of Motohira, 268; aids Yoshitsune, 307 ; provincial governor (1182), 308; death, $323-4$

- Hidesato (called Tawara Tōda), sides with Taira, 254, 256 ; founder of provincial branches of Fujiwara, 266

- Hirotsugu (715-741), governor, impeaches Gembō, 191 - Ietaka (1158-1237), poet, 471

- Jōye, Buddhist student in China (653-65), 166, 192

- Kamatari, muraji of Nakatomi, chief Shintō official, plots against Soga Iruka (645), 148-9; Daika, 160; in China, 165, 166; origin of uji name, 168; Kasuga shrine, 209; 147 (ill.)

- Kaneiye (929-99), rivalry with Kanemichi, 259; plot against' Kwazan, 259; regent for Ichijō, 260

- Kanehira (1228-94), founds house of Takatsukasa, 358

- Kanemichi (925-77), father of Enyu's Empress, 259

- Kanezane (1147-1207), son of Tadamichi, minister of the. Right, 310 ; nairan and kwampaku, 330; descendants called Kujō, 330, 358

- Kinsuye (958-1029), son of Morosuke, 259

- Kinto (966-1041) poet, one of Shinagon, 261

- Kiyohira (d. 1126), founds Mutsu branch, 267, 268, 307 - Kiyotada opposes advice of Masashige, 394

- Korechika (974-1010), son of Michitaka, 260

- Korekata induces Nobuyori to join Heiji plot, 292

- Korekimi, 205

- Koretáda $(942 \div 72)$, son of

Morosuke, regent, 259

- Kunimutsu, avenges his father Suketomo, 378 
Fujiwara Maro (695-736), | Fujiwara Norimichi (996founder of Kyo-ke branch, 203 - Masatada, governor 262

- Matate (716-67), sccond councillor under Kōken, 200

- Michilye (1192-1252), ancestor of Nijō and Ichijō families, 358

- Michikane (955-95), gets Kwazan to become monk, $259-60$; regent, 260

- Michinaga (966-1027), regent, his daughter Empress, 260 ; power, 261

- Michinori (d. 1159), called Shinzei, Go-Shirakawa's adviser, 291 ; killed, 292

- Michitaka (953-95), regent, 260

- Momokawa (722-79), privy councillor, 200 ; favours succession of Shirakabe and Yamabe, 204

- Morokata aids Go-Daigo (1331), 379-80

- Moronaga (1137-92), chancellor, banished by Taira Kiyomori, 298

- Morosuke (908-60), minister of Right, 257-8; sons, 259

- Morotada, 257; accuses Takaaki of treason, 258

- Morozane (1042-1101), 272

- Motofusa (1144-1230), regent, 296; sides with GoShirakawa, is banished, 298; his daughter, 313

- Motohira (d. 1157), son and successor of Kiyohira, 268

- Motokata, father of Murakami's consort, 258

- Motomichi (1160-1233), advanced by Taira Kiyomori, 298; kwampaku, 330; ancestor of Konoe, 330,358

- Motomitsu, founder of Tosa academy of painters, 280,452

- Mototsune (836-91), 237; sesshō underYözei, first kwampaku (882) under Uda, 238-9

- Motozane (1143-66), regent, 294

- Muchimaro (680-736), founds the southern (Nanke) family, 203; Buddhist temples, 192

- Nagate (714-71), minister of the Left, 200; favours accession of Kōnin, 204

- Nagazane, father of one of

Toba's consorts, 273, 289

- Nakamaro (710-64), grand councillor, 197-8

- Nakanari (d. 810), in conspiracy of Kusu, 230

Shishi-ga-tani plot, 296

- Naritoki, father of Sanjō's Empress, 260

- Nobuyori (1133-59), in Heiji tumult, 292-3
1075), quarrels with Go-Sanjō, 271

- Noritane, compiler of Teiōkeizu, 448

- Otsuga (773-843), 204, 239 - Sadaiye(1162-1241), or Teika, poet and anthologist, 366 - Sadakuni, father-in-law of Daigo, 243

- Sanetaka, minister, 461

- Saneyori (900-70), father of Murakami's consort, 257; regent, 259

- Sari, scribe, 261

- Seigwa, or Seikwa, (1561-

1619), Confucianist, 578-9

- Shinzei see Fujiwara Michinori

- Sukeyo, scholar, 240

- Suketomo (d.' 1325) GoDaigo's minister, exiled, 378 - Sumitomo (d. 941) turns pirate, 255

- Tadahira (880-949), regent 253,257 ; revision of Rules and Regulations, 177

- T a d a k i y o, commands against Yoritomo, 306

- Tadamichi (1097-1164), regent for Konoe, in Högen insurrection, 289; saves his father, 291 ; estates, 252

- Tadazane (1078-1162), father of Toba's consort, 273, 289 ; in Hōgen tumult, 289; saved by his son, 291

- Takaiye (979-1044), repels Toi invaders, 262-3

- Tameiye (1197-1275), 366

- Tamemitsu, 259

- Tamesuke, 366

- Tameuji, artist, 280

- Tanetsugu (737-85), 205; Kwammu's minister, assassinated, 225-6; father of consort of Heijō, 230

- Tokihira (871-909), minister plots against Sugawara Michizane, 241-4; death, 245 - Tomiko, wife of Ashikaga Yoshimasa, 422, 428, 430

- Toshimoto (d. 1330), 378

- Toshinari (1114-1204),

poct, called Shunzei, 366

- Toyonari (704-65), minister of Köken, 200

- Tsugunawa (727-96), 205; sent against Yemishi, 220

- Tsunemune, 292

- Tsunetaka, 452

- Ujimune, Jókwan revision of Rules and Regulations, 177 - Umakai (694-736), founder of the Shiki-ki branch, 203; against Yemishi (724), 220

- Uwona (721-83), privy councillor of Köken, 200 - Yasuhira, (d. 1189), 324

- Yorimichi (992-1074), son, of Michinaga, regent, 261 ; in succession of Takahito 269; estates, 270; father of Shirakawa's consort, 271

${ }_{-}$Yorinaga $(1120-56)$ in $H \bar{o}-$ gen tumult, 289,291; 292

- Yoritada (924-89), son of Saneyori, kwampaku, 259

- Yoritsugu $(1239-56)$, shoguin (1244), 351, 354

- Yoritsune (1218-56), head of Minamoto (1219) shōgun (1226), 340; resigns (1244), 351,354 ; against $\mathrm{Hōjo} \mathrm{j}$ and Adachi (1247), 352

- Yoshifusa (804-72), minister, 236; marries Kiyo, 236; regent for Seiwa, (866), 237 ; makes Taka Seiwa's Empress, 238

- Yoshinobu, in Takahito's succession, 269

- Yoshitsugu (716-77), privy councillor under. Kōken, 200; favours Kōnin, 204

Fujiwara, wistaria, origin of uji name, 168

Fuki-ayezu,Jimmu's father,21 Fukuchi-yama, castle, 505

Fukuhara, now Kōbe, villa of Taira Kiyomori in, 298, 299; capital (1180) 300

Fukuri, Chinese saddler, 145 Fukushima Masanori (15611624), plot against Ishida, 558,562

Funabashi Hidekata (15551614), scholar, 578

Funada Yoshimasa, officer of Nitta Yoshisada, 384

Funai, in Büngo, Jesuit church and hospital, 533, 535 Funanoe, mount in Hôki, 382 Furniture, house, 209, 279

Furs, 68

Furubito, Prince, son of Jomei, candidate to succeed K'ógyoku, 147; death, 159

Fūry $\bar{u}$, dance, 605

Fusa-Kuni-Kazusa, 671

Fusan, Korea, Japanese re stricted to, (1572), 510; captured (1592), 513 ; landingplace for Japanese attack (1904), 713; Kamimura wins battle near, 717

Fushimi, 92d Emperor (128798), 356, 357

Fushimi, princely house, 621

Fushimi, Hideyoshi's MomoYama palace, 528.

Futodama and Imibe, 33, 61

Gaku-in, academies, 206

Gambling, 75, 214, 277, 458

Gamō Katahide (1534-84)

fávours Nobukatsu, 494 .

- Ujisato (1557-96), vassal

of Hideyoshi, 505

Garden bridge, 8 (ill.)

- gate, 175 (ill.)

Gate guards, in capital, 180; in kebiishi, 232 ; origin, 284 
Gates, (ill.), 76, 175, 376, 632

Gazan, priest; 454

Gei-ami, artist, 425

Géisha, 291, 620,625

Gembō, Buddhist of Hossō sect, 191; opposes Fujiwara, 191

Gemmyō, 43d Empress (70815), 185-188; historiography, 2 , 3 ; monument, 213

Gems; $67 ; 70$

Genbun, year-period, 1736-40, coins of, 617

Gen-e: (1269-1352), priest,

author, $447,448,454$

Genealogical bureau, 233

Genji Monogatari."narrative of Minamoto,"'work of Murasaki Shikibu, 249 f.n., 590

Genji or Gen, Chinese pronunciation of Minamoto, $206 \mathrm{f}$.n.; divisions of family, 265; epoch of Gen and Hei, 284335 .

Genkū see Hōnen

Genna, period, 1615-23, 570

Genpei (Gempei); Minamoto and Taira, 206 f.n.; epoch, 284-334; Genpei Seisuiki, Records of Minamoto and Taira, 295-6

Genre pictures, Ukiyoe, 600

Genroku, year period; 1688$1703,600,604-6$

Genshō, (44th) Empress (71523), 188; inaugurates lectures (721) on Nihon Shoki, 4 Genso, priest, interpreter to Korean embassy, 511

Gentile names; 73

Geology and fossil remains, 45 f.n.

Germans employed by Government 687

Germany joins France and Russia in note on Manchuria (1895), .702-3; seizes part of Shantung, 705

Gidō, scholar, adviser of Yoshimitsu' 448, 449

Gien see Ashikaga Yoshinori

Gifu, Nobunaga's headquarters in Minō, 480

Gijin see Ashikaga Yoshimi

Gion, temple in Kyōto, 274

Glazed póttery, 114, 374, 452

Glynn, J., Commander, U. S. N., in Nagasaki (1847), 663

Go, game, 278, 634

Go, prefix, "second," with -Emperor's name, 261

Goa, Jesuits at, 530

Go-Daigo, 96th Emperor $(1318-39) ; \quad 356, \quad 357,400$; against Hōjō, 378-9; dethroned 379 ; escapes from Oki, 382; re-enters 'Kyōto, 386 ; his rescripts, 387 ; after restoration, 388-90; tricked by Ashikaga Takauji, 396-7; death, 400 ; scholarship, 447
Go-Enyū, Northern Emperor $(1371-82), 406$

Go-Fukakusa, 89th Emperor (1246-59), 354, 356

Go-Fushimi, 93d Emperor (1298-1301), son of Fushimi, 356 ; opposes Go-Daigo, 379

Go-Hanazono, 102nd Emperor (1428-65); 412, 418, 460

Gohei, paper strips, 179 f.n.

Go-Horikawa, 86th Emperor (1221-32), 344

Go-Ichijō, 68th Emperor $(1017-36), 261$

Goji-in,-temple in Yedo, 602

Go-Kameyama, 99th Emperor (1372-92), 406, 411, 460; abdicates; 412

Go-Kashiwabara, '104th Emperor, $(1500-26), 460-2$

Go-Kōgon, Northern Emperor (1352-71), 406; 407; 409

Go-Komatsu, 100th Emperor $(1392-1412)$, in Northern dynasty (1382-92), 406, 412, 418,460

Go-Kōmyō, 110th Emperor (1643-54), 590-1

Gokuki-ji or Tō-ji, Shingon temple in Kyōto, 367; temple in Yedo, 602

Gokyōgoku Yoshitsune, work on landseape gardening, " 456 Gold in Japan; 186-7; 528 ; discovery in Mutsu, and used in great image of Buddha, 193; exported, 444 ; coins, 527 Gold lacquer, 279

Golden Pavilion (1397), 417

Golden Tatars in China. 358

Go-Mizu-no-o, 108th Emperor (1611-29), 589-90

Ge-Momozono, 118th Emperor $(1770-80), 621$

Go-Murakami, 97th Emperor (1339-68), 400, 460; escapes to Kanao, 402; asked to return after Sukō's removal, 407; death, 410

Go-Nara, 105th Emperor (1526-57), 460, 462

Gongen see Tokugawa Ieyasu Go-Nijo, 94th Emperor (13017); son of Go-Uda, 356, 357

Go-Reizei, 70th Emperor $(1046-68), 269$

Gorō see Tokimune

Go-Saga, 88th Emperor (124346), 354, 355-6

Go-Saien, 111th Emperor

(1654-63), 501

Go-Sakuramachi, (117th) Em-

press (1762-70), 621

Go-Sanjō, 71st Emperor (106972) Prince Takahito, 270-1

Go-Sannen, "After ThreeYears War," 1089-91, 267

Goseibai-shikimoku, criminal laws of Yasutoki, 448

Go-Sekke, "Five Regent Houses," $358,581,588 ; 416$
Gosen-shū, anthology, 251

Go-Shirakawa, 77th Emperor (1156-8), 289; camera government (1158-92), 291; life threatened, 296; confined in palace, 298; sent to Rokuhara, 299; under Yoshinaka's protection, 309-10; opposes Yoshinaka, 311; calls Yoritomo to Kyōto, 311; sends Yoshitsune to front, 317; relations with Yoritomo, 322, 323 , 329; death, 331

Go-Shujaku, 69th Emperor (1037-45), Prince Atsunaga, 269

Go-Toba, 82nd Emperor (1184-98), 310, 335, refuses to appoint Imperial prince shōgun, 340; called "original recluse," 341 ; quarrels with Yoshitoki, 342; exiled 344; Japanese verse, 366

Gotō Matabei defies Ieyasu, 565 ; defends Ōsaka castle, 567 - Yūjō (1435-1512), metalworker, 451

Go-Tsuchimikado, 103d Emperor (1465-1500), 460-1

Go-Uda, 91st Emperor (127487), son of Kameyama, 356

Government, , primitive administration, 62; connexion with worship, 63; early finance, 67; reign of Suinin, 84 ; two-fold classification, 96 ; $u j i, 97-8$; feudal and prefectural, 128; under Daika, 163; under Daiho, 178-80; of Ashikaga, 435-6; Hideyoshi's scheme, 523; early Tokugawa, 603-4; Tokugawa Bakufu, 632-43; centralized after Restoration, 681 ; local, in Meiji era, 688-9

Governor-general of 10 provinces, kwanryō, 387 ; of 4 , $k u b \bar{o}, 414$

Gö Yoshihiro, swordsmith, 451 Go-Yōzei, 107th Emperor (1586-1611), 460, 506, 580, 589

Gozu Tennō, "Emperor Oxhead," name of Susanoo, 60 Granaries, Imperial, miyake, 87 ; in Korea, 90, 96; in reign of Ankan, 120; of Senkwa, $121,124,164$

Grant, U.S., suggests compromise over Ryūkyū, 698

"Great Name Possessor," myth, 13, 18, 26

Great-Producing Kami, 16-17

Gromovoi, Russian cruiser at Vladivostok; 717

Guards, criticized by Miyoshi Kiyotsura, 247-8; duties transferred to kebiishi, 232 Guilds, be 71-2, 94; heads of kumi-gashira, in village rule, 637,643 
Gunkan Kyōjujo, naval college Han, Chinese dynasty, later at Tsukiji, 669

Gwangyo-ji, temple where Kwazan took tonsure, 260

Gyōgi, Korean Buddhist priest, propaganda and reconciliation of Buddhism and Shintō, 195, 228 f.n.

Gyokushitsu, priest, Emperor gives purple robes to, $589-90$ Hachijoshima, island, 561

Hachiman, War God, at Usa. oracle of, 199; tutelary of Minamoto, 303, 305; șhrine of, in Kamakura on Tsurugaoka hill, 305, 325 (ill.), 326, 339 ; revenue of temple, 439 ; patron of pirates; 446 f.n.; shrine of Iwashimizu, 452; shrine at Atsuta, 478

Hachiman Tarō see Minamoto Yoshiiye

Hachioka, temple of, 155

Hachisuka Iemasa (15581638), 497, 500

Hades, myth of, 10, 25, 30

Hae, mother of emperors Kensō and Ninken, 107

Hagiwara Shigehide, chief of Treasury, debases coinàge, 604, 605; his report, 608-9; impeached, 610

Haicheng in fighting of 1894, 702

Hair, racial mark, 58, 59

Hair-dressing and hair-cutting, ancient, 68 ; dividing the hair (mizura) goes out when official caps come in, 156 ; tied up in time of Temmu, 211; girl's hair bound up by lover, 216 ; in Heian epoch, 281 ; in Kamakura period, 373 ; in Sadanobu's laws, $625 ; 651$ (ill.)

Hair pins, as insignia, 156; cicada-shaped, marks of grade after Daika, 164

\section{Hai-ryong, Korea, 514}

Hakamadare Yasusake, bandit, 262

Hakata, in Chikuzen, defended against Toi, 262-3; port in Heian epoch, 281; Mongol envoys executed at, 362 ; China trade, 444; American vessels allowed in port, 666 Hakodate, Americans in, 666

Hakone, tolls at barrier, 439; guarded by Ōkubo, 592

Hakozaki Gulf, Chikuzen, -Mongol landing at, 359; bay fortified (1280), 361; base of second Mongol invasion, 362 Haku-chi, "White Pheasant," second nengo or year-period, 650-4 A.D., 165

Hakuseki see Arai Hakuscki Hall, Consul-General J. C., translation of Joei code, 349 50; Kemmu code, 403 f.n.; Laws of Military Houses; 574
(25-220 A.D.), 83; disorder after fall of, 101-2

Han, Land of, see Korea

Hanawa Naotsugu in defence of Osaka castle, 567

Hanazono, 95th Emperor, (1307-18), 356, 357, 396

Hand Bay near Kinchou, 715; Russian gunboats in, 716

Hanishi, potters, 113

Haniwa, clay effigies, buried instead of human sacrifices, 74,82

Haniyasu, half-brother of Sujin, rebels against him, 79 Hanshō, 18th Emperor (40611), 110; loyal brother of Richū, 109

Hara, castle in Shimabara, occupied by Christians, captured, 554-5

Haranobu see Takeda Shingen Harbin, Russian railway, 705 Hare in myth, 13-14

Harem, 636

Harima, province, fortifications in, (1280), 361; transferred from Akamatsu to Yamana (1441), 421 U. S. consul-general, concludes commercial treaty (1857), 666, 667

Harumoto sce Hosokawa Harumoto Harunari

Harvest Festival, 63

Hasegawa receive fief of Arima, 549

- Heizō in charge of Ishikawa house of correction, 626

Hashiba see Toyotomi Hideyoshi, 475 f.n.

- Hidekatsu (1567-93), son of Nobunaga, adopted by Hideyoshi, , 489, 505

- Hidenaga (1540-91), brother of Hideyoshi, 505, 522

- Hideyasu, Ogimaru, son of Ieyașu, 498

Hashimoto Sanae favours foreign trade, 667 ; leader in Imperial movement, 670

- Tsunatsune, Viscount 1909), 667

Hatahi, sister of Ōkusaka, marries Ôhat suse, 111

Hatakeyama family, estates, 409; Muromachi kwanryō, $414,427,436$; one of Five Regent Houses, 416 ; in Onin disturbance, 427; join Eastern Army (1472), 430; "province holders," 436

- Kunikiyo (d. 1364), general under Motouji, removed from office of shitsuji, 409

- Masanaga (d. 1493), succeeds Mochikuni, 427; dis-
Harris, Townsend (1803-78), placed; 428, driven from capital, 429 ; death; 432

- Mitsuiye (d. 1433) captures Sakai (1400), , 415;: Yoshimochi's minister, 418

- Mochikuni (1397-1455),

called Tokuhon, minister for Ashikaga Yoshimasa, 421; succession, 427

- Shigetada (1164-1205), at Ichi-no-tani, 315; adviser of Yoriiye, 335; - assassinated by Hōjō Tokimasa, 337

- Yoshinari (d. 1493), large estate, 426, succession, 427 ; kwanryō, 430

- Yoshitoyo (d. 1499), 432

Hatano, brothers killed by Nobunaga, 490

Hatsuse, Japanese battleship lost off Port Arthur, 717

Hatlo-gaki, Prohibitory Writings, code, (1742), 64

Hawking, 75, 106, 277, 612

Hayabito or Hayalo "Falcon Men"), palace guard, 21, 41; possibly Kumaso, 41

Hayama Muneyori, punished for cowardice, 332

Hayashi family, function of reading military laws, 576 ; true Confucianists; 613; education at Yedo, 626

- Dosshun or Razan (1583-

1657), Confucianist; on bell inscription, 566; 578; ethics and history, 579 ; traces dscent of Emperor from Chinese prince, 645

- Harukatsu, son of Razan;

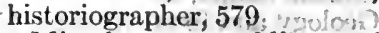
- Mitsukatsu, soldier of Nobunaga, 477

- Nobuatsu, Confucianist, 599 ; petitions for pardon of "47 Rōnins," 607"; lectures at Shōhei College, 613

- Razan see Hayashi Dōshun - Shibei (1754-93) urges ecast defense, 659

Head, racial marks, 58

Heaven, Plain of High, myth, $11,16,29,30,31-2$

"Heavenly Grandchild," ten. son, 33,66

Heavenly Young Prince, 16-17 Heguri, beginning of power of 105, 107, descendants of Takenouchi, 106; founder of family, Tsuku, in Richū's reign, 109 ; revolt of suppressed, 128, 129

Hei and Heike, Chinese name - for Taira, 206 f.n., 265-6 f.n.; Gen and Hei, 284-335

Heian epoch, capital at Kyötō, or Heian-jō (Castle of Peace), 794-1192 A.D., 224-83 Height as sign of race, $57-8$ Heihachiro, see Ōshio Heihachiro 
Heiji, year period, 1159-60, 252 ; the tumult of the year, 292-4; results, $294-5$

Heiin, 51 st Emperor (806-9), son of Kwammu, 230, 231

Heikautai, battle of (1905), $719-20,721$

Hemp, cultivation of, 67,71

Herb of longevity, 196

Hereditary office and rank, 62; in Shōtoku's 17-Article Constitution, 142; the Daika tries to abolish hereditary office holding, 160

$\mathrm{Hi}$, river, in myth 13,31

Hida, messenger in search for 'Buddhist devotees, 134

Hida, 128, 279, 461

Hida Takumi, architect, 251

Hidehito see Go-Momozono Hidekatsu see Hashiba Hidekátsu

Hideiye see Ukita Hideiye

Hidenaga see Hashiba Hidenaga

Hidetada branch of Tokugawa, extinct with Ietsugu (1716), 610

Hidetada see Tokugawa Hidetáda ${ }^{i}$

Hidetsugu see Toyotomi Hidetsugu

Hideyasu see Matsudaira Hideyasu'

Hideyori see Toyotomi Hideyori

Hideyoshi sce Toyotomi ${ }^{1}$ Hideyoshi

Hie-no-yama, monastery later called Hiei-zan, 228

Hiei-zan, mountain N. E. of Kyōtó, between Yamashiro and $\bar{O} \mathrm{mi}$, on - which - wás Enryaku-ji monastery, 228, $273,274,276,367,368,379$, $392,393,394,396$; power checked by Yoshinori, 420; and 'Takauji, 453-4; in' Hokke-ikki, 464; aids Yoshikage against Nobunagá, 484; punished by Nobunaga, 485 ; monastery rebuilt 505 ; abbot invites Vilela to Kyōto, 537

Higami, mother of Shōmu, consort of Mommu, 188, 191

Higashi-dera, temple in Kyōto, Takauji's headquarters, 396

Higashiyama, 113th Emperor $(1687-1710), 620$

Higashi-yama, hill E of Kyōto, site of. Yoshimasa's 'palace, 424,425 ; name used of craze for objets d'art, 450, and of lacquer, 451

Higúchi Kanemitsu, Yoshinaka's body guard, 313

Hiki Murietomo(d.1203),336-7

- Yoshikazu, in Bakufu council, plots against-Hōō and is assassinatéd 336

Hikoho no Ninigi, his descent

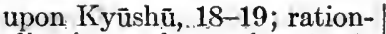
alization of myth, 31-2; founder of empire, 33

Hinayana, exoteric Buddhism, 132; the Small Vehicle, 369

Hino family, shikken in Camera palace, 440

Hirado; island, occupied by Mongols (1281), 363; Chinese trade, 444 f.n.; Xavier in, 531; Portuguese trade, 534; rivalry with Omura, 535; Dutch headquarters, 652 , and English, 653; English factory closed (1623), 654

Hirafu, warden of Koshi, campaigns against Sushen (658, 660), 34-5, and Yemishi (655), 38

Hiragana, syllabary, 250

Hirai, castle, 467

Hiräsaka, now Ifuyo-saka, 30

Hirata Atsutane (1776-1843) on Japanese goverument, 67 ; Shintō revival, 645; quoted, 649

Hirate Masahide, tutor of Nobunaga, suicide, 473

Hirohira, son of Murakami, set aside from succession, $258^{\circ}$

Hirose, commander, attempts to bottle-up Port Arthur, 715 Hirotada see Tokugawa Hirotada

Hirotsugu see Fujiwara Hirotsugu

Hirozumi see Sumiyoshi Gukei Hisaakira, Prince (1276-1328), shōgun (1289-1308), 354

Historiography, early, 1-8; the "Six National Histories" (697-887), 188; compilations of Tokugawa period, 579

Hitachi, 37; Taira in, 265

- Füdoki, ancient record (7.15 A.D.), 46

- Maru, Japanese transport sunk by Russians, 7.17

Hitomaru see Kakinomoto Hitomaru.

Hitotsubashi, branch of Tokugawa eligible to. shōgunate, 592, named from gate of Yedo, 618; Ienari's descent' from; 624

- Harunari, father of Ienari, 624 ; reactionary policy, 629 ; ambition opposed by Sadanobu, 630-1

Hiyeda Are (647); chamberlain, historiography, 2,3

Hiyoshi, Shintö temple, 274

Hizen, Tsuchi-gumo in, 42 ; Mongol invaders in (1281), 363 ; natives of, settle in China, 509; fiefs surrendered, 680 ; clan representation, 681 - Genji, or Matsuura, 265

"Hoe" "among early: implements, 47: distributed to farmers (723), 207.
Hoei, year-period, 1704-10, debased coinage of, 604

$H \bar{o}-e n$, year-period, $1135-40$, 252

Högen insurrection (1156; in year-period 1156-8), 289-91; result, $294-5$.

Hohodemi, myth of, $20-1,41$, 32 ; name applied to Iware in "Chronicles," 22

Hōjō, family: holding office of shikken, 327; power increased by Tokimasa, 336; Hōjō regency established, 340 ; excellent rule, 348 ; the nine regents, 353 ; control of shōgun, 354; Ōshū revolt, 377 ; Go-Daigo overthrows, 378-85; suicide of leaders, $385-6$; GoDaigo's rescript, 387 ; part of estates seized, 389 ; rising in 1334,390 ; system imitated by the Ashikaga, 403

- of Odawara, fight Satomi in Kwantō, 431; alliance.with Takeda, 466; their importance, 472 ; last eastern enemy of Nobunaga, 489 ; defeated by Hideyoshi, 502-4

Hojoki, Annals of a Cell, 367

Hōjö Kudaiki, on Kanazawabunkō library, 449

- Morotoki, regent. 1301-11, 353,377

- Nagatoki(1230-64), shikken (1256), 352

Nakatoki, fails to arrest Go-Daigo (1331), 380; escapes from Rokuhara, 384

- Sadatoki $(1270-1311)$ regent 1284-1301, and in camera to $1311,353,376,377$; succession to Fushimi, 357

- Sanetoki founds Kanazawabunko, 449

- Sōun, or Nagauji (14321519); reduces taxes 440 seizes Izu province, 465 (ill.)

- Takaiye,commander against Go-Daigo, 383-4

- Takatoki (1303-33), last of Hōjō. regents, 1311-33, 353. 377; Go-Daigo's quarrel, 37885 ; suicide, 386

- Tokifusa, leader against Kyōto in Shökyu struggle, 343 ; one of first tandai, 345 - Tókimasa -. (1138-1215), guardian of Yoritomo, 302-3; kills lieutenant-governor of Izu, 304; in Awa, 305; in Suruga, 306; messenger to Yoshitsune, 321; governs Kyōto, 323; military regent, 327 ; constables and stewards, 328; high constable at Court, 330 ; gives power of Minamoto to Hōjō, 336; kills Yoriiye, becomes shikken, 337 ; exiled, 338

-Tokimasu, death,(1333),384 
Hojō 'Tokimori, in southern Homuda, life name of Emperor Rokuhara, 347

- Tokimune (1251-84), son of Tokiyori, 352; regent (1256-84), 353, 376; Mongol invasion, 361 (ill:); Buddhism 361, and Buddhist temples, 366 ; Nichiren, 372

- Tokisada succeeds Tokimasa as high constable at Kyōto (1186), 330

- Tokiuji (1203-30) in northern Rokuhara, 347

- Tokiyori (1226-63), shikken (1246-56), Miura plot against, 351; cloistered regent, 351-2 (ill.); Buddhist temples, 366

-Tokiynki (d: 1353), captures Kamakura, 390-1

- Tsunetoki (1224-46), shikken, 351

-Ujimasa (1538-90), against Uesugi, 466-8; ally of Shingen, 483 ; defeated by Hideyoshi, '502-3

-Ujinao, son of Ujimasa, 503 - Ujinori, brother of Ujimasa, 503-4

- Ujitsuna (1487-1543), conquers Kwantō, 466

-Ujiyasu(1515-70), conquers Kwantō, 466

- Yasutoki (1183-1242) sent against Kyōto at outbreak of Shōkyñ war, 343 ; captures the capital, 344 ; explains treatment of ex-Emperors, 344-5; one of first tandai, 345; in regency, 347; thrift and generosity, 348; Jōei code, 349, 488; death, 351; Buddhist temples, 366

- Yoshitoki

(1163-1224), military regent, defeats Wada Yoshimori, 327, 338; in council of Bakufu, 336; in plot against Sanetomo, 339-40; Go-Toba quarrels with, 342 ; attitude toward Crown, 343; restored, 344; death, 346

Hokke, Hokke-shü, see Nichiren; Hokke-kyō-sutra, book of Nichiren doctrine, $400 ; \mathrm{Hok}$ $k e-i k k i$, war of the sect on Hongwan-ji, 464

Hokkyð Enzen, bonze; compiles $J \delta$ ei code, 349

Hōkō-ji, Buddhist temple in Asuka (587 A.D.), 138; image, 565; inscription on bell, 566

Hoku-chō, Northern court, 356

Hokuriku, Prince, 310-11

Home Affairs, Department of, in Restoration government, 681

Homestead, 50 houses, under Daika, 162, 164

Homma Saburō assassinates Hōjō Suketomo, 378

-'Saemon, Hōjō soldier, 385
Ojin, 73

Homutang, Russian stand at, 714

Honchō Hennén-roku, or Honcho Tsügan, history, 579

Honda Masanobu (1539-1617) adviser of Icyasu, 558, 563, 564,566

- Masazumi (1566-1637),563; Ōsaka castle, 568-9; under Hidetada, 580; punished for secret marriage, 594

Tadakatsu (1548-1610), Ieyasu's general at Sekigahara, 560 (1133-1212), preaches Jödo doctrine, 367,370

Hongi, Original Records of the Free People, 2

Hongo, Yedo, college at, 599 Hongwan-ji, Shin temple in Kyōto, 272 (ill.); monks in 16 th century wars, 434 ; feud with Enryaku-ji, 463-4; aid Mōri, Takeda and Hōjō, 4856 ; divided by Ieyasu, 578

Honnō-ji, temple, 490

Hori, gencral of Ieyasu, 560

Horigoe, Izu, fort, 425,464

Horikawa, 73rd Emperor (1087-1107), 272-3

Horses, cavalry, 488; "horse hunting," 612; wooden pictures, votive offerings 472 (ill.); racing, 92, (ill.)

Hōryū-ji, Buddhist temple at Nara (607), 154 (ill.); ideographic inscription in, 153 f.n.; dancers' masks and records, 156 ; statues, 185 (ill.)

Hoshikawa, son of Kara, seizes treasury and plots for throne, 117

Hoshina Masayuki (1609-72), guardiañ of Ietsuna, 584

Hōshō-ji, temple built :- by Shirakawa, 272 ; cherry picnics, 277; image, 280

Hosoi Kótaku, calligraphist, 601

Hosokawa, Harima; manor given to Fujiwara Tameiyc, 366 ; family favours Takauji, 406; large estates, 409; Muromachi kwanrȳo, 414, 436; one of Five Regent Houses; 416; power in 15th century, 427; Yamana family, 427-8; Eastern army in Ónin struggle, 429; crushed by Miyoshi, 434, 464; " province holders," 436 ; in Sanuki, 470

- Harumoto (1519-63), son of Sunimoto, in civil war, 4334 ; joined by Kōkyō, 464

- Katsumoto(1430-73), kwanryō, 421 ; estates, 426 ; feud with the Hatakeyama, 427;
Hōnen Shōnin, or Genkū, quarrels with Yamana, shitsuji, 428; death, 430

- Kiyouji (d: 1362), goes over to Southern Court, 409; defeated, 410

- Masomoto (1466-1507), 432

- Mitsumoto (1378-1426), minister to Ashikaga Yoshimochi, 418

- Sumimoto (1496-1520), kwanryō, (1507), 432; exiled, 433

- Sumiyuki (d. 1507), 432

- Tadaoki (1564-1645)," discloses plot against Ieyasu, 557 ; tries to kill Ishida, 558 ; helps Ieyasu, 559

- Takakuni (d. 1531), 432 . driven out by Sumimoto's son, 433; death, 434

- Yoriyuki (1329-92), guardjan of Ashikaga Yoshimitsu, 410; administration and death, 411, 416

Hospitals, Jesuit, 533, 535

Hossō, first Buddhist sect in Japan (653), 367, 368; Gembō studies tenets, 191

Hostages, women, "Pillow children," 86 ; of feudatories at Yedo, 581, 586

Hosuseri, myth of, 20-1, 32,41 Hotta family, Bakufu ministers from, 624

- Masamori (1606-51),' minister of Iemitsu, suicide, 582 - Masamutsu' (1810-64) aids Townsend Harris, 667

- Masatoshi (1631-84), on succession to shoggunate, 596 ; chief minister, 597 ; assassinated, 598

Hottō, Buddhist abbots, 144

Household, unit of administration under Daihō, 162, '164, 181

Household Department, under Daika, 164, and Daihō, 179

Hsia Kwei, Kamakura painter, 365

Hsuan-ming calendar revised (1683), 599

Hsu Fuh, Chinese Taoist, search for clixir of life, 78 .

Hulbert, History of Korea quoted, 511

Human sacrifice, at funerals, replaced by use of effigies, $47,50,74,82$, abolished, 163 ; in public works, 105

Hun river, Manchuria, 720 , 721

Hunting in prehistoric times, 75 ; kecping dogs or falcons forbidden by Shōtoku, 212

Hyakunin-isshū, "Poems of a Hundred Pocts," 366

Hyecha; Buddhist priest, instructor of Prince Shōtoku, 143 
Hyōgo, now Kōbe, in Ashikaga Iki, island, in early myth, 28; revolt, 394, 395; battle, 433; trade with China, 444; English demonstration against, $675-6$

Hyuga, Kumaso in, 40

Ibaraki-dōji, bandit, 262

Ice storage, 106

Ichijo,,, 66th Emperor (9871011), 260

- family, one of "Five Regent Houses," 358; leave Court for Tosa, 461

- Fuyuyoshi, scholar, 447

Kaneyoshi (1402-81), regent, adviser of Ashikaga Yoshihisa, 431; author, 447, 448; on religions, 452

Ichiman see Minamoto Ichiman

Ichinei (I Ning, or Nei-issan), Buddhist priest, 365

Ichi-no-tani, near Hyōgo, in Settsu, defeat of Taira at, 314 Ichō-mura, birthplace of Hideyoshi, 475

Ideographs, Chinese, histori,cal writing, 2,3 ; and Japanese language, 57; date of introduction, 103, 153 f.n.; adapted for syllabic purposes, 104 ; in early laws, 349 Ieharu see Tokugawa Ieharu

Iehisa see Shimazu Iehisa

Iemitsu see Tokugawa Iemitsu Iemochi see Tokugawa Iemochi

Ienari see Tokugawa Ienari

Ienobu see Tokugawa Ienobu Iesada see Tokugawa Iesada

Ieshige see Tokugawa Ieshige

Ietsugu see Tokugawa Ietsugu

Ietsuna see Tokugawa Ietsuna

Ieyasu see Tokugawa Ieyasu.

Ieyoshi see Tokuggawa Ieyoshi

Iga,'Prince; see Ötomo.

Iharu Atamaro, leader of Yemishi (780), 220

Ii, adherents of Southern Court, $400 ;$ Bakufu ministers from, 624; tamarizume, 636

- Naomasa (1561-1602), general at Sekigahara, 560

- Naosuke, Kamon no. Kami (1815-60), advocates foreign intercourse, 665; prime minister at Y Yedo, 668; Tokugawa Nariaki's opposition to, 662; foreign policy, $669-70$ (ill.); assassinated, 671

-Naotaka (1590-1659), minister of Iemitsu, 581, and of Ietsuna, 584

Ikeda Isshinsai, friend of Harunari, 631

- Nobuteru (1536-84), councillor after Nobunaga's death, 494; defeated, 498

- Terumasa (1564-1613), in plot against Ishida, 558; favours Ieyasu, 559 attacked by. Toi, 262, by Mongols, 359, 362; held by Japan, 703

Ikki; "revolt," 463-4

Ikkō, Shin sect; I Ikkō-ikki, war of 1488,463

Ikkyū Zenji (1394-1481), priest of Daitoku-ji, 454

Ikuno, silver mines, 528

Imagawa, family, gives refuge to Ashikaga Yoshimichi, 465; against Hōjō, 466; in Suruga and Mikawa, 468; Ieyasu's relations with, 556

- Motome, general under Date Masamune, 471

- Sadayo (Ryōshun), tandai of Kyūshū, 411; recalled, 414 - Ujizane (1538-1614); son of Yoshimoto, 479, 486

- Yoshimoto (1519-60) rules Suruga, Tōtōmi and Mikawa, 468; threatens : Owari, 476 ; defeated at Okehazama (1560), 477

Imai Kanehira, one of Yoshinaka's four body-guards; 312 ; sacrifices himself for his master, 313

Imibe, corporation or guild of mourners, descent, " 33,61 ; guard Imperial insignia, 63; abstainers, 71, 130; commissary agents in provinces, 93 ; in charge of Treasury, 114

Imjin River, Korea, 514, 517

Immigration, shadowed: in myths, 29, 34; from Siberia, China, Malaysia and Polynesia, 45; Japanese ethnologists on, 59-60; of Koreans and Chinese in 3rd \& 4th centuries, 102; and later, 144; from Shiragi (608), 151

Imna see Mimana

Imoko (Ōno Imoko), envoy to China (607 A.D.), 145

Imperial lands; 87,95

Imprisonment, 641,642

Imun, Korea, secured by $\mathrm{Ku}$ dara with Japan's help, 123

Inaba; Princess Yakami of, 13

- Masayasu, assassin of

Hotta Masatoshi, 598

Inaba-yama, castle of Saitō, 480

Inahi, brother of Jimmu, 60

Iname see Soga Iname

Inamura-ga-saki, "cliff

Kamakura, 385 f.n

Incense fêtes, 277,457

Incest, 73, 111

India, first Japanese visitor to, Takaoka or Shinnyo, 231

Indian architecture; influence of, through Buddhism, 153

Indigo growing in Awa, 617

Industrial class, in Kama-

kura period, 372

Industry, early Japanese, 71 -
72 ; impulse given by Buddhism in Nara epoch, 208; development in time of Yoshimune; 617-18; modern manufactures, 694

Infantry, use of, 488

Inheritance, law of, in Daihō legislation, 184; in feudal system of Tokugawa, 593

I Ning see Ichinei

Inishiki, Prince, 85

Inkyō : Ingyō), 19th Emperor (412-53), 110-11;87;97

In-memoriam: services, Shintö, 276

Inokami, consort - of Kōnin; 204

Inokashira lake and Yedo water-supply, 587

Inokuma, general of the Left, executed, 573

Ino Tadayoshi, survey of Northern islands (1800), 658

Inouye Kaoru, Marquis (b. 1835-), 683

-Tetsujiro, Dr., on Bushi ethics, 287; on Chutsz and Wang Yang-ming, 627-8:

Inquisitors, Bakufu officials at .Court after $S h \bar{o} k y \bar{u}$ war 345

Insei see Camera government Insignia, sacred Imperial, mirror, sword, jewel, $33,63,79$, $319,380,397,412$

Inspectors of district officials, after Daika; 165; of provincial government, 200 ; in " temple service, 634

Interest on loans, 202

Interior decoration, Yamato schoól, 452; (ill.); 442

"Interior,". Granary of; 90

- Ministry of, created - by

Daika (645), 160

"Invisible" Kami, 8 (f.n. 2)

Iratsuko, rebel against Yüry-

aku, famous archer, 137

Iris festival, 214

Iroha-uta, text book, 448

Iron in Kórea, 60; foundry at Akunoura, 669

Irrigation, under Sujin, 80; under Nintoku, 105, in 6th and 7 th centuries, 155 ; rice land, 182; in Nara epoch, 207; in Heian epoch, 282; under Yoshimune, 618

Iruka see Soga Iruka

Isa, early carriage-builder, 126

Isawa, headquarters moved from Taga to, 222

Ise, shrine of Sun at, 13,82 ; Yamatodake at-shrine, 37; swords offered, 85; oracle calls Amaterasu an avatar of Buddha, 195; Watarai shrine, 64 ; revolt of 1414 in, 412 ; rebuilding shrines, 461,493 , 583 ; Oda seize, 468, 480 ; Mori insults the shrine, 691 Ise Heishi, branch of Taira, 265 
Ise Monogatari, 590

- Sadachika (1417-73) page of

Yoshimasa, 424, 425; marries

Yoshitoshi's sister, 428; in-

fluence of, 430

Ishida Katsushige, soldier of

Hideyoshi, 505; brings about

Hidetsugu's death, 522-3; ordered to Korea, 524; plot against Ieyasu, 557, 558; takes Ōsaka, 560; death, 561

Ishide 'family in charge of

Yedo prison, 642

Ishidō family favours Tadayoshi, 406

Ishikawa Island, house of correction on, 626

Ishikawa Jinshirō relieves suffering in Kyöto, 624

Ishi-yama, temple 486

Ishizu, battle, Akiiye defeated

(1338) by Kō Moronao', 399

Iso-takeru (Itakeru), son of

Susanoo, 14f.n., 31

Isuraka, Korean artist, 127

Itagaki Taisuke, Count (b. 1837), 683; resigns from cabinet and works for parliament, 684, 689; organizes Liberal party, 690; invited into Cabinet, 693

Itakura Katsushige (15421624), in " bell-inscription plot, 567 ; in Kyōto, 580,643

- Shigemune (1587-1656); protests against Go-Kömyō's activities, 591

Italians employed by Government in fine arts, 687

Itō Hirobumi, Prince (18411909), 683; premier (1885), 691; framer of constitution, 692 (ill.); head of Liberal party, 693; treaty with China, 702; assassinated, 729

- Jinsai (1627-1705), Confucianist, 626

- Sukechika (d. 1181), guardian of Minamoto Yoritomo, 302-3; crushes Yoritomo's army, 304

Ito, or Wado, Chinese name for Japanese, 84

Itsukushima-Myōjin, Buddhist shrine, 299; (ill.) 347

Itsutse, brother of Jimmu, 21, 23

Iwa, consort of Nintoku, of Katsuragi family, 107

Iwai (Ihawi) ruler of Kyūshū, blocks invasion of Korea (527) but is defeated by Arakaho (528), 123

Iwaki, son of Kara, contests throne with Seinei, 117

Iwaki-uji, branch of Taira, 265

Iwakura Tomoyoshi, Prince (1825-83), leader of moderate party, 673, 683-4 (ill.)

Iware, life-time name of Jimmu, 73
Iwasaka, fort in Mikawa, 498 Iwatsuki, in Musashi, fortified, 426

Iyo, province, 28 ; oldest ideographic inscription (596 A.D.), 153 f.n.; held by Kōno, 470

Izanagi and Izanami, male and female Kami, creators of Japanese islands, $9,10,19,25$, $26,28-29,34,109$

Izayoi-nikki, journal of Abutsu-ni, 366

Izu, early ship-building in, 22, $72,99,126$; Minamoto Tametomo exiled to, 291; Yoritomo in, 294, 302-304; peaceful under Kamakura rule, 409; seized by Hōjō Sōun (1491), 465

Izumi province, rising of 1399 in, 415

- Chikahira revolts against Hōjō, 338

- Shikibu, poetess of 11th century, 261

Izumo in early myth, 15, 17, 19, 30,31 ; revolt in causes withdrawal of court from Yamato, 32; gems in, : 67; conquered by Mōri, 470

Jade," curved-jewel," 26,33 f.n. Japan, name a. Dutch (15th century) perversion of $J i h$ pen; 77 ; early naimes, 145

Jenghiz Khan, 358

Jerome, Father, 544-5

Jesuits in Japan, 530-55; banished, 540 , but stay, 541; order to leave checked by Hideyoshi's death, 544; Ieyasu plays off Franciscans against, 545; denounce Dutch ship as pirate, 515; treated well by: Ieyasu; 546

Jesus, Jerome de (d. 1602), Franciscan, interview with Ieyasu, 544-5

Jewel, curved, chaplet, one of Imperial insignia, $18,26,33$, 63

Jih-pen, "Sunrise. Island," name used by Chinese, 77

Jimmu, Emperor $(660-585$ B.c.) 76-7; chronology dating from accession, 6; ancestrý, 21 ; leader in expedition against Yamato, 22-4, 32; 34; poem mentioning Yemishi, 36 ; strategem: against Tsuchigumo, 41; successors, 78; tomb, 76 (ill.)

Jimyō-in family, afterwards Hoku-chō or Northern Court, 356, holding Chōkōdō estates, 357; gets throne, 418

Jingi-ry $\overline{0}$, quoted on Board of Religion, 178

Jingō; Empress (201-69); 8891; Chinese and Japanese chronology of reign; 6; succession, 90; excluded from dynasties by Dai Nihon-siri, 645

Jingu-ji, temple built by Fujiwara Muchimaro, 192

Jinnō Shōtōki; "Emperor's Gencalogy," work on idiviné right by Kitabatake Chikafusa, 403-4

Jinshin, cyclical name for 672 A.D., civil war, 170 ?

Jishō-ji, monastery in Higashiyama, art-gallery,"424 arsuli

Jitō, (41st) Emprest') (690-6), wife : of Temmu, 172-5; - historiography, 2 ; Sushen, 35 Jiyū-tō, Liberal party organized by Itagaki, 690 sjinter ? Jōben, one of "four kings" of poetry, 367 arilf. $55 \%$ mentirtol. Jōchō, wood-carver, 280 ก๕:r Jōdo, Buddhist rect introduced (1196) by Hōnen, 367 ; creed, 370 \% $J \tilde{e} e$, year-period, 1232-3; code of $1232,349-50$; basis of Kemmu code, 403

Jōkaku, sculptor) 280

Jókwañ, year-period, 859-77, revision of Rules and Regulations, 177 :

$J \bar{o} k y \overline{0}$, year-period, $1684-7$, trade limitations, 609

Jomei, 34 th Emperor : 629 41), Tamura, 146:

Jō Nagáshige, próvineial governor, defeated; 308

Jorin, scholar, adviser of Yoshimitsu, 448

Josetsu (end of 14th century), bonze of Shōkoku-ji, painter, 450

Jōye see Fujiwara Jōye Jukō seé Shukō

Jun, mother of Michiyasu (Montoku), 235 (I)

Junna, 54th Emperor (82433), 234-5 , uteces 3 A utanl Junnin, 47th Emperor (75864), $198 \div 9$

Juntoku, 84th Emperor (121121), son of Go-Toba, abdicates, called Shin-in;"newrecluse," 341; 'exiled; 344

Juraku-tei, "Mansion " of Pleasure," 506, 527, 528 1 1

Jūrō see Sukenari

Justice, Department of, Gyōbu-shō, under Daika, 164; under Daihō 179,232 ; in Meiji government, 681

Justice, court of, $633,635,639$

Justices, land grants to, 183 :ri

Justo Ukondono see Takayáma

Kada Arimaro (1706-69) re-

-vises code, 641

- Azumamaro (1668-1736), scholar, restores Japanese literature, 645 ; quoted, 646

Kaempfer, Engelbert (1651 1716), historian, 6 
Kagoshima, in Satsume, land- | Kamo, Yamashiro, shrine in, | Kasai Motochika (d.1507),432

ing-place (1549) of St. 64

Francis Xavier, 530; bombarded by English, 673, 674

Kagu, Mt., in sun myth, 12

Kai, peaceful under Kamakura rule, 409 ; won by Takeda Shingen, 466, 467; "black horse of, " 115

Kaigen, priest in charge of -Ashikaga-gakkō, 449

Kai-koku Hei-dan, book by Hayashi: Shibei, urging coast defense, 659

Kaikwa, 9th Emperor (157-

98 в.c.), 77

Kaizan, priest of Myōshin-ji, 566

Kajiwara Kagetoki (d. 1200), fighting against Yoritomo, sympathizes ; with him, 305; military governor, 316 ; in command of fleet quarrels with Yoshitsune, 317; warns Yoritomo against Yoshitsune, 321

Kakinomoto Hitomaru, poet, end of 7 th century, 214

Kamada Masaie, companion of Yoshitomo, death, 293

Kamako see Nakatomi Kama-

ko

Kamakura, S: of present Yokohama, Yoritomo's headquarters, 305, 330-1 ; military centre for 150 years, 325; shrines built by Yoritomo, 326 ; school of art, 365 ; growth of luxury, 377; fall of city (1333), 385; headquarters of Ashikaga family, 398; Takauji removes to Kyōto, 402, keeping Kamakura as secondary basis, 403; Ashikaga driven out, Uesugi come in, 414

- Gongorō, 'soldier of Three Years'War, 267

- Jidaishi, quoted on parties in Shōky ū struggle, 341-2

Kamatari, 148-9; see Fujiwara Kamatari

Kamegiku, dancer, 342

Kameyama, 90th Emperor $(1259-74), 356,357$

Kami in Japanese mythology,

8,9 ; "creation" of chiefs, 30 ; used in "Chronicles" of Yemishi chiefs, 36 ; trinity of, 61 ; two classes, 64 ; the Kami class or Shimbetsu, 92 ; worship of, in early 7 th century, 142, 157; uji no Kami elective in Temmu's time, 172; Shinto $K .$, Buddha's avatars, 193, $195-6,228$ f.n.

Kamimura, Japanese admiral, crushes Vladivostok squadron, 717

Kamitsuke (now Kōtsuke), early dukedom, 82
Kamo Chōmei, author of Hōjōki, 367

- Mabuchi (1697-1769), restores Japanese ethics, 645 (ill.); quoted, 646-7

Kana, syllabary, 250

Kana-ga-saki (Kanasaki), in Echizen, taken by Ashikaga, 399

Kanamura, $\bar{o}$-muraji, advises cession (512 A.D.) of part of Mimana to Kudara, 122; helps Kudara to get Imun (513 A.D.), 123; puts down revolt of Heguri Matori, 129

Kanaoka see Koze Kanaoka

Kanazawa, fortress, in Three Years' War, 267

Kanazawa, Prof. S., on Korean and Japanese languages, 57

- Akitoki, son of Hōjō Sanetoki, 449

- bunkō, school : founded about 1270 by Hōjō Sanetoki, 449

- Sadaaki, son of Akitoki, scholar, 449

Kane see Nakatomi Kane

Kaneakira, Prince (914-87), son of Daigo, poet, 261

Kanenaga, Prince (1326-83), Mongol fugitives, 443

Kanenari, life-name of $\mathrm{Em}$ peror Chūkyō, 344 f.n.

Kanin, princely house, 621; Kōkaku chosen from, 622

Kankō-Maru, steamship presented by Dutch government, 669

Kannabi, Mt., sacred rock, 65

Kanō school of painting, 450 , 452; patronized by Tokugawa, 600

- Masanobu see Masanobu

- Motonobu see Motonobu

Kanshin (687-763), Chinese Buddhist missionary, builds Shōdai-ji temple, 191

Kanzaki, port in Heian epoch, 281

Kaō, painter of Kamakura school, 365, 450

Kara, Princess, wife of Yürya$\mathrm{ku}, 117$

Kara, Korea, 80; war with Shiragi, 81

Karako, Japanese general, killed in Korea by Oiwa, 122

Karano, 100-ft . ship (274 A.D.), 72,$126 ; 99-100$

Karu, Prince, son of Inkyo, suicide, 73,111

- Prince, brother of Empress

Kōgyoku, in Kamatari's plot, 148-9; see Kōtoku.

- son of Kusakabe, succeeds to throne, 175 ; see Mommu

Kasagi, refuge of Go-Daigo, 380
Kasanui, Shrine of, 79

Kashiwa-bara, palace at, 76

Kasuga, cruiser, sinks Yoshino, 717

- shrine at Nara (767-69) in honour of Fujiwara Kamatari, 198 (ill.), 209, 280; school of painting, 365

- Tsubone, mistress of Ashikaga Yoshimasa, 422

Katagiri Katsumoto, bugyō of Toyotomi, 564; bronze. Buddha, 565-6; bell-inscription, 566-7

Katakana, fragments of characters, syllabary, 190 f.n., 250

Katana, general, suppresses Yemishi revolt, 38

Katari-be, raconteurs, 1, 71

Katō Kiyomasa (1562-1611), commands second corps in invasion of Korea, 513, 514, 517 ; sides with Yae at court, 522,557 ; in plot against Ishida, 558, 559; studies Chinese classics, 578

- Shirōzaemon Kagemasa, potter, 374,452

- Tadahiro, son of Kiyomasa, banished, 594, 595

- Yoshiaki (1563-1631), plots against Ishida, 558

Katsu, Count (Rintarō), minister of Marine, 668-9

Katsuiye see Shibata Katsuiye Katsumi, 148; see Nakatomi Katsumi

Katsumoto see Hosokawa Katsumoto and Katagiri Katsumoto

Katsura, princely house, 621

- Tarō, Prince (1849-1913),

prime minister (1908-11),

693

Katsurabara, Prince (786853), ancestor of Taira, 205

Katsuragi, beginning of power of, 105, 107; descended from Takenouchi, 106; Kara, 117

Katsuragi Mount, 196

Kawabe Nie; in Korea, 150

Kawagoe, in Musashi, fortifications, 426

Kawajiri Shigeyoshi, appointed to Hizen, 492

Kawakatsu kills preacher of caterpillar worship, 158

Kawamura at Mukden, 722-3 Kawanaka-jima, battlefield, $467 ; 468$

Kaya, moor of, Oshiwa murdered on, 118; port, 281

Kaya-no-in, consort of Toba, 273,289

Kazuhito, Prince, son of GoFushimi, 379; nominally Emperor (Kōgon, 1332-35); 380,384

Kazuko, daughter of Hidetada, first Tokugawa consort, 580 
Kazumasu see Takigawa Kazumasu

Kazusa, revolt of Yemishi in, 38; Yoritomo enters, 305

Kebiishi, executive police (810-29), 179, 232, 246-7

Kegon, sect of Buddhists (736 A.D.), 367

Kehi-no-ura see Tsuruga

Keichō, year-period, 1596 1614, coinage of, 604, 610, 615,639

Keichū Ajari (1640-1701), scholar, 600

Keiki see Tokugawa Yoshinobu

Keiko, 12th Emperor (71130), 85-7; expeditions against Yemishi, 36, against Kumaso, 40, and Tsuchi-gumo in Bungo, 42; tree-worship, 65

Keitai, Emperor (507-31), 120, 129 ; serpent worship, 65 ; one province added, 87 ; nashiro, 125

Keiun, poet, 367

Kemmu era (1334-6), restoration of, 386 ; crushes military houses and puts court nobles in power, 388; name applied by Northern court to years 1336-8, 398

- Shikimoku, code of 1337, 403

Kenchō-ji, Zen temple in Kamakura, 365

Kenju, or Rennyo Shōnin, (1415-99), Shin priest; 454, 463

Kenko, daughter of Fujiwara Yorimichi, consort of Shirakawa, mother of Horikawa, 271-2, 273

Kenkō see Yoshida Kenkō

Kennin-ji, temple in Kyōto, Kaō's studio in, 450; one of the "Five," 455; priests alone could wear purple, 58990

Kennyo (1543-92), priest, intervenes for Sakai, 482-3; guides Hideyoshi in Kyūshū, 502; helps turn Hideyoshi against Christians, 540

Keno no Omi, in Korea, 123

Kenrei-mon-in, Takakura's consort, daughter of Taira Kiyomori, 295; drowned at Dan-no-ura, 319

Kenshin see Uesugi Kenshin'

Kensō, 23rd Emperor (485-7), originally called Ōke, 118; Yemishi do homage to, 38

Kesa, mistress of Endō Moritō (Mongaku), 304

Keumsÿong, capital of Sinra, Korea, 89

Khilkoff, Prince, Russian minister, 721-2

Khitan Tatars, in China, 358

$K i$, family founded by Ki no Kinoshita Junan
Tsunu, descendant of Take nouchi, 106-7; eligible to high office, 295

- Haseo (845-912), famous scholar, 240; plot to send him with Michizane to China, 241 ; prose, 249

- Hirozumi, leader against Yemishi, killed by them (780), 220

- Kosami (733-97), general against Yemishi (789), is defeated and degraded, 221; report of the campaign, 222

- Omaro, Japanese general in Korea, 6th century, 150

- Tsurayuki (883-946), prose preface to Kokin-shü, 251; Tosa Nikki, 251

Kibi, old name for Bingo, Bitchū and Bizen provinces, 29 ; Jimmu's stay in, 76

- no Mabi or Makibi (693775), Japanese student in China, minister of the Right, inventor of syllabary, 190,250 ; opposition to Fujiwara, 191; minister of the Right under Kōken, 199-200; opposes succession of Shirakabe (Kōnin), 204; as littérateur, 249

Kibumi, school of painters (604 A.D.), 155

Kidōmaru, famous bandit, 262

Kido Takamasa or Kooin (1834-77), in alliance of Chōshū and Satsuma, 677, 683 (ill.)

Kii, mythical land of trees, 14 ; in Yamato expedition, 23; promontory, 28; armed monks in Komaki war, 497; punished by Hideyoshi, 499500 ; orange growing; 617; Tokugawa of, 624

Kijima-yama, in Hizen, place for uta-gaki, 127

Kikaku, verse-writer, 601

Kikkawa in battle of Sekigahara, 561

- Motoharu (1530-86), son of Mōri Motonari, 469; adviser of Mori Terumoto, 491; general 500,502

Kikuchi, adherents of Southern Court, in Saikai-dō, 400 ; make trouble in Kyūshū, 421; defeated by Ötomo, 470, 471

Kimbusen, temple, 274

Kimiko Hidetake in Three Years' War, 267

Kimmei, 29th Emperor (54071), 131-4; Yemishi do homage to, 38; intercourse with China, 144

Kinai, five home provinces, 132 ; rice grants, 588

Kinchou, 2d Army wins battle of (1904);715-16

Kinoshita Junan (1621-98),
Confucianist, father of Torasuke, 613,626

- Torasuke, scholár, at Yedo, 613

- Yaemon, father of Hideyoshi, 475

Kinshüdan, "Embroidered

Brocade Discourse," 448

Kira family, masters of ceremonies, 635

- Yoshihide killed by "47

Rōnins" (1703), 607 .

- Yoshinaka, son of Yoshi-

hide, 607

Kiso river, boundary of Mino, crossed by Nobunaga (1561 and 1564), 480

Kiso Yoshinaka see Minamoto Yoshinaka

Kitabatake, adherents of Southern Court in Mutsu and Ise, 400; put down by Yoshinori, 420 ; rule in Ise, 468

- Akiiye (1317-38), 388; raisés siege of Kyōto, 393; killed in battle, 399

- Akinobu, 399

- Chikafusa (1293-1354), historian and statesman, as sistant governor of $\overline{\mathrm{O}}-\mathrm{U}, 388$; faithful to Go-Daigo, 397; Main leader of Southern army, 401-2; author of Jinnó Shōtoki, 403-4; attempts to unite courts, 407 ; death, 408; combines Shintō, Buddhism and Confucianism, 452; Shintō revival, $649-50$

- Mitsumase, revolts of, 412

- Morokiyo, piracy, 445

Kitamura Kigin (1618-1705) author, 600

- Sessan, calligraphist, 601

- Shunchō, son of Kigin, 600

Kitano, Shintō officials of, 439 ; tea fête, 507

Kitashirakawa, Prince, abbot of Kwanei-ji, 582

Kita-yama, Ashika Yoshimitsu's palace at, 417 ; given to Buddhist priests, 418

Kite, Golden, 24

Kiuliencheng, on Yalu, centre of Kuroki's line, 713-14

Kiyo, Princess, daughter of Saga, 236

Kiyomaro see Wake Kiyomaro Kiyomizu, temple, 297. (ill.), 578

Kiyomori see Taira Kiyomori Kiyosu, castle in Owari, eonference of Nobunaga's vassals, 493-4

- Naritada, scholar, 447

- Takenori, leader in Nine Years' Commotion, helps crush Abe Sadatō (1062), 266 ; family quarrel cause of Three Years' War, 267

Kiyowara, family eligible to high office, 295 
Ko An-mu, Chinese scholar in Japan (516 A.D.), 153

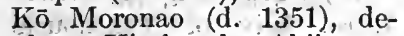
feats Kitabatake Akiiye at Ishizu, 399; defeats Masatsura, 402 ; shitsuji in Muromachi, 403, 436 ; plot against, $404-5$; killed by Uesugi, 406

- Moroyasu (d. 1351), 402; plot against, 404-5; death, 406 Koban, coin, 527, 528:

Kōbe, formerly Fukuhara, made capital by Kiyomori (1180), 300; Hyōgo, in Ashikaga revolt, 394

Kōben see Myōe

Kōbō Daishi, posthumous name of Kūkai (q.v.)

Kōbun;, 39th Emperor (672),

Prince Ōtomo (q.v.) succeeds

Tenchi, 169-170; included in

Dai Nihon-shi, 645

Koeckebacker, Nicholas,

Dutch factor, helps conquer castle of Hara, 554-5

Koetomi, merchant, envoy to China, 443

Kōuku-ji, Nara temple of Hossó sect, 191, 192, 193 f.n., 367 ; armed men of the monastery, 273; their quarrels and their treatment by Taira, 274 ; burnt by Taira (1180), 301 ; revenue of temple, 439

Koga, in Shimosa, seat of Ashikaga after Kamakura, 414; Shigeuji's castle, 425-6

Kōgen, 8th Emperor (214-158 B.C.); 77

Kōgon, Northern Emperor (1332-5), Prince Kazuhito (q.v.), gives commission (1336) to the Ashikaga, 394, and expects restoration to throne, 396; becomes Zen priest, 407

Kogo-shüi, ancient record quoted, $63,67,69,103$

Kōgyoku, (35th) Empress (642-5); 146-9; abdicates, becomes Empress Dowager, 160; again Empress - see Saimei-166, 460; Asuka palace, 154; worship of silkworm, 65

Kohayakawa Hideaki (15771602), nominally against Ieyasu, 559, but goes over in battle of Sekigahara, 561

- Takakage (1532-96), 469; adviser of Móri Terumoto, 491 ; eneral of Hideyoshi, 500 , 502 ; in Korean invasion, 517 ; signs Hideyoshi's laws of 1595,526

Koide Hidemasa (1539-1604), guardian of Hideyori, 564

Ko-jiki, Records of Ancient Things, 2 ; to 628 A.D., 3 ; on Chūai, 88; contains the Kuji-

hongi, 143; preface, 214
Kojima, adherents of Southern Court, 400

- Takanori, defender of GoDaigo, 381

Kokaku, 119th Emperor $(1780-1816), 622,629$; his rank and his father's, $630-1$

Kōken, (46th) Empress (74958), daughter of Shōmu, known in life as Abe, 197; abdicates but dethrones her successor, 198-9, 460; see Shōtoku

\section{-, son of Kenju, 461}

$\dot{K}^{\prime} \bar{k} i$, Record of the Country, 2

Kokin-shī, 10th century anthology, 237, 249, 250; Ki Tsurayuki's prose preface to, 251; comments by Keichü, 600

Kōkō, 58th Emperor (885-7), Prince Tokiyasu, 239; couplet tournaments, 277

Koku, coin, 438-9; unit of measure, 527

Kokubun-ji, official provincial temples, 194-5; affiliated with Tōdai-ji, 453; heavy expense of, 245

Kokuli, Korea, 81

Kokushi, provincial governor, 106; appointed by Throne, first mentioned in 374 . A.D., 129; after Daika (645), 161; over kuni, 180; Buddhist hierarchs, 194-5

Kōkyō, Ôsaka abbot, leads great revolt (1529), 464

Koma, Korea, now Pyongyang, $80-1$; increase of power, 114 , 121, 122; attacked by IJudara and Japan, 150; families in Japanese nobility, 153; falls, 167 ; migration, 168; ruler of Pohai recognized as successor of dynasty of, 223; envoys, 263 ; Mongol invasion, 358, 359

Koma, suzerain of Aya-uji, assassinates Sashun, 138-9

Koma-gōri, in Musashi, settlement in Japan from Koma, 168 Komaki war (1583), named from Komaki-yama, 497-8

Kömei, 121st Emperor (184667), 664

Kōmon Mitsukuni, 603

Komura Jutarō, Marquis (1853-1911), minister of foreign affairs, peace commissioner at Portsmouth, 725

Kōmyō, Imperiàl name of Asuka, wife of Shōmu and mother of Kōken, 190; story of miraculous conception, 192

Kōmyō, Emperor (1336-48)

of Northern dynasty, brother of Kogon, 396, 397, 406; abdicates and becomes : Zen priest, 407 .
Kondō, branch of Fujiwara in Kwantō, 266

Kongōbō-ji, Shingon temple on Koya-san, 367

Könin, 49th Emperor (77081 ), formerly Prince Shirakabe, 204; reforms local administration, 217; festival of his birthday, Tenchōsetsu, 218 Kōnin, year-period, 810-24, and revision of Rules and Regulations, 177

Konishi Yukinaga (d. 1600), commands first division in Korean invasion (1592), 513, 514 , 516; entrapped by Chinese diplomacy, 517; with last troops.. in Korea, 518; opposes Katō, 557; against Ieyasu, 559, 560; death, 561

Konnō, swordsman, 293

Kōno family in Iyo, 470

Konoe, 76th Emperor (114255), 273, 289

Konoe, Imperial guards, 232; origin, 284; name given to Fujiwara Motomichi's descendants, kwampaku alternately with Kujo, 330,357 ; one of "Five Regent

Houses," 358, 581

- Prince, leader of moderate party, 673

- Nobuhiro (1593-1643), minister of Right, 580

- Sakihisa (1536-1612), envoy to Shin monks, 486

Kōrai, or Koma, Korea, 80

Korea, alphabet, 104; architecture, 126; artisans, 113, 119 , 520; Buddhism, 131, 367-8; China, relations with, $83,84,144$; chronology, 6,7 , $77,81,89,90,99,114$; language, 56 ; music, 156 ; myth, $14,31,32,60$; pottery, sepulchral, 54; scholars, 153; treasury, Japanese, 110; early intercourse with Japan, 60, 80-1; Jingo's conquest, 88-9; granary, 124; Japanese relations in $540-645,149-52$; families in Japanese nobility, 153; war between Japan and China for, 167; precious metals, 186; 8th century relations, 223; Mongol invasion, 358; Japanese piracy, 442-3; Hideyoshi's invasion, 509-20; Arai Hakusekai's policy toward envoys, 608; break with, (1873), 683-4; treaty (1875), 685, 699; Chinese activity in, 699-700; independence recognized by 1895 treaty, 702; Russian aggression, 704-5; Japan's interests in, recognized by Treaty of Portsmouth, 725; Japanese occupation and annexation, 728-30 
Korehito, Prince, Emperor Seiwa, 236

Kiōrei, 7th Emperor (290-215 B.c.), 78

Korelimi see Fujiwara Korekimi

Koretaka, Prince (844-97),

Buddhist monk and poet, 236

Koreyasu, Prince, shōgun, $(1266-89), 354^{\circ}$

Korietz, Russian gunboat at Chemulpo, 712

Kōriyama, in Yamato, castle commanding Izumi and Kii, 505

Koromo, tunic, 68, and name of a fort, $266 \mathrm{f} . \mathrm{n}$.

Koromo-gawa; campaign on, against Yemishi, 222

Kōsa, abbot of Ishi-yama monastery, 486

Koshi, Yemishi in, 37, 38

Kotesashi moor, Takauji defeated at, 407

Koto, lute, 75, 100, 365 (ill.)

Kōtoku, 36th Emperor (64554), 159-166; Yemishi do homage to (646), 38

Kōtsuke, early Kamitsuke, a dukedom, 82; revolt of Yoshinaka in, (1180) 307-8; won by Kenshin, 468; silk growing in, 617

Koya, reptile Kami of, 128; snow festival of, 277

Koyama, branch of Fujiwara in Kwanto, 266; one of " 8 Generals" of IKwantö, 425

Koyane (Ame-no-Koyane) ancestor of Nakatomi, 33, 61 Köya-san, mountain in Kii, temple of Kongōbō-ji, 367; threatened after Komaki war, 500 ; shrine, 521 ; nobles enter, 561

Koyomaro, warden of Mutsu, killed by Yemisi (724), 219

Koze (Kose), family descended from Takenouchi, 106-7

Koze Fumio, scholar 240; Chinese prose, 249

- Kanaoka (850-90), painter and landscape artist of Kyōto, 241, 251, 279; school, 365

Kublai Khan and the Mongol invasion, 358-64

$K u b \overline{0}$, governor general of 4 provinces, 414, 436

Kuchiki Mototsuna (15491632) at battle of Sekigahara, 561

Kuchinotsu, port; Jesuits invited to, 536

Kudara, Korea, now Seoul, 80; Japanese alliance, 90; 120; weaver from, 102 ; scribe, 103 ; relations with Yüryaku, 114; story of Multa, 120; invaded by Koma, 122; secures Imun, 123; gains through friendship of Japan, 124; Buddhism, / Kuriyama Gen, contributor 132, 134, 138; wars with to Dai Nihon-shi, 645

Shiragi and Koma, 149; Kuro, lady of Takenouchi crushed by Shiragi and China, family, 109

167; migration from, 153, 168 Kuroda . Nagamasa "(1568Kudara Kawanari, painter, 1623) soldier of Hideyoshi, 251

Kudō Suketsune, killed in vendetta (1193), 332-3

Kuga family, eligible for office of highest rank, 295

¿- Nagamichi, minister under Go-Daigo, 388

Kugeshu-hatto, Ieyasu's law for Court nobles, 573, 576-7

Kugyö (1201-19), son of Yoriiye, assassinates Sanetomo, $339-40$

Kuhi : brings scales and weights from China, 155

Kujinongi, history, 143

Kujō, descendants of Fujiwara Kanezane, chosen Kwampaitu alternately with Konoc, 330, 357; one of "Five Regent Houses," 358

Kükai (posthumously, Kōbō Daishi), 774-835, Buddhist priest, called by some inventor of mixed Shintō, 196, 644; founder (809) of Shingon (True Word) system, 367, 369 , calligrapher, 234,365 , and inventor of hira-gana syllabary, $229,250,251$; portrait, 228 ; shrine (ill.), 229 IKuma, Southern tribe, 39,41

Kumagaye Naozane (d. 1208), kills 'Taira A tsumori, 315

Kumaso, early inhabitants of Kyũshū, 28, 34, 39-41; possibly of Korean origin, 41; may be identical with Hayato, 41 ; called Wado by Chinese, 77; Keikō's expedition against, 40, 85; Chūai's expedition, 88

Kume, Dr.; on Yamato-dake's route of 'march, $86 ;$ " on Takénouchi-no-Sukune, 106 .

- Prince, dies on expedition

to Shiragi, 151

- Kani, 33, 62

Kumebe, palace guards, 33 , $62,67,130$

Kunajiri, Russians seized at (1814), 659

Kunō, castle of, in Tōtōmi, 476

Kurama, temple of, Yoshitsune escapes from, $306-7$ Kurando or Kurōdo, Imperial estates bureau, office' established, 231; K.-dokoro precursor of kwampaku, 232 ; held by Minamoto Yorimasa, 299 Kurayamada, conspirator against Soga, 148; suicide $159-60$

Kuriles, Russians in, 658; Japanese title recognized, 693
498, 500; against Ishida, 558 ;

favours Ieyasu, ' 559 ; istudies Chinese classics, 578

Kurōdo see Kurando

Kuroki, Ibei; Count (b.1844), commands on Yalu, 713;'defeats Russians, 714 ; head of Ist' Army, 717, 7.18; attempts to turn Russian flank 719; at Mukden, 722 :

Kuromaro see Takamuku Kuromaro

Kuropatkin, Alexei Nikolaievitch (b.1848), Russian commander-in-chief in Manchuria, 713 ; plans before and after Liaoyang, 719-20; succeeded 'by' Linievitch, 723 Kusaka, defeat of Jimmu at, 23

Kusakabe, Prince, (d. 690)

son of Temmu and Jito, 172

Kusano support Southern Court, 400

Kusu (Kusuriko), daughter of Fujiwara Tanetsugu, consort of Heijo, 230, 231

Kusu, wife of Oto, kills him, 114

Kusunoki, adherents of Southern Court, 400

- Jirō, in attack on palace (1443), 412

- Masanori (d.1390),-minister, 407 ; jöins Northern pärty, 410 , returns to Southern, 411 - Masashige (1294-1336), called Nankō, defender of GoDaigo, 380-2, 386; provinicial governor, 388; ' against"-Ashikaga, 392 ; death, (ill) 3945 -Masatoki, death, 402 go 1 - Masatomo defeats $\mathrm{No}$ bunaga in Ise, 480 no - Masatsura (1326-48), son of Masashige, 395; receives Go-Daigo in Yoshimo, 397 ; campaign in Settsu, 402

Kuwana, castle of Takigawa Kazumas': in Ise, 495

Kuzuno, Prince, son of Kōbun, sacrifices his claim to throne (696), 174-5

Kuzuo, in Shinano, castle, 467 Kiwaifū-sō, anthology of poems (751), 214-15

Kwaikei, sculptor, 280

Kwammu, 50th Emperor (782-805), formerly Yamabe, $201-5,224$ (ill.)-30; changes capital to Kyōtō (792), 225 ; posthumous names first used, 21 ; sends Saichō to "study Chinese Buddhism, 368
- Masahide rebels in 1428,412 
Kwampáku, regent for grown Kyōgen, comic play, 459

Emperor, mayor of palace, Kyógoku, one of four princely office established (882), 239 ; hoüses, 621

decline of power under GoSanjō, 271 ; foreshadowed by Kurando-dokoro; 232; chosen alternately from Kujō, ánd Konoe, $330,357-8$; office abolished after Kemmu restoration, 387 ; unimportant after Tokugawa period, 588

Kwampeiera; 889-97, Counsels of, Uda's letter to Daigo, 242 Kwanei, year period, $1621-43$; Kwanei Shoke Keizu-den, genealogical record, 579 ;

Kwanei-ji, temple, 583

Kwangaku-in; uji academy, founded ( 821 ), 206, 233

Kwarigturig peninsula; in battle of Kinchou, 715

Kwang-wu, Chinese emperor, Japanese envoy to, 84

Kwanji, period, $1087-94,267$. Kwanki, period, 1229-32, erop failure and famine, 348

Kwankō see Sugawara Michizane

Kwanno Chokuyō establishes -school in Yedo, 614

Kwañnon, Mercy, Buddhist goddess; 192; Shirakawa's temple, 272; temple at Kamakura, 326

Kwanry $\vec{o}$; governor general, 387, list of Kamakura $k$., 413 ; title passes from :Ashikaga to Uesugi family, 414; also given (1367) to shitsuji in shögun's court, land held by Shiba; Hosokawa and Hatakeyama fanilies, $1414, \cdot 436$; compared with shikken and betto $;: 436$

Kwansei, year-period, 1789 1800, vagabonds in Yedo during, 626.

Kwanto, or Bando, many shell-heaps ; in, 46; army raised in, against Yemishi, 223; Taira and Minámóto fight in, 263; Minamoto supreme in, 264; Ashikaya supreme, 416; Eight Generals of, combine against Uesugi, -425; battle-ground, TC 425-6; war between branches of - Uésugi and Hōjō and Satomí, 431; in Battle Period, 464-8 Kwazan, 65th Imperor (9856), 259-60

Kwōbetsu, families of chieftains of the conquest; Imperial class, 77, 92; prehistoric administration, 98; classification in Seishi-roku, 233; revolt; 128-9; rank of Empress, 189

-Kyaku, "official rules," supplementing ' $Y \bar{o} \bar{o}$ 'laws,' 177; revised, 177; (819); 232 .
- Takatsugu

568

(1560-1609),

$K y \bar{o} h \bar{o}$, year-period, $1716-35$; $K .-k i n$, coins then minted, 615

Kyong-sang, Korea, 514

Kyorikü, verse-writer, 601

Kyöroku, year-period, $1528-31$, 462

Kyōto, oapital 7a4 A.D., 224 6(ill.), $275 ;$ two "cities and two markets, 281; capital momentarily moved to Fukuhara (1180);300; evacuated by'Taira (1183), 310 ; school of art 365 ; culture, 366 ; Go-Daigo's conspiracy, 379 in war of dynasties, 398; Takauji removes to, 402 ; ravaged, 462; 'Nobunaga' restores order, $479-80 ;$ under Hideyoshi, 481 ; Portuguese, 530; Xavier, 531-2; Jesuits, 537; Vilela, 538; Franciscan church, 542 ; patent to missioñaries, 546 ; shogun's deputy in, 561; Teyasu, 562; 'Iemitsu's' demonstration against, 581-2; Court excluded from power, 588 ; vendetta illegal in, 607 ; great fire $(1788)$; 624 ; rebuilding, 629-30; government, 632; 636 -7 ; loyalist intrigues in, $669-$ 70: extremists driven from, 675 ; foreign ministers invited to, 678

Kyūka, priest, 449

Kyūshü, early myth, 18-19; expedition against Yamato, 21,87 ; situation, 28; Kingdom called Wo by Chinese, 60 ; governmênt station, 83 ; Keikō's expedition against Kumaso, 85 ; granary, 121 , 124; trade, 281 ; Mongol invasion, $359-60$; revolt of 1349,405 ; taken from Ashikaga, 411; disorder, 414, 4212 , \{430; pirácy, 443; great families, 470 ; Hideyoshi's invasion, 500-2; early European intercourse, 530 ; Christians; 537, 539, 541

Lacquer, trees; planting of, required for - tenure of uplands; $182 ;$ development of art in Nara epoch, $208-9$; in -Heian, 279; ware exported, 445 ; manufacture in time of Yoshimasa, 451; (ill.), 184, 643 Ladies-in-waiting, uneme, at early court, 73 ; dancers, 115 ; Yoshimune's reforms, 611-12 Land and land holding, prehistoric, 95-6; royal fees, 120; taxation, 124 Daika reform; 162; all land Crown property,
164 ; 6-year lease, 165 ; sustenance grants lead to feudal'ism, 172; Daino laws, 178, 182-4; reclaimed uplands, 201 ; centralized holdings', 8 th century, 202; grants for reclamation, 207; maximum holdings, 207-8; , abuses in system, 246; large estates, 251-2; Go-Sanjo's reforms, 270 ; territorial name, 287; constables and stewards, 328; Shōky ū tumult, 341 ; new distribution, 346 ; Joe laws, $350 ;$; Go-Daigo's grants, 387; estates under Ashikaga, $409, \quad 426, \quad 435$; military holdings, 437 ; tax, 438; Crown lands pass to military houses, 461; Hideyoshi's laws, 526-7; taxes, 638,639

Landscape-gardening, in the Heian epoch, 278; in Kamakura period, 365; patronized by Yoshimasa, 424 , in $\mathrm{Mu}-$ romachi epoch, 456-7; at Momoyama; 521

Land 'steward, jitō, and chief steward, sō-jito, in Yorikomo's reform of land, 328 ; shimpo-jito, land holders and stewards after the Sho $\bar{o} y y \bar{u}$ war, 346

Language, $56-7$; in Heian epoch, 249; difficulties for preaching, 532-3

Lanterns; 8 (ill.), 679 (ill.)

La Pérouse, Strait of, claimed as Russian boundary, 697

Law, in time of Ojin, 1001 ; criminal, protohistoric period, 125; of Daiho, 176-84, 232 ; code of 1232 , A.D., 34950 ; Kemmu code, 403; Hideyoshi's legislation, $525-7$; Laws of Military Houses, 574-6, 584;' Laws for Court Nobles, 573, 576-7; of Temitsu and Ietsuna, 581-5; real code, $613 ; 641$; in Tokugawa period, $639-41$; codified after Restoration, 691; Department, in Meiji administration, 681

Leech, first offspring of $I z a-$ nági and Izanami, 9, 26

Left 'Minister of, Sa-daijin, office created by Daika, 160 Legs, length, as racial mark, 58-9

Lềse Majesté under Daihō code, 178

Liao River, Russians forced into valley of; 718

Liaotung peninsula, Chinese forces in, (1592), defeated by Japanese, 516-17; fighting in 1894 in, 701; Russian lease of, 705

Liaoyang, battle of, 719 
Liberal party, Jiyū-tō, organized (1878) by Itagaki, 690; unites with Progressists and forms Constitutionist party, 693

Library of Kanazawa-bunko, 449; of Shōhei-kō, 578; of Momijiyamia Bunko, 579; and Shintō, 644-5

Liefde, Dutch ship, 545, 652

Li Hung-chang (1823-1901), Chinese plenipotentiary 'for peace of 1895,702

Li Lungmin, artist, 450

Linievitch, Nikolai Petrovitch" (b.1834), Russian general, suceeeds IKuropatkin in command, defeated at Mukden, 723

Literature, in Nara epoch, 214 ; in Heian epoch, 248251; in Tenryaku era, 261; in Kamakura epoch, 366-7; in Muromachi period, 447-9; under Hideyoshi, 528; place of, in Military Houses' Laws, 574; in Court Laws, 577; Ieyasu's attitude, 578; Tsunayoshi encourages Japanese and Chinese, 600; favoured by Yoshimune, 613-14; Japenese, restoration of, 645; foreign, 659; Chinese, 104, $214,234,578-9,645-6$

Liu-Jen-kuei, Chinese general, defeats Japanese in Korca (662 A.D.), 167

Lloyd, Rev. A., on Buddhism, -Tendai, 228, - Hossō, 368; and Shintō, 368:f.n.

Longevity, herb of, 196

Longford's Korea cited, 39

Loochoo see Ryūkyū Islands

Lotteries, 277

Lotus festival, 214

Loyalty, in early times, 100 1, 109, 112; in Heian epoeh, 285; in Tokugawa period, 642-3

Lute, of Susanoo, 14; the koto, 75, made from the ship Karano, 100; biwa, 4-stringed Chinese lute, 458

Mabuchi see Kamo Mabuchi

Maeao, trade with, 529; Jesuits there, 530; annual vessel from, 536,546; embassy of 1640 from, 656

Machado; João Baptista de (1581-1617), Jesuit, executed, 551

Machi-ya, shop, 281

Madre de Dios, Pessoa's ship, 653

Maeda Gen-i or Munehisa (1539-1602), guardian of $\mathrm{Oda}$ Nobutada's son Sambōshi, 491; in charge of Kyōto Buddha, 506

- Toshiiye (1538-99), fails to help Shibata Katsuiye,
495-6; commands armies in / Mannen tsühö, coin, 201

Komaki war, 497, and against Hōjō, 503; one of 5 senior ministers, 523 (ill.), 526; attempt to make break; between Ieyasu and, 557 ; death, 558

- Toshinaga

(1562-1614), son of Toshiye, favours. Ieyasu, 559 , „560; simulates madness, 595

Magie and incantations, of Buddhist abbot ; Raigō, 274; general belief in, 282

Máhayana, Great: Vehicle, esoteric Buddhism, 132, 369 Mahitotsu, metal worker, 79 Makaroff,' Stephan Osipovitch (1848-1904), Russian admiral drowned with Petropavlovsk, 714

Maketsu, Chinese or Korean spinning woman, immigrant to Japan, 102

Maki, wife of Hōjō Tokimasa, favours her son-in-law, Minamoto.'Tomomasa, $337^{\prime}$

Makibi see Kibi no-Mabi

Makura Sōshi, book by Sei Shōnagon, 249

Mallets and "mallet-headed" swords, 42,51

Mamiya, Rinzō (1781-1845) discovers (1826) that Saghalien is not part of continent, 697

Mamta, Prince, in charge of Record of Uji, 233

Manabe Norifusa, minister under Ienobu, 608, and Ietsugu, 610; removed from Treasury by Yoshimune, 611 Manchu-Korean subdivision of Asiatic yellow race, 58

Mancharia, in colonization from northern. China, 60; part ceded to Japan, by treaty of 1895 , -but not occupied after Russian, German and French note, 702 ; Russian designs upon, 704.6; Russia's failure to evacuate, and negotaitions over "open door," 707; Russo-Japanese war, 710-24; evacuation of, provided for by treaty of Portsmouth, 725-6; Japanese position in, 727-8

Man-dokoro, administration bureau, one of three sections of Bakufu, formerly called kumon-jo, 327; in administration of Kyōto after Shōk$y \bar{u}$ war, 345 ; in Muromachi administration, 436

Mancko, atae of Iki, suicide, 101

Man-en,.: year-period, 1860 , coinage of, 639

Manhatlan,... American ship, enters Uraga, 665
Manners and customs, remote, 61-75; in time of Yuryaku, 115; in Muromachi period, 455 rol lis minte

Manors, large estates, shöen, $201-2,251-2 ;$ attempts to regulate, 270; kôden, tax free, granted ito Taira after Heiji tumult, 296; Yoritomo's memorial on, 326 ; abuses of, remedied by appointment of constables and land'stewards, 329 ; distribution after restoration of Kemmu, 389; gifts of Takauji, 426

Manumission of slaves, 174

Manyō-sh $\overline{\text {, }}$ "Myriad'Leaves,"

first . Japanese anthology, 214; compared with Kokinshü, 249; on character of soldier, 285; comments on', by Keichū, 600 s.s. Map, official, begun under

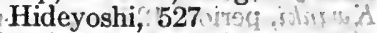

Market Commisisoners, after Daika, 164 Markets, ichi, in early Japan, 71; in Nara epoch, 209 Marquis, ásomi, title established by Temmu, 171 . T Marriage in early Japan; 7273 ; and the festival of utakai, 127; none recognized among slaves by Daika, 161; in Nara and earlier epochs, 212; in laws : of Military Houses, 575, 584; between military and court families, 620; child marriage, 564

Marubashi Chūya, leader in revolt of 1651,584

Masa, daughter of Hōjō Tokimasa, mistress of Minamoto Yoritomo, 303, 323; mother of Yoriiye and the power, with Tokimasa, in his administration, $335-6$; saves Sanetomo, 338; plea to generals of Bakufu, 343 ; death (1225); 346

Masakado see Taira Masakado

Masanobu (1453-90), painter, 450

Masanori see Kusunoki Masanori.

Masashige see Kusunoki Masashige

Masatomo see Ashikaga Masa: torno

Masatoshi sce. Hotta Masatoshi

Masayasu sce Inába Masayasu

Masks for dances, sculptured, 280; $n \bar{o}$ masks, 28, 56 (ill.)

Masses, Buddhist, 282

Masuda Nagamori (15451615), one of 5 administrators, plots with Ishida against 
irIeyasu, 557; enters monastery after Sekigahara, 561 Masukagami, history of 1184 1333, on literature, 366

Mats, tatami, floor-coverings, 279,373 ; tatsu-gomo, 126

Matsubara, Pine Plain, 507

Matsudaira, origin of family, 556; of Aizu, etc., 636

Hideyasu (1574-1607), son of Ieyasu, 557, 560

- Masatsuna (1567-1648), Tokugawa agent in Kyōto, 580

Mitsunaga (1615-1717), punished by: shōgun, 597 .

- Motoyasu see Tokugawa Ieyasu, 478

- Nobutsuna

minister of Iemitsu, 581, 594; and of Ietsuna, 584

- Norimura; minister of

Yoshimune, drafts code (1742) 613,641 ; succession to Yoshimune, 618

- Sadanobu (1758-1829), revises code, 613; minister under Ienari, 624; sumptuary laws, 624-6; educational reforms, 627 ; retires, $628-9$; matter of rebuilding palace, 629-30; rank of Tsunehito and Hitotsubashi Harunari; $630-1 ;$ revises rules of procedure, 641 (ill.)

- Tadanao, punished by Tokugawa in $1623,593+4$

- Tadateru (1593-1683), daïmyō of Echigu, 557; 591; removed, 593 .

-Y Yoshinaga, baron of Echizen, advocates foreign trade, 667; importance : in new Japan, 677

Mátsukura :Shigemasa (15741630), persecutes Christians, urges conquest of Philippines, 553

Matsumae, ruling Northern -islands, clash with Russians, 658,697

Matsunaga Hisahide (151077 ), kills Norinaga and the shōgun Yoshiteru, 434, 435; ally of Shingen, 483

Matsuo Bashō: (1644-94), verse writer, 601

Matsushita Yukitsuna," soldier under whom Hideyoshi served, 476

Matsuura, in Hizen, Toi attack - unsuccessfully; 263; branch of "Minamoto, 265; support Southern 'Court, 400; attitude toward Xavier, 531

Mayor of the palace, kwampaku, 239

Ma Yuan, painter, 365

Mayuwa kills Ankō; 111, 118

Measures, early, 155 ; standard "(senshi-mashu) :" of 1 Go-
Sanjō, 270; in Hideyoshi's laws, $526-7$

Medicinc, 126-7

Medicine-hunting, early court amusement, $156-7$

Meiji, "Enlightened Government, ", year-period 1868$1912,5,678,679-731$; posthumous name of Mutsuhito

Meitoku, year-period, 1390-3, and the rising of 1391, 411

Men, ideographic Japanese used by, 3

Menju Shosuke, impersonates Shibata Katsuiye and saves him, 495

Mercy, goddess, Kwannon, 192

Merit lands, Koden, granted for public services, 183

Mexico, Spanish ships from, 547,550

Michelborne, Sir Edward, on Japanese sailors (1604 or ' 5 ), $657-8$

Mićhi no Omi, ancestor of Ōtomo, 129

Michinaga see Fujiwara Michinaga

Michiyasu, Prince, 235; Emperor Montoku (q.v.)

Michizane see Sugawara Michizane

Mikado, origin of title, 63 ; - name appropriated for residence of Soga Emishi, 147

Mikata-ga-hara; war of, $(1572-3), 487$

Mikawa, province, Oda defeat Imagawa in, 468 ; fighting in Komaki war, 498

Mikena, brother of Jimmu, 60 Military Affairs, in ancient Japán, 66-67; first conscription (689 A.D.), 174; organization under Daihō, 180; during Nara epoch, 218-19; improvement in organization -in 12 th century, 314 ; development of tactics, 488; foreign military science, 668-9; conscription laws and samurai, 682; new army justified by Satsuma rebellion, 686; modern army organization, $695-6$ Military Art of Bushi, 286-7

- class; shi, 232; in Kamákura periöd, 372

code, Gumbō-ryo, of Daihō laws, 178

- dues, Buke-yaku, 426, 438, $-638$

- ethics, and Primer of Yamaga Sokō; 607

Military houses, buke, rise in

8th: century, $223 ;$ 10th, 256 ;

11th, 287; power increased by Högen and Heiji insurrections, 294; Minamoto ideals, 325 ; finances, 376 ; crushed by Kemmu restora- tion, 388; Northern Court follows system of, $398:-$ in Ashikaga times, 405; Onin disorder, 427; Muromachi period, 435; land holdings, 437; power in Tokugawa period;. 573; Laws: of, 574; intermarry with Court nobles, 620 ; weakness, 677

Militia, kondei, in 8th century, 218-19

Milk, 212

Milky Way in myth, 12,25

Millet as: substitute for rice, 207

Mimaki, life-time name of Emperor Sujin, 81

Mimana (Imna), Japanese name for Kara, Korea, 81; Japanese influence there, 83; 90 ; Tasa leads revolt in, 114 ; part eeded to Kudara, 122; Keno in, 123; pretended expedition against, 139; Shiragi overpowers, 149-50; Japan intervenes in war between Shiragi and, 151; Shiragi invades (622), 152; families from, in 9th century nobility, 153

Mimasaka, province, given to Yamana family (1441), 421

Mimashi, Korean teacher of music (612 A.D.), 156

Mime, Dengaku, 377 .

Mimoro, Prince, 37

Mimoro, Mt., in early myth, 15, $37 ;$ Kami of, a serpent. 65,128

Minamoto, princely family, 205; Fujiwara take wives from, 190; generals of Im. perial guards, 206; called Gen and Gen-ji, 206 f.n.; academy, 207, 283; manors and troops, 252 ; win 'Taira estates, 253; quarrel :with Taira, 254; 263; revolt against Fujiwara, 258; literature, $\quad 261 ; "$ military power in provinces, 262, especially - Kwantō; 264 ; "claws" of Fujiwara, 265; provincial branches, 265; war with Taira, 284-335; power taken by Hōjō, 336, 340

- Hikaru (845-913); son of

Nimmyo, accuses Sugawara Michizane, 243; death, 245 - Hiromasa (918-80); nusician; 261

- Ichiman - (1200-3), candidate for shōgun, killed, 337-8 - Kanetsuna, in Yorimasa conspiracy, 300

- Kugyō see Kugyō

- Mitsukune, erects monument to Kusunoki Masashige, 395

- Mitsumasa, founder of

Suruga Genji, 265 
Minamoto Mitsunaka (912$97)$, reveals conspiracy against Fujiwara (967), 258, 262; his influence, 261-5; founder of Shinano Genji, 265, 288; the two swords: 285

- Nakaakira, killed "with Sanetomo by Sugyō, 340

- Narinobu, poet, 261

- Noriyori (1156-93), sent against Yoshinaka, 312,313; at Ichino-tani, 315; commands force $1181-5,316$; blocks Taira from withdrawing into Kyūshū, 318 ; assássinated, 333

- Sanctomo (1192-1219), rival of Ichiman 336 ; block's Hōjō designs, 337 ; attempt to assassinate him, 338; death, $339-40$; patron of Fujiwara Tameiye, 366

- Senju-maru (1201-14), revolt, execution, 338

- Shigenari, pretends to bc Yoshitomo, 293

- Shitagō (911-83), littérateur, 261

- Tadaaki, in capture of Rokuhara, 384

- Tametomo (1139-70), great warrior of Hoggen tumult, 289-90; exiled to Izu, 290 f.n.; advice not followed 292

- Tameyoshi, in Hoggen; 'tumult, 289

- Tomomasa, Maki's candidate for shögun, killed, 337-8

- Tōru (822-95), minister of the Left under Uda, 240

- Toshikata (959-1027), poet, one of Shi-nagon; 261

- Tsuriemoto (894-961)

Prince Rokuson, founder of Seiwa Genji, 206, 287-8; in beginuing of hostilities with Taira', 254 f.n.

- Wataru, husband of Kesa, 304

+Yorichika (d. 1117); ancestor of Suruga Genji, 265

- Yoriiye (1182-1204), succeèds (1199) as lord high constable and chicf landsteward, 335; as! shögun (1202) 336 ; killed by Tokimasa, 337

- Yorimasa (1106-80), sides with Taira, killed, 298-300

- Yorimitsu (944-1021), soldier, 288; aids Michinaga, .262, 264; at Court, 265

- Yorinobú (968-1048), 262, 288; governor of Kai, drives back Taira Tadatsune, 264; helps Michinaga, 265

- Yoritomo (1147-99), / /son of Yoshitomo, 86; escapes after Heiji war, 293-4; war of $1180,301-2$; army crushed, 304; gains, 305 (ill.); quar- rels with Yoshinaka, 308; called to Kyōto, 311; sent against Yoshinaka, 312; relations with Yoshitsune, 316 , 320-1; Bakufu independent of 'Court; 324-30; 'memorial on manors, 326 ; becomes sei$i$ ta $i$-shògun, 331 ; death and character, $332-4$; patron of Saigyō Hōshi, 367; 'system imitated by Takauji, 402-3 - Yoriyoshi (995-1048), 264, $2 \mathrm{SS}$; in Nine Years' Commotion; 266

- Yoshichika (d. 1117) rebellion put down by Taira Masamori, 288

- Yoshihira, son of Yoshitomo, 307 f.n.

- Yoshiiye (1041-1108), 288; great areher, 264 ; called Hachiman Tarō, in Nine Year's Commotion and Three Year's war, 266-7; helps put down disorder of Enryaku-ji monks, 274

\section{- Yoshikata, 308}

- Yoshimitsu (1056-1127), founder of Tada Genji, 265; in Three Years'. War, 267

- (Kiso) Yoshinaka (1154 84), revolts in Shinano-Kotsuke, 307-8; quarrels with Yoritomo, $308-9$; defents Taira at: Tonami-yama, 309; Go-Shirakawa joins, 310; tries to get crown for Hokurika, 310-11; death, 311-13

- Yoshitaka marries Yoritomo's daughter, 309; death, 313

- Yoshitomo, supports GoShirakawa in Högen tumult, 289 ; joins in plot of Heiji, 292 ; advice overruled: by Nobuyori, :killed, 293; : his sons, $293-4$; loses great land holdings, 252

- Yoshitsuna (d.1134), brother of Yoshiiye, 274

- Yoshitsune (1159-89), ison of Yoshitomo, escapes after Heijitumult, 294; joins Yoritomo, 306-7; sent against Yoshinaka, 312, 313; at Ichino-tani, 315 ; wins battle of 'Yashima; 317-18;' relations to Yoritomo, 316, 320-4; attempted assassination, 322 ; protected by Fujiwara Hidehira, 323 , suicide, 324

- Yukiiye (d. 1186), 303; repeatedly defeated, 308 ; joins Yoskinaka, 309; Yoshinaka disapproves his choice to be governor of Bizen, 311 ; summary criticism of him, 31112; turns to Yoshitsune, death, 322, 323

-Yukitsuna betrays Shishiga-tani plot (1177), 296; oc- cupies Settsu and Kawachi (1183), 309

Minchō, called Chō Densu, (1352-1431), painter, 450

Ming, Chinese Emperor, mission for Buddhist Sutras, 131; dynasty, its fall, 586 .

Mining, Ieyasu's efforts (1609) to develop, 651,652

Ministers, system of three, under Daika; 160, 163; members of Privy Council Board under Daïho, 179; Hideyoshi's system, 523; council of, scparated from shógun; 601,632 ; senior and junior ministers, 632-3

Mino, province, Oda defeát Saitō in, 468,480

Miroku (Sanskrit Maitreya), stone image of: brought to Japan (584 A.D.), 134; 138 Mirror, in myth of Sun-Goddess 12 ; one of : Imperial insignia, 18, 33, 63,79; brónze, in sepulchral remains, 52

Mishchenko, Russian general. leads cavalry raid after fall of Port Arthur, 721

Misumi, adherents of Southern Court, in Sanin-do, $: 400$

Mita, Korean architect, 126 Mitigations (roku-gi) of penalty of Daihō code for rank, position and public service, 178

Mito, Tokugawa of, 624

Mitoshi, a Kami, 69

Mitsubishi : Company, first private dock yard, 669

Mitsuhide see Akechi Mitsuhide

Mitsukuni see Tokugawa Mitsukuni

Mitsunobu (Tosa no M.), painter, 'founder of Tosa school of painting, 450

Miura branch of 'Taira, 265; plot agáinst $\mathrm{Hōjō}, 351$, s

- Mitsuinura (d. 1247), suicide, 351

- Yasumara. (1204-47), in war with Hōjō, 351 f

- Yoshiaki, 333

- Yoshizumi (1127-1200), in Bakufu, 336

Miwa Sakō, commander of palace guards, 135

Miyake Atsuaki, contributor to Dai Nilon-shi, 645

Miyoshi, scholars in Ashikaga administration, 403; 1. lecturers, 449; in civil war of 1520-50, 433, 464; crush Hoshokawa, 434; in Awa, 470; attempt to take Kyōto, 481

- Kiyotsura (847-918), 240,

243; memorial (914), 245-8, on writing, 103-4; Chinese scholar, 249

- Masanaga, inheritance, 434 
Miyoshi Motonaga, 434, 464

- Nagateru(d. 1520), guardian of Hosokawa Sumimoto: and Takakuni, 432; death, 433

- Norinaga, called Chōkei (1523-64), in civil war, 434

- Yasunobu (1140-1221), son

of Yoritomo's nurse, 303; ancestor of Öta and Machino uji, 328 and f.n.; in Bakufu council, 336 ; advice at beginning of Shōkyu struggle, 343; death, 346

- Yasutsura, with Hōjō

Yasutoki plans Jōei code, 349

- Yoshitsugui (d.1573), revolts in Settsu, 484

Mizugaki, Sujin's court at, 79

Mizuha, life time name of $\mathrm{Em}$ peror Hanshō, 109

Mizuno, governor of Nagasaki, persecutes Christians, 553

-Echizen no Kami, prime minister of Ieyoshi, sumptuary laws and efforts at reform (1826), 661, sgg. 662

Mochifusa see Uesugi Mochifusa

Mochihito, Prince, (1150-80),

Yorimasa conspiracy; 299

Mogami of Yamagata, 471

- Yoshiakira (1546-1614),

one of Ieyasu's generals, 560

Moho, variant name of : Sushen or Toi, 262

Momijizyama Bunkō, Tokugawa library at Yedo, 579 Mommu, 42nd Emperor (697707), Prince Karu, accession, 175-6; succession and plan to move capital, 185

Momokiwa see Fujiwara Momokawa

Momonoifamily favours Tadayoshi, 406

Momo-yama, "Peach Hill," in

Fushimi, Hideyoshi's palace, 527; last epoch of Ashikaga shōgunate, 521 ; palace d destroyed (1596), 528; Ieyasu's castle taken (1600), 559-60

Momozono, 116th Emperor $(1735-62), 621$

Mon; coin, 187, 438 f.n.

Mongaku, priest, originally Endō Moritō, aids Yoritomo 303-4, 334

Mongol, subdivision of yellow race, 58 ; fold of eye, 59 ; invasion, 358-64

Monjū-dokoro, Bakufu department of justice, 328 ; in administration of Kyoto after Shōky ū war, 345 ; power passes to Hyōjōshu, 347; in Muromachi administration, 436

Monkey, worship of, 128; female divinity, 12,213

Mononobe, palace guard, 67, 284 ; uji of Kwami class, important especially in Yürya- ku's reign, : 129-30; oppose Buddhism, 133-4, 285

- Moriya, $\overline{0}-m u r a j i$, killed by Soga, 130, 138; their rivalry, 134; opposes Buddhism, 134, 285 ; supports Anahobe, 135 , 136; final contest with Soga, 136-7; property, 138

- Okoshi, $\bar{o}$-muraji, 130; opposes Buddhism; 133

Montoku, Emperor (851-58), 236-7, chronicle of reign; 5

Montoku Jitsuroku, National

History, 251

Monto-shū, Shin sect, 370 f.n.

Moon, Kami of, 11

Moonlight festivals, 277

Mori Arinori, Viscount (1847-

89 ), minister of public instruction, assassinated, 691

Mōri family, rapid rise in power, 469-70; Ashikaga Yoshiaki turns to, 482

- Hidemoto (1579-1650), in Ishida's army, 560

- Motonari (1497-1571), wins power of Ouchi, 469 (ill.)

Motonori (1839-96), of Chōshū, leader of extremists, expelled from Kyōto, 675

- Nagayoshi :(1558-84), general of Hideyoshi, 498

- Rammaru, lieutenant of Nobunaga, 474

- Terumoto (1553-1625) loses central Japan to Hideyoshi, 489; Akechi Mitsuhide joins, 490; peace with Hideyoshi, 491; senior minister, 523; signs Hideyoshi's laws, 526; favours Ishida, 559, leads his army, 560; loses estates, 561

Morihito, Emperor Nijō (q.v.) Morikuni, . Prince (1301-33), shōgun, 1308-33, 354

Morimasa see Sakuma Morimasa.

Morinaga, Prince, (1308-35), called Otō nó Miya, son of Go-Daigo, 379, and his defender, 381, 384; commanderin-chief, 387 ; death $389-90$

Moriya see Mononobe Moriya Morosada, Prince, see Kwazan Moroya, chief of Ōtomo, $\overline{0}-$ muraji, 129

Morrison, American ship in Yedo, 1837, 663

Mother-of-pearl and lacquer, 208,279

"Mother's Land," Shiragi,

Korea, 60

Motien Mountains, Russian campaign planned in, 713

Motonobu (1476-1559), painter, Kanō school, 450

Motoori Norinaga

$(1730$

1801), Shintō revival, 645; 646 (ill.); quoted, 648-9; on Shintō dualism, 65
Mourning colour, white, 212, earlier, black, 213; customs, 139 ; periods of, varying with rank, 213

Moxa, medicinal herb, touch of, defilement, 276

Mu Hsi, painter, 365

Mukden, Russian railway through, 705; battle of (1905), 721-3

Muko, Fukuhara harbour, 300 Mukuhara, Buddhist temple at, 133

Mulberry, early culture, 67; used with hemp to make cloth, 67; order for cultivation (472 A.D.), 113; planting of, condition of tenure of upland, 182

Multa, King of "Kudara, stories of his cruelty told of Emperor Muretsu, 120

Munemara, chief of trade, 155 Munetada see 'Tokugawa $\mathrm{Mu}$ netada

Munetaka, Prince (1242-74), shōgun in 1252-66, 354, 356 Munetake see Tokugawa Munetake

Munro, N. G., on Japanese archaeology, 46, 47, 49, 54; imibe, 71-2; rice-chewers, 74 f.n.; coins, 187 f.n.

Muraji, "chief," title, 73; applied to pre-conquest (Shimbetsu) rulers, 77, 92, 98; $\bar{o}-$ muraji, head of $\bar{o}-u j i, 98$; inferior title in Temmu's peerage, 171-2

Murakami, 62nd Emperor (947-67), 257-8

Murakami Genji, branch of Minamoto, 206

- Yoshihiro, of Iyo province, pirate chief, 445

- Yoshikiyo (1501-73), driven from Kuzuo by Takeda Shingen, 467

- Yoshiteru impersonates

Morinaga, 381

Murasaki Shikibu (d. 992), writer of Genji Monogatari, 249 f.n., 250 , (ill.), 261

Muravieff, Nikolai Nikolaievich (d. 1881), Russian commander in Far East, claims (1858) Saghalien, 697

Murdoch, J., quoted on Tadatsune's ravages of Kwantō,264 f.n.; on Heian epoch, 275-6; weakening of Fujiwara power, 294 f.n.; Bushi of Kwantō, 314 ; Jōei code, 349-50; downfall of Bakufu, 355; feudalism in war of dynasties, 401; literati in Ashikaga administration, 403; Kamakura rule in Kai, Izu and Mutsu, 409; revolt of 1443,412

Muretsu (Buretsu), 25th Emperor (499-506), 119-20 
Muro Nawokiyo, or Kyūsō,|Nagao Kagetora see Uesugi (1658-1734), Confucianist, historian of "47 Rōnins," 607 ; adviser to shōgun, 613 Muromachi, part of Kyōto, administrative headquarters of Ashikaga, 402; Ashikaga shöguns at, 413, 435-6

Musashi, immigrants from Koma settle in, 168; war of Taira and Minamoto in, 254; Hōjo and Uesugi in, 467

Mushroom picking, 458

Music, Korean and Buddhist, 156 ; and poetry, 215; in Heian society, 278; jorruri, 605-6

Musō Kokushi, "National Teacher," or Soseki (12711346), scholar, 448; head of Tenryūji, 454

Mutō, branch of Fujiwara in Kwantō, 266

- Sukeyori, founder of Shōni family, 470

Mutsu, 5 provinces, in Nara epoch, N. E. and N. littoral, 219 ; the Nine Years' Commotion (1056-64) in, 26667; 'Three Years' War (10891091) in; $267 ;(\bar{O}-\operatorname{sh} \bar{u})$ part of Ō-U, 388; peaceful under Kamakura rule, 409; revolt of 1413 in, 412 ; in 16th century wars, 471 ; silk growing, 617 ; famine of $1783-6$ in, 623

- branch of Fujiwara, descendants of Fujiwara Kiyohira, 268; give Yoshitsune asylum, 307,324 ; crushed by Yoritomo (1189), 324

Mutsuhito,(posthumous name, Meiji), 122nd Emperor (18671912), 677; seal, 694 (ill.)

Myōchin Nobuiye, metalworker and armourer, 451

Myöchō, Zen priest, 454

Myōe (or Kōben), bonze, quotation from his biography on Yasutoki, 344-5

Mýogaku-ji, temple, 491

Myong see Song Wang Myong Myōō, priest, 454

Myōshin-ji, Zen temple, W. of Kyōto, 454, 566

Myōshō, (109th) Empress (1629-43), Princess Oki, daughter of Go-mizu-no-ō and Tokugawa consort, 590 Mythology, 8-27, 33; rationalistic explanation of, $28-33$, by Japanese, 29

Nabeshima Naoshige (15371619), invasion of Korca, 509 Nagahama, Ōmi, headquarters of Hideyoshi, 485

Nagakude, battle of, 498

Nagamasa see Asai Nagamasa and Asano Nagamasa

Nagamori see MIasuda Nagamori

\section{Kènshin}

Nagaoka, Yamashiro, capital, 225-6

- uji, of princely descent, 205

Nagasaki, port, 529; church, trade, growth, 535; Jesuit church seized by Francisans, 542 ; missionaries receive patent 546; Martyrs' Mount, 548; execution of 'De 1 ' Assumption and Machado, 551; "Great Martyrdom," 552, 553; trade, 609; Pessoa at, 653; Dutch and English confined to, 651; Dutch factory, 656; Russians, come to, (1804), 658; Glynn and the Preble, 663; Americans allowed to trade, 666; military college at, 668

- Enki, guardian of Hōjo

Takatoki, 377

- Takashige, suicide, 386

- Takasuke (d.1333), minister of . Takatoki, 377; dethrones Go-Daigo, 379

Nagashino, castle, 487

Nagasune, governor of Yamato, 23-4, 76

Nagato, fortifications

(1280), 361-2

Nagatoshi, name given

Nawa Nagataka, 382

Nagauji see Hōō Sōun

Nagaya (684-729), minister of

the Left, 189,209

Nagoya, in Hizen, base of operations against Korea, 512 ; castle of, 562,521 (ill.) Nai-mul, king of Shiragi (364), first sends tribute to Yamato, 89

Naka, Prince, son of Kögyoku, 148; passed over, in succession, 159, 166; interregnum, 168; Great Reform, 160 ; expedition to Korea; 167 ; Emperor Tenchi (q.v.); 168

Nakachiko, Oshiwa's servant, 118

Nakahara family, scholars, secretaries in 'Bakufu, 328; in Ashikaga administration, 403; lecturers, 449

- Chikayoshi "(1142-1207), in Yoritomo's Bakufu, 32S f.n.; nominated : high constable at Court, but not appointed, 330; in Bakufu council, 336; ancestor of Otomo family of Kuyüshū, 470 - Kancto, rears Yoshinaka, 308; his four sons, Yoshinaka's guards, 312-13.

Nakai Seishi establishes school in Osaka, 614

Nakamaró see Abc Nákamoro and Fujiwara Nakamaro

Takamura Hiyoshi see Toyotomi Hideyoshi, 475 f.n.
Nakane Genkei, mathematician, translates Gregorian calendar into Japanese; 614 Nakanomikado, 114th Emperor $(1710-35) ; 620-1$

Nakano, suburb of Yedo, dog-kennel in, 602 .

Naka-Nushi, "Central Master," 61

Nakasen-dō, Central Mountain road, completed early in 8 th century, $210,392,560$

Nakashi, wife of OKusaka, 111 Nakatomi family, court priests, 130; descended from Koyane, 33,61 , guardians of 3 insignia; 63 , and of Shintō ceremionials, 133 ; oppose Buddhism, $133-4$, and Soga, 148-9

- Kamako, muraji; opposes Buddhism; 133

- Kamatari see Fujiwara

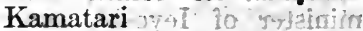

- Kane, muraji, minister, in conspiracy, against ) Oama (Temmu), 170

- Katsumi, muraji, killed (587 A.D.), 148

Nakatsu, Prince, 108

Nakaye 'Tōju (1608-48), Confucianist, follower of - Wang Yang-ming; 626; 628

Namamugi incident, 673,674 Nambu family, 471

- Saemon opposes Ieyasu, 565

Names and naming, Japanese system, 73 ; territorial, 287 i

Naniwa, now Ōsaka, capital of Emperor Nintoku, 105; Buddhist temple, (579), 134; immigrants from Kudara, 168; administration, Seltsushoku, under Daihō, 180; removal of capital to, by Kōtoku, 185; trade in Heián epoch, 281

Nankō, see Kusunoki Masashige

Nankwa (16th Cent.), scholar, 474

Na-no-Agata or Watazumino-Kuni,' Japanese intercourse with, 84

Nanshan, commanding Port Arthur, 715-16

Nanzen-ji, Zen temple, 454; one of the "Five," 455 ? Nara, Yamato province, removal of capital to (709 A.D.), 185-6; the Nara epoch (709-84), 185-223; the Nara image of Buddha, 193; city officials, revenues from public lands appropriated for, 775 A.D., 202; Kusu and Fujiwara Nakanari attempt to make it capital again, 230 ; power of armed monks controlled by Yoshinori 
420; rebel against Yoshimasá, 422; Takauji tries to check, 453

Nariaki see Tokugawa Nariaki Narimasa see Sasa Narimasa Narinaga, Prince (1325-38), kwanryō of Kwantō, 387; shögun at Kamakura, 391

Narita Kosabưōo assists Go-

Dáigo, 382

Näriyuki see Tokugawa Nariyuki

Nasu family, one of "8 Gengerals of "Kwantō," 425

"National Histories, Six," covering years 697-887 A.D., 188; five composed in Heian epoch, 251

Nature Worship, 65-6

Navarrete, Alonso (1617), Spanish Dominican, executed by Ōmura, 551

Navigation, 72; see Ships

Navy, Japanese, in Mongol invasion, 360 ; in invasion of "Korea, 515, 519; naval College, Gunkan Kyōjujo, at Tsukiji, 669, modern organization, 696 ; in war with China, 701-2; in war with 'Russia, 710-12, 714-15, 717, $718,723-4$

Nawa, adherents of Southern Court, in Sanin-dō, 400

- Nagatoshi (d. 1336), helps Go-Daigo escape, 382 ; provincial governor, 388; commands against the Ashikaga, 392 ; death, 396

Nazuka Masaiye, in charge of land-survey, 527

Needle, magic, as cure, 196

Negoro, in Kii, firearms made at, $489 ;$ headquarters of priests of Kii, 499

Nei-issan see Ichinei

Nemuro, Russian ship in (1792), 658

Nengo, era or period, in chronology, 5 ; different names in Northern and Southern courts, 398,406

Nenoi Yukichika, one of Yoshinaka's four guards, 312 Ne no Omi, messenger of Ankō, 111-12

Neo support Southern Court in Mino, 400

Neolithic culture, 46

N'estorian Christianity in China, 192 f.n!

Netșue, (ill.), 283

New Spain, Mexico, ships from, 547,550

New Year's celebration, 214

'Ng, Chinese writer on war (3d Cent. A.D.), 286

Nichira, Japanese at Kudara Court advises Bidatsu against Kudara, 150

Nichiren, Buddhist sect dating from 13th century, 367; its | Nishino Buntarō, assassin founder, 371 (ill.), 372; war with- other monks, 464

Nigihayahi, uncle of Jimmu, overlord of Nagasune, 76

Nihon Bummei Shiryaku, on early medicine, 126

Nihon Kodaihō Shakugi, on Board of Religion, 178

Nihon Kōki, Later Chronicles of Japan (792-833), 4, 251 Nihongi, Chronicle of Japan (720), 3; on Chüai and Jingo, 88-9; after 400 A.D., 108

Nihonmatsu family, 471

Nihon Shoki, Written Chronicles of Japan to 697 A.D. (720), revision of, 3 ; continuations, 4

Nijō, family founded by son of Fujiwara Michiiye, one of " Five "Regent Houses," 358

Nijo, 78 th Emperor (115966), 291-5

- Castle, Kyōto, destroyed, 624 ; officials of, 636

- Michihira (1287-1335), GoDaigo's minister, 387; 388

- Yoshimote

(1320-88),

scholar and author, 447

Nikaidō in office of shitsuji, 327 ; defeated by Date, 471

- Sadafúsa opposes the regent (1331), 379

Nikki favour Takauji, 406

Nikkō, Shimotsuke province, shrine of Ieyasu and tombs in, 582; annual worship at, 583,604

Nikolaiev'sk, "strategic situation, 704

Nimmyō, Emperor (834-50), 235-236; chronicle of his reign, 5 ; luxury, 245-6

Nine Years' Commotion, Zenkunen (1056-64), 266-7

Ningpo, trade with Japan, 444; sacked by Japanese, 445 Ninigi see Hikoho Ninigi

Ninken, 24th Emperor (48898), Prince Woke, 118-19

Ninkō, 120th Emperor (181746), 664

Nintoku, 16th Emperor (31399), 104-7; 7 provinces added by, 87 ; consort, Takenouchi's granddaughter, 91-105; love story, 101 ; remits taxes; 124

Nippon, "Sunrise Place," 145 f.n.

Nira-yama, Hōjō castle, 503

Nishi Hongwan-ji, temple, 502,235 (ill.)

Nishikawa Masayasu, astronomer under Yoshimune, 614 Nishina-uji; branch of Taira family, 265

Nishina .Moritō (d. 1221), Bakufu retainer, in Shōky ū war, 342
(1889) of Viscount Mori, 691

Nisi-no-shima, islet in Oki group, 382

Nitta family, Yoritomo's attempt to win, 306,307 ; adherents of Southern Court, 400 ; crushed by Ashikaga Ujimitsu, 416

-'Yoshiaki (d. 1338), son of Yoshisada and provincial governor, 388; suicide, 399

- Yoshimune (1332-68), in defeat of Takauji, 407

- Yoshioki (d. 1358), 407

Yoshisada (1301-38) in Kyōto revolt, 380; declares against Hōjō, 384, takes Kamakura, 385; provincial governor, 388 ; accuses Takauji of treason, 391 ; commands army against Takauji, 392; besieges Shirahata, 393; escapes, 395 ; faithful to' GoDaigo, 397, 398; death, 399

- Yoshishige (d. 1202), ancestor of Tokugawa, 556

Nittabe, Prince, residence of, site of Shödai-ji temple, 191

Niuchwang taken by Japanese (1894), 702

Niwa Nagahide (1535-85), soldier of Nobunaga, 481, 492 ; councillor, 494

$N \bar{o}$, dance and drama, 458-9, 605; Sadanobu regulates costume, 625; masks, 28, 56 (ills.) Nō-ami, artist, patronized by Yoshimasa, 425

Nobility, primitive, 62 ; administrative, 98; growth of power at expense of Emperor, 105; Daika attempts to distinguish from official ranks, $160 ;$ titles of hereditary aristocracy annulled : by Daika and estates escheated, 162; nobles state pensioners, 164; new titles under Tem$\mathrm{mu}, 171-2$; influence of hereditary-nobles against Daihō laws, 178; court society in Heian epoch, 277-8; in Meiji era, 691; see Court Houses, Military Houses

Nobukatsu see Oda Nobukatsu

Nobunaga see Oda. Nobunaga Nobuteru see Ikeda Nobuteru Nobuyoshi see Tokugawa Nobuyoshi

Nogi, Kiten, Count (18491912), commanding 3d Army, at Dalny, 717 ; receives surrender of - Port Arthur, 721; at Mukden; 722-3

Nomi-no-Sukune, suggests clay effigies instead of human funeral sacrifices, 82 ; wresfamily, 242 tler, 83; ancestor of Sugawara 
No-niwa, moor-garden, 365

Norimura see Akamatsu Norimura

Nori Sachhi sce Tori Shichi

Norito, ancient rituals, 63-4

Northeastern Japan, political importance of, 86

North-east gate, the Demon's gate, 228,283

Northern and Southern Dynasties, 396-412; table, 406;

Northern in control, 418

Northern Japan, more primitive culture of, 46

Novik, Russian 2d-class cruiser at Port Arthur, 711

Nozu, Michitsura, Count (1840-1908), commanding 4 th Army, 717-18; at Mukden, 722

Nuns, Buddhist, Imperial princesses become, 620

Nurses, provided for the Court by $M i b u, 71$

Ōama, younger brother of $\mathrm{Na}$ ka (Emperor Tenchi), administrator during 7-year interregnum (661-668), 168, 169; appointed Tenchi's successor, declines in face of conspiracy, 170; beconies Emperor Temmu (q.v.), 170 Ōba Kagechika (d.1182), hems in Yoritomo and crushes his army, 304-5

Oban, coin, 528

Obi, in Hyuga, Chinese trade, 444

Occupations, hereditary among prehistoric $u j i$ or families, 93

Oda family, one of " 8 Generals of Kwantō," 425; origin of family, 473

- Hidenobu (1581-1602),

grandson of Nobunaga, 561

- Katsunaga (1568-82), death, 491

- Nobuhide (d. 1549) aids Crown, 462, 473, 479

- Nobukatsu, son of Nobunaga, in Ise, 468; succession, 494; Komaki war, 497; peace with Hideyoshi, 498; Hideyoshi's treatment, 504; signs oath of loyalty, 507

- Nobunaga (1534-82), 466; seizes Ise, 468; career, 473 (ill.) -5 ; Hideyoshi serves under, 476; wins Okehazama, 477; alliance with Ieyasu and Shingen, 478-9; Court appeals to, 479,481 ; attitude toward Yoshiaki, 482; practically shōgun, 482, 483; makes peace, 484; friendly to Christians, 486, 538-9; aids Ieyasu, 487; death, 490; character, 492-3; cur'ency reform, 527-8

- Nobutada (1557-82), with
Takeda Katsuyori, death, 491; succession, 494 - Nobutaka (1558-83), 494, 496

- Sambōshi, called Hidenobu, (1581-1602), son of Nobutada, his successor, 494; 496

Odate $_{2}$ governor of Harima, and Oke and Woke, 118

Ôdate Muneuji, killed in attack on Kamakura, 385

Odawara, fortress of Hōjō; Odawara-hyōgi proverb of reluctance, 466 ; attacked by Kenshin, 467; surrenders (1590), 503

Ōeyama Shutendōji, bandit, 262

Office and official called by same name, 96; and rank, family qualifications for, before Heiji commotion, 295 Official or Court lands, kwanden, under Diahō laws, 183 - rank and aristocratic titles distinguished by the Daika, 160

- rules (kyaku) supplementing $Y \bar{o} r \bar{o}$ laws, 177

Oga, eighth of the great $u j i$, decended from Okuninushi, 130 Ogawa, at Sekigahara, 561

Ogigayatsu, family name taken by Uesugi Tomomune, 416; feud with Yamanouchi, 419,464 ; against $H^{\circ} \mathbf{j} \bar{o}, 466$ Ogimaru see Hashiba Hidekatsu

Ōguchi, battle of, Hideyoshi defeats Shimazu Iehisa, 501 Ogura, Mount, home of Fujiwara Sadaiye, 366

Ogyu $\bar{u}$ (or Butsu) Sorai (16661728), Confucianist, writes on "47 Rōnin," 607, and on government, 613 ; 626 ; revises code, 641

Ohama, nobleman, placates fishermen, 99

Ōhatsuse, brother of Ankō, 111; apparently instigates murder of all between him and crown, 112; succeeds as Yūryaku (q.v.)

Oiratsume, incestuous sister of Karu, 111

Öishi Yoshiyo (1659-1703), leader of "47 Rōnin," (1703), 606-7

Oiwa, general in Korea, tries to get throne of Kudara, 122 Ōjin, 15th Emperor (270-310), 99-104; 21 provinces added in his reign, 87; ship building, 126; palanquin, 126

Okabe Tadazumi kills Taira

Tadanori at Ichi-no-tani, 315 Okagami, historical work, 255 Oka-yama, castle in Bizen, 559

Okazaki, in Mikawa, Ieyasu's castle in, 479
Okazaki Masamune (12641344), swordsmith of Kamakura, 451

Ōke, Prince, 118; see Kensō

Okehazama, battle (1560), victory of Nobunaga, 477-8, 556 Oki, Princess, see Myōshō

Okimachi, 106th Emperor (1557-86), 460; honours. Kenshin, 467; summons Nobunaga to Kyōto, 479; Hideyoshì; 499,527 ; decrees against Christianity, 538

Okisada, 259; see Sanjō

Okitsugu see Tanuma Okitsugu Okiyo, Prince, governor of Musashi, 254.

Okoshi see Mononobe Okoshi

Oku Hokyo, Count, (b. 1844), commanding $2 \mathrm{~d}$ Army, wins battle of Kinchou, 715 , and of Telissu, $716-17 ; 718$; at Mukden, 722

Ōkubo family, guards of Hakone barrier, 592

- Tadachika (1553-1628)

punished for disobedience to Military law, 594

- Toshimitsu (1832-78) of Satsuma, in alliance with Chōshū, 676-7; and Korean question, $683-4$; assassinated, 690 (ill.)

Ōkuma Shigenobu, Count (b. 1838), 683; organizes Progressist party, 690; attack upon, retirement, 691 ; invited into Cabinet, 693

Ôkuni-nushi, Kami, "GreatName Possessor," 69; ancestor of Ōga-uji, 130

Ōkura-no-Tsubone, Yodo's

lady-in-waiting, 566, 567

Ôkusaka, uncle of Ankō, accused of treason, 111; Okusakabe formed in his honour, 113

Okuyama Yasushige (d. 1651), .582

Omi, muraji, befriends Ōke and Woke, 118

$\bar{O} m i$, "grandee," title, 73 ; applied to chiefs of conquest, 77,92 , and to subjects holding court office, 87, higher than muraji, 98; inferior title in Temmu's peerage, 172

Ômi, immigrants from Kudara settle in, 168; seat of Court and place of issue of Ömi statutes, 169, 176; capital moved to, 185; Asai contról 469; Buddhists help Asai in; 485 ; rice grants, 588

Omitsu, son of Susanoo, imports cotton from Korea, 60 Omiwa, Kami of, 15

Omura, fief in Hizen, 534; represented in embassy to Europe of 1582, 537

- Sumitada (1532-87) 
vites Jesuits to Ōmura in persecutes, 535 .

Omura Sumiyori (d. 1619), persecutes Christians, 551

$\bar{O}$-muraji, head of $\bar{o}-u j i$ or preeminent grandee; 98; office held by Ōtomo and then -Mononobe, 129-130; political rivalry with $\overline{0}-o m i, 133,135$; opposing Buddhism, 134; (property of, 138, unimportant after the Daika, 160; not in Temmu's scheme of titles, $-172$

Ōnakatsu, consort of Inkyō, 110

Onchi, or Yenchi, uplands, distinguished from irrigated rice land in Daihō code, 182 Ondo no 'Seto,' strait near Kōbe, 300

Onin, period, 1467-9, its records, 423 ; civil war of, $426-$ 30; beginning of Sengoku Jidai, 460

Ōnjō-ji, in Ōmi, temple of -Jimon branch of Tendai sect, built by Ōtomo Suguri, 193 f.n.; its armed men, 273; its abbot Raigō; 273-4; part played by monastery in - Yorimasa conspiracy, 300; burnt by Taira (1180), 301 Ono Tōfū, scribe, 261,365

Ono Azumahito (d. 742), lord of eastern marches, builds castle of Taga, 220

- Harunaga (d. 1615), son of 'Yodo's nurse, adviser of Hideyori, '565; plots "against Katagiri and Tókugawa, 567; advises surrender of Osaka, 568

- Imoko, Japanese envoy to China 607 A.D.), 145

- Yasumaro (d. 723), scribe, 2,4 ; preface to $K o-j i k i,-214$ -Yoshifuru, general of guards, crushes . revolt of Fujiwara Sumitomo, 255

Onogoro, mythic island in story of cosmogony, 9

Ōoka Tadasuke (1677-1751), chief-justice in Yedo, 613; revises code, 641

$\bar{O}$-oku, harem, 636

$\bar{O}$-omi, pre-eminent omi, head of Kuñbetsu-uji, 98; rivalry with $\bar{o}$-muraji, 133, 135; favour Buddhism, 134; preeminent after death of Mononobe Moriya, 138; title given by Soga Emishi to his sons, 147; no longer important after Daika (645), 160

Operative regulations, Shiki, supplementing Yōrō laws, 177 Oracle, of Sun Goddess at Ise, 195; War God at Usa, 199

Orange" (tachibana) "seeds brought from China (61 A.D.) 84 ; trees introduced, 208

Ordeal, 100; of fire, 19, 20 , 125; of boiling water, kugadachi, 65, 97, 101, 125; used in Korea by Keno, 123; in questions of lineage, 169

Organtino (1530-1609), Jesuit, Hideyoshi's treatment, 539

Orloff, Russian general, ambuscaded: at Liaoyang, 719 Orpheus-Eurydice legend, Japanese parallel, 10,25

Osabe; Prince Imperial, son of Kōnin, poisoned (772), 204 Osada Tadamune and his son Kagemune kill Minamoto Yoshitomo, 293

Osadame Hyakkajō, Hundred Articles of Láw, 613

Osafune, swordsmith, 450

Ōsaka, campaign from, against Sujin, 79 ; Hideyoshi's castle, 496, 527; Chinese envoýs, 518; Franciscan convent, 542 ; missionaries' residence, 546 ; castle attacked, 548; taken by Ishida, 560 ; party of, refuse oath of loyalty to Tokugawa, 565; castle partly destroyed, 567-9; taken, 570; vendetta illegal in, 607 ; Nakai Seishi's school; 614; rice exchange, 616; jojdai, 637; traders crush English and Dutch competition, 655, 656; opened by Hyōgō demonstration (1866), 675-6

Osaragi Sadanao, Hōjö

Osawa family; masters of ceremonies, 635

Ōsazaki', life name of Emperor Nintoku, 73

Oshihi, ancestor of Ōtomo chiefs, 33,62

Oshikatsu, Rebellion of, 198

Oshioki Ojómoku, code, 613

Ōshio Heihachirō (1792-1837)

leads revolt after fámine of $-1836-7,662$

Oshiwa, son of Richū, killed by Yūryaku, 117-118

Oshiyama, governor of Mimana, recommends cession (512) of part of Mimana to Kudara, 122 ; territorial ? dispute of 513,123

Ōshū,' or Mutsú (q.v.), subjugated (1189), 331; revolt of Andō, 377.

Ōta ${ }^{-}$Sukekiyo (1411-93), builds fort at Iwatsuki, 426

- Dōkwan or Sukenaga $(1432-86)$ builds fort at Yedo, 426; aids Ōgigayatsu branoh of Uesugi, 464 .

Otani, Nagamasa's castle, 484 , 485

Oto, sister of Ōnakatsu, concubine of Inkyō, 110-11
Oto, son of Tasa, 114

Ōto Miya see Morinaga

Otoko-yama, surrendered, 399

Ötomo family, descent, 33, $62,67,129$; gate-guards, 284 ; in 'Kyūshū, 414, 421, 470; treatment of Xavier in Bungo, 532 ; feudatory and son Christians, 535; persecute Buddhists, 537

- general, defeats Iwaki and Hoshikawa; 117

- Prince, prime-minister (671),169; conspiracy against Ōama,-succession as Kōbun (qu.v.), 170

-Chikayo, tandai of Kyūshū (1396), 470

- Satehiko, in Korea (562), 150 - Yakamochi (d.785), anthology, 214

- Yoshishige, called Sörin, $(1530-87)$, in wars in Ky $\vec{u}-$ shū, 470; defeated in Hizen, appeals to Hideyoshi, 501

Otsu, port, 281

Otsu, Prince, son of Temmu, 170 ; rebels against Jito and is killed, 173

Ôtsuki Heiji advocates foreign intercourse, 665

$\overline{\mathrm{O}}-\mathrm{U}, \overline{\mathrm{O}}-\mathrm{sh} \overline{\mathrm{u}}$ (Mutsu) and U-shū (Dewa), 388; in 16th century wars, 471

Ouchi family of Suwō, and the revolt of $1399,414-15$; conspires in behalf of Hosokawa Yoshitane, 433; tandai, 437 ; in charge of relations with Korea, 443, and China, 444; quarrel with Shōgun 445; superintend pirates, 446 ; scholarship, 449; gifts to Throne, 461,462 ; power in 16th century, 469, taken over by Mōri Motonari, 470 - Masahirō, pirate leader, 446

- Mochiyo (1395-1442), 426

- Yoshihiro (1355-1400), Muromachi general, negotiates -with Southern Court, 412; slanders Imagawa Ryôshun, 414 ; suicide, 415

- Yoshinaga (d. 1557), 470

- Yoshioki (1477-1528), deputy kwanryo to Hosokawa Yoshitane, 433; removes to Suwō, 461, 469

- Yoshitaka (1507-51), reestablishes (1548) trade with China, 445; Chinese literat: ure, 449-50; defeated by Suye Harukata, 469

Owari, province, Nobunaga in, 476; fighting in Komaki war, 498; Tokugawa of; 624

Oyama, Iwao, Prínce (b.1842), at Mukden, $722-3$

Oyamada. Takaiye, sacrifice saves Nitta Yoshisada, 395 
Oye family could hold office above 5 th rank, 295; scholars, 328 ; in Ashikaga administration, $403 ; 448,449$

- Hiramoto (1148-1225), first president of man-dokoro, 327; reforms (1185), 328, 330; sent to Kyōto after earthquake of 1185,330 ; in council of $B a k u$ $f u, 336$; remonstrates with Sanetomo, 339; urges offensive at beginning of Shōkyu struggle, 343 ; death, 346

- Masafusa, general in Nine Years' Commotion, 267; attempt to placate Raigō, 274 - Tomotsuna, littérateur, 261

$\mathrm{O}$ Yō-mei see Wang Yang-ming

Paddy-loom, introduction, 280

Pagoda, 7-storey, :194; 13storey, 208; many built by Shirakawa, 272

Pahan-Hachiman, of pirate ships, 446

Paikche, or Kudara, near Seoul, Japanese alliance with, 90; artisans from, 113 Paik-chhon-ku '(Ung-jin), Japanese and Kudara army defeated by Chinese, 662 A.D., 167

Painting, Chinese, in Japan, 113; and Korean, : 127; in years $540-640,155$; in Nara epoch, 209; in Heian epoch, 251, 280; in Kamakura period, 365 ; in : Muromachi : period, 450,452

Palace, ancient, 62 ; consecration, 63; in Nintoku's reign, 105; Asuka, 154; temporary, in burial, 139; Kyōto palace burned and rebuilt, 624, 62930 ; guards, 180; officials, 635 ; Yoshimitsu's, 417; , Yoshimasa's, 423; Hideyoshi's, 506, 521

Palanquin, koshi, of 3rd century, 126 ; one-pole, kago, 456; legislation about, 576,585 ; luxurious use of, in Genroku period, 606 ; (ill.), 396,530

Paletot, 211

Palisades, early defence, 62

Pallada, Russian cruiser at Port Arthur, 711

Paper currency, 604, 610, 639

Parkes, Sir Harry (1828-85), and Hyōgō demonstration, 675-6

Parks in Heian epoch in Kyōto, 278; in Kamakura period, 365; in Muromachi, 417, 456; see Landscape gardening

Parties, political, personal character of, 690; opposition to cabinet, 692-3; union of Liberals and Progressists, 693

Partitions in houses, 126, 280 Parturition hut, ubuya, 73
Paulownia, I

Pavilion, Golden, of Yoshimitsu, 417; Silver of Yoshimasa, 424,452

Pawnshops, heavy taxes on, 423,439

Peaches in myth of Izanagi and Izanami, 10; Chinese origin of story, 26

Peach Hill, Momoyama, Hideyoshi's palace, 521

"Peerage," Japanese, Seishiroku (814 A.D ), 233, 153

Pehchili, in Boxer Rebellion, 703

Peking, Japanese in march to, during Boxer Rebellion, 703 Penal law and penalties, ancient, 66, 96, 109, 117; proto-historic, $125-6$; ritsu of Daihō and Ýōrō, 169, 176-8, 231 ; in Joei code, 350 ; in Tokugawa period, 641-2

Perry, Matthew C. (17941858), Commodore, U. S. N., and treaty with Japan, 664-6 Persecution of Buddhists, 134, by Christians, 534, 535, 536, 537, influence Hideyoshi, 540; of Jesuits after edict of 1587 , 541; of Franciscans, 543; of Dominicans (1622), 552; of Japanese Christians (1613), 547 ; (1616), 549, (1622), 552, in Iemitsu's time, 553

Perseus-Andromeda

Japanese parallel, 25

Pescadores, ceded by China (1895), 702

Pessoa, Andrea, blows up his ship at Nagasaki, 653

Pestilence in reign of Sujin, 79 ; in 1182,301 ; in $1783-6$, 623; displeasure of gods at adoption of Buddhism, 134

Petition-box " (meyasu-bako) and right of petition $(645$ A.D.), 161 ; abuse of, pointed out in Miyoshi no Kiyotsura, 246 ; petition bell in Kamakura, 353 f.n.; boxes reintroduced, 612-13

Petropavlovsk, Russian battleship, sunk, 714

Pets, cats and dogs, 278

Pheasant in myth of Heavenly Young Prince, 16-17

- White, Haku-chi, nengo or year-period, 650-4 A.D., 165 Philippine Islands, promised to Hideyoshi by Franciscans, 542; Ieyasu's: embassies to, 545,651 ; conquest of, urged by Cocks, 550, and by Matsukura and Takenaka, 553; Japanese forbidden to vișit, 552 ; governor-general of, in Japan, 652

Phung-chang, prince of Kudara, 167
Physical chara
Japanese, $57-60$

Piece, $40 \mathrm{ft}$., unit of eloth measure, 437.f.n.

Pine-bark for food, 623

Pine trees in Yedo castle, 612 Pirates in Shikoku, Fujiwara Sumitomo sent against, 255; Japanese piracy in , Muromachi epoch, 442, 445-7; and invasion of IKorea, 510

Pit-dwellers, see ! Tsuchi-gumo Pitszewo: landing-place of $2 \mathrm{~d}$ Japanese army (1904), 715

Plum tree groves, 612; blossom festival, 214

Poctry, 127, 215; Nara epoch, 214; Heian, 250; Chinese style, 214-15; in battle, 260 ; in Genroku era, 600-1; bureau of, 251 ; quoted, 13 (f.n.), 14, $15,66,100,101,115,209,215$, $216,315,381,1402,475,492$, 524; see Couplet Composing Pohai, Korean kingdom of 8th century recognized by Japan as successor of Koma, 223 Pok-sin; Kudara general, defeats Shiragi troops $(660), 167$ Police, döshin, 637.

- Board, Danjō-dai, duties taken over by kebiishi, 232

- executive, kebiishi, (81029) 179,232

Poltava, Russian cruiser at Port Arthur, 711

Polygamy in early Japan, 73 Poly theism of early Buddhism, 368

Pontiff, $h \bar{o}-\overline{0}$, title taken by abdicating Emperor, 197 ill Porcelain, 451

Port Arthur, taken from Chinese (1894), 701, 702; Russian railway, 705 ; . Russian fleet at, crippled by Japanese, 710-12; Japanese attack on, was it warranted? - 712-13; fleet further crippled, 714 ; harbour entrance blocked, 715 ; movements toward, 71517; captured (end of 1904), $718,720-1$

Portsmouth; Peace of, 725, (text) $737+40$

Portuguese in Japan, 530-55; introduce fire-arms, $488-9$; Spanish jealousy of, 542 ; Dutch and English intrigue against, 549-50; instigate Christian revolt, 552; edict of 1637 against, 554; refuse grant in Yedo, 652; monopolize early trade, 653; end of trade, 655-6

Post bells, suzu, 218

Posthumous names, 21 (f.n.), 73,88 (f.n.); official rank first conferred, 168

Posting stations, 592

Potato, sweet, introduced, 618 
Powder, in costume, 279

Prayer; magic, etc., 281-2

Preble, American brig; in Nagasaki (1847), 663

Prefectural government as opsposed to feudal; 128-129; prefecture or ken, 688

Prices, official, (1735), 616

Priesthood; Buddhist, attempt ; to (bring - under law, 144; armed priests, $273,453,462-$ $4,497,: 499,505$; princes enter, 441,577 , except Crown Prince, 620; temporal power, 454-5; scholarship, 448, 449, 454

- Catholic, Ieyasu's attitude, 547; and see Jesuits; Franciscans Dominicans, Auguistins - Shintō, early rules, 64

Prime Minister, 85, development of political power, 90-1; office first established (671) 169

Primogeniture in early times, Imperial; 90; in the family, 93; Imperial; established 696 A.D., 175

Princely Houses, 621, 622

Princes, Imperial, change of status in Nara epoch,..205; many become priests in Ashikaga epoch, 441; abbots of Enryaku-ji and Kwanei-ji, 583 ; all but Crown Prince enter priesthood, 620 ; prince abbots, or monzeki, 633

Printing, Buddhist: amulets (770), 404; in China, 450; from : movable type, about 1592,520

\section{Prisons, 642}

Privy council, Daijo $($ dajō $)$ kwan, 171; Board of, 179

Progressist party, Shimpo-tō, organized (1881) by Ōkuma, 690; joins with Liberals, 693 Promotion, official, Chinese system introduced (603 A.D.), 146; under Daihō, 181

Prose of Nara epoch, 214; of Engi era wholly in Chinese, 248-9; IKi no Tsurayuki's preface to Kokin-shu, 251

Prosody, Japanese, 127; and see! Poetry, Couplet

Próstitution in Yedo, 620; Sadanobu's legislation, 625

Provinces, kuni, 91 in reign of Seimu, 87 ; classification, and subdivision into $k \bar{o} r i$, under Daih $\bar{o}, " 180$; difference between capital and provinces in Heian epoch, 251; lawlessness, 253,255 ; power of provincial families; 284 ; Bushi employed by provincial nobles; 287 ; shugo system, 328-9, abolished by Kemmu restoration, 388 ; local autonomy abolished, 681-2
Provincial rulers, in early times, 62; administration by imperial princes, 85,87 ; early kuni-no-miyatsuko, later kokushi, 106; kokushi under Daika, 161-162; 164; abuses under Shōmu and Kōken, 200; use forced labour to reclaim uplands, : 201; term reduced to 5 years $(774), 217$; administration criticized by Miyoshi no. Kiyotsura, 247; administration: after Önin war, 431-2; in Muromachi period, 436-7; and Christianity, 548

- temples, kokubun-ji, 195; expense; 245

$\because$ troops, abolished (792) except on frontiers, 218

Public.land, Kugaiden, 202

Purchase value of money, 187 (f.n.)

Purification, Great, Ôharai, 63,65 ; regular, harai, 65; bodily, misogi, 65 ; as punishment for persons of high rank, $-126$.

Purple court costume, 211; ecclesiastical robes, 589-90

Pyong-yang, Korea, 81, 83, 102 ; in campaign of 1592 , $513,514,516$; taken from Japanese by: Chinese (1593), 517; Chinese defeated at, (1894), 701

Queen's. Country, Chinese name for Kyūshū and westcoast provinces because of female rulers; 85

Queue-wearing and official caps, (603), 156

Quiver, 181

Race of Japanese, $58 s q q$.

Raconteurs or reciters, guild of, Kataribe: : 1; .71, 130 (ill.)

Raigō, abbot, influence, 273-4 Rai Miki (1825-59), in Imperial restoration movement, 670

Rai Sanyō $(1780-1832)$ on ethical effects of Chinese classics, 104; on Mintoku, 105; on Bakufu 377 ; on the Hōjō, 386 ; on Morinaga, 390 ; on Yoshisada, 399 ; on development of tactics, 488

Railways; Englișmen employed in planning, 686; modern building, 694

Rakuō, pen-name of ,Matsudaira Sadanobu, 629

Rank, hon-i, 205; changed by Taira Kiyomori after Heiji commotion, 295; and costúme, 575-6

Ranisetsu, verse-writer, 601

Ratio of copper and silver in coinage, 187; of silver and gold, 671-2
Reolamation, of upland, in 8th century, 201; and perpetual title, 207, 251, 253; in Yoshimune's time, 615-16, 617

Recluse Emperors, Three, 341 ; and see Camera Government Recorder, of judgments, 641 Recorders, Court of, 352 f.n. Records, early Japanese, 2, 3, $29,77,214$; local, 109

Red court costume, mark of highest rank, 211 ; colour of Taira ensign, 304 f.n.

Red Monk, name given to Yamana Mochitoyo, 421, 427 Red walls, 209

Reed, source of terrestrial life, 8 ; boat in Japanese myth, 26 Reform;. Great (645), 160-5 Regent for grown Emperor, mayor of palace, kwampaku, 239 , office abolished after Kemmu restoration, 387, in Tokugawa period, 588 ; to minor, sesshō, 237; military, shikken, 327

Regent Houses, Five, GoSekke, 358, 581, 588; 416

Registrar of Vessels, 155

Registration of land, 270

Reigen, 112th Emperor 1663-

86), 591 ; abdicates, 620

Rein, J. J., on chronology, 6 Reizei, 63rd Emperor (968969), grandson of Fujiwara no Morosuke, 258-9

Relief in crop-failure or sickness, under Daiho laws, 184; for debtors, $376,422,617$; for sufferers from fire and tornado, 614 ; for famine, 662

Religion, early rites 63, 65; rites reorganized, 79; Emperor at head of, 96 ; in protohistoric period, 127-8; Board of, 178; Miyoshi Kiyotsura's description, 246; Yoritomo's attitude, 325; in Muromachi period, 452-5; Department of, 681; and see Mythology, Shintō, Buddhism, Christianity

Ren, lady of Go-Daigo, conspires against Morinaga, for her son Tsunenaga, 389

Rennyo Shōnin see Kenju

Restoration, of Kemmu era, 386; of 1867, 677

Return, English ship, 655

Retvisan, Russian battleship

at Port Arthur, 711

Rhinoceros, fossil, $45 \mathrm{f:n}$.

Rice, castle, 62 ; diet, 68 ; culture, 71 ; chewers, nurses, 74 f.n.; corporation of cultivators, 87; for public use, 124; standard of exchange, 182; store-houses, for sale to travelers, 188; loaned to farmẹrs, 200; substitute crops 
urged, 207 ; boiled and dried, ration, 221 ; paddy-loom, 280 ; area cultivated, 15 th century, $437-8$, beginning of - $16 \mathrm{th}$ century, 439; currency, 439, 638 ; relief tax on feudatories, 614; production increased, 615 ; rice exchange, 616 ; classification of fields, 637-8; modern crops, 694

Richardson, English subject, killed in Namamugi, 673 "Rich Gem," Princess, in myth of Hosuseri and Hohodemi, 20,21

Riehū, 17th Emperor (400405 A.D.), first of "protohistoric" sovereigns, 108-10

Right, Minister of, 160

Rikken Seiyñkai, "Friends of the Constitution," 693

Riparian improvements under Nintoku, 105

Rituals, Ancient, 63-4

River of Heaven, Milky Way, 12,25

Rock, Sacred, on Kannabi mountains 65

Rodriguez, Joâo (1559-1633), Portuguese Jesuit, interpreter at Yedo, 546

$R \hat{o} j \bar{u}$, seniors, ćabinet, 632, 633; council of ministers, removed from proximity to shoguin, 601; and tax collecting, 639 ; judges, 640

Rokkaku, one of Five'Regent Houses, 416; Yoshihisa's eampaign against, 431

- Sadayori, see Sasaki Sadayori

- Takayori, see Sasaki Takayori

Rokuhara, n. and s. suburbs of Kyoto, offices of the Bakufu tandai, 345, 347; in Kyôtto revolt, 380,384

Rokujô, 79th Emperor (11661168), 295

Roku Kokushi, Six National Histories, 188, 251

Rokuon-ji, family temple of Yoshimitsu, 454

Roku-shōji, Six Temples built by Shirakawa, 272

Roman Empire, early trade with China, 60

Rōnin, frce lances, 565 ; revolt of, 584 ; " $47, " 606$ (ill.) -7

Roofs, 154, 209, 227, 373

Rope, straw, in ' myth, 12; paper-mulberry, used in fishing, 72

Rosen, Roman Romanoviteh, Baron, Russian peace commissioner at Portsmouth, 725

Rossia, Russian cruiser at Vladivostok, 717

Rouge, in costume, 279

Rozhdestvensky, Ziniry Petrovitch (b. 1848), commanding
Baltic squadron, defeated by 'Tōgō, 723-4

Rules for Decisions, 349; of Judicial Procedure, 641

- and Regulations of Three Generations, Sandai-Kyakushiki, 177 ; revised (819), 232 Rurik, Russian cruiser, 717

Russia, relations with, 18th and early 19th centuries, 658; joins France and Germany in note protesting against Japanese occupation of Manchurian littoral, 702; war with, 703-24; peace, $724-8$, (text) 737-40; situation in 1911; 730

Russian name Akuro-ō may be read $\bar{O}$ ro $-\overline{0}$ and mean, 222

Ryōbu Shintō, mixed Shintō, Kami being avatars of Buddhas, 193, 452, 644

Ryōgoku, bridge in Yedo, 586 Ryōken, priest of Nanzen-ji, 454

Ryōshun see Imagawa Sadayo Ryū, Shinki, artist, 113

Ryūkō, Buddhist priest, ' advises of Tsunayoshi, 602

Ryūkyũ : Islands, language cognate to Japanese, 56; King of; intervenes, 445 ; Japanese intereourse with islands, 447; king of, and Japanese invasion of mainland, 516; French in, (1846), 663; Formosa and, 684, 698; Chinese claims to, "given up, 698:9

Ryūzōki, Kyūshū family, defeat Shöni, 470, 471, 500

- Takanobu (1530-85), death, 500-1

Sacrifice, early, 64; human, $47, " 50,74, \cdot 82,105,163$; of weapons, 85; at grave, 212

Sadami, Prince, Emperor Uda (q.v.)

Sadanobu see Matsudaira

Sadanobu
Sadatō see Abe Sadatō

Sadatoki see ${ }^{\prime}$ Hōjō Sadatoki

Sadatsune;" Prince, sons, 441

Sadayori see Sasaki Sadayori

Sado, island, in early myth, 29 ; settlement, 34 ; silver mines, 528; penal establishment, 642

Sado Maru, Japanese transport sunk by Vladivostok squadron, 717 :

Sacguisa Moriyoshi (d. 1651), 582

Saeki family, member of, made state councillor, 225-6 Saga, 52nd Emperor (810$23), 231-3$; as calligrapher 234, 251; his children and the Minamoto, 206

- Genji, branch of Minamoto,
Sagami province conquered by Hơjō Sōun, 46.5; Hōjō and Uesugi, 467; tobacco in, 617

Sagara Prinee under Kwammu, 225-6

Saghalien, Russians in (18th century), 658 ; Russian-and Japanese claims in $697-8$; Russian title recognized (1875), 699, 704; Japan's claim to $\%$ after war with Russia, 725 ; not to be fortified, .726

Saho plots against Suinin, 82 Saichō, posthumously Dengyō Daishi, 805 "A.D. introduces Buddhist Tendai, 227 (ill.)$8,367,368$

Saigō Takamori or Kichinosuke $(1827-77)$, leader in anti-foreign - movement, 670; in alliance with Chōshü, 6767; urges war with Korea and resigns from cabinet (1873), 683-4; in Satsuma rebellion, 685-6 (ill.)

Saigyo Hōshi (1118-90), poet and ascetic, 367

Saikō, bonze, 296

Saikyő, western capital, 281

Saimei, Empress (655-61), the Empress Kōgyoku : sueceeds Kōtoku, 166, :460; Yemishi at coronation, 38 Saimyō-ji, Zen temple, 352 Saionji in Kawachi, 417

$\rightarrow$ Kimmochi, Marquis , (b. 1849), head of Constitutionist (Liberal) party, 693

Sairan Igen, book by Arai Hakusekai, 608 .

Saitō family, in Ise defeated by Oda, 468; feud in Mino, 480; helped by Buddhist priests, 485

- Hidetatsu, 480

- Tatsuoki, defeated by

Nobunaga, 480; leads revolt in Settsu, 484

- Yoshitatsu (1527-61), son of Hidetatsu, kills him, 480

Sajima, Prince, (d. 125 A.D.), 37

Sakai, near Ōsaka, Ōuchi Yoshihiro's castle at, 415; China trade, 444; Nobunaga's quarrel with, 482-3; firearms made at, 489 ; port, 529

- family, Bakufu ministers from, 624; tamarizume; 636 .

- Tadakatsu, minister of

Tokugawa, 584, 586, 594

- Tadakiyo (1626-81) takes over most of Shögun's power, 587; succession to Go-Mizuno-o, 590; succession to Ietsuna, 596; displaced, 597;601 206,265

- Tadayo, minister under Hidetada, 580 
Sakaibe Marise, uncle of Emishi, 146

Sakamoto, castle at, 485

Saka-no-ye Tamuramaro (758-811), against Yemishi, 221, 223; aids Saga, 230

- Karitamuro (728-86); chief of palace guards, 222

Sake manufacture of, taught by Sukuna, 69 ; dealers taxed, 439

Sakitsuya, killed for lêsemajesté (463 A.D.), 97

Sakugen, priest, 474

Sákuma Morimasa (1554-83), defeated, 495

-Nobumori (d. 1582), soldier of Nobunaga, $477,481,487$

Sakưra-jima, eruption, 619

Sákuramachi, 115th Emperor $(1735-47), 621$

Sakurayama," adherents of Southern Court, 400

- Koretoshi, commands force loyal to Go-Daigo, 381

Salaries, official, 615

Salt, use of, in early Japan, 69

Sanbō-in, temple, 522

Samisen, 3-stringed guitar, 606; 244 (ill.)

Samurai, soldier class, freelances, 584 ;' attitude of, toward foreigners, 671 ; place of, in making New Japan, 677, 679 ; attitude of Crown to, 682 ; abolition of, 685 ; Satsuma rebellion, 685-6

Samurai-dokoro, Central Staff Office, (1180) in Yoritomo's Bakufu system, 327 ; in administration of Kyōto after Shōkyü war, 345 ; in Muromachi administration, 436

Sanada Masayuki (15441608), accused of encroachment, 503 ; blocks Tokugawa Hidetada's army, 560

Yukimura (1570-1615), in defence of Ōsaka castle, 567 Sandai Jitsu-roku, True Annals of Three Reigns, 85987 (901), 5, 251

Sandai-Kyaku-shiki, Rules and Regulations of Three Generations,' 177

Sanetomo see Minamoto Sanetomo

San Felipe, Spanish galleon, wrecked in Tosa, 543

Sanjō, 67th Emperor (101216), 260-1

-Sanetomi, Prince (1837-

91), leader of extremist party, 673 ; in alliance of Chöshū and Satsuma, 677, 683 (ill.)

Sanjōnishi Sanetaka, scholar, 447.

Sankyō-ron, Shōtoku quoted in, on management of state, 142

Sano, branch of Fujiwara, 266
Sano Masakoto attempts to assassinate Tanuma Okitsugu, 619

Sanron, Buddhist sect, 191

Santa-Martha, Juan de, Spanish Franciscan, executed (1618), 551

Sanuki, province, $28,290,470$

Sapan wood, trade, 445

Sarcophagus, stone, clay, and terra cotta, of Yamato, 49

Saris, John, agent of East India Company, settles at Hirado, 653-4

Sarume, "monkey" female," dances before cave of Sun goddess, 213, 12

Sasa Narimasa in Komaki war, 497,500

Sasaki family, branch of the Minamoto, 265; favour Takauji, 406

- Mochikiyo; estates of, 426

- (Rokkaku) Sadayori (d. 1552) captures Kyōto, 433; reconciles hostile parties, 434 ; generosity to Crown, 461

- Shōtei general in forces against Nobunaga, 484

- Takayori (d. 1520), great estates, 426; campaign against, 432

Sasebo, Japanese sally from, on Port Arthur, 711

Sashihire, Hayato assassin (399) of Nakatsu, 41; death, 109

Sassulitch, Russian general, on Yalu, 713, 714

Satake family, Yoritomo's attempt to win, 306, 307; one of " 8 Generals of Kwantō," 425 ; of Hitachi, 47.1, allies of Shingen, 483

- Yoshinobu (1570-1633), opposes Ieyasu, 559, taking army over to Ishida, 560; fief reduced_(1600), 561

Satehiko see Ōtomo Satehiko Sato Tadanobu, impersonates Yoshitsune, 323

- Tsuginobu, 318

Satomi family, one of " 8 Generals of Kwantō," 425; fight Hōjō, 431; defeated, 466; allies of Shingen, 483

Satow, Sir Ernest, sceptical of dates in "Chronicles," 6 ; on revival of Shintō, $649 \mathrm{f} . n$. Satsuma, Xavier in; 531; later preaching, 533; foreign ships in, menace Tokugawa, 550 ; trade, 610 ; tobacco, 617 ; bonita, 618; moderate party, 673; against Tokugawa, 6767; predominant, 679-80; fiefs surrendered, 680 ; clan representation, 681; rebellion of 1877, 670, 684-6

Sawaga, monastery, 500

Sawing to death, 642
Scholars, Chinese and Korean, in Japan, 153; sophists, 240; in Bakufu, 328; in Ashikaga system, 403 ; literati at Court, 635; Japanese sent to Europe and America, 691

Scholarship recommended in Court Laws, 577; Ieyasu's attitude to, 578 ; revival of learning, 578-9; Tsunayoshi favours Chinese scholarship, 599 ; Western, 614

"Scrutator," nairan, Bakufu official at court, 330

Sculpture in Nara epoch, 208; in Heian, 280; Kamakura period, 374-5

Sea-Dragon, Castle of, myth $20,26,32-3$

Sea, Command of, in 1592 campaign, 515

Seals, 137 f.n.; of Taikō, 529, 578; (ill.), 301, 694, 731

Seal skins in early myth, 20 Seaweed as food, 69, 212

Sebastian, Spanish sailor, undertakes coast survey, 547

Secretaries in Bakufu, 633

Seed distribution by Crown (723), 207

Seidan, book on government by Ogyū Sorai, 613

Seidō, or Shohei college, 626, 627

Sei-i, "barbarian expelling," title of shōgun, $672 ;$ sei-i tai-shōgun, hereditary title, 331-2

Seikan, priest, 566

Seimu, 13th Emperor (131190 A.D.), 87-8

Seinei, 22nd Emperor, (480-4 117-19

Seishi-roku, record of nobles (814 A.D.), 233, 153

Sei Shōnagon, poetess, 249 f.n., 261

Seiwa, 56th Emperor (85976), 237; (ill.), 238; sons become Minamoto, 206

Seiwa Genji, branch of Minamoto, 206

Sekigahara, battle of (1600), 559-61

Sen, Japanese coin, 187

Senate, Genrō-in, organized (1875), 689

Sengoku Hidehisa (1551-1614) soldier of Hideyoshi, 497, 502 Senkwa, 28th Emperor (5369 ), succeeds his brother Ankan, 121-2

Seoul, Korea, 80; march upon (1592), 513-14, Japanese forced to give up, 517; Chinese resident in, blocks Japanese control, 699; foreign legations removed, Japanese resident-general in, 728

Sepulchres of Yamato, 49; contents, 51, 74 
Serpent, eight-forked killed by Susanoo, 13, 18, 25; possibly the name of a local chief, 31 , 70 ; early shrine, 65 ; worship, 128

Sesshū (1420-1506), painter of Kamakura school, 365, 450; academy, 452

Seta, Long Bridge of, 170

Settsu Dōjun, suicide, 386

Settsu, Buddhist temple in, 137; Kiyomori moves capital to Fukuhara in; 300 ; priests revolt, 484

Seven Generals plot against Ishida, 558

Sexagenary Cycle in Japanese chronology, 5 ; accounts for error of 120 years, 7, 99; Chinese origin of, 27

Shaho, battle of, 719

Shaka, Sakiya Muni, 368, 369

Shan-hai-ching, Chinese record (4th cent. A.D.), 60, 68

Shantung peninsula, fighting on, (1894), 701; part of, seized by Germany, 705

Shao-kang, mythical Chinese ancestor of Japanese kings, 32

Shell-heaps, 45-6

Shiba, district of Tokyō, Castle of, built (803), 222; temple with tomb of Hidetada, 581

- family, in office of Muromachi kwanryō, 414, 436; one of Five Regent Houses, 416; make trouble in Kyūshū, 421 ; in Ōnin war, 430 ; in Ōmi, 469

- Mochitane, estates of, 426

- Tachito, first Buddhist missionary, 131, 134

- Takatsune, revolts against Ashikaga, 410

- Yoshihige, minister of Ashikaga Yoshimochi, 418

- Yoshikada, rival of Masanaga, 428

- Yoshimasa (d. 1410), shitsu$j i$, first to be called kwanryo, 414,436

- Yoshitoshi estates, 426; Ōnin war, 428

Shibata Gonroku, 495

- Katsuiye (1530-83), general under Nobunaga, -477, 481,484 ; councillor, 494; death, 495-6

Shibukawa Noriyasu, government astronomer, 614

- Shunkai, revises calendar (1683), 599-600

Shi-dō, "Way of the Warrior," by Yamaga Sok̄̄, 607

Shidō Shōgun, Campaign of, 79-80

Shiga, in Ōmi, 176

Shigehide see Hagiwara Shigehide

Shigehito, Prince, 289, 291
Shigeko, mother of Ashikaga Yoshimasa, 423

Shigeyoshi see Shigeyoshi

Shihotari, Prince; commands government station in Anra, 83

Shijō, 87th Emperor (123342), 355

Shijō-nawate, in Kawachi,

battle (1348), 402

Shikken, military regent, in Yoritomo's system, head of the man-dokoro, great power of office held by Hōjō family, 327; Ashikaga substitute sccond shitsuji for, 403; kwanryō later equivalent to, 436; of Inchü, office held by Hino family, 440

Shikoku, early history, 28, 29 ; pirates in, (931-7), 255; in 16 th century wars, 470

Shikotan, inhabitants of, not pre-Ainu, 43

Shimabara, battle of, defeat of Ryūzōki Takanobu (1585), 501; Jesuits and trade at, 536 ; the S. revolt (1637-8), 554-5, puts end to Portuguese trade, 656

Shimada Yũya, judge, 639

Shimazu in Kyūshū, 470, 471; defeated by Hideyoshi, 500-2 - Ei-Ō, 631

- Hisamitsu or Saburō (182087), feudatory of Satsuma, in Namamugi incident, 673; in making of New Japan, 677; with Saigo in Satsuma, 684

- Iehisa (d. 1587), defeated by Hideyoshi, 501-2

- Tadahisa (12th century) founder of family, 471

- Tadakuni, in Ryūkū, 447

- Yoshihiro (1535-1619), successor of Yoshihisa, 502

- Yoshihisa (1536-1611), defeats Ryūzōki Takanobu, and is ousted by Hideyoshi, 5012 ; against Ieyasu, 559,560 ; escapes after Sekigahara, 561 Shimbetsu, families of preconquest chieftains or Kami class, 77; three sub-classés, 92 ; early administration, 98 ; help put down revolt of Heguri, 128, 129; and rank of Empress, 189; classification of Seishi-roku, 233

Shimizu, branch of Tokugawa, 592

- Muneharu, suicide, 490-1

Shimoda, residence given to Americans, 666

Shimonoseki, French, Dutch and Americans fired upon, attack, 674-5; peace with China concluded at, (1895), 702

Shimōsa, Taira Masakado's revolt in, 254; Taira Tadatsune's, 263-4

Shimpo-tō, Progressist party, organized (1881), 690

Shin, Buddhist sect (1224), 367,370 ; Hongwan-ji feud with Enryaku-ji, 462-3; internal quarrels, 463; revolt of 1488, Ikkō-ikki, 463-4; oppose Nobunaga, 486 ; interdieted in Shimazu, 502

Shinano, Yemishi in, 37; revolt of 'Minamoto' (Kiso) no Yoshinaka in, 307-8; Fakeda and Uesugi in, 467 ; silk growing, 617

- Genji, branch of Minamoto family, 265

Shingen see Takeda Shingen Shingon, "True Word," Buddhist sect founded by Kūkai, 229; Heijō and Shinnyo devoted to, 231 , esoteric character, 369

Shingū, Kii province, tomb of Hsu Fuh, 78; naval base of Southern army, 402

Shinki, Chinese painter, 127

Shinnō, painter, 450

Shinnyo, name in religion of Takaoka, 231

Shin $-\overline{0}$, bridge in Yedo, 586

Shino Sōshin and incensecomparing, 457

Shinran Shōnin (1184-1268), founder of Shin sect, 370 , 462,463 (ill.)

Shintō, sun-myth, 12-13; rules in Yengi-shiki, 64; therianthropy, 65 ; shrines 66 ; Board of Religion, 178-9; first use of name (c. 586), 135; relation to Buddhism, 132, 138; mixed, with Buddhism, $193,195,196,228,368,452$, 644 ; overshadowed by Buddhism, 225, and subservient, 229 ; insincerity, 246 ; in Heian epoch, 281; priests support Southern Court, 400; relations with Confucianism and Buddhism, 452-3; Pure Shintō, 453, 644; combined with Confucianism, 621; revival of, $614-50$

Shinzei see Fujiwara Michinori Ships, early, 22, 60, 72, 126; building, 22,80 , as tribute, 99,100 ; bureau of shipping, 155; China trade, 443 f.n., 444-5; size limited, 585, 655; limitation removed, 666; middle of 19 th century, 669 ; modern mercantile marine, 695 ; illustrations, 360 , '556, 654; see Navy

Shiragi, Korea, myth, 60; annals, 80; war with Kara, 81 ; king settles in Japan, 84 ; submits to Jingo, 89 ; Japanese attacks on, 89; Chinese 
immigration, 102; revolt against Yūryaku, 114, 121; weakened, 122 ; dispute over Imun, 123; ship-builders, 126; Buddhist image, 134; defeats Kudara and Mimana, 149-50; Japanese intervention, 151; invasion, 152; families in Japanese nobility, 153 ; travel to Japan forbidden, 167

Shirahata, in Harima, fortress held by the Ashikaga, 393-4; by the Akámatsu, 420, 421

Shirakabe; Prince, 204; see Kōnin

Shirakawa, 72nd Emperor (1073-86), 271-3

Shiren, priest, 454

Shiro-uji,! branch of Taira family, 265

Shishi-ga-tani plot

against Taira, 296

(1177)

Shitennö-ji, temple to Four - Guardian Kings of Heaven, 138

Shitsuji, manager, of mandokoro, office hereditary in Nikaidō family, 327; of monju-dokoro, 328 ; second $s$. created in Takauji's system, -403; and kwanry $\bar{o}, 414,436$ Shizuka, mistress of Yoshitsune, 322, 323

Shizugatake, bättle of, (1583), 495

Shōan, Student of Chow and Confucius, teacher of Naka and Kamatari, 148

Shōchö koban, góld coins of 1428,527

Shōdăi-ji, temple; 191

Shödan-chiyō, work of Ichijō Kareyoshi, 448

Shöen, great estates, manors, 251-2, 201-2; temple domains, 208; attempts to check, 270; effect - on agriculture, 281

Shōgun, "'general," 83, 181; head of Yoritomo's bakufu system, 327; attempt to have Imperial prince appointed, 340,353 ; unimportant under Hōjō, 354; Fujiwara, then Imperial princes, appointed, 354; Ashikaga in Northern Court, 398 ; powers transferred to kwanry $\overline{0}, 436$; under Tokugawa, 577; minister gets power, 587; separated from ministerial council, 601; Chinese classics lessen power, 614,621 ; court of last appeal, 639-40; Imperial rescript to, 673 ; power resigned to Crown, 677

Shōhei, Japañese pronunciation of Changping, Confucius's birthplace; Shoheibashi, bridge, 'Shōhei-kō, col- lege, near temple' to Confucius, 578; lectüres there, 613

Shōhei, period, 1346-69, 406

Shohyo era, 931-7, 206, 255

Shōkagu-in, academy of Minamoto (881), 206

Shōkō, 101st Emperor (1412--

28), son of Go-Komatsu, 412; 418, 460;

Shōkoku-ji, Zen temple in Kyōto, art school of Josetsu, 450; one of the "Five;". 455 Shōky $\bar{u}$, year period 1219-22, and the struggle between the Court and the military, $340 \div 4$ Shōmu, 45th Emperor (72448), 188-97.

Shōni, independent family of Kyūshū, 421, 444, 470

$\because$ Tokihisa (d. 1559), last of family, 470

Shonzui (16th century), manufacture of porcelain, 451

Shōren-in, temple in Kyōto; 419

Shōso-in, Nara, 216-17 (ill.)

Shōtoku, Empress (765-70),

Köken returns to throne, 199 , 460 ; orders amulets printed, 404

- Prince, or Taishi (572-621),

136 ; history, 1,143 ; on religions, 132-3;defeats Mononebe Moriya, 137 ; builds 'Buddhist temple, $137-8$; relations with Sushun, 138-40; opposes $u j i$ system, 140; his "Constitution," "140-2; death, 143; China, 144, 153, 367-8; official promotion system, 146; a painter, 155

- period, 1711-15, trade rules of, 609,613

Shrines, yashiro, early Shintō, 64; simple architecture of, 66 ; in reign of Suinin, 82 ; less important than temple after "mixed Shinto, 193; shrine and temple, ji-sha, 193; immune from shugo, 329 Shūbun, painter, 365,450

Shüi-shü, anthology, 251

Shujaku, 61st Emperor (93146), 253-6

Shukō or Jukō (1422-1502), Zen priest code and teaceremonial, 457 ;

Shunkai see Shibukawa Shunkai

Shunzei, nom de plume of

Fujiwara Toshinari, 366

Shuryō, Buddhist priest, envoy of Muromachi to China, 445

Shu-shi see Chutsz

Shūshin, Zen priest, 454

Silk in early times, 68 ; culture, 71,113 , curtains for partition, ' 126 ; mulberry trees on uplands, 182; in Nara epoch advanced by need of rich robes for priests, 208; exported, 444; growing in Kotsuke, Shinano, etc., 617 ; "silk clothiers," 102

Silkworm, worship of, 65

Silver:: and other precious metals, 186,528

Si Wang-mu, owner of miraculous peachtree, 26

"Six National Histories," 5

Slave, value of, 173-4

Slaves and slavery, prehistoric, 75 ; aliens become $n u h i$ at conquest, 77 ; prisoners of war and criminals, 95; Daika, 161; laws on slavery for debt, 173 ; Daihō laws, 178 ; provinces, 287; Christians and slave-trade, 539,540

Sleeves, legal regulation of; 211, 279

Small-pox interpreted as divine punishment, 134

Snow and snow festivals, 277; image of Dharma, 508 (ill:)

Sō family and Korean trade, 444

So-ami, artist, patronized by

Yoshimasa, 425; envoy to Ming court, 443

- Sadamori (1385-1452) and

Korean trade, 444

- Sukekuni (d. 127.4), governor of Tsushima, killed in battle with Mongols, 359

Sōden, inscription on Hōkō-ji béll, 566

Soga, family, descendants of Takenouchi, 106, 130; power, $105,107,109,115,130$; favour Buddhism, 133; relation to Imperial family, 135; crushed by Fujiwara, 148-9; usurpation causes Daika, 164 - Akae, minister of the Left, in conspiracy against Ōama, 170 - Emishi, $\bar{o}$-omi, successor of Umako, $146 ;$ aśsumes Imperial titles, 147 ; killed, 149

-Iname, $\overline{0}$-omi, 130 ; recommends adoption of Buddhism, 133; and Buddhist temple(552 A.D.), 138

- Iruka, powerful under Kōgyoku, 147; quarrels with Yamashiro, 147-8

- Sukeyasu, death, 333

-Umako (d. 626), historiography, 1,$143 ; \overline{0}$-omi, kills Mononobe Moriya, 130 ; power under Bidatsu, 134; guardian of Buddhist images, 134; relationship to Imperial family, 135; final success over Mononebe Moriya; 136-7; builds temple of Hōkō-ji (587 A.D.) 138; häs Sushun assassinated, 138-9; alliance with Shōtoku against military system, 140; death, 146 
Sogen (Chu Yuan), Chinesc priest, 361 ; and Kamakura calligraphy, 365

Soji-ji, temple, 454

Sokō see Yamaga Sokō

Solfataras of Unzen volcano, torture of Christians in, 553

Solitary Kami, 9

Sōma, branch of Taira, 265

Somedono, Empress, wife of Montoku, 236

Song Wang Myong, King of Kudara, and Buddhism, 132 Son-Kwang, Kudara prince, settles in Naniwa, 168

Son-D Jō-I, "Revere the Sovereign, expel the barbarians," motto, 669

Sōrin see Ōtomo Yoshishige

Soscki see Musō Kokushi

Sōsetsu, envoy to China of

Ouchi family, 445

Soshi-Mori, Korea, myth, 60

Sōtan, painter, 450

Sotelo Luis (1574-1624), Spanish Franciscan, attempts to survey Japanese coast, 547 Sōtō, sect, modification of Zen, 371

Sôun see Hōjō Sōun (Nagauji) Southern Court, Daikagu-ji, 356 ; war of dynasties, 396412; adherents, 400; rulers, 406; claims ignored in 1412 and $1428,412,418$

Southwestern Japan, comparative accessibility of, 86

Sow race, Borneo, probable source of Kumaso, 39

Sōya, strait of, 45

Sōzen see Yamana Mochitoyo Spaniards, in Manila, jealous of Portuguese, 542; in Tosa with "wrecked" galleon, 543; intrigue against Dutch, 547, 653; Dutch and English intrigue against, 549-50, 552; Hidetada orders deported (1624), 552, 655; invasion by, feared, and conquest of Philippines urged, 553; Spanish authorities forbid priests going to Japan, 553; refuse grant in Yedo, 651; trade unimportant, 652-3; end of trade, 655

Spear, jewelled, token of anthority of Kami, 9; sign of military authority, 30; heads of, 52; export of, 444 , 445; carrier (ill.), 622

Spinning in myth, 25; in early times, 67-8

Spirit, tama, survives body, 65 ; belief in activity of, 204 , $244,258,282,330$

Spying in Bushi system, 286; civil, 296, 612, 635 f.n.; in Tokugawa Laws of Military Houses, 574

Stackelberg, Baron, Russian general defeated by $\mathrm{Oku}$ at Telissu, 716-7

Stag's shoulder blade, use in divination, 27, 66

Stake, death at, 125, 642

Stars in cosmogony, 26

State, Central Department of, Nakalsukasa-shō, 179

Stature of Japanese, 58

Steel for swords, 374

Stirrups among sepulchral remains, 52 ; bridle, harness and, 61 (ill.)

Store-house, imikura, 63, 114; kura, 281, administrator of, kura-bugy o, 638

Stössel, Anatol Mikhailovitch, Russian gencral, surrenders Port Arthur, 720-1

Straw, famine food, 623

Straw mat, talsu-gomo, for carpet, 126

Straw rope in sun-myth, 12

Sugar culture, 617

Sugawara family descended from Nomi no Sukune, 242; scholars, 448, 449

- Fumitoki, littérateur, 261

- Hidenaga, lecturer, 448

- Michizane (845-903), called

Kwankō, schoolman, 240; plot to send him on embassy to China, 241; Fujiwara plot against, 242 (ill.), 4 ; one of authors of the fifth of " $\mathrm{Na}$ tional Histories,"188; Chinese prose, 249; shrine, 243 (ill.), 244,258 ; descendants, 664

- Toyonaga, patronized by Ujimitsu, 448

Suicide in early myth, 17-18; some examples, 101, 147, 189, $199,385-6,582$; at grave, $47,50,74,82,163,173,585$; in protest against policy, 415 ; as punishment, 642

Suiko, 33d Empress (593628), consort of Bidatsu, $140-6$; historiography 1,3 ; Chinese learning, 153

Suinin, 11th Emperor

B.c.-70 A.D.), 81-5; attempts to abolish human sacrifice, 50,82

Suisei, 2nd Emperor (581-549 B.c.), 78

Sujin, 10th Emperor (97-30 B.C.), 79-81; and ship building, 22

Sukenari (or Jūrō), 333

Suken-mon-in, mother of GoEnyū, relations with Yoshimitsu, 441

Sukō, Northern Emperor (1348-52), 406, 407

Sukuna Hikona, mythical pygmy healer, 15; inventor of sake, 69

Sukune family, growth of its power, 90, 105, 106; sce also Takenouchi-no-Sukune
Sulphur trade, 445

Surnida, river bridged, 586

Sumida-gawa, groves, 612

Sumitada see Omura Sumita-

da

Sumiyoshi, Kyōto school of painting, 365 ; decorations for Impcrial palace, 629

-, battle, defeat of Ashikaga, 402

- Gukei, or Hirozumi (1634 1705), 600 .

Summer Campaign, 57,0

Sumptuary laws in Nara epoch, 211; in Kamakura period, 355,375 ; of Hideyoshi 525 6 ; in military laws, 576,584 ; of Sadanobu, 624-6; in early 19 th century, 661

Sumpu, in Suruga, Ieyasu re tires to, $562,573,580$; vendetta illegal in, 607 ; jodai of, 637

Sun, and titles of nobles, 62

Sun-crow, in Yamato expedition, 23; on banners, 155

Sun goddess, withholds light, 12 , an incarnation of Buddha, 195

Sung, writer on war, 286

- philosophy, Gen-e introduces, 447- 8 ; painting, Josetsu introduces, 450

Sungari, Russian transport at Chemulpo, 712

Sunrise Island, Jih-pen, Chinese or Korean name for eastern islands, 77

Superstition; in 4 th-6th centuries, 127; in Nara epoch, 196; in Heian, 274, 281-2

Supply, Departments of in capital, under Daiho, 180

Suruga, brigands of, crushed by Yamato-dake, 37; province given to Ieyasu, 489 .

- Genji, branch of Minamoto family, 265

Survey for map under Hideyoshi, 527; coastal begun by Spanish, 547

Susanoo, Kami of Force, contest with Amaterasu, 11; expelled from heaven, kills great serpent, 13; as treeplanter, 22; rationalization of myth, 31 ; its bearings on relations with China and Korea, 60 ; purification of, 65 ; as guardian of forests, 71 ; ruler in Shiragi, 81

Sushen, Tungusic settlers on Sado Island (549 A.D.), 34; expeditions of Hirafu against, (658 \& 660), 34-5; captives of Yemishi, 38, 39; later called Toi, 262

Sushun, 32nd Emperor (58892), 138-40, 130

Su Ting-fang attacks Kudara (660 A.D.), 167 
Sutoku, 75th Emperor (112441), 273; "Hōgen" tumult, 289, 290-1

Sutras, Buddhist, 194; copying as atonement, 290

Suwō, brigands, 40 ; woman ruler in, 85; Ōuchi family of; 443,460

Suye Harukata, called Zenkyō (d. 1555), crushed by Mōri Motónari, 469

Suzuka-yama, apparent Tatar remains in shrine at, 222

Swan, Yamato-dake in form of, 65 ; in cure of dumbriess, 82

Sword; myth, Imperial insignia, $13,18,31,33,60,63$ 79,319 ; sepulchral remains, 51 ; single- and double-edged, 70; offered at shrines, 85; large and small, 181; Minamoto heirlooms, 285,299 ; swordsmiths, $374,450-1$; exported, 444, 445 ; hilts, "451, 302 (ill.); samurai and swordwearing, 682,685 ; illustrations $176,413,460,509$

Syllabary, phonetic,' development in Japanese away from Chinese ideograph, 3 ; in Heian epoch, kata-kana and hiragana, 250; used in Joei code, 349

$T a-b e$, rice-cultivators or rustic corporation, 87,96

Table and cookery in ancient Japan, 69; in Kamakura period; 374

Tachibana family, 240

1 Hayanari (d. 843), exiled with Tsunesada, 236; 'calligrapher, 234 f.n., 251

- Hiromi, scholar, 240

- Moroe (684-757), minister of the Right, acquiesces in rule of Kōken-Shotoku, 200; may have compiled anthology of "Myriad Leaves," 214

Tachiri Munetsugu, Court envoy to summon Nobunaga to Kyōto, 479,481

Tactics, of $B u s h i, 286$; gradual change in, 487-9

Tada Genji, branch of Minamoto, 265

Tadahiro see Katō Tadahiro

Tadakiyo see Sakai Tadakiyo

Tadamori see Taira Tadamori

Tadateru see Matsudaira Tadateru.

Tadayoshi see Ashikaga Tadayoshi and Tokugawa Tadayoshi

Tadong River, Korea, 81 ; in campaign of $1592,513,514$

Taema, Prince, and expedition against Shiragi (603 A.D.), 151 Taema-no-Kuehaya, wrestler, 83

Ta-fu; Japanese envoy to

China (A.D. 57),-84
Taga, Castle of, built in 724 to check Yemishi, 220; headquarters transferred to Isawa: 222

Taguchi Shigeyoshi, deserts with fleet to Minamoto in battle of Dan-no-ura, 319

Tai-hei-ki, historical work of 14th century, quoted on causes of $S h \bar{o} k y \bar{u}$. struggle, -341 ; on Yoshinaga, 393

Taihō see Daihō

Taiken-mon-in; consort of Toba, 273; intimacy with Shirakawa, 289

Taikō, $\lambda$ "sreat merit," 183; rex-regent, title of Hideyoshi, .522 ; Taiko-zan, temple at his birthplace, $4: 6$

Taiko ki, "Annals of the Taikō ': quoted on Hideyoshi's palace, 506-7

Taikwa see Daika

Tai Peh, Chinese prince, exile to Japan ( 800 B.C.), 32; Imperial descent from, 645

Taira, family, descended from Prinee Katsurabara, generals of Imperial guards, 205-6, 86; called Heike, 206 f.n.; manors and armed forces, 252; lose estates,: 253; quarrel with Minamoto, 254, 263; revolt against Fujiwara, 258; provincial branches, 265 ; treatment of priests, 274 the Gen-pei epoch, struggle with Minamoto, 284-335; genealology, 288; in Heiji tumult crush Minamoto, 292-3; hold most important offices, 295; Yorimasa conspiracy against, 299; defeated by Minamoto, 302-24

- Atsumori (1169-84), killed at Ichi-no-tani; 315

- Chikafusa, provincial governor, 308

- Hirotsune, favours Yori tomo, 305

- Kanetaka, lieutenant governor of Izu, 303; is killed by Tokimasa, 304

- Kiyomori (1118-81), wins manors, 252; treatment of priests, 274; crushes : Minamoto, $288 ; 292$; supports Go-Shirakawa, 289; alliance with Shinzei, 292; lessens power of Fujiwara, 294 ; supreme, 295 ; arbitrary rule, 296 ; crushes, Yorimasa conspiracy, 299-300; death, 301, 308

- Korehira, founder of IseHeishi, 265, 288

- Koremochi, founder of branches of Taira, 265

- Koremori, commands army sent against Yorimoto, 306
Taira Masakado (d. 940), 206, his revolt, 253-4, 275

- Masamori, crushes rebellion of Minamoto Yoshichika, 288

- Michimori, killed in battle of Ichi-no-tani, 315

- Munekiyo helps save life of Yóritomo, 293-4, 302 ; relations with Minamoto, 320

- Munemori (1147-85), Shishi-ga-tani plot; 296; abandons Kyōto, 309-10; refuses Yoshinaka's request for an alliance, 3.12 ; escapes after Ichi-no-tani, 315; defeated at Yashima, .317-18; executed, 319 ; possibly á changeling, 320 - Noritsune (1160-85), defeats Ashikaga Yoshikiyo in B tchū, 311; at Yashima, 318; drowned at Dan-no-ura, 319

- Sadamori defeats Taira Masakado, 254, 265, 288

--Shigehira (1158-85), sacks and burns three monasteries, 301 ; in 1181 attacks Minamoto Yukiiye, 308; taken prisoner at Ichi-no-tani, 315; death, 320

+ Shigemori '(1138-79), 265, 288; Fujiwara : Narichika's jealousy of, 296 ; restrains Kiyomori, 297; death, 298

- Shigenobu, in revolt against Fujiwara (967), 258

- Tadamasa, favours Sutoku in $: H o \overline{g e n}$ tumult, executed by Kiyomori, $289,290,291$ - Tadamori (1096-1153), body guard of Shirakawa, 288 f.n.; against Yoritomo, 306 ; descent; 206; treatment of priests, 274

- Tadanori (1144-84), killed at Ichi-no-tani, 315

- Tadatsune, defeated by Minamoto Yorinobu (1031), 263-4

- Takamochi, first: marquis (889) of Taira, 205-6

- Tomoakira, saves his father, 315

- Tomomori (1152-85) burns and sacks monasteries; 301 ; saved by his son at Ichi-notani, 315; drowned at Danno-ura, 319

- Tomoyasu, enemy of Yoshinaka, commands palaceguards, 312

-Tsunemasa, 264

- Yoritsuna, guardian of Sadatoki, crushes Adachi (1286), killed (1293), 376

- Yoshibumi, 265

Taishiden Hochū, Shōtoku in, on Buddhism, $132+3$; on property of Mononobe Moriya; 138 
'Taitsang, taken by pirates, 1560

'Taitsu, Chinese Emperor, protests against piracy, 443,445 Tajima, king of Shiragi, settles in, 84,88

- Mori, sent for orange seeds, 84

Taka becomes empress, 238 .

Takaaki, younger brother of Murakami, banished, 257-8 Takachiho, Mt.; in Hyũga (Saikaidō), 21.

Takahashi, Mr., on "Malletheaded" swords, 51

Takahira,'Kogoro, Baron :(b. 1864), peace commissioner at Portsmouth, 725

Takahito, Prince, son of GoShujaku, attempt:: to have him passed over, 269; see GoSanjō

Takaichi, Prince, 170; dies (696), 174

Taka-ichi, Yamato province, possibly the "Plain of High Heaven". of myth, 29, 30

Takakage see Kohayakawa Takakage

Takakuni see. Hosokawa:Takakuni

Takakura, 8 80th Emperor (1169-80), 295-8

Takamatsu, castle in Bitchū besieged by Hideyoshi, .490, 491

Takama-yama and Takamano, Yamato, 30

Takamochi, first of the Taira family, 205 .

Takamuku Kuromaro, literatus, national doctor, 160; leader of embassy to China (654, A.D.), 166; dies there, 168

Takanaga, Prince (1311-38), commander against Ashikaga Takauji, 392 ; in war of dynasties, 398 ; suicide, 399

Takano, consort of Kōnin, mother of Kwammu, 204

Takanori see Kojima Takanori

Takao, temple at, 304

Takaoka, monk, travels in India, 231

Takashima: Kihei, called Shirōdayū, or Shūhan, advocates foreign intercourse (1853), 665

Takata, sect of Shin, 463

Takatomo, Prince, adopted son of Ōkimachi, 505

Takatsukasa family founded by Fujiwara Kanehira, one of "Five Regent Houses," 358

Takatsuki, fief of Takayama, 538

Takatsune see Shiba Takatsune

Takauji see Ashikaga Takauji
Takayama (d: 1596) feudatory of Takatsuki, converted by Vilela; his son . Yüsho, "Don Justo Ukondono," 538 Takeda family of Kai favour Yoritomo, 305, 308; help in overthrow of Yoshinori, 428; alliance with Hōjō. and war with Uesugi, 466-7; his allies against Nobunaga, 483

- Katsuyori (1546-82), marries Nobunaga's daughter, 479 , but makes war on him, 487-8; defeated, 489

- Nobumitsu stirs up Yoritomo against Yoshinaka, 309

- Shingen, or Haranobu $(1521-73)$, war with Uesugi, 466-8 (ill.); alliance with Nobunaga; 479 , and with Ieyasu, 486-7;: death, 485; military art, 488; signature, 520 (ill.) Takenaka, of Nagasaki, persecutes Christians, 553

- Shigeharu, soldier of Hideyoshi, 480

Takenouchi-no-Sukune, several prominent officials, lst to 4th century; 106-7; against: Yemishi, 36; prime minister, 85 ; great duke of the Presence, 98; in conquest of I Korea;' 88-90; succession to Jingō, 90-1; ordeal for treason, $: 100-1$; $\rightarrow$ ! granddaughter, marries Nintoku, 105 ; descendants, 105,106 ; the Heguri, 127.

Takenouchi Shikibu(1716-71), teacher of Chinese classics, 621 ; forerunner of Restoration, 622

Taketori Monogatari, "Bamboo gatherer's narrative," classic, 251

Takigawa Kazumasu, : soldier of Nobunaga, kwanryo of Kwantō, 489; favours Nobutaka, 494; defeated by Hideyoshi, 495

Takinosawa, battle of, victory over Takeda, 488

Takuan (1573-1645), Emperor gives purple robe to, 589-90 Takuma artists, 280

Takushan, Manchuria, 4th Army lands at, 717

Takutsakasa Sukehira, prime minister in Kyōto, opposes Kōkaku, 631

Talien, taken from Chinese (1894), 701, 702; Russian railway, 705

Tallies used in trade with China, 444,:445

Tamba, urchins of, the princes Ôke and Woke, 118; rice grants charged to province, 588

Tamehira, younger brother of Murakami, 258
Tamibe, naturalized aliens in pre-historic time, 94

Tamichi, general, killed by

Yemishi, 367. A.D., 38

Tamon, $i$ e Ananda statue in castle of Azuchi, 486 Tamu no Mine, valley, site of shrine to Kamatari, 168

Tamura," Prince,' Emperor. Jomei (629), 146

Tamura family defeated by Date, 471

Tamuramaro see Saka-no-ye Tamuramaro Tan, land unit, 182, 527; tansen, area tax, $439,440,452$ Tanaka Harukiyo, rebuilds shrine of Hachiman, 452 it:

Tandai, inquisitors, -two representing Bakufu at Court, 345 ; the Ryo-Rokuhara, 347 ; similar offices at Hakozaki and Nagato, 362 ; in Muromachi period, $436 \div 7$

Tanegashima island where Portugese first landed, 530 ; name used for muskets they introduced, 488-9.

Tanetsugu see Fujiwara Tanetsugu

Tang, Chinese systems, and power of : Throne $(645-70)$, 128; most of features of Daika taken from, $160 \mathrm{f}$.n.? 164; respects in which not adaptable to Japan, 20:; Kyōtō: modelled on Tang metropolis, Changan, 226 inc

Tanners from Korea, 119

Tanuma Okitomo (Mototomo)

(d. 1781), son of Okitsugu, 619,623

- Okitsugu (Mototsugu)

- $(1719-88)$, favourite of Ieshige, prime minister of Ieharu, $618+19,623$

Tan Yang-i, Chinese scholar, 153

Taoism and Shintō, 648

Tao Lung see Dōryū

Tasa, omi of Kibi, removed by Yūryaku, 112; leads revolt in Mimana, 114.

Tatars, possibly prominent in Yemishi revolts of $\cdot 8$ th century, 222; Golden and Khitan in China, 358

Tate, fortress or warp; 266 f.n. Tate Chikatada, ono of Yoshinaka's four body guards, $: 313$ Tatebito, famous archer, 137 Tatsunokuchi, in 'Yédō, site of court of justice, 633

Tattooing as penalty, 66, 642; as decoration first in "protohistoric period, when penalty abandoned, 109

Tawara Tôda see Fujiwara Hidesato

Taxation, early, 67, 80 ; and land-holding, 95-6; war tax, 
97; land not taxed, 124; requisitions, 124-5; in Shōtoku's constitution, 142 ; Daika, 162 , 164-5; I Daihō, 183; Ashikaga period, 426, 438-9, 440; toll-gates, 430 ; tokusei riots, 431; under Tokugawa, 637-8

Tayasu branch of Tokugawa, eligible to Shōgunate, 592; named from gate of Yedo Castle, 618

- Munetake, or Tokugawa Munetake (q.v.), 624

Tea, plants introduced (814), 280; more generally (1191), 374 ; picking, in Uji, 623 (ill.); festivals, 425; ceremonial, 457,159 . (ill), influence on ceramics, 451 , and architecture, tea-parlours, 452, 131 (ill.); Hideyoshi's interest in, 507

Technical vocabulary, Japanese, 57

Teeth-blackening, 74,279

Teika see Fujiwara Sadaiye

Teikin-orrai, text book of letter-writing, 448

Teiō-keizu, Imperial genealogy, 448

Telissu, battle of, Russians defeated by $\mathrm{Oku}, 716-17$

Tembun koban, gold coins minted in $1532-55,527$

Tembyō, period (729-48), 193

Teminan, Tenjin, shrine of Michizane, 244

Temmangu see Michizane

Temmoku-zan, in Kai prov-

ince, defeat of Takeda at, 489

Temmu, 40th Emperor (673-

86), Prince Ōama, 170-2; historiography, 2 ; sumptuary laws, 211

Tcmples, early Buddhist, 1378 ; mixed Shintō, 193; provincial, 194; estates, 208, 329; the "Six," 272; Nara epoch, 209 ; at Kamakura, 439; the "Five," schools and scholarship, 448, 455; revenue, 439; commissioners, 436, 633, 634; Ieyasu's legislation, 577-8; under Imperial princes, 583, 588

Tempō, period, $1830-44$, famines, 661 ; reformation of, 662 Tenchi, 38th Emperor (66871), 168-9; burial mound, 50; painters, 127; Daika, 165; see Naka

Tendai, monastery and doctrine of Saicho, 228, 367, 368; -temple, 283

Tengai, abbot of Enryaku-ji, in bell-inscription affair, 566; temple at Nikko, 582; Kwanei-ji, 583

Tenjin, descendants of prineval trinity, sub-class of Shim- betsu, 92 ; name under which Michizane was apotheosized, 244

Tennōki, Record of the Emperors, 2

Tennō-zan; position in battle of Yamazaki, 493

Tenryaku, year-period, 947$57,258,261$

Tenryū-ji, temple at Saga, built by Takauji; T.-bune, merchantmen, sent to China for art objects; $T$-seiji, celadon vases from China, 442, 453,455

Tenshin," "kami of the descent," chieftains of expedition from Kyūshū 77

Tenshō, year period, $1573-91$, coins, 528 .

Tenson, "Heavenly grandchild," epithet of Hikoho Ninigi 33, 64; sub-class of Shimbetsu, descendants of Sun goddess, 92 ; superior position of, 98 :

Teraishi, Dr., on decoration of bronze bells, 49 (f.n:)

Terasaka Kichiemon, one of "47 Rōnin," 607

Terumoto see Mōri Terumoto

Terutora see Uesugi Kenshin Tetsuo, priest: of Daitoku-ji, 454

Text;books, 448

Thatch on houses, 154

Thermal springs, $127 ; 157$

Thirty-year census, 181

Three Years' War, Go-Sannen (1089-91), 267

Thunder, Kami of, in tree, 65 , 196 ; axes, 46

Tientai, Japanese Tendai, Chinese monastery, 228

Tientsin relieved by Japanese troops in Boxer Rebellion, 703

Tiger, magic taught by, 196

Tiles, peculiar to temples, 154 ; roofs of official buildings tiled in Nara epoch, 209; slatecoloured and green in city of Kyōtō, 227; in Kamakura period, 373 ; ill., 441

Timur gives up attack on Japan, 363

Ting, Chinese admiral, defeated at Weihaiwei, 701-2

Titles, or gentile names, 73 ; new under Temmu, 171

Toba, 74th Emperor (110823), 273; state domains, 253; palace, 272,273

Tobacco growing, 617; pipe and pouch, 107 (ill.)

Toda Izu no Kami, advocates foreign intercourse (1853), 665

-Tadanori, adviser of Nariaki, 662

Tôdài-ji,
Nara, bronze Buddha, 193, 367; procession in Kōken's reign, 197; great bell, 210 ; bell-tower, 453 (ill.); statue, 158 (ill.); gak-guards, 280; burnt by Taira, 301

Tōōō: Takatora (1556-1630)

helps Tokugawa, 580

Tōei-zan, Ueno hill, temple of Kwanei-ji, 583

Tōfuku-ji, Buddhist temple, S.E. of Kyōto, 454,455

Tōfuku-mon-in, Kazuko, first Tokugawa consort, 580; wife of Go-Mizu-no-o, 589

Togashi family splits in Önin war, 430

Tōgō Heihachiro, Count (b. 1857), Japanese admiral, attacks Russian fleet at Port Arthur, 711; blocks entrance to harbour, 714-15; defeats Russians at Tsushima, 723-4 Toi invade Japan (1019), 262-3

Toichi, wife of Kōbun, 170

Tōin see Dōin

Tō-ji, Shingon temple (Gokuku-ji) in Kyōto, 367

Tokaido, road from Kyôto to Tōkyō, 560

Toki see Doki

Tōkichi see Toyotomi Hideyoshi, 475 f.n.

Tokimasa see Hồjō Tokimasa

Tokimune (or Gorō) avenges father's murder, 333

Tokiuji see Yamano Tokiuji

Tokiwa, mistress of Yoshitomo, 294, 306

Tokiyasu, Prince, see Kōkō

Tokiyo, - Prince, marues daughter of Sugawara Michizane, 242-3

Toku, empress Kenrei-mon-in, 295; mother of Emperor Antoku, 297

Tokugawa, descent of family, 556 ; hereditary : system founded by leyasu, 504 ; shōgunate of family, 556-73; oath of loyalty to, 564-5; the T. Bakufu, 573-643; "Constitution," 576; school, Shōhei-ko, 578 ; Imperial family marries into, 580,589 ; strengthened, 581-2; attitude to feudatories, 593 ; Hidetada line succeeded by. Kii branch, 610-11; families in ministry, 624 ; decline of power, $661-78$; end of shōgunate, 677

-Chikauji (d. 1407?), ancestor of Matsudaira, 556 - Hidetada (1579-1632), shōgun (1605-22) 557, 562; antiChristian edict (1616), 550-1; orders Spaniards deported, 552 ; in war with Uesugi, 560 ; daughter weds Hideyori, 562; 
attaoks: Ōsaka, 567; Ieyásu's instructions to, 570 ; rule, death; character, 580-1; and Crown, 588

Tokugawa Hirotada (152649), 556

LHyakkajō, One Hundred Rules of 'Tokugawa, 641

- Ieharu (1737-86), shögun (1760-86), 618-20, 624

- Iemitsu (1603-51); shögun (1622-51), 581-3; treatment of Christians, 552-3; Ieyasu's instructions to, 570; requires nobles to reside at Yedo, 581-2; and feudal lords, 594

- Iemochi (1846-66); shōgun (1858-66), 668; marries Emperor's sister, 672 ; resigns, 676 - Ienari (1773-1841), shōgun (1786-1837), 624, 629; his father's rank, 630-1; abdication, 662

- Ienobu (1662-1712), shōgun (1709-12), 608-10; 621

- lesada (1824-58), shögun (1853-8), 667-8

- Ieshige (1702-61), 'shögun (1745-60), 618; his son, Shigeyoshi, ancestor of Shimizu braneh, 592

- Ietsugu (1709-16), shögun (1712-16), 610,620

- Ietsuna (1642-80), 4th shōgun (1651-80), 583-9; power passes to minister, 587; abdication of Go-Saien, 591; death, 596-7

- Ieyasu (1542-1616); 466, 478 (ill.) -9 ; in war on Asakura and Asai, 483, 484; alliance with Shingen, 486-7; defeats Takeda, 489; threatened, 492; in Komaki war, "497; peace with Hideyoshi, 499; against Hōjō, '503; receives Kwantō, 504; takes oath, 507 ; in Hideyoshi's scheme, 523, 524; Christianity, 544-9; Will Adams, 546; death, 549, 571 ; family , 556-7; succession to Hideyoshi, 557-9; wealth, 559; Sekigahara, 561; distribution of fiefs, $561-2$; shōgun, 562; Hideyori, 5634; defied at Ōsaka, 565; Hōkō-ji bell, 565-6; attacks Ósaka castle, 567-70; character, 571-2; legislation, 5738; literature, 578-9; Hidetada, 580; shrine, 582-3; patterned upon by Yoshimune, 611; Shintō revival, 614; foreign intercourse, 651 ; signature, 529 (ill:)

- Ieyoshi (1792-1853), shōgun (1838-53), 661-8

- Jidaishi, on Ieýaśu's laws, 578

- Mitsukuni

(1628-1700),

sympathizes with Masayasu,
598; interest in letters, 600 , 644 (ill.) -5

Munetada (1721-64), founder of Ilitotsubashi branch. 592,618

- Munetake (d. 1769) found: er of Tayasu branch, 592, 618,624

- Nariaki (1800-60), daimyō of Mito, anti-foreign policy of, 662 ; attempts to make his son shogun; 668; surrenders edict against shögun, $670-1 ; 677$

- (or Matsudaira) Nariyuki, feudatory of Kii, 668

- Nobuyasu (1559-79), 557; marriage, $\mathbf{4 7 9}$

$\rightarrow$ Nobuyoshi

daimyō of Mito, 557,591

- Shigeyoshi ? $(1745-95)$

founds Shimizu branch, 592

- Tadanaga

$(1605-33)$,

brother of Iemitsu, $594 ; 595$

- Tadayoshi (1580-1607),

daimyō of Kiyosu, 557, 591

- Tsiunàyoshi' (1646-1709), shōgun (1686-1709), 596-608; considerate for Crown, 620

- Yorifusa (1603-61), daimyō of Mito, 557; one of Sanke, 591

- Yorinobu (1602-71), daimyö of $\mathrm{Kii}, 557,591$

- Yoshimune "(1677-1751), shōgun $(1716-45), 611$ (ill.) 18 ; camera rule, 618 ; Tayasu and Hitotsubashi branches, 592,618

- Yoshinao (1600-50), daimyō of Owari, 557, 591; founds Shōhei-kō sehool, 578

- Yoshinobu or Keiki (183797), son of Nariaki and his candidate for shögun, 668; Crown urges his promotion, 673; guardian of shōgun, 674; shögun (1866-8), 676; resigns 677 ; surrenders Yedo, 678

Tokuhon see Hatakeyama Mochikuni

Tokunō support' Southern Court, 400

Tokunō Michikoto, defender of Go-Daigo," 382

Tokusei, "benevolent policy," lays of 1297,376 ; extension of policy under Ashikaga, $422-3$; riots, 431 ; for debtors; 617

Tokusō, priest, " 454

Tokyō, formerly Yedo, eastern capital, 281,682

Tomi see Fujiwara Tomiko

Tomoe, Yoshinaka's mistress, 313

Tomohira, Prince (963-1009), poet, 261

Tomohito, Prince, see Kōkaku Tomo, Princess, see Go-Sakuramichi
Tomo Kowamine; exiled (813) with Prince! Tsunesada, 236 Ton-a (1301-84); poet; 367 i:l

Tonami-yami, Echizen, defert of Tairal'at, 309 sisfiste

\section{Tonegawa, flood in, 619}

Tone-yaima, battle (1573), 485

Tonghak rebellion in Korea (1891), Chinese troops sent to quell, $700-1$

Tongkan, Korean history, its chronology, 90

Tori Shichi (Korean Nori Sachhi), Buddhist, 132 iat:

Torii Mototada $(1539-1600)$, dies in defense of 'Ieyasu's castle, $559-60$ is - yni Suneemon, 487

Tornado of 1718,614

Torres, Baltasar- de (15631626), Jesuit, companion of Xavier, 532,533, 534it i(.h)

Tortoise shell, divination, 66

Torture in ancient Jajuan, 66

Tosa, province, 28, Iehijō family rnove to, 461 ; seized by Chōsokabe, 470 ; bonita curing in, $617 ; \mathrm{T}$ memorial against Bakufu, 677;\% surrender of fiefs, 680 ; clan representation, 681

Tosa, Kyōto school of painting, $280,365,450,452$; patronized by Tsunayoshi, 600 ; decorations of palace, 629 i bejsira

- Mitsunobu see Mitsunobu Mitsuoki, teacher of Hirozumi, 600

Tosa Nikki, Tosa Diary, 251

Tósabō Shōshun, bonze, 322

Tosandō, mountain road, 503

Toshilye see Maeda Toshizye

Toshiyori-rōju, 633

Töshö-ji, temple, suicides in its cemetery after defeat of Hōjō, 385, 386

Towers, royal, 116,126 ; fire wateh tower, 108 (ill.) isariv

Toyohara Tokimoto, musician, 267

Toyohito see Kōgon

Toyokuni Daimyō-jin, temple of, sacred to Hideyoshi, destroyed by Ieyasu, 570

Toyonari see Fujiwara no Toyonari

Toyotomi, family, revolt of rónin $(1651), 584$; decline of influence, 594

- Hidetsugù (1568-95), adopted successor of Hideyoshi, 504, 522; Hideyoshi's letter to, 516 f.n.; death, 522-3 - Hideyori-(1593-1615), son of Hideyoshi, 496, 522; regent, 523; Christians : join him against Ieyasu, 548 ; Ishida favours; $1558-9$; naidaijin, marries Ieyasu's granddaughter, 562 ; leyasu's estímate, 563 ; opposes Ieyasu, 
565 ; refuses to surrender, 568 ; suicide, 570

Toyotomi Hideyoshi(1536-98), 466,475 (ill.) -7 ; battle of Okéhazama, 477-8; in Ise and Kyöto, 481; Sakai, 482; war with Asakura and Asai, 4835; against Takeda Katsuyori; 487; invades Chūgoku, 48991; plans war on China, 445, 489; peace with Mōri, 491; Nobunaga, it 492; ', defeats Mitsuhidè, 493; councillor, 494; crushes Takigawa Kazumasa and Shibuta Katsuiye; 495; Yỏdogimi; 496; Ōsaka castle, 496-7; in Komaki war, $497+8$; peace with Ieyäsu, 499 ; régent, 499,506 ; crushes remaining enemies, $500-4$; treatment of Ieyasu, 504-5; Buddhism, 505-6; pälace, $506-7$; 521; teafestivals, wealth, 507 -8 ; invasion of Korea, 509-18; death, 519, 523+4; family, 522; kills Hidetsugu, 522; character, 524; legislation, 525-7; Christianity, 539-44; tomb, 570

- Kunimatsu, son of Hideyori, killed by Ieyasu, 570

"Trade, Chief of " 155

Transportation; early, 80; roads in Nara epoch; 210 ; in Heian, 281 ; in Muromachi, 456 ; improved by Nobunaga, 492-3; laws, 585; Tokugawa improvements, 592 ; roadcommissioners, 635; railway building, 694

Treason under Daihō code, 178 Treasury established 405 A.D., 110 ; three in Yüryaku's reign, 114; burnt in 1659, 603-4; see Finance Department

Treaties with United States, Russia, Holland; England, 666; commercial treaty with United. States, 667; with Korea, 685 ; with China, 702; with Russia (Portsmouth), 724-8; with China (Peking), 727

Tree, sacred, of Buddhist temples, 274 ; tree worship, 65; myths of tree planting, $14,22,31$; stories of huge trees, 70

Trigrams, in divination; 66

"True Word," Shingon, 231, 369

Tsarevitch, Russian battleship at Port Arthur, 711

Tsin dynasty (265-317) and Chinese migration, 102

Tsuchi-gumo, "Earth-spiders" or. "Pit dwellers," 34, 41-4; called Wado by Chinese, 77 Tsuchi Mikado, 83d Emperor (1199-1210), 335; abdicates, 341 ; exile, 344
Tsugaru in 16th century wars, 471 ; remains of Tatar fortress, 223

- strait, controlled by Japan, 703

Tsugunawa see Fujiwara Tsugunawa

Tsuguno, architect, 126

Tsuka, Korean prince, ${ }^{\circ-}$ migrates to Japan, 102; carpenters, 126

Tsukiji, in Yedo, naval college at, 669

Tsukuda, island, 642

Tsukushi see Kyūshū

Tsunayoshi see Tokugawa Tsunayoshi

Tsunehito, Prince, father of Kōkaku, rank, 630-1.

Tsuneko, consort of Kwazan, 259

Tsunenaga, Prince (1324-38), conspiracy to make him heir; 389-90; poisoned by Takauji, 399

Tsunesada, Prince-(823-84), exiled (843), 236

Tsure-zure-gusa, "Weeds : of Tedium,: 367

Tsuruga; ancient Kehi-no-ura, 81, 88; fortifications (1280), 361

Tsurugaoka hill in Kamakura, shrine of Hachiman, 305

Tsushima, - islands, in early myth, 28; silver discovered (674) and gold (701), 186; attacked by Toi (1019), 262, by Mongols (1274), 359, and (1281) 362 ; attacked by Koreans in $1419, .443-4$; Korean trade, 444; Chinese squadron attacks, 445 ; outpost of Japan, 512; Hakuseki wishes to limit Korean envoys to, 608 ; commerce, 610 ; commanding strait, 703; Russian attempts upon, 701; battle of, Russian fleet: defeated by Tōgō, $723-4$

Tsutsui Junkei (1549-84), deserts Akechi Mitsuhide in battle of Yamazaki, 493; succession to Nobunaga, 494 Tsuwata Saburō, suicide, 313 Tsuying, king of Pohai, Korea, 223

203-Metre Hill, Port Arthur, fighting at; $720-1$

Uchida Ieyoshi, warrior, 313

- Masañobu (1619-51), suicide, 582

Uda, 59th Emperor (888-97)

Prince Sadami, 239-41

Uda Genji of Ōmi; branch of Minamoto, 265

Ueda castle, 560,580

Ueno park, Kiyomizu temple, 578 ; hill called Tōeizan, 583, 599; abbot of, candidate for throne in 1867,678
Uesugi, family, favours Tadayoshi, 406 ; overthrows Ashikaga, 409; kwanryō, 414; two branches, 416 ; quarrels, 419 , 431, 464; join against Hōjō, 466; shitsuji, 419; governorgeneral of Kwantō, 420; patronize schools, 449; against Mogami, - 471; Hideyosh i makes peace with, 500

- Akifusa, shitsuji to Shige-

uji, 425

- Akisada, estates, 426

- Akiyoshi, avenges hisfather, 406

- Fusaaki (1432-66), 425

- Kagekatsu (1555-1623),

lieutenant- of Hideyoshi in Komaki war, 497,500 ; against Hōjō, 503; senior minister, 523; with Ishida Katsushiga plots against Ieyasu, 558; open break with Ieyasu, 559 ; fiefs reduced after Sekigahara, 561

- Kenshin, originally Nagao Kagetora. (1530-78), kwanryō, war with Hojjō and Takeda, 466-7 (ill.), checked between Nobunaga and Shingen, 479 ; military art, 488

- Mochifusa, sent against Kamakura by Ashikaga Yoshinori (1439), 420

- Mochitomo (1416-67)

fortifies Kawagoe, 426

- Noriaki (1306-68), shitsuji, 403, 415; exile, 409

- Noriharu (d. 1379), suicide, 415

- Norimasa (1522-79), driven from Hirai by Ujiyasu, 467

- Norimoto (1383-1418), 419

- Noritada (1433-54), shitsu-

$j i$ to Shigeuji, death, 425

- Norizane (d. 1455), plot to kill, 419; helps defeat Kamakura forces (1439), 420

- Shigeyoshi (d. 1349), shitsu$j i$, exiled, 404-5.

- Tomomune, shitsuji, 41516

- Tomosada, shitsuji, 403

- Ujinori, 419

-Yoshinori (d. 1378), shitsuji, 415,416

Uji, families, rank, 92-3; government, 96,8 , established and abolished by Emperor, 96-7; taxation, 124-5, 142; feudal chiefs, 128; the Eight Great $U j i, \quad 129-30$; opposed by Shōtoku, 140 ; rank, 146 government, 164; Jinshin, 170; Kami elective, 172; princely families, 205-6; academies, 206; record, 233; territorial names, 287

Uji river, Yamashiro province, battle at, 300

Uiyasu see Hōjō. Ujiyasu 
Ukhtonsky, Rear-Admiral Prince, commanding Russian squadron at Port Arthur, 718 Ukita Hideiye (d. 1662), soldier of Hideyoshi, 497, against Chōsokabe, 500 ; commanderin-chief in Korea, 513, 516, 517 ; one of 5 senior ministers, 523; and Hideyoshi's laws, 526 ; against leyasu, 559,560 ; estates forfeited, 561

- Naoiye (1530-82), turns from Mōri to Nobunaga, 489 Umako see Soga Umako

Umashimade, ancestor of

Mononobe, 129

Umeda Genjirō, pen-name "Umpin" (1816-59), promotes Imperial restoration, 669

Umetada Akihisa, metalworker, 451

Unclean, eta and hinin, in

Kamakura classification, 372

Unebi, Mt., tomb of Jimmu, 24; Soga mansion, 148

Ung-jin (Paik-chhon-ku), Japanese defeat at, (662), 167 .

United States, Japanese relations with, 1837, '46, and '48, 663-4; Perry, 664-5; Townsend Harris, 666-7; Shimonoseki affair, 674; Americans in education, postoffice, agrieulture, ete., 6867 ; intervention in RussoJapanese war, 724; threats of war, 730

Unkei, sculptor, 280

Unzen, volcano, Christians tortured in solfataras, 553

Upland, onchi, 201, 207

Urabe Kanetomo (15th century), Shintō, 452-3

- Yoshida, Shinto doctrine of, 453

Uraga, English refuse for headquarters, $653-5 ;$ Manhattan enters, 663; Perry in, 664 Urup, island, Russians in, (1792), 658

Uryū Sotokichi (b. 1857), rear-admiral, destroys Russian cruisers at Chemulpo, 712

Usui Pass in Yamato-dake's march, identification of, 86

Usume, female Kami, 61

Usuri, won by Russia (1860), 704

Utsonomiya family, one of

"8 Generals of Kwantö," 425

Valegnani, Alexander (1537-

1606), Jesuit vice-general,

visits Kuchinotsu in 1578,

536; embassy, 541

Variag, Russian eruiser at Chemulpo, 712

Vehicles, proto-historic, .126; in Nara epoch, 210

"Vehicles" of Buddhism, 369

Veil in ancient costume, 68
Vendetta, beginning of in Japan (486 A. D.), 118-19; (1193), 332, 378; of Akō, 606-7; illegal in Kyōto, Yedo, Osaka and Sumpu, 607 Vermilion pillars, 209; stamp of Taiko, 529,578

Vilela, Gaspard (d. 1570), Portuguese Jesuit, in Kyōto, 537

Village, part of agata, 180; assemblies, 67 ; chief, 637

Vivero y Velasco, Rodrigo, governor of Philippines, agreement with Ieyasu (1609), 652

Vladivostok, strategic situation, 704; Russian squadron at, crushed by Kamimura, 717; objective of Rozhdestvensky, 723

Volcanic eruptions, 604, 619

Wa, "dwarf" or "subservient," early Chinese name for Japanese, 60, 83, 145 (f.n.)

Wada Yoshimori (1147-1213) son of Yoritomo's benefactor, 333 ; in Bakufu council, 336; bettō defeated and killed by Hōjō Yoshitoki, 327; 338 Wadded garments, first mentioned, in 643 A.D., 156 ; use prescribed, 585

Wado, Chinese name of western tribe of Japan, 77, 84

Wadō, copper era (708-15), 5,186

Wage, in 1498, 438 f.n.

Waka, wife of Tasa, taken from him by Yūryaku, 117 Waka-irutsako, younger son of Ojin, 105

Wake, funeral ceremony, 74

Wake, Prince, burial of, 74

- Kiyomaro (733-99), banished, 199; chooses site for new capital for IKwammu, 226

Wakiya Yoshiharu, son of Yoshisuke, in defeat of Takauji, 407

- Yoshisuke (d. 1340), brother of Nitta Yoshisada and provincial governor, 388 ; in command of Imperial army against the Ashikaga, 392, 399

Wakizaka Yasuharu (15541626) at battle of Sekigahara, 561

Wang Yang-ming (1472-1529) philosophy of, officially displaced by Chutsz's, 613; Nakaye Tōju follows, 626 ; summary of system, 627-8; 644

Wani, Korean scribe in Japan, 103, 109; his descendant, Wang-sin-i, 103, 153, 155

War, Department of, Hyobu$\operatorname{sh} \overline{0}, 164,179$
War God, Hachiman, Oracle of, 199

War Office, Heisci-kan, 171 Waseda University, Tōkýō, founded by Ōkuma, 691 ... Watanabe, fleet at, $e$ before battle of $Y$ ashima, 316 $\div 17$

Watanabe family, branch of Minamoto, 265 yins?

Watarai, temple of, in Ise, princess priest of, 64

Watazumi-no-Kuni, Japanese intercourse with, 84 in? Watch, in capital, 180

Water-supply of Yedo, 587.

Wave-men, rōnin, 565, 584, 587

Wax, vegetable, industry, 617 Weaving in early times; 67-68; early taxes paid by, 80 ; development, 617

Weights and measures, 155 .

Weihaiwei, taken from Chinese (1894), 701-2

Wei Records, A.D. 211-265, on Japanese markets, 71.

Western Army, Yamana forces in Ōnin war, 439

Whale, fossil remains, $45 \mathrm{f} . \mathrm{n}$.

White, mourning colour, 212 ; colour of Minamoto, 301

Wi-ju, Korea; 515; Rússians at, $(1904) ; 713$

Winter Campaign, 570

Wistaria, fujiwara, 168 ; bark used for mourning garments, 213

Witchcraft, in Nara epoch, 196 Wo (Japan), tributary to Chinese Kingdom of Yen, 60 Woke, see Ninken if ic is Women, use phonetic language, 3 ; warriors, $3,29,30$, 79 ; tribute to serpents: and marauders, 31 ; "prehistoric status, 75 ; rulers, 85,157 ; hostages, 86; morality; 216, 276-7; literature, 249-50; property rights, 350 ; in Tokugawa period, 643 ; punishment of, 642; shögun's harem, $636 ;$ illustrations, $612,616,660$

Wrestling in prehistoric times, 75; first recorded match (23 B.c.), 82-3; professional sport, 214 ; (ill.), 375

Wu, Chinese Emperor, and Buddhist propagarida, 131 Wu-Ti, Chinese emperor, conqueror of Korea, 83

$\mathrm{X}$ avier, St: Franeis (1506-52), Jesuit missionary, lands in Kagoshima (1549), 530-1; in Hirado, Yamaguchi, Kyōto, and Bungo, death, 531-2

Yada castle in Ise, 480

Yae, wife of Hideyoshi, followed by military clique; 522,557

Yaka, mistress of Tenchi, 169 
Yakami, Princess, of Inaba, 13, marries Great-Name Possessor, 14

Yakami, castle in Tamba, 490

Yakushi, Buddhist god of wisdom, inscription on image of, $153 ; y$ - $j i$, temple, 194 (ill.)

Yalu River, Korea, in 1592 campaign, 513, 515; Chinese cross, (1894), 701; Russians and Japanese on, (1904), 713; Russians defeated, 714 Yama, Indian god, 25

Yamabe, Prince, 204; see Kwammu

- Akahito, poet, 214

Yamabushi, priests, 196

Yamada, Tesshū, on Bushi, 386

Yamaga Sokō (1622-85), philosopher of bushido, 607-8; Chinese teaching, 626

Yamagata Daini (1725-67), executed, 621 ; fore-runner of Restoration, 622

Yamaguchi, Korean envoys come to, 443; Xavier in, 531, 532; Jesuits leave, 533; Christians in, 537

Yamamoto support Southern Court, 400

Yamana, family, joins Southern party, 407-8; controls ten provinces, 409, 411; turns to Northern Court, 410 ; crushed, 411 ; rehabilitated, 421 ; one of Five Regent Houses, 416; holdings, 426; Hosokawa, 427; forces in Onin war, Western Army, 429 ; "province holders." 436 - Mitsuyuki, in revolt against Northern Dynasty, 411

- Mochitoyo, called Sōzen, "Red Monk," (1404-73), gets Harima, 421; great estate, 426; in war on Hatakeyama, 427; forces choice of Shiba Yoshikado as kwanryō, 428; deserts Yoshimi, 429; death, 430

- Norikiyo receives province of Mimasaka, 421

- Noriyuki, captures Shirahita, 421

- Sōzen see Yamana Mochitoyo

- Tokiuji (d. 1372), joins Ashikaga, 410

- Ujikiyo rebels

against the Ashikaga, 411 Yamanobe, Princess, 173

Yamanouchi, family name taken by Uesugi Yoshinori, 416; feud with Ögigayatsu, 419,464 ; join them against Hōjō, 466

Yamashina, Kamatari's residence, 192

Yamashiro, Prince, candidate for throne in 629 and 641, 146; suicide 147-8
Yamashiro, early shrine, 64; campaign from, against Sujin, 79 ; canal, 155 ; meaning of name, 225; school of painters (604 A.D.), 155

Yamato, expedition from Kyūshū against, 21-4; meaning of name, 29,77 , as used by Chinese, 84; kindred race at time of conquest, 24, 32, 76; retirement to Tsukushi, 32; culture, 49-54; physiognomy, 54,58 ; relations with Caucasians, 55; language, 56 ; school of painting, 452

Yamato, Prince, human sacrifices at burial of (2 A.D.), 50 Yamato-dake and Susanoo's sword, 13,37 ; campaign against Yemishi, 36-7; against Kumaso, 40, 85-86; a swan, 65

Yamato Genji, branch of Minamoto, 265

- Oguna, earlier name of Yamato-dake, 40

Yamazaki, battle of, (1282), 493

- Ansai, follower of Chutsz, 621 ; forerunner of Restoration, 622

Yanada Takasuke, estates, 426

Yanagawa Seigan, Imperial restoration movement, 670

Yanagisawa . Yasuaki, or Yoshiyasu, (1658-1714), favourite of Tsunayoshi, 601$2,603,604,605$; dismissed by Ienobu, 608

Yanamoto Kataharu in civil war of 1520 sqq., 433

Yang-chou, taken by pirates (1556), 446

Yangtzuling, Russian defeat at, 718

Yashima, battle, (1185), 31718

Yashima, Japanese battleship lost off Port Arthur, 717

Yaso, daughter of Emperor Reigen, 620

Yasumaro see Ōno Yasumaro Year-period (Nengō), adoption of Chinese, 645 A.D., 161; under two dynasties, 398, 406 Yedo, fort built (1456), 426; capital - of Kwantō, 504; Franciscan mission, 545; Hidetada, 562; Bakufu, 563; castle, 580 ; nobles must reside in, 581-2; rebuilt after fire, 586 ; art centre, 601 ; vendetta forbidden, 607; tree planting in, 612; Kwanno Chokuyō's school, 614; fires, 614; degeneration, 18th century, 61920 ; vagabonds, 626 ; prison, 642 ; land offered to foreign traders, 652; called Tōkyō, 682 f.n.
Yellow Sea, Japanese victory over Chinese (1894), 701

Yemishi, early name of Ainu, 34; Hirafu's expedition, 35; description, 35-41; Yamatodake's expedition, 36-7 ; captives called Saekibe, 37; revolt in Kazusa, 38; language, Siberian origin, 56 ; migration, 59; revolts, 219-20, 222

Yen, Pechili, 60

Yengi-shiki, book of ceremonial law (927 A.D.), 64

Yen Hui, Chinese painter, 450

Yenisei, Russian mining-transport, sunk by mine at Port Arthur, 712

Yenomoto Takeaki, Viscount (1839-1909), admiral to the shōgun, tries to set up republic in Yezo, 678

Yezo, pit-dwellers' remains in, 42 ; name related to Yoso, 60 ; Yemishi in, 219; Russians and Japanese clash in, 658-9; Yenomoto's republic in, 678 Yi Sun-sin, Korean admiral, defeats Japanese fleet, 515-16 Yo-chang, prince of Kudara, defeats Koma (553), beaten by Shiragi, 149

Yōdō (Yamanouchi Yōdō) (1827-72), feudatory of Tosa, memorial to shōgun, 677

Yodo, estate of, 522

Yodo or Yodogimi, daughter of Asai Nagamasa and mother of Toyotomi Hideyori, 496; civil party sides with, 522 ; 557 ; against Ieyasu, 565 ; 566 ; Ieyasu promotes quarrel between Katagiri Katsumoto and, 566-7; intrigue through her sister, 568; death, 570

Yokohama, opened to American trade (1858), 667

Yoko-yama, castle of Naga-

masa, 484

Yolang, or Pyong-yang, Korea, 83

Yōmei, 31st Emperor (586-7), 135-6; Buddhism, 132

Yomi, hades, compared to Indian Yama, 25; identified with Yomi-shima, between Hoki and Izumo, 30

Yorifusa see Tokugawa Yorifusa

Yoriiye see Minamoto Yoriiye Yorimasa conspiracy (1180), 298-300

Yorinobu see Tokugawa Yorinobu

Yoritomo see Minamoto Yoritomo

Yoritsune see Fujiwara Yoritsune

Yōrō, year-period, 717-23, and legislation of $718,176-84$ Yorozu, story of, 137 
Yoshida Kenkō (1283-1350), recluse and poet, one of "four kings," 367

- Shöin (1831-60), leader of anti-foreign and Imperial movement, 670

Yoshifusa see Fujiwara Yoshi-

fusa

Yoshiiye see Minamoto Yoshiiye

Yoshikage see Asakura Yoshikage

Yoshikawa, adherents of

Southern Court, 400

Yoshimasa see Ashikaga

Yoshimasa

Yoshimi see Ashikaga Yoshimi

- , nephew of Yoritomo, 376

Yoshimine, princely uji, 205

Yoshimitsu see Ashikaga Yoshimitsu

Yoshimune sce Tokugawa Yoshimune

Yoshinaga (Norinaga), Prince, governor-general of O-U, 388; in the Ashikaga revolt, 393; see Go-Murakami

Yoshinaka see Minamoto Yoshinaka

Yoshinao see Tokugawa Yoshinao

Yoshino, in Yamato, Buddhist monastery at, rallying place for Furubito's followers, 159; Prince Ōama takes refuge at, 170 ; rendez-vous of GoDaigo's followers, 397; in war of dynasties, 401, 402
Yoshino, cruiser lost off Port Arthur, 717

Yoshinobu see Tokugawa Yoshinobu

Yoshisada see Nitta Yoshisada Yoshisuke see Wakiyá Yoshisuke

Yoshiteru see Murakami Yoshiteru Yoshitsune see Minamoto no Yoshitsune

Yoso, N. E. Korea, cradle of Yemishi, 60

Yōzei, 57th Emperor (87784), 238-9

Yuasa support Southern Court, 400

Yuge no Dōkyō, priest, Kōken's love for, 198-9

Yui Shōsetsu, leader in revolt of 1651,584

Yūki, branch of Fujiwara in Kwantō, 266; persuade Shigenji to kill Noritada, 425

- Munehiro, administrator in $\overline{\mathrm{O}}-\mathrm{U}, 388$

Yunglo, Chinese Emperor and year-period, 1403-22, called Eiraku in Japan, 418, 439, 527

Yura, Strait of, 28

Yūryaku, Emperor (457-79), cruelty of his reign, $112-4$; and Korea, 121; death of Hayato at his tomb, 41; serpent worship, 65 ; 3 provinces added in his time, 87; punishes Sakitsuya for lèsemajesté, 97 , succession, 117
Yushima, Yedo, shrine, 599

Yũsho see 'T'akayama

Yutahito, see Kōgon

Yūzu or Yutsuki, Chinese imperial prince, and Chinese migration to Japan, 102

Zejoboỏ, mathematician and surveyor, 527

Zekkai, scholar, adviser of Yoshimitsu, 448, 449

Zen (dhyana, 'meditation),

Buddhist sect of contemplation, 286; 367 ; and Hōjō Tokimune, 361 ; the soldier's creed, 371; and intereourse with China, 417 ; priests and literature and art, 450; tea ceremonial, 452 ; favoured by the Ashikaga " 453; great priests, 454; five temples in Kyōto, 455

Zenkō-ji, temple in Nagano with battle paintings, 467 Zenkyō see Suye Harukata

Zenyū, priest, liaison with Empress Taka, 238

Zōjō-ji, temple of Shiba, Tōkyō, tomb of Hidetada, $581,5 \mathrm{~S} 2$ Zoku Nihongi (or Nihonki) Supplementary Chronicles of Japan, 697-791 (798), 4,251 - Nihon Kóki, Supplementary Later Chronicles, 824-50 (869), 5, 251

Zuisa, Buddhist priest, envoy of shogun to China, 445

Zuñiga, Pedro de '(d. 1622), Spanish Dominican and martyr, 552 
3 


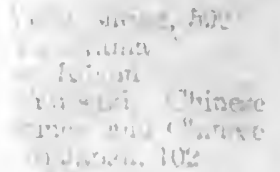

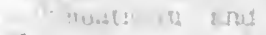

$$
\begin{aligned}
& \text { (in } 10.1 \text { is } \\
& \text { - }+2+2+30
\end{aligned}
$$

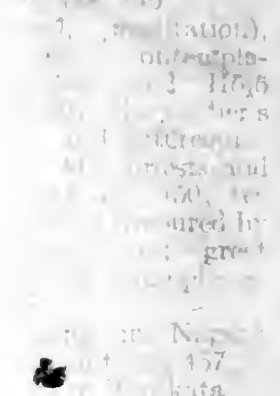

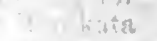

I 20 a 516

2: Tik in al, (1) is $\quad$ s.s. - ripplemen-

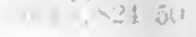

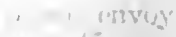

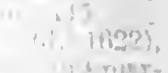

$$
\begin{aligned}
& \text { (4) }
\end{aligned}
$$


University of Callfornia

SOUTHERN REGIONAL LIBRARY FACILITY

Return this material to the library from which it was borrowed.

\section{SRL}

QL

31995 
